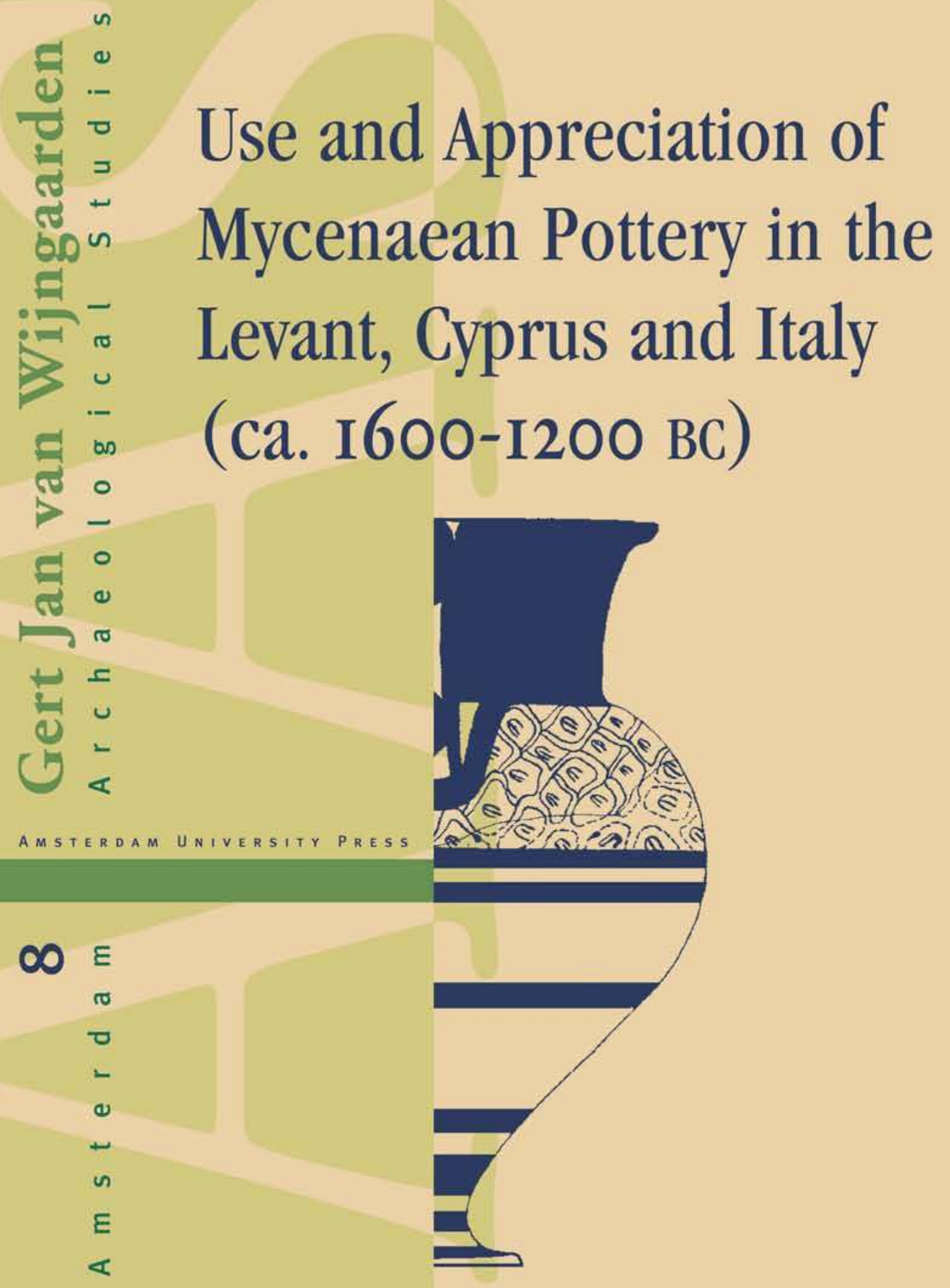


Use and Appreciation of Mycenaean Pottery in the Levant, Cyprus and Italy (I600-I200 BC) 



\title{
Use and Appreciation of Mycenaean Pottery in the Levant, Cyprus and Italy (I600-I200 BC)
}

\author{
Gert Jan VAN WijngaARden
}


This publication was funded by the Netherlands Organisation for Scientific Research (NWO). (0) This book meets the requirements of ISO 9706: 1994. Information and documentation -
Paper for documents - Requirements for permanence. ISO 9706

Cover illustration: Design by Virna van Wijngaarden, adapted from Schaeffer 1949, 156-7, fig. 60. Cover design: Kok Korpershoek, Amsterdam

Lay-out: Wouter Kool, Leiden

ISBN: 9053564829

NUR 682

(C) Amsterdam University Press, 2002

All rights reserved. Without limiting the rights under copyright reserved above, no part of this book may be reproduced, stored in or introduced into a retrieval system, or transmitted, in any form or by any means (electronic, mechanical, photocopying, recording or otherwise) without the written permission of both the copyright owner and the author of the book. 


\section{CONTENTS}

Preface

Part I InTRODUCTION

1. The Argument

2. Mycenaean Pottery in the Mediterranean

3. The archaeology of Trade and Consumption

Part II The Levant

4. Mycenaean Pottery in the Levant: Introduction 3I

5. Ugarit 37

6. Hazor $\quad 75$

7. Tell Deir 'Alla 99

8. The Cultural Significance of Mycenaean Pottery in the Levant Io9

Part III Cyprus

9. Mycenaean Pottery in Cyprus: Introduction I25

10. Enkomi-Ayios Iakovos I29

11. Athienou-Bamboulari tis Koukouninas I6I

12. Apliki-Karamallos $\quad$ I69

13. The Cultural Significance of Mycenaean Pottery in Cyprus $\quad$ I83

Part IV The central Mediterranean

14. Mycenaean Pottery in the Central Mediterranean: Introduction 203

$\begin{array}{ll}\text { 15. Lipari } & 207\end{array}$

16. Thapsos 229

17. Broglio di Trebisacce 237

18. The Cultural significance of Mycenaean pottery in Italy 249

Part V Conclusions

19. Variations in the Cultural Significance of Mycenaean Pottery 26I

20. The Role of Mycenaean Pottery in Mediterranean Exchange 275

$\begin{array}{ll}\text { TABLES } & 28 \mathrm{I}\end{array}$

$\begin{array}{lll}\text { MAPS } & 301\end{array}$ 


\section{Catalogues}

Catalogue I: Sites in the Mediterranean with Mycenaean pottery 323

Catalogue II: Mycenaean pottery at Ugarit $\quad 330$

Catalogue III: Mycenaean pottery at Hazor $\quad 343$

Catalogue IV: Mycenaean pottery at Deir 'Alla 345

Catalogue V: Mycenaean pottery at Enkomi 346

Catalogue VI: Mycenaean pottery at Athienou $\quad 376$

Catalogue VII: Mycenaean pottery at Apliki 377

Catalogue VIII: Mycenaean pottery at Lipari $\quad 379$

Catalogue IX: Mycenaean pottery at Thapsos 386

Catalogue X: Mycenaean pottery at Broglio di Trebisacce $\quad 387$

$\begin{array}{ll}\text { REFERENCES } & 397\end{array}$

INDEX

$\begin{array}{ll}\text { Geographical names } & 433\end{array}$

$\begin{array}{lr}\text { Subjects } & 438\end{array}$ 
The present monograph is a revised version of a dissertation written for the department of Classical Archaeology at the University of Amsterdam. The research was made possible by a generous scholarship from the UTOPA foundation. I would like to express my gratitude to the director, Mr L. Dijkman, for providing me with this opportunity and for his pleasant cooperation over the years. The Netherlands Organisation for Scientific Research (NWO) made a travel grant available which allowed me to visit many of the places mentioned in this volume. A publication grant, supplied by the same organisation, made the publication of this book possible.

This study could not have been completed without the active support of a number of friends. Over the years, Professor Joost Crouwel has read my work with alacrity and care. His detailed knowledge of a range of archaeological topics, as well as his consistent emphasis on clarity have contributed greatly to the results of my research. His academic rigour and in his enthusiasm have been a particular source of inspiration.

In the initial phases of my research, the late Vronwy Hankey helped me define the directions and the limitations of my research. My discussions with Vronwy provided an insight into the enormous complexity of the field I was about to enter. I consider myself fortunate to have been one of the many who were able to benefit from her kindness and expertise.

Dr Lucia Vagnetti kindly assisted me with the parts of this study that deal with the central Mediterranean. She also pointed me in the right direction when I was in Italy. Similarly, Professor Albert Leonard helped me with the sections on the Levant and Cyprus. I would like to express my gratitude to both scholars for sharing their expertise and for taking the time to read lengthy instalments.

A number of colleagues have discussed their work with me, shown me sites and material, and have given their views on parts of my research. In particular, I would like to thank Dr P. Attema, Dr M. Bettelli, Dr H. Catling, Dr N. Hirschfeld, Dr B. Kling, Dr G. van der Kooij, Dr S. Levi, Professor M. Marazzi, Mr G. Matteo and Professor R. Peroni.

I would also like to thank Professor N. Roymans, who agreed to include this work in the Amsterdam Archaeological Studies. In addition, the staff at Amsterdam University Press, particularly W. Poelstra and J. Wagenaar, have assisted me in many ways.

Finally, my heartfelt thanks go to my parents, Corrie and Jan van Wijngaarden, and to my wife Virna. Without their enduring encouragement and ceaseless support, this book would never have been completed. 



\title{
1 The argument
}

\author{
PURPOSE OF THIS STUDY
}

In this book, I aim to investigate the variations in the cultural significance of the imported Mycenaean pottery in the Levant, Cyprus and the central Mediterranean. Such pottery has been widely distributed in almost the whole Mediterranean. This body of material constitutes one of the archaeological sources by which to study relationships between the Aegean and other areas in the Mediterranean. As such, it has served as evidence for Mycenaean colonisation and commercial preeminence. The same body of evidence, however, has also been used to dismiss the importance of long-distance trade for the Mycenaean world. In my opinion, such a variability of interpretations on the basis of the same archaeological data has been possible because the role of Mycenaean pottery in international exchange during the Late Bronze Age is not properly understood. That role is dependant on the different patterns of consumption in the various areas where these ceramics have been imported. The main purpose of this research is to identify and compare these patterns of consumption for the three Mediterranean areas which have yielded the largest quantities of Mycenaean pots: the Levant, Cyprus and the Italian area.

\section{THE AEGEAN BACKGROUND}

On the mainland of Greece, at the end of the Middle Bronze Age, substantial changes are visible in the archaeological record, which have to do with an increase in social complexity. ${ }^{1}$ The most obvious examples of these changes are the Shaft-Graves in Mycenae, which are indicative of marked social stratification. ${ }^{2}$ In the succeeding periods, increasing centralisation resulted in the development of the Mycenaean palaces, of which those at Mycenae, Tiryns, Pylos and Thebes are the most notable. ${ }^{3}$ These palaces can be understood as centres which managed to control and monopolise specific aspects of society, such as the flow of goods and craft production, as well as military and various ceremonial activities. Increasingly, however, it has become clear that the palaces were never able to control the whole economy and it is likely that goods were produced and distributed outside the influence of the palatial centres. ${ }^{4}$ The Mycenaean palaces were eventually all destroyed and not rebuilt.

Changes in the settlement pattern and material culture indicate that, from the beginning of the Late Bronze Age onwards, the Argolid emerged as a leading centre in the development of Mycenaean

I Dickinson 1977, 51-54; Dietz 1991, 325-326; Rutter 1993, 787-793.

2 Graziado 1991, 404; Tournavitou 1995, 119.

$3 \quad$ Kilian 1987, 203-217; 1988a; Barber 1992, 21-23;
Shelmerdine 1997, 557-563 (all with many references).

4 Dickinson 1994, 81-83; Halstead 1992a, 72; 1992b, 113-114; Gillis 1995; Galaty \& Parkinson 1999, 6-8. 
culture. ${ }^{5}$ Wheel-made pottery from the first part of the Late Bronze Age was probably manufactured in a restricted number of production centres and was distributed all over the Peloponnese. ${ }^{6}$ During the palatial period, the Mycenaean world was probably made up of a number of independent polities. ${ }^{7}$ Nevertheless, there is a marked homogeneity in the material culture of the Greek mainland, while Mycenaean influences are visible in, for example, Crete, the Cyclades and Rhodes. ${ }^{8}$ Even though the actual presence of mainlanders elsewhere in the Aegean cannot be excluded, there is little evidence of a Mycenaean Aegean empire. Instead, we should envisage a cultural and technological koine in which the Argolid played a key role. In spite of this koine, local traditions in material culture seem to have continued in many regions of the Aegean. ${ }^{9}$ As is especially visible in ceramic production, the regional variations in the material culture increased towards the end of the palatial period and became particularly strong after the destruction of the Mycenaean palaces..$^{10}$

The specific development of the Mycenaean palatial civilisation is primarily due to internal Aegean factors. ${ }^{11}$ The material culture of mainland Greece during the Late Bronze Age clearly developed from the earlier Middle Helladic material record. In addition, relationships with other Aegean areas, in particular Minoan Crete, were important for the development of the Mycenaean civilisation. ${ }^{12}$ Nevertheless, this development cannot be separated from a wider Mediterranean context, as is particularly evident from the long history of palatial societies in the Near East. ${ }^{13}$ There are several sources by which we can investigate the relations between Mycenaean Greece and the Mediterranean. Firstly, epigraphic evidence in the Aegean, as well as in Anatolia, Egypt and the Levant may be considered. ${ }^{14}$ Secondly, a number of shipwrecks dating to the Late Bronze Age present physical evidence for the circulation of goods. ${ }^{15}$ Thirdly, there is a substantial number of objects in the Aegean that came from other areas in the Mediterranean. ${ }^{16}$ Finally, Mycenaean objects have been discovered outside the Aegean. Among these, ceramic vessels and figurines constitute the majority by far. ${ }^{17}$ This study, then, is restricted to one group of material - pottery - which is related to other evidence. Ultimately, I hope to contribute to our understanding of the Mycenaean world in its Mediterranean setting.

5 Dietz 1991, 326.

6 Dietz 1991, 31; Mountjoy 1993, 1-2.

7 Chadwick 1976, 35-60; Renfrew 1977; Kilian 1986.

$8 \quad$ For Crete, see Farnoux \& Driesen 1997; Haskell 1997. For the Cyclades, see Schallin 1993. For Rhodes and the Dodecanese, see Mee 1982, 88; Benzi 1988; 1992; 1996.

9 See, for example, Schallin 1993, 174-177; Benzi 1996, 973-974; Haskell 1997, 191-193 and other articles in the same volume.

Io Mountjoy 1990, 245; 1999.

II Kilian 1988, 298-300; Dietz 1991, 300-303; Barber 1992, 22-23; Rutter 1993, 776-778.

I2 Dickinson 1977, 56; Tournavitou 1995, 113-114.

13 Foster 1987, 15-16.

I4 Palaima 1991; Cline 1994, 108-131. References to international contacts in Homer's the Iliad and, especially, the Odyssey cannot be considered suitable to investigate Bronze Age trade due to the many Iron Age elements in these myths, see Crielaard 1994, 134 (with extensive bibliography on the subject).

Is To my knowledge, four wrecks dating to this period have so far been discovered in the Mediterranean. For the wreck near Cape Gelidonya on the south coast of Turkey, see Bass 1967; 1991. For the Ulu Burun wreck in the same area, see Bass 1991; Pulak 1988; 1997. For the wreck excavated off the coast near Haifa in Israel, see Galili, Shmueli \& Artzy 1986. For the wreck near point Iria, off the Argolid coast in the Aegean, see Lolos, Pennas \& Vichos 1995; Vichos \& Lolos 1997.

I6 Lambrou-Phillipson 1990a; Cline 1994.

${ }^{17}$ It is difficult to identify objects from other materials which unambiguously can be related to the Aegean. A variety of glass beads which occur in the central Mediterranean in particular, may or may not have an Aegean origin; see Taylour 1958, 51-52; Harding 1984, 87-103; Vagnetti 1989. Objects from the Mycenaean ivory industry may have circulated within 
The ceramic styles which can be associated to the period of the development of Mycenaean palatial civilisation range from Middle Helladic III until Late Helladic IIIB2, covering more than four centuries (ca. 1600-1180 BC) according to traditional chronology. ${ }^{18}$ I will not include in my research pottery produced after the destructions of the palaces, which is much less homogeneous and to a far larger extent imitated outside the Aegean. ${ }^{19}$ Considering the difficulties outside Greece to distinguish between LH IIIB and LH IIIC stratigraphically, this distinction will not be applied too rigidly. As a general rule, I will include LH IIIC pots in those cases where they occur in the same archaeological contexts as earlier pottery. I will adopt a similar attitude with regard to the origins of the vessels which are the subject of my research. Pottery produced in other areas of the Aegean than the Greek mainland, especially on Crete, should properly not be considered as Mycenaean. However, in some cases, especially when dealing with small fragments, Minoan and Mycenaean pots are difficult to distinguish. Moreover, pots from various parts of the Aegean probably were transported together to the east and west, both in the earlier and later periods. ${ }^{20}$ Sites with exclusively Minoan pots will not be discussed, ${ }^{21}$ but when such pots were found on a site which has yielded Mycenaean pottery as well, they are included. Likewise, Mycenaean-type pottery made in the Levant, Cyprus or Italy will be discussed when found together with true Aegean imports.

\section{THE MEDITERRANEAN B ACKGROUND}

The geographical area in which Mycenaean pottery has been distributed, is exceptionally large. The westernmost finds have been made in El Llanete de los Moros in Spain, in the Guadalquivir valley in the province of Andalusia. ${ }^{22}$ Finds at Meskene-Emar along the Euphrates river in Syria represent the easternmost finds, ${ }^{23}$ although a Mycenaean sherd has been reported from Babylon in Iraq. ${ }^{24}$ The southernmost finds come from Argo Island in ancient Nubia. ${ }^{25} \mathrm{~A}$ sherd found at Treazzano di Monsampolo in the province of Le Marche in Italy is the northernmost find. ${ }^{26}$

The societies which existed in these regions in the period during which Mycenaean pottery circulated, vary highly in their socio-political and economic organisation and complexity. In Egypt, this is the time of the 18th and 19th dynasties of the New Kingdom with its centrally governed, large empire and its developed, complex social and administrative structure. ${ }^{27}$ Large parts of Anatolia fell under

the eastern Mediterranean, but they often cannot easily be distinguished from products made elsewhere, especially on Cyprus, see Poursat 1977, 250-251. A few Late Minoan stone vases have been reported from Troy and the Levant, see Warren 1969, 188-189. The sword-type known as Naue type II has been found on several sites in Cyprus and the Levant as well as in Greece, but was also produced in Anatolia and southern Russia, see Cowen 1955, 63-68; Catling 1961, 118-119, Kilian-Dirlmeier 1993, 94-105.

I8 Warren \& Hankey 1989, 162. Throughout this book, the abbreviation LH is used to indicate 'Late Helladic', while LM and LC refer to 'Late Minoan' and 'Late Cypriot' respectively.

I9 French 1986, 281; Mountjoy 1990, 245; 1993, 90;
Sherratt 1991, 191-196; Jones \& Vagnetti 1991.

20 Cadogan 1973, 168, 172-173.

2I Middle Minoan finds have, of course, not been included here, see Kemp \& Merrillees 1980; Catling 1997, 378-381

22 Martin de la Cruz 1988, 86, 88; 1990.

23 Caubet 1982a, esp. 76.

24 Deubner 1957, 51-52, Plate 47. The photograph of this fragment is too unclear to say anything about the vessel type, its decoration, or its Mycenaean origin.

25 Hankey 1993b, 114.

26 Lollini 1982, 197-199. Mycenaean finds in the Po-area and the Veneto all seem to be of LH IIIC-date; see Bietti Sestieri 1982, 201-207.

27 See, for example, Trigger et al. 1983. 
the Hittites, who, likewise, ruled a centrally governed empire. ${ }^{28}$ In the Levant, there were a number of smaller states based upon large urban centres with a centralised political system. In the course of the period under consideration, these city-states came under Egyptian or Hittite domination, but they kept a relatively large autonomy. ${ }^{29}$ Each of these three areas may be considered as historical during this period, since contemporary textual sources are available to us, due to a variety of inscriptions as well as the existence of archives with cuneiform tablets. Similar epigraphical sources have not been discovered in Cyprus. On this island, a process of urbanisation began during this period and the practice of writing in Cypro-Minoan script was limited. ${ }^{30}$ The societies in the central Mediterranean should be considered as prehistoric and proto-urban. ${ }^{31}$ The level of social-economic organisation in this area was far lower than in the eastern Mediterranean.

The international economy and diplomacy within the Mediterranean during the Late Bronze Age constitutes a field of research which is much too large to adequately deal with here. One aspect of it concerns the nature of the flow of goods. This subject has been investigated in particular by scholars using textual evidence that has been found in Egypt, the Levant and Anatolia. ${ }^{32}$ It is important to realise that the cuneiform texts that deal with exchange should not be seen as facts, but rather as interpretations thereof. M. Liverani has convincingly demonstrated that the texts are cultural products themselves and not devoid of ideology or even propaganda. ${ }^{33}$ Moreover, the texts reflect the life of the same social sector in different political units: the royal palaces. It is now generally accepted that the societies in the Near East had multi-centred economies in which several spheres coexisted. ${ }^{34}$ From the third millennium onwards international exchange occurred both as ceremonial gift exchange among palaces and as more mercantile trade..$^{35}$ The texts provide accounts mainly of the exchange conducted in the sphere of the palaces. The nature of the trade outside this sphere largely escapes us. ${ }^{36}$

The ceremonial exchange that is reflected in the Near Eastern accounts was based on the political relationships among rulers. The language used, with the title 'brother' when equal partners were concerned and 'father' or 'son' for unequal relationships, reflects the diplomatic position of the sender. C. Zaccagnini has shown how this system, which originated in the third millennium BC, had acquired many commercial elements in the Late Bronze Age. ${ }^{37}$ Economic purposes - the need to import certain goods - had become important in establishing and maintaining diplomatic relationships. This commercialisation is visible, for example, in the role of silver as a standard of equivalence. ${ }^{38}$

Transactions outside the sphere of ceremonial exchange are only attested indirectly in the texts. It seems clear that raw materials and semi-elaborated goods found their way outside the sphere of the palace and circulated not only among élites, but also among lower strata of the population, being essentially employed as exchange goods and means of payment. ${ }^{39}$ However, private trade also seems to have been conducted by traders who were connected to the palace. ${ }^{40}$ These tamkars not only served as

28 See, for example, MacQueen 1986; Gurney 1990; Masson 1994; Bryce 1998, 44-63.

29 For overviews, see Leonard 1989; Falconer 1994.

30 For overviews, see Knapp 1997, 46-48; Keswani 1996, 217-220; Palaima 1989, 121-125.

3I For overviews, see Barker \& Stoddart 1994; Malone, Stoddart \& Whitehouse 1994

32 See, for example, Helck 1962, Heltzer 1978. For a short overview of the interpretation of economical and diplomatic cuneiform texts, see Liverani 1972, 297298.
33 Liverani 1990, 292-294.

34 Zaccagnini 1976, 468, 567; Knapp \& Cherry 1994, 152-155; Artzy 1997, 7.

35 Liverani 1972, 308-309; Zaccagnini 1973, 79-81; 1976, 567.

${ }_{36}$ Zaccagnini 1976, 501; 1984, 159.

37 Zaccagnini 1973, 117-121.

$3^{8}$ Liverani 1972, 308-310.

39 Zaccagnini 1984, 159.

$4^{\circ}$ Heltzer 1978, 127-129; Knapp 1991, 49; Cline 1994, 85. 
moneylenders using silver from their personal possessions, they are also known to have paid taxes out of income derived from private trading. Letters between administrators of different palaces show that prices for certain goods were established precisely before sending the shipment and that trade commodities were distinguished from additional gifts. ${ }^{41}$ Another reflection of commercial trade may be identified in the Amarna letters from Alashiya that have to do with the circulation of raw metals. ${ }^{42}$ In these letters a silver standard is used to calculate the value of gifts.

Commercial trade might also be reflected by the distribution of raw copper in the shape of socalled 'oxhide' ingots that have been found in many parts of the eastern and central Mediterranean. ${ }^{43}$ These ingots characterise a 'trade koine' for metals from the 16th to the 12th century BC. Although Egyptian pictorial evidence show ingots being offered as ceremonial gifts, ${ }^{44}$ the existence of over 200 tons of these ingots in the Ulu Burun wreck indicates that this metal was also traded in bulk. ${ }^{45}$ Moreover, the ship's diverse cargo shows that this was the case for other raw materials (tin, ivory, glass) and finished goods (glass beads, lamps, ceramics) as well. ${ }^{46}$ The 'oxhide' ingots are found on land in different types of context, both palatial and non-palatial, and there is a concentration of such finds in Cyprus, Crete and Sardinia. ${ }^{47}$ In the view of some scholars this distribution pattern can only be explained by assuming a commercial directional trade in metals, ${ }^{48}$ while others envision independent, travelling merchants. ${ }^{49}$

Whatever the character of non-ceremonial exchange, it seems clear that extra-economical factors always played a constraining role. ${ }^{50}$ Conversions between the two basic spheres of exchange were possible and goods belonging to different spheres seem to have participated in the same circuits of exchange in a fairly loose way. ${ }^{51}$ It is necessary, also, to realise the extreme slowness of international exchange. The Amarna letters testify to messengers having been away from home for years. ${ }^{52}$ This slow rhythm was partly due to the technology of transport, but also to political considerations. In any case it will have influenced the commercial nature of any trading activity.

\section{MYCENAEAN PRESENCE IN THE MEDITERRANEAN}

Another issue which is closely related to the subject of this book concerns the degree to which Aegeans actively participated in the international economy of the Late Bronze Age. Ideas about this topic have been formulated since the days of Heinrich Schliemann, who believed that the Shaft Graves at Mycenae could only be accounted for by a Phoenician invasion. ${ }^{53}$ The discovery of large amounts of Mycenaean pottery in tombs at Minet el-Beida and Ras Shamra (Ugarit) led C. Schaeffer to believe that these were the graves of Mycenaean colonists. ${ }^{54}$ Sir Arthur Evans endorsed this view by

4I Liverani 1972, 310-311. Especially when administrators were of unequal rank, the transactions often had a purely commercial character.

42 Liverani 1972, 308-309; 1990, 215.

43 For distribution maps of these ingots, including representations, see Gale 1991, 200-201.

44 See Bass 1967, 62-67, figs. 62, 64, 67, 68, 74, 75, 79, 82.

45 Pulak 1988, 6; Muhly, Maddin \& Stech 1988, 281.

${ }^{6}$ See Bass 1987; 1991; Pulak 1988; 1997; also Buchholz 1988, 225-227.
47 Muhly, Maddin \& Stech 1988, 289; for contexts, see Bass 1967, 57-62; Buchholz 1988, 203-212.

48 Muhly, Maddin \& Stech 1988, 289.

49 Buchholz 1988, 227.

so Liverani 1972, 305; Zaccagnini 1976, 468.

SI Zaccagnini 1987, 58.

s2 Liverani 1972, 316-317; EA 3, 13-14: "But now when I sent a messenger to you, you have detained him for six years..."

53 See Yannai 1983, 51.

54 Schaeffer 1936b, 78-99. He went so far to assume that 
comparing the architecture of the Ugaritic tombs with the Royal Tomb at Isopata near Knossos in Crete and by suggesting that the origin of the Syrian graves "...should be sought on Cretan soil". ${ }^{5}$ Several scenarios of Aegean pre-eminence have resulted from this view. Erik Sjöqvist imagined groups of Mycenaeans colonising Cyprus and the Near East in the 14th century BC, ${ }^{56}$ while Sarah Immerwahr had no doubts about a "Mycenaean commercial empire". ${ }^{57}$

In 1964, H.W. Catling was among the first to challenge this view. ${ }^{58}$ After a review of the available evidence he concluded that Mycenaeans could not have been present in Cyprus during LH I-LH IIIB (LC I-LC II). The large amounts of LH IIIA2 and LH IIIB pottery on the island could, according to Catling, only be explained by trade between Cyprus and the Aegean, without a Mycenaean presence on the island. Arguments against Mycenaean domination of Mediterranean trade were given by G. Bass. After excavating the wreck of Cape Gelidonya on the south coast of Turkey, he believed the ship to have belonged to 'Phoenicians' trading with the Aegean. He suggested that trade in this region in general may have been handled by Levantines rather than Mycenaeans. ${ }^{59}$ A Canaanite thalassocracy was likewise proposed by J.M. Sasson and E. Linder, ${ }^{60}$ A. Yannai suggested a leading role for Cypriots in the trade between the Aegean, the Near East and Egypt. ${ }^{61}$

Ideas about Mycenaean colonisers and traders in the Eastern Mediterranean were also influenced by the decipherment of Linear B in the 1950s. According to Moses Finley, the absence of references to trade and traders in the Linear B archives tablets indicates that long-distance exchange was not important for the Mycenaean palatial economies. ${ }^{62}$ Such trade as occurred, in his view, was controlled by the palace and took the form of diplomatic gifts. J.L. Bintliff likewise regarded the Mycenaean economy as based upon the redistribution of local foodstuffs rather than upon commerce. ${ }^{63}$ Marine trade occurred, in his regard, only in association with fishing activities.

Since the 1980s, there appears to be a renewed interest in long-distance trade and foreign contacts of the Bronze Age Aegean. Finds of the LH I period in Italy, for example, have been used to explain the sudden rise in material wealth attested by the Shaft Graves ${ }^{64}$ In addition, it has been proposed that control of contacts with the Eastern Mediterranean by the Aegean élites was a factor in the forming of palace societies on Crete and the Greek mainland. ${ }^{65}$ The hypothesis put forward by Susan Sherratt that Mycenaean pottery in the Aegean was specifically produced with the Near Eastern markets in mind, would mean that craft-production in the Aegean was influenced by wider economic developments. ${ }^{66}$ Such an influence may be visible in the evidence presented by Nicolle Hirschfeld that Cypriots somehow where involved in Mycenaean ceramic production. ${ }^{67}$ Foreign imports within the Aegean have also been used as evidence for the importance of long-distance exchange. According to Eric Cline, the orientalia found in the Aegean in LH IIIB contexts show that Mycenaean merchants

the city of Ugarit was under Mycenaean political control.

55 Evans 1935, 776.

s6 Sjöqvist 1940, 183-184.

57 Immerwahr 1960, 4; for Aegean thalassocracies, see also Knapp 1993, 333-334.

s8 Catling 1964, 35-50.

59 Bass 1967, 164-165. He upheld this standpoint after excavating the wreck of Ulu Burun, which he likewise presumed to have been Canaanite (Bass 1991, 74), although his excavation co-director, C. Pulak, believed the crew of the ship to be Mycenaean (Pulak 1988, 37).

60 Sasson 1966; Linder 1981.

6r Yannai 1983, 83-87.

62 Finley 1982, 206; Snodgrass 1991.

63 Bintliff 1977, 115-116.

${ }^{64}$ Rutter 1993, 796, with bibliography on the subject.

os Sherratt \& Sherratt 1991, 354, 358-360.

66 Sherratt 1982, 183; Jones 1986a, 599-600; Åkerström 1987, 119

${ }^{67}$ Hirschfeld 1993, 313-315; 1996, 291-293; 1999, 275277. 
and vessels were present in the Near East during this time, although C. Lambrou-Phillipson has suggested that they testify of the presence of Near Eastern traders and craftsmen in the Aegean. ${ }^{68}$ Exciting evidence for the presence of Mycenaeans in Egypt may be a papyrus from El Amarna which shows warriors with possible boar's tusk helmets who might be interpreted as Mycenaeans. ${ }^{69}$ The large-scale manufacture of Mycenaean pottery in the central Mediterranean from LH IIIB onwards is thought to indicate that Mycenaean craftsmen were present in this area. ${ }^{70}$

The pendulum swing that has occurred in thinking about a Mycenaean role in the trade networks of the Bronze Age Mediterranean underlines the fact that archaeological (and textual) data do not speak for themselves, but are subject to multiple interpretations. In this study, I accept the view of $M$. Liverani that there was a conditioned coexistence in the Mediterranean during the 15th-13th centuries BC..$^{71}$ This means that there were no thalassocracies, but that trade was carried out by many, among whom were local producers and distributors, palace-based traders and independent merchantmen. The mechanisms at work in such a system were diverse and complex, with objects travelling through several modes of exchange run by different participants before being deposited at their place of archaeological recovery. ${ }^{72}$

The presence of foreign objects in the Late Bronze Age Aegean, as well as the Mycenaean pottery in the Mediterranean show that Mycenaeans took part in the multi-faceted trade networks that are indicated above. The degree of this involvement is difficult to ascertain, although it seems clear that there was not a process of colonisation that is comparable to the later Greek expansion. ${ }^{73}$ The existence of Mycenaean trading colonies of merchants living among indigenous populations is, however, possible. Colonies of this kind have been proposed for the central Mediterranean, and for Troy. ${ }^{74}$ Such colonies are, however, very difficult to recognise archaeologically and their existence is by no means undisputed. That ships were employed in the Mycenaean world is without doubt and, since the Mycenaeans are here considered to be part of the international economy, it is likely that these ships were involved in long distance trade. ${ }^{75}$ However, it is not certain that they reached all the coastal places at which Mycenaean pottery is found.

The uncertainty about the presence of Mycenaeans in various areas of the Mediterranean is also due to the nature of the archaeological evidence. With a few exceptions, finds in Mediterranean areas which can be identified as Aegean with any degree of certainty, consist of ceramic vessels and figurines. The significance of these ceramic items in an international economy that was probably based on the circulation of metals is by no means clear. But this, of course, is a subject to which this book hopes to contribute.

70 Peroni 1983, 258; Jones \& Vagnetti 1991, 140-141; Vagnetti 1999, 148.

7I Liverani 1987, 67-68.
72 Knapp 1993, 340-341.

73 Kilian 1990, 465.

74 Smith 1987, 159-161; Kilian 1990, 458, 465.

75 On ships, see Casson 1973, 30-33; Morgan 1988, 212 223 (with bibliography). 



\section{Mycenaean pottery in the Mediterranean}

\section{N T R O D U C T I O N}

The data-set on which this study focusses, consists of Mycenaean pottery in areas beyond the Aegean. Catalogue I presents a list of sites in the Mediterranean where such pottery has been found. Considering the large differences between sites and areas in the intensity of archaeological research and publication, this list should be understood as much a result of archaeological research (including my own) as an indicator of the distribution of Mycenaean pottery.

Stylistically, the body of ceramic material under study ranges from LH I to LH IIIB2. The absolute chronology of the Aegean stylistic ceramical phases is by no means undisputed. ${ }^{1}$ The chronological frameworks in the Levant, Cyprus and Italy depend to a considerable extent on the stylistical classifications of the Mycenaean pottery. ${ }^{2}$ As a result, the interdependant absolute chronological frameworks are all hotly debated. For this reason, I will generally refrain from using absolute dates. A provisional chronological chart based on the traditional view is given in figure 2.1.

\section{THE CHARACTER OF MYCENAEAN POTTERY FOUND OUTSIDE}

\section{G R E E C E}

Mycenaean pottery, as a class of archaeological artefacts, is very well studied indeed. ${ }^{3}$ Already in early studies it was realised that the corpus of Mycenaean pottery found outside the Aegean differs in several respects from that found on the Greek mainland. ${ }^{4}$ One of the most readily apparent differences is that wheel-made, decorated fine wares constitute a far larger proportion of the material than in the Aegean..$^{5}$ In fact, with a few notable exceptions, undecorated coarse ware and plain fine wares import-

I See, for example, Betancourt 1987; 1990, 22; Manning 1988, 1989, 1990, 1991 who argue that the beginning of the Aegean Late Bronze Age should be dated around 1700 BC. For arguments against such a high date, see Warren 1996; Wiener 1998, 313-315.

2 For the Levant, see Leonard 1989, 6-7; FoucaultForest 1996, 11-17. For Cyprus, see French \& Åström 1980; Karageorghis 1982a, 9; Kling 1989, 2-4. For Italy, see Malone, Stoddart \& Whitehouse 1994, 170. 3 For brief historical overviews of the study of Mycea- nean pottery, see Mountjoy 1993, 1; Van Wijngaarden 1999b. The standard classification is still based on that devised by A. Furumark (1941a), who classified all vessels known to him according to shape and decorative motives and devised a numerical system for reference: Furumark Shape (FS) and Furumark Motif (FM).

4 Furtwängler \& Löschke (1886, IX), for example, comment that the Cypriots had a preference for chariot kraters and geometrically decorated flasks. 


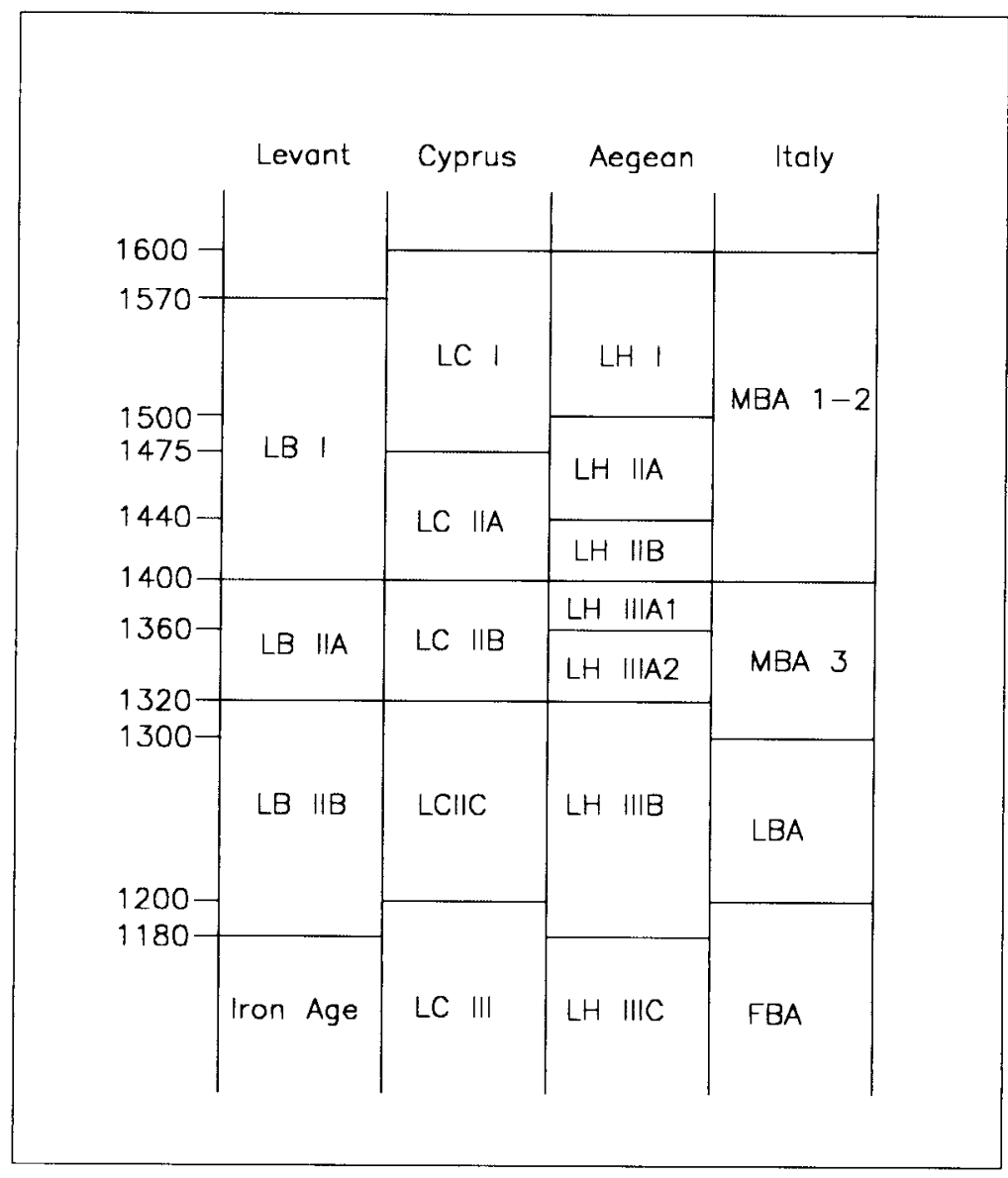

Fig. 2.1: Comparative chronology

ed from Mycenaean Greece are almost non-existent in most areas. ${ }^{6}$ Other differences are visible in the range of pot shapes found in the eastern and central Mediterranean. The occurrence in Cyprus, and to a lesser extent in the Levant, of vessel types which are rare in Greece led to the term LevantoHelladic ware, to indicate a group of pot shapes believed to have been produced in Cyprus. ${ }^{7}$ Shallow bowls (FS 295-296), chalices (FS 278), angular jugs (FS 139), amphoroid kraters (FS 53-55) and zoomorphic rhyta were all believed to belong to this class. ${ }^{8}$ The Mycenaean pottery with pictorial decoration, likewise found more often in the eastern Mediterranean than in Greece, was believed to belong to this class of Levanto-Helladic ware as well. ${ }^{9}$

The claims for large-scale production of Mycenaean pottery outside the Aegean before an advanced stage of the LH IIIB style could not be upheld, due to extensive research into the provenances

5 Compare, for example, the figures provided by French et al. 1984, 12, with those by Åström 1973, 123.

6 Substantial quantities of Mycenaean-type coarse and plain wares have been found at Miletus (Mee 1978, 234; Niemeyer 1997, 347) and the Aeolian and Flegrean islands (Re 1993, 331-334; 1994; Vagnetti 1991) only.
7 The term was first used in the first volume of the Swedish Cyprus Expedition, 1934; see Sjöqvist 1940, 3 where he explains his use of the word. The term was adopted by Furumark (1941a, 9-10) as "LevantoMycenaean".

8 Karageorghis 1965a, 204-228.

9 Vermeule \& Karageorghis 1982, 8. 
of such pottery by scientific investigation of the clays. ${ }^{10}$ Analyses carried out on material from Enkomi (site no. 56), Kouklia-Palaeopaphos (site no. 126), Kition (site no. 63), Alalakh (site no. 137), Ras Shamra (site no. 141), Tell Dan (site no. 170), Tell Abu Hawam (site no. 175) and Tell el-Amarna (site no. 268) established that most of the LH IIIA-LH IIIB material found in the eastern Mediterranean had been produced in Greece. ${ }^{11}$ The area of production, in most cases, seemed to have been the north-eastern Peloponnese; some pieces derived from Crete and Boeotia, while others came from areas in Greece that have not yet been identified. In the Italian region, analyses of LH I-II vessels from Vivara (site no. 342) and Capo Piccolo (site no. 320) pointed to an origin in the southern Peloponnese or Kythera. ${ }^{12}$ Investigation of LH IIIA2-LH IIIB imports from Taranto-Scoglio del Tonno (site no. 314), Broglio di Trebisacce (site no. 317) and Termitito (site no. 316) revealed Peloponnesian, Rhodian and Cretan origins for the clays.

Finds on the Greek mainland of pots typical of the Levanto-Helladic repertoire, likewise, have cast strong doubts on a Cypriot origin for this group of ceramic types. ${ }^{13}$ Shallow bowls (FS 295-296) have been found in Greece, for example in the Argolid and, possibly, in Boeotia. ${ }^{14}$ A number of chalices (FS 278) were discovered in the Peloponnese and in Boeotia. ${ }^{15}$ Moreover, the shape of the chalice appeared to have a Cretan, rather than an oriental, origin. ${ }^{16}$ As far as the pictorial pottery is concerned, Åkerström showed stylistic similarities between the pictorial representations found in Greece and those from the eastern Mediterranean; in some cases the hands of the same artists could be identified. ${ }^{17}$ This indicated a production of such pottery in one cultural area. Because the pictorial representations are part of the Minoan and Mycenaean artistic tradition, and the non-pictorial ornaments on these vessels are in accordance with the corpus of Mycenaean ceramic motifs, this area could only be Greece. ${ }^{18}$

Even though it is unlikely that there existed a school of Mycenaean potters based somewhere in the eastern Mediterranean which specialised in a particular range of vessel types, pottery in Late Helladic style was produced regionally or locally in all importing areas. ${ }^{19}$ In Miletus, there is evidence for the manufacture of Mycenaean ceramics from LH IIIA onwards, which is to be considered in relation to the likely presence of a Mycenaean population in the town. ${ }^{20}$ For Egypt, local production of Aegean-

Io For an overview of the techniques involved, see Jones 1986a, 15-85.

II For Enkomi, see Asaro \& Perlman 1973, 220-221; for Kouklia-Palaeopaphos, see Asaro \& Perlman 1973, 222; for Kition, see Asaro \& Perlman 1973, 222; for the origins of Mycenaean pots from various other sites in Cyprus, see Bryan et al. 1997. For Alalakh/Tell Atchana (site no. 137), see Jones 1986a, 561; for Ras Shamra (site no. 141) and Minet el-Beida (site no. 142), see Jones 1986a, 563; for Tell Dan (site no 170), see Gunneweg et al. 1992; for Tell Abu Hawam (site no. 175), see Asaro \& Perlman 1973, 222-223; French 1991, 123; 1993; for an overview of the origin of Mycenaean vessels in the Levant, see Killebrew 1998. For Tell el-Amarna (site no. 268) in Egypt, see Mommsen et al. 1992, 298-299.

I2 Jones \& Vagnetti 1991, 131-133.
I3 This issue has been discussed extensively by Sherratt (1980, 195-199); see, also, Jones 1986a, 599-601.

I4 Demakopoulou \& Crouwel 1984, 43-45.

Is Blegen et al. 1973, plate 174, no. 1; Spyropoulos 1982, 113: plate 61; Demakopoulou \& Crouwel 1984, 42.

I6 Hiller 1978.

17 Åkerström 1987, 104-114.

I8 Crouwel \& Morris 1985, 98.

I9 Aegean-style pottery of obviously non-Aegean provenance is often referred to as "local imitation". However, such vessels need not necessarily be produced at the place of recovery, but may be transported and traded. A stirrup jar from Tell es-Saidiyeh (site no. 191) which is of non-Greek manufacture, but certainly not produced in the area of the site, is a point in case; see Leonard et al. 1993, 106 note 7, 121.

2o Gödecken 1988, 311; Niemeyer 1997, 347; 1998, 30-34. 
style ceramics seems to have been limited to only a small number of vessels. ${ }^{21}$ In the Levant, some imitations of a variety of LH IIIA and LH IIIB vessels occur. ${ }^{22}$ On a somewhat larger scale, at the end of the LBII phase, a limited range of Mycenaean closed vessels, in particular stirrup jars and flasks, were produced in the Levant. ${ }^{23}$ On the island of Cyprus, the local ceramic industry incorporated a wide range of Mycenaean elements during an advanced stage of LCII, mainly relating to open vessel types such as bowls and kraters. ${ }^{24}$ One aspect of this development was a Cypriot version of the Mycenaean pictorial style, the so-called 'Rude-'or 'Pastoral Style'. ${ }^{25}$ The regional production of pottery in Mycenaean style was also extensive in the Italian area. Such production probably already began in a period contemporary to LH IIIA2 and increased with LH IIIB, during which imports seem to constitute a minority at many sites. ${ }^{26}$

The debate concerning the Levanto-Helladic ware found its origin in differences in the frequency of Mycenaean vessel types between Greece and the eastern Mediterranean. Such differences can also be attested among the various importing areas. For example, the mug (FS 225-226) and the rhyton, in conical or zoomorphic form, occur in larger quantities in the Levant than in Cyprus; the same is true for Mycenaean figurines. ${ }^{27}$ In general, Cyprus has proportionally more fine table wares than the SyroPalestinian littoral. V. Hankey has remarked that, even though the ceramic types of LH III ware in Egypt follow the pattern in Cyprus and the Levant, the range of shapes is sharply reduced. ${ }^{28}$ She also stated that the vertical flask (FS 187-189) is probably the most frequent vessel type, which distinguishes Egypt from other importing regions. For the central Mediterranean, Th. Smith argues that pottery types vary per region, with Sicily possessing mainly small containers, while large and small storage vessels are predominant in peninsular Italy; on the Aeolian and Flegrean islands, there is a comparatively high proportion of drinking vessels. ${ }^{29}$ In Anatolia, handleless and piriform jars seem to constitute a relatively high proportion among the LH IIIA2-LH IIIB vessels. ${ }^{30}$

For the eastern Mediterranean, at least, there is evidence that individual importing towns were able to exert preferences for certain Mycenaean pot shapes. Even though the most frequently occurring

21 Bell $(1982,150)$ identified only two imitations of the stirrup jar, probably based on LH IIIB prototypes. Additionally, Mycenaean stirrup jars were imitated in stone and faience, see Hankey 1995a, 117, 123.

22 Leonard et al. 1993, 106.

23 Leonard et al. 1993; Killebrew 1998, 161-162.

${ }_{24}$ Kling 1987, 103, 106; 1989, 130, 170-173; Sherratt 1991, 191-193.

25 Sherratt 1980, 196; Vermeule \& Karageorghis 1982, 59-67; Sherratt \& Crouwel 1987, 341-342.

26 Jones \& Vagnetti 1991, 131-134; Vagnetti 1993, 147. For LH IIIA-type sherds of local manufacture in Broglio di Trebisacce, see Vagnetti 1999, 139 note 10.

27 See Gilmour 1992, 115, for the mug and the zoomorphic rhyton. For conical rhyta, compare the catalogues provided by Åström (1972b, 354) and Leonard (1994, 90-93): Åström lists eleven conical rhyta (0.6\% of the total corpus) for Cyprus, while Leonard identifies sixty such vessels $(2.7 \%)$ for the Levant. Only a few additional Mycenaean rhyta have been found in Cyprus since the publication of Åström's list.

28 Hankey 1993b, 112.

29 Smith 1987, 128. It needs to be remarked that the material from Sicily investigated by Smith has to a far larger extent been found in tombs than on the Italian mainland. Likewise, the chronology of the Mycenaean imports is not the same for the various regions, with the Aeolian and Flegrean islands possessing more imports from an early era (LH I-LH II).

30 Özgünel (1997) list 35 of such vessels, which is almost $10 \%$ of the total. It needs to be remarked, however, that his list is not a full corpus. In comparison, such jars constitute $3.7 \%$ of the total in Cyprus (Åström 1972b) and $2.7 \%$ in the Levant (Leonard 1994). 
vessel types have been found at the majority of the important sites,${ }^{31}$ there are quantitative differences among them. For example, in Tell Abu Hawam, open vessels are more common than closed pots, which is in contrast with most sites in the Levant..$^{32} \mathrm{R}$ as Shamra-Ugarit has produced a relatively high number of conical rhyta (FS 199), ${ }^{33}$ while Tell el-Amarna possessed a large proportion of vertical flasks (FS 189)..$^{34}$

These differences in the repertoire of Mycenaean vessels and sites may be related to the specifics of exchange with particular areas within the Aegean. There is some evidence that certain individual sites in the Mediterranean obtained their Mycenaean pottery from specific areas in the Aegean. For example, most of the LH II pottery from Ayia Irini (site no. 103) in western Cyprus seems to derive from the island of Aegina, while the contemporary pottery from nearby Toumba tou Skourou (site no. 105) is predominantly Minoan in character..$^{35}$ After a stylistic and typological analysis of the Mycenaean pottery at Tell Abu Hawam (site no. 175), J. Balensi concluded that this material derived almost exclusively from the Argolid, which was confirmed by neutron activation analysis of a number of sherds. ${ }^{36}$ Likewise, analyses of sherds from Tell el-Amarna (site no. 268) indicated that the Mycenaean pottery found there had been produced in the Berbati area. ${ }^{37}$ On the basis of such evidence, hypotheses of direct trade contacts between these sites and the respective regions in the Aegean have been formulated..$^{38}$ However, at most sites, the Mycenaean pottery appears to derive from multiple sources in the Aegean. In Enkomi (site no. 56), for example, about a quarter of the LH IIIA samples analysed by Asaro and Perlman were thought to have been produced in the Argolid, while the remainder had originated elsewhere in Greece. ${ }^{39}$ Pottery from Minet el-Beida (site no. 142) and Ras Shamra (site no. 141) appeared to derive not only from mainland Greece, but also from Crete, the Dodecanese and Cyprus. ${ }^{40}$ The analysis of eleven sherds from Taranto-Scoglio del Tonno (site no. 314) in Italy revealed Rhodian, as well as Cretan and Peloponnese-type compositions. ${ }^{41}$ It therefore remains questionable whether exclusive connections between overseas places and particular regions in Mycenaean Greece were common practice.

\section{THE RANGE OF MYCENAEAN VESSEL TYPS}

From the overview presented in the previous section it is clear that the repertoire of Mycenaean pottery outside the Aegean encompasses a wide range of open and closed pot shapes. In order to identify patterns in the contextual distribution of such a wide range of vessels, they need to be classified in a suitable framework. In a study dealing with the use and appreciation of the vessels themselves, a classi-

3I Gilmour 1992, 115.

32 Balensi 1980, 485. Open shapes are more abundant than closed vessels at Ras Shamra and Minet el-Beida as well.

33 Karageorghis 1998, 1.

34 Hankey 1973, 130; 1997, 194.

35 Graziadio 1995, 8-17; Vermeule \& Wolsky 1978, 298299, 300-317; 1990, 381-384.

36 Balensi 1980, 472; Asaro \& Perlman 1973, 222-223; French 1991, 123.

37 Mommsen et al. 1992, 298-299: twenty-one of the twenty-three analysed sherds fell into the Berbati group and could be distinguished from samples from the Tiryns-Asine region.

$3^{8} \quad$ Balensi 1980, 568; Cline 1994, 86-87.

39 Asaro \& Perlman 1973, 221. Professor Perlman suggested Messenia as a possible origin (see the discussions in the same volume on p. 331), but this hypothesis has - to my knowledge - never been investigated.

40 Hirschfeld 2000, 70-71.

4I Jones \& Vagnetti 1991, 132. 


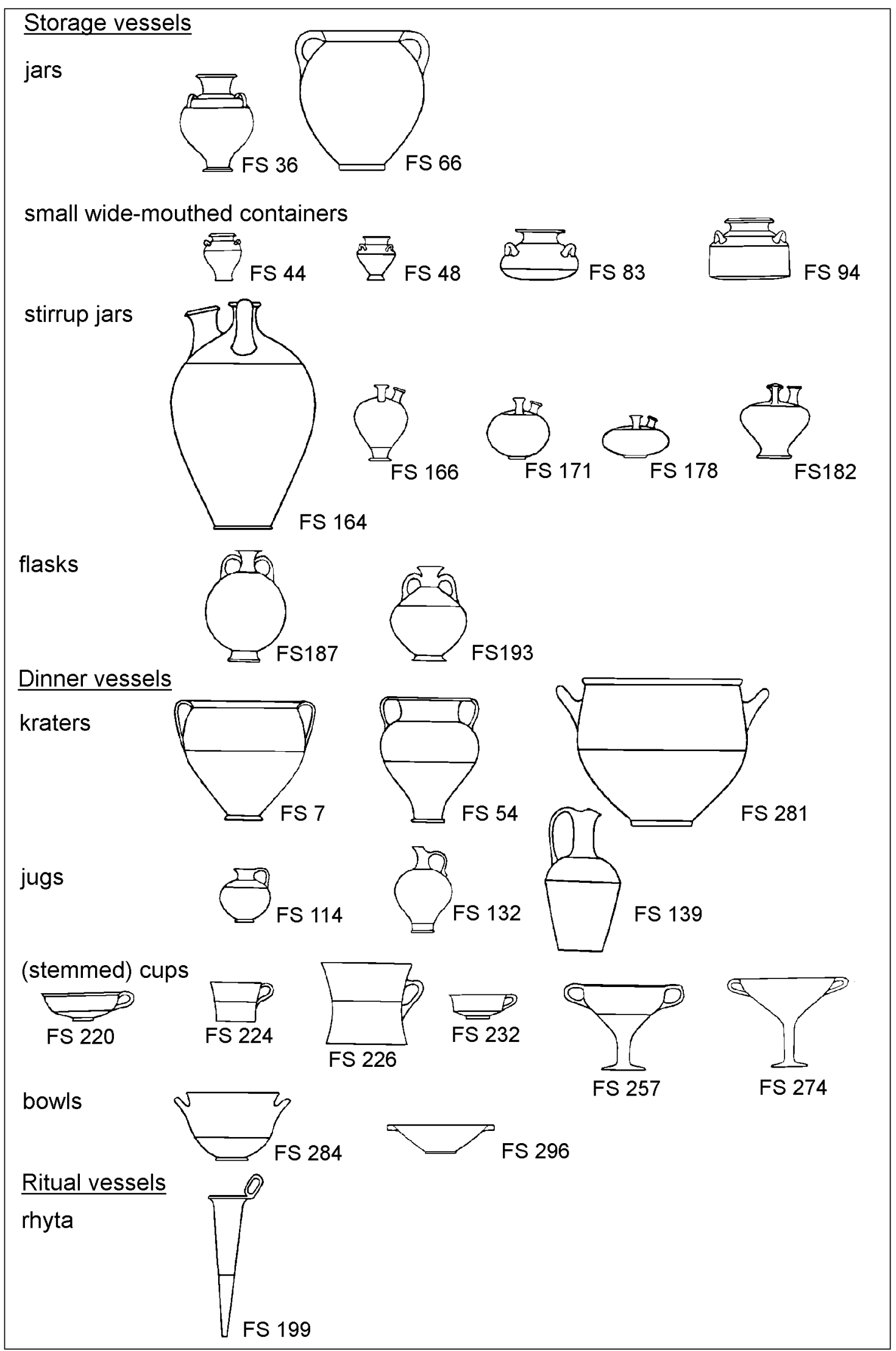

Fig. 2.2 Mycenaean vessel types which occur frequently outside Greece (cf. Table I) (scale = ca. 1:20) - Adapted from Mountjoy 1986, 206-218 figs 271-283. 
fication according to the purposes for which vessels may be employed seems more appropriate. The uses to which an object such as a Mycenaean pot is put is to a large extent determined culturally and not necessarily inherent in its physical characteristics. ${ }^{42}$ However, physical characteristics limit the range of cultural interpretations available for a product. The morphology of a ceramic vessel, then, incorporates restrictions defining functions for which it is suitable to be used or not. ${ }^{43}$ Such possible functions based on the morphology of the Mycenean vessels are the basis of the classification which I will employ in this study. Of course, some vessel types may have fulfilled multiple functions and should properly be classified in more than one category, while individual vessels may change function during their life span. Contextual analyses will reveal the extent to which the use of the Mycenaean pots in the various areas and places in the Mediterranean corresponds to functions indicated by their morphology.

Prudence Rice distinguishes three broad functional categories to classify ceramic vessels: storage, processing and transfer. ${ }^{44}$ Vessels in the first category are meant to hold substances for longer or shorter periods. Pots in the second category are usually referred to as cooking pots. Ceramic types in the third class serve to transport materials, either over long distances, such as transport amphorae, or over short distances, such as between kitchen and dining table, or between table and mouth. This general scheme has been worked out by Iphigenia Tournavitou for Mycenaean pottery found in four LH IIIB1 houses in the lower town of Mycenae. ${ }^{45}$ She distinguished six functional categories: storage vessels, pouring vessels, drinking vessels, eating vessels, cooking vessels and accessory vessels. Tournavitou emphasised that the distinction between the different categories is not always clear and that some vessels may have served multiple purposes.

In this study, the first broad category (see Fig. 2.2 and Table I in the tables section of this book) is identical with Tournavitou's first group: storage vessels. These pots are designed to hold liquid or dry substances for longer or shorter periods. They are generally characterised by a narrow neck and by handles to enable carrying. ${ }^{46}$ The second category concerns dinner vessels and includes Tournavitou's functional groups for pouring, drinking and eating. Open vessels, such as cups and bowls, fall into this class, as well as jugs, suitable for pouring and large open vessels in which substances could be mixed and served. ${ }^{47} \mathrm{~A}$ third category consists of domestic vessels, which are generally of coarse clay with large inclusions and suitable for a range of activities in the house, in particular the preparation of food. ${ }^{48}$ The fourth category consists of a few shapes which cannot be included in the storage, dinner or cooking classes. It concerns vessels such as conical rhyta (FS 199), the ring kernos (FS 197) and zoomorphic askoi and rhyta. These vessels obviously served special functions and have been found in ritual contexts. ${ }^{49}$ Therefore, such vessels are tentatively labelled ritual vessels. A final category is taken up by terra-cotta figurines.

42 Miller 1987, 109; Thomas 1991, 28; Van Dongen 1996, 12-14.

43 Sinopoli 1991, 84; Rice 1987, 237-238. Another way to infer the function of ceramics is by looking at the physical characteristics of the clay.

44 Rice 1987, 209.

45 Tournavitou 1992.

46 Tournavitou 1992, 205. Vessels designed to hold dry substances generally have wider necks; see Leonard 1981, 94. Not all storage vessels possess handles.

47 A number of vessels in this category could serve stor- age functions as well. The design of most types of jugs, for example, is specifically aimed to fulfil more than one function, such as to transport water from a well to the house (storage) and to pour liquids (dinner).

48 Sinopoli 1991, 84; Tournavitou 1992, 205-210. True cooking vessels generally have wide openings and particular clay compositions to enable them to withstand high temperatures. They are sometimes legged so as to be placed above a fire.

49 Mountjoy 1993, 124. Religious as well as domestic functions have been proposed for the conical rhyton; 


\section{SPATIAL DISTRIBUTION OF MYCENAEAN POTTERY IN THE}

\section{ME D I T E R R A N E A N}

The area in which Mycenaean pottery is distributed is represented in Map 1. This material has been found in at least fourteen modern nation states. ${ }^{50}$ The archaeology and history of each of these countries is completely different. Political events have greatly influenced the accessibility of regions and sites to conduct archaeological research. The conservation of excavated material in storerooms, as well as its accessibility also varies highly, as is sadly illustrated by the Turkish occupation of northern Cyprus. ${ }^{51}$ The history of archaeological research is also completely different in each of these areas. The large number of sites with Mycenaean pottery in Israel, for example, is partly due to the long history of research by scholars interested in the archaeology of the Bible. Finally, the organisation and interests of archaeological heritage and of the academic world is different in each of these countries. For all these reasons, it could be argued that it is impossible to include such a wide area in one study. However, we should also notice that the areas in which Mycenaean pottery has been discovered have experienced many of the same long-term processes concerning landscape and human settlement and interaction. ${ }^{52}$ In fact, the distribution map of Mycenaean pottery outside Greece (Map 1) coincides very well with definitions of the Mediterranean on geological, climatic and historical grounds. ${ }^{53}$ This Mediterraneanism justifies an investigation into a cultural aspect of such a large geographical area.

The sites which are visible in the distribution map are listed in catatalogue I, which contains a total of 348 sites outside the Aegean with LH I-LH IIIB pottery. ${ }^{54}$ Such a database is the result of specific circumstances of site survival and detection. Places that have not survived or been detected, naturally, will be absent. Other distortions might be even more serious. For example, if Troy (site no. 1), Enkomi (site no. 56), Ugarit (site no. 141) or Tell el-Amarna (site no. 268) had not been extensively excavated but only been subject to archaeological survey or even chance discoveries, they certainly would have figured less prominently in the distribution pattern. For all these reasons, it is clear that what is presented here is an archaeological pattern. Most likely, it reflects the historical distribution of this class of material. To what extent and in what way, however, is a matter for debate. Secondly, any conclusion drawn in this section should be subjected to further research. One way of doing so, is analysis of the contexts in which the Mycenaean pottery is found. That, of course, is the main subject of this book.

see Koehl 1981, 182-184.

so Spain, Italy, Malta, Albania, Greece, Turkey, Cyprus, Syria, Lebanon, Israel, the Palestine autonomy, Jordan, Egypt, Sudan. The report of a Mycenaean sherd in Iraq (Deubner 1957, 51-52) cannot be considered as secure. A Mycenaean stirrup jar has been reported from Carthage in Tunisia, see Annabi 1996, 54-55. The vessel was brought to an antique dealer. Reportedly, it came from a garden in Le Kram, but this origin could not be confirmed.

sI See, for example, Knapp \& Antoniadou 1998. Other articles in the same volume provide an interesting insight in the interplay between politics, national identity and archaeology in various areas in the eastern Mediterranean.

52 Braudel 1972; King 1997.

53 Compare, for example Map 1 with the six maps provided by King (1997, 4-7) which show various definitions of the Mediterranean. Only the sites along the Nile river do not fall within the Mediterranean.

54 The Mycenaean fragments which have been found in Spain have not been included, see Martin de la Cruz 1988, 86, 88; 1990. Likewise, a stirrup jar from Carthage has not been include here, see Annabi 1996, 54-55. 


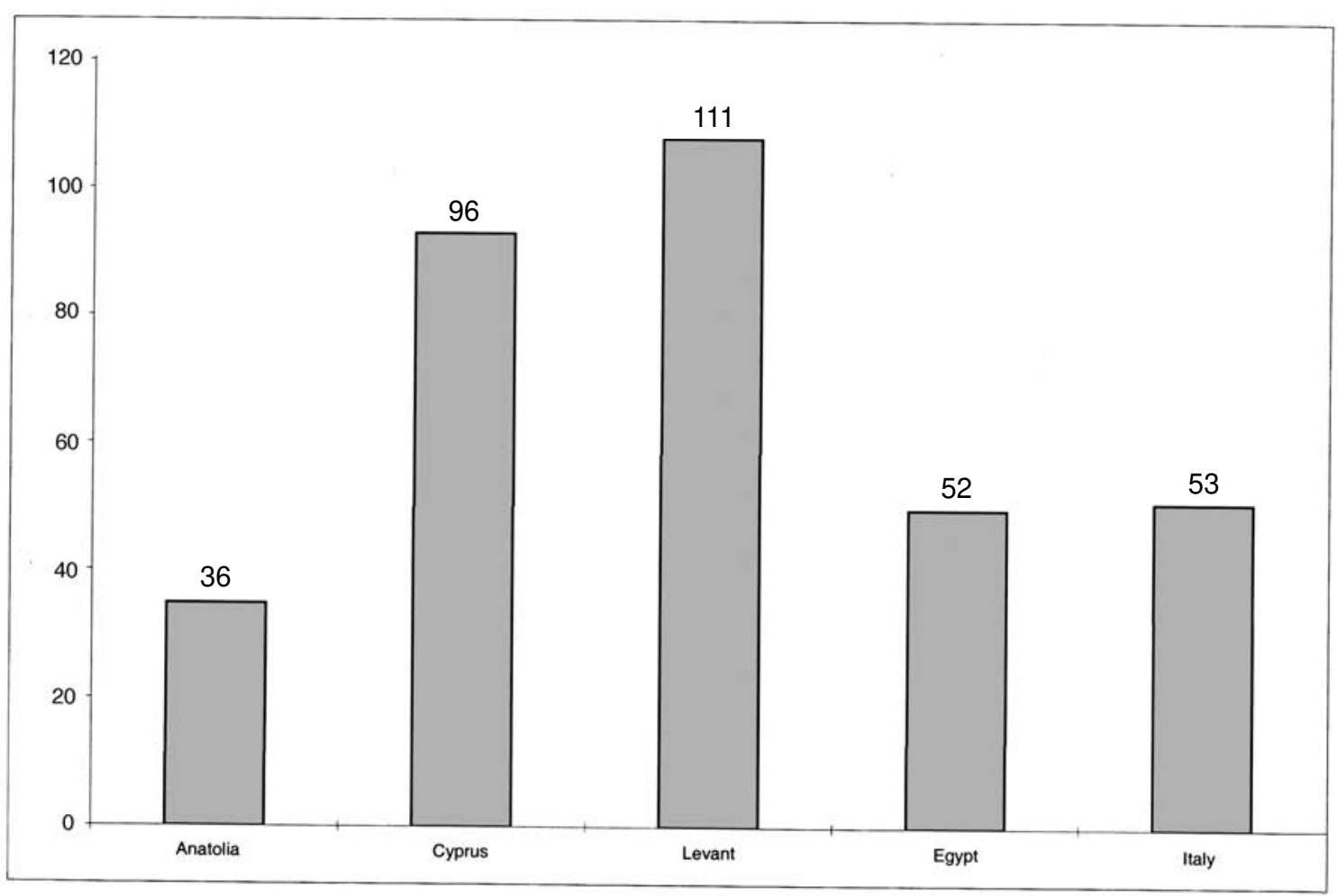

Fig. 2.3 Number of sites with Mycenaean pottery per area

The distribution of the 348 sites in Anatolia, Cyprus, the Levant, Egypt and the central Mediterranean is presented quantitatively in Fig. 2.3, while it is spatially represented in Map $1 .{ }^{55}$ The Levant possesses the highest number of sites at which Mycenaean pottery has been found, followed by Cyprus, Egypt, Italy and Anatolia respectively. The spatial distribution of sites with Mycenaean pottery shows that, in all areas, they are located both on the coast and in the interior. An exception to this is the Italian mainland, where all sites are located in the vicinity of the coast. ${ }^{56}$ Interior sites are present in Sardinia and Sicily.

Given the variation in size of these areas and the differences in the history of archaeological research, the absolute numbers of sites with Mycenaean pottery do not tell us much, just as any comparison between areas in absolute numbers is useless. The totals for each area presented in Table 3.1 can, however, serve to calculate proportions of sites with certain characteristics. These figures can fruitfully be compared among each other and with the average for the whole Mediterranean.

In Catalogue I the amount of Mycenaean pottery found on a site has been estimated on a scale from 1 to $5 .{ }^{57}$ Table 2.1 shows the relative proportions of these classes of sites in the five general areas. It is evident that everywhere the great majority of sites are of class 1 , i.e. they have yielded less than

ss The five areas are Anatolia (the Turkish mainland, including Cilicia, and the Aegean isles of Lesbos and Chios), Cyprus, the Levant (Syria, Lebanon, Israel including Gaza and the West Bank - and Jordan), Egypt (including the Sinai and Nubia) and Italy (including Malta, Sicily and Sardinia).
56 Only Sassano (site no. 340) in Campania, where one Mycenaean cup was found in a cave is an exception to the coastal pattern.

571 means less than 10 Mycenaean finds, 2 means 10-50, 3 means 50-100, 4 means 100-500, while 5 signifies more than 500 Mycenaean finds. 


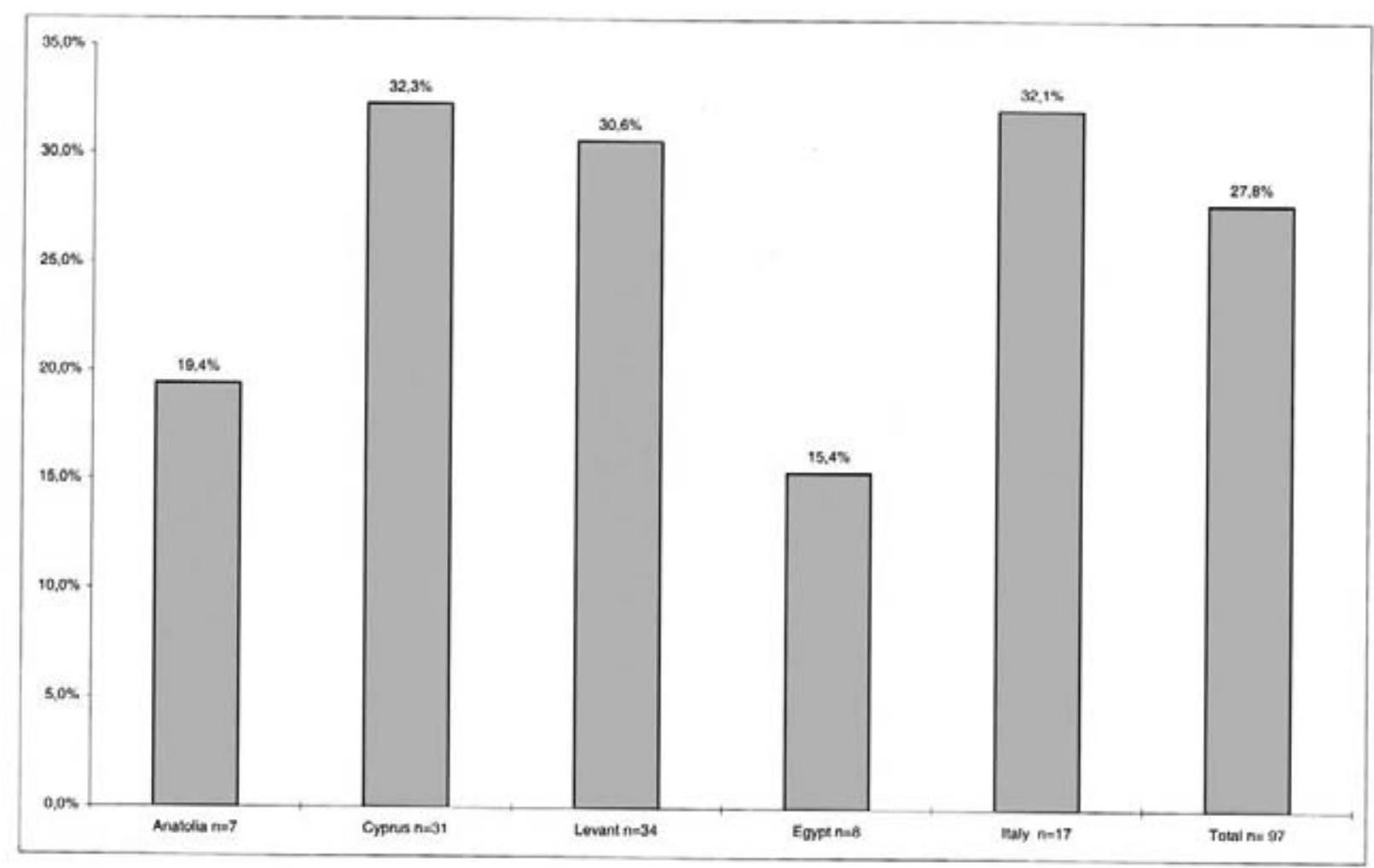

Fig. 2.4 Frequency of sites with more than ten Mycenaean finds

\begin{tabular}{|c|c|c|c|c|c|c|c|c|}
\hline \multirow[b]{2}{*}{ Anatolia } & \multicolumn{2}{|c|}{ class 1} & \multicolumn{2}{|c|}{ class 2} & \multicolumn{2}{|c|}{ class 3} & class 4 & class 5 \\
\hline & 29 & $(80.6 \%)$ & 3 & $(8.3 \%)$ & 1 & $(2.8 \%)$ & $1 \quad(2.8 \%)$ & $2 \quad(5.6 \%)$ \\
\hline Cyprus & 65 & $(67.7 \%)$ & 23 & $(23.9 \%)$ & 2 & $(2.1 \%)$ & $3 \quad(3.1 \%)$ & $3 \quad(3.1 \%)$ \\
\hline Levant & 77 & $(69.4 \%)$ & 20 & $(18.0 \%)$ & 7 & (6.3\%) & $5 \quad(4.5 \%)$ & $2 \quad(1.8 \%)$ \\
\hline Egypt & 44 & $(4.6 \%)$ & 5 & $(9.6 \%)$ & 1 & (1.9\%) & $1 \quad(1.9 \%)$ & $1 \quad(1.9 \%)$ \\
\hline Italy & 36 & $(67.9 \%)$ & 8 & $(15.1 \%)$ & 3 & $(5.7 \%)$ & $5 \quad(9.4 \%)$ & $1 \quad(2.1 \%)$ \\
\hline Total & 251 & $(72.1 \%)$ & 59 & $(17.0 \%)$ & 14 & $(4.0 \%)$ & $15 \quad(4.3 \%)$ & $9 \quad(2.6 \%)$ \\
\hline
\end{tabular}

Table 2.1 Sites with certain amounts of Mycenaean pottery per area (see note 57)

ten Mycenaean finds. We are, therefore, dealing with a distribution pattern that includes many sites with a few Mycenaean finds and some, but not many, concentrations.

In comparison with the Mediterranean average, the Levant, Cyprus and Italy, the three areas on which this research will focus, possess relatively few class 1 sites. Most likely, this reflects the absolute numbers of Mycenaean pottery in these areas, which are higher than in Anatolia and Egypt; this results in many class 2 sites in our areas. In the Levant the proportion of class 2 sites is lower than in Cyprus, while the proportion for Italy is lower still. In both Italy and the Levant the relatively low number of class 2 sites is partially caused by an abundance of sites of classes 3 and 4 . In Cyprus, as is the case for Egypt, there are relatively few sites of classes 3 and higher. All this suggests that there is variation in the concentration of Mycenaean pottery among the five areas.

If Mycenaean pottery would be concentrated in a few large centres, this would result in a distribution pattern in which there are many class 1 sites among a few but significant number of sites of classes 


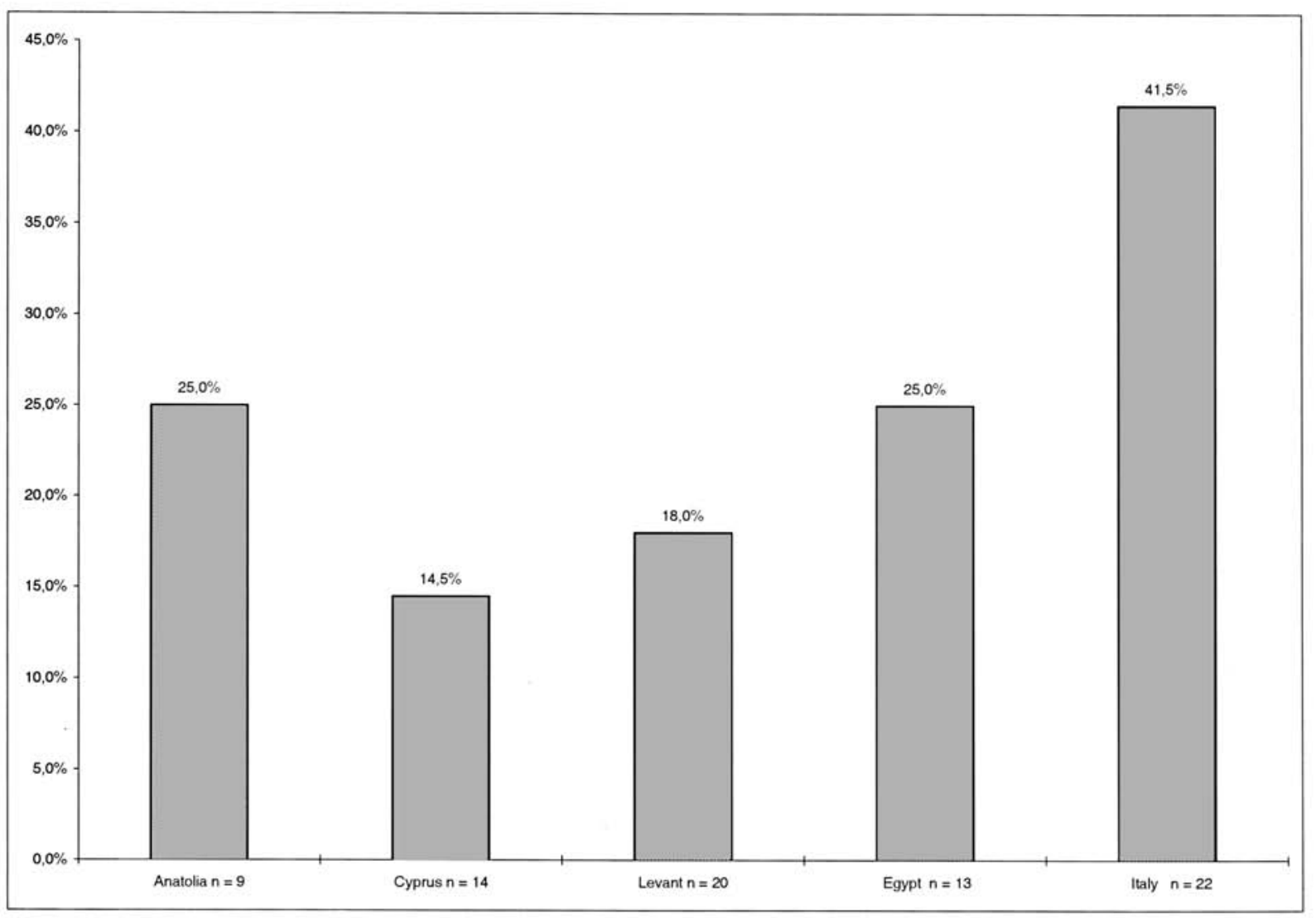

Fig. 2.5 Frequency of sites with LH I-LH IIIA1 pottery

5 and 4 . The concentration in the distribution pattern diminishes when a given area has a high proportion of sites of classes 2 and 3. On this basis, we can state that in Anatolia the concentration of Mycenaean pots is highest, since there are many sites of class 1, while Troy (site no. 1) and Miletus (site no. 19) are both of class 5. In Egypt too, there are many sites with less than ten Mycenaean finds, while only Tell el-Amarna (site no. 268) falls into class 5 . Only because there is also a class 4 (Deir el-Medina: no. 275) and a class 3 (Tell Dab'a-Qantir: no. 247) site, the concentration in Egypt is less marked than in Anatolia. In Italy Mycenaean pottery also seems to be concentrated at a few sites, but it should be noted that these fall mainly into class 4, while only Broglio di Trebisacce (site no. 317) belongs to class 5. Cyprus has the lowest frequency of sites of class 1 and there is a relatively high number of sites of class 2. The concentration of Mycenaean pottery on this island is enhanced, however, by the relative scarcity of sites of classes 3 and 4, while there are three class 5 sites: Enkomi (site no. 56), Kition (site no. 63) and Hala Sultan Tekke (site no. 65). The concentration of Mycenaean pottery seems least marked in the Levant, where there are many sites of classes 2 and 3, while only Tell Abu Hawam (site no. 175) and Ras Shamra (site no. 141) have been classified as belonging to class 5 .

Map 2 and Fig 2.4 present the spatial distribution of sites with more than ten Mycenaean finds. In Anatolia, such sites are absent in the interior. The same is true for Italy, where this was to be expected, since on the Italian peninsula virtually all sites with Mycenaean pottery are on or near the coast. In Sicily, where sites with Mycenaean pottery do occur in the interior, the three larger sites are likewise on the coast. A coastal pattern is less marked in Cyprus, where several sites of class 2 occur in the islands' interior. However, it should be noted that all sites of class 3 and high- 


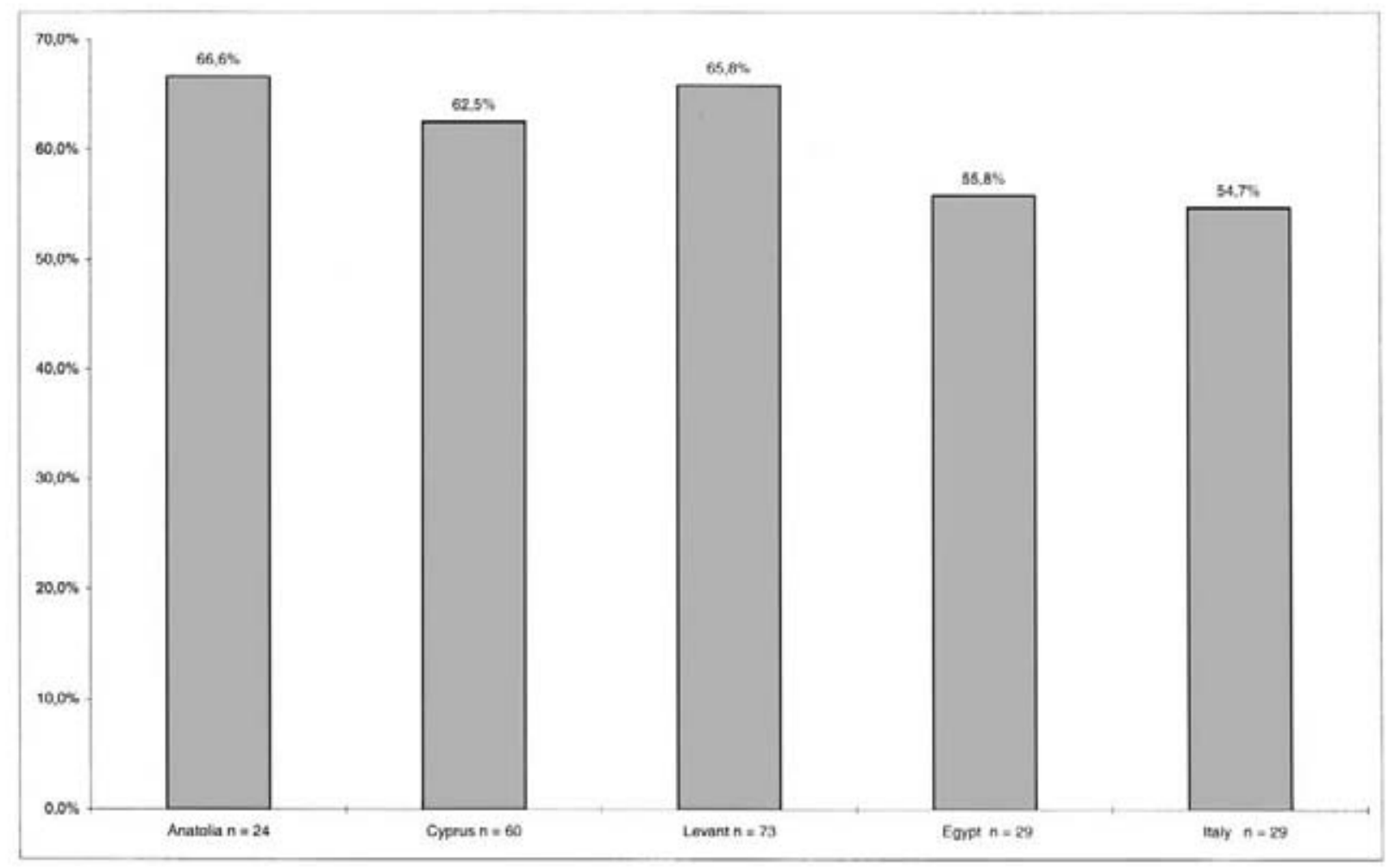

Fig. 2.6 Frequency of sites with LH IIIA2 pottery

er are situated near the coast. In the Levant, there are several sites of class 2 and higher in the interior; among these are Megiddo (site no. 181) and the Amman airport (site no. 194), which both belong to class 4 . In the northern Levant (Syria), however, Alalakh (site no. 137) is the only site of class 2 or higher situated at some distance from the coast. However, Alalakh is located along the Orontes river which leads to the sea. In Egypt a coastal preference cannot, of course, be discerned.

To sum up, it can be stated that all areas show a similar distribution pattern of many sites with little Mycenaean pottery and a concentration at some larger sites. Within this overall pattern, however, the areas reveal variations, especially with regard to the concentration of Mycenaean pottery at larger sites. This concentration seems to be very significant in Anatolia and Egypt, while it is low in the Levant. Differences are also discernible in the extent to which a coastal preference is apparent from the location of sites of class 2 and higher. Such a pattern is clear in Anatolia and Italy, while it is less marked in Cyprus and, in particular, the southern Levant.

The five areas can also be compared with regard to the presence of ceramic phases. In Fig 2.5, the extent to which sites with LH I-LH IIIA1 pottery occur is presented..$^{58}$ The spatial distribution of these

s8 The absolute amount of Helladic pottery present in all areas is higher for LH IIIA2 and LH IIIB style pottery than for the preceding stylistic phases; see, for example, Cadogan 1973, 168-169; Gilmour 1992, 113; Dickinson 1994, 252; Steel 1998, 286; Vagnetti 1999, 138-
140. In order to study the distribution of Mycenaean pottery in the Mediterranean, a division between early and later Helladic pottery at the end of LH IIIA1 seems more suitable than the LH II-LH III boundary. 


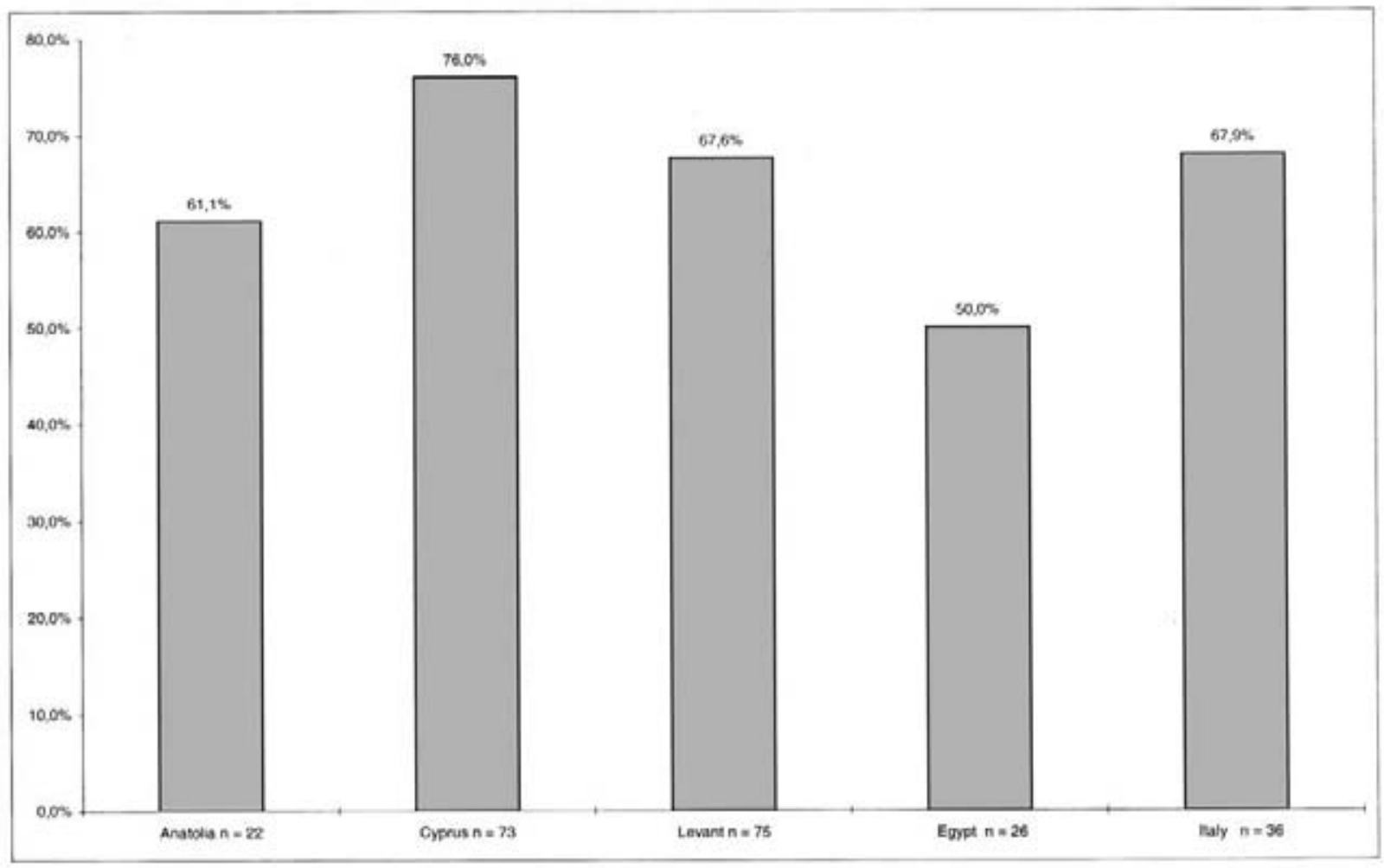

Fig. 2.7 Frequency of sites with LH IIIB pottery

sites is shown in Map 3. This early material has been found at less than a third of all sites in the four areas in the eastern Mediterranean. Taking the duration of the period involved into consideration, this distribution is limited indeed (Fig 2.1). Cyprus and the Levant have the lowest proportions of sites with early material. This indicates that the rise in imports which occurred from LH IIIA2 onwards was most marked in these two areas. In Anatolia and Egypt, sites with early Mycenaean pottery constitute a somewhat larger proportion of the total. A totally different pattern is visible for the Italian area, where LH I-LH IIIA1 pots have been found on more than forty percent of all sites.

With regard to the location of sites that have yielded early Mycenaean material (Map 3), a coastal preference is clear for Anatolia and Italy, where virtually all such sites are located close to the sea. In Cyprus, only a few sites with LH I-LH IIIA1 pottery are situated in the island's interior. In the Levant, however, early Mycenaean pottery is widely distributed in the interior, even though in the north there is only one inland site with this material, namely Alalakh (site no. 137), which is situated along the Orontes river leading to the sea. Further to the south, however, there are various places with early material, as far east as Transjordan. In Egypt, sites with early Mycenaean ceramics seem to cluster in three regions (the Saqqara area, the Fayum, and the area of western Thebes), although two sites with early material do occur in Nubia.

Figure 2.6 shows the proportion of sites in the five areas at which LH IIIA2 pottery is found. Map 4 presents the spatial distribution of this material. It is immediately clear that the pottery of this phase is abundant: in all areas it occurs at more than $50 \%$ of the sites. ${ }^{59}$ Anatolia and the Levant plot above

59 Sherds classified as LH IIIA2-LH IIIB have been included in both classes. 
the Mediterranean average, while Cyprus has a slightly lower proportion. In Egypt and Italy, LH IIIA2 pottery is present at slightly more than half of the total number of sites with Mycenaean pottery. The small differences between the proportions of sites with LH IIIA2 pottery result in a graph, which is very shallow and unpronounced (Fig 2.7). This graph shows that the distribution of LH IIIA2 pottery in the Mediterranean is fairly homogeneous.

The high proportion of sites at which LH IIIA2 is present, is also recognisable in a spatial sense (Map 4). The distribution pattern of this material is almost identical to that of all Mycenaean pottery in the Mediterranean (Map 1). The conclusion is that the distribution of LH IIIA2 pottery is wide and relatively homogeneous.

Figure 2.7 indicates the frequencies of sites with LH IIIB pottery in the five areas, while Map 5 presents the spatial distribution of this class of ceramics. Pottery in LH IIIB style is widely distributed: it is present in every area on at least half of all sites, even though this pattern is much less marked for Egypt. In general, the graph showing the proportions of sites with LH IIIB pottery is much more pronounced than the corresponding graph for LH IIIA2 (cf. the graphs in Figs. 2.7 and 2.8). This illustrates the relatively large quantitative differences between the various areas. The distribution pattern of LH IIIB pottery is less homogeneous than that of LH IIIA2 pots.

From the spatial distribution of LH IIIB vessels which is presented in map 5, it is clear that the pattern in most areas is virtually identical to that of all Mycenaean pottery. The exception to this is the Italian area, where the the Adriatic coast, as well as Sardinia figure more prominently in the distribution of LH IIIB pots than in that of previous periods. ${ }^{60}$ Obviously, in Italy more than elsewhere, shifts in time occurred with regard to sites where Mycenaean pots were concentrated.

6o See also Vagnetti 1982a, 30; 1993, 147. 


\title{
3 The archaeology of trade and consumption
}

\author{
I N T R O D U C T I O N
}

The wide distribution of Mycenaean pottery in many areas of the Mediterranean may be the result of various processes. As has become clear from the discussion in chapter 1, there is little evidence for Mycenaean colonisation on a significant scale. Nevertheless, it is conceivable that Aegean traders or travelling craftsmen deposited personal ceramic possessions in places that they visited, for example as votives in foreign temples. It is also possible that visitors to the Aegean took back pots and figurines as personal souvenirs. However, the quantities of Mycenaean pots at many places in the Mediterranean are too large to be explained in this way. I consider the bulk of Mycenaean pots in overseas areas to be the result of exchange processes.

\section{APPROACHES TOWARDS ANCIENT TRADE AND CONTACT}

Trade is a concept used by archaeologists ever since objects turned up in excavations that were similar to archaeological artefacts elsewhere. In the 19th and early parts of the 20th century, changes in material culture were generally seen as the result of the arrival of newcomers. ${ }^{1}$ Thus, the presence of Late Minoan III pottery in Sicily led Sir Arthur Evans to believe that there had been a Minoan colony on the island. ${ }^{2}$ Scholars generally viewed contact between peoples and cultures in terms of domination. Trade was therefore often interpreted as a means of controlling a certain area. ${ }^{3}$ The ideas about Minoan and Mycenaean thalassocracies are examples of this view.

Anthropologists in the second half of the 19th century formulated the theories of diffusionism and evolutionism. ${ }^{4}$ Evolutionists regarded the history of mankind as progress from undifferentiated homogeneity to complex heterogeneity. They stressed the relative independence of culture groups. Diffusionists, on the other hand, believed that peoples and cultures influence each other through the exchange of ideas, objects and individuals, which leads to ever increasing similarities between civilisations. ${ }^{5}$ In the first half of the 20th century, diffusionism, through the work of Gordon Childe, was to have the greatest impact on archaeology. The assumed spread of culture from the Aegean into other parts of Europe occurred, according to Childe, not through sequences of migrations but through a more gradual process in which 'lower' cultures were influenced by 'higher' cultures. The main vehicle

\footnotetext{
I Adams 1968, 194; he calls the 'theory of successive populations' the oldest and most widespread theory of historical causality.

2 Evans 1906, 109

3 These interpretations were probably influenced by the
} 
for this process was trade. ${ }^{6}$ In this, Childe was one of the first to recognise that economic processes could account for changes in the material record.

In the first half of the 20th century scholars, whether they were evolutionists or diffusionists, generally assumed trade to be self-evident and not in need of further evaluation. This changed when the writings of the economic historian Karl Polanyi reached archaeology. ${ }^{7}$ Polanyi did not concern himself much with change and development of societies. Rather, he studied the organisation of early state systems in which markets are not dominant, focusing in particular on the sociology of economic institutions, such as foreign trade or money. His main point of argument was that ancient economies were not early variants of 19th- and 20th century capitalism. To describe and analyse such economies, a terminology different from that of modern economic theory was necessary. The terminology that Polanyi arrived at was called 'substantivism'.

Central to substantivist analysis is the integration of economic processes that is visible in the institutional arrangements dealing with economy. ${ }^{8}$ Polanyi recognised three levels of increasing integration: reciprocity, redistribution and market-exchange. Each of these levels corresponded with forms of long-distance trade. Gift-exchange links trade partners in relationships of reciprocity. Administered trade, which is conducted through government-run channels in which there are no fluctuations of prices, is based on administrative methods and treaties between separate redistributive systems. In market-trade, the exchange itself relates the partners to each other. This last form is current in the capitalistic world, but, according to Polanyi, redistribution and administered trade were dominant among tribal and ancient societies. From the substantivist point of view, in non-monetary situations the organisation of foreign trade, its purposes and importance are all direct consequences of the internal organisation of the economy. Moreover, long-distance trade did not play a great role in tribal and archaic economies.

Influenced by the ideas of Polanyi, Moses Finley was among the first to interpret the Mycenaean palaces as redistributive centres. ${ }^{9}$ In his opinion, long-distance trade was not important in the Mycenaean economy. Such exchange as there may have been, was probably controlled by the palaces and likely to have taken the form of diplomatic gifts. This view of the Mycenaean economy and trade still prevails among Aegean Bronze Age archaeologists. ${ }^{10}$ The sheer quantity of Mycenaean vessels distributed outside the Aegean appears to be incompatible with these ideas, however. There is no evidence that pottery was considered suitable as a diplomatic gift, as may be indicated by its absence in the diplomatic records in the Near East. ${ }^{11}$ The possibility of specialised ceramic production for the eastern market in Mycenaean Greece is incompatible with a purely redistributive system in Polanyi's terms. Obviously, substantivism is not a suitable framework in which to investigate the distribution of Mycenaean pottery in the Mediterranean.

The most important contribution of substantivism to the study of ancient trade is the realization that exchange in early societies differs from that in the modern world. Polanyi makes clear that ancient trade was, to a large degree, constrained by the social organisation of the societies concerned. With respect to the subject of this book, Polanyi's ideas have the implication that we must take into account the socio-political organisation of the societies that were involved in the exchange of Mycenaean pottery. It may be expected that the large differences between the societies in the Levant, Cyprus and Italy constrained the circulation of Mycenaean pottery in different ways.

\footnotetext{
6 Childe 1925, 302.

Polanyi 1957; Dalton 1975.

8 Polanyi 1957, 251-263.
}

\footnotetext{
Finley 1982, 206 (first published in 1957).

Io For example, Halstead 1988, 520; Snodgrass 1991.

II Liverani 1986, 411; Sherratt 1999, 169.
} 
The 'New' or processual archaeology, which enjoyed popularity especially in the 1970s, has influenced the study of ancient trade in several ways. Processual archaeologists stressed that their discipline belonged to the social sciences and should look to anthropology in particular for its theoretical concepts and methodology. ${ }^{12}$ As a result, research focused on social organisation and change of past societies. For the archaeological study of trade, this has meant support for the substantivist position which also emphasised social organisation. In addition, the perceived general applicability of Polanyi's scheme contributed to its popularity among New Archaeologists, who claimed to be looking for general laws of human behaviour.

To processual archaeologists quantification of archaeological data was of the upmost importance. Studying the distribution of traded objects statistically through spatial analysis was, among other things, a result of this approach. A methodology often used to verify trade mechanisms was regression analysis. This type of spatial analysis of archaeological objects has become known, in particular, through the work of Colin Renfrew. ${ }^{13}$ He set out the frequency in which foreign objects occurred on a given site against the straight-line distance from site to source. This could be done for a number of sites and graphically visualised, resulting in a specific 'fall-off curve' for a certain group of objects. The fundamental assumption of this approach was that these different fall-off curves reflect specific trade mechanisms.

Several objections can be raised against this approach. The first is that the distribution of archaeologically recovered objects not necessarily reflects the actual spread of objects through trade. ${ }^{14}$ Many perishable objects are not included and formation processes are not taken into account. Also, distances in early societies cannot be measured as the crow flies, but depend on geographical factors - winds and currents, mountains and passes - and on the technology available to deal with these. Finally, it is not firmly established that different trade mechanisms result in distribution patterns that vary accordingly. ${ }^{15}$ Indeed, it has been shown that different mechanisms can produce similar fall-off patterns.

Spatial analysis of the distribution pattern of Mycenaean pottery in the Mediterranean will reveal areas and places that imported this material. In addition, such analyses are useful to describe where concentrations of this pottery are present. In the first chapter of this book, I argued that the movement of goods in the Late Bronze Age Mediterranean was highly complex and involved many groups of people and different types of exchange. Mycenaean pottery was only one part of a wider repertoire of goods that circulated in these complex distribution networks. ${ }^{16}$ It seems unlikely that spatial analyses of the distribution pattern of Mycenaean pottery will reveal the complex mechanisms at work in such networks. Other than as a tool to describe the archaeological distribution pattern, spatial analysis does not seem to be a suitable framework to investigate the exchange of Mycenaean pottery in the Mediterranean.

A fruitful impact of processual archaeology on the study of ancient trade is the insistence that archaeological propositions should be verified scientifically. In the study of ancient trade this is taken up especially with respect to the provenance of traded objects. In the past, similarities in form and deco-

I2 Trigger 1978, 6-10.

I3 Renfrew, Dixon \& Cann 1968; Renfrew 1972, 465$471 ; 1975,48-53$.

I4 McCAdams 1974, 24; Earle 1982, 7. This was realised by the practitioners themselves; see Renfrew 1972, 441; Hallam, Warren \& Renfrew 1976, 103.

Is Earle 1982, 7.
I6 This has become clear from the excavations of the shipwreck near Ulu Burun, where a few Mycenaean pots were part of a varied cargo including a wide range of raw materials and finished objects from various areas in the Mediterranean and beyond, see Bass 1967; 1991; Pulak 1988; 1997 
ration of objects found in different places were often merely taken to mean trade or contact between areas. The use of technical and statistical methods to analyse obsidian, pottery, metal and various other materials has proven wrong many of these assumptions. ${ }^{17}$ Identifying the exact origin of presumed imports through archaeometric methods is nowadays essential to establish the presence and extent of prehistoric exchange. Mycenaean pottery is one of the fields of research in which such investigations have had a particularly marked impact. ${ }^{18}$

Since the late 1970s the interest of archaeologists in long-distance trade and contact has increased, due in particular to World Systems theory. According to this theory, which was first fully formulated by Immanuel Wallerstein, regions can be systemically linked by economical processes. ${ }^{19}$ In such systems there is a geographical division of labour in which élites of core areas exploit the labour and surpluses of peripheral areas. This means that tasks requiring higher levels of skills and greater capitalisation are reserved for higher ranking areas. In these areas there exist strong state machineries with élites whose interests are served by the state being an autonomous entity, often resulting in a strong bureaucracy. Peripheral areas sometimes also have state organisations, but they are weak and often have a low degree of autonomy, as in a colonial situation. Economical tasks performed in these areas are dependant on incentives from the centre and are usually labour intensive, such as the provision of raw materials. Relations within such dependency systems are ever-changing and shifts of cores and peripheries may occur frequently.

Wallerstein formulated his ideas in order to explain the spread of capitalism since the sixteenth century $\mathrm{AD}$; others have modified the model so that it could be applied to earlier periods as well. ${ }^{20}$ In pre-capitalist situations, core areas can be described as groups of polities that have become net consumers of resources from other polities by a variety of relations of exploitation, while peripheries are polities of which the economies are directed to meet the demands for surplus product. Because bulk trade was assumed to have played a less dominant role in antiquity than in modern economies, coreperiphery relations were seen as created, maintained and changed mainly through the (unequal) exchange of prestige goods. The ruling élites, both in peripheries and cores, were viewed as the most important groups involved in such dependency relationships.

Among scholars working from a World Systems perspective, there seems to be the tendency to view all relations between societies in terms of dependency and much discussion seems to concentrate on the identification of cores and peripheries. ${ }^{21}$ However, many prehistoric societies in which evidence of foreign contact is attested do not fit the definitions of either category. The possibility of foreign relations on a different, for instance reciprocal, basis seems to be ruled out in advance. Secondly, the nature of this theory is highly economic. Central in World Systems theory stands the capitalist notion of the accumulation of wealth in core areas..$^{22}$ Apparently, this is regarded as a universal feature of societies. It is questionable whether such a concept can be applied to early economies, without taking the differences between these and modern society into account. ${ }^{23}$

It is questionable whether Mycenaean pots found outside the Aegean, in many cases only a few, can be considered as prestige goods that helped to create dependency relationships. ${ }^{24}$ Mycenaean pots can

${ }^{17}$ For an overview of methods available and of possibilities and problems involved, see Cherry \& Knapp, 1991.

I8 For an overview, see Van Wijngaarden 1999b, 27-28.

I9 Wallerstein 1974, 349-350.

$20 \quad$ Kohl 1987; Rowlands 1987.

2I Arafat \& Morgan 1994, 132.
22 Rowlands 1987, 5; Frank 1993, 390.

23 J.A. Barceló in Frank 1993, 406: "to speak of 'accumulation of capital' (...) is inappropriate when all we have is some evidence of prestige items".

24 Cf. Arafat \& Morgan 1994, 124. 
be understood as value-added products, which acquire significance not through the preciosity of their raw material, but through manufacture and the associations with other products. ${ }^{25}$ It is unlikely that such a product alone constitutes the result of a peripheral economy modified to suit the demands of centres elsewhere in the Mediterranean. The role of Mycenaean Greece in the Mediterranean during the Late Bronze Age, then, does not seem to fit Wallerstein's model and it is doubtful that World Systems theory provides a proper theoretical framework to study the Mycenaean pottery outside Greece. It is, however, important to realise that trade and foreign contacts are processes which contribute to the development of societies. Prestige goods have travelled often in small quantities, but their importance may have been "out of proportion to their bulk, for it was the need to acquire [such] supplies of valued materials which motivated the intensification of local production". ${ }^{26}$ In a way, World Systems theory underlines the need to investigate the role of Mycenaean pots in the society in which they were imported.

\section{A CONSUMPTION APPROACH}

Artefacts which are thought to have originated in a geographical area different from the one they are found in, constitute the main body of archaeological evidence for the study of ancient trade. In general, such objects have been found in contexts in which they have been used and discarded. ${ }^{27}$ It is logical to assume that the activities in the importing societies in which these objects have played a role have affected their deposition in the archaeological record..$^{28}$ Rather than the act of exchange, archaeological artefacts represent patterns of use and discard by consumers. The consumption of traded artefacts constitutes a dimension which has been neglected by many earlier approaches towards ancient exchange. ${ }^{29}$

Since the 1980s, increasing attention has been given in a number of academic disciplines to the consumption of material objects and to their relationships with human behaviour. ${ }^{30} \mathrm{~A}$ central concept within such material culture studies is that people do not only classify the world of objects according to their physical properties. ${ }^{31}$ Of course, artefacts can be defined by the fact that they are products of human labour, and the materials from which certain artefacts are made, impose constraints on the range of purposes for which they can be used. Also, the functions which objects can fulfil have proven to play a key role in people's categorisation of the material world around them. However, in most societies there exist a wide variety of different forms which are designed to serve identical purposes. For example, the many different ceramic containers that are used in the Dangwara tribe in central India for a limited range of purposes show that there is only a rather loose relationship between form and function. ${ }^{32}$

The ways in which particular objects are used and appreciated, then, are the result of other factors than function and material properties. ${ }^{33}$ Indeed, it is an object's relationship to social groups and cul-

25 For Mycenaean pottery as a value-added product, see Sherrattt 1994a, 62-63; 1998, 295-296.

26 Sherrattt \& Sherratt 1991, 354.

27 An exception to this are objects in shipwrecks, which, if part of the cargo, may be considered to have been found in a context of circulation.

28 Earle 1982, 9-10
29 See also Van Wijngaarden 1999a, 7-10.

30 For a history and overview of 'consumer studies', see Miller 1995, 1-2 and other articles in the same volume.

31 $\quad$ Miller 1987, 112-118.

32 Miller 1985, 51-74.

33 Indeed, a case can be made for the hypothesis that an artefact's capacity to disguise the immediacy of utility 
tural practices which imposes meanings on it. ${ }^{34}$ The workings of such processes of meaning-giving to the material world have been aptly described by Pierre Bourdieu. In his opinion, the social world does not function according to rules and models that scholars only have to find, but is shaped by strategies of social actors. ${ }^{35}$ An example is the case of gift exchange. According to Bourdieu, the essence of this system does not lie in the fact that there is a gift and a counter-gift, but in the lapse of time between the two, the size and value of each of the gifts, the persons who bring them, the phrases that are used and other elements which allow room for manipulation. Such manipulation creates numerous ways and degrees in which parties can be offended, honoured or in subtle ways be otherwise approached.

It is the suitability of objects to serve in strategies adopted by social actors that endows objects with specific meanings. Social strategies develop through conscious and unconscious choices which are determined not only by the circumstances, but also by the chooser's social, economical and individual background. ${ }^{36}$ Social reality, and hence the material record, is thus shaped by cultural choices, which are determined by many variables such as honour, local tradition, material need, individual ideas and the like. Because these elements are themselves part of the social reality, it can be stated that the material record is systematically structured according to social relations which are, in turn, influenced by material culture ${ }^{37}$ Material artefacts participate actively in shaping social relationships between groups of people. Objects may also be active components in the relationships between people and the spiritual world of gods and supernatural powers, as well as between the living and their ancestors. ${ }^{38}$ For this reason, the significance which objects acquire through their inclusion in strategies is not only social but, in a wider sense, cultural.

When the significance of objects is related to social reality and cultural practices, it is logical to expect that it is highly variable across cultural contexts. Indeed, anthropological research has revealed the extreme varieties of uses and connotations which can be attached to similar physical objects in different cultural contexts. ${ }^{39}$ Imported objects, in order to be relevant in their new surroundings, need to be recontextualised by the imposition of indigenous cultural associations.$^{40}$ Often, these cultural associations have to do with the fact that imports derive from far-away and mysterious places. They make the owner share in the world from which the artefacts derive and emphasise his or her capacity to extract the objects from that world. ${ }^{41}$ Objects which circulate in systems of supra-local exchange may be expected to experience various phases of such recontextualisations. ${ }^{42}$

The cultural meanings which become attached to objects when they are associated with social strategies and cultural practices are prime reasons why they are desired. ${ }^{43}$ According to Arjun Appadurai, demand and consumption are socially regulated. ${ }^{44}$ In modern society this is done through taste-making mechanisms such as fashion. In primitive societies, objects can, for example, be allowed to circulate only among certain groups of people. In such a situation, there are often restrictions in

enhances the status of an object and its owner, see Veblen 1899, 97-101. A good example are ornate, fragile, porcelain tea-cups.

34 Miller 1987, 118; Wiesner 1989, 57.

35 Bourdieu 1977, 3-10.

36 Bourdieu 1984, 170; 1989, 150-154.

37 Bourdieu 1977, 91; 1984, 101; Miller 1987, 129-130.

$3^{8} \quad$ Bourdieu 1977, 41-43

39 Miller 1987, 109; Thomas 1991, 28; Van Dongen
1996, 12-14.

40 Thomas 1992, 35-36.

4 I Strathern 1992, 177

${ }^{42}$ In this respects, Kopytoff (1986) speaks of cultural biographies of things. See, also, Thomas, 1991, 28.

43 Thompson 1979, 9; Bourdieu 1984, 100-101; Van Wijngaarden 1999c, 3-5.

44 Appadurai 1986. 
the exchange of objects as well. While such 'enclaving' is in the interest of the ruling élites, the diversion of artefacts to zones where exchange is less confined is frequently the recourse of the individual and of traders. Obviously, even within one cultural context, similar objects may have different significances for different groups of people..$^{45}$

The idea that the significance of material objects is determined by the cultural associations which are imposed on them by their inclusion in social strategies has been taken up by so-called contextual archaeology, of which Ian Hodder is a notable exponent. In his view, the archaeological record is the meaningful result of cultural choices made by social actors. ${ }^{46}$ An important consequence is that, according to Hodder, archaeological objects can only be understood within their proper cultural context. They have a meaning as members of categories opposed to other categories and as material expressions of associations and evocations. This meaning can be called the symbolism of an object. ${ }^{47}$ Any study of prehistoric exchange should, according to Hodder, take into account the symbolism of the exchanged artefact in the receiving society. ${ }^{48}$ The symbolism of types of traded objects can be inferred, according to Hodder, from its different associations: it may or may not be present in certain types of burials, in different types of settlements or in particular buildings within settlements, and so on. From the various and contrasting associations of exchanged objects, some picture can be obtained of their cultural significance.

In this research, contextual archaeology will provide the framework of analysis for the study of consumption and demand of Mycenaean pottery found in the Levant, Cyprus and the central Mediterranean. These three areas possess the majority of sites with such pottery. In addition, the material culture in each of these three areas is completely different from that in Greece and it is very clear that Mycenaean pots constituted a foreign element due to maritime exchange rather than to processes of acculturation. The great differences in the level of socio-political complexity between the contemporary cultures in these three areas will emphasise the different cultural associations attached to the Mycenaean ceramic objects. Variations in associations and contexts of Mycenaean pots in the Levant, Cyprus and Italy may shed light on variations in social strategies of which these objects were part.

The cultural meanings attached to a Mycenaean ceramic vessel at a given time in a place somewhere in the Levant, Cyprus or Italy surely varied from person to person. Any individual's biography results in psychological dispositions towards the material world. Even though such individual attitudes towards specific objects are not invisible in the archaeological record, they are hard to deal with on a general level. ${ }^{49}$ However, the same dispositions will have resulted in Mycenaean pots having been used in social strategies and cultural practices which supersede the individual. The cultural significance of Mycenaean pottery had local, regional and supra-regional or Mediterranean dimensions. On each of these three levels, a number of aspects serve to assert the cultural significance of Mycenaean pottery. Of particular importance are the social groups that used specific parts of the Mycenaean repertoire, the objects and activities with which they were associated and the extent to which these pots were part of social strategies.

45 Thompson 1979, 52; Appadurai 1986, 21.

46 Hodder 1982a, 207.

47 Hodder 1987, 3.
${ }^{48}$ Hodder 1982a, 207-208; see also Voutsaki 1995, 13.

49 Melas 1989, 138-142. 



\title{
4 Mycenaean pottery in the Levant: introduction
}

\author{
PREVIOUS RESEARCH
}

The Syro-Palestinian littoral, commonly known as the Levant, is now taken up by six modern nation states: Turkey, Syria, Lebanon, Israel, Jordan and the Palestine Autonomy. This configuration and the political instability in the region over the last fifty years have influenced archaeological research, and any interpretation of distribution patterns in this area is hazardous. This is true also for the distribution of Mycenaean pottery, which has been found at 111 sites, from Charchemish (site no. 133) in Turkey to Tell es-Shari'a (site no. 243) in northern Sinai (Map 6). The concentration of sites visible in the southern Levant is at least partly caused by the intensity of archaeological research since the foundation of Israel in 1948. ${ }^{1}$ Moreover, for a long time research has been difficult at many sites in Lebanon, which has influenced the quality of the information available.

The earliest report, to my knowledge, of Mycenaean pottery in the Levant is given by F.J. Bliss in 1894 who had discovered it at El-Hesy (site no. 231) in Palestine. ${ }^{2}$ F.B. Welch named Tell es-Safiyeh (site no. 228) as another site with Mycenaean imports and saw an Aegean influence in Levantine vase shapes and decoration. ${ }^{3}$ R.C. Bosanquet probably referred to these publications when he asserted the presence of Mycenaean pottery in southern Palestine. ${ }^{4}$ None of these scholars distinguished between actual Mycenaean pottery and so-called Philistine ware, a distinction that was first made by $\mathrm{H}$. Thiersch in $1908 .^{5}$

In the early decades of the twentieth century, several sites with Mycenaean pottery were excavated in southern Palestine, among them Garife (site no. 159), Gezer (site no. 224) and `Ain Shems (site no 227). ${ }^{6}$ As a result, D. Fimmen in 1924 was able to list six sites. ${ }^{7}$ The discovery of a tomb near Minet el-Beida (site no. 142) in Syria in 1928 and the subsequent excavations by C.F.A. Schaeffer at the site and at nearby Ras Shamra (site no. 141) can be considered a landmark in the research of Mycenaean pottery in the Levant. Not only did these discoveries establish the presence of Mycenaean pottery in the northern Levant, the amounts of that pottery on both sites at the time exceeded that on any other. Schaeffer's ideas about Mycenaean colonisation and even domination of Ugarit by Mycenaeans ${ }^{8}$ were not taken over by contemporary scholars working at other sites with a large amount of

I Hankey 1993a, 101. Before the establishment of the state of Israel, this area also received much archaeological attention by scholars interested in the archaeology of the Bible.

2 Bliss 1898, 61-63 (first published in 1894).

3 Welch 1899-1900, 119.

4 Bosanquet in Dawkins 1904, 127-128.

s Thiersch 1908, 378-384.
6 For Mycenaean pottery in Garife, see, for example, Woolley 1921, 181-183. For Gezer, see MacAlister 1912, 155-156 Pl. CLI; Thiersch 1909, 384-386. For 'Ain Shems, Mackenzie 1912-13, 10; Grant \& Wright 1938.

7 Fimmen 1924, 98, 106-107.

8 Schaeffer 1936b, 99-103. 
Mycenaean pottery, such as Tell Beit Mirsim (site no. 232), Alalakh/Tell Atchana (site no. 137) and Tell Abu Hawam (site no. 175). ${ }^{9}$

During and shortly after the Second World War several important studies appeared. Furumark treated Mycenaean pots from twenty-five Levantine sites and used them to help construct his basic typology and chronology of Mycenaean pottery. ${ }^{10}$ An analysis of Mycenaean pottery in the Levant was given in 1951 by F.H. Stubbings who listed 28 sites. ${ }^{11} \mathrm{He}$ did not only discuss the pottery, but also tried to connect its distribution with historical developments. Stubbings made a distinction between the northern Levant (Syria) and the southern part (Palestine) and concluded that most of the LH III material is found in the south, which was the area controlled by Egypt. ${ }^{12}$ Although cities like Ugarit (site no. 128) and Alalakh (site no. 137) were notable exceptions, Mycenaean trade with the Hittite area in the north seemed to Stubbings to have been restricted.

Stubbings' work was brought up to date in 1967 by Vronwy Hankey. She discussed the Mycenaean pottery from 57 sites in Syria, Lebanon, Jordan and Israel. On this basis she was able to make general observations of considerable importance. ${ }^{13}$ Hankey found only little evidence for the presence of LH II pottery in the Levant and even less for LH I. She stated that the repertoire of LH III pot shapes in the Levant is similar to that of Cyprus and differs from mainland Greece in the absence of kylikes, jugs and bowls. The quality of the pottery in the Levant equals that in Cyprus, although the island possesses larger quantities. Hankey also noted that there was very little LH IIIC pottery in the Levant and that imports seem to have ended at the end of the Late Bronze Age around $1200 \mathrm{BC}$. An important observation made by Hankey was that Mycenaean pottery in the Levant generally is found on sites where Cypriot pottery is also present. On the basis of these characteristics, Hankey evaluated Mycenaean trade with the Levant, thus providing a framework in which to view the import of Mycenaean pottery. Stubbings had suspected that much of the Mycenaean pottery found in the Levant was produced on Cyprus. ${ }^{14}$ Hankey, in contrast, assumed that the Mycenaean pottery originated in mainland Greece and that Cyprus had been the first stopping place of Mycenaean ships, which later continued to Near Eastern harbours. ${ }^{15}$

An overview of the available evidence for Mycenaean contacts with the Levant was given in 1974 by H.G. Buchholz. ${ }^{16}$ He presented a catalogue of sites and discussed Levantine finds in the Aegean. General remarks on the distribution of Mycenaean pottery in the Eastern Mediterranean were made by G. Cadogan in 1973. He commented on the fact that Mycenaean pottery is not only found on the Levantine coast, but also in the interior. ${ }^{17}$ In his view, this spread shows that there was a demand for Mycenaean pottery or their contents as luxury products. Cadogan also discussed the presence of LH IIIB2 material, which is thought to have been imported on a smaller scale than that of the previous phase. ${ }^{18}$ In the same volume, J.-C. Courtois likewise addressed the issue of late LH IIIB imports in the Levant. He discussed a group of amphoroid kraters from the latest phase of Ras Shamra, which were probably produced in the Dodecanese or the south-western coast of Asia Minor. According to Courtois, peripheral areas in the Aegean became more important for the im-

9 See Albright 1930-31; Woolley 1955; Hamilton 19341935 respectively.

Io Furumark 1941a, 644-654.

II Stubbings 1951, 53-87.

I2 Stubbings 1951, 104-105.

I3 Hankey 1967, 145-146.
14 Stubbings 1951, 87, 108.

Is Hankey 1967, 146-147; see also Hankey 1970, 20-23.

I6 Buchholz 1974, 389-439, with extensive bibliography.

17 Cadogan 1973, 170.

I8 Catling (1964, 35), was among the first remarking on this phenomenon. 
port of Mycenaean pottery during the final stages of LH IIIB2. ${ }^{19}$ This would tie in with evidence that the production of LH IIIB2 pottery within Greece was less centralised than in the preceding periods. ${ }^{20}$

Important information regarding the use and appreciation of Mycenaean pottery in the Levant was provided by Albert Leonard Jr. in 1981. He showed that the most popular open shapes filled specific gaps in the local ceramic repertoire, suggesting that the popularity of Mycenaean and Cypriot pottery in the Levant is somehow related to the Levantine pottery industry. ${ }^{21}$ Closed pots were, according to Leonard, imported for their contents. The stirrup jar most likely contained pourable oil, while the wide-mouthed alabastron, amphoroid jar and pyxis could have held more viscous oils or unguents. Leonard also commented on the social status of those who acquired Mycenaean pottery in Transjordan..$^{22}$ The fact that the chariot krater is also found in the interior of the Levant suggests, in his view, that the owners were familiar with the iconography of such a vase and would therefore most likely be influential persons in their communities. Using contextual evidence, Hankey likewise commented on the social status of those importing Mycenaean pottery. ${ }^{23}$ Mycenaean pottery found in palaces and temples testifies that the demand for it originated in the upper levels of the societies. However, according to Hankey, this pottery, like other exotic goods, trickled down to people of more modest stature as well.

Recent research has focused on the provenance of the Mycenaean pottery found in the Levant. Clay analyses have led to a better understanding of the extent to which Mycenaean pottery was imitated locally. ${ }^{24}$ In contrast to Cyprus and Italy, manufacture of Aegean-type pottery in the Levant was limited to a few closed pot shapes such as flasks and stirrup jars. ${ }^{25} \mathrm{~A}$ few overviews of the distribution of Mycenaean pottery in the Levant have been recently been published, in particular the index by A. Leonard, who catalogued the Mycenaean pottery from 89 sites by pot shape and decorative motives. ${ }^{26}$ Vronwy Hankey has discussed the contexts in which the pottery is found, the historical background and the development of the trade, thus providing a summary of all the available evidence. ${ }^{27}$

\section{DISTRIBUTION OF MYCENAEAN POTTERY IN THE LEVANT}

The distribution of Mycenaean pottery in the Levant is presented in Map 6, which shows that this class of material has been found at places along the coast, as well as in the interior. In Syria and Lebanon, sites with such pottery in the interior are concentrated in the Orontes and Beqa valleys, although there is a notable distribution in the direction of Carchemish (site no. 133) along the upper Euphrates. In the south, there is a clustering of sites in the valley of the Jordan river and its branches, including sites in Transjordan. Another grouping of sites leads from the coast near Tell Abu Hawam (site no. 175) to the Jordan valley. A large concentration of sites is also visible in south-western Israel, including the Gaza strip.

19 Courtois 1973, 149-165, 153 especially.

20 Sherratt 1980, 199; 1982, 185.

гा Leonard 1981, 90-96.

22 Leonard 1987, 264-266.

23 Hankey 1981b, 109-110, 115; 1993, 104.

24 Leonard et al. 1993; Killebrew 1998.

25 Killebrew 1998, 161-162. Levantine production of so- called 'Mycenaean IIIC1b' bowls began during a somewhat later period.

26 Leonard 1994. Earlier, B. Gregori and G. Palumbo (1986, 365-368, 389) listed a total of 111 sites and gave a very useful statistical analysis for each of the successive ceramic phases.

27 Hankey 1993a, 105-107. 
This pattern can be refined if we take the quantities of Mycenaean pottery into account (Map 7). It is clear that in Syria and Lebanon most of the more important find spots are situated along the coast. Only Alalakh (site no. 137) and Kamid el-Loz (site no. 168) are located inland, both along routes to the sea. In the southern Levant, sites with notable quantities of Mycenaean pottery occur in the interior more often. One site with more than a hundred Late Helladic finds is located in Transjordan: Amman Airport (site no. 194); Hazor (site no. 171), Beth Shean (site no. 187) and Dothan (site no. 184) each have yielded 50-100 Mycenaean finds. The largest quantities of Mycenaean pottery in northern Israel have been reported from Tell Abu Hawam (site no. 175) and Megiddo (site no. 181). In the south, there are a few sites with notable quantities of this pottery, among which are Lachisch (site no. 230) and Ashdod (site no. 222).

The first region that can be distinguished within the general distribution pattern of Mycenaean pottery in the Levant is the whole area north of the plain of Akkar and Homs in Lebanon and Syria (Map 7: north of site no. 150). The wide coastal plain slopes gently upwards to the Jebel Ansariyeh, the mountain range that contains the Orontes valley. ${ }^{28}$ During the Late Bronze Age, this whole region came relatively late under Egyptian domination and Egyptian presence was never as strong as in the south. this was never as strong as in the south. ${ }^{29}$ Moreover, this region in turn came under Hittite influence from the second half of the 14th century BC onwards. Of the twenty-two sites with Mycenaean pottery in this area (sites nos. 133-155), six have yielded more than ten Mycenaean finds: Alalakh (site no. 137), Ugarit (site no. 141), its port Minet el-Beida (site no. 142), Ras Ibn Hani (site no. 143), Tell Sukas (site 1145) and Tell Kazel (site no. 148). Of these, Minet el-Beida, Ras Ibn Hani and Tell Sukas all belonged to the kingdom of Ugarit. ${ }^{30}$

South of the plain of Akkar, the Lebanon and Palestine form distinct geographical units. From an archaeological point of view, however, it is more suitable to make a distinction between the coastal plain and valleys on the one hand and the uplands and Transjordan on the other. ${ }^{35}$ During the Late Bronze Age, Egyptian influence was much stronger in the coastal plain and the river valleys, which were of prime strategic importance. Most of the sites with more than ten finds of Helladic pottery are located in the coastal plain and the valleys, of which Byblos (site no. 156), Sarepta (site no. 162), Tell Abu Hawam (site no. 175), Ashdod (site no. 222) and Lachish (site no. 230) - each with more than 50 Mycenaean finds - are located in the coastal plain, while Hazor (site no. 171), Beth Shean (site no. 187) and Dothan (site no. 184) are situated in the Jordan and Jezreel valleys or their foothills. Some 25 of our sites are situated in the Palestine uplands and Transjordan. ${ }^{32}$ Of these, only Shechem (site no. 207), Tell es-Saidiyeh (site no. 191) and Amman Airport (site no. 194) have yielded more than ten Mycenaean finds.

In the succeeding chapters, I will discuss in detail the cultural context of the Mycenaean pottery from one site in each of the three regions mentioned above: Ugarit (site no. 141) in Syria, Hazor (site no. 171) in the Jordan valley and Deir 'Alla (site no. 192) in Transjordan. Ugarit was a large coastal town, which was heavily involved in maritime exchange, whereas Hazor constituted an inland city. Deir 'Alla is also located inland, but represents a much smaller, rural site. The large differences in

28 All geographical information about the Levant comes from Fisher 1978, 398-448; see, especially, Figs. 14.1 and 14.3

29 Astour 1981, 12-15; Liverani 1988, 559; Leonard 1989, 12-27; Falconer 1994, 305-306.

30 Saadé 1979-1980, 223.
3I Gonen 1992, 32-36; Bunimovitz 1995, 325.

32 Of course, the borders between uplands and lower areas are not always very clear. For several sites, individual analysis of the material culture would be necessary to be able to assign them definitively to one of these two regions. 
function and character between these three sites probably has had consequences for the use and appreciation of the imported Mycenaean pottery. Nevertheless, it is important to realise that these sites do not represent type-sites in the distribution of Mycenaean pottery in the Levant. The conclusions reached for Ugarit, Hazor and Deir 'Alla cannot simply be applied to other sites in the same region as well. 



\section{Ugarit}

\section{N T R O D U C T I O N}

The sites of Ras Shamra and Minet el-Beida are situated in the Syrian coastal plain, ca. $12 \mathrm{~km}$ north of the modern harbour town of Lattakia. Minet el-Beida is the name of a bay near which an urban zone has been excavated, less than a kilometre away from the tell of Ras Shamra, which is located somewhat inland. The sites have been excavated since 1928 by successive French missions, who have continued the research up to the present day. ${ }^{.}$The site at Minet el-Beida was explored from 1929 to1935. The earliest habitation at the harbour town dates to the first phase of the Late Bronze Age. ${ }^{2}$ In contrast, the lowest levels from Ras Shamra are from the preceramic Neolithic and the site appears to have been inhabited continuously until its destruction and abandonment at the end of the Late Bronze Age. ${ }^{3}$ Epigraphic evidence has shown that Ras Shamra was the capital of ancient Ugarit. ${ }^{4}$

The Late Bronze Age remains appear to have covered the whole tell of Ras Shamra, which encompasses about 26 ha., of which $1 / 6$ has been excavated (Fig. 5.1). ${ }^{5}$ The excavated parts of the ancient city are generally referred to as if they constitute city areas. It must be understood, however, that the excavations have largely been conducted independent of the town's urban layout and that the areas represent archaeological trenches, rather than town quarters. ${ }^{6}$ The western part of the site is occupied

I Until 1969 Claude F.A. Schaeffer was director of the excavations. Since then, the French archaeological mission has been under the responsibility of $\mathrm{H}$. de Contenson (1972-1973), J. Margueron (1975-1976), M. Yon (1978-1998) and Y. Calvet (1999-). For convenient summaries of the history of excavations see Saadé 1979, 39-54; Yon 1997a, 17-18.

2 Courtois 1979a, 1283.

3 Courtois 1979a, 1132-133; Yon 1997a, 25-35.

4 Albright 1931-1932, 165; Schaeffer 1932, 24-27. The ancient name of Minet el-Beida is most likely Ma'hadou, see Astour 1970, 113-127; Saadé 1995, 212; Yon 1997b. The name Ugarit is used here to indicate both sites.

5 Callot \& Yon 1995, 158. The situation in Minet elBeida is less clear, but Saadé (1995, 212-213) estimates that about 1.4 ha. have been excavated and that the total area of the site was much larger.

6 In 1970, a tomb was discovered; see Saliby 1979-1980; Courtois 1979a, 1279-1280. The exact location of this tomb is not known to me; it is indicated in Fig. 5.1 with an asterisk. In the succeeding pages, the names of the various areas on the tell of Ugarit will be abbreviated:

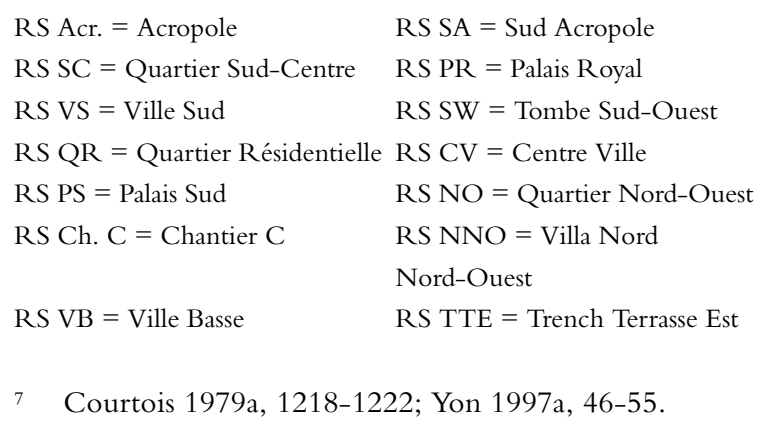




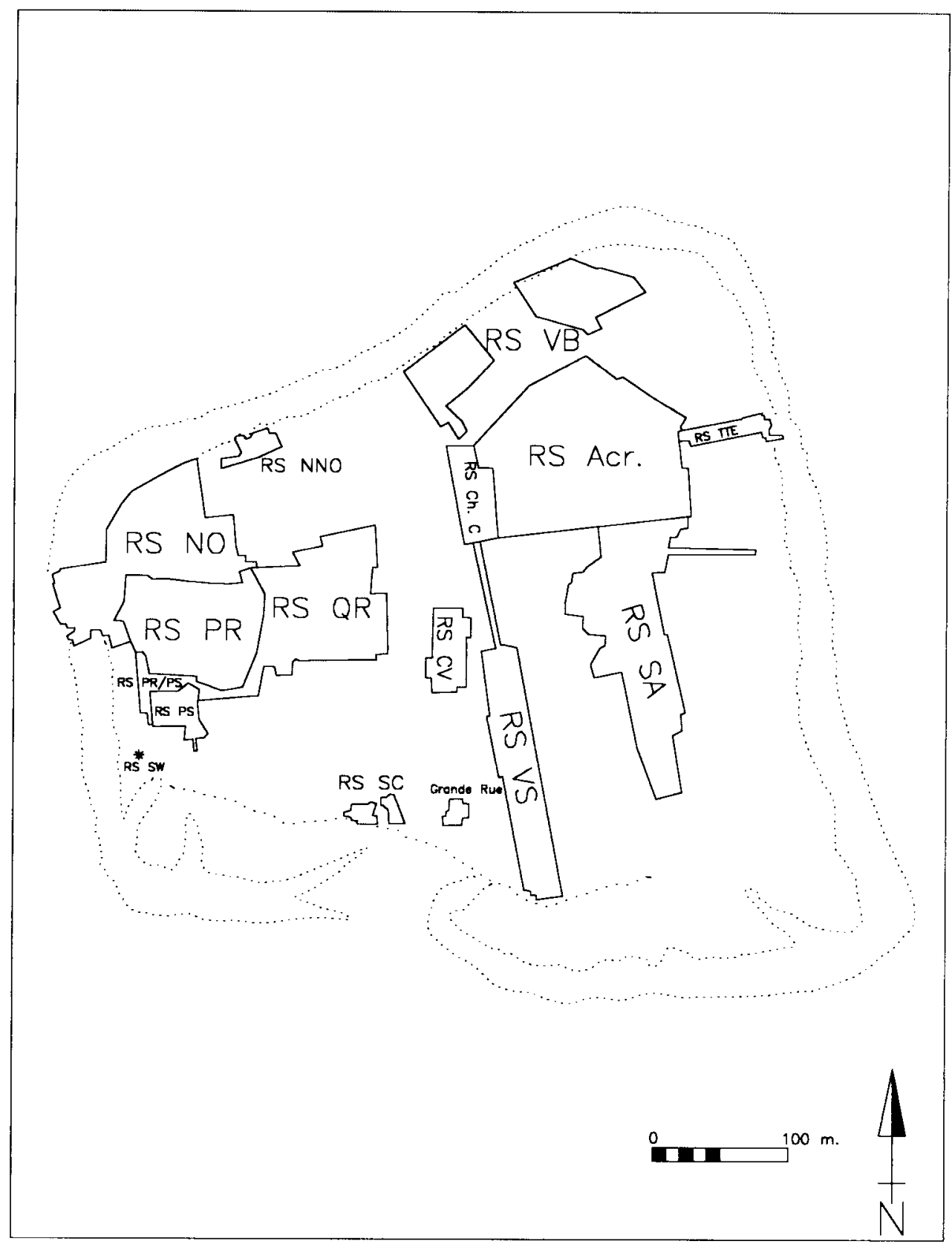

Fig. 5.1 Ras Shamra: the excavation trenches

by the vast royal palace, which contained ninety rooms and six courtyards. ${ }^{7}$ The palace was the only area at Ras Shamra that can be considered a specialised zone, designated for specific social groups and functions. ${ }^{8}$ The other excavation trenches have exposed tightly-knit urban zones, in which buildings meant for habitation were interspersed with shops, workshops and religious structures. Four buildings with cultic functions can be identified with certainty at Ras Shamra. However, it is clear that religious

8 Callot 1986, 753-754; Yon 1992a, 26-27; Callot \& 9 Tarragon 1995, 209-210. Yon 1995, 161. 
rites were practised outside structures with explicit cultic functions as well. ${ }^{9}$ Even though a site plan from Minet el-Beida has never been published, it is clear from the description by the excavators that tombs, houses, storehouses and workshops were discovered, as well as spaces designated to ritual practices. ${ }^{10}$ Notable both at Ras Shamra and Minet el-Beida are the vaulted tombs that were situated underneath the buildings." These tombs, most of which were pillaged long before excavations began, were used for many generations; in some cases evidence was found for several centuries of utilisation.

The kingdom of Ugarit is mentioned in cuneiform tablets found at a number of places in the eastern Mediterranean; in addition extensive epigraphical archives have also been discovered at the town itself. ${ }^{12}$ From these texts and from the extensive archives discovered at Ugarit itself, the history of the city during the Late Bronze Age has been reconstructed. ${ }^{13}$ The picture which has emerged is that of a city-state ruled by a dynasty of kings. Although subject to Egyptian and Hittite domination successively, the kingdom enjoyed relative autonomy and was heavily involved in overseas diplomacy and trade, for which its location at a crossroads of maritime and overland routes provided good opportunities. Within the society of Ugarit there was a distinction between the 'people of the king' and 'free people'. ${ }^{14}$ The royal court ranked above these two groups with an almost divine status for the king. The 'free people' were mainly farmers, who lived in villages among their estates. In the capital of Ugarit lived the 'people of the king', who were, at least partly, dependent on the palace for their income. More than forty different professions have been distinguished within this social group, varying from artisans such as bakers and carpenters to high-ranking military personnel, merchants and priests.

The material record of Ras Shamra and the standard of living for the urban population appears to have been fairly high. ${ }^{\text {is }}$ Even houses that can be qualified as modest are of good architectural quality and have produced inventories testifying to a considerable level of wealth. Imported objects from many areas of the Mediterranean have been discovered both at Ras Shamra and Minet el-Beida. and, even though they constitute only a small proportion of the total of finds, imports were an integral part of Ugaritic material culture ${ }^{16}$. The whole population of Ras Shamra may be considered as representing the upper social strata of the kingdom. However this population seems to have been internally stratified. Olivier Callot classifies the houses in the Ville Sud in three groups on the basis of their architecture and the archaeological inventories: rich, middle class and modest. ${ }^{17}$ In addition, a group of large mansions close to the palace constitutes a special class, testifying to a wealthy social group with strong connections with the court.

\section{THE MYCENAEAN POTTERY}

From numerous publications about the two sites, I have been able to isolate a total of 616 Aegean ceramic finds: 168 from Minet el-Beida, 443 from Ras Shamra, while 5 sherds may come from either of

Io Courtois 1979a, 1283-1287; Saadé 1995

п $\quad$ Courtois 1979a, 1201; Salles 1995; Marchegay 1999.

I2 The texts from Ugarit have been discussed in a wide array of publications. For a recent index giving access to most of these, see Yon 1997a, 189-190

ı3 See, for example, Liverani 1979; Yon 1992; 1997a, 2535.

I4 Liverani 1979, 1333-1341.
Is Callot 1994, 200-201.

I6 Courtois 1979a, 1283-1284

${ }_{17}$ Callot 1986, 744-746; 1994, 199-201.

I8 These figures vary somewhat from those by Leonard 1994, who lists 180 Mycenaean finds from Minet elBeida and 451 from Ras Shamra. This difference is caused to an extent by the fact that Leonard has included related pottery that is not produced in Greece, 
them..$^{18}$ This pottery is listed in Catalogue II. I have not been able to include the many vases and fragments that have been identified in the storerooms of the Louvre in Paris and which were published shortly before thís book went to press. ${ }^{19}$ However, I have compared my analyses with those of Yon, Karageorghis and Hirschfeld and I have incorporated the main conclusions reached in their very important book.

Even though very few chemical analyses have been conducted on Mycenaean pottery from the two sites, most of the ceramics included in the catalogue seem to have been produced on the Greek mainland. In 1945, the fabrics of an unknown number of samples from Ras Shamra were investigated by petrology and compared with pottery from Cyprus and the Greek mainland; it was determined that the Ugarit vessels resembled the sherds found in Greece more than the Cypriot examples. ${ }^{20}$ Five pictorial specimens from Minet el-Beida and one from Ras Shamra were later analysed by spectography and appeared to have been produced in the Argolid. ${ }^{21}$ On stylistic grounds, Courtois distinguished a group of amphoroid kraters that may have originated in the south-eastern Aegean. ${ }^{22}$ Pottery deriving from Crete has also been included in the catalogue: nine vessels can certainly be classified as Late Minoan, ${ }^{23}$ while eleven vases may derive from that island. ${ }^{24}$ The catalogue only includes pottery that was produced in the Aegean. Vessels of Mycenaean inspiration which were certainly produced on Cyprus, such as those in the 'Rude' or 'Pastoral' style, have been excluded from the catalogue. However, in a few cases it is unclear whether the vessels were produced in the Aegean or in Cyprus; these specimens have been included here. ${ }^{25}$ Seven vessels have been included of which it is uncertain whether they are imported or locally made. ${ }^{26}$ In addition to the 616 imported pots and figurines, I have identified thirty-four vessels, which, by their descriptions, are most likely to constitute Syrian

such as Cypriot 'Rude' or 'Pastoral' style pottery and local imitations. In some cases, Leonard has given separate catalogue entries to fragments which belong to the same pot; these are listed here under one number. Some finds included here, were not listed by Leonard

I9 Hirschfeld 2000a; 2000b; Karageorghis 2000; Yon 2000.

20 Immerwahr 1945, 555: note 77.

2I Anson 1980, 117, 121, Fig. 2. The analysed sherds are cat. nos. 17, 53, 80, 125, 135, 472; the specimen with cat. no. 191, which was found either at Ras Shamra or in the harbour town, likewise turned out to derive from the Argolid.

22 Courtois 1973, 149-164. Vessels of this type are those with cat. no. $77,175,314,315,371,372,374,375$ and 402 .

23 Cat. nos. 156, 408, 462, 474, 475, 476, 479, 521, 534.

24 Cat. nos. 129, 140, 161, 171, 201, 290, 378, 445, 477, 478, 502 are here referred to as Helladic, but might rather be Minoan.

25 Cat. nos. 42, 064, 103 and 518. Shallow bowls with horizontal handles (FS 295-296) were produced on Cyprus at the end of LCII as well; see Kling 1998;
1991; Sherratt 1980, 196-197; 1991. All such vessels have been included in the catalogue.

26 Cat. nos. 52, 172, 177, 267, 286, 438, 459. It has been suggested by E.B. Miller that some of the zoomorphic rhyta at Ugarit may have been made in the town itself, especially those with cat. nos. 136-138, which are all of the animal-head type. According to Miller, these vases deviate from Aegean examples in the carelessness of the decoration and the heavy proportions with too prominent rims. However, one should also note that these vessels are decorated with fill ornaments which are purely Mycenaean, notably parallel chevrons (FM 58) and lozenges (FM 73). Pending technical analysis of the clays of the zoomorphic vessels, I consider them Mycenaean imports.

27 This list is not complete; it is entirely possible that more such vessels have been found in Minet el-Beida and Ras Shamra; see, for example, the list provided by Karageorghis (2000, 64-65). At least some Mycenaean derivations appear to have been produced at Ugarit itself, see Monchambert 1983, 27-29. Without chemical analysis, however, it is impossible to distinguish between vessels produced locally and elsewhere outside the Aegean. 
products of Aegean-type vessels. These are separately listed in the third part of Catalogue II and are not included in the spatial analysis. ${ }^{27}$

It is clear that the ceramics which are listed in Catalogue II do not represent all the Mycenaean pottery which has been found at the sites. ${ }^{28}$ Two corpora céramique have been published that cover the campaigns from 1929 to1938 and 1959 to 1968, respectively. ${ }^{29}$ We can assume that most of the pottery found during these excavations and recognised as Mycenaean is included among our data. However, it is also certain that imported Aegean wares have been left out of these publications, especially in the case of the first corpus céramique. ${ }^{30}$ Material found during twenty campaigns has only been published in preliminary reports and in a variety of different places. The possibility that Mycenaean finds have been thrown away cannot be excluded, especially for the earlier campaigns. In Minet el-Beida, for example, the archaeologists working at the site in the 1930s thought for a long time that they were excavating a necropolis and realised only much later that they had actually discovered an urban area. ${ }^{35}$ Apart from the probable loss of Mycenaean pottery, the methodology of the earlier campaigns has had severe consequences for the amount of contextual information. In particular the lack of attention during the campaigns before the 1970s to undecorated pottery of local manufacture prevents comparisons between the deposition of imported and local pottery. ${ }^{32}$ Fortunately, the campaigns from 1978 to 1984 have been extensively published and only for these campaigns can we can consider the data-set to be more or less complete. ${ }^{33}$

Each archaeological expedition to Ras Shamra focused - naturally enough - on specific areas. The fact that the material of many of these campaigns has not been fully published means that there is unequal data for the different parts of the site. Similarly, the quality of the data varies spatially, as certain areas have been excavated more recently than others. All this prohibits a purely statistical approach to study the on-site distribution of Mycenaean pottery at Ras Shamra and Minet el-Beida. Instead, I will take into account only very marked quantitative differences between excavated areas. These differences need to be checked with regard to the extent to which they can be related to archaeological phenomena, rather than to insufficient data. Fortunately, the recently excavated and published Centre Ville can, in some cases, serve to compensate for the loss of data bearing on other areas.

\section{THE ON-SITE DISTRIBUTION OF MYCENAEAN POTTERY}

The 616 entries in Catalogue II consist of 554 ceramic vessels or sherds thereof and 62 (fragments of) figurines. The number of Mycenean finds published from each of the excavated areas, including Minet el-Beida, are indicated in Table 5.1. As is evident from Fig. 5.1, the various areas of Ras Shamra differ in size and in nature. Minet el-Beida, of course, is a site of its own. Some excavated areas of Ras Shamra are large trenches comprising habitation areas of substantial size in which several

28 The recent catalogue by Hirschfeld (2000b) of Mycenaean pottery at the Louvre includes 421 pieces which had remained unpublished.

29 Schaeffer 1949, 131-301; Courtois \& Courtois 1978, 192-370.

30 An example in case is the pottery from tomb VI in Minet el-Beida. From the notebooks it is known that this tomb contained 282 Late Helladic vessels and thir- ty-five Mycenaean figurines; see Courtois 1979a, 1283. However, only thirty-eight vessels and four figurines occur in the first corpus céramique.

3I Saadé 1995, 213.

32 Monchambert 1983, 26

33 Calvet \& Geyer 1987; Mallet 1987; Yon 1987; Yon, Lombard \& Renisio 1987, 11-128. 


\begin{tabular}{|c|c|c|c|}
\hline site area & pots and sherds & figurines & Total \\
\hline Minet el-Beida & 145 & 23 & 168 \\
\hline RS Acr. & 25 & 3 & 28 \\
\hline RS PR & 5 & 1 & 6 \\
\hline RS QR & 62 & 2 & 64 \\
\hline RS NO & 4 & & 4 \\
\hline RS VB & 38 & 2 & 40 \\
\hline RS SA & 49 & 9 & 58 \\
\hline RS VS & 78 & 2 & 80 \\
\hline RS CV & 61 & 15 & 76 \\
\hline RS Ch.C & 9 & & 9 \\
\hline RS TTE & 10 & & 10 \\
\hline RS SC & 8 & & 8 \\
\hline RS SW & 7 & & 7 \\
\hline RS PS & 9 & 3 & 12 \\
\hline RS NNO & 2 & & 2 \\
\hline RS PR/PS & 2 & & 2 \\
\hline RS unknown & 35 & 2 & 37 \\
\hline MeB or RS & 5 & & 5 \\
\hline Total & 554 & 62 & 616 \\
\hline
\end{tabular}

Table 5.1

houses, streets, squares, etc. have been revealed. ${ }^{34}$ Two other trenches are much smaller, ${ }^{35}$ while two areas concern single, albeit large, buildings ${ }^{36}$ and one 'area' (RS SW) is a single tomb. Finally, one 'area' has been included because the finds could not be ascribed to one of the other excavation trenches. ${ }^{37}$

In considering the figures in Table 5.1, one should always keep in mind that the extent to which the campaigns devoted to the different areas have been published varies, as does the quality of the excavations themselves. Moreover, these figures represent published finds from all archaeological strata. Objects from the surface layer, which came into being during the decay of the site and has been subject to extensive erosion, especially in the streets, ${ }^{38}$ may actually derive from other parts of the site than their find spot seems to indicate. Similarly, finds from levelling strata are not in their original spot of deposition either.

Nevertheless, it is clear that Mycenaean pottery has been found in all excavated parts of Ras Shamra and in the harbour town of the ancient city. This seems not to be completely true for Mycenaean figurines, which are absent in certain areas. However, the areas without figurines are mainly smaller trenches (RS TTE, RS SC and RS SW), a single building (RS NNO) and the ambiguous find spot of RS PR/PS. The only larger trenches without figurines are the Quartier Nord Ouest and the Chantier $C$. In the case of the latter, which has yielded the comparatively small number of nine Mycenaean sherds, it should be noted that it was here that treasure hunters were active before

34 RS Acr., RS PR, RS QR, RS NO, RS VB, RS SA, RS VS, RS CV, RS Ch. C can all be considered as such.

35 RS TTE and RS SC.

${ }^{36}$ The residence of RS NNO and the large mansion of
RS PS.

37 This is the case for the finds made in the square between the Palais Royal and the Palais Sud (RS PR/PS)

${ }^{38}$ Callot 1994, 186. 


\begin{tabular}{|c|c|c|c|c|c|}
\hline site area & unknown & funerary & domestic & ritual & settlement \\
\hline Minet el-Beida & 46 & 95 & 11 & 4 & 12 \\
\hline RS Acr. & 8 & 18 & & 2 & \\
\hline RS PR & 3 & 2 & 1 & & \\
\hline RS QR & 43 & 10 & 10 & & 1 \\
\hline RS NO & 2 & & 2 & & \\
\hline RS VB & 5 & 33 & 2 & & \\
\hline RS SA & 41 & 5 & 12 & & \\
\hline RS VS & 46 & 28 & 5 & & 1 \\
\hline RS CV & 13 & 0 & 26 & 33 & 4 \\
\hline RS Ch. C & 3 & 6 & & & \\
\hline RS TTE & 8 & 2 & & & \\
\hline RS SC & 4 & 0 & 4 & & \\
\hline RS SW & & 7 & & & \\
\hline RS PS & 8 & & 4 & & \\
\hline RS NNO & 2 & & & & \\
\hline RS PR/PS & & & & & 2 \\
\hline RS unknown & 34 & 1 & & & 2 \\
\hline $\mathrm{RS}$ or $\mathrm{MeB}$ & 5 & & & & \\
\hline Total & 271 & 207 & 77 & 39 & 22 \\
\hline
\end{tabular}

Table 5.2

1914. ${ }^{39}$ The absence of Mycenaean figurines in RS NO appears to be related to the generally small number of published Aegean finds for this vast area. Most of the buildings in the north-western quarter were related to the royal palace to the south..$^{{ }^{\circ}}$ From the palace itself, likewise, a remarkably small amount of Mycenaean pottery is represented in the catalogue. This, however, is misleading: the recent investigation of the Mycenaean pottery from Ugarit at the Louvre museum, has revealed that 118 Mycenaean vases can be attributed to depositional contexts within the royal palace. ${ }^{41}$ This high figure should be related to the large size of the palace; Mycenaean pottery appears to have been distributed fairly regularly in the many rooms and courtyards. ${ }^{42}$ This indicates that there was not a concentration of this type of pottery in the palace.

The presence of Mycenaean pottery in all excavated areas of Ras Shamra and at Minet el-Beida indicates that this class of material was in use in the whole city of Ugarit and not confined to people living in specific areas. A widespread distribution of Mycenaean pottery is also suggested by the recent excavations in the Centre Ville (Fig. 5.6 below). ${ }^{43}$ Mycenaean finds in Maisons A, B and C in this part of town were made in many rooms and courtyards, generally in single pieces and associated with local domestic objects.

39 Schaeffer 1936b, 113. The fact that Schaeffer in this report refers specifically to "céramique mycénienne de très bonne qualité" (p. 109) may indicate that more was found than that actually published in the first corpus céramique.

$4^{\circ}$ Courtois 1979a, 1209; Callot (1986, 748-754) states that in the thirteenth century the western part of the Quartier Nord-Ouest was part of the royal zone in the city, which, in an urbanistic sense, was separated from other areas. Before ca. 1370-1360 BC this area was the site of the first palace, the Palais Nord.

4I Hirschfeld 2000a, 68.

42 Yon 2000, 9.

43 Yon, Lombard \& Renisio 1987, 22-23, 40, 46, 53-55, 79, 85-89, 98-99, 103-104. 


\begin{tabular}{|c|c|c|c|c|c|}
\hline site area & II-IIIA1 & IIIA2 & IIIA2-IIIB & IIIB & undatable \\
\hline Minet el-Beida & 3 & 27 & 24 & 89 & 2 \\
\hline RS Acr. & & 7 & 4 & 14 & \\
\hline RS PR & & 1 & 2 & 1 & 1 \\
\hline RS QR & 1 & 13 & 7 & 41 & \\
\hline RS NO & & & & 4 & 0 \\
\hline RS VB & & 19 & 1 & 18 & \\
\hline RS SA & & 5 & 7 & 37 & \\
\hline RS VS & 3 & 12 & 10 & 53 & \\
\hline RS CV & & 1 & 7 & 35 & 18 \\
\hline RS Ch. C & & 1 & 4 & 4 & \\
\hline RS TTE & & 4 & 1 & 5 & \\
\hline RS SC & & & & 6 & 2 \\
\hline RS SW & & 1 & 1 & 5 & \\
\hline RS PS & & & 2 & 7 & \\
\hline RS NNO & & 2 & & & \\
\hline RS PR/PS & & & 1 & 1 & \\
\hline RS unknown & 1 & 3 & 10 & 21 & \\
\hline $\mathrm{RS}$ or $\mathrm{MeB}$ & & 2 & & 3 & \\
\hline Total & 8 & 98 & 81 & 344 & 23 \\
\hline
\end{tabular}

Table 5.3

The distribution of Mycenaean pottery can also be viewed from the perspective of the contexts in which it occurs (Table 5.2). From a large proportion of the Mycenaean finds the context can not be reconstructed. ${ }^{44}$ This is probably partly caused by the number of finds made in the surface layer or levelling strata, while the methods of excavation, registration and publication may be to blame as well.

Table 5.2 shows that Mycenaean pottery at Minet el-Beida and Ras Shamra occurs in different kind of contexts. Mycenaean pottery has been found in ritual contexts in Minet el-Beida, on the acropolis, and in the Centre Ville. ${ }^{45}$ No conclusions can be based, however, on the absence of Mycenaean finds in ritual contexts in other areas. Ritual practices in Ugarit seem to have taken place outside temples as well and buildings may have combined religious and more secular functions. ${ }^{46}$ Mycenaean artefacts have been discovered in contexts which are classified here as domestic but also have religious connotations. An example in point are the finds made in the Maison du prêtre Hurrite in RS SA (cat. nos. $247,288,294,306,498,499) .{ }^{47}$

44 Four broad categories of contexts have been distinguished: Funerary, meaning that the find is made in a tomb or in the dromos leading to it; Domestic, in which case the artefact was found in a house on the floor, or in a layer that can be associated with upper floors; Ritual, which means that the object was found in a building that clearly served as a temple, sanctuary or in other clear 'cultic' circumstances; and Settlement, which signifies that the object was found in the settlement, but cannot be attributed to a specific building: finds in streets, squares, etc. Refuse contexts, such as pits in which pottery is discarded, have not been distinguished separatly. They have been attributed to a domestic context if the pit could be assigned to a house and to a settlement context if this was not the case.

45 See, also, Yon 2000, 10.

46 Tarragon 1995, 209-210

47 Courtois 1979a, 1269-1277; 1979b 112-113; Yon 2000, 10. 


\begin{tabular}{lccccc}
\hline style & funerary & domestic & ritual & settlement & unknown \\
\hline II-IIA1 & 1 & & 1 & 2 & 4 \\
IIIA2 & 41 & 5 & 3 & 1 & 48 \\
IIIA2-IIIB & 19 & 16 & 2 & 4 & 40 \\
IIIB & 131 & 49 & 14 & 5 & 145 \\
Total & 192 & 70 & 20 & 12 & 237 \\
\hline
\end{tabular}

Table 5.4

Mycenaean pottery was used in Ugarit and its harbour town under different circumstances. This appears to have been the case everywhere in the city, as the pottery is found in most areas in more than one type of context. $4^{8}$ The absence of funerary contexts for Mycenaean pottery in the recently excavated Centre Ville seems remarkable. However, this area has produced only two tombs, one of which was out of use during the Late Bronze Age; the second tomb was found virtually empty as a result of looting. ${ }^{49}$ The evidence so far does not suggest that Mycenaean pottery was used only in specific situations. This class of material seems to have been appropriate for domestic use and to have been included in religious and funerary ceremonies.

The subdivision of the Late Helladic and Late Minoan pottery at Minet el-Beida and Ras Shamra according to chronological ceramic styles is presented in Table 5.3 in four groups..$^{50} \mathrm{It}$ is important to realise that the designation IIIA2-IIIB does not refer to a chronological group, but to those specimens which cannot be dated more accurately. Also important is the fact that the stylistic ceramic phases do not necessarily correspond to archaeological strata at Ras Shamra and Minet el-Beida. From Table 5.3 it is apparent that Aegean vessels from the early part of the Late Bronze Age are scarce at Ras Shamra and Minet el-Beida. Of the eight specimens listed here, one is Minoan (cat. no. 408: LM IIIA1) and another possibly so (cat. no. 161: LH IIA/LM IB). ${ }^{\text {sl }}$ Although the figures point to a concentration of these early vessels in the harbour town and in the Ville Sud, the occurrence of a small handleless jar (FS 77) of LH IIB-LH IIIA1 date in RS QR (cat. no. 207) indicates that such products were more widely distributed.

Vessels in LH IIIA2 and LH IIIB styles are widely distributed all over the site. Of all excavated parts of Ras Shamra, the Ville Basse is the only one where more LH IIIA2 pots have been found than vessels in LH IIIB style. This may partly be explained by the observation that almost all Mycenaean finds in this area were made in tombs (see Table 5.2), which in general have produced a relatively high proportion of LH IIIA2 ware (see Table 5.4). The Centre Ville, on the contrary, shows a high proportion

${ }^{8}$ The exceptions are the trenches which comprise singular buildings (RS PS and RS NNO), those which are much smaller than others (RS TTE, RS SC and RS SW), and the ambiguous area of RS PR/PS. Another exception is the Quartier Nord Ouest, from which few Mycenaean finds in general have been published.
49 Yon, Caubet, Mallet 1982, 179; Salles 1987, 173.

so Because the classification of the figurines is not as sharply chronologically defined as that of pottery (French 1971), they are not included in Table 5.3.

sI Furumark 1941a, 610 (FS 164: 11) initially assigned the stirrup jar with cat. no. 408 to LH IIIA1. Hankey (1979, 149: no. 10) later established its Minoan origin: LM IIIA1. 


\begin{tabular}{|c|c|c|c|c|c|}
\hline site area & dinner & storage & ritual & figurines & unknown \\
\hline Minet el-Beida & 70 & 47 & 15 & 23 & 13 \\
\hline RS Acr. & 11 & 10 & 2 & 3 & 2 \\
\hline RS PR & 2 & 1 & 1 & 1 & 1 \\
\hline RS QR & 25 & 15 & 9 & 2 & 13 \\
\hline RS NO & 2 & 1 & 1 & & \\
\hline RS VB & 8 & 25 & 4 & 2 & 1 \\
\hline RS SA & 17 & 18 & 9 & 9 & 5 \\
\hline RS VS & 35 & 32 & 4 & 2 & 7 \\
\hline RS CV & 17 & 17 & 11 & 15 & 16 \\
\hline RS Ch. C & 4 & 3 & 2 & & \\
\hline RS TTE & 2 & 4 & 3 & & 1 \\
\hline RS SC & 6 & 0 & & & 2 \\
\hline RS SW & 2 & 5 & & & \\
\hline RS PS & 6 & & & 3 & 3 \\
\hline RS NNO & 0 & 2 & & & \\
\hline RS PR/PS & 1 & 1 & & & \\
\hline RS unknown & 20 & 10 & 2 & 2 & 3 \\
\hline $\mathrm{RS}$ or $\mathrm{MeB}$ & 3 & 1 & 1 & & \\
\hline Total & 231 & 192 & 64 & 62 & 67 \\
\hline
\end{tabular}

Table 5.5

of LH IIIB pottery in comparison with the one specimen in LH IIIA2 style (cat. no. 464). This is explicable as the research in this area has focused on the latest habitation level.

The contextual distribution of Mycenaean vessels in the various ceramic styles, is presented in Table 5.4, which shows clearly that all chronological styles have been found in all types of contexts. The only exception in this case is that no LH II-LH IIIA1 sherds have been found in a domestic context. This would be an important observation arguing against a domestic use of these early vessels. However, the total number of specimens seems too small to draw such a conclusion. As far as differences in contextual distribution can be discerned between finds in LH IIIA2 and LH IIIB styles, a higher proportion of the later ceramic phase was found in a domestic context. This is, of course, explicable, as the end of LH IIIA2 dates long before the abandonment of Ugarit.

The question as to whether the chronological ceramic styles of the Mycenaean pottery correspond to the stratigraphical sequence of Minet el-Beida and Ras Shamra is difficult to address without explicit reference to stratigraphy in the publications. ${ }^{52}$ The fact that a lower proportion of LH IIIA2 vessels was found in domestic contexts seems to suggest that these vessels were not actively in use during the final phase of Ugarit. There are only two finds, which may be evidence of the long use of Mycenaean ceramic vessels. The first of these concerns a fragment in LH IIA/LM IB style (cat. no. 161), which was found in Minet el-Beida, reportedly in direct association with a cuneiform tablet. ${ }^{33}$

52 In many places at Ras Shamra, three subsequent floor levels are attested of Ugarit Récent 3; see Courtois 1974, 100. According to Courtois these three layers are reflected in the deposition of the pottery.

53 Schaeffer 1949, 226: no. 13. Schaeffer mentions that the finds were made in Minet el-Beida in 1929 near tomb IV. The tablet is not mentioned by Saade (1995, 214-215) in his overview of the texts found in the harbour town. 


\begin{tabular}{lcccc}
\hline ceramic phase & dinner & storage & ritual & unknown \\
\hline II-IIA1 & 1 & 4 & 1 & 2 \\
IIIA2 & 38 & 46 & 9 & 5 \\
IIIA2-III & 34 & 23 & 9 & 15 \\
IIIB & 153 & 115 & 45 & 31 \\
undatable & 5 & 4 & 64 & 14 \\
Total & 231 & 192 & & 67 \\
\hline
\end{tabular}

Table 5.6

The ceramic style of this fragment points to a date between 1500 and $1450 \mathrm{BC}$ according to traditional chronology. However, all cuneiform tablets are said to date from Ugarit Récent 3, e.g. after 1365 BC. ${ }^{44}$ Unfortunately, any further information about the tablet or its find circumstances is absent. A second case of a find made in a deposit that should be dated much later than its chronological style concerns a complete Mycenaean alabastron (cat. no. 464) that was found in a habitation level of the latest phase at Ugarit in Maison C of the Centre Ville.s5 It has been dated to LH IIIA2 and, if this is true, it would pre-date its context. ${ }^{56}$ These type of alabastra, however, are notoriously difficult to assign a date stylistically. There is therefore no real evidence for Aegean vessels which were still in use in Ugarit and its harbour town long after their manufacture..$^{57}$

Mycenaean pottery can also be subdivided according to functional vessel types (cf. fig. 2.2 and Table I). The figures in Table 5.5 show that dinner vessels are somewhat more common than storage vessels in Minet el-Beida and Ras Shamra. This pattern applies to most areas of Ras Shamra: of all large excavated areas, only the Ville Basse shows a strong dominance of storage over dinner vessels. It is unlikely that this is related to the high proportion of tomb finds in this area (Table 5.2). Minet el-Beida, RS Acr., RS Ch. C. and to a lesser extent in the Ville Sud have also yielded many Mycenaean finds from tombs, but they include predominantly dinner vessels. A possible relation might exist with the observation made above that the Ville Basse is the only area that has produced more finds from the $\mathrm{LH}$ IIIA2 stylistic phase than from LH IIIB. It can be deduced from Table 5.6 that the dominance of dinner vessels is most marked among finds from the latest stylistic ceramic phase, while among early finds and among those from LH/LM IIIA2 storage vessels are the more numerous.

In the Sud Acropole and the recently excavated Centre Ville the numbers of dinner and storage vessels are balanced. This is remarkable, because in both areas most finds by far are from the LH IIIB period (Table 5.3). A connection of this phenomenon with the rather low number of tomb finds from these areas is likely. The absence of storage vessels in the Palais Sud may also be noted. As far as the spatial

$54 \quad$ Van Soldt 1986, 57.

ss Yon, Gachet \& Lombard 1987, 178-179. The vessel was found with another alabastron (cat. no. 463) underneath a staircase.

s6 This date is given by Leonard 1994, 36: no. 393, most probably on the basis of the carefully executed N-pattern (FM 60:2) and the relatively slight concavity of the sides and convexity of the base.

57 Another possible example is a part of a LH IIIA2 rhy-

ton (cat. no. 287), which was found in a domestic context in the maison à portique à base de colonne in the Quartier Résidentielle (Courtois \& Courtois 1978, 308: no. 18). However, the depth of the find is not mentioned. The sherd of a LH IIIA2 mug (cat. no. 201), which was found at street level in the Ville Sud (Courtois \& Courtois 1978, 292: no. 2) may have been deposited there long before the final days of Ugarit. 


\begin{tabular}{lccrrr}
\hline context & dinner & storage & ritual & figurines & unknown \\
\hline Funerary & 77 & 102 & 5 & 13 & 10 \\
Domestic & 35 & 19 & 4 & 13 & 4 \\
Ritual & 8 & 5 & 0 & 3 & 9 \\
Settlement & 3 & 62 & 32 & 33 \\
unkown & 108 & 192 & 64 & 62 \\
\hline Total & 231 & & 67 \\
\hline
\end{tabular}

Table 5.7

\begin{tabular}{|c|c|c|c|c|c|c|c|}
\hline site area & d.c.w. & plain & linear & patterned & pictorial & plastic & decorated \\
\hline Minet el-Beida & 3 & 1 & 22 & 98 & 17 & 4 & \\
\hline RS Acr. & & & 2 & 14 & 4 & 2 & 3 \\
\hline RS PR & & & 2 & & 1 & & 2 \\
\hline RS QR & & & 9 & 39 & 7 & 4 & 3 \\
\hline RS NO & & & & 2 & 1 & & 1 \\
\hline RS VB & & & 13 & 19 & 4 & 2 & \\
\hline RS SA & 2 & & 5 & 25 & 13 & 4 & \\
\hline RS VS & & & 18 & 49 & 8 & 1 & 2 \\
\hline RS CV & 1 & & 24 & 19 & 4 & & 13 \\
\hline RS Ch.C & & & 2 & 4 & 1 & 2 & \\
\hline RS TTE & & & 4 & 3 & 2 & & 1 \\
\hline RS SC & & & & 1 & 6 & & 1 \\
\hline RS SW & & & 5 & 1 & 1 & & \\
\hline RS PS & & & 2 & 4 & 2 & & 1 \\
\hline RS NNO & & & & 2 & & & \\
\hline RS PR/PS & & & & & & & 2 \\
\hline RS unknown & & & 9 & 17 & 9 & & \\
\hline $\mathrm{RS}$ or $\mathrm{MeB}$ & & & 1 & 2 & 2 & & \\
\hline Total & 6 & 1 & 118 & 299 & 82 & 19 & 29 \\
\hline
\end{tabular}

Table 5.8

distribution of ritual vessels and figurines is concerned, it is apparent that they are rather homogeneously distributed. All important areas have yielded both categories; only the absence of rhyta in the Palais Sud, where there is a rather high proportion of figurines, may be of some significance.

Table 5.7 presents the contextual distribution Mycenaean vessels belonging to the various ceramic functional categories. It is clear that storage vessels predominate in funerary contexts, while in domestic environments dinner vessels occur more often. It is, however, not possible to define restrictions of use of the different functional types on the basis of this observation, as all types have been found in all contexts. Moreover, the presence of equal numbers of dinner and storage vessels in the domestic contexts of the Centre Ville shows that both categories were used in similar circumstances. The fourteen rhyta which have been found in ritual contexts seem to indicate that this type of vessel had a predominantly ritual use. However, eleven of these rhyta derive from one and the same sanctuary: the sanctuaire aux rhytons in the Centre Ville..$^{58} \mathrm{~A}$ significant number of rhyta have been found in contexts which

s8 Cat. nos. 434, 436-445; Yon 1982, 15; 1987. 


\begin{tabular}{|c|c|c|c|c|}
\hline site area & various animals & bulls & man & chariot \\
\hline Minet el-Beida & 11 & 1 & 3 & 2 \\
\hline RS Acr. & 1 & 1 & & 2 \\
\hline RS PR & 1 & & & \\
\hline RS QR & 1 & 2 & & 4 \\
\hline RS NO & 1 & & & \\
\hline RS VB & 4 & & & \\
\hline RS SA & 7 & 2 & 3 & 1 \\
\hline RS VS & 7 & & & 1 \\
\hline RS CV & 2 & & & 2 \\
\hline RS Ch. C & & & & 1 \\
\hline RS TTE & & & 1 & 1 \\
\hline RS SC & 1 & & 1 & \\
\hline RS SW & 1 & & & \\
\hline RS PS & 1 & & 1 & \\
\hline \multicolumn{5}{|l|}{ RS NNO } \\
\hline \multicolumn{5}{|l|}{ RS PR/PS } \\
\hline \multicolumn{5}{|l|}{ RS VS/CV } \\
\hline RS unknown & 1 & & 2 & 6 \\
\hline $\mathrm{RS}$ or $\mathrm{MeB}$ & & & 1 & 1 \\
\hline Total & 39 & 6 & 12 & 21 \\
\hline
\end{tabular}

Table 5.9

were not clearly ritual and have been classified here as 'domestic'. Figurines likewise do not seem to have been restricted to specific kinds of contexts.

A last subdivision of the Mycenaean pottery can be made according to decorative style or ware. The classification used here makes a distinction between coarse ware and fine ware. ${ }^{59}$ This latter group includes both plain vessels and others with linear, patterned, pictorial or plastic decoration. The term 'decorated' is used when fine ware is concerned of which the type of decoration is unknown. Table 5.8 represents the spatial distribution of these wares in Ras Shamra and Minet el-Beida. From this table it is immediately clear that undecorated Aegean pottery is extremely scarce at the two sites. The one specimen from Minet el-Beida that is listed as plain ware (cat. no. 50) is a lid (FS 334) which may well have belonged to a decorated vase. ${ }^{60}$ The six coarse ware vessels listed here are all large stirrup jars with painted decoration. ${ }^{6}$ Four of these vessels are surely of Minoan origin, the two others possibly so. ${ }^{62}$ The occurrence of such stirrup jars in the Sud Acropole of Ras Shamra and in RS CV shows that the use of these transport vessels was not limited to the harbour town.

Among the decorated fine ware, specimens with patterned decoration are dominant. This predominance of patterned decoration should probably be considered even more marked, as linear decorated

59 Mycenaean vessels of undecorated coarse ware have not been reported from Ras Shamra and Minet elBeida. The decorated coarse ware is listed here in the column 'd.c.w.' Figurines are excluded from this section.

6o Leonard (1994, 127-128) mentions collar-necked jars and straight-sided alabastra as pot shapes to which such a lid could have belonged

6r Cat. nos. 408, 462, 474, 475, 477, 478.

62 Of certain Minoan origin are: cat. nos. 408, 474, 475, 476. The specimens with cat. nos. 477 and 478 are designated here as Helladic, but are possibly Minoan. 


\begin{tabular}{|c|c|c|c|c|c|}
\hline ware & funerary & domestic & ritual & settlement & unknown \\
\hline d.c.w & 3 & & 1 & 1 & 1 \\
\hline plain ware & 1 & & & & \\
\hline linear & 52 & 13 & 12 & 1 & 40 \\
\hline patterned & 117 & 28 & 15 & 6 & 133 \\
\hline pictorial & 13 & 17 & 4 & 2 & 46 \\
\hline plastic & 2 & 3 & & & 14 \\
\hline decorated & 4 & 11 & 6 & 2 & 3 \\
\hline worn off & 2 & 1 & & 0 & \\
\hline Total & 194 & 73 & 38 & 12 & 237 \\
\hline
\end{tabular}

Table 5.10

sherds may have belonged to patterned (or pictorial) vessels. It is remarkable that the only important area presenting an exception to the predominance of patterned ware is the recently excavated Centre Ville. This calls into question the reliability of the figures in Table 5.8 for the areas which were excavated earlier. However, it also needs to be noted that the Centre Ville is the only important area from which tomb finds, which are generally more complete, are not reported. Moreover, this area has the highest proportion of sherds of which no illustrations are available to me.

Pictorial pottery has been found in all major areas of Ugarit and in its harbour town. Although a proportionally large amount of this type of pottery comes from the Sud Acropole, it does not seem to have been restricted to certain areas. The six pictorial vessels which come from the relatively small area of RS SC may indicate that this kind of pottery was particularly abundant among the inhabitants living there. ${ }^{63}$ The spatial distribution of pictorial motives is presented in Table 5.9 below. Most pictorial vessels show animals such as deer, stag, birds, etc. ${ }^{64}$ The second most frequent theme is the chariot scene, while scenes showing men engaged in other activities and bulls also occur. The fact that all of these motives have been found in various areas in Ras Shamra and in Minet el-Beida seems to indicate that the iconography of the decoration did not determine the on-site distribution.

The final category of pottery to be considered is vessels with plastic decoration, in all cases zoomorphic rhyta. ${ }^{65}$ These vessels have been found in most of the important areas of Ras Shamra and in Minet el-Beida. The Chantier $C$ has produced a relatively large amount of such vessels, for which there is no apparent explanation. In contrast, zoomorphic vessels have not been reported from the Centre Ville. As the rhyta stylistically belong to the LH IIIA2, LH IIIA2-LH IIIB and LH IIIB phases, it is unlikely that their absence from RS CV is caused by the paucity of LH IIIA2 pottery in this area. Nor, as will be seen below, can this absence be related to the fact that most finds in this area are from domestic contexts. In any case, the occurrence of plastically decorated vessels in various areas indicates that their use was not spatially restricted.

63 Five pictorial amphoroid kraters (cat. nos. 516, 551554) were found in the so-called house of Ourtenu, indicating that this wealthy trader may have assembled this type of vessel, see Yon 1995, 440; 2000, 8, 13.

${ }^{64}$ Apart from bulls, the following animals occur: octopus $(11 \mathrm{x})$, birds $(10 \mathrm{x})$, fish $(10 \mathrm{x})$, stag $(2 \mathrm{x})$, goat $(2 \mathrm{x})$, deer $(1 \mathrm{x})$, horse $(1 \mathrm{x})$

6s The animals attested are: hedgehog $(8 \mathrm{x})$, animal head $(7 \mathrm{x})$, and fish $(3 \mathrm{x})$. In one case (cat. no. 172), a horse's head is attached to the rim of a rhyton of possible local manufacture. 


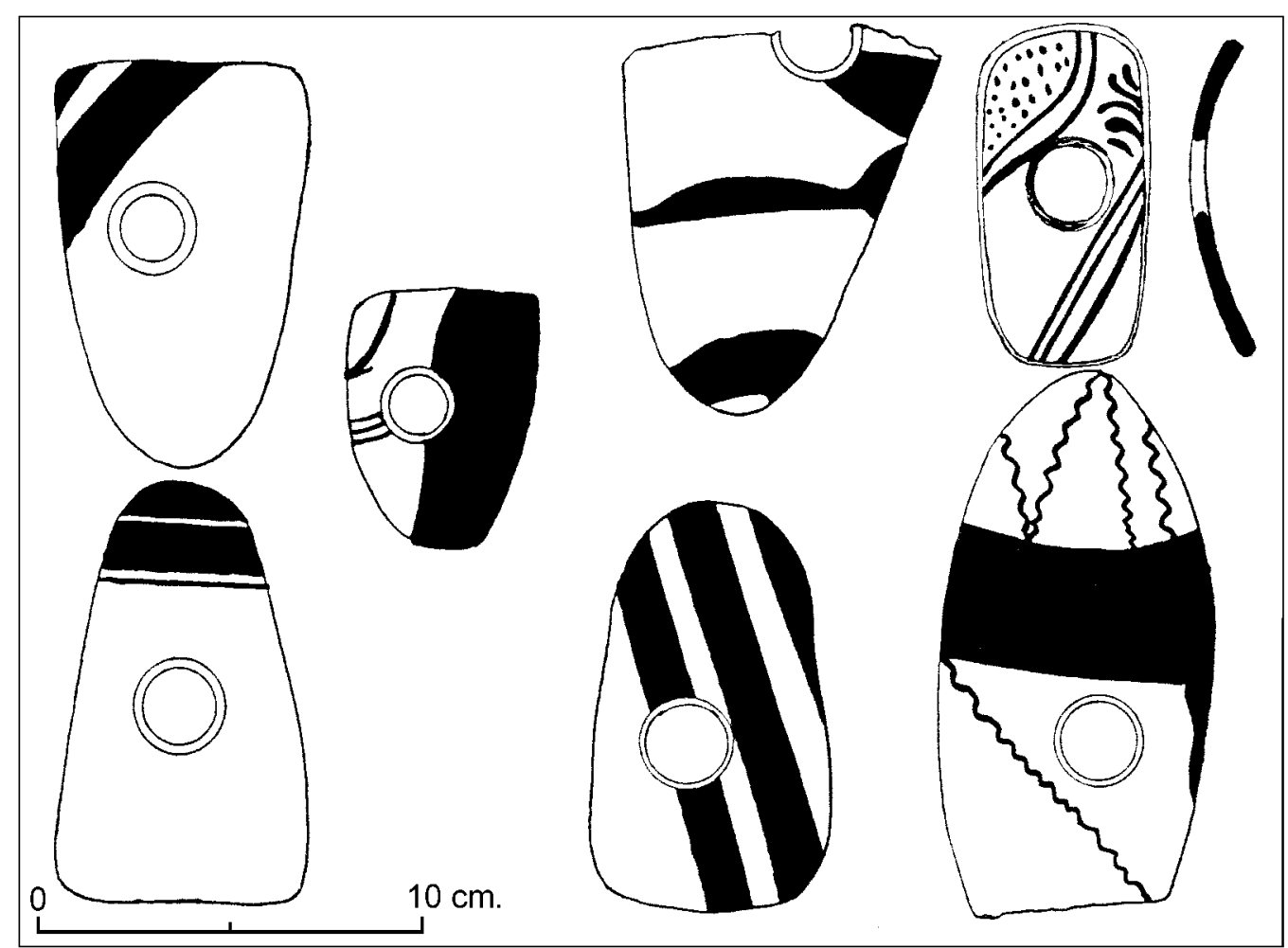

Fig. 5.2 Mycenaean amphoroid krater fragments with drilled hole (cat. nos. 489-492, 494-496) - After Schaeffer 1949, 233 fig. 98: nos. 7, 12.

The contextual distribution of the decorative styles and wares is shown in Table 5.10. Of the six coarse ware stirrup jars in Ugarit, three have been found in tombs ${ }^{66}$ and one in a sanctuary. ${ }^{67}$ These contexts may be somewhat surprising in view of the alleged function of these vessels as utilitarian jars for bulk transportation of liquids. ${ }^{68}$ Even though the sample of six such vessels is rather small, it appears that they could have been used at Ugarit and its harbour in funerary and religious ceremonies. The linear, patterned and pictorial pottery appears in all type of contexts. Neither of these categories seems to have been restricted to specific circumstances. With regard to the pictorial pottery, it is remarkable that it is more often reported from a domestic than from a funerary context. Although the high number of pictorial vessels from unknown context calls for caution, they do not appear to have had a primarily funerary function. Mycenaean vessels with plastic decoration have been found in both funerary and domestic contexts, but not in religious or clear cultic circumstances. However, considering the likelihood of religious practices conducted outside sanctuaries, a ritual function for plastically decorated pots cannot be excluded on these grounds.

66 Tombs III and V in Minet el-Beida each yielded one coarse ware stirrup jar (cat. nos. 474 and 475 respectively), while tomb 4093 in the Sud Acropole also contained such a vessel (cat. no. 478).

${ }_{67}$ The stirrup jar with cat. no. 462 was found in the sanctuary in the Centre Ville. A similar context is possi- ble for the vessel with cat. no. 408, which was found in a deposit inside the enceinte in Minet el-Beida, which was designated as ritual by Schaeffer $(1932,5)$ on the basis of many votive pits.

68 Haskell 1990. 


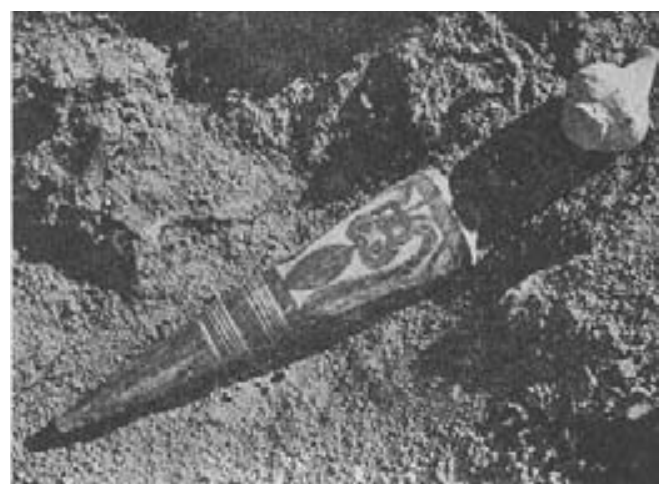

Fig 5.3 Photograph: Mycenaean conical rhyton with octopus in situ -Photograph from Schaeffer 1949, 218 fig. 91A

\section{SET T LEMENT CONTEXTS}

In Table II, which is presented separately at the end of this book, all non-funerary contexts in Ras Shamra and Minet el-Beida are listed in which Mycenaean pottery could be related to specific structures or activities. Too little is known of many of these deposits to analyse them sufficiently; only eleven deposits are discussed here. ${ }^{69}$ A major problem is the fact that many finds from Ras Shamra and Minet el-Beida have never been published. This is especially true for the local pottery. $.^{70} \mathrm{~J} .-\mathrm{Y}$ Monchambert has estimated that imported pottery, of which Aegean vessels are only a part, constitutes less than $1 \%$ of all the ceramics found at the sites. Local pottery, especially the coarse domestic wares, seems to have been abundant everywhere, but it is, paradoxically, almost non-existent in the publications. A second problem specifically concerns Minet el-Beida where the structures in which Mycenaean finds were made are not known in detail.

Minet el-Beida: pit in a house. ${ }^{71}$

Next to a pit in a house in Minet el-Beida, eight sherds from amphoroid kraters (FS 53-55) were found which had been secondarily used: holes had been pierced through the centre of the sherds and their sides had been smoothed (Fig. 5.2)..$^{72}$ Similar sherds have been found elsewhere in Minet elBeida as well, some of them made from Syrian pottery. ${ }^{73}$ From Ras Shamra one comparable piece has been reported: the Mycenaean pictorial amphoroid krater fragment of cat. no. 117.

It is remarkable that all these reused fragments concern amphoroid kraters, some of which with pictorial decoration (Fig. 5.2). This suggests that these vessels were deliberately chosen to be re-used. A second observation is that this deposit is the largest collection of esthèques in Minet el-Beida and

69 The names given by the early excavators, often on the basis of special finds or texts, should not be taken too literally. For example, Callot (1994, 186-188) has found no evidence for metalworking in the Quartier des orfêvres in the Ville Sud.

70 Monchambert 1983, 26.

7I Schaeffer 1949, 232-233.

72 Schaeffer postulated that they might have been used as esthèques: a potter's tool to scrape clay from vessels on the wheel. It must be emphasised, however, that no other evidence for the activities of potters at Minet elBeida has been published.

73 Schaeffer 1949, 232-233, nos. 2, 3 and 4 are examples of esthèques from local pottery. The sherd of cat. no. 491 is also from an amphoroid krater and has been found elsewhere in the harbour town. 


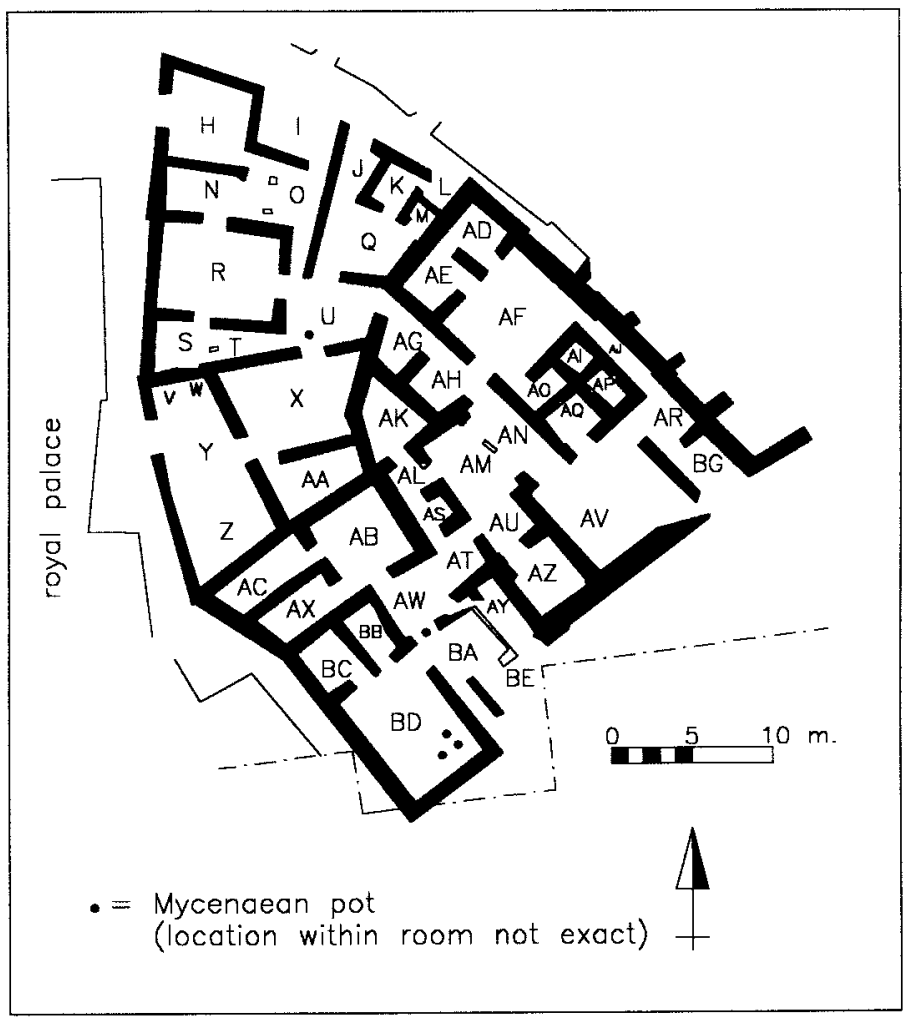

Fig. 5.4 Mycenaean pottery in the Maison d'Albâtres

Ras Shamra. This suggests that they have been deliberately deposited. The nature of this deposition is impossible to assess and depends on the function of the reused sherds and the (unknown) contents of the pit next to which they were found. The only observation that can be made on the basis of this assemblage is that here is an example of particular use of Mycenaean amphoroid kraters.

\section{Minet el-Beida: area with cistern and altar ${ }^{74}$}

In 1931 an area was discovered with benches, on and around which ceramics had been deposited. ${ }^{75}$ Near these benches was a cistern in which several skeletons of newly born children were found. Adjacent to this area was a building of ashlar masonry in which stood an ovoid stone altar. At its base lay pebbles, weights and, a little further away, several rhyta, among which was one of Aegean type decorated with an octopus (Fig. 5.3: cat. no. 129).

No other Mycenaean pottery has been reported from this area, and the rhyta found together with the Aegean specimen were of Syrian origin. The Mycenaean rhyton in this case has clear religious associations. It was used during local religious practices, together with other vessels of similar shape. This suggests that the imported vessel was not perceived as differing from the Syrian rhyta. It was its character as a rhyton rather than its Mycenaean origin that determined its use. As the Syrian rhyta

74 Schaeffer 1932, 2, 4 planche III; Yon 2000, 10.

75 Although no photographs of these benches were published, their description recalls the two benches in the central hall (room 36) of the sanctuary in the Centre Ville; see Mallet 1987, 220. 
were all undecorated, there are no indications that the octopus decoration of the Mycenaean vessel was important for the use that was made of it.

\section{Quartier Résidentielle: Maison d'Albâtres ${ }^{76}$}

This large mansion adjacent to the royal palace consists of more than fifty rooms and courts and contains one tomb (Fig. 5.4). The building as such occupies a whole insula but is considered to have constituted one unit, as all the rooms communicate with one another. However, in its last phase the south-eastern part of the building was isolated from the rest by a blocking of passages. The building can be divided into four different parts. The rooms in the east, where the entrance to a funerary cellar is situated, are labelled 'sacred' by the excavators. The floors of this part of the house were rather empty. In contrast, the southern part of the house, labelled as the domestic quarters, produced an abundance of finds. Among them were three Mycenaean conical rhyta (cat. nos. 415, 416, 417) in room BD, a hedgehog rhyton (cat. no. 418) in the hallway between rooms AW and BA and a locally made amphoroid krater in room AX. Room BD in particular was rich in finds. Apart from the Mycenaean rhyta, two of which were decorated with a bull (cat. nos. 415, 416), this room produced sixty-seven other ceramic vessels of local and Egyptian manufacture, pearls, amulets and a steatite statue. The northern part of the house is considered to have been the industrial zone and can be divided in two. The upper part, around court AF, was probably devoted to oil production as grinding stones and olive pits have been found there. No Mycenaean pottery has been reported in this part of the building. The exact nature of the activities in the lower part of the industrial zone cannot be determined, but seven imported artefacts were made, among which a Mycenaean LH IIIB shallow bowl (cat. no. 421). The mansion has also produced a second shallow bowl (cat. no. 525), of which the find spot is unknown.

As far as the distribution of the Mycenaean pottery within this building is concerned, it is to be noted that four of the five vessels with known find spots were found close together in the part of the house that was richest in finds. Moreover, it is remarkable that all these four vessels are rhyta. The three conical rhyta among them were even found close together in a corner of room BD. The association of these vessels with the wealthier part of the house contrasts with the single shallow bowl in the rest of the house. This bowl, found in the basin in courtyard $\mathrm{U}$, together with a Canaanite jar, is associated with the more industrial part of the mansion. In this case, there seems to be a difference in evaluation of two different categories of Mycenaean pottery. The rhyta, especially those of conical type from room BD, were considered appropriate to be included among objects of high value, while the shallow bowl was part of a more mundane assemblage. It needs to be reminded that the location of this house next to the palace, as well as its inventory suggest a high status for the owners. ${ }^{77}$ The evidence for a high regard for Mycenaean rhyta in such an environment is of considerable importance. The fact that two of these rhyta were pictorially decorated, while another was of hedgehog shape indicates that the decoration of such vessels was of consequence for their appreciation.

76 Contenson et al. 1974, 5-25.

77 The excavators, E. and J. Lagarce, suspect, on the basis of the number of finds with an Egyptian origin, that it was an Egyptian posted in Ugarit for diplomatic reasons, who owned the Maison d'albâtres; see Contenson et al. 1974, 21. 


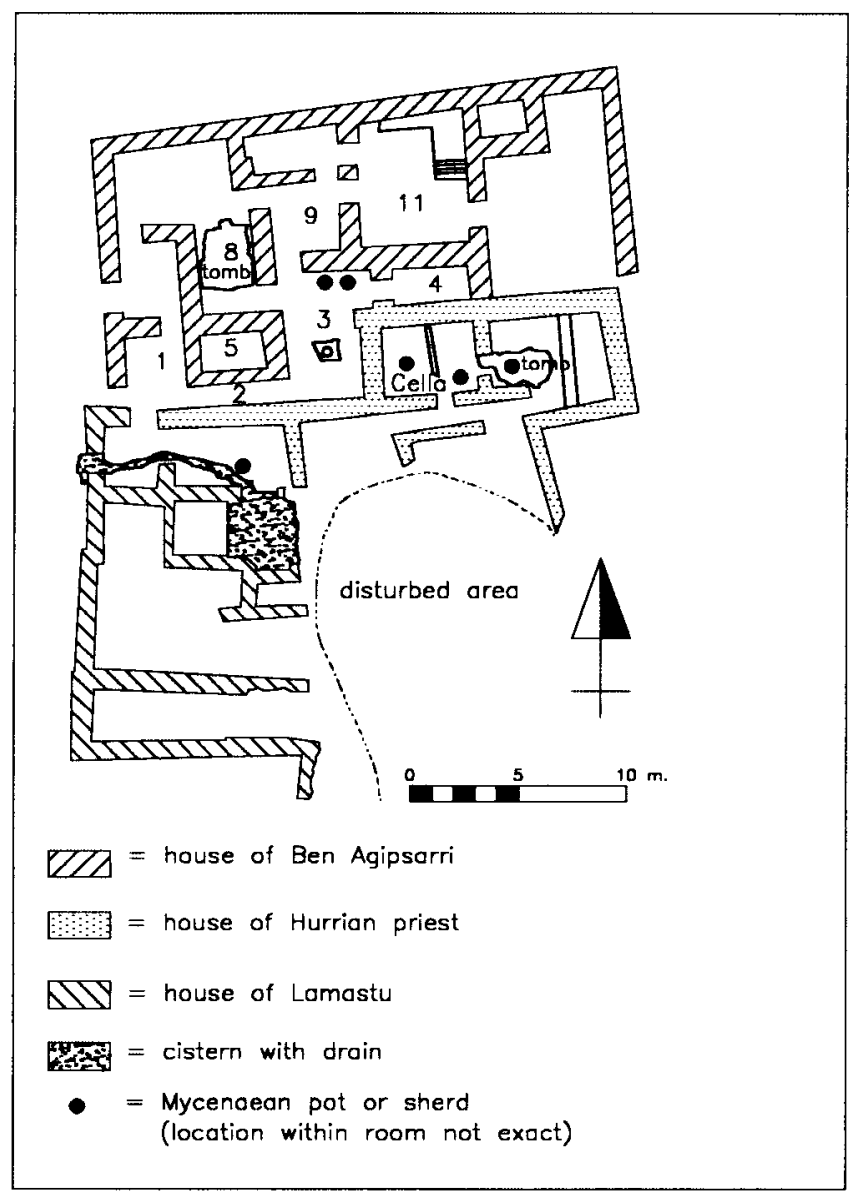

Fig. 5.5 Mycenaean pottery in the complex of the Maison an prêtre Hurrite

Ville Basse: Maison au frittes ${ }^{78}$

In 1935 in the western part of the lower town, north of the acropolis (chantier A), a house was discovered, of which the plan has never been published. There are two important things to note about this house. First of all, its tomb is one of the few at Ras Shamra and Minet el-Beida that had not been robbed. Secondly, a group of polychrome figurines in frit was discovered: two male figurines, a large part of a horse's head and parts of a chariot. Directly associated with this group were two hedgehog rhyta, one of Mycenaean origin (cat. no. 410) and another probably of local manufacture, imitating a Mycenaean type (cat. no. 2021). Some distance away from this group, two other rhyta were found: a LH IIIB conical rhyton of Mycenaean origin (cat. no. 147) decorated with fish, and a locally manufactured imitation of a conical rhyton (cat. no. 2017). No further information is available on this house and its inventory, nor is it known whether other Mycenaean vessels have been found here. In the funerary cellar, tomb 13, six LHIIIA2 vases were found (cat. nos. 92-96, 514), all predating the deposit of the frit figurines. ${ }^{79}$

Assuming that such figurines were not all too common, this deposit again testifies to rhyta being associated with valuable objects. In this case, the zoomorphic rhyta and the figurines were directly associated, while the conical rhyta were found together somewhat further away. The interpretation of the 
imitations of Mycenaean rhyta is based on stylistical arguments only. If correct, it is of importance to note that no distinction seems to have been made between imported Mycenaean rhyta and local imitations.

\section{Sud Acropole: building with the Maison au prêtre Hurrite $e^{80}$}

This building, possibly constituting more than one house, can be divided into three parts (Fig. 5.5) The northern part, which is described by Courtois as an "average house of rather large dimensions", ${ }^{8}$ consisted of at least eight rooms, two courtyards and a cellar..$^{82}$ Room 3, south of the courtyard, is a cellar, in which a stone basin and several pithoi and storage jars were found. Two LH IIIB conical rhyta (cat. nos. 288, 290) were also found in this cellar. The central part of the building consists of the so-called Cella and a room above the tomb. In the Cella, at depths varying from 1.5-4.5 m., a great number of tablets with mainly literary texts were found, among them ten in the Hurrite language an unusually large proportion. On the floor of the western part of the room, a stone libation tube was present, as well as a fragment of an LH IIIB conical rhyton (cat. no. 294). Below the floor, in a pit, more tablets were found, as well as two bowls (one of gold, the other electrum), models of livers and lungs, a local pictorial mug, Cypriot White Slip II pottery and a LH IIIB stirrup jar (cat. no. 306). The funeral chamber to the east, tomb 3709, produced another LH IIIB stirrup jar (cat. no. 289). Three other Mycenaean finds are reported from this part of the house, the contexts of which are unknown: a LH IIIA2 stirrup jar (cat. no. 247), a LH IIIA2 piriform jar (cat. no. 498) and a LH IIIB bull's head rhyton (cat. no. 499). The south-western part of the house possessed a paved area, from which a drain led to the exterior. Near this drain, a LH IIIB pictorial amphoroid krater was found (cat. no. 314).

The Mycenaean pottery seems rather dispersed through the building. The two conical rhyta, one of them pictorially decorated, found together in room 3 of the northern part of the house, are associated with storage facilities. On the basis of its inventory, the nature of this building is not immediately clear. The two archives contained documents of various types, including several examples of religious or magical content. The discovery of the liver models and the libation tube likewise point to religious practices. This house seems to be an example of the possibility that religious practices were not only conducted in temples, but also in other buildings. ${ }^{{ }_{3}}$ If this was the case, the storage facilities of which the two rhyta were a part may have been connected to such practices.

The presence of a rhyton and a stirrup jar among the tablets in the Cella is difficult to interpret. The models of livers and lungs in this part of the building indicate that the archival function cannot be considered separate from religious activities. The association of the conical rhyton with the libation tube in this room indicates that the Mycenaean vessel was used for ritual purposes. Courtois con-

8o This building consists of several parts (see Fig. 5.5) The northern part is often referred to as a separate house, the Maison de Ben Agipsarri; however, it communicates with the southern part through a door in the west; see Courtois 1979a, 1277; 1979b, 111-112. The central part, the Maison du prêtre Hurrite proper, consists of the Cella and the hallway and rooms directly to the south and east; see Schaeffer 1963a, 206-215; Courtois 1969, 91-119. The south-western part of the building is referred to as the Maison au textes Médico-magiques or the
Maison de Lamastu; see Schaeffer 1966, 131-137, and is connected to both other buildings.

8I Courtois 1979a, 1277.

82 A tomb is indicated in the drawings but never referred to in the publications. Its small dimensions suggest that it was of an earlier date; cf. Salles 1987, 173.

83 Tarragon 1995, 209-210 implies that the distinction between religious and more profane domains was not as strongly marked as is the case in modern Christianity. 


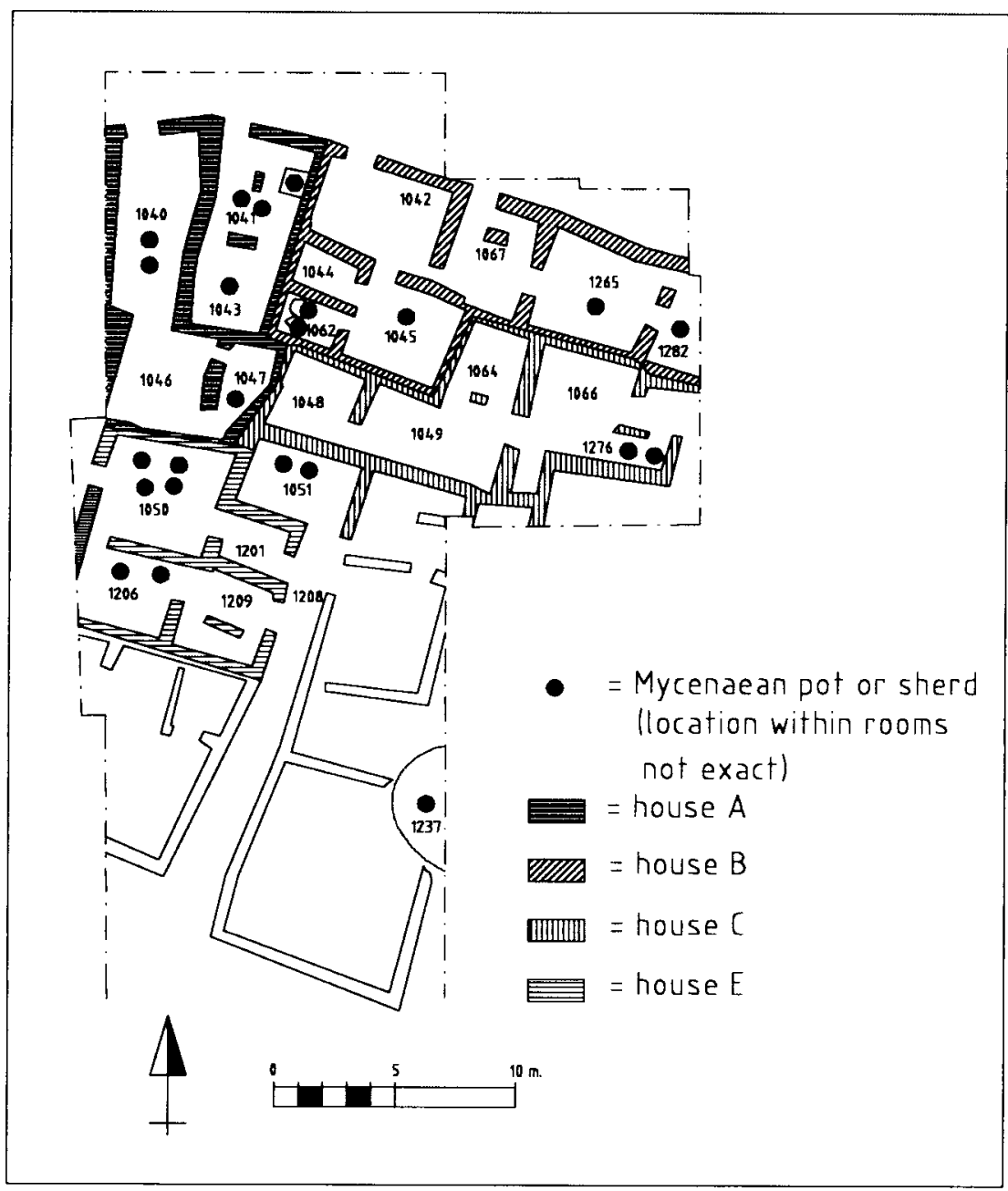

Fig. 5.6 Mycenaean pottery in the northern part of the Centre Ville

siders the pit in the cella in which the stirrup jar was found as votive. ${ }^{84}$ If this is indeed the case, the stirrup jar in the pit is also associated with religious activities. However, Schaeffer seems to think that the pit was part of a Middle Bronze Age tomb in which the objects fell after the floor of the Cella had cracked. ${ }^{85}$ In any case, the Mycenaean vases in this part of the building are associated with the various activities carried out in association with the archive. The isolated pictorial amphoroid krater found near the drain has no particular associations and may be related to domestic activities.

\section{Centre Ville: Maison $A^{\text {so }}$}

Maison $A$ is located in the north-western part of the Centre Ville and consists of four rooms and a courtyard (Fig. 5.6). During the rebuilding in the thirteenth century, these rooms were separated from those of Maison B, isolating Maison $A$ into an autonomous unit. The house is described as average, with utilitarian functions. A LH IIIB stirrup jar (cat. no. 448) and a Mycenaean fragment of unknown 
pot shape (cat. no. 447) were found on the floor of a hallway (room 1040), associated with Cypriot pottery, local pithoi, jars, cups and bottles, stone tools and a bronze pin. In the north-east of room 1041, a domestic installation was discovered, near which lay a Mycenaean bovine figurine (cat. no. 1043) and an Egyptian scarab. This area is described as the kitchen and because of a stone basin and a quantity of coarse ware vessels. In this room were also found a LH IIIB stirrup jar (cat. no. 450), a krater fragment (cat. no. 451), Cypriot Base Ring II vessels, local jars, pithoi, cups and a tablet with a seal impression. In courtyard 1043 a fragment of a LH IIIB pictorial krater (cat. no. 452) was found, associated with a 'Rude' or 'Pastoral' style krater, local kraters, a cup and a Cypriot wall bracket. The southern part of the house is considered to have been a storage area. In the small room 1047 a Mycenaean krater (cat. no. 449) was found in association with Cypriot pottery, an abundance of local vessels and several bronze arrowheads.

The Mycenaean pottery is dispersed through Maison A: all rooms but 1046 contain one or more pieces of such pottery. This seems to indicate that this material was an integral part of the everyday life on the ground floor of this building. ${ }^{87}$ The associations of the Mycenaean pottery are mainly domestic. The installation 1028 with the figurine is considered to be part of the kitchen. Although such a context evokes domestic associations for the figurine, the presence of a scarab near the figurine may suggest that different activities were also conducted here. The three kraters in this house are all related to domestic activities.

\section{Centre Ville: Maison $B^{88}$}

Maison $B$ is situated directly east of Maison $A$, forming part of the same insula and originally belonging to the same house (Fig. 5.6). This building is considered to be of better quality than Maison $A$, as it is larger and possesses an entrance hall with a well (room 1067). East of this room, courtyard 1265 is situated, in which a worn-off fragment of an LH IIIB ring-based krater was found (cat. no. 454) in association with White Slip II pottery, local bowls and jars, a cylinder seal and a bottle of faience. At the eastern end of this courtyard, there was an annexe, room 1282, which produced a LH IIIB globular stirrup jar (cat. no. 455). South of the entrance hall lies room 1045, in which the dromos of a tomb starts. In this space, a Mycenaean linear decorated shallow cup (cat. no. 453) was found, in association with stone and bronze tools, a faience cylinder and local jars and cups. It is because of this inventory that Yon, Lombard and Renisio suspect that the main function of the room was for storage and work, although funerary rites probably were conducted here as well. ${ }^{89}$ The tomb itself, which was pillaged, has produced no Mycenaean pottery. ${ }^{\circ \circ}$ West of this room were two small storage rooms. This function is clear from two pits (1269 and 1270), which were dug into the southernmost room. ${ }^{9 r}$ Two LH IIIB stirrup jars were found (cat. nos. 529, 531) in these pits, as well as two Mycenaean fragments (cat. nos. 532, 533). These were associated with Cypriot White Slip II pottery, Syrian plates and jugs, a faience pearl and stone tools and flint.

87 In room 1047 material could be identified that had collapsed from the floor above; see Yon, Lombard, Renisio 1987, 45. Among the reported finds (bronze axe, ivories, chalk plaque with a human figure), no Mycenaean pottery has been reported.

88 Yon, Lombard \& Renisio 1987, 61-88.

89 Yon, Lombard \& Renisio 1987, 78; see, also, Salles
1987, 132.

90 Yon, Caubet \& Mallet 1982, 179. Cypriot White Slip II and Base Ring II vessels are considered to have been part of the tomb inventory, just as Syrian Red Lustrous bottles.

91 Calvet \& Geyer 1987, 143-145. 
Except for the specimens found in the pits, all Mycenaean vases have been found isolated from each other; all were associated with local materials and with Cypriot pottery. Interestingly, the occurrence of the ring-based krater in the courtyard can be compared to a similar context for a krater in Maison $A$. However, in Maison B no other kraters have been reported from the courtyard. The stirrup jar in the annexe and the shallow bowl in room 1045 indicate that Mycenaean storage, as well as dinner vessels were part of the daily life carried out in the house. ${ }^{92}$

\section{Centre Ville: Maison $C^{93}$}

Maison $C$ is situated south of Maison B and consists of only five rooms (Fig. 5.6). Room 1066 was the entrance hall, where the staircase to the upper floor started. In a compartment underneath this staircase, two complete Mycenaean straight-sided alabastra (cat. nos. 463 and 464) were found, in association with a stone weight and some flint. This compartment served as a kind of closet or as a latrine. ${ }^{94}$

One of the alabastra (cat. no. 464) has been dated to LH IIIA2; the significance of such a vessel in a layer dating to the end of the city of Ugarit, has been commented upon above. The other alabastron has been assigned to LH IIIA2-LH IIIB. The room was created during the reconstruction of the building and it is clear from the report that these vases belong to the latest phase of the house. The fact that two straight-sided alabastra were found together is significant in itself. This pot shape (FS 9495) is relatively rare in Ras Shamra and Minet el-Beida: nine other specimens occur outside the Centre Ville, scattered over the site. ${ }^{95}$ In only one other case have two of these vases been found together: in tomb 2698 in the Ville Sud. In the Centre Ville, this pot shape occurs one more time: on square 1051, right next to Maison $C$, the rim of such a vase (cat. no. 428) was found on street level. The occurrence of two of these vases in this obscure part of Maison $C$ is remarkable and suggests that they served a special function.

\section{Centre Ville: Maison $E^{96}$}

Maison $E$ is situated south of Maison $A$ and only four rooms have been excavated (Fig. 5.6), which served domestic functions. A LH IIIB jug (FS 128-129; cat. no. 457) and a LH IIIB amphoroid krater (cat. no. 456) were found in courtyard 1206, associated with local jars and cups, a bronze axe or chisel, stone tools and a local imitation of an LH IIIB piriform jar (FS 36). ${ }^{97}$ North of this courtyard, room 1050 was situated, which apparently had a domestic function; on its floor were found a LM IIIA-LM IIIB large stirrup jar with linear decoration (cat. no. 534), and a LH IIIB stirrup jar (cat. no. 530). This room also produced another LH IIIB stirrup jar, which might be of local manufacture (cat. no. 459) and a LH IIIB shallow cup (cat. no. 458), but these two vases might have fallen from the upper floor.

92 Yon, Lombard \& Renisio 1987, 69 suspect that the people living in this house used the upper floors for habitation, while the ground floor was meant for storage and work.

93 Yon, Caubet \& Mallet 1982, 178, 181-182; Yon, Gachet \& Lombard 1987, 174-181.

94 Cf. house A, where, in room 1040, a toilet was located underneath a staircase.

95 The contexts in which they occur are either unknown or they are found in tombs: cat. nos. 9 and 52 come from tombs in Minet el-Beida, no. 307 from the Acropole, nos. 390 and 391 from tomb 2698 in RS VS, no. 95 from a tomb in the Ville Basse, no. 308 from RS TTE, no. 424 from the tomb in RS SW, while the find spot of cat. no. 120 is unknown.

96 Yon, Lombard \& Renisio 1987, 89-108.

97 Yon, Lombard \& Renisio 1987, 99, 101, Fig. 80: no. $81 / 981$. 


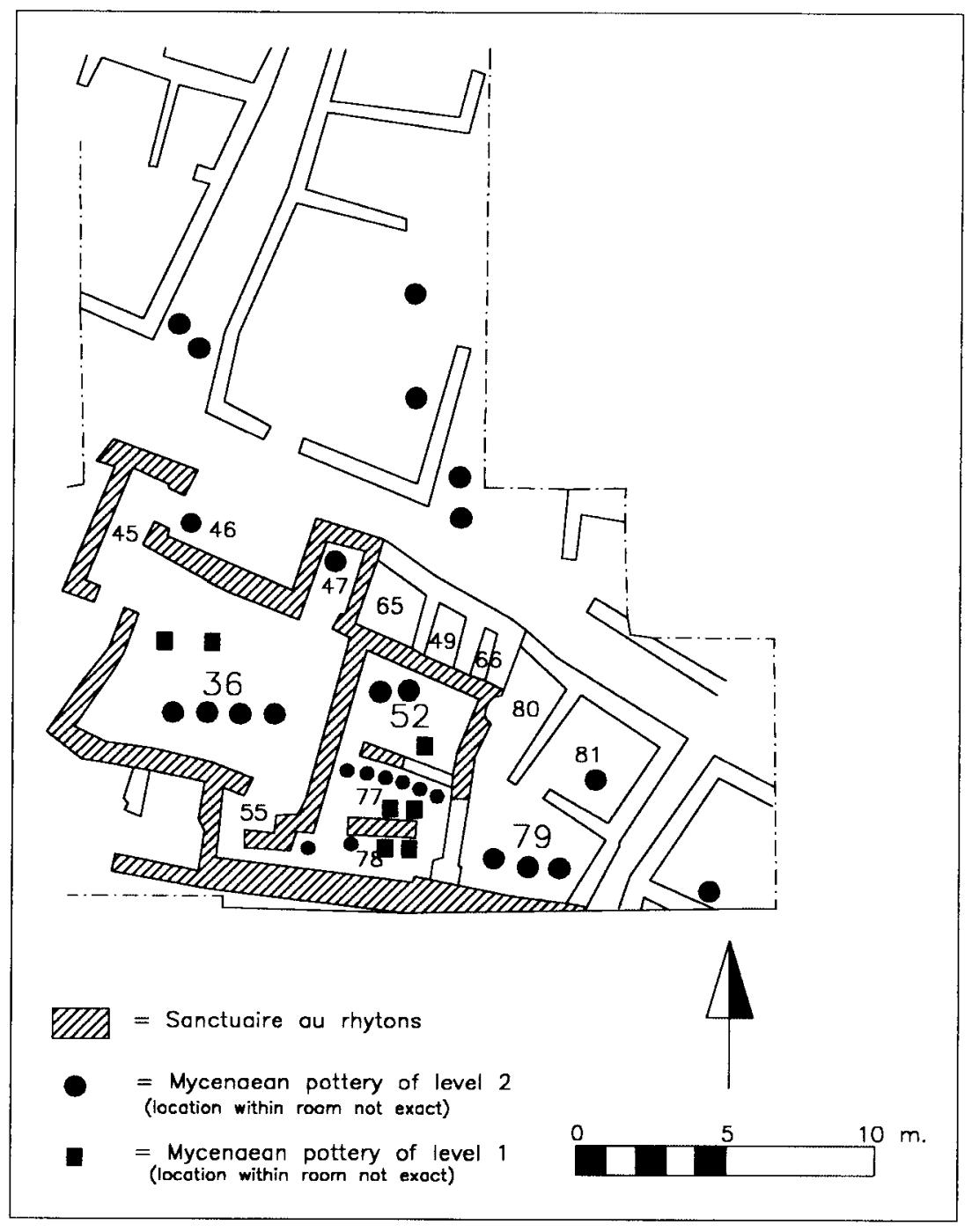

Fig. 5.7 Mycenaean pottery associated with the sanctuaire aux rhytons

As only four rooms of this house have been excavated, it is difficult to review the distribution of the Aegean pottery. In comparison with houses A, B and C, there seems to be a relative abundance of Aegean finds: the total of six imported specimens is only surpassed by the fully excavated Maison A. The LH IIIB jug and krater and the locally made piriform jar in courtyard 1206 can be associated with activities conducted in such a space. It may be noted that in this house, as in A and B, a krater is present in the courtyard. The jug might suggest that both of these vases were related to activities with fluids (water?). The association of these Mycenaean vases with a local imitation of Aegean ware suggests that imported vessels were not appreciated any more than such imitations.

Centre Ville: le sanctuaire aux rhytons ${ }^{98}$

In the south of the Centre Ville, a structure was excavated consisting of twelve rooms around the central room 36 (Fig. 5.7). This building has been interpreted as a sanctuary on the basis of the large size of

${ }_{98} \quad$ Mallet 1987; Yon 1987. 
room 36, the presence of an altar and benches in this room and the association of a number of rhyta with the building. ${ }^{99}$ Two floor levels have been discovered within the building, both dating from the last phase of the Late Bronze Age. The altar and benches in room 36 are associated with the latest level, niveau 2. Among the material belonging to level 2 in this room was a large quantity of Cypriot and Syrian pottery, as well as some fragments of Mycenaean pottery (cat. nos. 537-539). Fragments of amphoroid krater no. 527 were found on the same floor, while other pieces of the same vessel were dispersed throughout the south-eastern part of the building. On the lower level, the LH IIIB jug of cat. no. 461 was found in this room, as well as a sherd with horizontal bands (cat. no. 540). In the north-east, the sanctuary opened up to the small room 47, in which Syrian and Cypriot pottery and an ivory duck box were found on level 2. The debris near the walls, produced the Mycenaean fragment of cat. no. 541. Level 2 of room 52, directly east of room 36, yielded some stone tools, Syrian and Cypriot pottery, 3 fragments of a Mycenaean krater (cat. no. 542) and a Mycenaean conical rhyton (cat. no. 438). On the lower floor level a fragment with horizontal bands (cat. no. 543) was discovered. A concentration of Mycenaean pottery was found in room 77: 2 fragments of amphoroid kraters, (cat. no. 544 and 546), a small stirrup jar (cat. no. 547), a large stirrup jar (cat. no. 548), a straight-sided alabastron (cat. 549) and a fragment (cat. no. 545). Several Cypriot White Slip II bowls, as well as Syrian vases and a lamp were also found here on this level. The lower level, likewise, produced some fragments of an amphoroid krater (cat. no. 550) and two Mycenaean fragments of the same vase (cat. no. 486). South of this area, in room 78 , two conical rhyta (cat. nos. 441, 445) were attested in level 2, with a large amount of local and Cypriot pottery. Level 1 produced a fragment of the amphoroid krater that had been found previously in room 77 (cat. no. 550) and a linear fragment (cat. 487). Room 79, the entrance hall from street 120, produced 2 fragments of Mycenaean pottery (cat. no. 535, 536) and a coarse ware stirrup jar (cat. no. 462), while somewhat to the north, in room 81, a Mycenaean bovine figurine (cat. no. 1045) was found. Finally, room 46, flanking street 35, yielded a Mycenaean conical rhyton (cat. no. 436).

Although four rhyta have been found in the building itself (none of which is in central room 36), the name of the sanctuary derives particularly from the scatter of rhyta around the building. According to Yon, these rhyta were dispersed after the building was abandoned and pillaged. ${ }^{\text {100 }}$ Six Mycenaean conical rhyta (cat. nos. 434, 437, 439, 440, 442, 443) were found less than ten meters north of the sanctuary, while three Syrian rhyta were located in the same area. Another Mycenaean rhyton (cat. no. 444) was found directly east of the building, not far from a Syrian rhyton made of stone. ${ }^{\text {Ior }}$ Including the rhyta found in the sanctuary itself, fifteen such vessels are associated with the sanctuary, of which eleven are of Aegean manufacture.

In total, 33 Mycenaean pottery finds are associated with this building. Of these, eleven are conical rhyta, while there are five kraters, two stirrup jars, one small globular jug, one straight-sided alabastron and a figurine. ${ }^{102}$ From this we can deduce that conical rhyta served a specific function in this building. Moreover, the dominance of Mycenaean rhyta over Syrian products suggests that the imported types were favoured, though not exclusively so, to fulfil this function. Although it is tempting to associate these rhyta with rituals performed in the sanctuary, it also needs to be noted that none has been found in its

99 Yon 1987, 343. It has been suggested that this building was the place where a confrérie assembled, rather than a temple in the classic sense; see Tarragon 1995, 206. This would explain its small size in comparison with the two temples on the acropolis and the absence of a courtyard with an altar suitable for animal sacrifices.

ro Yon 1987, 343.
Ior Another conical rhyton (cat. no. 435) was found somewhat further to the east in the excavation trench of the Ville Sud.

ro2 The dominance of rhyta may partly be due to the fact that only for this shape the distribution outside the building itself has been studied. 


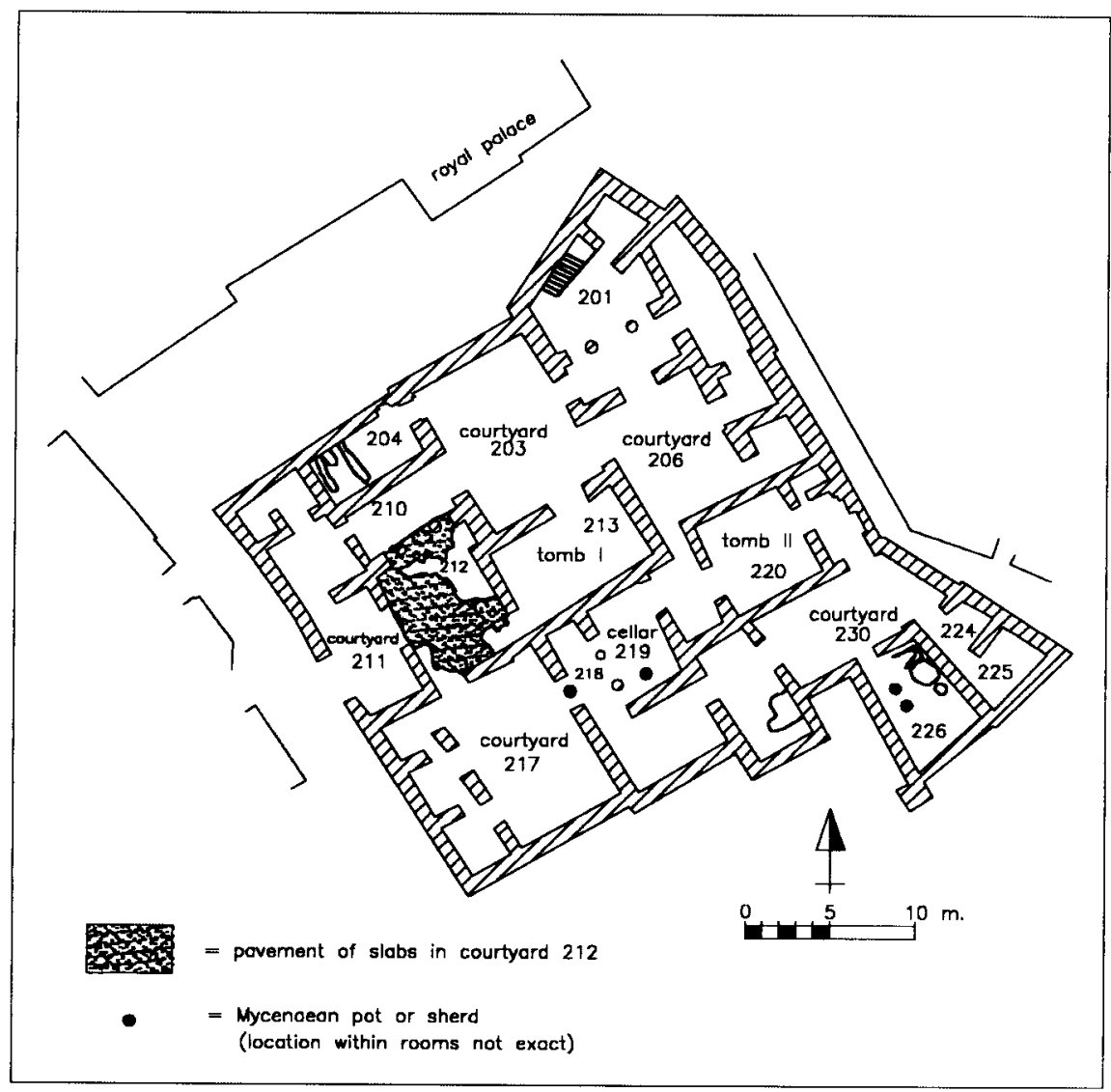

Fig. 5.8 Mycenaean pottery in the Palais Sud

central area where the altar was located. Only one of the rhyta associated with this building is decorated pictorially (cat. no. 445: octopus), which indicates that pictorial decoration was not of importance for the use that was made of the rhyta in the sanctuary. At first glance, the five krater fragments found in the building seem to suggest that this pot shape served a special function in the sanctuary as well. However, the occurrence of the five specimens here is not different from other, non-religious areas. None of these vessels is pictorially decorated. The occurrence of one bovine figurine in an annexe to the building does not suggest a special function of this type of object in the cult practised at the sanctuary.

The distribution of the Mycenaean pottery within the building shows a concentration in its southeastern part, especially in rooms $36,52,77,78$ and 79 . Other rooms in the sanctuary (for example rooms, 47, 65, 49, 66, 55) have yielded substantial quantities of Cypriot and Syrian wares, but reveal a relative paucity of Aegean pottery. Nevertheless, we may consider the Mycenaean pottery an integral part of the inventory of the sanctuary. Apart from the Mycenaean rhyta, the other Aegean vessels do not seem to have occupied a special status in the activities that took place in this building.

\section{Palais Sud ${ }^{103}$}

Situated directly south of the royal palace, this building was labelled the small, or southern, palace on the basis of its size and the quality of the finds (Fig. 5.8). ${ }^{104}$ Cuneiform tablets found in this building

ro3 Schaeffer 1962b, 121-127; 1966, 133-4; Courtois 1979a, cols. 1235-1240; Yon 2000, 8.
${ }^{104}$ Instead of a palace, it is more likely that this building is one of the large mansions which were in close proxim- 


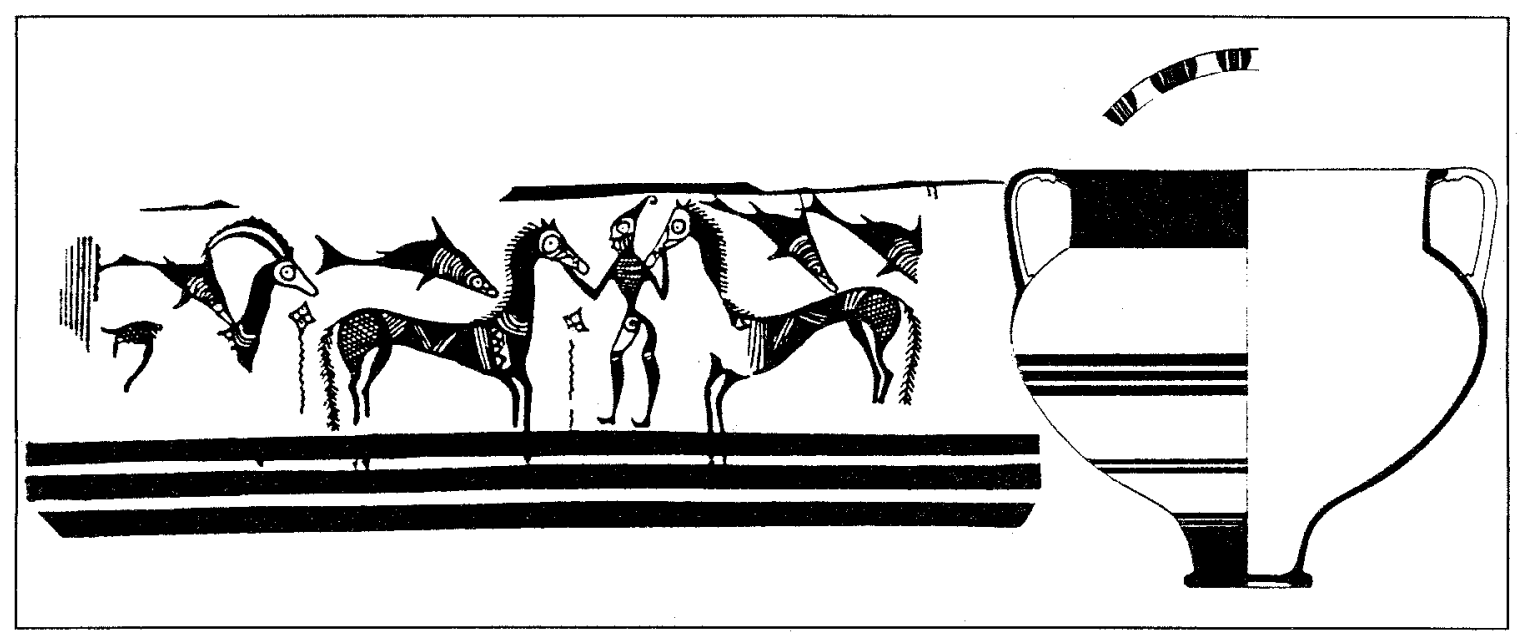

Fig. 5.9 Amphoroid krater with pictorial decoration (cat. no. 402) from room 219 in the Palais Sud - After Yon 1997a, 155: no. 32

mention a certain Yabninu, who probably was the owner of this large mansion at the time of the destruction of Ugarit. ${ }^{105}$ In total, twelve specimens of Mycenaean pottery can be associated with this house, including three figurines. However, from only a few vases the find spot within the house is certain. Directly east of the large tomb 1, in the centre of the building, there is a cellar, room 219, in which a great number of storage jars were found, as well as a Mycenaean pictorial amphoroid krater, the famous Maitre du Cheveaux (Fig. 5.9) dating to late LH IIIB (cat. no. 402). ${ }^{106}$ Directly south of this room, in the entrance from courtyard 217 to room 216, a Minoan amphoroid krater decorated with an octopus was situated (cat. no. 479), again amongst pithoi. A third amphoroid krater (cat. no. 358) was found in this house. Although the exact find spot of this Mycenaean krater is not known, it is reported to have come from the communs, which were located in the south-east of the building, near courtyard 230 and the kitchen 226. A LH IIIB deep bowl (cat. no. 214) likewise has been found in this area of the house. Of all other specimens of Mycenaean pottery associated with this house the find spot is unknown. Only of the equid figurine (cat. no. 1029) it is certain that it has been found within the building itself; the other finds may have been made outside.

The distribution of the Mycenaean pottery in this mansion is difficult to assess, as the find spot of so many pieces of Mycenaean pottery is unknown. There seems to be a rather high proportion of Aegean kraters. This may be of some significance, as it indicates that this vessel type was particularly appreciated by the inhabitants of the house. At the same time, it must be stressed that two of these kraters were found among storage pottery, while another was located in the area of the kitchen. This indicates that these vessels were not highly valued possessions; but were used in the everyday life in the mansion. ${ }^{107}$

ity to, but isolated from, the palace; see Callot 1986, 746.

ros Courtois 1990.

ro6 Courtois 1973, 155-161.

Io7 Yon $(2000,8)$ suggests that the krater with cat. no. 402

(Fig. 5.9) came from the nearby tomb 220 and was left in room 219 by grave robbers. Since the krater, even though in fragments, was found almost complete and much other pottery has been reported from room 219 , I consider the find spot of the krater to be its primary context. 
Interestingly, apart from the figurines and two fragments, all the Aegean vases coming from the Palais Sud are dinner vessels: four kraters, two kylikes, and a deep bowl. The size of the mansion and its proximity to the royal palace suggest a high status for the inhabitants of the house. This may indicate that Mycenaean dinner vessels were appreciated more highly by persons of high status than storage vases. The presence of Mycenaean pottery in this mansion shows that this material was in use among a group of very high-ranking citizens of Ugarit. At the same time, there is little evidence that they were prestige products.

The first purpose of this section is to review if a differentiation can be made within the general class of Mycenaean pottery in its occurrence among social groups within the society of Ugarit. The contexts which have been reviewed here can be grouped according to their function and role in society. The royal palace, seat of power and the administrative centre, has not been discussed here. Mycenaean pottery was found in the palace, widely dispersed among courtyards and rooms. ${ }^{108}$ This suggests that this type of pottery was widely used by many people in the palace and not reserved to specific groups or circumstances. In fact, Mycenaean pots appear to have been used by people working in the palace, as is most probably the case for a bowl (cat. no. 429) which was found in the southern archives. ${ }^{109}$ In general, the evidence does not indicate that the powerful rulers of Ugarit monopolised or restricted specific parts of the Mycenaean ceramic repertoire.

The large mansions, such as the Maison d'Albatres and the Palais Sud, which are located near the palace and probably were owned by officials high in the hierarchy of the state, ${ }^{\text {оo }}$ constitute a second contextual group. Mycenaean pottery was used by the inhabitants of these houses. On the basis of their context, the rhyta in the Maison d'Albatres appear to have been highly prized possessions. This cannot be said for dinner vessels, which occur in both mansions in contexts that associate them with domestic activities. Figurines were present in the Palais Sud, but storage vessels were absent from both mansions. Recently, the house of the trader Ourtenu has been investigated; it yielded at least five pictorial kraters. ${ }^{\text {II }}$

The smaller houses in Ugarit and its harbour town, which served domestic functions, but in which industrial and commercial activities were carried out as well, ${ }^{12}$ constitute the third group, comprising Houses A, B, C and E in the Centre Ville and possibly also the Maison au frittes. This type of house is the most abundant in Ras Shamra ${ }^{\mathrm{II}}$ and the limited but constant occurrence of Mycenaean pottery in these houses testifies to the wide use of such vessels among the population of Ugarit. Dinner and storage vessels occur in the houses that have been discussed here, just as figurines. However, Aegean rhyta occur only in the context of the Maison au frittes, of which it is not altogether certain that it belongs to this group.

Buildings in which religious or cultic associations are very strong, can be considered a fourth group, including the 'temples' in Minet el-Beida and the Centre Ville, as well as the complex with the Maison au prêtre Hurrite. Dinner and storage vessels occur in these contexts and both types may have been used in the rituals which took place in such buildings. This type of context has produced a high number of Mycenaean rhyta, which indicates that this vessel type had religious connotations. This does not seem to be the case for figurines, of which only one occurs in the Temple au rhytons.

\footnotetext{
ro8 Hirschfeld 2000b; Yon 2000, 9.

Iog Schaeffer 1962b, 101.

по Callot 1986, 746.
}

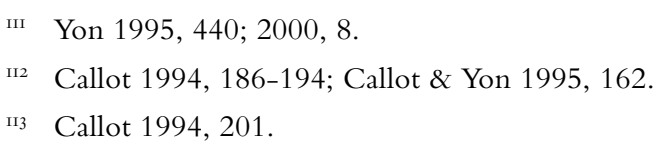

YII 1995,$440 ; 2000,8$

п3 Callot 1994, 201 
Buildings with a strong industrial or commercial character constitute a fifth group, of which no contexts have been discussed here. A concentration of nine Mycenaean figurines, however, has been discovered in an area in Minet el-Beida with many pits and signs of metal working. ${ }^{\mathrm{II}}$ In addition, a LH IIIB stemmed cup (cat. no. 116) was found in a house referred to as a "storehouse", because of its large quantities of pottery. ${ }^{\text {II }}$ Perhaps, the industrial area of the Maison d'Albattres should be included in this contextual group as well, showing that dinner vessels also occur in such areas.

It is clear that Mycenaean pottery, as a general class, was used by many social groups in the society of Ugarit and its harbour town, although substantially less so in the royal palace. However, there seems to be a differentiation with regard to vessel type. Mycenaean rhyta occur mainly in contexts with strong religious associations and in buildings that reveal wealth and high status: the palace and the Maison d'Albatres. In the case of the Maison au frittes, these vessels are similarly associated with cult or wealth. The size and selectivity of the sample reviewed here makes it difficult to detect a differentiation between dinner and storage vessels. However, it is of interest that no storage vessels have been reported from the two mansions and the palace. Such vessels do occur in the average houses and in buildings with religious or cultic associations, while they are dominant in refuse contexts. Figurines seem to occur in all kinds of contexts.

The second purpose of this paragraph is to review the extent to which Mycenaean pottery was particularised, i.e. circumstances in which Mycenaean vessels are found with clear indications that it was used for specific purposes for which it seems to have been deliberately chosen. ${ }^{\text {.16 }}$ In general, Mycenaean pottery in Ugarit does not seem to have been subject to such particularization: the majority of Mycenaean vessels and figurines are found in contexts indicating that they were part of a material assemblage that included mainly local objects and a minority of imported items. Even though the fact that the pottery was imported may have contributed to its significance, it is clear that it was an integral part of the cosmopolitan material culture. Nevertheless, there are a few occasions in Ras Shamra and Minet el-Beida which indicate that particularisation of Mycenaean pottery did occur.

The first of these concerns the group of reused amphoroid krater fragments from Minet el-Beida. It seems clear that Mycenaean amphoroid krater sherds were deliberately chosen to fulfil the unknown purpose of these artefacts. Moreover, they seem to have been deliberately deposited near the pit. A second example of particularization concerns the deposit of numerous Mycenaean figurines in the area with pits in Minet el-Beida. A third example are the straight-sided alabastra that were found together in Maison $C$ in the Centre Ville. The presence of a third vessel of the same type in the courtyard adjacent to this house suggests that these vessels were of a specific significance in and around this house.

The most obvious example of particularization concerns Mycenaean rhyta, which, as seen above, have been found in three cases in buildings with strong religious or cultic associations. Although the find contexts makes use of these vessels in religious ceremonies likely, it needs to be emphasised that both in the temple of Minet el-Beida and in the sanctuaire aux rhytons Syrian rhyta were found associated with the Mycenaean specimens. In the case of the Maison au prêtre Hurrite a Syrian libation tube was present. This suggests that it was the function as rhyton, rather than their Mycenaean origin which led to the particularization of these vessels. This seems less true for the Maison d'Albatres where

II4 Schaeffer 1929, 290-291. Cat. nos. 1014-1022.

IIs Schaeffer 1929, 287-289.

I6 Hugh-Jones 1992, 58-59 shows how western goods are put to a variety of uses by Amazonian Indians and provide opportunities for both technological and symbolic innovation. 
such rhyta were found in a context which indicates that they were highly prized possessions. However, the deposit in the Maison au frittes also has local imitations interspersed with original Mycenaean vessels.

Finally, it needs to be remarked that no contexts have been identified in which Mycenaean pottery seems to have been particularised on the ground of its pictorial or plastic decoration. ${ }^{\mathrm{II}}$ Although the decoration on the vessels will certainly have been noticed, it does not seem to have been of consequence for the way these vessels were used and deposited in the archaeological record.

\section{F U NERARY CONTEXTS}

The excavations at Ugarit began in 1928 with the chance discovery of a vaulted funerary cellar in Minet el-Beida. Six additional tombs were investigated soon afterwards, while recently such a tomb has been excavated, which, as yet, remains unpublished. ${ }^{\text {"8 }}$ At Ras Shamra, there were probably more than two hundred of such tombs; many of which remain unpublished. ${ }^{\text {"9 }}$ At both sites, these tombs are situated below the buildings. Schaeffer suspected that each house in Ras Shamra possessed its own tomb. ${ }^{120}$ Recent research, however, has shown that many houses did not have a funerary cellar, especially in the latest phase of Ugarit, while some tombs cannot be associated with a single structure. ${ }^{12}$ Moreover, most tombs seem to have had independent access from the outside. The relationship between the deceased in the tombs and the houses to which they belong architecturally, therefore, is not altogether clear. In addition, the tombs at Ugarit were used for many generations.

It is a premise of funerary analysis that the social life of deceased persons is reflected and reinterpreted in mortuary practices, which can be recognised in the archaeological record of the burial. ${ }^{122}$ For the reasons outlined above, however, it is impossible to determine whether the vaulted tombs of Ras Shamra and Minet el-Beida are related to one family or to a wider social group. Moreover, the long use of the cellars makes it impossible to assess which items of the tomb's inventory were part of one and the same funerary ceremony. Finally, all but two tombs have been pillaged, which complicates matters even further. ${ }^{23}$

Table III in the tables section of this book lists all the tombs in Ras Shamra and Minet el-Beida from which Mycenaean pottery has been published. These tombs can be analysed on a number of points. First, the amount of Mycenaean pottery in the tombs will be discussed. This will reveal the extent to which Mycenaean ceramics were considered appropriate as a funerary gift. Moreover, it may show differences among tombs in this respect. Secondly, the variety of Aegean pot shapes will be reviewed, in order to see if specific vessel types were popular in funerary ceremonies. Finally, the variety of the tomb inventories associated with the Mycenaean pottery will be considered. This may establish whether differences in the repertoire of the Aegean ceramics among tombs can be related to the rest of the inventory.

II7 The two pictorial rhyta found together in room BD of the Maison d'Albâtres and the two hedgehog rhyta in the Maison au frittes may be exceptions to this pattern. However, as all these vessels concern rhyta, it is more likely that their shape is responsible for the particularisation.

\footnotetext{
II8 Courtois 1979a, 1283-1287; Saadé 1995; Yon 2000, 3.

п9 Marchegay 1999.

I20 Schaeffer 1939a, 30; see, also, Courtois 1968, 20.

I2I Salles 1987, 159-160; Callot 1994, 168-169, 175-176.

122 Binford 1971; Hodder 1982b, 141-146.

${ }^{123}$ In the Ville Basse tomb 13 was found undisturbed; see
} 
Thirthy-eight graves with Mycenaean pottery are mentioned in Table III. All but two - a burial in the royal palace and an enchytrismos from the eastern end of the site - concern vaulted tombs. In Minet el-Beida a total of seven such tombs have been excavated. ${ }^{124}$ Of these, tomb I certainly contained Mycenaean pottery, as it was this grave which led to the beginning of archaeological research at Ugarit. However, as none of the finds of tomb I have been published, they are absent from the catalogue. No Mycenaean pottery has been reported from tomb II and tomb VII. Likewise, not all funerary cellars at Ras Shamra, contained Mycenaean ceramics. ${ }^{125}$ From the hundreds of tombs identified at Ras Shamra, only from some forty have finds been published. Among them, thirty-two tombs contained Mycenaean pottery, which indicates that in a majority of cases this material was part of the funerary inventory.

There are substantial differences between the tombs in the quantities of Mycenaean pottery that have been reported. It is clear that not all the material from some tombs has been published. ${ }^{226}$ The pillaging of the tombs may also have resulted in the loss of Mycenaean ceramics. Of the two tombs that have been found intact, tomb 13 in the Ville Basse produced six Aegean specimens, while tomb 4253 yielded two Mycenaean pots. These figures show that the numbers listed for most funerary cellars are not unrealistic: with the exception of tombs III, IV, V and VI in Minet el-Beida and tomb 2698 in the Ville Sud, the figures for most burials lie between one and eight Mycenaean pots. Considering the long time in which these tombs could be used and the number of burials, ${ }^{127}$ these figures indicate that, in general, Mycenaean pottery was only a minor item used during the funerary ceremonies.

Five tombs deviate from this pattern. In Minet el-Beida tomb III has produced eighteen pieces of Aegean ceramics, while from tomb IV nineteen, from tomb V fifteen and from tomb VI forty-three specimens of Aegean pottery have been published. At Ras Shamra, tomb 2698 in the Ville Sud has produced twenty-one Mycenaean vessels. The tombs at Minet el-Beida are exceptionally large in comparison with those at Ras Shamra and contained a rich and varied inventory. ${ }^{128}$ Nevertheless, it is clear that in these five tombs the associations with the Aegean are particularly strong.

Table $\mathrm{V}$ in the tables section lists the vessel shapes that occur in the tombs of Ugarit. The first observation to be made on the basis of this table, is that, in contrast with the general pattern at Ras Shamra and Minet el-Beida, storage vessels are more abundant in tombs than dinner vessels. This pattern is not completely consistent for all tombs: from seven burials more dinner than storage vessels have been published, while in six cases the proportions are equal. ${ }^{129}$ The predominance of storage vessels is al-

Schaeffer 1936b, 140-142, while in the Ville Sud tomb 4253 was intact; see L. Courtois, 1969, 120-137.

I24 Saadé 1995, 213-214.

I25 Such is the case for the Late Bronze Age tomb in the Centre Ville; see Yon, Caubet, Mallet 1982, 179. Tombs 22 and 28 at the Ville Basse contained local and Cypriot, but no Aegean, pottery; see Schaeffer 1949, 162-163. From three tombs only local imitations of Mycenaean pottery have been reported; see Monchambert 1983, 36-37: no. 3, Margueron 1977, 178 (tomb at A6dNO); Courtois \& Courtois 1978, 358: no. 1 (tomb 10), Schaeffer 1938, 319, Fig. 47 (tomb 50).

I26 Tomb VI in Minet el-Beida contained 282 Mycenaean pots and 35 Mycenaean figurines; see Courtois 1979a, 1283. However, only thirty-eight vessels and four figurines have been published.

127 In tomb 13 the remains of 44 individuals were recognised; see Vallois \& Ferembach 1962, 566

I28 Courtois 1979a, cols. 1283-1284.

I29 In tombs III and V from Minet el-Beida, as well as in tombs 1 and 5 or 6 in RS Acr., tomb 37 in RS Ch. C, tomb 4642 in RS QR and tomb 30 in RS VB, dinner vessels occur more often than storage vessels. Tombs 2 , 


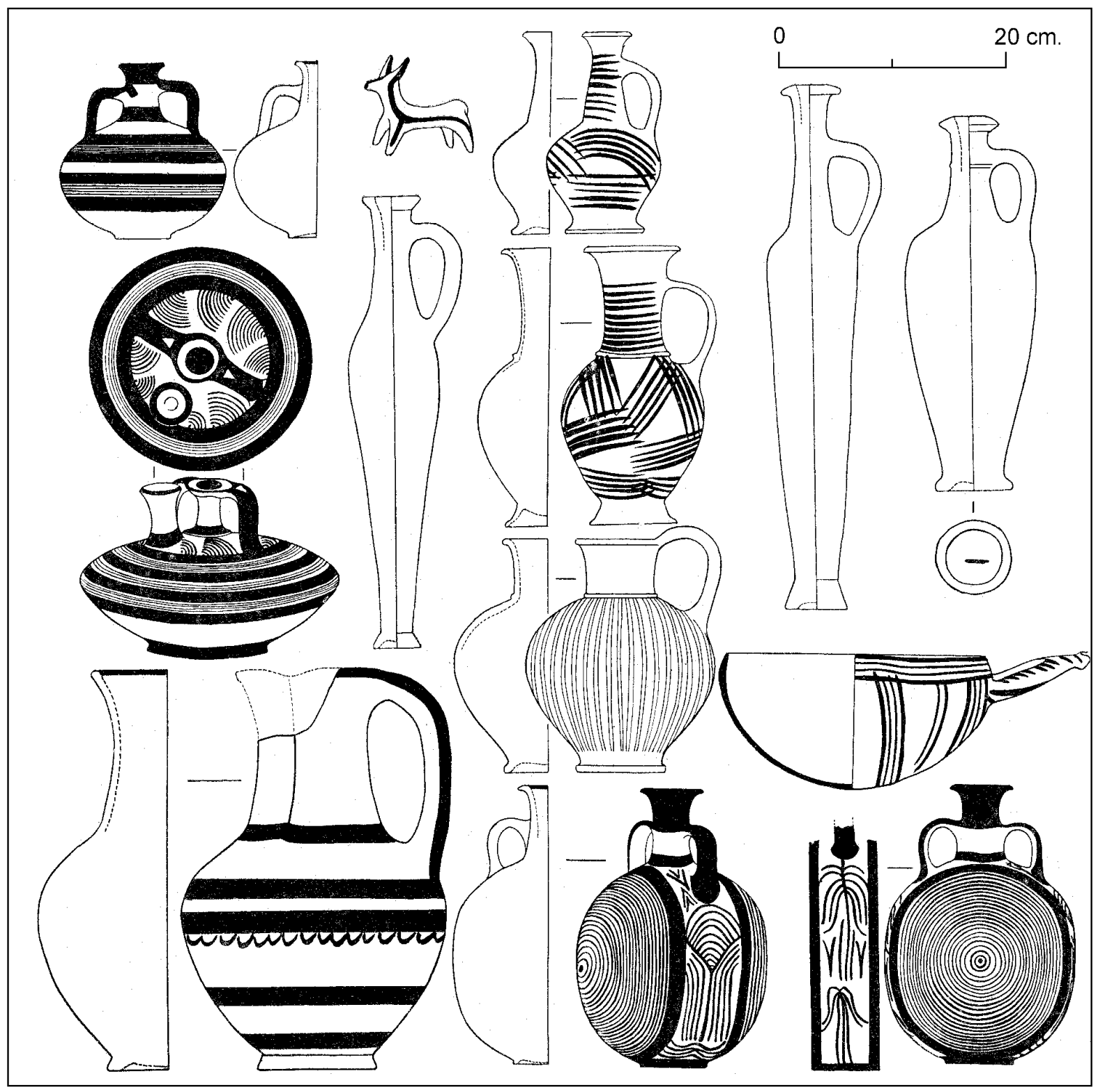

Fig. 5.10 Selections of Syrian, Cypriot and Mycenaean pottery from tomb 37 in the Chantier C - After Schaeffer 1949, 171 fig. 67

most entirely due to the number of stirrup jars found in tombs. These figures indicate that stirrup jars as a class, apparantly, were popular in funerary ceremonies.

Another vessel type which often has a funerary context are bowls. ${ }^{130}$ More than half of all Mycenaean bowls at at Minet el-Beida and Ras Shamra come from a tomb, which suggests that fu-

4, 29 (RS Acr.), tomb 23 (RS Ch. C), tomb 4642 (RS QR) and tomb 449 (RS SA) each have produced one specimen of either category. These deviations from the general pattern for tombs are slight and too random to represent a difference in funerary practices. They might, in fact, to a large extent be caused by circumstances of recovery and publication.

130 The largest class within this group are shallow bowls (FS 295-296): which occur 24 times in tombs. The other bowls are deep bowls (FS 284-285), which occur 
nerary use was an important function for this dinner vessel. The same may be said for cups, of which twenty out of a total of thirty-two specimens in Ras Shamra and Minet el-Beida have a funerary context. ${ }^{13 \mathrm{I}}$ In the case of kraters, however, which also often occur in a funerary context, a larger amount has been found outside tombs, ${ }^{132}$ as is the case for piriform jars. ${ }^{133}$

Mycenaean pictorial vessels are not very common in the tombs at Ugarit. As is clear from Table 5.10 , only a minority of this type of vases have been found in a funerary context. The large number of pictorial finds without a known context does argue for some caution, however. Only nine tombs listed in Table $\mathrm{V}$ have yielded Mycenaean pictorial pots, among which were kraters, bowls and a stemmed cup. ${ }^{134}$ The nine tombs are situated in various areas of Ras Shamra and Minet el-Beida and only three tombs have produced more than one Mycenaean pot with pictorial decoration: tombs IV and VI in Minet el-Beida and tomb 2698 in the RS VB. ${ }^{135}$ Each of these tombs has produced many Mycenaean pots in general and the presence of pictorial pots probably is a result of an accumulation of Mycenaean vessels. All this indicates that the pictorial decoration of Mycenaean pots does not seem to have been of consequence for their use in funerary practices. ${ }^{1{ }^{36}}$

There is clearly a pattern in the occurrence of the different Aegean vessel types in tombs. The pot shapes which have a high frequency in funerary contexts occur in the majority of tombs. Even vessel types that are not very current in this type of context appear in more than one funerary cellar. ${ }^{137}$ This relative homogeneity in the presence of Aegean pot shapes in the tombs suggests that various groups in the society at Ugarit used the same type of Mycenaean pots in their funerary practices. Figurines show an exception to this pattern, as they occur in only four funerary cellars: tombs III, IV and VI in Minet el-Beida and tomb 81 in the Ville Basse. Moreover, in these four cases, figurines are relatively abundant in comparison with the various Mycenaean vessel types. ${ }^{138}$ It appears, therefore, as if

twice in a funerary context, as do one-handled bowls (FS 244); one round-bottomed bowl (cat. no. 103) is present in tomb 30 in RS VB.

${ }^{\text {I3I }}$ Both examples of the carinated conical cup (FS 230) occur in tombs. This is also the case for the single specimens of the spouted cup, the one-handled cup and the hand made cup. Of the shallow cup (FS 220), however, only eight of the nineteen are from a funerary context.

${ }^{132}$ Of the seventy-five amphoroid kraters (FS 53-55) thirteen have been found in tombs. Of the six ring-based kraters (FS 281) this is the case for two specimens. A total of twenty sherds could not be assigned to either class of kraters; of these only one has been found in a tomb.

${ }^{133}$ A total of thirty-two piriform jars (FS 35-36, FS 4448) have been found at these sites; sixteen have been attested in a funerary context.

${ }^{134}$ Tombs IV and VI in Minet el-Beida, tombs 1 and 4 on the Acropole, tomb 4642 in RS QR, tomb 78 in the Ville Basse, tomb 449 in the RS SA, tomb 2698 in RS VS and the tomb of RS SW.
135 Tomb IV included an amphoroid krater sherd showing a man and horse (cat. no. 27), as well as a shallow bowl decorated with fish (cat. no. 17). Tomb VI included a chariot krater (cat. no. 80) and two shallow bowls, one of which showed a bull (cat. no. 53), while another showed a bird (cat. no. 60). Tomb 2698 produced two amphoroid kraters decorated with birds (cat. nos. 375 , 398).

${ }^{136}$ It has been suggested that Mycenaean pictorial pots were produced specifically to be included in funerary practices in the eastern Mediterranean; see Dikaios 1969, 249; Vermeule \& Karageorghis 1982, 8; Keswani 1989b, 58-69. The evidence from Ugarit, does not support such a hypothesis.

${ }^{137}$ The lid (cat. no. 50) and the part of a ring kernos (cat. no. 178), which are unique in the tombs, are, of course, exceptions to this pattern.

${ }^{138}$ In the case of tomb VI in Minet el-Beida, only five of the thirty-five Mycenaean figurines found have been published; see Courtois 1979a, 1283. It is possible that a similar situation exists for the other tombs in the harbour town. 
Mycenaean figurines played a special role in the funerary ceremonies for the owners of these four tombs.

The fact that virtually all the funerary cellars in Ugarit and its harbour town have been pillaged makes it impossible to analyse the tombs in terms of their wealth in finds. The fragmentary and selective publication of the funerary inventories, likewise, prevents any classification according to their wealth. What is certain is that the presence of Mycenaean pottery is not a reliable indicator for the status of the people buried in the funeral cellar. Tomb 50, in the Quartier Nord Ouest, for example, had a rich and varied inventory, but did not contain Aegean ceramics. ${ }^{139}$ On the other hand, the tomb in the royal palace, the top of Ugaritic society, did contain Mycenaean ware. ${ }^{\text {I40 }}$

In general, local Syrian pottery was much more abundant in the tombs of Ras Shamra than imported goods. This is true for the two tombs that have been found undisturbed, ${ }^{141}$ as well as for most other tombs from which the inventory can be reconstructed. ${ }^{142}$ An exception to this rule appears to be tomb 2698 in the Ville Sud, from which only the Mycenaean pottery, a local imitation of a Mycenaean stirrup jar and a Cypriot White Slip II bowl have been reported. ${ }^{143}$ However, it is possible that in this case the Syrian pottery has been left out of the publication. Cypriot pottery seems to have been at least as abundant in most tombs as Mycenaean wares. In several cases, Egyptian alabaster vases have been reported. ${ }^{144}$ Although the number of imports in most funeral cellars seem to be relatively small in comparison with local products, their occurrence in the majority of tombs indicates that they played a consistent role in Ugaritic funeral rites. The fact that Aegean pottery in funerary contexts almost always seems to be associated with other imports suggests similarities in appreciation.

With regard to their inventories, the tombs in Minet el-Beida constitute exceptional cases. Not only have they produced a wealth of finds, they are also the only tombs in which Mycenaean pottery seems the most abundant class of material. The large tomb VI in Minet el-Beida, which contained 282 Aegean pots and thirty-five Mycenaean figurines, also produced eighty-six pieces of Cypriot pottery, twenty-six specimens of local manufacture and some Egyptian alabaster vases. ${ }^{145} \mathrm{~A}$ krater of socalled Late Grey Minyan Ware, probably of north-western Anatolian origin, was also discovered in this tomb, just as a great number of faience flasks. From tomb III have been published eighteen specimens of Mycenaean pottery, eleven Cypriot and twenty-three local pots. ${ }^{146}$ Nineteen pieces of Aegean pottery are known from tomb IV, as are six Cypriot vases and ten local pots. ${ }^{147}$ Tomb V produced fifteen Aegean vessels. The amount of Cypriot pottery is unknown for tomb V, but three pieces of local pottery have been published.

I39 Schaeffer 1938, 317-320

I40 Schaeffer 1951a, 7-8. Egyptian alabaster vases and an ivory pyxis were also part of the inventory.

I4I Tomb 13 contained thirty Syrian flasks, bowls and jugs, four Cypriot Base Ring II jugs, one Cypriot WSII bowl; see Schaeffer 1936b, 121-123. Tomb 4253 produced forty-four local vases and six Cypriot WSII bowls; see L. Courtois 1969, 128-129.

${ }^{142}$ See, for example, tomb 37 in the Chantier $C$, from which seven local vases, one Cypriot White Slip II bowl and a Cypriot Base Ring II jug have been published: Schaeffer 1949, 164-165. From tomb 29 on the
Acropole, a Syrian flask, lamp and dipper have been reported, but no Cypriot ware: Schaeffer 1949, 162-163. From tomb 22 on RS Acr. local and Cypriot pottery is known, while tomb 28 apparently produced only local ware: Schaeffer 1949, 162-163.

I43 Courtois \& Courtois 1978, 342-345..

I44 See, for example, Courtois 1979a, 1283 (tomb VI); Margueron 1977, 178 (tomb at A6dNO); Schaeffer 1936b, 121-123 (tomb 13).

I45 Courtois 1979a, 1283-1284.

I46 Schaeffer 1949, 144-149.

I47 Schaeffer 1949, 150-151. 
According to Courtois, the tombs in Minet el-Beida distinguish themselves in the diversity of their inventories, in which a relatively large number of objects from the Aegean, Cyprus, Egypt and Anatolia are found. ${ }^{148}$ It is possible that the owners of these tombs wished to express foreign relationships in general and with the Aegean in particular in their funerary ceremonies.

\section{THE ROLE OF MYCENAEAN POTTERY IN THE MATERIAL CULTURE OF U G A R T}

Mycenaean and Minoan ceramic vessels and Mycenaean figurines are the only imports at Ugarit which are of certain Aegean origin. ${ }^{149}$ Even though imports constitute only a small percentage of the total of finds made at Ras Shamra and Minet el-Beida, the occurrence of objects from many different areas is a characteristic of the material culture in Ugarit and a sign of the cosmopolitan culture of the Levant in the LBA in general. ${ }^{50}$ Within such a material environment, ceramic vessels from the Aegean constitute only a small part of the total body of imported goods and cannot automatically be considered as highly valued on the basis of their exotic origin. Indeed, the main conclusion of this chapter is that Mycenaean pottery was fairly common at Ugarit: it has been found in all excavated parts of Ras Shamra and Minet el-Beida and it occurs in different type of contexts. Moreover, the analysis of closed deposits has revealed that Mycenaean pottery, even though a minor item from a quantitative point of view, was an integral part of the material culture at both sites.

Having said this, some other observations have been made in this chapter that shed light on the cultural significance of Mycenaean pottery. In all periods, such pottery was appreciated for its character as fine ware and not only for the contents of the closed vessels. The use of Mycenaean rhyta was restricted and they were incorporated in ritual ceremonies, together with local specimens of similar vessels. This indicates that it was the use of these vessels within the local cults of Ugarit which determined their high appreciation, rather than their Mycenaean origin. Similarly, we may assume that the popularity of Aegean stirrup jars in tombs can be ascribed to the role they and their contents served in funerary practices, for example the use of oil. ${ }^{15}$ The presence of some tombs with very large amounts of Mycenaean pottery and other imports, shows, firstly, that the import of Aegean pottery was of some significance within the society of Ugarit. Secondly, it shows that such ceramic objects were significant enough to become part of a social strategy of display. It may be stated, therefore, that, even if Mycenaean pottery was a fairly common element in Ugarit's material culture, its consumption was socially significant. ${ }^{152}$ This point is exemplified by the coarse ware stirrup jars that have been

${ }^{148}$ Courtois $1979 \mathrm{a}, 1283-1284$.

I49 The ivory pyxis lid figuring a potnia theroon, which was found in tomb III at Minet el-Beida reveals Aegean inspiration but appears to be of Syrian manufacture; see Kantor 1947, 91; Poursat 1977, 148. A sword found in the tomb investigated in 1970 by N. Saliby has been classified as a Mediterranean type II sword, which is found more often in Greece than in the Orient; cf. Catling 1961, 118-120; Kilian-Dirlmeier 1993, 94105.

Iso Courtois (1979a, 1284) mentions Anatolian, Myce- naean, Cypriot, Egyptian and Syrian finds in Minet elBeida. Egyptian and Cypriot material seems particularly abundant in Ras Shamra, while Hittite finds are less common; see, for example, Courtois 1979a, 1193. For the cosmopolitan character of the Levant in the Late Bronze Age in general, see Leonard 1989, 20-23.

ISI There is some epigraphical evidence that the bodies of the deceased were treated with oil during their deposition in the funeral cellar, see Kinet 1981; Salles 1995, 176.

Is2 The fact that only a minority of the inhabitants of 
found in funerary and ritual contexts. The use of these vessels in burial and religious ceremonies testifies that such objects were embodied with symbolic meanings going beyond the mere functional.

In addition to the imported Mycenaean vessels and figurines Aegean-type vessels appear to have been manufactured at Ugarit itself. ${ }^{\mathrm{IS} 3}$ Thirty-four of such likely imitations have been listed in the third part of Catalogue II; seven items included in the catalogue proper have a possible local origin. In some cases, the pots in the appendix imitate Aegean examples in both shape and decoration; ${ }^{154}$ in other cases aspects of Mycenaean pottery are adopted in vessels of non-Aegean type. ${ }^{155}$ In addition to these ceramic imitations, two examples exist of finds in different material which were clearly inspired by Aegean pottery. In the Ville Sud a conical rhyton made from electrum has been discovered. ${ }^{156}$ This vessel - a clear imitation of a Mycenaean rhyton, at least in shape - was found in a domestic context, associated with several Syrian bowls in gold and silver; it was probably produced locally. In Minet elBeida, a globular stirrup jar made from faience was found during the first campaign in 1929..$^{157}$

All the local pottery of Aegean inspiration at Ras Shamra and Minet el-Beida seems to imitate LH III ware; vessels deriving from LH II pottery have not been found. This is understandable in view of the small amount of early Mycenaean vessels occurring at Ugarit. Another observation which can be made concerns the functional types of the locally produced Aegean style pottery. Dinner and storage vessels, as well as rhyta, were imitated, but figurines of Syrian manufacture that imitate Aegean types have not been published. Two vessels in the appendix of Catalogue II can be considered as coarse ware, ${ }^{158}$ while two others may represent plain or monochrome examples. ${ }^{59}$ In addition, locally produced pots of Aegean type possess linear, patterned, pictorial and plastic decoration. It appears that imitation of Aegean ceramics was not confined to specific parts of the imported repertoire, but concerned all types of pottery.

Locally produced pottery of Mycenaean type was widely distributed in Ugarit: it occurs in most of the important excavated parts of Ras Shamra and in Minet el-Beida. Moreover, it has been found in domestic as well as in funerary contexts. In several instances local imitations have been discovered in association with similar imported vessels. ${ }^{160}$ All this suggests that the appreciation of locally produced

Ugarit chose to use Mycenaean pottery in such strategies may perhaps point to the existence of different regimes of value: situations where the same objects have different social meaning for different social groups; see Appadurai 1986, 14-15.

I53 Monchambert 1983, 27-29; Karageorghis 2000, 64.

${ }^{154}$ For example, the vertical flask (FS 186) with cat. no. 2016, the conical rhyton (FS 199) with cat. no. 2017 and the stirrup jar (FS 171-173) with cat. no. 2025.

iss For example, the rhyton with cat. no. 2019 and the alabastron with cat. no. 2033. Monchambert (1983, 2931) shows that the Ugaritic potters innovated Canaanite pottery according to their own cultural framework. The addition of foreign elements seem to have been part of such innovations.

is6 Schaeffer 1966, 131.

I57 Schaeffer 1929, pl. 52: no. 4. It is uncertain whether this specimen was produced in Ugarit itself. Imitations of Mycenaean stirrup jars in faience are mostly known from Egypt; see Bell 1983; Hankey 1995a, 117, 123, pl. 23.

is8 Cat. nos. 2002 and 2005. The publication of these vessels does not allow to determine if they were decorated.

I59 Cat. nos. 2003 and 2020. No. 2003 is the top of a stirrup jar with an incised sign on its handle; perhaps it should rather be classified as coarse ware. Moreover, it is possible that it was decorated. The rhyton with cat. no. 2019 deviates substantially from Mycenaean types.

I60 Such is the case in the Maison au frittes, in house E in the Centre Ville, in tombs III and VI in Minet el-Beida (cat. nos. 2001 and 2005 respectively) and in tomb 2698 in the Ville Sud (cat. no. 2032). 
Aegean vessels was similar to that of original imports. ${ }^{161}$ This consitutes an indication that Aegeanstyle pots were valued mainly for their functional use, rather than for their exotic origin.

The final question to be addressed in this chapter concerns the social groups within the society of Ugarit that made use of the imported Aegean pottery. As we have seen, the ruling élite does not appear to have used more Mycenaean pots than other people, nor did they monopolise specific parts of the ceramic repertoire. Indeed, Mycenaean pottery seems to have been an integral part of the material surroundings of most urban inhabitants, even if rhyta were limited to large mansions and religious buildings.

The population of the city of Ugarit was socially stratified. Even so, there is evidence that the capital was inhabited by the upper social strata within the kingdom as a whole. No systematic field survey has been conducted in the territory of Ugarit and we cannot assess the occurrence of Mycenaean pottery in the villages and towns in the kingdom. Within the territory of Ugarit, Mycenaean pottery has been found at Ras el-Bassit (site no. 139), ${ }^{162}$ Ras Ibn Hani (site no. 143), ${ }^{163}$ Lattakia (site no. 144), ${ }^{164}$ Tell Sukas (site no. 145) ${ }^{165}$ and Tell Nahr al-'Arab (site no. 140). ${ }^{166}$ From three other sites which have been explored marginally in the territory of Ugarit, Qat'at ar-Rouss, ${ }^{167}$ 'Arab al-Moulk, ${ }^{168}$ and Tell Darouk, ${ }^{169}$ no Mycenaean pottery has been reported. Most of the sites which did produce Late Helladic ware are located near the coast and fulfilled functions as a harbours. ${ }^{170}$

The picture that seems to emerge is that Mycenaean pottery was used mainly by the "people of the king'. This group of people, who lived in the capital and, possibly, in harbour towns, consisted mainly of specialists: priests, merchants and military personnel, as well as a multitude of artisans. ${ }^{171}$ The status of these groups within the social fabric of Ugaritic society varied. In some cases important posts and considerable wealth could be acquired. However, this was not the case for butchers, bakers, carpenters, potters, palace servants and many other professional groups. As a whole, this group constitutes a sub-élite in Ugaritic society, which was internally highly diversified. Imported Aegean ceramic ware seems to have served as a suitable means of expression for these groups of people.

I6I There is some additional evidence that local imitations were not without value. In the house of tomb 50 in the Quartier Nord-Ouest, such a vessel was found associated with vases in gold and silver; see Schaeffer 1939a, 130. A deep bowl that was locally manufactured (cat. no. 2023) has been found in the large mansion of the Palais Sud, while a piriform jar (cat. no. 2010) and a vertical flask (cat. no. 2016) have been found in the mansion of RS NNO.

I62 Courbin 1986, 181-183, 187.

I63 Bounni et al. 1979; 1987; Lagarce et al. 1983.

${ }^{164}$ Hankey 1967, 113: site no. 6.

I6s Ploug 1973, 6.

I66 Schaeffer 1933, 126-127. A trial trench was dug at this site, four kilometres north of Ras Shamra, in 1933; Cypriot and Mycenaean pottery was found.

${ }^{167}$ Forrer 1939, 113-125. A trial trench was dug here in 1935.

168 Riis 1959, 112-113. A trial trench was dug here in 1958.

I69 Riis 1960, 115-117. A trial trench was dug here in 1959.

170 The site Tell Nahr al-'Arab is located a few kilometres inland, near a river, leading to the sea.

${ }^{\text {17I }}$ At least forty different professional groups have been recognised among the people of the king; see Liverani 1979, 1339-1341. 



\section{Hazor}

\section{N T R O D U C T I O N}

Hazor is situated at the foot of the eastern ridge of the upper Galilee mountain range, in the northern Jordan valley, about $16 \mathrm{~km}$ north of Lake Tiberias and some $7 \mathrm{~km}$ west of the present-day course of the Jordan river. The site has been visited by various archaeological expeditions from 1928 up to the present day. ${ }^{1}$ It lies on a mound which has a higher part, referred to as the acropolis, in the south-east, while the vast lower plateau stretches to the north-west (Fig. 6.1). The earliest structures at Hazor have been discovered on the higher tell only and date from the Early Bronze Age II period. ${ }^{2}$ From this period onwards habitation seems to have continued on the acropolis until the third and second centuries BC. The lower plateau has been occupied during the Middle and Late Bronze Ages only.

In all the excavated trenches at Hazor (Fig. 6.1) remains from the Late Bronze Age have been discovered. The stratigraphy of the site for the Late Bronze Age is extremely complex, especially with regard to correlating the upper and lower city. ${ }^{3}$ There appear to have been three phases of settlement: Late Bronze I (ca. 1600-1400 BC), IIA (ca 1400-1300 BC) and IIB (ca. 1300-1200 BC). ${ }^{4}$ Even though it is difficult to ascertain because of the later disturbances on the higher part of the tell, the acropolis seems to have constituted a separate urban zone during the Late Bronze Age. ${ }^{5}$ Discoveries of temples and a palatial structure from the Late Bronze Age in areas A and $M$ indicate that this part of Hazor was an official area, designated for the royal court and for cult practices. The excavations at the lower plateau have revealed domestic buildings and various indications for artisan activities. ${ }^{6}$ Evidence for religious activities within the lower city comes from a monumental temple in area $\mathrm{H}$, as well as from a temple set among domestic structures in area C.

In 1928, J. Garstang conducted several soundings, see Garstang 1931, 381-383; Yadin 1972, 18-22. In the period from 1955 to 1968, five excavation campaigns were held by the Hebrew University at Jerusalem, all directed by Yigael Yadin; for overviews see Yadin 1972, 25; Ben-Tor et al. 1997, 1. Excavations have resumed at Hazor since 1990, led by Amnon Ben-Tor, as a joint project of the Berman centre for Biblical Archaeology at the Hebrew University and Complutense University of Madrid, in co-operation with Ambassador University from Texas and the Israel Exploration Society; for preliminmary reports, see
Ben-Tor 1992a; 1992b; 1994; 1995; 1996; 1998; Wolff 1996, 735-738.

$2 \quad$ Yadin 1972, 108-109, 119-120, 191-197.

3 Yadin et al. 1958, 99, 145; Yadin 1972, 32-37, 79-95; Yadin et al. 1989, 74-76, 166-171, 302; Ben-Tor et al. 1977, 15-50.

4 Yadin 1972, 108, 200; Fritz 1973.

5 Yadin 1972, 125-126, 128; Yadin et al. 1989, 74-75; Ben-Tor 1995, 12; 1998, 459-462.

6 Yadin et al. 1958, 76-79; 1960, 95-106, 134-140; Yadin 1972, 47-50, 67-95; Daviau 1993, 223-252; Foucault-Forest 1996, 68-72. 


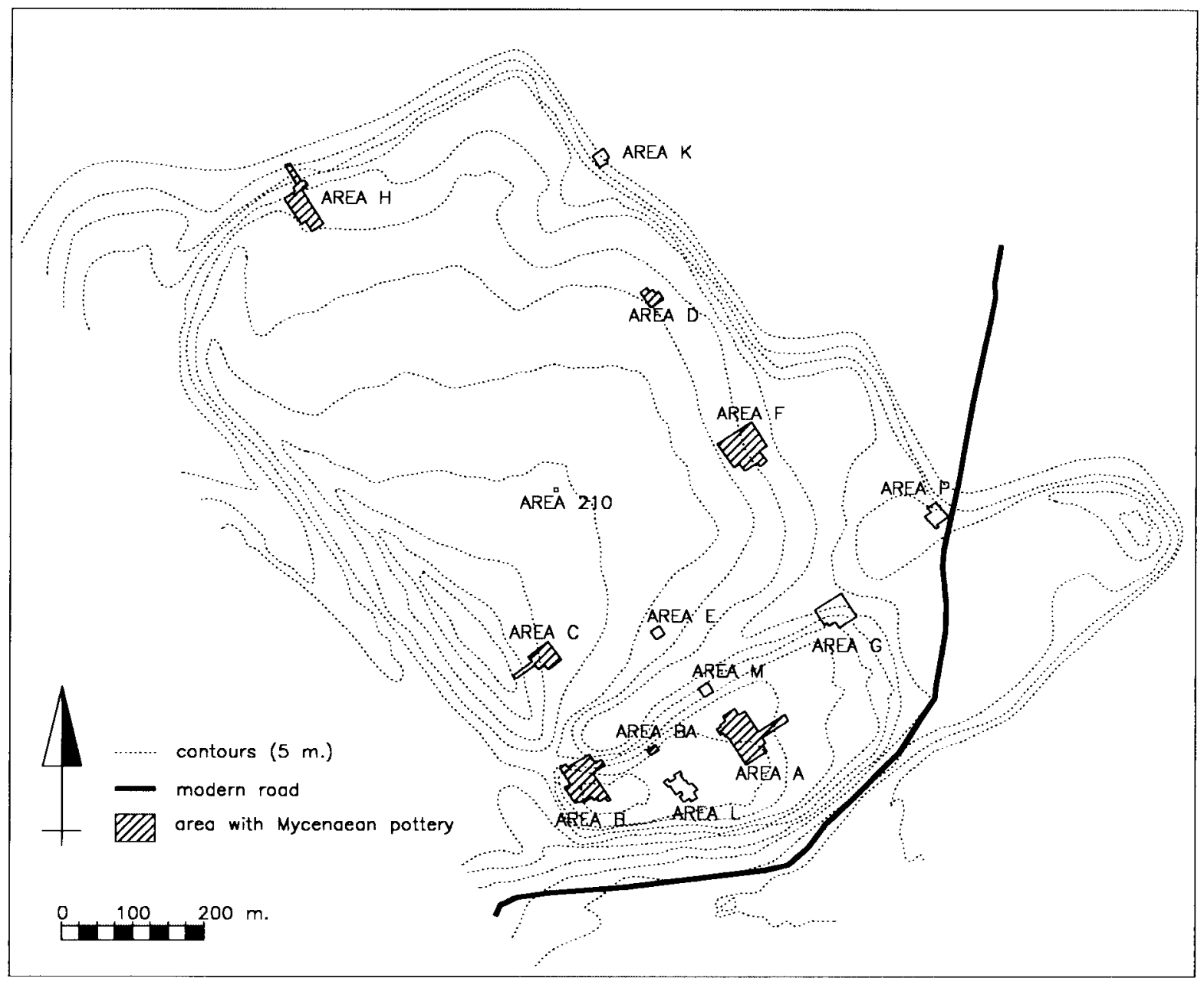

Fig. 6.1 Hazor: site plan

The material remains at Hazor, as well as the evidence for religious practices place the site firmly within the Canaanite culture of the Late Bronze Age Levant. ${ }^{7}$ Nevertheless, Hazor has been described as something of an enigma in comparison with contemporary sites in the same area. ${ }^{8}$ With its roughly eighty-five hectares, it is more than four times the size of the second largest settlement, Lachisch (site no. 230). Also, in contrast to contemporary cities to the south, Hazor managed to stay relatively independent of Egyptian rule. ${ }^{9}$

\section{THE MYCENAEAN POT TERY}

From the published excavations at Hazor, fifty-eight Mycenaean ceramic vessels and fragments can be identified, which have been listed in Catalogue III. ${ }^{10}$ None of these vessels or figurines has been sub-

7 Yadin 1972, 95, Ben-Tor et al. 1997, 89-98.

8 Gonen 1984, 66-68; Bienkowski 1987, 52-53; Daviau 1993, 255.
$9 \quad$ Bienkowski 1987

Io This total exceeds Leonard's (1994, 204-205) figure of fifty-four Mycenaean finds at Hazor. This is largely 
ject to scientific provenance research and their place of manufacture cannot be established with certainty. In terms of shape and decoration, the majority of the Mycenaean vessels at Hazor are fairly standard material. All the Mycenaean vessels are of pot shapes which occur more than five times in the Levant and Cyprus, ${ }^{11}$ and the decoration consists in all cases of a standard repertoire of linear and abstract designs. ${ }^{12}$ In addition, most vessels are of LH IIIA2-LH IIIB manufacture, with only a deep bowl (FS 284: cat. no. 11) being of secure LH IIIB2 date. I have argued in chapter 2 that a large part of the corpus of Mycenaean pottery in the eastern Mediterranean is likely to have been produced in the Peloponnese. In my view, this is also the case for the fairly standard repertoire of this pottery at Hazor. An exception should certainly be made for two Mycenaean stirrup jars (cat. nos. 24, 32) executed in the so-called 'Simple Style'. A Cretan origin for this style has been suggested, while such pots were probably also produced in Cyprus during LCII. ${ }^{13}$

The fifty-eight items in Catalogue III are not all the Mycenaean finds made in Hazor. The campaigns led by Yadin in 1955-1958 and in 1968 have been fully published and we may assume that our data set is complete for these excavations. The material from the 1928 excavations has never been published, but in his notebook Garstang refers to the complete absence of Mycenaean pottery. ${ }^{14}$ The results of the renewed excavations of the 1990s are known through preliminary reports only. ${ }^{15}$ Since 1995, a large Late Bronze Age building has been excavated, which has been referred to as a palace. Mycenaean sherds, albeit only a handful, have been mentioned from the latest excavations; these are not listed in Catalogue III. ${ }^{16}$ These fragments could provide contextual information for the Mycenaean pottery at Hazor different from that currently available.

\section{THE ON-SITE DISTRIBUTION OF MYCENAEAN POTTERY}

Of the fifty-eight entries in Catalogue III, fifty-three represent pots or sherds thereof, while five (fragments of) figurines have been published. The excavated areas of Hazor with Late Bronze Age remains (Fig. 6.1) each have produced the amounts indicated in Table 6.1. ${ }^{17}$ The various excavated areas of Hazor differ in size. Area A, for example comprises at least $2000 \mathrm{sqm},{ }^{18}$ while area 210 is a trench of only $25 \mathrm{sqm} .{ }^{19}$ Area L includes a impressive water reservoir from the Early Iron Age and only a few walls from the Late Bronze Age were exposed..$^{20} \mathrm{In}$ areas $\mathrm{P}$ and $\mathrm{K}$ multi-period city gates have been excavated, with little other architectural remains. ${ }^{21}$ Bronze Age architecture has been discovered in

due to the fact that three finds (cat. nos. 51-53) were published after the appearance of Leonard's book. A fragment of doubtful Mycenaean origin (cat. no. 45) has been included here, but was omitted by Leonard.

II Cf. Gilmour 1992, 115, Table 1.

I2 Leonard (1994) lists the following motives from Hazor: FM 9, FM 12, FM 19, FM 27, FM 32, FM 43, FM 44, FM 48, FM 51, FM 60, FM 64, FM 75. All these motifs are fairly common on Mycenaean vessels in the Levant.

I3 Popham 1979, 187; Sherratt 1980, 196-197 note 82; Koehl \& Yellin 1982, 273.
I4 Yadin 1975, 34.

Is Ben Tor 1992a,; 1994; 1995; 1996; 1998.

I6 Ben-Tor 1998, 462.

${ }^{17}$ In all tables the areas are listed according to size.

I8 Up to $1969 \mathrm{ca} .1900 \mathrm{sqm}$ had been excavated in area A; see Ben-Tor et al. 1997, 52, Plan II.6. During the recent excavations this area has been greatly enlarged.

I9 Yadin 1972, 47-50.

20 Ben-Tor et al. 1997, 209-217.

21 Yadin et al. 1989, 276-301 (area K); Ben-Tor et al. 1997, 353-386 (area P). 


\begin{tabular}{|c|c|c|c|}
\hline site area & pots and sherds & figurines & total \\
\hline unknown & & 1 & 1 \\
\hline area $\mathrm{A}$ & 10 & & 10 \\
\hline area B & 1 & & 1 \\
\hline area $F$ & 23 & 2 & 25 \\
\hline area $\mathrm{H}$ & 3 & 1 & 4 \\
\hline area C & 6 & & 6 \\
\hline \multicolumn{4}{|l|}{ area L } \\
\hline \multicolumn{4}{|l|}{ area $\mathrm{P}$} \\
\hline area $\mathrm{D}$ & 9 & 1 & 10 \\
\hline \multicolumn{4}{|l|}{ area $\mathrm{M}$} \\
\hline \multicolumn{4}{|l|}{ area $\mathrm{K}$} \\
\hline \multicolumn{4}{|l|}{ area $\mathrm{E}$} \\
\hline area BA & 1 & & 1 \\
\hline \multicolumn{4}{|l|}{ area 210} \\
\hline Total & 53 & 5 & 58 \\
\hline
\end{tabular}

Table 6.1

area M, but only in the renewed - and as yet unpublished - excavations of the 1990's; the campaign in 1968 was limited to Iron Age levels. ${ }^{22}$ Bronze Age levels were explored in just a small part area B. ${ }^{23}$ Since areas $\mathrm{E}$ and 210 are very small, the figures in Table 6.1 show that Mycenaean pottery has been found in all areas with substantial remains from the Late Bronze Age.

In considering the figures in Table 6.1, it must be remembered that unstratified finds, which may derive from other parts of the site, have been included. Even so, there is a concentration of Mycenaean pottery in area F, with twenty-five finds. This high figure is largely due to one tomb, which contained fourteen Mycenaean vessels. ${ }^{24}$ Even when these are discounted, the figure of eleven Mycenaean finds from settlement contexts in this area is higher than that for area A, the largest of the excavation trenches. To a lesser extent, a concentration of Mycenaean pottery is also visible in area $\mathrm{D}$, where the number of finds is equal to that of area $\mathrm{A}$, which is far larger. Again, one tomb is largely responsible for the concentration: four vessels were found associated with a burial in cistern $9027 .{ }^{25}$ The figure of six Mycenaean finds from settlement contexts in this area equals that of area $\mathrm{C}$, which is substantially larger (Fig. 6.1).

During the Late Bronze Age II areas D and F may be classified as average town quarters where the population of Hazor lived and worked. ${ }^{26}$ In contrast, a palace, temple and water reservoir were situated in area A, where a substantial amount of Mycenaean pottery has also been found. ${ }^{27}$ The occurrence of Mycenaean pottery in all these areas points to its use by inhabitants belonging to different social groups. Widespread use of Mycenaean ceramics is also suggested by its distribution in the houses in areas $\mathrm{C}$ and $\mathrm{F}$, where it has been found in several rooms and courtyards interspersed with local do-

22 Ben-Tor 1998, 462.

23 Yadin et al. 1989, 70.

24 Yadin et al. 1960, 150-151; tomb 8144-8145; cat. nos. $16-28,38$

25 Yadin 1958, 139-140; cat. nos. 8-12.
26 Yadin et al. 1958, 116-120 (area D); Daviau 1993, 244-252 (area F).

27 Yadin 1972, 125-128; Ben-Tor et al. 1997, 51-77; Ben-Tor 1998, 459-462. 


\begin{tabular}{|c|c|c|c|c|c|}
\hline site area & unknown & funerary & domestic & ritual & settlement \\
\hline unknown & 1 & & & & \\
\hline area $A$ & 4 & & 1 & 1 & 4 \\
\hline area B & & & & & 1 \\
\hline area $F$ & 1 & 15 & 8 & & 1 \\
\hline area $\mathrm{H}$ & & & & 3 & 1 \\
\hline area C & 1 & & 5 & & \\
\hline area $\mathrm{D}$ & 1 & 4 & 3 & & 2 \\
\hline area BA & & & 1 & & \\
\hline Total & 8 & 19 & 17 & 4 & 9 \\
\hline
\end{tabular}

Table 6.2

mestic objects (Figs 6.2 and 6.6 below).

The contextual distribution of the Mycenaean pottery in Hazor is presented in Table 6.2. Even though the find circumstances of a number of Mycenaean finds are not known, these figures reveal that Mycenaean pottery at Hazor occurs in different contexts. In all areas where domestic structures have been excavated, Mycenaean pots and sherds were among the finds made, suggesting that everywhere in the town the inhabitants used such pottery in their houses. Late Bronze Age burials have been found in areas D and F only. All these graves yielded Mycenaean finds.

Not in all areas has Mycenaean pottery been reported from religious contexts. A small temple and associated courtyard was discovered in area $\mathrm{C} ; ;^{28}$ while in area $\mathrm{F}$ the place of an LB I temple served as an open cult area during LB II. ${ }^{29}$ Both sanctuaries were situated among habitation structures and Mycenaean pottery has not been reported from them. The sanctuaries in areas $\mathrm{C}$ and $\mathrm{F}$ differ significantly from their counterparts in areas $\mathrm{A}$ and $\mathrm{H}$, which were larger and of more monumental character. ${ }^{30}$ Moreover, the area $\mathrm{H}$ temple was free-standing, while the area A temple was structurally separated from the surrounding buildings by a wall. ${ }^{31}$ Mycenaean pottery has been reported from these monumental temples, albeit in small numbers. By analogy with Meskène-Emar, it is quite possible that the monumental temples in areas $\mathrm{A}$ and $\mathrm{H}$ served the official cult that was related to the existing power structure in the city, while smaller shrines in habitation areas were used for daily religious practices. ${ }^{32}$ The attested difference between the two types of sanctuaries as regards the occurrence of Mycenaean pottery could indicate that the use of Mycenaean vessels in religious ceremonies was restricted to the official cult. In any case, the figures in Table 6.2 indicate that Mycenaean pottery was used at Hazor for a variety of cultural practices, be they domestic, religious or funerary.

Table 6.3 shows the spatial distribution of the Mycenaean chronological ceramic phases. ${ }^{33}$ It is clear that the few LH II-LH IIIA1 vessels are not widely distributed. ${ }^{34}$ Apart from a fragment of a possible Mycenaean one-handled cup (FS 219) from area H (cat. no. 45), ${ }^{35}$ all LH II-LH IIIA1 finds have been made in area A. A Mycenaean sherd from the same area (cat. no. 51) may possibly be assigned an LH IIB date. The restriction of Mycenaean vessels from this early period to a part of Hazor where a tem-

28 Yadin et al. 1960, 97; Yadin 1972, 67-74.

29 Yadin et al. 1960, 132-133; Yadin 1972, 100-102.

30 Ben-Tor et al. 1997, 89.

3I Yadin 1972, 75 (area H); Ben-Tor et al. 1997, 86-87 (area A).

32 Cf. Tarragon 1995, 209-210; Van der Toorn 1995a, 48. 


\begin{tabular}{|c|c|c|c|c|c|}
\hline site area & LH II-IIA1 & LH IIIA2 & LH IIIA2-LH IIIB & LH IIIB & unknown \\
\hline area $A$ & 3 & & 5 & & 2 \\
\hline area B & & & 1 & & \\
\hline area $\mathrm{F}$ & & 5 & 10 & 8 & \\
\hline area $\mathrm{H}$ & 1 & & 2 & & \\
\hline area C & & 1 & 5 & & \\
\hline area D & & 1 & 7 & 1 & \\
\hline area BA & & & & 1 & \\
\hline Total & 4 & 7 & 30 & 9 & 2 \\
\hline
\end{tabular}

Table 6.3

ple and palace were located indicates that such ceramics were not widely used among the inhabitants, but restricted to the social group associated with these official structures.

The fact that many of the vessels from the later Late Helladic phases cannot be dated more specific than LH IIIA2-LH IIIB makes it difficult to compare the spatial distribution of these two ceramic phases. However, LH IIIA2 and LH IIIB vessels occur in most of the excavated areas with substantial remains of the Late Bronze Age. This suggests that such pottery was widely used in Hazor and not restricted to certain social groups.

The chronology of the Mycenaean pottery at Hazor should, of course, be related to the complex stratigraphy at the site (Table 6.4). ${ }^{36}$ The stratigraphic location of the three finds in LH II-LH IIIA1 style from area $\mathrm{A}$ is unfortunately unknown. The sherd with cat. no. 51, which may possibly be assigned to an early stylistic phase, was found in a pit probably belonging to the first part of the Late Bronze Age. ${ }^{37}$ The only LH II-LH IIIA1 vessel which can with certainty be assigned to an LB I level is the cup from area $\mathrm{H}$ (cat. no. 45), of which the Mycenaean origin is uncertain. Even though none of the stylistically early vessels have been recovered from strata that were evidently later than their ceramic style, the many unstratified finds make it impossible to say whether LH II-LH IIIA1 vessels were still in use in an advanced stage of the Late Bronze Age.

Similar disappointing conclusions can be drawn for the second and third stratigraphical Late Bronze

33 The five figurines are omitted from this table.

34 The entries in the catalogue which have been classified as early are a LH IIB fragment (cat. no. 41), a LH IIB rounded alabastron (cat. no. 42) and two LH IIB-LH IIIA1 one-handled cups (cat. nos. 45 and 53).

35 The drawing published in Yadin et al. 1961, Plate 269: no. 45 is confusing. Apparently, the in- and outside of one sherd are shown, but they are not of the same size. The text accompanying the drawing and that in the text volume (Yadin et al. 1989, 240) clearly refers to one find, which is confirmed by a single registration number. Yadin et al. $(1989,240)$ consider the possibility that the vessel is Mycenaean, but this is not specifically stated in the text accompanying the drawing, see Yadin et al. 1961, Plate 269: no. 45. The vessel has not been included by Leonard (1994) in his corpus of Mycenaean pottery in the Levant. The shape of the vessel (FS 219), the striped handle and the description of the fabric make it possible that this fragment is Mycenaean.

${ }^{36}$ It must be remembered that it is not possible to distinguish between LB IIA and LB IIB in all excavated areas. Moreover, there is discussion about the dating of the strata in area $\mathrm{A}$.

37 Ben-Tor et al. 1997, 25, 85. Pit no. 548 disturbed Middle Bronze Age levels and should, consequently be later. However, the pit is not mentioned in the discussion of stratum 8 (LB I). Probably, the pit was dug before the building of the stratum 8 temple early in the Late Bronze I period. 


\begin{tabular}{|c|c|c|c|c|c|c|}
\hline stratum & LH II-IIIA1 & LH IIIA2 & LH IIIA2-LH IIIB & LH IIIB & unknown & Total \\
\hline LB IIIA & & & 3 & 1 & & 4 \\
\hline LB \|A & & 7 & 23 & 9 & & 39 \\
\hline LBI & 1 & & & & & 1 \\
\hline unstratified & 2 & & 2 & & & 4 \\
\hline unknown & 1 & & 3 & & 2 & 6 \\
\hline Total & 4 & 7 & 31 & 10 & 2 & 54 \\
\hline
\end{tabular}

Table 6.4

\begin{tabular}{|c|c|c|c|c|c|}
\hline date & domestic & funerary & religious & settlement & unknown \\
\hline LH II-IIIA1 & & & & 2 & 2 \\
\hline LH IIIA2 & 1 & 6 & & & \\
\hline LH IIIA2-LH IIIB & 8 & 10 & 3 & 7 & 2 \\
\hline LH IIIB & 7 & 3 & & & \\
\hline unknown & & & & 1 & 1 \\
\hline Total & 16 & 19 & 3 & 9 & 4 \\
\hline
\end{tabular}

Table 6.5

Age periods at Hazor. The large number of Mycenaean finds which cannot be dated more securely than LH IIIA2-LH IIIB prevents any statement on the longevity of use of Mycenaean vessels. The only observation to be made with certainty is that Mycenaean ceramics appear to have been present at Hazor during all three Late Bronze stratigraphical periods. Because such pottery also seems to have been deposited in every period, we can assume that this material did not arrive at the town in one batch, but over a substantial length of time.

The contextual distribution of the chronological Mycenaean ceramic phases is presented in Table 6.5. Again, the uncertain stratification of most of the stylistically early vessels, as well as the imprecise dating of many of the later pots prevent a differentiation between the various chronological styles regarding their find context. The only observation to be made on the basis of Table 6.5 is that LH IIIA2 and LH IIIB vessels were used in houses as well as in temples and tombs.

At Hazor, Mycenaean rhyta or kernoi have not been found and the class of ritual vessels identified in chapter 2 is absent in Table 6.6. It is clear from this table that Mycenaean storage vessels are much more abundant at Hazor than dinner vessels. Both categories of vessels are fairly widely distributed: they occur in most of the trenches with substantial remains from the Late Bronze Age. The absence of Mycenaean dinner vessels from area $\mathrm{C}$ seems remarkable, in view of the relatively wide distribution of such vases. This part of the city of Hazor has been interpreted as an area with manufacturing activities as well as storage and food preparation and consumption. ${ }^{38}$ At first glance, the absence of Mycenaean dinner vessels in such an environment seems to be in contrast to area F, which has produced three such vessels. However, only one of these (cat. no. 36) came from a domestic context, while two (cat. nos. 16, 17) were found in a tomb. In area $\mathrm{D}$, two dinner vessels (cat. nos. 10, 11) likewise had a fu-

${ }_{38}$ Daviau 1993, 223-243. Three potter's wheels, loom weights and spindle whorls constitute the main evi- dence for industrial activities. Shrine 6136 in the western part of the area was the focus of ritual activities. 


\begin{tabular}{|c|c|c|c|c|}
\hline site area & dinner & storage & figurines & unknown \\
\hline unknown & & & 1 & \\
\hline area $\mathrm{A}$ & 2 & 2 & & 6 \\
\hline area B & & 1 & & \\
\hline area $\mathrm{F}$ & 3 & 20 & 2 & \\
\hline area $\mathrm{H}$ & 3 & & 1 & \\
\hline area $\mathrm{C}$ & & 5 & & 1 \\
\hline area D & 4 & 5 & 1 & \\
\hline area BA & & 1 & & \\
\hline Total & 12 & 34 & 5 & 7 \\
\hline
\end{tabular}

Table 6.6

\begin{tabular}{|c|c|c|c|c|}
\hline context & dinner & storage & figurines & unknown \\
\hline domestic & 2 & 13 & 2 & 1 \\
\hline funerary & 4 & 15 & & \\
\hline ritual & 2 & & 1 & 1 \\
\hline settlement & 4 & 4 & & 2 \\
\hline unknown & & 2 & 2 & 3 \\
\hline Total & 12 & 34 & 5 & 7 \\
\hline
\end{tabular}

Table 6.7

nerary context. As is also clear from Table 6.7 below, it seems that Mycenaean dinner vessels were not widely used in the domestic life of the inhabitants of Hazor.

In view of the wide distribution of Mycenaean storage vessels at Hazor, it is of significance that such pottery is absent from area $\mathrm{H}$. The three Mycenaean vessels from the area of the temple (cat. nos. 45-47) are all dinner vessels, while a figurine (cat. no. 1003) has been found there as well. From Table 6.7 it becomes clear that Mycenaean storage vessels are absent from religious contexts in general. To the two dinner vessels from such contexts may be added the cup of cat. no. 45 , which was found in the courtyard of the stratum 2 temple in area $\mathrm{H}$ and to which a general 'settlement' context has been assigned. In combination with the evidence that Mycenaean dinner vessels were not widely used in domestic contexts, their frequency in ritual contexts indicates that these vases were used for activities of a special nature. It is also clear from Table 6.7 that funerary ceremonies were among these activities.

Apart from their absence in clear cultic circumstances, Late Helladic storage vessels have been found in all other types of context. Moreover, they occurred in all areas, except for area $\mathrm{H}$, which indicates that they were widely used among the inhabitants of Hazor. Mycenaean figurines do not seem to have been used in funerary ceremonies. Their presence in domestic contexts seems to indicate that these idols were used in the daily life of the inhabitants at Hazor. ${ }^{39}$ The bovine figurine from the temple of area $\mathrm{H}$ (cat. no. 1003) suggests that these objects possessed a ritual or magic significance.

It is difficult to establish with certainty whether the restriction of Mycenaean dinner vessels to spe-

39 Ceramic figurines of local manufacture have also been found in domestic contexts, for example in area C; see
Yadin et al. 1958, Plate 89 no. 15 (room 6117); 1960, Plate 127 no 14 (room 6235). 


\begin{tabular}{lccc}
\hline site area & linear & patterned & decorated \\
\hline area A & 3 & 6 & 1 \\
area B & 1 & & \\
area F & 17 & 6 & 2 \\
area H & 1 & 2 & \\
area C & 3 & 1 & 3 \\
area D & 6 & 3 & 3 \\
area BA & 1 & 18 & \\
\hline Total & 31 & &
\end{tabular}

Table 6.8

cial activities applies to all periods at Hazor in which these vases were used. If the cup of cat. no 45 is indeed Mycenaean, its find spot in stratum 2 of temple $\mathrm{H}$ may point to religious use of a Mycenaean dinner vessel already in the first phase of the Late Bronze Age, even though it has been found in the courtyard, quite far from the actual temple. ${ }^{40}$ Other finds from clear contexts dating to the first phase of the Late Bronze Age are unknown. ${ }^{41}$ In the LB IIA levels of temple $\mathrm{H}$, fragments of a Mycenaean bowl (cat. no. 46) were found in the main cult hall. In the LB IIB temple in area $\mathrm{H}$ a Mycenaean stemmed cup (cat. no. 47) was found, while another stemmed cup (cat. no. 40) was recovered from the corresponding stratum in the vicinity of the temple in area A. ${ }^{42}$ It appears that Mycenaean dinner vessels were used in religious circumstances in all three phases of the Late Bronze Age. Their limited occurrence in domestic contexts during LB IIA and LB IIB, however, shows that the use of this functional class of ceramics was not exclusively confined to religious activities.

As stated above, the decoration of the Mycenaean vessels at Hazor can be considered fairly standard. As is evident from Table 6.8, pots with pictorial decoration are absent at Hazor, nor have zoomorphic vessels been discovered. ${ }^{43}$ Likewise, Mycenaean coarse or plain ware vessels are absent from this site. ${ }^{44}$ It is evident from the figures in Table 6.8 that most of the Mycenaean pots at Hazor are decorated with lines only. ${ }^{45}$ All excavated areas with substantial Late Bronze Age remains have produced vessels with linear and patterned decoration, which suggest that none of these types were restricted to specific social groups at Hazor. However, it is of interest that in areas A and $\mathrm{H}$ vessels with patterned decoration occur more often than linear decorated pots. As stated above, these areas are considered to have served special, official functions. The predominance in these areas of Mycenaean vessels with pat-

40 Yadin et al. 1989, 240. Locus 2174 is situated in the "open space" outside the LB I propylaeum.

${ }^{4}$ I A possible exception is the sherd of cat. no. 51, found in a pit probably dug during LB I. However, the fragment is too small for it to be assigned to a specific pot shape.

42 The temple in area $\mathrm{A}$ does not seem to have been in use during the last phase of the Late Bronze Age, see Ben-Tor et al. 1997, 102-110. The area probably served religious functions after the abandonment of the temple, see Yadin 1972, 127.
43 Of the amphoroid krater of cat. no. 10 only the rim was found. Since many of these vessels are pictorially decorated, it is possible that this was the case for this particular vase as well.

44 The term 'decorated' is used when the precise decoration is not known.

45 The fragmentary nature of many of the Mycenaean finds argues for caution in this respect. Linear fragments may have belonged to vessels that were more elaborately decorated. 


\begin{tabular}{lccc}
\hline site area & linear & patterned & decorated \\
\hline Domestic & 12 & 3 & 1 \\
Funerary & 12 & 7 & \\
Ritual & 1 & 2 & 1 \\
Settlement & 5 & 4 & 1 \\
unknown & 2 & 2 & 3 \\
Total & 32 & 18 & \\
\hline
\end{tabular}

Table 6.9

terned decoration may indicate that such ceramics were considered more suitable for such special areas, while linear vessels were used by many inhabitants of the city.

A similar conclusion may be drawn from the figures in Table 6.9. The proportion of vessels with patterned decoration is higher for funerary contexts than for domestic contexts and for circumstances which have been labelled 'settlement' in general. ${ }^{46}$ In contexts with clear religious associations, Mycenaean pots with patterned decoration are more frequent than vessels with linear decoration. ${ }^{47}$ The difference in use between linear and patterned vessels is most likely related to vessel type. Of the eighteen patterned Mycenaean pots, eight are dinner vessels, while only six are storage pots; there are four patterned fragments. ${ }^{48}$ This suggests that the relative restriction in the use of Mycenaean dinner vessels may, at least partly, be connected to their more elaborate decoration.

\section{SET TLEMENT CONTEXTS}

At Hazor, there are nineteen situations where Mycenaean pottery can be related to specific settlement structures, which are listed in Table IV, in the tables section of this book. Of most of these find complexes, especially those in area A, too little is known to analyse them sufficiently. The eight situations which will be discussed here are all situated on the lower tell.

Area F: House $8039^{49}$ (Fig. 6.2)

As in the whole of area F, the stratum related to LB IIB in house 8039 essentially represents a rebuilding and reuse of structures dating to LB IIA. ${ }^{50}$ In many instances it was impossible to distinguish the two strata and the Mycenaean vessels from area F have all been assigned to LB II in general

House 8039 could be entered either from the north-west or from the south-east (Fig. 6.2). Near the north-western entrance was the small room 8030, which has been interpreted as a storeroom and contained a fragment of a LH IIIB Zygouries-type kylix (cat. no. 36: Fig. 6.3), associated with a local bowl,

${ }^{46}$ No doubt this is at least partly due to the fact that vessels from tombs are, in general, more complete than finds from settlement levels.

47 The sherd of doubtful Mycenaean manufacture (cat. no. 45) was found in the courtyard of the stratum 2 temple in area $\mathrm{H}$ and has been assigned a 'settlement' context. If the fragment is indeed Mycenaean, it may be another example of a patterned sherd from a reli- gious context, even though found quite far from the actual temple.

$4^{8}$ This means that the majority of the dinner vessels had a patterned decoration, while the majority of the storage pots were decorated with lines only.

49 Yadin et al. 1960, 134-136; Daviau 1993, 244-248; Foucault-Forest 1996, 71-72.

so Yadin et al. 1960, 128-129. 


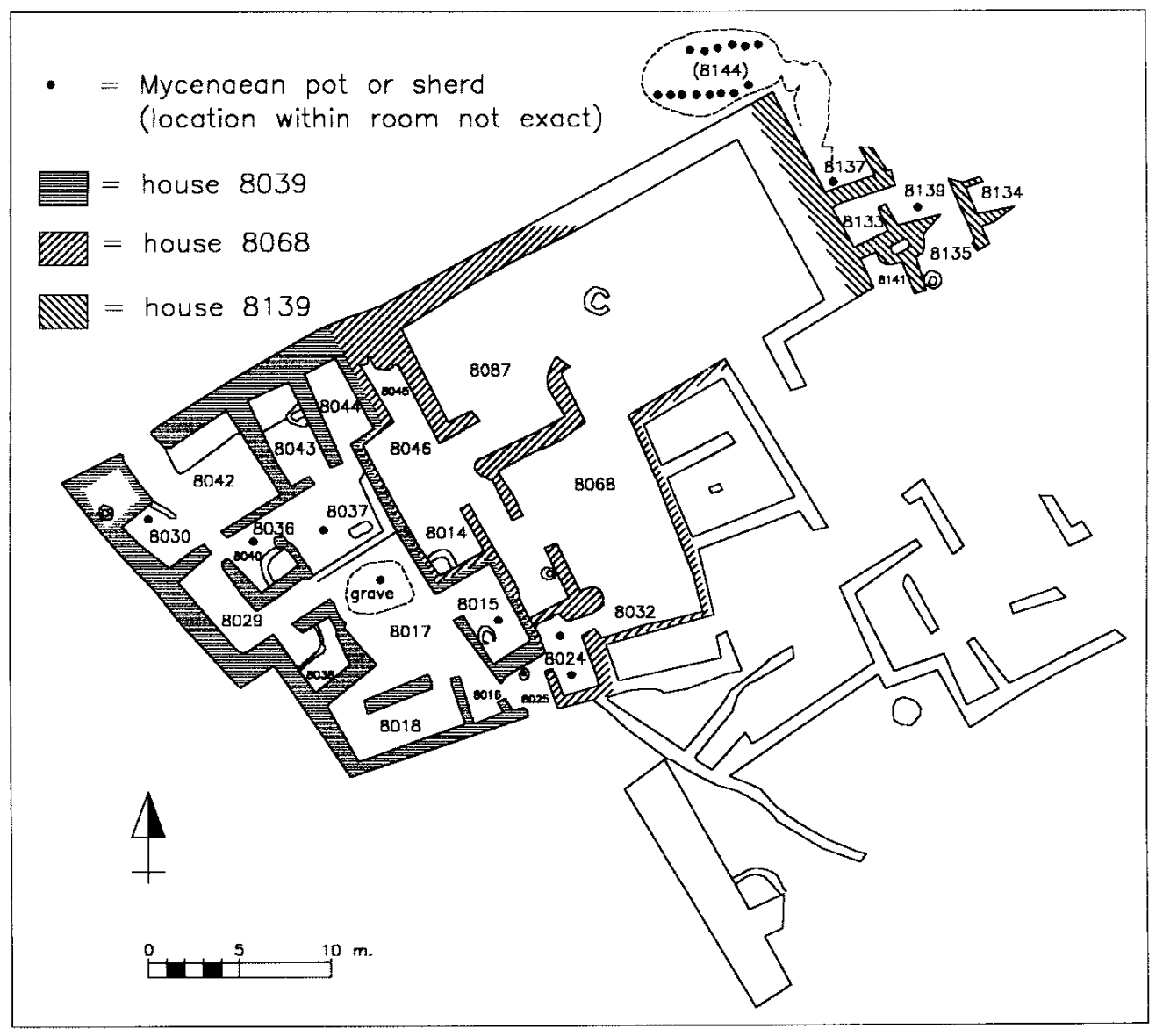

Fig. 6.2 Mycenaean pottery in area F (LBII stratum)

a pithos, a jar and two jugs. South of courtyard 8042, a small passageway (8036) with a silo (8040) in its south-eastern corner led to courtyard 8037. In this passageway, near the silo, a LH IIIB stirrup jar (cat. no. 32) was found. The top of a Mycenaean stirrup jar (cat. no. 34), two local pithoi and a clay button were discovered in courtyard $8037 .{ }^{51}$ To the south-east, the largest courtyard (8039/8017) of the structure was located. Below this courtyard, tomb 8065 was situated, in which a LH IIIA2 piriform jar (cat. no. 29) was found. The stratigraphy of the house indicates that tomb 8065 does not belong to the stratum 1 house, but to an earlier structure. ${ }^{52}$ From the central courtyard room 8015 could be entered, where a LH IIIB globular stirrup jar (cat. no. 35) was found, ${ }^{53}$ in association with a limestone disk, local jugs and a local stemmed cup. This inventory suggests that room 8015 served for habitation.

The Mycenaean pottery is rather widely dispersed through this house: a single Mycenaean find was

5I Daviau $(1993,247)$ suspects that this was a storeroom. Her statistical analysis of only four finds, however, cannot be considered valid.

52 Yadin et al. 1960, 141-142. The LH IIIA2 date of the Mycenaean piriform jar does not conflict with this reasoning, if the house was built late during LB IIA.

53 The stirrup jar was found at the same level as the top of the foundation wall. Yadin suspected that this was a floor level of LB IIB. Immanuel Dunayevsky, however, suggested that the foundation wall was deeper here than elsewhere because of the sloping of the terrain and that the stirrup jar should belong to LB IIA; see the discussion in Yadin et al. 1960, 144. 


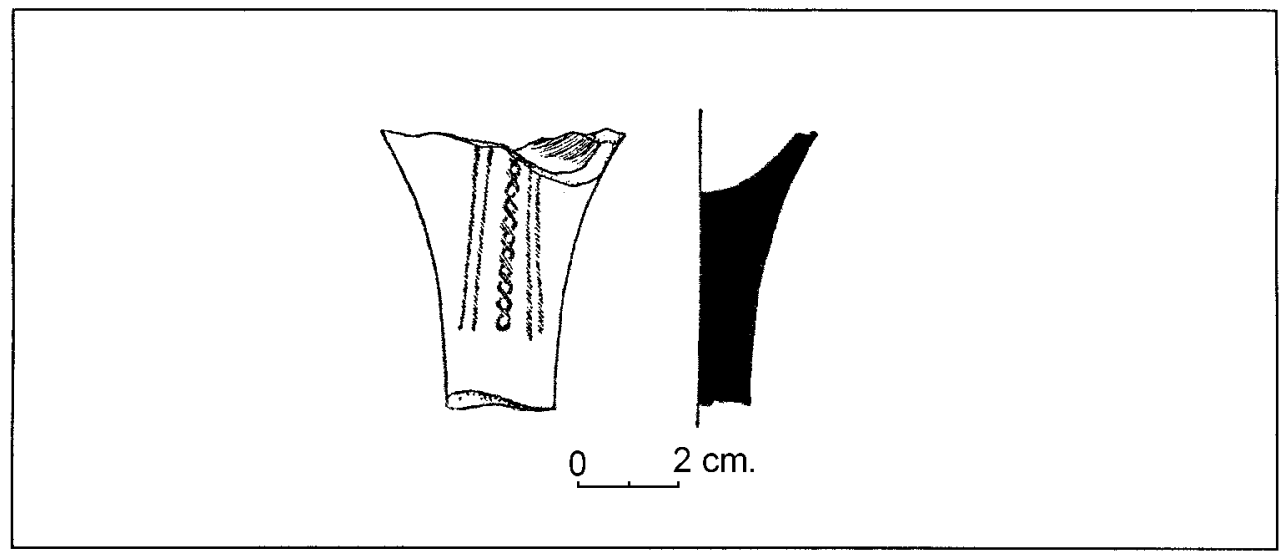

Fig. 6.3 Stem of Mycenaean kylix (cat. no. 36) from room 8030 - After Yadin et al. 1960, plate 148: no. 7

made in four rooms. The associations of the Mycenaean pottery in this house are habitation and storage. The storage associations for the Mycenaean kylix, which has a patterned decoration (Fig. 6.3), are somewhat surprising, as I concluded above that Mycenaean open vessels at Hazor were mainly reserved for activities of a special nature. This particular kylix may have been in storage for such an occasion. In any case, the evidence points to the Mycenaean pottery being an integral part of the everyday life in the building.

\section{Area F: house 8068 (LB II) $)^{54}$}

The northern part of house 8068 was situated on a slope and was heavily damaged by ploughing and erosion. The house was entered from the south-west (Fig. 6.2). A vestibule, (8025) which was shared with house 8039 and possessed an oven, gave entrance to room 8024, in which two LH IIIB lentoid flasks (cat. nos. 31, 33) were found. They were associated with two local bowls, two jugs, a pithos and a basalt mortar. The room has been interpreted as an area for food preparation and storage.

Because of the damage to the northern part of house 8068, it is difficult to asses the distribution of the Mycenaean pottery in this house. In comparison with house 8039, it may be of interest that two Mycenaean vessels were found together in a room. Both vessels are lentoid flasks, a type absent in the adjacent house. The two Mycenaean flasks are associated with items for food preparation and storage. We can conclude from this that they served in the daily life of the inhabitants of this house.

Area F: house 8139 (LB II) ${ }^{55}$

House 8139 was located on the lowest terrace of the area and was only partially excavated, as a result of which the entrance to the building cannot be reconstructed (Fig. 6.2). A courtyard was discovered (8139), in which a large fragment of a Mycenaean female figurine (cat. no. 1005) was found, in association with a bronze arrow-head. Other rooms yielded several vessels of unusually large dimensions. In room 8137, a LH IIIB lentoid flask (cat. no. 30) was discovered in association with a basalt bowl. From this room it was only a short distance to the dromos of rock-cut tomb 8144-8145, which yielded a total of fourteen Mycenaean vessels. The relationship between building 8139 and this tomb is un- 


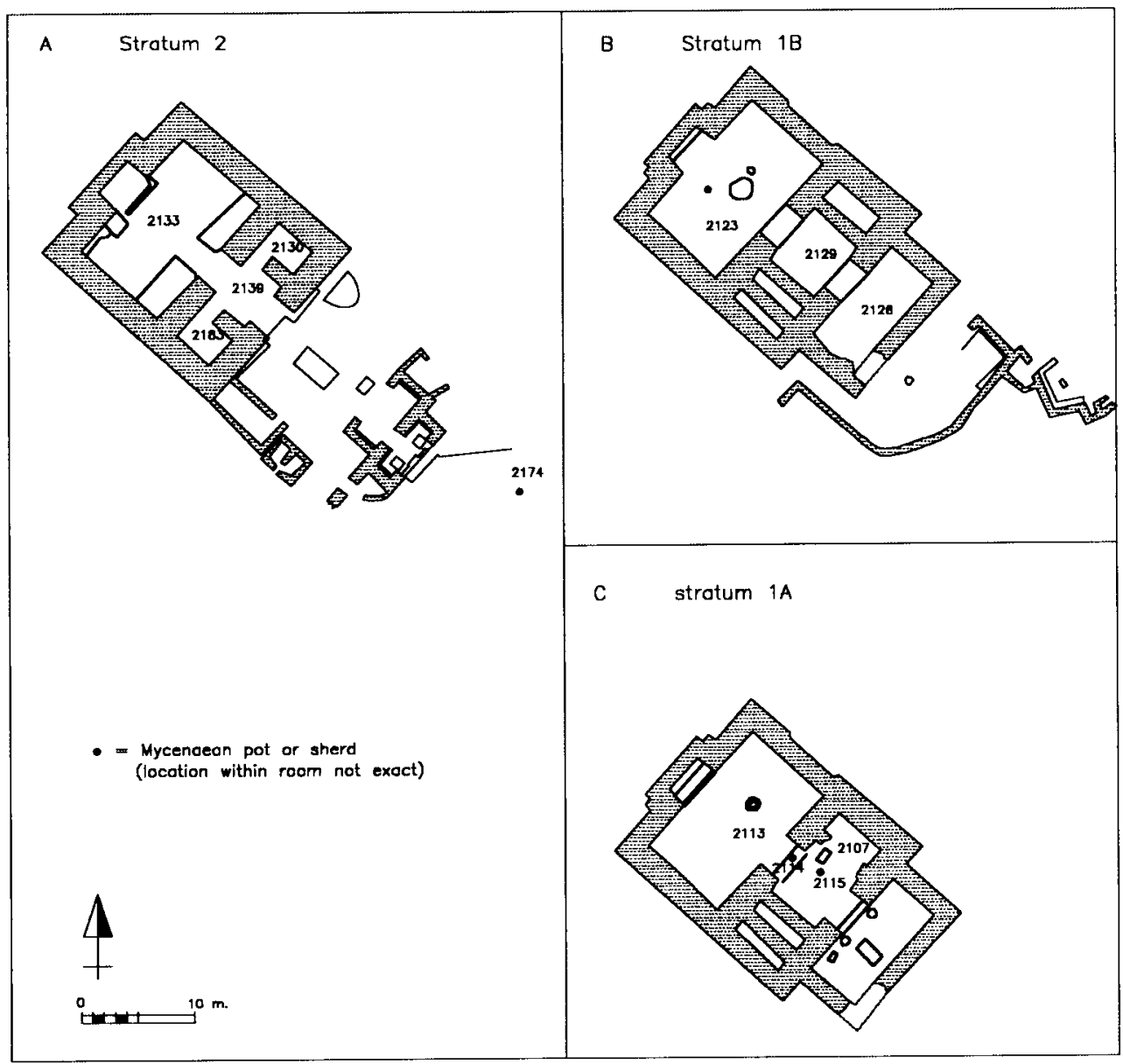

Fig. 6.4 Mycenaean pottery in the successive temples of area $\mathrm{H}$

clear, but both were in use at the same time.

The inventory of this house is atypical for the domestic structures at Hazor. It may be that the structure was inhabited by members of a specific social group, or that it served special functions, possibly to do with the nearby tomb. The presence of Mycenaean pottery in this structure shows that it was suitable to be used in such atypical circumstances. The fact that a Mycenaean figurine was found in the central courtyard of this atypical building may indicate that such objects possessed a special significance at Hazor.

Area H: temple ${ }^{56}$

A temple was first built in area $\mathrm{H}$ during MB II. The succeeding structure of the LB I period (Fig. 6.4A) possessed a courtyard, which sloped upward to the south-east. An elaborate propylaeum divided the square in two halves, thus creating a temenos in front of the temple which included several cult installations. Outside the propylaeum, where the pebbles of the floor of the courtyard were laid out in a decorative fashion, the LH IIB-LH IIIA1 cup (cat. no. 45) was found of which the Mycenaean origin

s6 Yadin 1972, 75-95; Yadin et al. 1989, 228, 240-248,

257-264; Ben-Tor et al. 1997, 87-89. 


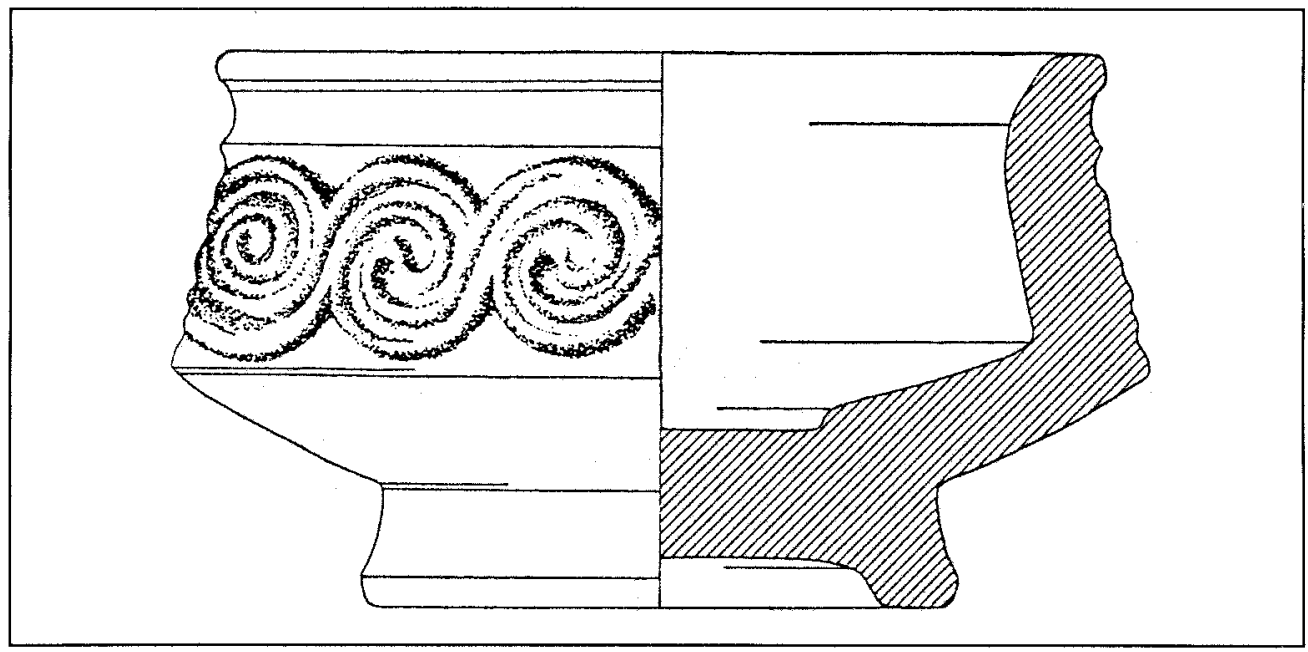

Fig. 6.5 Basalt krater with Aegean-type spiral from temple H, stratum 1A - After Yadin et al. 1961, plate 122: no. 4.

is uncertain. The only other object reported from the same area (locus 2174) is a ceramic lamp.

A new temple was built during phase 1B (Fig. 6.4B). It followed roughly the same plan as its predecessor, but an elaborate entrance hall (room 2128) was added. Two basalt pillar bases were discovered in the centre of the main hall of the temple, between which there was a deep pit. Outside the pit fragments of a Mycenaean bowl (cat. no. 46) were found, associated with local bowls and juglets, two ceramic anthropomorphic local figurines and a number of beads.

The LB IIB temple was virtually the same building as its predecessor, reconstructed with several changes and additions after a destruction (Fig. 6.4C). A long installation consisting of a concave basalt block stood in the south-western part of the large room 2115, with a square basalt slab on top of it. A Mycenaean bovine figurine (cat. no. 1003) was found in the vicinity of a basalt table in the northeastern part of the same room, in association with two engraved plaques made of bone. Nearby, on the threshold of doorway 2114, a Mycenaean stemmed cup (cat. no. 47) and a stone bead were discovered. In the main cult room of the temple a great number of cult objects were discovered, among which was a basalt krater with a 'Mycenaean-style' running spiral carved on its upper part (Fig. 6.5).

The religious associations of the Mycenaean pottery in the LB II temples are evident, but this is not the case for the one-handled cup found quite far away from the LB I structure - if it actually is Mycenaean. The presence of the Mycenaean bowl in the central cult room of LB IIA, together with some other ceremonial objects, suggest that the vessel served in the ceremonies that took place in the room. The same may be said of the Mycenaean finds from LB IIB. Even though these do not come from the main cult room, the presence of altar-like structures suggests that ceremonies were conducted in room 2115 as well. The fact that the Mycenaean dinner vessels and the figurine were considered suitable to serve in the temple sheds light on the appreciation of such imported ceramics at Hazor. In this respect, it is interesting to note that other imports - Syrian cylinder seals and an Egyptian scarabhave been found in the temples as well.

Area C: house 6063 (Fig. 6.6) (57 $^{57}$ 


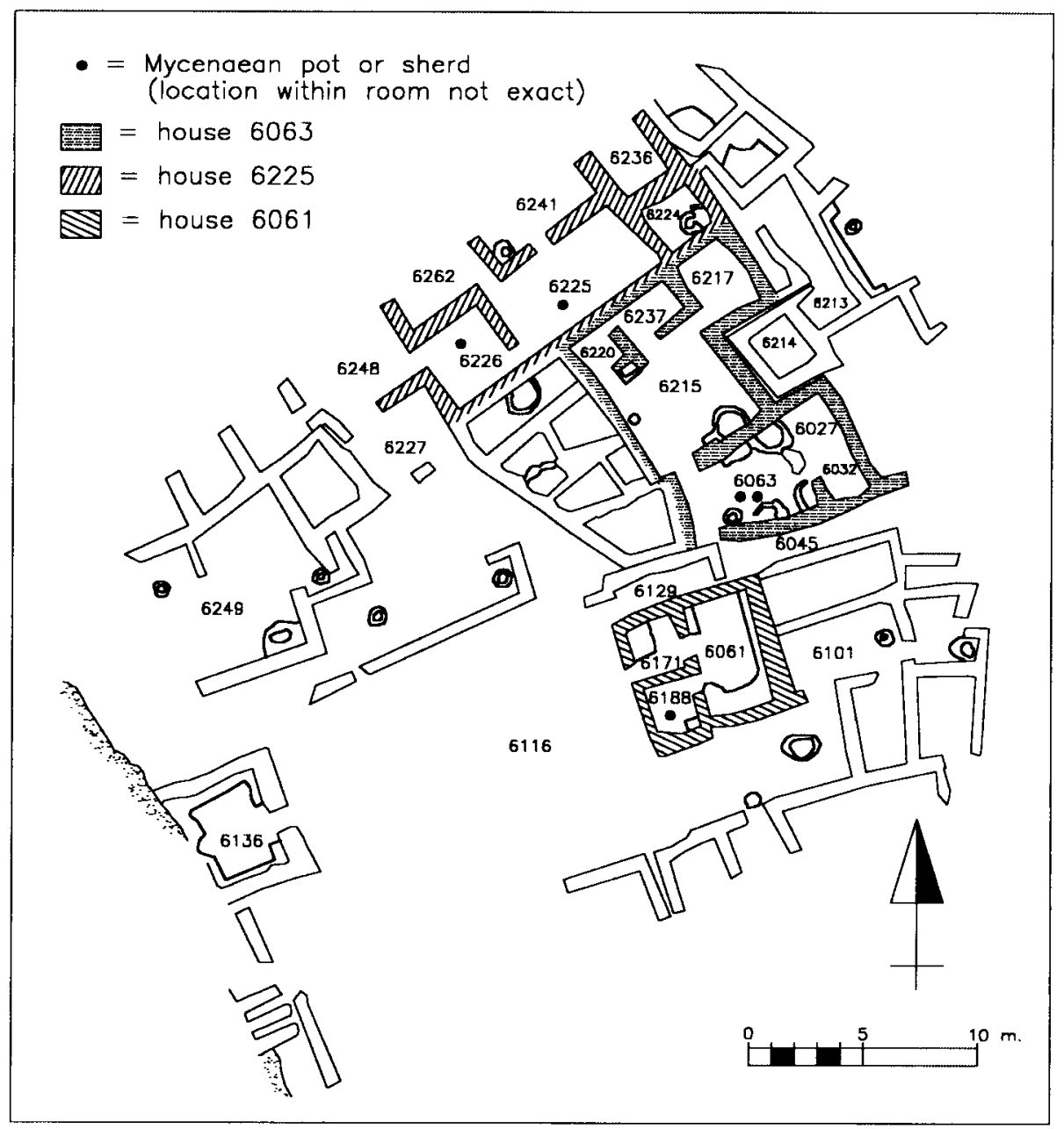

Fig. 6.6 Mycenaean pottery in area C (LBIIA)

In area $\mathrm{C}$, the buildings of LB IIA (stratum 1B) can be clearly distinguished from those of stratum 2, which were uncovered only in the south-eastern part. In contrast, only in the western part could LB IIA and IIB levels be distinguished. All Mycenaean pottery in area $\mathrm{C}$ was said to derive from the latest level of the LB IIA period. ${ }^{58}$ House 6063 consists of central court 6215, around which five rooms were situated (Fig. 6.6). The entrance from street 6045/6129 gave access to room 6063, where a variety of installations indicated a industrial activities and food processing. A Mycenaean straight-sided alabastron (cat. no. 1) and a Mycenaean piriform jar (cat. no. 2) were discovered in this room, in association with a pictorially decorated local storage jar, a pithos, a narrow-necked jar, three kraters, a cup, a bone whorl and a basalt grinder.

Since habitation rooms have not been identified in this house and there are no signs of an upper storey, the structure appears to have been designated exclusively to storage and manufacturing activities. Two potter's wheels and a large quantity of ceramics found in the house has led to the suggestion

57 Yadin et al. 1958, 76-77; Yadin 1972, 33-34; Daviau $\quad 58 \quad$ Yadin et al. 1960, 101.

1993, 228-235; Foucault-Forest 1996, 69-70. 
that pottery production was the most important activity; however it must be stressed that neither a kiln, nor wasters or misfirings have been reported from area C. ${ }^{59}$ The two Mycenaean vessels from house 6063 were found together in the same room. This suggests that these storage vessels were associated specifically with the industrial activities that were conducted there.

Area C: house 6225 (fig 6.6) ${ }^{60}$

In the second phase of LB IIA house 6225 was separated from house 6063 to the south-east. The former has not been fully excavated, but extended further to the north-west. From entrance 6248, room 6226 was entered, in which a Mycenaean straight-sided alabastron (cat. no. 13) was found in association with local bowls, a baking tray and a stone disc. ${ }^{61}$ From here one could go to the central courtyard 6225, where a large variety of objects was found pertaining to food preparation and pottery production: apart from a Mycenaean straight-sided alabastron (cat. no. 14), two potter's wheels, a clay mask, a loom weight, a basalt bowl and mortar, a local krater, a cooking pot and a narrow-necked jar. North of this courtyard were two rooms (6262 and 6241) that were only partly excavated and from which hardly any finds have been reported. Two rooms to the east (6224 and 6236) also belonged to this house.

As house 6225 has not been completely excavated, it is difficult to discuss the internal distribution of the Mycenaean vessels. It may be noted that the two vessels were not found together, but in separate, albeit communicating, rooms. This suggests that the Mycenaean vessels were part of the daily activities in the house: food preparation and the activities of artisans.

Area C: house 6061 (Fig. 6.6) 62

South of street 6129 is a small square building, which was entered from the public courtyard (6116) in front of shrine 6136 (Fig. 6.6). The entrance faced the shrine opposite the courtyard, which has led to the suggestion that both buildings were functionally related. A Mycenaean straight-sided alabastron (cat. no. 15) was found in this room 6188, in association with two hand-made local bowls. The peculiar architecture of this structure and the presence of several silos and stone shelves have led to its interpretation as a building for storage activities.

It is not uncommon for Bronze Age sanctuaries in the Levant to have an associated storeroom. The location of the entrance of house 6061 directly opposite the entrance of the shrine, as well as the presence of an Egyptian scarab may suggest a relation between the two buildings. If building 6061 indeed possessed religious associations, it may be of importance to note that the Mycenaean alabastron was found in a storage room and not directly related to the ceremonies conducted in the shrine.

area D: cistern $9017^{63}$

59 Possible additional evidence for pottery production in area C comes from house 6211 in the north-east, where ceramic vessels were found in a large variety and sometimes stacked in heaps, see Yadin 1972, 36. The pottery should properly be assigned to stratum 1A, but the house itself was built during the 1B phase.

60 Yadin et al. 1960, 101-103; Yadin 1972, 35; Daviau 1993, 235-237; Foucault-Forest 1996, 69.
${ }^{6}$ I It is possible that none of these finds were found on the floor itself, as Yadin (et al. 1960, 102) reports this room as empty, although the locus is mentioned in the accompanying plates; see Yadin et al. 1960 Plates 117 nos. 3, 29; 123 nos. 10, 13.

62 Yadin et al. 1958, 78; 1960, 98; Daviau 1993, 241; Foucault-Forest 1996, 70. 
In area $\mathrm{D}$ four cisterns and a number of caves were discovered which had been hewn out the rock during the Middle Bronze II period. All of the cisterns were reused during the Late Bronze Age. In the south-west, cistern 9027 was reused in the Late Bronze II period as a tomb; four Mycenaean vessels (cat. nos. 8-11) have been found in it. In the northern part, two LB II kilns point to industrial activities during that period. ${ }^{64}$ Just south-east of these kilns a cistern (9017) may be associated with the activities around the kilns. A large amount of pottery was found in cistern 9017, among which local bowls formed the largest group. In addition, the cistern contained local kraters, cooking pots, jugs and juglets, pithoi, lamps and a number of decorated vessels. A zoomorphic vessel of local manufacture was also found, just as two Cypriot bowls, one of White Slip II ware, the other of Base Ring fabric. A Mycenaean straight-sided alabastron (cat. no. 7) and a Mycenaean stemmed cup (cat. no. 6) were also found in cistern 9017.

Cistern 9017 has been interpreted as a kind of silo. This seems unlikely, because most of the ceramics found in it were dinner vessels. ${ }^{65}$ An interpretation of the cistern as a refuse pit seems more plausible. The fact that the Mycenaean vessels, as well as those of Cypriot origin, were discarded in the same manner as the local pottery could indicate that they were not regarded as different. However, the local ceramic repertoire from cistern 9017 is particularly varied and contains some unusual shapes and decorations. The Mycenaean pottery found here, among which a patterned kylix, is part of an atypical assemblage, which may have been used in specific circumstances. The kilns in the vicinity of the cistern point to the possibility that these circumstances were somehow related to industrial production.

The main purpose of this section was to review if a differentiation according to vessel type can be made with regard to the use of Mycenaean pottery among the population of Hazor. In this respect it is interesting to note that there is a difference between areas $\mathrm{C}$ and $\mathrm{F}$ in the presence of Mycenaean ceramic vessel types. Apart from the kylix found in house 8039 and the figurine in house 8139, all Mycenaean vessels from area $\mathrm{F}$ are narrow-mouthed container jars: three stirrup jars and three lentoid flasks. In contrast, all Mycenaean pots from area $\mathrm{C}$ are wide-mouthed storage vessels: four straightsided alabastra and a piriform jar. It is unlikely that this spatial difference is caused by a local geographical phenomenon, since both types of vessels have been found in area $\mathrm{D},{ }^{66}$ while stirrup jars have been found in areas $\mathrm{B}$ and $\mathrm{BA}^{67}$ and area A produced two alabastra ${ }^{68}$ Rather we should relate this spatial variation to the different functions of these areas in the society of Hazor. The Mycenaean vessels in area $\mathrm{C}$ all occur in structures which have yielded ample evidence for craft manufacture and associated storage.$^{69}$ In area D, where a straight-sided alabastron was found in pit 9017 , there were likewise indications of industrial activities. In the houses in area $\mathrm{C}$ which can be classified primarily as habitation structures (houses 6106, 6249), Mycenaean pottery has not been found. ${ }^{70}$ It seems, therefore, that

63 Yadin et al. 1958, 109-110, 115-116, 118, 127-140.

64 Yadin et al. $(1958,116)$ think that the southern kiln (9004) was used for pottery manufacture, while the northern kiln was for metals. Unfortunately, no finds were associated with these installations.

65 The imports in the cistern and the fact that most of the local vessels were labelled as 'reused' (Yadin et al. 1958, 118) make it unlikely that products from the nearby kiln were stored here.
66 Stirrup jar of cat. no. 4 and straight-sided alabastron of cat. no. 7

67 Cat. nos. 43 and 44 respectively

68 Cat. no. 39 (LH IIIA2-LH IIIB) and cat. no. 42 (LH IIB)

69 Only for building 6061 is this not the case. However, this house is situated among industrial structures and, in any case, its possible religious associations sets it apart from the other structure in areas $\mathrm{F}$ and $\mathrm{C}$. 
Mycenaean wide-mouthed containers at Hazor were mainly associated with manufacturing activities, while narrow-mouthed storage vessels were primarily appreciated for their use in habitation areas. The cause of this variation is likely to be related to differences in the contents of these vessel types.

The differences in the spatial and contextual distribution of Mycenaean dinner and storage vessels have already been commented upon. The stemmed cup with patterned decoration which has been found in area D in cistern 9107 can be considered as additional evidence that such vases were endowed with a special significance at Hazor, since it was part of an atypical ceramic repertoire. The only Mycenaean open vessel which has been found in a regular domestic context is the kylix from house 8039. In area D a stemmed cup (cat. no. 5) has been found in close proximity to a Mycenaean female figurine (cat. 1001). ${ }^{71}$ Otherwise, Mycenaean figurines have been found only in a-typical circumstances, namely in house 8139 and in the LB IIB temple in area H. This indicates that Mycenaean figurines were also endowed with a special significance at Hazor.

\section{F UNERARY CONTEXTS}

Only three graves from the Late Bronze Age II period have been found in Hazor, all of which contained Mycenaean pottery. In area D, cistern 9027 was intentionally cleared out during the Late Bronze Age and an individual interment of a young woman was placed inside it, surrounded by ceramics. ${ }^{72}$ After depositing the body, the cistern seems to have been intentionally filled with over $3 \mathrm{~m}$ of fill. In area F, below courtyard 8039, in a circular depression created by the collapse of an underground hall of the MB II period, an isolated inhumation of an adult male was found (Fig. 6.2). ${ }^{73}$ Also in area F, just north-west of building 8139, the rock-cut tomb 8144-8145 was discovered (Fig. 6.2). ${ }^{74}$ An almost vertical shaft was cut out in the rock. From there, the builders of the caves had begun to work in a south-eastern direction (locus 8145), but after encountering a tunnel from the MB period, they had laid out an oval chamber south-west of the vertical shaft (locus 8144). The deposition of the inventory indicated that the cave was used for multiple interments, probably spanning the entire duration of LB IIA.

These three graves are the only ones at Hazor which, on the basis of their pottery, can be related to the Late Bronze Age II. In area F a number of graves from the Late Bronze I period have been discovered. ${ }^{75}$ None of these tombs yielded Mycenaean pottery, which is in accordance with my conclusion that Mycenaean pottery in this period was not widely available to the inhabitants of Hazor.

The three tombs with Mycenaean pottery each have yielded different amounts (Table 6.10). The grave in cistern 9027 in area D produced four Mycenaean vessels, ranging in date from LH IIIA2 late to LH IIIB2. The fact that vessels from such wide ranging periods were found together in a grave

70 House 6249, see Daviau 1993, 237-238; House 6101, see Daviau 1993, 239.

${ }^{71}$ A Mycenaean stirrup jar (cat. no. 1001) was found in the near vicinity as well. The exact find spot of these objects is unclear, but they appear to have been found close to one another; see Yadin et al. 1958, 105, 107.

72 Yadin et al. 1958, 138-140; Of the nearby cistern 9028 only the upper layer was explored, Yadin et al. 1958,
140. Since the uppermost fill of this cistern was similar to that of no. 9027, it is possible that a Late Bronze Age burial is still present below this stratum.

73 Yadin et al. 1960, 141-142.

74 Yadin et al. 1960, 140-141.

75 Yadin 1972, 44-45; Yadin et al. 1989, 156-158. A LB I tomb was also discovered in a MB II drainage channel in area $\mathrm{F}$. 


\begin{tabular}{|c|c|c|c|}
\hline tomb & vessel type & amount & catalogue nos. \\
\hline \multirow[t]{3}{*}{ cistern 9027} & amphoroid krater & 1 & 10 \\
\hline & deep bowl & 1 & 11 \\
\hline & straight-sided alabastron & 2 & 8,9 \\
\hline pit 8065 & piriform jar & 1 & 29 \\
\hline \multirow[t]{6}{*}{ tomb 8144-8145 } & shallow cup & 2 & 16,17 \\
\hline & globular flask, horizontal & 3 & $21,22,23$ \\
\hline & lentoid flask & 1 & 18 \\
\hline & stirrup jar & 6 & $24,25,26,27,28,38$ \\
\hline & rounded alabastron & 1 & 19 \\
\hline & straight-sided alabastron & 1 & 20 \\
\hline
\end{tabular}

Table 6.10

with a single interment indicates that the alabastron dated to LH IIIA2 late (cat. no. 8) must have been at least half a century old at the time of its deposition. This pot had either been in use for a long time at Hazor or had circulated a long time before reaching the city.

In area F, tomb 8065 yielded only one LH IIIA2 piriform jar (cat. no. 29). The funerary chamber 8144-8145 possessed a total of fourteen Mycenaean vessels (cat. nos. 16-28, 38), ranging in date from LH IIIA2 to LH IIIB. The concentration of Mycenaean vessels in tomb 8144-8145 may, at least partly, be explained by its long use. ${ }^{76}$ Whereas the two other graves contained only single bodies, funerary cellar 8144-8145 was used for multiple interments. However, tomb 8144-8145 yielded a funerary inventory which was particularly varied in finds, also in comparison with settlement contexts. ${ }^{77}$ Although this tomb cannot really be compared to any other at Hazor, the quantity of Mycenaean pottery seems to be one aspect of burial practices that involved a number of special goods.

In terms of Mycenaean vessel types, the Mycenaean pottery from funerary contexts have yielded a varied repertoire (Table 6.10). Moreover, dinner vessels were present in both tombs with more than one Mycenaean pot, suggesting that it was not unusual to include such vases in funerary ceremonies. In addition, there are a number of pot shapes from the graves, which have not been found elsewhere on the site. This is the case for the amphoroid krater and the deep bowl from cistern 9027, as well as for the shallow cups and globular flasks from tomb $8144-8145 .^{78}$ This suggests that these ceramic types were specifically chosen to be used in funerary ceremonies. However, none of the vessel types unique to Hazor occur in more than one tomb. In fact, only straight-sided alabastra, a type frequent in settlement contexts as well, are present in more than one funerary context. The low number of Late Bronze Age tombs at Hazor prevents any statement on the popularity of specific vessel types in funerary contexts. The most frequent vessel type in graves was the stirrup jar, of which six specimens occurred in funerary cave $8144-8145$.

Because of the low number of burials at Hazor from the LB II period, it is difficult to analyse these

76 Yadin et al. (1960, 141) show that the funerary cellar was used during the whole LB IIA period.

77 In particular, this tomb contained a large number of imports and metal vessels, see Yadin et al. 1960, 145153.
78 Of seven Mycenaean finds (cat. nos. 3, 41, 48-52) the vessel type is unknown. It is possible that one of these finds are from vessel types otherwise known only from tombs. 
three funerary cellars in terms of the social status of the deceased. It is clear that the inventory of tomb 8144-8145 was richer than that of the two other graves. The inventories of the other two graves consisted exclusively of pottery. ${ }^{79}$

Even though the larger quantity of finds in funerary cave $8144-8145$ may be related to the longer use of this tomb, the presence of a varied repertoire of metal, bone and stone objects indicates that the proprietors of this tomb expressed a greater material wealth in their funerary ceremony. This may also be indicated by the fact that this tomb was specially created for Late Bronze Age II burial ceremonies, while the other two burials took place in existing structures: a MB II cistern in the case of grave 9027 and a depression in the case of grave 9065. In terms of effort expenditure, this points to a higher status of the owners of tomb 8144-8145. ${ }^{80}$ Apart from the Mycenaean pottery, all three burials contained imports from other areas: a White Slip II bowl (Cyprus) in the case of cistern 9027, three Base Ring jugs (Cyprus) in the case of burial 8065, and three scarabs (Egypt), as well as Base Ring and White Slip vessels (Cyprus) for cave 8144-8145. This suggests that imports, among which was Mycenaean pottery, played a role in strategies of funerary display.

\section{The Role of Mycenaean POtTERy in The MAterial Culture OF HAZOR}

Mycenaean ceramic vessels and figurines are the only imports at Hazor of certain Aegean origin. In comparison with some large coastal centres in the southern Levant, imports which are archaeologically immediately recognisable are relatively scarce at Hazor. ${ }^{81}$ Nevertheless, Egyptian imports at Hazor constitute a varied repertoire of finds from various parts of the site: a number of scarabs, ${ }^{82}$ faience beads, ${ }^{83}$ and alabaster vessels ${ }^{84}$ have been found, as well as two ceramic bowls (possibly locally imitated ${ }^{86}$ and an Egyptian-style bottle with red slipped exterior. ${ }^{87}$ In addition, a bronze bowl containing two cymbals of the same material finds its best parallels at Aniba (site no. 287) in Nubia. ${ }^{87}$ Objects from Syria and Mesopotamia are more limited in their distribution and variety: a large number of cylinder seals have been found in the stratum $1 \mathrm{~A}$ temple in area $\mathrm{H}$, but these were clearly several centuries old ${ }^{88}$ In stratum 1B of the same area a number of basalt statues were discovered, which appear to have been imported from Syria. ${ }^{89}$

The most numerous imports at Hazor were Cypriot ceramic vessels, which have been discovered in all areas and arrived from the MB II period onwards. ${ }^{90} \mathrm{~A}$ fair number of these finds are bowls, either in the White Slip or in the Base Ring tradition. Base Ring juglets, as well as a juglet in White Shaved

79 Yadin et al. 1960, 152 (tomb 8065); Yadin 1958, 138140 (cistern 9027).

so Brown 1981, 29.

${ }^{81}$ Bienkowski 1987, 51-52. It must be emphasised that research into the occurrence of regional imports employing scientific methods has not been carried out, to my knowledge.

82 For example: Yadin et al. 1958, Plate 86 no. 22 (area C) Plate 89 no. 19 (area C); 1960, 153 (area C); Goldwasser 1997 (areas A and F).

83 For example: Yadin et al. 1958, Plate 161 no. 12 (area C), Plate 170 no. 12 (area D); Ben-Tor et al. 1997, 56-
57 Fig. II.18 no. 31 (area A).

${ }^{84}$ For example: Yadin et al. 1960, 158 (area F), Plate 150; Ben-Tor et al. 1997, 68-69 Fig. II.25 no. 19 (area A). Area $F$ in particular was rich in Egyptian alabaster finds.

85 Yadin et al. 1989, 233 (area $\mathrm{H})$

86 Ben-Tor et al. 1997, 215 photo III.21 (area L)

87 Yadin et al. 1958, 85 (area C)

88 Beck 1989a, 310-321.

89 Beck 1989b, 322-338.

9o Yadin et al. 1958, 117. 
ware (LB I) and a Cypriot zoomorphic vessel, have also been found..${ }^{91}$ It may be of significance that, at least in domestic contexts, these Cypriot vessels have not often been found in direct association with Mycenaean vessels. In the investigated settlement contexts, Cypriot vessels never have been reported from the same rooms as the Mycenaean pots, although they were found in the same houses..$^{92}$ In area BA a WS II bowl was found together with a Mycenaean stirrup jar (cat. no. 44) in a domestic context, ${ }^{93}$ while in area A a Mycenaean alabastron (cat. no. 39) was found together with WS II bowls on the pavement of a possible street. The spatial separation in domestic contexts of these two imported classes of ceramics seems to reflect the extent to which both classes were integrated in the local material culture: they are both found with local domestic pottery and utensils and were not set apart as imports. However, Mycenaean and Cypriot pottery have been discovered together in contexts of a special nature: in cistern 9017, and in all three Late Bronze Age tombs. This suggests that in specific occasions the foreign origin of these items could be emphasised by combining them with other imports and objects of a special significance.

It may be expected in a material environment in which imports were not very abundant, that objects from international exchange possessed some kind of social significance. A concentration of Mycenaean pottery has been observed in area F and, to a lesser extent, in area D. Such an unequal distribution pattern may be caused by social strategies resulting in unequal access to Mycenaean pottery by different social groups at Hazor. A number of observations have been made in this chapter suggesting that a differentiation within the general class of Late Helladic ceramics is necessary in this respect. The domestic contexts in area $\mathrm{F}$ mainly produced Mycenaean narrow-mouthed container vessels, while wide-mouthed containers in domestic contexts in area $\mathrm{C}$ were primarily associated with the activities of artisans. Because a similar distinction between areas $\mathrm{C}$ and $\mathrm{F}$ cannot be made for the locally manufactured pottery, ${ }^{94}$ it is possible that this disparity is caused by unequal access for various social groups to the Mycenaean vessel types. Late Helladic dinner vessels, often with patterned decoration, were not widely used in domestic contexts. However, they are the most frequent Mycenaean type in the monumental temple in area $\mathrm{H}$, which suggests that such an institution had wide access to these vessels. Finally, Mycenaean pots from the first part of the Late Bronze Age are concentrated in area $\mathrm{A}$, where a temple and palace were located. This suggests that the social groups associated with these structures had exclusive access to Mycenaean pottery during this period. The fact that in the later period various groups within the society of Hazor had unequal access to different parts of the Mycenaean repertoire indicates that the possession and use of these vessels was of social significance.

There are several other indications that Mycenaean pottery possessed a certain value at Hazor. Its occurrence in contexts with clear ritual associations, such as the temple in area $\mathrm{H}$, shows that it was considered suitable to serve in ceremonies of a highly symbolical nature. Moreover, the varied repertoire of Mycenaean pots present in the three Late Bronze Age tombs suggests that these vessels, in association with other imports, were used in strategies of funerary display. In a few cases Mycenaean pottery has been discovered in atypical contexts, such as cistern 9017 in area D and house 8139 in area $\mathrm{F}$, showing that this material could be associated with objects of special significance. At the same time, the wide distribution of Mycenaean ceramics, both on the site as a whole as within single struc-

9I Yadin et al. 1960, 110 (area C)

92 Yadin et al. 1958, 80, 106, 109; 1960, 109-110, 151153; 1989, 22, 25.

93 Yadin et al. 1989, 130.

94 Compare Tables 4.4-4.8 (area C) with Table 4.9 (area
F) given by Daviau (1993). In both areas there is a strong predominance of local bowls, while kraters, pithoi, narrow-necked jars, jugs and juglets arealso common. 
tures, suggests that this class of material was an integral part of the material culture at Hazor during the second phase of the Late Bronze Age.

In view of its apparent value at Hazor and also in comparison with other sites in the Levant, it is remarkable that no obvious imitations of Mycenaean pottery of Syro-Palestine manufacture have been reported from Hazor. ${ }^{95}$ Elsewhere, such Levantine derivatives of Aegean pottery do occur, mostly produced at the end of the 13th and in the 12th centuries BC. ${ }^{96}$ Such Aegean style pottery made in the Levant also seems to have circulated in systems of regional exchange, and its absence at Hazor may indicate that the city was not heavily involved in such trade. ${ }^{97}$

The final question to be addressed in this chapter concerns the social groups within the society of Hazor that made use of the Mycenaean pottery. The abundance of this material in area A, where a palace and monumental temple were situated during the Late Bronze Age, indicates that the royal court, the existence of which is certain from the Amarna tablets, made use of these ceramics. ${ }^{98}$ At the very least the Mycenaean finds in this area attest to the use of Mycenaean pottery in official contexts. Indeed, Mycenaean vessels from the first part of the Late Bronze Age may have been monopolised by high-level social groups. Mycenaean pottery, in particular dinner vessels, is also associated with groups involved in the performance of religious rites in the monumental temple $\mathrm{H}$. The evidence from areas $\mathrm{C}$ and $\mathrm{D}$ indicates that artisans working in the city used Mycenaean storage vessels in their daily life, while the frequency of this material in area $\mathrm{F}$ testifies that it also occurred in habitation structures. It therefore seems that Mycenaean pottery was available to all social groups at Hazor, even though access to specific vessel types appears not to have been equal.

The extent of the territory controlled by Hazor is uncertain. A survey of the upper Jordan valley revealed no Late Bronze Age settlements in the central and northern parts of the region and only six sites in the southern part. ${ }^{99}$ No Mycenaean pottery was reported from any of these sites. The nearest site where such material has been found is Kinneret (site no. 172) on the north-western coast of Lake Tiberias (Map 6). ${ }^{100}$ This site possessed its own defences during the Late Bronze Age and appears to have been the focal point for a rebellion against Egyptian rule in the seventh year of pharaoh Amenophis II. ${ }^{101}$ The relationship of Kinneret with Hazor is unclear. To the north, Tell Dan (site no. 170) has produced substantial amounts of Mycenaean pottery. This site, ancient Laish, is mentioned separately in the Egyptian list of cities destroyed by Thutmosis III and was most likely independent of Hazor. ${ }^{102}$ At Tell Dan, Mycenaean pottery has been found in domestic, as well as in funerary contexts. ${ }^{103}$ Beyond Tell Dan, Mycenaean finds have been reported from Khan Selim (site no. 169). ${ }^{104}$

95 The absence of scientific investigations of the fabrics argues for caution in this respect. The description of the fabrics accompanying the drawings are, however, fairly homogeneous: yellow to pink levigated, wellfired clay.

$96 \quad$ Leonard et al. 1993, 106; Killebrew 1998.

97 Killebrew 1998. Since the Aegean style pottery manufactured in the Levant seems to have circulated mainly at the very end of the 13th and in the 12th centuries BC, its absence at Hazor may be a chronological phenomenon.

98 No Mycenaean pottery has been reported from the small section of the palace (building 389) excavated by
Yadin and his team, see Yadin et al. 1989, 23-24. BenTor $(1998,462)$ mentions that a handful of Mycenaean (and Cypriot) finds have been made in this area during the most recent excavations.

99 Epstein \& Goodman 1972, 244-250; Bienkowski 1987, 54.

100 A single Mycenaean pot has been reported from this site by Hankey \& Leonard (1989). The site is absent from Leonard's (1994) gazetteer of sites in the Levant with Mycenaean pottery.

го Gonen 1984, 65; Bienkowski 1987, 54 (with references).

Iо2 Gonen 1984, 68; Ilan 1996, 108. 
Even further to the north, in the Beqaa valley, large quantities of Mycenaean pottery have been found at Kamid el-Loz (site no. 168). ${ }^{105}$ Egyptian influences at this site are stronger than at Hazor and the possibility of an Egyptian garrison at Kamid el-Loz has been raised. ${ }^{106}$

The emerging picture is that Mycenaean pottery in the northern Jordan valley was used primarily by people living in urban communities. Within the city of Hazor this pottery was used by all social strata in the society. The unequal access by different population groups to specific Mycenaean vessel types shows the socially active role of this class of imports for various groups among the urban population.

го3 Biran 1993, 326; Biran 1994a, 105-123; 1994b, 8.

ro4 Gregori \& Palumbo 1986, 383: site no. 35.

ros Hachmann \& Kuschke 1966, 56-58; Hachmann 1970 ,
25-43; Echt 1984; Marfoe 1995, 131, 137, 140, 141, 147, 151, 156.

Io6 Echt 1984; Bienkowski 1987, 59. 



\section{$7 \quad$ Tell Deir 'Alla}

\section{N T R O D U C T I O N}

Deir 'Alla is the name of an artificial hill in the central Jordan valley, about $45 \mathrm{~km}$ north-west of Amman and $60 \mathrm{~km}$ north-east of Jerusalem. The tell is situated some $5 \mathrm{~km}$ east of the present day course of the Jordan river. The site is being excavated by joint Dutch and Jordanian teams since 1960. ${ }^{1}$ The oldest finds at Deir 'Alla date from the Chalcolitic period, but the first true settlement at the site, belongs to the Middle Bronze Age, of which two phases have been discovered. ${ }^{2}$ Since that period, the site appears to have been settled more or less continuously until its abandonment shortly before the Hellenistic age.

The discovery of Late Bronze Age remains at the south-western foot of the tell, as well as in the eastern and north-western parts, indicates that the whole site was settled during this period. ${ }^{3}$ On the northern slope (Fig. 7.1), eight phases of the Late Bronze Age have been discovered, labelled A to H. ${ }^{4}$ The most extensive remains, those of phase E, were destroyed by an earthquake and subsequent fires sometime in the 12 th century BC. ${ }^{5}$ The remains of stratum E on the northern slope, consist of structures grouped around a temple, the so-called cella (Fig. 7.2). Soundings in the cella determined that it had been rebuilt five times, with the first phase belonging to the 16th century BC. Adjacent to the cella, in the west, two rooms (nos. 7 and 8) were excavated, which have been interpreted as storerooms on the basis of their inventories. Directly north and west of these rooms a number of spaces (nos. 9-14) of unknown purpose were discovered. East of the cella was a courtyard, on the other side of which there was a building (rooms nos. 4-6), which has been interpreted as a treasury. Further east, another building was situated, of which three rooms could partly be recovered (nos. 1-3). ${ }^{6}$ On the basis of their inventories, these rooms have been interpreted as a shrine, a kitchen and a storeroom or pantry respectively.

The part of Transjordan in which Deir 'Alla is situated can be identified as ancient Gilead, a producer of agricultural products such as fruits and cattle, as well as oils and resin. ${ }^{7}$ These goods were

I For an overview of the history of archaeological research at Deir 'Alla, see Van der Kooij \& Ibrahim 1989, 22-24. From 1960 until 1967 H.J. Franken of the University of Leiden directed the expeditions. Excavations resumed in 1976 headed by Franken and M. Ibrahim from the Department of Antiquities in Jordan. In 1979 G. van der Kooij replaced Franken as head of the Dutch team.

2 Franken 1961, 371; Van der Kooij \& Ibrahim 1989, 76-92.
3 Ibrahim \& Van der Kooij 1997, 104-109; G. Van der Kooij, pers. comm.

4 Franken 1992, 2.

5 Calibrated radiocarbon dates point to the destruction having occurred around 1300 BC, see Franken 1992, 117. However, an Egyptian faience vase found in stratum E bears the cartouche of Queen Taousert, indicating a date post quem of 1186 BC, cf. Kitchen 1987, 52.

6 Franken 1992, 38-53.

7 Franken 1992, 170-176. A number of biblical place 


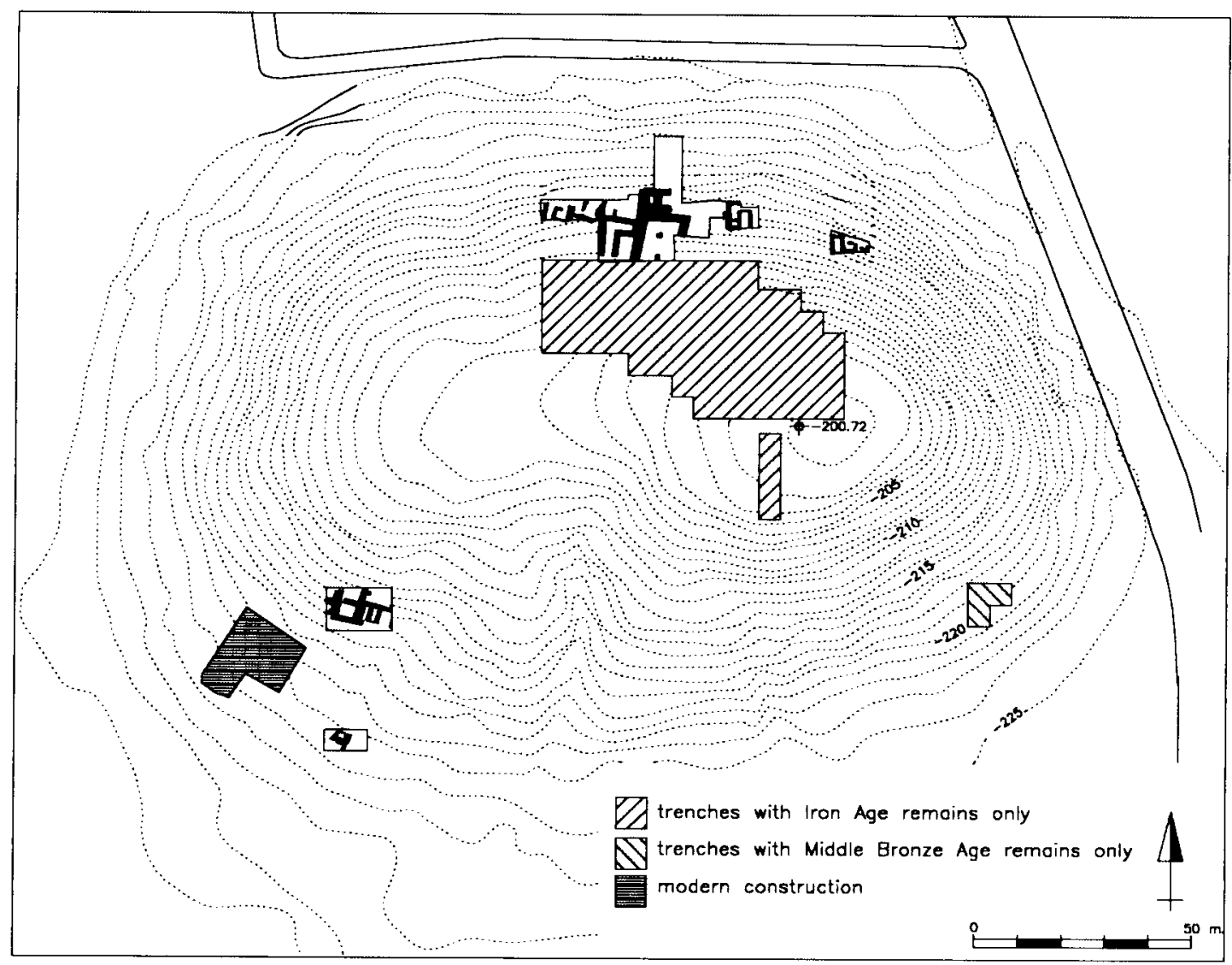

Fig 7.1 Deir 'Alla: site plan

traded, in particular with Egypt, via Palestine. The ceramic repertoire should be characterised as Jordanian, rather than as true Palestinian. ${ }^{8}$ Apart from local manufacture, pottery was also imported into Deir "Alla from different areas in Jordan. ${ }^{9}$ The prominence of the cella and the absence of a substantial city in the near vicinity of the site have led to an interpretation of the site as a sanctuary, serving as a trading post. ${ }^{10}$

\section{THE MYCENAEAN POTTERY}

In total, five Mycenaean vessels and one derivative of Syro-Palestinian manufacture have been published from Tell Deir "Alla (see Catalogue IV). One of these five vessels (cat. no. 2) may have a Minoan origin. ${ }^{11}$ Since none of the pots has been subject to scientific provenance research, the origin of the vessels cannot be established with certainty. However, in view of the provenances for Mycenaean pottery in Palestine in general, it is conceivable that most of the vessels at Deir 'Alla were produced on the Peloponnese. ${ }^{12}$

names have been suggested for the site itself.

8 Franken 1992, 152-162; Van der Kooij \& Ibrahim 1989, 80. Cf. also Kafafi 1977, 464-465.

9 Franken 1992, 105-109.
Io Franken 1992, 167-178.

II Warren \& Hankey 1989, 161.

I2 See chapter 2 . 


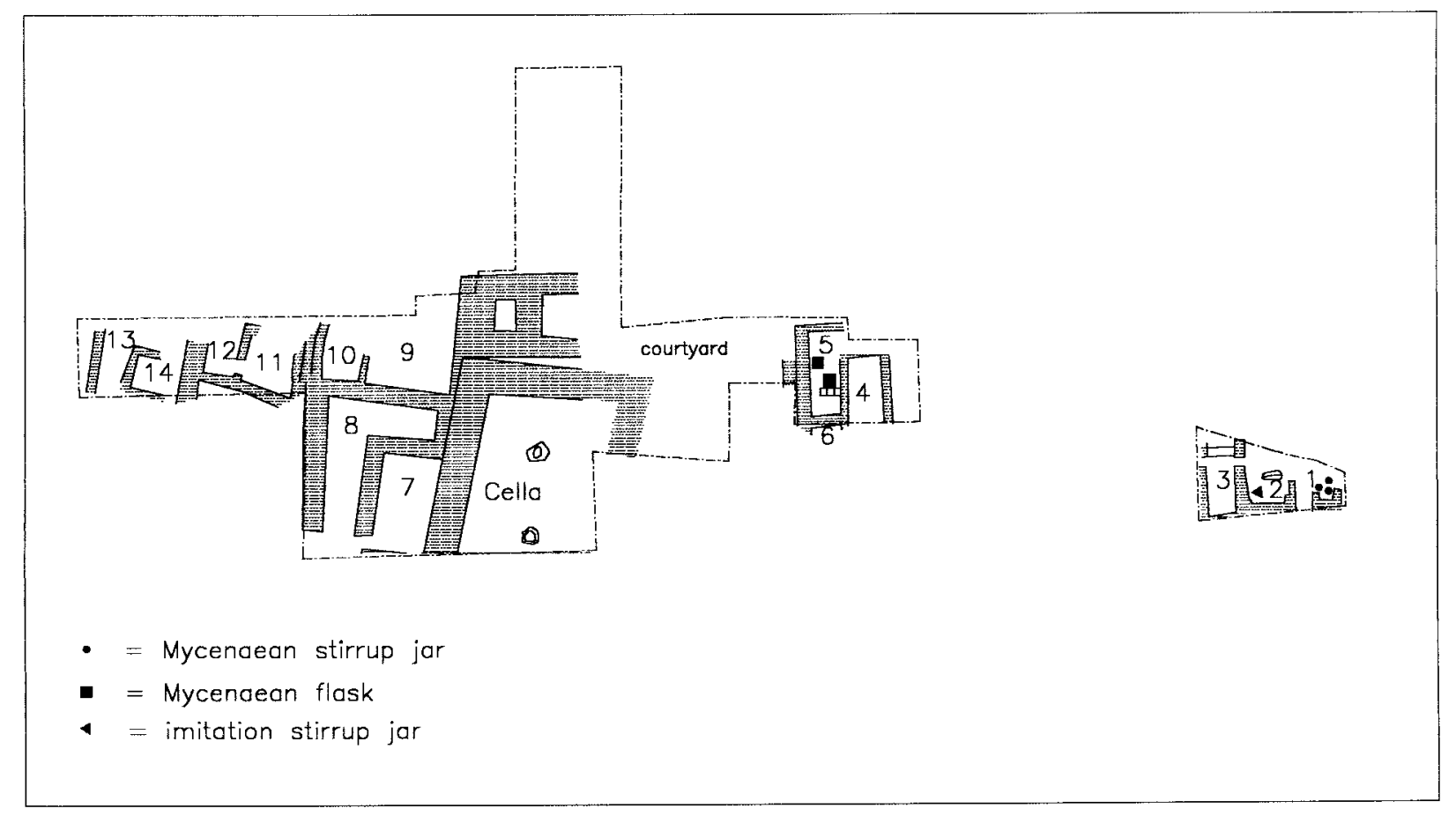

Fig. 7.2 Mycenaean pottery in the Late Bronze Age buildings on the northern slope (stratum E).

It is certain that these six examples constitute all the Aegean-style pottery from the Late Bronze Age that has been found at Deir 'Alla. The excavations of the Bronze Age levels on the northern slope have been fully published. ${ }^{13}$ Moreover, the special attention of the excavators for pottery makes it unlikely that any Mycenaean sherds have been thrown away or remained unnoticed. Some of the excavations in the south-western part of the site have been discussed in a preliminary report only. ${ }^{14}$ According to the excavators, Aegean-type pottery has, so far, not been found in this part of the site. ${ }^{15}$

\section{THE ON-SITE DISTRIBUTION OF MYCENAEAN POTTERY}

The six entries in Catalogue IV have been found in two buildings only: the easternmost structure with rooms 1-3 and the treasury adjacent to the courtyard (see Fig. 7.2 and Table 7.1).

It is remarkable, especially with such a low number of finds, that in each of these buildings more than one Mycenaean vessel has been found. This indicates that these pots were not used everywhere at the site, but served special functions.

On the basis of the architecture and inventories, the excavators were able to assign different functions to the rooms. ${ }^{16}$ It is noteworthy that none of our vessels has been found in the cella, which yielded a number of other imports. ${ }^{17}$ Mycenaean pottery has not been found in the storerooms (Rooms 7

I3 Franken 1992.

I4 The 1994 campaign has been reported upon by Ibrahim \& Van der Kooij 1997; the 1996 and 1998 campaigns have, so far, not been published.

I6 Franken 1992, 163-165.

${ }_{17}$ Franken 1992, 28. 


\begin{tabular}{lcc}
\hline building & room & amount \\
\hline easternmost building & room 1 & 3 \\
& room 2 & 1 \\
& room 3 & \\
treasury & room 4 \\
& room 5 & 2 \\
& room 6 & \\
\hline
\end{tabular}

Table 7.1

and 8) either, which served the cella. This indicates that Aegean vessels were not used during the ceremonies which were practised in the cella, nor were they offered as votives. The functions of Rooms 9 and 10 are not known. However, the nature of the pottery indicates that these were domestic quarters. ${ }^{18}$ If such an identification is correct, the absence of Mycenaean pottery in these rooms suggests that these ceramics were not part of domestic activities at the site.

The two buildings in the east are comparable to the cella in the presence of luxury objects. ${ }^{19}$ Two Mycenaean vessels were found in the treasury (cat. nos. 4 and 5); four of our vessels can be associated with the easternmost building. The relation of the easternmost building with the cella and treasury is difficult to assess, but the wealth of finds in this area suggests that it had some kind of official function. In any case, the distribution of Mycenaean pottery at Deir "Alla clearly shows that the few vessels were restricted to the wealthier, official areas.

From a stylistic point of view, the earliest Mycenaean vessel probably is the squat stirrup jar of cat. no. 3, which can be compared to similar vessels at Tell el-Amarna in Egypt and may be assigned a late LH IIIA2 date (Fig. 7.3). ${ }^{20}$ The two horizontal flasks of cat. nos. 4 and 5 can be assigned to LH IIIA2LH IIIB1 (Fig. 7.3), ${ }^{21}$ while the other three vessels are of LH IIIB types. ${ }^{22}$ All these vessels were in use at the time of destruction of phase E, which is dated by the cartouche of Queen Taousert after 1186 BC. If the stirrup jar indeed belongs to LH IIIA2, this means that it was more than a century old at the time of its deposition; the two flasks were at least half that age. These finds clearly show that Aegean vessels remained in use long after their manufacture. The occurrence of the LH IIIA2 stirrup jar in direct association with LH IIIB types suggests that the older vessel was not regarded as different.

All the Mycenaean pots in Deir 'Alla are storage vessels. The absence of dinner and ritual vessels at the site is noteworthy, as these types elsewhere constitute a significant proportion of the repertoire of Mycenaean ceramics. Within the general class of storage pottery, two vessel types are present at Deir 'Alla: the globular flask (cat. nos. 4 and 5) and the stirrup jar (cat. nos. 1-3 and 6). The stirrup jar is generally thought to be a container for (perfumed) oil, ${ }^{23}$ while the globular flask could also hold oil, as

I8 These rooms produced mainly kitchen pottery and a variety of utilitarian objects, see Franken 1992, 84-91.

I9 Franken 1992, 165

20 Hankey 1967, 131-132. Leonard (1994, 62 no. 761), however, assigns this vessel to LH IIIB.

2I Hankey 1967, 131-132; Leonard 1994, 88 nos. 1134-
1135.

22 Hankey 1967, 132; Leonard 1994, 55 no. 633, 61 no. 740, 79 no. 1199 .

23 Leonard 1981, 94; Tournavitou 1992, 190-195; Negbi \& Negbi 1993, 324-325. 


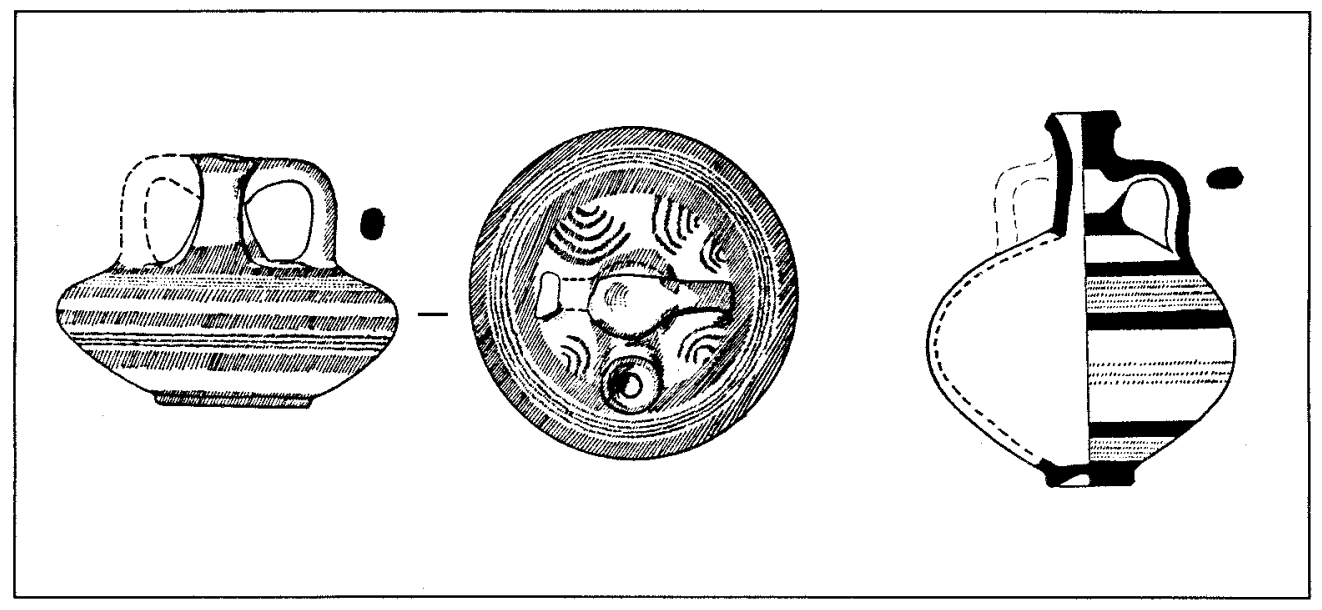

Fig. 7.3 LHIIIA2 (?) stirrup jar (cat. no. 3) and LHIIIA2-LHIIIB flask (cat no. 4) from phase E - After Hankey 1967, 131 fig. 5: nos a, b.

well as wine or other liquid substances. The spatial distribution of these two vessel types indicate restrictions of use to specific buildings at Deir 'Alla: the flasks were found in the treasury, whereas all the stirrup jars occurred in the easternmost building (Fig. 7.2). This spatial separation is contextual as well, because the two buildings have been assigned different functions. From such a distribution it is clear that Mycenaean vessels were restricted to specific functions.

All the Mycenaean vessels at Tell Deir 'Alla are of fine, decorated ware. Only the LH IIIA2 squat stirrup jar of cat. no. 3 has a patterned decoration (Fig. 7.3): five groups of multiple stem and tongue pattern on the shoulder (FM 19). The other vessels, including the imitation stirrup jar of cat. no. 2005, are decorated with bands and lines only. Apparently, only vessels with simple decoration arrived at the site.

\section{SET T LEM E N T C ON TEXT S}

The buildings at Deir "Alla were grouped around the cella, which was built on a raised platform. ${ }^{24}$ The cella and the rooms immediately to the west can be considered as one architectural complex, to which the treasury also belonged, as it was connected to the main building by a courtyard. The easternmost building appears to have been isolated from the main complex and it may be assumed that it fulfilled separate, special functions. ${ }^{25}$ The treasury and the easternmost building are comparable to the cella in the quantities of luxury objects and ceremonial pottery ${ }^{26}$ from which we may conclude that both buildings served official, ceremonial functions. The abundance of utilitarian objects and 'kitchen' pottery in the eastern part of the site in comparison with the cella, however, suggests that the activities conducted here did not have an exclusively cultic character.

24 Franken 1992, 21-22.

pottery classes, including the Mycenaean, which are

25 Franken 1992, 51.

26 Franken tentatively assigns the label 'ceremonial' to all not common at Deir 'Alla; Franken 1992, 164-165. 
Easternmost building (Fig. 7.2) 27 $^{27}$

Three rooms have been excavated from the easternmost building, of which the northern walls have eroded away. There is evidence of another room east of Room 1. In Room 1 three Mycenaean stirrup jars have been found, associated with local dippers and bowls, a fenestrated pot, some cylinder seals and beads. Because this inventory compares well with that of the cella, this room has been interpreted as a space designated for ritual practices of some kind. The most numerous class of artefacts in the room, however, was a large number of 'spindle whorls' made of bone. ${ }^{28}$ Such objects were not found in the cella. In Room 2, which has been interpreted as a kitchen, a Levantine derivative of a Mycenaean stirrup jar has been found, associated with many local bowls. Room 3 did not yield any Mycenaean pottery. Because the ceramic inventory of this room compared well to that of Rooms 7 and 8 , Room 3 has been interpreted as a pantry or storeroom.

The three Mycenaean stirrup jars were found in the room which was richest in finds, indicating that these vessels were among the highly valued items used in this building. The spatial separation of the original Mycenaean vessels from the Levantine derivative, which may have been a regional import, suggests that the inhabitants were, at least to a degree, aware of the differences in origin of the vessels. The fact that the imitation stirrup jar was found in an archaeological context with far fewer luxury objects than that of the originals indicates that original Mycenaean vessels enjoyed a higher appreciation than regional derivatives.

Treasury (Fig. 7.2) $)^{29}$

The treasury consisted of at least three rooms, two of which (rooms 4 and 5) have been excavated (almost) completely. Room 6 extended further to the south. The two Mycenaean flasks reported from this building, were both found in Room 5, where they were associated with local ceremonial and domestic pottery, some alabaster objects, three administrative tablets, three seals and a large number of beads. The fact that this room is considered old by the excavators relates well to the ceramic styles of the Mycenaean vessels (LH IIIA2-LH IIIB1), which must have been at least fifty years old at the time of their deposition..$^{30}$

The rich inventory of Room 5 is paralleled by that of Room 4 and 6, which have likewise produced administrative tablets, ceremonial pottery, seals and beads. A functional differentiation between the rooms cannot be made and the significance of the two Mycenaean vessels in Room 5 cannot be assessed. However, the presence of the two Mycenaean flasks in this material environment shows that they were highly valued.

27 Franken 1961, 366-368; 1992, 38-53.

28 Franken (1992, 165) lists ten spindle whorls from Room 1, which makes this the most numerous class of artefact in the room. The small size of these objects and the fact that they were made of bone suggests that they may have been used as beads rather than for spinning activities. Elsewhere at Deir 'Alla, in Rooms 2, 7 and 8 these objects occurred only in one or two specimens per room.

29 Franken 1992, 53-66.

30 According to G. Van der Kooij (pers. comm.), the accumulation of soil outside of the building could have taken place in only a few years, depending on the particular erosion patterns on this part of the site. 


\begin{tabular}{|c|c|c|c|c|c|c|c|c|c|c|c|c|c|}
\hline & R1 & R2 & R3 & R4 & R5 & R6 & Cella & R7 & R8 & R9 & R10 & sw & elsewhere \\
\hline Aegean & $x$ & $x$ & & & $x$ & & & & & & & & \\
\hline Egyptian & $x$ & & & $x$ & $x$ & $x$ & $x$ & $x$ & & & & $x$ & \\
\hline Syrian & & & & & & $x$ & $x$ & & & & & & \\
\hline Cypriot & & & & & & & & & & & & & $X(P 700)$ \\
\hline Tablets & & & & X & $x$ & $x$ & & & & & & $x$ & \\
\hline
\end{tabular}

Table 7.2

\section{THE ROLE OF MYCENAEAN POTTERY IN THE MATERIAL CULTURE} OF DEIR 'A L L A

Mycenaean ceramic vessels are the only imports at Deir 'Alla which can be identified as coming from the Aegean. In addition, three fragments of Cypriot White Slip II milk bowls have been discovered, while a fourth sherd is likewise labelled as Cypriot. ${ }^{31}$ A number of cylinder seals from northern Syria have been found, as well as a variety of objects from Egypt, such as seals, faience amulets, scarabs and a faience vessel. ${ }^{32}$ The spatial distribution of these imports at the tell is indicated in Table 7.2. ${ }^{33}$ From this table it is clear that, of all imports, Egyptian objects are most widely distributed, as they have been found in many rooms, as well as in the south-western area. ${ }^{34}$ In contrast, the Syrian, Mycenaean and Cypriot finds are concentrated at a few find spots. In terms of quantity, the imports from Egypt far outnumber those from other regions. Moreover, the variety of objects is larger as well: beads, seals, scarabs, amulets and faience and alabaster vessels have been reported as Egyptian objects, while from Syria only cylinder seals have been discovered and from the Aegean and Cyprus only ceramic vessels. It seems that the relations of Late Bronze Age Deir 'Alla with Egypt were particularly strong. This comparison with other imports suggests that the restricted use of Mycenaean vessels was comparable to other imports from far-away regions with which contact was infrequent. As was already suggested in reference to the difference in archaeological context between the original Aegean stirrup jars and the Levantine imitation, the origin of the vessels appears to have influenced their appreciation.

Investigation of the fabrics of the Levantine pottery found at Deir 'Alla has established that a substantial proportion of the vessels can be considered regional imports. ${ }^{35}$ These regional imports have

3I Franken 1992, 131, 134 Fig. 7-13 nos. 42-46. In addition, a WSII sherd was found in later levels; G. Van der Kooij, pers. comm.

32 Van der Kooij \& Ibrahim 1989, 80.

33 After Franken 1992; Ibrahim \& Van der Kooij 1997. Only objects of which the imported character is certain are included in this table. The Syrian objects are all cylinder seals. More seals have been found, in par- ticular in Room 4, which may have a North-Syrian origin. If so, R4 should be added to the table as a find spot of Syrian objects.

34 Ibrahim \& Van der Kooij (1997, 104 Fig. 10.2) report an Egyptian seal impression on a possible jar stopper.

35 Franken (1992, 105-114) distinguishes eight different wares, of which the groups $\mathrm{C}-\mathrm{H}$ are definitely not produced locally, while this is possibly the case for group 
been found at many places at the site and can be considered as consistent elements in the material culture of Deir "Alla. ${ }^{36}$ The regional wares and the pottery that was locally produced include a large range of vessel types, among which small containers for liquids are represented as well. ${ }^{37}$ From a functional point of view, therefore, the Mycenaean pottery does not stand out in the total ceramic repertoire of Deir "Alla. From the perspective of the quality of the fabrics, however, the vessels produced in the Aegean are completely different. In the southern Levant, potters returned to using the slow wheel during the Late Bronze Age, whereas they had been using the fast wheel during the Middle Bronze Age. ${ }^{38}$ Towards the end of the Bronze Age, much of the art of potting was lost in the region of Deir 'Alla: painted decoration over one or two slip layers was no longer practised and light-weight pots with thin walls were no longer produced. ${ }^{39}$ In such a ceramic environment, the Mycenaean stirrup jars and flasks represented high-quality ceramic products.

The decline in the quality of local ceramics has been tentatively related to the influx of substantial quantities of Aegean and Cypriot ceramics by A. Leonard. ${ }^{40}$ The evidence of Deir 'Alla does not support this hypothesis, because the number of imported vessels from these areas is very low indeed. Rather, the decline in pottery technology may be related to a changing role of pottery in the societies in Palestine during the Late Bronze Age, because of which there was no widespread use for fine wares. ${ }^{41}$ For a religious institution such as the sanctuary at Tell Deir 'Alla, in which customs and traditions may have survived over a very long period, ${ }^{42}$ it may have become increasingly difficult to acquire fine ware vessels. The high value ascribed to the Mycenaean vessels at Deir 'Alla should perhaps be seen in this light.

At the end of the 13th and in the 12th centuries BC, there was a substantial production of Aegeantype stirrup jars in the southern Levant. ${ }^{43}$ Analyses of such vessels at Tell Nami (site no. 200) and Tell Miqne-Ekron (site no. 225) suggest that these vessels were involved in regional exchange. It is possible that the stirrup jar of Levantine manufacture discovered in Room 2 at Deir 'Alla arrived at the site through such regional trade. However, it is also conceivable that the high value of the imported stirrup jars stimulated local potters at Deir 'Alla to try and imitate them.

Despite the numerous imports, the material record of Deir 'Alla suggests that the settlement was under the control of population groups living in Transjordan. ${ }^{44}$ The abundance of Egyptian imports indicates that the site should be interpreted in the context of trade between Egypt and Gilead. ${ }^{45}$ The evidence from the regional pottery imports suggests that Deir 'Alla was the focal point for a number of regional exchange networks. At such a point, products from Transjordan could be exchanged with regional traders from Palestine and Egypt. ${ }^{46}$ The Mycenaean, Cypriot and Syrian objects found at

D.

36 Franken 1992, 108-109.

37 Franken $(1992,164)$ reports twenty-one small jugs among the registered pottery. In addition, pilgrim flasks, one of which with pictorial decoration, have been found in Rooms 4 and 6 and in the cella, see Franken 1992, 55 no. 28; 29 no. 11; 64 nos. 10-11.

$3^{8} \quad$ Knapp et al. 1988; Franken 1992, 149-152; Van der Steen 1997, 89.

39 Franken 1992, 152.

40 Leonard 1981, 91.

4I Knapp et al. 1988, 89.
42 Soundings in the cella have determined that the first building phase of the temple should be dated in the first phase of the Late Bronze Age, which means that the building must have been in use for at least four centuries.

43 Leonard et al. 1993, 119; Killebrew 1998, 161-163.

44 Franken 1992, 174-175.

45 Van der Steen 1996, 66; Franken (1992, 178-179), who interpreted the site as a free-standing sanctuary, goes so far as to suggest that it was founded through Egyptian initiative.

${ }^{46}$ Franken 1992, 178. 
Deir 'Alla can be interpreted as objects from international exchange networks, which had entered these regional systems.

A number of sites with Late Bronze Age remains have been identified on the East Bank of the Jordan river. ${ }^{47}$ The site nearest to Deir 'Alla from which Mycenaean pottery has been reported is Tell esSaidiyeh (site no. 191). The architecture and burial customs at this site indicates that it was under Egyptian control during the later part of the 13th and the earlier part of the 12th century BC. ${ }^{48}$ In this respect, it may be compared to the site of Beth Shean (site no. 187) some $30 \mathrm{~km}$ to the north, which was the location of an Egyptian military garrison. ${ }^{49}$ Mycenaean finds from Tell es-Saidiyeh derive from the tombs at the lower tell, as well as from the settlement remains of stratum XII at the upper tell..$^{50}$ Evidence of Egyptian influence is also clear at Pella (site no. 190), where a so-called 'Governor's Residency', as well as sarcophagi tombs have been found; Mycenaean pottery has been reported from the floor of this 'Residency', as well as from Late Bronze and early Iron Age layers elsewhere on the site. ${ }^{51}$ In addition, some Late Bronze Age tombs have produced such vessels.

Further to the east, where Egyptian influence was less strong, Mycenaean pottery has been found in a sanctuary context at the Amman Airport site (site no. 194). Hankey estimates that a total of fifty to sixty Mycenaean pots were found at the Amman airport site. ${ }^{52}$ Even though the religious nature of the square building has been contested, ${ }^{53}$ the large number of imported objects and burned bone make it clear that the Mycenaean pottery was used in situations of a highly symbolical nature. Moreover, the fact that Mycenaean sherds in LH II style were found in this building which is thought to have been used for a short period in the 13th century BC only suggests that the Mycenaean vessels were specially selected to be brought to the building. ${ }^{54}$ All this points to a special significance for Mycenaean ceramics, which is in agreement with the conclusions for this type of pottery found at Deir 'Alla.

At other places in Transjordan, Mycenaean pottery has mainly been reported from funerary contexts. In Tell Irbid (site no. 189), Madaba (site no. 197) and Umm ad-Dananir (site no. 193) such ceramics were found in tombs. ${ }^{55}$ As for settlement contexts, Mycenaean vessels have been reported from Sahab (site no. 195) in association with a city wall, probably dating from the end of the thirteenth century. ${ }^{56}$ The evidence from Sahab, as well as from Deir "Alla, suggests that the paucity of Mycenaean finds from settlement contexts in Transjordan is due to the absence of large-scale excavations of settlement sites. It is as yet unclear whether the special significance of Mycenaean pottery evident from Deir 'Alla can be parallelled at other settlements in Transjordan.

47 Van der Steen 1996, 53, 61-63.

${ }_{48}$ Tubb 1990, 99-100, 105; 1997, 452-453.

49 James \& McGovern 1993, 235-248.

so Hankey 1967, 129; Pritchard 1980, 4-5; Tubb 1990; 1997. Stratum XII is dated to the 12 th century BC.

sI Hankey 1967, 128; McNicoll et al. 1992, 67, 87; Bourke 1997, 108.

s2 Hankey 1974, 133; 1995b; McGovern 1992, 180.

53 Fritz 1971; Herr (1983) argues for a function as a crematorium.
54 Hankey 1974, 131; according to Van der Steen (1996, 57), the local pottery suggests a date in the transitional period from the Bronze to the Iron Age, e.g. in the 12 th century BC.

55 Dornemann 1983, 21 (Tell Irbid); Harding \& Isserlin 1953, 32 (Madaba); McGovern 1986, 13-16; Koehl 1986, 194-198 (Umm ad-Dananir).

56 Ibrahim 1997, 451. At least some of these sherds appear to have been Levantine derivatives of Mycenaean ware. 



\title{
8 The cultural significance of Mycenaean pottery in the Levant
}

\author{
I N T R O D U C T I O N
}

The detailed contextual analyses of the Mycenaean pottery at Ugarit, Hazor and Deir 'Alla enable a discussion of the use and appreciation of Mycenaean pottery in the Levant in general. The evidence from other find spots of Mycenaean pottery in the Levant will be discussed here in order to check how representative the conclusions reached for Ugarit, Hazor and Deir 'Alla are. Before discussing the social groups in the Levant who used Mycenaean pottery, their appreciation of different parts of this class of material and its social significance, I will briefly comment on the repertoire of Mycenaean pots and figurines itself.

\section{Y C E NA E A N REPERTOIRE}

From the preceding chapters it has become clear that Ugarit has yielded a wider repertoire of Mycenaean pottery than Hazor and Deir 'Alla. The large quantity of Mycenaean vessels at Ugarit is paralleled only at other coastal cities. From Tell Abu Hawam (site no. 175) some 700 Mycenaean finds have been reported. ${ }^{1}$ Excavations in a very limited area at Sarepta (site no. 162) produced some 130 Mycenaean finds, ${ }^{2}$ while a nearby tomb had earlier yielded another 67 Mycenaean vessels. The variety of Mycenaean vessel types at Ugarit is paralleled only at Tell Abu Hawam, where a similar range of storage and dinner vessels have been found, as well as rhyta and Mycenaean figurines. ${ }^{3}$ Another similarity between these two sites is the predominance of dinner vessels. ${ }^{4}$ Ashdod (site no. 222), also a coastal settlement, is the only other site in the Levant with a majority of Mycenaean dinner vessels. ${ }^{5}$

I Balensi 1980, 423, 490. All derive from levels $\mathrm{V}$ and IV. In addition, thirty-seven Minoan pieces have been reported from this site, see Balensi 1980, 499-510.

2 Koehl 1985, 37-43; Anderson 1988, 267-274; Baramki 1958, 129-142. Soundings X and Y together comprise less than 700 sq.m., see Khalifeh 1988, 356 Plate 2.

3 Balensi 1980, 422-498. Among the Mycenaean storage vessels, all groups from Table I are represented at Tell Abu Hawam. Among dinner vessels narrow-necked jugs, spouted cups and bowls are the only vessel groups absent. Rhyta have been found in conical and zoomorphic shape, while Tell Abu Hawam and Ugarit are the only sites in the Levant where ring-kernoi have been found; see Leonard 1994, 89. In comparison with
Ugarit, Mycenaean figurines are infrequent at Tell Abu Hawam: only eleven have been reported, among which are eight Psi-type female figurines and three bovines.

4 Balensi 1980, 498. As at Ugarit, the predominance of dinner vessels is due entirely to the large number of LH IIIB vessels of this type.

5 Leonard 1994, 203; Dothan \& Porath 1996, 31-36, 48, 58. The figures provided by Leonard show that fragments from which the vessel type cannot be determined (23) constitute more than a third of the total (60) of Mycenaean finds at Ashdod, which argues for some caution in this respect. 
At all other sites storage vessels are more frequent. ${ }^{6}$ This is also the case at Sarepta, which has yielded a great quantity of stirrup jars in particular. ${ }^{7}$ A conical rhyton, a wide range of cups and bowls, as well as female, bovine and chariot figurines testify to the varied character of the Mycenaean repertoire at Sarepta.

It appears that the repertoire of Mycenaean vessels and figurines is generally larger and more varied at coastal centres than at inland sites. Such a distribution pattern has been explained by suggesting a model of the circulation of Mycenaean pottery involving 'ports of trade'. ${ }^{8}$ In this model, Mycenaean pottery arrived in the coastal towns, where a first choice was made of items which were to remain there. A more limited repertoire was then distributed to secondary centres, where a similar process took place. The repeated sequence of choice and further distribution in such a model would result in a diminishing of quantities and a narrowing of vessel types in the repertoire of Mycenaean pottery the further down the line of exchanges a site was incorporated in the system.

This model of 'ports of trade' would explain the large quantities and wide variety of Mycenaean pottery at Ugarit and Tell Abu Hawam. However, there are a number of situations relatively far away from the coast where a wide variety of Mycenaean vessels has also been found. Such is the case at the Amman airport site (site no. 194), where finds included a LH II piriform jar, as well as a variety of dinner and storage vessels from the LH III period. ${ }^{9}$ The Late Bronze Age temple at Kamid el-Loz (site no. 168) produced thirteen specimens of Mycenaean pottery, among which were storage and dinner vessels, zoomorphic and conical rhyta, along with a female figurine. ${ }^{10}$ Two Mycenaean conical rhyta, a zoomorphic rhyton, as well as a score of dinner vessels and figurines were found in a building associated with ritual activities at Tell Sera' (site no. 237). ${ }^{11}$ At Hazor, the three graves from the Late Bronze Age yielded a more varied Mycenaean repertoire than that found in the settlement levels. A similar situation may be seen at Tell Dan (site no. 170), where the 'Mycenaean tomb' produced a rich collection of Mycenaean dinner and storage vessels. ${ }^{12}$

These examples indicate that sites situated far from the coast could have access to a wide range of Mycenaean vessels and figurines. The differences in the Mycenaean ceramic repertoires between large coastal cities such as Ugarit and Tell Abu Hawam on the one hand and inland sites such as Hazor on the other cannot solely be attributed to factors of availability. At Deir 'Alla, Mycenaean stirrup jars and flasks were found in contexts which attest to a high regard for these vessels. The same pottery types are quite common at Ugarit and Hazor, where they predominate in average domestic contexts. This suggests that the variability in the Mycenaean repertoire at Levantine sites is related to differences in the use and appreciation of this material. This may also be inferred from the fact that varied deposits of Mycenaean pottery were found in temples at Tell Sera', Kamid el-Loz and the Amman airport site, and in tombs at Hazor and Tell Dan. Each of these contexts represent situations of a high symbolical content.

A high regard for specific Mycenaean vessel types may, of course, be related to their availability, which is determined by the distribution of these types according to the 'port of trade' model. However, in many societies the flow of specific goods is closely related to existing power structures,

\footnotetext{
Figures taken from Leonard 1994, 201-211.

Koehl $(1985,37-43)$ lists more than fifty stirrup jars.

Renfrew 1972, 465-471; Gilmour 1992, 118-120.

9 Hankey 1974.

Io Hachmann 1980, 43, 84, 88, Tafels 5, 24-27; 1982, 33,

Tafels 5, 6, 8 .
}

II $\quad$ Oren \& Netzer 1974, 265.

I2 Biran 1994a, 111-116. The Mycenaean finds from settlement levels at Tell Dan have not been fully published, because of which it is impossible to compare them with the funerary finds. 
because the effectiveness of specific material goods to serve in consumptive strategies which reproduce the identity of consumers is determined by dominant groups in society. ${ }^{13}$ The subject of access to a wide range of Mycenaean vessel types is, therefore, itself connected to the use and appreciation of these vessels in the places where they were acquired.

\section{SOCIAL GROUPS TO BE ASSOCIATED WITH MYCENAEAN POTTERY}

The evidence from Ugarit and Hazor indicates that Mycenaean pottery, as a general class of material, was widely used by various social groups in these cities. The widespread use of Mycenaean pottery among urban population groups is evident at other sites in the Levant as well. Many of the Mycenaean finds reported from Alalakh (site no. 137) cannot be ascribed to architectural structures with certainty, but at least some of them have been found in buildings meant for habitation. ${ }^{14}$ Indeed, in discussing levels Ia - Ic at Alalakh, Woolley states that "...it is certain that in all three phases Mycenaean pottery was freely used" and that "by this time it must have been cheap". ${ }^{15}$ At Tell Sukas (site no. 145) more than fifty Mycenaean sherds were found in three habitation structures. ${ }^{16}$ At Sarepta (site no. 162) soundings in areas $\mathrm{X}$ and $\mathrm{Y}$ revealed Late Bronze Age domestic architecture and industrial installations such as bins and basins. ${ }^{17}$ The structure from levels XVII-XIV at Tyre (site no. 163), likewise associated with domestic and industrial activities, yielded Mycenaean dinner and storage vessels, as well as a female and bovine figurine. ${ }^{18} \mathrm{~J}$. Balensi's study of the finds made by R.W. Hamilton in the 1930s at Tell Abu Hawam (site no. 175) showed that Mycenaean pottery was widespread there too. ${ }^{19}$ In stratum V (phases V2-áV) such pottery occurred in almost all structures, among which were residential houses and buildings testifying of industrial activities. ${ }^{20}$ The distribution of Mycenaean pottery at Megiddo (site no. 181) has recently been analysed by A. Leonard and E. Cline. In strata VIII-VIIA this material was concentrated in areas AA and CC, associated with a palace and with residential structures respectively. ${ }^{21}$ Even though such an unequal distribution pattern indicates that Mycenaean pottery was not used widely among the inhabitants of Megiddo, the finds from residential contexts as well as from a palace suggest that various social groups made use of these vessels. At Ashdod (site no. 222) Mycenaean cups, kylikes and stirrup jars were recovered from the stratum 2 structure in area B. ${ }^{22}$ On the basis of the presence of a courtyard, silos, storage pits and three ovens, this structure may be interpreted as a domestic structure, possibly with industrial associations. Mycenaean pottery has also been reported from the small Late Bronze Age brick houses in area $\mathrm{H}$ at Ashdod. ${ }^{23}$ At Kamid el-Loz (site no 168) a domestic structure just north of the temple produced Mycenaean storage vessels. ${ }^{24}$ The domestic structures found in levels VIII and VII to the south-east of the temple at Beth Shean (site no. 187) yielded eleven Mycenaean vessels, scattered about various rooms and associated with local pottery and a few imports. ${ }^{25}$ Other sites from which Mycenaean pot-

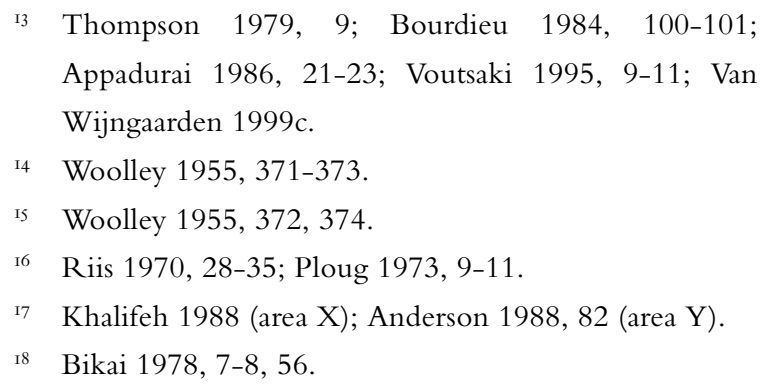

I9 Balensi 1980, 315.

20 Balensi 1980, 25-250.

21 Leonard \& Cline 1998, 3-9.

22 Dothan \& Freedman 1967, 96, Fig. 21.

23 Dothan 1993, 96.

24 Hachmann \& Kuschke 1966, 56; Marfoe 1995, 156, Fig. 101.

25 Hankey 1993c. 
tery has been reported from domestic contexts include Tell Dan (site no. 170), ${ }^{26}$ Pella (site no. 190) ${ }^{27}$ and Bethel (site no. 208). ${ }^{28}$

Mycenaean pottery has also been reported in association with buildings testifying of a certain level of wealth. At Tell Batash (site no. 226) a large structure was excavated in levels VIII and VII, which has been interpreted as a patrician's house, probably belonging to important land-owners in the Sorek valley. ${ }^{29}$ In the destruction layer of the level VII building, dated to the 13th century BC, a LH IIIA2 straight-sided alabastron was found, in association with a Cypriot bull-vase, cylinder seals and scarabs. A building comparable to the one at Tell Batash has been excavated at nearby 'Ain Shems (site no 227), from which Mycenaean pottery has also been reported. ${ }^{30}$ At Aphek (site no. 215), in stratum $\mathrm{X} 13$, which has been dated to the second half of the thirteenth century BC, a wealthy structure was built in the south-western corner of the area where a palace had stood previously. ${ }^{31}$ This building is the earliest example of a so-called 'Governor's residency', a type of building that has been associated with an Egyptian administrative presence in Palestine. ${ }^{32}$ A Mycenaean stirrup jar was found in this building, associated with local and Egyptian bowls, as well as with Cypriot White Slip II bowls. ${ }^{33}$

At Ugarit, the ruling élite did make use of Mycenaean pottery, albeit not to a greater extent than other inhabitants of the city. At Ras Ibn Hani (site no. 143) two large buildings have been excavated, which can be associated with the royal court of Ugarit. ${ }^{34}$ The largest of these buildings, the Palais Sud, was apparently cleared out before the end of the Late Bronze Age. Even though, as a result, very few finds were made, a fragment of a LH IIIB amphoroid krater as well as two Mycenaean sherds have been reported from this building. ${ }^{35}$ The second structure at Ras Ibn Hani, the Palais Nord, yielded a number of cuneiform tablets which made clear that the inhabitants had a kinship relationship with the royal family of Ugarit. ${ }^{36}$ The western part of this building served as a metal workshop, while in the eastern part habitation quarters were situated. In the courtyard between these two parts three fragment of Mycenaean stirrup jars were found, while a LH IIIB amphoroid krater was discovered in one of the habitation quarters. ${ }^{37}$ The tomb associated with the Palais Nord, of the same architectural type as those found in the capital of Ugarit, produced a Mycenaean amphoroid krater, along with two stirrup jars, one of which was of the large, coarse ware variety (FS 164)..$^{38}$

The Mycenaean vessels from the settlement levels of the two palaces at Ras Ibn Hani indicate that the social groups attached to these structures made use of such material. The presence of metal working facilities at the Palais Nord suggests that some of the Mycenaean pottery found in this structure may be associated with people working in the building, rather than with the inhabitants themselves.

26 Biran 1994a, 120; 1994b, 8.

27 McNicoll et al. 1992, 67, 87 (area II); Bourke 1997, 108.

28 Kelso 1968, 28-31, Plate 37: nos. 11-14.

29 Kelm \& Mazar 1995, 63-64.

30 Bunimovitz \& Lederman 1993, 249; Leonard 1994, 202.

${ }^{3} \quad$ Beck \& Kochavi 1985, 29-30.

32 Oren 1984, 49-50. The majority of 'Governor's Residencies' date to the twelfth century BC. According to Bryan $(1996,38)$ these buildings do not necessarily imply an Egyptian administrative presence, but may be the result of Egyptianising trends among the local Canaanite population.

33 Beck \& Kochavi 1985, 35-36.

34 Lagarce 1982; Lagarce et al. 1983; Bounni et al. 1987.

35 Bounni, et al. 1976, 275-276, Fig. 26 nos. 2-4.

36 Lagarce et al. 1983, 257; 277-278. According to the tablets found in the Palais Nord, the building belonged to a queen, perhaps the mother of king Ammistamru II (1260-1230 BC).

37 Bounni et al. 1979, 240, fig 19 nos. 2-4; 1981, 293, Fig. 53.

38 Toueir 1975. 
In comparison with other buildings at Ugarit, such as those in the recently excavated Centre Ville, the Mycenaean pottery reported from the palatial structures at Ras Ibn Hani is by no means abundant. Apparently, social groups associated with the royal palace did not make more extensive use of Mycenaean pottery than other groups in Ugaritic society. This may also be concluded from the three Mycenaean finds from the tomb at Ras Ibn Hani. These may be compared to similar quantities in the majority of tombs at Ras Shamra, including those in the royal palace. Even though Mycenaean pottery, apparently, was considered suitable to be included in the funerary inventories of high-level social groups, the quantities from these tombs are by no means extraordinary. The evidence from Ras Ibn Hani, therefore, seems to confirm the conclusions for the royal palace of Ugarit itself.

At Alalakh (site no. 137) a LH IIIA piriform jar has been reported from room 16 in the palace uncovered in level V (Niqme-pa's palace). ${ }^{39}$ From the palace in level IV at this site, probably to be dated to the 13th century BC, no Mycenaean pottery has been published, but fragments of a piriform jar, a jug and two stirrup jars have been reported from the area of the palace in strata III-I. ${ }^{40}$ Because of the likelihood that many finds from Alalakh remain unpublished, the evidence of this site is difficult to interpret, and the only statement to be made is that here too Mycenaean pottery has some association with the ruling élite.

A succession of palaces from the beginning to the end of the Late Bronze Age was found at Kamid el-Loz (site no. 168) in levels P1-P5. ${ }^{41}$ The so-called 'Schatzhaus' of the palace was actually a tomb from the first building phase, which during stratum P5 was restructured as a storage room..$^{42} \mathrm{~A}$ great many imports from various regions have been reported from the early phases of this structure, among which was a LM IB bridge-spouted jar. A fragment of a Mycenaean stirrup jar was discovered in the palace workshops. ${ }^{43}$ The only other Mycenaean find from a palatial context at Kamid el-Loz is a straight-sided alabastron, possibly of Levantine manufacture. ${ }^{44}$ In comparison with the temple excavated at Kamid el-Loz (see below) and with other settlement structures (see above), the quantity of Aegean finds from the palace area is relatively small. Moreover, the stirrup jar found in the area of the palace workshops indicates that this vessel was associated with artisans working at the palace rather than with the royal court itself. All this is in agreement with the evidence from Ugarit and Ras IbnHani that social groups connected to the palace did have access to Mycenaean pottery, but did not make more extensive use of it than other urban social groups.

A palatial structure, building 2041, has also been excavated in levels VIII-VIIA at Megiddo (site no. 181). ${ }^{45}$ From the stratum VIII palace a LH IIIB stirrup jar as well as a body sherd from an amphoroid krater dating to the same period have been reported. ${ }^{46}$ Four of the seven Mycenaean fragments from stratum VIIB at Megiddo were found in palace 2041: a squat stirrup jar, a bovine figurine and a sherd of unidentifiable shape. ${ }^{47}$ Nine Mycenaean finds came from the stratum VII palace. Seven of these,

39 Woolley 1955, 370.

40 Woolley 1955, 110-131; 371-373. These strata were heavily disturbed and some finds may derive from lower levels.

4I Hachmann 1978a; 1978b, 1982; Frisch, Mansfeld \& Thiele 1985; Marfoe 1995, 121-128.

42 Adler 1994, 133, 208-211.

43 Frisch, Mansfeld \& Thiele 1985, 119, Tafel 30.4 no. 118.

44 Marfoe 1995, 147, Fig. 92 no. 4.
45 Loud 1948, 24-29. The absolute dates of these strata have been much debated, see Leonard \& Cline 1998, 3-9.

46 Leonard \& Cline 1998, 3. The amphoroid krater sherd should probably be excluded from this account, as it was reportedly found within a wall, see Loud 1948, 131. A total of thirteen Mycenaean finds from this stratum were made in areas directly outside the palace.

47 Leonard \& Cline 1998, 5-7 
four globular flasks, two stirrup jars and a stemmed cup, occurred in a small tripartite building connected to palace 2041 during this phase. Elsewhere in the building a globular flask and a sherd of unidentifiable shape were found. From this account it is clear that Mycenaean vessels were in use among the residents of palace 2041.

At Hazor, finds from the recently excavated palace have not yet been published. The significant amounts of Mycenaean pottery reported from the area adjacent to the palace (area A), however, indicates that Mycenaean pottery was used by the social groups associated with official structures. This picture seems to be confirmed by the discussion above of Mycenaean pottery found in structures at other sites which can be associated with local ruling élite groups. At the same time, however, it is clear that at none of these sites Mycenaean pottery appears to be concentrated in the palaces.

Mycenaean pottery has been found at Ugarit and Hazor in contexts which testify of religious practices. At Kamid el-Loz (site no. 168), a large structure with two courtyards has been excavated, that has been interpreted as a temple dating to the Late Bronze Age. A variety of Mycenaean open and closed vessels, conical and zoomorphic rhyta, as well as a female figurine have been found in this building, in association with cultic objects such as a group of snake figurines. ${ }^{48}$ At Tell Abu Hawam (site no. 175), a large number of Mycenaean dinner vessels, as well as some storage vessels, a zoomorphic rhyton and a kernos were found in the first deposit of temple 50, associated with Cypriot, Egyptian and local ceramics and with objects such as faience pearls, steatite cylinder seals and bronze knives. ${ }^{49}$ A later deposit in the same temple produced three LH IIIB drinking vessels, similarly associated with Cypriot, Egyptian and local wares and with faience and bronze objects. ${ }^{50}$ In the level VII and VIII temple precinct at Beth Shean (site no. 187) a mixed Egyptian and Syro-Palestinian cult was practised..$^{51} \mathrm{~A}$ total of seventeen Mycenaean vessels can be associated with this temple: thirteen storage and four dinner vessels. Of particular interest is a group of five vessels found below the temple floor in association with Egyptian and Levantine cultic objects..$^{52}$ This deposit has been interpreted as a foundation offering and it shows that Mycenaean pottery could be part of ceremonies of a highly symbolical nature. At Tell Mevorakh (site no. 203) a succession of temples from the Late Bronze Age were excavated on a small mound. ${ }^{53}$ Because no contemporary settlement was discovered, the building at Tell Mevorakh has been interpreted as an isolated sanctuary site. In stratum X of this building fourteen Mycenaean sherds were discovered, all from LH IIIA2 storage pots. ${ }^{54}$ It is uncertain whether the square building at Amman Airport site (site no. 194) can be interpreted as a temple. ${ }^{55}$ The nature of the archaeological material discovered in the square building, which included a large and varied body of Mycenaean pottery, however, indicates that activities of a symbolical nature were practised here. In the so-called 'Fosse temple' at Lachisch (site no. 230) a LH II one-handled cup was part of a group of objects discovered on a bench altar. ${ }^{56} \mathrm{~A}$ LH II goblet was found elsewhere in the temple area. ${ }^{57} \mathrm{~A}$ Mycenaean chariot krater was discovered in the central hall of the acropolis temple at the same site. ${ }^{58}$

48 Hachmann 1980, 43, 84, 88, Tafels 24-26; 1982, 33, Tafels 5, 6, 8 .

49 Balensi 1980, 83-84.

so Balensi 1980, 88-89.

sI Hankey 1993c; James \& McGovern 1993, 239-240.

s2 Hankey 1993c; James \& McGovern 1993, 7, 12. The Mycenaean repertoire in this deposit consisted of a piriform jar, a small jug, a stirrup jar, a globular flask and a deep bowl.

53 Stern 1984.

54 Hankey 1984, 20.

55 Fritz 1971; Hankey 1974; 1995b, 172-173; Herr 1983 , 225-229

56 Tufnell 1958, 211-212; Hankey 1981b, 109.

57 Kantor 1947, 36; Stubbings 1951, 56.

s8 Ussishkin 1993, 901. 
At Tell Sera' (site no. 237) building 1118 has also been interpreted as a structure in which cultic activities were practised. ${ }^{59}$ On the floor of stratum $\mathrm{X}$ of this building, dated to the thirteenth century BC, two Mycenaean conical rhyta and a hedgehog rhyton were found together with a variety of Egyptian imports, Syrian cylinder seals and Cypriot vessels. ${ }^{60}$

It is clear that Mycenaean pottery can be associated with Levantine cultic practices. The religious structures at Hazor, Kamid el-Loz, Beth Shean and Lachisch which have produced Mycenaean pottery can be classified as urban, monumental temples, to be related to the official religion at state level ${ }^{61}$ Each of these temples is structurally separated from surrounding buildings and possesses at least one courtyard and a number of associated storage rooms. It may be expected that professional priests were attached to these temples, with whom the Mycenaean pottery can be associated. The same may be true for the temples at Tell Mevorakh and Amman, which were free-standing. The Temple au rhytons at Ugarit is an example of a structure in which cult was practised at a lower level of society. Building 1118 at Tell Sera', with a large silo and a number of refuse pits, may possibly be interpreted as a shrine as well. ${ }^{62}$ These two examples show that Mycenaean vessels could also be used in religious practices of a less official nature. The evidence from Hazor, where smaller religious structures in habitation areas did not produce Mycenaean ceramics, however, indicates that this was not always the case.

This overview of Levantine sites with Mycenaean pottery appears to confirm the conclusions drawn in the chapters on Ugarit and Hazor. Mycenaean pottery was widely used by different social groups in the urban communities of the Levant. It was a fairly common class of material in a wide variety of urban contexts. The case of Deir 'Alla, however, shows that not everywhere Mycenaean pottery was a common class of material used by different social strata. The special significance of such pottery at Deir 'Alla may, in a different way, be reflected at the Amman Airport building. Large quantities of Mycenaean vessels were specially selected to be brought to the square structure. ${ }^{63}$ At a few other sites too, Mycenaean pottery has been found in small numbers in contexts which indicate that these vessels were highly appreciated. In the patrician's residence at Tell Batash (site no. 226) a single straightsided alabastron was found in an impressive dwelling and associated with a number of other imports. ${ }^{64}$ At the site of Aphek (site no. 215) all the Mycenaean finds were associated with the so-called 'Governor's Residency' and with a tomb found nearby this impressive building. ${ }^{65}$ Likewise, the majority of the Mycenaean finds from settlement levels at Tell Sera' (site no. 237) were found in association with structure 1118, which also produced Egyptian alabaster vases, cylinder seals and faience jewellery. ${ }^{66}$ Each of these sites is comparable with Deir "Alla in the sense that they constitute small regional centres, rather than large urban communities. Moreover, with the exception of Aphek, all of them are situated in the Palestine uplands which, like Transjordan, may be considered as more marginal areas, which during the Late Bronze Age remained relatively independent of Egyptian cultural influence. ${ }^{67}$

59 Oren 1993, 1331.

60 Oren \& Netzer 1974, 265

6I For a distinction in the Late Bronze Age Levant between the official religion at state level, clan cults at the level of clan relations within the urban community and family cults connected to the family, see Van der Toorn 1995a, 48.

62 Oren \& Netzer $(1974,265)$ are in doubt whether to interpret the structure as a residential building or as a sanctuary.

63 Hankey 1974, 131.

64 Kelm \& Mazar 1995, 63.

6s Kochavi 1981, 81; Beck \& Kochavi 1985, 35.

66 Oren \& Netzer 1974, 265; Oren 1993, 1331.

${ }_{67}$ Bunimowitz 1995, 325; Gonen 1992, 32-36. 
Only a few systematic field surveys in the Levant have been published. A survey in the eastern part of the Wadi Arabah showed that Late Bronze Age sites were absent in this area. ${ }^{68}$ This was not the case in the Wadi el Hasá, just south-east of the Dead sea, where three to five MBA-LBA sites were discovered, none with Mycenaean pottery. ${ }^{69}$ From the Kerak plateau in Jordan, 109 LBA sites were reported, most of which consisted of relatively small concentrations of sherds. ${ }^{70}$ Imported ware was not found at these sites. The Judaea, Samaria and Golan surveys in Israel did not yield any Mycenaean finds. ${ }^{71}$ A survey in the lower Galilee mountains, roughly the area between Hazor and Megiddo, resulted in only four Late Bronze Age sites, none of which with Mycenaean finds. ${ }^{72}$ During the regional project in the central Jezreel valley a few sites with small quantities of Mycenaean pottery were investigated, such as Tel Qasis (site no. 176), Tell Qiri (site no. 177) and Tell Yoqne'am (site no. 178). ${ }^{73}$ Each of these sites may be interpreted as a small regional centre. A number of smaller Late Bronze Age sites that without Mycenaean pottery were identified in this region.

It appears that a widespread use of Mycenaean pottery among different social groups is characteristic mainly for the urban culture of the Late Bronze Age Levant. At smaller regional centres these vessels appear to have been scarce, while they seem absent at rural sites. The evidence from Deir 'Alla, Tell Batash and Aphek indicates that at smaller regional centres Mycenaean pottery was restricted to specific, wealthy social groups.

\section{DIFFERENTIATION WITHIN THE REPERTOIRE OF MYCENAEAN P O T T ERY}

Mycenaean pottery in LH I-LH IIIA1 style, although not abundant, appears to have been restricted at Hazor to areas of an official nature. A similar restriction was not recognised at Ugarit, where such early pottery occurred in various contexts in three different excavated parts of the site. As was made clear in chapter 2, Minoan and Mycenaean pottery from the first part of the Late Bronze Age has been reported from twenty sites in the Levant, both on the coast and more inland. Even though this is less than a fifth of the number of sites in the Levant with Mycenaean pottery from all periods, it is noteworthy that vessels in LH I-LH IIIA1 have been found in all regions in the Levant. ${ }^{74}$ Such a distribution pattern indicates that, even though not numerous, this material circulated widely and was not spatially restricted in a regional sense.

The specific contexts of many of the early Aegean finds in the Levant is not known. Sherds in LH IIB-LH IIIA1 style from Ras el-Bassit (site no. 139) were found in a large structure from the second phase of the Late Bronze Age, indicating that these vessels may have been in use for a long time. ${ }^{75} \mathrm{~A}$ LH IIB semi-globular cup was found at Sarepta (site no. 162) in a settlement context belonging to period I, which has been dated to before $1450 \mathrm{BC} .{ }^{76}$ Four additional sherds in LH II style were found in levels belonging to period II (ca 1450-1350 BC). At Kamid el-Loz (site no. 168), a LM IB bridgespouted jar has been found in the funerary chamber of the so-called 'Schatzhaus', in association with

68 McDonald 1992, 71.

69 McDonald 1988, 155-170.

70 Miller 1991, 189-190; 308-309.

${ }^{71} \quad$ Kochavi (ed.) 1972.

72 Gal 1992, 56.
73 Ben-Tor \& Rosenthal 1978; Ben-Tor 1980.

74 See chapter 2 and map 3.

75 Courbin 1986, 181-183.

${ }^{6}$ Koehl 1985, 37-38; Khalifeh 1981, 73-81. 
a number of other imports. ${ }^{77}$ At Tell Ta'anek (site no. 183) a LM IB spouted jug was discovered associated with large quantities of Cypriot and Canaanite ceramics in a cave deposit assigned to the LB I period. $^{78}$ A LH IIA piriform jar, as well as a similar vessel in LH IIB-LH IIIA1 style and an open vase from the same period have been reported from the airport site at Amman (site no. 194) in a level dated to the end of the 13th century at the very earliest. ${ }^{79}$ The LH II one-handled cup from Lachisch (site no. 230) was found in the vicinity of the altar in the 'Fosse temple', associated with local cultic objects and imports from other areas. ${ }^{80}$ In addition, a LH II goblet was discovered in the area of the temple. ${ }^{81}$

An important conclusion from this overview of LH II-LH IIIA1 pottery in the Levant is that quite a large number of these vessels have been found in contexts which have been assigned a much later date. Even though in some cases this may be due to stratigraphical intrusion, in other cases, such as at the Amman airport building, it is evident that such pottery was still in use centuries after their manufacture. Three hypotheses may be formulated concerning the high age of these vessels. Firstly, they may have been exported when they were already old. Secondly they may have been in circulation for a very long time. Thirdly, they may have arrived at the place of their deposition when they were relatively new and kept for a long time as heirlooms or antiques. At the Amman airport building, which was used for a short period at the end of the 13th to the beginning of the 12 th centuries only, ${ }^{82}$ it is clear that the LH II-LH IIIA1 vessels must have arrived at the site when they were already old. To this site at least, the third hypothesis does not apply. On the other hand, the discovery of Aegean vases in contexts dating to the LB I period at Sarepta, Tell Ta'anek, Kamid el-Loz and Lachisch indicates that during this period pottery from the Aegean did arrive in the Levant, which argues against the first hypothesis.

Taking into account the wide distribution of the Mycenaean and Minoan vessels in early ceramic styles, it is most likely, in my opinion, that imported ceramic vessels could be in circulation for substantial periods of time. The LH IIIA2 stirrup jar in the easternmost building at Tell Deir 'Alla, as well as the two LH IIIA2-LH IIIB1 flasks from the treasury at that site were all found in contexts dating to the beginning of the 12th century. In stratum VIIA at Megiddo a number of LH IIIA vessels have been found, which, likewise, were old at the time of their deposition..$^{83}$ These examples indicate that Mycenaean pottery from later eras could be in circulation for long periods as well.

On the basis of anthropological research it has been postulated that objects in pre-monetary exchange often retain elements of their former owners. ${ }^{84}$ Depending on the status of the owners, such embodiments may superimpose prestige upon the objects. The likelihood that Aegean pottery could circulate for long periods means that these objects may have been endowed with such embodiments. It is therefore to be expected that these ceramics possessed a certain prestige.

It is difficult to ascertain whether Aegean vessels in early ceramic styles were restricted to specific social groups, as appears to be the case at Hazor. The LM IB jar from the 'Schatzhaus' tomb at Kamid el-Loz indicates that this vessel was used by the royal court, while the finds at Tell Ta'anek and Lachisch signify that such pottery could be included in wealthy inventories. The finds at Ras el-Bassit

79 Hankey 1974, nos. 1, 2, 105. In addition, four Mycenaean finds (nos. 6, 7, 100, 106) are assigned by Hankey to LH IIIA1-LH IIIA2.

8о Tufnell 1958, 211-212.
8I Kantor 1947, 36; Stubbings 1951, 56.

82 Hankey 1974, 131; Van der Steen 1996, 57.

83 Leonard \& Cline 1998, 9.

84 See, for example, Gregory 1982, with extensive bibliography. 
were made in the largest building of the site. ${ }^{85}$ The evidence from Ugarit, as well as from Sarepta, however, suggest that at these cities Aegean pottery in early stylistic phases was used by different urban social groups. The restriction of stylistically early Aegean vessels to official, high level contexts does not seem to be a uniform phenomenon in the Levant. Possibly, the length of time during which these vases circulated also plays a role in this respect.

At Hazor Mycenaean dinner vessels appear to have possessed a special significance in comparison with storage vessels, a phenomenon that is not paralleled at Ugarit. It is difficult to investigate whether a distinction between Mycenaean dinner and storage vessels was made in other places in the Levant. At Alalakh (site no. 137) a LH IIIA piriform jar was found in room 16 of Niqme-pa's palace, indicating that a storage jar was used at the uppermost level of the urban society. From the Palais Sud at Ras Ibn Hani (site no 143) a pictorially decorated fragment of an amphoroid krater has been reported, while such a vessel was also found in room VII of the residential part of the Palais Nord. ${ }^{86}$ Stirrup jars have been reported from this building as well, although not from its habitation quarters. ${ }^{87}$ At Tell Sukas (site no. 145) Mycenaean kraters and a number of sherds from open pots of which the exact vessel type is uncertain have been reported from domestic contexts. ${ }^{88}$ These sherds were interspersed with fragments of Mycenaean storage vessels. The site of Sarepta (site no. 162) produced sixteen Mycenaean dinner vessels, a relatively small amount in comparison with the large number of storage vessels. ${ }^{89}$ Each of these sixteen finds was associated with domestic architecture and industrial installations. The domestic and industrial structure excavated at Tyre (site no. 163) also produced dinner and storage vessels. ${ }^{90} \mathrm{~A}$ domestic building at Kamid el-Loz (site no. 168) yielded a number of stirrup jars and two straight-sided alabastra, while a stemmed cup was also found in the area. ${ }^{91}$ In contrast, Mycenaean finds from the temple at this site included kylikes, bowls and rhyta and only a few storage vessels. ${ }^{92}$ The two Mycenaean finds from the palace at Kamid el-Loz are both storage vessels. ${ }^{93}$ At Tell Abu Hawam (site no. 175) a large number of Mycenaean dinner vessels were associated with the cult deposit in temple 50, indicating that such vessels could be part of religious ceremonies. ${ }^{94}$ However, similar vessels have been found in domestic contexts. Among the finds in the palatial building 2041 at Megiddo (site no. 181) were Mycenaean storage as well as dinner vessels, which was also the case in the residential area CC ${ }^{95} \mathrm{~A}$ concentration of eight fragments of amphoroid kraters was found in a single room within a residential building in area CC. These krater fragments indicate that such vessels could be assembled by urban inhabitants. At Beth Shean (site no. 187) only one dinner vessel, an amphoroid krater, was found in the domestic quarters to the south-east of the temple, while four dinner vessels were found in the contemporary sanctuary. ${ }^{96}$ The structure in area B at Ashdod (site no. 222) yielded a large number of Mycenaean kylikes, cups, bowls and kraters, while relatively few storage vessels - all stirrup jars - were found there. ${ }^{97}$

85 Courbin 1986, 181. Nothing, however, is known about the functions of this building, nor is the stratigraphy of the finds altogether clear.

86 Bounni et al. 1976, 240; 1981, 293.

87 Bounni et al. 1979, 241.

88 Ploug 1973, 9-11; Riis \& Jensen 1996.

89 Koehl 1985, 37-43.

90 Bikai 1978, 56; Leonard 1994, 211

9I Hachmann \& Kuschke 1966, 56, Hachmann 1970,
Tafels 20 and 21.

92 Hachmann 1980, Tafels 25-26; 1982, Tafel 6.

93 Frisch, Mansfeld \& Thiele 1985, 119, Tafel 30.4 no. 118. Marfoe 1995, 147, Fig. 92 no. 4.

94 Balensi 1980, 63, 188.

95 Leonard \& Cline 1998, 3-7.

96 Hankey 1993c, 106-107.

97 Dothan \& Freedman 1967, 96 Fig. 21; Dothan 1971, 80, Fig. 35. 
Above, I have argued that the variability in the repertoire of Mycenaean pottery was dependant on the appreciation of the vessels in the places where they were used, which, in turn, was related to the access different sites had to this class of material. In this respect, it is of interest to note that the restriction of Mycenaean dinner vessels to official contexts at Hazor seems to be paralleled at Kamid el-Loz and Beth Shean. Each of these three sites is situated relatively far away from the coast and was dependant on regional exchange for its supply of Mycenaean pottery. A difference in appreciation for Mycenaean dinner and storage vessels cannot be established for large coastal centres and for a regional centre such as Megiddo. However, such centres seem to have been able to restrict the flow of Mycenaean dinner vessels to inland sites. The high regard for dinner vessels attested at sites such as Hazor, Kamid el-Loz and Beth Shean seems to be the result of a strategy of restricted distribution. The case of Deir 'Alla suggests that a similar process took place with respect to storage vessels which were distributed to sites in more marginal areas, such as the Palestine uplands and Transjordan.

In contrast to Ugarit, the sites of Hazor and Deir 'Alla did not yield Mycenaean pictorial pottery. Elsewhere in the Levant, Mycenaean pictorial pottery does occur, even though no other site has yielded quantities comparable to those at Ugarit. ${ }^{98}$ Most of the sites which have produced Mycenaean pictorial pots can be considered as large urban centres, which received a substantial amount of Mycenaean pottery in general. Exceptions to this are a sherd decorated with a chariot from Ras elBassit (site no. 139), which was situated in the territory of Ugarit. ${ }^{99}$ Another exception is the fragment of a chariot krater that has been reported from Sahab (site no. 195) in Transjordan. ${ }^{100}$ It seems then, that Mycenaean pictorial pottery was not very abundant in the Levant and mainly restricted to coastal centres. Indeed, inland centres such as Megiddo (site no. 181) or Beth Shean (site no. 187) have produced very few Mycenaean pots with pictorial decoration. ${ }^{101}$ The Syrian coastal area appears to be an exception, with a relatively large number of these type of vessels, at Ugarit and, very likely at Alalakh (site no. 137)..$^{102}$

At Ugarit, the number of Mycenaean pictorial pots in funerary contexts was quite low and they occurred in different types of tombs. The presence of these type of pots in settlement levels at this site indicated that they were used widely among the urban population and were part of average domestic activities. On this basis, I conclude that Mycenaean pictorial pots did not have a particular cultural significance at Ugarit. The chariot krater from Tell Dan (site no. 170) was found in the so-called 'Mycenaean tomb', in which a varied body of goods were assembled. ${ }^{103}$ At the Amman airport (site no. 194), likewise, two chariot kraters were part of an exceptional body of Mycenaean pots and other objects. ${ }^{104}$ This shows that Mycenaean pictorial pots in these instances were collected together with other Mycenaean pots. Rather than to a special significance of Mycenaean pictorial pottery, the scarcity of these type of vessels at many sites in the Levant appears to be related to the strategies of restricted distribution of which all types of Mycenaean pottery were part.

98 Leonard 1994; Steel 1999a, 805.

99 Courbin 1986, 391 (not illustrated).

Io Ibrahim 1976, 78, Plate 34.3.

ror At Megiddo, a Mycenaean krater has been found, which probably showed a human being, while a few vessels with birds and octopi also occurred; see Leonard 1994, 143, 147, 157. At Beth Shean, only a few vessels decorated with a variety of animals have been found, see Leonard 1994, 46, 157.

Io2 Crouwel \& Morris 1985. Much of the Mycenaean pottery from Alalakh remains unpublished.

Io3 Biran 1970; Gunneweg et al. 1992.

Io4 Hankey 1974, 147-148. 
Among the group of Mycenaean ritual vessels the conical rhyton is the most numerous find in the Levant. According to the figures provided by Leonard, this vessel type (FS 199) has been found at only eight sites. ${ }^{105}$ If functionally related shapes such as domestic funnels (FS 198), ostrich egg rhyta (FS 201) and zoomorphic vases are taken into account, the figure of sites with Mycenaean rhyta grows to eleven. ${ }^{106}$ Even though found at a limited number of places, the area of distribution of Mycenaean rhyta is quite large, reaching as far east as Tell es-Salihyeh (site no. 166). In terms of quantity, however, there is a strong concentration of Mycenaean rhyta at Ugarit, where more than $70 \%$ of all such vessels in the Levant have been found. ${ }^{107}$ The contexts of these vessels at Ugarit clearly shows that this Mycenaean vessel type was highly regarded in that city. ${ }^{108}$

At Tell Kazel (site no. 148) a Mycenaean rhyton was found in an unstratified position, but near a Late Bronze Age pebble floor and brick wall of a probable residential structure. ${ }^{109}$ At Tell Abu Hawam (site no. 175) a Mycenaean rhyton was discovered in the first deposit of temple 50, in association with a number of imports from other areas and objects such as seals and faience beads. ${ }^{110}$ Two more conical rhyta, as well as three of zoomorphic type have been reported as coming from the from the area of this temple. ${ }^{111}$ A conical rhyton was also found at Sarepta (site no. 162) in association with domestic architecture. ${ }^{12} \mathrm{~A}$ hedgehog rhyton, as well as three rhyta of conical type were found in the temple at Kamid el-Loz (site no. 168). ${ }^{113}$ Two of these were discovered in the vicinity of an altar and were associated with Levantine fenestrated pots of similar type as those found at Deir 'Alla. Finally, two Mycenaean conical rhyta and one in the shape of a hedgehog were found in Building 1118 at Tell Sera' (site no. 237), where a number of Egyptian imports and objects such as cylinder seals and ivory inlays were also discovered. ${ }^{114}$

From this overview it is clear that Mycenaean rhyta could be employed in local ritual practices. However, as at Ugarit, such vessels have been found in domestic contexts as well. It seems safe to assume that the high regard for these vessels, which was evident at Ugarit, is paralleled in other areas in the Levant. The widespread occurrence of rhyta in contexts which testify of cultic activities indicates that this high regard was due to the role these vessels could fulfil in Levantine ritual ceremonies. Libations of wine, honey, ghee and milk as part of ceremonies in which the gods were ritually fed had a long history in the Levant. ${ }^{115}$ The concentration of Mycenaean rhyta at Ugarit not only attests to the

ros Leonard 1994, 90-93, map 23: Ras Shamra and Minet el-Beida, Tell Kazel (site no. 148), Sarepta (site no. 162), Kamid el-Loz (site no. 168), Tell Abu Hawam (site no. 175), Ashkelon (site no. 223) and Tell Sera' (site no. 237).

ro6 Domestic funnels (FS 198) have only been found at Tell Abu Hawam (site no. 175), see Leonard 1994, 90. Ostrich-egg rhyta (FS 201) have been found at Ras Shamra (site no. 141), Minet el-Beida (site no. 142), Beth Shean (site no. 187) and Lachisch (site no. 230), see Leonard 1994, 93. Zoomorphic rhyta have been found at Ras Shamra, Minet el-Beida, Kamid el-Loz (site no. 168), Tell es-Sahliyeh (site no. 166), Tell Abu Hawam (site no. 175) and Tell Sera' (site no. 237), see Leonard 1994, 94-95.

107 Of the sixty-two conical rhyta reported by Leonard
(1994, 90-93), forty-seven were discovered at Ras Shamra and Minet el-Beida. Two of the four ostrich egg rhyta came from these sites as well, while seventeen of the total of twenty-six zoomorphic vessels came from Ugarit. Figures taken from Leonard 1994, 90-95.

108 See also Van Wijngaarden 1999c.

rog Yon \& Caubet 1990, 106 no. 25; Badre 1990, 68.

по Balensi 1980, 93.

III Balensi 1980, 441. The temple also produced a Mycenaean ring kernos.

"I2 Koehl 1985, 103; Khalifeh 1988, 11-15.

ґз Hachmann 1980, 84, 87, Tafel 24 nos. 1, 4; 1982, 33, Tafels 5 no. 3, Tafel 6 no. 1 .

I4 Oren \& Netzer 1974, 265.

IIS Van der Toorn 1995b, 2053. 
wealth of this city, but also to its ability to exert a preference for these vessels. The limited occurrence of rhyta elsewhere in the Levant suggests that they were employed in strategies of restricted regional distribution, as has also been suggested for Mycenaean dinner vessels and pictorial pottery.

The final class of Mycenaean pottery to be considered are terra-cotta figurines. According to the figures provided by Leonard, Mycenaean female figurines have been found at eighteen sites in the Levant. ${ }^{116}$ If bovine figurines and types such as chariots are included, the number of sites with Mycenaean figurines grows to twenty-two. ${ }^{117}$ The find places of Mycenaean figurines are widely distributed, including inland sites such as Kamid el-Loz (site no. 168) and 'Ain Shems (site no. 227). In a quantitative sense, however, the distribution shows a marked concentration at Ugarit: nineteen female figurines (31.6\% of the total) and forty-five of bovine and other type (68\% of the total) have been found at Ras Shamra and Minet el-Beida. At Ugarit, these idols did not appear to have been restricted in any spatial or contextual sense. The case of the area with pits in Minet el-Beida, where a large quantity of such figurines were found together indicates that these objects could be endowed with some special meaning. At Hazor, in contrast, where fewer of these idols were found, they appeared to possess special significance.

At Tell Sukas (site no. 145), which was part of the kingdom of Ugarit, nineteen figurines were discovered, all in domestic contexts. ${ }^{118}$ A Mycenaean female figurine was found in funerary chamber 2 of necropolis K at Byblos (site no. 156), while chamber 11 yielded a chariot type. ${ }^{119}$ At Sarepta (site no. 162) three female figurines, four of bovine type, as well as three chariot types were found in settlement levels. ${ }^{120}$ The domestic and industrial structure at Tyre (site no. 163) yielded a female and a bovine figurine. ${ }^{121}$ A Psi-type female figurine was found in room D of the temple at Kamid el-Loz. ${ }^{122}$ (site no. 168). In comparison with the large quantities of Mycenaean pottery present at Tell Abu Hawam (site no. 175), a relatively small number of twelve figurines have been discovered at this site. ${ }^{123}$ One of these was found in association with a conical rhyton in the cult deposit at temple 50. Palace 2041 at Megiddo (site no, 181) produced a zoomorphic bovine figurine in stratum VIIB. ${ }^{124}$ A Phitype figurine was found on the remains of the stratum 1 floor in the residential building of area B at Ashdod (site no. 222)..$^{125}$

From this overview of the contexts of Mycenaean figurines in the Levant, it is clear that these idols were employed in both domestic and industrial contexts, as well as in situations which testify of ritual practices. The evidence from Ugarit that Mycenaean figurines could occasionally serve special functions in a limited number of funerary ceremonies may be paralleled at Byblos. It seems logical to in-

"I6 Leonard 1994, 137-138: Ras Shamra and Minet elBeida, Tell Sukas (site no. 145), Byblos (site no. 156), Sidon (site no. 160), Sarepta (site no. 162), Tyre (site no. 163), Kamid el-Loz (site no. 168), Hazor (site no. 171), Tell Abu Hawam (site no. 175), Tell Ta'anek (site no. 183), Ashdod (site no. 222), 'Ain Shems (site no. 227), Lachisch (site no. 230) and Tell el-Hesi (site no. 231).

II7 Leonard 1994, 138-141: Ras Shamra and Minet elBeida, Tell Sukas (site no. 145), Tell Kazel (site no. 148), Byblos (site no. 156), Sarepta (site no. 162), Tyre (site no. 163), Hazor (site no. 171), Tell Abu Hawam (site no. 175), Megiddo (site no. 181), Beth Shean (site 187) and 'Ain Shems (site no. 227). To this list, Tel Dan (site no. 170) should be added, see Biran 1994a, 119 no. 9.

II8 Ploug 1973, Plate 2 nos. 31-39.

II9 Salles 1980, 37, Plate 29.

I20 Koehl 1985, 105-109.

I21 Bikai 1978, Plate 43, no. 33, Plate 88 no. 7.

I22 Hachmann 1980, 89, no. 23, Tafel 27 no. 6.

I23 Balensi 1980, 93. 471.

${ }^{124}$ Leonard \& Cline 1998, 5.

I25 Dothan \& Freedman 1967, 83. 
terpret Mycenaean terra-cotta figurines as objects which were used in daily cult practices, while they could occasionally also serve in activities of a higher symbolical nature, such as in religious and funerary ceremonies. The marked concentration of Mycenaean figurines at Ugarit testifies that this city was able to exert a preference for these objects, as in the case of Mycenaean rhyta.

The appreciation of different Mycenaean vessel types does not appear to have been homogeneous everywhere in the Late Bronze Age Levant. Vessel types which were widely used in domestic contexts at some sites could be highly valued at other sites. The desirability of Mycenaean pottery seems to derive from the functions it fulfilled in Levantine cultural practices. Because these functions may have varied between sites, these ceramic imports were suitable to be included in strategies of restricted regional distribution. Since the desire for and access to different parts of the Mycenaean ceramic repertoire were unequal, the appreciation of these vessels also varied. ${ }^{126}$

\section{F U N E RARY E V I D E N C E}

The occurrence of Mycenaean vessel types in the tombs at Ugarit and Hazor reflects the widespread use of this class of material among the urban population. However, for some groups in both cities Mycenaean pottery was suitable to be included in funerary strategies of display. Aegean pottery has been found in funerary contexts at a large number of Levantine sites. In the majority of cases only a limited number of Mycenaean vessels are found in the tombs, often accompanied by Cypriot and local ceramics. Such deposits have been discovered, for example, at Beirut (site no. 158), ${ }^{127}$ Akko (site no. 173), ${ }^{128}$ Tell Abu Hawam (site no. 175), ${ }^{129}$ Tell el-Far'ah (north) (site no. 185), ${ }^{130} \mathrm{Umm}$ ad-Dananir (site no. 193), ${ }^{131}$ Aphek (site no. 215), ${ }^{132}$ Lachisch (site no. 230), ${ }^{133}$ and Tell el-Far'ah (south) (site no. 240). ${ }^{134}$ The wide distribution of tombs with a limited number of Mycenaean finds appears to be a reflection of the widespread occurrence of this material in the Levant in general. However, as at Ugarit, there are a number of cases which testify to Mycenaean pottery possessing a special significance in funerary ceremonies.

At Byblos (site no. 156), a necropolis has been discovered consisting of eleven chamber tombs hewn out in the rock. A total of sixty-five Mycenaean finds were made in this cemetery, dating from LH IIIA2 to LH IIIC. Among the Mycenaean finds were dinner and storage vessels; in particular, a large number of stirrup jars have been found. ${ }^{135}$ Seven of the twelve chambers produced relatively small amounts of Mycenaean pottery, varying from one to seven items. In room K11, however, fortyone Mycenaean finds were made, including a figurine. Even though the tombs were all heavily disturbed because of later use, the concentration of Mycenaean finds in room K11 may present a reflection of a situation similar to the funerary pattern at Ugarit and Hazor.

At Sarepta (site no. 162), only one tomb has been discovered: a circular cave hewn out in the natural rock. ${ }^{136}$ This cave produced a total of sixty-seven Mycenaean vases, some of them of Levantine
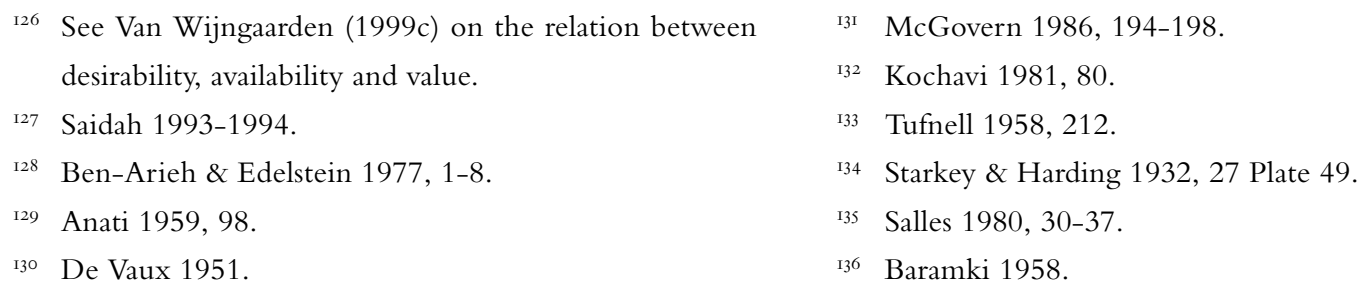
manufacture. Among the Mycenaean finds in this tomb, stirrup jars constituted the majority. In addition, a number of lentoid flasks were found along with a cup and some bowls; a Mycenaean female figurine was also included in the funerary inventory. Apart from the ceramic material, the tomb produced a scarab and two faience amulets, probably imported from Egypt. The inventory of the funerary cave at Sarepta is comparable to that of the exceptional tombs at Minet el-Beida. This similarity does not only concern the presence of large quantities of Mycenaean pottery, but also the presence of Mycenaean figurines and imports from other Mediterranean areas.

The same may be said of the so-called 'Mycenaean tomb' at Tell Dan (site no. 170). This tomb had been dug under the floor of a Late Bronze Age residential structure; the corbelled vault recalls the funerary cellars of Ugarit. ${ }^{137}$ Inside the tomb were the remains of some forty skeletons, apparently both male and female. A total of 108 ceramic vessels were discovered in the tomb, of which some thirty were imported from Mycenaean Greece; four vases came from Cyprus. ${ }^{138}$ Among the Mycenaean pottery were stirrup and piriform jars, alabastra, flasks, bowls and an amphoroid krater with pictorial decoration. All have been assigned to late LH IIIA2, or to LH IIIB1. ${ }^{139}$ Apart from the Mycenaean and Cypriot imports, the tomb yielded a large variety of objects, such as alabaster vases, cosmetic boxes made of hippopotamus tusk, faience and glass vessels, a stone cylinder seal possibly imported from Cyprus and a scarab. In addition, numerous Levantine ceramic vessels were found, as well as bronze metal vessels and arms, spindle whorls and gold and silver jewellery. Olive pits and the skeleton of a sheep may be testimony of funerary rites. The 'Mycenaean' tomb is the only funerary evidence from Late Bronze Age Tell Dan, because of which it is impossible to indicate whether it constitutes an atypical example.

The cemetery on the south-eastern slopes of the mound at Megiddo (site no. 181) was excavated in 1925-1930. ${ }^{140}$ Only eleven tombs containg Mycenaean pottery have been published. ${ }^{141}$ Most of these graves had only a few Mycenaean pots, varying from one to three specimens. Tomb 912, however, contained seven Mycenaean vases: one straight-sided alabastron, five small stirrup jars and one large, transport stirrup jar, all dating to the LH IIIA2 or LH IIIB periods. The difference between tomb 912 and the other tombs at Megiddo in terms of the quantity of Mycenaean pottery is much smaller than that attested for the tombs at Ugarit, but it is a possibility that tomb 912 constitutes another example of a tomb with a disproportionate amount of Mycenaean vessels.

A total of fifteen Late Bronze Age graves were discovered on the lower tell at Tell es-Saidiyeh (site no. 191). ${ }^{142}$ Most of these graves consisted of simple trenches cut into the earth, but four tombs (nos. $101,102,108,117)$ were more elaborate: lined with mud-bricks and then roofed to form a true tomb. In two of these tombs $(102,117)$, the body had been placed on a stone bed. Of all the graves, only three have produced Mycenaean pottery. A single Mycenaean stirrup jar was found in the simple graves 107 and 109S. Tomb 117, one of the more elaborate graves, however, yielded four Mycenaean vases, among which were two stirrup jars, a straight-sided alabastron and a jug, all in LH IIIB style. In general, the inventories of the graves at Tell es-Saidiyeh reflected the ceramic repertoire of settlement levels, with a notable absence of cooking wares. The richest tomb (no. 101), however, possessed a number of objects in silver, electrum, carnelian, bronze and ivory. This tomb was situated in the cen-

I37 Biran 1994a, 111-116.

${ }_{138}$ Neutron Activation Analysis on a number of Mycenaean vessels from the tomb, including the famous so-called 'charioteer vase', showed that they had been produced in the Argolid; see Gunneweg et al.
1992.

I39 Biran 1970, 92-94.

${ }^{140}$ Guy \& Engberg 1938.

I4I Leonard \& Cline 1998, 9-13.

I42 Pritchard 1980, 28-30. 
tre of the necropolis. Close to tomb 101 were graves 102 and 117. This last grave was special because it was particularly rich in imported wares: apart from the four Mycenaean vessels, a Cypriot Base Ring jug, as well as an alabaster goblet and a faience bowl were found, probably imported from Egypt. Even though the quantities involved are far lower than at Ugarit, or even Hazor, tomb 117 is another case of unequal display of Mycenaean pottery in a funerary context. As is the case elsewhere, a number of imports from other regions were are associated with the Mycenaean pottery from tomb 117. It may be of importance that tomb 117, although special, was not the wealthiest grave.

Early in the 20th century, large quantities of Mycenaean pottery were reported from extra-mural deposits termed the East Grotto ${ }^{143}$ and Tomb I at 'Ain Shems (site no. 227). ${ }^{144}$ Even though very little is known of these deposits, they may constitute other examples of burials with large quantities of Mycenaean pottery.

This overview of Mycenaean pottery in funerary contexts in the Levant shows that the pattern established for Ugarit and Hazor is reflected on a regional scale: many tombs have produced only a few Mycenaean finds, while there are a number of cases in which large quantities of Mycenaean pottery were found in graves, usually associated with imports from other regions. Among the sites which have yielded only tombs with small amounts of Mycenaean pottery are Tell Abu Hawam and Lachisch; both sites produced large amounts of Mycenaean pottery in settlement levels. The unequal occurrence of Mycenaean pottery in tombs therefore appears not to be related to the availability of this material in different cities. Rather, we can assume that among large groups of people, at many places, small quantities of Mycenaean pottery were considered suitable to be included in funerary inventories. ${ }^{145}$ At various sites, widely distributed in the Levant, a minority among the inhabitants included larger numbers of Mycenaean vessels in tombs, often in association with other imports

The five tombs at Ugarit which have produced large amounts of Mycenaean pottery were situated in the harbour town of Minet el-Beida and in the habitation quarter of the Ville Sud. Tomb 81448145 at Hazor, likewise, was situated in a habitation quarter, albeit possibly associated with building 8139, which possessed an atypical inventory. This shows that at both sites the people who included large quantities of Mycenaean pottery in their funerary ritual did not belong to the uppermost élites, but to more average urban social groups. Similar evidence comes from Tell es-Saidiyeh, where it was not the wealthiest tomb which included a larger quantity of Mycenaean pottery, but one associated with it. Apparently, Mycenaean pottery served in strategies of funerary display only for specific urban social groups.

The social significance of Mycenaean pottery, then, appears to have varied according to social group in the Levantine urban societies. The exceptional tombs at Ugarit and Hazor, as well as those at Sarepta, Tell Dan and Tell es-Saidiyeh included a relatively large number of imports from other areas together with the Mycenaean pottery. It may be that for some groups in the urban societies of the Levant the imported character of these vessels was of importance. Whereas for most urban inhabitants the social significance of these vessels appears to have derived from the extent to which they were integrated in the local material culture, specific groups enhanced the imported nature of Mycenaean pottery by including them in large quantities in funerary inventories and by associating them with other imports.

I43 MacKenzie 1911, 61-72; Bunimowitz \& Lederman 1993, 251.

${ }^{144}$ Grant 1929, 163-204.

I45 It is likely that the suitability of small numbers of
Mycenaean containers is related to the uses of oils in funerary practices, see Kinet 1981, 146-147; Salles 1995, 176. 


\section{Mycenaean pottery in Cyprus: Introduction}

\section{P REVIOUS RESEAR CH}

That Mycenaean pottery was very abundant in Cyprus was already realised by Furtwängler and Löschke at the end of the 19th century. ${ }^{1}$ They mentioned thirty-seven Mycenaean pots and three findspots, while stating that there were many more from the island, scattered over several collections. Furtwängler and Löschke noticed that in comparison to mainland Greece, chariot kraters and decorated flasks were more frequent in Cyprus. Differences in the corpus of Mycenaean pottery between Cyprus and mainland Greece were also noted by Myres and Ohnefalsch-Richter, who argued for the production of Mycenaean pottery on the island itself. ${ }^{2}$ They were the first to make a distinction between genuine Mycenaean ware and local imitations on the basis of a description of fabrics. A distinction between Minoan, Cycladic and Helladic pottery in Cyprus was made in 1926 by Gjerstad, who stated that already during the LC I period pots produced on the Greek mainland exceeded those from Crete or the Aegean islands. ${ }^{3}$ He also reported that the number of Aegean finds in Cyprus was well over a thousand, while Fimmen was able to list twenty findspots of Mycenaean pottery on the island. ${ }^{4}$

In the 1930s the first three volumes of the Swedish Cyprus Expedition were published. ${ }^{5}$ Among the sites discussed, Enkomi (site no. 56), where the Swedes had excavated part of the necropolis is especially important. In 1951, Frank Stubbings emphasized that the differences between Mycenaean pottery from Cyprus and mainland Greece was one of repertoire only. ${ }^{6}$ In his view, technique, shape and decoration all pointed to manufacture on mainland Greece. Stubbing's work is also important because he showed a difference in the distribution of Mycenaean pottery on Cyprus between LH IIIA2 and LH IIIB. In comparison with the relative homogeneity of LH IIIA2 pottery, Stubbings noted more local imitations of the LH IIIB style and a growing number of local peculiarities in shape and decoration, coupled with some differences in the texture of the clay. In his view, these changes testified to the LH IIIB pottery being imported not only from the Peloponnese, but also from peripheral areas of the Mycenaean region, such as Rhodes.

Scientific analysis of the composition of Late Helladic ware on Cyprus had already been carried out in the 1940s. ${ }^{7}$ Later work by H.W. Catling and A. Millett indicated that most of the Mycenaean pottery imported in Cyprus during LC II was produced in the north-east Peloponnese. ${ }^{8}$ These results, although initially questioned by V. Karageorghis, gave support to Catling's view that the Mycenaean

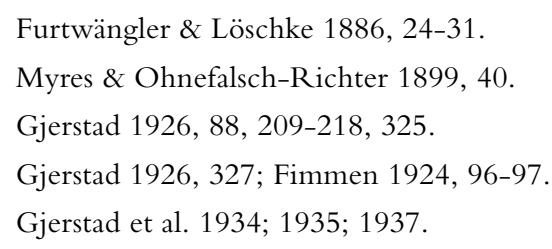

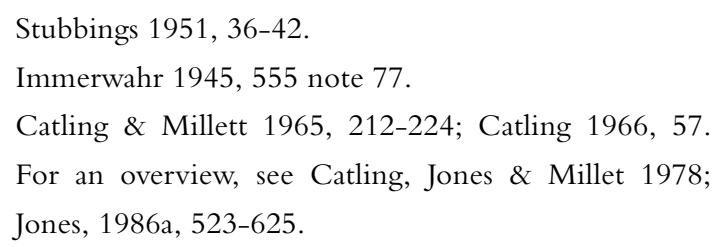


pottery from before LH IIIC had arrived on Cyprus principally through trade, without the actual presence of Mycenaeans. ${ }^{9}$ Even though the majority of Mycenaean pots on the island is now thought to have been made in the Aegean, it has also become clear that the Cypriot ceramic industry at the end of LC IIC began to incorporate parts of the Mycenaean repertoire, such as the 'Rude' or 'Pastoral' pictorial style, as well as a variety of bowls. ${ }^{10}$

The discovery in 1934 by Schaeffer of the town of Enkomi (site no. 56) enabled a comparison between the Mycenaean pottery in tomb deposits and in settlement strata. ${ }^{11}$ Schaeffer's work at Enkomi was supplemented by that of Dikaios, who paid special attention to the stratigraphy of the imported Mycenaean pottery. ${ }^{12}$ His account of the contents of domestic strata not only showed clearly the variety of contexts in which that pottery was found, it also provided information about the length of time in which different types of Mycenaean pottery were used. The excavations at Kition (site no. 63) by Karageorghis testified of Mycenaean vessels being used in both funerary and religious practices. ${ }^{13}$ A site comparable to Enkomi and Kition, at least as far as the quantities of Mycenaean pottery are concerned, is Hala Sultan Tekke (site no. 65), which has been excavated by the Swedes. ${ }^{14}$ The excavation of the remains of Toumba tou Skourou (site no. 105) has provided evidence for the import of Minoan pottery dating to the beginning of Aegean contact with Cyprus. ${ }^{15}$ Of particular importance is the fieldwork that has been carried out in the Kalavassos valley and adjacent regions in central southern Cyprus. ${ }^{16}$ The survey carried out in the valley and the excavations at Maroni (site nos. 116 and 117) and Kalavasos-Ayios Dhimitrios (site no. 114) have all contributed to a better understanding of the distribution of Mycenaean pottery on a regional level. The contextual analysis of the Mycenaean pottery at Kalavasos-Ayios Dhimitrios sheds light on the social function of that pottery during LC IIC. ${ }^{17}$

A corpus of all the Mycenaean and Minoan pottery found in Cyprus has been published by Paul Åström. ${ }^{18}$ In this corpus, finds are arranged according to shape and find spot and painted motifs are listed, enabling a statistical analysis of the distribution of Mycenaean pottery in Cyprus. ${ }^{19}$ Such statistics show, among other things, that an increase in the importation of Mycenaean pottery started during LH IIIA1 and continued during LH IIIA2, while there was a regress during LH IIIB. For the early period, K. Nicolaou, has isolated the sites with early Mycenaean (LH I-LH IIIA1) material, showing that these are mainly, but not exclusively, situated along the coasts and in mining regions. ${ }^{20}$

9 Catling 1964, 35-50; Karageorghis 1965a, 202 note 2.

Io Sherratt \& Crouwel 1987, 341-342; Kling 1987; 1989, 80-81; 1991; Sherratt 1991, 191; Åström 1998.

II Schaeffer 1936a, 83-93.

I2 Dikaios 1969; 1971.

I3 Begun in 1959: Karageorghis 1960a. For the the Mycenaean pottery from Kition, see Karageorghis 1981; 1985a, 1985b.

${ }^{14}$ The Swedish excavations started in Hala Sultan Tekke in 1971; for overviews, see Åström 1985, 176-181; 1986b; 1996.

Is Vermeule \& Wolsky 1978, 298-299, 300-317; 1990, 381-384.

I6 See, for example, Todd 1986a; South 1989.

17 South \& Russell 1993, 304-309; Steel 1998.

I8 Åström 1972b, 289-408. Of course, many more Mycenaean pots have been found on the island since the early 1970s.

19 Åström 1973, 122-123.

20 Nicolaou 1973, 51-58. 
The geography of Cyprus is determined by two mountain ranges: the Kyrenia and the Karpass in the north and the Troodos in the south. Between these lies the Mesaoria plain. The distribution of LH ILH IIIB pottery on the island is presented in Map 8, from which it is immediattely clear that sites with such pottery are only absent deep in the Troodos mountains. ${ }^{21}$ It is difficult to distinguish any regionalisation in this dense distribution pattern. Some clusters on the south coast are visible: around Pyla-Kokkinokremos (site no. 58), around Kition (site no. 63) and Hala Sultan Tekke (site no. 65), near Kalavasos (site no. 114) and Maroni (site no. 116) and around Kourion (site no. 122).

This pattern of clusterings becomes more marked when we take the quantities of Mycenaean finds into account (Map 9). To the string of important sites on the south coast Kouklia-Palaeopaphos (site no. 126) needs to be added, while the cluster near Pyla-Kokkinokremos (site no. 58) lacks a site with very large quantities of Mycenaean pottery. In the eastern part of the Mesaoria, the prominence of Enkomi (site no. 56) is clear, and this site may have been a centre for the distribution of Mycenaean pottery in much of the northern half of the island. In the north-west, there is a notable clustering of sites in the Morphou area, but sites of class 3 and higher are absent there. This may indicate the lack of an important centre, but can also be caused by the fact that a significant part of Toumba tou Skourou (site no. 98) was destroyed before excavations began. ${ }^{22}$

The island of Cyprus is small in comparison with the whole of the Levant and the central Mediterranean, which argues against a subdivision into regions to select sites for contextual analysis of the Mycenaean pottery. Moreover, the archaeological record has shown that during the Late Bronze Age, the island possessed a relatively uniform material culture. ${ }^{23}$ The Late Cypriot settlements seem to have belonged to a number of regional polities centred on the large coastal towns. ${ }^{24}$ These polities probably were organised around the production and exchange of copper, in which several sites were systemically involved. Priscilla Keswani describes a complex network of coastal centres, inland centres, mining and agricultural villages, which were related through exchanges of luxury and staple goods. She distinguishes at least eight of these regional exchange systems, centred on Toumba tou Skourou (site no. 98), Enkomi (site no. 56), Kition (site no. 63), Hala Sultan Tekke (site no. 65), Maroni (sites no. 116), Kalavassos-Ayios Dhimitrios (site no. 114), Kourion or Alassa (site nos. 122, 123) and Kouklia-Palaepaphos (site no. 126), respectively. The power of these centres appears to have been based to a large extent on access to international maritime exchange. ${ }^{25}$

Even though the circulation of metals and foreign contacts appear to have been important in all of these polities, their internal social organisation was not the same. According to Keswani, the Cypriot centres can be divided into two distinct types of social organisation. ${ }^{26}$ On the one hand there are sites such as Enkomi (site no. 56), Toumba tou Skourou (site no. 105), Kition (site no. 63) and Hala Sultan Tekke (site no. 65). In these towns there is evidence of a complex social organisation in which no single group managed to exert central control. The clearest evidence of this social complexity is the fact

2I This is easily explained by the fact that there seems to have been no settlement in these mountains during the LC period; see Catling 1966, 50.

22 Moreover, not all the excavated pottery from this site could be published because of the Turkish invasion of 1974; see Vermeule \& Wolsky 1990, 3-5.

23 Herscher 1984, 27; Knapp 1986b; 1997, 46-47; Muhly
1989, 302, 310; Cadogan 1993, 92.

24 Stech 1982, 113; Merrillees 1992, 321; Keswani 1993, 74-76; 1996, 224, 236.

25 See also Knapp 1985, 249-250; 1986b, 70-72; 1996a, $20-22$.

26 Keswani 1996. 
that buildings testifying to the central administration and monopolisation of storage facilities and craft production are lacking in these towns. ${ }^{27} \mathrm{~A}$ second type of urban social organisation in Cyprus can be classified as hierarchical and is visible at sites such as Kalavasos-Ayios Dhimitrios (site no. 114), MaroniVournes (site no. 116) and Alassa (site no. 123). In these towns, a specific élite group appears to have been been able to acquire ruling power. Evidence for such a social hierarchy are the monumental buildings at these three sites. The extensive storage facilities and the presence of clay balls with Cypro-Minoan script in these buildings testify of administration and the control of the flow of goods. ${ }^{28}$

All the coastal towns described by Keswani as centres in regional systems possess notable quantities of Mycenaean pottery, with Enkomi (site no. 56), Kition (site no. 63) and Hala Sultan Tekke (site no. 65) taking the lead with more than 500 Mycenaean finds. In the following chapter, the cultural context of the Mycenaean pottery from Enkomi will be discussed in detail. According to Keswani, Enkomi is one of the sites with a complex, so-called heterarchical social organisation. In chapter 13, I shall contrast this site with a more hierarchically organised coastal centre such as Kalavasos-Ayios Dhimitrios.

In the model of socio-political organisation presented above, the coastal cities are linked through exchange with inland centres, which maintain relations with the outlying mining and agricultural towns. ${ }^{29}$ Mycenaean pots probably were among the goods transferred in these exchanges and we can expect that notable amounts of such pottery was present at inland centres. I will discuss in detail the Mycenaean finds from Athienou-Bamboulari tis Koukouninas (site no. 74), which has been interpreted as a secondary inland centre, with a role in the regional exchange of goods. In addition, I will study in detail the cultural context of the Mycenaean pottery at Apliki-Karamallos (site no. 108), which is situated in a mining district.

27 This social complexity is referred to by Keswani with the term heterarchy. Probably the urban centres at Kourion-Bamboula (site no. 102) and KoukliaPalaepaphos (site no. 105) also had a heterarchical social organisation.
28 For Maroni-Vournes, see Cadogan 1989; 1992; 1996 For Kalavasos-Ayios Dhimitrios, see South 1984, 40; Karageorghis 1990, 3-5; Keswani 1996, 230-232. For Alassa, see Hadjisavvas 1986, 1989, 1996.

29 Keswani 1993, 79. 


\section{Enkomi-Ayios Iakovos}

\section{N T R O D U C T I O N}

Spurs of the southern uplands form an abrupt escarpment in the western part of the Mesaoria, leaving a gap of about $2 \mathrm{~km}$ only. Just north of this gap lies the site of Enkomi-Ayios Iakovos, situated some 3 $\mathrm{km}$ from the coast. The plundering of tombs seems to have been an important activity at the site already during the 19th century; more systematic research began in 1896, when a team from the British Museum investigated some hundred tombs. ${ }^{1}$ Since then, the site has been visited frequently by British, Swedish, French and Cypriot expeditions. ${ }^{2}$ Unfortunately, Enkomi has been inaccessible since 1974 due to the occupation of northern Cyprus by Turkish military forces.

The site of Enkomi is defined by a fortification wall, which encompasses an area of ca. 2.5 ha (Fig. 10.1). Late Bronze Age remains have been discovered in every excavated part of the site, but the stratigraphy and absolute dates of the various layers have been heavily debated. ${ }^{3}$ Apart from scatter's of MC III and LC I sherds, a few buildings dating to the first settlement period in LC IA have been discovered. Apparently, during this early period a number of fairly large buildings were situated in the settlement area, relatively far away from each other and without a discernible street pattern. ${ }^{4}$ The succeeding period LC IIA-LC IIB is relatively poorly documented in terms of settlement architecture, but the city was substantially rebuilt during LC IIC. An important new feature was the defensive wall, which surrounded the city on the northern, western and southern sides (Fig. 10.1). ${ }^{5}$ The city wall possessed gates that corresponded with the new street layout of the city, the basis of which is a long north-south street. ${ }^{6}$ The streets divide the city area into insulae that were occupied by houses of various sizes. Apart from domestic spaces, there are buildings that can clearly be associated with industrial activities, especially metalworking. ${ }^{7}$ Buildings clearly meant for religious purposes dating before the LC III period, have, however, not been identified. ${ }^{8}$ This indicates that cult was practiced at Enkomi not in official, public structures, but at group or family level in domestic buildings. Just as at Ugarit,

Murray, Smith \& Walters 1900, 1-54.

The British expedition in 1913 was headed by Sir John Myres, see Myres 1945, 70. The director of the Swedish team in 1930 was Einar Gjerstad, see Gjerstad et al. 1934, 467-575. From 1934 until 1971 successive French excavation campaigns were directed by Claude Schaeffer, see Schaeffer 1936a; 1952; Courtois 1981, 1984; Lagarce \& Lagarce 1985. From 1948 until 1958, the French were supported by a Cypriot team headed by Porphyrios Dikaios, see Dikaios 1969; 1971.

3 For overviews of the stratigraphy, see Dikaios 1969 ,
438; Schachermeyer 1979, 60-61; Ionas 1984a; Negbi 1986; Courtois, Lagarce \& Lagarce 1986, 7.

4 Courtois, Lagarce \& Lagarce 1986, 5.

5 Dikaios 1969, 44; Courtois, Lagarce \& Lagarce 1986, 3-5.

6 Courtois, Lagarce \& Lagarce 1986, 5-7.

7 Dikaios 1969, 21-34, 44-66; Courtois 1982, 16; Courtois, Lagarce \& Lagarce 1986, 30-32; Keswani 1989a, 141-142.

$8 \quad$ Ionas 1984b, 98. 


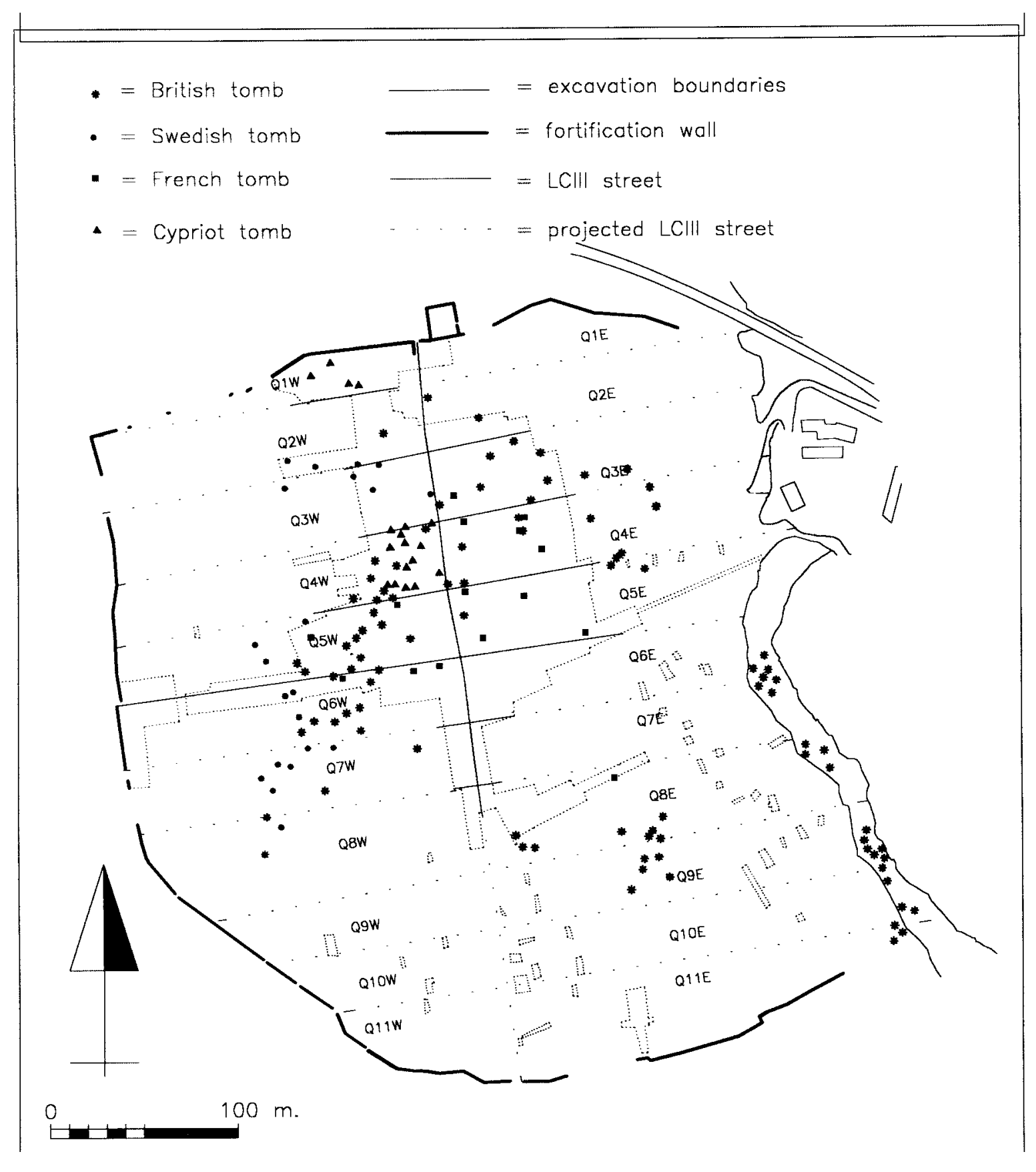

Fig. 10.1 Enkomi: site plan

tombs were found within the settlement area. ${ }^{9}$ The most frequent type of tomb at the site were rockcut chamber tombs, which were used for multiple internment, sometimes for many generations.

Several buildings at Enkomi show signs of elaborate architecture, but a building that may have served as the seat of a central government is conspicuously absent in the town. ${ }^{10}$ The unequal distribution in the tombs of Enkomi of gold and of exotic and symbolic grave goods indicates that already in 
the early stages of LC II there was a stratified élite in the city. ${ }^{11}$ The existence of such an élite at an even earlier date may be inferred from the concentration of copper at one building, along with possible evidence for administrative activities such as a Cypro-Minoan tablet. ${ }^{12}$ During LC IIC, social complexity increased considerably, and distinct élite groups can be recognised through the differentiation of wealth in tombs. ${ }^{13}$ Probably, the whole population of the city should be regarded as élite groups from the point of view of the residents of outlying communities.

The material culture of Enkomi from LC II fits into the rather homogeneous archaeological record for Late Bronze Age Cyprus in general. ${ }^{14}$ In addition, a wide variety of imports from many Mediterranean and Near Eastern areas have been identified, from the MC III-LC IA period onwards. This indicates that the participation in international exchange, coupled with an interest in copper working, was of crucial importance to the city. ${ }^{15}$ The cosmopolitan material record of the city, of which objects from international exchange were a small but integral part, is exemplified by the evidence for literacy provided by the Cypro-Minoan text fragments on tablets, lumps of clay, potsherds and cylinder seals which have been found in the city. ${ }^{16}$ This cosmopolitism has led to the idea that Enkomi was the capital of Alashiya, a name known from Near Eastern cuneiform texts. ${ }^{17}$ The lack of a residency for a royal court, however, seems to contradict such an idea and, in any case, other sites in Cyprus could lay equal claim to the title.

\section{THE MYCENAEAN POTTERY}

In a wide array of publications, 1472 Mycenaean ceramic finds from Enkomi could be identified, in styles ranging from LH I to LH IIIB-LH IIIC; these are listed in Catalogue V. ${ }^{18}$ Six of these finds concern ceramic figurines, while there are 1466 pots or sherds thereof. The majority of the Mycenaean pots at Enkomi appears to originate in Greece. Nine out of eleven Mycenaean pictorial sherds analysed by Catling and Millett using OES did appear to have an origin in the Peloponnese. ${ }^{19}$ For two sherds an origin could not be established. An additional six pictorial fragments submitted to the OES technique appeared to derive from the Peloponnese. ${ }^{20}$ Twenty-one non-pictorial sherds analyzed by the same methodology had similar clay compositions. ${ }^{21}$ However, ten other sherds analysed by OES, which had been singled out as being possibly of local manufacture, could not be assigned to any identified composition group and may be of Cypriot manufacture. ${ }^{22}$ Another sherd (cat. no. 1442) ap-

II Keswani 1989b, 62, 69.

I2 Dikaios 1969, 22-23; Keswani 1996, 222.

I3 Keswani 1989b, 68-69.

I4 Knapp 1986a, 39-40; Muhly 1989, 302, 310.

Is Knapp 1986b; 1996a, 19-20.

I6 Dikaios 1971, 881-887; Masson 1970; 1971a; 1971b; Palaima 1989.

${ }^{17}$ R. Dussaud in Schaeffer 1952, 1-10; see also Hellbing 1979; Knapp 1996b.

I8 This is considerably more than the 912 Mycenaean vessels from the same stylistic periods (excluding vessels in 'Rude' or 'Pastoral' style), which were presented by Åström (1972b, 289-382). The difference is largely due to a number of publications which have appeared after Åström's report. Also, he assigned a number of vessels, in particular shallow cups (FS 220) and shallow bowls (FS 295-296) to his class of White Painted Wheelmade III Ware (Åström 1972b, 276-289), which have been included by me.

I9 Catling \& Millett 1965, 215-219.

20 Anson 1980, 117.

2I Catling, Richards \& Blin-Stoyle 1963, 103-109; Millett \& Catling 1966, 93-94; Catling, Jones \& Millet 1978, 72.

22 Catling, Richards \& Blin-Stoyle 1963, 111; Catling, Jones \& Millett 1978, 77. 
peared to have a Cretan origin. Neutron Activation analyses carried out by F. Asaro and I. Perlman on sherds from Enkomi indicated that of sixteen LH IIIA finds from the site, about a quarter could safely be assigned an Argolid provenience. ${ }^{23}$ The remainder were slightly different, but it was thought that they were probably from the Aegean. The LH IIIB finds analysed by the same team showed a similar pattern, with a somewhat higher proportion of finds to be assigned to the Argolid. Sixteen LH IIIB shallow bowls, however, revealed compositions similar to vessels in 'Rude or Pastoral' style and were assigned a Cypriot origin. Whenever it was certain - on the basis of fabric and decorative style - that a vessel was of Cypriot manufacture, it has been excluded from the catalogue. In several cases, however, a Cypriot origin is possible, but not certain. Such vessels have been included. A few vessels - in particular large, coarse ware stirrup jars - may have a Cretan origin. ${ }^{24}$

It is certain that the 1472 items in Catalogue $\mathrm{V}$ do not represent all Mycenaean pottery that has been found at Enkomi. The Cypriot excavations carried out by Dikaios' team have been fully and superbly published and we may consider our dataset to be more or less complete for the areas investigated by it. The French campaigns however, have only been partially published. Schaeffer has described Bâtiment 18 in considerable detail, ${ }^{25}$ while a number of tombs investigated by the French have also been fully published. ${ }^{26}$ Important contextual information is available through the publication of the non-ceramic settlement material in the Cyprus Museum and the Louvre. ${ }^{27}$ As to the rest, information concerning the French excavations is available through a number of preliminary reports and a few summarising overviews only. Since the French excavated the largest areas in the settlement, the incompleteness of the data from these excavations is a serious drawback. Even though the Swedish did not recognise the existence of the city in the same area as the tombs, the descriptions of the tomb inventories are remarkably complete. We may assume that our data-set for these tombs is more or less complete, even though many fragments probably were left out of the publications. ${ }^{28}$ The excavations conducted by Myres and Gunnis have not been published and any Mycenaean pottery found in these excavations is not included in Catalogue V. Not all tombs have been published from the British Museum expedition in 1896, nor have all objects from the published tombs been included in their description. ${ }^{29}$ Finally, of course, the area of Enkomi had been subject to tomb robbing for a long time. Surely some of the Mycenaean vessels listed by Åström as without provenance came from Enkomi. ${ }^{30}$

The data presented in Catalogue $\mathrm{V}$, therefore, is very unequal for different parts of the site of Enkomi. In particular, the evidence available from settlement areas is virtually limited to the areas excavated by the Cypriot team. The focus on tombs by the earlier expeditions has created a bias in favour of funerary evidence.

23 Asaro \& Perlman 1973, 221.

24 On the origin of coarse ware stirrup jars, Haskell 1990; Day \& Haskell 1993.

25 Schaeffer 1952, 238-317.

26 Johnstone 1971; Courtois 1981; Lagarce \& Lagarce 1985.

27 Courtois 1984; Caubet, Courtois \& Karageorghis 1987.
28 Mossberg (1975) and Andersson (1980) have published fragments from Swedish tombs 3, 5, 7, 11 and 18 which are now in the Medelhavsmuseet in Stockholm. This implies that similar unpublished fragments exist for other Swedish tombs.

29 L. Mol (pers. comm.).

30 Åstrom 1972b, 289-381. 


\section{THE ON-SITE D ISTRIBUTION OF THE MYCENAEAN POT TERY}

The spatial distribution of Mycenaean pottery at Enkomi can be investigated with the help of the cityquarters created by the rectangular street-layout (Fig. 10.1), even though many finds predate the actual town plan. Each of the excavated city quarters has yielded the amounts indicated in Table 10.1. ${ }^{31}$ The areas, of course, vary highly in size. More importantly, they differ in the extent to which they have been excavated and published. The apparent concentration of Mycenaean finds in Q4W, for example, is easily explained by the fact that this area has been excavated and fully published by the Cypriot team. The same may be said for Q1W, which is the other area excavated by the Cypriots and rates second in the amount of published Mycenaean material. The substantial difference between these two areas in the number of Mycenaean finds is not due to a difference in size, which is approximately the same, but to the larger number of tombs in Q4W. The number of Mycenaean finds from settlement contexts does not show significant differences. ${ }^{32}$

The importance of the tombs for the spatial distribution of Mycenaean pottery is also clear from the other areas which have produced relatively large quantities of Mycenaean pottery. Most of the Mycenaean finds in Q5E, Q5W and Q7W can be attributed to tombs. There appears to be a concentration of tombs in the north-west and in the west of the site (Fig. 10.1). Tomb concentrations may also be seen in Q8E/Q9E and along the eastern scarp. The reason for the lower frequency or even absence of tombs in other areas is unclear, ${ }^{33}$ but it is possible that not every part of the settlement area served as a burial ground. Considering the number of Mycenaean tomb finds (see below), any spatial variation in the frequency of Mycenaean pottery at Enkomi may be related to the spatial distribution of tombs.

The figures in Table 10.1, therefore, mainly reflect the extent of publication and the distribution of tombs. However, what may also be deduced from this table is that Mycenaean pottery was not restricted to one or a few parts of the settlement area. Within the urban zone excavated by the French and Cypriots (Fig. 10.1), only from Q1E, Q6E and Q7E has Mycenaean pottery not been reported. Q1E was part of Dikaios' area III, but was excavated down to LC IIIA levels only. ${ }^{34}$ Mycenaean pottery has not been reported from the structures of this level, among which were the building blocking the northern gate and the large 'tower' just outside it. Only very small parts from Q6E and Q7E were excavated, and these have not been published. From all other excavated city precincts and from a number of outlying areas has Mycenaean pottery been reported. This suggests that such vessels were widely available in the city. It is clear from Table 10.1 that Mycenaean figurines were not frequent at Enkomi. However, the six examples found came from five different parts of the settlement area, which suggests that the use of these objects was not restricted.

The predominance of Mycenaean tomb finds also becomes apparent from Table 10.2, which shows the contextual distribution of the Mycenaean finds at Enkomi. The majority of the Mycenaean vessels

${ }^{3 \mathrm{I}}$ The locations of many of these tombs have been deduced through superposition of the British and Swedish field plans upon the later plans. In some cases, it was impossible to identify the exact town quarter in which a tomb must have been situated, but its location was narrowed down to a choice of two adjacent parts, for example Q1E/Q2E.

32 Q4W and Q1W produced 209 and 192 Mycenaean finds respectively from settlement levels.

33 Myres (1945, 70) was unable to locate tombs in 'Mukhtar's field', which was situated somewhere in the south.

34 Dikaios 1969, 125-129. Some of the pottery in the catalogue without precise find context but designated as from Q1W may actually derive from Q1E, since Dikaios included both these quarters in his area III. 


\begin{tabular}{|c|c|c|c|}
\hline site area & pots and sherds & figurines & Total \\
\hline unknown & 113 & 1 & 114 \\
\hline Q1W & 195 & & 195 \\
\hline Q1W-west & 3 & & 3 \\
\hline \multicolumn{4}{|l|}{ Q1E } \\
\hline $\mathrm{Q} 1 \mathrm{E} / \mathrm{Q} 2 \mathrm{E}$ & 11 & & 11 \\
\hline $\mathrm{Q} 2 \mathrm{~W}$ & 13 & & 13 \\
\hline $\mathrm{O} 2 \mathrm{~W} / \mathrm{Q} 2 \mathrm{E}$ & & 1 & 1 \\
\hline Q3W & 105 & & 105 \\
\hline Q3E & 1 & & 1 \\
\hline Q3W/Q4W & 19 & & 19 \\
\hline $\mathrm{Q} 4 \mathrm{~W}$ & 321 & 2 & 323 \\
\hline Q4E & 62 & & 62 \\
\hline Q4E/Q5E & 4 & & 4 \\
\hline Q5W & 192 & & 192 \\
\hline Q5E & 210 & & 210 \\
\hline Q6W & 59 & & 59 \\
\hline \multicolumn{4}{|l|}{ Q6E } \\
\hline Q7W & 112 & & 112 \\
\hline \multicolumn{4}{|l|}{ Q7E } \\
\hline $\mathrm{Q} 8 \mathrm{~W}$ & 11 & & 11 \\
\hline $\mathrm{Q} 8 \mathrm{E}$ & 0 & 1 & 1 \\
\hline Q9E & 10 & 1 & 11 \\
\hline Q9E/Q10E & 5 & & 5 \\
\hline ogw & 7 & & 7 \\
\hline Q11E & 2 & & 2 \\
\hline eastern scarp & 11 & & 11 \\
\hline Total & 1466 & 6 & 1472 \\
\hline
\end{tabular}

Table 10.1

was found in funerary contexts and these are widely distributed. Only in the two city quarters which have been fully published do settlement finds outnumber those with a funerary context. ${ }^{35}$ This indicates that the impression that Mycenaean pottery at Enkomi was mainly used for funerary purposes is not correct. Rather, the methodology of excavation and publication has created a strong bias in favour of funerary contexts. The evidence from Q1W and Q4W, as well as the scatter of Mycenaean finds from settlement contexts in other areas, suggest that everywhere in the city this material was also used for other than funerary purposes.

Mycenaean pottery has not been reported from religious contexts, which is due to the absence of identifiable religious architecture prior to the LC IIIB period. From the defensive tower in Q1E, which may have served religious functions, no Mycenaean pottery has been reported. ${ }^{36}$ Mycenaean finds from domestic contexts may, of course, have been included in religious ceremonies practised on the household level.

35 As in preceding chapters, a 'domestic' context has been assigned when Mycenaean objects were found in buildings. A 'settlement' context has been assigned in those cases where finds occurred in pits, or in other structures, which could not definitively be assigned to specific buildings.

36 Catling (1975) assigns a religious function to this building, while Fortin (1984, 173-176) thinks it served 


\begin{tabular}{|c|c|c|c|c|}
\hline site area & unknown & funerary & domestic & settlement \\
\hline unknown & 59 & 45 & 9 & \\
\hline Q1W & & 3 & 109 & 83 \\
\hline Q1W-west & & & & 3 \\
\hline \multicolumn{5}{|l|}{ Q1E } \\
\hline $\mathrm{Q} 1 \mathrm{E} / \mathrm{Q} 2 \mathrm{E}$ & & 11 & & \\
\hline $\mathrm{O} 2 \mathrm{~W}$ & & 13 & & \\
\hline \multicolumn{5}{|l|}{$\mathrm{Q} 2 \mathrm{E}$} \\
\hline Q2W/Q2E & & & & 1 \\
\hline Q3E & & 1 & & \\
\hline Q3W & & 105 & & \\
\hline Q3W/Q4W & & 19 & & \\
\hline Q4E & & 61 & & 1 \\
\hline $\mathrm{Q} 4 \mathrm{~W}$ & & 114 & 160 & 49 \\
\hline Q4E/Q5E & & 4 & & \\
\hline Q5E & & 198 & & 12 \\
\hline Q5W & & 183 & 2 & 7 \\
\hline Q6W & & 59 & & 1 \\
\hline Q7W & & 112 & & \\
\hline \multicolumn{5}{|l|}{ Q7E } \\
\hline Q8W & & 11 & & \\
\hline $\mathrm{Q} 8 \mathrm{E}$ & & & & 1 \\
\hline Q9E & & 11 & & \\
\hline Q9E/Q10E & & 5 & & \\
\hline Q9W & & 7 & & \\
\hline Q11E & & & 2 & \\
\hline eastern scarp & & 11 & & \\
\hline Total & 59 & 973 & 273 & 167 \\
\hline
\end{tabular}

Table 10.2

The spatial distribution of the Late Helladic and Late Minoan pottery at Enkomi according to chronological ceramic styles is presented in Table 10.3. ${ }^{37}$ From these figures it is apparent that Aegean vessels from the first half of the Late Bronze Age (LH I-LH IIIA1) are scarce at Enkomi in comparison with the large quantities of later material. However, the number of thirty-eight pots assigned to LH I-LH IIIA1 is quite substantial in comparison with other Cypriot sites. ${ }^{38}$ Moreover, at Enkomi some very early Mycenaean pots have been found, among which are two semi-globular cups (cat. nos. 930, 931) dated to LH I, and a rounded alabastron (cat. no. 932) of similar date. A handleless cup (cat. no. 205) appears to date to LH IIA. The distribution of these very early vessels is limited to a sin-

religious, as well as defensive purposes.

37 The group assigned to 'IIIA2' also includes LH IIIA1LH IIIA2 vessels. The class of pottery labeled LH/LM III cannot be assigned to a specific ceramic style and may be considered undatable. Figurines are not included in this table.

${ }^{38}$ Mycenaean finds dating to LH I-LH IIIA1 and their
Minoan counterparts have been reported from ten other sites at Cyprus. Only at Toumba tou Skourou have more than ten Aegean pots from the first part of the Late Bronze Age been found, most with a Cretan origin, see Vermeule 1980; Vermeule \& Wolsky 1990, 381-384 


\begin{tabular}{|c|c|c|c|c|c|c|c|c|c|}
\hline site area & I-IIA & IIB-IIIA1 & IIIA2 & IIIA2-IIIB & IIIB & IIIB-IIIC & LH/LM III & undatable & total \\
\hline unknown & & 5 & 22 & 25 & 34 & 5 & 18 & 4 & 113 \\
\hline Q1W & 3 & 3 & 62 & 11 & 112 & 4 & & & 195 \\
\hline Q1W-west & & & & & 3 & & & & 3 \\
\hline Q1E/Q2E & & 1 & 5 & 5 & & & & & 11 \\
\hline \multicolumn{10}{|l|}{ Q2E } \\
\hline O2W & & 3 & 4 & 6 & & & & & 13 \\
\hline Q3E & & & & 1 & & & & & 1 \\
\hline Q3W & & & 34 & 38 & 29 & 4 & & & 105 \\
\hline Q3W/Q4W & & & 3 & 4 & 5 & & 7 & & 19 \\
\hline Q4E & & 3 & 12 & 20 & 23 & & 2 & 2 & 62 \\
\hline Q4E/Q5E & & & 1 & 1 & 1 & & 1 & & 4 \\
\hline Q4W & & 8 & 90 & 51 & 165 & 3 & 4 & & 321 \\
\hline Q5E & & 5 & 30 & 34 & 42 & 10 & 76 & 3 & 210 \\
\hline Q5W & & 3 & 15 & 49 & 110 & & 15 & & 192 \\
\hline Q6W & & 3 & 14 & 25 & 15 & & 2 & & 59 \\
\hline \multicolumn{10}{|l|}{ Q7E } \\
\hline Q7W & & & 20 & 63 & 23 & 1 & 5 & & 112 \\
\hline \multicolumn{10}{|l|}{ Q8E } \\
\hline Q8W & & & 2 & 5 & 4 & & & & 11 \\
\hline Q9E & & & 3 & 7 & & & & & 10 \\
\hline Q9E/Q10E & & & & 5 & & & & & 5 \\
\hline Q9W & & & 2 & 3 & 2 & & & & 7 \\
\hline Q11E & & & & & 1 & & 1 & & 2 \\
\hline eastern scarp & 1 & & 4 & 4 & 1 & & 1 & & 11 \\
\hline Total & & 34 & 323 & 357 & 570 & 27 & 132 & 9 & 1466 \\
\hline
\end{tabular}

Table 10.3

gle building in Q1W and British Tomb 40 on the eastern scarp. This could indicate that these vessels were not widely used among the inhabitants of the city, but the number of vessels is too low to draw such a conclusion on the basis of the distribution alone.

The Mycenaean finds dating to LH IIB-LH IIIA1 from the first part of the Late Bronze Age have been found in many different parts of the Enkomi settlement area, which suggests that this material was not spatially restricted but used by inhabitants in different parts of the city. Mycenaean vessels in LH IIIA2 and LH IIIB styles was also widely distributed in the urban space of Enkomi.

Of course, Mycenaean chronological styles must be correlated to the stratigraphy at Enkomi. It is difficult to include the funerary finds in such a correlation, since many of the Enkomi tombs have been in use during several stratigraphical periods. Table 10.4 therefore relates the ceramic styles of the Mycenaean settlement finds at Enkomi to the stratigraphy of the site. ${ }^{39}$ A LH I rounded alabastron (cat. no. 932) and one dated to LH IIIA1 (cat. no. 933), as well as two LH I semi-globular cups (cat. nos. 930-931), were found in Level I (LC IA) of the fortress in Q1W. This shows that Mycenaean vessels stylistically belonging to the first part of the Late Bronze Age did actually arrive at Enkomi during the same period. Three stemmed cups assigned to LH IIB-LH IIIA1 (cat. nos. 970, 971) and LH IIIA1 (cat. no. 972) were discovered in a building dating to LC IIC in Q4W. Two of these (cat.

39 Figurines have not been taken into account. 


\begin{tabular}{|c|c|c|c|c|c|c|c|c|}
\hline stratum & I-IIA & IIB-IIIA1 & LHIIIA2 & LHIIIA2-LHIIIB & LHIIIB & LHIIIB-LHIIIC & undatable & total \\
\hline unstratified & & & 5 & & 9 & 4 & & 18 \\
\hline $\mathrm{LCl}$ & 3 & 1 & & & & & & 1 \\
\hline LCIA-LC\|B & & & 42 & 11 & & & & 53 \\
\hline LCII & & & 4 & 2 & 1 & & 6 & 13 \\
\hline LCIIC & & 3 & 29 & 14 & 95 & 5 & 4 & 150 \\
\hline LCIIC-LCIIIA & & & 2 & 1 & 13 & & & 16 \\
\hline LCIIIA & & 1 & 16 & 7 & 86 & & & 110 \\
\hline LCIIIA-LCIIIB & & & & 3 & 1 & & & 4 \\
\hline LCIIIB & & & 5 & 2 & 29 & & & 36 \\
\hline LCIIIB-LCIIIC & & & & & 1 & & & 1 \\
\hline LCIIIC & & & & & 7 & & & 7 \\
\hline LCIII & & 1 & 2 & 3 & 7 & 2 & 3 & 18 \\
\hline LCIII-EIAI & & & & & 1 & & & 1 \\
\hline Total & 3 & 6 & 105 & 43 & 250 & 11 & 13 & 428 \\
\hline
\end{tabular}

Table 10.4

nos. 971, 972) are fragments found in levels between floors and these may be the result of stratigraphical disturbance. However, a fairly large fragment of the stemmed cup with cat. no. 970 was discovered in the LC IIC destruction level and it is possible that the cup was still in use during that period. A fragment of a LH IIIA1 shallow cup (cat. no. 1086) was found in a level dated to the end of LC IIIA. A similar LH IIIA1 shallow cup (cat. no. 1341) was found in the fourth burial period of Cy. T. $10 .{ }^{40}$ These examples suggest that Mycenaean pottery may have been used for long periods of time.

The largest group of Mycenaean settlement finds in LH IIIA2 style was found in level IIA (LC IIALC IIB), which is in accordance with the relative chronology established for this ceramic style. ${ }^{41}$ Quite a number of LH IIIA2 finds, however, have come to light in LC IIC levels. For most of these finds their stratigraphical position may have resulted from levelling operations or other disturbances. However, a LH IIIA2 kylix (cat. no. 1024) on the LC IIC floor of room 31 in Q1W is another possible example of a Mycenaean vessel which appears to have been in use long after its manufacture. The number of LH IIIB finds from levels dated after LC IIC suggest that the same may have been the case for vessels in this ceramic style. ${ }^{42}$

The contexts in which the different Mycenaean ceramic styles were discovered are indicated in Table 10.5. From this table it is apparent that the predominance of funerary contexts is valid for all Mycenaean ceramic styles from LH IIB onwards. Three of the four earliest Mycenaean vessels, however, have been found in a domestic context.

The spatial distribution of the Mycenaean functional vessel types is presented in Table 10.6. Dinner vessels clearly are more frequent at Enkomi than storage vessels. ${ }^{43}$ Both functional classes of pottery

40 The cup may have belonged to previous burials, the earliest of which has been dated to LC I, see Dikaios 1969, 393.

${ }_{41}$ Dikaios $(1969,481-484)$ dates the end of level IIB around $1300 \mathrm{BC}$, while Karageorghis (1982a, 9) proposes a date of ca.1325 BC for the end of LC IIB. Both dates correlate well with the proposed end for the LH IIIA2 style of around 1320/1300 BC, see Wiener 1998.

42 A large fragment with complete foot of a LH IIIB bowl (cat. no. 1307) was found on floor IV (LC IIIB) of the 'Sanctuary of the Horned god', see Dikaios 1969, 320, Plate 99: no. 4.

43 The class of dinner vessels includes jugs of various 


\begin{tabular}{lcccc}
\hline date & unknown & funerary & domestic & settlement \\
\hline I-IIA & & 1 & 3 & 1 \\
IIB-IIIA & 3 & 25 & 5 & 26 \\
IIIA2 & 7 & 205 & 85 & 14 \\
IIIA2-IIIB & 8 & 304 & 29 & 108 \\
IIIB & 23 & 295 & 143 & 9 \\
IIIB-IIIC & 1 & 13 & 6 & 7 \\
undatable & 17 & 954 & 272 & 165 \\
\hline Total & 59 & & & \\
\hline
\end{tabular}

Table 10.5

\begin{tabular}{|c|c|c|c|c|c|c|}
\hline site area & fragments & dinner & ritual & storage & figurines & total \\
\hline unknown & 21 & 57 & 1 & 34 & 1 & 114 \\
\hline Q1E/Q2E & & 4 & 1 & 6 & & 11 \\
\hline Q1W & 28 & 126 & 5 & 36 & & 195 \\
\hline Q1W-west & & 3 & & & & 3 \\
\hline $\mathrm{Q} 2 \mathrm{~W}$ & & 8 & 1 & 4 & & 13 \\
\hline Q2W/Q2E & & & & & 1 & 1 \\
\hline Q3E & & 1 & & & & 1 \\
\hline Q3W & & 62 & & 43 & & 105 \\
\hline Q3W/Q4W & & 2 & & 17 & & 19 \\
\hline Q4E & 4 & 34 & 1 & 23 & & 62 \\
\hline Q4E/Q5E & & 1 & & 3 & & 4 \\
\hline Q4W & 35 & 201 & 2 & 83 & 2 & 323 \\
\hline Q5E & 65 & 65 & 1 & 79 & & 210 \\
\hline Q5W & 3 & 109 & 1 & 79 & & 192 \\
\hline O6W & & 27 & & 32 & & 59 \\
\hline Q7W & 1 & 50 & & 61 & & 112 \\
\hline Q8W & & 6 & & 5 & & 11 \\
\hline Q8E & & & & & 1 & 1 \\
\hline Q9E & & 8 & & 2 & 1 & 11 \\
\hline Q9E/Q10E & & 3 & & 2 & & 5 \\
\hline Q9W & & 2 & & 5 & & 7 \\
\hline Q11E & 2 & & & & & 2 \\
\hline eastern scarp & & 4 & 1 & 6 & & 10 \\
\hline Total & 159 & 773 & 14 & 520 & 6 & 1472 \\
\hline
\end{tabular}

Table 10.6

are widely distributed at Enkomi, which indicates that neither of these types were spatially restricted. Three important areas, Q5E, Q7W and Q10W, reveal a dominance of storage vessels, which is in contrast with the general pattern of the site. ${ }^{44}$ None of these precincts have been fully published, and

kind, see Table I in the tables section of this book.

When a distinction is made between open and closed vessels - with jugs assigned to the latter category there is a majority of 705 open vessels at Enkomi, against 600 closed vessels and 142 fragments.

44 In the case of Q5E it needs to be remarked that the number of fragments published from this part of the city, almost all found in Fr. T. 1336 which was published in detail by Johnstone (1971), is large enough to turn the relative proportions of these functional classes around. 


\begin{tabular}{|c|c|c|c|c|}
\hline date & fragments & dinner & ritual & storage \\
\hline IIIA & & 3 & & 1 \\
\hline ||B-IIIA1 & & 14 & & 20 \\
\hline IIIA2 & 14 & 193 & 6 & 120 \\
\hline$\||| A 2-\| \mid B$ & 11 & 170 & 3 & 174 \\
\hline$\| \mathrm{BB}$ & 47 & 353 & 5 & 165 \\
\hline$\||| B-\| \mid C$ & 3 & 22 & & 1 \\
\hline undatable & 84 & 18 & & 39 \\
\hline Total & 159 & 770 & 14 & 519 \\
\hline
\end{tabular}

Table 10.7

it is impossible to say at present whether this inconsistency indicates that in these areas Mycenaean storage vessels were particularly desired.

Of the four earliest Mycenaean pots at Enkomi, the majority belong to the class of dinner vessels, as is visible in Table 10.7. A predominance of Mycenaean dinner vessels can also be observed for Mycenaean vessels from LH IIIA2 onwards. Only among Mycenaean vessels in LH IIB-LH IIIA1 style do most belong to the storage category. However, if pots in LH IIIA1 style are considered separately, a balance is visible in the numbers of storage and dinner vessels. ${ }^{45}$ This suggests that in this period, during which an increase is visible in the number of Mycenaean imports at Enkomi, a larger proportion of dinner vessels began to arrive at the site. This trend is emphasised by the sharp increase in Mycenaean imports at the beginning of LH IIIA2 and continued into the LH IIIB period.

The category of Mycenaean ritual vessels consists of six conical rhyta (cat. nos. 1, 75, 162, 194, 204, 1064), three bull's head rhyta (cat nos. 49, 1046, 1323), two ostrich egg rhyta (cat nos. 911, 1378), one fragment of a bird which may have been attached to an ostrich-egg rhyton (cat. no. 1044) and a fragment of a rhyton of indeterminable shape (cat. no. 1150). Even though this class of pottery is relatively scarce in comparison with the total number of Mycenaean vessels at Enkomi, it is of interest that nowhere on Cyprus so many of these vases have been found together. ${ }^{46}$ The same may be said for figurines ${ }^{47}$ Moreover, it should be noted that both classes of pottery are widely distributed and do not seem to have been restricted in a spatial sense.

The contextual distribution of the four different Mycenaean ceramic categories is presented in Table 10.8. In all three types of context distinguished here, dinner vessels are more abundant than storage vessels. This phenomenon, however, is much less marked in funerary contexts than in houses or settlement levels in general. There does not seem to have been any restriction of specific Mycenaean functional categories to particular types of contexts (Table 10.9). The quantities of pots found in funerary contexts is for almost every Mycenaean vessel type far greater than the number of settlement finds. Only bowls are found more often in settlement levels, while the numbers are almost

45 Of the 25 LH IIIA1 pots, twelve are dinner vessels, thirteen storage pots.

${ }^{46}$ Apart from Enkomi, Åström (1972b, 354) mentions Kourion-Bamboula (site no. 122), Myrtou-Pigadhes (site no. 99) and Sinda (site no. 54) as sites with Mycenaean conical rhyta. Of these, only from Myrtou-Pigadhes he reports more than one specimen, namely two. Ostrich-egg and animal-shaped rhyta have been reported from Enkomi only. A conical rhyton has also been discovered at Kition (site no. 63), see Karageorghis 1985a, 89: no. 3442. Rhyta have also been found at Hala Sultan Tekke (site no. 65), see Öbrink 1983, 25: no. 51; Niklasson-Sönnerby 1989, 78 Fig. 143 (no. F6517), 79 Fig. 147 (F6521). 


\begin{tabular}{|c|c|c|c|c|c|c|}
\hline context & fragments & dinner & ritual & storage & figurines & total \\
\hline unknown & 17 & 29 & & 13 & 1 & 59 \\
\hline Funerary & 69 & 466 & 9 & 426 & 2 & 954 \\
\hline Domestic & 40 & 176 & 1 & 53 & 1 & 273 \\
\hline Settlement & 33 & 102 & 2 & 28 & 2 & 167 \\
\hline Total & 159 & 773 & 12 & 520 & 6 & 1453 \\
\hline
\end{tabular}

Table 10.8

\begin{tabular}{|c|c|c|c|c|c|c|}
\hline shape & unknown & funerary & domestic & pits & settlement & total \\
\hline kraters & 18 & 131 & 38 & 12 & 17 & 216 \\
\hline cups & 3 & 178 & 56 & 2 & 19 & 258 \\
\hline bowls & 5 & 83 & 55 & 9 & 34 & 186 \\
\hline stemmed cups/bowls & 1 & 18 & 13 & 1 & 2 & 35 \\
\hline jugs & 2 & 57 & 14 & 2 & 3 & 78 \\
\hline rhyta & & 8 & 2 & 1 & 1 & 12 \\
\hline composite vessel & & 1 & & & & 1 \\
\hline stirrup jars & 7 & 180 & 24 & 2 & 9 & 222 \\
\hline piriform jars & 5 & 165 & 19 & 1 & 13 & 203 \\
\hline other jars & & 4 & & & & 4 \\
\hline alabastra & 1 & 51 & 4 & & 2 & 58 \\
\hline flasks & & 25 & 6 & & 1 & 32 \\
\hline fragment & 17 & 68 & 41 & 1 & 33 & 160 \\
\hline
\end{tabular}

Table 10.9

equal for stemmed cups and bowls. In spite of the predominance of tomb finds for all Mycenaean vessel types, it is clear that none of the individual vessel types was restricted to funerary use. Even amphoroid kraters, which have often been assigned funerary functions, occurred outside tombs in substantial numbers. ${ }^{48}$ Similar conclusions may be drawn for the class of ritual vessels and for figurines. ${ }^{49}$

47 L. Åström (1972, 511-512) lists Alambra (site no. 71), Maroni (site no. 116), Sinda (site no. 54) and Hala Sultan Tekke (site no. 65) as find spots of Mycenaean terra-cotta figurines. Only Maroni and Alambra have produced more than one figurine, namely two. In Idalion (site no. 72), one Mycenaean female figurine has also been found, see Herscher 1998, 333. At Kition (site no. 63), a concentration of Mycenaean figurines has been found in the temple area, see Karageorghis 1985a, 98-99, 105, 170. Other figurines at this site came from the tombs, see Karageorghis 1974, 33, 44.

48 See, for example, Dikaios 1969, 249; Keswani 1989b, 58-69, who state that amphoroid kraters have specific funerary functions. Out of a total of 125 amphoroid kraters at Enkomi, thirty-six (30.4\%) have been found in settlement levels; seventy-eight (62.4\%) were discovered in tombs.

49 Five conical rhyta (cat. nos. 1, 75, 162, 194, 204) have been found in a tomb, while one (cat. no. 1064) occurred in a domestic context. One bull's head rhyton (cat. no. 49) was discovered in a tomb, while two others (cat. nos. 1046, 1323) occurred in settlement contexts. Ostrich egg rhyta occurred only in funerary deposits (cat. nos. 911, 1323). However, a clay fragment of a bird (cat. no. 1044) probably belonged to a similar vessel and was found in a settlement context. Three figurines came from settlement contexts, while two were discovered in a tomb. 


\begin{tabular}{|c|c|c|c|c|c|c|c|}
\hline site area & d.c.w. & plain & linear & patterned & pictorial & plastic & unknown \\
\hline unknown & 2 & & 16 & 56 & 26 & & 13 \\
\hline Q1E/Q2E & & & & 9 & 1 & 1 & \\
\hline Q1W & 8 & & 59 & 103 & 10 & 3 & 12 \\
\hline Q1W-west & & & 1 & 2 & & & \\
\hline Q2W & & & 1 & 11 & 1 & & \\
\hline Q3E & & & 1 & & & & \\
\hline Q3W & & 1 & 32 & 55 & 16 & & 1 \\
\hline Q3W/Q4W & & & 1 & 12 & 1 & & 5 \\
\hline Q4E & & & 8 & 29 & 16 & & 9 \\
\hline Q4E/Q5E & & & & 2 & 1 & & 1 \\
\hline Q4W & 9 & 2 & 136 & 133 & 30 & 1 & 10 \\
\hline Q5E & & & 65 & 101 & 3 & 1 & 40 \\
\hline Q5W & 4 & & 62 & 83 & 26 & & 17 \\
\hline Q6W & & & 16 & 33 & 3 & & 7 \\
\hline Q7W & & & 35 & 59 & 8 & & 10 \\
\hline Q8W & & & 1 & 8 & 2 & & \\
\hline Q9E & & & & 8 & 2 & & \\
\hline Q9E/Q10E & & & 2 & & & & 3 \\
\hline Q9W & & & 1 & 2 & 2 & & 2 \\
\hline Q11E & & & 1 & 1 & & & \\
\hline eastern scarp & & & 1 & 4 & 3 & & 3 \\
\hline Total & 23 & 3 & 439 & 711 & 151 & 6 & 133 \\
\hline
\end{tabular}

Table 10.10

The last subdivision of Mycenaean pottery of which the spatial and contextual distribution will be investigated is that according to type of ware and decoration (Table 10.10)..$^{50} \mathrm{~A}$ substantial number of coarse ware vessels have been found at Enkomi, in all cases large stirrup jars, possibly derived from Crete. The fact that these vessels have been found in both areas which have been fully published, as well as in Q5W, suggests that the use of these vessels at Enkomi was not restricted in a spatial sense. A limited quantity of plain ware vessels has been found, in all cases cups (cat. nos. 389, 1296, 1318). The great majority of Mycenaean vessels at Enkomi, however, has a decoration of abstract and floral patterns. ${ }^{51}$ Such a predominance of vessels with patterned decoration can be established for all city precincts, with the exception of Q4W, where a larger amount of linear decorated vessels has been found. Q4W has been fully published and the fragmentary nature of much of the ceramic material found in habitation levels is without doubt partially the cause of this high frequency of linear finds. However, Q1W has also been fully published but a high proportion of Mycenaean linear finds cannot be observed. It is possible that Mycenaean vessels with linear decoration were used more often than elsewhere in Q4W.

Only a few vessels with plastic decoration have been found at Enkomi. Three of these are bull's head rhyta (cat. no. 49, 1046, 1323), while there are two ostrich egg rhyta to which a bird has been

so In Table 10.10, the term 'unknown' includes finds of which the decoration is worn off, small, monochrome pieces of, for example, a foot or rim; and finds of which the decoration is not known to me, but which were clearly decorated. The abbreviation d.c.w refers to decorated coarse ware.

SI Considering the number of small fragments found in the settlement excavations, it is likely that many of the Mycenaean linear finds belonged to pots with patterned or pictorial decoration. 


\begin{tabular}{|c|c|c|c|c|c|}
\hline decoration & unknown & funerary & domestic & settlement & total \\
\hline unknown & 9 & 100 & 8 & 16 & 133 \\
\hline d.c.w. & 2 & 5 & 9 & 7 & 23 \\
\hline plain & & 1 & 2 & & 3 \\
\hline linear & 9 & 261 & 103 & 66 & 439 \\
\hline patterned & 26 & 494 & 126 & 65 & 711 \\
\hline pictorial & 13 & 106 & 22 & 10 & 151 \\
\hline plastic & & 3 & & 3 & 6 \\
\hline Total & 59 & 970 & 270 & 167 & 1466 \\
\hline
\end{tabular}

Table 10.11

\begin{tabular}{|c|c|c|c|c|c|}
\hline decoration & unknown & funerary & domestic & settlement & total \\
\hline hanging loops & 2 & & & & 2 \\
\hline various animals & 5 & 36 & 4 & 1 & 46 \\
\hline bulls & 1 & 24 & 6 & 2 & 33 \\
\hline men & & 7 & & & 7 \\
\hline chariot scene & 5 & 39 & 12 & 6 & 62 \\
\hline ship scene & & 1 & & & 1 \\
\hline Total & 13 & 107 & 22 & 9 & 151 \\
\hline
\end{tabular}

Table 10.12

attached (cat. nos. 911, 1378), and a fragment probably from a similar vessel (cat. no. 1044). Even though their number is fairly small, plastically decorated vessels do not seem to have been concentrated in particular parts of the city.

Vessels with pictorial decoration occur in most parts of the site. However, in Q5E, which figures prominently in terms of the presence Mycenaean pottery in general, pictorial vessels are absent, while Q1W, has produced relatively small quantities of it. In contrast, relatively a large number of Mycenaean pictorial vessels have been found in Q3W and Q5W. The spatial distribution of Mycenaean vessels with pictorial decoration, therefore, appears to differ from that of Mycenaean pottery in general. Even though pictorial pottery does not seem to have been spatially restricted, it may not have been used to the same extent everywhere in the city.

The unequal spatial distribution of Mycenaean pictorial pottery does not seem to be related to its use in tombs. Table 10. 11 shows that the proportion of Mycenaean pictorial pottery in tombs (70.1 $\%)$ is a little bit higher than that of Mycenaean pottery in general (66.1\%). However, this difference can be explained by the fact that tombs produce more complete vessels. The contextual distribution of different Mycenaean pictorial motifs is presented in Table 10.12.

Chariot scenes are the most frequent motif on the Mycenaean pictorial pottery at Enkomi, while bulls and various other animals also occur in substantial quantities. ${ }^{52}$ Most vessels in each of these categories have been found in tombs, but all of them occur in settlement levels as well, which suggests that none of these motifs had a specifically funerary connotation. Obviously, neither Mycenaean pictorial pottery as a general class, nor specific figurative motifs can be assigned exclusively funerary functions, as has been assumed..$^{53}$ Decorated coarse ware stirrup jars have also been found in tombs

52 Apart from bulls, other creatures represented among the Mycenaean pictorial pottery at Enkomi are: birds, stags, deer, fish, goats, lions, octopi and sphinxes.

53 For example, Dikaios 1969, 249; Keswani 1989b, 58-69. 


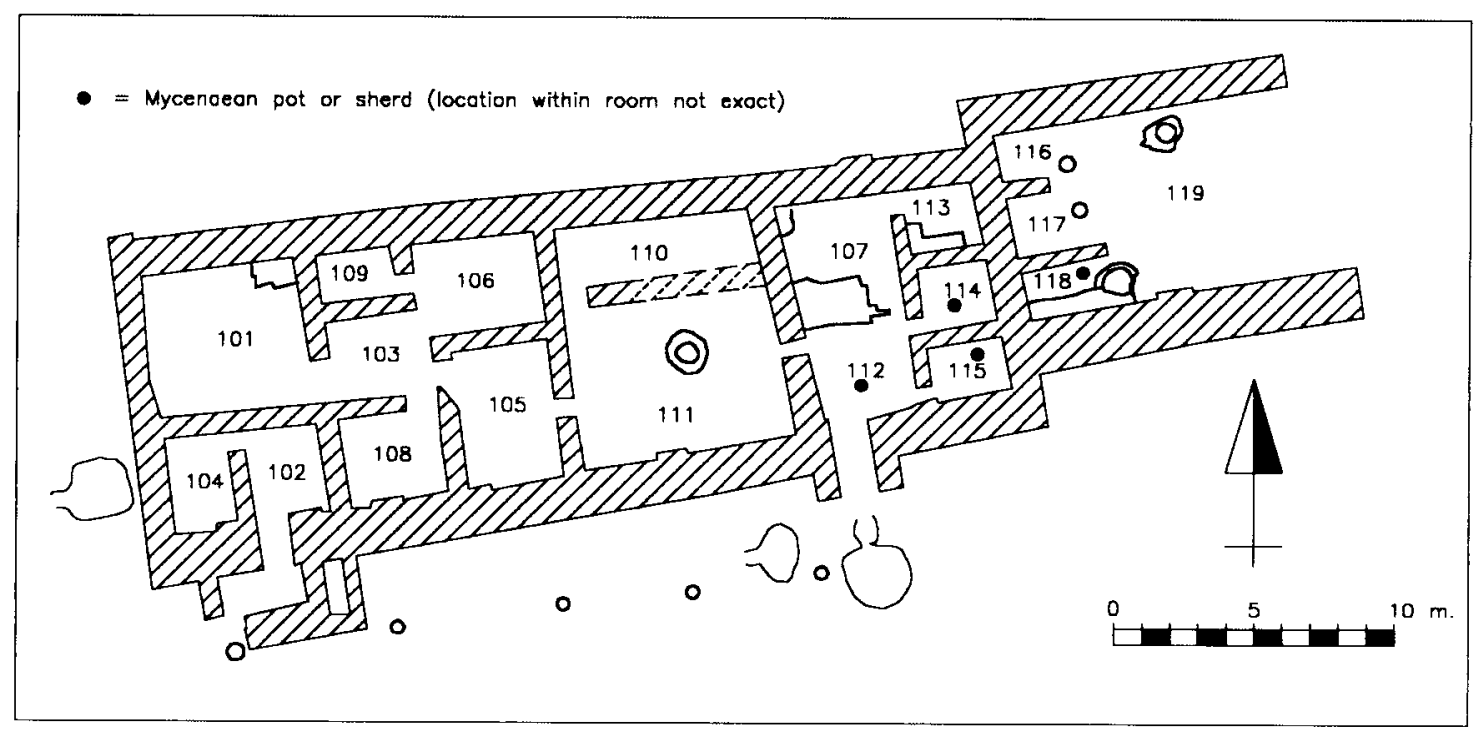

Fig. 10.2 Enkomi: Mycenaean pottery in the so-called Fortress

(Table 10.11), which may be somewhat surprising in view of their function as transport jars. Their presence in funerary contexts suggests that the use of this type of pottery was not purely functional, but had a symbolical dimension as well.

\section{SET T LEMENT CONTEXTS}

In Table VI, which is presented in the tables section of this book, all the non-funerary contexts in Enkomi have been listed in which Mycenaean pottery could be related to specific structures or activities. Many of these concern finds in leveling strata of which very little can be said, while in other cases we only know that a Mycenaean pot has been found. In some structures, such as in the so-called Ashlar building in area Q4W, most of the Mycenaean-type finds are in LH IIIC style. ${ }^{54}$ Even though earlier finds in these structures may indicate a prolonged use of Mycenaean vessels, they will not be discussed here. It must be emphasised that in many cases the Mycenaean (and other) ceramic finds in these buildings consisted of fragments only.

Q1W: Fortress - LC IB ${ }^{55}$ (Fig. 10.2)

The so-called fortress was a large, free-standing building of massive construction, containing at least two courtyards and seventeen rooms. The building possessed two entrances, both in the southern façade. During LC IB the western part of the building was completely devoted to metal working activities; a fragment of a clay tablet with Cypro-Minoan script in room 103 is possible testimony of ad-

54 Dikaios (1971, 485-486) claimed that LH IIIC sherds had been found in the make-up of the earliest floors of his Ashlar building and he dated the house to the LC IIIA period. Others, however, have stated that the construction of the building took place during LC IIC. In any case, it is clear that the major phases of occupation fall beyond the limits of the period which is investigated here.

ss Dikaios 1969, 16-34; 1971, 543-553. 


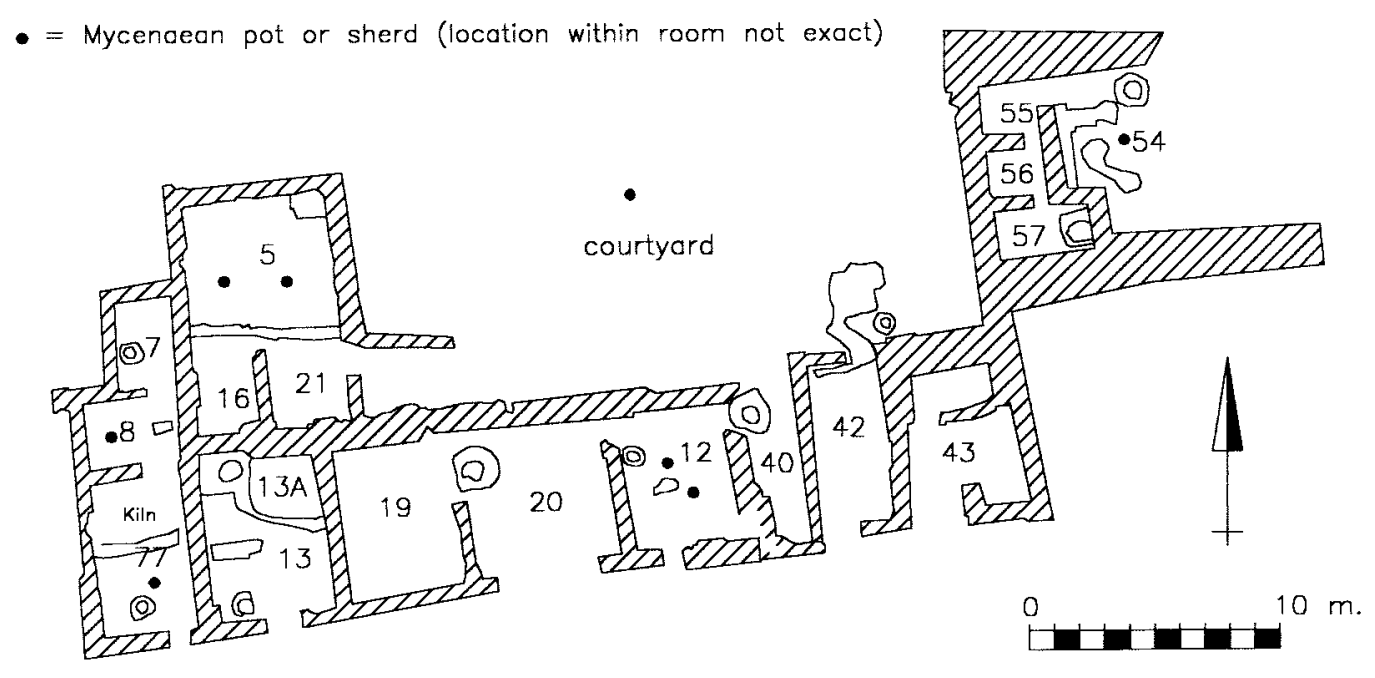

Fig. 10.3 Enkomi: Mycenaean pottery in the Q1W level IIA building

ministration of these activities. The eastern part of the building served residential purposes. The eastern entrance led to room 112, in which a succession of floors was attested, on the uppermost of which a fragment of a LH IIIA1 rounded alabastron (cat. no. 933) was found. From room 112, one could reach the three smaller rooms 113-115. In room 114, a well has been found and near the eastern wall there was a pit in which an amphora of Syro-Palestinian type was discovered. Floor VII of this room produced a fragment of a LH I rounded alabastron (cat. no. 932). A Syro-Palestinian amphora was also found in room 115, together with a LH I semi-globular cup (cat. no. 930). East of these three rooms was a courtyard and a kind of portico. Within the portico, in room 118 part of a LH I semi-globular cup (cat. no. 931) was found.

It is important to realise that the fortress covers a long period of use and that the Mycenaean and other finds may not have been in use simultaneously. Nevertheless, the Mycenaean pottery in this building is concentrated in the residential part, where imports from other areas have also been discovered. This shows that Mycenaean vessels during this early period were restricted to specific activities and it is likely that they were of special significance for the residents of this large house, who most probably were in control of metalworking facilities aimed at overseas exchange. ${ }^{56}$ The Mycenaean pottery in this building, then, is part of an inventory invoking wealth and international relationships. In this respect, it may be of significance that Mycenaean pottery dating to this period has not been reported from settlement contexts elsewhere on the site.

Q1W level IIA building - LC IIA-LC IIB ${ }^{57}$ (Fig. 10.3)

At the beginning of LC IIA, a new building was constructed at the site of the LC I fortress, which remained in use until the end of LC IIB. The ground plan of the new building consisted of three aisles around a central court, which was open on its northern side (Fig. 10.3). The long southern façade

s6 Keswani 1996, 222. Courtois $(1982,161)$ identifies evidence for metal working in the same period in area Q5W, which indicates that such activities were not re- stricted to the fortress.

57 Dikaios 1969, 34-46, 310, 1971, 554-560. 


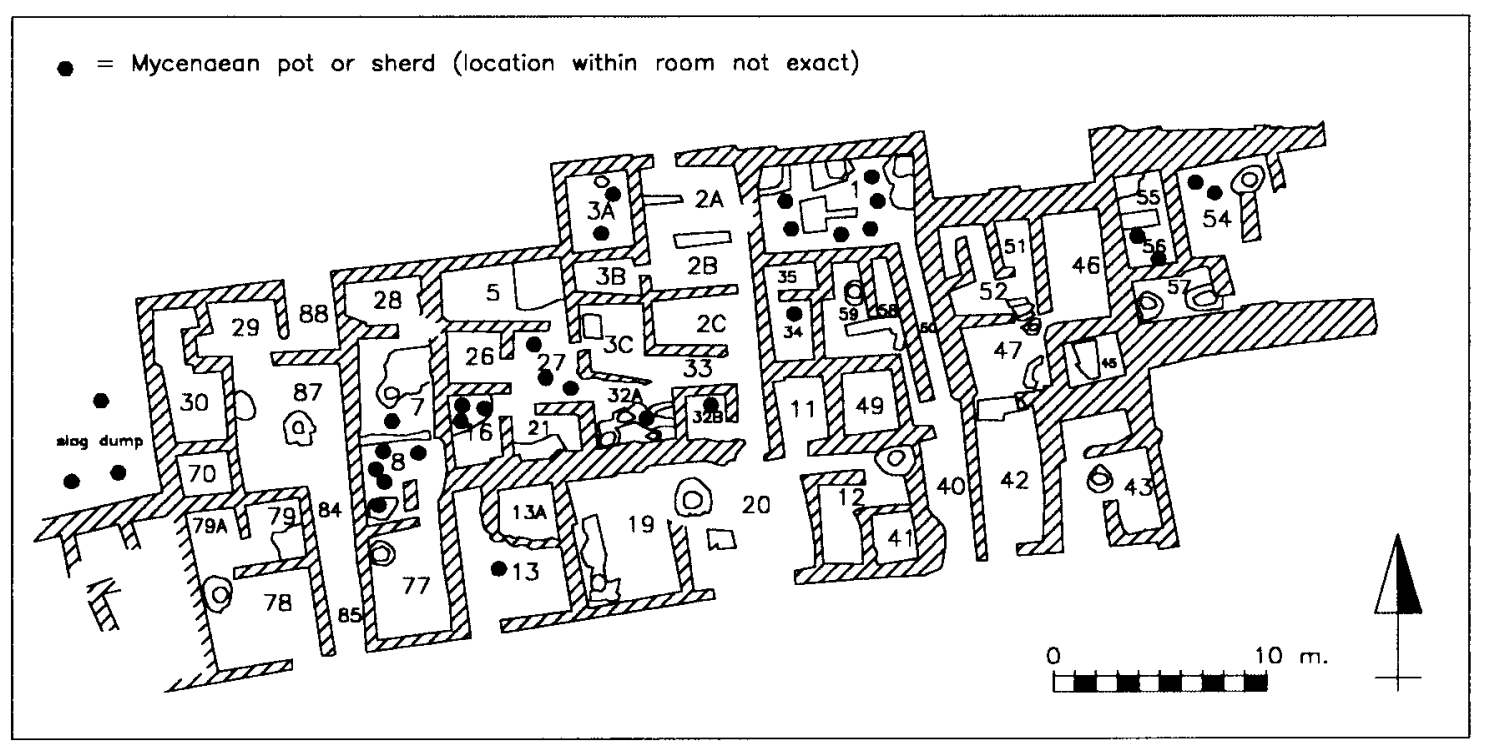

Fig. 10.4 Enkomi: Mycenaean pottery in the Q1W level IIB building

was broken up by a number of entrances. The westernmost entrance led to room 77 , which had traces of copper smelting. In this room, above a floor, a fragment of a LH IIIA2 stirrup jar (cat. no. 966) was found. One could continue to room 8 , which was probably used as a basement. Here, parts of a Mycenaean one-handled bowl were found (cat. no. 962). In the large room 5 a pit containing many animal bones was discovered, while a slab of baked clay indicated the position of a hearth. In this room, which has been interpreted as an area for food preparation, fragments of two Mycenaean vessels were found on the original floor: a shallow cup (cat. no. 961) and a LH IIIA2 amphoroid krater (cat. no. 968) decorated with a bull or goat. The succession of floors in this room produced a range of Mycenaean fragments, among which were six shallow cups (cat. nos. 960, 1189, 1190, 1193, 1194, 1196), two kraters (cat. nos. 1191, 1192), a stirrup jar (cat. no. 1197) and a flask (cat. no. 1195). ${ }^{58}$ From room 5, one could go to the large central courtyard, where a handle of a Mycenaean amphoroid krater (cat. no. 969) was found, together with the remains of copper working.

The central entrance to the building was probably in room 20. This part of the building presumably served as its residential section. Part of a Mycenaean piriform jar (cat. no. 964) was discovered just above the original floor of room 12, while a fragment of another piriform jar (cat. no. 963) was found in the same room at a higher level. a Syro-Palestinian amphora was found on the original floor in room 43. The north-eastern part of the building has been interpreted as fulfilling a variety of domestic purposes. Room 54 was probably a courtyard; a Mycenaean piriform jar fragment (cat. no. 963) was discovered here.

Mycenaean pottery is widely distributed in this building and has been found interspersed with objects testifying of daily activities. This indicates that this pottery was an integral part of the material culture of the inhabitants of the building. The clearest signs of copper working have been attested in room 77 and room 54. The occurrence of a stirrup jar and two piriform jars in these rooms suggests

s8 The high concentration of Mycenaean finds in this room is caused by the fact that Dikaios $(1969,310)$ has included this room in a section on 'special groups' of pottery which could be used to study the stratigraphy in detail. The vessels from this room derive from different levels in the room and it is uncertain whether similar layers in other rooms contained this much Mycenaean pottery. 


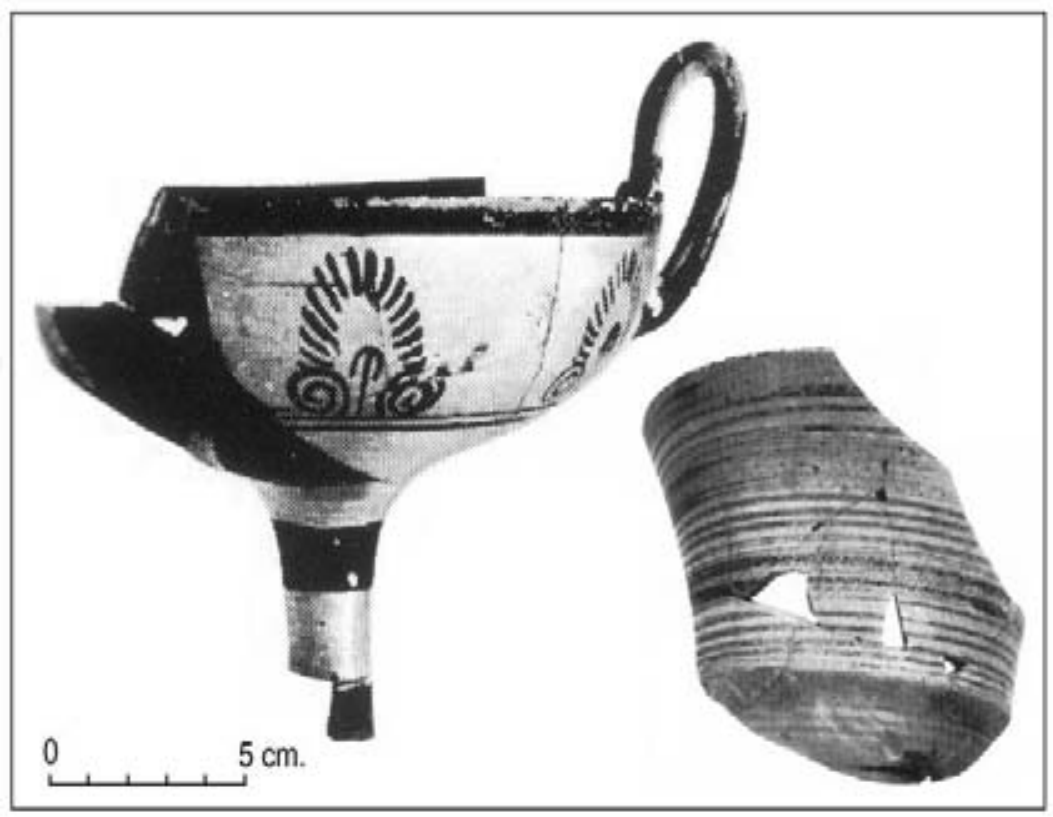

Fig. 10.5 Mycenaean kylix and chalice found together with Cypriot dinner vessels in room 3 A of the level IIB building - Photograph taken from Dikaios 1969 vol IIIa, Plate 67 nos. 1, 20 .

that storage vessels in particular were associated with these industrial activities. The one-handled bowl in basement 8 , however, shows that a Mycenaean dinner vessel also could occur in association with copper working. Moreover, the two Mycenaean piriform jars in room 12 show that storage vessels were present in a residential part of the building. The rooms with signs of a variety of domestic functions have produced mainly Mycenaean dinner vessels, although storage pots were present as well.

Q1W level IIB building - LC IIC ${ }^{59}$ (Fig. 10.4)

After the destruction at the end of LC IIB, a new structure was built in Q1W at the beginning of LC IIC. The building consisted of three distinct sections, each fulfilling specific functions. ${ }^{60}$ In the central section, a copper workshop was installed in the large room 1. In this room were found four Mycenaean shallow bowls (cat. nos. 1030, 1031, 1032, 1035), a fragment of an amphoroid krater with a chariot scene (cat. 1020) and a large coarse ware stirrup jar (cat. no. 1045), probably of Minoan origin. To the south of this workshop, a group of smaller rooms produced evidence for artisan activities. In room 34 a LH IIIA2 fragment (cat. no. 1168) was found together with an ivory pin, a wall bracket and a terra-cotta bead. West of this group of rooms was a residential area. In room 3A Base Ring and White Slip bowls were found, together with a Mycenaean kylix (cat. no. 1024) and chalice (cat. no. 1038) (Fig. 10.5). A locally produced derivative of a Mycenaean shallow bowl was also found here. Together with animal bones these vessels indicate that dining occurred in this room. In the rooms $3 \mathrm{~B}$ and $3 \mathrm{C}$, which also belonged to the residential section, a variety of luxury objects, such as a silver ring, a paste bead, a bone stylus and a cylinder seal were found. To the south, rooms 32A and 32B were courtyards; two Mycenaean shallow cups (cat. nos. 1018, 1019) were found here. One could

59 Dikaios 1969, 46-66; 1971, 561-571.

6o These sections are separated from each other by walls and the rooms do not communicate. One could argue that they represent independent entities. 


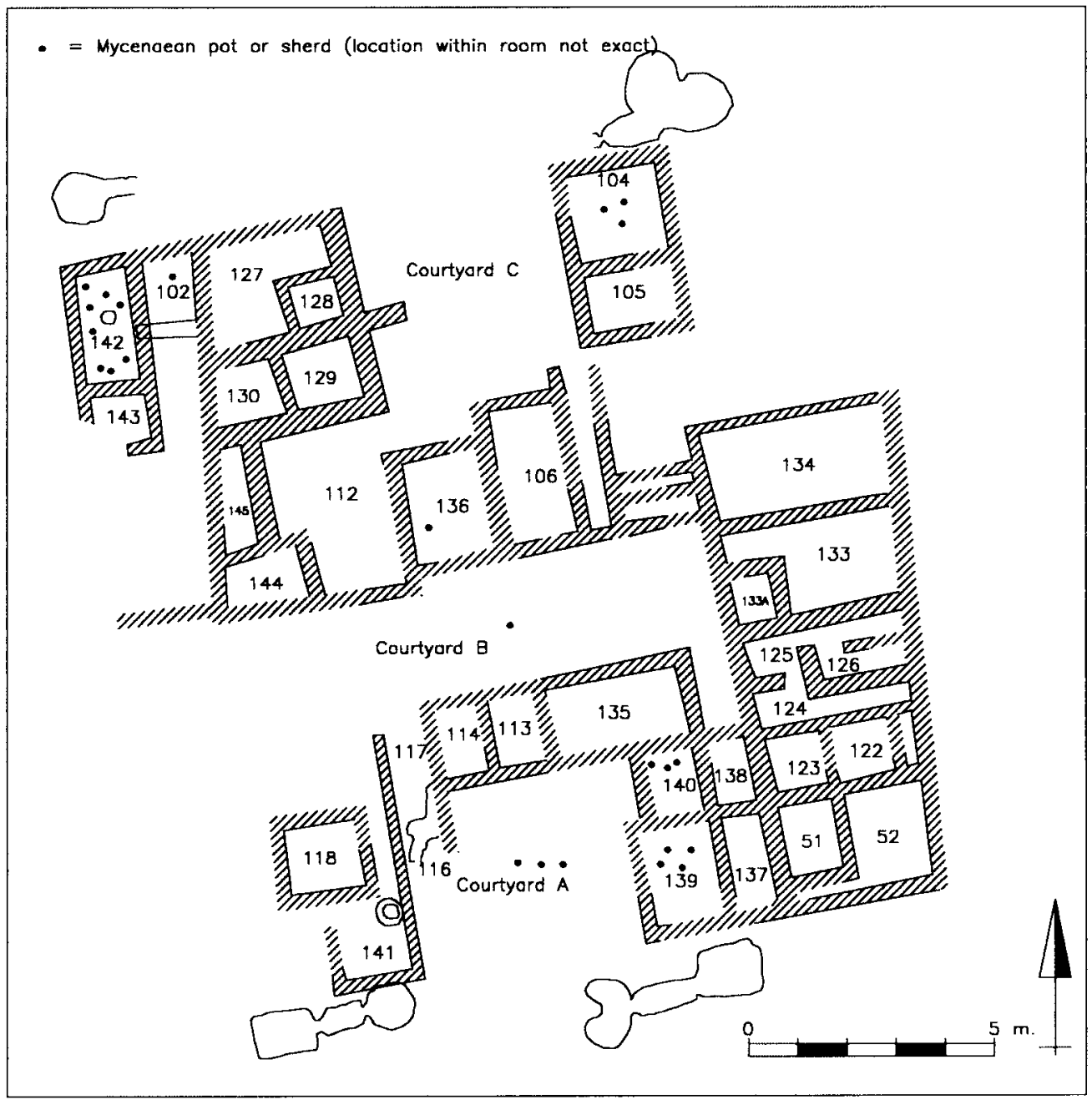

Fig. 10.6 Enkomi: Mycenaean pottery in the Q4W level IIb structure

continue to room 27, where a bird-shaped fragment, probably from a Mycenaean ostrich egg rhyton (FS 201) was discovered (cat. no. 1044), together with a bowl of white glass. A Mycenaean shallow cup (cat. no. 1028) and shallow bowl (cat. no. 1037) were also found here. A pit with three grinders and deer antlers testify of food preparation in room 16; three Mycenaean shallow cups (cat. nos. 1011, 1012, 1017) were also discovered in this pit. Via a staircase in room 21, one could reach room 13, where a fragment of a Mycenaean bull's head rhyton (cat. no. 1046) was found, in association with a clay ball with engraved Cypro-Minoan signs.

The western section of the building has produced the most extensive evidence for copper working. In room 7 a plastered floor and a well suggest water-related activities; a LH IIIB-LH IIIC deep bowl (cat. no. 1029) was found on the latest level of this room. Room 8 contained a bench, in the masonry of which a Mycenaean krater fragment was found (cat. no. 1023). On the floor of this room crucibles, copper slag, a cylinder seal and six clay balls with Cypro-Minoan signs were discovered, as well as three Mycenaean shallow cups (cat. nos. 1014, 1015, 1016) and an amphoroid krater fragment (cat. no. 1022). Slag dumps were located to the north-west of the building. Two Mycenaean shallow bowls (cat. nos. 1255-1256) and a fragment (cat. no. 1254) were found in these dumps. 
The eastern section of the building has been interpreted as serving a variety of domestic and industrial functions. Room 56 produced a cylinder seal, a stone bead and a Mycenaean chariot krater (cat. no. 1021), as well as a small globular jug (cat. no. 1040). Room 54, probably a courtyard, produced a Mycenaean ring-based krater (cat. no. 1026) and a stirrup jar (cat. no. 1042).

A few concentrations of this pottery are visible in this building: in room 1 in the central section and in rooms 7 and 8 in the eastern section. Both areas can be associated with copper working, indicating that Mycenaean kraters, bowls, cups and stirrup jars, were associated with these activities. The domestic part in the centre of the building has produced a number of Mycenaean vessels of types which are not very frequent at Enkomi: a bull's head rhyton, a fragment probably deriving from an ostrich egg rhyton, a kylix and a chalice (Fig. 10.5). The two Mycenaean drinking vessels were found together with similar vases of Cypriot manufacture. This indicates that Mycenaean cups were not appreciated any more or less than local drinking vessels. It is, of course, interesting that the bull's-head and ostrich egg rhyta have been found close together. They may be testimony of the use of Aegean vessels in ritual ceremonies in this part of the house.

Q4W level IIB structure - LC IIC ${ }^{61}$ (Fig. 10.6)

In Q4W, in the beginning of LC IIC, a large structure was built with an elaborate architectural layout, comprising at least three courtyards and some forty rooms. ${ }^{62}$ Two fragments of a LH IIB-LH IIIA1 stemmed cup (cat. no. 971) were found in courtyard A, together with part of a LH IIIB ringbased krater (cat. no. 1006) decorated with a bull; a shallow cup fragment (cat. no. 975) was also discovered here. The mud-and-mortar floors of rooms 139 and 140 as well as their location suggest that these rooms served residential purposes. In room 140, fragments of a Mycenaean stemmed cup (cat. no. 972), a shallow cup (cat. no. 975) and a LH IIIB fragment (cat. no. 1005) were found, but all in the make-up of the floor or just below it. In the larger room 139 fragments of a Mycenaean piriform jar (cat. no. 1001), a stemmed cup (cat. no. 970), a krater (cat. 1004) and a shallow bowl (cat. no. 988) were found in levels above the floors, showing that dinner as well as storage vessels were used in this part of the house.

In the eastern wing (rooms 51, 52, 122-126, 133-134), which probably had a residential purpose, few objects were found on the floors. The central part of the structure adjoined a courtyard on both the northern and southern sides. In room 136 part of a LH IIIB deep bowl (cat. no. 982) was found on floor IV, which produced very few other finds. The north-western wing of the building (rooms 102, $112,127-130,144,142-145)$ included the remains of the level IIA building. Few finds have been reported from this area, but the stratigraphic description of room 142 reveals that fragments of Mycenaean stirrup jars (cat. nos. 998, 1010), jugs (cat. no. 997, 1167), shallow cups (cat. nos. 973, 983, 1162, 1163, 1164, 1166), shallow bowls (cat. nos. 987, 992, 1169-1170) and of a cylindrical cup (cat. no. 985) and a piriform jar occurred on and between the floors attributed to LC IIC. The presence of such a wide variety of Mycenaean vessel types together suggests that these were appreciated similarly. In the north-eastern corner of the building, rooms 104 and 105 are somewhat isolated from the rest of the house. Room 104 yielded Cypriot hand-made sherds, as well as Base Ring and White Slip II vessels. A Mycenaean amphoroid krater fragment with a chariot scene (cat. no. 977) was found in this room as well, just as shreds from a LH IIIB kylix (cat. no. 995) and a shallow bowl (cat. no. 986).

6r Dikaios 1969, 163-170; 1971, 561, 573.

62 Dikaios $(1969,168)$ considered the building to be one coherent whole, but the presence of three courtyards, one of which separates the southern and northern parts, suggests that the structure may have consisted of more than one house. 
Mycenaean pottery appears to be concentrated in the southern, north-western and north-eastern sections of this building. However, this picture is caused by the lack of finds in the other rooms. Because of these circumstances the cultural associations of the Mycenaean pottery in this building are not fully known. Signs of industrial activities have not been reported; the structure appears to have possessed a predominantly residential character. A wide range of Mycenaean vessels, among them two pictorial kraters, was part of the inventory of this building.

The purpose of this section was to determine whether a differentiation can be made within the general class of Mycenaean pottery in its occurrence in settlement levels at Enkomi. In terms of repertoire, it is clear that the LC IIA-LC IIB building yielded a wide variety of Mycenaean pots. A similar variety of stirrup jars, piriform jars, amphoroid kraters, shallow cups, bowls and a number of jugs has been published from a room in the contemporary building in Q4W. ${ }^{63}$ The variety of Mycenaean vessel types was even higher in the LC IIC phase, when kylikes, ring-based kraters and deep bowls were added to the repertoire. The two investigated LC IIC buildings have produced more or less the same Mycenaean repertoire. The successive buildings in Q1W all served residential purposes, while at the same time they were the location for copper working. The buildings in Q4W have not produced much evidence for the activities of artisans. Even though the superimposed structures in this area were all large and probably served multiple purposes, their main function appears to have been residential. Indeed, it is possible that the large buildings included more than one house. The structures in Q4W, therefore, differ in character from those in Q1W. The fact that these buildings have produced similar ranges of Mycenaean pottery suggests that this material was not subject to consumptive restrictions at Enkomi.

I have found no situations in which specific Mycenaean types appear to have been deliberately chosen for specific purposes. Such particularisation did not occur with respect to Mycenaean vases with pictorial decoration. According to Keswani, the iconography of Mycenaean chariot kraters fits in with aristocratic lifestyles and these vessels may be associated with social élites at Enkomi ${ }^{64}$ Such a krater (cat. no. 949) occurred together with other Mycenaean vessels in a LC IIA-LC IIB building in Q4W. ${ }^{65}$ A fragment of such a vessel decorated with a bull or goat (cat. no. 967) was discovered in level IIA just outside the Q1W building in an area where slag was dumped. Two chariot scenes have been reported from the LC IIC building in Q1W; one came from the copper workshop and was found together with a coarse ware stirrup jar, while another occurred in a residential area and was associated with a bead and cylinder seal. From the same period, a chariot krater has been discovered in the Q4W building in association with local coarse ware bowls. Another chariot krater was found in a pit dating to LC IIIA in the so-called Ashlar building, together with pots in LH IIIC style and implements for the making of stone tools. ${ }^{66}$

The evidence above shows that there are a few instances at Enkomi in which Mycenaean pictorial pottery has been found together with other valuable objects. However, this was not the case for most of the pictorial vessels and, in general, the contexts of such vessels are not different from that of other, non-pictorial pottery. Even though the Mycenaean pictorial finds discussed here do not represent complete vessels, it seems that vessels with pictorial decoration were not restricted to certain social

63 Dikaios 1969, 237-239; 308.

${ }^{64}$ Keswani 1989a, 562-565; 1989b, 62. See, also, Leonard 1987, 264-266.
65 Dikaios 1969, 308.

66 Dikaios 1969, 177. 
groups or to specific activities. In non-funerary situations, these vessels do not seem to have served in strategies of consumptive display.

\section{F U NERARY CONTEXTS}

It has been estimated that as many as one thousand tombs had been discovered at Enkomi, of which the overwhelming majority by clandestine tomb robbers. ${ }^{67}$ Somewhat more than 180 tombs have been investigated more or less systematically, but the extent to which these have been published varies. ${ }^{68}$ All burials have been found within the enclosure of the city wall, in the settlement area (fig 2.1). However, not all burials appear to have been directly related to settlement structures. Twentyfour tombs were discovered on the eastern scarp, where other architecture seems unlikely. Other tombs date from before the rectangular street layout and probably were originally situated in open spaces between the buildings. ${ }^{69}$ Only a limited number of funerary cellars has been discovered which clearly formed a structural part of the building below which they were situated. ${ }^{70}$

The lack of any data from the numerous pillaged tombs and the incomplete information for many of the published tombs severely limit the possibilities for funerary analyses. In addition, the majority of the tombs have served for collective burial. Many tombs were in use for a very long period and frequently opened for reuse, during which funerary assemblages were disturbed and valuable objects may have been removed. ${ }^{71}$ The relationship between individual tombs and social groups at Enkomi is difficult to assess. It is uncertain whether the use of a tomb was confined to specific people and, if so, whether these were families or wider social groups. Nevertheless, the tombs may be used as units for analysis and important work in this respect has been done by P. Keswani, who has studied variabilities in tomb architecture and in find assemblages. ${ }^{72}$

In Table VII in the tables section seventy-nine tombs are listed from which Mycenaean pottery has been reported. This figure is relatively low in comparison with the ca. 180 tombs which have been investigated, which is probably caused by the extent to which the inventories have been published. ${ }^{73}$ It

67 Keswani 1989a, 335.

68 Descriptions, in many cases very short, of the inventories of ninety-six tombs investigated by the British Museum expedition have been published; see Murray Smith \& Walters 1900, 51-54; Myres \& OhnefalschRichter 1889, 183-186. No description has appeared from British tombs 13, 18, 26 and 42. The inventories of this expedition have been investigated by Keswani (1989a, 468-475; 1989b), who also studied the field notebooks, and by L. Mol (pers. comm.). The inventories of the twenty-two tombs explored by the Swedish mission have been extensively published, see Gjerstad et al. 1934, 468-575. This is also the case for the tombs excavated by Dikaios' team; see Dikaios 1969, 333434. Of the thirty-seven French tombs, eighteen have been published in some detail, the inventories of other tombs are only partly known; see Schaeffer 1952, 105237, Johnstone 1971; Courtois 1981; Lagarce \&
Lagarce 1985.

69 Several tombs were sealed by street pavement or by walls of houses when the street layout was created, see, for example, Courtois, Lagarce \& Lagarce 1986, 29 (Fr. T. 5); Dikaios 1969, 357 (Cy. T. 10).

70 For example Fr. Tombs 1322, 1394 and 1409; see Courtois, Lagarce \& Lagarce 1986, 24-26 Fig. 4.

${ }^{71}$ Keswani 1989b, 52. French tomb 5 appears to have been in use from LC I into LC III, a period of at least four centuries; see Schaeffer 1952, 220-226.

72 Keswani 1989a, 335-345, 567-602; 1989 b.

73 In the publication of Br. T. 19, for example, a brief reference is made to a Mycenaean krater (cat. no. 1450) but no other pottery has been published, see Murray, Smith \& Walters 1900, 33. According to Keswani (1989b, 77 Table 1), other Mycenaean vessels derive from this tomb, but these are unknown to me. 
is very likely that Mycenaean pottery has been found in more tombs than listed in Table VII. The majority of the seventy-nine tombs at Enkomi with Mycenaean pottery are of the rock-cut chamber type, but such material has also been reported from two tholos tombs (Sw. T. 21 and Fr. T. 1336). Of the two other tholos tombs at Enkomi, Br. T. 71 has not been published, while Fr. T. 1432 was found completely empty. ${ }^{74}$ Mycenaean pottery has also been reported from two ashlar-built tombs (Br. T. 12, 66). Very little is known about the other ashlar tombs. Only short descriptions of the inventories of British tombs 1 (= Fr. Tomb 1409) and 11 have appeared, ${ }^{75}$ while French tomb 1394 was found almost empty. ${ }^{76}$ Twenty shaft graves have been reported from Enkomi, none of which produced Mycenaean vessels. The absence of this type of pottery from shaft graves may partly be caused by the relative paucity of finds from such tombs in general. ${ }^{77}$ In addition, the majority of such graves at Enkomi date from an advanced stage of LC III. It is clear then that Mycenaean pottery at Enkomi was not restricted to a particular type of tomb. Even though it is difficult to relate the different types of tombs to social groups in the society of Enkomi, ${ }^{78}$ it seems that the use of Mycenaean pottery in funerary ceremonies was not confined to specific inhabitants, but a widespread phenomenon. The wide spatial distribution of the tombs at Enkomi with Mycenaean pottery may be taken as additional evidence for such a widespread use of this material.

The tomb at Enkomi from which the largest amount of Mycenaean pottery has been reported is French tomb 1336, which has produced ninety-eight vessels. This tomb, a tholos tomb situated in Q5E, has been published in detail. ${ }^{79}$ The five other tombs which also have produced large quantities of Mycenaean material are fully published. ${ }^{80}$ From all other tombs far fewer Mycenaean vessels have been reported. Sw. T. 19 and Br. T. 66 each produced twenty-eight Late Helladic vases, but in most cases only a few Mycenaean finds were made. ${ }^{81}$ This suggests that the quantities of Mycenaean vessels indicated in Table VII primarily reflect the state of publication and tell us very little about possible variation among social groups at Enkomi with respect to including Mycenaean pots in their funerary ritual. What may be noted, however, is that the six tombs with large amounts of Mycenaean pottery are situated in five different city quarters. This is another indication that the inclusion of large amounts of Mycenaean pottery in tombs was not confined to specific groups within the society of Enkomi.

The long use of the Enkomi tombs makes it difficult to differentiate chronologically among them. On the basis of the primary components of their inventories, Keswani has been able to distinguish four chronological groups: MC III-LC I (1), LC IA/B-LC IIA/B (2), LC IA/B-LC IIC/LC III (3) and LC IIC/LC IIIA-LC IIIB (4). ${ }^{82}$ The second and third groups overlap chronologically, but, ac-

74 Courtois, Lagarce \& Lagarce 1986, 49-50; Keswani 1989b, 53-54.

75 The only information available for Br. T. 1 is that a lapis lazuli gem and two golden earrings were found in this tomb, see Murray, Smith \& Walters 1900, 41. Of Br. T. 11 we know only that a fragment of a faience zoomorphic rhyton was found in it, see Murray, Smith \& Walters 1900, 51.

$7^{6}$ Courtois, Lagarce \& Lagarce 1986, 24-26; Keswani 1989b, 54-55

77 Keswani 1989b, 56, 69.

78 In terms of effort expenditure (Brown 1981, 29) the tholos and ashlar tombs would rate higher than the rock- cut chamber tombs. However, such a ranking does not seem evident from their inventories, which argues for caution; see, also, Keswani 1989b, 54-55.

79 Johnstone 1971

8o Sw. T. 18 (78 pots), see Gjerstad et al. 1934, 551-557; Cy. T. 10 (75 pots), see Dikaios 1969, 357-394; Sw. T. 11 (62 pots), see Gjerstad et al. 1934, 515-524; Sw. T. 3 (54 pots), see Gjerstad et al. 1934, 477-485; Fr. T. 110 (43 pots), Courtois 1981, 131-257.

81 Less than five Mycenaean finds have been reported from forty-three tombs.

82 Keswani 1989a, 567-600. The first group is not discussed in Keswani 1989b. 


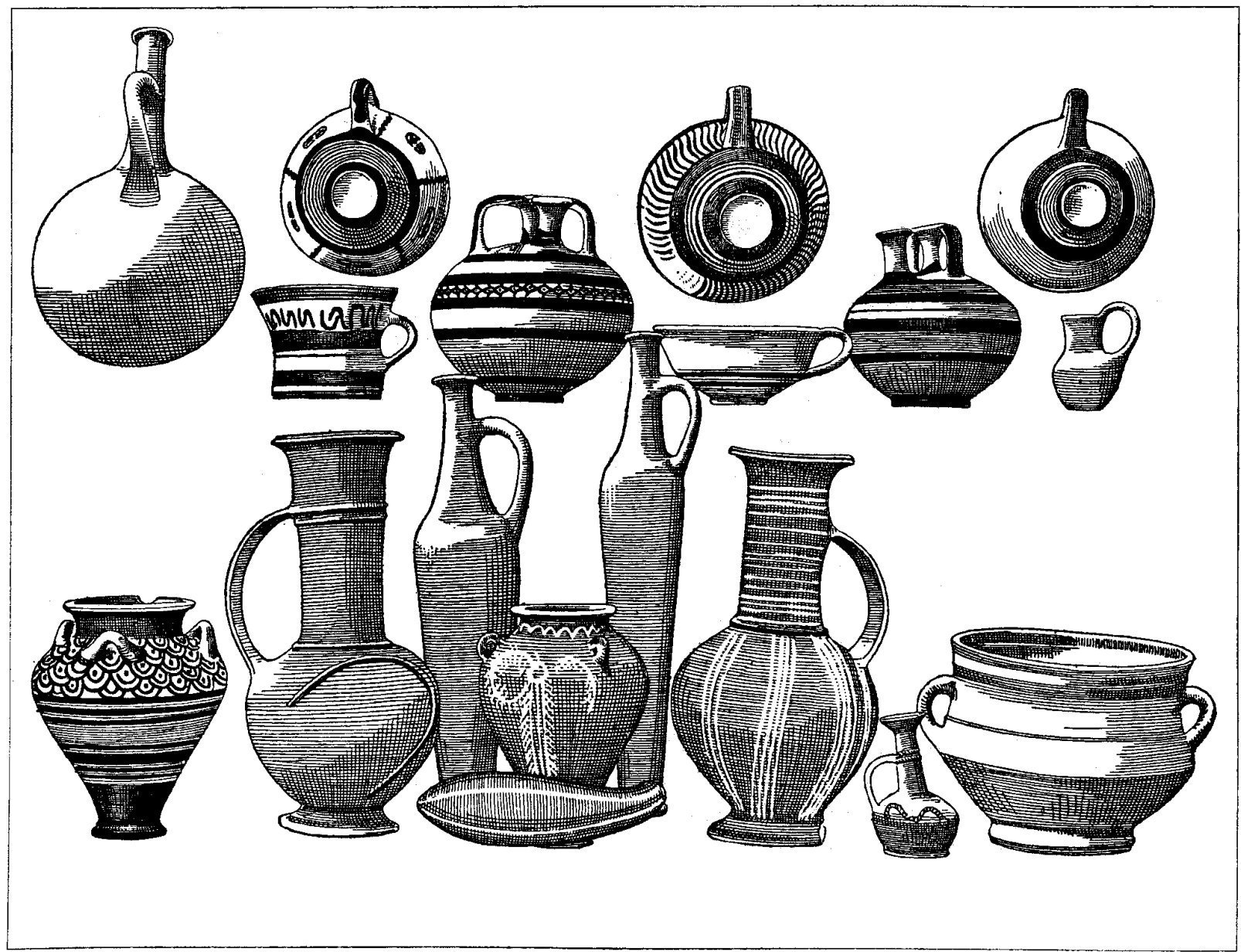

Fig 10.7 Enkomi: Mycenaean and other objects from Br. T. 84 - After Murray, Smith \& Walters 1900, 66 fig. 38

cording to Keswani, tombs in the second group have their primary use before LC IIC. Tombs in the third group were either used for a very long period from LC I onwards or had their primary use in LC IIC. Only a limited number of tombs can be assigned definitively to the second and third groups. ${ }^{83}$ None of the tombs which have produced Mycenaean pottery can be assigned to the first group, which is logical in view of their early date.

Eight tombs listed in Table VII can be assigned to the second chronological group: British tombs 19 and 67, Swedish tombs 2 and 17, French tombs 2, 11 and 110 and Cypriot tomb 19. None of these are among the tombs which have produced large quantities of Mycenaean pottery; French tomb 2 provided most Mycenaean finds: seventeen vessels. This may not be surprising in view of the state of publication of the British and French tombs. ${ }^{84}$ The Swedish and Cypriot tombs are fully published, however, and the absence of large amounts of Mycenaean pottery in the tombs from this chronological group suggests that the quantities of this material included in funerary rituals were smaller in the

83 Keswani (1989b, 77-78) assigns thirteen tombs to group 2 and sixteen to group 3 . The remaining tombs with a LC I-LC II date apparently could not be as- signed to either group.

${ }^{84}$ Moreover, we should realise that most of these tombs were pillaged before they were excavated. 
period before LC IIC than in that period itself. Four of the six tombs with large quantities of Mycenaean pottery can definitively be assigned to Keswani's third group. ${ }^{85}$ Only one tomb $-\mathrm{Br}$. T. 58, from which a LH IIIA2 piriform jar (cat. no. 231) has been reported - can be assigned to Keswani's fourth chronological group.

Table VIII in the tables section provides an overview of the frequency of Mycenaean vessel types in the tombs of Enkomi. These figures show that Mycenaean dinner vessels are only slightly more abundant in the tombs than storage vessels. This is not in agreement with the general pattern at Enkomi, where the quantitative difference between these two classes is far greater. A high frequency of Mycenaean dinner vessels cannot be observed in all funerary cellars. In fact, of all the tombs from which more than ten Mycenaean finds have been reported, a majority of fifteen possessed more storage than dinner vessels. ${ }^{86}$ A few tombs however, such as Sw. T. 18 and 3, as well as Cypriot tomb 10, have produced a great many cups, bowls and kraters to which the predominance of Mycenaean dinner vessels in tombs can largely be attributed. In general, it seems that Mycenaean dinner vessels and storage pots were considered equally suitable to be included in funerary inventories.

Cups, in particular of the one-handled, semi-globular variety (FS 219-220), are the most frequent Mycenaean vessel type in the Enkomi tombs. ${ }^{87}$ Just as abundant are stirrup jars, of which a similar quantity has been found in the funerary cellars. Mycenaean piriform jars and kraters also are frequent in the tombs. Apart from the large quantities of these four vessel types in funerary contexts, they also appear to have been widely available: the majority of tombs which have produced more than ten Mycenaean pots include these types. However, stirrup jars and piriform jars occur in more tombs than cups and kraters. ${ }^{88}$ This suggests that the use of kraters and cups in funerary rituals was less widespread than that of stirrup jars and piriform jars. The distribution of Mycenaean bowls in funerary contexts likewise appears to have been somewhat restricted, but this is not the case for stemmed cups and bowls, jugs, alabastra and flasks. The relative concentration in the distribution of cups, bowls and kraters in the tombs at Enkomi - albeit low - indicates that not all inhabitants of Enkomi included these vessels, which can directly be associated with dining, in funerary ceremonies.

Nine tombs at Enkomi have produced Mycenaean ritual vessels and figurines. It is of interest that these items, which were scarce in Enkomi in general, have been found widely distributed: British tomb 53 produced a Mycenaean bovine figurine (cat. no. 2001) in association with a conical rhyton (cat. no. 1); all the other specimens from tombs are singletons. In some cases these tombs contained many other Mycenaean finds, such as Br. T. 88, Br. 67, Br. T. 12, Cy. T. 10, Cy. T. 110, but this may not always have been the case. ${ }^{89}$ Mycenaean rhyta, whether of conical or other shape, were scarce at Enkomi and such objects probably belonged to the paraphernalia of cult and other ceremonies. ${ }^{90}$ The fact that these objects have not been found concentrated in a few tombs may suggest that funerary use

85 Swedish tombs 3, 11 and 18; Cypriot tomb 10.

86 These tombs are Br. T. 43, 45, 67, 68, 78, 83, 88, 91; Fr. T. 2, 5, 11, 110, 1907; Sw. T. 11, 13. Eleven tombs yielded a majority of dinner vessels: Br. T. 12, 48, 66, 69, Cy. T. 10, Fr. T. 12, 1336, Sw. T. 18, 19, 3, 6.

${ }^{87}$ A total of 138 semi-globular, shallow cups have been found. In addition, conical cups (FS 230-232) cups with horizontal handles (FS 242-244) and handleless cups (FS 207-210) occur.

${ }_{88}$ Piriform jars are the most widely distributed
Mycenaean vessel type among funerary contexts: they have been reported from forty-eight tombs, while stirrup jars occurred in fort-six tombs. In contrast, cups and kraters have been discovered in thirty-eight and thirty-nine tombs respectively.

89 From Br. T. 70, Br. T. 93 and Br. T. 53 less than ten Mycenaean finds have been reported. None of these tombs, however, has been fully published.

90 Yon 1986; Zaccagnini 1987, 58. 
of these vases was not restricted to a few persons, but their number is actually too small to draw any conclusions.

The long use of the Enkomi tombs, their pillaging and the sometimes poor state of publication make it difficult to analyse them in terms of the wealth of their inventories. Nevertheless, it is clear that differences in social status were expressed in the tombs through the inclusion of material wealth and special objects in their inventories, at least from LC IB-LC IIA onwards. ${ }^{91}$ Rich tombs possessed a range of elaborate gold jewelry, metal vases, objects of a high iconographic content, such as signet rings and seals, and objects such as weights that refer to trade in metals. Mycenaean pottery could be part of such wealthy funerary inventories, as is testified, for example, by British tomb 67 in Q1E/Q2E, which contained eleven Mycenaean vases in addition to a large quantity of gold jewellery, among which were two signet rings, stone beads and weights, as well as imported alabaster vases. ${ }^{92}$ Another example is Swedish tomb 17, which also yielded substantial quantities of gold jewellery, ivory and a stone cylinder seal and seven Mycenaean pots. ${ }^{93}$ However, Mycenaean vessels have also been discovered in substantial quantities in tombs with less evidence of material wealth, such as French tomb 1907, which did not produce any golden objects. ${ }^{94}$ Another example is Swedish tomb 13, which produced only one golden earring, along with three objects of faience. ${ }^{95}$ The occurrence of Mycenaean pottery in tombs with varying degrees of material and symbolical wealth indicates that such vessels were considered suitable to be included in the funerary rituals of inhabitants belonging to different social groups at Enkomi. As a general class of material these vessels cannot be considered indicative of high, or indeed any, status.

The above statement should be differentiated with regard to Mycenaean vessel types. According to Keswani, the distribution of Mycenaean kraters is not equal, with some tombs possessing none or only a few, while others have produced notable quantities of such vessels. ${ }^{96}$ According to her, this may be related to the iconography of the pictorial scenes with chariots or bulls, which relate well to an aristocratic lifestyle. ${ }^{97}$ Concentrations of Mycenaean kraters are notable in Swedish Tomb 3, which has produced twenty-two such vessels; ${ }^{98}$ British tomb 12 yielded thirteen, ${ }^{99}$ and the side chamber of Sw. T. 18 had eleven kraters. ${ }^{100}$ In each of these tombs some of the kraters possessed pictorial decoration. Also, in the cases of Swedish tombs 3 and 18 substantial amounts of gold jewelry and other valuable objects have been found, ${ }^{101}$ indicating that such vessels were indeed associated with material wealth. At the same time, it should be noted that only limited amounts of Mycenaean kraters have been reported from some very wealthy tombs such as British tombs 19 and $93 .{ }^{102}$ Moreover, all the kraters from Swedish tomb 18 came from the side chamber, while the main chamber, which was considerably more wealthy, did not produce any such vessels. ${ }^{103} \mathrm{~A}$ few tombs with an otherwise modest

91 Keswani 1989b, 68-70.

92 Murray, Smith \& Walters 1900, 52.

93 Gjerstad et al. 1934, 543-546: cat. nos. 499-505.

94 Lagarce \& Lagarce 1985, 139-141: cat. nos. 915-929.

95 Gjerstad et al. 1934, 530-535.

96 Keswani 1989b, 64-65.

97 Keswani 1989a, 562-565.

98 Cat. nos. 340, 355, 364-371, 375, 377-386

99 Cat. nos. 67-71, 184, 185, 188, 189-191, 1430.

Iоo Cat. nos. 533, 549, 583, 550-556, 558 .

го Gjerstad et al. 1934, 486-487, 558-559.

1о2 British tomb 19 is considered by Keswani (1989b, 77) to be the wealthiest of her second chronological group; in the third chronological group this position is held by British tomb 93. From British tomb 19 only one Mycenaean krater has been reported (cat. no. 1450), while from British tomb 93 two such vessels (cat. nos. $6,276)$ have been published.

Io3 Gjerstad et al. 1934, 551-554. A group of nineteen Mycenaean vessels, among them cups, stirrup jars, bowls and jugs, were found in the main chamber, in association with golden jewellery, bronze weapons and bronze and faience bowls. 
inventory, such as British tomb 83, produced as many as five Mycenaean kraters. ${ }^{104}$ A similar situation applies to French tomb 2, which also produced five kraters, of which two with pictorial decoration. ${ }^{105}$ We should also take into account the widespread distribution of small numbers of Mycenaean kraters in general. Apparently, some people within the society of Enkomi chose to distinguish themselves by including a substantial quantity of Mycenaean kraters into their funerary ritual. The tombs in which this is the case are not all very wealthy and it cannot automatically be assumed that they belong to the upper social strata at Enkomi. ${ }^{106}$

It is difficult to determine whether the restricted distribution of Mycenaean kraters in the Enkomi tombs is related to their decoration. The majority of such vessels from tombs possess pictorial decoration, mostly consisting of chariot scenes. ${ }^{107}$ However, kraters with non-pictorial decoration are also present in the tombs. Every tomb which has produced more than three Mycenaean kraters included non-pictorial specimens. Moreover, several tombs contained only non-pictorial Mycenaean kraters. ${ }^{108}$ The distribution of pictorial kraters, therefore, does not seem to differ from their non-pictorial counterparts. This suggests that the unequal distribution of Mycenaean kraters, generally, is not related to the decoration of these vessels.

When we consider the frequency in tombs of Mycenaean vessels of all types with pictorial decoration, we see that many tombs have yielded a few of such vessels. ${ }^{109}$ Only six tombs produced more than three pictorial vessels: Sw. T. 3 (sixteen vases), Br. T. 12 (thirteen vases), British tomb 54 (four vases) Br. T. 48 (five vases), Sw. T. 18 (ten vases) and Sw. T. 7 (four vases). Swedish tombs 3 and 18 each produced very large numbers of Mycenaean finds and are among the tombs with a rich and varied funerary inventory in general. ${ }^{110}$ Obviously Mycenaean pictorial pottery was considered suitable to be included in such a funerary repertoire. Br. T. 12, a built ashlar tomb, did not produce a particularly varied inventory of finds: apart from pottery, one golden ring, a gold bead and an ivory box were reported. ${ }^{111}$ However, this tomb has produced a relatively large amount of Mycenaean pictorial vases, which suggests that they possessed some special meaning in the funerary rituals connected to this tomb. The same is true to a lesser extent for Br. T. 54, 48 and Sw. T. 7, none of which can be included among the very wealthy tombs. ${ }^{112}$ Each of these four tombs contained several pictorial Mycenaean

${ }^{104}$ Cat. nos. 5, 146, 149, 152, 154. These vessels were found in association with a faience bowl, an alabaster pyxis lid and with Cypriot and Mycenaean pottery, see Murray, Smith \& Walters 1900, 47-48, 83.

ros Cat. nos. 645, 659, 660-662. These vessels were found in association with golden jewellery, silver tableware, faience cups and bowls, glass beads and alabaster vases, see Schaeffer 1952, 111-135.

ro6 It has been asserted by Louise Steel (1998) that Mycenaean dinner vessels and in particular kraters were reserved for ruling élite groups in Kalavasos-Ayios Dhimitrios (site no. 114). This pattern contrast with the funerary evidence at Enkomi that has been investigated here.

107 Of nine Mycenaean kraters found in a funerary context the decoration is not known to me; two are decorated with bands and lines only, while twenty seven possess patterned decoration. Ninety-two kraters are pictorially decorated, of which thirty-six with a chariot scene. Other scenes include bulls and a variety of other animals. Human beings engaged in activities other than chariot riding are also depicted; in one case men are shown boxing (cat. no. 6). One amphoroid krater (cat. no. 369) shows a ship scene.

ro8 See Br. T. 69 (cat. no. 78), Cy. T. 1 (cat. no. 1330), Fr. T. 1336 (cat. no. 803), Br. T. 79 (cat. no. 91), Br. T. 78 (cat. no. 255). Each of these tombs produced only one krater.

ro9 In all, thirty-seven tombs have produced Mycenaean pictorial vessels. Apart from kraters, jugs, rhyta a stemmed bowl, stirrup jar and piriform jar were pictorially decorated.

по Keswani 1989b, 78 Table 2.

III Murray, Smith \& Walters 1900, 38.

II2 These four tombs are absent in Keswani’s (1989b, 77-8) tables. 


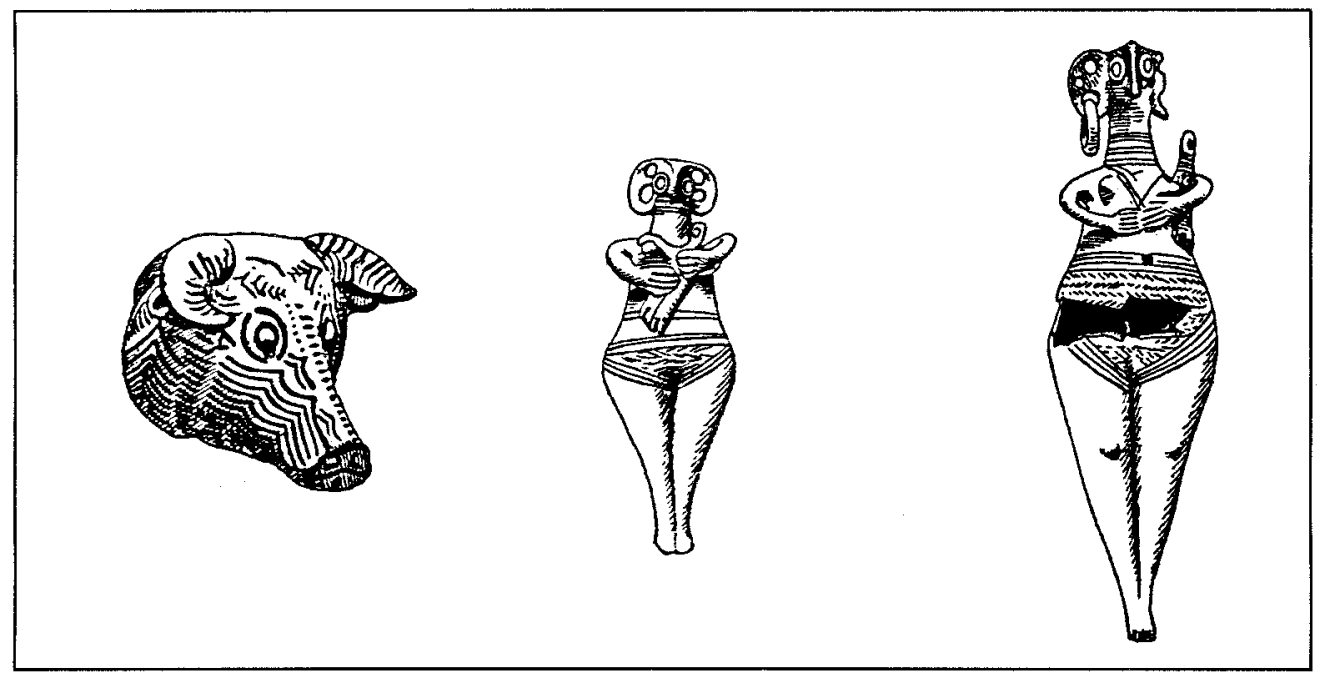

Fig. 10.8 Mycenaean animal head rhyton (cat. no. 49) and Cypriot terra-cotta figurines from Br. T. 67 - After Murray, Smith \& Walters 190037 fig. 65

kraters. ${ }^{113}$ Obviously, for specific groups of inhabitants at Enkomi Mycenaean pictorial kraters possessed a special significance in funerary rituals.

The evidence presented above suggests that Mycenaean kraters were not appreciated in the same way by all the inhabitants of Enkomi, at least as far as their funerary use was concerned. This may also be the case for Mycenaean ritual vessels, which have been found in seven tombs (see Table VIII). A Mycenaean composite vessel (cat. no. 10), consisting of two small three-handled piriform jars attached to one another in the belly zone and both decorated with $\mathrm{N}$-patterns and scale patterns, was found in British tomb 88. From this tomb, the location of which is unknown, a zoomorphic faience rhyton, as well as three Cypriot terra-cotta figurines and a glass pomegranate vase have been reported. ${ }^{114}$ Apparently the owners of this tomb distinguished themselves with items which can be related to cult practices. ${ }^{115}$ Similar evidence may be seen in the case of Br. T. 67, which produced a Mycenaean bull's head rhyton (cat. no. 49) in association with two terra-cotta figurines of local manufacture (Fig. 10.8). ${ }^{116}$ Br. T. 69 produced a Mycenaean conical rhyton (cat. no. 75), also associated with local figurines, ${ }^{117}$ as were the Mycenaean conical rhyton and figurine from Br. T. 53. ${ }^{118}$ The association of these Mycenaean ritual vessels with objects of possible ritual significance of local manufacture or imported from elsewhere shows that the Aegean items were used in local ritual practices. Moreover, it appears that some groups at Enkomi distinguished themselves through the inclusion of religious paraphernalia in their funerary inventories. ${ }^{119}$

匹3 These four tombs did not contain kraters with patterned decoration. The decoration of one ring-based krater (cat. no. 186) from tomb 12, as well as of an amphoroid krater (cat. no. 221) from Br. T. 48 and a ringbased krater (cat. no. 407) is not known to me.

II4 Murray, Smith \& Walters 1900, 33-34.

IIs For the ritual associations of rhyta, see Courtois, Lagarce \& Lagarce 1986, 152-156, Yon 1986. For the ritual associations attached to Cypriot figurines, see
Courtois, Lagarce \& Lagarce 1986, 77.

II6 Murray, Smith \& Walters 1900, 37.

II7 Murray, Smith \& Walters 1900, 39-40.

II8 Murray, Smith \& Walters 1900, 44. A Base Ring bull vase was found with the Mycenaean rhyton and figurine.

II Keswani (1989b) argues that the complex symbolism visible in French tomb 2 relates the dead buried there to the cosmic order rather than distinguishing them 


\section{THE ROLE OF MYCENEAN POTTERY IN THE MATERIAL CULTURE}

\section{O F E N K O M I}

Apart from the Mycenaean vessels, few other objects produced in the Aegean have been found at Enkomi. A bronze jug from the main burial chamber of Sw. T. 18, dated to LC IIC, is certainly not Cypriot in shape and finds its best parallels in the Aegean. ${ }^{120}$ Considering the extensive evidence for copper working at Enkomi, however, it is possible that this jug was produced at Enkomi itself. A silver Vapheio-cup in British tomb 92 shows that an Aegean vessel in precious metal was imported already at an early date. ${ }^{121}$ Two semi-globular cups of the same material, from French tomb 2 and British tomb 66, probably derive from the Aegean as well, even though their wish bone handles are familiar also from Cypriot ceramics. ${ }^{122}$ A mould for a dagger of a type unknown at Cyprus and possibly of Aegean inspiration may suggest that objects intended for specific overseas markets were manufactured at Enkomi. ${ }^{123}$ Apart from this mould, no weapons of Aegean type have actually been found at Enkomi in levels earlier than an advanced stage of LC III. A fragment of an ivory head showing a bearded warrior with a so-called boar's tusk helmet may have been imported from the Aegean, just as an ivory pyxis which has parallels at Mycenae and Sparta. ${ }^{124}$ However, ivory was also produced at Enkomi itself and it may be that these objects were the products of local ivory workshops. ${ }^{125}$

Objects from a wide range of other areas in the Mediterranean have also been found at Enkomi. Stone and alabaster vases may have been imported from Egypt, even though a local production also existed of such vessels. ${ }^{126}$ Some faience and glass vessels may have been imported from Egypt as well, but this material was also locally produced. Ivory duck vases and gaming boards probably came from the Syro-Palestinian region. ${ }^{127}$ Seals were produced locally and came from the Levant, while scarabs came from Egypt. ${ }^{128}$ Ceramic arm-shaped vessels in Red Lustrous Ware may have been imported from the Hittite area. ${ }^{129}$ The cosmopolitan character of the material culture at Enkomi is also evident from its metal production, which shows a variety of artistic influences from the Levant, Egypt and the Aegean. ${ }^{130}$ Nevertheless, the products of the metal industry at Enkomi generally fit into a Cypriot tradition, as does the material record as a whole. ${ }^{131}$ The imported objects and the apparent artistic influ-

from other human beings. This indicates that varying groups at Enkomi expressed different things in their material funerary record.

I20 Gjerstad et al. 1934, 554: no. 120; Catling 1964, 151152; Matthäus 1985, 233-234.

I2r Davis 1973, 318-319: LH I-LH II.

I22 Davis 1973, 313-317; Matthäus 1985, 122.

I23 Courtois, Lagarce \& Lagarce 1986, 64, Plate XVII no. 1.

${ }^{124}$ Courtois, Lagarce \& Lagarce 1986, 128, Plate XXIV no. 1 (ivory head); Plate XXV no. 10 (pyxis).

I25 Evidence for an ivory workshop has been discovered in Q1W in a level dated to LC IIIA, see Dikaios 1969, 99-100. See also Krzyszkowska 1992.

I26 Courtois, Lagarce \& Lagarce 1986, 122-127; 138-158.

${ }_{127}$ Dikaios 1971, 511; Courtois, Lagarce \& Lagarce 1986, 134-138. In British tomb 58 an ivory gaming box was found, see Murray, Smith \& Walters 1900, 31, Plate 1.
A fragmentary gaming board, likewise from ivory, was found by the French in a pit which contained the remnants of a robbed tomb, see Courtois, Lagarce \& Lagarce 1986, 138, Plate XXIV no. 2. Pieces of a similar board were found in a domestic context in room 27 of area Q4W in LC IIC levels (H24), see Dikaios 1969, Plate 128 nos. 65-66.

I28 Courtois, Lagarce \& Lagarce 1986, 171-197.

129 Courtois, Lagarce \& Lagarce 1986, 163-164. More than fifty of such vessels have been found in Boghazköy, see Bittel 1957, 32-42 figs. 12-16, Plate 28 nos. 5-8. Eriksson (1991) has argued for a Cypriot origin of Red Lustrous Wheel-made Ware, including the arm-shaped vessels.

I30 Catling 1964.

I31 Courtois, Lagarce \& Lagarce 1986, 64-65; Knapp 1986a, 39-40; Muhly 1989, 302. 
ence on the material record at Enkomi shows that the city participated in the cosmopolitan, international networks of the eastern Mediterranean in the Late Bronze Age.

In a material environment with such diverse imports and influences, ceramic vessels from the Aegean probably did not automatically acquire a special significance as a result of their imported nature. According to figures provided by Dikaios, during LC IIA-B Mycenaean pottery constituted 9.91 $\%$ of the total ceramic assemblage in Q4W.132 During the same period, the corresponding figure for Q1W was $4.82 \%$. During LC IIC $14.5 \%$ of the pottery found in Q4W was LH IIIA1-LH IIIB, while this was the case for $9.8 \%$ in Q1W. During LC IIIA, $9 \%$ of all ceramics found in Q4W could be assigned LH IIIA2 or LH IIIB date, while as much as $45 \%$ consisted of LH IIIC-type ceramics. For Q1W the corresponding figures are $11.5 \%$ of LH IIIA2-LH IIIB vases and $48 \%$ of pots in LH IIIC style. These figures indicate that the quantities of Mycenaean pottery at Enkomi increased during the second part of LC II. Nevertheless, before the occurrence of pottery in LH IIIC style, imported Aegean ceramics were only a relatively small, but significant part of the total ceramic record at Enkomi. Apart from the general conclusion that Mycenaean pottery was used widely by the inhabitants of Enkomi, a few observations have been made in this chapter which clarify the use and appreciation of this material in more detail. The earliest Mycenaean vases at Enkomi were restricted to specific, residential activities. From LH IIIA1 onwards the proportion of Mycenaean dinner vessels grew steadily. Initially, these Mycenaean dinner vessels were to some extent reserved for use in residential activities. However, in later phases there were no restrictions in the use of Mycenaean dinner and storage vessels. Apparently the use and appreciation of this class of ceramics at Enkomi evolved in relation to the quantities that were imported into the city.

The spatial distribution of vessels with pictorial decoration seems to differ somewhat from the general pattern. From LC IIA onwards Mycenaean pictorial pottery was not regarded differently in settlement contexts. However, for a specific group of people at Enkomi Mycenaean pictorial kraters did serve a special function in funerary ritual. This difference between settlement and funerary use shows that the appreciation of Mycenaean vessels varied according to the cultural associations assigned to them. The presence of five large, coarse ware stirrup jars (cat. nos. 142, 559-561, 1336) in tombs shows how such transport jars could acquire a symbolic significance beyond their function in a similar way. The relative concentration of Mycenaean cups and kraters in tombs as compared with stirrup jars and piriform jars may be caused by similar processes. In any case, it is clear that specific Mycenaean vessel types at Enkomi were considered suitable to be part of social strategies of distinction.

The fact that at Enkomi Mycenaean pottery, at least some parts of the ceramic repertoire, was socially active and could be included in consumptive strategies may have been a factor involved in the imitation of this type of pottery. Before an advanced stage of LC IIC, however, imitation appears not to have been very common. ${ }^{133}$ In French tomb 3 an imitation of a three-handled piriform jar has been found, carried out in Base Ring I technique. ${ }^{134}$ A similar vessel, decorated with a floral motif covering the whole body, has been found in Br. T. $84 .{ }^{135}$ In addition, a rounded alabastron in Base Ring technique has been found in Br. T. 50, while a similar vessel occurred in British Tomb 88. ${ }^{136}$ These three examples can all be related to the LH IIIA2 style and show that Mycenaean pottery was imitated as

132 Dikaios 1971, 447, 451, 458. Dikaios' so-called 'Late Mycenaean IIIB' vessels, which were probably made in Cyprus, are included in these figures.

I33 Cadogan 1991, 169.
134 Schaeffer 1936a, Plate 31 no. 2.

I35 Murray, Smith \& Walters 1900, 38 Plate 66 no. 1189.

${ }^{136}$ Smith 1925, IIca Plate 4 no. 9; Murray, Smith \& Walters 1900, 34 Fig. 62: no. 1252. 
early as LC IIA, ${ }^{137}$ the period in which Mycenaean pottery began to arrive at Enkomi in large quantities. Somewhat later, probably from LC IIB onwards, the amphoroid krater was adopted into the local ceramic repertoire in Plain White Wheel-made ware. ${ }^{138}$ Such vessels have been found in large numbers in the tombs of Enkomi, for example in Sw. T. 11, and in Sw. T. 19. ${ }^{139}$ In most cases these imitations of Mycenaean pottery were associated with genuine Mycenaean pottery, suggesting that the same groups of people used both the originals and the local products. ${ }^{140}$

In an advanced stage of LC IIC the local production of Mycenaean style pottery increased sharply with the appearance of Rude or Pastoral style kraters and with the introduction of shallow bowls in the local ceramic repertoire. ${ }^{141}$ Shallow bowls have been reported in abundance from both settlement and funerary contexts at Enkomi. ${ }^{142}$ The same can be said for Pastoral style kraters. ${ }^{143}$ Cypriot-made Mycenaean-style pottery has been found in direct association with original imports in both settlement and funerary contexts at Enkomi. ${ }^{144}$ Sherratt has argued that the introduction of the Aegean vessel types in a local ceramic class should be understood as a phenomenon related to a gradual development towards a Cypriot wheel-made, painted ceramic class, which occurred in the context of urbanization and centralization. ${ }^{145}$ The fact that vessels from this local production have been found directly associated with their Aegean prototypes, suggests, firstly, that not only shapes and motives were copied, but also the functional and symbolic meanings attached to specific vessel types. Secondly, the close relationship between imports and local products suggest that, by the end of LC IIC, the imported nature of Mycenaean vessels was of no consequence for the way they were used and appreciated in local cultural practices.

In addition to the ceramic imitations of Mycenaean pottery, two faience stirrup jars have been found at Enkomi and another in glass. ${ }^{146}$ One faience stirrup jar was found in Br. T. 50, while another was found Fr. T. 5. The glass stirrup jar was also found in Fr. T. 5, which suggests that the owners of these tombs had special access to such vessels. Faience and glass vases were probably not produced at Enkomi, but imported from the Levant or Egypt. ${ }^{147}$

${ }^{137}$ Similar vessels have been found elsewhere in Cyprus, see Cadogan 1991, 169-170. It is unclear whether the examples from Enkomi were produced in the city itself, or imported from elsewhere in the island.

138 Kling 1989, 167.

I39 Gjerstad et al. 1934, Plate 82: row 1: nos. 9-10, Plate 83: row 1 nos. 7-9, row 5 nos. 2, 3, 7-8; Plate 91: row 1 nos. 1-2, 4-5.

I40 Contra Cadogan (1991, 169), who states that these vases represent "cheaper versions of the more valuable imports for poorer people."

I4I Cadogan 1991, 170; Sherratt 1980, 196-197; 1991, 193-195 (with full bibliography). Sherratt (1991, 192 note 11) argues that the Cypriot Pastoral style may have started as early as the Amarna period in Egypt, which would coincide with LH IIIA2 or - possibly early LH IIIB and with LC IIA.

${ }^{\text {I42 }}$ For settlement levels, see Dikaios 1969, 308-314; for a funerary context, see, for example, the side chamber of Sw. T. 18: Gjerstad et al. Plate 90 rows 4-6.

I43 For settlement levels, see Dikaios 1969, 308-314; for a funerary context, see, for example, Sw. T. 19, Plate 91: row 3 nos. 3-5.

${ }^{144}$ In room $3 \mathrm{~A}$ in the level IIB building in Q1W two Mycenaean stemmed cups were found together with a shallow bowl of local manufacture and with Base Ring and White Slip wares. In the special descriptions of the stratigraphy of room 5 in Q1W (Dikaios 1969, 310311) and room 142 in Q4W (Dikaios 1969, 309), locally produced Mycenaean style pottery has been reported in association with original imports in LC IIC and LC IIIA levels. In British tomb 45 two pictorial kraters in 'Rude or Pastoral' style have been discovered with two imported types (cat. nos. 108-109), see Murray, Smith \& Walters 1900, 45 Fig. 71: nos. 931^ and 933 .

I45 Sherratt 1991, 191-192.

${ }^{146}$ Murray, Smith \& Walters 1900, 52; Schaeffer 1952, 210-214 Planche supplémentaire.

${ }^{147}$ Courtois, Lagarce \& Lagarce 1986, 139. See also Peltenburg $(1985,256)$ who does not see any evidence for faience production anywhere in Cyprus. 
The final question to be addressed in this chapter concerns the social groups at Enkomi who used the Mycenaean pottery. In its early phase, Enkomi consisted of a number of widely spaced large structures, each surrounded by tombs. ${ }^{148}$ Such a plan suggests the presence of a number of heterogeneous groups, possibly deriving from different communities, which converged in order to control the production of copper and to engage in international trade. ${ }^{149}$ The presence of metal working in several parts of the city from an early period onwards, the - more or less contemporaneous - construction of monumental ashlar buildings and built tombs in several parts of the city, as well as the absence of building with centralized administrative functions suggest that the population of the city was never integrated in a single hierarchy, but kept a certain heterogeneity. ${ }^{150}$ We may assume that this pottery was used by a number of different social groups in the city.

Enkomi was probably the centre of a regional polity, which was organised around the production and exchange of copper. ${ }^{151}$ Within such a polity mining and agricultural villages as well as inland centers and sanctuaries were systematically linked to the coastal centre through the exchange of luxury and staple goods. Because of the lack of settlement excavations and of systematic surveys in eastern Cyprus, it is not certain which sites may be considered to have participated in the Enkomi system. Nearby Sinda (site no. 54), where a city wall similar to the one at Enkomi was erected early in LC IIC, ${ }^{152}$ was possibly an inland centre related to the coastal city. From this site twenty Mycenaean vessels in styles antedating LH IIIC have been reported, among which were storage and dinner vessels, while a conical rhyton was also found. ${ }^{153}$ Such a wide range of vessels compares well to the Mycenaean repertoire found at Enkomi and it shows that a wide variety of Mycenaean vases could occur in a regional center. The site of Ayios Iakovos (site no. 51), located to the north of Enkomi and probably a sanctuary, also produced Mycenaean vessels from settlement levels. ${ }^{154}$ Mycenaean vessels were also found in settlement contexts in Athienou (site no. 74), which appears to have been a sanctuary site related to nearby mining districts (chapter 11). Smaller quantities of Mycenaean pottery have been reported in funerary contexts in nearby sites such as Milia (site no. 55), Kalopsidha (site no. 57), Ayios Sozomenos (site no. 73) and Nicosia Ayia Pareskevi (site no. 75). Such a wide scatter of sites with Mycenaean pottery in the Mesaoria plain and its bordering hills indicates that this material was incorporated into the exchange systems which linked the coastal centers to secondary inland centres, sanctuaries and mining regions.

The emerging picture shows that Mycenaean pottery was widely used by the commercial élites residing at Enkomi. It is likely, because of the heterogeneity of the social structure in the town, that the social use of this class of ceramic material varied according to different social groups. The differences in the funerary use of Mycenaean kraters which has been discussed above may be testimony of such variations in social function. However, the use of Mycenaean pottery was not limited to the urban élite. By being incorporated in local exchange mechanisms which linked inland sites to the coastal centres, Mycenaean pottery became available to regional and local groups situated far away from the coast.
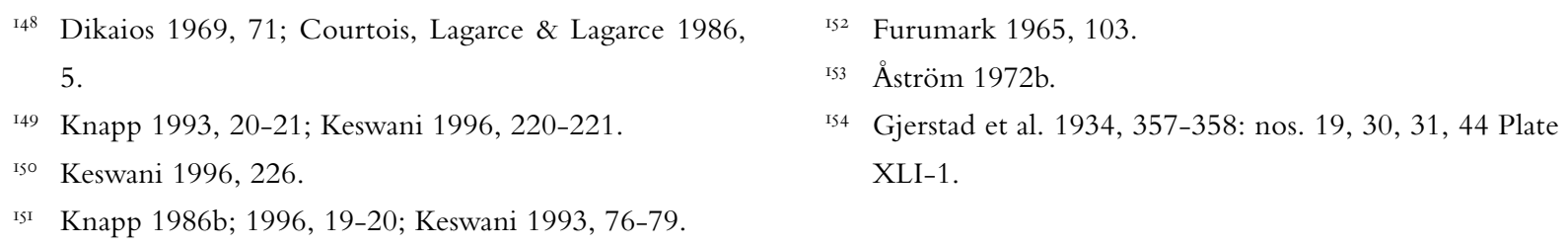


\section{Athienou - Bamboulari tis koukouninas}

\section{N T R O D U C T I O N}

In the central part of Cyprus, the Mesaoria plain is bordered on its southern side by limestone hills. Athienou is situated in the foothills, in close proximity of both the central plain and mining districts such as Troulli or Sha. The site of Bamboulari tis Koukouninas is situated on a natural hillock, which rises some $2 \mathrm{~m}$ above its surroundings. It covers some $2500 \mathrm{sqm}$ which have been excavated down to virgin soil for more than $90 \%$ (Fig. 11.1)..$^{1}$ The lowest archaeological layers which have been attested during these excavations have been assigned to the transitional period MC III-LC I. ${ }^{2}$ From then on, the site was continually occupied until the first part of LC III.

The Late Bronze Age remains have been discovered in three strata (strata IV-II). In stratum IV (MC III-LC I), only a few deep and shallow pits were discovered; they did not contain any Mycenaean pottery. ${ }^{3}$ Some of the remains in stratum III may have an LC I date, but the majority date to LC II. ${ }^{4}$ Architectural remains belonging to this phase have been found in the north-western part of the site only (Fig. 11.1). One building has been discovered with a large room, possessing a plaster floor. At least two other rooms, also with a plaster floor, belonged to this building as well. South of these three rooms, a courtyard has been discovered. Three pits dug were dug in the pavement of the courtyard. Directly east of the courtyard, there were three deep, cylindrical pits; a group of pits further east were more shallow. During LC III, the building was enlarged with several rooms in the eastern part of the site. ${ }^{5}$ Other constructions, mainly to do with metal working, also date to this period.

The total number of miniature juglets which have been found in stratum III at AthienouBamboulari tis Koukouninas has been estimated at 10,000. ${ }^{6}$ Consequently, the site has been interpreted as a sanctuary, which formed a regional centre in networks of production and exchange. ${ }^{7}$ Associated with the cultic activities was metal production, as is indicated by copper ore and nodules. ${ }^{8}$ No other settlement remains have been discovered in the vicinity of the site, but the nearby cemetery reportedly has Late Bronze Age graves. ${ }^{9}$ It is unclear who controlled the sanctuary. Possibly, people living in

In 1952 H.W. Catling visited Bamboulari tis Koukouninas during the Cyprus survey, see Catling 1962, 161: site no. 23. In 1958 soundings were made by $\mathrm{Ch}$. Paraskeva on behalf of the Department of Antiquities of Cyprus, see Karageorghis 1959, 354; Megaw 1959 , 26-27. In 1971 and 1972 the Hebrew University of Jerusalem conducted two excavation campaigns, which were directed by T. Dothan and A. Ben-Tor, see Dothan \& Ben Tor 1983. Archaeological research to the south-west of the site has been in progress since
1990, see Herscher 1998, 339-340 (with further refs.).

2 Dothan \& Ben-Tor 1983, 3-6, 14-21, 139-140.

3 Dothan \& Ben-Tor 1983, 20-21.

4 Dothan \& Ben-Tor 1983, 14-20.

5 Dothan \& Ben-Tor 1983, 6-14. These rooms were situated in the area of pits 552 and 637, east of wall 4 .

6 Dothan \& Ben-Tor 1983, 139.

7 Keswani 1993, 77; Knapp 1996a, 20; 1997, 31;

$8 \quad$ Maddin, Muhly \& Wheeler 1983.

9 Dothan \& Ben-Tor 1983, 1. 


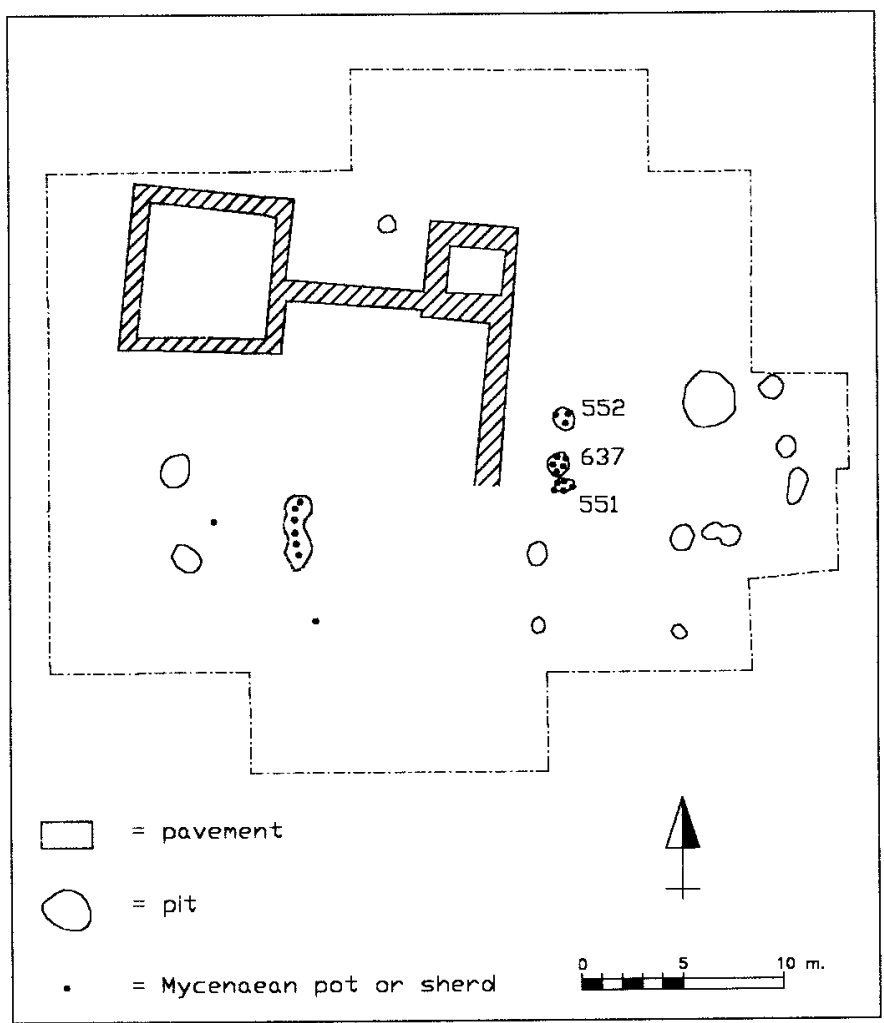

Fig. 11.1 Athienou: site plan indicating Mycenaean pottery

the vicinity had claims on the workings of the sanctuary. The important role of the site in the distribution of copper from the mining districts to coastal centres, however, makes it likely that élites from an urban coastal centre also exerted strong influence. ${ }^{10}$

\section{THE MYCENAEAN POTTERY}

A total of twenty-five Aegean-type vessels have been reported from Athienou-Bamboulari tis Koukouninas, which are listed in Catalogue VI. ${ }^{11}$ None of these vessels has been subject to any scientific investigations regarding their provenance. The two shallow bowls (cat. nos. 7-8) are of a type which was manufactured in Cyprus at the end of the LC II period. ${ }^{12}$ The ware and the debased decoration of the ring-based krater (cat. no. 9) suggest that this vessel was made on the island as well. Two coarse ware stirrup jars (cat. nos. 24-25) have tentatively been assigned a Minoan origin, even though such vessels were also produced on the Greek mainland. ${ }^{13}$

Twenty-one of our vessels derive from the excavations conducted in 1971 and 1972. Since these campaigns are fully published, it is certain that these are all the Mycenaean finds made by the Israeli

Io Keswani 1993, 78; Knapp 1997, 57, 67.

II In addition, five so-called 'Mycenaean IIIC:1b' deep stratum II, see Dothan \& Ben-Tor 1983, 115-117. bowls of Cypriot manufacture have been discovered in

I2 Kling 1987, 101, 1989, 131-136.

I3 Day \& Haskell 1995, 97. 


\begin{tabular}{lc}
\hline site area & amount \\
\hline unknown & 4 \\
structure & 2 \\
courtyard & 10 \\
east & 9 \\
north-east & 0 \\
\hline Total & 25 \\
\hline
\end{tabular}

Table 11.1

team. Four additional Mycenaean finds from Athienou Bamboulari tis Konkouninas were seen by Paul Åström in the Cyprus Museum in Nicosia. These probably were found during the trial excavations conducted in 1958 by the Department of Antiquities. If more Mycenaean finds had been made during this campaign, we may expect that Åström would have noted them. It appears that all Mycenaean vessels found at our site are presented in Catalogue VI.

\section{THE ON-SITE DISTRIBUTION OF MYCENAEAN POTTERY}

The remains of stratum III, as well as those of stratum II, can be grouped in four different spatial areas (Fig. 11.1). ${ }^{14}$ In the north-western part of the site, the floors and walls of the structure clearly belong together. To the south of this building extended the large paved courtyard, which constitutes a second area. A third area is situated in the east, where a building was erected during stratum II, while a number of storage pits were present here during stratum III. The north-east, where the stratum II lime platform is situated, can be considered a separate area. The distribution of the Mycenaean pottery in these four areas is presented in Table 11.1.

It is clear that the Mycenaean finds were concentrated in the courtyard and in the eastern area. In both cases, the majority of our finds have been made in pits; only a bowl and jug (cat. nos. 18-19) were found on the pavement of the courtyard itself. In the north-eastern area, only small soundings were made below the lime platform, which helps to explain the absence of Mycenaean pottery from this area. Two Mycenaean fragments (cat. nos. 20 and 21) only were found in the area of the building itself; both not in context in stratum II. The absence of Mycenaean finds from this building indicates that Mycenaean pottery was primarily associated with the activities that were conducted in the courtyard and in the eastern area.

Two Mycenaean fragments (cat. nos. 2 and 4) cannot be assigned a stylistical date, and four finds (cat. nos. 1, 18, 19, 22) have been dated to LH IIIA2-LH IIIB in general. All other Mycenaean vessels can securely be given a LH IIIB date. The great majority of our finds have been found in features belonging to stratum III..$^{15}$ LH IIIB vessels have been discovered together with Cypriot pottery dating to

I4 Cf. Dothan \& Ben-Tor 1983, 6-20.

is Seventeen finds in our catalogue have been assigned to stratum III. The stratigraphy of the four vessels found during the 1958 campaign is uncertain.
I6 White Slip II bowls were found in pit 637, see Dothan \& Ben-Tor 1983, 36. A Base Ring bowl was discovered in pit 551, see Dothan \& Ben-Tor 1983, 40-41: no. 6; the same pit yielded a bucchero juglet, see 


\begin{tabular}{lccc}
\hline site area & unknown & dinner & storage \\
\hline unkown & 1 & 2 & 1 \\
structure & 2 & & \\
courtyard & 10 & 3 \\
east & 1 & 5 & 4 \\
Total & 4 & 17 & \\
\hline
\end{tabular}

Table 11.2

\begin{tabular}{lccccc}
\hline site area & unknown & d.c.w. & linear & patterned & pictorial \\
\hline $\begin{array}{l}\text { unkown } \\
\text { structure }\end{array}$ & 4 & & & 2 & \\
$\begin{array}{l}\text { courtyard } \\
\text { east }\end{array}$ & & 10 & 2 & 1 \\
\hline Total & 4 & 2 & 14 & 4 & 1 \\
\hline
\end{tabular}

Table 11.3

LC II, ${ }^{16}$ in pits that were sealed off when the stratum II rooms in the east were built. ${ }^{17}$ This indicates that the use of these Mycenaean vessels did not extend beyond LC IIC. However, four of our vessels were retrieved from stratum II, which has been dated to LC III. Two of these are unstratified fragments (cat. nos. 20 and 21). Two other finds, however, are large parts of shallow cups (cat. nos. 5 and 6), which were found together in pit 620 belonging to stratum II. ${ }^{18}$ It is possible that these two drinking vessels were deposited long after they were manufactured.

From Table 11.2 it is clear that Mycenaean storage jars were not very frequent at Athienou. In fact, two of the storage vessels in the catalogue (nos. 24, 25) are probably Minoan. ${ }^{19}$ A stirrup jar of Mycenaean origin (cat. no. 10) has also been found. The fourth Mycenaean storage vessel is a straight-sided alabastron (cat. no. 1) that was found during the 1958 excavations. The great majority of Mycenaean finds are classified as dinner vessels. However, six of these (cat. nos. 11-16) are miniature jugs, which may have had a purely ceremonial function. ${ }^{20}$ The presence of these vessels shows that the Mycenaean pottery was part of the rituals that were carried out in the sanctuary.

It is of interest that the two large coarse ware stirrup jars (cat. nos. 24 and 25) were found together in pits in the eastern part of the site, in the same area that produced the stirrup jar with cat. no. 10. ${ }^{21}$ In the beginning of the period that is represented by stratum II, a structure was built in this area, which possessed storage functions, as is evident from a number of large pithoi. ${ }^{22}$ The concentration of Mycenaean containers of large size suggests that the deep, cylindrical pits in this area served similar functions during the time of stratum III. ${ }^{23}$

Table 11.3 shows the types of decoration which occur on the Mycenaean vessels at Athienou. The two coarse ware stirrup jars are decorated with lines only. This is also the case for most other

Dothan \& Ben-Tor 1983, 65-66: no. 1.

17 Dothan \& Ben-Tor 1983, 12-14.

I8 Dothan \& Ben-Tor 1983, 11, 46.

19 Dothan \& Ben-Tor 1983, 49-53.

20 Dothan \& Ben-Tor 1983, 49.

21 Fragments of both Minoan stirrup jars were found in the pits 63 and 552; fragments of the Mycenaean stirrup jar came from pits 552 and 551. These three pits were situated close to one another (Fig. 11.1).

22 Dothan \& Ben-Tor 1983, 12-14; 113-115.

23 Large containers of Cypriot ware have not been reported from stratum III. 


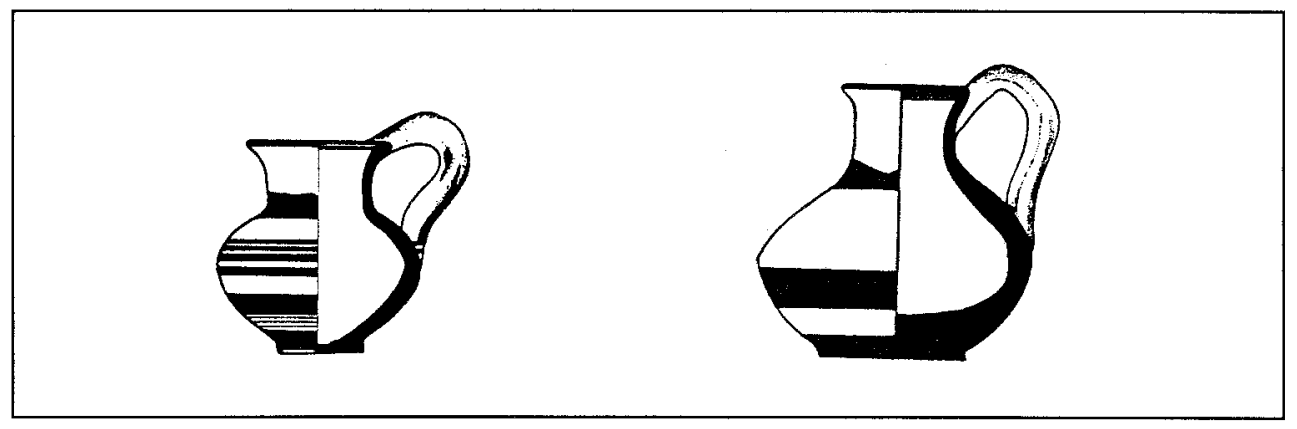

Fig. 11.2: Mycenaean small hand-made jugs from the courttyard pit in Athienou (cat nos. 11, 12) - After Dothan \& Ben Tor 1983, 50 fig. 14.

Mycenaean pots, but a ring-based krater (cat. no. 9) and three fragments (cat. nos. 20-22) have a patterned decoration. Quite remarkable is a cylindrical jug (cat. no. 23), of which the shoulder is decorated with two fighting bulls. ${ }^{24}$ Even though it may be significant that no Mycenaean vessels with patterned decoration have been found in the courtyard, there does not seem to be a distinctive pattern in the distribution of the different decorational types at Athienou.

\section{SETTLEMENT C ON TEXTS}

The site of Athienou-Bamboulari tis Koukouninas has been interpreted as a single unified sanctuary. As such, all the Mycenaean finds at the site may be considered to derive from a single context. However, in order to study variations in the cultural associations attached to the Aegean finds, it is useful to compare the two most important find places: the three pits in the eastern area and the group of pits in the central courtyard (see Table IX in the tables section).

\section{Courtyard pit complex (Fig 11.1)}

During the excavation of the stratum II courtyard, a large irregular pit was discovered, of which the deeper part certainly belongs to stratum III, while this is probably also the case for the higher parts. ${ }^{25}$ The uppermost part of the pit contained two Mycenaean miniature jugs (cat. nos 11, 12: see Fig. 11.2), as well as a variety of Cypriot pottery, stone beads and a spindle whorl. Four additional Mycenaean hand-made miniature jugs (cat. nos. 13-16) were found in deeper levels, together with Cypriot vessels, a spindle whorl and a faience bead. Both the upper and lower levels contained miniature votive vessels and metal scrap and nodules.

Obviously, this pit is related to the cultic activities carried out in the courtyard of the sanctuary. We possibly have to do with a bothros containing objects from a clearing of the courtyard. In any case, the Aegean miniature vessels were part of local cultural practices. Many miniature vessels found in the courtyard and the pit imitate larger type pottery. ${ }^{26}$ Even though one miniature jug (cat. no. 11) appears to be of good Aegean fabric, the other juglets may have been manufactured in Cyprus. ${ }^{27}$ It is

24 Dothan and Ben-Tor $(1983,49)$ attribute this vase to the 'Painter of Bulls and Bull Protomes', of whom other vases have been discovered in Cyprus. See Karageorghis 1971.
25 Dothan \& Ben-Tor 1983, 11, Plate 9:2, 20.

26 Dothan \& Ben-Tor 1983, 57-73.

27 Dothan \& Ben-Tor 1983, 49. 


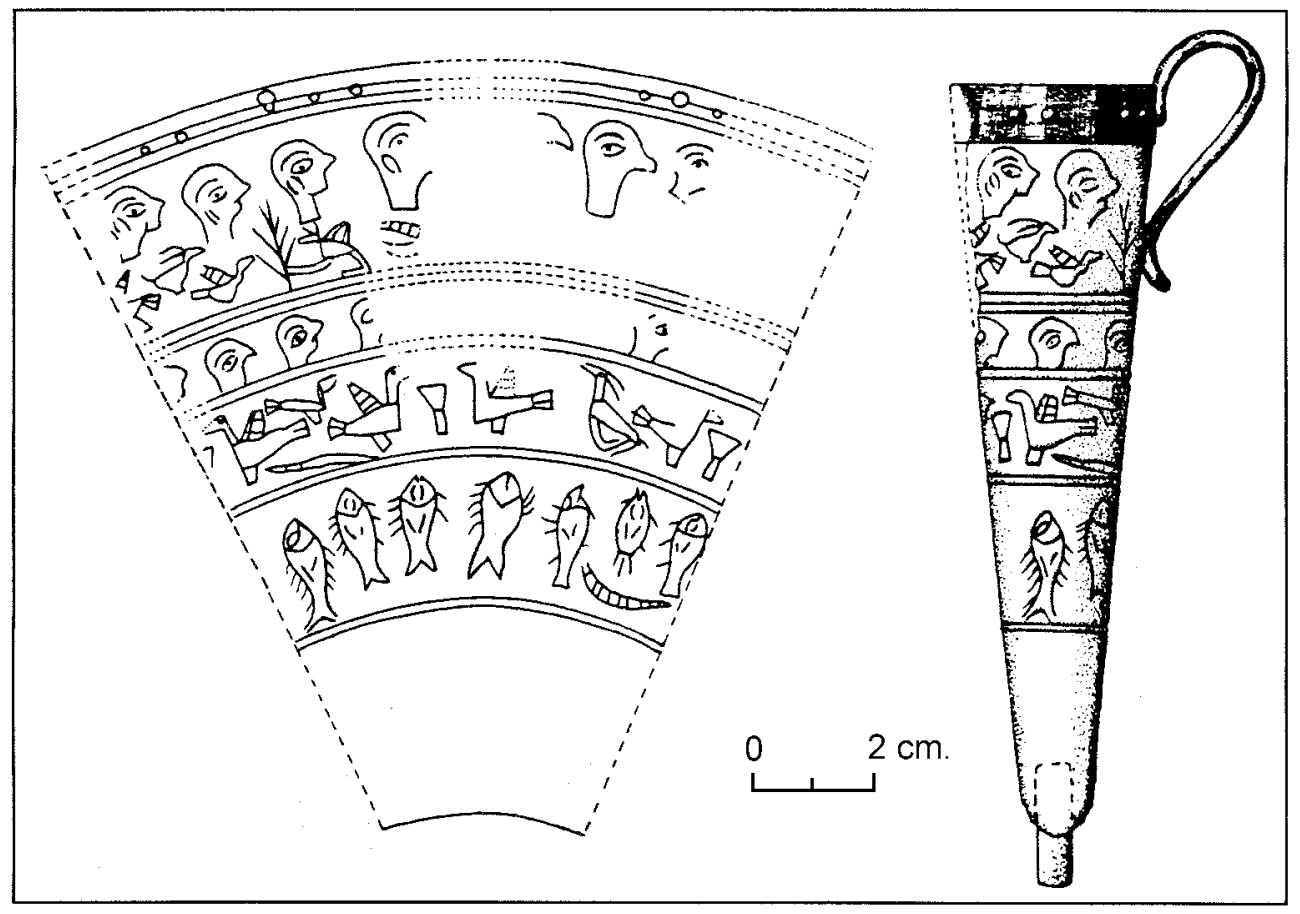

Fig. 11.3 Ivory rhyton of Mycenaean type from pit 552 at Athienou - After Dothan \& Ben-Tor 1983, 123 fig. 56.

possible that Mycenaean-type jugs were part of a range of miniature vases that was specifically produced to serve as votive offerings. It is remarkable, however, that all of the Aegean-type miniature jugs at Athienou have been found in this pit. From the courtyard, where heaps of votive vessels have been attested, a Mycenaean stemmed bowl (cat. no. 18) and a piriform jug (cat. no. 19) have been reported. If the courtyard pit indeed constitutes a bothros, it is possible that this concentration of Mycenaean votive juglets is due to these vessels having been popular at a specific period. However, it is also possible that the courtyard pit served a specific function, in which Mycenaean-type juglets had a special significance.

\section{Eastern pit complex (Fig. 11.1)}

The three pits 551, 552 and 637, situated closely together, were cylindrical and much deeper than most other pits at the site. ${ }^{28}$ Pit 551 had a depth of almost $5 \mathrm{~m}$ below stratum III, while pit 552, the shallowest of all, was almost $2 \mathrm{~m}$ deep. The rim of pit 551 was lined with stones, which, together with their cylindrical shape, indicates that, at least for some period of time, these pits were not filled. Pit 551 yielded two Mycenaean shallow bowls (cat. nos. 7-8) and a globular jug (cat. no. 17). In addition, fragments were found of a stirrup jar (cat. no. 10) and of a pictorial cylindrical jug (cat. no. 23). Loom weights, local pottery and a number of local miniature juglets were also found in this pit. From pit 552 come three Aegean stirrup jars (cat. nos. 10, 24, 25); of each of these jars sherds were identified in other pits as well. A handle fragment of a LH IIIB-LH IIIC-type deep bowl of local manufacture was also found in pit 552, together with a Mycenaean-type conical rhyton made of ivory (Fig. 11.3),

28 Dothan \& Ben-Tor 1983, 20. 
a decorated wall bracket and some Cypriot pots. Pit 637, which lay in between the other two, produced large parts of a ring-based krater (cat. no. 9), which may be of Cypriot origin. In addition, sherds were found of the pictorial cylindrical jug (cat. no. 23) and of the two Minoan stirrup jars (cat. nos. 24, 25). Pit 637 also contained stone weights, a wall bracket, Cypriot pottery and an object that has tentatively been interpreted as a 'snake house'. ${ }^{29}$

Considering the many joints between Mycenaean vessels from different pits, it is likely that all our pots belong to the intentional fill of the pits. It is probable that this fill derived from the same part of the site, when it was levelled to construct the eastern rooms of stratum II. In any case, the objects and activities associated with the Mycenaean pots in this area are more diverse than in the courtyard pit complex. The ivory rhyton, as well as the wall brackets and the 'snake house' may be considered special objects. The direct association of Aegean vessels with such rare objects may be of some significance.

\section{THE ROLE OF MYCENEAN POTTERY IN THE MATERIAL CULTURE}

\section{OF A T H I N O U}

Apart from the Mycenaean pots, no other objects have been discovered at Athienou that can clearly be identified as coming from the Aegean. The ivory conical rhyton, albeit of Aegean type, has obvious Cypriot and Levantine decorative elements, which indicates that it was made by a Cypriot artist. In this sense, it may be compared to similar rhyta in faience, such as the famous example found at Kition (site no. 63). ${ }^{30}$ The two cylinder seals found at Athienou were most likely made on Cyprus, even though one has a representation of a Bes-like figure, indicating Egyptian associations. ${ }^{31} \mathrm{~A}$ frit scarab and a bronze ring appear to be the only other objects at the site which clearly were imported from outside the island. ${ }^{32}$ Metal finds, apart from waste from bronze production, are scarce and include a situla handle, a fibula, an arrowhead and a diadem, all of which have good parallels elsewhere in Cyprus. ${ }^{33}$ It appears, then, that the Mycenaean pottery was part of a small repertoire of objects that had connotations with the international world of maritime exchange. It is likely that the cultural significance of the Mycenaean pots at Athienou have to do with its international character.

Athienou has been interpreted as fulfilling an intermediary role in the distribution of metal from the mining districts to the coast. ${ }^{34}$ The chief role of such a centre was to control the production and distribution of copper and to provide storage facilities for staples and other localised goods. The sanctuary is thought to have helped legitimise the relationships between inland sites and coastal centres. Even though Late Bronze Age burials have been reported from a nearby necropolis, ${ }^{35}$ it is uncertain whether habitation took place in the near vicinity of the sanctuary. The absence of Bronze Age sites in the Mallouri valley to the south-west, however, seems to suggest that the sanctuary was free-standing. ${ }^{36}$

Nearby Ayios Sozomenos (site no. 73) in the Yalias valley, where three late Bronze Age cemeteries and a large settlement area have been identified, probably also served as an inland centre. ${ }^{37}$ This site

\footnotetext{
29 Dothan \& Ben-Tor 1983, 53; cf. Karageorghis 1972.

30 Peltenburg 1974, 116-126.

3I Porada 1983, 120-121.

32 Giveon 1983, 121.

33 Dothan \& Ben-Tor 1983, 125-126.
}

\footnotetext{
34 Keswani 1993, 77-78; Knapp 1997, 57-59.

35 Dothan \& Ben-Tor 1983, 1.

36 Toumazou, Yerkes \& Kardulias 1998, 172.

37 Catling 1982; Knapp 1997, 57.
} 
yielded some LH IIIA2 and LH IIIB sherds. To the north-west, in the Mesaoria plain Nicosia-Ayia Pareskevi (site no. 75), may have been a secondary centre related to agricultural production, but only tombs have been excavated there..$^{38}$ At Idalion (site no. 72), a short distance to the west of Athienou, one tomb contained LH IIIA2-LH IIIB pottery, while some Mycenaean-type fragments from the acropolis may have an LH IIIB date. ${ }^{39}$ Settlement remains so far discovered on the top of the acropolis and on the west terrace have been dated to LC III and are contemporary with the stratum II building at Athienou.

Mycenaean pottery appears to have been part of exchange mechanisms which linked coastal centres to the interior and which connected interior sites. All other extraordinary objects at AthienouBamboulari tis Koukouninas are of Cypriot manufacture, but symbolically refer to a wider world of international relations. The rather limited repertoire of Aegean-type pots at our site fits this pattern well..$^{40}$ Quite probably, these pots were part of the regional exchanges of prestige goods, which have been described by Priscilla Keswani. ${ }^{41}$ Even though it is uncertain which groups controlled the sanctuary, it may be stated that the Mycenaean pots at Athienou represent luxury items for inland élites, who were in contact with urban coastal groups.

${ }^{38} \quad$ Kromholz 1982.

39 Gjerstad et al. 1935, 637: no. 24; Ålin 1978, 74, 95103; Adelman 1989, 138-201; Schulte-Campbell 1989, 119-137; Hadjicosti 1997, 50-51.

40 Eight Mycenaean vessels may be of local manufacture: cat. nos. 7-9, 12-16. In addition, a cup of 'Decorated Late Cypriot IIIA-B ware, clearly inspired by Aegean pottery, has been found in pit 637, see Dothan \& BenTor 1983, 46-47 Fig. 12: no. 3. Five LH IIIB-IIIC bowls of local manufacture have also been found, see Dothan \& Ben-Tor 1983, 116-117 Fig. 53.

${ }_{41}$ Keswani 1993, 78-79. She uses the term 'wealth finance' when such prestige goods exchange systemically link urban centres and smaller settlements. 


\section{Apliki-Karamallos}

\section{N T R O D U C T I O N}

On their northern side, outliers of the Troodos mountains reach almost to the coast of Morphou bay. In the valley of the Marathasa river, the plateau of Karamallos is situated some $8 \mathrm{~km}$ from the coast. The altitude of the ancient site is some $300 \mathrm{~m}$ and it is situated in a well-known copper region. Archaeological remains have been discovered at various places and the site probably covered the whole plateau. ${ }^{1}$ Various finds at the site indicate that some activities must have occurred at the site during LC IIB. ${ }^{2}$ The earliest buildings, however, have been dated to LC IIC and habitation continued into the early stages of LC IIIA, when the site was abandoned.

On the Karamallos plateau, six trenches have been excavated (Fig. 12.1), while area C, where the Cyprus Mines Corporation cut into the surface, also yielded archaeological finds. Only two trenches have revealed the remains of buildings: area A near the rock outcrops in the south, and the long trench of area B in the eastern part of the site. In area A, a building was discovered, which consisted of at least eight rooms. ${ }^{3}$ In one room of this building, fifteen large jars were discovered and it has been suggested that the building fulfilled storage functions surpassing the household level. ${ }^{4}$ Another room showed evidence for cultic practices. The long narrow trench B revealed the remains of at least three houses, of which one (house B III) possessed an elaborate storage pit. ${ }^{5}$ Trench D did not yield any finds, but traces of walls and pits in the trenches E, F, G and $\mathrm{H}$ indicate that the settlement extended northwards and southwards.

Apliki-Karamallos has been interpreted as a mining settlement. ${ }^{6}$ The large amounts of copper slag and other implements to do with the production of metals seem to support such an interpretation. Grains found at the site appear not to have been grown in the near vicinity, which indicates some sort of food import, possibly in exchange for metals. ${ }^{7}$ Such a food supply fits well into the model proposed by Priscilla Keswani in which mining settlements are related to inland centres through a form of 'staple finance'. ${ }^{8}$ The size of the area at Apliki Karamallos in which Late Bronze Ages structures have been found, as well as the evidence for supra-household storage, suggest a full-fledged town rather than a

After discoveries by the Cyprus Mines Corporation, rescue operations were undertaken in the summer of 1939 on behalf of the departement of Antiquities by a team led by Joan du Plat Taylor, see Taylor 1952, 133. The site was visited by A. Steinberg and A. Koucky in 1972 in the context of a survey of sites with evidence of ancient copper smelting, see Steinberg \& Koucky 1974, 150-151 note 4, Fig. 109.

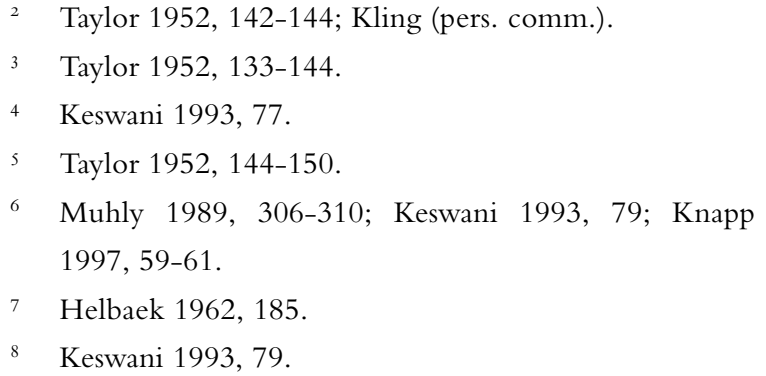




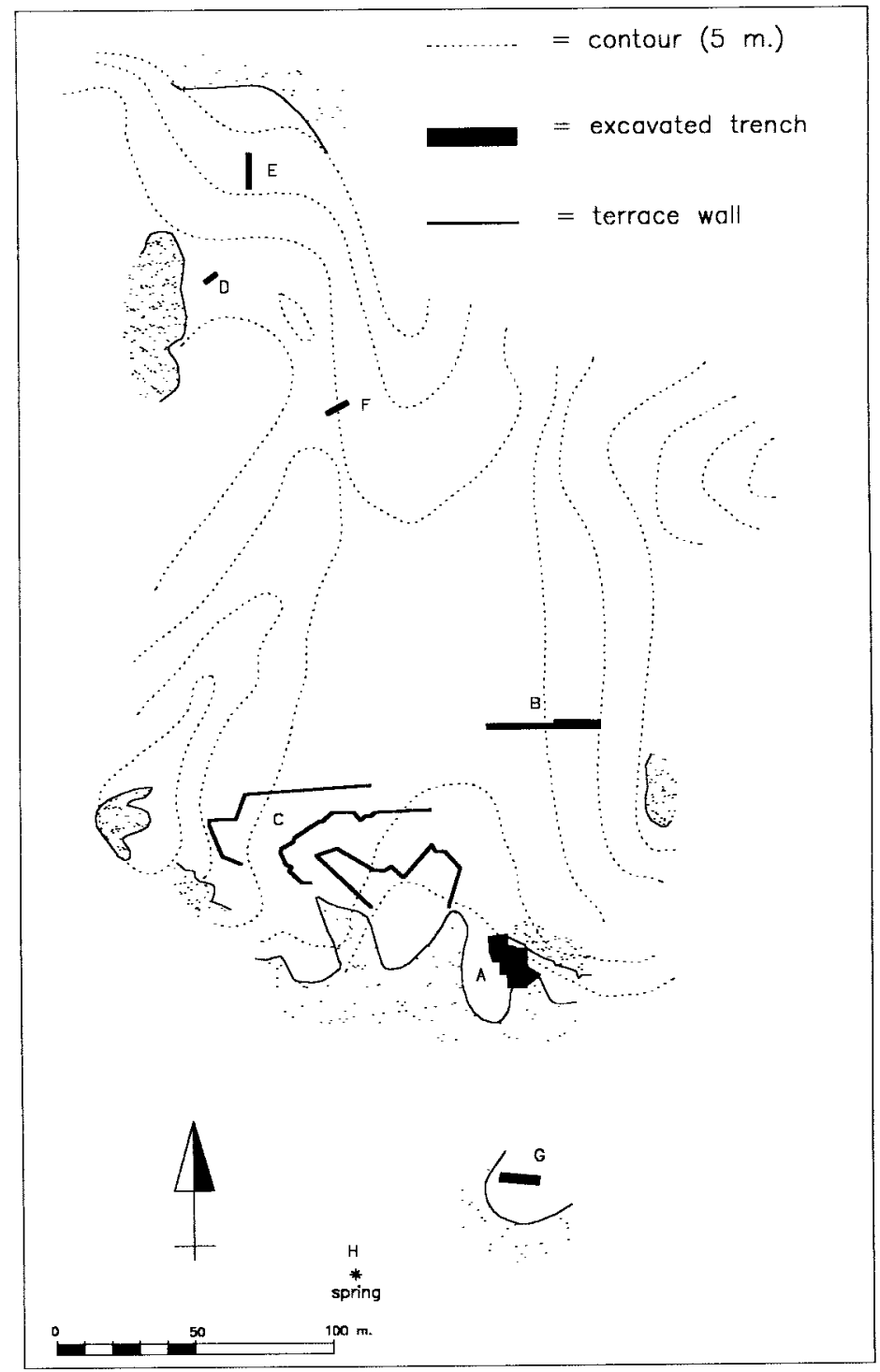

Fig. 12.1 Apliki: site plan

small-scale, one-purpose settlement. We may expect that a wide range of activities took place here, even if the vicinity of copper ores was crucial to the existence of the town.

\section{THE MYCENAEAN POTTERY}

Catalogue VII lists fifty-three Mycenaean-type pots and sherds thereof found at Apliki. These finds range in date from LH IIIA2 to LH IIIC. ${ }^{9}$ In her report Taylor noted that some Mycenaean pots were of a hard light buff ware, while there were also pots of softer to greenish buff fabric. ${ }^{10}$ She assumed that the first fabric type was earlier, while the second was 'Levanto-Mycenaean', by which she pre-

9 Five entries in the catalogue (nos. 3, 8, 9, 23, 45) have been assigned a LH IIIC date.
Io Taylor 1952, 153-154. She labelled the two types A and $\mathrm{B}$ respectively. 


\begin{tabular}{lc}
\hline site area & amount \\
\hline A & 31 \\
$B$ & 15 \\
C & 6 \\
unknown & 1 \\
\hline Total & 53 \\
\hline
\end{tabular}

Table 12.1

sumably wanted to indicate manufacture in Cyprus. Even though none of the Mycenaean finds from Apliki has been subject to scientific provenance analysis, it is likely that a substantial proportion of the Mycenaean-type finds at Apliki were indeed made on the island. ${ }^{11}$ A number of shallow and deep bowls are of types produced in Cyprus during LC IIC-LC IIIA. ${ }^{12}$ Two carinated cups (cat. nos. 8, 9) and two round-bottomed bowls (cat. nos. 24, 25) are of unusual shapes and may be considered hybrids of Cypriot and Mycenaean pottery. ${ }^{13}$ All other Mycenaean pots from Apliki are of types which occur often in Cyprus and for which manufacture on the Greek mainland is the most likely.

The Mycenaean pottery in Catalogue VII derives from a list supplied by Taylor in the excavation report. Eight Mycenaean finds in my catalogue (nos. 46-53) are mentioned in Taylor's text only and do not occur in her find list; it is not impossible that inconspicuous finds have been left out altogether. Also, it must be realised that only about $400 \mathrm{sqm}$ have been excavated of a site encompassing at least 5 ha. We have no idea to what extent the four buildings excavated to date may be considered representative of the town at large.

\section{ON SITE DISTRIBUTION OF THE MYCENAEAN POTTERY}

Even though the excavation report states that the Late Bronze Age sherds from area $\mathrm{E}$ were similar to those from areas $\mathrm{A}$ and $\mathrm{B}$, no Mycenaean pottery has been reported from trench $\mathrm{E} .{ }^{14}$ The same is true for trenches D, F, G and H. All Aegean-type pottery has been found in trenches A and B, or during the surface investigations of the large area $\mathrm{C}$ (Table 12.1).

According to the figures in Table 12.1, there appears to be a concentration of Mycenaean finds in area $\mathrm{A}$. The difference in size between trenches $\mathrm{A}$ and $\mathrm{B}$, however, should be acknowledged. In addition, the buildings in area $\mathrm{B}$ were abandoned gradually and it is possible that the occupants took useful objects with them..$^{15}$ Instead, house A was destroyed early in LC IIIA. ${ }^{16}$ Nevertheless, the concentration of Mycenaean pottery in trench A is rather large and may be the result of particular groups of people using these vessels more extensively than other people at the site. The Mycenaean finds from area $\mathrm{B}$ and $\mathrm{C}$ do show that, in general, these pots were widely distributed. Most of the Mycenaean

II To a total of seventeen entries in the catalogue, the remark "possibly Cypriot" has been added.

I2 For a discussion of these shapes, see Kling 1987, 101102; 1989, 94-108.

I3 Kling 1991, 183.

I4 Taylor 1952, 150.
Is Taylor 1952, 149. Only House B I produced evidence for destruction.

I6 Taylor $(1952,144)$ believed that an earlier destruction at the beginning of LC IIIA also took place in house A. However, the stratigraphical evidence for this is fragile; B. Kling (pers. comm.). 


\begin{tabular}{|c|c|c|c|c|c|}
\hline date & unknown & area $A$ & area B & area $\mathrm{C}$ & total \\
\hline undatable & 1 & & 9 & 1 & 11 \\
\hline LH IIIA2-LH IIIB & & 2 & & & 2 \\
\hline LH IIIB & & 12 & 2 & & 16 \\
\hline LH IIIB-LH IIIC & & 15 & 2 & 4 & 19 \\
\hline LH IIIC early & & 1 & 1 & 1 & 3 \\
\hline LH IIIC & & 1 & 1 & & 2 \\
\hline Total & 1 & 31 & 15 & 6 & 53 \\
\hline
\end{tabular}

Table 12.2

\begin{tabular}{lcccc}
\hline vessel type & area A & area B & area C & unknown \\
\hline dinner vessels & 26 & 10 & 6 & 1 \\
storage vessels & 5 & 1 & & total \\
not assignable & & 4 & & 4 \\
\hline Total & 31 & 15 & 6 & 1 \\
\hline
\end{tabular}

Table 12.3

pots from areas $\mathrm{A}$ and $\mathrm{B}$ were associated with buildings and can be assigned a domestic context. ${ }^{17}$ Nine Mycenaean vessels from area B were found in pits in House B I and B III. ${ }^{18}$ In the absence of an excavated pit in area $\mathrm{A}$, the significance of the relatively large number of Mycenaean finds from pits in area $\mathrm{B}$ cannot be assessed.

Habitation in area A may have continued after the buildings in area $\mathrm{B}$ had been abandoned. ${ }^{19}$ However, the chronological styles of the Mycenaean pots in all areas do not give any indication of an earlier abandonment of area B (Table 12.2). In both areas there are only a few vessels which have been assigned a LH IIIC date. In the case of area B, the LH IIIC vessels are a semi-globular cup (cat. no. 3) and a one-handled bowl (cat. no. 23). They were found together in a pit in room 3 of House B I. In area A, a carinated cup (cat. no. 8) and a ring-based krater (cat. no. 45) have been assigned a LH IIIC date. It should be remarked that House A yielded four LH IIIB-LH IIIC bowls (cat. nos. 19-22) of a type (FS 284) often considered to indicate the LC IIIA phase. ${ }^{20}$ Such vessels are absent from area B.

17 Two Mycenaean finds (cat. nos. 17, 18) were found outside House A below a floor; another find (cat. no. 42) was discovered below the lowest floor of room 2 in the same building. In area $\mathrm{B}$, Mycenaean fragments (cat. nos. 50-51) were found in fill layers above Houses B II and B III. All these finds have been assigned a general settlement context. All other finds from these areas (twenty-eight for area A and ten for area B) have been assigned to a domestic context.

I8 House B I possessed a pit in room 3, which produced four Mycenaean pots (cat. nos. 3, 7, 23, 28); The large pit from House B III yielded three such finds (cat. nos.
$10,12,29)$.

19 Taylor 1952, 149. B. Kling (pers. comm.) has noted that Cypriot White Slip pottery is more abundant in area $\mathrm{B}$ than in area $\mathrm{A}$, but she is, as yet, uncertain that whether area $\mathrm{B}$ was indeed abandoned earlier than area A.

20 Sjöqvist 1940, 120-131; Åström 1972b, 689-696; Kling 1987, 99. At least one of these deep bowls (cat. no. 20) has been found in Taylor's phase I, which shows that this vessel type cannot be used to distinguish between LC IIC and LC IIIA. 


\begin{tabular}{|c|c|c|c|c|c|}
\hline vessel type & area $A$ & area $B$ & area $\mathrm{C}$ & unknown & total \\
\hline ring-based krater & 1 & & & & 1 \\
\hline cups & 3 & 3 & 3 & & 9 \\
\hline stemmed cup & 2 & 3 & & 1 & 6 \\
\hline bowls & 12 & 4 & 3 & & 19 \\
\hline jugs & 8 & & & & 8 \\
\hline stirrup jar & 2 & & & & 2 \\
\hline large piriform jar & 1 & & & & 1 \\
\hline jar & 1 & 1 & & & 2 \\
\hline lentoid flask & 1 & & & & 1 \\
\hline fragment & & 4 & & & 4 \\
\hline
\end{tabular}

Table 12.4

Moreover, area B produced a higher quantity of White Slip pottery, which could also signify earlier abandonment of area B. Pending more detailed publication of the stratigraphy and pottery, however, it seems best to understand both excavation areas as having been inhabited in one period during the LC IIC-LC IIIA transition.

The figures in Table 12.2 show that the earliest Mycenaean pottery have been assigned to LH IIIA2-LH IIIB. The vessels concerned include a small fragment of a shallow cup (cat. no. 2); the other vessel is a semi-globular cup (cat. no. 1) with linear decoration only. In two cases has LH IIIB pottery been found in direct association with pots that have been assigned to LH IIIC. ${ }^{21}$ Given the relatively short duration of settlement occupation at Apliki, however, this cannot be taken as evidence that Mycenaean pots were kept as antiques or heirlooms.

As Table 12.3 indicates, there is a significant preference for Mycenaean dinner vessels at Apliki, with only a few storage vessels. This predominance of dinner vessels is true for all Mycenaean stylistical ceramic phases. ${ }^{22}$ It is of interest to note that almost all storage vessels have been found in area A; only one jar fragment (cat. no. 46) came from House B I. Such a concentration of storage vessels could indicate that the people associated with building A made more use of this type of vessel.

Table 12.4 shows the distribution of the actual Mycenaean vessel types at Apliki Karamallos. There are quite a number of Mycenaean jugs among the dinner vessels found at the site, showing that not all Mycenaean dinner vases are of open pot shapes. However, the great majority of Mycenaean dinner vessels are bowls, many of types that were produced in Cyprus itself. ${ }^{23}$ Such Aegean-type dinner vessels appear to have been used by many people in the town.

The figures in Table 12.5 show a predominance of linear pottery that may be somewhat exaggerated, since small sherds may have belonged to pots with more elaborate decoration. The distribution of

2I In House A, the floor of room $3 \mathrm{~W}$ contained a $\mathrm{LH}$ IIIB narrow-necked jug (cat. no. 35) together with a LH IIIC carinated cup (cat. no. 8) and two LH IIIBLH IIIC vessels (cat. nos. 22, 34). The pit of room 3 in House B I contained a LH IIIB stemmed cup (cat. no. 28) and a cylindrical cup (cat. no. 7) of the same date; in addition the pit yielded a LH IIIC one-handled bowl (cat. no. 23) and a semi-globular cup (cat. no. 3).

22 The two vessels assigned to LH IIIA2-LH IIIB are all of dinner types. Among LH IIIB vases, there are eleven dinner vessels and three storage pots. Among the Mycenaean vessels assigned to LH IIIB-LH IIIC, nineteen are dinner vessels, while there are two storage vessels. All of the five LH IIIC vases are of dinner types.

23 There are six skyphoi or deep bowls: cat. nos. 5, 1922, 44. Nine shallow bowls have been found: cat. nos. $10-18$. 


\begin{tabular}{|c|c|c|c|c|c|}
\hline decoration & area $A$ & area $B$ & area $\mathrm{C}$ & unknown & total \\
\hline linear & 19 & 5 & 4 & & 28 \\
\hline patterned & 6 & 1 & 2 & & 9 \\
\hline pictorial & 2 & & & & 2 \\
\hline unknown & 4 & 9 & & 1 & 14 \\
\hline
\end{tabular}

Table 12.5

Mycenaean pots decorated with floral and abstract patterns shows that patterned pottery was not restricted to a specific part of the site. Two Mycenaean vessels bear pictorial decoration. A fragment of a shallow bowl (cat. no. 11) preserves part of a fish, while a jar fragment (cat. no. 43) shows a bull's head. Both fragments were found in area A.

\section{SETTLEMENT CONTEXTS}

The contexts of the Mycenaean pottery at Apliki which has been found in closed deposits, is presented in detail in Table $\mathrm{X}$ in the tables section of this book. The buildings at Apliki were built on terraces cut into the rock. The walls of the structures in area $\mathrm{B}$ were of rubble patched with mud and most of the floors were of beaten earth. ${ }^{24}$ The walls discovered in areas $\mathrm{C}$ and $\mathrm{E}$ are similar to those attested in area B, suggesting that similar houses were situated in these areas. In comparison, the building in area $\mathrm{A}$ is of exceptional quality. Its walls were ca. $75 \mathrm{~cm}$ thick and it had floors of gypsum plaster. ${ }^{25}$ In addition, it possessed a courtyard and extensive storage facilities in room 1 . On this basis, it has been suggested that House A represents an official residence and workplace from which the local mining and primary processing of copper were controlled. ${ }^{26}$ Considering the extent of the site of Apliki, however, there is no way of knowing whether this structure was unique at the site.

House A (Fig. 12.2) ${ }^{27}$

House A was L-shaped and possessed a stone-paved courtyard in the south-west. The pit in the centre of this courtyard has not been excavated. To the east of the courtyard lay room 1, where three rows of five storage jars were discovered. These jars, of which only six were recovered in situ, were originally ca. $1.5 \mathrm{~m}$ high and $1 \mathrm{~m}$ wide. The bases of the jars had been set in rings of gypsum. The spaces between the jars were filled with a packing consisting of rubble and soil. From this packing, a number of Mycenaean finds at Apliki was recovered (cat. nos. 2, 11, 19, 26, 27, 38, 40, 41). It is doubtful whether the Mycenaean vessels can be associated to the supra-household storage practices of which the large pithoi in this room bear evidence. ${ }^{28}$

Room 2 served as a kind of hallway to the main room 3. On the upper floor in room 2 lay two Mycenaean-type round-bottomed bowls (cat. nos. 24, 25), as well as a Mycenaean deep bowl (cat. no. 21) and a jug (cat. no. 31). They were associated with various utilitarian objects such as a wall bracket and stone tools. The lower floor of this room produced a larger and more varied Mycenaean repertoire, including a LH IIIB jar (cat. no. 43) decorated with a bull's head. ${ }^{29}$ In addition, two Mycenaean

24 Taylor 1952, 144-150.

25 Taylor 1952, 134-136.

26 Keswani 1993, 77.
27 Taylor 1952, 133-144.

28 Keswani 1993, 77.

29 This jar is mentioned in Taylor's report, but not 


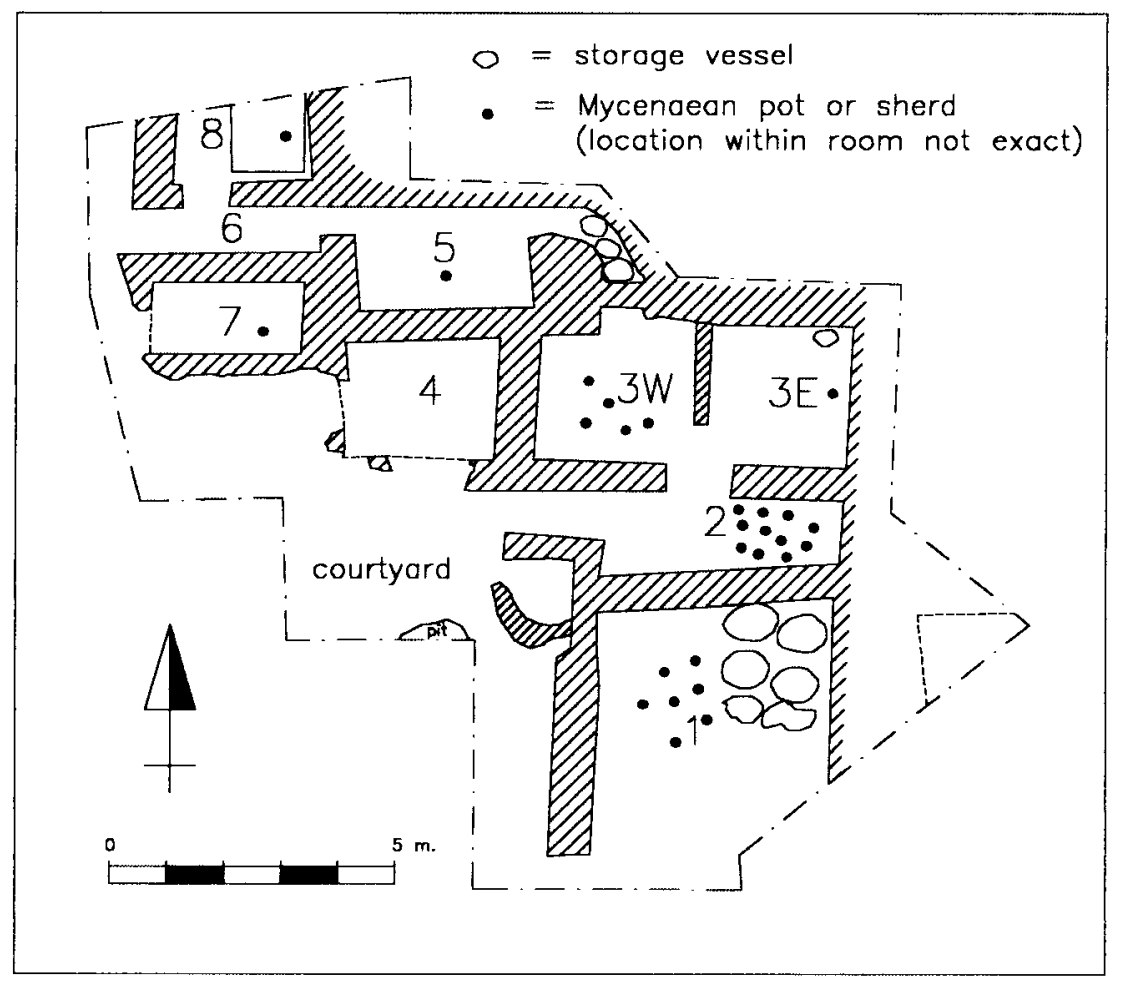

Fig. 12.2 Mycenaean pottery in house A

shallow bowls (cat. nos. 13, 14) were found, together with a Mycenaean deep bowl (cat. no. 20), a lentoid flask (cat. no. 39 and a narrow-necked jug (cat. no. 33). Other items on the lower floor were slag, some stone tools and Cypriot bowls, jugs and flasks.

Room 3 was divided up into two parts ( 3 and $3 \mathrm{~W})$, but had originally been one room. In its advanced phase, the eastern part of room 3 seems to have served as a storage room. On the upper floor, in the centre of the room, two deposits of grain have been discovered, ${ }^{30}$ as well as a group of ten spindle whorls. Near the eastern wall, a LH IIIB narrow-necked jug (cat. no. 33) was found, together with a serpentine square seal, a terra-cotta wall bracket, slag and stone tools. Room $3 \mathrm{~W}$ has been interpreted as habitation space, on the basis of a large quantity of domestic pottery (Fig. 12.3), some stone implements and a wall bracket. Associated with these domestic items were two LH IIIB-LH IIIC narrow-necked jugs (cat. nos. 34, 35), a deep bowl (cat. no. 22) and a carinated cup, probably of Cypriot manufacture, which has been assigned to LH IIIC (cat. no. 8) (Fig. 12.1). In its earlier phase, the large room 3 possessed a wooden structure, as is indicated by two post holes. The inventory on the lower floor contained a number of stone tools and tuyère fragments. Close together, in the western part, were found a Mycenaean shallow bowl (cat. no. 15), a golden earring, a bronze pin, fragments of a bone comb and a local bowl. This concentration of valuables is unique at Apliki and indicates that room 3 fulfilled an important function.

shown. It has not been included in the corpus of Mycenaean pictorial pottery by E. Vermeule and V. Karageorghis (1982).
30 These grains were analysed and discussed by Helbaek (1962).

3I $\quad$ Keswani 1993, 77. 


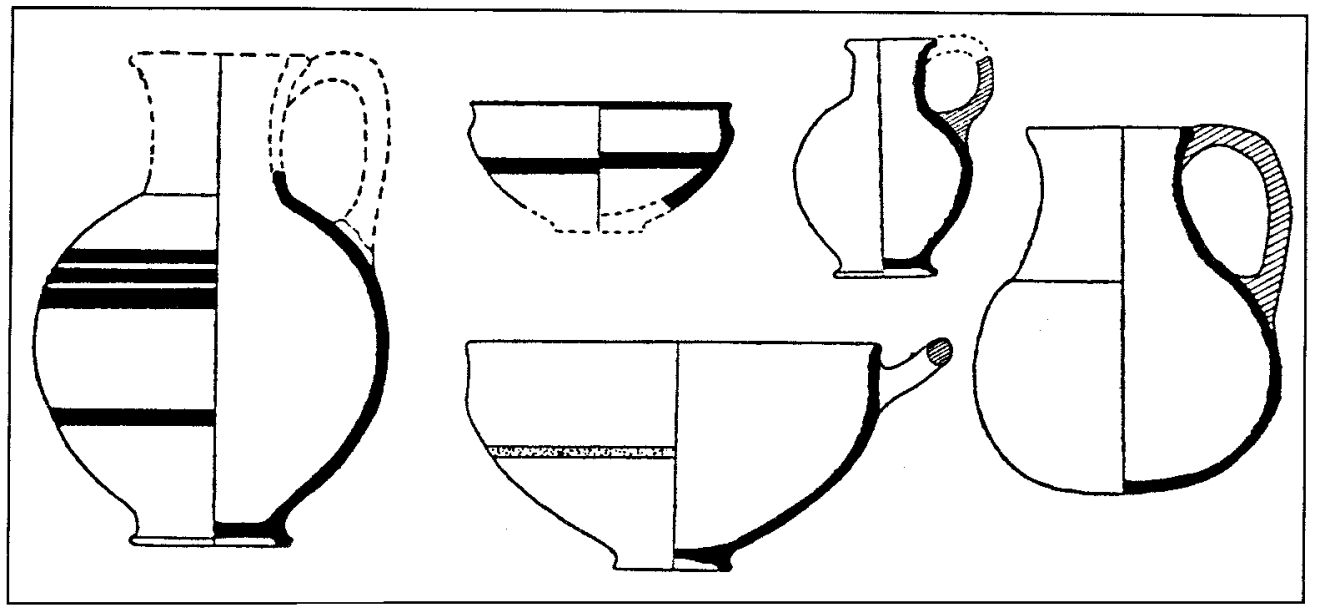

Fig. 12.3 Deposit of domestic pottery from the floor of room 3 in house A, among which a Myenaean-type jug (cat. no. 34) and a carinated cup (cat. no. 8) - After Taylor 1952, 137 fig. 5.

From room 3, one could originally enter room 5 through a narrow hallway. This hallway was blocked, however, and served as a storage room at the time of destruction. On the floor in the centre of the room lay a LH IIIB narrow-necked jug (cat. no. 36) together with local jugs and some stone tools. It seems that manufacturing activities took place in this room. Room 7 produced an abundance of slag, in addition to stone tools, Cypriot pottery and a fragment of a LH IIIC ring-based krater (cat. no. 45). Room 8 was not completely excavated. It was entered from hallway 6 and contained a mudbrick bench, on and near which lay several jugs and juglets, fragments of terra-cotta figurines and a steatite cylinder. Among the jugs on the bench was one of LH IIIB type (cat. no. 37). It is possible that this bench served some ceremonial or cultic function. ${ }^{31}$

The distribution of Mycenaean pottery in House A shows a clear concentration in rooms 1, 2 and 3. However, the Mycenaean finds in room 1 should not be taken into account, since they are all in secondary contexts. Together, rooms 2 and 3 comprise the residential section of the building. The concentration of the Mycenaean bowls, jugs and cups in this part of the building indicates that these vessels had predominantly domestic associations. The western part of the building possessed mainly industrial functions. Only two Mycenaean finds were made here, showing that such pottery was only rarely associated with craft production. The presence of a Mycenaean jug in a possible cultic context indicates that Mycenaean pottery could be part of ceremonies of a symbolic nature.

House B I (fig 12.4) $)^{32}$

In the eastern part of the long trench $\mathrm{B}$, at least five rooms were excavated belonging to a building which must extend to the north and south. The easternmost room 2, was very small and had a floor consisting of a thin layer of beaten earth resting on the natural rock. A large number of terra-cotta discs were found on this floor, in addition to local coarse and fine pottery. Taylor also mentions Mycenaean pottery (cat. no. 46), but nothing is known about vessel type or decoration. To the west of room 2 lay room 1, which was somewhat larger and had a mud floor, on which stood a large jar in the north-eastern corner. Room 3 was larger and opened up to a passageway in the south-east. The floor, consisting of beaten mud, again produced a number of terra-cotta discs and some stone tools.

32 Taylor 1952, 144-146. 


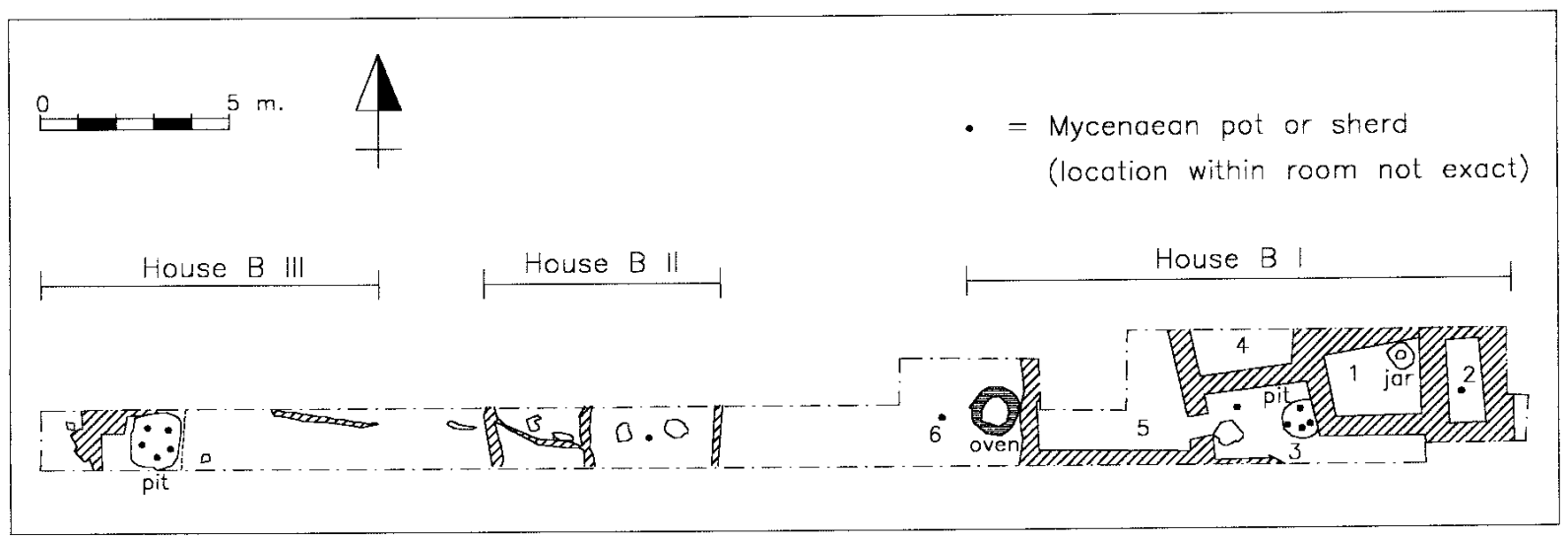

Fig 12.4 Mycenaean pottery in area B

At least one fragment of Mycenaean pottery (cat. no. 48) was also recovered. Room 4 also produced terra-cotta discs. The large room 5 possessed a lime floor and its walls were of good quality. It may be, then, that this room served a special function in the building, but this is not clear from its material inventory, which contained pottery discs and some White Slip and 'Apliki' sherds. To the west of room 5 , an area was discovered which has been called room 6 , but which most likely was situated outside the building. A conical oven was situated close to the eastern wall. From the floor of this probable courtyard, a Mycenaean jar (cat. no. 47) has been reported, together with a cooking pot and, again, terra-cotta discs.

The mud floor in room 3 had been cut to form a pit of about $1 \mathrm{~m}$ wide and $75 \mathrm{~cm}$ deep. This pit produced a small concentration of four Mycenaean vessels, among which were two small cups (cat. nos. 3, 7), a one-handled bowl (cat. no. 23) and a stemmed cup with patterned decoration (cat. no. 28) (Fig. 12.5). These dinner vessels have been assigned to different stylistical phases: two to LH IIIB (cat. no. 7, 28) and two others to LH IIIC (cat. no. 3, 23). In addition to the Mycenaean pottery, the pit yielded Cypriot coarse and fine wares, a loom weight and terra-cotta discs. Taylor also reports that the filling of sand and rock chippings was impregnated with copper. This suggests that this pit should be considered as a refuse pit, filled after cleaning part of the building.

The three Mycenaean fragments of unknown shape from the floors in rooms, 2, 3 and 6 indicate that this pottery was used at various places in the building. However, we should also note that there is a very limited repertoire of Mycenaean pots in this building, consisting of a few open dinner vessels only. The concentration of four drinking vessels in the pit indicates that these vessels were not used very often and were not widely available to the residents. It is unclear which activities were carried out in House B I, but it is of interest that numerous terra-cotta discs has been reported from this building. ${ }^{33}$ Even though the function of such implements is unclear, it suggests that specialised activities were carried out in this building. Apparently, Mycenaean pottery was only to a limited extent associated with these activities.

33 Terra-cotta discs have been reported from other structures in small numbers only; see Taylor 1952, 136, 142. 


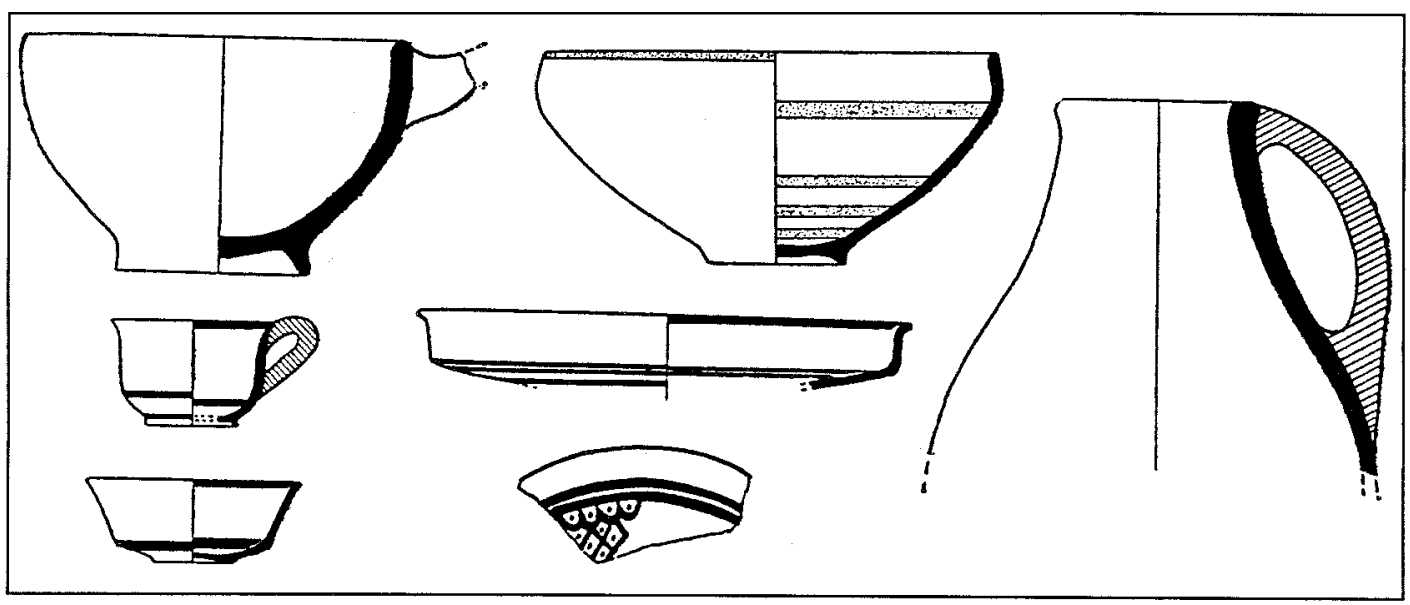

Fig. 12.5 Pottery from the pit in room 3 of House B I, among which four Mycenaean vessels (cat. nos. 3, 7, 23, 28) - After Taylor 1952, 145 fig. 10.

\section{House BII (Fig. 12.4) 34}

Few traces remained of House II in area B. On the earth floor in the easternmost room a Mycenaean bowl (cat. 49) was discovered, together with Cypriot jugs and bowls and a stone tool. Mycenaean pottery was not found on the floors in the western part, but from the fill above this part of the building a Mycenaean fragment (cat. no. 50) has been reported.

Very little can be said about this structure, or about the Mycenaean pottery associated with it. It is of interest, however, that this is a case in which Mycenaean pottery, albeit very few and inconspicuous, is associated with a poor quality building.

\section{The pit BIII (Fig. 12.4) 35}

The deep pit in BIII was associated with a well-built mud-brick wall on a stone footing and, to the east, with a thinner wall at right angles to it. This indicates that the pit was situated in a building, which has been labelled House B III. Two post-holes in the area of the pit suggest a wooden superstructure. The pit contained several strata, the uppermost of which appeared to indicate use as a rubbish dump. In this layer, which was more than $2 \mathrm{~m}$ deep, many sherds of Mycenaean cups (cat. no. 52) and a goblet (cat. no. 53) have been reported, in association with a whole tuyère, a terra-cotta larnax, as well as Cypriot jugs and bowls. The bronze blade of a knife was also found in this layer. It is unsure whether the deeper strata represent earlier fillings of the pit. Stratum 3, which was over $1 \mathrm{~m}$ thick, contained Cypriot pottery, as well as bones and slag. The bottom stratum 4 contained two Mycenaean shallow bowls (cat. nos. 10, 12) and a stemmed cup (cat. no. 29). In addition, Cypriot pottery was found and more bones. Since it is likely that all the layers in this pit are the result of rubbish dumping, it is difficult to assess the significance of the Mycenaean pottery.

In the previous section, I pointed to a concentration of Mycenaean vessels in House A. The material culture in this building in general was wealthier than that in the structures in area B and the Mycenaean pots conform to this picture. Apart from the larger quantities of Mycenaean finds in House A, a wider repertoire of Mycenaean vessel types has been noted. In addition to the cups, bowls 
and stemmed cups which also occur in area B, area A yielded jugs and a few storage vessels such as stirrup jars and a flask. Apparently, such vessels did not circulate widely within the settlement.

The Mycenaean vessels in both areas A and B are primarily associated with domestic activities. It is of interest to note that the few rooms with non-domestic functions in House A have produced Mycenaean pottery types other than open drinking vessels: the lower floor in room 2, on which slag was found, yielded a Mycenaean flask, jar and jug; room 5, likewise with an industrial inventory, also produced a jug, as did the possible cultic bench in room 8. This contextual distinction between Mycenaean vessel types indicates that the appreciation of this pottery was related to the functions of the pots and the extent to which they were part of local practices. The use of these Mycenaean pots probably was restricted to specific circumstances.

THE ROLE OF MYCENAEAN POTTERY IN THE MATERIAL CULTURE O F A P L I K I

Apart from the Mycenaean pottery, very few objects have been found at the site of Karamallos which may be classified as international imports. The ivory of a probable box stopper, must have been imported, but the object itself may have been manufactured somewhere in Cyprus. ${ }^{36}$ The small fragment of a bone comb is undecorated. ${ }^{37}$ It belongs to a rectangular, one-sided comb of a type also occurring elsewhere in Cyprus. ${ }^{38}$ The serpentine square seal has Cypro-Minoan signs, which demonstrates manufacture on the island. ${ }^{39} \mathrm{~A}$ similar origin can be assumed for the cylinder seal, which was unworked. The golden earring found in House A, as well as the scarce bronze objects, all have good parallels in Cyprus and may have been produced on the island.

The imported Mycenaean pots, then, represent the only objects at the site which derive from international maritime exchange. The Mycenaean-type pots which are of Cypriot manufacture are comparable to the other a-typical objects at the site: they refer to a wider world, without actually deriving from it. From the spatial distribution of the special objects as presented in Table 12.6 it is clear that there is some correlation between the presence of Mycenaean pottery and other a-typical objects. With the exception of the pit in room 3 in House B I, all concentrations of Mycenaean pottery were associated with other special finds. Moreover, in all places where more than one different type of valuable object has been found (e.g. rooms 1, 2, 3, 8 and the pit in B III), Mycenaean pottery has also been observed. At the same time, it should also be noted that individual finds of Mycenaean pottery have been made in rooms without any other a-typical objects.

The presence of Mycenaean pottery in a house such as House B II shows that these vessels were an integral part of the material culture. However, in House A, the Mycenaean pottery is concentrated in a few rooms, while in area B there are two concentrations of this material in pits (Fig. 12.4). The fact that substantial quantities of Mycenaean pottery are usually associated with other valuables indicates that Mycenaean vessels were highly appreciated and that their use was confined to specific circumstances.

Apliki-Karamallos has been interpreted as a mining village, which depended on exchange with inland

36 For the manufacture of ivory objects in Cyprus, see

1986, 127-130; Karageorghis 1985c; Krzyszkowska Dikaios, 1969, 99-100; L. Åström 1972, 608-616; 1992.

Poursat 1977, 159-160; Courtois, Lagarce \& Lagarce 


\begin{tabular}{|c|c|c|c|c|c|c|c|}
\hline rooms & Myc & ivory & seal & bone objects & gold & bronze objects & slag \\
\hline house $A$, room 1 & $x$ & $x$ & & & & $x$ & \\
\hline house $\mathrm{A}$, room 2 & $x$ & & & & & $x$ & $x$ \\
\hline house $A$, room 3 & $x$ & & $x$ & $x$ & $x$ & $x$ & $x$ \\
\hline house $A$, room 4 & & & & & & $x$ & \\
\hline house $\mathrm{A}$, room 5 & $x$ & & & & & $x$ & \\
\hline house $A$, room 6 & & & & & & $x$ & \\
\hline house $A$, room 7 & $x$ & & & & & & $x$ \\
\hline house $A$, room 8 & $x$ & & $x$ & & & $x$ & \\
\hline \multicolumn{8}{|l|}{ house B I, room 1} \\
\hline house B I, room 2 & $x$ & & & & & & \\
\hline house B I, room 3 & $x$ & & & & & & \\
\hline house B I, room 3: pit & $x$ & & & & & & \\
\hline \multicolumn{8}{|l|}{ house B I, room 4} \\
\hline \multicolumn{8}{|l|}{ house B I, room 5} \\
\hline house B I, room 6 & $x$ & & & & & & \\
\hline house B II, room 1 & $x$ & & & & & & \\
\hline \multicolumn{8}{|l|}{ house B II, room 2} \\
\hline \multicolumn{8}{|l|}{ house B II, room 3} \\
\hline \multicolumn{8}{|l|}{ house B II, room 4} \\
\hline \multicolumn{8}{|l|}{ house B III } \\
\hline house B III: pit & $x$ & & & & & $x$ & $x$ \\
\hline area $\mathrm{C}$ & $x$ & & & & & & \\
\hline
\end{tabular}

Table 12.6

and coastal centres for the influx of foodstuffs and valuables. ${ }^{40}$ In the near vicinity of Apliki, the necropolis of Katydhata (site no. 107) has also produced substantial amounts of Mycenaean pottery. The Mycenaean vessels from the tombs there have been assigned stylistically to LH IIIA1, LH IIIA2 and LH IIIB. ${ }^{41}$ The large number of tombs, all serving for multiple inhumations, cover the periods from Middle Cypriot I to LC IIIA. Six of the latest tombs have been assigned to LC IIC and LC IIIA and may be contemporary to Apliki Karamallos. ${ }^{42}$ Even though a settlement has not been discovered near Katydhata, it is logical to assume that mining villages similar to that discovered at Apliki Karamallos were situated in the area.

Along the coast of Morphou bay, Mycenaean pottery has been reported from Loutros-Adhkia (site no. 110), Soloi (site no. 109) and Pendayia (site no. 106). In each case it concerns only one Mycenaean find of which nothing further is known. The urban centre nearest to Apliki is that of Morphou-Toumba tou Skourou (site no. 105) in the marshy lowlands near the coast of Morphou bay.

37 Taylor 1952, 164 Fig. 13: no. 1.

${ }^{38}$ Gjerstad et al. 1936, T. 18 no. 13, Plate 152; Dikaios 1969-1971, Plate 127: nos. 23, 42. According to Karageorghis (1985c, 336), single-sided combs such as the one found at Apliki, have an Aegean origin, while the double-sided comb is Near-Eastern. Buchholz (1984-1985, 110-116) acknowledges that double-sided combs occur in Cyprus and the Near-East during the
Bronze Age, while these are absent in the Aegean. Both types, were apparently manufactured in Cyprus until the Archaic period.

39 Taylor 1952, 163-164.

40 Keswani 1993, 77-79; Knapp 1997, 59-61.

4I Åström 1989, 59.

42 LC IIC: tombs 11, 17, 18, 83, 88; LC IIIA: tombs 11, 104. 
Even though this site has been badly damaged by construction activities and by the Turkish army, it is clear that it possessed monumental architecture and was involved in international maritime exchange. ${ }^{43}$ The site has also produced some evidence for copper working. ${ }^{44}$ Most of these activities seem to have taken place in MC III-LC I, well before the establishment of Apliki-Karamallos. A LC IIB level was identified only in a small area in the south of Toumba tou Skourou; some LH IIIB pots from wells and from unstratified deposits testify of even later activities. ${ }^{45}$ It is doubtful, however, whether the site can be considered a coastal centre in the period during which Apliki-Karamallos flourished. It is therefore not certain whether Apliki-Karamallos may be associated with Toumba tou Skourou. Instead, it may have had relations with several other centres. Passing along the coast or through the mountains, such contemporary centres as Maa-Palaeokastro (site no.130), KoukliaPalaepaphos (site no. 126), Alassa (site no. 123), Kalavassos-Ayios Dhimitrios (site no. 114) and MaroniVournes (site no.116) could be reached with relative ease.

The concentration of valuables and storage facilities in House A, as well as its superior architecture, indicates that it was related to an élite group in the population of the town. The scarcity of metal objects and other valuables shows that this group was in contact with coastal centres, but received only a modest share of objects belonging to a more cosmopolitan life-style. The restricted repertoire of Mycenaean-type vessels obviously was part of such a system of restricted wealth finance. ${ }^{46}$ The presence of substantial quantities of this pottery in specific rooms only, usually associated with other valuables, shows that these pots served in consumptive strategies of local élite groups.

43 Vermeule \& Wolsky 1990, 397-400; Keswani 1996, 220-221.

44 Stech 1982, 108; Vermeule \& Wolsky 1990, 327. 



\title{
13 The cultural significance of Mycenaean pottery in Cyprus
}

\author{
I N T R O D U C T I O N
}

The settlement at Enkomi covers virtually the whole Late Cypriot Bronze Age, whereas the occupation of Athienou and Apliki only took place in the later part of that period. Differences between the conclusions reached for Enkomi and the other two sites may be the result of developments in time. By including evidence from other sites in Cyprus such chronological patterns will become apparent. However, the differences and similarities between these sites may also be related to the variations in the specific roles of these settlements in Cypriot society during the Late Bronze Age.

\section{MYCENAEAN REPERTOIRE}

Considerable differences have been observed between the quantity of Mycenaean pottery reported from Enkomi on the one hand and from Athienou and Apliki on the other. At least as much Mycenaean pottery as at Enkomi has been found at Hala Sultan Tekke (site no. 65), both from the settlement and from tombs. ${ }^{1}$ At Kition (site no. 63) substantial quantities of Mycenaean pottery have also been discovered: from tombs $4 / 5$ and the two burial layers in tomb 9 came more than $300 \mathrm{LH}$ IIIA2-LH IIIB vessels $;^{2}$ large quantities of such pots have been discovered settlement levels as well. ${ }^{3}$ Smaller, but nevertheless significant amounts of Mycenaean pottery have been found in KalavasosAyios Dhimitrios (site no. 114), ${ }^{4}$ Maroni-Vournes (site no. 116), ${ }^{5}$ Kourion-Bamboula (site no. 122$)^{6}$ and Kouklia-Palaepaphos (site no. 126). ${ }^{7}$ There are no sites in the interior of the island which have pro-

I Åström (1986a, 63-64) reports 3,467 Mycenaean finds, while according to Sherratt (1999, 170), more than 4,300 Mycenaean pottery fragments are known from published trenches alone.

2 Karageorghis 1974.

3 Karageorghis (1981) publishes forty-four Mycenaean finds. However, this is only a small selection of this material found in the settlement. There are at least 600 entries in the catalogue of settlement finds at Kition mentioning LH IIIA, LH IIIB or 'Late Myc.' pottery, see Karageorghis 1985a, 1-249. Many of these entries concern more than one fragment.

4 South \& Russell (1993) report fifty-three Mycenaeantype finds from a pit in Building X, while other parts of the settlement yielded Mycenaean pots and sherds thereof as well. In addition, various tombs produced significant amounts of Mycenaean pottery, notably $\mathrm{T}$. 11, 13, 14 and 19, see South 1997, 163-171; South \& Russell 1993, 306; Steel 1998.

5 Johnson (1980) lists more than 100 Mycenaean-type vases from tombs that had been excavated at the end of the 19 th century.

6 Benson 1972, 106-122. From the tombs and from the settlement levels at Kourion, 193 Mycenaean-type finds have been reported; there were three sherds of Minoan origin.

7 More than 300 Mycenaean finds have been reported from tombs, wells and the area of the sanctuary, see 
duced more than 100 Mycenaean vessels or fragments thereof. Apparently, concentrations of large quantities of Mycenaean pottery were restricted to the urban coastal centres, which participated directly in international exchange networks. ${ }^{8}$ In spite of the high numbers of Mycenaean pots from the coastal towns, we should always remember that this material is only a fraction of the total of ceramic finds in both settlement and funerary contexts.

Apart from a larger quantity, Enkomi has also yielded a wider variety of Mycenaean pots than Athienou and Apliki. At Kition (site no. 63), a wide variety of Mycenaean storage vessels has been reported from tombs $4 / 5$ and 9 , including piriform jars, alabastra, stirrup jars and flasks. ${ }^{9}$ However, both tombs have produced many more Mycenaean dinner vessels, among which were kraters, jugs, cups and stemmed cups. Mycenaean dinner and storage vessels have been discovered in settlement levels at Kition; ${ }^{10}$ it is unclear, however, which of these two functional types predominate. Mycenaean female and bovine figurines have been discovered at Kition, ${ }^{11}$ while a Mycenaean conical rhyton has also been discovered at that site. ${ }^{12}$ From the tombs at Hala Sultan Tekke (site no. 65) which were excavated by the British Museum in the 19th century, a variety of Mycenaean pots has been reported, among which is a relatively small proportion of dinner vessels. ${ }^{13}$ The two tombs investigated by V. Karageorghis in 1968 did include a substantial number of Mycenaean dinner vessels, but here too there was a predominance of storage pots. ${ }^{14}$ The same was the case for deposit F6031, which was found in area 22 but probably derived from a tomb. ${ }^{15}$ In addition, a well-deposit at Hala Sultan Tekke had a high content of Mycenaean storage vessels. ${ }^{16}$ It is evident that Mycenaean dinner and storage vessels are widely distributed in the tombs and in the settlement levels at Hala Sultan Tekke, ${ }^{17}$ even though the proportion of storage vessels at this site seems to be relatively high in comparison to Kition and Enkomi. In addition, Mycenaean ritual vessels such as rhyta have been reported from Hala Sultan Tekke, ${ }^{18}$ as well as a female figurine. ${ }^{19}$ The tombs at Kalavasos-Ayios Dhimitrios (site no. 114) yielded a variety of LH IIIA2-LH IIIB dinner and storage vessels, ${ }^{20}$ while the same was the case for the settlement levels. ${ }^{21}$ Among the Mycenaean finds reported from the tombs at Maroni (site no. 116), there is a high proportion of dinner vessels. ${ }^{22}$ Even though this may partly be due to a bias in the archaeological data due to the attention paid by early explorers to pictorial kraters, the presence of a

Maier \& Karageorghis 1984, 54-63.

8 Stech 1982, 113; Keswani 1993, 76; Knapp 1997, 5455; Sherratt 1999, 297.

9 Karageorghis 1974, 16-94.

Iо Karageorghis (1981, 1-15; 1985a, 1985b) reports Mycenaean finds from floors IV and IIIA in areas I and II.

II Karageorghis 1974, 33: no. 238; 44: no. 13; 1985a, 98-99, 105, 170: nos. 3219, 3222, 3225, 3251, 3323, 3213.

I2 Karageorghis 1985a, 89: no. 3442.

I3 Bailey 1976.

I4 Karageorghis 1976, 72-83.

Is Öbrink 1979.

I6 Öbrink 1983, 29 Table 2.

${ }_{17}$ Frizell (1977, 43-57) reports Mycenaean cups, bowls, kylikes, kraters and stirrup jars from area 21; Hult
(1978, 58-71; 1981, 36) mentions Mycenaean open and closed vessels from area 8, while Öbrink (1979, 23) reports Mycenaean bowls and piriform jars from area 22; Håkansson $(1989,21)$ speaks of bowls and cups in LC II levels in area 8.

I8 Öbrink 1983, 25: no. 51. A fragment of a possible ring-rhyton (FS 203) was found in a tomb at Hala Sultan Tekke, see Walters 1912, 129: no. C679; Bailey 1976, 25-26.

19 Åström 1983, 147 Fig. 397, 150 Fig. 402q, 153 fig 410n.

20 For example, T13 produced Mycenaean piriform jars, stirrup jars and straight-sided alabastra, but also two kraters, juglets, cups and a kylix, see South 1997, 163168.

2I Russell 1989, 7-8; South \& Russell 1993; South 1997.

22 Johnson 1980, 77 tableau 1. 
ring kernos, a zoomorphic rhyton and a fragment possibly representing a ship testifies to an exceptionally wide variety of Mycenaean pottery at Maroni. ${ }^{23}$ From Kourion-Bamboula (site no. 122) stirrup jars, piriform jars, flasks and alabastra have been reported, along with kraters, jugs, kylikes and bowls. ${ }^{24}$ The same can be said for Kouklia-Palaepaphos (site no. 126). ${ }^{25}$ Obviously, all primary centres along the coast had a wide variety of Mycenaean pots.

At sites with smaller amounts of Mycenaean pottery the ceramic repertoire varies highly. The settlement at Sinda (site no. 54) probably constituted an inland centre related to Enkomi. Furumark reports that a great quantity of LH IIIB pottery was found in the lowest settlement levels at Sinda. ${ }^{26}$ The pots he refers to probably are those listed by Åström, who mentions a wide variety of Mycenaean dinner and storage vessels as coming from this site, as well as a LH IIIB conical rhyton and a Mycenaean female figurine. ${ }^{27}$ In the buildings excavated in areas I and II in Pyla-Kokkinokremos (site no. 58) mainly Mycenaean dinner vessels have been found; ${ }^{28}$ the tombs at nearby Pyla-Verghi (site no. 61) produced dinner as well as storage vessels. ${ }^{29}$ At the Late Bronze Age settlement of Kalopsidha (site no. 57), Mycenaean cups and bowls have been found, as well as closed vessels; among the latter were a piriform jar and a straight-sided alabastron..$^{30}$ The Mycenaean finds made in the settlement area of Idalion (site no. 72) are all very fragmentary, but a nearby tomb yielded a wide variety of Mycenaean pottery, including many stirrup jars; a Mycenaean figurine has also been discovered at this site. ${ }^{31}$ It is clear that secondary and tertiary settlements in Cyprus could possess a wide variety of Mycenaean pottery, even if the quantities are far lower than at primary coastal centres.

A much more restricted repertoire of Mycenaean pottery has been found at Ayios Iakovos-Melia (site no. 51), where each of the three tombs dating to LC II has produced a few Mycenaean vessels, mostly of the storage type. ${ }^{32}$ This necropolis is possibly related to the nearby sanctuary site of Ayios Iakovos-Dhima (site no. 47). Together, these two sites may have belonged to an inland centre comparable to Athienou. ${ }^{33}$ In the Late Bronze Age levels of the sanctuary at Dhima four Mycenaean piriform jars were found, as well as a jug and a krater. ${ }^{34}$ The settlement of Myrtou-Pigadhes (site no. 99), which included a Late Bronze Age sanctuary, also yielded a restricted repertoire of Mycenaean pottery, among which were kraters and many small jugs. ${ }^{35}$ Two conical rhyta and a hedgehog rhyton have also been reported from this site. In the necropolis at Angastina (site no. 77) predominantly storage vessels have been found, among which were a large number of stirrup jars. ${ }^{36}$ A similarly restricted range of Mycenaean pots was present in tomb 6 at Nicosia-Ayia Pareskevi (site no. 75) ${ }^{37}$ and in the tombs excavated in Akhera (site no. 92) ) $^{38}$ and Politiko (site no. 89). ${ }^{39}$ Not all sites with smaller amounts of Mycenaean pottery, then, had a wide variety of it. However, it should be noted that the sites with a restricted Mycenaean repertoire are all tomb sites or sanctuaries. It is likely that

23 Johnson 1980, 27: no. 173 (ring kernos), 21: no. 100 (hedgehog rhyton), 23: no. 132 (ship fragment).

24 Benson 1972, 106-121.

25 Maier \& Karageorghis 1984, 50-63; Maier \& Von Wartburg 1985, 146-152.

26 Furumark 1965, 105.

27 Åström 1972b,189-384; L. Åström 1972, 512 below no. 2

28 Karageorghis \& Demas 1984, 33-49.

29 Dikaios 1971, 914.

30 Åström 1966, 70-71.
$31 \quad$ Overbeck \& Swiney 1972; Herscher 1998, 333.

32 Sjöqvist 1934, 325-333 (tomb 8), 345-348 (tomb 13), 349-354 (tomb 14).

33 Knapp 1997, 58.

34 Sjöqvist 1934, 357-358.

35 Catling 1957; Taylor 1957, 1.

${ }_{36}$ Karageorghis 1964, 13-16.

37 Kromholz 1982, 246-247.

$3^{8}$ Karageorghis 1965a, 119, 132.

39 Karageorghis 1965b, 20, Fig. 4. 
the relatively narrow range of Mycenaean pots is related to the special nature of the activities at such places.

This overview shows that the urban centres along the southern coast of Cyprus possessed a wide variety of Mycenaean pots, as was also the case for Enkomi. However, there are specific differences in the repertoires of Mycenaean pots among these sites, such as the probable predominance of storage vessels at Hala Sultan Tekke. This suggests that preferences existed in the coastal centres for specific classes of Mycenaean pottery. The wide Mycenaean ceramic repertoire at Apliki-Karamallos, Sinda, Pyla, Kalopsidha and Idalion shows that the regional distribution of Mycenaean pottery was not limited to a restricted range of vessel types. Indeed, the occurrence of a wide variety of dinner and storage vessels at many sites, as well as the sporadic presence of ritual vessels and figurines in smaller centres, indicate that the differences in the Mycenaean repertoires between smaller towns and urban centres primarily concern amounts. As at Athienou-Bamboulari tis Koukouninas, the Mycenaean repertoire at secondary or tertiary sites of a special nature such as sanctuaries and necropoleis is restricted, indicating that the regional distribution of Mycenaean pots was related to specific cultural practices.

The conclusion that a wide variety of Mycenaean pots was present not only in primary coastal centres, but also at secondary and tertiary sites, may not be valid for all periods. Among the very first Mycenaean vessels imported at Enkomi (LH I-LH IIA) are dinner vessels as well as a storage pot. The same pattern is visible at Toumba tou Skourou (site no. 105), where the Aegean pottery from the first phase of the Late Bronze Age is exclusively Minoan in origin and includes many cups, some jugs and a large jar. ${ }^{40}$ In three LC I tombs at Ayia Irini-Palaeokastro (site no. 103), a number of semi-globular cups have been found that belong either to LM I or to LH I-LH II. ${ }^{41}$ At Maroni (site no. 116), a LH IIA alabastron has been dicovered in a tomb, ${ }^{42}$ while a LM IA cup has been reported from KoukliaPalaepaphos (site no. 126). ${ }^{43}$ Even though the actual numbers of Aegean pottery from this very early period are small, a relatively wide variety of vessel types appears to have been present at the island, with a rather high proportion of dinner vessels.

At Enkomi, the LH IIB-LH IIIA1 pottery comprises a majority of storage vessels, but there is also a good proportion of dinner vessels. A similar pattern can be seen among the predominantly Minoan pottery from Toumba tou Skourou (site no. 105) where a LM IIIA1 jug, stirrup jar and flask have been found, as well as a LH IIIA1 shallow cup. ${ }^{44}$ At Maroni (site no. 116) LH IIB-LH IIIA1 pots include piriform jars, alabastra, as well as bowls. ${ }^{45}$ The earliest Mycenaean find at Hala Sultan Tekke (site no. 65) is a LH IIB-LH IIIA1 alabastron picked up from the surface. ${ }^{46}$ Among the LH IIIA1 finds from this site are piriform jars, cups and a beaked jug. ${ }^{47}$ At the site of Milia (site no. 55), somewhat to the west of Enkomi, a Mycenaean kylix was found which has been dated to LH IIB-LH IIIA1. ${ }^{48}$ A LH IIIA1 stirrup jar has been reported from Idalion (site no. 72 ) ${ }^{49}$ At Dhikomo-Onisia (site no. 83) a

$40 \quad$ Vermeule \& Wolsky 1978; 1990, 381-383

4I Pecorella 1977, 21, 26: nos. 16, 29 (tomb 3), 112: nos. 38-39 (tomb 20); Quilici 1990, 142 (additional tomb); Graziado 1995

42 Manning \& Monks 1998, 203: no. MT 616.

43 Maier \& Karageorghis 1984, 71

44 Vermeule \& Wolsky 1990, 382.

45 Johnson 1980, 17-18; 27-28; Manning \& Monks 1998, 320-321.

46 Catling 1964, 36; Frankel \& Catling 1976, 65: no. 90.
A cup found during the excavations of area 8 has been assigned to LH IIB-LH IIIA2, see Håkansson 1989, 21 : no. F1712.

47 Åström 1972b, 320: no. 84c, 321, 332: no. 144a, 357: no. $219 \mathrm{~b}$.

$4^{8} \quad$ Nicolaou 1973, 54.

49 Nicolaou 1973, 55: no. 17. H.W Catling (pers. comm.) has expressed doubts if this vessel is indeed as early as LH IIIA1. 
sherd was found from a LH IIIA1 cup, ${ }^{50}$ while an alabastron in the same ceramic style from Katydhata (site no. 107), ${ }^{51}$ as well as a jug fragment at Nicosia-Ayia Pareskevi (site no. 75) may also be assigned to this ceramic style. ${ }^{52}$ Obviously, a wide range of Aegean dinner and storage vessels reached Cyprus during this period.

The distribution in Cyprus of finds dating to the very beginning of Aegean contacts with the island (LM I/LH I-LH IIA) is very limited and restricted to a few places on the coast. Even though only Aegean cups have been found at Ayia Irini-Palaeokastro, the finds at Toumba tou Skourou and Enkomi show that a wide variety of pots found their way to the large centres from early on. A concentration at coastal sites can also be noted for the succeeding LH IIB-LH IIIA1 phases. However, the kylix at Milia, the cup at Dhikomo and the alabastron at Katydhata show that some Mycenaean pots were distributed to the interior of the island, among which were dinner and storage vessels. This indicates that the presence of a wide variety of Mycenaean vessels at secondary and tertiary sites in Cyprus is not a phenomenon typical of the LC IIC period, but already began much earlier.

The Mycenaean pots in Cyprus are almost all decorated and differ from the products of the local ceramic industry, which were not made on the potter's wheel. ${ }^{53}$ Their obvious character as manufactured imports, made Mycenaean pots suitable to serve as symbols referring to a wider world of international relations. ${ }^{54}$ The fact that a relatively wide range of Mycenaean vessels could find their way to secondary and tertiary sites in Cyprus, suggests that these vessels represented a specific life style, involving various cosmopolitan practices, among which were dining and personal care. ${ }^{55}$ The low numbers of these vessels indicate that access to such a life-style was restricted for groups in the interior.

\section{SOCIAL GROUPS ASSOCIATED WITH THE MYCENAEAN POTTERY}

Mycenaean pottery was used widely by different groups in the societies of Enkomi and Apliki and was associated with day-to-day activities. At Kition (site no. 63) LH IIIB pottery has been reported from various rooms of the level IV building in area I. ${ }^{56}$ Furnaces and slag show that this building served as an industrial complex and included several copper workshops. Additional Mycenaean finds in the same area came from higher levels in which LH IIIC-type pottery was present as well. ${ }^{57}$ Even though habitation at Hala Sultan Tekke (site no. 65) probably began at the end of the Middle Bronze Age, most settlement remains date to advanced stages of LC III..$^{58}$ The few places where earlier deposits have been attested contained LH IIIA-LH IIIB pottery. In general, pottery in LH IIIB and LH IIIC styles is very abundant everywhere at Hala Sultan Tekke. In several parts of the site at Kalavasos-Ayios Dhimitrios (site

so Nicolaou 1973, 55: no. 15.

sI Nicolaou 1973, 55: no. 12. Åström 1989, 59.

s2 Catling (1964, 36) mentions a jug fragment with a curved stripe, which he compares to a LH IIIA1 beaked jug from Maroni (site no. 116).

$53 \quad$ Sherratt 1991, 191-193; 1994a, 37.

54 Keswani 1996, 79-80. Cf. the role of glass beads in the relationships between native American Indians and Dutch settlers during the 17th and 18th centuries along the eastern coast of the modern USA, see Francis Jr. 1996.

55 Cf. Steel 1998, 289-292.

56 Karageorghis 1985a; Demas 1985, 10.

57 Karageorghis 1985a, 9-77.

s8 Åström 1985, 174; 1976, 37; 1986a, 63-64; 1996; Frizell 1977, 50-57; Öbrink 1979, 14; 1983; Håkansson 1989, 21.

59 South \& Russell 1993, 305. 
no. 114), Mycenaean pottery has been found, but seems to have been significantly less abundant in the area where more modestly sized houses have been excavated..$^{59} \mathrm{~A}$ concentration of Mycenaean dinner vessels has been found in a pit in the elaborate Building X; ashlar structures adjacent to Building X also produced Mycenaean dinner vessels. ${ }^{60}$ The exact find spots of Mycenaean pots from the settlement at Kourion-Bamboula (site no. 122) are difficult to assess, but it is clear that this material has been found in areas A, B, D and E, which can be classified as habitation areas with a variety of houses of simple and more elaborate construction. ${ }^{61}$ At Kouklia-Palaepaphos (site no. 126), likewise, Mycenaean pottery was found among the Late Bronze Age building remains in the Asproyi area. ${ }^{62}$ From this overview it is clear that Mycenaean pots occurred in average domestic contexts in the primary centres along the coasts, as well as in contexts associated with craft production.

Among the settlements which have produced smaller amounts of Mycenaean pottery than the urban coastal centres, Pyla-Kokkinokremos (site no. 58) is one that shows a wide distribution of this material. In area II at this site, Mycenaean vessels were found in three of the four structures. ${ }^{63}$ Moreover, within these buildings the Mycenaean pots were widely distributed on the floors of various rooms and were interspersed with Cypriot pottery and domestic objects such as terra-cotta wall brackets, stone tools and some metal objects. The Aegean pottery found in LC II levels at Toumba tou Skourou (site no. 105) came from various rooms in Houses B and C and from a few pits in these houses. ${ }^{64}$ This pottery was interspersed with objects of Cypriot manufacture and appears to have been an integral part of the inventory of these buildings, which were related to large-scale production of pottery. At the site of Kalopsidha (site no. 57) no buildings were found intact, but in undisturbed levels in trench 9, seven Mycenaean fragments of both storage and dinner vessels were discovered together with a variety of Cypriot domestic wares. ${ }^{65}$ At Myrtou-Pigadhes (site no. 101), Mycenaean pottery was not very abundant, but it occurred in various rooms in levels V and VI. ${ }^{66}$ Such material was not only found in the courtyard of the ashlar altar, but also in the rooms surrounding the courtyard and the building to the east. Finally, at Maa-Palaeokastro (site no. 130), which was founded during the period of the LC IIC-LC IIIA transition, pottery in LH IIIB and LH IIIC styles was widely distributed in all parts of the settlement. ${ }^{67}$ Obviously, Mycenaean pottery was also used by various groups in the population at a number of smaller sites.

Mycenaean pottery also occurs in contexts which are indicative of a certain level of wealth, prestige and power. According to Priscilla Keswani, the Cypriot centres can be divided into two distinct types of social organisation. ${ }^{68}$ On the one hand there are sites such as Enkomi, Toumba tou Skourou, Kition and Hala Sultan Tekke. In such towns there is evidence of a complex social organisation in which no single group managed to exert a controlling hegemony. The clearest evidence of this social complexity is the fact that buildings testifying to central administration and monopolisation of storage facilities and craft production are lacking in these towns. ${ }^{69} \mathrm{~A}$ second type of urban social organisation in Cyprus can be classified as hierarchical and is visible at sites such as Kalavasos-Ayios Dhimitrios, Maro-

6o South 1988; 1991, 134; 1997, 158; South \& Russel 1993, 305.

6r Benson 1972, 107-121; Weinberg 1983, 32-51.

62 Maier \& Karageorghis 1984, 52-55.

63 Karageorghis \& Demas 1984, 33-49.

64 Vermeule \& Wolsky 1990, 383-385.

65 Åström 1966, 56-57.
66 Catling 1957, 46.

67 Karageorghis \& Demas 1988, 100-215.

68 Keswani 1996.

69 This social complexity is referred to by Keswani with the term heterarchy. The urban centres at KourionBamboula and Kouklia Palaepaphos probably also had a heterarchical social organisation. 
ni-Vournes and Alassa. In these towns, a specific élite group had been able to acquire ruling power over other social groups. ${ }^{70}$ Evidence for such a social hierarchy are the monumental buildings at these three sites with extensive storage capacity. It is likely that the role of Mycenaean pottery among Cypriot élite groups varied according to the type of social organisation.

At Enkomi, a number of impressive architectural buildings employing ashlar masonry have been discovered, dating to the period of the LC IIC-LC IIIA transition. The level IIB building in area Q4W, with an elaborate architectural layout, may be assumed to constitute a predecessor of such élite buildings. ${ }^{71}$ The repertoire of Mycenaean pots found in this building did not differ from that found in contemporaneous buildings elsewhere at the site. The ashlar structures at Hala Sultan Tekke (site no. 65) are to be dated somewhat later than those at Enkomi..$^{72}$ They have yielded a relative abundance of valuables, but notable concentrations of LH IIIB and LH IIIC-type pottery in such buildings have not been reported. At Kourion-Bamboula (site no. 122) monumental architecture has not been discovered, but the domestic buildings differ in size and quality, probably reflecting social stratification. ${ }^{73}$ On the basis of the published reports, it is difficult to relate Mycenaean finds to specific structures at Kourion, but is clear that such material has been found in areas A, B, D and E. The elaborate architecture of house B at Toumba tou Skourou (site no. 105) and a pithos with storage functions are indicative of a certain level of wealth. ${ }^{74}$ The floors and a well in this building produced a wide variety of Aegean dinner and storage vessels. ${ }^{75}$ Several Mycenaean sherds were also found in a well in the adjacent house C. At all these sites Mycenaean pots appear to have been used by élite groups, but other groups in the society also had access to this class of material.

The clearest settlement evidence for controlling élite groups has been found in Kalavasos-Ayios Dhimitrios (site no. 114), where Building X represents an administrative centre, as is indicated by the ashlar masonry, the extensive storage facilities and five clay cylinders with Cypro-Minoan script. ${ }^{76}$ In comparison with other buildings at the site, the floor levels of Building $\mathrm{X}$ did not so much yield a larger quantity of Mycenaean pottery as a wider repertoire of it, including kylikes and bowls. ${ }^{77}$ In addition, a pit in room A173 in the eastern part of Building X produced a large number of Mycenaean dinner vessels, associated with many animal bones and other evidence for feasting. ${ }^{78}$ Such a concentration of Mycenaean pottery clearly shows that the groups associated with Building X had wider access to Mycenaean pottery than other groups at the site.

Monumental structures indicative of central control similar to the one at Kalavasos have also been found at Maroni-Vournes (site no. 116) and at Alassa (site no. 123)..$^{79}$ Both sites have only been published in preliminary reports and it is uncertain whether the distribution of Mycenaean pottery is comparable to the situation at Kalavasos. Nevertheless, there is a clear difference in the concentration of Mycenaean pottery in élite structures between Enkomi, Hala Sultan Tekke and Kourion-Bamboula on the one hand and Kalavasos-Ayios Dhimitrios on the other. It is likely that this difference can be related to specific roles of élite groups within their respective communities. ${ }^{80}$ The absence of concentra-

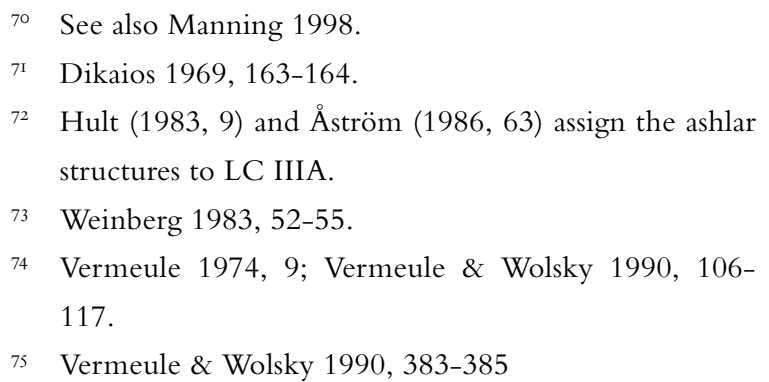

76 South 1984, 40; Karageorghis 1990, 3-5; Keswani 1996, 230-232.

77 South \& Russell 1993, 304.

78 South 1988; South \& Russell 1993, 305-306.

79 For Maroni Vournes, see Cadogan 1989; 1992; 1996. For Alassa, see Hadjisavvas 1986, 1989, 1996.

8o According to Knapp (1996a, 22), access to foreign goods helped to legitimise the regime of the metal 
tions of Mycenaean pottery in élite structures at sites with a complex, heterarchical organisation may reflect the failure of élite groups to monopolise the flow of of goods. The restriction of large quantities of Mycenaean pottery at Kalavasos-Ayios Dhimitrios to a specific group shows the firm grip of these people on the flow of goods. The concentration of a large number of Mycenaean pots in House A in Apliki may suggest that Mycenaean pots played a role similar to that at Kalavasos-Ayios Dhimitrios.

At Athienou-Bamboulari tis Koukouninas Mycenaean pots were found in a sanctuary. They were clearly used in local cultic practices. At Ayios Iakovos-Dhima (site no. 47) a circular area has been interpreted as a sanctuary, which should be dated somewhat earlier than Athienou. ${ }^{81}$ The paved area was divided into an upper and lower part, with two stone podia in the north-east. All the votive finds were made in the lower section in the east. In the centre of this lower section, a terra-cotta basin was placed in a shallow pit. In this pit, LH IIIA2 pottery was associated with a variety of objects such as a Red Lustrous arm-shaped vessel, bronze arrow heads and tools and faience and glass items. The deposit suggests that at Ayios Iakovos too Mycenaean pottery served in a local cultic ritual, together with other valuables. The sanctuary at Myrtou-Pigadhes (site no. 99) probably was not free-standing like those at Athienou and Ayios Iakovos, but may have been a small settlement temple comparable to Near Eastern examples. ${ }^{82}$ The courtyard surrounding the ashlar altar at Myrtou-Pigadhes produced more than ten Mycenaean pots dating from LH IIIA2-LH IIIB to LH IIIC. ${ }^{83}$ One LH IIIC-type deep bowl was deposited in an ash-filled pit in the courtyard, which indicates that the vessel had been part of some kind of ritual. Rooms 6 and 7, which may have belonged to the sanctuary, also produced Mycenaean pots.

A cultic area has been excavated at Kition (site no. 63), consisting of various temples, of which temples 2 and 3 were already in existence during LC IIC. ${ }^{84}$ In temple 2, on floor IV, Mycenaean stirrup jars, as well as drinking vessels have been discovered; hardly any finds were made on the contemporary floor in temple $3 .^{85}$ During LC IIIA at least four temples functioned simultaneously at Kition; in addition there were several workshops in the area. LH IIIB and LH IIIC-type vessels were widely distributed in the layers belonging to LC IIIA. ${ }^{86}$ At the site of the later Aphrodite sanctuary at Kouklia-Palaepaphos (site no. 126) a cultic precinct existed already during the Late Bronze Age. ${ }^{87}$ Mycenaean pottery, although unstratified, has been found in this sanctuary. It is clear, then, that Mycenaean pottery occurred not only in sanctuaries at smaller centres, but also in cultic precincts associated with coastal cities. In both the urban and rural sanctuaries Mycenaean pottery was directly involved in Cypriot cultic practices.

Mycenaean pottery was available to various groups in Cypriot society at many places. In conjunction with the wide distribution of this material in Cyprus, we may state that it was quite common and an integral part of the material culture of the LC II period on the island. However, only at coastal centres such as Enkomi, do large quantities of this pottery appear to have been available for various groups among the urban population. Elsewhere, in settlements such as Kalavasos and Apliki, substantial quantities of this pottery were assembled by the ruling élite. It is possible that the character of

controlling élite.

8I Sjöqvist 1934, 355-361. The excavators date the structure from MC III-LC IIC.

82 Ionas 1985.

83 Catling 1957, 43-48.
${ }^{8}$ Demas 1985.

8s Karageorghis 1985a, 88-91.

86 Karageorghis 1985a, 93-135.

87 Maier \& Karageorghis 1984, 99. 
Mycenaean pots as manufactured imports made them suitable as symbols of power. ${ }^{88}$ As the association of Mycenaean pots with cultic activities indicate, a religious dimension may have been part of the symbolic role of Mycenaean pottery.

\section{DIFFERENTIATION WITHIN THE REPERTOIRE OF MYCENAEAN P O T T E R Y}

The role of Mycenaean pots in cultural practices probably varied not only according to social group or place. Different Mycenaean pot shapes or types of decoration may also have been endowed with a different meanings. In addition, we need to review the significance of Mycenaean vessels in the various chronological styles. The earliest Aegean imports at Enkomi were used by a very limited group. However, LH IIB-LH IIIA1 finds have been discovered in tombs in various parts of the site, indicating that Aegean pottery gradually became available to many inhabitants. At Toumba tou Skourou (site no. 105), a substantial body of Late Minoan I pottery has been discovered that is contemporaneous to the earliest imports at Enkomi. ${ }^{89} \mathrm{~A}$ concentration of thirteen of these vases has been found in tomb 1 , which also produced objects of gold, silver and bronze, as well as ceramic imports from Egypt. Only a few fragments of Minoan pottery have been found in other contemporaneous tombs at Toumba tou Skourou; the retrieval of a few Minoan fragments in the settlement area suggests that this pottery was also used in non-funerary practices. ${ }^{90}$ At Ayia Irini-Palaeokastro (site no. 103), nine tombs were discovered dating to LC IA-LC IB. ${ }^{91}$ In only three of these tombs, cups were found which were imported from the Aegean. Obviously, here too Aegean pottery was not available to many people. The only other site in Cyprus with contemporary Aegean pottery is Kouklia-Palaepaphos (site no. 126), where a rim fragment of a LM IA cup was found in a well at the locality of Evreti. ${ }^{92}$ This one fragment is not enough to decide whether the use of the earliest Aegean ceramic imports at this site too was confined to a restricted group of people. The same should be said for Maroni (sites no. 116-117), where a LH IIA alabastron has been found in tomb $03 .^{93}$

Various tombs at Maroni produced a range of LH IIB-LH IIIA1 vessels. ${ }^{94}$ LM II finds have not been discovered at Toumba tou Skourou (site no. 105), but tomb II at this site yielded a LM IIIA1 beaked jug, while a LH IIIA1 shallow cup was found unstratified in settlement levels. ${ }^{95}$ From Hala Sultan Tekke (site no. 65), various LH IIB-LH IIIA1 finds have been reported, mostly without secure contexts; a number of LH IIIA1 fragments were found in a well. ${ }^{96}$ Nothing can be said about the groups in the society at Hala Sultan Tekke which may be associated with the imported Aegean pottery in these styles. The same is true for Kalavasos-Ayios Dhimitrios (site no. 114), where fragments of a LH IIB-LH IIIA1 alabastron were found unstratified. ${ }^{97}$ All other sites which have yielded Mycenaean pottery dating to the time before the introduction of LH IIIA2 on the island have produced only single examples of it. ${ }^{98}$ Nevertheless, the occurrence of LH IIB-LH IIIA1 vessels at a number of sites in the

$88 \quad$ Knapp 1988b, 154.

89 Vermeule \& Wolsky 1978; 1990, 381-383.

90 Vermeule \& Wolsky 1990, 93-98; 114.

9I Pecorella 1977; Quilici 1990, 142; Graziado 1995.

92 Maier \& Karageorghis 1984, 71.

93 Manning \& Monks 1998: 203: no. MT 616.
94 Johnson 1980, 17-18, 27-28.

95 Vermeule \& Wolsky 1990, 382.

96 Frankel \& Catling 1976, 65: no. 90; Catling 1964, 36; Öbrink 1983, 29; Håkansson 1989, 21: no. F1712.

97 South 1997, 156.

${ }_{98}$ Nicolaou 1973; see also below, chapter 2. 
interior of Cyprus, as well as the evidence from Maroni and Enkomi, suggests that ceramic vessels imported from the Aegean gradually became available to various different groups in the society in Cyprus during LC II.

At Maa-Palaeokastro (site no. 130) a complete LH IIIA2 globular flask was found in room 73 on floor II that has been dated to LC IIC-LC IIIA. ${ }^{99}$ At Myrtou-Pigadhes (site no. 99), a complete LH IIIA2 conical rhyton was found on the level VI floor (LC IIC-LC IIIA) of a room in the building to the east of the ashlar altar. ${ }^{100}$ Other instances in Cyprus where it is clear that Mycenaean vessels were present in archaeological strata of much later date than the ceramic style, are not known to me. ${ }^{101}$ However, the signs of repair on a Mycenaean pictorial krater from Pyla-Kokkinokremos (site no. 52) (02 $^{10}$ suggests use for a considerable length of time. In addition, signs of wear and intensive use have been observed on kraters which were deposited in tombs. ${ }^{103}$ When a ceramic vessel arrives in the archaeological record a long time after its manufacture, this may mean that it was kept very long as an heirloom or antique. It could also indicate that it was imported when already old, or that it circulated for a long period. The Aegean pots dating to the earlier phases of Cypro-Aegean contacts which have been found in archaeological strata or tombs which conform with their ceramic date show that such pots did arrive on the island during these periods. Moreover, the wide distribution of LH I-LH IIIA1 vessels within Cyprus suggests that these vessels were part of regional distribution networks. ${ }^{104}$ On this basis, it seems most likely that Aegean pots could circulate in regional exchange systems for substantial periods of time, in a few cases more than several centuries.

At Enkomi-Ayios Iakovos there were no obvious differences in the spatial and contextual distribution between Mycenaean dinner and storage vessels. Such a pattern has not been observed for AplikiKaramallos and Athienou, where Mycenaean storage vessels seem to have possessed a specific cultural significance. It is difficult to determine whether Mycenaean dinner and storage vessels were appreciated differently at other sites in Cyprus. Each of the three Late Bronze Age burials reported from Kition (site no. 63) produced a large quantity of dinner vessels. ${ }^{105} \mathrm{~A}$ widespread use of Mycenaean dinner vessels is also suggested by their presence in various rooms on floor IV of the industrial complex in area I at the site. ${ }^{106} \mathrm{~A}$ large number of storage and dinner vessels have also been reported from contemporary levels in area II at Kition. ${ }^{107}$ At Hala Sultan Tekke (site no. 65) very few structures dating before LC III have been discovered. In the LC II tombs at the site Mycenaean dinner vessels were present in significant numbers, even though, generally, there was a relatively high proportion of Myceanean storage vessels. ${ }^{108}$ A LC II deposit from a well at the site contained a majority of Mycenaean storage jars, but it also included at least one krater, a kylix and a bowl. ${ }^{109}$ In general, Mycenaean sherds of various pot shapes appear to have been distributed widely at Hala Sultan Tekke. ${ }^{110}$ At the site of Kourion-Bamboula (site no. 122) both Mycenaean dinner and storage vessels

$99 \quad$ Karageorghis \& Demas 1988, 231, Plate 79: no. 287.

Iоo Catling 1957, 42.

го It has been suggested by Öbrink $(1979,16-17)$ that the LH IIIA2 pots in deposit F6031 at Hala Sultan Tekke may have been heirlooms. However, if this deposit indeed derives from a looted tomb, as is suggested by Öbrink herself, the earlier vessels may simply have been part of a funerary inventory in a tomb that was in use for several generations.

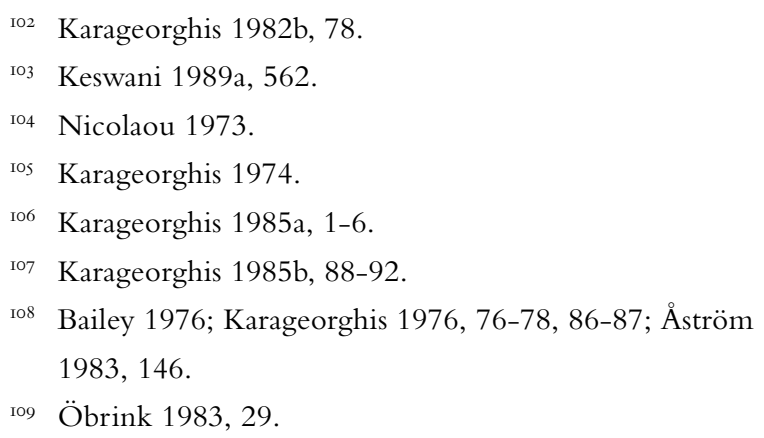

102 Karageorghis 1982b, 78.

Ios Karageorghis 1974.

106 Karageorghis 1985a, 1-6.

107 Karageorghis 1985b, 88-92.

Bailey 1976; Karageorghis 1976, 76-78, 86-87; Åström

Öbrink 1983, 29 
were distributed widely in the settlement deposits and in tombs. ${ }^{111}$ The frequency of Mycenaean dinner and storage vessels in the tombs at Kourion is not equal, but both types widely distributed. It seems, then, that as at Enkomi there was no difference in the appreciation between Mycenaean dinner and storage vessels in most of the other coastal centres.

A clear distinction in the cultural significance between Aegean dinner and storage vessels has been observed for Kalavasos-Ayios Dhimitrios (site no. 114), where a limited range of Mycenaean storage jars occurred in average houses, while kylikes and bowls were found on the floors of the elaborate Building X. ${ }^{112}$ In addition, the pit in room A173 in the eastern part of Building X produced a large number of Mycenaean dinner vessels. ${ }^{113}$ The presence of many animal bones in this pit suggests that these vessels had been part of an élite dining ritual. The association of Mycenaean pots with élite dining practices has at Kalavasos also been observed in tombs, of which only the richest contained imported dinner vessels. ${ }^{114}$ It has recently been argued by Louise Steel that in Cyprus Mycenaean dinner vessels were specifically monopolised by the élite in order to be employed in such occasions of ceremonial dining and drinking. ${ }^{115}$ It should be noted, however, that as yet such a pattern can only be established for Kalavasos-Ayios Dhimitrios. As stated above, the social organisation at Kalavasos-Ayios Dhimitrios was more hierarchical than elsewhere and specific élite groups had been able to acquire central control there. ${ }^{116}$ It is quite possible that élite dining ceremonies in which Mycenaean dinner vessels were used, were related to the legitimisation of the power of these groups. ${ }^{117}$ In such a case, the large numbers of Mycenaean drinking vessels in tombs and in a pit at Kalavasos-Ayios Dhimitrios could be testimony of conspicuous consumption by which valuables were taken out of circulation. ${ }^{118}$

In contrast to the monopolisation of Mycenaean dinner vessels by the élite at Kalavasos, in urban centres of more heterarchical nature not one group needed to monopolise Mycenaean vessels associated with dining - or was able to do so. In a state of continuous competition between various groups, the status of valuables is in flux and there is repeated redefinition of the significance of objects. ${ }^{119}$ It is interesting that the contextual analysis of the level IIA building in Q1W at Enkomi revealed that in this early period Mycenaean dinner vessels were restricted to residential activities. It may well have been the competition between various groups, which by LC IIC had devaluated the suitability of Mycenaean dinner vessels to serve as prestige items in cities with a complex heterarchical social structure such as Enkomi.

The monopolisation of Mycenaean drinking vessels, such as attested at Kalavasos, is in contrast with the relatively wide dispersal of Mycenaean drinking vessels which has been demonstrated for Apliki and Athienou. At Pyla-Kokkinokremos (site no. 58) LH IIIB dinner vessels, likewise, were widely distributed in the habitation complexes and they were interspersed with a large variety of Cypriot domestic items. ${ }^{120}$ Mycenaean storage vessels have not been reported from the habitation buildings in area II, but a Minoan coarse ware stirrup jar was found there. In level VI at Myrtou-Pigadhes (site no. 99), Mycenaean-type bowls, as well as kraters, kylikes and cups were also widely distributed. ${ }^{121}$

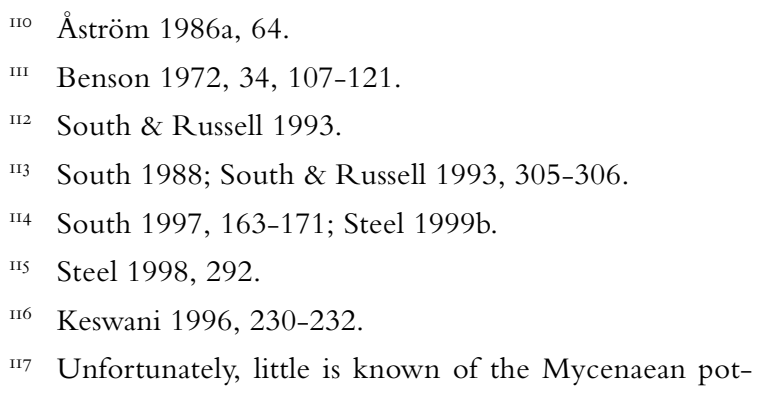


Aegean storage vessels, were also found in various parts of that site, but were less abundant than dinner vessels. At Maa-Palaeokastro (site no. 130) bowls and cups in LH IIIB and LH IIIC style were widely distributed all over the site. ${ }^{122}$ Obviously, at a number of places with relatively small amounts of Aegean pottery, Mycenaean dinner vessels were relatively widely distributed. It should be noted that all the sites mentioned here date to the very end of LC IIC, or to the LC IIC-LC IIIA transition.

Above, I have concluded that the small quantities, but representing a wide repertoire, of Mycenaean pottery at secondary and tertiary sites in Cyprus should be understood as the result of restricted access to an élite life-style. In this respect, it is of interest that at both Athienou and Apliki concentrations of Mycenaean finds have been found in association with objects that refer to a cosmopolitan world, without actually being part of it. The associations with élite dining rituals so clearly indicated at Kalavasos-Ayios Dhimitrios, may well have been an element making Mycenaean dinner vessels particular suitable to serve in systems of restricted distribution from primary centres to lower order sites. ${ }^{123}$ The élite connotations of Mycenaean dinner vessels made them active components of strategies of regional distribution.

The widespread use of Mycenaean dinner vessels at smaller sites at the end of LC IIC indicates that the exclusivity of this pottery by that time had devaluated. It is of interest that the Cypriot ceramic industry during an advanced stage of LC IIC began to incorporate various Mycenaean pot shapes, among which were mostly dinner vessels. ${ }^{124}$ It is possible that social groups not belonging to the urban coastal élite groups increasingly emulated the cosmopolitan life-style. ${ }^{125}$ The role of Mycenaean dinner vessels as a symbol of such a life-style seems to have resulted in the appropriation of these vessels by many groups to the point that these vessels were actually manufactured locally. Most Mycenaean storage vessels in Cyprus are quite small and probably contained oils or unguents. ${ }^{126}$ Activities involving these substances were probably quite widespread in antiquity and the Mycenaean storage pots do not seem to have had specifically élite connotations. ${ }^{127}$ It is of interest to note that such pots are not very abundant at Apliki and Athienou and were restricted to specific circumstances. Obviously, due to their less active role in social strategies, the use of Mycenaean storage pots was not subject to the same emulation as dinner vessels.

It has repeatedly been asserted that Mycenaean vessels with pictorial decoration were specifically produced for and used by élite groups in Cyprus and the Near East. ${ }^{128}$ Evidence for such a hypothesis may come from Enkomi, where specific groups expressed themselves by including notable quantities of pictorial kraters in their funerary ritual. The tombs in which these concentrations of pictorial kraters have been attested do not distinguish themselves in any other way from the rest of the funerary cellars at Enkomi and it is difficult to identify the social groups at Enkomi for whom this type of vessel seems to have been a medium to distinguish themselves. ${ }^{129}$

I22 Karageorghis \& Demas 1988, 216-232.

I23 The restricted distribution of Mycenaean pottery was probably part of the system of wealth finance in which small quantities of prestige goods figured, see Keswani 1993.

I24 The vessel types which are most frequently mentioned as being produced on Cyprus from LC IIC onwards are shallow bowls, deep bowls and 'Rude' or 'Pastoral' style kraters; see Sherratt \& Crouwel 1987, 341-342;
Kling 1987, 103, 106; 1989, 130, 170-173; Sherratt 1991, 191-193.

I25 See, for example, Veblen 1899, 22-34; Appadurai 1986, 57; Glennie 1995, 180-181; Miller 1995, 27-28.

I26 Leonard 1981, 94-101.

I27 Steel 1998, 294-296.

I28 Sherratt 1982, 183; Leonard 1987, 264-266; Keswani 1989a, 562-565; 1989b, 58-69; Steel 1998, 292-294.

I29 Sherratt (1999, 185-188) has argued that pictorial kraters were aimed at sub-élite groups in Cypriot soci- 
In each of the three Late Bronze Age burials at Kition (site no. 63) pictorial vessels were included in the funerary inventory. ${ }^{130}$ Mostly, such decoration occurred on jugs and bowls, while pictorial kraters were exclusively in the 'Rude' or 'Pastoral' style. Even though a few non-pictorial Mycenaean kraters came from these tombs, it does not seem that at Kition specific people used these vessels to distinguish themselves by including large quantities of them in their funerary ritual. The widespread occurrence of Mycenaean pictorial pots on floor IV in areas I and II indicates that these vessels were available to many people at Kition. ${ }^{131}$ A differentiation in the presence of Mycenaean pictorial pottery between various tombs can possibly be seen at Hala Sultan Tekke (site no. 65), where one of the tombs excavated in 1968 produced six Aegean kraters, several of which have pictorial decoration. ${ }^{132}$ Mycenaean pictorial pottery was virtually absent from the three LC II tombs that have been investigated in area 6 at the same site. ${ }^{133}$ Fragments of Mycenaean pictorial pottery have been found in various parts of the settlement at Hala Sultan Tekke, indicating a relatively wide distribution of this kind of pottery. ${ }^{134}$ At Maroni (site no. 116) Mycenaean pictorial pottery was discovered in a number of tombs. ${ }^{135}$ At Kourion-Bamboula (site no. 122) only very few Mycenaean pictorial vessels have been found, mainly amphoroid kraters. ${ }^{136}$ At Kouklia-Palaepaphos (site no. 126) Mycenaean pictorial pottery was apparently extremely rare. ${ }^{137}$ It appears that this type of pottery is not equally distributed among the coastal centres in Cyprus and it may have been restricted to a certain extent to specific social groups.

At Kalavasos-Ayios Dhimitrios (site no. 114) three tombs have produced Mycenaean pictorial kraters. ${ }^{138}$ These graves were situated among the ashlar buildings and had rich inventories, on the basis of which they have been interpreted as élite tombs. Other tombs in the vicinity did not produce Mycenaean pictorial vessels, nor did graves elsewhere at the site. ${ }^{139} \mathrm{~A}$ few Mycenaean bowls with pictorial decoration were among the vessels from the pit in room A173, ${ }^{140}$ while fragments of a Mycenaean pictorial krater were discovered in Building XIV and during the survey of the site. ${ }^{141}$ In addition, a bowl with bull protomes was found in a tomb at nearby Kalavasos-Mangia (site no. 115). ${ }^{142}$ At Kalavasos-Ayios Dhimitrios, the evidence for restricted access by the élite to Mycenaean pictorial pottery is much stronger than for Enkomi, or any of the other coastal sites. Such a marked pattern is probably related to the restricted distribution of Mycenaean dinner vessels at Kalavasos.

Mycenaean pictorial pottery has also been found at Athienou-Bamboulari tis Koukouninas and Apliki-Karamallos, albeit in very small numbers. At both sites, however, the Mycenaean pictorial repertoire consists of animals decorating dinner vessels such as a jug and a shallow bowl; more elaborate vessels with a more complex iconography, such as chariot kraters, have not been found at these sites. At the majority of sites which have produced smaller amounts of Mycenaean pottery, vessels

ety - e.g. those people who could not afford real valu-

able objects such as metal vases and for whom the nearest they ever got to owning a chariot would be a picture of it painted on a pot.

ז30 Karageorghis 1974, 17-33, 43-56, 67.

ז31 Karageorghis 1981.

I32 Karageorghis 1976, 72-76, 78-86.

I33 Åström 1986a, 64.

${ }^{134}$ See, for example, Frizell 1977, 53 Fig. 39; Hult 1981, 36; Öbrink 1979, 86 Fig. 236. Also, see Åström 1986a, 64.
I35 Johnson 1980, 15-17, 22-30, 32-34; Manning \& Monks 1998, 334, 327, 344, 346.

ז36 Benson 1972, 112-115.

${ }^{137}$ Maier 1984, 10. Only some fragments decorated with bulls in the 'Rude' or 'Pastoral style' have been found.

I38 South \& Russell 1993, 306; South 1997, 163-171.

I39 Russell 1989; South 1997, 163-171.

I40 South 1988, 223.

${ }^{141}$ South, Russell \& Keswani 1989, 142; South 1997, 158.

I42 South 1987, 84. 
with pictorial decoration are absent. ${ }^{143}$ At Pyla-Kokkinokremos (site no. 58) a LH IIIB pictorial ringbased krater was found on the floor of a courtyard in a habitation structure. ${ }^{144}$ Pictorial amphoroid kraters, as well as similar vessels with patterned decoration, were found in a tomb at nearby PylaVerghi (site no. 61). ${ }^{145}$ In the hinterland of Larnaca, pictorial pottery has been reported from tombs at Arpera Chiflik (site no. 68) and Klavdhia (site no. 67). ${ }^{146}$ At Myrtou-Stephania (site no. 100) a pictorial krater was also found in a tomb. ${ }^{147}$ Among the settlement finds at Myrtou-Pigadhes (site no. 99) a fragment has been identified with the legs of a bull. ${ }^{148}$ Reports of isolated Mycenaean pictorial vessels have also come from sites such as Galinoporni (site no. 38) and Psilatos-Moutti (site 52). ${ }^{149}$ From the overview given here, it is clear that only very small quantities of Mycenaean pictorial pottery occur at secondary and tertiary sites in Cyprus. Obviously, the regional distribution of this type of pottery was restricted.

The evidence from Kalavasos-Ayios Dhimitrios indicates that Mycenaean pictorial pottery was used in élite cultural practices. The concentrations of Mycenaean pictorial kraters in tombs at Enkomi indicate that these vessels served distinctive roles in the funerary practices of specific social groups in the town. Possibly, these concentrations represent strategies by specific groups of people in the continuous social competition in the town. The restricted regional distribution of Mycenaean pictorial pottery is surely related to the active role of this type of pottery in Cypriot social strategies.

At Enkomi and Athienou Aegean coarse ware vessels have been discovered, in all cases large stirrup jars (FS 164). These jars, which are distributed widely within the Aegean and beyond, have been interpreted as transport jars, most probably containing oil. ${ }^{150}$ The presence of such vessels in tombs and at a sanctuary shows that these vessels could be endowed with a symbolical meaning beyond their primary function. It should be noted, however, that only few people at Enkomi included such stirrup jars in their funerary rituals, which may indicate that the symbolic significance for these pots was restricted to a small group of people.

A large number of Aegean coarse ware stirrup jars have been published from Kourion-Bamboula (site no. 122). ${ }^{151}$ Most of these are represented by small fragments only, but two vessels could be almost completely reconstructed. Both these vessels, as well as most fragments were found in settlement levels; at least one similar vessel came from a tomb. Aegean coarse ware stirrup jars were included in the inventories of tomb 4/5 and tomb 9 at Kition (site no. 63); ; ${ }^{152}$ in addition, a few fragments of similar vessels have been reported from settlement levels in areas I and II. ${ }^{153}$ At Hala Sultan Tekke (site no. 65) a Mycenaean coarse ware stirrup jar has also been reported from a tomb. ${ }^{154}$ At Kouklia (site no. 126) two large fragments of similar stirrup jars have been identified from the cemetery near the locality of

I43 According to Crouwel $(1991,51)$, some twenty sites in total in Cyprus have produced this type of pottery. We should never forget that many museums possess Mycenaean pictorial vessels, many probably from Cyprus, which do not have a known provenance.

${ }^{144}$ Karageorghis $1982 \mathrm{~b}, 78$.

I45 Dikaios 1971, 913-925, plates 231-235.

${ }^{146}$ Crouwel 1991, 46 Fig. 1, 49-50 figs. 8-9.

I47 Hennessy 1963, 2.

${ }^{148}$ Catling 1957, 42.

I49 Crouwel 1991 47-48.
150 For the provenance and distribution of coarse ware stirrup jars, see Haskell 1990; Day \& Haskell 1995.

IsI Benson (1972,117-118) mentions twenty six Aegean coarse ware stirrup jars (FS 164). See also Åström 1972b, 335-336.

Is2 Karageorghis 1974, 27, 51.

I53 See, for example, Karageorghis 1985a, 16 (area I), 132 (area II).

Is4 Bailey 1976, 15: T.8.

Is5 Catling \& Karageorghis 1960, 121. 
Mantissa, ${ }^{155}$ while other stirrup jars were discovered in settlement levels. ${ }^{156}$ It is clear that Aegean coarse ware stirrup jars have been found in the majority of the coastal centres, even though these centres differ greatly in the absolute numbers of these jars. The practice to put this type of jar in tombs does not appear to have been common at any of the coastal sites, even though everywhere some people did so.

The presence of Aegean coarse ware stirrup jars is not limited to large coastal centres. In addition to the two jars at Athienou, such vessels have also been found at a number of other sites in Cyprus on the coast and in the interior. ${ }^{157}$ Only in a few cases have these vessels been found in tombs. This was the case in Tomb 2 at Myrtou-Stephania (site no. 100) ${ }^{158}$ and in a tomb at Lapithos-Ayia Anastasia (site no. 97). ${ }^{159}$ The presence of small numbers of Aegean coarse ware jars at sites all over the island is indicative of the phenomenon observed above that a relatively wide repertoire of Aegean vessels was involved in regional exchange networks. The limited deposition of coarse ware stirrup jars in tombs in the interior of Cyprus corresponds to the pattern established for the urban coastal centres.

The final class of Mycenaean pottery to be considered consists of specialised ritual shapes such as rhyta, composite vessels and figurines. At Enkomi, Mycenaean rhyta were not restricted to specific groups of people or activities. There is evidence, however, that rhyta and figurines had cultic connotations. At Kition (site no. 63), a Mycenaean conical rhyton was found on floor IV in temple II. ${ }^{160}$ A concentration of Psi-type female figurines was found in a pit below floor IIIA in temenos A at the same site; the floor itself produced two additional figurines. ${ }^{161}$ Considering the cultic nature of area II at Kition, it is logical to assume that these ritual objects were used in ceremonies at the sanctuary. In tombs at Hala Sultan Tekke (site no. 65), individual Mycenaean rhyta and figurines have been discovered, ${ }^{162}$ while two conical rhyta occurred in levelling strata in area 22 at this site. ${ }^{163}$ Figurines and rhyta, as well as a ring kernos have also been found in the tombs at Maroni (site no. 116). ${ }^{164}$ From a tomb at Kourion (site no. 122), one conical rhyton has been reported. ${ }^{165}$ This overview shows that various primary coastal centres are similar to Enkomi with regard to the presence of these specialised Mycenaean ceramic items. However, it should also be noted that Mycenaean figurines or ritual vessels have not been reported from other important sites such as Kalavasos-Ayios Dhimitrios (site no. 114) and Kouklia-Palaepaphos (site no. 126).

A few sites with relatively small numbers of Mycenaean pottery have also produced specialised shapes such as figurines or rhyta. At Myrtou-Pigadhes (site no. 99), one Mycenaean conical rhyton and a hedgehog rhyton were found when villagers dug a well near the site. ${ }^{166}$ In addition, another Myce-

ז56 Maier \& Karageorghis 1984, 71; Maier \& Von Wartburg 1985, 149.

I57 Åström (1972b, 335-336) reports such jars from Nitovikla-Korovia (site no. 39), Akanthou-Moulos (site no. 50), Kalopsidha (site no. 57), Pyla-Kokkinokremos (site no. 58), Idalion (site no . 72), Dhenia-Kafkalla (site no. 95), Lapithos-Ayia Anastasia (site no. 97), Myrtou-Stephania (site no. 100).

Is8 Hennessy 1963, 2: no. a.

ז59 Pieridou 1966, 9: 98a-c.

160 Karageorghis 1985a, 89: no. 3442.

г6r Karageorghis 1985a, 98-99, 105, 170: nos. 3213, 3219,
$3222,3225,3251$ and 3323 .

162 For a possible ring-rhyton and a zoomorphic rhyton, see see Walters 1912, 129: no. C679; Bailey 1976, 2526; Öbrink 1983, 25: no. 51. For Mycenaean figurines at Hala Sultan Tekke, see Åström 1983, 147-153; L. Åström 1983, 69: no. N2000.

I63 Niklasson-Sönnerby 1989, 78 Fig. 143 (no. F6517), 79 Fig. 147 (F6521).

${ }^{164}$ Johnson 1980, 24: no. 141, 25: no. 149, 27: no. 173

I65 Åström 1972b, 354: no. 199d.

I66 Taylor 1957, 1. 
naean conical rhyton was found on a floor in the building east of the ashlar altar. ${ }^{167}$ It is tempting to think that this rhyton was used in rituals performed at the sanctuary. A conical rhyton has been reported from Sinda (site no. 54), in addition to a female figurine. ${ }^{168} \mathrm{~L}$. Åström mentions a female figurine from the site of Alambra (site no. 71). ${ }^{169}$ Recently, a Mycenaean female figurine has also been discovered at Idalion (site no. 72). ${ }^{170}$

It is clear that Mycenaean specialised ceramic objects with possible ritual connotations were scarce at Cyprus. The unequal distribution of these objects among sites at the coast indicates that preferences existed for specific parts of the Mycenaean ceramic repertoire. It is clear that the Mycenaean rhyta and figurines were used in local cult rituals in a number of places on the island. In this respect, they are in agreement with the evidence from Athienou, where Mycenaean juglets have been deposited in a votive pit together with Cypriot wares.

The appreciation of the various categories of Aegean vessels in Cyprus is not uniform through time and space. The earliest Aegean vessels were available to a very small group of people who can be associated with wealth and international contacts and who lived in the emerging coastal centres. Gradually, however, Aegean vessels became available to larger parts of the Cypriot population and they became incorporated in regional distribution systems. Apparently, some vessels could circulate for a long time in such systems. There is evidence that Mycenaean dinner vessels were highly appreciated initially by élite groups in particular, probably because they could be used in ceremonial sessions. ${ }^{171}$ However, at sites where different groups were in competition, the exclusivity of Aegean drinking vessels seems to have eroded during LC IIC. Nevertheless, specific groups in Cypriot society continued to distinguish themselves by including substantial numbers of pictorial kraters in their tombs.

The symbolic meaning of Mycenaean pots found its origin in specific cultural practices of emerging urban élites. As such, these pots were symbols in the acquisition and legitimisation of power on the part of these groups. ${ }^{172}$ The deposition of Aegean coarse ware transport jars in tombs by a few people all over the island shows that Mycenaean pottery could be endowed with meanings beyond the purely functional. The inclusion of small numbers of Mycenaean rhyta and figurines in Cypriot cultic rites at various sites throughout Cyprus suggests that religious aspects also played a role in the cultural significance of Mycenaean pottery. Obviously, a variety of different meanings relating to Cypriot social reality and cultural practices could be imposed on the imported ceramic vessels and figurines.

\section{F U N E R A R Y E V I D E N C E}

The majority of the Mycenaean pots which are known to have been found in Cyprus probably derive from tombs, which have been subject to pillaging from ancient until modern times. Most sites in Cyprus where Mycenaean pottery has been found are tomb sites. ${ }^{173}$ At Enkomi, it is clear that the inclusion of Mycenaean pots in tombs was a widespread phenomenon. At Kition (site no. 63), tombs

I67 Catling 1957, 42 no. 187.

168 Åström 1972b, 354: no. 199k; L. Åström 1972, 512.

I69 L. Åström 1972, 512

${ }^{170}$ Herscher 1998, 333.

171 Steel 1998, 289-292;
${ }_{172}$ Webb \& Frankel 1994, 19; Knapp 1996a, 20-22; 1997 , 62

173 Forty-three Cypriot sites in Catalogue I have produced only tombs, while at twenty-six sites there were funerary as well as settlement remains. Fifteen sites were set- 
have been discovered in area I only. ${ }^{174}$ The inventory of tombs $4 / 5$ included a wide variety of Cypriot pottery, together with a Red Lustrous bottle, stone vessels and a few small objects of ivory, glass paste and faience. The Aegean pottery, which constituted almost forty percent of the total number of objects which came from these tombs, comprised a wide repertoire of pot shapes, among which piriform jars, stirrup jars and jugs were frequent. ${ }^{175}$ Particularly abundant, however, were Mycenaeantype shallow bowls which were probably produced on the island itself. The lower burial of tomb 9 at Kition, which dated to LC IIC, also produced some Mycenaean stirrup jars, as well as a rather large number of kylikes and shallow bowls. In addition, alabaster, glass and faience vases were found, along with golden beads and a ring, ivory and stone objects. An equally wealthy inventory, including a variety of golden and bronze jewellery as well as metal vessels and weapons, was associated with the upper burial of tomb 9, which can be dated to the period of the LC IIC-LC III transition. The Mycenaean repertoire of this tomb was limited, however, consisting mainly of a large number of shallow bowls. The three tombs at Kition were situated close together and it is possible that they represent a specific group in the population of that town. Nevertheless, the repertoire of Mycenaean pots in these tombs is comparable to the pots found in the funerary cellars at Enkomi. This suggests that at Kition the practice of including Mycenaean pottery in funerary ceremonies was widespread.

A far larger number of tombs have been excavated at Hala Sultan Tekke (site no. 65), a site that has been subject to various archaeological expeditions in the 19th and 20th centuries. ${ }^{176}$ As a result, the inventories of many tombs are only partially known. The reinvestigation of objects from the old excavations have made clear that Mycenaean pottery was included in the majority of tombs. ${ }^{177}$ This picture is confirmed by the two tombs that were excavated in 1968, which are comparable to the tombs at Enkomi and Kition in terms of the variety of their funerary inventories and the repertoire of Mycenaean pots. ${ }^{178}$ In addition, four tombs, all of which were pillaged, have been investigated in area 6 at Hala Sultan Tekke; these also produced substantial quantities of Mycenaean pottery. ${ }^{179}$ It would seem that the Mycenaean pottery from funerary contexts at Hala Sultan Tekke presents a similar picture to that at Enkomi. The same can be said for Kourion-Bamboula (site no. 122), where the majority of LC II tombs produced Mycenaean pots. ${ }^{180}$

A large Late Bronze Age cemetery was excavated in 1897 at Maroni (sites nos. 116, 117). ${ }^{181}$ Objects from twenty-eight graves have recently been retrieved, which has made clear that most tombs contained Mycenaean pottery. A few tombs seem to have produced a larger quantity of Mycenaean vessels than others, as well as a somewhat wider variety of vessel types. ${ }^{182}$ From the letters written by the excavators, it is certain that there were many more tombs, which were considered "not productive", i.e. they contained "only local wares or fragmentary pieces of pottery." 183 A recent survey of the cemetery has produced evidence for fourteen Late Cypriot tombs, most of which contained Mycenaean sherds. ${ }^{184}$ This is an indication that small amounts of Aegean pottery may have been pre-

tlements only.

${ }^{174}$ Karageorghis 1974, 16-35.

${ }^{175}$ Karageorghis 1974, 36-87.

${ }^{176}$ Bailey (1976) reports on twenty-one tombs, but it is certain that more have been investigated: Crowfoot opened up some fifty tombs in 1898 , but considered only eleven worth commenting upon, see Åström 1986b, 7-8.

177 Bailey 1976
${ }_{178}$ Karageorghis 1976.

I79 Åström 1983.

I80 Benson 1972, 10-35.

I8I Johnson 1980, 5-6; Cadogan 1992.

I82 See Johnson 1980, 14-15.

${ }^{183}$ Letter by H.B. Walters, 3 December 1897, see Manning 1998, 43.

I84 Manning \& Monks 1998, 308-347. 
sent in many tombs at Maroni, which makes it unlikely that the presence of Mycenaean pots in tombs is indicative of élite status, as has recently been stated by S. Manning and L. Steel. ${ }^{185}$ It may be that large quantities of Mycenaean pots, together with other prestige goods, were reserved for élite groups.

At Kalavasos-Ayios Dhimitrios (site no. 115), several graves yielded Mycenaean vases, but only a limited number contained substantial quantities and a wide variety of drinking vessels. ${ }^{186}$ It seems, then, that at Kalavasos a restricted group distinguished itself by including larger quantities and a wider variety of Mycenaean pottery in their tombs, which may also have been the case at Maroni. This pattern is much more marked for Kalavasos than for Enkomi, where Mycenaean drinking vessels were relatively widely distributed in the tombs. Other coastal centres appear to confirm the picture of Enkomi. It seems logical to assume that the variation in the role of Mycenaean pots in the funerary rituals between Enkomi, Kition, Hala Sultan Tekke and Kourion on the one hand and Kalavasos and Maroni on the other is related to the differences in socio-political organisation that have been commented upon before.

From many other sites tombs with Myceanean pottery have been reported. In the eastern part of the island, Ayios Iakovos-Melia (site no. 51) produced three tombs of LC II date, each containing a variety of Mycenaean storage vessels. ${ }^{187}$ At the site of Angastina (site no. 77) five tombs were investigated, of which only one has been published. In addition to a wide variety of Cypriot pottery and a glass cylinder seal, this tomb yielded several Mycenaean storage vessels and one shallow bowl. ${ }^{188}$ Two LC tombs have been discovered at Nicosia-Ayia Pareskevi (site no. 75), of which only tomb 6 contained Mycenaean pots, mostly storage vessels. ${ }^{189}$ The same was also the case for a tomb near the locality of Kafkallia in the area of Idalion (site no. 72 ). ${ }^{190}$ In the hinterland of Larnaca, several sites have yielded Late Bronze Age tombs. At Laxia tou Riou (site no. 64) four tombs were discovered, from which three Mycenaean piriform jars and one stirrup jar have been reported. ${ }^{191}$ From Aradhippou (site no. 62) a Mycenaean deep krater with pictorial decoration, as well as a ring-based krater showing a hunting scene have been reported, presumably from one or more tombs. ${ }^{192}$ From a tomb at Klavdhia (site no. 67) came a large jug with cut-away neck that can be dated to LH IIB-LH IIIA1. ${ }^{193}$ A range of later Mycenaean vessels from various tombs have also been reported from this site, among which were piriform jars, stirrup jars, flasks, cups and kraters. ${ }^{194}$ Tombs excavated in the nineteenth century at Dromoloxia-Trypes (site no. 66), not more than two kilometres from Hala Sultan Tekke, produced Mycenaean stirrup jars, piriform jars and a jug. ${ }^{195} \mathrm{~A}$ tomb excavated in the same area during a rescue excavation in 1977 yielded Mycenaean jugs, piriform jars and shallow bowls, in addition to kraters in the 'Rude' or 'Pastoral' style. ${ }^{196}$ To the east along the south coast of the island, at Pyla-Verghi (site no. 61), a looted tomb was investigated and produced a wide variety of Mycenaean vessels, including at least seven kraters. ${ }^{197}$

The site of Kalavasos-Mangia (site no. 115), situated along the south coast in the vicinity of Ayios Dhimitrios, was a cemetery with at least six Late Bronze Age tombs. Four of these contained

\footnotetext{
I8s Manning 1998, 42-47; Steel $1999 \mathrm{~b}$.

I86 South \& Russell 1989, 44, 55; 1993, 306; South 1997, 163-171; Steel 1998.

I87 Sjöqvist 1934, 325-333, 345-354. The only pots that can be classified as dinner vessels are two globular jugs.

I88 Karageorghis 1964, 4-16.

I89 Kromholz 1971, 246-247.

I90 Overbeck \& Swiney 1972, 20-21
}

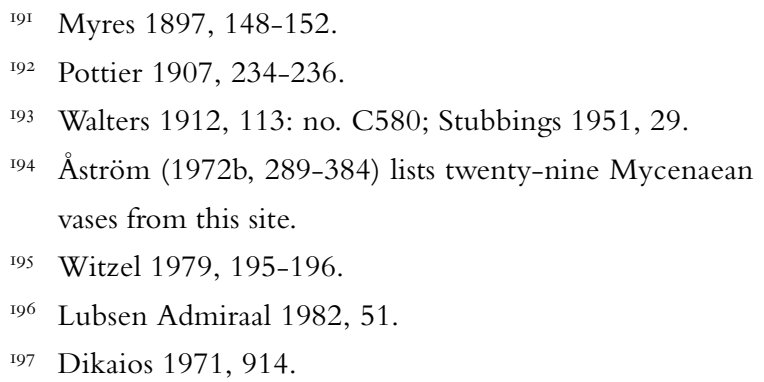


Mycenaean pottery, mainly of the storage type, but a shallow bowl decorated with bull protomes was also discovered. ${ }^{198}$ Unfortunately, very little is known of the other cemeteries along the southern and south-western coast. In the north-west of the island, tomb II at Toumba tou Skourou (site no. 105) yielded a LM IIIA1 jug in addition to two LH IIIA2 storage vessels. ${ }^{199}$ At Myrtou-Stephania (site no. 100), a total of fourteen tombs have been excavated, mostly belonging to the MC III-LC I period. ${ }^{200}$ The few tombs which could be assigned to LC II yielded only a few Mycenaean vessels. At Akhera (site no. 92) in the Troodos mountains, two tombs have been assigned a LC IIC date, each of which contained many Mycenaean storage vessels and a few small dinner vessels. ${ }^{201}$ The nearby site of Politiko (site no. 89) produced a tomb with a similar Mycenaean inventory, even though the vessels are somewhat earlier than at Akhera. ${ }^{202}$

From the overview presented above, it is clear that the practice of including Mycenaean pots in tombs was widely known in all parts of the island. In agreement with the general distribution pattern, however, the quantities of Mycenaean pottery in tombs at secondary and tertiary sites are far lower than in tombs at the urban coastal centres. Moreover, it should be noted that the presence of Mycenaean dinner vessels in graves at the lower order sites is limited. Even though jugs or small drinking vessels have been reported in a few cases, storage vessels predominate and large Mycenaean kraters, even though they do occur, are less frequent. The importance of Mycenaean dinner vessels in strategies of funerary display in the coastal centres apparently resulted in restricted access to similar vessels at inland sites. ${ }^{203}$ In order to distinguish themselves in their funerary ritual, regional élite groups in the island's interior made use of small quantities of modest Aegean drinking vessels and storage pots. An exception to this pattern may be seen in the hinterland of Larnaca, where tombs at Aradhippou, Klavdhia and Dromolaxia did produce a wide variety of Mycenaean pots, among which were a great many kraters. This may indicate that smaller sites in the vicinity of large coastal centres had wider access to ceramic imports than sites situated further away.

It is possible that the widespread occurrence of Mycenaean pots in tombs and the restricted range of shapes in funerary contexts at inland sites are not indicative of all periods during which this type of pottery was imported. At Enkomi, the earliest Mycenaean pots in the tombs belonged to the LH IIA stylistical phase, while several LH IIB-LH IIIA1 pots also were found in funerary contexts. At Maroni (sites nos. 116, 117) a LH IIA alabastron was found in a tomb, and several tombs yielded pots in LH IIB-LH IIIA1 styles. ${ }^{204}$ The largest concentration of Aegean pottery of an early date has been found in Toumba tou Skourou (site no. 105), where nine LM I dinner vessels and a so-called 'flower pot' were found in tomb I. ${ }^{205}$ In addition, two sherds in similar ceramic styles were found in tomb II, while another fragment came from tomb III. Three tombs at Ayia Irini-Palaekastro (site no. 103) produced Minoan or Mycenaean semi-globular cups which also date to the very beginning of the Aegean contacts with Cyprus. From these finds, it is clear that Aegean vessels were included in Cypriot funerary rituals from an early period onwards. However, a difference is visible between Enkomi and Maroni on the one hand, where exclusively Mycenaean storage vessels were deposited in tombs, and Toumba tou

198 Todd 1988, 203-208.

199 Vermeule \& Wolsky 1990, 383-385.

2oо Hennessy 1963, 2-10, 31.

201 Karageorghis 1965a, 111-121.

202 Karageorghis 1965b, 20-23.

203 In this case it is significant that at Pyla-Verghi (site no. 61) many Mycenaean kraters were found. The coastal location, as well as the lay-out of nearby PylaKokkinokremos (site no. 62) and the extensive other necropoleis in the area, are indicative of a coastal centre.

204 Johnson 1980, 17-18, 27-28; Manning \& Monks 1998, 321.

2os Vermeule \& Wolsky 1990, 381-383. 
Skourou and Ayia Irini on the other hand, where only Aegean dinner vessels were deposited. Obviously, in the very beginning of the presence of Myceanean pots in Cyprus, their suitability to serve in funerary ceremonies was regarded differently in different areas.

LH IIB-LH IIIA1 vessels have been found in tombs at a number of sites in Cyprus. ${ }^{206}$ Most of these sites are situated in the vicinity of the coast, but Milia (site no. 55) and Katydhata (site no. 107) are inland sites. The relatively wide distribution of LH IIB-LH IIIA1 vessels in Cypriot tombs shows that the practice of putting Mycenaean pots in tombs spread in the island during the earlier stages of LC II. By LC IIC, the role of Mycenaean vessels in funerary ceremonies varied not according to geography but the site's place in regional distribution networks.

206 In addition to Enkomi and Maroni, such pottery has been found in tombs at Milia (site no. 55), Hala Sultan Tekke (site no. 65), Arpera (site no. 68), Kalavasos-
Ayios Dhimitrios (site no. 114), Toumba tou Skourou (site no. 105) and Katydhata (site no. 107). 


\title{
14 Mycenaean pottery in the central Mediterranean: Introduction
}

\author{
P REVIOUS RESEARCH
}

The fifty-three sites in the central Mediterranean at which Mycenaean pottery has been found are situated in a large area encompassing the Italian peninsula and the two largest islands in the Mediterranean, Sicily and Sardinia (Map 10). Malta and the Aeolian islands are also included. In 1877, L. Mauceri described two amphoroid jars from a tomb near Syracuse which had been found in 1871, without knowing they were Mycenaean. ${ }^{1}$ P. Orsi discovered Mycenaean pottery on several Sicilian sites and commented on their historical significance. ${ }^{2}$ The large quantities of Late Helladic pottery in the upper stratum of the site at Scoglio del Tonno in Taranto (site no. 314), excavated by Quagliati in 1899-1900, made it clear that southern Italy had known important Mycenaean connections. ${ }^{3}$ Fimmen mentioned five sites in Sicily and three on the mainland where Mycenaean pottery had been found, while T.J. Dunbabin added another to both regions. ${ }^{4}$ According to Dunbabin, the ceramic evidence and that for the introduction of fibulae and a new type of tholos tomb pointed to the presence of permanent Mycenaean settlements on Sicily.

In the 1940s and 1950s L. Bernabò Brea and M. Cavalier started several important excavations on the Aeolian islands, north of Sicily. ${ }^{5}$ The Aegean pottery of Filicudi (site no. 321), Lipari (site no. 325) and Panarea (site no. 324) was discussed by Taylour in his overview of Mycenaean pottery in Italy. ${ }^{6} \mathrm{He}$ stated that much of the Aegean pottery was early in comparison with most other sites: LH I and LH II wares are present at these islands in quantities that equal the LH IIIA and LH IIIB pottery. Taylour also discussed the Mycenaean pottery from Scoglio del Tonno (site no. 314), indicating stylistical affinities with the islands of Rhodes and Cyprus. ${ }^{8}$ The excavation of Porto Perone (site no. 313), also in the region of Taranto, did not only reassert the importance of this area in Mycenaean times. ${ }^{9}$ It also provided a better understanding of the stratigraphical sequences in which the Mycenaean pottery in Apulia occurred.

The decipherment of the Linear B tablets in Greece and the conclusion that references to the Italian region were absent led to a revision of the nature of the Aegean contacts with the central

Mauceri 1877, 57-58, Tav. E6.

Orsi 1893, 29-36; Orsi 1906.

Quagliati 1900, 416-420. He found over 750 Aegean sherds and 2 figurines of probable Mycenaean provenance.

4 Fimmen 1924, 99; Dunbabin 1948, 2-6.

5 Full publication of these excavations was realised in
Melingunis Lipàra Vols. I-VI, see Bernabò-Brea \& Cavalier 1980

6 Taylour 1958, 7-53.

7 Taylour 1958, 182-183.

8 Taylour 1958, 81-137, especially pp. 128-136.

9 Lo Porto 1963, 359-360. 
Mediterranean..$^{10}$ The view of Mycenaeans colonizing the Italian coasts was abandoned and scholars began to focus on the interaction between Aegeans and native populations. L. Vagnetti and S. Tinè gave an overview of the Mycenaean finds in Italy and discussed the integration of the Mycenaean finds in the local material culture. ${ }^{11}$ An important study was presented by M. Marazzi and S. Tusa in 1979. They gave an overview of theoretical and methodological approaches by which to study the Mycenaean relation with the Italian region. ${ }^{12}$ Among other things, they stressed the need to consider the Mycenaean imports in the cultural context into which they arrived. They also reviewed the development of the Mycenaean contacts and showed that there is a difference between the early phase (LH I-LH II), in which the level of integration was low, and the second phase, which had a higher level of integration.

Excavations at the small island of Vivara (site no. 342) revealed that Mycenaean pottery similar to that from Filicudi (site no. 321) and Lipari (site no. 325) had arrived at the Campanian coast as early as LH I. ${ }^{13}$ Recent discoveries have also added the island of Sardinia to the distribution map of Mycenaean pottery in Italy. ${ }^{14}$ Although most of the material on Sardinia seems to be of LH IIIC style, some LH IIIB has been found as well, while an alabastron from Nuraghe Arrubiu (site no. 347) may be of LH IIIA2 date.

Overviews of the Mycenaean contacts with the central Mediterranean have been given by Lucia Vagnetti, who distinguishes three successive chronological phases. ${ }^{15}$ The first phase starts with the distribution of LH I and LH II pottery. In addition to Helladic pottery with lustrous decoration, a variety of coarse and matt-painted wares have been found in Italy during this phase. ${ }^{16}$ Most of the Aegean pottery from this phase seems to have come from mainland Greece, but some fabrics have Minoan features. Concentrations of these types of pottery have been attested at the Aeolian island and on Vivara, while smaller amounts have also been found in Apulia and Sicily. The second chronological phase in the Mycenaean contacts with the Italian region comprises the distribution of LH IIIA and LH IIIB pottery. In the early part of this phase (LH IIIA), the distribution centres on the Aeolian islands and Vivara, on south-eastern Sicily and various parts of Apulia. Later in this phase (LH IIIB), the imports diminish in Sicily, while sites in Apulia and Basilicata seem to have gained importance. The third phase in the Mycenaean contacts with Italy covers LH IIIB-HIIIC, which are often difficult to distinguish. ${ }^{17}$ Sardinia and the Adriatic coast seem to have gained prominence during this era.

An analysis of Mycenaean trade with the central Mediterranean was given by Thyrza Smith in 1987. ${ }^{18}$ Among other things, she showed that the context in which this pottery is found varies according to region. In Sicily, the evidence comes mainly from tombs, while elsewhere in Italy settlement contexts predominate.

Recent research on the Mycenaean pottery in Italy has focused on provenance determination by chemical and petrographical means. ${ }^{19}$ It has revealed the enormous complexity of the corpus of Aegean pottery in Italy, with a substantial part of it being of local manufacture, at least from LH IIIB onwards. The LH I-II finds from Vivara (site no. 342) seem to derive from mainland Greece, but some of the

Io See Pugliese Carratelli 1958; Stella 1958.

II Vagnetti 1970.

12 Marazzi \& Tusa 1979, 309-341.

I3 Buchner et al. 1978, 215-225; Marazzi \& Re 1986; Marazzi 1994; 1995.

${ }^{14}$ Ferrarese Ceruti 1979; Vagnetti 1982a, 14

Is Vagnetti 1982a; 1993, 145; 1999, 138-142.
I6 Taylour 1958, 16, 33, 47; Vagnetti 1982a, 16-17; Cavalier \& Vagnetti 1983, 343-344; 1984, 150-151; Marazzi 1994, 30-31.

${ }_{17}$ Vagnetti 1982a, 19-20; 1993, 139.

I8 Th. Smith 1987.

19 Jones 1986b, 207-208; Jones \& Vagnetti 1991, 131 132 . 
Aegean-type domestic pots have a composition indistinguishable from local material. In addition, domestic wares appear to have been imported, not only from various places in Greece, but possibly from the Levant as well. ${ }^{20}$

\section{DISTRIBUTION OF MYCENAEAN POTTERY IN THE CENTRAL}

\section{ME D I T E R R A N E A N}

Within the central Mediterranean a geographical distinction must, of course, be made between the Italian mainland, Sicily and Sardinia; the Maltese islands, should also be considered separately. The Italian peninsula is geographically determined by the Apennine mountain range, which stretches from Piemonte (near Genoa) into northern Calabria. A general distinction can be made between the coastal plains and valleys and the highlands in the interior. On the Italian mainland, the overall distribution of Aegean pottery reveals a distinctive coastal pattern, the only exception being Sassano (site no. 340) in the interior of Campania (Map 10). ${ }^{21}$ This is different in Sicily and Sardinia, where Mycenaean pottery has also been found in the interior. Along the Adriatic and Ionian coasts, there is a long string of sites from the Gargano Peninsula to the Sybaris plain in northern Calabria. The scatter of sites along the Tyrrhenian coast is less dense. Notable clusterings of sites are also visible in central and south-eastern Sicily, as well as on the Aeolian islands. In Sardinia, there are two sites with LH I-LH IIIB pottery.

If we look for sites that have yielded substantial amounts of Mycenaean pottery (Map 11), this pattern becomes more marked. The southern coast along the Ionian gulf stands out with several important sites, such as Scoglio del Tonno-Taranto (site no. 314), Termitito (site no. 316) and Broglio di Trebisacce (site no. 317). Elsewhere on the Italian Mainland, sites with more than fifty Mycenaean finds have not been discovered, but the island of Vivara (site no. 342) in the Gulf of Naples is a class 4 site. On Sicily, the site of Thapsos (site no. 327) is the only one in the area of Syracuse with substantial amounts of Mycenaean pottery; the sites of Cannatello (site no. 334) and Monte Grande (site no. 335) in southern Sicily are situated close together. In southern Sardinia, Antigori (site no. 348) is a class 4 site.

Several attempts have been made to regionally subdivide the (proto-)Apennine culture of the mainland Middle and Late Bronze Ages on the basis of the distribution of variations in artefact and pottery characteristics. ${ }^{22}$ These attempts have been heavily criticised, partly because the distribution of the different characteristics does not overlap and partly because the cultural significance of these variations is disputed. ${ }^{23} \mathrm{~A}$ more useful differentiation can be made by reviewing the nature of external influences that are recognisable in separate regions. On this basis, Bietti Sestieri makes a distinction between the Ionian and Adriatic regions on the one hand and Calabria and the Tyrrhenian coast on the other hand. ${ }^{24}$ The material culture in Apulia and Basilicata, although typologically connected with the rest of Italy and with trans-Alpine Europe, shows strong evidence of contact with the Aegean, especially in its bronze industry. Our sites, Porto Perone (site no. 313), Scoglio del Tonno (site no. 314), Termi-

$20 \quad \operatorname{Re} 1993,331-334$.

${ }^{21}$ This is not due to an absence of Middle and Late Bronze Age sites in the interior: see Barker \& Stoddart 1994, 148 Fig. 5.3; Malone, Stoddart \& Whitehouse
1994, 173

22 See for example Peroni 1994a.

23 Lukesh 1983, 14.

24 Bietti Sestieri 1983, 66-102; 1988, 33. 
tito (site no. 316) and Broglio di Trebisacce (site no. 317), belong to this group. The material culture in Calabria and the Tyrrhenian coast, on the other hand, is characterised by a strong connection with contemporary societies in Sicily and the Aeolian islands. Our sites in Campania and Latium belong to this group, even though Vivara and Ischia "do not entirely correspond to the general cultural trend of the region." ${ }^{25}$

The culture of eastern Sicily in the Middle and Late Bronze Age is characterised by the type site of Thapsos (site no. 327). ${ }^{26}$ Evidence for the Thapsos culture comes mainly from cemeteries which are scattered over the eastern and central part of the island. The material culture shows affiliations both with the Italian mainland and with Malta in the Borg en Nadur phase. On the Aeolian islands, the Early and Middle Bronze Ages are the scene of the Capo Graziano and Milazzese cultures - named after type sites on the islands of Lipari (site no. 325) and Panarea (site no. 324) respectively. ${ }^{27}$ The material culture of the Capo Graziano phase distinguishes itself from that of the Italian mainland, as well as from that of Sicily. ${ }^{28}$ The succeeding Milazzese culture, however, shows close relationships with the Sicilian Thapsos culture, as well as with mainland Campania. The material culture of the Aeolian islands during the Late Bronze Age is called Ausonio I, which shows close ties with sub-Apennine mainland Italy. Sardinia, of course, must be culturally distinguished from the other regions in the central Mediterranean. This island is characterised by the imposing Nuraghe, of which there are said to exist at least 7000 which were built in the period from 1500-500 BC. ${ }^{29}$ The period from 1500 to $1200 \mathrm{BC}$ is generally referred to as the proto-Nuragic age.

In addition to the geographical and cultural regionalisation in the distribution pattern of Mycenaean pottery in the central Mediterranean, the chronological differentiation which has been described by Vagnetti should be taken into account in order to select sites for contextual analysis. In the subsequent chapters, the cultural context of the Mycenaean pottery at Lipari (site no. 325), Thapsos (site no. 327) and Broglio di Trebisacce (site no. 317) will be discussed. At Lipari, which is situated in the Tyrrhenian region, substantial quantities of Mycenaean pots have been found from all chronological phases. This will enable me to discuss the contexts of the LH I and LH II pottery and to compare it with later material. The Mycenaean vessels from the cemetery at Thapsos are predominantly from the LH IIIA2-LH IIIB phase. This site brings the region of Sicily in the discussion, while it opens up a funerary perspective. The site of Broglio di Trebisacce is situated on the Gulf of Taranto and represents the third chronological phase. As was the case for the selected sites in the Levant and Cyprus, none of these sites can be considered as type-sites for any region or period.

25 Bietti Sestieri 1983, 87.

26 Malone, Stoddart \& Whitehouse 1994, 174-175; Leighton 1999, 147-157.

27 Bietti Sestieri 1980-1981, 40-45; Malone, Stoddart \&
Whitehouse 1994, 174-178.

28 Bernabò-Brea \& Cavalier 1980, 688-696.

29 Lo Schiavo 1981, 255-341; Balmuth 1992, 677. 


\section{Lipari}

\section{N T R O D U C T I O N}

Lipari is the largest of the seven islands in the Aeolian archipelago. On its south-eastern coast, the acropolis, nowadays called il Castello or Cittáde rises to a height of almost $44 \mathrm{~m}$. The archaeological site is situated on top of the acropolis, which is also the historical centre of the modern town (Fig. 15.1). Excavations were conducted at the site in the 1950s and 1960s. ${ }^{1}$ They have revealed continuous habitation at the acropolis from the Early Bronze Age until the present day. ${ }^{2}$ During this long period, settlement at the acropolis was continually related to the plain of contrada Diana below the acropolis, where settlement structures and graves have also been found. ${ }^{3}$ The archaeological strata in the plain that have produced the most extensive remains are precisely those with less finds on the acropolis; the same is true the other way around.

In the main excavation area a sequence of four Bronze Age layers has been distinguished below a thick fill with Bronze Age and Greek finds. The earliest habitation at the acropolis took place during an advanced phase of the Capo Graziano culture of the Early Bronze Age. ${ }^{4}$ Remains of this early habitation phase (ca. 1600-1400 BC) have been found in the main excavation area, as well as in the majority of trenches elsewhere on the acropolis. It is therefore likely that the settlement occupied the whole surface of the acropolis. Some twenty architectural structures of the Capo Graziano period have been found in the main excavation area (Fig. 15.3). Most of these huts are fairly small, some 4.5 x $3 \mathrm{~m}$, and oval in shape. They appear to have been situated in concentrations of five to six structures, which suggests an important role for kinship groups in the society. Burials dating to the Capo Graziano period have been discovered at contrada Diana; they involve cremation and secondary burial in large pithoi. ${ }^{5}$ The material culture of the Capo Graziano phase distinguishes itself from that of the Italian mainland, as well as from that of Sicily, even though some imports from both areas have been found. ${ }^{6}$ In fact, the practice of cremation is very similar to practices at Malta and the island of Ognina near Syracuse. ${ }^{7}$

Remains from the Milazzese phase (ca. 1400-1300 BC) have been unearthed in various trenches and in the main excavation area, which suggests that habitation at that that time covered most of the

\footnotetext{
The excavations were headed by Professor Luigi Bernabò-Brea and Madeleine Cavalier. From 1950 until 1952 they carried out soundings on the acropolis and the adjacent Cività plateau. Large scale excavations were then carried out from 1952-1959 and in 19651965. Since then, cleaning and restoration work has occasionally revealed additional discoveries.
}

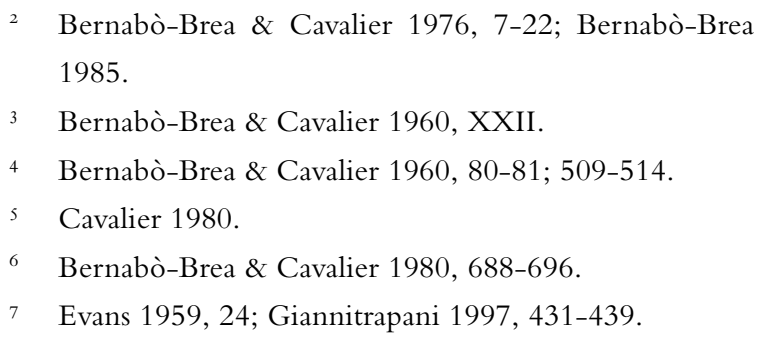




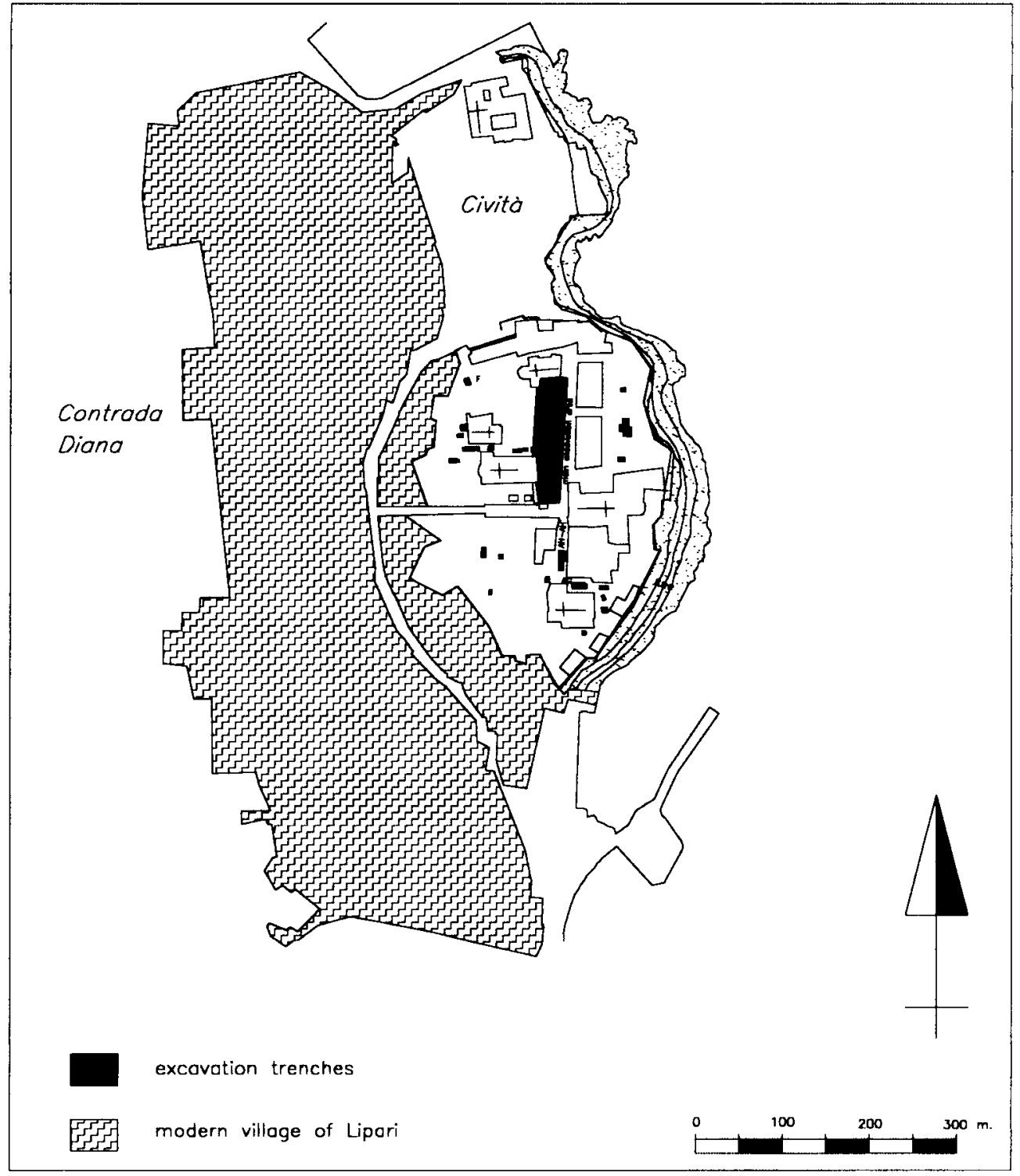

Fig. 15.1 Lipari acropolis: site plan

top of the acropolis. ${ }^{8}$ Eighteen huts have been found in the main excavation area (Fig. 15.4); as in the preceding phase, they are generally small and they have a round or oval shape. In terms of material culture, the Milazzese culture is closely related to the contemporary Thapsos culture in eastern and central Sicily. ${ }^{9}$ But a substantial number of vases originating in the Apennine culture of mainland Italy have also been discovered at Lipari.

The third period of Bronze Age occupation at Lipari is referred to as Ausonio I (ca. 1300-1200)..$^{10}$ The main excavation area yielded the remains of some twenty structures belonging to this period (Fig. 15.5). ${ }^{11}$ In comparison with the previous periods, the habitations of Ausonio I appear larger and

8 Bernabò-Brea \& Cavalier 1980, 163-215; 545-548.

9 Bernabò-Brea \& Cavalier 1980, 550-551, 699-701.
Io Bernabò-Brea \& Cavalier 1980, 705-709.

II Bernabò-Brea \& Cavalier 1980, 112-114; 560-563. 
the variety in plan is generally larger. Below the floors of several huts large jars have been found with contemporary cremation remains. In terms of material culture, Ausonio I represents a complete change with the previous period. ${ }^{12}$ It shows strong affinities with the material record of the subApennine culture in mainland Italy; a number of painted fragments have been found of a type originating in southern Sicily, even if some specimens were produced on Lipari itself. Ausonio I slowly developed into Ausonio II which probably lasted until the middle of the 9th century BC. ${ }^{13}$

\section{THE MYCENAEAN POT TERY}

Catalogue VIII lists 319 Mycenaean finds, all from settlement levels at the acropolis. ${ }^{14}$ With one exception, the female figurine with cat. no. 501, all are sherds of ceramic vessels, many of which are very small. None of these finds have been subject to scientific provenance research and the place of their manufacture cannot be stated with certainty. A number of early finds (cat. nos. 46, 192, 202) have been assigned a Minoan origin. However, most of the earlier material has affinities with the finds at Mycenae rather than with Crete. ${ }^{15}$ This would suggest an Argolid provenance for the majority of finds. However, Taylour also noted some stylistic similarities with pottery found in Messenia. ${ }^{16} \mathrm{~A}$ specific group of Mycenaean finds was labeled as local matt-painted by Taylour, who believed this class to be of Middle Helladic, Cycladic or local origin. ${ }^{17}$ It has been shown, however, that such pottery continued to be produced as late as the LH IIIA period, for example in Attica. ${ }^{18}$ Possibly, the matt-painted finds at Lipari originated in Attica, or in another Greek region which continued a local production of this type of pottery into the Late Bronze Age.

Given the care with which the excavations of Lipari have been published, it is likely that the catalogue includes all the Mycenaean pottery that was found. Considering the importance of this class of material for the chronology of the Bronze Age at Lipari, we can also assume that any such find in areas outside the acropolis would have been reported. therefore, with regard to the Mycenaean pottery that has been found, our data-set for Lipari appears to be complete. However, we should allow for the disturbances caused by the long history of habitation at the site after the Bronze Age, which may have had a serious effect on the possibilities to reconstruct contexts.

I2 Bernabò-Brea 1979, 582-583; Bernabò-Brea \& Cavalier 1980, 565-568, 705.

I3 Bernabò-Brea \& Cavalier 1980, 710-718.

I4 In Catalogue VIII, 303 finds derive from the catalogue published by Taylour in 1980, which contained 327 entries. The difference between these figures is largely due to the fact that some of Taylour's fragments derived from the same vessels. In addition, a hand-made fragment (Taylour 1980, 809-810: no. 247) and the “pseudo-Minyan” bowl (Taylour 1980, 815: no. 327) have been excluded by me on the grounds of their Italian manufacture. Cavalier \& Vagnetti (1984, 149-
150) show that the jar fragments with cat. nos. 81,109 and 219 also belong to the same vessel. Because they have been found in different levels they have been kept separate here. According to Lucia Vagnetti (pers. comm.) two Mycenaean sherds have been found elsewhere on Lipari, at the minor site of Castellaro.

is Taylour 1958, 48.

I6 Taylour 1958, 51.

${ }_{17}$ Taylour 1958, 33-35, 51.

I8 Vagnetti 1982a, 16-17; Cavalier \& Vagnetti 1983; 1984, 150-151. 


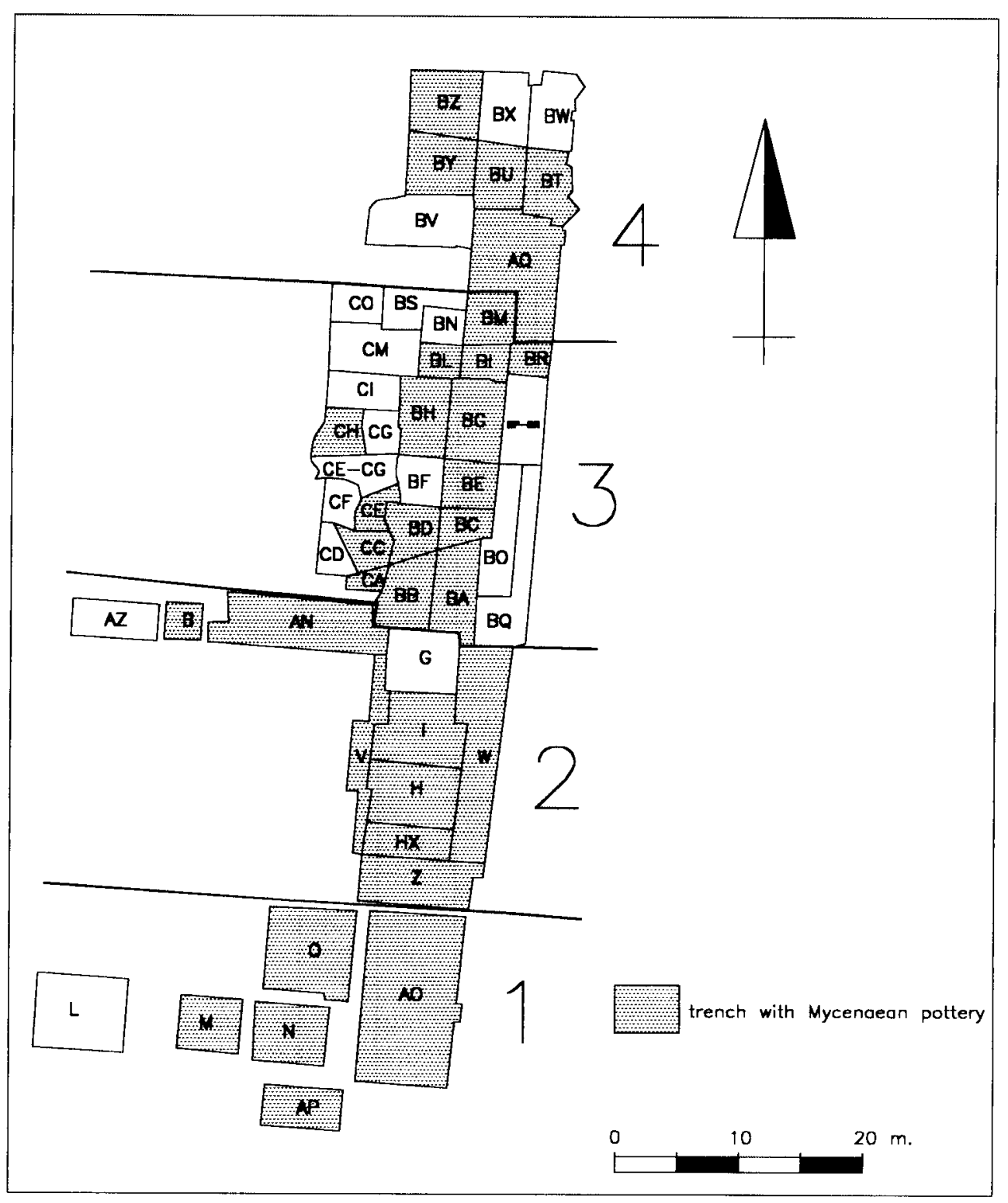

Fig. 15.2 Lipari acropolis: presence of Mycenaean pottery in the excavation trenches

\section{ON-SITE DISTRIBUTION OF THE MYCENAEAN POTTERY}

The main excavation area at Lipari can be divided into four parts which have been numbered from south to north (Fig. 15.2). Each of these parts is subdivided in excavation trenches of varying size, which are referred to by letters of the alphabet. This sub-division, to which the soundings outside the main area may be added, can be used to study the spatial distribution of the Mycenaean pottery at Lipari (Table 15.1).

From these figures, it is evident that a relatively large number of Mycenaean finds have been found in the rather small area 1 of the main excavations. This is due to a large extent to trench AO, which produced sixty-three Mycenaean finds. In this part of the site, two thick layers were attested directly 


\begin{tabular}{|c|c|c|c|c|c|c|c|c|c|}
\hline \multicolumn{2}{|c|}{ area 1} & \multicolumn{2}{|c|}{ area 2} & \multicolumn{2}{|c|}{ area 3} & \multicolumn{2}{|c|}{ area 4} & \multicolumn{2}{|c|}{ remaining } \\
\hline trench & amount & trench & amount & trench & amount & trench & amount & trench & amount \\
\hline AP & 1 & Z & 5 & CA & 3 & $\mathrm{AQ}$ & 4 & trench $A G$ & 3 \\
\hline $\mathrm{AO}$ & 63 & V & 12 & CC-CE & 2 & BT & 7 & trench $\mathrm{AH}-\mathrm{AH}^{\prime}$ & 2 \\
\hline M & 4 & $H X$ & 6 & BB & 4 & $\mathrm{BU}$ & 4 & trench $\mathrm{F}$ & 1 \\
\hline $\mathrm{N}$ & 16 & $\mathrm{H}-\mathrm{HX}$ & 8 & BA & 1 & BY & 2 & unknown & 2 \\
\hline \multirow[t]{11}{*}{$\mathrm{O}$} & 10 & $\mathrm{H}-\mathrm{I}$ & 9 & $\mathrm{BD}$ & 5 & $B Z$ & 1 & & \\
\hline & & $\mathrm{H}-\mathrm{V}$ & 10 & $\mathrm{BC}$ & 7 & & & & \\
\hline & & $\mathrm{H}-\mathrm{W}$ & 1 & $\mathrm{BF}$ & 12 & & & & \\
\hline & & $\mathrm{H}$ & 4 & $\mathrm{BE}$ & 1 & & & & \\
\hline & & $H X-V$ & 8 & $\mathrm{CH}$ & 3 & & & & \\
\hline & & I & 7 & $B G$ & 1 & & & & \\
\hline & & I-W & 1 & $\mathrm{BG}-\mathrm{BH}$ & 2 & & & & \\
\hline & & B & 1 & $\mathrm{BH}$ & 28 & & & & \\
\hline & & AN & 1 & $B L-B \mid$ & 1 & & & & \\
\hline & & W & 17 & $\mathrm{BM}$ & 28 & & & & \\
\hline & & & & $\mathrm{BR}$ & 10 & & & & \\
\hline Total & 94 & Total & 90 & Total & 108 & Total & 18 & Total & 8 \\
\hline
\end{tabular}

Table 15.1

\begin{tabular}{|c|c|c|c|c|c|c|c|}
\hline site area & unstratified & C.G. & C.G.-Mil & Mil & Mil-Aus I & Aus I & Aus II \\
\hline area 1 & 20 & 57 & 13 & 2 & & 2 & \\
\hline area 2 & 4 & 10 & 6 & 69 & & 2 & 2 \\
\hline area 3 & 9 & 15 & 21 & 26 & 8 & 12 & 5 \\
\hline area 4 & 3 & 6 & 3 & 1 & & 10 & 5 \\
\hline trench AG & & & 2 & & & & 1 \\
\hline trench $\mathrm{AH}-\mathrm{AH}$ ' & & & & 1 & & & 1 \\
\hline trench F & & & & 1 & & & \\
\hline unkown & 2 & & & & & & \\
\hline Total & 38 & 88 & 45 & 100 & 8 & 26 & 14 \\
\hline
\end{tabular}

Table 15.2

below the surface that have been interpreted as leveling strata. ${ }^{19}$ Thirteen entries in our catalogue derive from these strata. ${ }^{20}$ In trench $\mathrm{N}$, a similar layer was encountered more than two meters in thickness, which yielded sixteen of our sherds. ${ }^{21}$ An additional thirteen finds included among those ascribed to trench AO derive from the cleaning operations near capanna $\delta$ III. ${ }^{22}$ These came from mixed layers in a hole dug behind a wall of that hut, and their stratigraphy is not altogether clear. If we leave out these forty-two finds, the figure for area 1 becomes fifty-two Mycenaean finds. Even though less than the figures for areas 2 and 3, this is still a relatively high figure in comparison with the limited surface of area 1. It appears, then, that there was a concentration of Mycenaean finds in the southern part of the main excavation area.

I9 Bernabò-Brea \& Cavalier 1980, 342.

252-266, 277.

20 Cat. nos. 278, 279, 284-286, 291, 293-296, 300-302.

22 Cavalier \& Vagnetti 1984, 144-145.

2I Bernabò-Brea \& Cavalier 1980, 311-312. Cat. nos. 


\begin{tabular}{|c|c|c|c|c|c|c|c|c|}
\hline date & unstratified & C.G. & C.G.-Mil & Mil & Mil-Aus I & Aus I & Aus II & Total \\
\hline undatable & 13 & 37 & 22 & 39 & 4 & 13 & 5 & 133 \\
\hline LH/LM I & 2 & 8 & 4 & 4 & & & & 18 \\
\hline LH/LM I-II & 6 & 27 & 6 & 2 & & 1 & & 42 \\
\hline LH II & 3 & 13 & 4 & 10 & & & & 30 \\
\hline LH II-LH IIIA1 & 3 & 1 & 4 & 3 & & & & 11 \\
\hline LH IIIA1 & & 1 & 1 & 3 & & & & 5 \\
\hline LH IIIA1-LH IIIA2 & 1 & 1 & 2 & 11 & & & & 15 \\
\hline LH IIIA2 & 1 & & 1 & 5 & 1 & & & 8 \\
\hline LH IIIA2-LH IIIB & 3 & & 1 & 14 & 3 & & & 21 \\
\hline LH IIIB & 1 & & & 7 & & 7 & 3 & 18 \\
\hline LH IIIB-LH IIIC & & & & & & 4 & 2 & 6 \\
\hline LH IIIC & 5 & & & & & & & \\
\hline
\end{tabular}

Table 15.3

Such a concentration may be explained if we investigate the spatial distribution for the various stratigraphical phases (Table 15.2). It is evident that most Mycenaean finds from stratified contexts derive from Capo Graziano and Milazzese levels. The higher levels yielded far less Mycenaean finds. The northern part of the main excavation area, areas 3 and 4 , have produced a relatively high number of Mycenaean finds from the Ausonio periods. It appears that the concentration of our finds in the southern part of the site has to do with the extent to which the Ausonio I and II levels have been excavated. These strata were not present in the south..$^{23}$ In the northern area, however, they are well represented and at various places prevented investigation of lower levels. Even though we must acknowledge that the upper levels suffered worse damage through later activities, it is clear that the quantities of Mycenaean pottery imported at Lipari were larger in the Capo Graziano and Milazzese periods than later.

Taking into account stratigraphical variations, then, the Mycenaean pottery is fairly widely distributed in the excavation areas. A few concentrations, however, can be associated with structures or surfaces. In trench AO a concentration is visible in association with hut $\delta$ III of the Capo Graziano period, in which twenty-one Mycenaean finds were made (cat nos. 173-193). In trench W, thirteen Mycenaean finds were associated with the annex of Milazzese structure $\gamma$ VI (cat nos. 91-103). In trench BM, twelve Mycenaean finds were found inside hut $\gamma$ XII of the same period (cat. nos. 155166), while ten additional finds were associated with a wall, the so-called dromos, of Ausonio I hut $\beta$ IV (cat nos. 19-28). Such a distribution pattern suggests that Mycenaean pottery was not restricted to specific groups in the society of Lipari; it is possible, however, that some inhabitants made substantially more use of this material than others.

The occurrence of Aegean chronological styles in the successive archaeological strata at Lipari is indicated in Table 15.3. From these figures it is evident that pots in ceramic styles earlier than LH IIIA2 are more frequent than later Mycenaean finds. Indeed, LH IIIA2 finds are rather scarce at Lipari, even though we must allow for the high number of sherds which could not be assigned to a specific stylistic period. LH IIIB finds appear to be somewhat more frequent than those dating to LH IIIA2, but, given the difference in duration between these two periods, it can be concluded that the import of Mycenaean pottery at Lipari dropped sharply with the beginning of LH III.

Stratigraphically, the Mycenaean vessels from the earlier stylistic phases are concentrated in the Capo Graziano and Milazzese levels, while LH IIIA2 and LH IIIB finds occur from the Milazzese pe- 


\begin{tabular}{|c|c|c|c|c|c|c|c|c|}
\hline date & area 1 & area 2 & area 3 & area 4 & trench AG & trench $\mathrm{AH}-\mathrm{AH}^{\prime}$ & trench F & unknown \\
\hline undatable & 41 & 37 & 44 & 9 & 1 & & 1 & \\
\hline LH/LM I & 3 & 7 & 8 & & & & & 1 \\
\hline LH/LM I-II & 29 & 3 & 5 & 3 & 1 & & & \\
\hline LH II & 11 & 7 & 10 & 2 & & & & \\
\hline LH II-LH IIIA1 & 2 & 3 & 5 & 1 & & & & \\
\hline LH IIIA1 & 1 & 1 & 3 & & & & & \\
\hline LH IIIA1-LH IIIA2 & & 11 & 2 & & & 1 & & 1 \\
\hline LH IIIA2 & & 2 & 6 & & & & & \\
\hline LH IIIA2-LH IIIB & 1 & 10 & 10 & & & & & \\
\hline LH IIIB & 1 & 6 & 9 & 1 & & 1 & & \\
\hline LH IIIB-LH IIIC & & 2 & 3 & 1 & & & & \\
\hline LH IIIC & 5 & 1 & 3 & 1 & 1 & & & \\
\hline
\end{tabular}

Table 15.4

riod onwards. The LH I-LH II rounded alabastron (cat. no. 271) from an Ausonio I context was found in a pit. ${ }^{24}$ It is a relatively small fragment and the varied contents of the pit suggest that it was not in its primary context. The Milazzese period has produced Mycenaean finds from all periods, including a base fragment (cat. no. 60) which Taylour assigned to LH IIIC. ${ }^{25}$ This fragment was found associated with the floor of hut $\gamma$ II, together with eight other Mycenaean finds (cat. nos. 52-59) ranging in style from LH I to LH IIIA2-LH IIIB. Such a mixture of chronological styles could indicate that vessels from different periods were used together. However, the small size of the fragments and the fact that a structure of the Capo Graziano (hut $\delta$ VII) period has been found directly below $\gamma$ II indicate that we cannot consider this a closed context. ${ }^{26}$ At the lower floor of hut $\gamma \mathrm{I}$, seven Mycenaean finds dating to LH IIIA2 and LH IIIB (cat. nos. 39-45) were found together with part of a LM I hole-mouthed jar (cat. no. 46). Again, however, the small size of this fragment makes it doubtful that it was retrieved from its primary context. In other words, there is no evidence that the wide chronological variety of the Mycenaean finds from the Milazzese period is due to long use of Aegean ceramic vessels.

The spatial distribution of the Mycenaean chronological types at Lipari, which is indicated in Table 15.4 , is of course influenced by the variations in the stratigraphy among the four parts of the main excavation area. The apparent concentration of LH I and LH II finds in area 1, for example is partly due to the large number of Mycenaean sherds from the leveling strata in areas $\mathrm{AO}$ and $\mathrm{N}$ below the Graeco-Roman levels. ${ }^{27}$ However, sixteen Mycenaean finds dating to these periods have been found in association with capanna $\delta$ III,${ }^{28}$ which suggests that the people associated with this structure had

23 Taylour $1980,816$.

24 Bernabò-Brea \& Cavalier 1980, 350-352.

25 Taylour (1958, 42: no. 111, Plate 6:26) assigns this fragment to LH IIIC without further comments. It is the base of a closed vessel, on which the marks made by the string in detaching it from the potter's wheel are visible. Only the underside of the fragment is illustrated and there does not seem to be any decoration. In my opinion, the fragment ought to be classified as of undeterminable date.

26 In fact, Bernabò-Brea \& Cavalier $(1980,171)$ note that these sherds come from the floor of capanna $g$ II and from directly below the floor.

27 Seventeen Mycenaean finds from LH I to LH II (cat. nos. 198, 200, 202, 207, 252-257, 262, 265, 266, 277 279) have been found unstratified in areas $\mathrm{N}, \mathrm{AO}$ and AP.

28 Cat. nos. 176-185, 192, 308, 310, 313, 314. 


\begin{tabular}{|c|c|c|c|c|}
\hline site area & fragments & dinner & storage & figurine \\
\hline area 1 & 47 & 41 & 6 & \\
\hline area 2 & 50 & 33 & 7 & 1 \\
\hline area 3 & 62 & 35 & 11 & \\
\hline area 4 & 9 & 9 & & \\
\hline trench $A G$ & 1 & 1 & 1 & \\
\hline trench $\mathrm{AH}-\mathrm{AH}^{\prime}$ & 1 & 1 & & \\
\hline trench $\mathrm{F}$ & 1 & & & \\
\hline unknown & & 2 & & \\
\hline Total & 171 & 122 & 25 & 1 \\
\hline
\end{tabular}

Table 15.6

\begin{tabular}{|c|c|c|c|c|c|}
\hline stratum & unkown & dinner & figurine & storage & total \\
\hline unstratified & 18 & 18 & & 2 & 38 \\
\hline C.G. & 45 & 37 & & 6 & 88 \\
\hline C.G.-Mil & 22 & 18 & & 5 & 45 \\
\hline Mil & 55 & 36 & 1 & 8 & 99 \\
\hline Mil-Aus I & 5 & 2 & & 1 & 8 \\
\hline Aus I & 16 & 8 & & 2 & 26 \\
\hline Aus II & 10 & 3 & & 1 & 14 \\
\hline
\end{tabular}

Table 15.6

special access to this material in the Capo Graziano period. In general, however, Mycenaean finds in all chronological styles have been found in various areas at the site, suggesting that this material was not restricted to specific groups among the inhabitants of Lipari.

When we differentiate the Mycenaean pottery at Lipari according to functional vessel type, as is done in Table 15.5, it seems that dinner vessels are more abundant than storage vessels. Such a pattern, however, is due to the large number of fragments of which the vessel types cannot be determined exactly. For many fragments, Taylour has indicated whether they were from a closed or open vessel type, and there are somewhat more closed vessels than open shapes. ${ }^{29}$ Even though closed vases, in particular jugs, may be considered to be dinner vessels, the abundance of closed fragments suggests that the proportion of storage vessel types may be larger than that indicated in Table 15.5. In any case, the occurrence of both dinner and storage vessels in most parts of the main excavation area suggests that neither type was restricted to particular groups of people.

The stratigraphy of the Mycenaean functional types is presented in Table 15.6. It is clear that, from the Capo Graziano period onwards, both dinner and storage vessels were imported. ${ }^{30}$ This remained

29 A total of 146 entries in the catalogue has been assigned to a closed, shape. There are 110 open shapes, while for sixty-two fragments it could not be established to what type they belonged. It must be emphasised that Taylour does not specify which vessel types he regards as open or closed. Kraters and some bowls, for example, are classified by him among closed vessels, see Taylour 1980, 807, 811, 812.

30 The differences in quantity between dinner and storage vessels in the different levels are, as before, due to the 


\begin{tabular}{|c|c|c|c|c|c|c|}
\hline stratum & unknown & plain & matt-painted & monochrome & linear & patterned \\
\hline unkown & & & & & 1 & 1 \\
\hline area 1 & 2 & 5 & 1 & 6 & 27 & 53 \\
\hline area 2 & & 15 & 5 & 4 & 26 & 42 \\
\hline area 3 & 6 & 15 & & 8 & 38 & 39 \\
\hline area 4 & & 1 & & 4 & 6 & 7 \\
\hline trench $A G$ & & & & & 2 & 1 \\
\hline trench $\mathrm{AH}-\mathrm{AH}^{\prime}$ & & & & 1 & & 1 \\
\hline trench $\mathrm{F}$ & & & & & & 1 \\
\hline Total & 9 & 36 & 6 & 23 & 100 & 145 \\
\hline
\end{tabular}

Table 15.7

\begin{tabular}{|c|c|c|c|c|c|c|}
\hline stratum & unknown & plain & matt-painted & monochrome & linear & patterned \\
\hline unstratified & 1 & 6 & & & 11 & 20 \\
\hline C.G. & 1 & 9 & 3 & 6 & 23 & 46 \\
\hline C.G.-Mil & 1 & 4 & & 3 & 10 & 27 \\
\hline Mil & 4 & 16 & 4 & 8 & 30 & 37 \\
\hline Mil-Aus I & 2 & & & 1 & 3 & 2 \\
\hline Aus I & & & & 4 & 17 & 5 \\
\hline Aus II & & & & 1 & 6 & 7 \\
\hline
\end{tabular}

Table 15.8

true for all periods, even though the relative proportions of these two Mycenaean functional vessel categories may have varied somewhat. Among the earlier vessels (LH I and LH II) cups were particularly popular, but a number of jars dating to these stylistical phases have also been found. From LH IIIA onwards, jugs take up an sizable proportion of the imported Mycenaean repertoire, while cups also remain important. Kraters begin to be imported from LH IIIA2 onwards, just as amphorae, but drinking cups remain the most frequent vessel type. It may be concluded that the repertoire of Mycenaean pots imported at Lipari remained fairly constant over a long period of time.

Table 15.7 shows the spatial distribution at Lipari of various Mycenaean decorational types. The predominance of Mycenaean vessels with patterned decoration is probably even larger than indicated, since plain, monochrome and linear sherds may have belonged to vessels with patterned decoration. Indeed, all monochrome sherds are very small and several belong to rims, handles and bases; these probably belonged to vessels decorated with lines or patterns. The same can be said of plain sherds, none of which constitutes a substantial part of a vessel. Matt-painted pottery appears to be concentrated in area 2. However, three sherds from this area assigned to this class (cat. nos. 81, 109, 219) belong to the same vessel. ${ }^{31}$ The stratigraphical distribution of the various decorational types, presented

high number of fragments. When open and closed vessels are considered instead, there is an equilibrium for the Capo Graziano period (thirty-six open and thirtyseven closed Mycenaean vessels), while during the Milazzese (twenty-seven open, fifty closed), Ausonio I (eight open, thirteen closed) and Ausonio II (three open, eight closed) periods, closed vessels predominate.

3I Cavalier \& Vagnetti 1984, 149-150. 


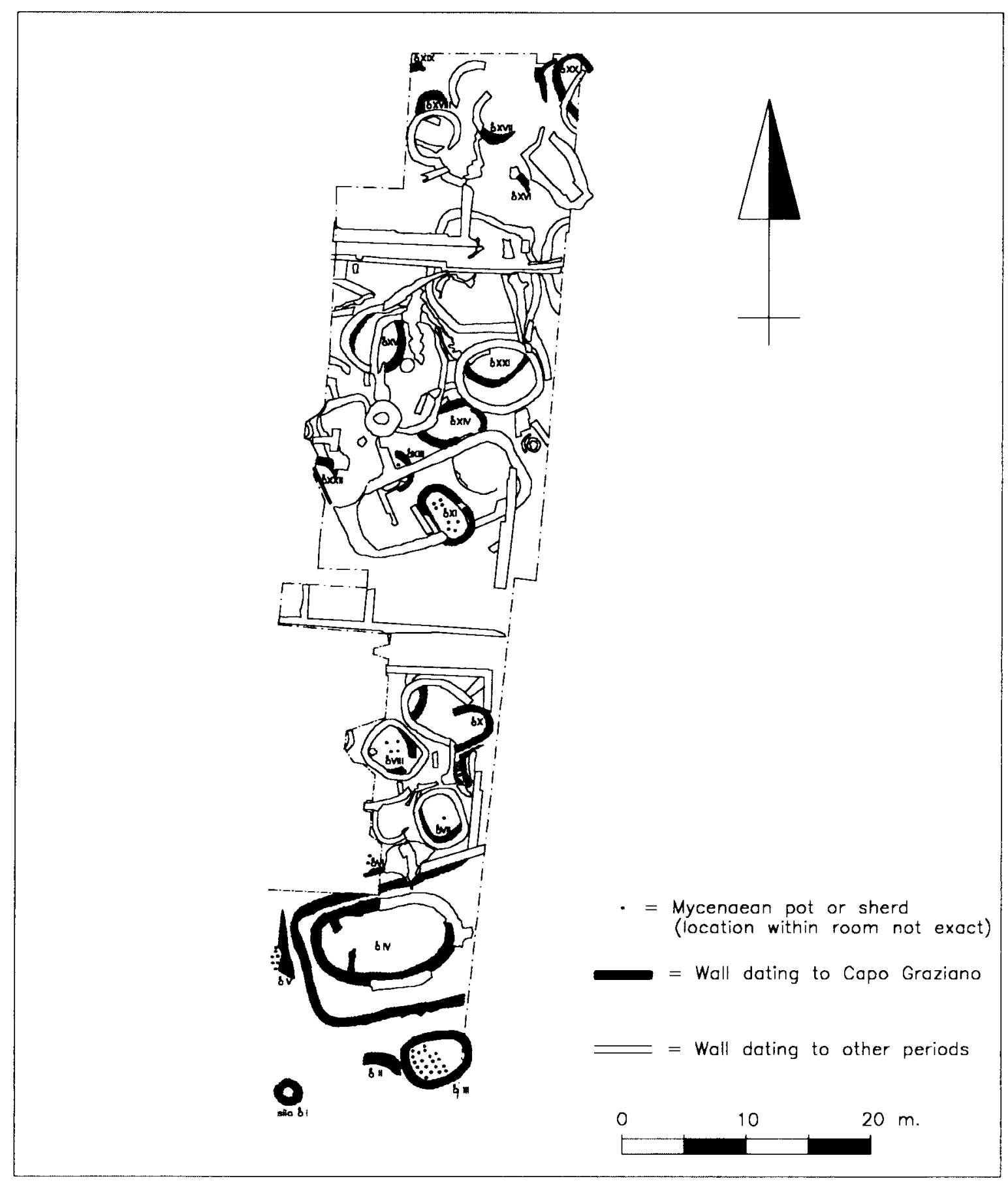

Fig. 15.3 Lipari: Mycenaean pottery in Capo Graziano structures

in Table 15.8, shows that the predominance of Mycenaean vessels with patterned decoration is marked only during the Capo Graziano and Milazzese periods. All the plain ware sherds may be attributed to these early periods as well, as is also the case for matt-painted pottery. It appears that the Mycenaean pottery imported at Lipari during the later periods, in terms of decoration, was less varied than that of earlier periods. The wide spatial distribution of the various Mycenaean decorational types at Lipari does not indicate that there were any restrictions in the use of this class of pottery based on its decoration. 


\section{SET T LEM E N T C ONTEXTS}

In the three successive settlements at Lipari which concern us here, there are twenty-seven situations where Mycenaean pottery can be related to specific settlement structures; these are listed in Table XI in the tables section of this book. The single-room structures make it impossible to study the distribution of the Mycenaean vessels in individual buildings. In order to assess the cultural associations attached to this material, we need to investigate its distribution in the settlements in general.

The Capo Graziano settlement (Fig. 15.3)

In the southern part of the main excavation area, a concentration of Mycenaean pottery is associated with structure $\delta$ III. ${ }^{32}$ This is a building of average size, of which the interior has been exposed completely. Possibly, the door of the house was situated in its northern wall. The floor of the building was of battered earth. In the eastern end, two large, almost complete vases were discovered, set on a stone base. The earth around this base was heavily burned and it is likely that this feature constitutes a fireplace. On the floor of this building, twenty-one Mycenaean finds were made, which is the largest concentration of this class of material at Lipari. In addition, thirteen unstratified finds (cat. nos. 306318) can be associated with the building. Among the Mycenaean finds on the floors, four are sherds of LH I-LH II cups (cat. nos. 176-178, 184), one belongs to a goblet (cat. no. 173: Fig. 15.4) and three to rounded alabastra (cat. nos. 181-182, 185). All other finds are small fragments of uncertain vessel types. These Mycenaean sherds were found together with a great many vases of local impasto, among which are both dinner and storage types. A schist plaque was also found. Obviously, this concentration of Mycenaean vessels has primarily domestic associations.

Structure $\delta$ IV is an oval building, three times the size of the average Capo Graziano hut. ${ }^{33}$ On the outside, it was surrounded by a perimeter wall, which delineated a rectangular area. The room inside the building was divided into a larger hall and a smaller room in the west. On the floor of the building lay large masses of sherds, from which several complete vases have been restored. Twelve miniature vases suggest that specific activities, possibly of a cultic nature, took place in this building. Mycenaean pottery has not been discovered on the floor. However, two fragments of Vapheio cups (cat. nos. 208, 210) and one handle fragment of a LH IIB goblet (cat. no. 209) were found in the fill above the floor. It is therefore possible that the people associated with this exceptional building did make use of Mycenaean drinking vessels. Structure $\delta \mathrm{V},{ }^{34}$ situated adjacent to $\delta \mathrm{IV}$, yielded seven Mycenaean finds. Only a very small section of wall and floor have been exposed, since two fruit trees prevented further excavation to the west. In such a limited area, the seven fragmentary Mycenaean finds, among which are a LH IIA bridge-spouted jug (cat. no. 212) and three semi-globular cups (cat. nos. 213, 214, 216), represent a considerable concentration. Other finds in $\delta \mathrm{V}$ included impasto globular vases and carinated cups.

To the north of structure $\delta$ IV, in area 2, much less Mycenaean pottery has been found in situ, which is at least partly caused by the concentration of Milazzese huts in this area. In the quadrangular hut $\delta$ VII, ${ }^{35}$ a small Mycenaean fragment (cat. no. 220) was found on the floor, associated with local bowls and jars and carinated cups. Directly below the floor, however, in a level belonging to an earlier phase of the structure, a large part of a LH IIB-LH IIIA1 shallow cup was found, together with some spindlewhorls as well as a large variety of local pottery. To the northwest of $\delta$ VII, structure $\delta$ VIII has

32 Bernabò-Brea \& Cavalier 1980, 220-223.

33 Bernabò-Brea \& Cavalier 1980, 225-232.
34 Bernabò-Brea \& Cavalier 1980, 232-233.

35 Bernabò-Brea \& Cavalier 1980, 234-236. 


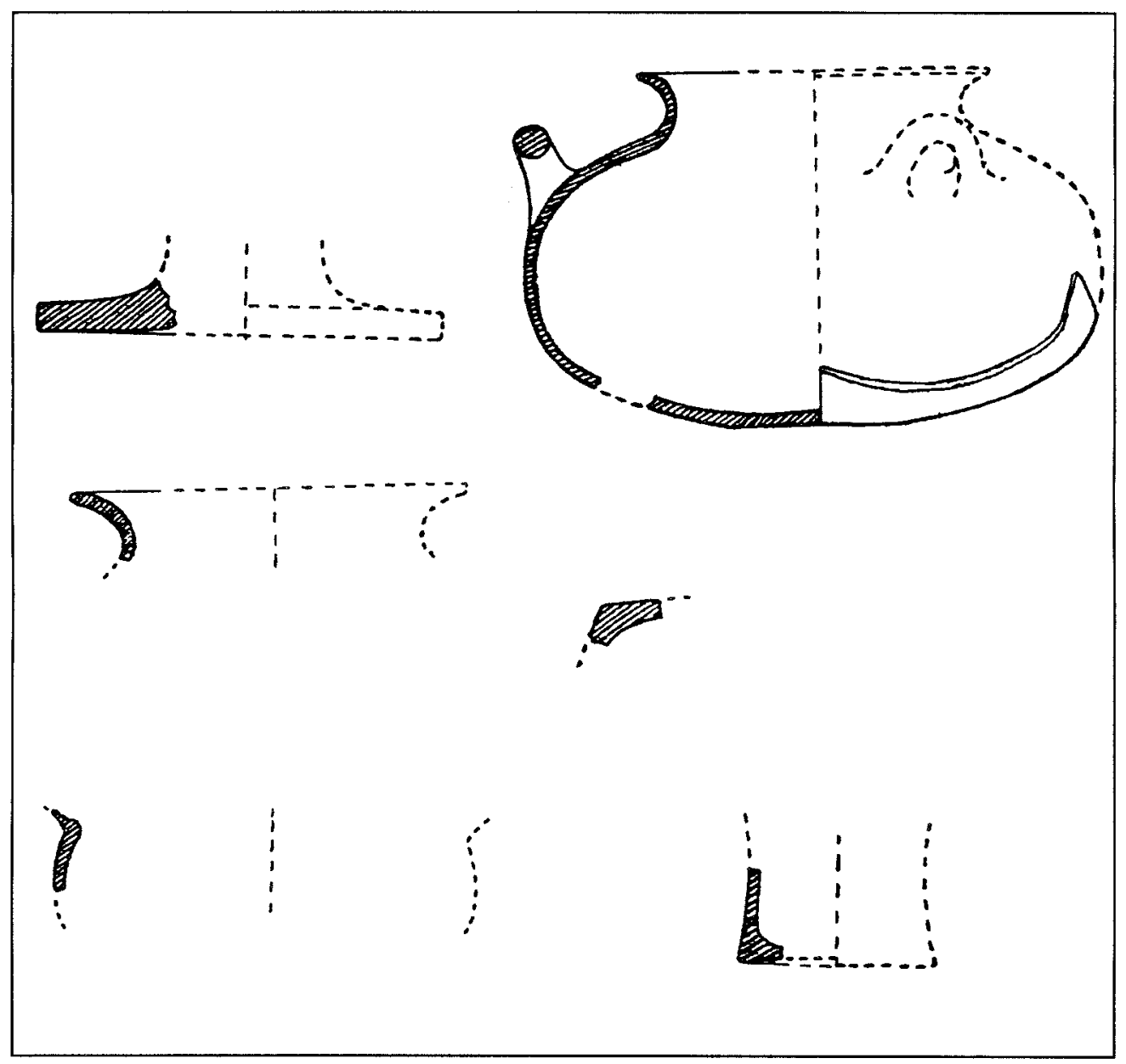

Fig. 15.4 Mycenaean pottery from the floor levels of capanna d III (cat. nos. 173, 185, 181, 182, 176, 177) - After Bernabò-Brea \& Cavalier 1980, Plate 145: nos. a, b, h, j, Plate 147: no. a, Plate 161: no. a.

been exposed, ${ }^{36}$ which was almost circular in shape and had a doorway to the south-east. The floor of this building produced soil and animal bones which have been described as kitchen waste. Two Mycenaean fragments (cat. nos. 222, 224), as well as part of a Vapheio cup (cat. no. 223) have also been found on this floor, in association with spindle whorls, jar fragments, a pithos, jugs and carinated cups. On a somewhat higher level, a fragment of a LH I jar (cat. no. 225) was found. Again, the Mycenaean pottery in this area has clear domestic associations.

Directly north of the cardo III of the Graeco-Roman city, parts of hut $\delta$ XII have been discovered. ${ }^{37}$ In the north-eastern part, burned earth and wasters suggest the presence of a pottery kiln. None of the Mycenaean sherds found near the floor were associated with the pottery kiln. All were found in the eastern and south-western part of the structure, together with a number of stone axes, a bronze needle and some spindle whorls. Among the vessels were a LM I jug (cat. no. 235), a LH I holemouthed jar (cat. no. 231) and a LH IIA semi-globular cup (cat. no. 228). In addition, five Mycenaean fragments of undeterminable type were found (cat. nos. 229, 230, 232-234). This concentration of Mycenaean pottery obviously can be associated with the activities of artisans. 
In considering the presence of Mycenaean pottery in the Capo Graziano phase at Lipari, we must allow for the disturbances post-dating this period. The absence of Mycenaean finds in situ from the northern part of the main excavation area is surely caused by the presence of many later structures; because of these the deepest level could be explored only to a limited extent. Nevertheless, three concentrations of Mycenaean ceramic vessels are apparent, in huts $\delta$ III, $\delta \mathrm{V}$ and $\delta$ XII, suggesting that these vessels were used more extensively by specific groups among the inhabitants at Lipari. The two largest concentrations have been observed in structures adjacent to the exceptional structure $\delta$ IV. The exact nature and status of this building is unclear, but it is possible that it served ceremonial functions. ${ }^{38}$ If true, the virtual absence of Mycenaean pottery in this building indicates that this material was not extensively used in ceremonies, but had mainly domestic associations. The fact that the people living nearest to this exceptional structure made the most extensive use of Mycenaean pottery, however, testifies to the social significance of these vessels.

\section{The Milazzese settlement (Fig. 15.5)}

The southernmost part of the main excavation area has not produced any structures from the Milazzese period. ${ }^{39}$ Area 2, however, produced a group of at least eight buildings, most of which were fairly small and of oval shape. The smallest of this group of huts is $\gamma \mathrm{I}$, which is situated in the southwest. ${ }^{40}$ In a destruction layer, two Mycenaean fragments were found (cat. nos. 37-38), among which was one from a LH IIIB shallow cup. Below this layer, a floor was attested on which lay eight small Mycenaean fragments (cat. nos. 39-46), of which one came from a LH IIIB cup (cat. no. 45), one from a LH IIIA2 jug (cat. no. 40) and one from a LM I hole-mouthed jar (cat. no. 46). Also found were a bronze ring, and a large amount of decorated and impasto pottery, among which were a great many cups.

To the east of $\gamma$ I lay the larger cabin $\gamma \mathrm{II},{ }^{41}$ which used the walls from the Capo Graziano cabin $\mathrm{d}$ VII as a foundation. In addition, there is evidence for at least one rebuilding during the Milazzese period. A floor level was indicated by a line of objects, such as a grinding stone and a pounder, but the actual floor itself has not been recognized. The approximate floor level contained eight Mycenaean finds (cat. nos. 52-60), among which were a fragment of a LH II Vapheio cup (cat. no. 54) and a rounded alabastron (cat. no. 53). Two jugs (cat. nos. 55, 56) have been dated to LH IIB-LH IIIA1 and LH IIIA1-LH IIIA2 respectively, while a shallow cup (cat. no. 57) is in LH IIIA2-LH IIIB style. The small size of the fragments, the variety in their stylistical chronology and the absence of a true floor suggest that these finds were not in situ. A LH IIIA2-LH IIIB fragment was found in the destruction debris of this building, which may belong to an amphoroid krater (cat. no. 50); the debris also contained a Mycenaean fragment (cat. no. 51) of undetermined shape. The Mycenaean fragments in both levels were associated with some pottery fragments imported from mainland Italy and with an abundance of local decorated and impasto vessels.

To the north of $\gamma$ I lay the quadrangular structure $\gamma$ III. ${ }^{42}$ This building is generally of lower architectural quality than others of the same period. In a level directly above the floor, fragments of a Mycenaean jug (cat. no. 65) were found, of which other fragments have been discovered in structure $\gamma$ II. A small fragment of a LH IIIA1-LH IIIA2 shallow cup (cat. no. 66) and one of a stirrup jar (cat.

${ }_{38}$ It needs to be acknowledged that the inventory of $\mathrm{d}$ IV included many items which may be assigned a domestic function.

39 Bernabò-Brea \& Cavalier 1980, 163.

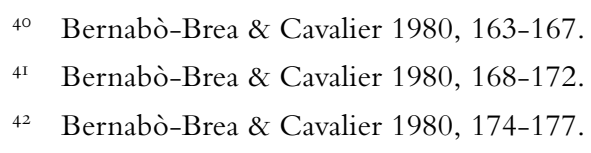

${ }^{42}$ Bernabò-Brea \& Cavalier 1980, 174-177. 


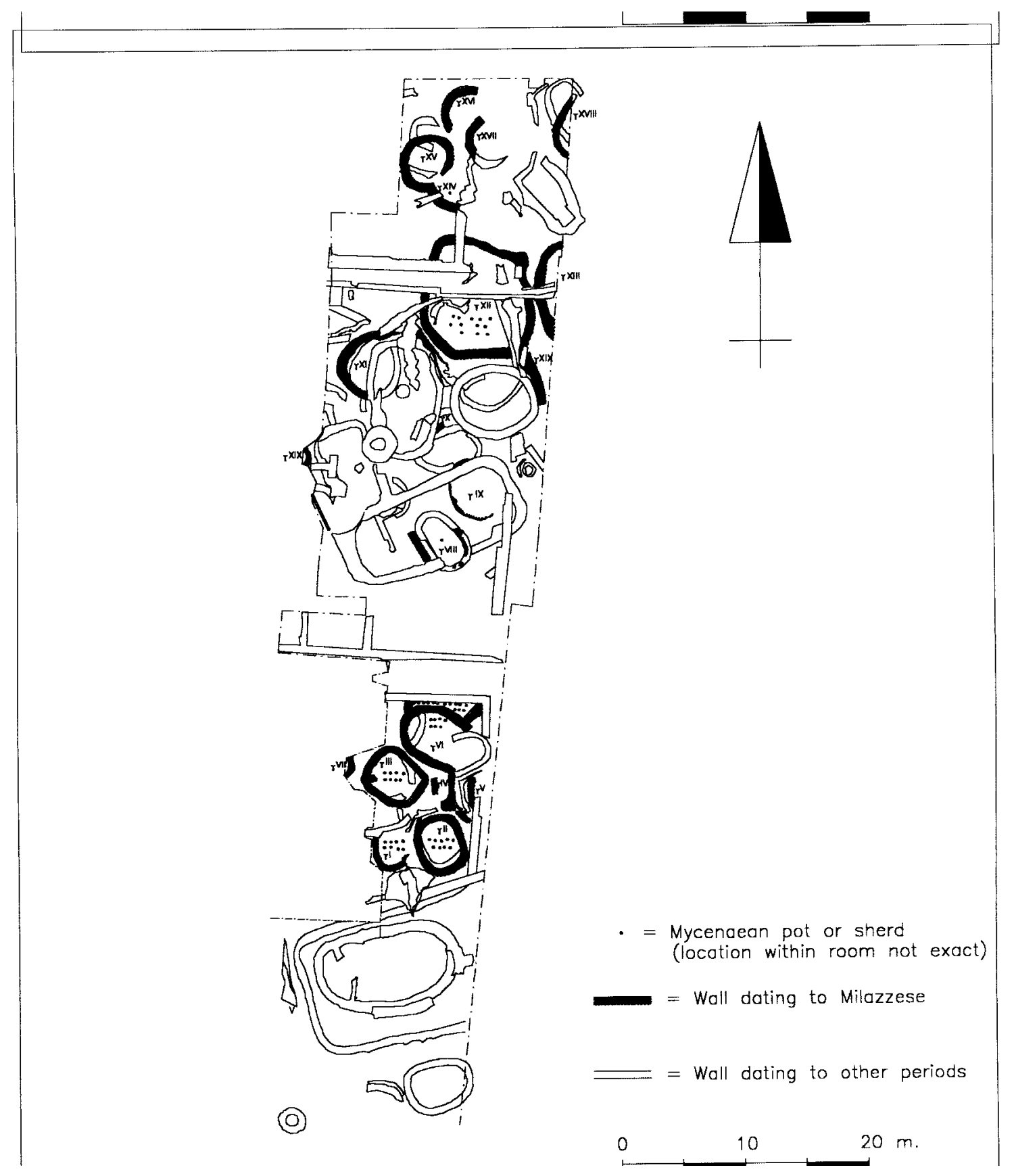

Fig. 15.5 Lipari: Mycenaean pottery in Milazzese structures

no. 67: Fig. 15.2)) were discovered as well. This stirrup jar is the only one of this vessel type found at Lipari. Another unique discovery is a large part of a Mycenaean female proto-phi figurine (cat. no. 501). A fragment of imported Appennine pottery and also local dinner and storage vessels were associated with the Mycenaean finds. An anthropomorphic figurine of local clay was also recovered. ${ }^{43}$ Even though the internal stratigraphy of this hut is not altogether clear, it is obvious that the

43 Bernabò-Brea \& Cavalier 1980, Plate 185: no. 1. 
Mycenaean pottery in structure $\gamma$ III had predominantly domestic associations. The fact that the only Mycenaean figurine found at Lipari occurred together with a local statuette suggests that it was employed in local cultural practices.

The largest Milazzese structure in this part of the excavation area is $\gamma$ VI, which is also of superior architectural quality. ${ }^{44}$ On the northern side, two walls suggest the presence of an annex or courtyard, similar to the ones known from contemporary structures on the island of Panarea. ${ }^{45}$ Below the destruction level, which contained the stones of the superstructure, a floor was attested. In the layer associated with this floor, an LH II Vapheio cup (cat. no. 85), as well as two LH IIIA jugs (cat. nos. 86, 87) and a LH IIIA2-LH IIIB shallow cup (cat. no. 88) have been discovered together with two small Mycenaean fragments (cat. no. 89-90), Appennine dinner and storage vessels imported from the Italian mainland, and a wide variety of local pottery, much of it decorated with incision. The annex of $\gamma$ VI extends below the cardo III of the Greek and Roman town and, for that reason, could not be fully excavated. The stratigraphy of the annex is not altogether clear, but a total of thirteen Mycenaean finds (cat. nos. 91-103) have been made in the small section that was excavated. Among the Mycenaean finds were fragments of a LH IIIB miniature jug (cat. no. 93), a matt-painted carinated cup (cat. no. 102) and an amphora (cat. no. 103). All other Mycenaean finds are fragments of undeterminable shape, except for a jug fragment (cat. no. 97). This material was associated with a fragment of imported impasto and with a variety of local pottery. The Mycenaean repertoire from the annex is varied, with two vessels - the miniature jug and the carinated cup - of types unique to Lipari. The amphora has only two parallels at the acropolis site (cat. nos. 18, 27), both from Ausonio I contexts. The association of these vessels with a large and elaborate structure may indicate that the people associated with this structure had access to a wider repertoire of Mycenaean vessels than inhabitants from most other buildings.

Fragmentary remains of building $\gamma$ VIII have been discovered somewhat north of cardo III of the Greek and Roman town. ${ }^{46}$ A fragment of a LH II-LH IIIA1 goblet (cat. no. 114) was found on the floor, associated with a wide variety of local impasto vessels. The destruction layer above the floor produced three Mycenaean fragments (cat. nos. 110, 111, 113) and a large part of a LH IIIA2-LH IIIB kylix (cat. no. 112), together with a spindle whorl and various local open and closed pot shapes. Capanna $\gamma$ VIII may be considered average, both in terms of architecture and in terms of inventory. The presence of two Mycenaean stemmed cups in such a building shows that the use of such drinking vessels was not a restricted practice.

Structure $\gamma$ XII differs completely from all other Milazzese structures. ${ }^{47}$ It has a polygonal shape, with five regular sides. The northern and south-eastern walls of the structure were made of large stones rounded by water, which must have been transported from a beach specifically for this purpose. Such stones do not make very good walls and it is questionable whether the structure was roofed. The inside of this structure was destroyed to a large extent by a later cistern. In the central and northern parts, however, a floor was attested, on which lay fragments of a LH II cup (cat. no. 155), a LH IIIA2 mug (cat. no. 156), a LH II squat jug (cat. no. 159) and a LH II Vapheio cup (cat. no. 162), along with eight fragments of indeterminable shape. These sherds were associated with an imported Appennine jar and a variety of local impasto vessels. The fill above the floor produced a fragment of a large piriform jar (cat. no. 154), together with three Mycenaean fragments (cat. nos. 151-153), local pottery and a stone axe. The nature of this extraordinary building is not known. Even though unconventional in terms of architecture, the inventory of $\gamma$ XII, including the Mycenaean pottery, compares well with that of contemporary structures.

44 Bernabò-Brea \& Cavalier 1980,181-186

45 Bernabò-Brea \& Cavalier 1968, 50-70.
46 Bernabò-Brea \& Cavalier 1980, 188-190.

47 Bernabò-Brea \& Cavalier 1980, 201-206. 


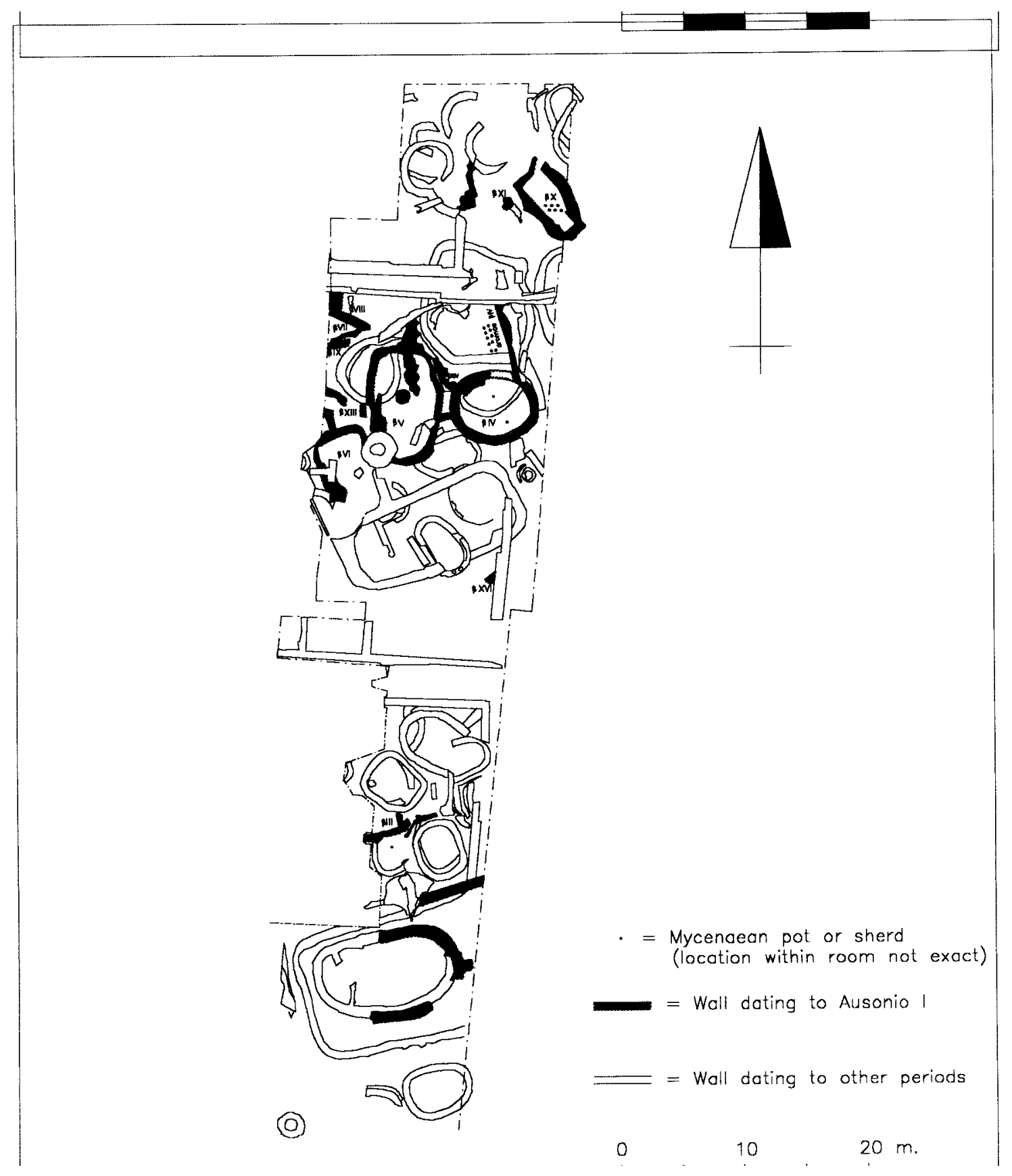

Fig. 15.6 Lipari: Mycenaean pottery in Ausonio I structures

From the distribution of Mycenaean pottery among the Milazzese structures, we can conclude that this material was widely used by the population of the village. A large number of buildings from this period has produced substantial amounts of this pottery, usually including a standard repertoire of Vapheio and shallow cups, as well as jugs. In a few Milazzese structures, some vessels were found which are not very common at Lipari. This is the case for the alabastron and krater at $\gamma$ II, the stirrup jar and figurine at $\gamma$ III, the stemmed cups at $\gamma$ VIII and the mug at $\gamma$ XII. A small concentration of 
three uncommon Mycenaean vessels has been found in the annex to $\gamma$ VI. This may suggest that the people associated with this extraordinary structure had special access to imported Mycenaean goods. It may also be that the extraordinary repertoire is related to the activities carried out in such an annex, which may be different from those inside the cabins.

\section{The Ausonio I settlement (Fig. 15.6)}

Levels belonging to the Ausonio I period had all but disappeared in the two southern areas of the main excavation. In area 3, however, several large huts have been found, which, unfortunately, were heavily damaged by cisterns dating from the Greek period to the modern age. In the eastern part of area 3, a well preserved oval hut was attested, which has been labeled $\beta$ IV. ${ }^{48}$ The architecture of this building is of exceptional quality. The doorway was approached by a long pathway, flanked by a wall extending for almost $7 \mathrm{~m}$, which has been called the dromos. Within the structure, a succession of three floors dating to Ausonio I has been attested, while two later floors yielded Ausonio II material. On the latest Ausonio I floor, a LH IIIB krater fragment (cat. no. 17) has been discovered, in association with a possible bronze weapon, a fibula, ovoid stone bowls and a variety of local pottery. The second floor of the building did not produce Mycenaean finds, but on the original floor, a fragment of a Mycenaean amphora (cat. no. 18) has been found, together with imported pottery from an unknown origin. A stone bowl, terra-cotta spindle whorls and local impasto pottery were also present on the original floor. The area of the dromos was heavily disturbed by a modern cistern. It was excavated in two parts, one near the doorway of the cabin and one in the area of the lower cabin $\gamma$ XII. Ten Mycenaean finds (cat. nos. 19-28) were made in the second part, but their stratigraphy is not certain. Among them are two LH IIIB deep bowls (cat. nos. 19, 21), an amphora dating to the same period (cat. no. 27) and a LH IIIB-LH IIIC kylix (cat. no. 28). Numerous fragments of two vessels of Sicilian type were also found in the dromos. ${ }^{49}$

An unusual structure $\beta \mathrm{X}$ was discovered in the northernmost part of the main excavation area. ${ }^{50}$ The building had a rectangular shape, was orientated north-west to south-east, and had very thick walls. A substantial number of Mycenaean finds were made in this building, belonging to seven vessels (cat. nos. 29-35), among which were a LH IIIB-LH IIIC deep bowl (cat. no. 34) and a LH IIIB stemmed bowl (cat. no. 35). All other fragments belonged to large, closed vessel shapes. These fragments were found together with local cups and jars.

In comparison with the earlier stratigraphical phases, Mycenaean pottery was not very abundant during the Ausonio I period. The small number of Mycenaean finds which can be related to settlement structures is partly due to the disturbances of this level. However, it is remarkable that two concentrations of Mycenaean finds during his phase have been found in association with a-typical structures. One of these, structure $\beta \mathrm{IV}$, also produced relatively large numbers of pottery imported from Sicily and Sardinia. ${ }^{51}$ The concentration of the Mycenaean vessels suggests that the use of this pottery during this period was not widespread, but restricted to specific groups among the inhabitants at Lipari.

48 Bernabò-Brea \& Cavalier 1980, 121-131.

49 Bernabò-Brea \& Cavalier 1980, 566. It is not sure whether these vessels are local imitations of Sicilian types or genuine imports.

so Bernabò-Brea \& Cavalier 1980, 155-156.

SI Bernabò-Brea \& Cavalier 1980, 566, 568. 
The three successive strata vary in the extent to which they have produced objects other than the Mycenaean ceramic vessels deriving from international and regional exchange. In the Capo Graziano level, a bead of white-blue glass paste was found in structure $\delta$ XXI. ${ }^{52}$ An Aegean origin for the glass beads in Italy has been proposed. ${ }^{53}$ However, a production of glass products within the central Mediterranean cannot be excluded, as is suggested by the evidence for the circulation of glass ingots in the eastern Mediterranean. ${ }^{54}$ Together with the glass bead from $\delta$ XXI, an amber bead was found, which must have been imported. The same may be said of a decorated comb made of bone ( Fig. 15.7). ${ }^{55}$ This object is exceptional in comparison with the other items of worked bone found in the same level and an Aegean origin has been suggested. It is more likely that the Lipari comb was produced in the Italian area; however, other bone combs from the Bronze Age are known from the Levant, Greece and the Balearic islands. ${ }^{56}$ The Lipari comb, then, may be understood as an object associated with an international world. Additional imports at Lipari constitute a few ceramic vessels found in Capo Graziano levels which may have been produced in Sicily. ${ }^{57}$

The finds mentioned above testify that Lipari participated in interregional exchange during the Capo Graziano period. However, in terms of quantities, the ceramic vessels of Aegean origin constitute imports which were present in relative abundance. We have seen that during the Capo Graziano period Mycenaean pottery was widely available to the inhabitants of Lipari. At the same time, residents living in the vicinity of the exceptional building $\delta$ IV possessed more of this material than others. This indicates that this material was part of consumptive strategies. It seems logical to assume that the fact that these vessels were imported was an important ground for their social significance.

The Milazzese levels at the acropolis of Lipari have produced far fewer objects which may be identified as imports than the previous phase. A number of Appennine vessels imported from the Italian mainland have been found in several structures belonging to these levels. ${ }^{58}$ However, such pottery is much less frequent at Lipari than in contemporary levels on Panarea and Salina. ${ }^{59}$ In addition, few metal objects have been found and no objects other than pottery which were clearly imported. Within such a material environment, it is possible that Mycenaean pottery acquired a special significance. Precisely during the Milazzese phase, however, the Mycenaean pottery is widely distributed and an integral part of the local material culture in almost all structures. Apparently, the fact that these vessels were imported did not result in sumptuary restrictions to specific social groups. Even though Aegean vessels during this period may have been highly appreciated for their quality, they do not seem to have been part of social strategies.

In comparison with the previous periods, Mycenaean ceramic vessels were relatively scarce during the Ausonio I period. Other imports dating to this period are a glass bead and one made from amber,

52 Bernabò-Brea \& Cavalier 1980, 516.

s3 Taylour 1958, 51-52; Vagnetti 1989. See, however, Harding (1984, 87-103), who concludes that most beads of glass/faience in the central and western Mediterranean, as well as in trans-alpine Europe, are local or regional products.

54 Pulak 1988, 14; Vagnetti, pers. comm.

ss Bernabò-Brea \& Cavalier 1980, 516, Plate 158: no. 1.
56 For a discussion of the Lipari comb and later examples in the central Mediterranean, see Vagnetti 1986, 211. For the distribution of combs during the Bronze Age, see Tusa 1986, 134-136; Buchholz 1984-1985.

57 Bernabò-Brea \& Cavalier 1980, 516.

58 Bernabò-Brea \& Cavalier 1980, 171, 176, 179, 183, 187, 205.

59 Bernabò-Brea \& Cavalier 1980, 551. 


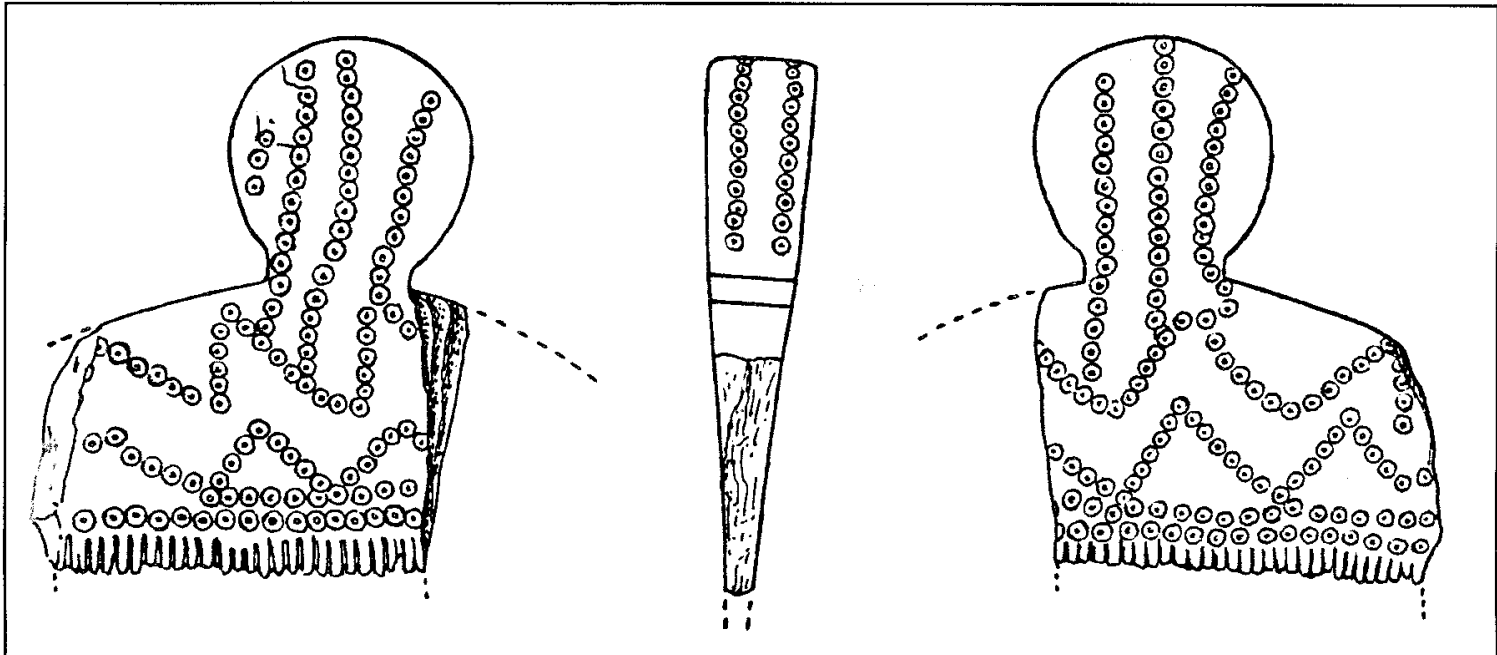

Fig. 15.7 Decorated bone comb from the Capo Graziano period - After Bernabò-Brea \& Cavalier 1980, Plate 153: no. g.

which were found in cremation urns on the acropolis. ${ }^{60}$ In comparison with earlier periods, metal objects were relatively abundant, among which were pins, fibulae and a dagger. ${ }^{61}$ The metal hoard discovered below hut a III, which comprised a large number of bronze weapons and tools and was initially assigned to Ausonio I, however, probably belongs to the earlier stages of Ausonio II. ${ }^{62}$ Among the impasto pottery, vessels imported from Sicilia, Sardinia and the Italian mainland have been attested. ${ }^{63}$ Within such a material environment, Mycenaean pottery is only one class of objects associated with maritime exchange. Sicilian and Sardinian pottery was found associated with the Mycenaean ceramics in the exceptional building $\beta$ IV. It seems, then, that the restricted distribution of the Mycenaean pottery during the Ausonio I period is related to its imported nature. Apparently, ceramic imports were socially significant and used in sumptuary strategies. The differences between the three periods at Lipari in the appreciation of Mycenaean ceramic vessels appear to be related to the degree to which maritime contacts were significant.

In various periods during the Neolithic and the Bronze Age, the Aeolian islands featured a local pottery industry ${ }^{64}$ With only a few exceptions, the impasto pottery found in Capo Graziano levels at the Lipari acropolis were produced locally. ${ }^{65}$ The kiln in cabin $\delta$ XII, in fact, is evidence for local pottery manufacture during this period. In addition, pits have been attested with thick layers of clay, which have been interpreted as containers associated with pottery production. ${ }^{66} \mathrm{In}$ addition to local production, there is evidence for regional circulation of pottery. A wreck dating to the first Capo Graziano phase was discovered in the bay of Lipari and containing a wide range of local ceramics. ${ }^{67}$ Also, Capo Graziano vessels, in particular pithoi, have been found at Tindari in Sicily. ${ }^{68}$ However, the impasto

60 Bernabò-Brea \& Cavalier 1980, 586.

6r Bernabò-Brea \& Cavalier 1980, 583-586.

62 Bernabò-Brea \& Cavalier 1980, 733-789; Moscetta 1988.

63 Bernabò-Brea 1979, 583; Bernabò-Brea \& Cavalier 1980, 566-568.
64 Williams 1980.

6s Bernabò-Brea \& Cavalier 1980, 517-518; Williams 1980. 863-866.

66 Bernabò-Brea 1976-1977, 37.

67 Bernabò-Brea 1978, 36-42; Ciabatti 1985.

68 Cavalier 1970. 
pottery from the Capo Graziano settlement on Filicudi (site no. 321) was produced on that island itself and shows substantial typological differences from that found on Lipari. ${ }^{69}$ This fact suggests that regional exchange of ceramics during the second Capo Graziano phase was of a limited scale. The small number of vessels produced in Sicily found at Lipari during Capo Graziano may be evidence of the same phenomenon.

During the Milazzese and Ausonio I periods, the ceramic repertoire of the Aeolian islands is much more homogeneous than in the preceding period. ${ }^{70}$ Moreover, the finest ceramics are made of local clay and covered with a slip originating in Sicily, which testifies to a regional transport of clay for pottery production. ${ }^{71}$ In comparison with the Capo Graziano period, regional pottery exchange seems to have been much more substantial during Milazzese and Ausonio I, as may also be deduced from the larger quantities of pottery imported from the Italian Mainland, Sicily and Sardinia. Notwithstanding the quality and variation of the local impasto, the imported, wheel-made and painted Mycenaean vessels stand out as distinctive, high-quality items. It is possible that it was supplemented to the pottery circulating in regional exchange networks.

Lipari is the largest of the Aeolian islands and the successive settlements discovered at the acropolis are generally larger than their counterparts on the other islands. ${ }^{72}$ In addition, the Lipari Castello has by far the most strategic position and it is the only location with a continuous settlement lasting from the beginning of the Neolithic until the Iron Age. It is tempting, then, to regard Lipari as a centre in successive systems of regional exchange. The Mycenaean pottery that has been found in smaller quantities on Filicudi (site no. 321), Salina (sites nos. 322, 323) and Panarea (site no. 324), would also appear to fit such a pattern. We need to realise, however, that all settlements on the islands are very small, comprising only a few hundred inhabitants at the most. ${ }^{73}$ In terms of the sophistication of architecture or the presence of imported goods and metals, there is little evidence for a social-political hierarchy, both within and among the settlements on the islands and the nearby coasts. ${ }^{74}$

At the site of Vetta della Montagnola on Filicudi (site no. 321), more than eighty Mycenaean finds have been made in levels dating to the Capo Graziano and Milazzese phases. ${ }^{75}$ Even though such an amount is smaller than that found at the acropolis at Lipari, it should be acknowledged that the latest Mycenaean imports at Filicudi have been assigned to LH IIIA1, while Lipari has produced pottery in later ceramic styles. If we compare the number of finds from Lipari in styles earlier than LH IIIA1, the difference with Filicudi is not substantial. ${ }^{76}$ The Mycenaean vessels on Filicudi were distributed rather homogeneously among the structures at the site. ${ }^{77}$ The repertoire of Mycenaean decorated vessels found on Filicudi compares well with that of Lipari. However, an important difference with the acropolis site on Lipari is the presence of substantial quantities of early matt-painted pottery and coarse ware. On this basis, it can be stated that the corpus of Mycenaean pottery on Filicudi is different from that that found at Lipari, especially during the earlier Capo Graziano period.

The excavations at Punta Milazzese on Panarea (site no. 324) have revealed some fifty huts, which

69 Bernabò-Brea \& Cavalier 1980, 518-519, 549.

70 Bernabò-Brea \& Cavalier 1980, 548-550, 563-565.

${ }^{71}$ Bernabò-Brea \& Cavalier 1980, 564; Williams 1980, 863-866.

72 Cavalier 1992-1993, 6; Malone, Stoddart \& Whitehouse 1994, 176-177.

73 Bernabò-Brea \& Cavalier 1980, 509-510.
74 Bietti Sestieri 1997, 475-477.

75 Taylour 1958, 13-16; Vagnetti 1991, 264-279.

${ }^{76}$ The Capo Graziano and Milazzese levels have yielded 198 Mycenaean finds, which have either been assigned a stylistical date before LH IIIA1-LH IIIA2 or remain undated.

77 Vagnetti 1991, 286-289. 
have all been dated to the Milazzese period. ${ }^{78}$ Some forty Mycenaean sherds have been found, dating from LH II to LH IIIB and which occurred in twenty huts, with a concentration in cabins X and XI. ${ }^{79}$ Disturbed levels of the Capo Graziano and Milazzese period were also found near Serro dei Cianfi (site no. 322) on Salina. ${ }^{80}$ The nearby site of Portella (site no. 323) on the same island, has been assigned to the Milazzese period exclusively and yielded only eight buildings. ${ }^{81}$ The few Mycenaean vessels, dating to LH IIB-LH IIIA, were found concentrated in cabin F, together with items from at least two necklaces containing beads of stone, glass and faience. ${ }^{82}$ It is clear that the three chronological periods differ in the extent to which Mycenaean pottery was distributed among the islands.

Given their geographical position, we can assume that maritime contacts have always constituted an important element in the societies of the Aeolian islands. Regional pottery exchange, however, appears to have been relatively limited during the Capo Graziano period and it is possible that the Mycenaean pottery arrived on Filicudi and Lipari independently. During this period at Lipari, Mycenaean pottery was widely used, but some groups among the inhabitants made more use of this material than others. In the Milazzese period, there appears to have been extensive regional pottery exchange and Mycenaean vessels were widely distributed as well. At Lipari during this period, Mycenaean pottery was widely used among the inhabitants of the village and it was not subject to sumptuary regulations. This may have been different, however, on Panarea and at Portella on Salina, where concentrations of this material have been noted. Finally, during the Ausonio I period, exchange between the islands was halted, due to the destructions of the villages on the minor ones. By this time, Mycenaean pottery had become scarce at Lipari and it was monopolised by specific social groups. There appears to have been a correlation between the intensity of regional maritime exchange and the social role of Aegean pottery. Such a correlation is an indication that Aegean contacts were of importance for the scale and scope of regional exchange. ${ }^{83}$ In addition, it can be stated that their association with maritime trade made the Aegean vessels at Lipari suitable to be part of social strategies during different periods.

78 Bernabò-Brea \& Cavalier 1968, 50-70.

79 Bernabò-Brea \& Cavalier 1968, 186-189. Structures X and XI also yielded higher quantities of local pottery, indicating that the concentration of Mycenaean pottery in these huts depended on an extensive use here of pottery in general.

8o Cavalier 1957, 9; Bernabò-Brea \& Cavalier 1968, 138-
143.

8I Cavalier 1957, 10; Bernabò-Brea \& Cavalier 1968, 144-148.

82 Bernabò-Brea \& Cavalier 1968, 166-167.

${ }_{33}$ See also, Bernabò-Brea 1976-1977, 40; Bernabò-Brea \& Cavalier 1980, 695; Bietti Sestieri 1997, 475. 



\section{Thapsos}

\section{N T R O D U C T I O N}

North of Syracuse, at the Ionian coast of Sicily, the peninsula of Magnisi, ancient Thapsos, is connected to the Sicilian mainland by a narrow strip of land (Fig. 16.1). Archaeological expeditions initially focused on the tombs near the lighthouse in the north, but settlement remains have been excavated as well, near the isthmus. ${ }^{1}$ The earliest traces of human activity on the peninsula date to the Early Bronze Age. All of the tombs and most of the settlement remains belong to the Middle Bronze Age, a period in which Thapsos is a Sicilian type site. ${ }^{2}$ A second settlement phase may be dated from the 12th to the 9th centuries BC. Even though tombs were reused in the Iron Age, the peninsula appears to have remained uninhabited. ${ }^{3}$

The settlement at Thapsos is located in the area where the narrow isthmus joins the peninsula (Fig. 16.1). ${ }^{4}$ The first settlement phase consisted of small round, oval and irregular huts, while the second phase produced at least two large buildings consisting of rectangular chambers. ${ }^{5}$ Necropoleis were situated outside the settlement. Most tombs have been found near the lighthouse along the northern and the north-eastern coasts, but smaller concentrations of tombs have been found in the centre of the peninsula and in the south. ${ }^{6}$ The majority of tombs consists of a chamber which is hewn out in the rock. Orsi estimated that some 300 of such tombs were present at Thapsos, of which more than 100 have been excavated. ${ }^{7}$ They were used for multiple burials; in two cases almost fifty skeletons were retrieved from one tomb. ${ }^{8}$ Apart from these rock-cut tombs, nine enchytrismoi have been found, for which large pithoi were used. ${ }^{9}$

I F.S. Cavallari explored several tombs during two campaigns in 1873 and 1879, see Cavallari 1880, 122. In 1894 Paolo Orsi excavated a large number of tombs, see Orsi 1895. Nine additional tombs were excavated in 1951, see Gentili 1953, 215-216. Another five tombs were investigated by L. Bernabò-Brea in 1962; in 1964 he investigated traces of the settlement, see Bernabò-Brea 1966, 113-114; 1970. The archaeological service conducted a series of excavations from 1968-1975, which were directed by Giuseppe Voza, see Voza 1972; 1973a; 1973b; 1985.

2 Voza 1973a, 136, 144; 1973b, 15.
3 Voza 1976-1977, 568; 1980-1981, 679.

4 Bernabò-Brea 1970, 142-144; Voza 1972, 177-178; Tusa 1983, 391-393

s Voza 1973a, 136-138, Tav. I.; 1984-1985, 666-668; Tusa 1983, 393-395.

6 Orsi 1895, 92-94; Voza 1972, Tav. 1; Tusa 1983, 395 396.

7 Orsi 1895, 94; Bernabò-Brea 1970, 140.

8 Tomb 10 and the tomb excavated in 1970 each contained forty-nine skeletons, see Orsi 1895, 105; Voza 1972, 195

9 Voza 1972, 200-204. 


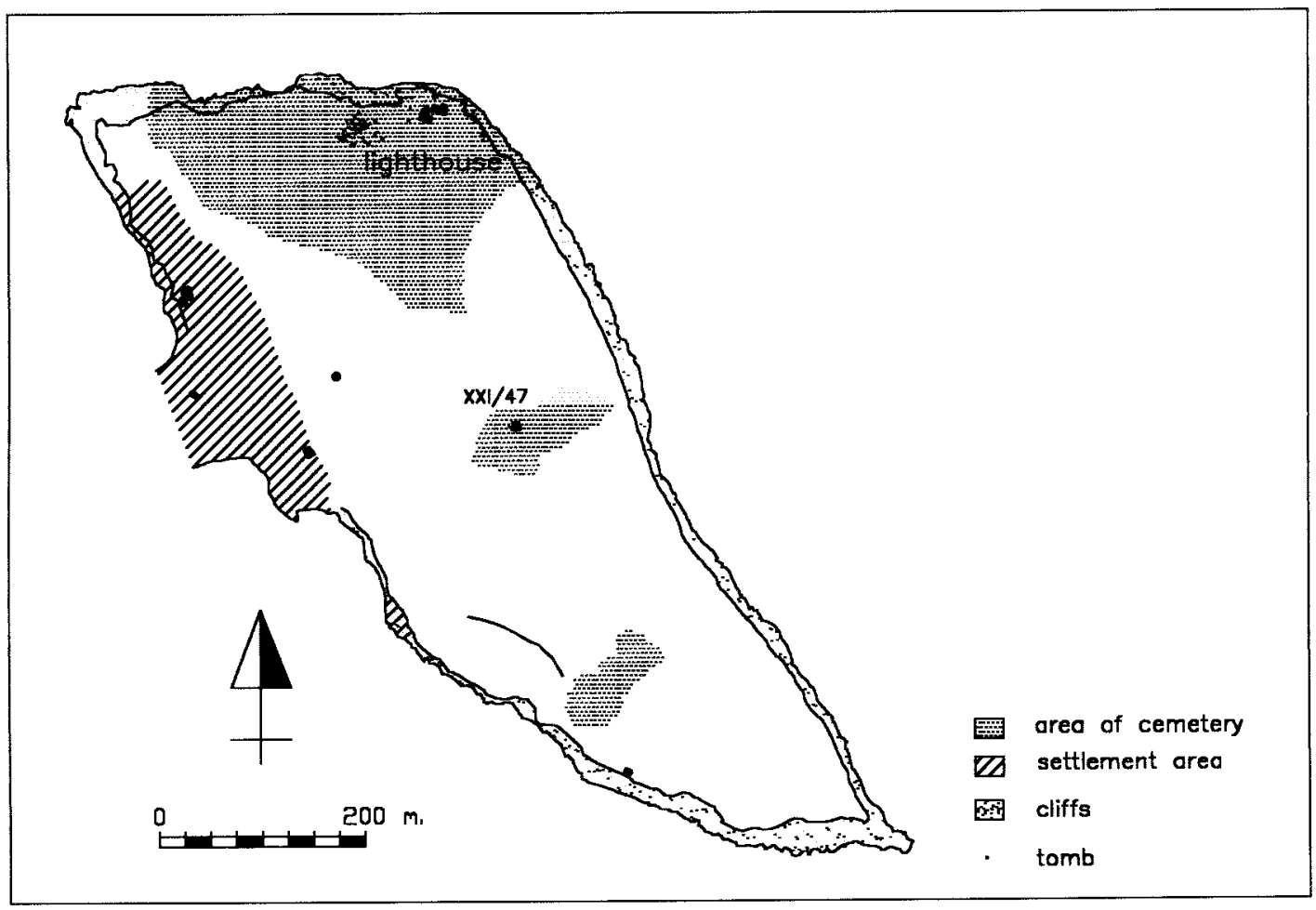

Fig. 16.1 Thapsos: Plan of the peninsula

\section{THE MYCENAEAN POT TERY}

The thirty-eight Mycenaean vessels and sherds in Catalogue IX derive from the tombs at Thapsos. In the settlement, Mycenaean pottery has also been found. ${ }^{10}$ However, these vessels or their contexts have not been published and they are excluded here. None of the material in Catalogue IX has been subject to scientific provenance research. Taylour noted that many of the decorative motifs on the Mycenaean pottery from Thapsos had their best parallels at Chalcis on Euboea in Greece. ${ }^{11}$ In his opinion, various other vessels were related to the 'Levanto-Helladic' class of pottery. It would seem, then, that most of the Mycenaean vessels from the tombs at Thapsos were indeed imported from Greece. Taylour ruled out a Rhodian origin, as had been suggested previously.

It is not certain that the thirty-seven vases in the catalogue are all the Mycenaean pots found at the necropolis. Of twenty-four of the sixty-six tombs excavated by Orsi no description is given. The nine tombs excavated in 1951 have never been published, although Taylour studied the Mycenaean material. ${ }^{12}$ The five tombs excavated in 1962, likewise, have never been published. The special attention paid by the excavators to Aegean pottery, as well as its distinctiveness from the impasto wares makes it highly unlikely that such sherds have been thrown away. However, the fact that all published Mycenaean items from Orsi's excavation appear to belong to almost complete vessels, argues for some caution. Also, many of the tombs were in a very bad state when excavations began: the dromo $i$ were open to the sea and water and sand could enter the funeral chambers. ${ }^{13}$ In addition, there was clear

Io Voza 1972, 205. According to Leighton (1999, 152) the Mycenaean pots from the Thapsos settlement are to be dated LH IIIA1-LH IIIC.
II Taylour 1958, 65-66.

12 Taylour 1958, 58: nos. 10 and 11.

I3 Orsi 1895, 94-96. 


\begin{tabular}{|c|c|c|}
\hline tomb & cat. no. & associated objects \\
\hline 1 & 1 & br.: ring, drill?; tc.: figurines; p.: loc., jars, basin, bowls \\
\hline 2 & $2,3,4$ & br.: daggers, fragments; p.: loc. basin \\
\hline 7 & 5,23 & p.: stemmed bowls, jars, flasks \\
\hline 10 & 6 & br.: fragm. of dagger, bracelets, wires; p.: flasks, basins, stemmed bowls, pictorial jug, jars \\
\hline 14 & 7 & br.: disk; p.: impasto \\
\hline 27 & 8 & p.: loc. basin, cup \\
\hline 28 & 9 & st.: axe \\
\hline 30 & 10,11 & p.: cup, globular jar, decorated lid \\
\hline 37 & 12 & br.: dagger, wire; p.: impasto \\
\hline 40 & 22 & \\
\hline 48 & 13 & iron: wire, br.: fragments; p.: loc. basins, jars, jugs, flask, bowl \\
\hline 51 & 14 & glass: pearl; p.: loc. basin, dishes \\
\hline 53 & 15 & p.: loc. basins, stand, bowls, dishes \\
\hline 56 & 21 & \\
\hline 61 & 16 & glass: beads; p.: jars, cup, bowl \\
\hline 63 & 17 & p.: impasto \\
\hline 64 & $18,19,20$ & p.: basins, jars, cup, stemmed bowl, amphora; Maltese cups \\
\hline $1951-1$ & 24 & \\
\hline $1951-2$ & 25 & \\
\hline $1951-3$ & 26 & \\
\hline $\mathrm{XXI} / 47$ & $30,31,32,33,34,35,36,37$ & gold: fragments; br.: sword; glass: beads; st; p.: loc. jars, jugs, pyxis, pictorial jar; p.: Cyp., Maltese \\
\hline A1 & 38 & p.: Cyp., loc. impasto cups, flasks, pictorial bowl/jar, jars; pithoi. \\
\hline
\end{tabular}

Table 16.1

evidence of looting from ancient time onwards, while limestone miners had substantially damaged the tombs as well.

\section{F U N E RARY C O N T EX T S}

In total, sixty-seven tombs from Thapsos have been published, including the nine enchytrismoi. ${ }^{14}$ Mycenaean pottery has been reported from twenty-two of these, as is indicated in Table 16.1 below. Such a figure could indicate that only a minority of the tombs contained Mycenaean pottery. However, the heavy disturbances in many of the funerary cellars, as well as the small number of Aegean vessels in most of the tombs, argues for caution in this respect. Little can be said about the spatial distribution of the tombs with Mycenaean pottery. Most tombs excavated by Orsi were situated in the large necropolis near the lighthouse in the north of the peninsula (Fig. 16.1). Although he also excavated some tombs in the south, we may assume that most of our tombs were located in the area near the lighthouse. ${ }^{15}$ Tomb A1 was also situated in this area. ${ }^{16}$ The tomb excavated in quadrant $\mathrm{XXI} / 47$, however, is situated in the necropolis at the centre of the island, while this was also the case

I4 The figure of sixty-seven includes forty-two tombs enchytrismoi. published by Orsi (1895), nine tombs from the 1951

is Orsi 1895, 94. campaign, five tombs from 1962, two tombs (XXI/47,

I6 Voza 1973b, 31. 


\begin{tabular}{|c|c|c|c|c|c|c|c|c|c|c|}
\hline tomb & amphora & stirrup jar & piriform jar & alabastron & jug & shallow cup & stemmed cup & deep bowl & fragment & total \\
\hline 1 & & & 1 & & & & & & & 1 \\
\hline 2 & & & 1 & 1 & 1 & & & & & 3 \\
\hline 7 & & & 1 & 1 & & & & & & 2 \\
\hline 10 & & & 1 & & & & & & & 1 \\
\hline 14 & & & 1 & & & & & & & 1 \\
\hline 27 & & & 1 & & & & & & & 1 \\
\hline 28 & & & 1 & & & & & & & 1 \\
\hline 30 & & & & & & & & & 2 & 2 \\
\hline 37 & & & & & 1 & & & & & 1 \\
\hline 40 & & & & 1 & & & & & & 1 \\
\hline 48 & & & 1 & & & & & & & 1 \\
\hline 51 & 1 & & & & & & & & & 1 \\
\hline 53 & & 1 & & & & & & & & 1 \\
\hline 56 & & 1 & & & & & & & & 1 \\
\hline 61 & & & 1 & & & & & & & 1 \\
\hline 63 & & & & & 1 & & & & & 1 \\
\hline 64 & & & 2 & 1 & & & & & & 3 \\
\hline $1951-1$ & & & 1 & & & & & & & 1 \\
\hline $1951-2$ & & & & 1 & & & & & & 1 \\
\hline $1951-3$ & & & & 1 & & & & & & 1 \\
\hline$X X I / 47$ & & & 3 & 3 & & 1 & 1 & 1 & & 9 \\
\hline A1 & & & 1 & & & & & & & 1 \\
\hline \multicolumn{3}{|c|}{ tombs 1962} & & & & & & & 2 & 2 \\
\hline Total & 1 & 2 & 16 & 9 & 3 & 1 & 1 & 1 & 4 & 38 \\
\hline
\end{tabular}

Table 16.2

for the tombs excavated by Bernabò-Brea in 1962. ${ }^{17}$ It appears that Mycenaean pottery was not concentrated in a specific spatial group of tombs.

The descriptions of the tombs given by Orsi, in some cases, are very short. Nevertheless, it is clear that Mycenaean pottery has been found in tombs with a dromos,${ }^{18}$ as well as with a so-called chimney entrance. ${ }^{19}$ Moreover, tombs with only one funeral chamber, as well as those with a vestibule have yielded Mycenaean material. ${ }^{20}$ Finally, the tombs with Mycenaean pottery vary in the number of niches attached to the funerary chamber; ${ }^{21}$ the same can be said for the size of the cellar and the elaborateness of its entrance. ${ }^{22}$ Among the tombs without Mycenaean pottery, the same characteristics can also be found. Our vessels, therefore, do not seem to be limited to a specific type of tomb. ${ }^{23}$ We may state that Mycenaean pottery, even though very limited in a quantitative sense, was relatively widely distributed in the necropolis of Thapsos.

17 Voza 1972, 195; Tusa 1983, 395.

I8 For example, tombs 1, 2, 28, 37, 48, 61.

19 For example tombs, 51, 53 and XXI/47.

20 Tombs 1 and XXI/47 possessed a vestibule, see Orsi 1895, 95-98; Voza 1972, 195.

${ }^{21}$ Tomb XXI/47 possessed two niches, while tomb 48 possessed five of them. For all the other tombs with
Mycenaean finds no niches have been described.

22 Whereas most of our tombs had a rather small funerary chamber, tomb 10 was particularly large. Tomb 28 possessed a monumental entrance consisting of posts cut out of the rock, see Orsi 1895, 113-116.

23 The enchytrismoi did not contain any goods, see Voza 1973, 200 
Such a wide distribution is also apparent when we look at the quantities of Mycenaean pottery in each of the Thapsos tombs (Table 16.1). The large majority of tombs have yielded only one Mycenaean find, whereas only four tombs have produced two or three of our vessels. One funerary cellar constitutes an exception to this rule: tomb XXI/47 produced nine Mycenaean finds, which is three times the maximum of any other tomb. Tomb XXI/47 has been excavated recently and it may be that the more thorough methodology used by Voza in comparison with that of Orsi seventy-five years earlier is partly responsible for this large quantity of finds. ${ }^{24}$ Moreover, this tomb is situated at the centre of the island and had not been subject to the heavy erosion by the sea. Nevertheless, it would seem that there is a relative concentration of Mycenaean pottery in this tomb.

Table 16.2 shows the vessel types which occur in the funerary cellars at Thapsos. The only types which occur in substantial quantities in the tombs are piriform jars and alabastra. Together, these two classes of storage vessels constitute more than half of the total number of Mycenaean pots at the site. A limited range of other vessel types are also present, none of which occurs more than a few times in the tombs. Stylistically, these vessels range from LH IIIA1 to LH IIIA2-LH IIIB. ${ }^{25}$ There do not seem to be any concentrations of vessels from specific stylistical periods, which is in agreement with the idea that these tombs have been used for substantial periods of time.

The distribution of the Mycenaean vessel types is rather uniform. Many tombs have produced one, in some cases two, piriform jars, while the alabastra, likewise, are generally found in isolated, single examples. Neither of these vessel types appear to be concentrated in one tomb, although it is clear that tomb XXI/47 has produced more of these Mycenaean types than any other tomb. All other vessel types occur as single, isolated examples in a number of tombs. It is remarkable, however, that all three open dinner vessels - a shallow cup (cat. no. 35), a stemmed cup (cat. no. 36) and a deep bowl (cat. no. 37) - have been found in tomb XXI/47. ${ }^{26}$ It appears that this tomb did not just possess a larger quantity of Mycenaean pots of vessel types which also occur in other tombs; it produced a wider variety of Mycenaean pots as well.

Given the natural and man-caused destructions, it is difficult to classify the Thapsos tombs according to the wealth of their inventories and architecture. Orsi has indicated the number of burials for each tomb, mainly based on the presence of human skulls, which varied from one to forty-nine. Most tombs, however, produced less than twenty-five skeletons and the two that yielded forty-nine burials, tombs 10 and XXI/47, are exceptional. Both of these tombs have produced a wide variety of grave goods, such as bronze jewelry and local pictorial pottery in the case of tomb $10,{ }^{27}$ and gold, a bronze sword and glass beads in the case of tomb XXI/47. ${ }^{28}$ Both tombs also contained Mycenaean pottery.

24 This tomb was excavated in 1970, see Voza 1973b, 34: tomba D.

25 A small piriform jar (cat. no. 7) and a squat alabastron (cat. no. 25) can be assigned a LH IIIA1 date. Two small piriform jars (cat. nos. 1, 18) are classified as $\mathrm{LH}$ IIIA1-LH IIIA2. Eight piriform jars (cat. nos. 6, 8, 13, 19, 24, 33, 34, 38), two jugs (cat. nos. 12, 17), one straight-sided alabastron (cat. no. 29), one shallow cup (cat. no. 35) have a LH IIIA2 date. Five straight-sided alabastra (cat. no. 2, 5, 20, 26, 30), four piriform jars (cat. nos. 3, 9, 16, 32), a globular jug (cat. no. 4), a stirrup jar (cat. 15), a stemmed cup (cat. 36) and a deep bowl (cat. no. 37) have been assigned to LH IIIA2-LH IIIB. The remaining eight finds (cat. nos. 10, 11, 14, 21-23, 27, 28) have not been assigned a stylistical date.

26 Closed dinner vessels, e.g. jugs, have been found in single specimens in three tombs (cat. nos. 4, 12, 17), which is in accordance with the pattern for the storage vessels.

27 A local impasto jar has incised figures of animals, see Orsi 1895, 104, Tav. IV 14.

28 Voza 1973b, 34-40. 


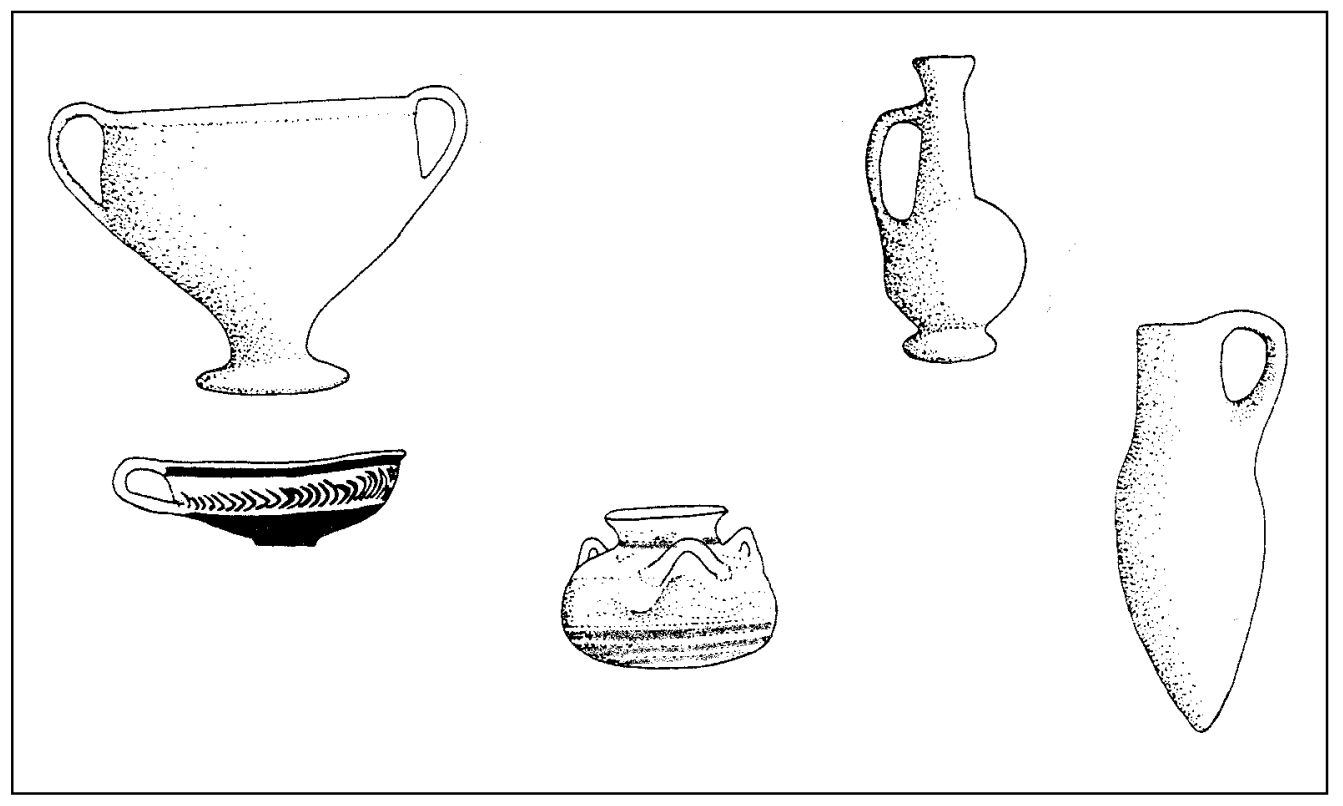

Fig. 16.2 Mycenaean and Cypriot vessels from Thapsos tomb XXI/47 (cat nos. 31, 35, 36) - After Leighton 1999, 171 fig. 90: nos. 2, 4, 5. 7, 8

These tombs indicate that the wealth of the funerary inventory is, at least to some degree, dependent on the sheer quantity of burials.

The presence of a dromos in front of a tomb cannot be considered an architectural feature indicative of status or wealth, since it seems to have been determined mainly by the location of the tombs. ${ }^{29}$ The presence of a vestibule in front of the actual burial chamber is rare, however, and may be indicative of a certain elaborateness of the funerary ritual. ${ }^{30}$ The same can be said of a number of niches in the main funeral chamber ${ }^{31}$ and of a certain monumentality in the tomb entrances through carved posts and lintels. ${ }^{32}$ Two tombs are described by Orsi as "exceptionally large". ${ }^{33}$ On these grounds, twelve tombs may be considered to be of elaborate architecture, which, in terms of effort expenditure, could indicate a special status for the group associated to these tombs. ${ }^{34}$ Of these twelve tombs, a minority of five (tombs 1, 10, 28, 48 and XXI/47) produced Mycenaean pottery. With the exception of XXI/47, each of these tombs yielded only a single specimen of such pottery. In terms of the presence of Mycenaean pottery, therefore, these tombs do not distinguish themselves from the others.

As far as the funerary inventories are concerned, there are a few classes of artifacts which may be considered special because of their scarcity in the tombs, in particular gold, bronze jewellery and weaponry, as well as glass beads (Table 16.1). Among the thirteen tombs possessing such special objects, eight (tombs 1, 2, 10, 14, 37, 51, 61 and XXI/47) also produced Mycenaean pottery. Most of these eight funerary cellars produced only one Mycenaean vessel; tomb 2, however, possessed three

29 Orsi 1895, 92-94; Tusa 1983, 395. Of course, the location of the tombs itself may be of importance for the symbolism of the burials. Chronology possibly plays a role in the location of the tombs as well.

30 Such a vestibule is present only at tombs $1,6,25,31$, and XXI/47, see Orsi 1895, Voza 1972, 195.
${ }^{1}$ Such niches have been reported for tombs 25, 31, 33, 38, 48 and XXI/47, see Orsi 1895, Voza 1972, 195.

32 Tombs 23, 28 and 62 possess such a monumental entrance, Orsi 1895, 11-114, 134.

33 Tombs 10 and 25, see Orsi 1895, 104-105, 112.

34 Brown 1981, 29. 
imported pots and tomb XXI/47, of course, produced nine such specimens. In terms of the presence of Mycenaean pottery, however, the tombs with rare objects in their funerary inventories do not stand out from others.

A few classes of ceramic objects in the Thapsos tombs may be considered to have possessed a high symbolical significance. This may have been the case for the elaborately decorated stemmed basins, which appear to have served a special role in funerary ceremonies since they have been found in most of the tombs at the site..$^{35}$ Local pottery decorated with incised representations of animals occurred in only a limited number of tombs, ${ }^{36}$ of which the majority (tombs 10, A1 and XXI/47) yielded Mycenaean pottery as well. Only two tombs possessed pottery imported from Cyprus (Fig. 16.2), ${ }^{37}$ both of which also yielded Mycenaean pottery. In a few tombs, cups have been found which have their best parallels at Borg en-Nadur on Malta; a concentration of such vessels was found in tomb 64, in which three Mycenaean pots were also found. ${ }^{38}$ Even though it must be acknowledged that Mycenaean pottery is more abundant in the Thapsos tombs than Maltese or Cypriot vessels, it appears that these imported classes are associated with each other. In this respect it may be of importance that three of the four tombs with glass objects, which possibly were imported as well, ${ }^{39}$ also contained Mycenaean pots. ${ }^{40}$ It appears that the imported nature of the Mycenaean pots was of significance in their inclusion in the tombs at Thapsos.

On the basis of its architecture, as well as because of its inventory comprising metal, glass and imports, tomb XXI/47 can be considered the wealthiest by far. Even though, as stated above, this may be due to the number of burials in this funerary cellar, tomb 10, with an equal number of burials, cannot be considered nearly as wealthy. The fact that a relatively large quantity of Mycenaean pottery has been found in tomb XXI/47 indicates, firstly, that this material was considered suitable to be associated with a wealthy inventory. Secondly, in comparison with the scatter of Mycenaean pots in the other tombs, it suggests that Mycenaean vessels through variations in quantity and variety could actively be involved in strategies of display. The fact that Mycenaean open dinner vessels were concentrated in this tomb indicates that such vessels possessed a special significance in the funerary practices of Thapsos.

\section{THE ROLE OF MYCENAEAN POTTERY IN THE MATERIAL CULTURE}

\section{OF THAPSO S}

Mycenaean, Cypriot and Maltese imported pottery form only a small part of the ceramic record in the tombs at Thapsos. Maltese cups have been found in relative abundance in the settlement contemporary with the necropolis. ${ }^{41}$ The same cannot be said for Myceanean - or Cypriot - pottery, which appears to have been scarce among the settlement finds. ${ }^{42}$ This could indicate that Mycenaean pottery

35 Orsi 1895.

36 Tombs nos. 10, 38, A1, XXI/47.

37 Tomb XXI/47 produced two Base Ring II ware vessels and one White Shaved ware jug. In tomb A1 another White Shaved ware jug was discovered, see Voza 1973b, 36, 40: nos. 85-87, 118.

38 Bernabò-Brea 1958, 133.

39 Taylour 1958, 51-52; Vagnetti 1989. Harding (1984,
87-103), however, considers them local or regional products.

40 Glass beads have been found in tombs 29, 51, 61 and 2147; of these, tomb 29 did not produce any Mycenaean pottery.

4I Voza 1973a, 147-149.

42 See the reply by G. Voza to a question in: Voza 1972, 205. 
served predominantly for funerary purposes at Thapsos. However, the scarcity of Mycenaean finds at Thapsos could also have a chronological cause, ${ }^{43}$ and it seems best to be cautious in this respect until the publication of the settlement. For now it seems clear that Mycenaean pottery could serve in strategies of funerary display. As concluded above, the imported nature of Mycenaean vessels appears to have been important for their social significance.

Thapsos is the type site of Late Bronze Age culture of south-eastern Sicily, which is mainly known from tombs. ${ }^{44}$ A number of necropoleis have been discovered in the area of Syracuse. At Syracuse (site no. 330) itself, a group of tombs has been discovered of which one contained a LH IIIA2 straightsided alabastron and a Cypriot Base Ring jug. ${ }^{45}$ At Molinello (site no. 326), a LH IIIA2 piriform jar was found in a tomb which was part of a group of six tombs in the southern part of the site. ${ }^{46}$ At Matrensa (site no. 329), some forty tombs were excavated, all dated by Orsi to the Bronze Age. ${ }^{47}$ Only one tomb, accidentally discovered in 1871, produced two Mycenaean piriform jars. ${ }^{48}$ At Cozzo del Pantano (site no. 331), likewise, a substantial necropolis of at least thirty-six tombs has been excavated. ${ }^{49}$ Only one Mycenaean vessel was discovered in tomb VII: a LH IIIA2 kylix. ${ }^{50}$ At Floridia (site no. 328), two tombs have been discovered close to one another, one of which yielded a LH IIIA2-LH IIIB straight-sided alabastron. ${ }^{51}$ The LH IIIB stirrup jar from Maiorana (site no. 332) was also found in a tomb, but nothing is known about its location. ${ }^{52}$

In the area of Syracuse, then, many necropoleis from this period have produced some Mycenaean vessels. The actual quantity of this type of pottery is very low, but, at the same, time, it must be acknowledged that the cemeteries are much smaller than the one at Thapsos. Nevertheless, it is fair to say that Thapsos yielded a relatively high proportion of ceramic vessels imported from the Aegean. In terms of Mycenaean vessel types, the repertoire of pots found in the cemeteries in the area is comparable to the corpus in Thapsos. The Mycenaean kylix found at Cozzo del Pantano, however, may be considered remarkable since such vessels have been shown to be very rare at the type site and restricted to the group of people associated with tomb XXI/47.

Thapsos, with its large proto-urban settlement, its extensive necropolis and its coastal location, probably constituted the centre in a regional system of exchange. ${ }^{53}$ The fact that Mycenaean pottery comparing well to that of Thapsos has been found in necropoleis in the interior shows that such ceramics were not restricted to the coastal centre, but circulated, to a limited extent, in regional exchange networks. Even though wealth appears to have been concentrated at Thapsos, the Mycenaean vessels in the hinterland suggest that there was a system that linked the coastal proto-urban inhabitants to groups in the interior through the limited distribution of wealth (wealth finance). The role of imported Mycenaean pottery in the relationships between the communities in the interior and on the coast is testimony of the symbolic value embodied by these objects deriving from maritime trade. It is likely that it was exactly this symbolism which made these vessels suitable to be employed in strategies of funerary display.

43 Vagnetti pers. comm.

44 On the Thapsos culture, see Tusa 1983, 399-425 (with bibliography).

45 Vagnetti \& Lo Schiavo 1989, 237 note 1.

46 Orsi 1902, 413-421; Taylour 1958, 60-61; Tusa 1983, 482-485.

47 Orsi 1899, 26-42; Tusa 1983, 490-491.
$4^{8}$ Taylour 1958, 62.

49 Orsi 1893, 1-36.

so Taylour 1958, 61-62.

sI Orsi 1909, 374-378.

s2 Taylour 1958, 64.

53 Tusa 1983, 504-505. 


\section{Broglio di Trebisacce}

\section{N T R O D U C T I O N}

Broglio di Trebisacce is situated $1 \mathrm{~km}$ from the coast on a high terrace in the foothills of the Pollino massif at the northern end of the plain of Sybaris. The site is one of more than twenty pre- and protohistoric sites in the hills surrounding the, suggesting that the area was substantially populated from the Middle Bronze Age onwards. ${ }^{1}$ Excavations at Broglio began in 1979 and are still continuing. ${ }^{2}$ Even though some Neolithic finds have been made, settlement at the site appears to have begun in the Middle Bronze Age and continued into the Early Iron Age. ${ }^{3}$

The site of Broglio di Trebisacce coveres the whole terrace. ${ }^{4}$ Five restricted areas have been excavated up to 1985 (fig 17.1). The Areas A and C, were heavily damaged by erosion and ploughing, and the virgin soil appeared directly below the top soil. ${ }^{5}$ In Area E, five post holes have been interpreted as the remains of a Middle Bronze Age hut. ${ }^{6}$ In the south-eastern part of trench B, a ditch has been discovered with eight post holes and field stones. Together with post holes in the vicinity they may have belonged to a Middle Bronze Age structure, but no pavement or surface has been recognised. In the same area, pits and post holes dating to the Late Bronze Age may represent two or three successive structures. A sequence of terraces has been discovered in trench $\mathrm{D}$, the earliest of which can be dated to the Middle Bronze Age. A short section of a wall as well as pavement dating to an advanced stage of the Middle Bronze Age have been discovered in the eastern and southern parts of the trench.? These possible structures may have been the predecessors of a Late Bronze Age structure, of which a ditch with six post holes has been attested. ${ }^{8}$ This building was superseded by a structure which was cut into the slope and which has been labeled the 'central habitation building', or complesso a monte. ${ }^{9}$ This building, which is only partly preserved, had a plan in the shape of a horse-shoe (Fig. 17.2). The few, fragmentary remains of other structures identified at the site all belong to later periods.

Peroni \& Vagnetti 1982; Buffa \& Peroni 1982; Belardelli et al. 1994

2 The excavations are conducted by the Cattedra di protostoria Europea of the University of Rome ' $\mathrm{La}$ Sapienza', in collaboration with the Centro studi di Protostoria and headed by Renato Peroni. The campaigns until 1985 have been fully published, see Bergonzi \& Cardarelli 1982b; Peroni 1982b; Peroni 1984; Peroni \& Trucco 1994. See, also, the other articles in the same volumes. Since 1990 excavations have resumed at Broglio, again headed by Peroni; these have only been published in preliminary fashion, see Peroni \& Vanzetti 1993; 1998.
3 Peroni 1982a, 1-2; Peroni 1994. For absolute dates, see Malone, Stoddart \& Whitehouse 1994, 170; Peroni 1998.

4 Peroni 1982a, 2-3. Remains of a Bronze Age tomb were discovered on a hill directly to the south of the site; see Bergonzi \& Cardarelli 1982a, 37; Peroni 1994, 839; Peroni \& Trucco 1994a, 39, tav. 26.14.

5 Bergonzi \& Cardarelli 1982b, 42.

6 Trucco 1994, 85-89.

7 Peroni \& Trucco 1994, 52, 53-58.

8 Peroni \& Trucco 1994, 65.

9 Peroni 1982b, 15-21; 1984, 26-27; Barbieri, Peroni \& Trucco 1984, 15-21; Trucco 1994, 95-97. 


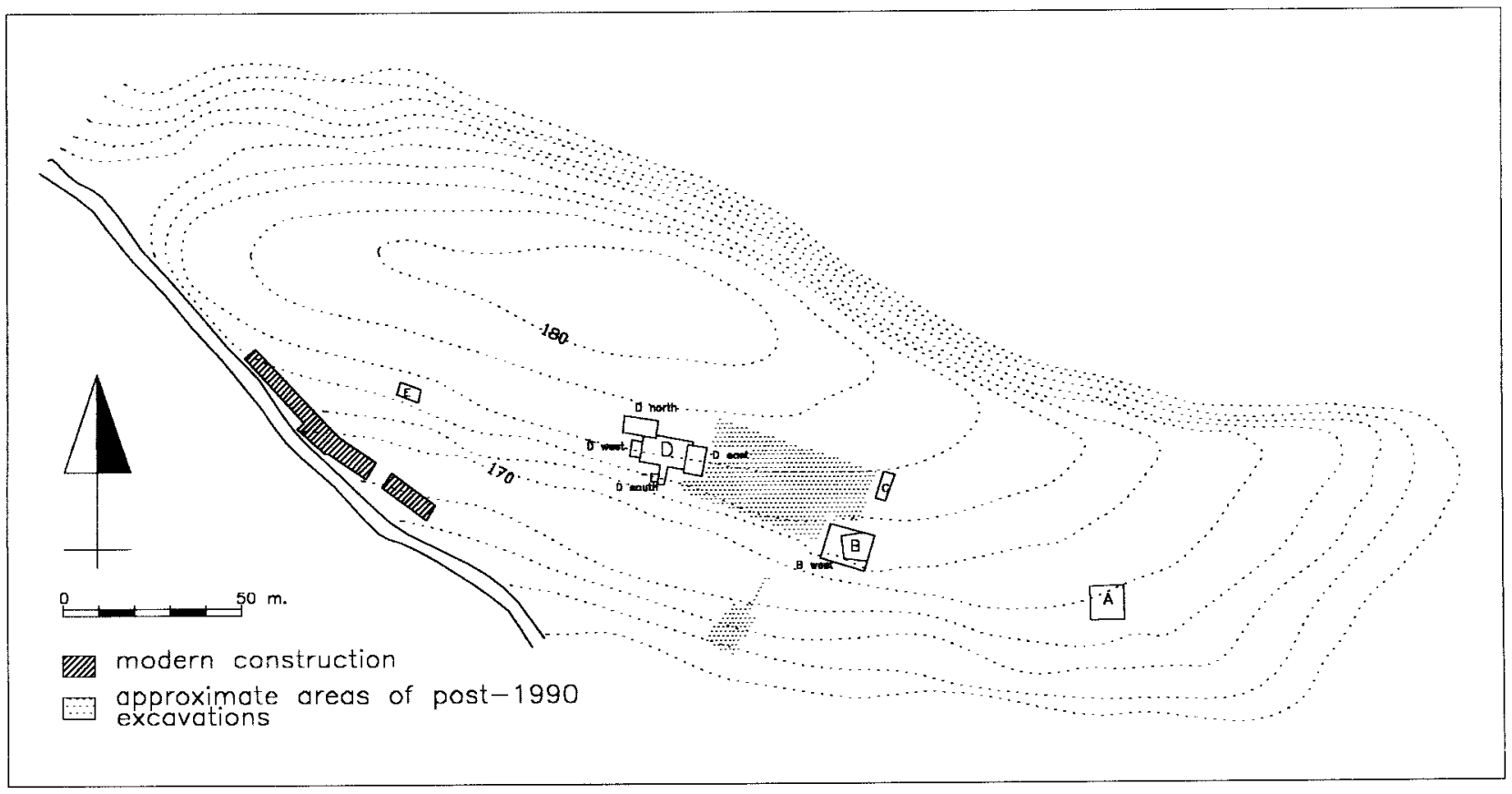

Fig. 17.1 Broglio di Trebisacce: site plan

It has been estimated that the population of Broglio during the Bronze Age consisted of some 1100 individuals. ${ }^{10}$ Quite probably, this population was internally stratified from the Middle Bronze Age onwards. ${ }^{11}$ The material culture at Broglio di Trebisacce during the Middle Bronze Age is very similar to that of sites in the Taranto region. ${ }^{12}$ The remains of the Late Bronze age conform to the homogeneity of the sub-Appennine culture. ${ }^{13}$ From the Middle Bronze Age onwards, the ceramic record at Broglio reveals strong influences of Aegean pottery techniques. ${ }^{14}$ A substantial part of the Aegeantype pottery is locally made (see below; in addition there exist a class of wheel-made grey ware, often decorated with Aegean motifs, and wheel-refined dolia. Both classes differ radically in technique from the hand-made impasto. Such an extensive Aegean influence on the local ceramic industry has been explained by the transference of Aegean craftsmen to southern Italy. ${ }^{15}$

\section{THE MYCENAEAN POTTERY}

The Aegean type pottery found at Broglio di Trebisacce is presented in Catalogue X, which contains a total of 352 entries. ${ }^{16}$ The catalogue has been subdivided into two parts: the first part (cat. nos. 1-12)

Io Vallino 1984, 315; Peroni 1994b, 835-838.

II Vallino 1984; Tagliacozzo 1994; Peroni 1994b, 845846.

I2 Peroni 1994b, 838-839.

I3 Malone, Stoddart \& Whitehouse 1994, 176-178.

I4 Vagnetti 1999, 142-149 (with further refs).

is Peroni 1983, 258; Jones \& Vagnetti 1991, 140-141; 1992.
16 This figure differs somewhat from that given by Vagnetti \& Panichelli (1994, 399), who state that somewhat less than 350 Mycenaean finds from Broglio have been published. The difference is caused by the inclusion in my catalogue of a few finds which were not drawn, but referred to in the publications (cat. nos. $1215,1230-1234,1238,1240,1242,1266,1275$, 1340). 
contains the twelve finds which are considered to be imports. The clay of most of these finds (cat. nos. $6,7,10,11,12)$ has chemical compositions indicating that they were produced on the Peloponnese. ${ }^{17}$ Three finds (cat. nos. 2, 8, 9) derived either from central Greece (Boeotia, Locris), or from Crete; production on the Greek mainland seems most likely on stylistical grounds. Two Mycenaean finds (cat. nos. 3, 5) revealed compositions distinct from those of the Sybaris region, although the area of their production has as yet not been determined and may even be in Italy. Two other finds (cat. nos. 1, 4) are suspected to be imports on visual grounds only. The second part of the catalogue (cat. nos. 1001-1340) presents all Aegean type finds of local manufacture. They reveal stylistical influences from the Greek mainland, but in particular from Crete. ${ }^{18}$

It is certain that these 352 sherds do not represent all Mycenaean pottery which has been found at Broglio; in total a number of 647 Aegean-type sherds have been found during the 1979-1985 excavations; the remaining unpublished finds were all very small and undiagnostic. ${ }^{19}$ In addition, Mycenaean finds from excavations since 1990 have not been included in the catalogue. According to the excavators, however, relatively few Mycenaean finds have been made so far, all very small and most of them thought to date to LH IIIC. ${ }^{20}$ It may safely be assumed that the catalogue constitutes a representative range of Mycenaean vessels found at Broglio di Trebisacce. However, the fragmentary nature of many of the Aegean-type finds has prevented a stylistical classification, which leads to a degree of uncertainty in the on-site distribution patterns.

\section{THE ON-SITE DISTRIBUTION OF THE AEGEAN-TYPE POTTERY}

Aegean-type pottery has not been reported from areas A, C and E, all of which had been subject to heavy erosion. The figures in Table 17.1 show that the spatial distribution of Aegean imports and local products of Aegean type is similar, with a concentration in areas D and D west. ${ }^{21}$ This concentration can to a large extent be ascribed to the successive levels (1 A, 1 A' and 1B) which can be associated with the complesso a monte. This building produced a total of 101 Aegean-type finds, among which were three imports. ${ }^{22}$ Moreover, thirty six Aegean-type finds derived from the contemporary layers in area $\mathrm{D}$ west, which was situated at a short distance from the building. ${ }^{23}$ This concentration of Aegean-type ceramics has been an important argument in assigning a special function to the complesso a monte. ${ }^{24}$

It should be acknowledged that few other structures have been discovered at Broglio. Even though Aegean-type sherds have been found in levels dating to the Middle Bronze Age, none of our sherds

${ }^{17}$ Jones 1986b, 205-214; Vagnetti \& Jones 1988, 337347; Jones \& Vagnetti 1991, 131-132; 1992; Jones et al. 1994; Vagnetti \& Panichelli 1994, 399.

I8 Vagnetti \& Panichelli 1994, 407.

I9 Vagnetti \& Panichelli 1994, 412; Vagnetti pers. comm.

20 S. Levi \& M. Betelli pers. comm.

2I See, also, Vagnetti \& Panichelli 1994, 412-413.

22 Level 1A produced fifty-one Mycenaean finds, among which is one imported jar (cat. no. 3). Level 1A' yielded seven Aegean finds of local imitation, while level from level 1B forty-two Mycenaean finds have been reported, among which are two imported fragments (cat. nos. 4 and 5). One fragment (cat. no. 1277) was found between $1 \mathrm{~A}$ and $1 \mathrm{~B}$.

23 Level 2B and level 3 each produced twenty two Mycenaean finds all of local manufacture. At the surface of level 3 inf, fourteen Aegean-type finds were made, among which are three imported LH IIIB amphorae (cat. nos. 9-11)

24 Peroni 1982a, 3. 


\begin{tabular}{lcc}
\hline area & imports & local produce \\
\hline B & 2 & 15 \\
B west & 1 & 26 \\
D & 3 & 187 \\
D east & 2 & 46 \\
D south & & 1 \\
D west & 4 & 65 \\
\hline Total & & 340 \\
\hline
\end{tabular}

Table 17.1

can be associated with the MBA structures attested in areas E, B-B west and D west, ${ }^{25}$ all of which were very damaged. To the scanty remains of a possible structure discovered in $\mathrm{D}$ west and $\mathrm{D}$ east, which are assigned to the beginning of the Late Bronze Age, a total of thirty-eight Aegean-type finds have been attributed, among which are four imports (cat. nos. 9-12). To the pits and post holes dating to Late Bronze Age levels in area B-B west six Aegean-type sherds can be related, all of local manufacture. Two Mycenaean sherds, one of which is a fragment of a LH IIIB2-LH IIIC cup (cat. no. 6), may be associated with two post holes in a level dated to the Final Bronze Age in area B-B west. ${ }^{26}$

The only structure contemporary to the complesso a monte, then - the Late Bronze Age features in B-B west - has yielded few Mycenaean finds. In fact, the only other structure which has produced substantial quantities of Aegean-type pottery are the remains from the beginning of the Late Bronze Age in $\mathrm{D}$-east and $\mathrm{D}$ west. These remains predate the complesso a monte, and the relative abundance of Mycenaean finds may indicate that a predecessor of the central habitation building was situated in the same area.

Substantial amounts of Mycenaean pottery have also been found in area B. Rather, the concentration of Mycenaean finds in area D indicates that the people associated with the complesso a monte made more extensive use of Mycenaean pottery than inhabitants of other parts of the site. There does not seem to be a difference in the spatial distribution of imported Mycenaean vessels and those of local manufacture. Even though the number of imports is too small to be certain, Table 17.1 suggests the same pattern for both classes: a wide distribution, with a concentration in areas D and D west. This indicates that these classes of pottery were used by the same groups among the inhabitants of Broglio.

Only a small part of the Aegean-type sherds found at Broglio can be classified stylistically. ${ }^{27}$ At least twenty of the Aegean-type vessels which are locally produced reveal Minoan influences, ${ }^{28}$ but none of the imports can be assigned a definite Cretan origin. Only one locally produced LM IIIB fragment (cat. no. 1217) has been found in area B. All the other 'Minoan' finds derive from areas D and D west.

25 Trucco 1994, 85-86 (area E, below level 3B), 86-89 (area B-B west, levels 4 inf/4A), 91-93 (area D east, level 2F).

26 Peroni \& Trucco 1994, 29: level 1A. A piece of amber was found in the same level, see Buffa 1994b, 572, Tav. 120.1.

27 Vagnetti \& Panichelli $(1994,411)$ state that only fiftyfive Aegean type sherds can be assigned with certainty to a specific Helladic or Minoan ceramic class. Following the stylistic dates suggested by them in in the various reports, many of which have a certain measure of uncertainty, I arrive at 119 finds, which can be given a stylistic date.

28 Catalogue nos. 1019, 1025, 1033, 1049, 1081, 1105, $1106,1146,1152,1153,1154,1156,1164,1167$, 1217, 1251, 1267, 1294, 1295, 1297. 


\begin{tabular}{|c|c|c|c|c|c|c|c|c|c|c|c|c|c|}
\hline \multirow[b]{2}{*}{ date } & \multicolumn{2}{|l|}{ B } & \multicolumn{2}{|c|}{ B west } & \multicolumn{2}{|l|}{ D } & \multicolumn{2}{|c|}{ D east } & \multicolumn{2}{|c|}{ D south } & \multicolumn{2}{|c|}{ D west } & \multirow[t]{2}{*}{ Total } \\
\hline & imported & local & imported & local & imported & local & imported & local & imported & local & imported & local & \\
\hline undatable & & 10 & & 19 & 1 & 136 & & 34 & & 1 & & 34 & 235 \\
\hline LH IIIA1-LH IIIA2 & 1 & & & & & & & & & & & & 1 \\
\hline LH/LM IIIA & & 1 & & 1 & 1 & & & 1 & & & & 1 & 5 \\
\hline LH IIIA2 & & & & & & 1 & & & & & & & 1 \\
\hline LH/LM IIIA2-IIIB & 1 & & & & & 1 & & & & & & 1 & 3 \\
\hline LH/LM IIIB & & & & 2 & & 21 & & 3 & & & 4 & 3 & 33 \\
\hline LH IIIB-LH IIIC & & 4 & 1 & 4 & 1 & 16 & 1 & 8 & & & & 16 & 51 \\
\hline LH IIIC & & & & & & 12 & 1 & & & & & 10 & 23 \\
\hline
\end{tabular}

Table 17.2

Fragments originating on the Greek mainland or with strong Helladic influences seem to have been more homogeneously distributed. ${ }^{29}$ The distinction between Minoan and Helladic is problematic for vessels which have been locally produced and, in any case, many fragments cannot be ascribed to either of these classes. However, it appears that Minoan-type pottery was more or less restricted to the central habitation building in area D. ${ }^{30}$

The earliest Aegean type vessel can be dated to LH IIIA1-LH IIIA2 (Table 17.2). An imported jar (cat. no. 2), which was probably produced in central Greece, ${ }^{31}$ can be assigned to this early phase. The fact that the earliest vessel has a Greek provenance indicates that Aegean-type pottery was imported before it was manufactured locally. A locally made mug (cat. no. 1278) and three fragments (cat. nos. $1005,1204,1251)$ that have been assigned a LH/LM IIIA date, however, show that local production began not long after the first imports arrived. Imports with a secure LH IIIA2 date are lacking, even though the fragment decorated with a wavy line (FM 53) (cat. no. 5) may belong to this style. Only one local product in LH IIIA2 style has been found (cat. no. 1135) and it is clear that the LH IIIA style is generally at Broglio. It is evident from Table 17.2 that both imports and local production of Aegean-type pottery at Broglio increased sharply from the LH IIIB period onwards and continued well into LH IIIC. The fact that this chronological pattern is the same for imports and locally produced vessels indicates that these two classes were complementary. This means that, for Broglio di Trebisacce, the local produce did not replace the imports.

As is clear from Table 17.3, the earliest levels in which Aegean type pottery has been found date

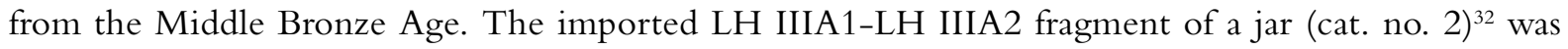
found in area B at a level dating to an advanced stage of the Late Bronze Age. ${ }^{33}$ In the MBA level a locally made cup or bowl (cat. no. 1011) was discovered, proving stratigraphically that local production

29 Vagnetti \& Panichelli (1994, 411) assign a Helladic style to twenty-four finds. Six of these are found in area $\mathrm{B}$, while $\mathrm{D}$ east and $\mathrm{D}$ west have produced five and eight finds respectively.

30 Eleven 'Minoan' finds (cat. nos. 1019, 1025, 1033, 1049, 1146, 1152-1154, 1156, 1164, 1167) have been recovered directly associated with this building. Four Minoan-style finds (cat. nos. 1267, 1294, 1295, 1297) were made in contemporary levels in the adjoining trenches $\mathrm{D}$ east and $\mathrm{D}$ west.

3I Vagnetti \& Panichelli 1994, 398-399.

32 Vagnetti \& Panichelli $(1994,399)$ tentatively suggest that the fragment may have belonged to a small handleless jar (FS 77), in which case it should be dated no later than LH IIIA1.

33 Bergonzi \& Cardarelli 1982b, 47-49. 


\begin{tabular}{|c|c|c|c|c|c|c|c|c|c|c|}
\hline date & unstratified & MBA & MBA late & LBA early & LBA & LBA late & FBA early & FBA & FBA late & EIA \\
\hline undatable & 122 & 2 & 2 & 3 & 87 & 10 & 3 & 1 & 3 & 2 \\
\hline LH IIIA1-LH IIIA2 & 1 & & 1 & & & & & & & \\
\hline LH/LM IIIA & & & 1 & & 1 & 1 & & & & \\
\hline LH IIIA2 & 1 & & & & 1 & & & & & \\
\hline LH/LM IIIA2-IIIB & 1 & & & & 2 & & & & & \\
\hline LH/LM IIIB & 12 & & & 1 & 19 & 1 & & & & \\
\hline LH/LM IIIB-IIIC & 22 & & & & 24 & 3 & & 1 & & 1 \\
\hline LH IIIC & 6 & & & & 14 & 3 & & & & \\
\hline Total & 165 & 2 & 4 & 4 & 148 & 18 & 3 & 2 & 3 & 3 \\
\hline
\end{tabular}

Table 17.3

\begin{tabular}{|c|c|c|c|c|c|c|c|c|c|c|c|c|c|}
\hline \multirow[b]{2}{*}{ date } & \multicolumn{2}{|l|}{ B } & \multicolumn{2}{|c|}{ B west } & \multicolumn{2}{|l|}{ D } & \multicolumn{2}{|c|}{ D east } & \multicolumn{2}{|c|}{ D south } & \multicolumn{2}{|c|}{ D west } & \multirow[t]{2}{*}{ Total } \\
\hline & imported & local & imported & local & imported & local & imported & local & imported & local & imported & local & \\
\hline fragments & 7 & & 23 & 2 & 135 & 2 & 33 & & 1 & & 39 & 4 & 238 \\
\hline amphora & 2 & & & & 21 & & 2 & & & 3 & 12 & 3 & 37 \\
\hline collar-necked jar & 1 & & 1 & & 2 & & 3 & & & & 3 & & 10 \\
\hline alabastron & 1 & & & & & & & & & & & & 1 \\
\hline stirrup jar & 1 & & & & 3 & & & & & 1 & 1 & 1 & 5 \\
\hline jar & 1 & & & 1 & 2 & & 1 & & & & 1 & 2 & 4 \\
\hline jug & & & 1 & & 1 & & & & & & & & 2 \\
\hline amphoroid krater & & & & & & & & & & & 1 & & 1 \\
\hline krater or bowl & & & & & 1 & & & & & & & & 1 \\
\hline conical cup & & & & & & & & & & & 1 & & 1 \\
\hline carinated cup & & & & & 3 & & 1 & & & & & & 4 \\
\hline shallow cup & & & & & 1 & & & & & & & & 1 \\
\hline cup & & & & & 3 & & 3 & & & & & & 6 \\
\hline kylix & & & & & & & & & & & 1 & & 1 \\
\hline mug & & & & & 3 & & & & & & 1 & & 4 \\
\hline bowl or cup & 1 & 1 & & & 3 & & & & & & & 1 & 4 \\
\hline deep bowl & 3 & & & & 8 & & 3 & & & & 5 & & 19 \\
\hline bowl & & & 1 & & 1 & & & & & & & & 2 \\
\hline
\end{tabular}

Table 17.4

of Aegean-type pottery at Broglio di Trebisacce had already begun at an early stage. The other finds in Middle Bronze Age contexts (cat. nos. 1012, 1204, 1236 and 1237) testify to the same practice.

The fragmentary nature of many of the Aegean-type finds, as well as the fact that ceramic styles of vessels produced in Italy may not always reflect Aegean styles directly, argue for some caution in applying a chronology to this pottery. ${ }^{34}$ Yet, the stylistical chronology appears to follow the stratigraphy at Broglio quite consistently, with LH IIIB finds concentrated in the Late Bronze Age and LH IIIC, which begins during the LBA, continuing into the Final Bronze Age. The LH IIIA fragment decorated with a wavy line (cat. no. 5), which has been found in the complesso a monte, may be evidence of use for a substantial period of time. However, its small size argues for caution in this respect. The rela-

34 Vagnetti \& Panichelli 1994, 408. 


\begin{tabular}{|c|c|c|c|c|c|}
\hline site area & unknown & coarse ware & plain & linear & patterned \\
\hline B & & & 2 & 13 & 2 \\
\hline B west & & & 1 & 14 & 12 \\
\hline D & 3 & 6 & 7 & 121 & 53 \\
\hline D east & 3 & & 5 & 21 & 19 \\
\hline D south & & & & 1 & \\
\hline D west & 3 & 1 & 3 & 32 & 30 \\
\hline Total & 9 & 7 & 18 & 202 & 116 \\
\hline
\end{tabular}

Table 17.5

tive scarcity of clear LH IIIB finds in contexts dating to the later phase of the Late Bronze Age or the Final Bronze Age suggests that such pottery was not used for a long period of time.

The small size of the Aegean-type sherds at Broglio does not allow the majority of finds to be assigned to specific vessel types. Moreover, in several of the 110 cases where a pot shape has been suggested, the classification should be considered tentative. Nevertheless, it is clear from Table 17.4 that only a limited ceramic repertoire has been discovered at Broglio, with slightly more storage than dinner vessels. ${ }^{35}$ Imported Mycenaean vessels are mostly of storage type with the exception of one cup or bowl (cat. no. 6). This is different for the locally made repertoire, among which there is a substantial proportion of dinner vessels. This suggests that the range of production by the local manufacturers was not determined by the Aegean pottery arriving at Broglio, but by a wider repertoire. This, in my opinion, reinforces the hypothesis that itinerant craftsmen were to some degree responsible for the production of Aegean-type pottery at Broglio.

A second observation to be made on the basis of Table 17.4 is that Aegean type storage vessels appear to be more widely distributed than dinner vessels. Twenty four Aegean-type dinner vessels have been found in area $\mathrm{D}$, of which eighteen can directly be associated with the complesso a monte. In addition, nine Mycenaean finds were discovered in levels contemporary to this complex in area $\mathrm{D}$ west. Even though the large number of fragments argues for caution, it appears that Aegean-type dinner vessels were concentrated in the central habitation building, implying that the inhabitants associated to this structure made more extensive use of this ceramic class than other groups in the town.

The fragmentary nature of many of the Mycenaean finds casts doubts on the classification of decorational types and different kinds of ware, which is presented in Table 17.5. Many of the small plain sherds or those with linear decoration may have belonged to vessels that were more elaborately decorated and the apparent predominance of linear decoration is probably emphasised by these conditions. It is clear that only a few coarse ware vessels have been found, one of which is an imported stirrup jar (cat. no. 12). All other Aegean-type coarse ware finds are fragments of locally made closed vessel types, possibly including jars meant for transportation. ${ }^{36}$ Five of these (cat. nos. 1027, 1037-140) have

35 In the cases of many fragments, it was possible to indicate whether they derived from closed or open pot shapes. In total, a number of 223 closed shapes have been discovered, against 78 open vessels. Even though we must allow for closed dinner vessels (i.e. jugs), the predominance of storage pottery may have been even more marked.

${ }^{36}$ Cat. nos. 1018, 1027, 1037-1040 


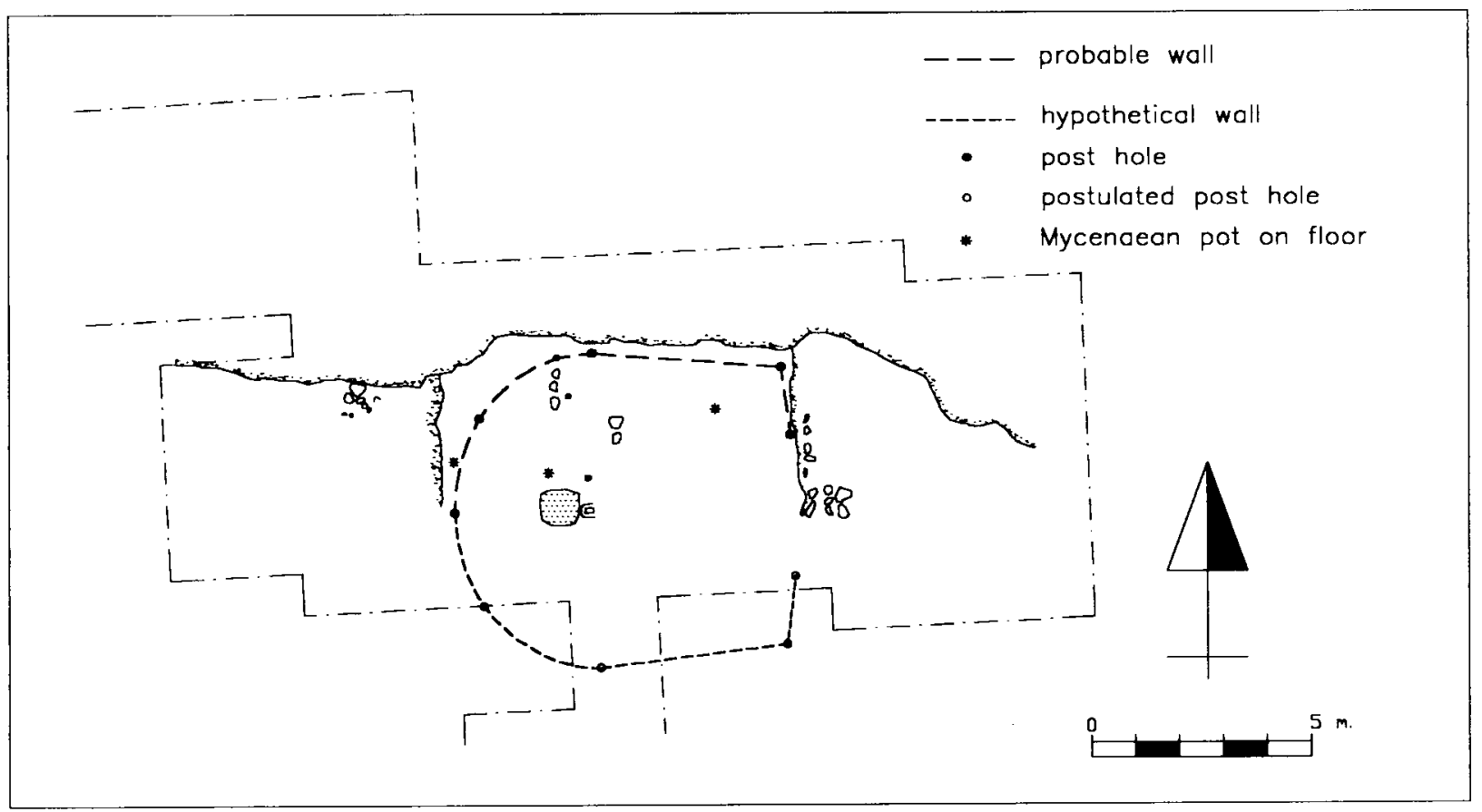

Fig 17.2 Broglio di Trebisacce: Mycenaean pottery in the complesso a monte

been found in the complesso a monte, while another (cat. no. 1018) came from the topsoil above this structure. The imported stirrup jar derived from an LBA surface in area D west, close to the central building. It seems, therefore, that such coarse ware vessels were restricted to this structure.

Among the imported pottery, seven finds (cat. nos. 1, 3-8) have a patterned decoration, while a fragment of a jar is decorated with a line only. Considering the high number of linear decorated sherds among the pottery of local manufacture, it would seem as if the imported vessels were generally more elaborately decorated than the Mycenaean-type pottery made at Broglio. ${ }^{37}$ In any case, the spatial distribution of linear sherds and those decorated with geometric and floral motifs as indicated in Table 17.5 shows that the use of Aegean-type pottery was not restricted on the basis of its decoration.

\section{SET TLEMENT CONTEXTS}

The structures at Broglio di Trebisacce in the Middle and Late Bronze Ages are characterised by posts at a relative large distance from one another, sometimes set in a ditch, while stones are used for reinforcements only. ${ }^{38}$ Mycenaean pottery has been found in association with only three of the total of seven architectural structures that have been identified at the site. Thirty-eight Aegean-type finds are

37 Vagnetti \& Panichelli (1994, 405-406) suggest the possibility that the decoration of the sherds with cat. no. 1285 constitutes a bird (FM 7). If so, this sherd would constitute the only pictorial specimen found at Broglio. However, the strange loop on the larger frag- ment, as well as the occurrence of a type of net pattern on vessels from the same vase, make it highly unlikely that it is a bird motif; J.H. Crouwel, pers. comm.

$3^{8}$ Trucco 1994, 99-100. 
associated with a structure of which traces have been discovered in areas D east and D west. ${ }^{39}$ The remains of this structure, however, are too scanty for further analysis.

Area B-B west: Late Bronze Age structure (levels $2 A-2 B)^{40}$

At level $2 \mathrm{~B}$ in trench $\mathrm{B}$ west, a few stretches of battered earth were uncovered. Six post holes uncovered in the same level indicate the presence of an architectural structure in this area. In the adjacent trench $\mathrm{B}$, three post holes have been found in level 2, as well as an occupation surface at the same level in the eastern part of the trench. Even though it is not entirely certain whether the remains from trenches $\mathrm{B}$ and $\mathrm{B}$ west belong to the same building phase, the reconstruction shows a large rectangular building. Level 2B is associated with this structure, while level $2 \mathrm{~A}$, in which three post holes were attested, either belongs to the same building or to a slightly later phase. Both strata have been dated to the Late Bronze Age.

Eight Aegean-type finds may be associated with this building. Three fragments from level 2B (cat. nos. 1213-1215) are decorated with lines only, but a fragment with patterned decoration found between 2A and 2B has been assigned to a LH IIIB2-LH IIIC collar-necked jar (cat. no. 1216). Level 2A yielded one linear fragment (cat. no. 1218) and one (cat. no. 1217) with patterned decoration which has been classified as LM IIIB. Level 2B west in trench B also produced a linear fragment (cat. no. 1010), as well as an imported LH IIIA2-LH IIIB fragment from a straight-sided alabastron (cat. no. 1), the only one of its kind found at Broglio. Level 2B also yielded bowls, cups, jars and cooking pots in local impasto, as well as carinated cups and bowls in wheel-made grey ware and some fragments from rounded dolia. ${ }^{41}$ Pounders and pestles and a piece of engraved bone were also found.

It is of interest to note that the two Mycenaean vessels of which the type can be identified are closed pot shapes, while in other ceramic classes there is a high proportion of dinner vessels. It should also be noted that an original import and a fragment of local manufacture with Minoan affiliations were present in this house. It is at this stage uncertain whether these pots and the object of worked bone should be considered luxury objects.

Area D: complesso a monte (levels $1 A-1 B)$ (Fig. 17.2) ${ }^{42}$

This building was situated directly above the steep descent of the southern slope and, in fact, only the northern half has been recovered, the southern part having been washed down the hill. Six post holes and several lines of field stones have been identified. The reconstruction shows a horse shoe-shaped building (Fig. 17.2). The floor of the building, consisting of battered earth, was in the west substantially higher than in the east and a wooden floor may have been used to make up for the difference. On the floor, two large stones and the remains of two small ovens were found. In the northernmost corner a series of stones was laid, below which a possible foundation offering was found: an impasto bowl with an engraved swastika and one of the handles removed. Above the floor, two strata were excavated. Layer 1B, which was situated directly above the floor, is to be associated with the period of use of the building, while layer $1 \mathrm{~A}$ probably constitutes a fill dating to the period after the abandonment of the building, but joints connect it to layer 1B.43

39 Trucco 1994, 93-95.

40 Bergonzi \& Cardarelli 1982a; Peroni 1984, 17; Peroni \& Trucco 1994, 32-36; Trucco 1994, 97-99.

4I Bergonzi \& Cardarelli 1982b, 47; 1984, 151; Capofieri \& Giardino 1984a, 58; Belardelli 1994, 270; Giardino 1994a, 185-195; Tenaglia 1994, 347.
42 Peroni 1982b, 15-21; 1984b, 19-27; Barbieri, Peroni \& Trucco 1984, 15-28. For the reconstruction of the complex, see Barbieri, Peroni \& Trucco 1984, 33-36; Trucco 1994, 95-97.

43 Peroni 1982b, 21; 1984, 19. 


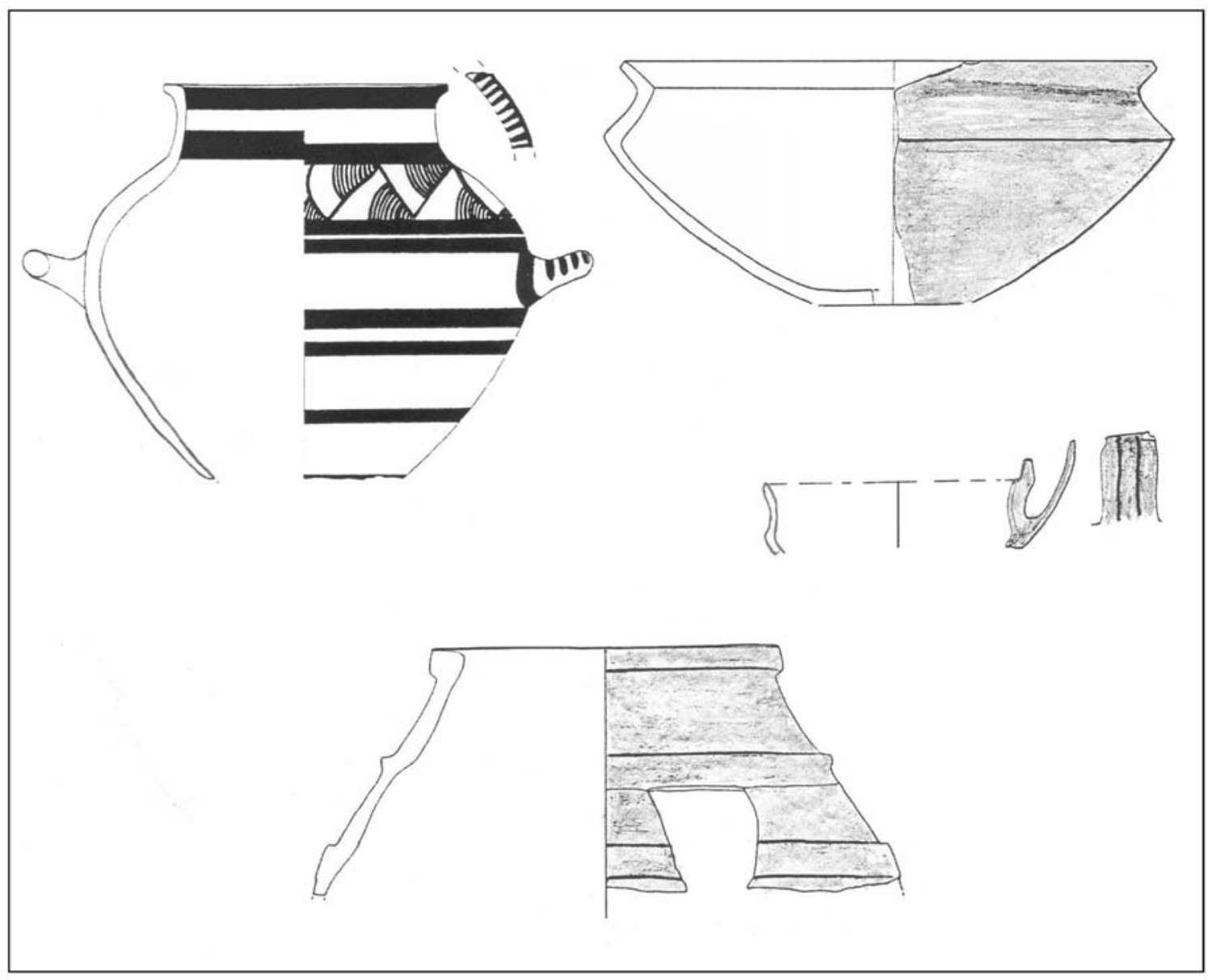

Fig. 17.3 Ceramic objects from the floor of the complesso a monte: Aegean-type amphora (cat. no. 1146), impasto and grey ware carinated cups, dolium - After Vagnetti 1984b, 172 Plate 46: no. 3; Capofieri \& Giardino 1984b, 67 Plate 2: no. 6; Belardelli 1984, 136 Plate 29: no. 12; Buffa1984a, 165 Plate 41: no. 4.

On the floor of the building three Aegean-type vessels have been found (Fig. 17.3). A small fragment of a LH IIIC deep bowl (cat. no. 1145) decorated with a wavy line was recovered at the western end of the pavement. Part of an LM IIIB-style amphora (cat. no. 1146) decorated with linked whorl shells was found in the area of the little ovens, while several fragments of the same vase were also found in levels $1 \mathrm{~B}$ and $1 \mathrm{~A}$. The same levels contained fragments of a similar vase (cat. no. 1049) decorated with isolated semicircles and paneled patterns found in the north-eastern part. These vessels were associated with three carinated cups and a jar in local impasto, as well as with a carinated cup in grey ware and three dolium fragments. ${ }^{44}$

In level 1B a small fragment of an imported open vessel (cat. no. 4) decorated with a possible spiral was found, as well as a fragment of an imported closed pot (cat. no. 5). ${ }^{45} \mathrm{~A}$ number of amphorae (cat. nos. 1019, 1033, 1152-1156, 1164) were also discovered, most of which with Minoan affiliations. In addition, level 1B contained another LH IIIC deep bowl (cat. no. 1151), along with some cups and bowls of uncertain shape dated to LH IIIB-LH IIIC (cat. nos. 1029, 1030, 1148, 1163). The level also

44 Capofieri \& Giardino 1984b, 68; Belardelli 1984, 137; Buffa 1984a, 161

45 The chemical composition of the clay of this vessel in- dicates that it may have been produced in Italy, but not in the region of Broglio; see Vagnetti \& Panichelli 1994, 399 
produced a full range of open and closed shapes in local impasto, as well as a variety of carinated cups, bowls and jars in wheel-made grey ware and eleven dolia fragments. ${ }^{46}$

Level 1A was particularly rich in ceramic finds. ${ }^{47}$ Apart from a full range of vessels in local impasto, grey ware, and dolia, fifty-nine Mycenaean-type finds were made, among which is a small fragment of an imported jar (cat. no. 3) with linear decoration. Locally made carinated cups (cat. nos. 1023, 1061, 1166) in LH IIIB style, as well as LH IIIB mugs (cat. nos. 1169-1182), a LH IIIB-LH IIIC deep bowl (cat. no. 1168) and a possible LH IIIC krater or bowl (cat. no. 1070) were also found. Among storage vessels, amphorae (cat. nos. 1025, 1026, 1167, 1173, 1183, 1184) in LM IIIB-LM IIIC style were most numerous, although two similar fragments $(1054,1072)$ showed Helladic affiliations. The level also produced a small fragment of a possible coarse ware stirrup jar (cat. no. 1021). All the bronzes associated with the complesso a monte - a ring, a fragment of a vase, a violin fibula and a fragment of a pendant - came from level $1 \mathrm{~A}$ as well. ${ }^{48}$

The direct association of Aegean-type pottery with various classes of local material show that it was an integral part of the material culture in this building. It may be noted that Aegean-type storage and dinner vessels are both well represented. This corresponds to the repertoirs of types in local impasto and grey ware. There are no indications that the two imports associated with this building were regarded differently from locally made Aegean type pottery.

\section{ThE ROLE OF MYCENAEAN POT TERY IN THE MATERIAL CULTUR OF B R O G L I O D I T R E B I S A C C E}

Apart from a small piece of amber discovered in levels dating to the Final Bronze Age, ${ }^{49}$ the twelve Aegean pots are the only clearly identifiable imports which have been discovered at Broglio di Trebisacce. The few bronzes from the site may also have been imported from elsewhere, but they have their best parallels on the Italian mainland and do not seem to derive from international maritime exchange..$^{50}$ Mycenaean pottery, which consists of well-levigated clay and is wheel-made, is of an entirely different technical tradition than the local hand-made impasto. ${ }^{51}$ It may be argued that Aegean pots possessed a special significance within such a material environment, probably based on its association with a far-away, international world. Indeed, the observed concentration of Aegean-type finds in the complesso a monte seems to confirm such a high regard for this class of material.

This being said, a number of observations have been made in this chapter which shed light on the use and appreciation of Mycenaean-type pottery at the site in more detail. Firstly, the spatial distribution, as well as the contextual associations of Aegean imports and Aegean type vessels of local manu-

46 Giardino 1982, 50; Bergonzi \& Cardarelli 1982c, 8687, 96; Capofieri \& Giardino 1984a, 58; 1984b, 68-74; Buffa 1984a, 161; Belardelli 1984, 137-139.

47 Giardino 1982, 50-54; Bergonzi \& Cardarelli 1982c, 85-86, 96; 1984, 137-141, 153-155; Belardelli 1984, 139-145; Buffa 1984a, 161-162; Capofieri \& Giardino 1984a, 60-74; 1984b, 74-92.

48 Capofieri \& Giardino 1984a, 28; Buffa 1984b, 197198; 1994b.
49 Peroni \& Trucco 1994, 29; Buffa 1994a, 503; 1994b, 572, Tav. 120.1

so Buffa 1994b.

sI Bergonzi 1985, 361-368; Vagnetti 1999. The wheelmade grey wares, in many cases decorated with Aegean motifs and encompassing vessel types familiar to the Aegean and to the local repertoires, may be considered as a class of material which developed locally under Aegean influence. 
facture proved to be similar, which suggests that these two classes were appreciated in the same way. This possibly signifies that a notion of originality and a high regard for it did not exist during the Bronze Age at Broglio. ${ }^{52}$ It is also possible that the distinctive technique of Aegean-type pottery alone was sufficient to invoke prestige. ${ }^{53}$ The fact that a difference in origin appears to have been irrelevant for the appreciation of Aegean-type pottery, however, may also be taken as evidence that Aegean craftsmen were involved in the local production of this type of material at Broglio.

A second important observation is that the use of Mycenaean dinner vessels in particular was concentrated at the complesso a monte. The fact that a similar observation cannot be made for local impasto or grey ware indicates, firstly, that Mycenaean-type pottery was indeed perceived as a distinctive category of material by the inhabitants at Broglio. Secondly, it shows that the restricted distribution of Mycenaean dinner vessels should be related to a high regard for such vases and was not due to a specific functional differentiation to do with activities associated with the buildings. All this suggests that Mycenaean-type pottery was a culturally relevant class of material at Broglio and could actively be involved in strategies of consumption.

The site of Broglio di Trebisacce has been interpreted as constituting an autonomous socio-political unit in the Sibaritide area during the Middle and Late Bronze Ages. ${ }^{54}$ Among the more than twenty pre- and proto-historic sites in the region, ${ }^{55}$ only at Torre del Mordillo (site no. 319) have substantial quantities of Mycenaean pottery also been found. ${ }^{56}$ From the site of Timpone della Motta near Francavilla Marittima (site no. 318) one fragment of a Mycenaean stirrup jar has been reported, which, to date, remains the only find of its kind at this site, even though the recent excavations have exposed Middle and Late Bronze Age features and levels. ${ }^{57}$ It appears, then, that the circulation of Aegean-type pottery was restricted, which is in contrast with the evidence for a considerable regional exchange of dolia and impasto vessels. ${ }^{58}$ This indicates that Aegean-type pottery remained confined to a few centres, such as Broglio di Trebisacce, which were probably in direct contact with the Aegean world. In these centres, Mycenaean decorated vessels served specifically as a means of expression for élite groups, although they were used by various social groups.

52 It may seriously be questioned whether the distinction between 'original' and 'imitation' has any relevance in pre-modern situations, see van Wijngaarden 1999b, 34, note 107.

53 See, for example, Hugh-Jones 1992, 59

54 Peroni 1994b, 834-853.
55 Peroni \& Vagnetti 1982; Buffa \& Peroni 1982; Belardelli et al. 1994.

56 Arancio et al. (1995, 227-239); Vagnetti pers. comm.

57 Lattanzi \& Vagnetti 1983-1984; Kleibrink \& Attema, pers. comm.

s8 Levi et al. 1998, 437. 


\section{The cultural significance of Mycenaean pottery in Italy}

\section{N T R O D U C T I O N}

The distribution of Mycenaean pottery in Italy has been subdivided by Lucia Vagnetti into three broad chronological periods: LH I-LH II, LH IIIA-LH IIIB and LH IIIB-LH IIIC. ${ }^{1}$ Even though all three sites which have been discussed in the preceeding chapters cover more than one of these periods, the Mycenaean pottery at each of them is concentrated in specific periods. Most of the Mycenaean pottery at Lipari belongs to the early period (LH I-LH IIIA1); at Thapsos most Aegean vessels can be assigned a LH IIIA2-LH IIIB date, while Broglio yielded predominantly Mycenaean material from LH IIIB and later. The differences and similarities between these sites, therefore, may be the result of chronological developments. They may also be caused by the different nature of the archaeological remains at these three sites.

\section{MYCENAEAN REPERTOIRE}

The large quantities of Mycenaean pottery at Lipari and Broglio are paralleled only at a few other sites in the central Mediterranean. More than 340 Mycenaean sherds have been published from the island of Vivara (site no. 342), ${ }^{2}$ while the excavations at Scoglio del Tonno in Taranto (site no. 314) produced more than 150 Mycenaean finds. ${ }^{3}$ In Nuraghe Antigori (site no. 348), where Bronze Age levels have been reached in a limited number of rooms, more than forty Mycenaean finds were made, but over 100 Mycenaean sherds were found in a dump of clandestine excavators. ${ }^{4}$ Two trenches of limited extent at Termitito (site no. 316) yielded more than forty Mycenaean sherds. ${ }^{5}$ The latest Mycenaean find on Vivara dates to LH IIIA1 and the sites on this island should be grouped with Lipari in

Vagnetti 1982a, 18-19; 1993, 145-147; 1999. The separations between the phases ought not to be taken too strict. On the basis of the local manufacture of LH IIIB pottery, the second phase has been subdivided into an earlier stage covering LH IIIA and a later stage contemporary with LH IIIB, which should be discussed together with the LH IIIB-LH IIIC phase. The earliest of Vagnetti's phases may possibly be subdivided into earlier and later stages as well, see Marazzi 1994, 3032.

Panichelli \& Re 1994; Re 1994. This figure concerns the finds from excavations until 1982 only. The excavations have been resumed since 1994 and yearly campaigns have been conducted; additional Myceanean pottery has been found, see Marazzi 1993a; 1995; 1999.

3 Taylour (1958, 81-137) published 152 Mycenaean finds from the excavations at Scoglio del Tonno by Quagliati in 1899; see also Fisher 1988. For additional Mycenaean finds in Taranto, see Gorgoglione 1996.

4 Ferrarese-Ceruti 1979; 1986, 183-192; FerrareseCeruti \& Assorgia 1982.

5 De Siena \& Bianco 1982, 77-83; De Siena 1986, 4348. 
Vagnetti's first phase of the import of Mycenaean pottery in Italy. ${ }^{6}$ Scoglio del Tonno, instead, has produced substantial amounts of Aegean pottery in LH IIIA style and later, and this site belongs to Vagnetti's second and third phases. As in Broglio di Trebisacce, most Mycenaean finds at Termitito and Nuraghe Antigori are in LH IIIB and LH IIIC style, and these sites belong to the third period. Obviously, in each chronological phase of the Mycenaean contacts with Italy, only very few sites imported large quantities of this material.

In contrast to Lipari and Broglio, the repertoire of Aegean-type pottery from the Thapsos tombs does not include classes such as matt-painted Aegean pottery, coarse ware, local imitations and wheelmade grey ware. A large concentration of matt-painted Aegean pottery has been found at Vivara (site no. 342), ${ }^{7}$ while nine finds of such pottery have been reported from Filicudi (site no. 321). ${ }^{8}$ Smaller quantities of similar pottery have been found in Apulia at Grotta Manaccora (site no. 297), ${ }^{9}$ Giovinazzo (site no. 301), ${ }^{10}$ Punta Le Terrare (site no. 306) ${ }^{11}$ and Porto Perone-Saturo (site no. 313); ${ }^{12}$ in Sicily at Monte Grande (site no. 334) ${ }^{13}$ and in the Vallo di Diano in the interior of Campania at Sassano (site no 340) ${ }^{14}$ Different kinds of matt-painted pottery of Middle Helladic tradition circulated in the Aegean during the early stages of the Late Bronze Age. ${ }^{15}$ Its occurrence in the central Mediterranean at a number of sites indicates that the circulation of pottery in Italy was connected to contemporary exchange networks in the Aegean. Objects from different areas in the Aegean, could thus end up together at an Italian site.

Coarse ware fragments of Aegean type have been found in substantial quantities at Vivara (site no. 342). ${ }^{16}$ At Filicudi (site no. 316) such pottery constituted more than a quarter of the Mycenaean finds. ${ }^{17}$ The coarse ware vessels from these islands should be distinguished chronologically from the imported coarse ware stirrup jar found at Broglio di Trebisacce. The Aegean coarse pottery at Vivara and Filicudi compares well to that found in the wells at the Athens acropolis. ${ }^{18}$ It can be dated to the beginning of the Greek Late Bronze Age and, consequently, may be considered as one of the classes of ceramics which were in circulation alongside Aegean matt-painted pottery and decorated fine ware. Similar coarse ware pottery dating to this early period has been found at Punta le Terrare (site no. 306) $)^{19}$ on the Adriatic coast of Apulia and at Monte Grande (site no. 334) ${ }^{20}$ in southern Sicily.

The imported stirrup jar at Broglio di Trebisacce should be dated to LHIIIB may be compared to similar vessels, which have been distributed widely in the Aegean and the eastern Mediterranean. ${ }^{21}$ In the settlement at Torre Santa Sabina (site no. 305) numerous coarse ware jars of Aegean type have been found in association with LH IIIC material. ${ }^{22}$ Porto Perone-Saturo (site no. 313) produced two large coarse ware storage vessels in LH IIIB style, ${ }^{23}$ while a sherd at Grotta Manaccora (site no. 297) has been interpreted as belonging to a transport stirrup jar from the same period. ${ }^{24}$
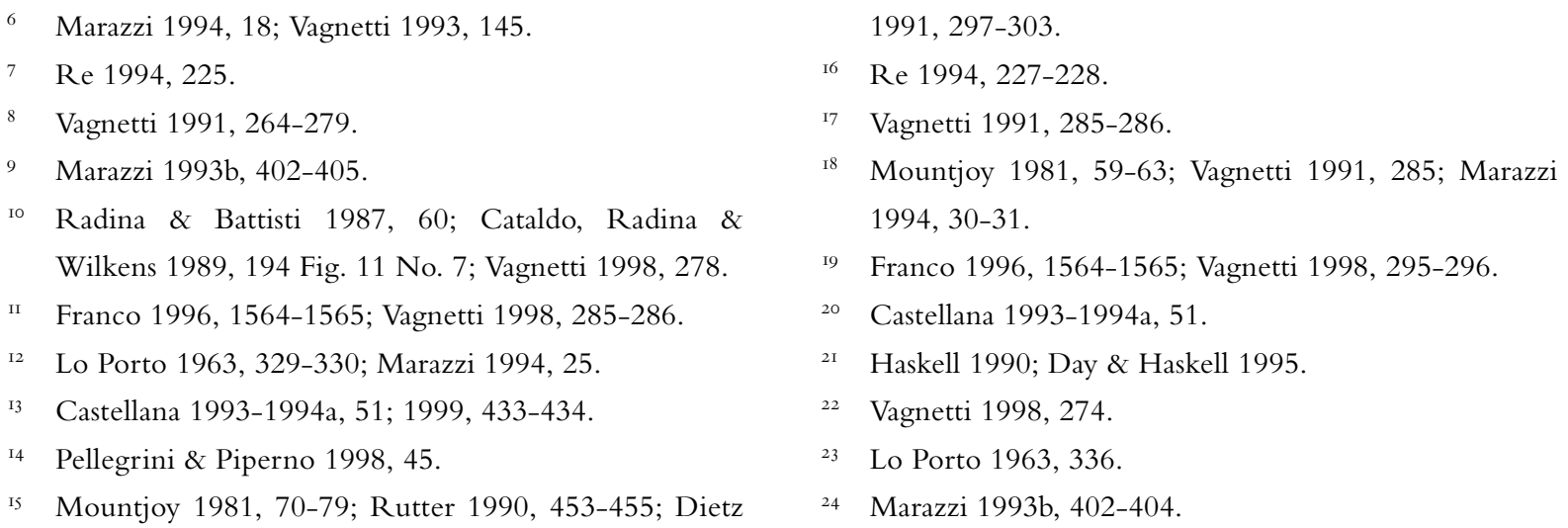
Scientific analyses have shown that some of the coarse ware Aegean-type pottery found at Vivara was made in the region of Naples, while the fine ware vessels and most of the coarse pots from the island were imported from the Aegean. ${ }^{25}$ These results seem to suggest that some local production of Aegean-type pottery, albeit only coarse ware, occurred already in the earliest phase of Mycenaean imports into Italy. For LH IIIB-LH IIIC pottery, such local or regional production has been proven not only at Broglio di Trebisacce but also at Termitito (site no. 316), Casale Nuovo (site no. 344) ${ }^{26}$ and in Sardinia. ${ }^{27}$ At Broglio, the existence of ceramica grigia and large wheel-refined dolia has been interpreted as evidence for Aegean influence on the local pottery industry. Similar vessels in grey ware have been found at Coppa Nevigata (site no. 299) ${ }^{28}$, Torre Castelluccia (site no. 311), ${ }^{29}$ Taranto (site no. 314), ${ }^{30}$ Porto Perone-Saturo (site no. 313) ${ }^{31}$ and at Torre del Mordillo (site no. 319). ${ }^{32}$ In addition, this pottery has been discovered at sites without Mycenaean-type pottery. ${ }^{33}$ It may be of significance that ceramica grigia has not been reported from other sites with much LH IIIB-LH IIIC material such as Santa Maria di Leuca (site no. 309), ${ }^{34}$ Scalo di Furno (site no. 310), Termitito (site no. 316) ${ }^{35}$ and Antigori (site no. 348). The absence of grey ware at these sites could indicate that such pottery was locally produced at specific sites and did not circulate regionally.

The unequal distribution of grey ware in the latest phase of Mycenaean pottery in the central Mediterranean resembles similar concentrations of matt-painted and coarse ware pottery in the first phase. Such unequal distribution patterns may be the result of developments in the circulation of Mycenaean pottery which cannot be detected due to the relatively wide margins of the stratigraphical and ceramic chronology. For example, the higher quantities of Aegean matt-painted pottery and coarse ware on Vivara and Filicudi, in comparison with Lipari, may be explained by suggesting that the bulk of the imports at the latter island arrived at a later moment - when the circulation of mattpainted and coarse wares had diminished. Similarly, the absence of grey ware at a number of sites with LH IIIB-LH IIIC pottery may be caused by a relatively short-lived production of this pottery within the long LH IIIB and LH IIIC phases. However, such unequal distribution of various Aegean-type wares may also be the result of choices made by the inhabitants of different sites in various periods.

The repertoire of Mycenaean vessel types at Lipari and Broglio di Trebisacce includes both dinner and storage vessels in substantial quantities. The high number of LH I-LH II cups, particularly of Vapheio type, at Lipari show that Mycenaean dinner vessels constituted a substantial proportion of the imported repertoire from the earliest period onwards. Among the Aegean decorated fine ware found on Vivara (site no. 342) open pot shapes constitute only a small proportion. ${ }^{36}$ The same can be said for the matt-painted and coarse Aegean-type fabrics found at the same site. ${ }^{37}$ Among the LH I-IIIA1 material on Filicudi (site no. 321) open vessels are a small minority and the Mycenaean repertoire on this

25 Jones \& Vagnetti 1991, 131; Jones 1994, 307.

26 Angle et al. 1993, 212-213.

27 Jones \& Vagnetti 1991, 132-134.

28 Belardelli 1993, 347-348.

29 Taylour 1958, 152.

30 Gorgoglione 1996, 1574-1577.

${ }_{31} \quad$ Lo Porto 1963, 330-333; 1964, 195-197.

32 Arancio et al. 1995, 230.

33 Belardelli 1993, 349: Bello Luco, Santa Maria del Castello di Castrovillari in Apulia and Amendolara in
Calabria.

34 Benzi \& Graziado 1996, 1526.

35 De Siena $(1986,46)$ states specifically that wheel-refined dolia and ceramica grigia have not been found at Termitito, even though Aegean-type pottery was manufactured in the area of the site, see Jones \& Vagnetti 1991, 132

36 Panichelli \& Re 1994, 212-214.

37 Re 1993, 237, 245-247, 250, 255-261, 265, 267. 
island seems to be comparable to that on Vivara. ${ }^{38}$ This is also the case for the Sicilian site of Monte Grande (site no. 335). ${ }^{39}$ At the sites with smaller quantities of early Mycenaean finds, dinner vessels dating to this period have not been found at Capo Piccolo (site no. 320) in Calabria, ${ }^{40}$ at Madre Chiesa di Gaffa (site no. 336) in Sicily ${ }^{41}$ or at the two sites on Salina (sites no. 322-323). ${ }^{42}$ The earliest Mycenaean finds at Punta le Terrare (site no. 306) date to LH II-LH IIIA1 and include several storage jars, whereas a LH II-LH IIIA1 cup has also been reported. ${ }^{43}$ Finally, there are a few sites where open vessels constitute the only early Mycenaean finds, such as Giovinazzo (site no. 302) ${ }^{44}$ and PortoPerone-Saturo (site no. 313). ${ }^{45}$ Clearly, there is a variation among the sites in Italy with Mycenaean finds from the first chronological phase in the extent to which open drinking vessels were imported.

At Thapsos, the majority of the Mycenaean vessels is from closed pot shapes, whereas at Lipari most of the finds dating from LH IIIA2 to LH IIIB-LH IIIC are of open pot shapes. The site in the central Mediterranean with the widest variety of contemporary Mycenaean finds is Scoglio del Tonno at Taranto (site no. 314), where more than 100 Mycenaean finds dating from LH IIIA2 until LH IIIBLH IIIC have been made. ${ }^{46}$ Among these finds there is a slight majority of storage vessels in comparison to dinner vessels. The relative proportions of these two Mycenaean ceramic functional classes appear to have changed over time, as the frequency of storage vessels is highest among LH IIIA finds, while LH IIIB dinner vessels occur more often than contemporary storage vessels. Among the storage vessels at Scoglio del Tonno, the large piriform jar (FS 34-36) occurs most often, while there are also many stirrup jars. Among the dinner vessels, the kylix is most common, but there are also a fair number of kraters. The repertoire of Mycenaean pot shapes at Porto Perone-Saturo (site no. 313) is very similar to that found at Scoglio del Tonno, even though LH IIIA finds are absent. ${ }^{47}$ The LH IIIA2-LH IIIB finds at the Milazzese levels at Panarea are comparable to those at Lipari. ${ }^{48}$ At sites in the central Mediterranean with smaller quantities of Mycenaean pottery, both dinner and storage vessels occur.

Possibly, the relatively high proportion of Mycenaean storage vessels at Thapsos is due to the funerary context in which the finds at that site have been made. At other cemeteries in Sicily contemporary to Thapsos, mainly storage vessels have been found as well. ${ }^{49}$ It is of interest to note, however, that the contemporary settlement at Cannatello (site no. 333) in southern Sicily also appears to have had a preference for closed Mycenaean pot shapes. ${ }^{50}$ The only funerary context in Apulia which dates to the same period - grave no. 12 in the tumulus at Torre Santa Sabina (site no. 305) - yielded one LH IIIA2 cup and a LH IIIA2-LH IIIB alabastron. ${ }^{51}$ Apparently, the inhabitants of the sites in Sicily had a preference for Mycenaean storage vessels during the second phase of Aegean connections with Italy, while in other regions larger quantities of Mycenaean dinner vessels were imported. To a larger extent than in the LH I-LH II phase, which showed significant local differences, regional patterns are visible in the distribution of Mycenaean pottery in Italy.

At Broglio di Trebisacce, both Mycenaean dinner and storage vessels have been found in substantial quantities. Among the LH IIIB-LH IIIC pottery from Scoglio del Tonno (site no. 314), dinner vessels predominate, but storage vessels dating to LH IIIC are numerous as well. In particular, a variety of LH

$3^{8} \quad$ Vagnetti 1991, 284 diagram 2.

39 Castellana 1999, 433-438.

40 Vagnetti 1987, 37-42.

${ }_{41}$ Castellana 1993-1994a, 49.

42 Bernabò-Brea \& Cavalier 1968, 142-143, 166-167.

43 Bocuccia 1998, 176; Vagnetti 1998, 284-285.

44 Lo Porto 1967, 162.
45 Lo Porto 1963, 333-334

46 Taylour 1958, 81-137; Fisher 1988.

47 Lo Porto 1963, 333-337; 1964, 197-198.

48 Taylour 1958, 44-47.

49 See chapter 16.

so De Miro 1996, 998-999.

sI Lo Porto 1993, 10-11. 
IIIC amphorae have been found at this site, of types (FS 58-70) which also occur at Broglio di Trebisacce. At Porto Perone-Saturo (site no. 299), where substantial amounts of Mycenaean pottery from this later period have also been found, dinner vessels are the most frequent. ${ }^{2}$ At the site of Coppa Nevigata (site no. 299), where most of the Mycenaean pottery appears to be of LH IIIC date, closed vessels are more numerous, even though there is a fair proportion of open vessels. ${ }^{53}$ Among the Mycenaean finds from the settlement at Torre Santa Sabina (site no. 305), which date to an early phase of LH IIIC, dinner vessels appear to be more frequent, but storage jars have been found as well. ${ }^{54}$ Most of the Mycenaean finds at Punta Meliso di Leuca (site no. 309) belong to an advanced stage of LH IIIC..$^{55}$ Among the earlier finds, an amphora could be of LH IIIB-LH IIIC date. From Torre Castelluccia (site no. 312), a variety of drinking vessels dating to LH IIIB-LH IIIC have been reported. ${ }^{56}$ At Termitito, where a regional production of Mycenaean pottery similar to that at Broglio di Trebisacce has been attested, dinner vessels seem to be more numerous than storage pots. ${ }^{57}$ In Latium, storage vessels appear to have been the most frequent, ${ }^{58}$ which may also have been the case at Antigori (site no. 348) on Sardinia..$^{59}$

From this overview it is clear that the Mycenaean ceramic repertoire in the beginning of the third phase of Aegean contacts with Italy was relatively homogeneous in comparison with the earlier periods. Differences in the relative proportions of storage and dinner vessels occur, but both classes have been found in reasonable numbers in southern Italy, Sicily and in the Tyrrhenian region; Latium and Sardinia show a distinctive preference for storage vessels.

Mycenaean vessels which can be interpreted as of ceremonial types are almost absent in the central Mediterranean. Only in room A at the Nuraghe Antigori (site no. 348) has a LH IIIB conical rhyton been discovered. ${ }^{60}$ Three Mycenaean terra-cotta figurines have been found in the central Mediterranean: one at Lipari and two more female Psi-type figurines were discovered at Scoglio del Tonno (site no. 314). ${ }^{61}$ Apparently, these kind of specialised ceramics occurred only at sites with abundant Mycenaean imports.

Mycenaean pottery with pictorial decoration should also be considered to be of a specialised nature. Such decoration has not been found on the Aegean pots from Lipari, Thapsos and Broglio. Fish are visible on two sherds from Scoglio del Tonno (site no. 300); ${ }^{62}$ another fragment from Scoglio probably shows the hind legs of a horse. ${ }^{63} \mathrm{~A}$ concentration of Mycenaean pictorial pottery has been found at Termitito (site no. 316). ${ }^{64} \mathrm{~A}$ fragment of a LH IIIB krater from this site depicts a goat, while another fragment from an open vessel with light-on-dark decoration may show a similar animal. In addition, representations of horses, a bird and an octopus have also been found. Quite unique is the stirrup jar, which is depicted on a sherd from this site. ${ }^{65}$ The Mycenaean pictorial pottery at Termitito

52 Lo Porto 1963, 337-339; 1964, 198-200.

53 Belardelli 1993, 347-348.

54 Vagnetti 1998, 274.

s5 Benzi \& Graziado 1996, 1524.

s6 Taylour 1958, 147-148.

57 De Siena \& Bianco 1982, 75-76; De Siena 1986, 45.

58 For Casale Nuovo (site no. 344), see Angle \& Zarattini 1987, 252; Angle et al. 1993, 201. For Luni sul Mignone (site no. 346), see Östenberg 1967, 128.

59 Ferrarese-Ceruti \& Assorgia 1982, 172-176; FerrareseCeruti 1986, 184-187.
60 Ferrarese-Ceruti \& Assorgia 1982, 172-173: no. 5.

6I Taylour 1958, 115.

62 Taylour 1958, 104: no. 99, 109: no. 116.

63 Taylour 1958, 97: no. 70.

${ }^{64}$ De Siena \& Bianco 1982, tav. XXII-XXIII; De Siena 1986, 51 figs. 5-6.

6s At Cannatello (site no. 289) a large stirrup jar with stylised octopi has been discovered, see De Miro 1997, 998. An octopus design may also be present on a kylix sherd at Borg en Nadur (site no. 283) on Malta, see Buchholz 1974, 328-329. 
shows that preferences existed with regard to the Aegean-type ceramics that were imported or manufactured. The high variation among sites in the extent to which Mycenaean dinner vessels dating to an early period have been found show that preferences were exerted already in the first phase of Mycenaean contacts with Italy.

\section{SOCIAL GROUPS TO BE ASSOCIATED WITH MYCENAEAN POTTERY}

In the Capo Graziano settlement at the Lipari acropolis, Mycenaean pottery appears to have been used by all inhabitants at the site during this period, but the people living near structure $\delta$ IV possessed more of it than others. On the nearby island of Filicudi, the Mycenaean material found in contemporary levels was widely distributed, but a concentration of Mycenaean finds in structure no. XXV indicates that a particular group within society made more use of this material than others. ${ }^{66}$ Most of the Mycenaean pottery on Vivara (site no. 342) has been found at Punta d'Alaca at the western end of the small island. ${ }^{67}$ This concentration may have chronological reasons, since the site at Punta Mezzogiorno predates the one at Punta d'Alaca ${ }^{68}$ At both sites, Mycenaean drinking and storage vessels have been found in average domestic contexts. ${ }^{69}$ A concentration of this pottery, however, was discovered in association with two storage pits in Punta d'Alaca, which probably belonged to the single large building excavated in the area. It may be that also on Vivara a specific group in the society also made more use of Mycenaean pottery than other groups.

At Molinella (site no. 298) a LH IIB fragment was found below the floor of a Middle Bronze Age hut, which yielded a variety of domestic implements. ${ }^{70} \mathrm{~A}$ LH I goblet was found on the floor of hut a at Porto Perone-Saturo (site no. 313), in which a matt-painted fragment was also found. ${ }^{71}$ Another matt-painted fragment derived from structure g. A fragment dating to LH II from Capo Piccolo (site no. 320) also came from a domestic context. ${ }^{72}$ These examples indicate that during the first phase of Mycenaean contacts with Italy Aegean pottery occurred in average habitation contexts. At Monte Grande (site no. 334) in southern Sicily, a number of LH I-LH II sherds have been found in association with a sanctuary dating to the Sicilian Early Bronze Age (ca. 2000-1400 BC). ${ }^{73}$ This shows that Mycenaean pots could be part of activities with a high symbolical content. Possibly, the few Mycenaean finds which were found together with miniature cups in the fill of the large building $d$ IV on Lipari testify of use in similar circumstances. The fact that some inhabitants of Lipari, Filicudi and Vivara made substantially more use of Aegean vessels than other people in the same societies may be related to such symbolic use of this material in native ceremonies.

LHIIIA2 and LHIIIB pots were used widely among the populations of Milazzese Lipari and at Broglio. This was also the case at Thapsos, even if this material had a special significance for the groups associated with tomb XXI/47 at this site. At Taranto (site no. 314) a large quantity of Mycenaean pots has been found at Scoglio del Tonno, in association with a large building. ${ }^{74}$ Habitation at this site extended to the peninsula of the città vecchia, where Mycenaean pottery has re-

66 Vagnetti 1991, 285.

${ }_{67}$ Panichelli \& Re 1994, 178-211; Re 1994, 229-267.

68 Giardino 1994b, 69-71.

69 Cazzella \& Moscoloni 1994, 107-109; Tusa 1994, 118119.

70 Nava 1982.
${ }^{71} \quad$ Lo Porto 1963, 301.

72 Marino \& Festuccia 1995, 241-242.

73 Castellana 1993-1994a, 51; 1993-1994b, 737-741; 1999.

74 Quagliati 1900, 417-420. 
cently been found at San Domenico, some $200 \mathrm{~m}$ from Scoglio del Tonno. ${ }^{75}$ This wide dispersion of the Mycenaean material suggests that it was used by different groups in the society of Bronze Age Taranto. At Scalo di Furno (site no. 310), also in Apulia, a number of huts have been discovered, some of which may have served as workshops for impasto pottery. ${ }^{76}$ LH IIIA2-LH IIIB finds were made in several of these huts, which suggests that it was not restricted to specific inhabitants. These examples seem to confirm the picture from Lipari that Mycenaean pottery was not concentrated among specific groups in society. However, at the site of Capo Milazzese (site no. 324) on the island of Panarea, Mycenaean pottery has also been found distributed widely between several houses, but with a concentration in structures X and XI. ${ }^{77}$ Both huts also yielded a large amount of locally made pottery and have been considered as evidence for social stratification in the settlement. If true, it would indicate that Mycenaean pottery was more extensively used by local élite groups. At Cannatello (site no. 333) in southern Sicily, a concentration of pottery has been discovered in a rectangular hut, among which several Mycenaean pots. ${ }^{78}$ At both Capo Milazzese and Cannatello, the concentration of Mycenaean finds is associated with an abundance of local objects, which suggests that the Aegean pottery was part of processes in which many different goods were controlled by specific groups of people.

The LH IIIB and LH IIIC pottery at Broglio di Trebisacce was concentrated at the complesso a monte in excavation area $\mathrm{D}$, while at Lipari the Mycenaean pottery from Ausonio I levels was concentrated in a few atypical buildings. At Coppa Nevigata (site no. 299) in Apulia, which had a distinctively urban organisation during the Late Bronze Age, most Mycenaean sherds from sub-Appennine levels came from a relatively restricted area near the top of the hill, ${ }^{79}$ which may indicate a restriction of this material to specific social groups. In strata $b$ and $c$ at Porto-Perone (site no. 313) four oval huts dating to the sub-Appennine period have been discovered ${ }^{80}$ On the floors of structure A lay six LH IIIB-LH IIIC sherds, while other huts did not produce such ceramics. In structure D, a complete LH IIIB stirrup jar has been found. At Termitito (site no. 316) a large deposit of LH IIIB-LH IIIC pottery was discovered in association with a pit, which has been interpreted as a silo serving purposes of ostentatious possession. ${ }^{81}$ Obviously, the Mycenaean pottery served an important role in such a strategy. However, Mycenaean pottery has also been found elsewhere at Termitito, which shows that its use was not limited to symbolic display. At Luni Sul Mignone in Lazio (site no. 346) two of the three rectangular structures have yielded Mycenaean pottery and a concentration has not been attested.$^{82}$ The same may be said for Nuraghe Antigori (site no. 348) in Sardinia, where Mycenaean pottery has been found widely dispersed.

It is difficult to identify social groups in the population of central and southern Italy during the Middle and Late Bronze Age. It is generally recognised that these regions should be considered 'proto-urban', in the sense that a differentiation of wealth between settlements and concentrations of people in larger communities existed only to a limited extent. ${ }^{83}$ Nevertheless, the evidence of houses and tombs suggests that in most areas there existed hierarchies between groups and that dominant

75 Gorgoglione 1996, 1571-1575.

$7^{6}$ Lo Porto 1986, 15-16.

77 Taylour 1958, 44-47; Bernabò-Brea \& Cavalier 1968, 50-70; Vagnetti 1991, 290; Malone, Stoddart \& Whitehouse 1994, 176.

${ }_{78}$ De Miro 1996, 997-999; 1999.

79 Cazzella \& Moscoloni 1987, 141.

8o Lo Porto 1963, 292-300.
81 De Siena \& Bianco 1982; De Siena 1986, 43-45.

82 Östenberg 1967, 128, 141-145. The middle structure, which was somewhat smaller, did not yield any Mycenaean pottery.

83 Whitehouse 1973; Bergonzi 1985, 355; Tusa 1983, 473-475; Bietti Sestieri 1983, 78; Malone, Stoddart \& Whitehouse 1994, 171-172; d'Agata 1997, 457. 
élites were able to control specific sectors of society, such as subsistence, trade and religion. ${ }^{84}$ The presence of warriors, attested by an increasing number of weapons, and the presence of specialised artists working with metals and pottery also suggest some differentiation within the societies. ${ }^{85}$

The evidence presented above shows a development in the extent to which Mycenaean pottery may be associated with specific groups in the Italian Bronze Age societies. In the earliest period, Mycenaean vessels appear to have been used widely, but at some places specific groups were able to acquire substantially more of this material. Such concentrations have been attested in particular at the islands of Lipari, Filicudi and Vivara, which may suggest that the symbolic significance of overseas contacts was of importance for the social use of Mycenaean pottery. In a later period, LH IIIA2-LH IIIB pottery appears to have been used everywhere among many different population groups and to have been an integral part of the material culture. At the end of the Late Bronze Age and in the beginning of the Final Bronze Age, Mycenaean pottery was monopolised by specific groups in society in almost all regions. Apparently, this pottery served in social strategies by which élites distinguished themselves from other people.

\section{DIFFERENTIATION WITHIN THE REPERTOIRE OF MYCENAEAN}

\section{P O T T E R Y}

The matt-painted pottery dating to the earliest phases of Aegean contacts with Italy has at Lipari been found together with 'lustrous' Mycenaean decorated pottery. On Filicudi (site no. 321), matt-painted and coarse ware pottery has similarly been found in several structures in association with 'true' Mycenaean vessels. ${ }^{86}$ On Vivara (site no. 342), one matt-painted fragment has been found in Punta Mezzogiorno, while all other fragments came from Punta d'Alaca, where such pottery was found together with other Aegean imports. ${ }^{87}$ At Punta Le Terrare (site no. 306), an Aegean fragment of probable red-burnished ware was found in proto-Appennine B levels, together with a fragment of Mycenaean decorated ware.$^{88}$ In strata 1a and 2a at Monte Grande in Sicily (site no. 334), Aegean matt-painted sherds have also been found together with fragments with more lustrous decoration. ${ }^{89}$ It appears that in the first phase of Mycenaean contacts with Italy, the appreciation for Mycenaean decorated vessels was not substantially different from that for imported vessels in Middle Helladic tradition.

At Broglio di Trebisacce in the latest phase of Aegean connections with Italy, we have not been able to recognise any differences between the appreciation for genuine Mycenaean imports and for Aegean-type pottery that was locally produced. The locally produced grey ware at Broglio di Trebisacce, likewise, has been found in direct association with true Mycenaean pottery, as have large wheel-refined dolia. ${ }^{90}$ A stemmed bowl of grey ware was found together with a LH IIIB cup or bowl at the San Domenico site at Taranto (site no. 314). ${ }^{91}$ At Porto Perone-Saturo (site no. 313) these different classes of wheel-made pottery have also been discovered together..$^{92}$ It appears that the appreciation for wheel-made pottery of Aegean and non-Aegean type in the Late Bronze Age was similar.

${ }^{84}$ Cipolloni Sampò 1991-1992, 284-285; Peroni 1994a, 249-254, 260-282, 306-314 (with bibliography).

8s Bergonzi 1985, 359-365.

86 Vagnetti 1991, 286.

$87 \quad$ Re 1994

88 Franco 1996, 1564-1565.
89 Castellana 1993-1994a, 51; 1999.

90 Bergonzi \& Cardarelli 1982c; Buffa 1984a; Vagnetti 1999.

9г Gorgoglione 1996, 1574-1575.

92 Lo Porto 1963, 332. 
The imported nature of ceramic vessels does not seem to have been of any consequence for the way these vessels were used during this period.

At Lipari, in both Capo Graziano and in Milazzese levels, Mycenaean dinner and storage vessels were not appreciated differently. However, at Thapsos and Broglio, Mycenaean drinking vessels had a special significance. On the island of Filicudi (site no. 321) the majority of Mycenaean pottery finds was very fragmentary and could not be assigned to specific vessel types. Only nine Aegean fragments have been assigned to open vessels, of which six were distributed among three different buildings. ${ }^{93}$ It may be of significance that three of these Mycenaean open shapes derive from building XXV. However, a number of fragments of closed shapes were also found in this structure. On Vivara, likewise, only a small minority of the Aegean finds could be assigned to an open pot shape. ${ }^{94}$ The silos a and $b$, which have been discovered at Punta d'Alaca, have produced varying quantities of Mycenaean open and closed vessels. ${ }^{95}$ According to Tusa, this indicates a functional differentiation between these two storage pits. A difference in the social significance between Aegean storage and dinner vessels is, however, not attested.

At Capo Milazzese (site no. 324) on the island of Panarea, Mycenaean open vessels have been found in three different structures - always directly associated with imported closed vessels. ${ }^{96}$ Mycenaean dinner and storage vessels alike are concentrated in buildings X and XI, but both types also occur in other structures. Such a distribution pattern argues against a special significance for Mycenaean dinner vessels. Likewise, the LH IIIA2 and LH IIIB finds at Cannatello (site no. 333) in Sicily have all been found together within one of the large buildings at this site and a differentiation in appreciation between storage and drinking vessels cannot be determined. At Porto-Perone Saturo (site no. 313), however, seven LH IIIB cup fragments were found together on the floor of building A, in direct association with a variety of local cups and globular vases. ${ }^{97}$ This concentration of cups may indicate a special significance of such vessels at this site. Possibly, a special significance of Mycenaean drinking vessels during this period, as attested at Thapsos, was a local phenomenon, which required specific circumstances - such as funerary ceremonies.

Termitito (site no. 316) has produced a large quantity of Mycenaean pottery, which is roughly contemporary to the finds at Broglio di Trebisacce..$^{98}$ Much of this material came from a large silo, which yielded more Mycenaean dinner vessels than storage pottery. A large number of open vessels of local manufacture has also been found and the pit contained seeds and other evidence for food storage or consumption. Elsewhere on the site, a smaller silo yielded Mycenaean pottery of similar type. The fact that a relatively large proportion of Mycenaean dinner vessels was found in these structures indicates that such vessels had a special significance, as they did at Broglio. At Luni sul Mignone (site no. 346) or at Nuraghe Antigori (site no. 348), however, both types of imported Mycenaean pottery have been found together and a difference in appreciation cannot be established. It appears that in southern Italy Mycenaean dinner vessels served a special role in the beginning of the third period of Aegean contacts with Italy. A similar role cannot be seen in central Italy and in Sardinia.

In the earliest phase of Mycenaean connections with Italy the use of Mycenaean pottery was widespread, but at some places specific groups were able to acquire large quantities of this pottery. The

\footnotetext{
93 Vagnetti 1991, 263-277.

94 Panichelli \& Re 1994, 211-214; Re 1994.

95 Tusa 1994, 120, 122: fig 1.

96 Taylour 1958, 44-47.
}

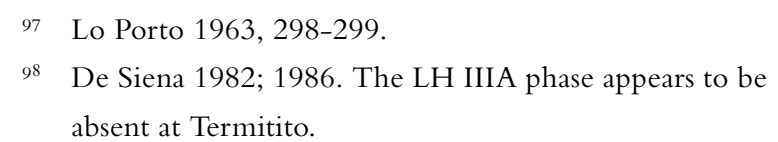


equal appreciation for Mycenaean dinner and storage vessels during this phase indicate that such concentrations were not related to the functions of the Aegean vessels. Rather, the very fact that these pots were imported was of significance. In a later phase, LH IIIA2-LH IIIB pottery was used at all sites in Italy by many different population groups and it was an integral part of the material culture. In the third phase of Mycenaean pottery in Italy specific groups appear to have monopolised Aegeantype pottery. For southern Italy, there is evidence that such monopolisation was related to a high appreciation for Mycenaean drinking vessels. Instead of the Mycenaean origin, it appears that in this period the function of the Mycenaean vessels was of crucial importance for their cultural significance.

\section{F U NERARY EVIDEN C E}

Very few Bronze Age sites have been discovered in Italy with both a settlement and a necropolis. At Thapsos, the excavations of the settlement have not been published, while the Ausonio I and II cremation burials at Lipari have not yielded any Aegean pottery. At Molinella (site no. 298) a dolmen has been excavated, but Mycenaean pottery has only been found in the associated proto-Appennine B settlement. ${ }^{99}$ Another dolmen (site no. 302) ${ }^{100}$ containing a LH I-LH II cup has been discovered some kilometres from the town of Giovinazzo where a contemporary settlement (site no. 301) has been investigated. ${ }^{101}$ The distance between the two sites shows that they should be considered separately. At Torre Santa Sabina (site no. 305) a tumulus with some twenty-five graves has been discovered near the settlement, but the chronological relationship with the habitation site is not altogether clear. ${ }^{102}$ Remains of funerary caves have been excavated on the island of Filicudi (site no. 321), yielding a few rather undiagnostic Mycenaean sherds. ${ }^{103}$ This overview shows that it is not possible to relate the Mycenaean finds from tombs to associated settlements; the funerary contexts can only be investigated separately. In addition to the sites mentioned above, Mycenaean pottery has been found in funerary contexts in Sicily at Floridia (site no. 328), Matrensa/Milocca (site no. 329), Syracusa (site no. 330), Cozzo del Pantano (site no. 331), Buscemi (site no. 332) and Milena (site no. 333). On the Italian mainland, Bronze Age burials have been discovered either in monumental dolmens serving for collective burial, or in natural caves which were used for a long time. ${ }^{104}$ Apart from the two dolmens mentioned above, Mycenaean pots have been found in isolated caves in Grotta Manaccora (site no. 297), Praia a Mare (site no. 339) and Sassano (site no. 340).

Mycenaean pottery was used widely in the tombs at Thapsos, but the remarkable repertoire of such vessels from tomb XXI/47 shows the active role of this type of pottery in a symbolic strategy of funerary display. In the dolmen of Giovinazzo (site no. 302) a LH I-LH II cup has been found in association with a variety of local drinking cups and bowls. ${ }^{105}$ This dolmen was very elaborate and included a tholos-type structure with a dromos of large stone slabs below a tumulus. The inclusion of a Mycenaean drinking cup in this structure shows that such a drinking vessel could be included in ceremonies of a highly symbolic content already at an early date. The same may be said for the early Mycenaean finds at Grotta Manaccora (site no. 297), which included matt painted sherds. ${ }^{106}$ At

99 Bernabò-Brea 1985, 167.

roo Lo Porto 1967.

го Radina \& Battisti 1987.

102 Lo Porto 1993, 12; Coppola \& Cinquepalmi 1998, $149-150$.
Io3 Vagnetti 1991, 279: nos. 83-84.

104 Cipolloni Sampò 1987; 1991-1992.

ros Lo Porto 1967, 162

${ }^{106}$ Marazzi 1993b. A LH IIIB stirrup jar has also been found, testifying of the caves' long use. 
Sassano (site no. 342) in Campania, a matt-painted fragment of a closed vessel has been found in a funerary cave. ${ }^{107}$

The number of LH IIIA2-LH IIIB vessels in the tombs at sites in eastern Sicily is relatively low, but the repertoire of pots is comparable to that of Thapsos. At the site of Torre Santa Sabina (site no. 305) in Apulia a tumulus has been discovered which contained some twenty-five pit graves. ${ }^{108}$ Most tombs, containing either children or adults, did not contain any grave goods at all; three graves had a limited repertoire of impasto vessels. Of a special nature is grave 12, which was situated in the centre of the tumulus. It was somewhat larger than the others and one of the few with a small bench on which the head of the dead had been placed. It yielded a LH IIIA2 cup and a LH IIIA2-LH IIIB alabastron. In addition, a one-handled jug has been discovered, which was most likely imported. ${ }^{109}$ A bronze knife, possibly of Aegean origin, was also discovered in grave 12. Clearly, in the case of this grave, the Mycenaean finds were considered suitable to be involved in a ceremony of funerary display in which other imports also functioned. Moreover, the absence of similar objects in the other graves clearly show that such display was limited to specific persons. ${ }^{110}$ From this example it is apparent that not only in Sicily, but also in Apulia ceramic vessels imported from the Aegean could play an active role in the funerary practices of particular people.

107 Pellegrini \& Piperno 1998, 45.

Io8 Lo Porto 1963; 1993.

ro9 Lo Porto 1993; Vagnetti 1998, 274.

по Coppola \& Cinquepalmi (1998 150) suggest a chronological cause for the concentration of status objects in grave 12. Considering the position of this grave in the centre of the tomb and its more elaborate architecture, it is altogether probable that differences in the funerary practices are responsible for the variation among the graves. 



\title{
19 Variations in the cultural significance of Mycenaean pottery
}

\author{
M Y C E NA EA N REPERT O IRE S
}

As is clear from the discussions in chapter 2, the Levant has the most sites with Mycenaean pottery, but the density is highest in Cyprus, as is the absolute number of pots. A common characteristic of the distribution pattern in all areas is that everywhere a large number of sites has produced very few Mycenaean finds, while only a few sites have yielded substantial quantities of it. Several large urban centres along the Levantine coast have produced large amounts of this pottery; however, it also occurs in quantity at sites in the interior of the Levant. This was not the case in Cyprus, where extremely large quantities of Mycenaean pottery have been found exclusively at sites near the coast. Just as the coastal cities of the Levant, all Cypriot urban centres with major deposits of Mycenaean pottery are towns which played important roles in regional and supra-regional trade networks. In Italy, too, the places which have produced substantial quantities of Myceanean pottery can be understood as nodes where international and regional exchange systems coincided. ${ }^{1}$ In comparison with the Levant and Cyprus, however, clear shifts in time can be noted with regard to the sites in the central Mediterranean with large quantities of Mycenaean pottery. The unequal presence of large quantities of Mycenaean pottery, which is characteristic of all areas, suggests that everywhere this pottery was imported in only a few places, after which it was distributed through regional exchange networks.

In Cyprus, a few LH I-LH IIA pots have been found, while some contemporary Minoan pottery is also present on the island. An increase in the Aegean imports in the island may be noted during the LH IIB and especially during the LH IIIA1 ceramic phases, of which substantially more finds have been made, even in places far away from the coasts. ${ }^{2}$ From LH IIIA2 onwards, large quantities of Mycenaean pottery reached all parts of the island. This remained the case until an advanced stage of LC IIC, when pottery in Aegean style began to be produced on the island itself and Aegean imports diminished.

The chronological pattern in the presence of Mycenaean pottery in the Levant is similar to that in Cyprus, but not exactly the same. LH I vessels are absent in the Levant and only a few pots have been found assignable to LH IIA. ${ }^{3}$ A few isolated contemporary Minoan pots have also been found. LH IIB and LH IIIA1 finds occur somewhat more often in the Levant, but the quantities are very small, Ugarit possessing a relatively 'large' amount of six Aegean pots dating to these stylistic phases. Substantial amounts of Mycenaean pottery begin to arrive in the Levant only during LH IIIA2. Apparently, in the early stages of the import of Mycenaean pottery, the Levant lagged somewhat behind Cyprus. The chronological pattern for the presence of Mycenaean pottery is similar for the

2 Nicolaou 1973, 56; Åström 1973, 123; Cadogan 1973, $\quad 3 \quad$ Re 1999, 411. 
Levant and Cyprus at the end of the 13th century BC, when Mycenaean-type vessels seem to have been imported from peripheral areas of the Aegean world, such as the Dodecanese and probably Cyprus. ${ }^{4}$ As in Cyprus, Mycenaean-type pottery appears to have been produced in the Levant at the end of LB II. ${ }^{5}$ LH IIIC-type pottery, which is abundant in Cyprus, occurs only at a restricted number of sites in the Levant, mainly in the southern coastal plain. ${ }^{6}$

A completely different chronological pattern in the presence of Mycenaean pottery can be observed for the central Mediterranean. Large quantities of LH I and LH II pottery have been discovered on the Aeolian islands, as well as on Vivara (site no. 342). In addition, a range of sites along the Apulian coast have produced smaller quantities of contemporary Mycenaean pottery. ${ }^{7}$ Even though the number of sites with LH IIIA finds in Italy is somewhat higher than those with earlier Aegean finds, ${ }^{8}$ there is a concentration of LH IIIA2-LH IIIB finds in a few centres such as Taranto-Scoglio del Tonno (site no. 314), Thapsos, Cannatello (site no. 334) and Lipari. A sharp increase in the import of Mycenaean pottery during LH IIIA2, such as is visible in Cyprus and the Levant, is clearly lacking in the central Mediterranean. The extensive local production of Mycenaean pottery which has been demonstrated for various sites in the central Mediterranean appears to have been a feature from $\mathrm{LH}$ IIIB onwards. ${ }^{9}$

Even though there are some differences between Cyprus and the Levant in the presence of Aegean pots from the various stylistic phases, it is clear that the chronological pattern in the import of Mycenaean pottery in these areas is roughly similar. Both areas reveal the sequence of introduction, growth and decline, that has been outlined by Gerald Cadogan. ${ }^{10}$ In contrast, the central Mediterranean shows a more disjointed pattern, with distinct regions and sites gaining prominence during specific periods. On this basis, it is likely that the cultural significance of Mycenaean vessels fluctuated more through time and space in the Italian region than in Cyprus and the Levant.

In each of the three areas under consideration, decorated fine wares constitute the majority of the Mycenaean repertoire. In the Levant and Cyprus, Aegean coarse ware vessels are almost exclusively large transport stirrup jars, which may be of Minoan origin..$^{11}$ In Cyprus, these vessels are relatively widely distributed, with notable concentrations at Kourion-Bamboula (site no. 122) and Enkomi. In the Levant, this type of vessel is limited to large urban centres on the coast. ${ }^{12}$ In the central Mediterranean, coarse ware stirrup jars comparable to the vessels in Cyprus and the Levant have been found in Broglio di Trebisacce and in Scoglio del Tonno-Taranto (site no. 314).

Much larger quantities of Aegean-type coarse ware date to the earliest period of Mycenaean pottery in Italy and have been discovered on Vivara (site no. 342) and Filicudi (site no. 321). This type of

4 Courtois 1973, 149-164; see also chapter 2.

5 Lambert, McLaughlin \& Leonard 1978, 119; Leonard et al. 1993, 119; Killebrew 1998, 162.

6 Killebrew 1998, 163. Scientific analysis of the LH IIIC-type pottery from Ashdod (site no 222) and Tel Miqne (site no. 225) indicates that all these so-called 'Mycenaean IIIC:1b' pots were produced in the Levant itself, see Asaro, Perlman \& Dothan 1971; Gunneweg et al. 1986; Sherratt 1998, 302.

7 Marazzi 1994, 23-25; Martin 1999, 2-6; Re 1999, 412 .
$8 \quad$ Vagnetti 1999, 139.

9 Jones \& Vagnetti 1991, 132-133, 140. A few locally made sherds decorated with LH/LM IIIA patterns have been identified at Broglio di Trebisacce (catalogue X: nos. 1005, 1135, 1204, 1278), see Vagnetti \& Panichelli 1994.

ı Cadogan 1973, 168-169.

II Catling et al. 1980, 92-93; Day \& Haskell 1995 (both with extensive bibliography)

I2 Leonard 1994, 46-47. 
pottery included a range of shapes, among which were storage and dinner vessels. ${ }^{13}$ Smaller quantities of Aegean coarse ware pottery have also been found in Punta le Terrare (site no. 306) on the Apulian coast and in Monte Grande (site no. 334) in Sicily. Together with matt-painted pottery of Middle Helladic tradition, this coarse ware circulated alongside decorated fine wares of LH I and LH II type. The presence of matt-painted and coarse ware pottery in Italy should be related to the relatively large body of Aegean ceramics from the early Mycenaean period in this area in general. However, it also indicates that Mycenaean pottery arrived in Italy through a variety of contacts between Italic groups of people and inhabitants of the Aegean. Regional exchange networks in the two areas seem to have been interconnected. In Cyprus and the Levant, Mycenaean coarse and matt-painted wares are absent and small quantities of exclusively Mycenaean decorated fine wares circulated during the same period. This indicates that the Mycenaean pottery arrived in the eastern Mediterranean through different types of interconnections than in the central Mediterranean.

In the Levant the relative proportions of Mycenaean dinner and storage vessels varied between individual sites. At urban coastal centres such as Ugarit, Tell Abu Hawam (site no. 175) and Ashdod (site no. 222) a majority of Mycenaean dinner vessels has been found; elsewhere Mycenaean storage vessels were more abundant. Inland centres such as Hazor and Beth Shean (site no. 187) yielded far fewer Mycenaean dinner vessels and a relatively narrow range of Mycenaean storage vessels. In general, the Mycenaean repertoire in smaller centres in more marginal areas, such as Deir "Alla, was restricted to a few storage vessels only. Primary centres in Cyprus, likewise, yielded a large body of Mycenaean dinner vessels in addition to storage pottery of the same origin. In contrast with the Levant, sites in the interior of the island could also possess a wide variety of Mycenaean pots from LH IIIA1 onwards, including both dinner and storage types. In the central Mediterranean, Mycenaean dinner vessels, in particular cups and kylikes, were part of the Aegean ceramic repertoire from the earliest period onwards. In certain periods, specific areas could exert preferences for particular categories of Mycenaean pottery, as is indicated by the abundance of LH IIIA2-LH IIIB storage vessels in Sicily. The widespread occurrence of Mycenaean dinner vessels in all three areas clearly shows that the ceramic vessels themselves were appreciated and not just the contents of containers.

The repertoire of Mycenaean pot shapes in Cyprus and the Levant is roughly similar: only a few vessel types that occur more than five times in Cyprus are absent in the Levant, while there are no vessel types occuring in substantial numbers in the Levant that have not been found in Cyprus. ${ }^{14}$ As was observed in chapter 2, however, the proportions in which various Mycenaean vessel types occur in these areas may vary considerably. This shows that Cyprus and the Levant obtained Mycenaean pottery from a common source, but that choices were made with regard to which vessels to import. The concentration of Mycenaean ceremonial vessels and figurines in Ugarit shows that such choices were made at a local level in the urban centres of the Levant. ${ }^{15}$ The variations in the repertoire of Mycenaean pottery that have been observed between the primary centres in Cyprus indicates that this was also the case on this island. Because Mycenaean vessels became part of regional exchange networks in both Cyprus and the Levant, such local cultural choices had consequences for the regional distribution pattern of this pottery.

The fact that specific shapes occur more often in the east than in the Aegean may be taken as an indication that there was a specialised production and marketing of Mycenaean pottery for external 
markets. ${ }^{16}$ In contrast, the type of LH I-LH II pottery that is found in Italy encompasses a variety of cups and jars, which are not part of the Levanto-Helladic repertoire but reflect the ceramic range of shapes in various parts of Greece. ${ }^{17}$ Among the LH IIIA2 and LH IIIB pottery from Scoglio del Tonno-Taranto (site no. 314) there are several vessels which would fit into the Levanto-Helladic repertoire, such as a variety of piriform jars, an amphoroid krater and chalices. ${ }^{18}$ At most contemporary sites in Italy, however, such vessels are scarce. The LH IIIA2 and LH IIIB vessels in the central Mediterranean comprise a range of alabastra, jugs, cups and kylikes which, even though not absent in the eastern Mediterranean, are not part of the Levanto-Helladic repertoire but are frequent in Greece. ${ }^{19}$ In addition, Mycenaean amphorae, both small (FS 58-62) and large (FS 68-69), occur in substantial quantities in Italy, wheras they are completely absent in the east.

Even though sites in the central Mediterranean did receive some Aegean vessels that were specifically produced for overseas exchange, a much larger body of specialised products went to the east. The same phenomenon can be observed for other Mycenaean specialised ceramics. Only one conical rhyton has been found in the Italian area: in Nuraghe Antigori (site no. 348) ${ }^{20}$ Other ritual vessels are completely absent in the central Mediterranean. A concentration of Mycenaean pottery with pictorial representations has been found in Termitito (site no. 316), ${ }^{21}$ the only other specimens being three fragments from Taranto-Scoglio del Tonno (site no. 314). ${ }^{22}$ Only three Mycenaean figurines have been found in the central Mediterranean, one at Lipari (Catalogue VIII no. 501) and two more at Taranto-Scoglio del Tonno (site no. 314). ${ }^{23}$ Obviously, specialised production of Mycenaean pottery was not primarily aimed at Italy. The fact that some specialised vessels did end up in this part of the Mediterranean demonstrates the strong interconnections between exchange networks in various areas. The concentration of Mycenaean pictorial pottery at Termitito shows the influence of local cultural choices on the international flow of goods.

The presence of Mycenaean pottery in the Levant and Cyprus, then, was due to specialised production and marketing in international exchange. Archaeologically, these supra-regional strategies have resulted in a relatively clear-cut quantitative pattern of growth and decline in the presence of Mycenaean pottery and in a relatively homogeneous repertoire of pot shapes. ${ }^{24}$ In contrast, Mycenaean ceramic vessels arrived in the Italian area as part of much more diffuse processes, in which regional distribution networks within the Aegean and in the central Mediterranean were connected to one another. Here, we see a much more disjointed quantitative and geographical pattern in the presence of Mycenaean pottery, in addition to a less homogeneous ceramic repertoire. In all three areas, cultural choices made in key places in the inter-regional distribution networks, could substantially influence the circulation of Mycenaean pots.

I6 Sherratt 1982, 183; 1999, 182-184; Jones 1986a, 599600 .

${ }^{17}$ Vagnetti 1991, 293-294.

I8 Taylour 1958, 128-133; Biancofiore 1967, 44, 55; Fisher 1988

I9 Sherratt 1999, 194; cf. Åström 1973, 126.

$20 \quad$ Ferrarese Ceruti \& Assorgia 1982, 172-173: no. 5.

2I De Siena \& Bianco 1982, tav. XXII-XXIII; De Siena
1986, 51 figs 5-6.

22 Taylour 1958, 97: no. 70, 104: no. 99, 109: no. 116.

23 Taylour 1958, 115.

24 In this respect, it is interesting that both the quantitative pattern of Mycenaean pottery in the east, as well as the ceramic repertoire, become less homogeneous when the specialised production and marketing seems to have ended sometime during LH IIIC, see Sherratt 1991, 192; 1999, 184. 


\section{SOCIAL GROUPS ASSOCIATED WITH MYCENAEAN POTTERY}

The three areas which have been investigated in this study vary greatly with regard to their socio-political organisation. Even though urbanism seems to have declined somewhat in the Levant during the Late Bronze Age, a complex, differentiated society with large urban nuclei had already been in existence for a long time and there was a complex network of supra-local relationships. ${ }^{25}$ In spite of domination by foreign powers and growing internal oppositions between different population groups, palatial rule in most city states appears to have been stable. ${ }^{26}$ Mycenaean pottery was an integral part of this urban culture and was widely used by various population groups in the cities. Outside the main urban centres, however, Mycenaean vessels were quite scarce and their use was restricted to specific people and particular situations, as has become clear especially from the detailed analysis of the Mycenaean vessels found at Deir 'Alla. In Cyprus, urbanisation did not have such a long history and large urban centres, in fact, were not very common during most of the Late Bronze Age. ${ }^{27}$ The development of supra-local polities precisely during this period suggests that in Cyprus relationships between various population groups were much less stable than in the Levant. At Enkomi, and even at Kalavasos-Ayios Dhimitrios (site no. 114), where there is evidence that Mycenaean pottery possessed a special significance, various groups in the society used small quantities of this class of ceramics. ${ }^{28}$ In contrast to the Levant, however, smaller regional centres and even tertiary production sites on the island could also acquire substantial amounts of Mycenaean pottery, encompassing a wide ceramic repertoire.

The difference between the Levant and Cyprus in the extent to which social groups outside the urban centres made use of Mycenaean vessels is probably related to the different level of supra-local complexity. In the Levant opposition between urban groups connected to ruling élites and rural nonurban populations appears to have been quite strong..$^{29}$ In addition, the degree to which foreign powers were present in the Levant enhanced differences in the material culture between sites along the coast and in the major valleys on the one hand and sites in more marginal areas on the other hand. ${ }^{30}$ These strong oppositions are visible in the extent to which non-urban groups were able to make use of Mycenaean pottery. The comparatively wide use of the same type of pots by non-urban groups in Cyprus indicates that oppositions between cities and rural regions did not exist on the island, or were at least of a different nature. ${ }^{31}$

The central Mediterranean, at best, can be called proto-urban during the period concerned. In fact, a process of increasing site hierarchy appears to have been related to the development of interregional contacts, as is evident from structures such as the defensive walls in Apulia or the large building at Scoglio del Tonno-Taranto (site no. 314) which are associated with Mycenaean pottery. ${ }^{32}$ In all pe-

25 Falconer 1994; Bunimovitz 1995, 324.

26 Liverani 1987, 66-67.

27 Catling 1979, 199; Negbi 1986, 97; Keswani 1996, 217-220; Knapp 1997, 56-57.

28 South \& Russell 1993.

29 Liverani 1979, 1342-1347; 1987, 69-70; Falconer 1994, 326-329.

30 Leonard 1989, 5; Gonen 1992, 32-36; Falconer 1994, 326; Bunimovitz 1995, 325.

3I The complex systems of relationships between settle- ments that has been described by Keswani (1993) and Knapp (1997) presume a strong interdependence between groups living in various parts of the island.

32 Whitehouse 1973, 622-623; Marazzi \& Tusa 1979a, 340-341; Malone, Stoddart \& Whitehouse 1994, 171 Giardino 1994b. It should be noted that features of complexity such as defensive works and status differentiations in tombs were well established in south-eastern Italy prior to the Aegean contacts, see CipolloniSampò 1986, 32 . 
riods during which Mycenaean pots are found in Italy, they appear to have been used by various groups within societies, as is clear from the relatively wide distribution of this material at Lipari, Thapsos and Broglio. At the same time, however, we need to realise that a coastal pattern in the distribution of Mycenaean pottery is more evident in Italy than elsewhere. This suggests that Mycenaean pottery was used mainly by groups that took part in regional exchange networks; these had been developing in various regions of Italy. ${ }^{33}$ Of course, for the central Mediterranean one cannot speak of oppositions between urban and non-urban sites. However, the virtual absence of Mycenaean pottery from sites in the interior is, in a way, comparable to the situation in the Levant.

In the urban centres in the Levant, Mycenaean pottery has not only been found in average domestic contexts and in contexts bearing evidence of craft production, but it could also be associated to social groups that possessed both wealth and a high status. Indeed, Mycenaean vessels have been found in structures that can directly be related to the ruling élite, for example in the palaces at Ugarit and Hazor. It has also been shown, however, that within the urban communities, high-ranking groups did not make substantially more use of Mycenaean pots than other social groups. At Ugarit, for example, concentrations of Mycenaean pottery have not been observed in the palace, but in tombs in the harbour town. Those Mycenaean vessels which can be associated with palatial structures in the Levant appear to be evidence of the extent to which this pottery was part of the material culture. All indications are that Mycenaean pottery was used by urban inhabitants of various status. ${ }^{34}$

A concentration of Mycenaean pottery among average urban social groups may also be seen in Cyprus at Enkomi, where this material was widely distributed as well. However, for Cyprus a distinction needs to be made between coastal sites with a complex, heterarchical social structure and a site such as Kalavasos-Ayios Dhimitrios (site no. 114), which had a more hierarchical organisation. There is clear evidence at the latter site that large quantities of Mycenaean dinner vessels were assembled by the inhabitants that were associated with the exceptional building X. ${ }^{35}$ At Enkomi the use of Mycenaean pots was restricted only during an early period. I have argued that it was due to the competition between various population groups in this city that Mycenaean pottery became available to many people in the urban society. In contrast with the Levant, then, the use of Mycenaean pottery in Cyprus originated in the upper levels of society, even though during LC II it gradually became available to other groups.

In the central Mediterranean, during the first phase of Mycenaean pottery import, specific groups in the societies of Vivara (site no. 342) and Lipari appeared to have acquired more Mycenaean vessels than others. Considering the relation between the development of social complexity in this part of the Mediterranean and supra-regional exchange, we may assume that the social groups which managed to control access to Mycenaean pottery were among the emerging élite groups. LH IIIA2 and LH IIIB pottery seems to have been more homogeneously distributed. However, it has also been observed that such pottery was concentrated at relatively few large centres. Moreover, the inventory of

33 Bietti Sestieri 1988, 34; Marazzi 1988, 6-7; 1994, 3132; Di Gennaro 1997.

34 It remains to be seen whether the concepts of sub-élite and substitute-élite, which are employed by Sherratt $(1999,185)$ to refer to the groups at whom Mycenaean pottery was aimed, is valid in this respect. As is evident from the case of Ourtenu, in whose house at Ugarit various Mycenaean kraters have been found, such pots could be assembled by a person who possessed considerable wealth and high status, but was not of royal lineage, see Yon 1995, 427.

35 South 1988; South \& Russell 1993, 305-306; Steel 1998. 
tomb XXI/47 at Thapsos shows that an élite group could acquire a wider repertoire of Mycenaean pottery than other people. In the third phase of Mycenaean pottery imports in Italy, there is again evidence that specific groups were able to acquire substantially more Mycenaean vessels than others. Obviously, during all phases, the use of Mycenaean pottery was to some extent concentrated among élite groups on the coasts in the central Mediterranean. Other groups in the coastal settlements, however, appear to have had access to these pots as well.

Evidence for cult or other ritual activities within settlements is scarce for the central Mediterranean in the period concerned. ${ }^{36}$ The Mycenaean cups in the fill above the floor of the exceptional building $\delta$ IV at Lipari may indicate that such vessels were used in local rituals. It is very probable that during the Italian Bronze Age ritual practices continued to be carried out in caves, as they had during the Neolithic. ${ }^{37}$ Probably, such rituals were also carried out in the caves at Manaccora (site no. 297) in Apulia or Sassano (site no. 340) in Campania, both of which yielded Aegean pottery. ${ }^{38}$ Mycenaean pottery was certainly used in Levantine cultic rituals, where they were an integral part of religious practices at various levels in the urban societies of the Levant. This was also the case in Cyprus, where the Mycenaean juglets in Athienou were evidence for religious use. Obviously, the three areas under investigation in this study are similar in that Mycenaean vessels were included in cultic rituals. Of course, it is likely that the specific roles of these vessels within the rituals varied.

\section{DIFFERENTIATION WITHIN THE REPERTOIRE OF MYCENAEAN}

\section{P O T T E R Y}

The variations in the chronological build-up of the Mycenaean repertoire between the three areas have been commented upon before. The concentration at Hazor of LH II-LH IIIA1 finds in an area where the palace was located and near the official temple in area $\mathrm{H}$ has been taken as evidence that their use was confined to specific circumstances and high-level social groups. The evidence from Ugarit, however, where such finds came from various contexts, indicated that this was not the case everywhere in the Levant. In Cyprus, both at Enkomi and in Toumba tou Skourou (site no. 105), the use of Aegean pottery from the very first part of the Late Bronze Age was clearly restricted to specific groups of people. However, the wider distribution of LH IIB-LH IIIA1 vessels shows that during LC II this class of pottery gradually became available to more people.

Much more than in the Levant, one can observe a pattern in Cyprus in which the significance of Mycenaean pottery gradually changes from a rare, exotic prestige good to a commodity that is a rather common element in the material culture at many sites on the island. Differentiations between settlements and regions were being forged in Cyprus precisely during the period in which Mycenaean pottery was imported..$^{39}$ It is likely that the close association of Mycenaean pots with Cypriot élite practices made these vessels suitable to be actively involved in sumptuary strategies between various groups on the island. This socially active role of Mycenaean pottery triggered processes of emulation,

${ }^{36}$ Malone, Stoddart \& Whitehouse 1994, 188.

37 Whitehouse 1990; 1992.

$3^{8}$ For Manaccora, see Baumgartel 1951; 1953. For
Sassano, see Pellegrini \& Piperno 1998.

39 Knapp 1988a; 1996a, 219-222; Merrillees 1992, 320325; Keswani 1996, 217-218. 
due to which this class of material became available to many people in Cyprus. ${ }^{40} \mathrm{~A}$ similar pattern is not visible for the Levant, where relationships between sites and regions during the Late Bronze Age were much more stable. ${ }^{41}$ In this area, the social role of Mycenaean pottery seems to have been aimed at processes of opposition rather than emulation.

In the first phase of Mycenaean contacts with Italy, imported vessels were widely used by various social groups, but some people managed to acquire more of it than others. Later, LH IIIA2-LH IIIB pottery seems to have been concentrated at a few major centres, which is indicative of regional strategies of restriction. In the third phase of the use of Mycenaean pots in Italy, élite groups seem to have been able to monopolise specific parts of the Mycenaean ceramic repertoire. As in Cyprus, then, Mycenaean pottery in the central Mediterranean was actively involved in the changing relations between various groups in the society, both at a local and regional level. ${ }^{42}$

In Cyprus Mycenaean dinner vessels could be used in ceremonies of conspicuous consumption, as has become evident in particular at Kalavasos-Ayios Dhimitrios (site no. 114) ${ }^{43}$ In centres with a more complex social structure, such as Enkomi, a special significance of Mycenaean dinner vessels could only be noted for earlier periods; the competition between various élite groups gradually devaluated the exclusivity of such Mycenaean vessels. By the end of LC IIC, Aegean-type dinner vessels were widely used by many groups all over the island. Mycenaean storage vessels, apparently, were also used by many people in Cypriot society and were not exclusively associated with élite behaviour and sumptuary display. ${ }^{44}$ As a result, the appreciation of this type of pottery does not show a clear chronological development: small quantities of Mycenaean storage pots were widely dispersed from $\mathrm{LH}$ IIIA1 onwards. The fact that the Cypriot ceramic industry at the end of LC IIC emulated dinner vessels in particular, is a clear illustration of the differences in attitude towards Mycenaean storage and dinner vessels on the island..$^{45}$

In the Levant, in primary centres such as Ugarit or Megiddo (site no. 181), there does not seem to have been a difference between the appreciation of Mycenaean storage and dinner vessels. However, at inland centres with a far more restricted Mycenaean repertoire, such as Hazor, Kamid el-Loz (site no. 168) and Beth Shean (site no. 187), Aegean dinner vessels were confined to official, high level contexts. This indicates that the appreciation of Mycenaean dinner vessels in the Levant was highly dependant on their availability. The high appreciation of relatively ordinary Mycenaean storage vessels at Deir 'Alla shows that a similar process took place with respect to storage vessels which were distributed to sites in more marginal areas, such as Transjordan and the Palestine uplands. To a far larger extent than in Cyprus the appreciation of various Mycenaean functional classes in the Levant appears to have been due to strategies of restricted regional distribution. In this respect, it is interesting that Levantine production of Mycenaean-type pottery which began only at the very end of the Late Bronze Age and was of limited scale, initially was confined to Mycenaean closed vessels such as stirrup

$4^{\circ}$ On the subject of emulation, see, for example, Veblen 1899, 22-34; Appadurai 1986, 57; Glennie 1995, 180181; Miller 1995, 27-28.

4 I Liverani 1987, 69-70; Falconer 1994, 326; Bunimovitz 1995, 324-325.

42 Marazzi \& Tusa 1979a, 314-323; Bergonzi 1985, 359369; Bietti Sestieri 1988, 46-49; Marazzi 1994, 92-93.

43 South \& Russell 1993, 304-306; Steel 1998, 291 note
43.

44 Steel 1998, 294-296.

45 The vessel types which are most frequently mentioned as being produced in Cyprus from LC IIC onwards are shallow bowls, deep bowls and 'Rude' or 'Pastoral' style kraters; see Sherratt \& Crouwel 1987, 341-342; Kling 1987, 103, 106; 1989, 130, 170-173; Sherratt 1991, 191-193. 
jars and flasks. ${ }^{46}$ Both vessel types probably have to do with oil and were widely used and highly regarded in places far away from the coast.

In the central Mediterranean, during the first period of Aegean contact, there does not seem to have been any difference in the appreciation of Mycenaean dinner and storage vessels. Indeed, it was the imported nature of the vessels, rather than their functions, which was of particular significance. During the period in which LH IIIA2-LH IIIB pottery was distributed in Italy, differences in the appreciation of dinner and storage pottery could occur, but was not a general phenomenon. In a later period, however, Aegean-type dinner vessels appear to have acquired a special significance, at least in southern Italy, as is clear from the concentration of this functional class in the complesso a monte at Broglio di Trebisacce. Apparently, the appreciation of Mycenaean vessels in the central Mediterranean increasingly depended on specific cultural practices with which they could be associated, for example dining and storage activities.

In the Cypriot coastal centres specific groups appeared to have used Mycenaean pictorial pottery, in particular large kraters, to distinguish themselves in their funerary ritual. It is difficult to identify these groups within Cypriot society, but the high appreciation of Mycenaean pictorial pottery at KalavasosAyios Dhimitrios (site no. 114) suggests that this type of pottery was related to practices of consumption by Cypriot élite groups. A similar appreciation of Mycenaean pictorial pottery has not been encountered in the Levant. At Ugarit, such pottery was found in a variety of contexts in all areas of the site and the number of pictorial vessels from tombs was actually quite low. Although individuals living in the Levant certainly will have noted the pictorial representations on Mycenaean pots and may have had specific associations with them, a broader social significance of Mycenaean pictorial scenes was confined to Cyprus.

Mycenaean pictorial vessels in Cyprus were not used exclusively in funerary practices. At Enkomi, such pottery was widely distributed in the settlement and it was not restricted to specific buildings or contexts. This indicates that the special significance of Mycenaean pictorial pottery was related to Cypriot burial practices. It is not so much that the pots and their decoration were special, but the fact that they could be included in funerary ceremonies of specific persons. A similar relationship between burial practices and Aegean pottery is to be seen with respect to coarse ware stirrup jars, which have been found in small numbers in tombs at various Cypriot sites. Obviously, the transportation vessels, with or without their contents, acquired a meaning beyond their functional use when they were deposited in a tomb. Coarse ware stirrup jars have also been found in a number of tombs at Levantine sites. ${ }^{47}$ All the same, the practice appears not to have been very widespread in either Cyprus or the Levant.

Mycenaean conical rhyta and related ritual pot shapes were highly regarded in Ugarit. ${ }^{48}$ The evidence from the sanctuaire aux rhytons shows that these vessels were used in local rituals, which was also the case elsewhere in the Levant, such as at Tell Abu Hawam (site no. 175) and Kamid el-Loz (site no. 168). ${ }^{49}$ It is logical to assume that the high appreciation of these vessels in the Levant originated in their suitability for inclusion in local rituals. This is another example of cultural practices being re-

${ }^{46}$ Killebrew 1998, 161-162.

47 As we have seen, this was the case at Ugarit for six Aegean coarse ware stirrup jars. In addition, such vessels occurred in a tomb at Megiddo (site no. 181) and Ras Ibn Hani (site no. 143), see Guy \& Engberg 1938,
157; Toueir 1975, 68.

${ }_{48}$ See also Van Wijngaarden 1999c.

49 For Tell Abu Hawam, see Balensi 1980, 93. 441; for Kamid el-Loz, see Hachmann 1980, 84, 87. 
sponsible for the special significance of a Mycenaean vessel type. The fact that Mycenaean terra-cotta figurines in the Levant have been found primarily in domestic contexts indicates that the use of these items, likewise, was determined by local behaviour. In Cyprus, Mycenaean rhyta and figurines were more scarce than in the Levant. The deposition of a number of Psi-type figurines in a pit in temenos A at Kition (site no. 63),,$^{50}$ or the Mycenaean rhyta near the sanctuary at Myrtou-Pigadhes (site no. 99 $)^{51}$ indicate that these items could be associated with Cypriot cultic practices. It is likely that the use of such ceramic items in local rituals made them particularly subject to strategies of restricted distribution. The fact that by far the most Mycenaean rhyta and figurines have been found at Ugarit shows, firstly, the central position of this city in supra-regional exchange networks and its power to acquire and control highly desired items. Secondly, it demonstrates the extent to which local customs could influence the supra-regional circulation of Mycenaean pottery.

The different Aegean-type ceramic wares, such as matt-painted pottery in the first period of Aegean contacts and ceramica grigia in a later period, generally, have been found together and there is no evidence that they were used by different groups of people. At the same time, it has been noted that these ceramic classes were not distributed equally among sites in the central Mediterranean. This suggests that there were regional preferences for specific classes of Mycenaean pottery. In contrast with the Levant and Cyprus, not so much local cultural practices, but the specific workings of internal systems of distribution should be regarded as responsible for the disparities in the distribution pattern of Mycenaean pottery in the central Mediterranean. Only in the later period, when there is evidence that élites in southern Italy monopolised Mycenaean-type drinking vessels, it is clear that the appreciation of Mycenaean pots became directly related to local cultural practices.

\section{F U N E RARY US E}

In each of the three areas under consideration, Mycenaean pottery has found its way into the tombs of the deceased. Even more so than is the case for settlement contexts, one should be very careful in comparing archaeological patterns relating to funerary behaviour of different culture areas. As archaeological deposits, tombs are the result of very specific rituals with a highly symbolic significance. Not only is it likely that such rituals varied considerably in time and space, they may not have been the same for different groups within one society. ${ }^{52}$ In general, funerary patterns can only be understood in their proper cultural context. Nevertheless, I feel that it is useful to compare the extent to which Mycenaean pottery was included in funerary contexts in the three areas. This may shed light on the suitability of Mycenaean pottery to be part of ceremonies of a symbolic nature. In particular, it may be useful to investigate the extent to which specific groups in the respective societies deliberately chose Mycenaean vessels as a means of expression in funerary behaviour.

The most marked pattern considering the funerary use of Mycenaean pottery is visible for the Levant. Many groups in the urban societies along the Syro-Palestinian littoral included small quantities of Mycenaean pottery in their tombs, in particular small storage vessels that may be related to the uses of oils in Levantine funerary practices. ${ }^{53}$ At various places, in the Levant, however, specific groups included large quantities of Mycenaean pottery in their tombs, usually encompassing a wide range of pot shapes and often associated with other imports. It seems that for some groups the imported nature

so Karageorghis 1985a, 98-99, 105, 170.

sI Taylor 1957, 1; Catling 1957, 42: no. 187.
52 O'Shea 1981, 49-52; Morris 1987, 41-42.

53 Kinet 1981, 146-147; Salles 1995, 176. 
of the Mycenaean vessels was a reason to assemble them and to display them ostentatiously in a funerary ritual. It is impossible to identify with certainty the groups in the Levant for whom imported Mycenaean vessels possessed such a symbolic significance. However, these groups were not part of the uppermost élite, but of the more average urban population.

In Cyprus the practice of including Mycenaean pots in tombs seems to have been even more widespread than in the Levant. Not only did such vessels occur widely in many tombs at Enkomi; they have been found in funerary deposits all over the island. At Kalavasos-Ayios Dhimitrios (site no. 114) there is clear evidence that the inclusion of Mycenaean drinking vessels in tombs was restricted to élite groups, showing that funerary use of this type of pottery was related to behavioural patterns of the living. ${ }^{54}$ The wide occurrence of Mycenaean dinner vessels in tombs at Enkomi and other coastal centres can be explained by the devaluation of such pottery due to competition between various élite groups. The fact that specific groups at Enkomi seem to have included more pictorial kraters in their funerary inventories than other people probably indicates a specific sumptuary strategy in this continuous competition. Mycenaean storage vessels seem to have fulfilled a similar role at smaller sites.

The practice of including Mycenaean pots in tombs in Cyprus, then, seems to have been part of strategies in the competitions between various groups in the society of the living. The widespread occurrence of Mycenaean pots in tombs on the island indicates that specific élite practices became increasingly available to many people in Cypriot society. In contrast, in the Levant the close association of a specific group of people with Mycenaean pottery appears to have resulted in a highly specific funerary pattern restricted to a minority of graves. For the central Mediterranean, it is clear that Mycenaean pottery could also be included in funerary ceremonies. However, this practice may have been less widespread than in either the Levant or Cyprus. The extraordinary repertoire of Mycenaean (and Cypriot) vessels from tomb XXI/47 at Thapsos, as well as from grave 12 in the tumulus at Torre Santa Sabina (site no. 305), indicates that this pottery could be an active component of funerary strategies of display by élite groups.

\section{ONCLUSIONS}

In each of the three areas which have been the focus of this study, Mycenaean pottery is completely different from the products of the local and regional potting-industries. In the Levant, during the Late Bronze Age, potters had returned to using a slow wheel for ceramic production and painted decoration was not very common. ${ }^{55}$ In Cyprus, even though a standardised wheel-made ceramic industry developed during LC IIC, pottery generally was handmade and comprised a comparatively restricted range of vessel types ${ }^{56}$ Painted decoration, mostly consisting of abstract patterns, had a long history of the island, but most of the fine wares were left plain. In the central Mediterranean, the local impasto was also hand-made, with a plain burnished surface or with incised decoration. ${ }^{57}$ In comparison with the local pottery in each of these areas, the imported Mycenaean pots represented high-quality products: they were hard-fired, often elaborately painted and they came in a wide range of pot shapes. It is likely that these physical properties of the Mycenaean pots played a role in their attraction for consumers in the Levant, Cyprus and the central Mediterranean. Likewise, we may assume that Myce-

54 South \& Russell 1993, 306; Steel 1998, 291 note 43 in particular.

ss Leonard 1989, 20; Franken 1992, 149-152.
56 Sherratt 1991, 191-193; 1994a, 37.

57 Vagnetti 1999, 137. 
naean pots could fulfil specific functions which were relevant, such as storing oil or drinking liquids. However, as has become clear in all the preceeding chapters, Mycenaean imports had a significance in each of the three areas that went far beyond their physical and functional characteristics.

In Cyprus the cultural significance of Mycenaean pots originated in élite practices in the coastal centres. The imported ceramic vessels, which were of better quality than native wares, were used by élite groups to distinguish themselves. This was the case especially for Mycenaean dinner vessels, which could directly be included in élite cultural practices such as ceremonial dining. The élite connotations of this class of pottery ensured that it became a symbol of a cosmopolitan lifestyle. As such, Mycenaean pottery could be an active component in the sumptuary strategies which defined relations between various social groups on the island. On a local level, this is visible for example in the concentration of Mycenaean pictorial kraters in a restricted number of tombs in Enkomi. On a regional level, the symbolism of Mycenaean pottery is apparent from the presence of a wide repertoire of such pots at smaller, secondary and tertiary sites. The active role of Mycenaean pottery in social competition led to emulation and redefinition of the status of these objects. ${ }^{58}$ As a result, we can see that during LC II Mycenaean vessels gradually became available to many groups everywhere on the island. The end result of this process was that Mycenaean-type pottery became such an integral part of the Cypriot material record that it eventually was incorporated into the local ceramic industry.

In the Levant the cultural significance of Mycenaean pottery originated not so much in practices of the ruling élite, but in its use by various groups among the urban populations. For such groups, the use of these imported items created possibilities to define their position in the complex social fabric of the Levantine city-states. The specific association of some people in the Levant with large quantities of Mycenaean pottery among other imports in funerary rituals shows that this pottery could be an active part of sumptuary strategies on a local level. Sites in the Levant situated far away from the coast have produced a far smaller range of Mycenaean vessels. This can be taken as evidence for an active role of Mycenaean pottery in strategies of restricted distribution, which defined oppositions between urban and rural population groups. Whereas in Cyprus Mycenaean pots were used to enhance the interdependence between primary centres and secondary and tertiary sites, the same pots were used in the Levant to emphasise differences between different types of settlement. Outside the large urban centres, Mycenaean pottery did not become an integral part of the material culture. As a result, the Mycenaean pottery had a limited effect on the local potting industry, which, in contrast to Cyprus and Italy, initially incorporated only a few container shapes.

In the central Mediterranean the presence of various classes of Mycenaean pottery was related to the importance of overseas contacts in this area. As such, the cultural significance of Mycenaean pottery originated with the social groups on the coast who operated regional networks of maritime exchange. There is evidence that, initially, Mycenaean pots were symbols of relations with an international world. This indicates that the imported nature of the vessels was of prime importance for their significance. The presence of a varied body of Mycenaean pots in one tomb at Thapsos and in a grave at Torre Santa Sabina shows that this class of pottery could be an active component in funerary strategies on a local level. The concentration of large amounts of LH IIIA2 and LH IIIB pots at a few sites such as Taranto-Scoglio del Tonno and Lipari shows that strategies of restricted distribution on a regional level were at work as well. In a later period, when there is evidence that élite groups in southern Italy monopolised Mycenaean-type drinking vessels, it is clear that the appreciation of Mycenaean pots became intrinsically related to local cultural practices. The diminished significance of the im-

s8 Cf. Bourdieu 1984, 208-225; Appadurai 1986, 21, 56-

57 ; 
ported nature of the Mycenaean pots is reflected in the development of local manufacture and exchange of Mycenaean-type pottery in various parts of the central Mediterranean.

It is obvious that the cultural significance of different types of Mycenaean pottery was not the same everywhere. Mycenaean pots may be considered as 'added value products' ${ }^{59}$ Neither the material of which these pots are made nor elaborate techniques of manufacture endowed these pots with intrinsic value. Susan Sherratt has suggested that Mycenaean vessels acquired significance through association with objects of different material, in particular metals and textiles. ${ }^{60}$ The range of Mycenaean vessels distributed in the Mediterranean, albeit limited in comparison to the Aegean, consists of different pot shapes and types of decoration. Not all parts of this repertoire can be related to metals or textiles. The stirrup jar, for example, which is one of the most frequently occurring vessel types everywhere, is a purely ceramic form. ${ }^{61}$ Likewise, the decoration of most pots consists either of simple lines or of floral and abstract patterns which have a long history in Aegean (vase) painting. ${ }^{62}$

Instead of a general association with objects of other materials, value seems to have been added to Mycenaean pots through their incorporation in varying social strategies and cultural practices on a regional and local level. In Cyprus, the importance of metal production and international maritime exchange gave products associated to these activities a special significance. ${ }^{63}$ The parallels between Mycenaean pots and metal vessels or between decorative motifs on ceramics and textiles, then, can also be understood as an aspect of the specialised production for an external market. As also seems to have been the case for pictorial pottery, this specialised production aimed specifically to enlarge the suitability of Mycenaean pots to be associated with Cypriot social strategies.

In all three investigated areas, Mycenaean vessels and figurines were part of symbolic cultic and funerary ceremonies. The acquisition of symbolic meanings is a general characteristic for manufactured objects that are imported into foreign cultural contexts. ${ }^{64}$ This may have been the case in particular for objects made from material with little intrinsic value such as pottery. The variations in the cultural meanings that consumers attached to Mycenaean pots may be considered as the rationale behind the distribution of this pottery in the Mediterranean. Because of these variations, Mycenaean pottery could serve in strategies on a supra-regional level, the mechanism of which was the long-distance exchange of goods.

59 Sherratt 1994a, 62-63; 1998, 294-296.

6о Sherratt 1999, 186-189.

6г Haskell 1985, 222-223.

62 Crouwel \& Morris 1985, 98.
63 Knapp 1996a, 19-22.

64 Thomas 1992, 35-36; Strathern 1992, 177; Van Dongen 1996, 12-14. 



\title{
20 The role of Mycenaean pottery in Mediterranean exchange
}

\author{
I N T R O D U C T I O N
}

I argued in the first chapter to this book, that supra-regional exchange in the eastern Mediterranean was complex and conducted on various social levels. Many groups of people were involved in these exchanges, among whom were palace-based traders and independent merchants. Considering the complexity of supra-regional trade, the question of who exchanged and transported the Mycenaean ceramic vessels is not the right one to ask. ${ }^{1}$ Rather, we should investigate the interest of particular groups in the distribution of Mycenaean pottery in the Mediterranean.

The motivations which constituted the rationale behind Bronze Age trade in the Mediterranean probably ranged from the purely diplomatic to the purely commercial, while different actors may not have had the same motivations at various points in the exchange networks. ${ }^{2}$ Since Mycenaean pots probably travelled through various modes of exchange before being deposited in the archaeological record, it is useless to ask about the type of exchange or the specific mechanisms of which these vessels have been part. Instead, it seems relevant to investigate the role of the Mycenaean pots in comparison to other trade goods.

\section{ROLE OF THE C Y P RIOTS}

The large quantities of Mycenaean pots in Cyprus, the size of which is small in comparison which such vast areas as Anatolia, the Levant, Egypt and the central Mediterranean, indicates that the island played a special role with regard to the distribution of Mycenaean pots in the Mediterranean. Such a special role is emphasised by the observation that in the Levant and Egypt, Cypriot and Mycenaean pots are often found together. Cyprus had a long tradition of pottery export to the Levant and Egypt and it seems logical to assume that the Mycenaean pots were supplemented to an already existing international circulation of Cypriot ceramics.

During the Late Bronze Age, a complex urbanised society developed in Cyprus which was related to the exploitation of copper resources for external exchange. ${ }^{3}$ The importance of copper production

\footnotetext{
The discussions surrounding the 'nationality' of the Cape Gelidonya and Ulu Burun shipwrecks, both of which had cargoes with goods from many geographical areas, are examples of the difficulty of applying ethnic labels in the study of the complex trade networks in the Late Bronze Age Mediterranean, see Bass 1967, 165; 1991, 74; Pulak 1988, 37; 1997, 252-254.
}

2 In other words, what is 'gift exchange' for one, can be a commercial transaction for the trade partner. See, for example, Humphrey \& Hugh-Jones 1992, esp. p. 14 On the arbitrariness of distinguishing between these two types of exchange, see Parry \& Bloch 1989, 7-8.

3 Knapp 1985, 249-250; 1986b, 70-72; 1996a, 20-22; Keswani 1993, 78. 
and of international trade for the development of complex societies in Cyprus gave items relating to these activities a special significance. It is for this reason that Mycenaean pottery in Cyprus could become a symbol of a cosmopolitan lifestyle and could fulfil active roles in internal local and regional strategies.

The active role of Mycenaean pottery in Cyprus originated in an élite lifestyle and was related to specific cultural practices, such as ceremonial dining and activities to do with unguents and oils. The specialised production in the Aegean of Mycenaean pottery for a foreign market, as is testified by the existence of the Levanto-Helladic class of pottery, ${ }^{4}$ was aimed specifically at these cultural practices in Cyprus. For this reason, the pictorial scenes on Mycenaean kraters, seem to have been socially relevant for burial practices in Cyprus, whereas this was not the case in the Levant. For Cyprus, then, it cannot be stated that pictorial kraters where primarily aimed at sub- or substituteélite groups, as has been argued by Susan Sherratt. ${ }^{5}$ Even if, through emulation and devaluation, these pots ended up among lower groups of the Cypriot population, their significance originated in élite practices.

The development of a complex urban society in Cyprus during the Late Bronze Age is rather late in comparison with neighbouring areas such as the Levant and Hittite Anatolia. ${ }^{6}$ In spite of references to the king of Alashiya in the diplomatic records of the Hittite area, the Levant and Egypt, ${ }^{7}$ it is unlikely that administrative centres comparable to Levantine or Mycenaean palaces ever developed in Cyprus. Even though the ashlar structures at Alassa, Maroni-Vournes and Kalavasos-Ayios Dhimitrios testify to the existence of hierarchical structured polities, these do not seem to have controlled the flow of goods in a manner requiring centralised administration. ${ }^{8}$ Instead, the movement of goods within Cyprus seems to have been based upon series of exchanges. ${ }^{9}$ The importance of trade in the island probably is reflected in the existence of increasingly powerful commercial groups in coastal centres such as Enkomi. ${ }^{10}$ The high concern of the king of Alashiya with the commercial aspects of the ceremonial exchange with the pharaoh of Egypt also points to the particular importance of commercial exchange in Cyprus. ${ }^{11}$

In the Levant, raw materials and manufactured goods found their way outside the sphere of ceremonial exchange and circulated among urban groups and lower strata of the population as exchange goods. ${ }^{12}$ Even though such transactions probably were not completely devoid of ceremonial aspects, commercial motives were the most important. The absence of pottery from the epigraphical record indicates that this class of material circulated precisely in such low-level exchanges. ${ }^{13}$ The concentration of the use of Mycenaean pots among urban groups in the Levant is in accordance with such a pattern. It indicates that commercial exchange was conducted between urban inhabitants in Cyprus and comparable groups among the average population in the Levant and that Mycenaean pottery became part of these exchanges. The observation made above that the Levant lagged somewhat behind Cyprus in the beginning of the import of Mycenaean pots, indicates that the Levant, at least initially, relied on Cypriot initiative to acquire these vessels.

4 Sherratt 1982, 183; 1999, 182-184; Jones 1986a, 599600 .

Sherratt 1999, 185.

6 Knapp 1997, 47; Keswani 1996, 217-220.

7 Hellbing 1979, 67; Knapp 1996b, see, however, Merrillees 1987.

$8 \quad$ Keswani 1996, 235.
9 Keswani 1993, 78-80; Webb \& Frankel 1994; Knapp 1997, 48-52.

Io Sherratt 1998, 297; 1999, 181-182 note 44.

II Zaccagnini 1973, 119-120.

I2 Zaccagnini 1984, 159.

I3 Liverani 1986, 411; Sherratt 1999, 177-178. 
One conclusion of this study is that competition on local and regional levels between various groups within Cyprus devaluated the significance of Mycenaean pottery on the island. Mycenaean pots were part of a more varied body of paraphernalia relating to an international world, as is evident from the ivory rhyton, cylinder seals and a scarab found in Athienou and the collection of Cypriotmade 'Mediterranean' items in Apliki. We may assume that devaluation similar to the one observed for Mycenaean dinner vessels also affected other prestige items in Cyprus. Continuous competition in systems of exchange may have resulted in an increasing demand for an ever-widening repertoire of prestige goods. The large amounts in Cyprus of a wide variety of luxury imports such as jewellery, glass, faience and ostrich eggs are possibly the result of the active social role of imports. ${ }^{14}$ The most likely sources for these materials were the urban populations of Levantine city-states, with whom the Cypriot traders were in close contact. As such, the Mycenaean pottery became important to Cypriot urban social groups not only for its suitability to serve in local and regional sumptuary strategies, but also to acquire other valuables. It is probably this regional and supra-regional importance of Mycenaean pots that caused Cypriots to be actively involved in the Aegean in the transport and even the production of Mycenaean pots. ${ }^{15}$

The range of Mycenaean pots in the Levant and Cyprus is relatively homogeneous. Considering the comparatively large amounts of this type of pottery in Cyprus, it has been suggested that the vessels arrived in the Levant on ships which had previously put in at Cypriot harbours. ${ }^{16}$ The Mycenaean vessels in the Levant would then be remainders from cargoes aimed at Cyprus. Such a scenario does not take into account the cultural choices made in large primary centres in both Cyprus and the Levant with regard to which Mycenaean vessels to import. At various places in this book, I have shown that considerable variations in the Mycenaean repertoires occur between regions and between individual sites. Rather than the direct result of sailing routes, the circulation of Mycenaean pots in the Mediterranean was influenced by local cultural practices of which these vessels became part. The exploitation of the differences between these local practices may have enhanced the active role of Cypriot middlemen in the circulation of Mycenaean pottery. ${ }^{17}$

\section{THE RELATION OF MYCENAEAN POT TERY WITH OTHER GOODS}

The international economy in the Late Bronze Age Mediterranean was probably based on the circulation of raw materials such as copper and tin. This may be concluded from the remains of three shipwrecks in the Mediterranean dating to this period, each of which contained large amounts of these metals. ${ }^{18}$ In addition, as is particularly clear from the wreck at Ulu Burun, various other raw material such as glass and ivory were traded, as well as a whole range of manufactured items. ${ }^{19}$ In contrast to

I4 See, for example, Knapp 1985, 149-150.

Is Hirschfeld 1993, 313-315; 1996, 291-293.

i6 Hankey 1967, 146-147. Catling (1980, 17-18) has raised the possibility that such ships first went to Ugarit, after which Mycenaean vessels were distributed to Cyprus.

17 On the importance of Cypriot middlemen in Mediterranean exchange in the thirteenth century, see Sherratt 1998, 296; 1999, 187.
I8 For the wreck at Cape Gelidonya, see Bass 1967, 1991. For the Ulu Burun wreck, see Bass 1987, 1991; Pulak 1988, 1997. For a wreck excavated off the coast near Haifa, see Galili, Shmueli \& Artzy 1986.

I9 Among all the goods which are repeatedly mentioned by scholars as possible trade goods are wine, oils, precious stones and textiles; for an overview, see Cline $1994,95$. 
many other trade goods, decorated pottery is not made of a material that is scarce and its relative significance among trade goods is difficult to assess. It has been suggested that pots travelled as spacefillers or ballast in Bronze Age ships which transported a more valuable cargo. ${ }^{20}$ However, the suitability of a breakable material such as pottery to serve as ballast or space fillers may be questioned..$^{21}$ In addition, one of the results of my research is that Mycenaean pots served relevant roles in the societies of the Levant, Cyprus and Italy. It is unlikely that the supply of such a culturally significant class of artefact depended on available space in ships carrying other cargoes.

Due to the significance of Mycenaean pots in social strategies and cultural practices in the Levant, Cyprus and in the central Mediterranean, this class of pottery was exchanged and sought after in its own right. Even though a fair proportion of the Mycenaean ceramic vessels in all areas are dinner vessels, storage vessels are at least as numerous. It is likely that the significance of Mycenaean storage vessels in exchange processes was related to its contents, which probably consisted of wine, oils and unguents. ${ }^{22}$ Such substances appear to have moved in fairly large quantities all over the Mediterranean, as is clear from their frequent occurrence in the epigraphical record and from the distribution of a wide variety of small container vessels in clay, faience and stone. ${ }^{23}$ The exchange of these substances often had a kind of 'coals to Newcastle' effect, in the sense that unguents and oils often appear to have been exchanged for similar substances. ${ }^{24}$ It is possible that the containers added value and identity to these substances, as is also the case for modern perfumes. Small Mycenaean stirrup jars and flasks had been in use for very long periods at Deir 'Alla. Since it is likely that these had been refilled a number of times, it may well be that the ceramic containers themselves signalled the quality of their contents.

Mycenaean ceramic containers, dinner vessels and figurines were part of a body of manufactured objects that circulated widely over very large areas. A number of these objects may be recognised in the cargo of the Ulu Burun shipwreck: glass and amber beads, Egyptian scarabs and Mesopotamian and Levantine cylinder seals. ${ }^{25} \mathrm{~A}$ wide variety of objects of similar nature have been found in the Aegean, ${ }^{26}$ among which are the concentration of worn Cypriote and Levantine cylinder seals in Boeotian Thebes. ${ }^{27}$ In many contexts which have been investigated in detail in my study, similar objects were associated with Mycenaean pots: Cypriot ceramic vessels and wall brackets, Egyptian scarabs and amulets, Levantine cylinder seals, glass beads and bone combs. It is clear that there must have been substantial exchange of such objects, to which items of perishable material should probably be added. The importance of trade in such manufactured artefacts appears to have increased gradually as the volume and diversity of goods increased. ${ }^{28}$ Rather than depending directly on a trade in raw materials, Mycenaean pots appear to have been part of a growing body of manufactured objects that circulated widely and symbolised an international culture. As the results of my research indicate, the specific use of these symbols could vary among different places in the Mediterranean.

20 Artzy 1985.

21 McGrail 1989, 357-358; Sherratt 1999, 179 note 41.

22 Leonard 1981, 94-101; Shelmerdine 1984, 94.

23 Leonard 1981, 92-99; Cline 1994, 95-97.

24 Liverani 1972, 299-305.
25 Bass 1987, 1991; Pulak 1988, 1997, 243-250.

26 Lambrou-Philipson 1990a; Cline 1994, 133-233.

27 Porada 1981/1982.

28 Sherratt 1999, 176-178. 


\section{THE EXTENT OF THE INTERNATIONAL TRADING NETWORKS}

The presence in the central Mediterranean of different categories of Aegean pottery dating to the very beginning of the Late Bronze Age indicates that regional exchange networks in this area were interconnected with networks in the Aegean. It has been suggested that during this early period Mycenaean trade was aimed at the central Mediterranean because the eastern Mediterranean networks were being monopolised by the Minoans, and that only after the take-over of Knossos did the eastern routes become available to the Mycenaean..$^{29}$ An argument against such a hypothesis is the fact that LM I-LM II pots in the eastern Mediterranean are not more abundant than contemporary Mycenaean pots. The repertoire of LH IIIA2-LH IIIB pots in Cyprus and the Levant, as well as the homogeneous chronological pattern in the deposition of these pots, indicate that at that time specialised production and marketing was responsible for the distribution of the Mycenaean vessels in the east. ${ }^{30}$ It is likely that such specialisation was necessary for Mycenaean products to become part of the complex network of exchanges in the eastern Mediterranean. The scarcity of LH I-LH II pots in the east probably indicates the lack of specialisation in the economy of the pre-palatial societies in mainland Greece.

The presence of substantial quantities of LH I-LH II pottery in the central Mediterranean indicates that the circulation of goods in this area initially was separated from similar processes in the east. ${ }^{31}$ It is likely that the Canaanite jar fragments found in Vivara and in Monte Grande arrived there together with the Aegean wares through the interconnecting regional networks. ${ }^{32}$ In a later period, the specialised LH IIIA2-LH IIIB products intended for the eastern Mediterranean were never specifically aimed at the central Mediterranean. However, in some cases settlements in the central Mediterranean were able to acquire such specialised products, as is clear in particular from the concentration of Mycenaean pictorial sherds at Termitito ${ }^{33}$ and from the conical rhyton in Antigori in Sardinia. ${ }^{34}$ These $^{2}$ examples indicate that during the Late Bronze Age the circulation of goods in the central Mediterranean increasingly became related to Mediterranean exchange, rather than just to Aegean regional networks. The number of objects in the central Mediterranean from other areas, such as the Cypriot-type vessels found in tomb XXI/47 in Thapsos, also indicate that the central Mediterranean, in the period contemporary to LH IIIB, more and more participated in long-distance Mediterranean networks of exchange. ${ }^{35}$ One of the conclusions of this research is that the significance of Mycenaean pottery in the Italian area during the same period increasingly became connected to specific cultural practices, as had already been the case in Cyprus and the Levant. It is likely that this change is related to the growing involvement of the Italian area in the wider international world of Mediterranean culture.

The picture which has emerged is that the distribution of Mycenaean pottery in the Mediterranean is testimony to the growth of complex networks of exchanges originating in the urban societies of the

29 Cadogan 1973, 168; French 1986, 277; Cline 1994, 92.

30 Sherratt 1982, 183; Jones 1986a, 599-600.

3I Marazzi 1988, 6-7; 1994, 33-37; Re 1999, 412-413.

32 Re 1993, 332; Castellana 1999, 434-435. For Canaanite jars in the Aegean during LH I-LH II, which are not many, see Cline 1994, 49.
33 De Siena \& Bianco 1982, tav. XXII-XXIIIl; De Siena 1986, 51 figs 5-6.

34 Ferrarese Ceruti \& Assorgia 1982, 172-173: no. 5.

35 Lo Schiavo, MacNamara \& Vagnetti 1985, 62-63; Vagnetti 1986, 213; Vagnetti \& Lo Schiavo 1989, 231; Graziado 1997. 
eastern Mediterranean. ${ }^{36}$ Various groups of people participated in these networks, among whom Cypriots must have played a pivotal role. The exchange networks operated on an essentially economic and commercial basis. It is possible that the commercial exchanges were subordinate to high-level ceremonial exchanges and to trade in large quantities of raw material. However, the various types of exchanges may also have been interrelated, as may be concluded from the diverse cargo of the Ulu Burun wreck. ${ }^{37}$ The commercial nature of growing exchange networks is likely to have stimulated continuous expansion and diversification, because of which an ever-increasing variety of goods became part of these trade systems. ${ }^{38}$ The incorporation of the Mycenaean world in the international circulation of goods is attested by the development of specialised pottery production. The central Mediterranean became part of the international networks at a later stage. Within these expanding trade networks, a body of goods emerged, including Mycenaean pots, which became symbols of international culture. As is the case for products of modern mass consumption, the significance of these artefacts varied in different places and regions in the Mediterranean.

36 See also Artzy 1997, 7; Sherratt 1999, 301-302.

37 According to Artzy $(1997,7)$, trade in the Late Bronze Age was specialised to the extent that instigators and financiers of exchange were not necessarily the same people as those who transported the goods.

${ }^{38}$ Sherratt 1999, 176. 
TABLES 

Table I Classification of Mycenaean vessel types

\begin{tabular}{|c|c|c|c|}
\hline group & Furumark form & Furumark Shape & Function \\
\hline \multicolumn{4}{|l|}{ Storage vessels } \\
\hline pithoi & pithos (form 6) & FS 13 & storage \\
\hline \multirow[t]{3}{*}{ jars } & piriform jar (form 7) & FS $14-42$ & storage \\
\hline & amphora (form 11) & FS 66-70 & storage liquid \\
\hline & jar with vertical handles (form 13) & FS 74 & storage liquid \\
\hline \multirow{5}{*}{ small wide-mouthed containers } & piriform jar (form 7) & FS $44-49$ & storage dry \\
\hline & small handleless jar (form 15) & FS 76-79 & storage dry \\
\hline & rounded alabastron (form 16) & FS 80-86 & storage dry \\
\hline & squat jug (form 17) & FS 87 & storage \\
\hline & straight-sided alabastron (form 19) & FS 89-99 & storage dry \\
\hline \multirow[t]{2}{*}{ stirrup jars } & large stirrup jar (form 46) & FS 164 & storage liquid \\
\hline & small stirrup jar (form 46) & FS 165-184 & storage liquid \\
\hline \multirow[t]{3}{*}{ flasks } & lentoid flask (form 47) & FS 186 & storage liquid \\
\hline & vertical flask (form 48) & FS 187-189 & storage liquid \\
\hline & horizontal flask (form 49) & FS 190-193 & storage liquid \\
\hline miscellaneous & lid (form 102) & FS 334-335 & storage \\
\hline \multicolumn{4}{|l|}{ Dinner vessels } \\
\hline \multirow[t]{3}{*}{ kraters } & deep krater (form 3) & FS 6-10 & mixing/serving \\
\hline & amphoroid krater (form 8) & FS 52-57 & mixing/serving \\
\hline & ring-based krater (form 80) & FS 279-282 & mixing/serving \\
\hline \multirow[t]{8}{*}{ spouted jugs } & hole-mouthed jar (form 20) & FS 100-101 & pouring \\
\hline & bridge-spouted jug (form 22) & FS 103-104 & pouring \\
\hline & jug with cut-away neck (form 34-37) & FS 131-137 & pouring \\
\hline & cylindrical jug (form 39) & FS 139 & pouring \\
\hline & beaked jug (form 40-41) & FS $140-149$ & pouring \\
\hline & stirrup jug (form 42) & FS $150-154$ & pouring \\
\hline & strainer jug (form 43) & FS 155-157 & pouring \\
\hline & feeding bottle (form 45) & FS 159-163 & pouring \\
\hline \multirow[t]{3}{*}{ wide-necked jugs } & tall domestic jug (form 23) & FS 105-107 & pouring (storage) \\
\hline & globular wide-necked jug (form 24) & FS 109-111 & pouring (storage) \\
\hline & small globular jug (form 25) & FS 112-115 & pouring \\
\hline \multirow[t]{5}{*}{ narrow-necked jugs } & ewer (form 27) & FS 117 & pouring (storage) \\
\hline & various narrow necked jugs (form 28) & FS 118 & pouring (storage) \\
\hline & narrow-necked jug (form 29) & FS 119-124 & pouring (storage) \\
\hline & handmade miniature jug (form 31) & FS 126 & pouring (storage) \\
\hline & hydria (form 33) & FS $128-130$ & pouring (storage) \\
\hline \multirow[t]{14}{*}{ cups } & handleless cup (form 57) & FS 205-210 & drinking \\
\hline & semi-globular cup (form 58) & FS 211-218 & drinking \\
\hline & straight-sided cup (form 59) & FS 221 & drinking \\
\hline & shallow cup (form 58,60 ) & FS 219-220, 222-223 & drinking \\
\hline & mug (form 62) & FS 224-229 & drinking \\
\hline & carinated conical cup (form 63) & FS 230-232 & drinking \\
\hline & dipper (form 65-67) & FS 234-236 & drinking/serving \\
\hline & ring-handled cup (form 68) & FS 237-238 & drinking/serving \\
\hline & carinated one-handled cup (form 69-70) & FS 239-240 & drinking/serving \\
\hline & carinated two-handled cup (form 70-71) & FS 240-241 & drinking/eating \\
\hline & one-handled conical bowl or cup (form 72-74) & FS 242-244 & drinking/eating \\
\hline & cup with horizontal handles (form 75) & FS 245 & drinking \\
\hline & lug-handled cup (form 77) & FS 247 & drinking/eating \\
\hline & brazier (form 91-92) & FS 311-312 & serving \\
\hline \multirow[t]{2}{*}{ stemmed cups } & goblet (form79) & FS 254-255 & drinking \\
\hline & kylix (form 79) & FS 256-278 & drinking \\
\hline
\end{tabular}


Table / cont.

\begin{tabular}{|c|c|c|c|}
\hline group & Furumark form & Furumark Shape & Function \\
\hline \multirow[t]{2}{*}{ spouted cups and bowls } & spouted cups (form 78) & FS 248-253 & pouring \\
\hline & spouted bowl (form 87) & FS 298-302 & pouring \\
\hline \multirow[t]{3}{*}{ bowls } & deep bowl (form80) & FS 283-288 & eating \\
\hline & kalathos (form 82) & FS 290-291 & eating \\
\hline & shallow bowl (form 83-86) & FS 292-297 & eating \\
\hline \multirow[t]{2}{*}{ stemmed bowls } & stemmed deep bowl (form 88) & FS 303-306 & drinking/serving \\
\hline & stemmed shallow bowl & FS 308-310 & drinking/serving \\
\hline \multicolumn{4}{|l|}{ Ritual vessels } \\
\hline \multirow[t]{4}{*}{ rhyta } & conical rhyton (form 54) & FS 199 & liquids \\
\hline & funnel (form 53) & FS 198 & liquids \\
\hline & pear rhyton (form 55-56) & FS 200-202 & liquids \\
\hline & zoomorphic rhyton & & liquids \\
\hline \multirow[t]{3}{*}{ askoi } & baseless askos (form 50) & FS 194 & \\
\hline & based askos (form 51) & FS 195 & \\
\hline & zoomorphic askos & & \\
\hline \multirow[t]{2}{*}{ composite vessels } & kernos (form 52) & FS 196-197 & \\
\hline & miscellaneous (form 99) & FS 323-325 & \\
\hline
\end{tabular}

Miscellaneous and cooking vessels

cylindrical domestic jar (form 2) $\quad$ FS 2-5

perforated vessels (form 93)

FS 313-315

basket vase (form 94)

FS $317-319$

cauldron (form 95)

FS 320

\section{Figurines}

$\begin{array}{ll}\text { anthropomorphic } & \text { naturalistic } \\ & \text { proto-Phi type } \\ & \text { phi type } \\ & \text { transitional type } \\ & \text { tau type } \\ & \text { hollow psi type } \\ & \text { psi type } \\ & \text { high-waisted psi type } \\ & \text { late psi type } \\ & \text { kourotrophos } \\ & \text { bare head } \\ & \text { polos head } \\ & \text { unusual piece } \\ & \text { chariot } \\ & \text { driven oxen } \\ & \text { ridden oxen } \\ & \text { seated figurines and thrones } \\ & \text { miscellaneous } \\ & \text { wavy type 1 } \\ \text { group figurines } & \text { wavy type 2 } \\ & \text { linear type 1 } \\ \text { linear type 2 } & \text { spine type 1 } \\ \text { spine type 2 } & \text { ladder type } \\ & \text { handled type } \\ & \text { unusual type } \\ & \text { equid } \\ \text { zoomorphic (bovine) } & \end{array}$


Table II Ugarit: Mycenaean finds in settlement context

\begin{tabular}{|c|c|c|c|}
\hline site area & context type & context specification & catalogue numbers \\
\hline Minet el-Beida & Domestic & large habitation complex & 1054 \\
\hline Minet el-Beida & Domestic & on floor next to tomb VII & 188 \\
\hline Minet el Beida & Refuse & next to a pit in a house & $489,490,492,493,494,495,496,497$ \\
\hline Minet el-Beida & Settlement & in area near tomb ॥ & $\begin{array}{l}\text { 1014, 1015, 1016, 1017, 1018, 1019, 1020, } \\
\text { 1021, 1022, }\end{array}$ \\
\hline Minet el-Beida & Ritual & cult area & $133,140,141$ \\
\hline Minet el-Beida & Ritual & cult area with cistern & 129 \\
\hline Minet el-Beida & Settlement & area of surroundig wall & 408 \\
\hline Minet el-Beida & Domestic & on floor of "Cella A" & 134 \\
\hline Minet el-Beida & Settlement & on floor near tomb IV & 161 \\
\hline Minet el-Beida & Domestic & near a wall in "storehouse" & 116 \\
\hline RS Acr. & Ritual & in area of Temple of Dagon & 127 \\
\hline RS Acr. & Ritual & votive deposit with statues & 119 \\
\hline RS PR & Domestic & in southern archives & 429 \\
\hline RS QR & Domestic & House with large bathtub & 261 \\
\hline RS QR & Domestic & Maison au porche a colonnes & 287 \\
\hline RS QR & Domestic & Maison d'âlbatres & $415,416,417,418,421,525$ \\
\hline RS QR & Settlement & street & 330 \\
\hline RS NO & Domestic & house east of tomb 50 & 486,487 \\
\hline RS VB & Domestic & Maison au frittes & $147,410,2017$ \\
\hline RS SA & Domestic & building with the Maison au prêtre Hurrite & 247, 288, 290, 294, 306, 314, 498, 499, \\
\hline RS SA & Domestic & Maison de Patilu-wa & $299,303,357,385,[2022]$ \\
\hline RS VS & Domestic & Maison au Cratère & 244 \\
\hline RS VS & Domestic & Maison B, llot 13, piece 8 & 1061 \\
\hline RS VS & Domestic & maison E, llot 14, piece 22 & 1062 \\
\hline RS VS & Domestic & maison F, Ilot, 13 & 366 \\
\hline RS VS & Domestic & Maison A, Ilot VI & 476 \\
\hline RS CV & Domestic & Maison A & $447,448,449,450,451,452$ \\
\hline RS CV & Domestic & maison B & $453,454,455,513$ \\
\hline RS CV & Refuse & Maison B; storage pit 1269/1270 & $529,531,532,533$ \\
\hline RS CV & Domestic & Maison C & 463,464 \\
\hline RS CV & Domestic & Maison E & $456,457,458,459,530,534,[2025]$ \\
\hline RS CV & Domestic & building south of Sanctuaire aux Rhytons & 502,520 \\
\hline RS CV & Refuse & pit 1237 & 510 \\
\hline RS CV & Settlement & in street 120 & 1041 \\
\hline RS CV & Ritual & Sanctuaire aux Rhytons & $\begin{array}{l}436,438,441,445,461,462,527,535,536-552, \\
1045\end{array}$ \\
\hline RS CV & Ritual & area of Sanctuaire aux Rhytons & $434,437,439,440,442,443,444$ \\
\hline RS CV & Settlement & square 1051 & 446,528 \\
\hline RS CV & Settlement & street 1208 & 521 \\
\hline RS SC & Domestic & chantier A: room 2056 or 2057 & 519 \\
\hline RS SC & Domestic & chantier A: room 2072 & 501,516 \\
\hline RS PS & Domestic & Palais Sud & $\begin{array}{l}214,221,222,273,336,358,383,402,479 \\
1026,1028,1029\end{array}$ \\
\hline RS PR/PS & Settlement & square & 430,431 \\
\hline
\end{tabular}


Table III Ugarit: tombs with Mycenaean pottery

\begin{tabular}{|c|c|c|c|}
\hline site area & tomb nr. & total & catalogue nos. \\
\hline Minet el-Beida & tomb III & 18 & $2-14,474,1001-1004$ \\
\hline Minet el-Beida & tomb IV & 19 & $15-30,468,1005,1006$ \\
\hline Minet el-Beida & tomb V & 15 & $31-42,467,470,475$ \\
\hline Minet el-Beida & tomb VI & 43 & 43-80, 1007-1011 \\
\hline RS Acr. & tomb "sous dalles" & 1 & 505 \\
\hline RS Acr. & tomb 1 & 5 & $83-87$ \\
\hline RS Acr. & tomb 2 & 2 & 81,82 \\
\hline RS Acr. & tomb 4 & 3 & $121,190,411$ \\
\hline RS Acr. & tomb 5 or 6 & 2 & 522,523 \\
\hline RS Acr. & tomb 22 & 1 & 91 \\
\hline RS Acr. & tomb 29 & 2 & 89,90 \\
\hline RS Acr. & tomb 41 & 1 & 88 \\
\hline RS PR & royal tomb & 1 & 488 \\
\hline RS PR & burial near NW corner & 1 & 465 \\
\hline RS QR & tomb 4642 & 5 & $202,215,224,280,284$ \\
\hline RS QR & tomb 4698 & 4 & $259,264,379,382$ \\
\hline RS QR & tomb 6015 & 1 & 370 \\
\hline RS VB & tomb 7 & 1 & 122 \\
\hline RS VB & tomb 13 & 6 & $92-96,514$ \\
\hline RS VB & tomb 30 & 4 & $100-103$ \\
\hline RS VB & tomb 36 & 8 & $193-198,506,507$ \\
\hline RS VB & tomb 53 & 1 & 199 \\
\hline RS VB & tomb 75 & 7 & $110-115,503$ \\
\hline RS VB & tomb 78 & 1 & 192 \\
\hline RS VB & tomb 81 & 5 & 107-109, 1012, 1013 \\
\hline RS SA & tomb 449 (Patilu-Wa) & 2 & 316,348 \\
\hline RS SA & tomb 3709 (prêtre Hurrite) & 1 & 289 \\
\hline RS SA & tomb 3955 & 1 & 260 \\
\hline RS SA & tomb 4093 & 1 & 478 \\
\hline RS VS & tomb 2698 & 21 & $254,338,375,381,386-400,404,526$ \\
\hline RS VS & tomb 3048 & 5 & $203,206,208,326,335$ \\
\hline RS VS & tomb 4253 & 2 & 432,433 \\
\hline RS Ch. C & tomb 21 & 1 & 104 \\
\hline RS Ch. C & tomb 23 & 2 & $105-106$ \\
\hline RS Ch. C. & tomb 37 & 3 & $97-99$ \\
\hline RS TTE & enchytrismos & 1 & 469 \\
\hline RS TTE & eastern tomb & 1 & 311 \\
\hline RS SW & tomb SW & 7 & $422-428,205$ \\
\hline
\end{tabular}


Table IV Hazor: settlement contexts with Mycenaean pottery

\begin{tabular}{|c|c|c|c|c|}
\hline site area & context type & period & context specification & catalogue numbers \\
\hline A & Domestic & LB $\| B$ & locus 335a-b: room near water reservoir & 50 \\
\hline A & Refuse & & locus 548: pit & 51 \\
\hline A & Refuse & & locus 583 & 53 \\
\hline A & Ritual & LB ॥B & locus 239b: courtyard of orthostats temple & 49 \\
\hline A & Settlement & LB ॥B & locus 263b: on pavement & 40 \\
\hline A & Settlement & LB IIA & locus 270B: on pavement & 39 \\
\hline A & Settlement & & locus 351a: pavement outside water resevoir & 48 \\
\hline B & Settlement & & locus 3284: on floor & 43 \\
\hline $\mathrm{F}$ & Domestic & LB II & house 8039 & $32,34,35,36$ \\
\hline $\mathrm{F}$ & Domestic & LB II & house 8068 & 31,33 \\
\hline $\mathrm{F}$ & Domestic & LB II & house 8137 & 30,1005 \\
\hline $\mathrm{F}$ & Settlement & LB II & tunnel 8153 & 37 \\
\hline $\mathrm{H}$ & Ritual & LB IIB & temple $1 \mathrm{~A}$ & 47,2003 \\
\hline $\mathrm{H}$ & Ritual & LB IIA & temple 1B & 46 \\
\hline $\mathrm{H}$ & Settlement & LB I & locus 2174 & 45 \\
\hline C & Domestic & LB IIA & house 6063 & 1,2 \\
\hline C & Domestic & LB IIA & house 6225: locus 6225 & 13,14 \\
\hline C & Domestic & LB IIA & house of 6061 & 15 \\
\hline $\mathrm{D}$ & Refuse & LBII & subarea D3: cistern 9017 & 6,7 \\
\hline BA & Domestic & LBII & locus 4017: on floor & 44 \\
\hline
\end{tabular}


Table V Ugarit: Mycenaean vessel types and figurines in the tombs

\begin{tabular}{|c|c|c|c|c|c|c|c|c|c|}
\hline SITEAREA & CONTEXT SPEC & tal vessels & krater & cups & stemmed cups & bowls & jugs & rhyta & ring kernos \\
\hline MB & tomb III & 14 & 2 & 3 & 1 & 2 & & & \\
\hline MB & tomb IV & 17 & 2 & & 1 & 3 & & & 1 \\
\hline MB & tomb V & 15 & & 1 & 1 & 3 & 2 & 2 & \\
\hline MB & tomb VI & 38 & 4 & 3 & & 8 & 1 & & \\
\hline RS Acr. & tomb "sous dalles" & 1 & & & & & & & \\
\hline RS Acr. & tomb 1 & 5 & 2 & & 1 & & & & \\
\hline RS Acr. & tomb 2 & 2 & & 1 & & & & & \\
\hline RS Acr. & tomb 4 & 3 & & & & 1 & & 1 & \\
\hline RS Acr. & tomb 5 or 6 & 2 & & & & 2 & & & \\
\hline RS Acr. & tomb 22 & 1 & & & & & & & \\
\hline RS Acr. & tomb 29 & 2 & & & & 1 & & & \\
\hline RS Acr. & tomb 41 & 1 & & & & & & & \\
\hline RS PR & royal tomb & 1 & & & & & & & \\
\hline RS PR & burial in NW corner & 1 & & & 1 & & & & \\
\hline RS QR & tomb 4642 & 5 & 1 & 1 & & 1 & & 1 & \\
\hline RS QR & tomb 4698 & 4 & & & & & & & \\
\hline RS QR & tomb 6015 & 1 & & 1 & & & & & \\
\hline RS VB & tomb 7 & 1 & & & & & & & \\
\hline RS VB & tomb 13 & 6 & & & & 1 & 1 & & \\
\hline RS VB & tomb 30 & 4 & & 1 & & 2 & & & \\
\hline RS VB & tomb 36 & 8 & & & & & & & \\
\hline RS VB & tomb 53 & 1 & & & & & & & \\
\hline RS VB & tomb 75 & 7 & & & & & 1 & & \\
\hline RS VB & tomb 78 & 1 & & & & 1 & & & \\
\hline RS VB & tomb 81 & 3 & & & & & & & \\
\hline RS SA & tomb 3709 (Hurrian Priest) & t) 1 & & & & & & & \\
\hline RS SA & tomb 3955 & 1 & & & & & & & \\
\hline RS SA & tomb 4093 & 1 & & & & & & & \\
\hline RS SA & tomb 449 (patilu-wa) & 2 & 1 & & & & & & \\
\hline RS VS & tomb 2698 & 21 & 4 & 3 & & 2 & & & \\
\hline RS VS & tomb 3048 & 5 & & 4 & & & & & \\
\hline RS VS & tomb 4253 & 2 & & 1 & & & & & \\
\hline RS Ch. C & tomb 21 & 1 & & & & & & & \\
\hline RS Ch. C & tomb 23 & 2 & & 1 & & & & & \\
\hline RS Ch. C & tomb 37 & 3 & & & & 1 & 1 & & \\
\hline RS TTE & enchytrismos & 1 & & & & & & & \\
\hline RS TTE & eastern tomb & 1 & & & & & & & \\
\hline RS SW & tomb SW & 7 & & & 1 & 1 & & & \\
\hline RS unknown & & 1 & & & & & & & \\
\hline \multirow{2}{*}{\multicolumn{2}{|c|}{ RS Acr. unknown }} & & & & & & & & \\
\hline & & 194 & 16 & 20 & 6 & 29 & 6 & & 4 \\
\hline
\end{tabular}

$\begin{array}{lc}\text { Total dinner vessels } & 77 \\ \text { Total storage vessels } & 101 \\ \text { Total ceremonial vessels } & 5 \\ \text { Total figurines } & 13 \\ \text { Total miscellaneous } & 1 \\ \text { Total undeterminable } & 9 \\ \text { Total } & 206\end{array}$




\begin{tabular}{|c|c|c|c|c|c|c|c|c|c|}
\hline & stirrup jar & piriform jar & alabastron & flask & lid & undeterminable & fragment & figurines & totals \\
\hline & 2 & 1 & 1 & & & 1 & 1 & 4 & 18 \\
\hline & 6 & & & 2 & & & 2 & 2 & 19 \\
\hline & 4 & 1 & & & & & 1 & & 15 \\
\hline & 16 & 3 & 1 & & 1 & & 1 & 5 & 43 \\
\hline & 1 & & & & & & & & 1 \\
\hline & 2 & & & & & & & & 5 \\
\hline \multirow{3}{*}{\multicolumn{2}{|c|}{1}} & & & & & & & & 2 \\
\hline & & 1 & & & & & & & 3 \\
\hline & & & & & & & & & 2 \\
\hline & 1 & & & & & & & & 1 \\
\hline \multirow{5}{*}{\multicolumn{2}{|c|}{1}} & & & & & & & & 2 \\
\hline & & 1 & & & & & & & 1 \\
\hline & & & & & & 1 & & & 1 \\
\hline & & & & & & & & & 1 \\
\hline & & 1 & & & & & & & 5 \\
\hline \multirow{3}{*}{\multicolumn{2}{|c|}{2}} & 1 & & & & & 1 & & 4 \\
\hline & & & & & & & & & 1 \\
\hline & & 1 & & & & & & & 1 \\
\hline & 2 & & 1 & 1 & & & & & 6 \\
\hline & 1 & & & & & & & & 4 \\
\hline & 6 & & & 2 & & & & & 8 \\
\hline & 1 & & & & & & & & 1 \\
\hline \multirow{2}{*}{\multicolumn{2}{|c|}{3}} & 3 & & & & & & & 7 \\
\hline & & & & & & & & & 1 \\
\hline & 1 & & & 2 & & & & 2 & 5 \\
\hline & 1 & & & & & & & & 1 \\
\hline & 1 & & & & & & & & 1 \\
\hline \multirow{2}{*}{\multicolumn{2}{|c|}{1}} & & & & & & & & 1 \\
\hline & & 1 & & & & & & & 2 \\
\hline & 8 & 1 & 2 & & & & 1 & & 21 \\
\hline & 1 & & & & & & & & 5 \\
\hline \multirow{2}{*}{\multicolumn{2}{|c|}{1}} & & & & & & & & 2 \\
\hline & & & & 1 & & & & & 1 \\
\hline & 1 & & & & & & & & 2 \\
\hline & 1 & & & & & & & & 3 \\
\hline & 1 & & & & & & & & 1 \\
\hline & 1 & & & & & & & & 1 \\
\hline \multirow{3}{*}{\multicolumn{2}{|c|}{3}} & & 1 & 1 & & & & & 7 \\
\hline & & & 1 & & & & & & 1 \\
\hline & & 1 & & & & & & & 1 \\
\hline 1 & & 70 & 15 & 6 & 9 & 1 & 2 & 13 & 207 \\
\hline
\end{tabular}


Table VI Enkomi: settlement contents with Mycenaean pottery

\begin{tabular}{|c|c|c|c|c|}
\hline stratum & site area & context type & context specification & catalogue nos. \\
\hline I & Q1W & Domestic & Fortress & $930-933$ \\
\hline$\| \mathrm{A}$ & Q1W & Domestic & building in Dikaios' area III & $960-966,968,969,1189-1192$ \\
\hline$\| A$ & Q4W & Domestic & building in Dikaios' area I & 934-955, 957-959, 1151-1161 \\
\hline$\|A-\| B$ & Q1W & Domestic & room 5 in building in Dikaios' area III & 1193-1197 \\
\hline IIB & Q1W & Settlement & floor level below ciasemate 63 & $1210-1216,1221-1222$ \\
\hline IIB & Q1W & Settlement & floor level (kerb) below casemate 64 & $\begin{array}{l}1224-1233,1235-1236,1238- \\
1239\end{array}$ \\
\hline IIB & Q1W & Settlement & floor level below casemate 65 & $1240-1253$ \\
\hline IIB & Q1W & Domestic & building in Dikaios' area III & $\begin{array}{l}1011-1042,1045,1046,1199- \\
1206\end{array}$ \\
\hline IIB & Q1W & Settlement & slagheap below rooms 86 and 83 & $1254-1256$ \\
\hline IIB & Q1W west & Settlement & tunnel along fortification wall & 1257 \\
\hline IIB & Q4W & Domestic & building in Dikaios' area I & $\begin{array}{l}970-975,977-981,982-1010 \\
1162-1167,1169-1170,1276- \\
1279,1288-1289\end{array}$ \\
\hline LCII & Q5W & Settlement & below floors of bâtiment 18 & $705-711$ \\
\hline LCIIC & Q4E & Refuse & pit 215 & 1425 \\
\hline$\| B-I I A$ & Q1W & Settlement & destruction debris in room 55 & $1207-1209$ \\
\hline$\|B-\| \mid A$ & Q4W & Refuse & dump below floor III of Ashlar building & $1280-1285$ \\
\hline IIIA & Q1W & Domestic & building in Dikaios' area III & 1061-1066, 1086-1123, \\
\hline IIIA & Q1W & Settlement & on floor near fortification wall & 1260 \\
\hline IIIA & Q4W & Domestic & Ashlar building & $\begin{array}{l}1047-1049,1050-1055,1057- \\
1060,1067-1085,1262-1269 \\
1287,1294-1301,1308,1309, \\
1318\end{array}$ \\
\hline IIIA-IIIB & Q4W & Settlement & destruction layer in Ashlar building & $1302,1310,1312$ \\
\hline IIIB & Q4W & Domestic & Ashlar building & $\begin{array}{l}\text { 1124-1130, 1270-1274, 1303- } \\
1307,1311,1313-1317\end{array}$ \\
\hline IIIB-IIIC & Q4W & Domestic & Ashlar building & 1275 \\
\hline LCIII & Q4W & Settlement & in wells near sanctuary of the 'Horned God' & 724,756 \\
\hline LCIII & Q5E & Settlement & lower pavement above Fr. T. 1336 & 759 \\
\hline LCIII & Q5E & Settlement & below floors of sanctuary of the 'Ingot God' & 863-868 \\
\hline LCIII & Q5E & Settlement & upper pavement above Fr. T. 1336 & 758 \\
\hline LCIII & Q5W & Domestic & on floor of bâtiment 18 & $712-713$ \\
\hline
\end{tabular}


Table VII Enkomi: tombs with Mycenaean pottery

\begin{tabular}{|c|c|c|c|c|}
\hline site area & tomb no. & quantity & catalogue nos. & Associated objects \\
\hline unknown & Br. T. 77 & 5 & $129-133$ & gold: bands; t.c.: bull figurine; p.: Cyp. \\
\hline unknown & Br. T. 81 & 2 & 259,260 & \\
\hline unknown & Br. T. 82 & 2 & $261-262$ & $\begin{array}{l}\text { gold: earrings, mouthpiece, diadems; } \\
\text { br.: bowl, iv.; alab.: vases }\end{array}$ \\
\hline unknown & Br. T. 88 & 15 & $10-19,170,273-275$ & $\begin{array}{l}\text { faience zoomorphic rhyton, stone seal, } \\
\text { figurines; } p .: \text { Cyp. }\end{array}$ \\
\hline unknown & Fr. T. 10 & 1 & 622 & p.: Сур. \\
\hline unknown & Sw. T. 5 & 2 & $1446-1447$ & br.: bowl; st.: mortar; p.: cyp., LHIIIC \\
\hline Q1E/Q2E & Br. T. 67 & 11 & $52-56,235-237$ & $\begin{array}{l}\text { gold: ornaments, ring; br. ring; st. } \\
\text { beads, weights; t.c. figurines (local); } \\
\text { alab. vases;p.: Cyp, Syr. }\end{array}$ \\
\hline Q1W & Су. Т. 16 & 2 & $1421-1422$ & p.: Сур. \\
\hline Q1W & Су. Т. 19: uppermost burial & 1 & 1423 & t.c.: female figurine; p.: Cyp. \\
\hline Q2W & Br. T. 69 & 13 & $73-85$ & $\begin{array}{l}\text { p.: Myc., Cyp.; gold: ornaments; br.: } \\
\text { rings; fai.: vase; terr.c.: female figurine } \\
\text { (loc) }\end{array}$ \\
\hline Q3E & Br. T. 60 & 1 & 233 & $\begin{array}{l}\text { gold: beads, spirals; br.: spearhead; } \\
\text { glass: ring; p.: Cyp. }\end{array}$ \\
\hline Q3W & Br. T. 65 & 1 & 234 & gold: diadem, ring \\
\hline Q3W & Fr. T. 1907: dromos & 10 & $916-921,924-927$ & br.: rings, bowl; fai.: cup.; p.: Cyp., RS. \\
\hline Q3W & Fr. T. 1907: east chamber & 5 & $915,922,923,928,929$ & $\begin{array}{l}\text { silv.: rings, br.: earrings, rings; iv.: spin- } \\
\text { dle whorls; fai.: pearl; st.: crystal; p.: } \\
\text { Cyp., Myc. }\end{array}$ \\
\hline Q3W & Sw. T. 2 & 3 & $330-332$ & fai.: cylinder; st.: cylinder; p.: Cyp. \\
\hline Q3W & Sw. T. 3 & 67 & $333-386,1451-1463$ & $\begin{array}{l}\text { gold: beads, diadem, ; br.: daggers; iv.: } \\
\text { lid; glass: beads, bottle, rings; fai.: } \\
\text { beads, bowls, cups; st.: weights; p.: } \\
\text { Cyp., Syr. }\end{array}$ \\
\hline Q3W & Sw. T. 6: chamber A & 18 & $388-405$ & $\begin{array}{l}\text { gold: bands; silver: ring; br.: bracelets; } \\
\text { fai.: beads; glass: bottles; st.: spindle } \\
\text { whorls, bowl; iv.: pin, disc; p.: Cyp. }\end{array}$ \\
\hline Q3W & Sw. T. 6: chamber B & 1 & 405 & p.: Cyp. \\
\hline Q3W/Q4W & Br. T. 58 & 1 & 231 & iv.: box \\
\hline Q3W/Q4W & Br. T. 68 & 18 & 238-248, 319-325 & gold: bead, fai.: bowl; p.:Cyp. \\
\hline Q4E & Br. T. 10 & 4 & $178-181$ & р.: Сyp. \\
\hline Q4E & Br. T. 12 & 23 & $65-72,182-194,621,1430$ & p.:Cyp., Syr.; fai.: cylinder, vase \\
\hline Q4E & Br. T. 19 & 1 & 1450 & $\begin{array}{l}\text { gold; diadems, mouthpieces, necklaces, } \\
\text { rings, earrings; iv.: disks; fai.: rhyton; p.: } \\
\text { loc. }\end{array}$ \\
\hline Q4E & Br. T. 59 & 3 & $232,318,617$ & $\begin{array}{l}\text { gold: bands, earring; silver: rings; } \\
\text { faience: beads; alab.: vase; p.:Cyp. }\end{array}$ \\
\hline Q4E & Br. T. 66 & 28 & $21-48$ & $\begin{array}{l}\text { gold: ornaments; silver: bowl: glass \& } \\
\text { faience \& alab. vessels; p.: Cyp. }\end{array}$ \\
\hline Q4E/Q5E & Br. T. 14 & 1 & 307 & $\begin{array}{l}\text { gold: bands, beads, earrings, mouth- } \\
\text { piece; silver: earring; fai.: cylinder, seal, } \\
\text { bowl; iv.: figurine; t.c.: figurine; p.: Cyp. }\end{array}$ \\
\hline Q4E/Q5E & Br. T. 17 & 3 & 195-197 & iv.: mirror handle \\
\hline Q4W & Br. T. 53 & 4 & $1,2,223,2001$ & $\begin{array}{l}\text { gold: diadem, mouthpiece; alab.: vase, } \\
\text { t.c.: figurine (Сyp.), p.: Cyp. }\end{array}$ \\
\hline Q4W & Br. T. 54 & 4 & $224-227$ & $\begin{array}{l}\text { gold: two bands; silver: pin, ring; p.: } \\
\text { Myc., Cyp. }\end{array}$ \\
\hline Q4W & Br. T. 91 & 13 & 95-107 & $\begin{array}{l}\text { gold: ornaments; fai.; scarab; st.: } \\
\text { scarab }\end{array}$ \\
\hline Q4W & Су. Т. 1 & 3 & $1329-1330$ & $\begin{array}{l}\text { br.: vessel; iv.: disks; glass: vessel; t.c.: } \\
\text { spindle whorls; st.: beads; p.: Cyp., RS }\end{array}$ \\
\hline Q4W & Cy. T. 10: 2nd burial layer & 10 & $1386,1402-1410$ & p.: Сур., Мyс. \\
\hline Q4W & Сy. T. 10: 3rd burial layer & 16 & $1385,1387-1401$ & $\begin{array}{l}\text { gold: mouthpieces, strips, necklaces; } \\
\text { fai.: vessels; p.: Cyp. }\end{array}$ \\
\hline
\end{tabular}


Table VII cont.

\begin{tabular}{|c|c|c|c|c|}
\hline site area & tomb no. & quantity & catalogue nos. & Associated objects \\
\hline $\mathrm{Q} 4 \mathrm{~W}$ & Су. Т. 10: 4th burial layer & 48 & $1337-1384$ & $\begin{array}{l}\text { gold: earrings, bracelets, strips; br.: hel- } \\
\text { mets; fai.: vessels; st.: beads; ostrich } \\
\text { egg; p.: Cyp. }\end{array}$ \\
\hline Q4W & Су. Т. 10: unspecified burial layer & 1 & 1411 & \\
\hline Q4W & Су. Т. 11 & 7 & $1412-1418$ & t.c.: wall bracket; p.: Сур.. \\
\hline Q4W & Су. Т. 12 & 2 & $1419-1420$ & \\
\hline Q4W & Су. T. 2: main chamber & 6 & $1331-1336$ & $\begin{array}{l}\text { gold; spiral; br.: statuette, chisel; p.: } \\
\text { Cyp. }\end{array}$ \\
\hline Q5E & Fr. T. 11 & 15 & $666-672,675-679$ & gold: bands, p.: Cyp. \\
\hline Q5E & Fr. T. 110 & 43 & $870-912$ & $\begin{array}{l}\text { gold: earrings, pearls; br.: rings, } \\
\text { bracelets; fai.: cup, pearls; st.: scarab; } \\
\text { p.: Cyp. }\end{array}$ \\
\hline Q5E & Fr. T. 1336 & 69 & 764-832 & $\begin{array}{l}\text { br.: pin, fragments; iv.: peg; bone: pin; } \\
\text { fai.: bead; st.: spindle whorls; p.: LHIIIC, } \\
\text { Cyp. }\end{array}$ \\
\hline Q5E & Fr. T. 1336: dromos & 29 & 833-861 & p.: Сур. \\
\hline Q5E & Fr. T. 2 & 17 & $641,645,648-662$ & $\begin{array}{l}\text { gold: bands, rings; silv.: cups; fai.: bowl; } \\
\text { glass: beads; st.: seals, alab. vase; p.: } \\
\text { Cyp. }\end{array}$ \\
\hline Q5E & Fr. T. 5: unknown stratum & 2 & 647,674 & \\
\hline Q5E & Fr. T. 5: 2nd stratum & 6 & $673,680-682,690-691$ & $\begin{array}{l}\text { br.: bowls, rings; iv.: spindle whorl, } \\
\text { pyxis; st.: vases, pin, beads; glass: bot- } \\
\text { tle; p.: Cyp. }\end{array}$ \\
\hline Q5E & Fr. T. 5: 3rd stratum & 14 & $683-687,692-700$ & $\begin{array}{l}\text { gold: earrings, bands; br.: rings; iv.: box; } \\
\text { fai.: bottle, pearls stirrup jar; st.: cylin- } \\
\text { der, glass: bottle; p.: Cyp. }\end{array}$ \\
\hline Q5E & Fr. T. 5: 4th stratum. & 3 & 688-689, 701 & $\begin{array}{l}\text { gold: earrings; br.: rings; fai.: cup; glass: } \\
\text { stirrup jar, bottle, beads; st.: beads; p.: } \\
\text { Cyp. }\end{array}$ \\
\hline Q5W & Br. T. 42 & 4 & $309-312$ & \\
\hline Q5W & Br. T. 43 & 13 & $207-216,313-315$ & $\begin{array}{l}\text { gold; diadems, mouth pieces; br.: spear } \\
\text { heads, mirrors, knife blades; st.: spindle } \\
\text { whorls; alab.: vases; iv.; t.c.: bull vessel; } \\
\text { p.: RS., Cyp. }\end{array}$ \\
\hline Q5W & Br. T. 45 & 20 & $108-124,217,218,316$ & $\begin{array}{l}\text { gold: ornaments; fai.: vases; t.c. bull } \\
\text { vase; p..Cyp. }\end{array}$ \\
\hline Q5W & Br. T. 48 & 14 & $125,134-145,221$ & gold; br. bowl; fai.: cup \\
\hline Q5W & Br. T. 50 & 2 & $219-220$ & $\begin{array}{l}\text { gold: band, fai.: cup, stirrup jar; p.: RS., } \\
\text { Cyp. }\end{array}$ \\
\hline Q5W & Br. T. 51 & 1 & 156 & iv.: vase \\
\hline Q5W & Br. T. 52 & 1 & 222 & p.: Сур. \\
\hline Q5W & Br. T. 55 & 4 & $228-230,317$ & gold: necklace, ring, spirals; p: Cyp. \\
\hline Q5W & Br. T. 70 & 6 & $157-162$ & $\begin{array}{l}\text { p.: Myc., Cyp.; gold earring, scarabs } \\
\text { (flies) }\end{array}$ \\
\hline Q5W & Br. T. 74 & 1 & 249 & $\begin{array}{l}\text { gold: spirals; Iron: pin; st.: cylinder; p.: } \\
\text { Cyp. }\end{array}$ \\
\hline Q5W & Br. T. 89 & 7 & $163-169$ & p.: Сур. \\
\hline Q5W & Sw. T. 18: 1st chamber group & 6 & $519,521,522,525,526,530$ & $\begin{array}{l}\text { gold: hairring, diadems, mouthpieces,; } \\
\text { glass: bottle, iv.: discs, box, p.: Cyp. }\end{array}$ \\
\hline Q5W & Sw. T. 18: 2nd chamber group & 19 & $506-518,520,523-524,527-52$ & $\begin{array}{l}\text { 9gold: hair-, ear-, finger-, toerings, } \\
\text { diadems, mouthpieces, bead, necklace, } \\
\text { pinhead; br.: weapons, mirror, rings, } \\
\text { chisel, jug, bowls; fai.: bowl; iv.: disc, } \\
\text { buttons, box, pin, combst.: bowls; p.: } \\
\text { Cyp. }\end{array}$ \\
\hline Q5W & Sw. T. 18: side chamber & 53 & $531-542,544-583$ & $\begin{array}{l}\text { gold: hair-, toe-, finger-, earrings, } \\
\text { diadems, mouthpieces; br.: bowls; } \\
\text { glass: bottles; ostrich egg; p.: Cyp., RS }\end{array}$ \\
\hline Q5W & Sw. T. 19: chamber & 28 & $584-611$ & $\begin{array}{l}\text { gold: hair, finger-, earrings, mouthpiece; } \\
\text { silv.: bracelet; br.: rings, mirror, bowls, }\end{array}$ \\
\hline
\end{tabular}




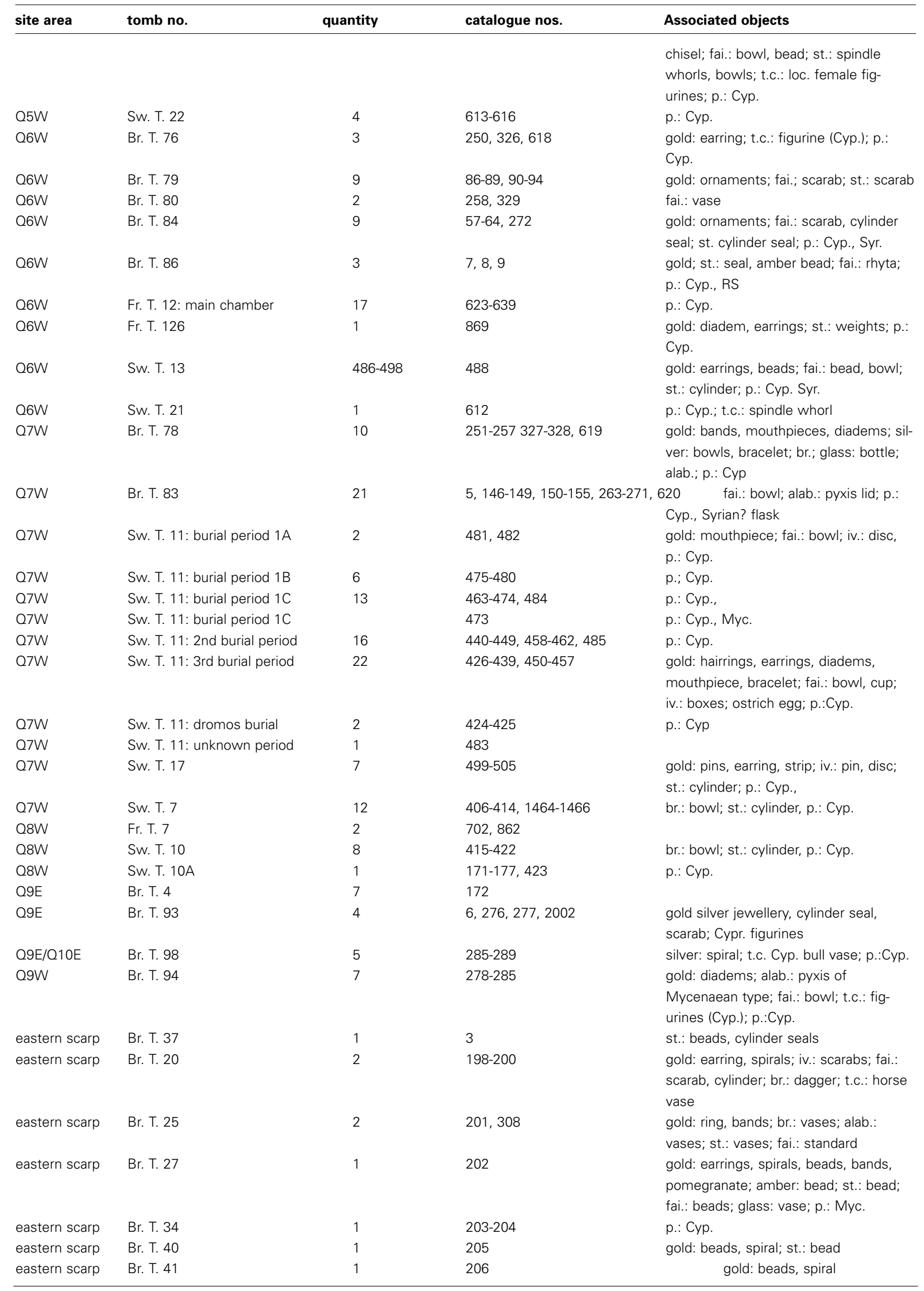


Table VIII Enkomi: distribution of Myceaean vessel types in tombs

\begin{tabular}{|c|c|c|c|c|c|c|c|}
\hline site area & tomb no. & kraters & cups & bowls & stemmed cups/bowls & jugs & figurines \\
\hline unknown & Br. T. 77 & & & & & & \\
\hline unknown & Br. T. 81 & 1 & & & & & \\
\hline unknown & Br. T. 82 & 2 & & & & & \\
\hline unknown & Br. T. 88 & & 3 & 1 & & 1 & \\
\hline unknown & Fr. T. 10 & & & & & 1 & \\
\hline unknown & Sw. T. 5 & 1 & & & & & \\
\hline unknown & unknown tomb British excavations & 9 & 2 & 1 & & & \\
\hline Q1E/Q2E & Br. T. 67 & 3 & 1 & & & & \\
\hline Q1W & Су. Т. 16 & & & & & & \\
\hline Q1W & Су. T. 19: uppermost burial & & 1 & & & & \\
\hline Q2W & Br. T. 69 & 1 & 2 & 1 & 2 & 2 & \\
\hline Q3E & Br. T. 60 & & & & & 1 & \\
\hline Q3W & Br. T. 65 & & & & & & \\
\hline Q3W & Fr. T. 1907: dromos & & & 1 & 3 & & \\
\hline Q3W & Fr. T. 1907: east chamber & 1 & & 1 & & & \\
\hline Q3W & Sw. T. 2 & & & & & & \\
\hline Q3W & Sw. T. 3 & 22 & 12 & 4 & & 5 & \\
\hline Q3W & Sw. T. 6: chamber A & & 5 & 4 & 1 & 2 & \\
\hline Q3W & Sw. T. 6: chamber B & & 1 & & & & \\
\hline Q3W/Q4W & Br. T. 58 & & & & & & \\
\hline Q3W/Q4W & Br. T. 68 & 1 & & 1 & & & \\
\hline Q4E & Br. T. 10 & & & & & & \\
\hline Q4E & Br. T. 10 or 12 & 2 & & & & & \\
\hline Q4E & Br. T. 12 & 13 & & & 1 & & \\
\hline Q4E & Br. T. 19 & 1 & & & & & \\
\hline Q4E & Br. T. 59 & & & & & & \\
\hline Q4E & Br. T. 66 & 1 & 6 & 4 & 4 & 3 & \\
\hline Q4E/Q5E & Br. T. 14 & & & & & & \\
\hline Q4E/Q5E & Br. T. 17 & 1 & & & & & \\
\hline Q4W & Br. T. 53 & & 1 & & & & 1 \\
\hline $\mathrm{Q} 4 \mathrm{~W}$ & Br. T. 54 & 3 & & & & 1 & \\
\hline Q4W & Br. T. 91 & 1 & 1 & & & 2 & \\
\hline Q4W & Су. T. 1 & 1 & 1 & 1 & & & \\
\hline Q4W & Су. T. 10: 2nd burial layer & 1 & 5 & & & & \\
\hline Q4W & Су. T. 10: 3rd burial layer & & 6 & & & & \\
\hline Q4W & Су. T. 10: 4th burial layer & 2 & 18 & 9 & 1 & & \\
\hline Q4W & Сy. T. 10: unspecified burial layer & & 1 & & & & \\
\hline Q4W & Су. Т. 11 & & 2 & & 1 & & \\
\hline Q4W & Су. Т. 12 & & 1 & & & 1 & \\
\hline Q4W & Су. T. 2: main chamber & & 1 & 1 & & 1 & \\
\hline Q5E & Fr. T. 11 & & 5 & & & & \\
\hline Q5E & Fr. T. 110 & & 13 & 1 & & 2 & \\
\hline Q5E & Fr. T. 1336 & 1 & 2 & 14 & 1 & 7 & \\
\hline Q5E & Fr. T. 1336: dromos & & & & & & \\
\hline Q5E & Fr. T. 2 & 5 & 1 & & & & \\
\hline Q5E & Fr. T. 5 & & & & & & \\
\hline Q5E & Fr. T. 5: 2nd startum in S. & & & 1 & & & \\
\hline Q5E & Fr. T. 5: 2nd stratum in N. & & & & & & \\
\hline Q5E & Fr. T. 5: 2nd stratum in S. & & & & & & \\
\hline Q5E & Fr. T. 5: 3rd stratum in S. & & & & & & \\
\hline Q5E & Fr. T. 5: 3rd stratum in N. & & 1 & 1 & & 1 & \\
\hline Q5E & Fr. T. 5: 3rd stratum in $\mathrm{S}$ & & & & & & \\
\hline Q5E & Fr. T. 5: 3rd stratum in S. & & 4 & & & & \\
\hline Q5E & Fr. T. 5: 4th stratum in $\mathrm{N}$. & & 1 & & & & \\
\hline Q5E & Fr. T. 5: 4th stratum in S. & & & & & & \\
\hline Q5W & Br. T. 42 & & & & & & \\
\hline Q5W & Br. T. 43 & 3 & & & & & \\
\hline Q5W & Br. T. 45 & 4 & 1 & & & 1 & \\
\hline Q5W & Br. T. 48 & 6 & & 3 & & 1 & \\
\hline Q5W & Br. T. 50 & & & & & & \\
\hline Q5W & Br. T. 51 & 1 & & & & & \\
\hline
\end{tabular}



Table VIII cont.

\begin{tabular}{|c|c|c|c|c|c|c|c|}
\hline site area & tomb no. & kraters & cups & bowls & stemmed cups/bowls & jugs & figurines \\
\hline Q5W & Br. T. 52 & & & & & 1 & \\
\hline Q5W & Br. T. 55 & & & & & 1 & \\
\hline Q5W & Br. T. 70 & 1 & 2 & & & & \\
\hline Q5W & Br. T. 74 & & & & & & \\
\hline Q5W & Br. T. 89 & 3 & 2 & & 1 & & \\
\hline Q5W & Sw. T. 18: 1st chamber group & & 2 & 2 & & 2 & \\
\hline Q5W & Sw. T. 18: 2nd chamber group & & 6 & 8 & 1 & 2 & \\
\hline Q5W & Sw. T. 18: side chamber & 11 & 2 & 16 & 2 & 4 & \\
\hline Q5W & Sw. T. 19: chamber & 2 & 12 & 1 & & 1 & \\
\hline Q5W & Sw. T. 22 & & 3 & & & & \\
\hline Q6W & Br. T. 76 & & & & & & \\
\hline Q6W & Br. T. 79 & 1 & 2 & & & & \\
\hline Q6W & Br. T. 80 & & & & & & \\
\hline Q6W & Br. T. 84 & & 6 & & & & \\
\hline Q6W & Br. T. 86 & & 2 & 1 & & & \\
\hline Q6W & Fr. T. 12: main chamber & 2 & 3 & 3 & & 2 & \\
\hline Q6W & Fr. T. 126 & & & & & & \\
\hline Q6W & Sw. T. 13 & & 3 & & & 1 & \\
\hline Q6W & Sw. T. 21 & & & & & & \\
\hline Q7W & Br. T. 78 & 1 & 3 & & & & \\
\hline Q7W & Br. T. 83 & 5 & 3 & & & 2 & \\
\hline Q7W & Sw. T. 7 & 7 & & 1 & & 1 & \\
\hline Q7W & Sw. T. 11: 2nd burial period & 1 & 4 & & & 1 & \\
\hline Q7W & Sw. T. 11: 3rd burial period & 1 & 6 & & & 1 & \\
\hline Q7W & Sw. T. 11: burial period 1A & & 2 & & & & \\
\hline Q7W & Sw. T. 11: burial period 1B & & 3 & & & & \\
\hline Q7W & Sw. T. 11: burial period $1 \mathrm{C}$ & & 4 & & & 1 & \\
\hline Q7W & Sw. T. 11: dromos burial & & & & & & \\
\hline Q7W & Sw. T. 11: unknown period & & & & & 1 & \\
\hline Q7W & Sw. T. 17 & 1 & 1 & & & & \\
\hline Q8W & Fr. T. 7 & 1 & & & & 1 & \\
\hline Q8W & Sw. T. 10 & & 2 & 2 & & & \\
\hline Q8W & Sw. T. $10 \mathrm{~A}$ & & & & & & \\
\hline Q9E & Br. T. 4 & & 4 & & & 2 & \\
\hline Q9E & Br. T. 93 & 2 & & & & & 1 \\
\hline Q9E/Q10E & Br. T. 98 & & 2 & & & 1 & \\
\hline Q9W & Br. T. 94 & 2 & & & & & \\
\hline Q11E (SW) & Br. T. 37 & & & & & & \\
\hline eastern scarp & Br. T. 20 & 2 & & & & & \\
\hline eastern scarp & Br. T. 25 & 1 & & & & & \\
\hline eastern scarp & Br. T. 27 & & & & & & \\
\hline eastern scarp & Br. T. 34 & & & & & & \\
\hline eastern scarp & Br. T. 40 & & 1 & & & & \\
\hline eastern scarp & Br. T. 41 & & & & & & \\
\hline
\end{tabular}

Total Dinner vessels $\quad 467$

Total Storage vessels 426

Total Ritual vessels $\quad 10$

Total figurines 2

Total fragments $\quad 68$ 


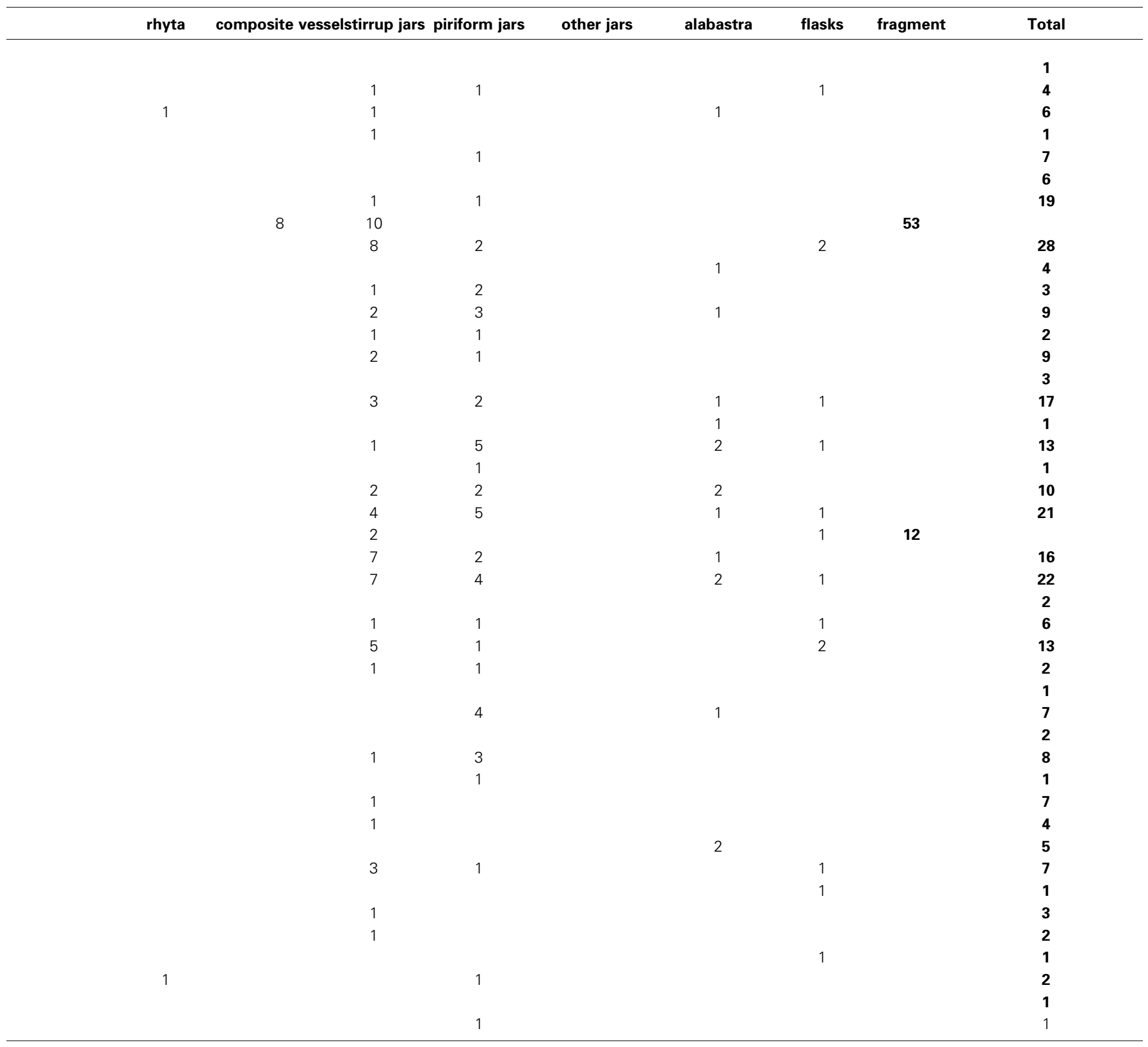

297 
Table IX Athienou: contexts with Mycenaean pottery

\begin{tabular}{|c|c|c|}
\hline context type & catalogue nos. & associated objects \\
\hline courtyard pavement & 18 & $\begin{array}{l}\text { p.: WSII bowl, White Painted jug, White Shaved juglets, } \\
\text { monochrome bowls and jugs, coarse jugs, miniature vessels }\end{array}$ \\
\hline pit 620 (stratum II) & 5,6 & \\
\hline pit 503 & 11,12 & st.: beads, spindle whorl; p.: loc. BR bowls, juglets, imitation \\
\hline pit 531 & 13 & $\begin{array}{l}\text { BR bowls, Plain handmade juglets, miniature vessels, pithos } \\
\text { br.: scrap, nodules; t.c.: spindle whorl; p.: loc.decorated cups, } \\
\text { monocrom juglets, White Shaved juglets, coarse ware juglet, } \\
\text { miniature juglets }\end{array}$ \\
\hline pit 563 & $14,15,16$ & $\begin{array}{l}\text { br.: scrap, nodules; fai.: bead; p.: loc. bowls, BR II jugs, mono- } \\
\text { chrome juglets, White Shaved juglets, coarse ware juglets, } \\
\text { miniature vessels }\end{array}$ \\
\hline pit 551 & $7,8,10,17,23$ & $\begin{array}{l}\text { st.: loom weight; t.c.: loom weight; p.: loc. jar, wheel-made } \\
\text { bowl, BR juglets }\end{array}$ \\
\hline pit 552 & $10,24,25$ & $\begin{array}{l}\text { iv.: conical rhyton; t.c.: wall bracket, bead; p.: loc. Wheel-Made } \\
\text { bowl, LH IIIB-LH IIIC-type deep bowl }\end{array}$ \\
\hline pit 637 & $9,23,24,25$ & $\begin{array}{l}\text { st.: weights; t.c.: 'snake house', wall bracket, loom weight, } \\
\text { bead; p.: loc. WSII bowls, cups, jars }\end{array}$ \\
\hline
\end{tabular}


Table X Apliki: contexts with Mycenaean pottery

\begin{tabular}{|c|c|c|c|}
\hline house & context specification & catalogue nos. & associated objects \\
\hline A & room 1: packing of storage jars & $2,11,19,26,27,38,40,41$ & $\begin{array}{l}\text { br.: sheet fragments; iv.: cylinder; t.c.: spindle } \\
\text { whorls, loom weights, disc, scraper, tuyère; p.: gob- } \\
\text { let, cups, bowls, jars, jugs }\end{array}$ \\
\hline A & room 2: upper layer & $21,24,25,31$ & $\begin{array}{l}\text { st.: mace-head, pestles, rubber; t.c.: cone, wall } \\
\text { bracket; p.: bowls }\end{array}$ \\
\hline A & room 2: on lower floor & $1,13,14,20,32,39,43$ & $\begin{array}{l}\text { br.: slag; st.: spit support, scraper, loom weight, } \\
\text { spindle whorl, mace-head, rubber; t.c.: cone; p.: } \\
\text { bowls, jug, flask }\end{array}$ \\
\hline A & room 3 & 33 & $\begin{array}{l}\text { br.: slag; st.: serpentine seal, quern, rubbers; ; t.c.: } \\
\text { wall bracket; p.: jug and bowl }\end{array}$ \\
\hline A & room 3W: upper floor & $8,22,34,35$ & st.: querns; t.c.: wall bracket; p.: bowls, jugs, jars \\
\hline A & room 3W: on lower floor & 15 & $\begin{array}{l}\text { gold: earring; br.: pin; bone: comb; st.: quern, bowl; } \\
\text { p.: bowl }\end{array}$ \\
\hline A & room 5: on floor & 36 & $\begin{array}{l}\text { st.: quern, loom weight, rubbers, mace head; p.: } \\
\text { jugs }\end{array}$ \\
\hline A & room 7 & 45 & $\begin{array}{l}\text { br.: sackful of slag, st.: loom weight, quern, pestle, } \\
\text { rubbers; p.: krater, bowls, jars }\end{array}$ \\
\hline A & room 8: on bench & 37 & $\begin{array}{l}\text { br.: graver; st.: steatite cylinder, polisher; t.c.: fig- } \\
\text { urines; p.: bowl, jugs, amphorae }\end{array}$ \\
\hline B I & room 2: on floor & 46 & t.c.: disks; scraper; bowl, jugs, jars \\
\hline B I & room 3: on floor & 48 & st.: quern, pestle; t.c.: disks; scraper; p.: jar, BR jug \\
\hline B I & room 6: on floor & 47 & oven; t.c.: disk; p.; bowl, jar \\
\hline B I & room 3: pit & $3,7,2328$ & $\begin{array}{l}\text { t.c.: loom weight, disks; p.: bowl, cups, goblet, } \\
\text { jugs, jar }\end{array}$ \\
\hline B II & east room: on floor & 48 & st.: quern; bowls, jugs, BR, WSI-II. \\
\hline B III & pit layer 2 & 52,53 & $\begin{array}{l}\text { br.: knife; t.c.: tuyères, larnax; p.: loc. jugs, bowls, } \\
\text { cups, goblet, jars }\end{array}$ \\
\hline B III & pit layer 4 & $10,12,29$ & t.c.: scraper; bones; p.: bowls, goblets, jug \\
\hline
\end{tabular}


Table XI Lipari: contexts with Mycenaean pottery

\begin{tabular}{|c|c|c|c|c|c|}
\hline stratum & area & context type & context specification & cat. nos. & associated objects \\
\hline C.G. & 1 & Domestic & cap. d III: inside & $173-193$ & $\begin{array}{l}\text { st.: rectangular plaque; p.: loc. jars, } \\
\text { amphorae, globular vases, carinated cups, } \\
\text { bowl, basin }\end{array}$ \\
\hline C.G. & 1 & Domestic & cap. d IV & & $\begin{array}{l}\text { st.: bowl, plaque, grinding stone; p.: jars, } \\
\text { globular vases, carinated cups, bowls, cups, } \\
\text { miniature vases }\end{array}$ \\
\hline C.G. & 1 & Domestic & cap. d V: inside & $211-217$ & p.: loc. globular vases, carinated cups \\
\hline C.G. & 2 & Domestic & cap. d VI & 218 & p.: loc. globular vases, carinated cups \\
\hline C.G. & 2 & Domestic & cap. d VII: inside & $220-221$ & $\begin{array}{l}\text { t.c. spindle whorls; p.: loc. pithoi, jars, small } \\
\text { jars, small globular vases, carinated cups, } \\
\text { spherical bowl, dish, miniature vases }\end{array}$ \\
\hline C.G. & 2 & Domestic & cap. d VIII: inside & $222-225$ & $\begin{array}{l}\text { t.c.: spindle whorls; p.: loc. globular vases, } \\
\text { jug, jars, carinated cups, pithos }\end{array}$ \\
\hline C.G. & 2 & Domestic & cap. d IX: inside & 226 & $\begin{array}{l}\text { p.: loc. globular vases, carinated cups, } \\
\text { stemmed biconical cups }\end{array}$ \\
\hline C.G. & 2 & Domestic & cap. $d X$ : inside & 227 & $\begin{array}{l}\text { st.: tool; obs.: cores, blades; p.: loc. pithoi, } \\
\text { jars, globular vases, carinated cups, dishes }\end{array}$ \\
\hline C.G. & 2 & Domestic & cap. d XII: inside & $228-235$ & $\begin{array}{l}\text { br.: needles; st.: axes, plaque, bowls, t.c.: } \\
\text { spindle whorl; p.: loc.: pithoi, globular vases, } \\
\text { jars, bowls, cups, wasters from kiln; seeds }\end{array}$ \\
\hline C.G. & 3 & Domestic & cap. d XIII: inside & 236 & $\begin{array}{l}\text { t.c.: spindle whorl; p.: loc. ovoid jar, carinat- } \\
\text { ed cup }\end{array}$ \\
\hline C.G. & 3 & Domestic & cap. $d X X I$ : interior & 247 & $\begin{array}{l}\text { amber: bead; glass: bead; p.: globular vases, } \\
\text { carinated cups }\end{array}$ \\
\hline Mil & 2 & Domestic & cap. c I: lower floor & $39-46$ & $\begin{array}{l}\text { br.: ring; bone; t.c.: spindle whorls?, frag- } \\
\text { ments; p.: loc impasto cups, jars, dish, flaks }\end{array}$ \\
\hline Mil & 2 & Domestic & cap. c II: floor & $52-60$ & st.: grinding stones; p.: App.; loc. \\
\hline Mil & 2 & Domestic & cap c III: inside & $65-71,501$ & $\begin{array}{l}\text { t.c.: stand, spindle whorl; figurine; p.: App., } \\
\text { loc. decorated, impasto, cups, jars, pithoi }\end{array}$ \\
\hline Mil & 2 & Domestic & cap. c IV: inside & $77-81$ & $\begin{array}{l}\text { p.: App., loc. decorated, stemmed cups, loc. } \\
\text { impasto, pithoi }\end{array}$ \\
\hline Mil & 2 & Domestic & cap. c VI: inside & $85-90$ & $\begin{array}{l}\text { p.: App., loc. decorated, cups, jar, stemmed } \\
\text { cuo }\end{array}$ \\
\hline Mil & 2 & Settlement & cap. c VI: annex & $91-103$ & $\begin{array}{l}\text { p.: import, loc. decorated, stemmed cups, } \\
\text { dish, loc. impasto, jars, cup, pithos }\end{array}$ \\
\hline Mil & 3 & Domestic & cap. c VIII: destruction layer & $110-113$ & $\begin{array}{l}\text { t.c.: spindle whorl; bone; p.: loc. decorated } \\
\text { and impasto, stemmed cups, dish, flasks, } \\
\text { pithoi, jars, carinated cups }\end{array}$ \\
\hline Mil & 3 & Domestic & cap. c VIII: inside & 114 & $\begin{array}{l}\text { t.c.: stand; p.: loc. decorated and impasto, } \\
\text { stemmed cups, flask, jar, cup }\end{array}$ \\
\hline Mil & 3 & Domestic & cap. c XII: inside & $155-166$ & $\begin{array}{l}\text { p.: App., loc decorated, stemmed cups, } \\
\text { flasks, impasto, jars, small cup }\end{array}$ \\
\hline Mil & 4 & Domestic & cap. c XIV: inside & 171 & $\begin{array}{l}\text { p.: loc. decorated, stemmed cups, ovoid } \\
\text { flasks; impasto, jars, pithoi, dish }\end{array}$ \\
\hline Aus 1 & 1 & Refuse & cap. c I: Aus I pit & $271-272$ & p.: carinated cups \\
\hline Aus 1 & 1 & Domestic & cap. b IV: 3rd floor & 17 & $\begin{array}{l}\text { br.: dagger?, chunk, fibula; st.: disk, bowl; } \\
\text { t.c.: weight, spindle whorl, disks; p.: loc. } \\
\text { painted; impasto cups bottles, bowls, pithoi }\end{array}$ \\
\hline Aus 1 & 1 & Domestic & cap. b IV: 1st floor & 18 & $\begin{array}{l}\text { br.: fragments; st.: bowl; p.: imported } \\
\text { Nuragic, unknown; p. loc. painted, impasto, } \\
\text { cups, lid, jars, buckets }\end{array}$ \\
\hline Aus I & 3 & Settlement & cap. b IV: dromos & $19-28$ & $\begin{array}{l}\text { t.c.: spindle whorl; p.: Sicilian, loc. impasto, } \\
\text { cups, buckets, jars, plates }\end{array}$ \\
\hline Aus I & 4 & Domestic & cap. bX & 29-35 & p.: loc. impasto \\
\hline Aus 1 & 4 & Settlement & pavement b XII & 36 & $\begin{array}{l}\text { br.: 'crucifix', ring; st.: plate; p.: grayish ware, } \\
\text { loc. painted, impasto, cups, bowls, pan, } \\
\text { pithos }\end{array}$ \\
\hline
\end{tabular}


MAPS 


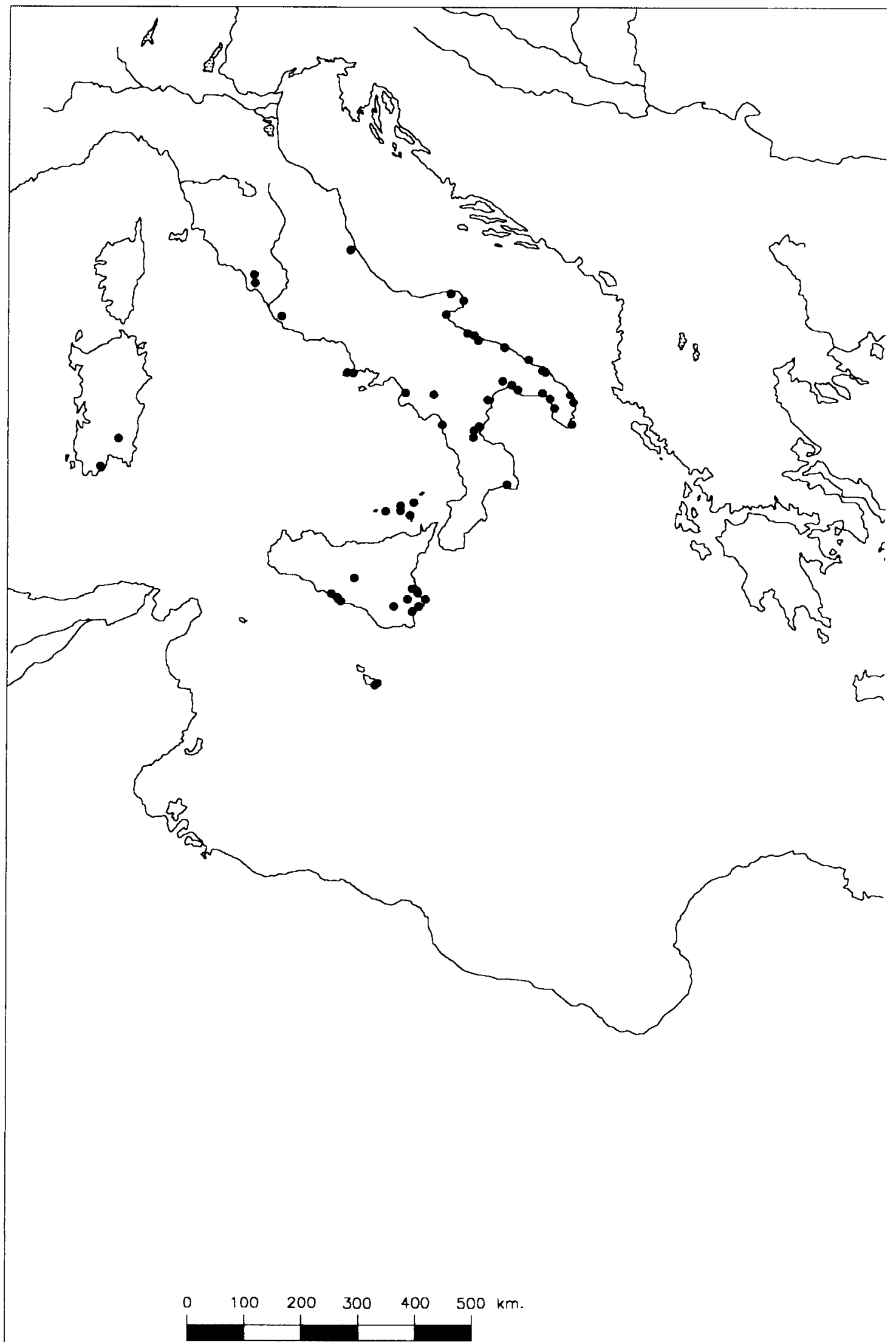

MAP I

Sites in the Mediterranean with Mycenaean pottery (LH I - LH IIIB)

Total $=348$ 


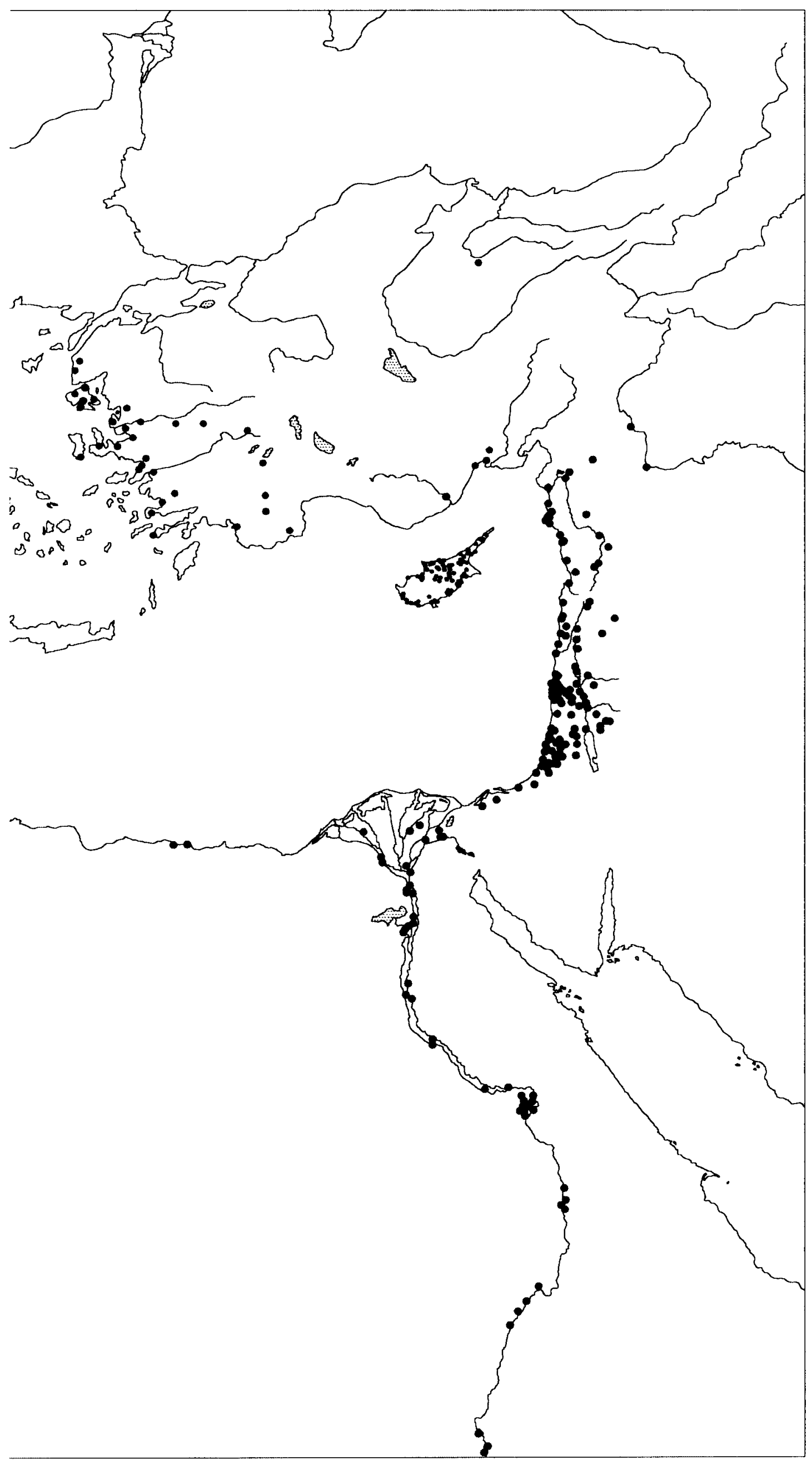




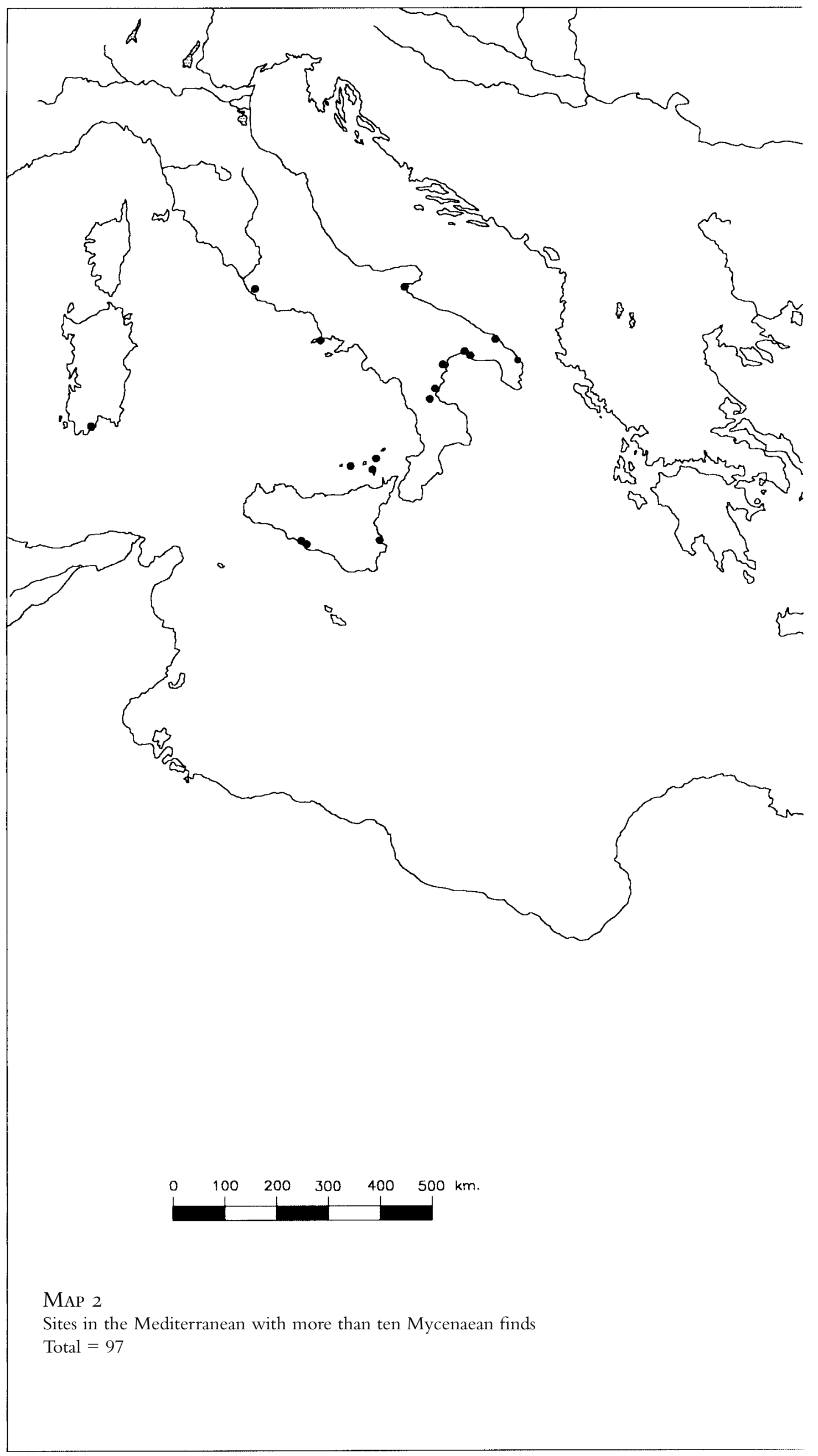




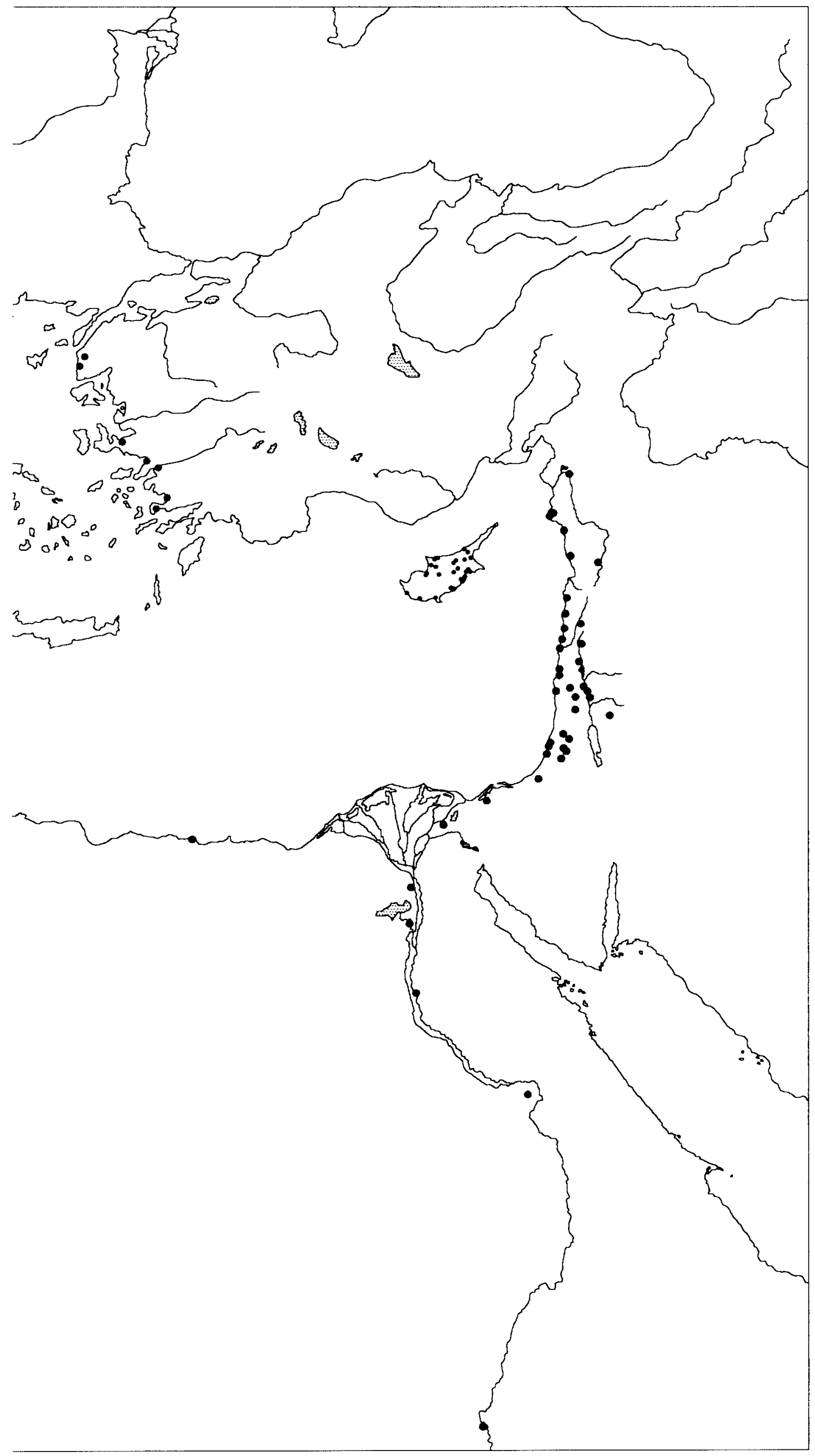




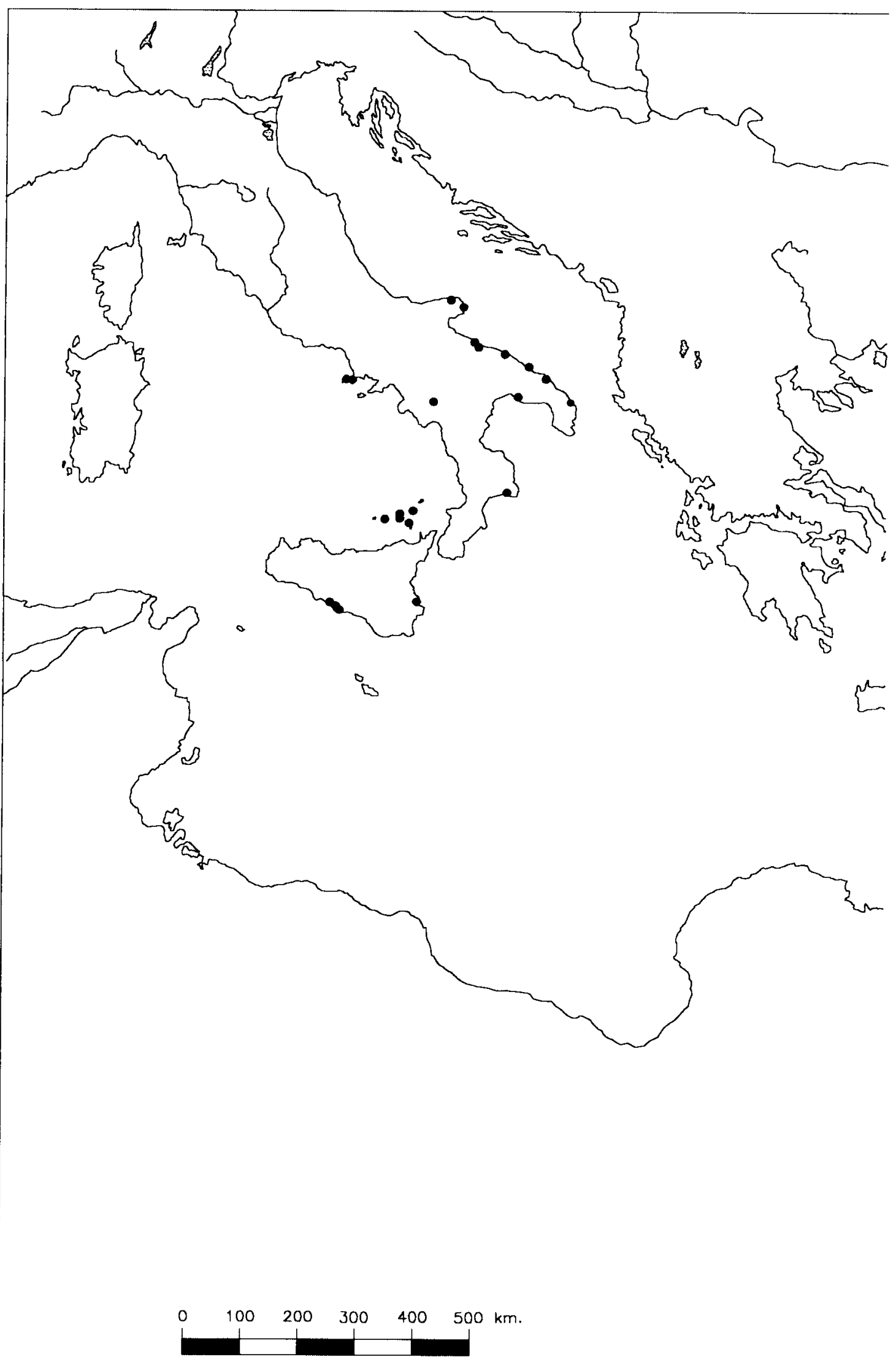

MAP 3

Sites in the Mediterranean with LH I - LH IIIA1 pottery

Total $=78$ 


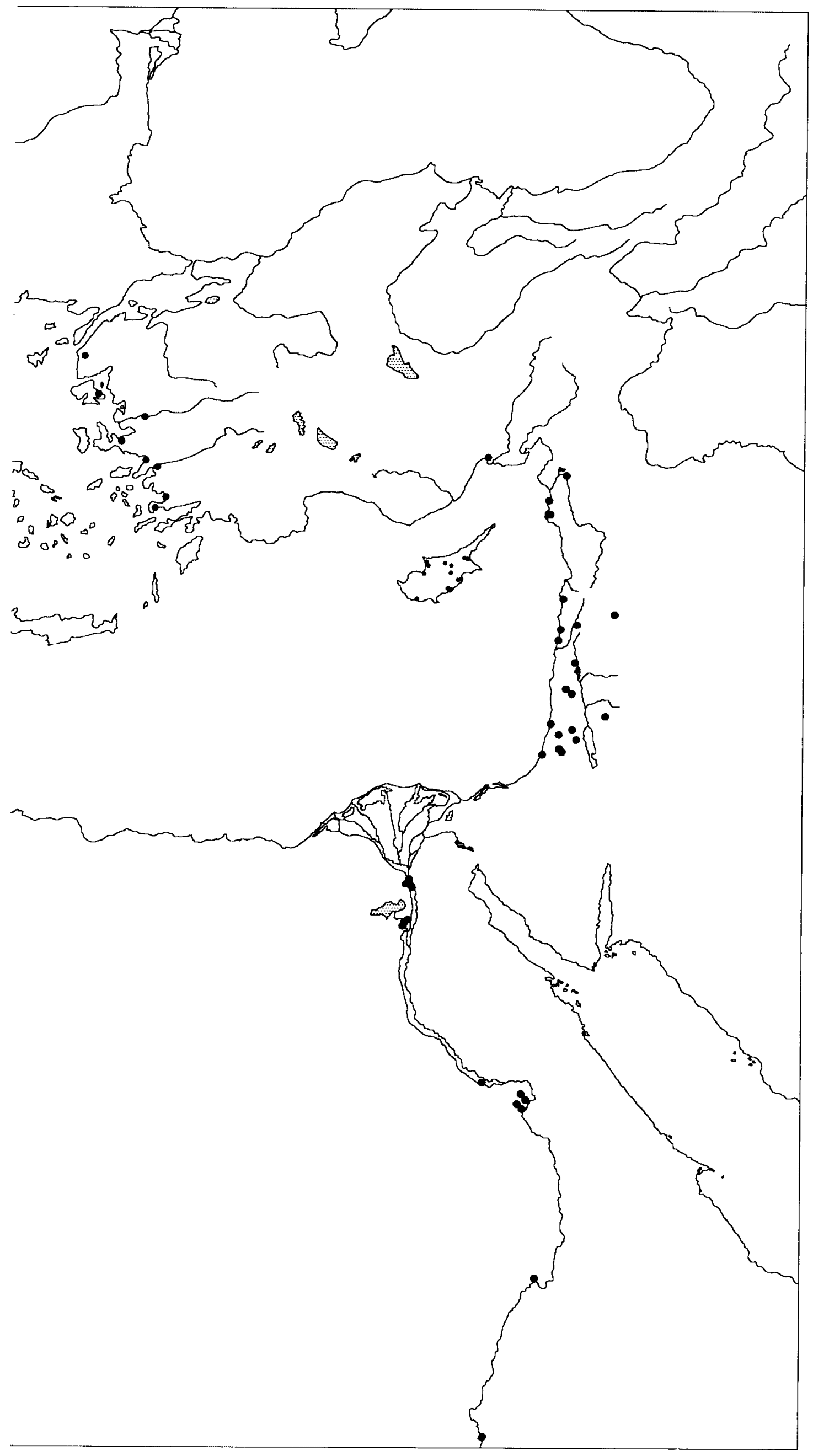




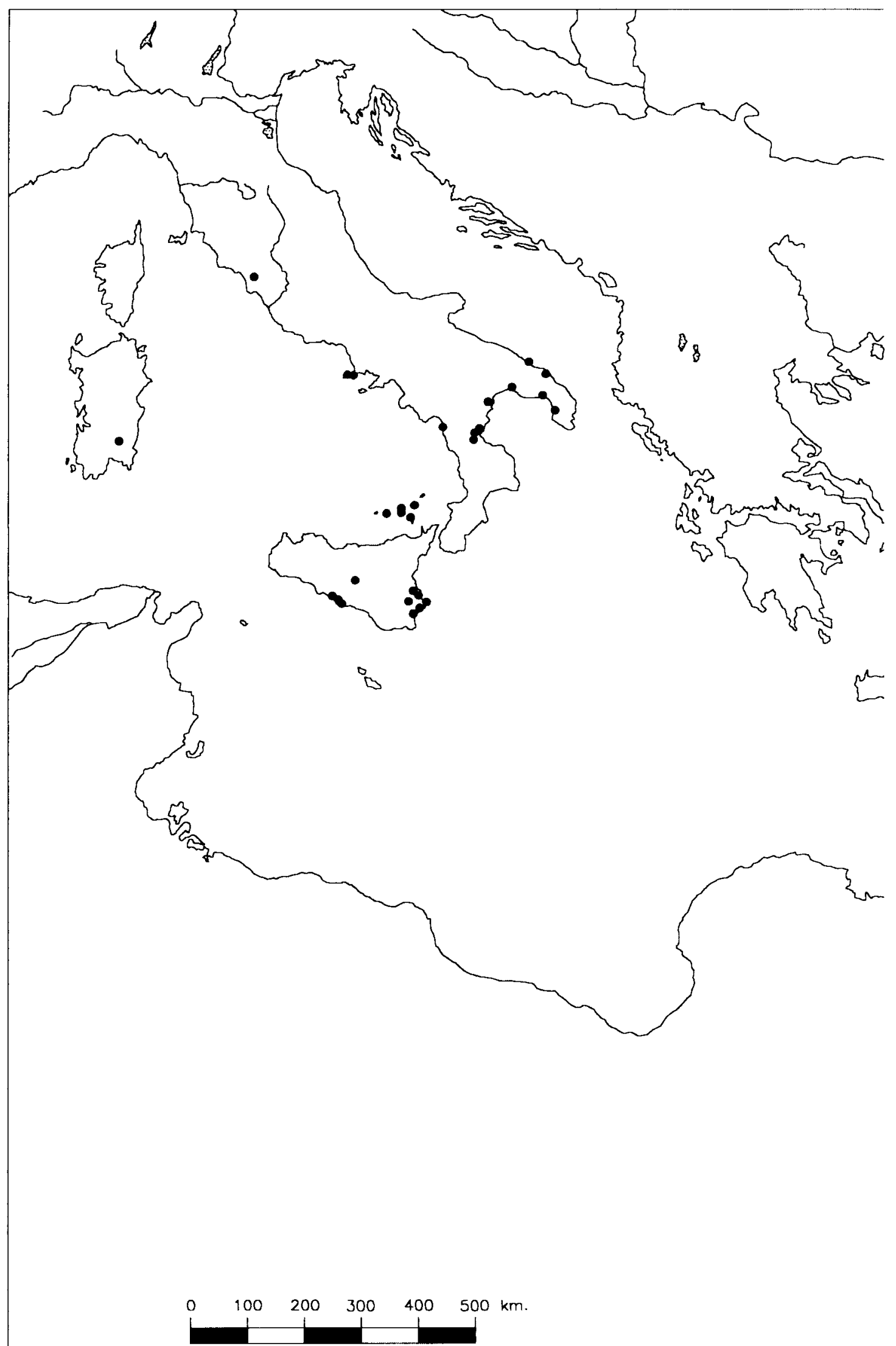

MAP 4

Sites in the Mediterranean with LH IIIA2 pottery

Total $=215$ 


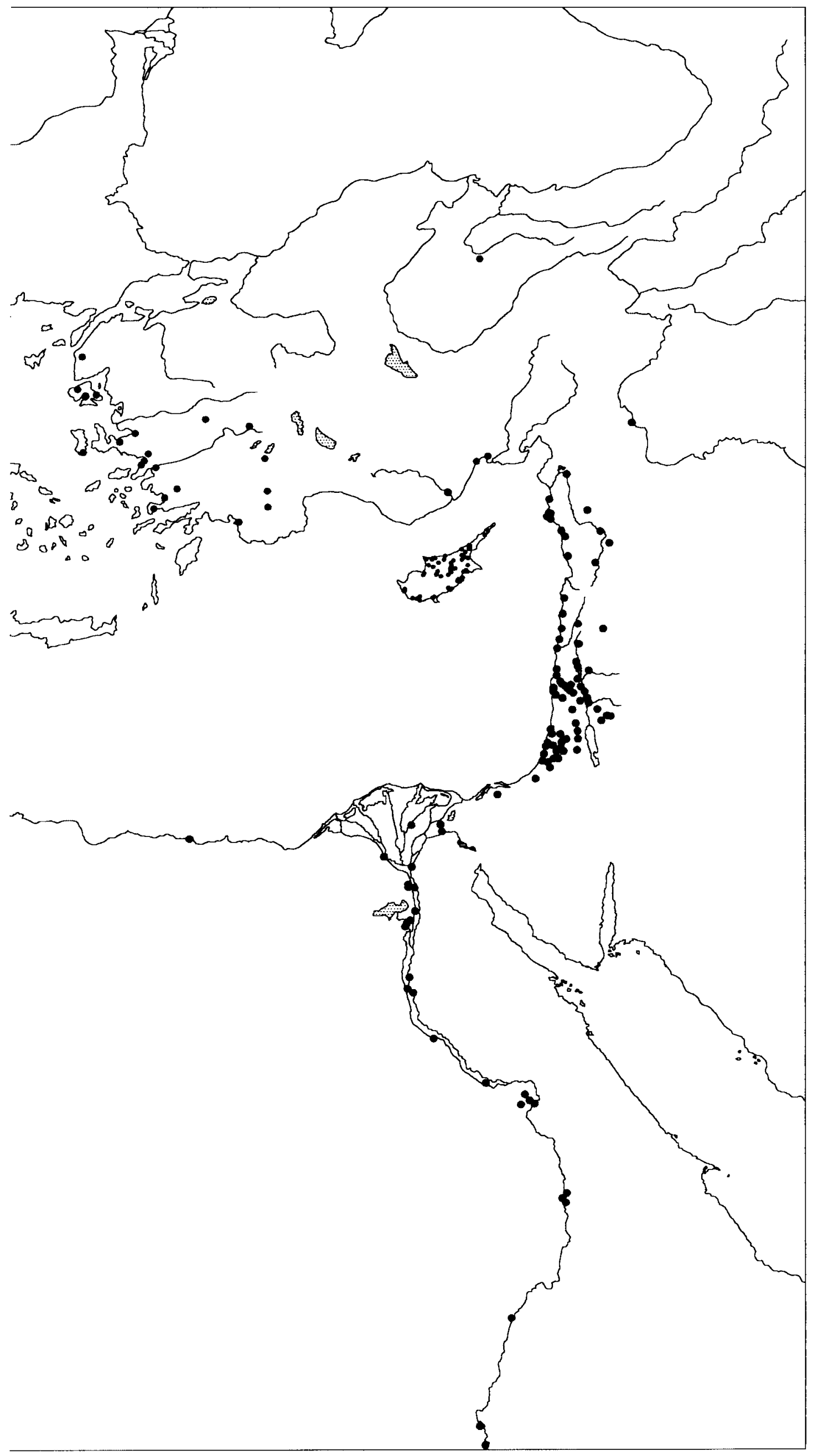




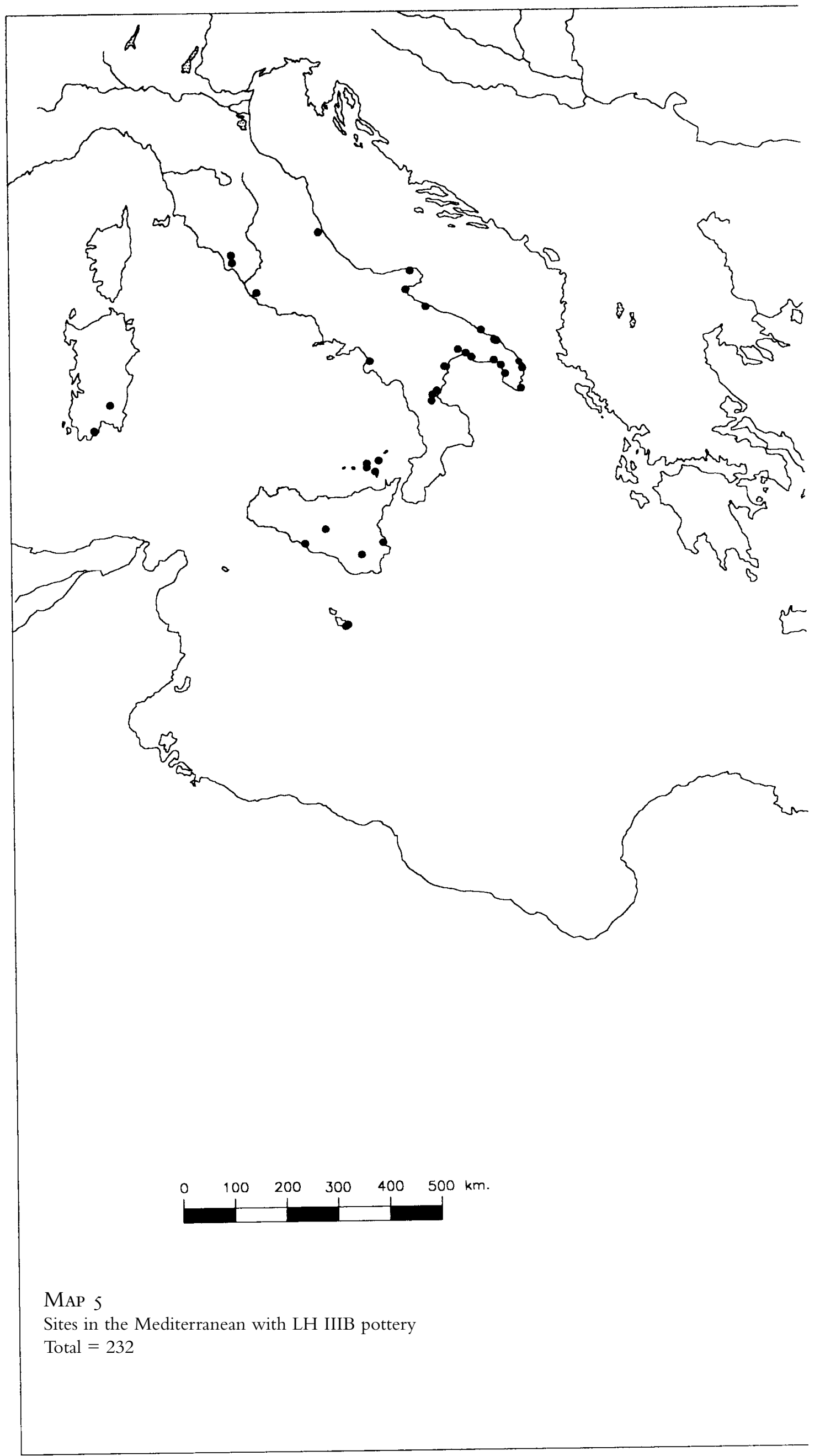




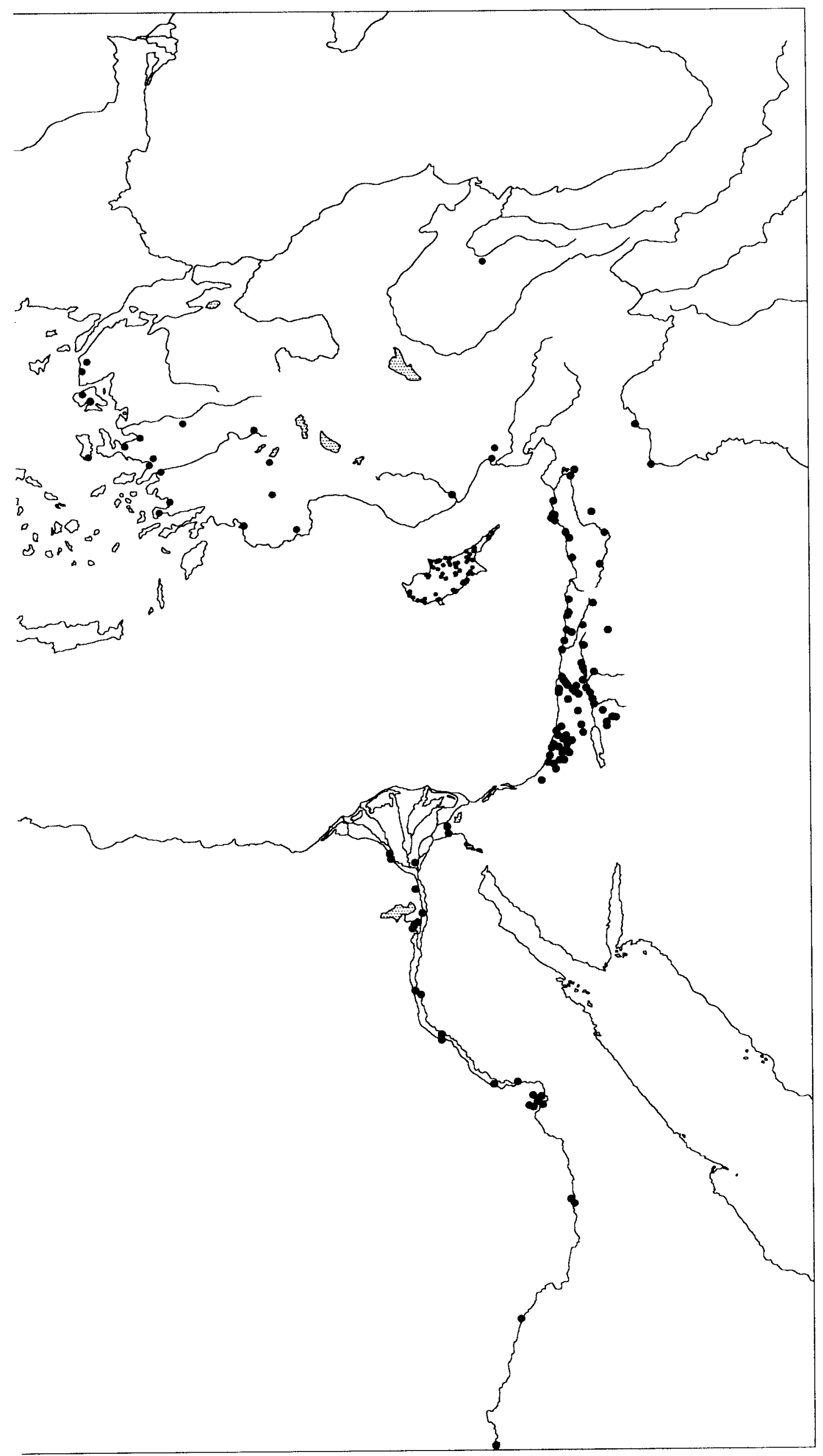




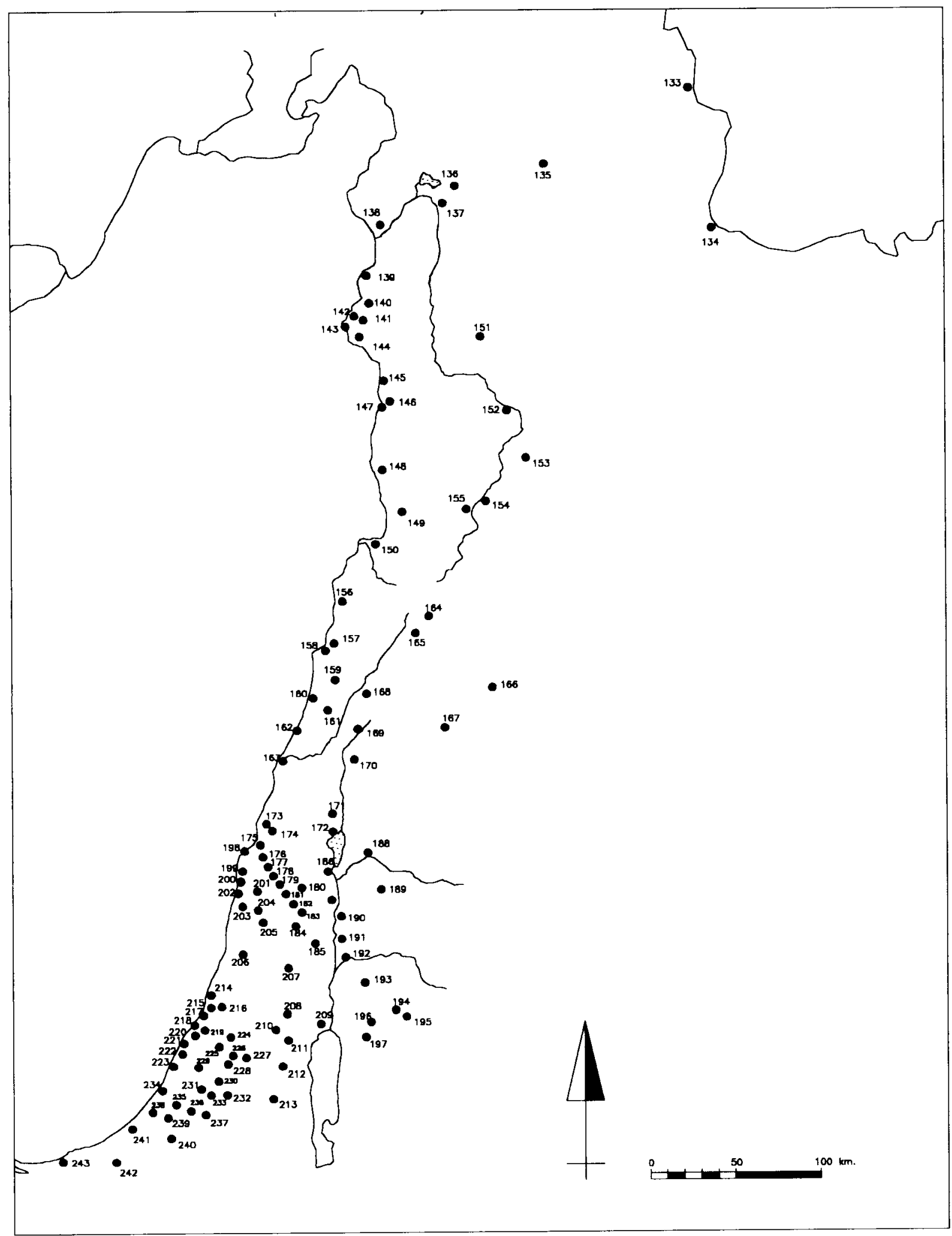

MAP 6

Levant: all sites with LH I - LH IIIB pottery Total $=111$ 


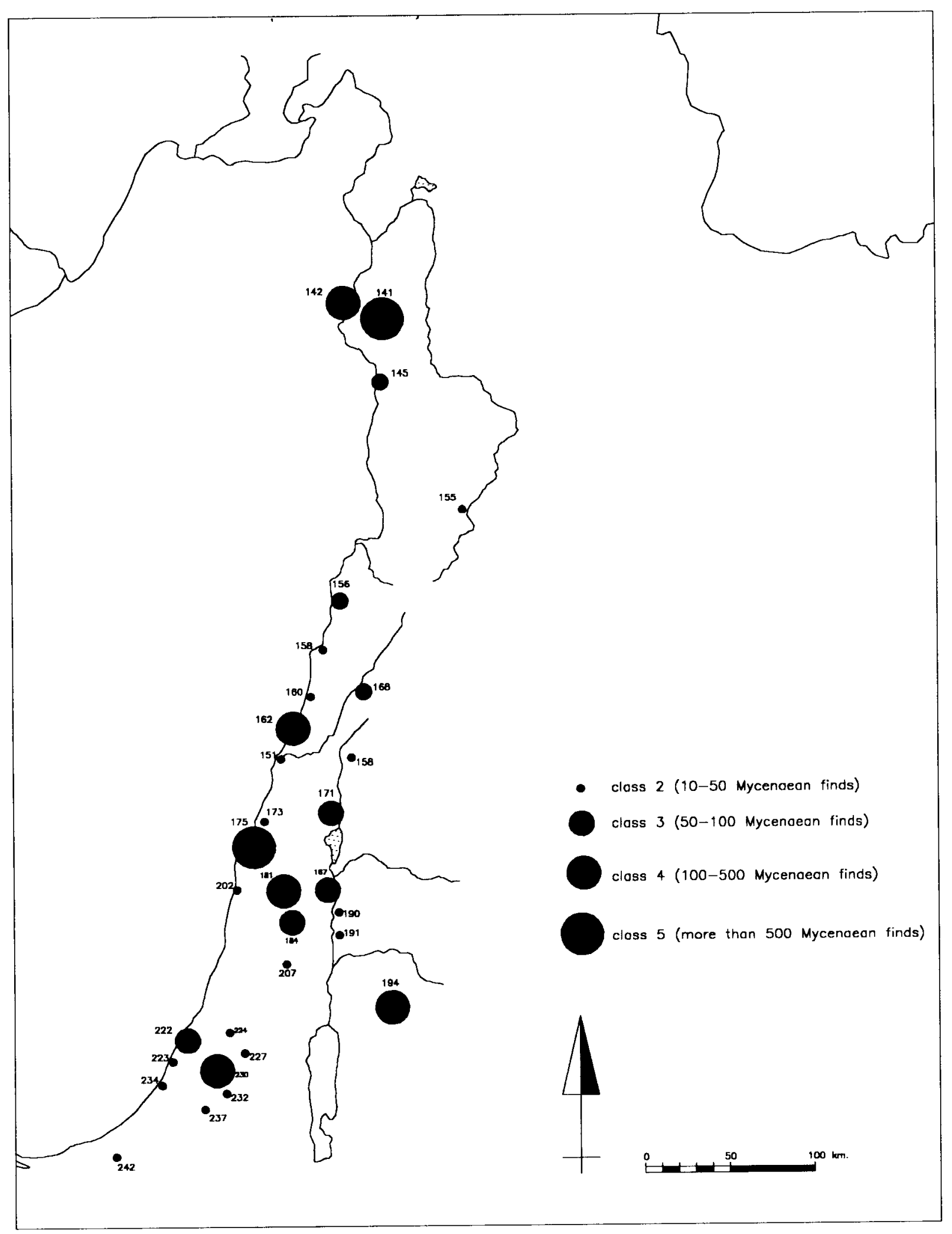

MAP 7

Levant: sites with more than ten Mycenaean finds Total $=34$ 


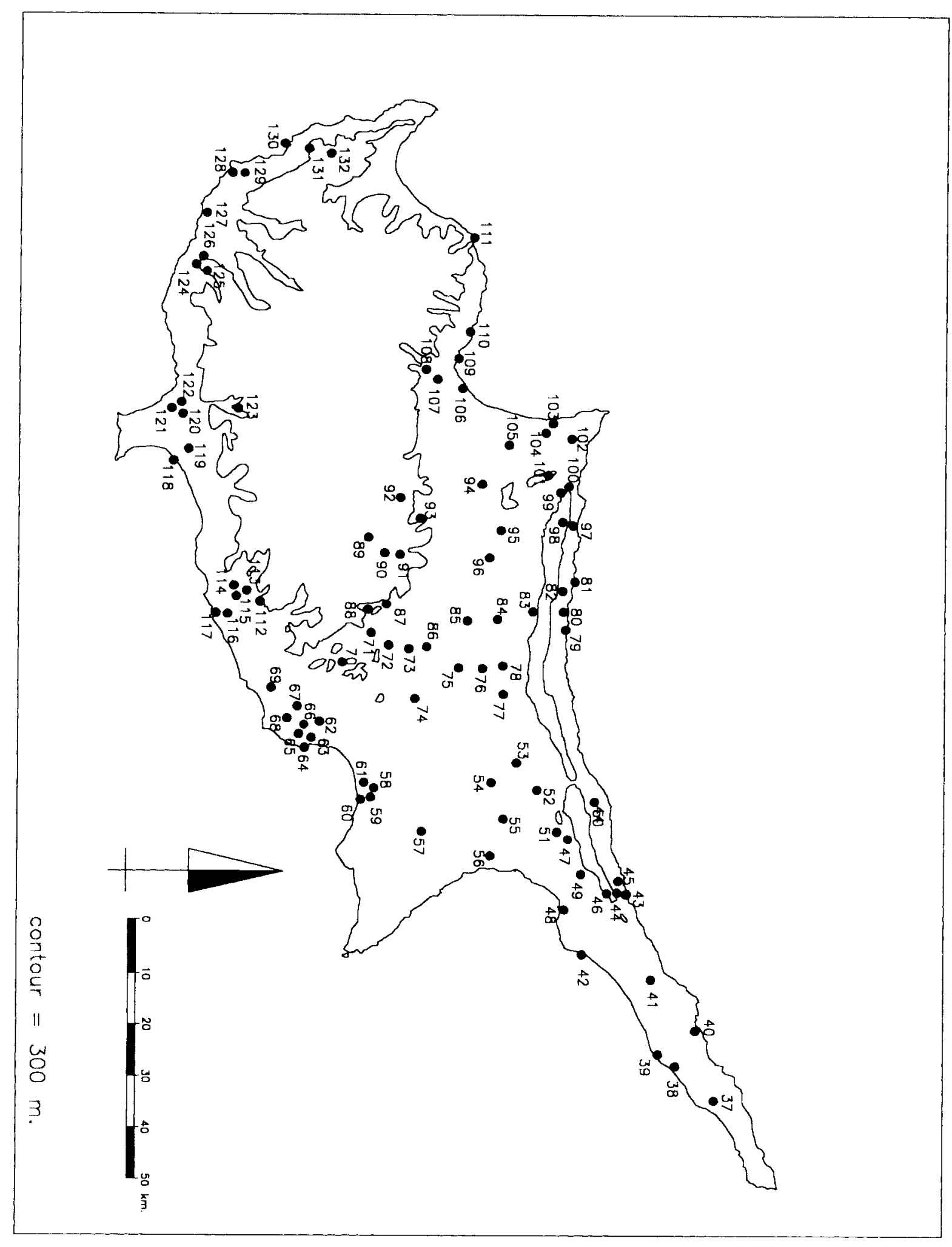

MAP 8

Cyprus: all sites with LH I - LH IIIB pottery Total $=96$ 


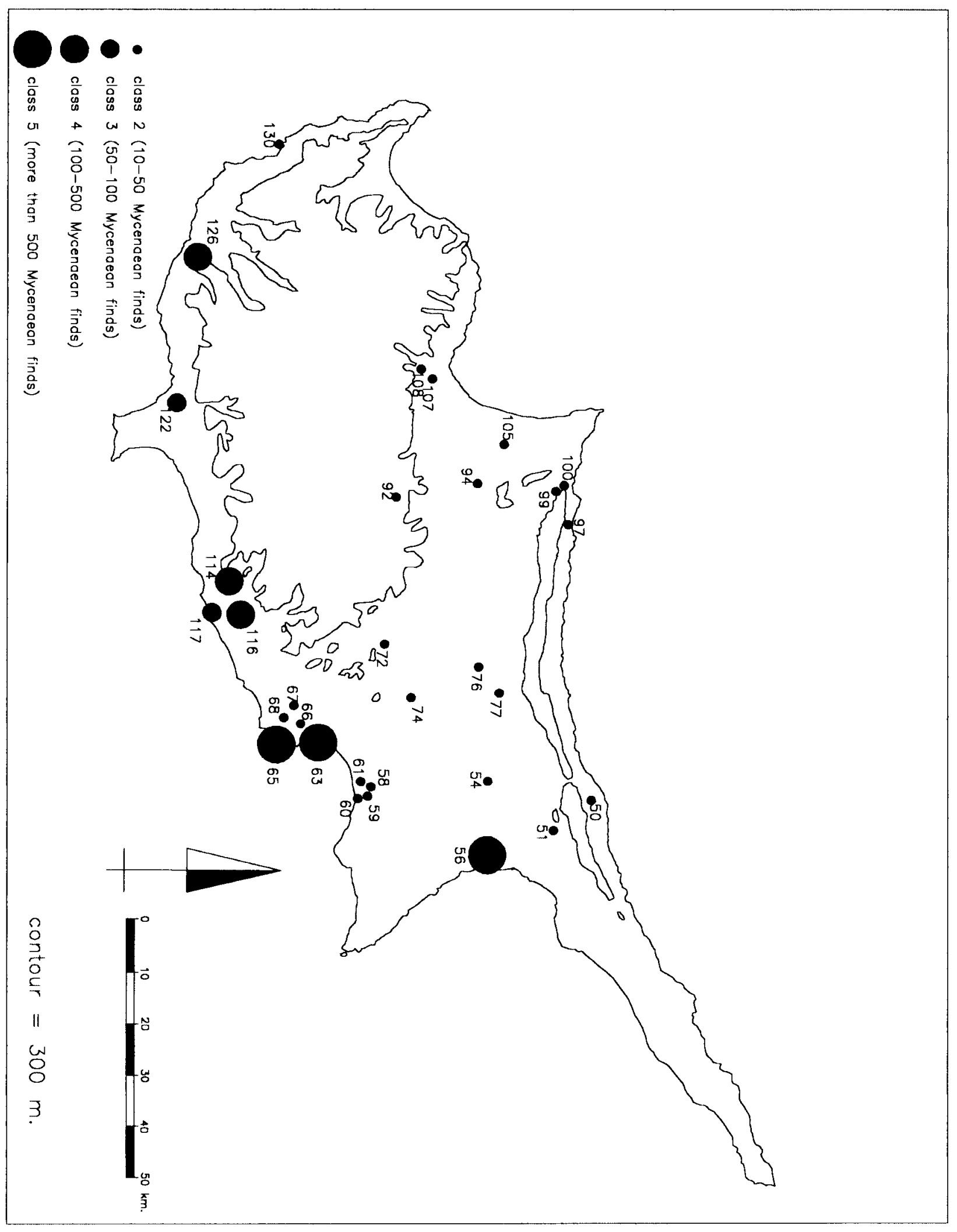

MAP 9

Cyprus: sites with more than ten Mycenaean finds Total $=31$ 


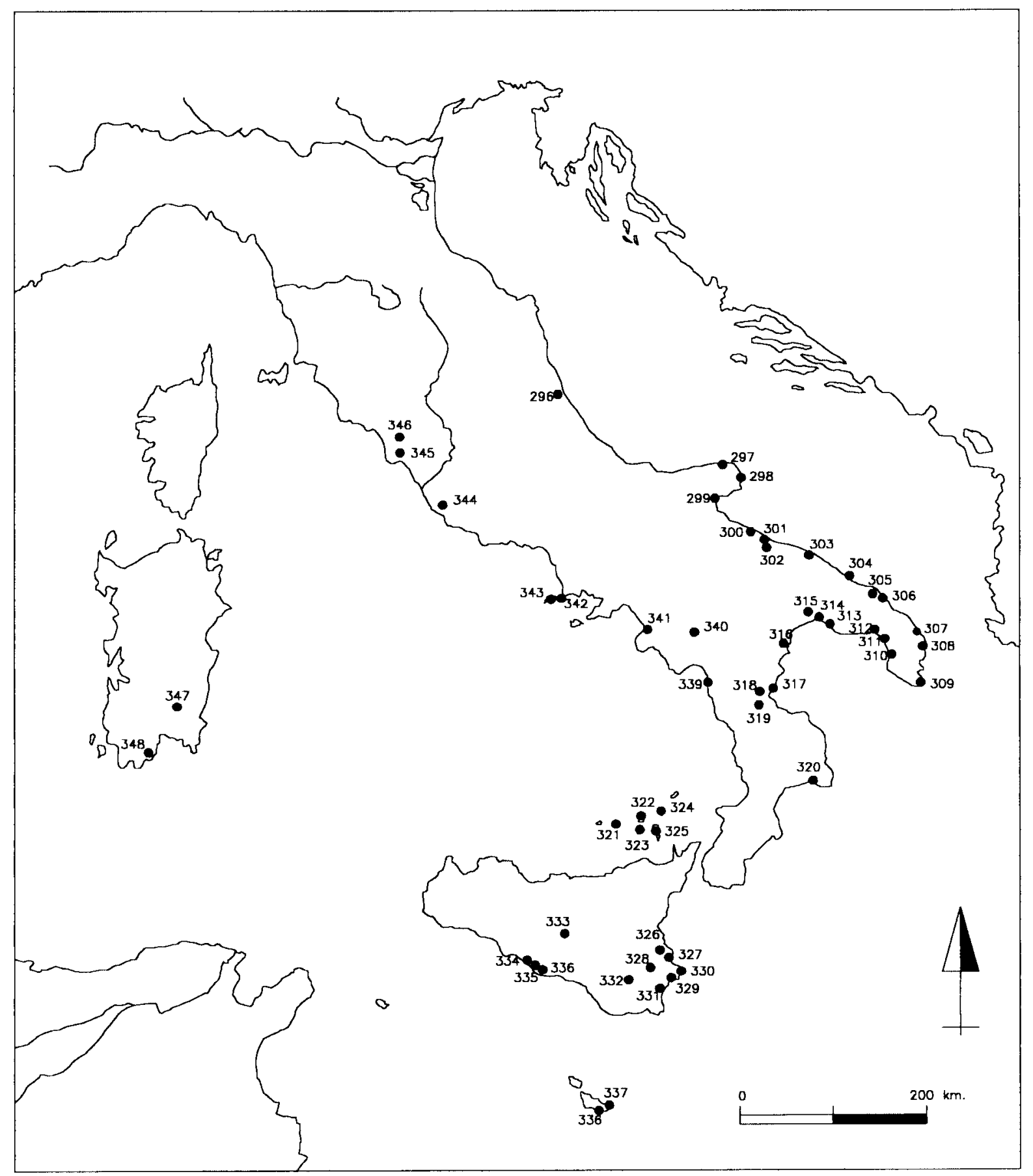

MAP IO

Italy: all sites with LH I - LH IIIB pottery Total $=53$ 


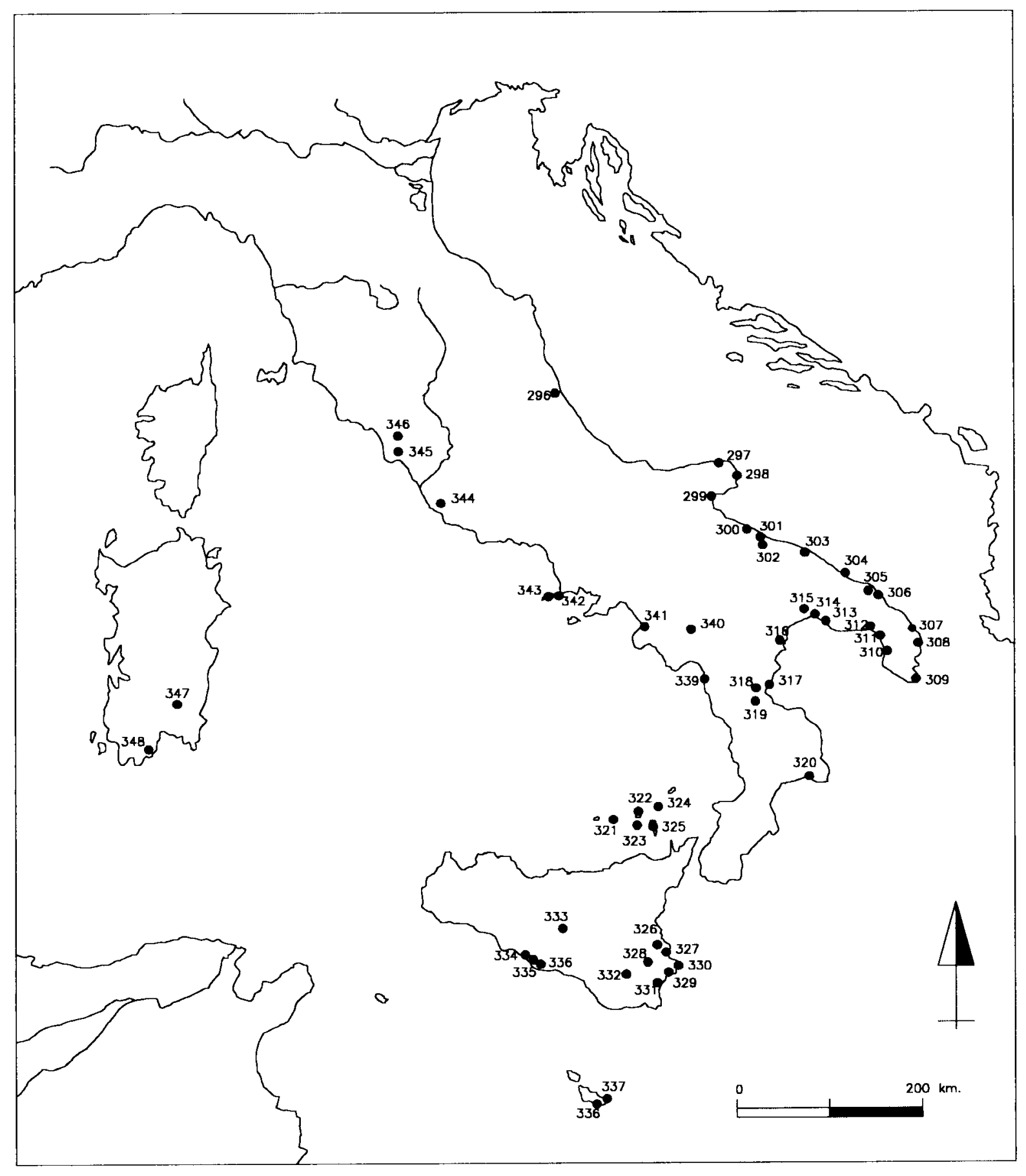

MAP II

Italy: sites with more than ten Mycenaean finds Total $=17$ 


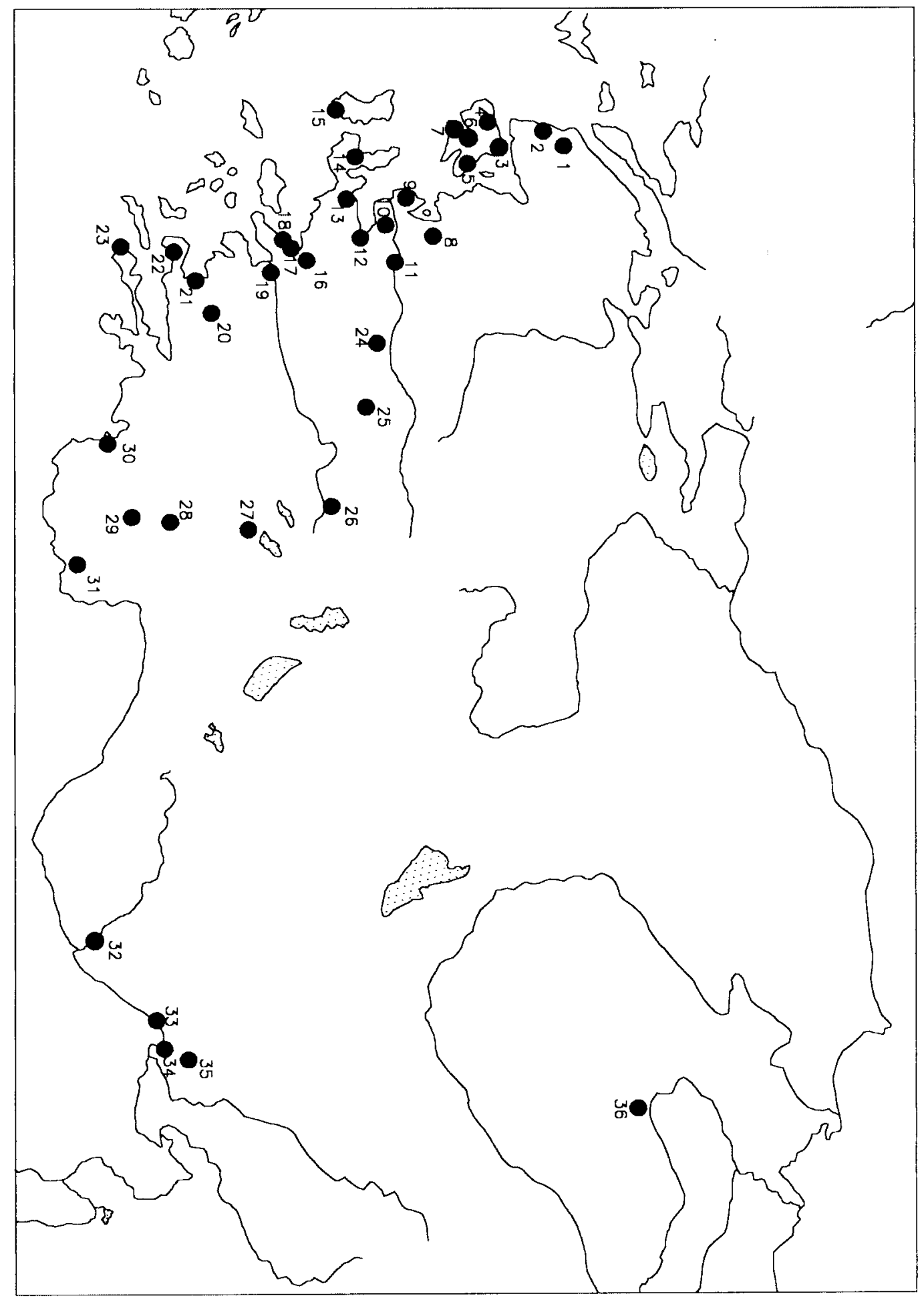

MAP I2

Anatolia: sites with Mycenaean pottery Total $=36$ 


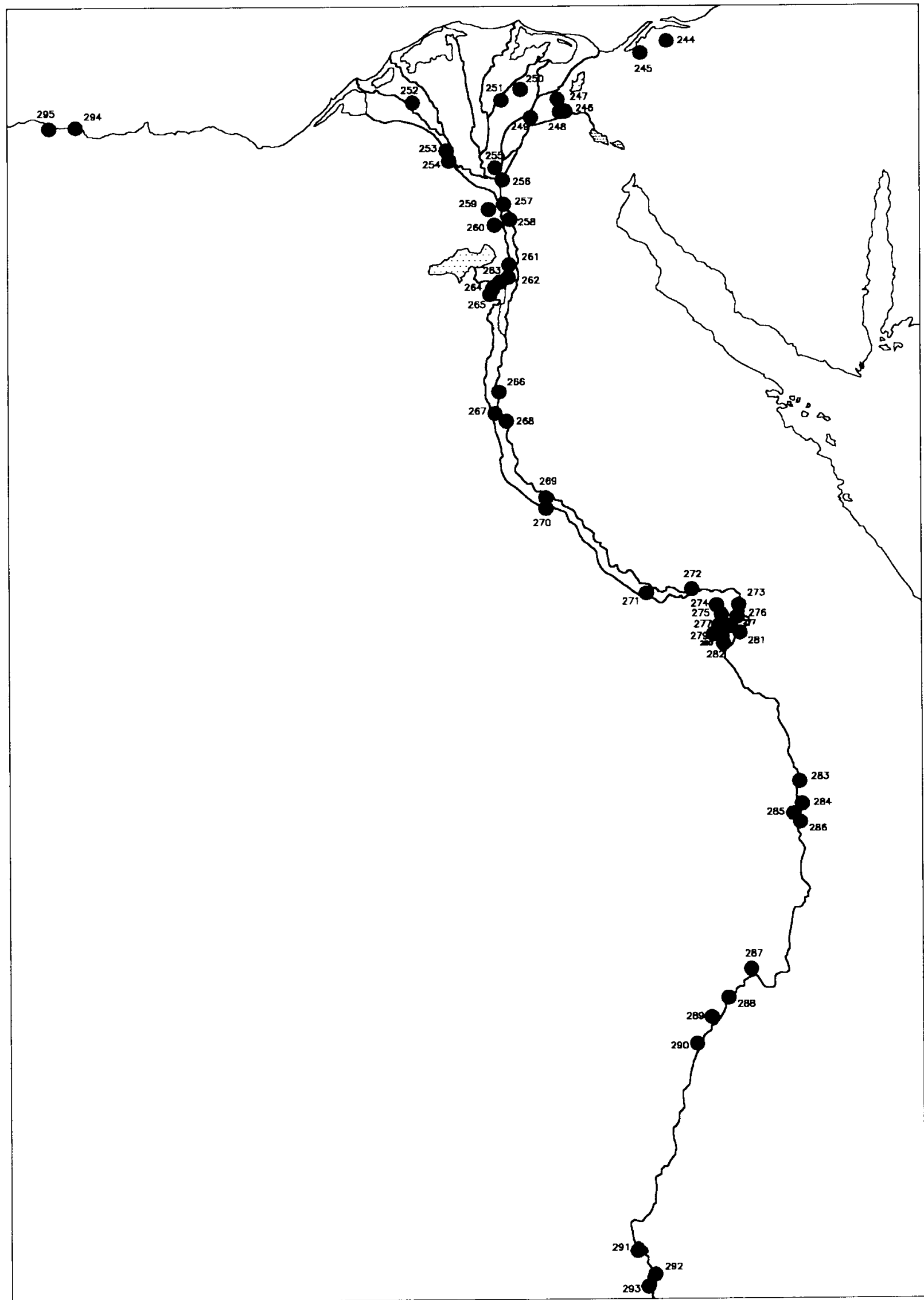

MAP I3

Egypt: sites with Mycenaean pottery Total $=53$ 

Catalogues 
Catalogue I: Sites in the Mediterranean with Mycenaean pottery

\begin{tabular}{|c|c|c|c|c|c|c|c|}
\hline & Site name & I-IIA & IIB-IIIA1 & IIIA2 & IIIB & IIIC & AMOUNT * \\
\hline \multicolumn{8}{|c|}{ Anatolia } \\
\hline 1 & Troy-Hissarlik & $x$ & $x$ & $x$ & $x$ & $x$ & 5 \\
\hline 2 & Besik-tepe & & & & $x$ & $x$ & 2 \\
\hline 3 & Methymna & & & & & & 1 \\
\hline 4 & Antissa & & & $x$ & $x$ & & 1 \\
\hline 5 & Thermi & & $x$ & $x$ & & & 1 \\
\hline 6 & Pyrrha & & & $x$ & $x$ & & 1 \\
\hline 7 & Kourtir & & & & & & 1 \\
\hline 8 & Elaia & & & & & & 1 \\
\hline 9 & Phocaia (Eski Foca) & & & & & & 1 \\
\hline 10 & Panaztepe & & & & & & 1 \\
\hline 11 & Çerkes Sultaniyou & & $x$ & & & & 1 \\
\hline 12 & Bayrakli (Old Smyrna) & & & $x$ & $x$ & & 1 \\
\hline 13 & Clazomenae (Liman tepe) & $x$ & $x$ & $x$ & $x$ & $x$ & 2 \\
\hline 14 & Reisdere (Erythrae) & & & & & & 1 \\
\hline 15 & Emporio & & & $x$ & $x$ & $x$ & 1 \\
\hline 16 & Halkapinar & & & $x$ & $x$ & & 1 \\
\hline 17 & Ephesus (Selcuk) & & $x$ & $x$ & $x$ & $x$ & 2 \\
\hline 18 & Kusadasi & & & $x$ & & & 1 \\
\hline 19 & Miletus & $x$ & $x$ & $x$ & $X$ & $x$ & 5 \\
\hline 20 & Mylasa (Milas) & & & $x$ & & & 1 \\
\hline 21 & lasos (Kuren) & $x$ & $x$ & $x$ & $x$ & $x$ & 3 \\
\hline 22 & Musgebi & & $x$ & $x$ & $x$ & $x$ & 4 \\
\hline 23 & Knidos (Kinidos) & & & & & & 1 \\
\hline 24 & Sardis & & & & $x$ & $x$ & 1 \\
\hline 25 & Gavurtepe & & & $x$ & & & 1 \\
\hline 26 & Beycesultan & & & $x$ & $x$ & & 1 \\
\hline 27 & Duver & & & $x$ & $x$ & & 1 \\
\hline 28 & Derekoy & & & $x$ & $x$ & & 1 \\
\hline 29 & Beylerbey & & & $x$ & & & 1 \\
\hline 30 & Telmessos (Fethiye) & & & $x$ & $x$ & & 1 \\
\hline 31 & Lymira & & & & $x$ & $x$ & 1 \\
\hline 32 & Kilise Tepe & & & $x$ & $x$ & & 1 \\
\hline 33 & Mersin (Yuemuektepe) & & & $x$ & & $x$ & 1 \\
\hline 34 & Kazanli Hoeyuek & $x$ & & $x$ & $x$ & $x$ & 1 \\
\hline 35 & Tarsus & & & & $x$ & $x$ & 1 \\
\hline 36 & Masat Hoeyuek & & & $x$ & $x$ & & 1 \\
\hline \multicolumn{8}{|c|}{ Cyprus } \\
\hline 37 & Rizokarpasso & & & $x$ & $x$ & & 1 \\
\hline 38 & Galinoporni & & & $x$ & $x$ & & 1 \\
\hline 39 & Korovia Nitovikla & & & & $x$ & & 1 \\
\hline 40 & Ayios Thyrsos Vikla & & & & & & 1 \\
\hline 41 & Leonarissio & & & & & & 1 \\
\hline 42 & Ayios Theodoros & & & & & & 1 \\
\hline 43 & Dhavlos Pyrgos & & & & & & 1 \\
\hline 44 & Anochora & & & & & & 1 \\
\hline 45 & Phlamoudhi Sapilou & & & $x$ & $x$ & & 1 \\
\hline 46 & Kantara & & & $x$ & $x$ & & 1 \\
\hline
\end{tabular}

* Amount of Myceneaan finds: 1 = 1-10; 2 = 10-50; 3 =50-100; 4 = 100-500; 5 = 500 and more. 


\begin{tabular}{|c|c|c|c|c|c|c|c|}
\hline & Site name & I-IIA & IIB-IIIA1 & IIIA2 & IIIB & IIIC & AMOUNT \\
\hline 47 & Ayios lakovos Dhima & & & $x$ & $x$ & & 1 \\
\hline 48 & Gastria Ayios loannis & & & & & & 1 \\
\hline 49 & Ovgoros & & & $x$ & $x$ & & 1 \\
\hline 50 & Akanthou Moulos & & & $x$ & $x$ & & 2 \\
\hline 51 & Ayios lakovos Melia & & & $x$ & $x$ & & 2 \\
\hline 52 & Psilatos Moutti & & & $x$ & $x$ & & 1 \\
\hline 53 & Marathovouni & & & & & & 1 \\
\hline 54 & Sinda & & & $x$ & $x$ & $x$ & 2 \\
\hline 55 & Milia & & $x$ & $x$ & $x$ & & 1 \\
\hline 56 & Enkomi & $x$ & $x$ & $x$ & $x$ & $x$ & 5 \\
\hline 57 & Kalopsidha & & & $x$ & $x$ & $x$ & 1 \\
\hline 58 & Pyla Kokkinokremos & & & & $x$ & & 2 \\
\hline 59 & Dhekelia Steno & & & $x$ & $x$ & & 2 \\
\hline 60 & Dhekelia Koukouphoudhkia & & & $x$ & $x$ & & 2 \\
\hline 61 & Pyla Verghi & & & $x$ & $x$ & & 2 \\
\hline 62 & Aradhippou & & & $x$ & $x$ & & 1 \\
\hline 63 & Kition & & & $x$ & $x$ & $x$ & 5 \\
\hline 64 & Laxia tou Riou & & & $x$ & $x$ & & 1 \\
\hline 65 & Hala Sultan Tekke & & $x$ & $x$ & $x$ & $x$ & 5 \\
\hline 66 & Dromolaxia trypes & & & $x$ & $x$ & & 2 \\
\hline 67 & Klavdhia & & & $x$ & $x$ & & 2 \\
\hline 68 & Arpera Chiflik & & $x$ & $x$ & $x$ & & 2 \\
\hline 69 & Kivisil Gyppos & & & & & & 1 \\
\hline 70 & Lythrodhonda Moutti & & & & & & 1 \\
\hline 71 & Alambra & & & $x$ & $x$ & & 1 \\
\hline 72 & Idalion & & $x$ & $x$ & $x$ & $x$ & 2 \\
\hline 73 & Ayios Sozomenos & & & $x$ & $x$ & $x$ & 1 \\
\hline 74 & Athienou Bamboulari & & & $x$ & $x$ & & 2 \\
\hline 75 & Nicosia Ayia Paraskevi & & $x$ & $x$ & $x$ & & 1 \\
\hline 76 & Kaimakli Evretadhes & & & $x$ & $x$ & & 2 \\
\hline 77 & Angastina & & & $x$ & $x$ & & 2 \\
\hline 78 & Palekythro & & & & $x$ & & 1 \\
\hline 79 & Ayios Epiktetos & & & $x$ & $x$ & & 1 \\
\hline 80 & Kazaphani Ayios Andronikos & & & $x$ & $x$ & & 1 \\
\hline 81 & Mylopetres & & & & $x$ & & 1 \\
\hline 82 & Karmi & & & & & & 1 \\
\hline 83 & Dhikomo Onisia & & $x$ & $x$ & $x$ & & 1 \\
\hline 84 & Nicosia Bairaktar & & & & $x$ & $x$ & 1 \\
\hline 85 & Strovolos Dromero & & & & & & 1 \\
\hline 86 & Yeri Phoenikias & & & $x$ & & & 1 \\
\hline 87 & Analionda Palioklichia & & & & $x$ & & 1 \\
\hline 88 & Mathiatis & & & $x$ & & & 1 \\
\hline 89 & Politiko-Lambertis & & & $x$ & $x$ & & 1 \\
\hline 90 & Pera & & & & $x$ & & 1 \\
\hline 91 & Tamassos Litharkes & & & & & & 1 \\
\hline 92 & Akhera & & & $x$ & $x$ & & 2 \\
\hline 93 & Meniko Kyra tou Dhiakou & & & $x$ & $x$ & & 1 \\
\hline 94 & Akaki & & & $x$ & $x$ & & 2 \\
\hline 95 & Dhenia & & & $x$ & $x$ & & 1 \\
\hline 96 & Kokkini Trimithia & & & & & & 1 \\
\hline 97 & Lapithos Ayia Anastasia & & & $x$ & $x$ & $x$ & 2 \\
\hline 98 & Larnaca tis Lapithou & & & & $x$ & & 1 \\
\hline
\end{tabular}




\begin{tabular}{|c|c|c|c|c|c|c|c|}
\hline & Site name & I-IIA & IIB-IIIA1 & IIIA2 & IIIB & IIIC & AMOUNT \\
\hline 99 & Myrtou Pigadhes & & & $x$ & $x$ & $x$ & 2 \\
\hline 100 & Myrtou Stephania & & & $x$ & $x$ & & 2 \\
\hline 101 & Dhiorios Kupous & & & & $x$ & & 1 \\
\hline 102 & Kormakiti Ayious & & & $x$ & $x$ & & 1 \\
\hline 103 & Ayia Irini Palaeokastro & $x$ & $x$ & & & & 1 \\
\hline 104 & Ayia Irini Temple Site & & & & $x$ & $x$ & 1 \\
\hline 105 & Toumba tou Skourou & $x$ & $x$ & $x$ & $x$ & & 2 \\
\hline 106 & Pendayia & & & & & & 1 \\
\hline 107 & Katydhata & & $x$ & $x$ & $x$ & & 2 \\
\hline 108 & Apliki & & & $x$ & $x$ & $x$ & 2 \\
\hline 109 & Soloi & & & & $x$ & & 1 \\
\hline 110 & Loutros Adhkia & & & & & & 1 \\
\hline 111 & Pomos & & & & & & 1 \\
\hline 112 & Kirokitia Skasmata & & & & & & 1 \\
\hline 113 & Kalavassos Mavrovouni & & & & $x$ & & 1 \\
\hline 114 & Kalavasos Ayios Dimithrios & & $x$ & $x$ & $x$ & & 4 \\
\hline 115 & Kalavasos Mangi & & & $x$ & $x$ & & 1 \\
\hline 116 & Maroni Vournes & $x$ & $x$ & $x$ & $x$ & & 4 \\
\hline 117 & Maroni Tsaroukkas & & $x$ & $x$ & $x$ & & 3 \\
\hline 118 & Limassol Kapsalos & & & & & & 1 \\
\hline 119 & Polemidhia Oufkia & & & & & & 1 \\
\hline 120 & Erimi Kafkalla & & & $x$ & $x$ & & 1 \\
\hline 121 & Kourion Episkopi & & & $x$ & $x$ & & 1 \\
\hline 122 & Kourion Bamboula & & & $x$ & $x$ & $x$ & 3 \\
\hline 123 & Alassa & & & & $x$ & & 1 \\
\hline 124 & Kouklia Skales & & & $x$ & $x$ & & 1 \\
\hline 125 & Kouklia Hadji & & & $x$ & $x$ & $x$ & 1 \\
\hline 126 & Kouklia Palaepaphos & $x$ & $x$ & $x$ & $x$ & $x$ & 4 \\
\hline 127 & Yeroskipou & & & $x$ & $x$ & & 1 \\
\hline 128 & Paphos & & & & & & 1 \\
\hline 129 & Peyia Koutsourous & & & & $x$ & & 1 \\
\hline 130 & Maa Palaeokastro & & & & $x$ & $x$ & 2 \\
\hline 131 & Arodhes & & & $x$ & $x$ & & 1 \\
\hline 132 & Drousha Appiourka & & & $x$ & $x$ & & 1 \\
\hline \multicolumn{8}{|c|}{ Levant } \\
\hline 133 & Charchemish (Jerablus) & & & $x$ & $x$ & & 1 \\
\hline 134 & Meskene Emar & & & & $x$ & & 1 \\
\hline 135 & Oumm el-Mara & & & & & & 1 \\
\hline 136 & Catal Hueyuek & & & & $x$ & & 1 \\
\hline 137 & Alalakh (Tell Atchana) & $x$ & $x$ & $x$ & $x$ & & 2 \\
\hline 138 & Sabouni & & & & & & 1 \\
\hline 139 & Ras el-Bassit & & $x$ & $x$ & $x$ & $x$ & 1 \\
\hline 140 & Tell Nahr al-'Arab & & & & & & 1 \\
\hline 141 & Ugarit (Ras Shamra) & $x$ & $x$ & $x$ & $x$ & & 4 \\
\hline 142 & Minet el-Beida & $x$ & $x$ & $x$ & $x$ & & 4 \\
\hline 143 & Ras Ibn Hani & & & $x$ & $x$ & $x$ & 2 \\
\hline 144 & Lattakia (Ramitha) & & & $x$ & $x$ & & 1 \\
\hline 145 & Tell Sukas & & & $x$ & $x$ & $x$ & 3 \\
\hline 146 & Arab al Mulk & & & $x$ & $x$ & & 1 \\
\hline 147 & Tell Daruk & & & & & & 1 \\
\hline 148 & Tell Kazel & & & $x$ & $x$ & & 2 \\
\hline
\end{tabular}




\begin{tabular}{|c|c|c|c|c|c|c|c|}
\hline & Site name & I-IIA & IIB-IIIA1 & IIIA2 & IIIB & IIIC & AMOUNT \\
\hline 149 & Tell Hayat & & & & & & 1 \\
\hline 150 & Tell 'Arqa & & & & & & 1 \\
\hline 151 & Khan Sheikoun & & & $x$ & $x$ & & 1 \\
\hline 152 & Hama & & & $x$ & $x$ & & 1 \\
\hline 153 & Qatna (Mishrife) & & & $x$ & & & 1 \\
\hline 154 & Tell Ouaouieh & & & & & & 1 \\
\hline 155 & Qadesh (Tell Nebi Mend) & & & $x$ & $x$ & & 2 \\
\hline 156 & Byblos (Jbail) & $x$ & $x$ & $x$ & $x$ & $x$ & 3 \\
\hline 157 & Beirut Dog river & & & & $x$ & & 1 \\
\hline 158 & Beirut (centre) & & & $x$ & $x$ & & 2 \\
\hline 159 & Garife & & & & & & 1 \\
\hline 160 & Sidon (Saida) & & $x$ & $x$ & $x$ & & 2 \\
\hline 161 & Qraye & & & & $x$ & & 1 \\
\hline 162 & Sarepta (Sarafand) & & $x$ & $x$ & $x$ & $x$ & 4 \\
\hline 163 & Tyre & & & $x$ & $x$ & $x$ & 2 \\
\hline 164 & Tell el Ghassil & & & & & & 1 \\
\hline 165 & Tell 'Ain Sherif & & & & $x$ & & 1 \\
\hline 166 & Tell es Salihyeh & & $x$ & & & & 1 \\
\hline 167 & Deir Khabie & & & $x$ & $x$ & & 1 \\
\hline 168 & Kamid el-Loz & $x$ & $x$ & $x$ & $x$ & & 3 \\
\hline 169 & Khan Selim & & & & & & 1 \\
\hline 170 & Tell Dan (Tell el-Qadi) & & & $x$ & $x$ & & 2 \\
\hline 171 & Hazor & & $x$ & $x$ & $x$ & & 3 \\
\hline 172 & Kinneret (Kh. al-Urema) & & & $x$ & $x$ & & 1 \\
\hline 173 & Akko & & & $x$ & & $x$ & 2 \\
\hline 174 & Tell Bir el-Gharbi & & & & & & 1 \\
\hline 175 & Tell Abu Hawam & & & $x$ & $x$ & & 5 \\
\hline 176 & Tell Qasis & & & & $x$ & & 1 \\
\hline 177 & Tell Qiri & & & $x$ & $x$ & & 1 \\
\hline 178 & Tell Yoqne'am & & & $x$ & $x$ & & 1 \\
\hline 179 & Abu Shushe & & & $x$ & & & 1 \\
\hline 180 & Afula & & & $x$ & $x$ & & 1 \\
\hline 181 & Megiddo (Tell el-Mutesselim) & & $x$ & $x$ & $x$ & & 4 \\
\hline 182 & Tell Kadesh & & & $x$ & $x$ & & 1 \\
\hline 183 & Tell Ta'annek & $x$ & $x$ & $x$ & $x$ & & 1 \\
\hline 184 & Dothan & & & & & & 3 \\
\hline 185 & Tell el Far'ah (North) & & & $x$ & & & 1 \\
\hline 186 & Tell Yin'am & & & $x$ & $x$ & & 1 \\
\hline 187 & Beth Shean & & & $x$ & $x$ & & 3 \\
\hline 188 & Tell Ashari & & & $x$ & $x$ & & 1 \\
\hline 189 & Tell Irbid & & & & & & 1 \\
\hline 190 & Pella (Tabaqat Fahil) & & & $x$ & $x$ & & 2 \\
\hline 191 & Tell es Saidiyeh & & & $x$ & $x$ & & 2 \\
\hline 192 & Deir Alla & & & $x$ & $x$ & & 1 \\
\hline 193 & Umm ad Dananir & & & $x$ & $x$ & & 1 \\
\hline 194 & Amman Airport & $x$ & $x$ & $x$ & $x$ & & 4 \\
\hline 195 & Sahab & & & $x$ & $x$ & & 1 \\
\hline 196 & Hesban & & & $x$ & $x$ & & 1 \\
\hline 197 & Madeba & & & & $x$ & & 1 \\
\hline 198 & Tell es Samak & & & & & & 1 \\
\hline 199 & Atlit & & & & & & 1 \\
\hline 200 & Tell Nami & & & $x$ & $x$ & & 1 \\
\hline
\end{tabular}




\begin{tabular}{|c|c|c|c|c|c|c|c|}
\hline & Site name & I-IIA & IIB-IIIA1 & IIIA2 & IIIB & IIIC & AMOUNT \\
\hline 201 & Tell Eran & & & & & & 1 \\
\hline 202 & Dor (Tell el Burj) & & & $x$ & $x$ & & 2 \\
\hline 203 & Tell Mevorakh & & & $x$ & & & 1 \\
\hline 204 & Tell Aron & & & & & & 1 \\
\hline 205 & Jatt & & & $x$ & $x$ & & 1 \\
\hline 206 & Tell Burgatha & & & & & & 1 \\
\hline 207 & Shechem (Tell Balata) & & & $x$ & $x$ & $x$ & 2 \\
\hline 208 & Bethel (Beitin) & & & $x$ & $x$ & & 1 \\
\hline 209 & Jericho & & & & & & 1 \\
\hline 210 & Gibeon (el Jib) & & $x$ & & & & 1 \\
\hline 211 & Jerusalem & & & $x$ & $x$ & & 1 \\
\hline 212 & Khirbet Judur & & $x$ & $x$ & & & 1 \\
\hline 213 & Khirbet Rabud (Debir) & & & $x$ & & & 1 \\
\hline 214 & Tell Michal & $x$ & & & & & 1 \\
\hline 215 & Aphek (Antipatris) & & & $x$ & $x$ & & 1 \\
\hline 216 & Izbet Sartah & & & & $x$ & & 1 \\
\hline 217 & Tell Jerishe & & & $x$ & $x$ & & 1 \\
\hline 218 & Yavneh Yam & & & & & & 1 \\
\hline 219 & Dahrat al Humrayah & & & $x$ & $x$ & & 1 \\
\hline 220 & Tell Mor & & & & & & 1 \\
\hline 221 & Ashdod-Yam & & & & & & 1 \\
\hline 222 & Ashdod & & & $x$ & $x$ & $x$ & 3 \\
\hline 223 & Ashkelon & & & $x$ & $x$ & & 2 \\
\hline 224 & Gezer & $x$ & $x$ & $x$ & $x$ & & 2 \\
\hline 225 & Tell Miqne & & & & $x$ & $x$ & 1 \\
\hline 226 & Tell Batash & & & $x$ & $x$ & & 1 \\
\hline 227 & Ain Shems (Beth Shemesh) & & & $x$ & $x$ & & 2 \\
\hline 228 & Tell es Safiyeh & & & $x$ & $x$ & & 1 \\
\hline 229 & Tell Sippor & & & $x$ & $x$ & & 1 \\
\hline 230 & Lachish (Tell ed Duweir) & $x$ & $x$ & $x$ & $x$ & & 4 \\
\hline 231 & Tell el Hesi & & & $x$ & $x$ & & 1 \\
\hline 232 & Tell Beit Mirsim & & $x$ & $x$ & $x$ & & 2 \\
\hline 233 & Tell Nagila & & & & & & 1 \\
\hline 234 & Tell ‘Ajjul (Gaza) & $x$ & $x$ & $x$ & $x$ & & 2 \\
\hline 235 & Qudur el Walaida & & & & & & 1 \\
\hline 236 & Tell Haror & & & $x$ & $x$ & & 1 \\
\hline 237 & Tell Sera' & & & $x$ & $x$ & & 2 \\
\hline 238 & Deir el Balah & & & $x$ & $x$ & & 1 \\
\hline 239 & Gerar (Tell Jemmeh) & & & $x$ & $x$ & & 1 \\
\hline 240 & Tell el Far'ah (south) & & & $x$ & $x$ & & 1 \\
\hline 241 & Tell er Ridan & & & & & & 1 \\
\hline 242 & El-Harruba & & & $x$ & $x$ & $x$ & 2 \\
\hline 243 & El 'Arish (Tell esh-Shari'a) & & & & & & 1 \\
\hline \multicolumn{8}{|c|}{ Egypt } \\
\hline 244 & Bir el Abd & & & & & & 2 \\
\hline 245 & C 86 & & & $x$ & & & 1 \\
\hline 246 & Ali Mara & & & & & & 1 \\
\hline 247 & Tell el Dab'a-Qantir & $x$ & & $x$ & $x$ & & 3 \\
\hline 248 & Tell el-Rataba & & & $x$ & $x$ & & 1 \\
\hline 249 & Az-Zaqaziz & & & & & & 1 \\
\hline 250 & Tell ar-Rubai & & & & & & 1 \\
\hline
\end{tabular}




\begin{tabular}{|c|c|c|c|c|c|c|c|}
\hline & Site name & I-IIA & IIB-IIIA1 & IIIA2 & IIIB & IIIC & AMOUNT \\
\hline 251 & Tell el-Muqdam & & & $x$ & & & 1 \\
\hline 252 & Kom Firin & & & & & & 1 \\
\hline 253 & Mostai (Tell Om Harb) & & & & $x$ & & 1 \\
\hline 254 & Kom Abu Billa & & & $x$ & $x$ & & 1 \\
\hline 255 & Tell el-Yahudiyeh & & & & $x$ & & 1 \\
\hline 256 & Heliopolis & & & $x$ & & & 1 \\
\hline 257 & Abusir el-Meleq & $x$ & & & & & 1 \\
\hline 258 & Memphis (Kom Rabi'a) & $x$ & & $x$ & & & 1 \\
\hline 259 & Saqqara - Teti area & $x$ & $x$ & $x$ & & & 1 \\
\hline 260 & Saqqara-N.K. necropole & & & $x$ & $x$ & & 2 \\
\hline 261 & Riqqeh & & & $x$ & $x$ & & 1 \\
\hline 262 & Meydum & & & & & & 1 \\
\hline 263 & Kahun (al-Lahun) & & $x$ & $x$ & $x$ & & 1 \\
\hline 264 & Gurob & $x$ & $x$ & $x$ & $x$ & & 2 \\
\hline 265 & Sedment & $x$ & $x$ & $x$ & $x$ & & 1 \\
\hline 266 & Zawyet el-Amwat & & & $x$ & & & 1 \\
\hline 267 & Tuneh el-Gebel (E Ash.) & & & $x$ & $x$ & & 1 \\
\hline 268 & Tell el Amarna & & & $x$ & $x$ & & 5 \\
\hline 269 & Assyut & & & & $x$ & & 1 \\
\hline 270 & Rifeh & & & $x$ & $x$ & & 1 \\
\hline 271 & Abydos & $x$ & & $x$ & $x$ & & 1 \\
\hline 272 & Balabisch & & & & $x$ & & 1 \\
\hline 273 & Deir el-Ballas & & & & & & 1 \\
\hline 274 & Kom el-Abd & & & & & & 1 \\
\hline 275 & Deir el-Medina & $x$ & $x$ & $x$ & $x$ & & 4 \\
\hline 276 & Naqada & & & & $x$ & & 1 \\
\hline 277 & Qasr al-Aguz & & & & & & 1 \\
\hline 278 & Gurna (Abd el-Qurna) & & $x$ & $x$ & $x$ & & 1 \\
\hline 279 & Dira Abu n Naga & $x$ & & $x$ & $x$ & & 1 \\
\hline 280 & Malkata & & & & $x$ & & 1 \\
\hline 281 & Karnak & & & $x$ & $x$ & & 1 \\
\hline 282 & Armant & $x$ & & & & & 1 \\
\hline 283 & Elephantine (Assuan) & & & & & & 1 \\
\hline 284 & Arabi Hilla & & & $x$ & & & 1 \\
\hline 285 & Daqqa & & & $x$ & $x$ & & 1 \\
\hline 286 & Qubban & & & $x$ & $x$ & & 1 \\
\hline 287 & Aniba & $x$ & & & & & 1 \\
\hline 288 & Arminna & & & & & & 1 \\
\hline 289 & Debeira & & & & & & 1 \\
\hline 290 & Buhen & & & $x$ & $x$ & & 1 \\
\hline 291 & Sesebi & & & $x$ & & & 2 \\
\hline 292 & Kerma & $x$ & & & & & 1 \\
\hline 293 & Tabo - Argo Island & & & $x$ & $x$ & & 1 \\
\hline 294 & Marsa Matruh (Bates' Island) & & & $x$ & & & 2 \\
\hline 295 & Zawiyet Umm el-Rakham & & & & & & 1 \\
\hline \multicolumn{8}{|c|}{ Central Mediterranean } \\
\hline 296 & Treazano di Monsampolo & & & & $x$ & & 1 \\
\hline 297 & Grotta Manacorra & $x$ & & & $x$ & & 1 \\
\hline 298 & Molinella & & $x$ & & & & 1 \\
\hline 299 & Coppa Nevigata & & & & $x$ & $x$ & 2 \\
\hline 300 & Trani (Capo Colonna) & & & & $x$ & $x$ & 1 \\
\hline
\end{tabular}


Catalogue I cont.

\begin{tabular}{|c|c|c|c|c|c|c|c|}
\hline & Site name & I-IIA & IIB-IIIA1 & IIIA2 & IIIB & IIIC & AMOUNT \\
\hline 301 & Giovinazzo - via Marco Polo & $x$ & & & & & 1 \\
\hline 302 & Giovinazzo-dolmen site & $x$ & & & & & 1 \\
\hline 303 & Bari Santa Maria B.C. & & $x$ & & & & 1 \\
\hline 304 & Monopoli & & $x$ & $x$ & $x$ & $x$ & 1 \\
\hline 305 & Torre Santa Sabina (Carovigno & & & & $x$ & $x$ & 1 \\
\hline 306 & Punta le Terrare & & $x$ & $x$ & $x$ & & 2 \\
\hline 307 & Roca Vecchia & $x$ & $x$ & & $x$ & $x$ & 2 \\
\hline 308 & Otranto & & & & $x$ & $x$ & 1 \\
\hline 309 & Leuca (Punta Meliso) & & & & $x$ & $x$ & 1 \\
\hline 310 & Scalo di Furno (Porto Cesareo & & & $x$ & $x$ & $x$ & 1 \\
\hline 311 & Avetrana & & & & $x$ & $x$ & 1 \\
\hline 312 & Torre Castelluccia & & & $x$ & $x$ & & 1 \\
\hline 313 & Porto Perone - Saturo & & $x$ & & $x$ & $x$ & 2 \\
\hline 314 & Taranto & & & $x$ & $x$ & & 4 \\
\hline 315 & Cozzo Marziota & & & & $x$ & & 1 \\
\hline 316 & Termitito & & & $x$ & $x$ & $x$ & 4 \\
\hline 317 & Broglio di Trebisacce & & & $x$ & $x$ & $x$ & 5 \\
\hline 318 & Francavilla Marittima & & & $x$ & $x$ & & 1 \\
\hline 319 & Torre del Mordillo & & & $x$ & $x$ & $x$ & 3 \\
\hline 320 & Capo Piccolo & $x$ & & & & & 1 \\
\hline 321 & Filicudi & $x$ & $x$ & $x$ & & & 2 \\
\hline 322 & Salina Sierra dei Cianfi & & $x$ & $x$ & $x$ & & 1 \\
\hline 323 & Salina Portella & & $x$ & $x$ & $x$ & & 1 \\
\hline 324 & Panarea (Milazzese) & & $x$ & $x$ & $x$ & & 2 \\
\hline 325 & Lipari & $x$ & $x$ & $x$ & $x$ & $x$ & 4 \\
\hline 326 & Molinello & & & $x$ & & & 1 \\
\hline 327 & Thapsos & & $x$ & $x$ & $x$ & $x$ & 3 \\
\hline 328 & Floridia & & & $x$ & & & 1 \\
\hline 329 & Matrensa-Milocca & & & $x$ & & & 1 \\
\hline 330 & Syracusa & & & $x$ & & & 1 \\
\hline 331 & Cozzo del Pantano & & & $x$ & & & 1 \\
\hline 332 & Buscemi & & & & $x$ & & 1 \\
\hline 333 & Milena & & & $x$ & $x$ & $x$ & 1 \\
\hline 334 & Cannatello & & $x$ & $x$ & $x$ & & 2 \\
\hline 335 & Monte Grande & $x$ & $x$ & $x$ & & & 3 \\
\hline 336 & Madre Chiesa di Gaffa & & $x$ & $x$ & & & 1 \\
\hline 337 & Tas Silg & & & & $x$ & & 1 \\
\hline 338 & Borg en Nadur & & & & $x$ & & 1 \\
\hline 339 & Praia a Mare (Grotta Cardini) & & & $x$ & & & 1 \\
\hline 340 & Sassano & $x$ & & & & & 1 \\
\hline 341 & Paestum & & & & $x$ & $x$ & 1 \\
\hline 342 & Vivara & $x$ & $x$ & $x$ & & & 4 \\
\hline 343 & Ischia-Castiglione & & $x$ & $x$ & & & 1 \\
\hline 344 & Casale Nuovo & & & & $x$ & $x$ & 2 \\
\hline 345 & Monte Rovello & & & & $x$ & $x$ & 1 \\
\hline 346 & Luni sul Mignone & & & $x$ & $x$ & $x$ & 1 \\
\hline 347 & Nuraghe Arrubiu (Orroli) & & & $x$ & $x$ & & 1 \\
\hline 348 & Antigori & & & & $x$ & $x$ & 4 \\
\hline
\end{tabular}


Catalogue II: Mycenaean pottery at Ugarit

1 Mycenaean vessels and fragments

\begin{tabular}{|c|c|c|c|}
\hline ID & date & shape & published \\
\hline 1 & LH IIIA2 & shallow cup & Schaeffer 1949, 138-9, fig. 51: no. 1 \\
\hline 2 & LH IIIB & & Schaeffer 1949, 144-5, fig. 54: no. 8 \\
\hline 3 & & fragment & Schaeffer 1949, 144-5, fig. 54: no. 14 \\
\hline 4 & LH IIIB & squat stirrup jar & Schaeffer 1949, 144-5, fig. 54: no. 16 \\
\hline 5 & LH IIIB & amphoroid krater & Schaeffer 1949, 144-5, fig. 54: no. 17 \\
\hline 6 & LH IIIA2-LH IIIB e & amphoroid krater & Schaeffer 1949, 144-5, fig. 54: no. 19 \\
\hline 7 & LH IIIB & chalice & Schaeffer 1949, 146-7, fig. 55: no. 4 \\
\hline 8 & LH IIIB & piriform jar & Schaeffer 1949, 146-7, fig. 55: no. 9 \\
\hline 9 & LH IIIB & straight sided alabastron & Schaeffer 1949, 146-7, fig. 55: no. 11 \\
\hline 10 & LH IIIB & shallow bowl & Schaeffer 1949, 146-7: fig. 55: no. 13 \\
\hline 11 & LH IIIA2 & shallow cup & Schaeffer 1949, 146-7, fig. 55: no. 14 \\
\hline 12 & LH IIIA2-LH IIIB & mug & Schaeffer 1949, 146-7, fig. 55: no. 15 \\
\hline 13 & LH IIIB & shallow bowl & Schaeffer 1949, 146-7, fig. 55: no. 17 \\
\hline 14 & LH IIIA2 & mug & Schaeffer 1949, 146-7, fig. 55: no. 19 \\
\hline 15 & LH IIIA2 & kylix & Schaeffer 1949, 150-1, fig. 57: no. 1 \\
\hline 16 & LH IIIB & squat stirrup jar & Schaeffer 1949, 150-1, fig. 57: no. 7 \\
\hline 17 & LH IIIB & shallow bowl & Schaeffer 1949, 150-1, fig. 57: no. 8 \\
\hline 18 & LH IIIA2-LH IIIB & fragment & Schaeffer 1949, 150-1, fig. 57: no. 9 \\
\hline 19 & LH IIIB & shallow bowl & Schaeffer 1949, 150-1, fig. 57: no. 15 \\
\hline 20 & LH IIIA2-LH IIIB & stirrup jar & Schaeffer 1949, 150-1, fig. 57: no. 16 \\
\hline 21 & LH IIIA2-LH IIIB & stirrup jar & Schaeffer 1949, 150-1, fig. 57: no. 19 \\
\hline 22 & LH IIIB & shallow bowl & Schaeffer 1949, 150-1, fig. 57: no. 20 \\
\hline 23 & LH IIIA2 & stirrup jar & Schaeffer 1949, 150-1, fig. 57, no. 21 \\
\hline 24 & LH IIIB & stirrup jar & Schaeffer 1949, 150-1, fig. 57: no. 24 \\
\hline 25 & LH IIIA2-LH IIIB & fragment & Schaeffer 1949, 150-1, fig. 57: no. 25 \\
\hline 26 & LH IIIA2 & vertical flask & Schaeffer 1949, 150-1, fig. 57: no. 27 \\
\hline 27 & LH IIIA2-LH IIIB e & amphoroid krater & Schaeffer 1949, 150-1, fig. 57: no. 29 \\
\hline 28 & LH IIIA2 & vertical flask & Schaeffer 1949, 150-1, fig. 57: no. 30 \\
\hline 29 & LH IIIB & stirrup jar & Schaeffer 1949, 150-1, fig. 57: no. 31 \\
\hline 30 & LH IIIB & amphoroid krater & Schaeffer 1949, 150-1, fig. 57: no. 32 \\
\hline 31 & LH IIIB & fragment & Schaeffer 1949, 152-3, fig. 58: no. 1 \\
\hline 32 & LH IIIB & shallow bowl & Schaeffer 1949, 152-3, fig. 58: no. 3 \\
\hline 33 & LH IIIB & hedgehog rhyton & Schaeffer 1949, 152-3, fig. 58: no. 4 \\
\hline 34 & LH IIIB & shallow bowl & Schaeffer 1949, 152-3, fig. 58: no. 5 \\
\hline 35 & LH IIIB & stemmed shallow bowl & Schaeffer 1949, 152-3, fig .58: no. 6 \\
\hline 36 & LH IIIB & conical rhyton & Schaeffer 1949, 152-3, fig .58: no. 8 \\
\hline 37 & LH IIIB & globular stirrup jar & Schaeffer 1949, 152-3, fig. 58: no. 9 \\
\hline 38 & LH IIIB & globular stirrup jar & Schaeffer 1949, 152-3, fig. 58: no. 10 \\
\hline 39 & LH IIIB & small piriform jar & Schaeffer 1949, 152-3, fig. 58: no. 12 \\
\hline 40 & LH IIIB & feeding bottle & Schaeffer 1949, 152-3, fig. 58: under no. 14 \\
\hline 41 & LH IIIB & squat stirrup jar & Schaeffer 1949, 152-3, fig. 58: no. 16 \\
\hline 42 & LH IIIB I & deep bowl & Schaeffer 1949, 152-3, fig. 58: no. 17 \\
\hline 43 & LH IIIA2 & small piriform jar & Schaeffer 1949, 154-5, fig. 59: no. 2 \\
\hline 44 & LH IIIB & shallow bowl & Schaeffer 1949, 154-5, fig. 59: no. 3 \\
\hline 45 & LH IIIB I & stirrup jar & Schaeffer 1949, 154-5, fig. 59: no. 4 \\
\hline 46 & LH IIIB & stirrup jar & Schaeffer 1949, 154-5, fig. 59: no. 5 \\
\hline 47 & LH IIIB & stirrup jar & Schaeffer 1949, 154-5, fig. 59: no. 6 \\
\hline 48 & LH IIIB & stirrup jar & Schaeffer 1949, 154-5: fig. 59: no. 13 \\
\hline
\end{tabular}




\begin{tabular}{|c|c|c|c|}
\hline ID & date & shape & published \\
\hline 49 & LH IIIB & stirrup jar & Schaeffer 1949, 154-5, fig. 59: no. 14 \\
\hline 50 & LH IIIA2-LH IIIB & lid & Schaeffer 1949, 154-5: fig. 59: no. 17 \\
\hline 51 & LH IIIA2 & stirrup jar & Schaeffer 1949, 154-5, fig. 59: no. 32 \\
\hline 52 & LH IIIB & straight sided alabastron & Schaeffer 1949, 154-5, fig. 59: no. 33 \\
\hline 53 & LH IIIB & shallow bowl & Schaeffer 1949, 154-5, fig. 59: no. 34 \\
\hline 54 & LH IIIA2-LH IIIB & stirrup jar & Schaeffer 1949, 154-5, fig. 59: no. 35 \\
\hline 55 & LH IIIB & shallow bowl & Schaeffer 1949, 154-5, fig. 59: no. 36 \\
\hline 56 & LH IIIA2 & stirrup jar & Schaeffer 1949, 154-5, fig. 59: no. 37 \\
\hline 57 & LH IIIB & stirrup jar & Schaeffer 1949, 154-5, fig. 59: no. 38 \\
\hline 58 & LH IIIB & shallow bowl & Schaeffer 1949, 154-5, fig. 59: no. 39 \\
\hline 59 & LH IIIB & shallow bowl & Schaeffer 1949, 154-5, fig. 59: no. 40 \\
\hline 60 & LH IIIB & shallow bowl & Schaeffer 1949, 154-5, fig. 59: no. 41 \\
\hline 61 & LH IIIB & globular stirrup jar & Schaeffer 1949, 154-5, fig. 59: no. 42 \\
\hline 62 & LH IIIB & piriform jar & Schaeffer 1949, 154-5, fig. 59: no. 43 \\
\hline 63 & LH IIIB & shallow bowl & Schaeffer 1949, 154-5, fig. 59: no. 44 \\
\hline 64 & LH IIIB & ring-based krater & Schaeffer 1949, 154-5, fig. 59: no. 45 \\
\hline 65 & LH IIIA2 & shallow cup & Schaeffer 1949, 156-7, fig. 60: no. 1 \\
\hline 66 & LH IIIB & one-handled bowl & Schaeffer 1949, 156-7, fig. 60: no. 2 \\
\hline 67 & LH IIIB & stirrup jar & Schaeffer 1949, 156-7, fig. 60: no. 3 \\
\hline 68 & LH IIIB & stirrup jar & Schaeffer 1949, 156-7, fig. 60: no. 4 \\
\hline 69 & LH IIIB & stirrup jar & Schaeffer $1949,156-7$, fig. 60 : no. 5 \\
\hline 70 & $\mathrm{LH} I I I \mathrm{~B}$ e & narrow necked jug & Schaeffer 1949, 156-7, fig. 60: no. 8 \\
\hline 71 & LH IIIB & squat stirrup jar & Schaeffer 1949, 156-7, fig. 60: no. 9 \\
\hline 72 & LH IIIB & globular stirrup jar & Schaeffer 1949, 156-7, fig. 60: no. 10 \\
\hline 73 & LH IIIB & conical stirrup jar & Schaeffer 1949, 156-7, fig. 60: no. 14 \\
\hline 74 & LH IIIB & fragment & Schaeffer 1949, 156-7, fig. 60: no. 15 \\
\hline 75 & LH IIIB & mug & Schaeffer 1949, 156-7, fig. 60: no. 16 \\
\hline 76 & LH IIIB & mug & Schaeffer 1949, 156-7, fig. 60: no. 17 \\
\hline 77 & $\mathrm{LH} I I I \mathrm{~B}$ e & amphoroid krater & Schaeffer 1949, 156-7, fig. 60: no. 19 \\
\hline 78 & LH IIIB & piriform jar & Schaeffer 1949, 156-7, fig. 60: no. 20 \\
\hline 79 & LH IIIA2 & amphoroid krater & Schaeffer 1949, 156-7, fig. 60: no. 21 \\
\hline 80 & LH IIIB & krater & Schaeffer 1949, 158-9, fig. 61 B-C \\
\hline 81 & LH IIIB & stirrup jar & Schaeffer 1949, 160-1, fig. 62: no. 1 \\
\hline 82 & LH IIIA2 & shallow cup & Schaeffer 1949, 160-1, fig. 62: no. 7 \\
\hline 83 & LH IIIA2-LH IIIB & amphoroid krater & Schaeffer 1949, 160-1, fig. 62: no. 4 \\
\hline 84 & LH IIIB & stirrup jar & Schaeffer 1949, 160-1, fig. 62: no. 8 \\
\hline 85 & LH IIIA2 & stemmed cup & Schaeffer 1949, 160-1, fig. 62: no. 9 \\
\hline 86 & $\mathrm{LH} I I \mathrm{~B}$ & stirrup jar & Schaeffer 1949, 160-1, fig. 62: no. 10 \\
\hline 87 & LH IIIB e & amphoroid krater & Schaeffer 1949, 160-1, fig. 62: no. 24 \\
\hline 88 & LH IIIA1-LH IIIA2 & small piriform jar & Schaeffer 1949, 160-1, fig. 62: no. 13 \\
\hline 89 & LH IIIB & shallow bowl & Schaeffer 1949, 162-3, fig. 63: no. 2 \\
\hline 90 & LH IIIA2 & stirrup jar & Schaeffer 1949, 162-3, fig. 63: no. 4 \\
\hline 91 & LH IIIA2-LH IIIB & stirrup jar & Schaeffer 1949, 162-3, fig. 63: no. 14 \\
\hline 92 & LH IIIA2 & conical piriform stirrup jar & Schaeffer 1936b, 121, fig. 13: Q \\
\hline 93 & LH IIIA2 & vertical flask & Schaeffer 1936b, 121, fig. 13: R \\
\hline 94 & LH IIIA2 & globular stirrup jar & Schaeffer 1936b, 121, fig. 13: S \\
\hline 95 & LH IIIA2 & straight sided alabastron & Schaeffer 1936b, 121, fig. 13: T \\
\hline 96 & LH IIIA2 & small globular jug & Schaeffer 1936b, 121, fig. 13: U \\
\hline 97 & LH IIIA2-LH IIIB & small globular jug & Schaeffer $1949,164-5$, fig. 64, no. 8 \\
\hline 98 & LH IIIB & conical stirrup jar & Schaeffer 1949, 164-5, fig. 64: no. 9 \\
\hline 99 & LH IIIB & shallow bowl & Schaeffer 1949, 164-5, fig. 64: no. 10 \\
\hline
\end{tabular}




\begin{tabular}{|c|c|c|c|}
\hline ID & date & shape & published \\
\hline 100 & LH IIIA2 & carinated conical cup & Schaeffer 1949, 166-7, fig. 65: no. 13 \\
\hline 101 & LH IIIB & stirrup jar & Schaeffer 1949, 166-7, fig. 65: no. 14 \\
\hline 102 & LH IIIB & shallow bowl & Schaeffer 1949, 166-7, fig. 65: no. 15 \\
\hline 103 & LH IIIB & round bottomed bowl & Schaeffer 1949, 166-7, fig. 65: no. 17 \\
\hline 104 & LH IIIA2-LH IIIB & horizontal flask & Schaeffer 1949, 166-7, fig. 65: no. 12 \\
\hline 105 & LH IIIB & stirrup jar & Schaeffer 1949, 166-7, fig. 65: no. 25 \\
\hline 106 & LH IIIA2 & carinated conical cup & Schaeffer 1949, 166-7, fig. 65: no. 26 \\
\hline 107 & LH IIIB & horizontal flask & Schaeffer 1949, 170-1, fig. 67: no. 9 \\
\hline 108 & LH IIIB & squat stirrup jar & Schaeffer 1949, 170-1, fig. 67: no. 14 \\
\hline 109 & LH IIIA2 & vertical flask & Schaeffer 1949, 170-1, fig. 67: no. 19 \\
\hline 110 & LH IIIA2 & small piriform jar & Schaeffer 1939b, 281, fig. 3: A \\
\hline 111 & LH IIIA2 & squat stirrup jar & Schaeffer 1939b, 281, fig. 3: B \\
\hline 112 & LH IIIB & squat stirrup jar & Schaeffer 1939b, 281, fig. 3: C \\
\hline 113 & LH IIIB & squat stirrup jar & Schaeffer 1939b, 281, fig. 3: D \\
\hline 114 & LH IIIA2 & small piriform jar & Schaeffer 1939b, 281, fig. 3: G \\
\hline 115 & LH IIIA2 & small piriform jar & Schaeffer 1939b, 282, fig. 4: G \\
\hline 116 & $\mathrm{LH} I I I B$ & stemmed bowl & Schaeffer 1949, 172-3, fig. 68: no. 21 \\
\hline 117 & LH IIIA2-LH IIIB & amphoroid krater & Schaeffer 1949, 180-1, fig. 72: no. 3 \\
\hline 118 & LH IIIB e & krater & Schaeffer 1949, 180-1, fig. 72: no. 15 \\
\hline 119 & LH IIIA2-LH IIIB & small globular jug & Schaeffer 1949, 180-1, fig. 72: no. 19 \\
\hline 120 & LH IIIB & straight sided alabastron & Schaeffer 1949, 180-1, fig. 72: no. 26 \\
\hline 121 & LH IIIB I & deep bowl & Schaeffer 1949, 190-1, fig. 77: "tombe IV" \\
\hline 122 & LH IIIB & piriform jar & Schaeffer 1949, 190-1, fig. 77: no. 9 \\
\hline 123 & LH IIIA2-LH IIIB & fragment & Schaeffer 1949, 202-3, fig. 83: no. 6 \\
\hline 124 & LH IIIB & shallow stemmed bowl & Schaeffer 1949, 202-3, fig. 83: no. 7 \\
\hline 125 & LH IIIB e & amphoroid krater & Schaeffer 1949, 214-7, figs. 89-90 \\
\hline 126 & LH IIIB & animal head rhyton & Schaeffer 1949, 218-9, fig. 91: no. 1 \\
\hline 127 & LH IIIB & fragment & Schaeffer 1949, 218-9, fig. 91: no. 2 \\
\hline 128 & LH IIIB I & deep bowl & Schaeffer 1949, 218-9, fig. 91: no. 3 \\
\hline 129 & LH IIIA1 & conical rhyton & Schaeffer 1949, 218-9, fig. 91: nrs. 7, 15, fig. 91 A \\
\hline 130 & LH IIIB & conical rhyton & Schaeffer 1949, 218-9, fig. 91: no. 8 \\
\hline 131 & LH IIIB & conical rhyton & Schaeffer 1949, 218-9, fig. 91: no. 9 \\
\hline 132 & LH IIIB & conical rhyton & Schaeffer 1949, 218-9, fig. 91: no. 10 \\
\hline 133 & LH IIIA2 & conical rhyton & Schaeffer 1949, 218-9, fig. 91: nrs. 12, 13 \\
\hline 134 & LH IIIB & conical rhyton & Schaeffer 1949, 218-9, fig. 91: no. 14 \\
\hline 135 & LH IIIB & conical rhyton & Schaeffer 1949, 218-9, fig. 91: no. 5, 16 \\
\hline 136 & LH IIIA2-LH IIIB & animal head rhyton & Schaeffer 1949, 220-1, fig. 92: A-D \\
\hline 137 & LH IIIA2-LH IIIB e & animal head rhyton & Schaeffer 1949, 220-1, fig. 92: E-F \\
\hline 138 & LH IIIA2-LH IIIB e & animal head rhyton & Schaeffer 1949, 222-3, fig. 93: nrs. 2, 3 \\
\hline 139 & LH IIIA2 & animal head rhyton & Schaeffer 1949, 222-3, fig. 93: nrs. 5-7 \\
\hline 140 & LH IIIA2 & ovoid rhyton & Schaeffer 1949, 222-3, fig. 93: no. 1 \\
\hline 141 & LH IIIA2 & chalice & Schaeffer 1949, 222 under no. 1 (not illustrated) \\
\hline 142 & LH IIIB & fish rhyton & Schaeffer 1949, 222-3, fig. 93: no. 4 \\
\hline 143 & LH IIIB & krater & Schaeffer 1949, 224-5, fig. 94: B \\
\hline 144 & LH IIIB & amphoroid krater & Schaeffer 1949, 224-5, fig. 94: C \\
\hline 145 & LH IIIA2 & amphoroid krater & Schaeffer 1949, 224-5, fig. 94: D \\
\hline 146 & LH IIIB & fragment & Schaeffer 1949, 224-5, fig. 94: F \\
\hline 147 & LH IIIB I & conical rhyton & Schaeffer 1949, 224-5, fig. 94: down left \\
\hline 148 & LH IIIA2 & amphoroid krater & Schaeffer 1949, 224-5, fig. 94: down right \\
\hline 149 & LH IIIB & shallow bowl & Schaeffer 1949, 226-7, fig. 95: no. 1 \\
\hline 150 & LH IIIA2 & fragment & Schaeffer 1949, 226-7, fig. 95: no. 2 \\
\hline
\end{tabular}




\begin{tabular}{|c|c|c|c|}
\hline ID & date & shape & published \\
\hline 151 & LH IIIB & conical rhyton & Schaeffer 1949, 226-7, fig. 95: no. 3 \\
\hline 152 & LH IIIA2 & kylix & Schaeffer 1949, 226-7, fig. 95: no. 4 \\
\hline 153 & LH IIIB & fragment & Schaeffer 1949, 226-7, fig. 95: no. 5 \\
\hline 154 & LH IIIB & amphoroid krater & Schaeffer 1949, 226-7, fig. 95: no. 6 \\
\hline 155 & LH IIIB & kylix & Schaeffer 1949, 226-7, fig. 95: no. 7 \\
\hline 156 & LM IIIA & cup & Schaeffer 1949, 226-7, fig. 95: no. 8 \\
\hline 157 & LH IIIA2 & kylix & Schaeffer 1949, 226-7, fig. 95: no. 9 \\
\hline 158 & LH IIIB & fragment & Schaeffer 1949, 226-7, fig. 95: no. 10 \\
\hline 159 & LH IIIB & krater & Schaeffer 1949, 226-7, fig. 95: no. 11 \\
\hline 160 & LH IIIB e & kylix & Schaeffer 1949, 226-7, fig. 95: no. 12 \\
\hline 161 & LH IIA/LM IB & fragment & Schaeffer 1949, 226-7, fig. 95: no. 13 \\
\hline 162 & LH IIIA2 & kylix & Schaeffer 1949, 226-7, fig. 95: no. 14 \\
\hline 163 & LH IIIB & fragment & Schaeffer 1949, 226-7, fig. 95: no. 15 \\
\hline 164 & LH IIIA2-LH IIIB & amphoroid krater & Schaeffer 1949, 226-7, fig. 95: no. 16 \\
\hline 165 & LH IIIB e & kylix & Schaeffer 1949, 226-7, fig. 95: no. 17 \\
\hline 166 & LH IIIB & deep bowl & Schaeffer 1949, 226-7, fig. 95: no. 18 \\
\hline 167 & LH IIIA2-LH IIIB & kylix & Schaeffer 1949, 226-7, fig. 95: no. 19 \\
\hline 168 & $\mathrm{LH} I I \mathrm{~B}$ & deep bowl & Schaeffer 1949, 226-7, fig. 95: no. 20 \\
\hline 169 & LH IIIA2 & kylix & Schaeffer 1949, 226-7, fig. 95: no. 21 \\
\hline 170 & $\mathrm{LH} I I \mathrm{~A} 2$ & piriform jar & Schaeffer 1949, 226-7, fig. 95: no. 22 \\
\hline 171 & & stirrup jar & Schaeffer 1949, 226-7, fig. 95: no. 23 \\
\hline 172 & LH IIIA2-LH IIIB & rhyton & Schaeffer 1949, 226-7, fig. 95: no. 24 \\
\hline 173 & LH IIIA2 & one handled bowl? & Schaeffer 1949, 226-7, fig. 95: no. 25 \\
\hline 174 & LH IIIA2-LH IIIB & kylix & Schaeffer 1949, 226-7, fig. 95: no. 26 \\
\hline 175 & LH IIIB & amphoroid krater & Schaeffer 1949, 226-7, fig. 95: no. 27 \\
\hline 176 & LH IIIA2 & vertical flask & Schaeffer 1949, 226-7, fig. 95: no. 28 \\
\hline 177 & LH IIIB I & deep bowl (?) & Schaeffer 1949, 226-7: fig. 95: no. 29 \\
\hline 178 & LH IIIB & ring kernos & Schaeffer 1949, 226-7: fig. 95: no. 30 \\
\hline 179 & LH IIIA2 & fragment & Schaeffer 1949, 226-7, fig. 95: no. 32 \\
\hline 180 & LH IIIA2-LH IIIB & kylix & Schaeffer 1949, 226-7, fig. 95: no. 33 \\
\hline 181 & LH IIIA2 & globular stirrup jar & Schaeffer 1949, 226-7, fig. 95: no. 35 \\
\hline 182 & LH IIIA2 & vertical flask & Schaeffer 1949, 226-7, fig. 95: no. 37 \\
\hline 183 & LH IIIA2 & piriform jar & Schaeffer 1949, 226-7, fig. 95: no. 38 \\
\hline 184 & LH IIIB & globular stirrup jar & Schaeffer 1949, 226-7, fig. 95: no. 39 \\
\hline 185 & $\mathrm{LH} I I I B$ & squat stirrup jar & Schaeffer 1949, 226-7, fig. 95: no. 40 \\
\hline 186 & LH IIIA2-LH IIIB & stirrup jar & Schaeffer 1949, 228-9, fig. 96: no. 13 \\
\hline 187 & LH IIIA2-LH IIIB & stirrup jar & Schaeffer 1949, 228-9, fig. 96: no. 19 \\
\hline 188 & LH IIIB & piriform jar & Schaeffer 1949, 228-9, fig. 96: no. 25 \\
\hline 189 & LH IIIB & piriform jar & Schaeffer 1949, 228-9, fig. 96: no. 26 \\
\hline 190 & LH IIIB & piriform jar & Schaeffer 1949, 228-9, fig. 96: no. 27 \\
\hline 191 & LH IIIA2 & krater & Schaeffer 1949, 286-7, fig. 124: no. 9 \\
\hline 192 & LH IIIB & shallow bowl & Schaeffer 1949, 254-5, fig. 108: no. 3 \\
\hline 193 & LH IIIB e & squat stirrup jar & Schaeffer 1938, 202, fig. 5: X \\
\hline 194 & LH IIIB & squat stirrup jar & Schaeffer 1938, 202, fig. 5: Y \\
\hline 195 & LH IIIA2 & vertical flask & Schaeffer 1938, 202, fig. 5: Z \\
\hline 196 & LH IIIB & vertical flask & Schaeffer 1938, 202, fig. 5: a \\
\hline 197 & LH IIIA2 & globular stirrup jar & Schaeffer 1938, 202, fig. 5: d \\
\hline 198 & LH IIIA2 & globular stirrup jar & Schaeffer 1938, 202, fig. 5: e \\
\hline 199 & LH IIIA2 & con.-pir. stirrup jar & Schaeffer 1938, 210, fig. 11: Y \\
\hline 200 & LH ॥A-LH ॥B & small handleless jar & Courtois \& Courtois 1978, 292-3, fig. 33: no. 1 \\
\hline 201 & LH IIIA2 & mug & Courtois \& Courtois 1978, 292-3, fig. 33: no. 2 \\
\hline
\end{tabular}




\begin{tabular}{|c|c|c|c|}
\hline ID & date & shape & published \\
\hline 202 & LH IIIB & mug & Courtois \& Courtois 1978, 292-3: fig. 33: no. 3 \\
\hline 203 & LH IIIA2 & shallow cup & Courtois \& Courtois 1978, 292-3, fig. 33: no. 5 \\
\hline 204 & LH IIIA1 & shallow cup & Courtois \& Courtois 1978, 292-3, fig. 33: no. 4 \\
\hline 205 & LH IIIA2-LH IIIB & rounded alabstron & Courtois \& Courtois 1978, 292-3, fig. 33: no. 6 \\
\hline 206 & LH IIIB & shallow cup & Courtois \& Courtois 1978, 292-3, fig. 33: no. 7 \\
\hline 207 & LH IIB-LH IIIA1 & small handleless jar & Courtois \& Courtois 1978, 292-3, fig. 33: no. 8 \\
\hline 208 & LH IIIA2-LH IIIB & shallow cup & Courtois \& Courtois 1978, 292-3, fig. 33: no. 9 \\
\hline 209 & LH IIIA2-LH IIIB & shallow cup & Courtois \& Courtois 1978, 292-3, fig. 33: no. 10 \\
\hline 210 & LH IIIB I & deep bowl & Courtois \& Courtois 1978, 292-3, fig. 33: no. 11 \\
\hline 211 & LH IIIB & shallow bowl & Courtois \& Courtois 1978, 294-5, fig. 33: no. 12 \\
\hline 212 & LH IIIB & shallow cup & Courtois \& Courtois 1978, 294-5, fig. 33: no. 13 \\
\hline 213 & LH IIIA2 I & shallow cup & Courtois \& Courtois 1978, 294-5, fig. 33: no. 14 \\
\hline 214 & LH IIIB I & deep bowl & Courtois \& Courtois 1978, 294-5, fig. 33: no. 16 \\
\hline 215 & LH IIIA2 & one-handled bowl & Courtois \& Courtois 1978, 294-5, fig. 33: no. 17 \\
\hline 216 & LH IIIA2 & shallow cup & Courtois \& Courtois 1978, 294-5, fig. 33: no. 18 \\
\hline 217 & LH IIIB & stemmed shallow bowl? & Courtois \& Courtois 1978, 294-5, fig. 33: no. 19 \\
\hline 218 & LH IIIB & shallow bowl & Courtois \& Courtois 1978, 294-5, fig. 33: no. 20 \\
\hline 219 & LH IIIB & stemmed shallow bowl & Courtois \& Courtois 1978, 294-5, fig. 33: no. 21 \\
\hline 220 & LH IIIB & krater & Courtois \& Courtois 1978, 294-5, fig. 33: no. 22 \\
\hline 221 & LH IIIB & ring-based krater & Courtois \& Courtois 1978, 294-5, fig. 33: no. 23 \\
\hline 222 & LH IIIB & fragment & Courtois \& Courtois 1978, 294-5, fig. 33: no. 24 \\
\hline 223 & LH IIIA2 & amphoroid krater & Courtois \& Courtois 1978, 296-7, fig. 34: nrs. 1, 2 \\
\hline 224 & LH IIIA2-LH IIIB e & amphoroid krater & Courtois \& Courtois 1978, 296-7, fig. 34: no. 3 \\
\hline 225 & LH IIIA2 & amphoroid krater & Courtois \& Courtois 1978, 296-7, fig. 34: no. 4 \\
\hline 226 & LH IIIA2-LH IIIB e & amphoroid krater & Courtois \& Courtois 1978, 296-7, fig. 34: no. 5 \\
\hline 227 & LH IIIA2-LH IIIB & amphoroid krater & Courtois \& Courtois 1978, 296-7, fig. 34: no. 6 \\
\hline 228 & LH IIIA2 & amphoroid krater & Courtois \& Courtois 1978, 296-7, fig. 34: no. 7 \\
\hline 229 & LH IIIA2 & amphoroid krater & Courtois \& Courtois 1978, 296-7, fig. 34: no. 8, 9 \\
\hline 230 & LH IIIA2 & amphoroid krater & Courtois \& Courtois 1978, 296-7, fig. 34: no. 10 \\
\hline 231 & LH IIIB e & amphoroid krater & Courtois \& Courtois 1978, 296-7, fig. 34: no. 11 \\
\hline 232 & LH IIIB e & amphoroid krater & Courtois \& Courtois 1978, 296-7, fig. 34: no. 12 \\
\hline 233 & LH IIIB & krater & Courtois \& Courtois 1978, 296-7, fig. 34: no. 13 \\
\hline 234 & LH IIIB & ring-based krater & Courtois \& Courtois 1978, 296-7, fig. 34: no. 14 \\
\hline 235 & LH IIIB & krater & Courtois \& Courtois 1978, 298-9, fig. 34: nrs. 15, 16, 21 \\
\hline 236 & LH IIIB & amphoroid krater & Courtois \& Courtois 1978, 298-9, fig. 34: no. 17 \\
\hline 237 & LH IIIA2-LH IIIB & amphoroid krater & Courtois \& Courtois 1978, 298-9, fig. 34: no. 18 \\
\hline 238 & LH IIIB & vertical flask & Courtois \& Courtois 1978, 298-9, fig. 34: no. 19 \\
\hline 239 & LH IIIB & amphoroid krater & Courtois \& Courtois 1978, 298-9, fig. 34: no. 20 \\
\hline 240 & LH IIIA2-LH IIIB & amphoroid krater & Courtois \& Courtois 1978, 298-9, fig. 34, no. 22 \\
\hline 241 & LH IIIB & krater & Courtois \& Courtois 1978, 298-9, fig. 34: no. 23 \\
\hline 242 & LH IIIB & krater & Courtois \& Courtois 1978, 298-9, fig. 34: no. 24 \\
\hline 243 & LH IIIB & krater & Courtois \& Courtois 1978, 298-9, fig. 34: no. 25 \\
\hline 244 & LH IIIA2 I & amphoroid krater & Courtois \& Courtois 1978, 300, fig. 34 bis \\
\hline 245 & LH IIIA2 & stirrup jar & Courtois \& Courtois 1978, 302-3, fig. 35: no. 1 \\
\hline 246 & LH IIIB & stirrup jar & Courtois \& Courtois 1978, 302-3, fig. 35: no. 2 \\
\hline 247 & LH IIIA2 & stirrup jar & Courtois \& Courtois 1978, 302-3, fig. 35: no. 3 \\
\hline 248 & LH IIIB & stirrup jar & Courtois \& Courtois 1978, 302-3, fig. 35: no. 4 \\
\hline 249 & LH IIIB & stirrup jar & Courtois \& Courtois 1978, 302-3, fig. 35: no. 5 \\
\hline 250 & LH IIIB & squat stirrup jar & Courtois \& Courtois 1978, 302-3, fig. 35: no. 7 \\
\hline 251 & $\mathrm{LH} I I I \mathrm{~B}$ & stirrup jar & Courtois \& Courtois 1978, 302-3, fig. 35: no. 8 \\
\hline 252 & LH IIIB & stirrup jar & Courtois \& Courtois 1978, 302-3, fig. 35: no. 9 \\
\hline
\end{tabular}




\begin{tabular}{|c|c|c|c|}
\hline ID & date & shape & published \\
\hline 253 & LH IIIA2-LH IIIB & stirrup jar & Courtois \& Courtois 1978, 302-3, fig. 35: no. 10 \\
\hline 254 & LH IIIB & globular stirrup jar & Courtois \& Courtois 1978, 302-3, fig. 35: no. 11 \\
\hline 255 & LH IIIA2-LH IIIB & stirrup jar & Courtois \& Courtois 1978, 302-3, fig. 35: no. 12 \\
\hline 256 & LH IIIA2-LH IIIB & stirrup jar & Courtois \& Courtois 1978, 302-3, fig. 35: no. 13 \\
\hline 257 & LH IIIB & stirrup jar & Courtois \& Courtois 1978, 302-3, fig. 35: no. 14 \\
\hline 258 & LH IIIA2-LH IIIB & stirrup jar & Courtois \& Courtois 1978, 302-3, fig. 35: no. 15 \\
\hline 259 & LH IIIB & globular stirrup jar & Courtois \& Courtois 1978, 304-5, fig. 35: no. 16 \\
\hline 260 & LH IIIB & globular stirrup jar & Courtois \& Courtois 1978, 304-5, fig. 35: no. 17 \\
\hline 261 & LH IIIB & globular stirrup jar & Courtois \& Courtois 1978, 304-5, fig. 35: no. 18 \\
\hline 262 & LH IIIB & globular stirrup jar & Courtois \& Courtois 1978, 304-5, fig. 35: no. 19 \\
\hline 263 & LH IIIB & globular stirrup jar & Courtois \& Courtois 1978, 304-5, fig. 35, no. 20 \\
\hline 264 & LH IIIB & squat stirrup jar & Courtois \& Courtois 1978, 304-5, fig. 35: no. 21 \\
\hline 265 & LH IIIB & stirrup jar & Courtois \& Courtois 1978, 304-5, fig. 35: no. 22 \\
\hline 266 & LH IIIB & conical stirrup jar & Courtois \& Courtois 1978, 304-5, fig. 35: no. 23 \\
\hline 267 & LH IIIB & squat stirrup jar & Courtois \& Courtois 1978, 304-5, fig. 35: no. 24 \\
\hline 268 & LH IIIB & squat stirrup jar & Courtois \& Courtois 1978, 304-5, fig. 35: no. 25 \\
\hline 269 & LH IIIB & stirrup jar & Courtois \& Courtois 1978, 304-5, fig. 35: no. 26 \\
\hline 270 & LH IIIB e & kylix & Courtois \& Courtois 1978, 306-7, fig. 36: no. 1 \\
\hline 271 & LH IIIB e & kylix & Courtois \& Courtois 1978, 306-7, fig. 36: no. 2 \\
\hline 272 & LH IIIB e & kylix & Courtois \& Courtois 1978, 306-7, fig. 36: no. 3 \\
\hline 273 & LH IIIA2-LH IIIB e & kylix & Courtois \& Courtois 1978, 306-7, fig. 36: no. 4 \\
\hline 274 & LH IIIB & piriform jar & Courtois \& Courtois 1978, 306-7, fig. 36: no. 5 \\
\hline 275 & LH IIIA2-LH IIIB & fragment & Courtois \& Courtois 1978, 306-7, fig. 36: no. 6 \\
\hline 276 & LH IIIB & piriform jar & Courtois \& Courtois 1978, 306-7, fig. 36, no. 7 \\
\hline 277 & LH IIIA2 & vertical flask & Courtois \& Courtois 1978, 306-7, fig. 36: no. 8 \\
\hline 278 & LH IIIA2 & vertical flask & Courtois \& Courtois 1978, 306-7, fig. 36: no. 9 \\
\hline 279 & LH IIIB & piriform jar & Courtois \& Courtois 1978, 306-7, fig. 36: no. 10 \\
\hline 280 & LH IIIA2 & small piriform jar & Courtois \& Courtois 1978, 308-9, fig. 36: no. 11 \\
\hline 281 & LH IIIB & piriform jar & Courtois \& Courtois 1978, 308-9, fig. 36: no. 12 \\
\hline 282 & LH IIIA2-LH IIIB & large piriform jar & Courtois \& Courtois $1978,308-9$, fig. 36, no. 13 \\
\hline 283 & $\mathrm{LH} I I I \mathrm{~B}$ & piriform jar & Courtois \& Courtois 1978, 308-9, fig. 36: no. 14 \\
\hline 284 & LH IIIB & conical rhyton & Courtois \& Courtois 1978, 308-9, fig. 36: no. 15 \\
\hline 285 & LH IIIA2-LH IIIB & conical rhyton & Courtois \& Courtois 1978, 308-9, fig. 36: no. 16 \\
\hline 286 & LH IIIA2-LH IIIB & rhyton & Courtois \& Courtois 1978, 308-9, fig. 36: no. 17 \\
\hline 287 & LH IIIA2 & conical rhyton & Courtois \& Courtois 1978, 308-9, fig. 36: no. 18 \\
\hline 288 & LH IIIB & conical rhyton & Courtois 1969, 118, fig. 17 \\
\hline 289 & LH IIIB & squat stirrup jar & Schaeffer 1963b, fig. 30 \\
\hline 290 & LH IIIB & conical rhyton & Courtois \& Courtois 1978, 310-1, fig. 37: no. 1 \\
\hline 291 & LH IIIB & conical rhyton & Courtois \& Courtois 1978, 310-1, fig. 37: no. 2 \\
\hline 292 & LH IIIA2 & conical rhyton & Courtois \& Courtois 1978, 310-1, fig. 37: no. 3 \\
\hline 293 & LH IIIB & conical rhyton & Courtois \& Courtois 1978, 310-1, fig. 37: no. 4 \\
\hline 294 & LH IIIB & conical rhyton & Courtois \& Courtois 1978, 310-1, fig. 37: no. 5 \\
\hline 295 & LH IIIB & amphoroid krater & Courtois \& Courtois 1978, 310-1, fig. 37: no. 6 \\
\hline 296 & LH IIIB & conical rhyton & Courtois \& Courtois 1978, 310-1, fig. 37: no. 7 \\
\hline 297 & LH IIIA2 I & conical rhyton & Courtois \& Courtois 1978, 310-1, fig. 37: no. 8 \\
\hline 298 & LH IIIA2 & conical rhyton & Courtois \& Courtois 1978, 310-1, fig. 37, no. 9 \\
\hline 299 & LH IIIB & conical rhyton & Courtois \& Courtois 1978, 310-1, fig. 37: no. 11 \\
\hline 300 & LH IIIB & conical rhyton & Courtois \& Courtois 1978, 310-1, fig. 37: no. 12 \\
\hline 301 & LH IIIA2-LH IIIB & amphoroid krater & Courtois \& Courtois 1978, 312-3, fig. 38: nrs. 1-2 \\
\hline 302 & LH IIIB & amphoroid krater & Courtois \& Courtois 1978, 312-3, fig. 38, no. 3 \\
\hline 303 & LH IIIB & piriform jar & Courtois \& Courtois 1978, 312-3, fig. 38: no. 4 \\
\hline
\end{tabular}




\begin{tabular}{|c|c|c|c|}
\hline ID & date & shape & published \\
\hline 304 & LH IIIB & krater & Courtois \& Courtois 1978, 312-3, fig. 38: no. 5 \\
\hline 305 & LH IIIA2 & one-handled bowl & Courtois \& Courtois 1978, 312-3, fig. 38: no. 6 \\
\hline 306 & LH IIIB & squat stirrup jar & Courtois \& Courtois 1978, 314-5, fig. 39: no. 1 \\
\hline 307 & LH IIIA2 & straight sided alabstron & Courtois \& Courtois 1978, 314-5, fig. 39: no. 2 \\
\hline 308 & LH IIIA2 & straight sided alabstron & Courtois \& Courtois 1978, 314-5, fig. 39: no. 3 \\
\hline 309 & LH IIIB & horizontal flask & Courtois \& Courtois 1978, 314-5, fig. 39: no. 4 \\
\hline 310 & $\mathrm{LH} I I I \mathrm{~B}$ e & kylix & Courtois \& Courtois 1978, 314-5, fig. 39: no. 5 \\
\hline 311 & LH IIIB & globular stirrup jar & Courtois \& Courtois 1978, 314-5, fig. 39: no. 6 \\
\hline 312 & LH IIIB & animal head rhyton & Courtois \& Courtois 1978, 316-7, fig. 40: no. 1 \\
\hline 313 & LH IIIB & amphoroid krater & Courtois \& Courtois 1978, 316-7, fig. 40: no. 2 \\
\hline 314 & LH IIIB & amphoroid krater & Courtois \& Courtois 1978, 318-9, fig. 41: no. 1 \\
\hline 315 & LH IIIB & amphoroid krater & Courtois \& Courtois 1978, 318-9, fig. 41: no. 2 \\
\hline 316 & LH IIIB & piriform jar & Courtois \& Courtois 1978, 318-9, fig. 41: no. 3 \\
\hline 317 & LH IIIB & shallow bowl & Courtois \& Courtois 1978, 318-9: no. 41: no. 4 \\
\hline 318 & $\mathrm{LH} I I \mathrm{~B}$ e & amphoroid krater & Courtois \& Courtois 1978, 318-9, fig. 41: no. 7 \\
\hline 319 & LH IIIB & fragment & Courtois \& Courtois 1978, 318-9, fig. 41: no. 8 \\
\hline 320 & LH IIIB & deep bowl & Courtois \& Courtois 1978, 318-9, fig. 41: no. 9 \\
\hline 321 & LH IIIA2 I & stirrup jar & Courtois \& Courtois 1978, 320-1, fig. 42: no. 1 \\
\hline 322 & LH IIIB & stirrup jar & Courtois \& Courtois 1978, 320-1, fig. 42: no. 2 \\
\hline 323 & LH IIIB & stirrup jar & Courtois \& Courtois $1978,320-1$, fig. 42 : no. 3 \\
\hline 324 & LH IIIB e & kylix & Courtois \& Courtois 1978, 320-1, fig. 42, no. 4 \\
\hline 325 & LH IIB-LH IIIA1 & fragment & Courtois \& Courtois 1978, 320-1, fig. 42, no. 5 \\
\hline 326 & LH IIIB & shallow cup & Courtois \& Courtois 1978, 320-1, fig. 42: no. 6 \\
\hline 327 & LH IIIB & fragment & Courtois \& Courtois 1978, 320-1, fig. 42, no. 7 \\
\hline 328 & LH IIIB & stirrup jar & Courtois \& Courtois $1978,320-1$, fig. 42 : no. 8 \\
\hline 329 & LH IIIB & fragment & Courtois \& Courtois 1978, 320-1, fig. 42: no. 9 \\
\hline 330 & LH IIIB & fragment & Courtois \& Courtois 1978, 320-1, fig. 42: no. 10 \\
\hline 331 & LH IIIB & krater & Courtois \& Courtois 1978, 320-1, fig. 42: no. 11 \\
\hline 332 & LH IIIB I & deep bowl & Courtois \& Courtois 1978, 320-1, fig. 42: no. 12 \\
\hline 333 & LH IIIB & fragment & Courtois \& Courtois 1978, 320-1, fig. 42: no. 13 \\
\hline 334 & LH IIIB & fragment & Courtois \& Courtois 1978, 321-2, fig. 42: no. 14 \\
\hline 335 & LH IIIA2-LH IIIB & stirrup jar & Courtois \& Courtois 1978, 321-2, fig. 42: no. 15 \\
\hline 336 & LH IIIB & fragment & Courtois \& Courtois 1978, 321-2, fig. 42: no. 16 \\
\hline 337 & LH IIIB I & deep bowl & Courtois \& Courtois 1978, 321-2, fig. 42: no. 17 \\
\hline 338 & LH IIIB & shallow bowl & Courtois \& Courtois 1978, 321-2, fig. 42, no. 18 \\
\hline 339 & LH IIIB & deep bowl & Courtois \& Courtois 1978, 321-2, fig. 42: no. 19 \\
\hline 340 & LH IIIB & fragment & Courtois \& Courtois 1978, 321-2, fig. 42: no. 20 \\
\hline 341 & LH IIIB & fragment & Courtois \& Courtois 1978, 321-2, fig. 42: no. 21 \\
\hline 342 & LH IIIA2 & fragment & Courtois \& Courtois 1978, 321-2, fig. 42: no. 22 \\
\hline 343 & LH IIIA2-LH IIIB & fragment & Courtois \& Courtois 1978, 321-2, fig, 42: no. 23 \\
\hline 344 & LH IIIA2 & piriform jar & Courtois \& Courtois 1978, 321-2, fig. 42: no. 24 \\
\hline 345 & LH IIIB & fragment & Courtois \& Courtois 1978, 321-2, fig. 42: no. 25 \\
\hline 346 & LH IIIB & fragment & Courtois \& Courtois 1978, 321-2, fig. 42, no. 26 \\
\hline 347 & LH IIIA2 & fragment & Courtois \& Courtois $1978,321,-3$, fig. 42 : no. 27 \\
\hline 348 & LH IIIA2-LH IIIB & fragment & Courtois \& Courtois $1978,321,-3$, fig. 42 : no. 28 \\
\hline 349 & LH IIIA2-LH IIIB & fragment & Courtois \& Courtois 1978, 321, -3, fig. 42, no. 29 \\
\hline 350 & LH IIIA2-LH IIIB & amphoroid krater & Courtois \& Courtois $1978,321,-3$, fig. 42 : no. 30 \\
\hline 351 & LH IIIA2 I & fragment & Courtois \& Courtois 1978, 321, -3, fig. 42: no. 31 \\
\hline 352 & LH IIIA2-LH IIIB & amphoroid krater & Courtois \& Courtois 1978, 321, -3, fig. 42: no. 32 \\
\hline 353 & LH IIIB & fragment & Courtois \& Courtois 1978, 321, -3, fig. 42: no. 33 \\
\hline 354 & LH IIIA2-LH IIIB & fragment & Courtois \& Courtois $1978,321,-3$, fig. 42 : no. 34 \\
\hline
\end{tabular}




\begin{tabular}{|c|c|c|c|}
\hline ID & date & shape & published \\
\hline 355 & LH IIIA2-LH IIIB & fragment & Courtois \& Courtois 1978, 321, -3, fig. 42: no. 35 \\
\hline 356 & LH IIIA2 & hedgehog rhyton & Courtois \& Courtois 1978, 321, -3, fig. 42: no. 36 \\
\hline 357 & LH IIIB & amphoroid krater & Courtois \& Courtois 1978, 321, -3, fig. 42: no. 37 \\
\hline 358 & LH IIIB & amphoroid krater & Courtois \& Courtois 1978, 321, -3, fig. 42: no. 38 \\
\hline 359 & LH IIIB & amphoroid krater & Courtois \& Courtois 1978, 321, -3, fig. 42: no. 39 \\
\hline 360 & LH IIIB & hedgehog rhyton & Courtois \& Courtois 1978, 324-5, fig. 43: no. 1 \\
\hline 361 & LH IIIB & fish rhyton & Courtois \& Courtois 1978, 324-5, fig. 43: no. 1 bis \\
\hline 362 & LH IIIA2 & hedgehog rhyton & Courtois \& Courtois 1978, 324-5, fig. 43: no. 2 \\
\hline 363 & LH IIIB & hedgehog rhyton & Courtois \& Courtois 1978, 324-5, fig. 43: no. 4 \\
\hline 364 & LH IIIB & hand made cup & Courtois \& Courtois 1978, 324-5, fig. 43: no. 6 \\
\hline 365 & LH IIIB & shallow bowl & Courtois \& Courtois 1978, 328-9, fig. 44: no. 1 \\
\hline 366 & LH IIIB & piriform jar & Courtois \& Courtois $1978,328-9$, fig. 44: no. 2; fig. 44 A \\
\hline 367 & LH IIIB-LH IIIC e & amphoroid krater & Courtois \& Courtois 1978, 330-1, fig. 45: no. 3 \\
\hline 368 & LH IIIB & amphoroid krater & Courtois \& Courtois 1978, 330-1, fig. 45: no. 4 \\
\hline 369 & LH IIIB-LH IIIC e & deep bowl & Courtois \& Courtois 1978, 332-3, fig. 46: no. 1 \\
\hline 370 & LH IIIB I & spouted cup & Courtois \& Courtois 1978, 332-3, fig. 46: no. 2 \\
\hline 371 & LH IIIB I & amphoroid krater & Courtois \& Courtois 1978, 332-3, fig. 46, no. 3 \\
\hline 372 & LH IIIB & amphoroid krater & Courtois \& Courtois 1978, 332-3, fig. 46: no. 4 \\
\hline 373 & LH IIIB I & krater & Courtois \& Courtois 1978, 332-3, fig. 46: no. 6 \\
\hline 374 & LH IIIB & amphoroid krater & Courtois \& Courtois 1978, 332-3, fig. 46: nrs. 7, 8 \\
\hline 375 & LH IIIB I & amphoroid krater & Courtois \& Courtois 1978, 332-3, fig. 46: no. 9 \\
\hline 376 & LH IIIB & fish rhyton & Courtois \& Courtois 1978, 334-5, fig. 47: no. 1 \\
\hline 377 & LH IIIA2-LH IIIB & stirrup jar & Courtois \& Courtois 1978, 334-5, fig. 47: no. 3 \\
\hline 378 & LH IIIB & stirrup jar & Courtois \& Courtois 1978, 334-5, fig. 47: no. 6 \\
\hline 379 & LH IIIB & piriform jar & Courtois \& Courtois 1978, 334-5, fig. 47: no. 7 \\
\hline 380 & LH IIIB & fragment & Courtois \& Courtois 1978, 334-5, fig. 47: no. 8 \\
\hline 381 & LH IIIB & amphoroid krater & Courtois \& Courtois 1978, 334-5, fig. 47: nrs. 2, 9 \\
\hline 382 & LH IIIA2-LH IIIB & fragment & Courtois \& Courtois 1978, 336-7, fig. 48: no. 1 \\
\hline 383 & LH IIIA2-LH IIIB & fragment & Courtois \& Courtois 1978, 336-7, fig. 48: no. 2 \\
\hline 384 & LH IIIB & ring-based krater & Courtois \& Courtois 1978, 338-9, fig. 49: no. 1; fig. 50 \\
\hline 385 & LH IIIB e & amphoroid krater & Courtois \& Courtois 1978, 338-9, fig. 49: no. 2, fig. 51 \\
\hline 386 & LH IIIB & small piriform jar & Courtois \& Courtois 1978, 342-3, fig. 52: no. 1 \\
\hline 387 & LH IIIB & shallow bowl & Courtois \& Courtois 1978, 342-3, fig. 52: no. 2 \\
\hline 388 & LH IIIB & shallow cup & Courtois \& Courtois 1978, 342-3, fig. 52: no. 3 \\
\hline 389 & LH IIIB & shallow cup & Courtois \& Courtois 1978, 342-3, fig. 52: no. 4 \\
\hline 390 & LH IIIA2 I & straight sided alabastron & Courtois \& Courtois 1978, 342-3, fig. 52: no. 5 \\
\hline 391 & LH IIIA2 I & straight sided alabastron & Courtois \& Courtois 1978, 342-3, fig. 52: no. 6 \\
\hline 392 & LH IIIB & squat stirrup jar & Courtois \& Courtois 1978, 342-3, fig. 52: no. 7 \\
\hline 393 & LH IIIA2-LH IIIB & shallow cup & Courtois \& Courtois 1978, 342-3, fig. 52: no. 8 \\
\hline 394 & LH IIIB & squat stirrup jar & Courtois \& Courtois 1978, 342-3, fig. 52: no. 9 \\
\hline 395 & LH IIIB & conical stirrup jar & Courtois \& Courtois 1978, 342-3, fig. 52: no. 10 \\
\hline 396 & LH IIIB & squat stirrup jar & Courtois \& Courtois 1978, 342-3, fig. 52: no. 11 \\
\hline 397 & LH IIIB & globular stirrup jar & Courtois \& Courtois 1978, 342-3, fig. 52: no. 12 \\
\hline 398 & LH IIIB I & amphoroid krater & Courtois \& Courtois 1978, 344-5, fig. 53: no. 2 \\
\hline 399 & LH IIIB & stirrup jar & Courtois \& Courtois $1978,344-5$, fig. 53 , no. 3 \\
\hline 400 & LH IIIB & conical piriform stirrup jar & Courtois \& Courtois 1978, 344-5, fig. 53: no. 6 \\
\hline 401 & LH IIIB & squat stirrup jar & Courtois \& Courtois 1978, 344-5, fig. 53: no. 5 \\
\hline 402 & $\mathrm{LH} I I I \mathrm{~B}$ & amphoroid krater & Courtois \& Courtois 1978, 346-7, fig. 54: no. 1; 348-50: nrs. 54 P, B, C \\
\hline 403 & LH IIIA2-LH IIIB & fragment & Courtois \& Courtois 1978, 352-3, fig. 55: no. 15 \\
\hline 404 & LH IIIB & fragment & Courtois \& Courtois 1978, 352-3, fig. 55, no. 16 \\
\hline 405 & LH IIIA2-LH IIIB & fragment & Courtois \& Courtois 1978, 352-3, fig. 55: no. 17 \\
\hline
\end{tabular}




\begin{tabular}{|c|c|c|c|}
\hline ID & date & shape & published \\
\hline 406 & LH IIIB & shallow bowl & Courtois \& Courtois 1978, 352-3, fig. 55: no. 19 \\
\hline 407 & LH IIIB & fragment & Courtois \& Courtois 1978, 352-3, fig. 55: no. 20 \\
\hline 408 & LM IIIA1 & large stirrup jar & Schaeffer 1939a, 77, fig. 68 \\
\hline 409 & LH IIIA2 & amphoroid krater & Schaeffer 1939a, 98: fig. 93 \\
\hline 410 & LH IIIA2-LH IIIB & hedgehog rhyton & Schaeffer 1949, pl. 37: no. 2 \\
\hline 411 & LH IIIB & hedgehog rhyton & Karageorghis 1965a, 228: no. 8; pl. XXII: no. 2 \\
\hline 412 & LH IIIB & piriform jar & Contenson et al. 1972, 22-3, fig. 23 \\
\hline 413 & LH IIIB & krater & Contenson et al. 1973b, 124: (not illustrated) \\
\hline 414 & LH IIIB & stirrup jar & Contenson et al. 1973b, 126: (not illustrated) \\
\hline 415 & LH IIIB & conical rhyton & Contenson et al. 1974, p. 8, 11, pl. Il: 1a \\
\hline 416 & LH IIIB & conical rhyton & Contenson et al. 1974, 8, 11, pl. Il: 1b \\
\hline 417 & LH IIIB & conical rhyton & Contenson et al. 1974, 8, 11, pl. II: 1c \\
\hline 418 & $\mathrm{LH} I I I B$ & hedgehog rhyton & Contenson et al. 1974, 12 (not illustrated) \\
\hline 419 & LH IIIB & deep bowl & Contenson et al. 1974, 20 (not illustrated) \\
\hline 420 & LH IIIB & shallow bowl & Contenson et al. 1974, 20: (not illustrated) \\
\hline 421 & LH IIIB & shallow bowl & Contenson et al. 1974, 5: (not illustrated) \\
\hline 422 & LH IIIB & globular stirrup jar & Saliby 1979-1980, 108: no. 9 \\
\hline 423 & LH IIIA2 & vertical flask & Saliby 1979-1980, 108: no. 10 \\
\hline 424 & LH IIIA2-LH IIIB & straight sided alabastron & Saliby 1979-1980, 108: no. 11 \\
\hline 425 & LH IIIB & squat stirrup jar & Saliby 1979-1980, 108: no. 12 \\
\hline 426 & LH IIIB & squat stirrup jar & Saliby 1979-1980, 108: no. 13 \\
\hline 427 & LH IIIB & stemmed cup & Saliby 1979-1980, 108: no. 14 \\
\hline 428 & LH IIIB & shallow bowl & Saliby 1979-1980, 108: no. 15 \\
\hline 429 & LH IIIA2-LH IIIB & bowl & Schaeffer 1962b, 101: (not illustrated) \\
\hline 430 & LH IIIB & shallow bowl & Schaeffer 1962b, 117: (not illustrated) \\
\hline 431 & LH IIIA2-LH IIIB & vertical flask & Schaeffer 1962b, 117: (not illustrated) \\
\hline 432 & LH IIIA2 & globular stirrup jar & L. Courtois 1969, 128-9, fig. 6: A \\
\hline 433 & LH IIIA2 & shallow cup & L. Courtois 1969, fig. 6: B \\
\hline 434 & LH IIIB & conical rhyton & Yon 1987, 346-7, fig. 2: no. 1 (78/63+101) \\
\hline 435 & LH IIIB & conical rhyton & Yon 1987, 346-7, fig. 2: no. 2 (79/3072) \\
\hline 436 & LH IIIB & conical rhyton & Yon 1987, 347-8, fig. 2: no. 3 (79/5590) \\
\hline 437 & LH IIIB & conical rhyton & Yon 1987, 347-8, fig. 2: no. 4 (79/5733) \\
\hline 438 & LH IIIB & conical rhyton & Yon 1987, 347-8, fig. 2: no. 5 (79/5766) \\
\hline 439 & LH IIIB & conical rhyton & Yon 1987, 347-8, fig 2: no. 6 (79/5829) \\
\hline 440 & LH IIIB & conical rhyton & Yon 1987, 348: no. 7 (79/5880); (not illustrated) \\
\hline 441 & LH IIIB & conical rhyton & Yon 1987, 347-8, fig. 2: no. 8 (80/5091) \\
\hline 442 & LH IIIB & conical rhyton & Yon 1987, 347-8, fig. 2: no. 9 (81/1060) \\
\hline 443 & LH IIIB & conical rhyton & Yon 1987, 347-8, fig. 2: no. 10 (81/1061-1063) \\
\hline 444 & LH IIIB & conical rhyton & Yon 1987, 347-8, fig. 2: no. 11 (83/5097) \\
\hline 445 & LH IIIB & conical rhyton & Yon 1987, 347-8, fig. 2, 4: no. 12 (17/RS-17) \\
\hline 446 & LH IIIB & fragment & Yon et. al. 1987, 22-23, fig. 8: no. 79/562 \\
\hline 447 & LH IIIB & fragment & Yon et. al. 1987, 40: no. 79/153 (not illustrated) \\
\hline 448 & LH IIIB & stirrup jar & Yon et. al. 1987, 40: no. 79/102 (not illustrated) \\
\hline 449 & LH IIIB & krater & Yon et. al. 1987, 46: no. 79/889 (not illustrated) \\
\hline 450 & LH IIIB & stirrup jar & Yon et. al. 1987, 54-5, fig. 36 no. 79.473 \\
\hline 451 & LH IIIB & krater & Yon et. al. 1987, 54-5, fig. 36: no. 79/785 \\
\hline 452 & LH IIIB & ring-based krater & Yon et. al. 1987, fig. 36: no. 79/661 \\
\hline 453 & LH IIIA2-LH IIIB & shallow cup & Yon et. al. 1987, fig. 57: no. $84 / 499$ \\
\hline 454 & LH IIIB & ring-based krater & Yon et. al. 1987, 85-6, fig. 66: no. 84/331 \\
\hline 455 & LH IIIB & globular stirrup jar & Yon et. al. 1987, 87-8, fig. 68: no. 84/602 \\
\hline 456 & LH IIIB & amphoroid krater & Yon et. al. 1987, 99, 101, fig. 80: no. 81/971 \\
\hline
\end{tabular}




\begin{tabular}{|c|c|c|c|}
\hline ID & date & shape & published \\
\hline 457 & LH IIIB & jug & Yon et. al. 1987, 98-9, 101, figs. 78,80 : no. 81/890 \\
\hline 458 & LH IIIB & shallow cup & Yon et. al. 1987, 103-4, fig. 84: no. 81/761 \\
\hline 459 & LH IIIB & stirrup jar & Yon et. al. 1987, 103-4, fig. 84: no. 81/796 \\
\hline 460 & LH IIIB e & amphoroid krater & Yon, Caubet \& Mallet 1982, 189-90, fig. 12: h: no. 80/5216 \\
\hline 461 & LH IIIB & small globular jug & Yon, Caubet \& Mallet 1982, 189-90, fig. 12: f \\
\hline 462 & LM IIA-LM ॥B & stirrup jar & Yon et al. 1983, 222: no. 81.5094 (not illustrated) \\
\hline 463 & LH IIIA2-LH IIIB & straight-sided alabastron & Yon, Gachet \& Lombard 1987, 179, fig. 5, no. 86/226 \\
\hline 464 & LH IIIA2 & straight-sided alabastron & Yon, Gachet \& Lombard 1987, 179, fig. 5: no. 86/227 \\
\hline 465 & LH IIIB & high stemmed chalice & Schaeffer 1949, 180-1, fig. 72: no. 23 \\
\hline 466 & LH IIIB & high stemmed chalice & Schaeffer 1949, 226-7, fig. 95: no. 31 \\
\hline 467 & LH IIIB & feeding bottle & Schaeffer 1949, 152-3, fig. 58: no. 14 \\
\hline 468 & LH IIIB & ring kernos & Schaeffer 1949, 150-151, fig: 57: no. 5 \\
\hline 469 & LH IIIB & conical stirrup jar & Schaeffer 1960, 135 (not illustrated) \\
\hline 470 & LH IIIB & mug & Schaeffer 1949, 152-3, fig 58: no. 11 \\
\hline 471 & $\mathrm{LH} \| \mathrm{B}$ & rounded alabastron & Stubbings 1951, 53: fig. 9 \\
\hline 472 & $\mathrm{LH} \| \mathrm{IB}$ e & amphoroid krater & Anson 1980, fig. 3: no. 82 \\
\hline 473 & LH IIIB & shallow bowl & Vermeule \& Karageorghis 1982, no. V 122 \\
\hline 474 & LM IIIB & large stirrup jar & Schaeffer 1949, 144-5, fig. 54: no. 15 \\
\hline 475 & LM IIIB & large stirrup jar & Schaeffer 1949, 152-3, fig. 58: no. 15 \\
\hline 476 & LM IIIA2 & pyxis & Courtois \& Courtois $1978,318-9$, fig. 41 : no. 5 \\
\hline 477 & LH IIIB & stirrup jar & Courtois \& Courtois $1978,334-5$, fig. 47 : no. 4 \\
\hline 478 & LH IIIB & stirrup jar & Courtois \& Courtois 1978, 334, fig. 47: no. 5 \\
\hline 479 & LM IIIB & amphoroid krater & Courtois \& Courtois 1978, 346-7, fig. 54: no. 2 \\
\hline 480 & LH IIIA2 I & amphoroid jug & Schaeffer 1932, 4, pl. II: no. 2 \\
\hline 481 & LH IIIB & cylindrical jug & Schaeffer 1949, pl. 39 (right) \\
\hline 482 & LH IIIA2 & globular stirrup jar & Margueron 1977, 181, PI. X: no. 1 \\
\hline 483 & LH IIIA2 & piriform jar & Margueron 1977, 181: pl X: no. 2 \\
\hline 484 & LH IIIA2 & amphoroid krater & Buchholz 1993, 102-3, fig. 4 \\
\hline 485 & LH IIIB & one-handled bowl & Schaeffer 1949, 180-1, fig. 72: no. 14 \\
\hline 486 & & fragment & Mallet 1987, 234, note 56: no. 83/5305 (not illustrated) \\
\hline 487 & & fragment & Mallet 1987, 236-237, note 68: no. 83/5378 (not illustrated) \\
\hline 488 & & & Schaeffer 1951a, 7-8 (not illustrated) \\
\hline 489 & LH IIIA2-LH IIIB & amphoroid krater & Schaeffer 1949 232-3, fig. 98: no. 7 \\
\hline 490 & LH IIIA2-LH IIIB & amphoroid krater & Schaeffer 1949, 232-3, fig. 98: no. 12 \\
\hline 491 & LH IIIA2-LH IIIB & amphoroid krater & Schaeffer 1949, 232-3, fig. 98: no. 5 \\
\hline 492 & LH IIIA2-LH IIIB & amphoroid krater & Schaeffer 1949, 232-3, fig. 98: no. 8 \\
\hline 493 & LH IIIA2-LH IIIB & amphoroid krater & Schaeffer 1949, 232-3, fig. 98: no. 1 \\
\hline 494 & LH IIIA2-LH IIIB & amphoroid krater & Schaeffer 1949, 232-3, fig. 98: no. 6 \\
\hline 495 & LH IIIA2-LH IIIB & amphoroid krater & Schaeffer 1949, 232-3, fig. 98: no. 11 \\
\hline 496 & LH IIIA2-LH IIIB & amphoroid krater & Schaeffer 1949, 232-3, fig. 98: no. 10 \\
\hline 497 & LH IIIA2-LH IIIB & amphoroid krater & Schaeffer 1949, 232-3, fig. 98: no. 9 \\
\hline 498 & LH IIIA2 & piriform jar & Courtois 1969,109 , fig. 12: bottom right \\
\hline 499 & LH IIIA2-LH IIIB & animal head rhyton & Courtois 1969, 109, fig 12: bottom left \\
\hline 500 & LH IIIB I & piriform jar & Courtois \& Courtois 1978, 332-333, fig. 46: no. 5 \\
\hline 501 & LH IIIB I & amphoroid krater & Yon, Gachet \& Lombard 1990, 20, 22, fig. 16 no. 88/2221 \\
\hline 502 & LH IIIB I & amphoroid krater & Yon, Gachet \& Lombard 1990, 16-17, fig. 10: 86/5158 \\
\hline 503 & LH IIIA2 & small piriform jug & Schaeffer 1939b, 67, fig 3E \\
\hline 504 & LH IIIA2-LH IIIB & feeding bottle & Courtois \& Courtois 1978, 294-5, fig. 33: no. 15 \\
\hline 505 & LH IIIB & stirrup jar & Schaeffer 1949, 226-7, fig. 95: no. 36 \\
\hline 506 & LH IIIB & biconical stirrup jar & Schaeffer 1938, 202, fig. 5B \\
\hline 507 & LH IIIB & biconical stirrup jar & Schaeffer 1938,202 , fig. 5 C \\
\hline
\end{tabular}




\begin{tabular}{|c|c|c|c|}
\hline ID & date & shape & published \\
\hline 508 & LH IIIA2 & stirrup jar & Courtois \& Courtois 1978, 302-303, fig. 35: no. 6 \\
\hline 509 & LH IIIA2-LH IIIB & stirrup jar & Kuschke 1962, 264-265, Tafel I: no. 1 \\
\hline 510 & LH IIIA2-LH IIIB & stirrup jar & Yon, Gachet \& Lombard 1987, 172 (not illustrated) \\
\hline 511 & LH IIIB & conical rhyton & Schaeffer 1936b, PI. 19: no. 2 \\
\hline 512 & LH IIIB & one-handled cup & Schaeffer 1949, 180-1, fig. 72: no. 14 \\
\hline 513 & LH IIIB & deep bowl & Yon et. al. 1987, 81, fig. 57: no. 80/15 \\
\hline 514 & LH IIIA2 & one-handled bowl & Schaeffer 1936b, 121, fig. 130 \\
\hline 515 & LH IIIB & spouted bowl & Leonard 1994, 126: no. 1898a \\
\hline 516 & & krater & Yon, Gachet \& Lombard 1990, 20: no. 88.2227 (not illustrated) \\
\hline 517 & & & Yon, Gachet \& Lombard 1990, 19 (not illustrated) \\
\hline 518 & LH IIIB & fragment & Courtois \& Courtois 1978, 352-3, fig. 55: no. 18 \\
\hline 519 & LH IIIB & & Yon, Gachet \& Lombard 1987, 189: RS 86.2406 (not illustrated) \\
\hline 520 & LH IIIA2-LH IIIB & & Yon, Gachet \& Lombard 1990, 16: no. 88.5203 (not illustrated) \\
\hline 521 & LM IIIA-LM IIIB & stirrup jar & Yon et. al. 1987, 20-21, fig. 20: no. 81/639 \\
\hline 522 & $\mathrm{LH} I I I B$ & shallow bowl & Stubbings 1951, 73, PI. 16: no. 2 \\
\hline 523 & LH IIIB & shallow bowl & Stubbings 1951, 73, PI. 16: no. 4 \\
\hline 524 & LH IIIB I & amphoroid krater & Courtois 1973, 150, fig. 5 \\
\hline 525 & LH IIIB & shallow bowl & Contenson et al. 1974, 21 (not illustrated) \\
\hline 526 & LH IIIB & amphoroid krater & Courtois 1973, 152: fig. 7 \\
\hline 527 & $\mathrm{LH} I I I B$ & amphoroid krater & Mallet 1987, 239, 242-3, figs. 17-18: no. 79/5047 \\
\hline 528 & LH IIIB & alabastron & Yon, Lombard \& Renisio 1987, 22-3, fig. 8: no. 79/462(3) \\
\hline 529 & LH IIIB & stirrup jar & Calvet and Geyer 1987, 138, 159, PI. II: no. c-e 84/1183 \\
\hline 530 & LH IIIB & stirrup jar & Yon, Lombard \& Renisio 1987, 102, 104, fig. 84: no. 81/797 \\
\hline 531 & LH IIIB & stirrup jar & Calvet and Geyer 1987, 144, 156, PI. VIk: no. 84/1123 \\
\hline 532 & LH IIIB & fragment & Calvet and Geyer 1987, 144, 156, PI. Vli: no. 84/1103 \\
\hline 533 & LH IIIB & fragment & Calvet and Geyer 1987, 144, 156, PI VIh: no. 84/1102 \\
\hline 534 & LM IIIA-LM IIIB & large stirrup jar & Yon, Lombard \& Renisio 1987, 102, 104, fig. 84: no. 81/734 \\
\hline 535 & & fragment & Yon et al. 1983, 222: no. 81/5076 (not illustrated) \\
\hline 536 & & fragment & Yon et al. 1983,222, no. $81 / 5077$ (not illustrated) \\
\hline 537 & & fragment & Mallet 1987, 220, note 9: no. 83/5034 (not illustrated) \\
\hline 538 & & fragment & Mallet 1987, 220, note 9: no. 83/5178 (not illustrated) \\
\hline 539 & & fragment & Mallet 1987, 220, note 9: no. 83/5181 (not illustrated) \\
\hline 540 & & fragment & Mallet 1987, 224, note 29: no. 83/5264 (not illustrated) \\
\hline 541 & & fragment & Mallet 1987, 227, note 34: no. 79/5417 (not illustrated) \\
\hline 542 & & krater & Mallet 1987, 231, note 42: no. 83/5383 (not illustrated) \\
\hline 543 & & fragment & Mallet 1987, 232, note 46: no. 83/5354 (not illustrated) \\
\hline 544 & & krater & Mallet 1987, 233, note 51: no. 80/5128 (not illustrated) \\
\hline 545 & & fragment & Mallet 1987, 233, note 51: no. 80/5158 (not illustrated) \\
\hline 546 & & amphoroid krater & Mallet 1987, 233, note 51,: no. 79/5977 (not illustrated) \\
\hline 547 & & small stirrup jar & Mallet 1987, 233, note 51: no. 79/5978 (not illustrated) \\
\hline 548 & & large stirrup jar & Mallet 1987, 233, note 51: no. 79/5976, (not illustrated) \\
\hline 549 & & alabastron & Mallet 1987, 233, note 51: no. 79/5981 (not illustrated) \\
\hline 550 & & amphoroid krater & Mallet 1987, 234, 237 notes 56, 68: no. 83/5303 (not illustrated) \\
\hline 551 & LH IIIB & amphoroid krater & Yon 1995, 440: no. RS 92.2176 (not illustrated) \\
\hline 552 & $\mathrm{LH} \| \mathrm{IB}$ & amphoroid krater & Yon 1995, 440: no. RS 94.2207 (not illustrated) \\
\hline 553 & LH IIIB & amphoroid krater & Yon 1995, 440: no. RS 94.2208 (not illustrated) \\
\hline 554 & LH IIIB & amphoroid krater & Yon 1995, 440: no. RS 94.2210 (not illustrated) \\
\hline
\end{tabular}




\section{Mycenaean figurines}

\begin{tabular}{|c|c|c|c|}
\hline ID & date & sort & published \\
\hline 1001 & LH IIIA-LH IIIB & bovine & Schaeffer 1949, 146-7, fig. 55: no. 1 \\
\hline 1002 & LH IIIA2-LH IIIB & bovine & Schaeffer 1949, 146-7, fig. 55: no. 2 \\
\hline 1003 & LH IIIA-LH IIIB & single equid & Schaeffer 1949, 146-7, fig. 55: nrs. 3,7 \\
\hline 1004 & LH IIIA2-LH IIIB & bovine & Schaeffer 1949, 146-7, fig. 55: no. 6 \\
\hline 1005 & LH IIIA/LH IIIB & female & Schaeffer 1949, 150-1, fig. 57: no. 17 \\
\hline 1006 & & chariot & Schaeffer 1949, 154-5, fig. 59: no. 7 \\
\hline 1007 & LH IIIB & bovine & Schaeffer 1949, 154-5, fig. 59: no. 9 \\
\hline 1008 & LH IIIA2 & chariot & Schaeffer 1949, 154-5, fig. 59: no. 10 \\
\hline 1009 & LH IIIA2-LH IIIB & female & Schaeffer 1949, 154-5, fig. 59: no. 12 \\
\hline 1010 & LH IIIB & bovine & Schaeffer 1949, 154-5, fig. 59: no. 18 \\
\hline 1011 & LH IIIA-LH IIIB & chariot & Schaeffer 1949, 154-5, fig. 59: no. 19 \\
\hline 1012 & LH IIIA2-LH IIIC & bovine & Schaeffer 1949, 170-1, fig. 67: no. 8 \\
\hline 1013 & & chariot & Schaeffer 1949, 180-1, fig. 72: no. 17 \\
\hline 1014 & LH IIIA2-LH IIIB & bovine & Schaeffer 1949, 230-1, fig. 97, no. 9 \\
\hline 1015 & LH IIIA-LH IIIB & chariot & Schaeffer 1949, 230-1, fig. 97: no. 13 \\
\hline 1016 & LH IIIA-LH IIIB & chariot & Schaeffer 1949, 230-1, fig. 97, no. 14 \\
\hline 1017 & LH IIIB & bovine & Schaeffer 1949, 230-1, fig. 97: no. 15 \\
\hline 1018 & LH IIIA-LH IIIC & bovine & Schaeffer 1949, 230-1, fig. 97: no. 16 \\
\hline 1019 & LH IIIA-LH IIIBe & bovine & Schaeffer 1949, 230-1, fig. 97: no. 17 \\
\hline 1020 & LH IIIB late & female & Schaeffer 1949, 230-1, fig. 97: no. 18 \\
\hline 1021 & LH IIIB late & female & Schaeffer 1949, 230-1, fig. 97: no. 19 \\
\hline 1022 & LH IIIB & bovine & Schaeffer 1949, 230-1, fig. 97: no. 20 \\
\hline 1023 & LH IIIA-LH IIIB & female & Courtois \& Courtois 1978, 351, 353, fig. 55: no. 1 \\
\hline 1024 & LH IIIA-LH IIIB & female & Courtois \& Courtois 1978, 351, 353, fig. 55: no. 2 \\
\hline 1025 & LH IIIA-LH IIIB & female & Courtois \& Courtois 1978, 351, 353, fig. 55: no. 3 \\
\hline 1026 & LH IIIB & female & Courtois \& Courtois 1978, 351, 353, fig. 55: no. 4 \\
\hline 1027 & LH IIIA2-LH IIIC & equid & Courtois \& Courtois 1978, 351, 353, fig. 55: no. 5 \\
\hline 1028 & LH IIIA2-LH IIIC & bovine & Courtois \& Courtois 1978, 351, 353, fig. 55: no. 6 \\
\hline 1029 & LH IIIB & equid & Courtois \& Courtois 1978, 351, 353, fig. 55: no. 7 \\
\hline 1030 & LH IIIB & bovine & Courtois \& Courtois 1978, 351, 353, fig. 55: no. 8 \\
\hline 1031 & LH IIIB & bovine & Courtois \& Courtois 1978, 351, 353, fig. 55: no. 9 \\
\hline 1032 & LH IIIA2-LH IIIB & bovine & Courtois \& Courtois $1978,351,353$, fig. 55: no. 10 \\
\hline 1033 & LH IIIA2-LH IIIB & bovine & Courtois \& Courtois 1978, 351, 353, fig. 55: no. 11 \\
\hline 1034 & LH IIIA2-LH IIIB & bovine & Courtois \& Courtois 1978, 352-3, fig. 55: no. 12 \\
\hline 1035 & LH IIIA2-LH IIIB & bovine & Courtois \& Courtois 1978, 352-3, fig. 55: no. 13 \\
\hline 1036 & LH IIIA2-LH IIIB & female & Schaeffer 1939a, 99, fig. 94 \\
\hline 1037 & LH IIIA2-LH IIIB & female & Schaeffer 1939a, 99, fig. 94 \\
\hline 1038 & LH IIIB-LH IIIC & female & Schaeffer 1956, 169 (not illustrated) \\
\hline 1039 & LH IIIA-LH IIIB & female & Monloup 1987, 320-1: no. 15 \\
\hline 1040 & LH IIIB-LH IIIC & female & Monloup 1987, 320-1: no. 16 \\
\hline 1041 & LH IIIA-LH IIIB & female & Monloup 1987, 320-1: no. 17 \\
\hline 1042 & LH IIIA-LH IIIB & female & Monloup 1987, 320-1: no. 18 \\
\hline 1043 & LH IIIA2-LH IIIC & bovine & Monloup 1987, 322: no. 19 \\
\hline 1044 & LH IIIA-LH IIIB & bovine & Monloup 1987, 322: no. 20 \\
\hline 1045 & LH IIIA-LH IIIB & bovine & Monloup 1987, 322, 328: no. 21 \\
\hline 1046 & LH IIIA2-LH IIIC & bovine & Monloup 1987, 323, 328: no. 22 \\
\hline 1047 & LH IIIA2-LH IIIB & bovine & Monloup 1987, 323: no. 23 \\
\hline 1048 & LH IIIA2-LH IIIB & bovine & Monloup 1987, 323: no. 24 \\
\hline 1049 & LH IIIA-LH IIIB & bovine & Monloup 1987, 323, 328: no. 25 \\
\hline 1050 & LH IIIA-LH IIIB & bovine & Monloup 1987, 324, 328: no. 26 \\
\hline
\end{tabular}




\begin{tabular}{|c|c|c|c|}
\hline ID & date & shape & published \\
\hline 1051 & LH IIIB & bovine & Monloup 1987, 324: no. 27 \\
\hline 1052 & LH IIIA2-LH IIIB & bovine & Monloup 324: no. 28 \\
\hline 1053 & LH IIIA2-LH IIIB & bovine & Monloup 1987, 324, 328: no. 29 \\
\hline 1054 & LH IIIA-LH ॥IB & female & Schaeffer 1935, 169: (not illustrated) \\
\hline 1055 & LH IIIA2-LH IIIB & equid & Schaeffer 1949, 230-1, fig. 97: no. 4 \\
\hline 1056 & LH IIIA-LH IIIB & female & Schaeffer 1931, pl. IV: no. 4 left \\
\hline 1057 & LH IIIA-LH IIIB & female & Schaeffer 1931, pl. IV: no. 4 centre \\
\hline 1058 & LH IIIA-LH IIIB & female & Schaeffer 1931, pl. IV: no. 4 right \\
\hline 1059 & LH IIIA-LH IIIB & bovine & Kuschke 1962, 264-5: Tafel I: no. 20 \\
\hline 1060 & LH IIIA2-LH IIIB & female & French 1971, 119 (not illustrated) \\
\hline 1061 & & & Callot 1994, 224: no. RS 23.110 (not illustrated) \\
\hline 1062 & & & Callot 1994, 225: no. RS 23.225 (not illustrated) \\
\hline
\end{tabular}

3 Probable Syrian imitations and derivations of Aegean pottery

\begin{tabular}{|c|c|c|c|}
\hline ID & date & shape & published \\
\hline 2001 & LH IIIB & stirrup jar & Schaeffer 1949, 156-7, fig. 60: nr. 12 \\
\hline 2002 & & stirrup jar & Schaeffer 1949, 228-9, fig. 96: nr. 16 \\
\hline 2003 & & stirrup jar & Schaeffer 1949, 228-9, fig. 96: nr. 24 \\
\hline 2004 & & conical rhyton & Schaeffer 1949, 218-9, fig. 91: nr. 6 \\
\hline 2005 & LH IIIB & conical rhyton & Schaeffer 1949, 146, fig. 55: nr. 18 \\
\hline 2006 & & conical rhyton & Schaeffer 1949, 218-9, fig. 91: nr. 4 \\
\hline 2007 & LH IIIB & piriform jar & Courtois \& Courtois 1978, 362-3, fig. 58: nr. 1 \\
\hline 2008 & LH IIIB & piriform jar & Courtois \& Courtois 1978, 362-3, fig. 58: nr. 3 \\
\hline 2009 & LH IIIB & piriform jar & Courtois \& Courtois 1978, 362-363, fig. 58: nr. 2 \\
\hline 2010 & LH IIIB & piriform jar & Courtois \& Courtois 1978, 362-3, fig. 58: nr. 4 \\
\hline 2011 & LH IIIB & piriform jar & Monchambert 1983, 36-7, fig. 1: nr. 2 \\
\hline 2012 & LH IIIB & amphoroid krater & Courtois \& Courtois 1978, 362-3, fig. 58: nr. 7 \\
\hline 2013 & LH IIIB & tall domestic jug & Courtois \& Courtois 1978, 362-3, fig. 58: nr. 8 \\
\hline 2014 & LH IIIB & stirrup jar & Monchambert 1983, 36-37, fig. 1: nr. 1 \\
\hline 2015 & LH IIIB & stirrup jar & Courtois \& Courtois 1978, 358-9, fig. 57: nr. 1 \\
\hline 2016 & LH IIIB & vertical flask & Monchambert 1983, 36-37, fig. 1: nr. 4 \\
\hline 2017 & LH IIIA2-LH IIIB & conical rhyton & Schaeffer 1936b, 115, fig. 8: nr. C \\
\hline 2018 & LH IIIA2-LH IIIB & conical rhyton & Courtois \& Courtois 1978, 310-1, fig. 37: nr. 10 \\
\hline 2019 & LH IIIA2-LH IIIB & conical rhyton & Schaeffer 1949, 198-9, fig. 81: nr. 12 \\
\hline 2020 & LH IIIB & stirrup jar & Schaeffer 1949, 180-1, fig. 72: nr. 24 \\
\hline 2021 & LH IIIA-LH IIIB & hedgehog rhyton & Schaeffer 1949, pl. 37: upper \\
\hline 2022 & LH IIIB I & deep bowl & Courtois \& Courtois 1978, 362-3, fig. 58: nr. 5 \\
\hline 2023 & LH IIIB & deep bowl & Courtois \& Courtois 1978, 360-1, fig. 57: nr. 16 \\
\hline 2024 & LH IIIB & jug & Schaeffer 1938, 319: fig. 47 \\
\hline 2025 & LH IIIB & piriform jar & Yon, Lombard \& Renisio 1987, 99, 101, fig. 80: nr. 81/981 \\
\hline 2026 & LH IIIB & stirrup jar & Schaeffer 1949, 182-3, fig. 73: nr. 22 \\
\hline 2027 & LH IIIB & squat globular stirrup jar & Schaeffer 1949, 182-3, fig. 73: nr 26. \\
\hline 2028 & & stirrup jar & Courtois \& Courtois 1978, 358-9, fig. 57: nr. 2 \\
\hline 2029 & & stirrup jar & Courtois \& Courtois 1978, 358-9, fig. 57: nr. 3 \\
\hline 2030 & & stirrup jar & Courtois \& Courtois 1978, 358-9, fig. 57: nr. 4 \\
\hline 2031 & & stirrup jar & Courtois \& Courtois 1978, 358-9, fig. 57: nr. 5 \\
\hline 2032 & LH IIIB & stirrup jar & Courtois \& Courtois 1978, 358-9, fig. 57: nr. 6 \\
\hline 2033 & & straight sided alabastron & Courtois \& Courtois 1978, 358-9, fig. 57: nr. 9 \\
\hline 2034 & LH IIIB & krater & Courtois \& Courtois 1978, 360-1, fig. 57: nr. 14 \\
\hline 2035 & LH IIIB & piriform jar & Yon et al. 1983,212 fig. $12 \mathrm{G}$ \\
\hline
\end{tabular}




\section{Catalogue III: Mycenaean pottery at Hazor}

\section{Mycenaean vessels and fragments}

\begin{tabular}{|c|c|c|c|}
\hline ID & date & shape & published \\
\hline 1 & LH IIIA2-LH IIIB & straight-ided alabastron & Yadin et al. 1958, 77 Plate 86503 (C2301) \\
\hline 2 & LH IIIA2-LH IIIB & piriform jar & Yadin et al. 1958 Plate 86: no. 2 (C5245) \\
\hline 3 & LH IIIA2-LH IIIB & fragment & Yadin et al. 1958, 83 Plate 89 no 12 (C1179) \\
\hline 4 & LH IIIA2-LH IIIB & stirrup jar & Yadin et al. 1958, 109 Plate 99: no. 25 (D1709) \\
\hline 5 & LH IIIA2-LH IIIB & stemmed cup & Yadin et al. 1958, 109 Plate 99: no. 26 \\
\hline 6 & LH IIIA2-LH IIIB & stemmed cup & Yadin et al. 1958122 Pale 110: no. 6 (D2980) \\
\hline 7 & LH IIIA2-LH IIIB & straight-sided alabastron & Yadin et al. 1958, 122 Plate 110: no. 7 (D4154) \\
\hline 8 & LH IIIA2 late & straight-sided alabastron & Yadin et al. 1958, 139-140 Plate 131: no. 9 (D5457) \\
\hline 9 & LH IIIA2-LH IIIB & straight-sided alabastron & Yadin et al. 1958, 139-140 Plate 131: no. 10 (D5450 + 5471 \\
\hline 10 & LH IIIA2-LH IIIB & amphoroid krater & Yadin et al. 1958, 140 Plate 131: no. 11 (D1734) \\
\hline 11 & LH IIIB2 & deep bowl & Yadin et al. 1958, Plate 131: no. 12 (D11734) \\
\hline 12 & LH IIIA2-LH IIIB & stirrup jar & Yadin et al. 1958, Plate 104: no. 28 (D3305) \\
\hline 13 & LH IIIA2-LH IIIB & straight-sided alabastron & Yadin et al. 1960, 109 Plate 123: no. 10 (C1204/7) \\
\hline 14 & LH IIIA2 & straight-sided alabastron & Yadin et al. 1960, 109 Plate 123: no. 11 (C848/1) \\
\hline 15 & LH IIIA2-LH IIIB & straight-sided alabastron & Yadin et al. 1960, 109 Plate 123: no. 12 (C351/10) \\
\hline 16 & LH IIIA2-LH IIIB1 & shallow cup & Yadin et al. 1960, 150-151 Plate 137: no. 1 (F1076/172) \\
\hline 17 & LH IIIA2-LH IIIB1 & shallow cup & Yadin et al. 1960, 150-151 Plate 137: no: 2 (F1076/27) \\
\hline 18 & LH IIIB & lentoid flask & Yadin et al. 1960, 147 Plate 137: no. 3 (F1076/152) \\
\hline 19 & LH IIIA2 & rounded alabastron & Yadin et al. 1960, 150 Plate 137: no. 4 (F1076/335) \\
\hline 20 & LH IIIA2-LH IIIB & straight-sided alabastron & Yadin et al. 1960, 150 Plate 137: no. 5 (F1076/336) \\
\hline 21 & LH IIIA2-LH IIIB1 & globular flask, horizontal type & Yadin et al. 1960, 151 Plate 137: no. 6 (F1076/185) \\
\hline 22 & LH IIIA2-LH IIIB1 & globular flask, horizontal type & Yadin et al. 1960, 151 Plate 137: no. 7 (F1089/26) \\
\hline 23 & LH IIIA2-LH IIIB1 & globular flask, horizontal type & Yadin et al. 1960, 151 Plate 137: no. 8 (F1076/19) \\
\hline 24 & LH IIIA2-LH IIIB & globular stirrup jar & Yadin et al. 1960, 151 Plate 137: no. 10 (1076/53) \\
\hline 25 & LH IIIA2 & globular stirrup jar & Yadin et al. 1960, 151 Plate 137: no. 11 (F1076/54) \\
\hline 26 & LH IIIA2 & globular stirrup jar & Yadin et al. 1960, Plate 137: no. 12 (F1076/184) \\
\hline 27 & LH IIIB & squat stirrup jar & Yadin et al. 1960, 151 Plate 137: no. 9 (F1076/174) \\
\hline 28 & LH IIIA2 & conical piriform stirrup jar & Yadin et al. 1960, 151 Plate 137: no. 13 (F1076/173) \\
\hline 29 & LH IIIA2 & piriform jar & Yadin et al. 1960, 151 Plate 140: no. 4 \\
\hline 30 & LH IIIB & lentoid flask & Yadin et al. 1960, 157 Plate 148: no. 4 (F1015/1) \\
\hline 31 & LH IIIB & lentoid flask & Yadin et al. 1960, 157 Plate 148: no. 5 (F194/1) \\
\hline 32 & LH IIIB & stirrup jar & Yadin et al. 1960, 157 Plate 148: no. 3 (F700/8) \\
\hline 33 & LH IIIB & lentoid flask & Yadin et al. 1960, 157 Plate 148: no. 6 (F194/2) \\
\hline 34 & LH IIIA2-LH IIIB & stirrup jar & Yadin et al. 1960, 157 Plate 148: no. 1 (F461/19) \\
\hline 35 & LH IIIB & globular stirrup jar & Yadin et al. 1960, 157 Plaet 148: no. 2 (F83/3) \\
\hline 36 & LH IIIB & kylix, Zygouries type & Yadin et al. 1960, 157 Plate 148: no. 7 (F250/26) \\
\hline 37 & LH IIIA2-LH IIIB & straight-sided alabastron & Yadin et al. 1960, 142 Plates 152: no. 13; 195: no. 1 (F1164/21) \\
\hline 38 & LH IIIA2-LH IIIB & stirrup jar & Yadin et al. 1960, Plate 188: no. 10 (F 1076/337a) \\
\hline 39 & LH IIIA2-LH IIIB & straight-sided alabastron & Yadin et al. 1961, Plate 158: no. 29 (A6547/1); 19891989, 22 \\
\hline 40 & LH IIIA2-LH IIIB & stemmed cup & Yadin et al. 1961, Plate 163: no. 24 (A6047/1); 1989, 25 \\
\hline 41 & LH IIB & fragment & Yadin et al. 1961, Plate 196: no. 20 (A5174/1) \\
\hline 42 & LH IIB & rounded alabastron & Yadin et al. 1961, Plate 196: no. 21 (A6470/1) \\
\hline 43 & LH IIIA2-LH IIIB & stirrup jar & Yadin et al. 1961, Plate 200: no. 22 (B5019/4) \\
\hline 44 & LH IIIB & squat stirrup jar & Yadin et al. 1961, Plate 237: no. 21; 1989, 130 (BA 20/6) \\
\hline 45 & LH IIB-LH IIIA1 & one-handled cup & Yadin et al. 1961, Plate 269: no. 45 (H1298/1); 1989, 240. \\
\hline 46 & LH IIIA-LH IIIB & bowl & Yadin et al. 1961, Plate 276: no. 35 (H515/1); 1989, 256 \\
\hline 47 & LH IIIA2-LH IIIB & stemmed cup & Yadin et al. 1961, Plate 282: no. 13 (H242/1); 1989, 271 \\
\hline 48 & LH IIIA2-LH IIIB & fragment & Yadin et al. 1961, Plate 312: no. 26 \\
\hline
\end{tabular}


Catalogue III cont.

\begin{tabular}{llll}
\hline ID & date & shape & published \\
\hline 49 & LH IIIA-LH IIIB & fragment & Yadin et al. 1961, Plate 312: no. 27 (A4148/1) \\
50 & LH IIIA-LH IIIB & fragment & Yadin et al. 1961, Plate 312: no. 28 (A3545) \\
51 & & fragment & Ben-Tor et al. 1997, 166-167, fig. II.61: no. 17 (A490/1) \\
52 & & fragment & Ben-Tor et al. 1997, 166-167, fig II.16: no. 17 (A490/1) \\
53 & LH IIB-LH IIIA1 & one-handled cup & Ben-Tor et al. 1997, 166-167, fig. II.61: no. 17 (A742/7) \\
\hline
\end{tabular}

\section{Mycenaean figurines}

\begin{tabular}{llll}
\hline ID & date & sort & published \\
\hline 1001 & LH IIIA-LH IIIB & female & Yadin et al. 1958, 109 Plate 99: no. 24 (D8081) \\
1002 & LH IIIA2-LH IIIB1 & female & Yadin et al. 1960, Plate 176: no. 7 (C907/1) \\
1003 & LH IIIA-LH IIIB & bovine & Yadin et al. 1961, Plate 282 no. 14 (H263); 1989, 271 \\
1004 & LH IIIA-LH IIIB & female & Yadin et al. 1960, Plate 148: no. 8 \\
1005 & LH IIIA-LH IIIB & female & Yadin et al. 1960, Plate 148: no. 9 (F864/4) \\
\hline
\end{tabular}


Catalogue IV: Mycenaean pottery at Deir 'Alla

1 Mycenaean vessels and fragments

\begin{tabular}{llll}
\hline ID & date & shape & published \\
\hline 1 & LH IIIB & globular stirrup jar & Franken 1992, 38, 44: 4-3:19: 1020 \\
2 & LH IIIB & squat stirrup jar & Franken 1992, 38 fig 4-3:18: 627 \\
3 & LH IIIA2 & squat stirrup jar & Franken 1992, 38, fig. 4-3:17: 626 \\
4 & LH IIIA2-LH IIIB1 & globular flask, horizontal type & Franken 1992, 63, fig. 4-20:15: 1569+N311 \\
5 & LH IIIA2-LH IIIB1 & globular flask, horizontal type & Franken 1992, 63 (not illustrated) \\
2005 & LH IIIB & globular stirrup jar & Franken 1992, 43 fig 4-6:9: 628 \\
\hline
\end{tabular}




\section{Catalogue V: Mycenaean pottery at Enkomi}

\section{Mycenaean vessels and fragments}

\begin{tabular}{|c|c|c|c|}
\hline ID & date & shape & published \\
\hline 1 & LH IIIB & conical rhyton & Murray, Smith \& Walters 1900, 6, fig. 6: no. 983 \\
\hline 2 & LH IIIA2-LH IIIB & squat stirrup jar & Murray, Smith \& Walters 1900, 6, fig. 6: no. 984 \\
\hline 3 & LH IIIA2 & lentoid fllask & Murray, Smith \& Walters 1900, 6, fig. 6: no. 913 \\
\hline 4 & LH IIIA2 & amphoroid jug & Murray, Smith \& Walters 1900, 6, fig. 6: no. 1300 \\
\hline 5 & $\mathrm{LH} I I I A 2$ & amphoroid krater & Murray, Smith \& Walters 1900, 7 fig. 10: no. 1151 \\
\hline \multirow[t]{2}{*}{6} & $\mathrm{LH} I I I A 2$ & amphoroid krater & Murray, Smith \& Walters 1900, 9 fig. 15: no. 1287 \\
\hline & & & Murray, Smith \& Walters 1900, 9, fig. 15: no. 1287 \\
\hline 7 & LH IIIB & shallow bowl & Murray, Smith \& Walters 1900, 33, fig. 61: no. 1209 \\
\hline 8 & LH IIIA2-LH IIIB & shallow cup & Murray, Smith \& Walters 1900, 33, fig. 61: no. 1208 \\
\hline 9 & $\mathrm{LH} I I I B$ & cup with horizontal handle & Murray, Smith \& Walters 1900, 33, fig. 61: no. 1207 \\
\hline 10 & LH IIIA2-LH IIIB & composite vessel & Murray, Smith \& Walters 1900, 34 fig. 62: no. 1227 \\
\hline 11 & $\mathrm{LH}$ IIIA2 & piriform jar & Murray, Smith \& Walters 1900, 34 fig. 62: no. 1253 \\
\hline 12 & LH IIIA2-LH IIIB & horizontal flask & Murray, Smith \& Walters 1900, 34 fig. 62: no. 1222 \\
\hline 13 & $\mathrm{LH} I I I A 2$ & carinated conical cup & Murray, Smith \& Walters 1900, 34 fig. 62: no. 1254 \\
\hline 14 & $\mathrm{LH} I I I A 2$ & shallow cup & Murray, Smith \& Walters 1900, 34 fig. 62: no. 1223 \\
\hline 15 & LH IIIA2-LH IIIB & globular stirrup jar & Murray, Smith \& Walters 1900, 34 fig. 62: no. 1219 \\
\hline 16 & LH IIIB & squat stirrup jar & Murray, Smith \& Walters 1900, 34 fig. 62: no. 1243. \\
\hline 17 & LH IIIB & shallow bowl & Murray, Smith \& Walters 1900, 34 fig. 62: no. 1225 \\
\hline 18 & LH IIIB & squat stirrup jar & Murray, Smith \& Walters 1900, 34 fig. 62: no. 1220 \\
\hline 19 & LH IIIB & cylindrical jug & Murray, Smith \& Walters 1900, 34 fig. 62: no. 1221 \\
\hline 20 & $\mathrm{LH} I I I A 2$ & horizontal flask & Murray, Smith \& Walters 1900, 34 fig. 62: no. 1246 \\
\hline 21 & LH IIIA2 & globular jug & Murray, Smith \& Walters 1900, 35 fig. 63: no. 1036 \\
\hline 22 & LH IIIB & shallow bowl & Murray, Smith \& Walters 1900, 35 fig. 63: no. 1026 \\
\hline 23 & $\mathrm{LH} I I I \mathrm{~B}$ & stemmed shallow bowl & Murray, Smith \& Walters 1900, 35 fig. 63: no. 1004 \\
\hline 24 & LH IIIA2-LH IIIB & straight-sided alabastron & Murray, Smith \& Walters 1900, 35 fig. 63: no. 1016 \\
\hline 25 & LH IIIB & shallow bowl & Murray, Smith \& Walters 1900, 35 fig. 63: no. 1027 \\
\hline 26 & LH IIIB & large piriform jar & Murray, Smith \& Walters 1900, 35 fig. 63: no. 1039 \\
\hline 27 & LH IIIB & ring-based krater & Murray, Smith \& Walters 1900, 35 fig. 63: no. 1038 \\
\hline 28 & LH IIIA2-LH IIIB & squat stirrup jar & Murray, Smith \& Walters 1900, 35 fig. 63: no. 1012 \\
\hline 29 & LH IIIA2-LH IIIB & straight-sided alabastron & Murray, Smith \& Walters 1900, 36 fig. 64: no. 1014 \\
\hline 30 & LH IIIA2-LH IIIB & shallow cup & Murray, Smith \& Walters 1900, 36 fig. 64: no. 1019 \\
\hline 31 & LH IIIA2-LH IIIB & straight-sided alabastron & Murray, Smith \& Walters 1900, 36 fig. 64: no. 1015 \\
\hline 32 & $\mathrm{LH} I I I A 2$ & piriform jug with cut-away neck & Murray, Smith \& Walters 1900, 36 fig. 64: no. 1035 \\
\hline 33 & LH IIIB & shallow spouted cup & Murray, Smith \& Walters 1900, 36 fig. 64: no. 1024 \\
\hline 34 & LH IIIA2-LH IIIB & shallow cup & Murray, Smith \& Walters 1900, 36 fig. 64: no. 1018 \\
\hline 35 & LH IIIA2-LH IIIB & shallow cup & Murray, Smith \& Walters 1900, 36 fig. 64: no. 1017 \\
\hline 36 & LH IIIA2-LH IIIB & shallow cup & Murray, Smith \& Walters 1900, 36 fig. 64: no. 1020 \\
\hline 37 & LH IIIA2-LH IIIB & shallow cup & Murray, Smith \& Walters 1900, 36 fig. 64: no. 1021 \\
\hline 38 & $\mathrm{LH} I I I B$ & shallow bowl & Murray, Smith \& Walters 1900, 36 fig. 64: no. 1025 \\
\hline 39 & LH IIIB & shallow stemmed bowl & Murray, Smith \& Walters 1900, 36 fig. 64: no. 1005 \\
\hline 40 & LH IIIB & piriform jar & Murray, Smith \& Walters 1900, 36 fig. 64: no. 1033 \\
\hline 41 & LH IIIB & shallow stemmed bowl & Murray, Smith \& Walters 1900, 36 fig. 64: no. 1003 \\
\hline 42 & LH IIIB & shallow bowl & Murray, Smith \& Walters 1900, 36 fig. 64: no. 1007 \\
\hline 43 & LH IIIB & globular jug & Murray, Smith \& Walters 1900, 36 fig. 64: no. 1034 \\
\hline 44 & LH IIIB & squat stirrup jar & Murray, Smith \& Walters 1900, 36 fig. 64: no. 1010 \\
\hline 45 & LH IIIA2-LH IIIB & globular stirrup jar & Murray, Smith \& Walters 1900, 36 fig. 64: no. 1009 \\
\hline 46 & LH IIIA2-LH IIIB & globular stirrup jar & Murray, Smith \& Walters 1900, 36 fig. 64: no. 1008 \\
\hline 47 & LH IIIB & kylix & Murray, Smith \& Walters 1900, 36 fig. 64: no. 1008 \\
\hline
\end{tabular}




\begin{tabular}{|c|c|c|c|}
\hline ID & date & shape & published \\
\hline 48 & LH IIIA2-LH IIIB & straight-sided alabastron & Murray, Smith \& Walters 1900, 36 fig. 64: no. 1013 \\
\hline 49 & LH IIIA2 & bull's head rhyton & Murray, Smith \& Walters 1900, 37 fig. 65: no. 1077 \\
\hline 50 & LH IIIA1-LH IIIA2 & piriform jar & Murray, Smith \& Walters 1900, 37 fig. 65: no. 1079 \\
\hline 51 & LH IIIA2-LH IIIB & shallow cup & Murray, Smith \& Walters 1900, 37 fig. 65: no. 1084 \\
\hline 52 & LH IIIA1 & amphoroid krater & Murray, Smith \& Walters 1900, 37 fig. 65: no. 1076 \\
\hline 53 & LH IIIA2-LH IIIB & globular stirrup jar & Murray, Smith \& Walters 1900, 37 fig. 65: no. 1081 \\
\hline 54 & LH IIIA2 & amphoroid krater & Murray, Smith \& Walters 1900, 37 fig. 65: no. 1088 \\
\hline 55 & LH IIIA2 & deep krater & Murray, Smith \& Walters 1900, 37 fig. 65: no. 1089 \\
\hline 56 & LH IIIA2-LH IIIB & straight-sided alabastron & Murray, Smith \& Walters 1900, 37 fig. 65: no. 1083 \\
\hline 57 & LH IIIA2-LH IIIB & shallow cup & Murray, Smith \& Walters 1900, 38 fig. 66: no. 1185 \\
\hline 58 & LH IIIA2 & mug & Murray, Smith \& Walters 1900, 38 fig. 66: no. 1184 \\
\hline 59 & LH IIIB & globular stirrup jar & Murray, Smith \& Walters 1900, 38 fig. 66: no. 1182 \\
\hline 60 & LH IIIA2-LH IIIB & shallow cup & Murray, Smith \& Walters 1900, 38 fig. 66: no. 1188 \\
\hline 61 & LH IIIA2-LH IIIB & shallow cup & Murray, Smith \& Walters 1900, 38 fig. 66: no. 1187 \\
\hline 62 & LH IIIB & globular stirrup jar & Murray, Smith \& Walters 1900, 38 fig. 66: no. 1181 \\
\hline 63 & LH IIIA2-LH IIIB & shallow cup & Murray, Smith \& Walters 1900, 38 fig. 66: no. 1186 \\
\hline 64 & LH IIIA2 & piriform jar & Murray, Smith \& Walters 1900, 38 fig. 66: no. 1183 \\
\hline 65 & LH IIIB & piriform jar & Murray, Smith \& Walters 1900, 39 fig. 67: no. 845 \\
\hline 66 & LH IIIA1 & deep krater & Murray, Smith \& Walters 1900, 39 fig. 67: no. 844 \\
\hline 67 & LH IIIA2 & amphoroid krater & Murray, Smith \& Walters 1900, 39 fig. 67: no. 838 \\
\hline 68 & LH IIIA2 & amphoroid krater & Murray, Smith \& Walters 1900, 39 fig. 67: no. 832 \\
\hline 69 & LH IIIA2-LH IIIB & amphoroid krater & Murray, Smith \& Walters 1900, 39 fig. 67: no. 842 \\
\hline 70 & LH IIIA2 & amphoroid krater & Murray, Smith \& Walters 1900, 39 fig. 67: no. 836 \\
\hline 71 & LH IIIA2 & amphoroid krater & Murray, Smith \& Walters 1900, 39 fig. 67: no. 833 \\
\hline 72 & LH IIIA2-LH IIIB & squat stirrup jar & Murray, Smith \& Walters 1900, 39 fig. 67: no. 848 \\
\hline 73 & LH IIIA1 & wide-mouthed jug & Murray, Smith \& Walters 1900, 40 fig. 68: no. 1101 \\
\hline 74 & LH IIIA1 & stemmed goblet & Murray, Smith \& Walters 1900, 40 fig. 68: no. 1092 \\
\hline 75 & LH IIIA2 & conical rhyton & Murray, Smith \& Walters 1900, 40 fig. 68: no. 1091 \\
\hline 76 & LH IIIA2 & globular flask & Murray, Smith \& Walters 1900, 40 fig. 68: no. 1103 \\
\hline 77 & LH IIIA2-LH IIIB & small jug & Murray, Smith \& Walters 1900, 40 fig. 68: no. 1100 \\
\hline 78 & LH IIIA2 & deep krater & Murray, Smith \& Walters 1900, 40 fig. 68: no. 1103 \\
\hline 79 & LH IIIA2-LH IIIB & piriform jar & Murray, Smith \& Walters 1900, 40 fig. 68: no. 1097 \\
\hline 80 & LH IIIA2-LH IIIB & shallow cup & Murray, Smith \& Walters 1900, 40 fig. 68: no. 1095 \\
\hline 81 & LH IIIA1 & rounded alabastron & Murray, Smith \& Walters 1900, 40 fig. 68: no. 1107 \\
\hline 82 & LH IIIA2-LH IIIB & shallow cup & Murray, Smith \& Walters 1900, 40 fig. 68: no. 1094 \\
\hline 83 & LH IIIA2-LH IIIB & straight-sided alabastron & Murray, Smith \& Walters 1900, 40 fig. 68: no. 1096 \\
\hline 84 & LH IIIA2-LH IIIB & shallow stemmed bowl & Murray, Smith \& Walters 1900, 40 fig. 68: no. 1093 \\
\hline 85 & LH IIIA2 & one-handled bowl & Murray, Smith \& Walters 1900, 40 fig. 68: no. 1099 \\
\hline 86 & LH IIIA2 & carinated conical cup & Murray, Smith \& Walters 1900, 40 fig. 69 no. 1141 \\
\hline 87 & LH IIIA2-LH IIIB & shallow cup & Murray, Smith \& Walters 1900, 40 fig. 69: no. 1142 \\
\hline 88 & LH IIIA2-LH IIIB & rounded alabastron & Murray, Smith \& Walters 1900, 40 fig. 69: no. 1140 \\
\hline 89 & LH IIIB & large piriform jar & Murray, Smith \& Walters 1900, 40 fig. 69: no. 1137 \\
\hline 90 & LH IIIA1 & piriform jar & Murray, Smith \& Walters 1900, 40 fig. 69: no. 1139 \\
\hline 91 & LH IIIA2 & deep krater & Murray, Smith \& Walters 1900, 40 fig. 69: no. 876 \\
\hline 92 & LH IIIA2-LH IIIB & squat stirrup jar & Murray, Smith \& Walters 1900, 40 fig. 69: no. 1136 \\
\hline 93 & LH IIIB & globular stirrup jar & Murray, Smith \& Walters 1900, 40 fig. 69: no. 1135 \\
\hline 94 & LH IIIA1-LH IIIA2 & piriform jar & Murray, Smith \& Walters 1900, 40 fig. 69: no. 1138 \\
\hline 95 & LH IIIA2-LH IIIB & globular stirrup jar & Murray, Smith \& Walters 1900, 42 fig. 70: no. 1273 \\
\hline 96 & LH IIIA2-LH IIIB & straight-sided alabastron & Murray, Smith \& Walters 1900, 42 fig. 70: no. 1280 \\
\hline 97 & LH IIIA2-LH IIIB & squat stirrup jar & Murray, Smith \& Walters 1900, 42 fig. 70: no. 1274 \\
\hline 98 & LH IIIA2-LH IIIB & shallow cup & Murray, Smith \& Walters 1900, 42 fig. 70: no. 1281 \\
\hline
\end{tabular}




\begin{tabular}{|c|c|c|c|}
\hline ID & date & shape & published \\
\hline 99 & LH IIIA2 & piriform jar & Murray, Smith \& Walters 1900, 42 fig. 70: no. 1217 \\
\hline 100 & LH IIIB1 & jug & Murray, Smith \& Walters 1900, 42 fig. 70: no. 1270 \\
\hline 101 & LH IIIA2-LH IIIB & small globular jug & Murray, Smith \& Walters 1900, 42 fig. 70: no. 1279 \\
\hline 102 & $\mathrm{LH} I I I B$ & globular stirrup jar & Murray, Smith \& Walters 1900, 42 fig. 70: no. 1271 \\
\hline 103 & LH IIIB & ring-based krater & Murray, Smith \& Walters 1900, 42 fig. 70: no. 1269 \\
\hline 104 & LH IIIA2-LH IIIB & globular stirrup jar & Murray, Smith \& Walters 1900, 42 fig. 70: no. 1272 \\
\hline 105 & LH IIIA2 & conical piriform stirrup jar & Murray, Smith \& Walters 1900, 42 fig. 70: no. 1275 \\
\hline 106 & LH IIIA1-LH IIIA2 & piriform jar & Murray, Smith \& Walters 1900, 42 fig. 70: no. 1278 \\
\hline 107 & LH IIIA2-LH IIIB & piriform jar & Murray, Smith \& Walters 1900, 42 fig. 70: no. 1276 \\
\hline 108 & LH IIIB & ring-based krater & Murray, Smith \& Walters 1900, 45 fig. 71: no. 931 \\
\hline 109 & LH IIIB & ring-based krater & Murray, Smith \& Walters 1900, 45 fig. 71: no. 930 \\
\hline 110 & LH IIIA2 & amphoroid krater & Murray, Smith \& Walters 1900, 45 fig. 71: no. 929 \\
\hline 111 & LH IIIA2-LH IIIB & shallow cup & Murray, Smith \& Walters 1900, 45 fig. 71: no. 955 \\
\hline 112 & LH IIIA1-LH IIIA2 & piriform jar & Murray, Smith \& Walters 1900, 45 fig. 71: no. 945 \\
\hline 113 & LH IIIA2 & globular flask & Murray, Smith \& Walters 1900, 45 fig. 71: no. 948 \\
\hline 114 & LH IIIA2-LH IIIB & globular stirrup jar & Murray, Smith \& Walters 1900, 45 fig. 71: no. 948 \\
\hline 115 & LH IIIA2-LH IIIB & straight-sided alabastron & Murray, Smith \& Walters 1900, 45 fig. 71: no. 947 \\
\hline 116 & LH IIIA2-LH IIIB & globular stirrup jar & Murray, Smith \& Walters 1900, 45 fig. 71: no. 943 \\
\hline 117 & LH IIIA2-LH IIIB & straight-sided alabastron & Murray, Smith \& Walters 1900, 45 fig. 71: no. 946 \\
\hline 118 & LH IIIA2-LH IIIB & globular stirrup jar & Murray, Smith \& Walters 1900, 45 fig. 71: no. 946 \\
\hline 119 & LH IIIA2 & globular jug & Murray, Smith \& Walters 1900, 45 fig. 71: no. 950 \\
\hline 120 & LH IIIA2 & globular flask & Murray, Smith \& Walters 1900, 45 fig. 71: no. 949 \\
\hline 121 & LH IIIA2-LH IIIB & globular stirrup jar & Murray, Smith \& Walters 1900, 45 fig. 71: no. 940 \\
\hline 122 & LH IIIB & conical stirrup jar & Murray, Smith \& Walters 1900, 45 fig. 71: no. 939 \\
\hline 123 & LH IIIA2-LH IIIB & piriform jar & Murray, Smith \& Walters 1900, 45 fig. 71: no. 944 \\
\hline 124 & LH IIIA2 & conical piriform stirrup jar & Murray, Smith \& Walters 1900, 45 fig.71: no. 938 \\
\hline 125 & LH IIIB & ring-based krater & Murray, Smith \& Walters 1900, 8 fig. 14; 45 fig 71: no. 927 \\
\hline 126 & LH IIIA2-LH IIIB & shallow cup & Murray, Smith \& Walters 1900, 47 fig. 72: no. 870 \\
\hline 127 & LH IIIA2-LH IIIB & shallow cup & Murray, Smith \& Walters 1900, 47 fig. 72: no. 871 \\
\hline 128 & & bowl & Murray, Smith \& Walters 1900, 47 fig. 72: no. 869 \\
\hline 129 & LH IIIA2-LH IIIB & piriform jar & Murray, Smith \& Walters 1900, 47 fig. 72: no. 1130 \\
\hline 130 & LH IIIA2-LH IIIB & piriform jar & Murray, Smith \& Walters 1900, 47 fig. 72: no. 1129 \\
\hline 131 & LH IIIA2-LH IIIB & piriform jar & Murray, Smith \& Walters 1900, 47 fig. 72: no. 1131 \\
\hline 132 & LH IIIA2-LH IIIB & piriform jar & Murray, Smith \& Walters 1900, 47 fig. 72: no. 1132 \\
\hline 133 & LH IIIA2-LH IIIB & piriform jar & Murray, Smith \& Walters 1900, 47 fig. 72: no. 1133 \\
\hline 134 & LH IIIB & ring-based krater & Murray, Smith \& Walters 1900, 48 fig. 73: no. 966 \\
\hline 135 & LH IIIB & ring-based krater & Murray, Smith \& Walters 1900, 48 fig. 73: no. 965 \\
\hline 136 & LH IIIB & shallow bowl & Murray, Smith \& Walters 1900, 48 fig. 73: no. 973 \\
\hline 137 & LH IIIB & shallow bowl & Murray, Smith \& Walters 1900, 48 fig. 73: no. 972 \\
\hline 138 & LH IIIB & shallow bowl & Murray, Smith \& Walters 1900, 48 fig. 73: no. 971 \\
\hline 139 & LH IIIA2-LH IIIB & globular jug & Murray, Smith \& Walters 1900, 48 fig. 73 : no. $972^{*}$ \\
\hline 140 & LH IIIA2 & amphoroid krater & Murray, Smith \& Walters 1900, 48 fig. 73: no. 937* \\
\hline 141 & LH IIIB & conical stirrup jar & Murray, Smith \& Walters 1900, 48 fig. 73: no. 968 \\
\hline 142 & $\mathrm{LH} I I \mathrm{~B}$ & large stirrup jar & Murray, Smith \& Walters 1900, 48 fig. 73: no. 967 \\
\hline 143 & LH IIIB & globular stirrup jar & Murray, Smith \& Walters 1900, 48 fig. 73: no. 969 \\
\hline 144 & LM IIIA2 & amphoroid krater & Murray, Smith \& Walters 1900, 48 fig. 73: no. 964 \\
\hline 145 & LH IIIB & squat stirrup jar & Murray, Smith \& Walters 1900, 48 fig. 73: no. 970 \\
\hline 146 & LH IIIA2 & amphoroid krater & Murray, Smith \& Walters 1900, 48 fig. 74: no. 1149 \\
\hline 147 & LH IIIA1-LH IIIA2 & piriform jar & Murray, Smith \& Walters 1900, 48 fig. 74: no. 1152 \\
\hline 148 & LH IIIA2-LH IIIB & shallow cup & Murray, Smith \& Walters 1900, 48 fig. 74: no. 1156 \\
\hline 149 & LM IIIA2 & amphoroid krater & Murray, Smith \& Walters 1900, 48 fig. 74: no. 1147 \\
\hline
\end{tabular}




\begin{tabular}{|c|c|c|c|}
\hline ID & date & shape & published \\
\hline 150 & LH IIIA2-LH IIIB & piriform jar & Murray, Smith \& Walters 1900, 48 fig. 74: no. 1164 \\
\hline 151 & LH IIIA2-LH IIIB & globular stirrup jar & Murray, Smith \& Walters 1900, 48 fig. 74: no. 1160 \\
\hline 152 & LH IIIA2 & deep krater & Murray, Smith \& Walters 1900, 48 fig. 74: no. 1148 \\
\hline 153 & LH IIIA2-LH IIIB & globular stirrup jar & Murray, Smith \& Walters 1900, 48 fig. 74: no. 1162 \\
\hline 154 & LH IIIB & ring-based krater & Murray, Smith \& Walters 1900, 48 fig. 74: no. 1150 \\
\hline 155 & $\mathrm{LH} \| I \mathrm{~A} 2$ & rounded alabastron & Murray, Smith \& Walters 1900, 48 fig. 74: no. 1169 \\
\hline 156 & LH IIIB & amphoroid krater & Murray, Smith \& Walters 1900, 49 fig. 75: no. 981 \\
\hline 157 & LH IIIA2 & shallow cup & Murray, Smith \& Walters 1900, 49 fig. 75: no. 1118 \\
\hline 158 & LH IIIA2-LH IIIB & straight-sided alabastron & Murray, Smith \& Walters 1900, 49 fig. 75: no. 1116 \\
\hline 159 & LH IIIA2 & amphoroid krater & Murray, Smith \& Walters 1900, 49 fig. 75: no. 1113 \\
\hline 160 & LH IIIA2-LH IIIB & globular stirrup jar & Murray, Smith \& Walters 1900, 49 fig. 75: no. 1115 \\
\hline 161 & LH IIIA2-LH IIIB & shallow cup & Murray, Smith \& Walters 1900, 49 fig. 75: no. 1117 \\
\hline 162 & $\mathrm{LH} I I I A 2$ & conical rhyton & Murray, Smith \& Walters 1900, 49 fig 75: no. 1114 \\
\hline 163 & LH IIIB & large piriform jar & Murray, Smith \& Walters 1900, 49 fig. 76: no. 1263 \\
\hline 164 & LH IIIB & kylix & Murray, Smith \& Walters 1900, 49 fig. 76: no. 1264 \\
\hline 165 & LH IIIB & ring-based krater & Murray, Smith \& Walters 1900, 49 fig. 76: no. 1262 \\
\hline 166 & LH IIIB & ring-based krater & Murray, Smith \& Walters 1900, 49 fig. 76: no. 1260 \\
\hline 167 & LH IIIA2-LH IIIB & shallow cup & Murray, Smith \& Walters 1900, 49 fig. 76: no. 1265 \\
\hline 168 & LH IIIB & ring-based krater & Murray, Smith \& Walters 1900, 49 fig. 76: no. 1261 \\
\hline 169 & LH IIIA2-LH IIIB & shallow cup & Murray, Smith \& Walters 1900, 49 fig. 76: no. 1266 \\
\hline 170 & LH IIIA2-LH IIIB & shallow cup & Murray, Smith \& Walters 1900, 34 fig. 62: no. 1224 \\
\hline 171 & LH IIIA2-LH IIIB & shallow cup & Karageorghis 1963, IIC, Plate 27: no. 3 (A1516) \\
\hline 172 & LH IIIA2-LH IIIB & shallow cup & Karageorghis 1963, IIC, Plate 27: no. 5 (A1515) \\
\hline 173 & LH IIIA2-LH IIIB & shallow cup & Karageorghis 1963, IIC, Plate 32: nos. 7-8 (A1532) \\
\hline 174 & LH IIIA2-LH IIIB & shallow cup & Karageorghis 1963, IIC, Plate 32: nos. 9-10 (A1533) \\
\hline 175 & LH IIIA2-LH IIIB & small globular jug & Karageorghis 1963, IIC, Plate 29: no. 4 (A1561) \\
\hline 176 & LH IIIA2 & tall beaked jug & Karageorghis 1963, IIC, Plate 28: no. 8 (A1561) \\
\hline 177 & LH IIIA2-LH IIIB & globular stirrup jar & Karageorghis 1963, IIC, Plate 22: no. 4 (A1603) \\
\hline 178 & LH IIIA2-LH IIIB & straight-sided alabastron & Smith 1925, IICb, Plate 4: no. 10 \\
\hline 179 & LH IIIA2-LH IIIB & piriform jar & Smith 1925, IICb, Plate 1: no. 35 \\
\hline 180 & LH IIB-LH IIIA1 & rounded alabastron & Catling 1964, 36 (not illustrated) \\
\hline 181 & $\mathrm{LH}$ IIIA2 & conical piriform stirrup jar & Smith 1925, IICb, Plate 2: no. 18 \\
\hline 182 & LH IIIB & fragment & Walters 1912, 130 no. C 686 (not illustrated) \\
\hline 183 & LH IIIB & kylix & Walters 1912, 130 fig. 255: no. C688 \\
\hline 184 & LH IIIB & ring-based krater & Walters 1912, 83: no. C406 (not illustrated) \\
\hline 185 & LH IIIA2 & amphoroid krater & Walters 1912, 74 fig. 121: no. C374; 130 fig. 249: no. C681 \\
\hline 186 & LH III & fragment & Åström 1972b. 383: no. 1958/l-1019 \\
\hline 187 & LH IIB-LH IIIA1 & squat alabastron & Karageorghis 1963, IIC, Plate 23: nos. 1-2 \\
\hline 188 & LH IIIA2 & amphoroid krater & Walters 1912, 79 fig. 134: C396 \\
\hline 189 & $\mathrm{LH} \| \mathrm{IIA} 2$ & amphoroid krater & Catling \& Millettt 1965, 222, Plate 59: no. 2 \\
\hline 190 & LH IIIB & ring-based krater & Åström 1972b, 369: no. 281e2 (not illustrated) \\
\hline 191 & LH IIIB & ring-based krater & Walters 1912, 83: no. C406 (not illustrated) \\
\hline 192 & LH IIIB & piriform jar & Åström 1972b, 305: unpublished (not illustrated) \\
\hline 193 & LH IIIB & squat stirrup jar & Smith 1925, IICb, Plate 3: no. 22 \\
\hline 194 & LH IIIA2-LH IIIB & conical rhyton & Åström 1972b, 354 no. 199e; 412 fig. 46d \\
\hline 195 & LH IIIA2 & piriform jar & Smith 1925, IICb, Plate 1: no. 27 \\
\hline 196 & LH IIIA2-LH IIIB & globular flask, horizontal type & Walters 1912, 111: no. C573 (not illustrated) \\
\hline 197 & LH IIIB & ring-based krater & Karageorghis 1963, IIC, Plate 11: nos. 4-6 \\
\hline 198 & LH IIIA2-LH IIIB & amphoroid krater & Myres \& Ohnefalsch-Richter 1899, 183: under no. 20 (not illustrated) \\
\hline 199 & LH IIIB & small globular stirrup jar & Karageorghis 1963, IIC, Plate 21: no. 4 \\
\hline 200 & LH IIIA2-LH IIIB & amphoroid krater & Myres \& Ohnefalsch-Richter 1899, 183: under no. 20 (not illustrated) \\
\hline
\end{tabular}




\begin{tabular}{|c|c|c|c|}
\hline ID & date & shape & published \\
\hline 201 & LH IIIA2-LH IIIB & amphoroid krater & Āström 1972b, 318 (not illustrated) \\
\hline 202 & LH IIIA2 & globular flask, vertical type & Åström 1972b, 351: no. 189o (not illustrated) \\
\hline 203 & LH IIIA2-LH IIIB & piriform jar & Smith 1925, IICb, Plate 1: no. 14 \\
\hline 204 & LH IIIA2 & conical rhyton & Walters 1912, 117: no. C605 (not illustrated) \\
\hline 205 & LH IIA & handleless cup & Smith 1925, IICb, Plate 4: no. 29 \\
\hline 206 & LH IIIA2 & large piriform jar & Karageorghis 1963, IIC, Plate 19 no. 2 (A1552) \\
\hline 207 & LH IIIA2-LH IIIB & straight-sided alabastron & $\begin{array}{l}\text { Myres \& Ohnefalsch-Richter 1899, 184: under no. } 184 \text { (not illustrat- } \\
\text { ed) }\end{array}$ \\
\hline 208 & LH IIIA2-LH IIIB & straight-sided alabastron & Åström 1972b, 322: no. 94m (not illustrated) \\
\hline 209 & LH IIIA2-LH IIIB & piriform jar & Åström 1972b, 298: no. 45b2 (not illustrated) \\
\hline 210 & LH IIIB & piriform jar & Karageorghis 1963, IIC, Plate 19: no. 8 (A1705) \\
\hline 211 & LH IIIB & piriform jar & Karageorghis 1963, IIC, Plate 19: no. 9 (A1704) \\
\hline 212 & LH IIIA2-LH IIIB & globular stirrup jar & Karageorghis 1963, IIC, Plate 21: no. 2 (A1595) \\
\hline 213 & LH IIIB & ring-based krater & Karageorghis 1963, IIC, Plate 4: no. 4 (A2026b) \\
\hline 214 & LH IIIA2-LH IIIB & straight-sided alabastron & Karageorghis $1963, \| C$, Plate \\
\hline 215 & LH IIIA2 & amphoroid krater & Karageorghis 1963, IIC, Plate 16: no. 3 (A1649) \\
\hline 216 & LH IIIA2-LH IIIB & amphoroid krater & Åström 1972b, 318: no. A2062c \\
\hline 217 & LH IIIB & large piriform jar & Stubbings 1951, Plate 13: no. 8 \\
\hline 218 & LH IIIA2 & amphoroid krater & Walters 1912, 63: no. C333 (not illustrated) \\
\hline 219 & LH IIIA1 & small handleless jar & Gjerstad 1926, 212: jar 1 \\
\hline 220 & LH IIIA1 & piriform jar & Walters 1912, 96: no. C476 (not illustrated) \\
\hline 221 & LH IIIA2-LH IIIB & amphoroid krater & Åström 1972b, 316: 53-55h (2019) (not illustrated) \\
\hline 222 & LH IIIA2-LH IIIB & small globular jug & Karageorghis 1963, IIC, Plate 29: no. 2 (A1564) \\
\hline 223 & LH IIIB & handleless cup & Walters 1912, 128: no. C674 (not illustrated) \\
\hline 224 & LH IIIA2 & jug & Karageorghis 1963, IIC, Plate 3: no. 5 (A2024k) \\
\hline 225 & LH IIIB & ring-based krater & Karageorghis 1963, IIC, Plate 10: no. 5 (A2033A) \\
\hline 226 & LH IIIA2 & deep krater & Karageorghis 1963, IIC, Plate 16: no. 6 (2023e) \\
\hline 227 & LH IIIB & ring-based krater & Karageorghis 1963, IIC, Plate 14: no. 6 (A2023e) \\
\hline 228 & LH IIIA2 & three-handled beaked jug & Karageorghis 1963, IIC, Plate 28: no. 1-2 (A1579) \\
\hline 229 & LH IIIA2-LH IIIB & globular flask, horizontal type & Åström 1972b, 353: no. A1579 (not illustrated) \\
\hline 230 & LH IIIA1 & large piriform jar & Karageorghis 1963, IIC, Plate 17: no. 3 (A1686) \\
\hline 231 & LH IIIA2 & piriform jar & Åström 1972b, 305: no. 1694 (not illustrated) \\
\hline 232 & LH IIIA2-LH IIIB & piriform jar & Åström 1972b, 305: no. A1666 (not illustrated \\
\hline 233 & LH IIIA2-LH IIIB & small globular jug & Smith 1925, IICb, Plate 12: no. 11 \\
\hline 234 & LH IIIA2-LH IIIB & piriform jar & Smith 1925, IICb, Plate 1: no. 9 \\
\hline 235 & LH IIIA2 & conical piriform stirrup jar & Smith $1925, \| \mathrm{Cb}$, plate 2: no. 14 \\
\hline 236 & LH IIIA2-LH IIIB & piriform jar & Smith 1925, IICb, Plate 1: no. 40 \\
\hline 237 & LH IIIA2-LH IIIB & piriform jar & Smith 1925, IICb, Plate 1: no. 20 \\
\hline 238 & LH IIIB & large piriform jar & Karageorghis 1963, IIC, Plate 19: no. 4 (A1650b) \\
\hline 239 & LH IIIB & large piriform jar & Karageorghis 1963, IIC, plate 17: no. 5 (1941/NII-5/2) \\
\hline 240 & LH IIIA2-LH IIIB & straight-sided alabastron & Åström 1972b, 322: no. 94q (not illustrated) \\
\hline 241 & LH IIIA2-LH IIIB & straight-sided alabastron & Åström 1972b, 322: no. 94p (not illustrated) \\
\hline 242 & LH IIIB & amphoroid krater & Karageorghis 1963, IIC, Plate 8: nos. 1-4 (A1614) \\
\hline 243 & LH IIIA2-LH IIIB & piriform jar & Åström 1972b, 298: no. 45c2 (not illustrated) \\
\hline 244 & LH IIIA2-LH IIIB & piriform jar & Åström 1972b, 298: no. 45d2 (not illustrated) \\
\hline 245 & LH IIIA2 & lentoid flask & Karageorghis 1963, IIC, Plate 31: nos. 1, 3 (A1732) \\
\hline 246 & LH IIIB & large piriform jar & Karageorghis 1963, IIC, Plate 19: no. 6 (A1650) \\
\hline 247 & LH IIIB & shallow bowl & Karageorghis 1963, IIC, Plate 32: nos. 1-2 (A1537) \\
\hline 248 & LH IIIA2 & globular flask, vertical type & Karageorghis 1963, IIC, Plate 30: nos. 1-2 (A1572) \\
\hline 249 & LH IIIA2 & conical piriform stirrup jar & Walters 1912, 132 fig. 260: no. C697 \\
\hline 250 & LH IIIB & piriform jar & Åström 1972b, 305: no. A1680 (not illustrated) \\
\hline
\end{tabular}




\begin{tabular}{|c|c|c|c|}
\hline ID & date & shape & published \\
\hline 251 & LH IIIA2-LH IIIB & piriform jar & Karageorghis 1963, IIC, Plate 19: no. 3 (A1699) \\
\hline 252 & LH IIIA2-LH IIIB & shallow cup & Karageorghis 1963, IIC, Plate 26: no. 5 (A1513) \\
\hline 253 & LH IIIA2-LH IIIB & shallow cup & Karageorghis 1963, IIC, Plate 27: no. 7 (A1526) \\
\hline 254 & LH IIIA2-LH IIIB & shallow cup & Åström 1972b, 359: no. 220v2 (not illustrated) \\
\hline 255 & LH IIIA2 & deep krater & Karageorghis 1963, IIC, Plate 16: nos. 1-2 (A1548) \\
\hline 256 & LH IIIA2-LH IIIB & straight-sided alabastron & Karageorghis 1963, IIC, Plate 24: no. 7 (A1713) \\
\hline 257 & LH IIIA2-LH IIIB & straight-sided alabastron & Karageorghis 1963, IIC, Plate 24: no. 8 (A1716) \\
\hline 258 & LH IIIA2-LH IIIB & piriform jar & Åström 1972b, 305: no. A1670 (not illustrated) \\
\hline 259 & LH IIIA2-LH IIIB & piriform jar & Smith 1925, IICb, Plate 3: no. 41 \\
\hline 260 & LH IIIA2 & deep krater & Karageorghis 1963, IIC, Plate 9: no. 3 (A2031) \\
\hline 261 & LH IIIA2-LH IIIB & amphoroid krater & Åström 1972b, 316: no. 53-55i (not illustrated) \\
\hline 262 & LH IIIB & ring-based krater & Karageorghis 1963, IIC, Plate no. 10: nos. 1-3 (A1546) \\
\hline 263 & LH IIIA2-LH IIIB & small globular jug & Smith 1925, IICb, Plate 12: no. 28 \\
\hline 264 & LH IIIA2 & globular flask, vertical type & Smith 1925, IICb, Plate 12: no. 33 \\
\hline 265 & LH IIIA2-LH IIIB & squat stirrup jar & Stubbings 1951, 42, Plate 13: no. 17 \\
\hline 266 & LH IIIA2-LH IIIB & shallow cup & Smith 1925, IICb, Plate 5: no. 6 \\
\hline 267 & LH IIIB & handleless cup & Walters 1912, 120: C622 (not illustrated) \\
\hline 268 & LH IIIB & piriform jar & Walters 1912, 99: no. C500 (not illustrated) \\
\hline 269 & LH IIIA2-LH IIIB & small globular jug & Walters 1912, 114: no. C590 (not illustrated) \\
\hline 270 & LH IIIA2-LH IIIB & globular stirrup jar & Smith 1925, ॥Cb, Plate 3: no. 33 \\
\hline 271 & LH IIIA2 & piriform jar & Smith 1925, IICb, Plate 1: no. 21 \\
\hline 272 & LH IIIA2 & shallow cup & Karageorghis 1963, IIC, plate 26: no. 4 (A1517) \\
\hline 273 & LH IIB & rounded alabastron & Walters 1912, 99: no. C497 (not illustrated) \\
\hline 274 & LH IIIA2-LH IIIB & globular stirrup jar & Smith 1925, IICb, Plate 2: no. 7 \\
\hline 275 & LH IIIA2-LH IIB & globular stirrup jar & Smith 1925, IICb, Plate 2: no. 3 \\
\hline 276 & LH IIIA2 & amphoroid krater & Smith 1925, IICb, Plate 11: no. 12 \\
\hline 277 & LH IIIA2-LH IIIB & globular stirrup jar & Smith 1925, IICb, Plate 3: no. 25 \\
\hline 278 & LH IIIB & conical stirrup jar & Karageorghis 1963, IIC, Plate 22: no. 1 (A1623) \\
\hline 279 & LH IIIB & squat stirrup jar & Karageorghis 1963, IIC, Plate 22: no. 11 (A1632) \\
\hline 280 & LH IIIA2-LH IIIB & globular stirrup jar & Karageorghis 1963, IIC, Plate 21: no. 1 (A1583) \\
\hline 281 & LH IIIA2 & amphoroid krater & Karageorghis 1963, IIC, Plate 4: nos. 1-3 (A2022a-e) \\
\hline 282 & LH IIIA2 & amphoroid krater & Karageorghis 1963, IIC, Plate 6: no. 1 (A2027a) \\
\hline 283 & LH IIIA2-LH IIIB & flask & Åström 1972b, 353: no. A1576 (not illustrated) \\
\hline 284 & LH IIIA2-LH IIIB & piriform jar & Åström 1972b, 298: no. $45 f 2$ (not illustrated) \\
\hline 285 & LH IIIA2-LH IIIB & shallow cup & Karageorghis 1963, IIC, Plate 27: no. 8 (A1523) \\
\hline 286 & LH IIIA2-LH IIIB & shallow cup & Åström 1972b, 359: no. 220n3 (not illustrated) \\
\hline 287 & LH IIIA2-LH IIIB & small globular jug & Karageorghis 1963, IIC, Plate 29: no. 6 (A1568) \\
\hline 288 & LH IIIA2-LH IIIB & straight-sided alabastron & Åström 1972b, 322: no. 94w (not illustrated) \\
\hline 289 & LH IIIA2-LH IIIB & straight-sided alabastron & Åström 1972b, 324: no. 95h ter (not illustrated) \\
\hline 290 & LH IIIA2-LH IIIB & amphoroid krater & Åström 1972b, 316: no. 53-55f (not illustrated) \\
\hline 291 & LH IIIA2-LH IIIB & amphoroid krater & Åström 1972b, 316: no. 53-55g (not illustrated) \\
\hline 292 & LH IIIA2-LH IIIB & piriform jar & Mayence 1926, IIIA, Plate 2: no. 19 \\
\hline 293 & LH IIIA1 & large piriform jar & Stubbings 1951, 27, Plate 6: no. 2 \\
\hline 294 & LH IIIA2 & amphoroid krater & Mayence \& Verhoogen 1929, IIC, Plate 3: no. 10 \\
\hline 295 & LH IIIA2 & amphoroid krater & Mayence \& Verhoogen 1929, IIC, Plate 3: no. 16 \\
\hline 296 & LH IIIA2 & amphoroid krater & Mayence \& Verhoogen 1929, IIC, Plate 3: no. 14 \\
\hline 297 & LH IIIA2 & amphoroid krater & Mayence \& Verhoogen 1929, IIC, Plate 3: no. 17 \\
\hline 298 & LH IIIA2 & amphoroid krater & Mayence \& Verhoogen 1929, IIC, Plate 3: no. 18 \\
\hline 299 & LH IIIA2 & amphoroid krater & Mayence \& Verhoogen 1929, IIC, Plate 3: no. 19 \\
\hline 300 & LH IIIA2 & amphoroid krater & Mayence \& Verhoogen 1929, IIC, Plate 3: no. 20 \\
\hline 301 & LH IIIA2 & amphoroid krater & Ure \& Ure 1954, IIIA, Plate 1: no. 18 \\
\hline
\end{tabular}




\begin{tabular}{|c|c|c|c|}
\hline ID & date & shape & published \\
\hline 302 & LH IIIA2 & amphoroid krater & Ure \& Ure 1954, IIIA, Plate 1: no. 20 \\
\hline 303 & LH III & stirrup jar & Åström 1972b, 348: no. A1620 (not illustrated) \\
\hline 304 & LH III & stirrup jar & Åström 1972b, 348: no. A1628 (not illustrated) \\
\hline 305 & LH III & stirrup jar & Åström 1972b, 348: no. A1927 (not illustrated) \\
\hline 306 & LH IIIA2-LH IIIB & globular stirrup jar & Smith 1925, IICb, Plate 3: no. 21 \\
\hline 307 & LH III & stirrup jar & Åström 1972b, 348: no. A 1617 (not illustrated) \\
\hline 308 & LH III & stirrup jar & Myres \& Ohnefalsch-Richter 1899, 184: under no. 25 (not illustrated) \\
\hline 309 & LH III & stirrup jar & Åström 1972b, 348: no. A1600 (not illustrated) \\
\hline 310 & LH III & stirrup jar & Åström 1972b, 348: no. A1604 (not illustrated) \\
\hline 311 & LH III & stirrup jar & Åström 1972b, 348: no. A1607 (not illustrated) \\
\hline 312 & LH III & stirrup jar & Åström 1972b, 348: no. A1614 (not illustrated) \\
\hline 313 & LH III & stirrup jar & Åström 1972b, 348: no. A1619 (not illustrated) \\
\hline 314 & LH III & stirrup jar & Åström 1972b, 348: no. A1621 (not illustrated) \\
\hline 315 & LH III & stirrup jar & Åström 1972b, 348: no. A1637 (not illustrated) \\
\hline 316 & LH III & stirrup jar & Åström 1972b, 348: no. A1634 (not illustrated) \\
\hline 317 & LH III & stirrup jar & Myres \& Ohnefalsch-Richter 1899, 185: under no. 55 (not illustrated) \\
\hline 318 & LH III & stirrup jar & Åström 1972b, 348: no. A1592 (not illustrated) \\
\hline 319 & LH III & stirrup jar & Åström 1972b, 348: no. A1593 (not illustrated) \\
\hline 320 & LH III & stirrup jar & Åström 1972b, 348: no. A1596 (not illustrated) \\
\hline 321 & LH III & stirrup jar & Åström 1972b, 348: no. A1633 (not illustrated) \\
\hline 322 & LH III & stirrup jar & Åström 1972b, 348: no. A1636 (not illustrated) \\
\hline 323 & LH III & stirrup jar & Myres \& Ohnefalsch-Richter 1899: under no 68 (not illustrated \\
\hline 324 & LH III & stirrup jar & Myres \& Ohnefalsch-Richter 1899: under no 68 (not illustrated \\
\hline 325 & LH III & stirrup jar & Myres \& Ohnefalsch-Richter 1899: under no 68 (not illustrated \\
\hline 326 & LH III & stirrup jar & Åström 1972b, 348: no. A1615 (not illustrated) \\
\hline 327 & LH III & stirrup jar & Åström 1972b, s48: no. A1599 (not illustrated) \\
\hline 328 & LH III & stirrup jar & Åström 1972b, 348: no. A1610 (not illustrated) \\
\hline 329 & LH III & stirrup jar & Åström 1972b, 348: T80 \\
\hline 330 & LH IIIA2-LH IIIB & piriform jar & Gjerstad et al. 1934-1937, 473: no. 10, Plate 76: row 3 : \\
\hline 331 & LH IIIA2-LH IIIB & piriform jar & Gjerstad et al. 1934-1937, 473: no. 19, Plate 76: row 3:2 \\
\hline 332 & LH IIIA2 & piriform jar & Gjerstad et al. 1934-1937, 474: no. 45, Plate 76: row 2:1 \\
\hline 333 & LH IIIB & narrow-necked jug & Gjerstad et al. 1934-1937, 477: no. 1, Plate 78: row 5:1 \\
\hline 334 & LH IIIA2-LH IIIB & straight-sided alabastron & Gjerstad et al. 1934-1937, 477: no. 8, Plate 77: row 6:11 \\
\hline 335 & LH IIIB & shallow cup & Gjerstad et al. 1934-1937, 477: no. 9, Plate 77: row 11:1 \\
\hline 336 & LH IIIA2-LH IIIB & straight-sided alabastron & Gjerstad et al. 1934-1937, 477: no. 11, Plate 77: row 6:4 \\
\hline 337 & LH IIIB & shallow bowl & Gjerstad et al. 1934-1937, 477: no. 15, Plate 77: row 11:10 \\
\hline 338 & LH IIIB & piriform jar & Gjerstad et al. 1934-1937, 478: no. 17, Plate 77: row 5:4 \\
\hline 339 & $\mathrm{LH} I I I A 2$ & amphoroid beaked jug & Gjerstad et al. 1934-1937, 478: no. 22, Plate 119: no. 5 \\
\hline 340 & $\mathrm{LH} I I I A 2$ & amphoroid krater & Gjerstad et al. 1934-1937, 478: no. 31, Plate 77: row 8:9 \\
\hline 341 & $\mathrm{LH} \| I \mathrm{~A} 2$ & small globular jug & Gjerstad et al. 1934-1937, 478: no. 33, Plate 77: row 6:10 \\
\hline 342 & LH IIIA2-LH IIIB & globular flask, horizontal type & Gjerstad et al. 1934-1937, 478: no. 35, Plate 77: row 6:8 \\
\hline 343 & LH IIIA2 & conical piriform stirrup jar & Gjerstad et al. 1934-1937, 478: no. 38, Plate 77: row 5:5 \\
\hline 344 & LH IIIA2-LH IIIB & one-handled cup & Gjerstad et al. 1934-1937, 478: no. 39, Plate 77: row 6:14? \\
\hline 345 & LH IIIB & mug & Gjerstad et al. 1934-1937, 478: no. 41, Plate 77: row 12:16 \\
\hline 346 & LH IIIA2-LH IIIB & piriform jar & Gjerstad et al. 1934-1937, 478: no. 43, Plate 77: row 5:11 \\
\hline 347 & LH IIIA2-LH IIIB & shallow cup & Gjerstad et al. 1934-1937, 478: no. 45, Plate 77 \\
\hline 348 & LH IIIA2-LH IIIB & shallow cup & Gjerstad et al. 1934-1937, 479: no. 65, Plate 77: row 11:4 \\
\hline 349 & LH IIIA2 & piriform jar & Gjerstad et al. 1934-1937, 479: no. 66, Plate 77: row 5:8 \\
\hline 350 & LH IIIA2-LH IIIB & piriform jar & Gjerstad et al. 1934-1937, 479: no. 67, Plate 77: row 5:3 \\
\hline 351 & LH IIIA2-LH IIIB & globular stirrup jar & Gjerstad et al. 1934-1937, 479: no. 78, Plate 77: row 6:5 \\
\hline 352 & LH IIIA2-LH IIIB & piriform jar & Gjerstad et al. 1934-1937, 479: no. 79, PLate 77: row 6:9 \\
\hline
\end{tabular}




\begin{tabular}{|c|c|c|c|}
\hline ID & date & shape & published \\
\hline 353 & LH IIIA2-LH IIIB & globular stirrup jar & Gjerstad et al. 1934-1937, 480: no. 119, Plate 77: row 6:6 \\
\hline 354 & LH IIIA2-LH IIIB & small globular jug & Gjerstad et al. 1934-1937, 480: no. 122, Plate 77: row 3:8 \\
\hline 355 & LH IIIA2 & amphoroid krater & Gjerstad et al. 1934-1937, 481: no. 163, Plate 77: row 7:3 \\
\hline 356 & LH IIIA1-LH IIIA2 & straight-sided alabastron & Gjerstad et al. 1934-1937, 481: no. 165, Plate 77: row 5:6 \\
\hline 357 & LH IIIB & squat stirrup jar & Gjerstad et al. 1934-1937, 481: 170, Plate 77: row 6:12 \\
\hline 358 & LH IIIB & one-handled conical bowl & Gjerstad et al. 1934-1937, 481: no. 177, Plate 77: row 11:13 \\
\hline 359 & LH IIIA2-LH IIIB & piriform jar & Gjerstad et al. 1934-1937, 481: no. 183, Plate 77, row6:7 \\
\hline 360 & LH IIIA2-LH IIIB & shallow cup & Gjerstad et al. 1934-1937, 482: no. 197, Plate 77: row 11:11 \\
\hline 361 & LH IIIA2-LH IIIB & shallow cup & Gjerstad et al. 1934-1937, 482: no. 208, Plate 77: row 11:3 \\
\hline 362 & LH IIIA2-LH IIIB & piriform jar & Gjerstad et al. 1934-1937, 482: no. 210, Plate 77: row 5:10 \\
\hline 363 & LH IIIA2-LH IIIB & shallow cup & Gjerstad et al. 1934-1937, 482: no. 216, Plate 77: row 11 \\
\hline 364 & LH IIIA2 & amphoroid krater & Gjerstad et al. 1934-1937, 483: no. 257, Plate 77: row 7:5 \\
\hline 365 & LH IIIB & amphoroid krater & Gjerstad et al. 1934-1937, 483: no. 258, Plate 77: row 7:4 \\
\hline 366 & LH IIIA2 & amphoroid krater & Gjerstad et al. 1934-1937, 483: no. 259, Plate 77: row 1:4 \\
\hline 367 & LH IIIA2 & amphoroid krater & Gjerstad et al. 1934-1937, 483: no. 260, Plate 77: row 7:1 \\
\hline 368 & LH IIIA2 & amphoroid krater & Gjerstad et al. 1934-1937, 483: no. 261, Plate 77: row 7:6 \\
\hline 369 & LH IIIB & amphoroid krater & Gjerstad et al. 1934-1937, 484: no. 262, Plate 77: row $1: 5$ \\
\hline 370 & LM IIIA2 & amphoroid krater & Gjerstad et al. 1934-1937, 484: no. 263, Plate 77: row 1:6 \\
\hline 371 & LH IIIA2 & amphoroid krater & Gjerstad et al. 1934-1937, 484: no. 264, Plate 77: row 7:7 \\
\hline 372 & LH IIIA2-LH IIIB & one-handled cup & Gjerstad et al. 1934-1937, 484: no. 265, Plate 77: row 7:13 \\
\hline 373 & LH IIIA2-LH IIIB & piriform jar & Gjerstad et al. 1934-1937, 484: no. 266, Plate 77: row 5:9 \\
\hline 374 & LH IIIA2 & large piriform jar & Gjerstad et al. 1934-1937, 484: no. 267 (not illustrated) \\
\hline 375 & LH IIIA2-LH IIIB & amphoroid krater & Gjerstad et al. 1934-1937, 484: no. 272, Plate 77: row 7:2 \\
\hline 376 & LH IIIA2 & amphoroid krater & Karageorghis 1960b, 140, Plate III: no. 3.276 \\
\hline 377 & LH IIIA2-LH IIIB & amphoroid krater & Karageorghis 1960b, 136, Plate I : no. 3277 \\
\hline 378 & LH IIIA2 & amphoroid krater & Karageorghis 1960b, 141, Plate IV: no. 3/278 \\
\hline 379 & LH IIIA2 & amphoroid krater & Karageorghis 1960b, 143, Plate IV: nos. 1-2 \\
\hline 380 & LH IIIA2 & amphoroid krater & Karageorghis 1960b, Plate VI: nos. 3-5 \\
\hline 381 & LH IIIA2 & amphoroid krater & Karageorghis 1960b, 145, Plate VII: nos I-II \\
\hline 382 & LH IIIA2 & amphoroid krater & Karageorghis 1960b, 145-146, Plate IX: no. 3/NI \\
\hline 383 & LH IIIA2 & deep krater & Karageorghis 1960b, 144-145, Plate VIII: no. 1-2 \\
\hline 384 & LH IIIB & deep krater & Åström 1972b, 292: under type 9 \\
\hline 385 & LH IIIB & ring-based krater & Karageorghis 1960b, 147, Plate X: nos. 9-10 \\
\hline 386 & LH IIIB & ring-based krater & Karageorghis 1960b, 146, Plate X: no. 8 \\
\hline 387 & LH IIIA2-LH IIIB & shallow cup & Gjerstad et al. 1934-1937, 493: no. 1, Plate 79.2: row 5:12 \\
\hline 388 & LH IIIB & stirrup jar & Gjerstad et al. 1934-1937, 493: no. 2, Plate 79.2: row 6:2 \\
\hline 389 & LH IIIA2-LH IIIB & shallow cup & Gjerstad et al. 1934-1937, 493: no. 4, Plate 79.2: row 5:14 \\
\hline 390 & LH IIIB & $\begin{array}{l}\text { shallow stemmed bowl without } \\
\text { handles }\end{array}$ & Gjerstad et al. 1934-1937, 494: no. 12, Plate 79.2: row 7:3 \\
\hline 391 & LH IIIB & shallow bowl & Gjerstad et al. 1934-1937, 494: no. 13, Plate 79.2: row 5:7 \\
\hline 392 & LH IIIB & squat stirrup jar & Gjerstad et al. 1934-1937, 494: no. 34, Plate 79.2: row 6:12 \\
\hline 393 & LH IIIB & globular stirrup jar & Gjerstad et al. 1934-1937, 494: no. 35, Plate 79.2: row 6:11 \\
\hline 394 & LH IIIB-LH IIICe & perked-up jug & Gjerstad et al. 1934-1937, 494: no. 47 \\
\hline 395 & LH IIIB & shallow spouted cup & Gjerstad et al. 1934-1937, 494: no. 48, Plate 79.2: row 4:5 \\
\hline 396 & LH IIIB & conical cup & Gjerstad et al. 1934-1937, 494: no. 49, Plate 79.2: row 5:5 \\
\hline 397 & LH IIIB-LH IIICe & deep bowl & Gjerstad et al. 1934-1937, 495: no. 52, Plate 79.2: row 6:6 \\
\hline 398 & LH IIIB-LH IIICe & perked-up jug & Gjerstad et al. 1934-1937, 495: no. 55, Plate 79.2: row 6:4 \\
\hline 399 & LH IIIB & conical piriform stirrup jar & Gjerstad et al. 1934-1937, 495: no. 64, Plate 79.2: row 6:9 \\
\hline 400 & LH IIIB & squat stirrup jar & Gjerstad et al. 1934-1937, 495: no. 65, Plate 79.2: row 6:3 \\
\hline 401 & LH IIIB & shallow bowl & Gjerstad et al. 1934-1937, 495: no. 73, Plate 79.2: row 4:6 \\
\hline 402 & LH IIIB & globular stirrup jar & Gjerstad et al. 1934-1937, 495: no. 80, Plate 79.2: row 6:10 \\
\hline
\end{tabular}




\begin{tabular}{|c|c|c|c|}
\hline ID & date & shape & published \\
\hline 403 & LH IIIA2-LH IIIB & shallow cup & Gjerstad et al. 1934-1937, 495: no. 85, Plate 79.2: row 5:12 \\
\hline 404 & LH IIIB & shallow bowl & Gjerstad et al. 1934-1937, 495: no. 92, Plate 79.2: row 5:15 \\
\hline 405 & LH IIIB & conical cup & Gjerstad et al. 1934-1937, 496: no. 2, Plate 79.2: row 3:8 \\
\hline 406 & LH IIIB & shallow bowl & Gjerstad et al. 1934-1937, 499: no. 4, Plate 81.1: row 4:7 \\
\hline 407 & $\mathrm{LH} \| \mathrm{BB}$ & ring-based krater & Åström 1972b, 371: no. 281k3 (not illustrated) \\
\hline 408 & LH III & fragment & Åström 1972b, 383: E.7 suppl. (not illustrated) \\
\hline 409 & LH IIIA2 & amphoroid krater & Karageorghis 1960b, 148-149, Plate XI: nos. 3-4 \\
\hline 410 & LH IIIA2 & amphoroid krater & Karageorghis 1960b, 151, Plate XIII \\
\hline 411 & LH IIIA2 & deep krater & Karageorghis 1960b, 149-150, Plate XII \\
\hline 412 & LH IIIA2 & amphoroid krater & Karageorghis 1960b, 152, Plate XIII \\
\hline 413 & LH III & stirrup jar & Åström 1972b, 348: E.Sw.T7 \\
\hline 414 & LH III & ring-based krater & Karageorghis 1960b, 150, Plate XIII:IV \\
\hline 415 & LH IIIB & shallow bowl & Gjerstad et al. 1934-1937, 508: no. 20, Plate 81.1: row 4:7 \\
\hline 416 & LH IIIA2-LH IIIB & piriform jar & Gjerstad et al. 1934-1937, 508: no. 25, Plate 81.1: row 4:5 \\
\hline 417 & LH IIIB & shallow bowl & Gjerstad et al. 1934-1937, 508: no. 30, Plate 81.1: row 4:2 \\
\hline 418 & LH IIIA2 & conical piriform stirrup jar & Gjerstad et al. 1934-1937, 508: no. 32, Plate 81.1: row 4:3 \\
\hline 419 & LH IIIA2-LH IIIB & shallow cup & Gjerstad et al. 1934-1937, 508: no. 33, Plate 81.1: row 4:1 \\
\hline 420 & LH IIIA2-LH IIIB & piriform jar & Gjerstad et al. 1934-1937, 508: no. 35, Plaste 81.1: row 4:4 \\
\hline 421 & LH IIIA2-LH IIIB & piriform jar & Gjerstad et al. 1934-1937, 508: no. 44, Plate 81.1: row 4:6 \\
\hline 422 & LH IIIB & handleless cup & Gjerstad et al. 1934-1937, 509: no. 51, Plate 81.1: row 4:8 \\
\hline 423 & LH IIIA2-LH IIIB & piriform jar & Gjerstad et al. 1934-1937, 509: no. 2, Plate 81.3 \\
\hline 424 & LH IIIB & squat stirrup jar & Gjerstad et al. 1934-1937, 515: no. 1, Plate 83: row 8:15 \\
\hline 425 & LH IIIB & piriform jar & Gjerstad et al. 1934-1937, 515: no. 4 (not illustrated) \\
\hline 426 & LH IIIB & large piriform jar & Gjerstad et al. 1934-1937, 515: no. 5, Plate 83: row 5:4 \\
\hline 427 & LH IIIA2-LH IIIB & shallow cup & Gjerstad et al. 1934-1937, 516: no. 9, Plate 83: row 7:15 \\
\hline 428 & LH IIIB & globular stirrup jar & Gjerstad et al. 1934-1937, 516: no. 9, Plate 83: row 7:8 \\
\hline 429 & LH IIIA2-LH IIIB & straight-sided alabastron & Gjerstad et al. 1934-1937, 516: no. 13, Plate 83: row 8:9 \\
\hline 430 & LH IIIB & conical piriform stirrup jar & Gjerstad et al. 1934-1937, 516: no. 14, Plate 83: row 7:12 \\
\hline 431 & LH IIIB & squat stirrup jar & Gjerstad et al. 1934-1937, 516: no. 15, Plate 83: row 7 no. 13 \\
\hline 432 & LH IIIA2-LH IIIB & shallow cup & Gjerstad et al. 1934-1937, 516: no. 16, Plate 83: row 7:4 \\
\hline 433 & LH IIIB & squat stirrup jar & Gjerstad et al. 1934-1937, 516: no. 18, Plate 83: row 7:6 \\
\hline 434 & LH IIIB & large piriform jar & Gjerstad et al. 1934-1937, 516: no. 24, Plate 83: row 5:6 \\
\hline 435 & LH IIIB & conical stirrup jar & Gjerstad et al. 1934-1937, 516: no. 25, Plate 83: row 7:7 \\
\hline 436 & LH IIIA2-LH IIIB & piriform jar & Gjerstad et al. 1934-1937, 516: no. 26, Plate 83: row 7:11 \\
\hline 437 & LH IIIB & squat stirrup jar & Gjerstad et al. 1934-1937, 516: no. 27, Plate 83: row 7:14 \\
\hline 438 & LH IIIA2-LH IIIB & shallow cup & Gjerstad et al. 1934-1937, 516: no. 30, Plate 83: row 7:4 \\
\hline 439 & LH IIIB & amphoroid krater & Gjerstad et al. 1934-1937, 516: no. 33, Plate 83: row 5:5 \\
\hline 440 & LH IIIA2-LH IIB & globular stirrup jar & Gjerstad et al. 1934-1937, 517: no. 50, Plaet 83: row 3:15 \\
\hline 441 & LH IIIA2-LH IIIB & globular stirrup jar & Gjerstad et al. 1934-1937, 517: no. 55, Plate 83: row 3:14 \\
\hline 442 & LH IIIA2-LH IIIB & globular stirrup jar & Gjerstad et al. 1934-1937, 517: no. 56, Plate 83: row 3:13 \\
\hline 443 & LH IIIA2 & amphoroid krater & Gjerstad et al. 1934-1937, 517: no. 58, Plate 83: row 2:9 \\
\hline 444 & LM IIIB & squat stirrup jar & Gjerstad et al. 1934-1937, 517: no. 60, Plate 83: row 3:8 \\
\hline 445 & LH IIIA2-LH IIIB & piriform jar & Gjerstad et al. 1934-1937, 518: no. 76, Plate 83: row 3:12 \\
\hline 446 & LH IIIA2-LH IIIB & piriform jar & Gjerstad et al. 1934-1937, 518: no. 84, Plate 83: row 3:11 \\
\hline 447 & LH IIIA2-LH IIIB & shallow cup & Gjerstad et al. 1934-1937, 518: no. 85 \\
\hline 448 & LH IIIA2-LH IIIB & shallow cup & Gjerstad et al. 1934-1937, 518: no. 86, Plate 83: row 3:19 \\
\hline 449 & LH IIIA2-LH IIIB & shallow cup & Gjerstad et al. 1934-1937, 518: no. 89, Plate 83: row 3:18 \\
\hline 450 & LH IIIA2-LH IIIB & shallow cup & Gjerstad et al. 1934-1937, 518: no. 93, Plate 83: row 7:17 \\
\hline 451 & LH IIIA2-LH IIIB & straight-sided alabastron & Gjerstad et al. 1934-1937, 518: no. 101, Plate 83: row 7:2 \\
\hline 452 & LH IIIA2-LH IIIB & small globular jug & Gjerstad et al. 1934-1937, 518: no. 106, Plate 83: row 7:1 \\
\hline 453 & LH IIIB & squat stirrup jar & Gjerstad et al. 1934-1937, 518: no. 108 , Plate 83: row 7:5 \\
\hline
\end{tabular}




\begin{tabular}{|c|c|c|c|}
\hline ID & date & shape & published \\
\hline 454 & LH IIIA2-LH IIIB & shallow cup & Gjerstad et al. 1934-1937, 518: no. 110, Plate 83: row 7:16 \\
\hline 455 & LH IIIA2-LH IIIB & piriform jar & Gjerstad et al. 1934-1937, 519: no. 112, Plate 83: row 7:9 \\
\hline 456 & LH IIIA2-LH IIIB & shallow cup & Gjerstad et al. 1934-1937, 519: no. 113, Plate 83: row 7:3 \\
\hline 457 & LH IIIA2 & globular flask, vertical type & Gjerstad et al. 1934-1937, 519: no. 123, Plate 83: row 7:19 \\
\hline 458 & LH IIIA2-LH IIIB & shallow cup & Gjerstad et al. 1934-1937, 519: no. 124, Plate 83: row 3:17 \\
\hline 459 & LH IIIA2-LH IIIB & straight-sided alabastron & Gjerstad et al. 1934-1937, 519: no. 125, Plate 83: row 3:7 \\
\hline 460 & LH IIIB & squat stirrup jar & Gjerstad et al. 1934-1937, 519: no. 126, Plate 83: row 3:9 \\
\hline 461 & LH IIIA2-LH IIIB & globular stirrup jar & Gjerstad et al. 1934-1937, 519: no. 127, Plate 83: row 3:10 \\
\hline 462 & LH IIIA2-LH IIIB & small globular jug & Gjerstad et al. 1934-1937, 519: no. 130, Plate 83: row 3:5 \\
\hline 463 & LH IIIB & stirrup jar & Gjerstad et al. 1934-1937, 519: no. 142, Plate 82: row 6:5 \\
\hline 464 & LH IIIA2-LH IIIB & globular stirrup jar & Gjerstad et al. 1934-1937, 519: no. 145, Plate 82: row 6:12 \\
\hline 465 & LH IIIB & squat stirrup jar & Gjerstad et al. 1934-1937, 519: no. 149, Plate 82: row 6:7 \\
\hline 466 & LH IIIA2-LH IIIB & squat flask, horizontal type & Gjerstad et al. 1934-1937, 519: no. 151, Plate 82: row 6:14 \\
\hline 467 & LH IIIA2-LH IIIB & globular stirrup jar & Gjerstad et al. 1934-1937, 520: no. 163 , Plate 82 : row 6:6 \\
\hline 468 & LH IIIA2-LH IIIB & shallow cup & Gjerstad et al. 1934-1937, 520: no. 171, Plate 82: row 7:2 \\
\hline 469 & LH IIIA2-LH IIIB & shallow cup & Gjerstad et al. 1934-1937, 520: no. 177 , Plate 82: row 7:1 \\
\hline 470 & LH IIIA2-LH IIIB & shallow cup & Gjerstad et al. 1934-1937, 520: no. 178 , Plate 82: row 7:9 \\
\hline 471 & LH IIIA2-LH IIIB & globular stirrup jar & Gjerstad et al. 1934-1937, 520: no. 184, Plate 82: row 6:11 \\
\hline 472 & LH IIIA2-LH IIIB & piriform jar & Gjerstad et al. 1934-1937, 520: no. 193, Plate 82: row 4:15 \\
\hline 473 & LH IIIA2-LH IIIB & globular flask, horizontal type & Gjerstad et al. 1934-1937, 521: no. 197, Plate 82: row 6:13 \\
\hline 474 & LH IIIA2-LH IIIB & small globular jug & Gjerstad et al. 1934-1937, 521: no. 202, Plate 82: row 4:25 \\
\hline 475 & LH IIIA2-LH IIIB & shallow cup & Gjerstad et al. 1934-1937, 521: no. 203, Plate 82: row 7:3 \\
\hline 476 & LH IIIA2-LH IIIB & piriform jar & Gjerstad et al. 1934-1937, 521: no. 210, Plate 82: row 6:9 \\
\hline 477 & LH IIIA2-LH IIIB & globular flask, horizontal type & Gjerstad et al. 1934-1937, 521: no. 213, Plate 82: row 4:24 \\
\hline 478 & LH IIIA2 & conical piriform stirrup jar & Gjerstad et al. 1934-1937, 521: no. 215, Plate 82: row 4:13 \\
\hline 479 & LH IIIA2-LH IIIB & shallow cup & Gjerstad et al. 1934-1937, 521: no. 221, Plate 82: row 7:13 \\
\hline 480 & LH IIIA2-LH IIIB & shallow cup & Gjerstad et al. 1934-1937, 521: no. 221, Plate 82: row 7:13 \\
\hline 481 & LH IIIA2-LH IIIB & shallow cup & Gjerstad et al. 1934-1937, 521: no. 240, Plate 82: row 7:6 \\
\hline 482 & LH IIIA2-LH IIIB & shallow cup & Gjerstad et al. 1934-1937, 524: no. 256, Plate 82: row 7:5 \\
\hline 483 & LH IIIA2-LH IIIB & small globular jug & Gjerstad et al. 1934-1937, 524: no. 270, Plate 83: row 8: no. 18 \\
\hline 484 & LH IIIA2-LH IIIB & shallow cup & Gjerstad et al. 1934-1937, 519: no. 153, Plate 82: row 7:4 \\
\hline 485 & LH IIIB & squat stirrup jar & Gjerstad et al. 1934-1937, 517: no. 60, Plate 83: row 3:8 \\
\hline 486 & LH IIIA2-LH IIIB & globular flask, horizontal type & Gjerstad et al. 1934-1937, 530: no. 3, Plate 85: row 8:13 \\
\hline 487 & LH IIIA2 & piriform jar & Gjerstad et al. 1934-1937, 531: no. 57, Plate 85: row 10:10 \\
\hline 488 & LH IIIA2 & piriform jar & Gjerstad et al. 1934-1937, 532: no. 92, Plate 85: row 10:6 \\
\hline 489 & LH IIIA2 & piriform jar & Gjerstad et al. 1934-1937, 532: no. 106, Plate 85: row 10:9 \\
\hline 490 & LH IIIA1 & squat alabastron & Gjerstad et al. 1934-1937, 532: no. 109, Plate 85: row 10:8 \\
\hline 491 & LH IIIA2-LH IIIB & small globular jug & Gjerstad et al. 1934-1937, 532: no. 119, Plate 85: row 8:14 \\
\hline 492 & LH IIIA2-LH IIIB & straight-sided alabastron & Gjerstad et al. 1934-1937, 534: no. 175, Plate 85: roe 12:2 \\
\hline 493 & LH IIIA2-LH IIIB & shallow cup & Gjerstad et al. 1934-1937, 534: no. 191, Plate 85: row 13:14 \\
\hline 494 & LH IIIA2 & piriform jar & Gjerstad et al. 1934-1937, 534: no. 193, Plate 85: row 12:17 \\
\hline 495 & LH IIIA2-LH IIIB & globular stirrup jar & Gjerstad et al. 1934-1937, 534: no. 198, Plate 85: row 12:18 \\
\hline 496 & LH IIIB & carinated conical cup & Gjerstad et al. 1934-1937, 534: no. 202, Plate 85: row 12 no. 19 \\
\hline 497 & LH IIIA2-LH IIIB & piriform jar & Gjerstad et al. 1934-1937, 534: no. 204, Plate 85: row 10:7 \\
\hline 498 & LH IIIA2-LH IIIB & shallow cup & Gjerstad et al. 1934-1937, 534: no. 206, Plate 85: row 13:13 \\
\hline 499 & LH IIIA2 & amphoroid krater & Gjerstad et al. 1934-1937, 543: no. 1, Plate 86.3: row 7 \\
\hline 500 & LH IIIA2-LH IIIB & piriform jar & Gjerstad et al. 1934-1937, 543: no. 6, Plate 86.3: row 6:5 \\
\hline 501 & LH IIIA2-LH IIIB & shallow cup & Gjerstad et al. 1934-1937, 544: no. 30, Plate 86.3: row 6:8 \\
\hline 502 & LH IIIA2-LH IIIB & straight-sided alabastron & Gjerstad et al. 1934-1937, 544: no. 34, Plate 86.3: row 6:3 \\
\hline 503 & LH IIIA2-LH IIIB & piriform jar & Gjerstad et al. 1934-1937, 544: no. 45, Plate 86.3: row 6:6 \\
\hline 504 & LH IIIA2-LH IIIB & piriform jar & Gjerstad et al. 1934-1937, 544: no. 55, Plate 86.3: row 6:7 \\
\hline
\end{tabular}




\begin{tabular}{|c|c|c|c|}
\hline ID & date & shape & published \\
\hline 505 & LH IIIA2-LH IIIB & piriform jar & Gjerstad et al. 1934-1937, 544: no. 56, Plate 86.3: row 6:4 \\
\hline 506 & LH IIIB & conical cup & Gjerstad et al. 1934-1937, 551: no. 18, Plate 88: row 3:1 \\
\hline 507 & LH IIIB & shallow bowl & Gjerstad et al. 1934-1937, 552: no. 26, Plate 88: row 3:6 \\
\hline 508 & LH IIIB & shallow bowl & Gjerstad et al. 1934-1937, 552: no. 32, Plate 88: row 3:8 \\
\hline 509 & LH IIIB & conical cup & Gjerstad et al. 1934-1937, 552: no. 34, Plate 88: row 4:2 \\
\hline 510 & LH IIIB & shallow bowl & Gjerstad et al. 1934-1937, 552: no. 35, Plate 88: row 3:9 \\
\hline 511 & LH IIIB & conical cup & Gjerstad et al. 1934-1937, 552: no. 49, Plate 88: row 2:3 \\
\hline 512 & LH IIIB & conical cup & Gjerstad et al. $1934-1937,552$, no. 50, Plate 88 : row $4: 3$ \\
\hline 513 & LH IIIB & conical cup & Gjerstad et al. 1934-1937, 552: no. 51, Plate 88: row 4:1 \\
\hline 514 & LH IIIA2-LH IIIB & small globular stirrup jar & Gjerstad et al. 1934-1937, 552: no. 57, Plate 88: row 2:1 \\
\hline 515 & LH IIIB & shallow bowl & Gjerstad et al. 1934-1937, 553: no. 63, Plate 88: row 3:3 \\
\hline 516 & LH IIIB & piriform jar & Gjerstad et al. 1934-1937, 553: no. 64, Plate 88: row 2:4 \\
\hline 517 & LH IIIB & shallow bowl & Gjerstad et al. 1934-1937, 553: no. 67, Plate 88: row 3:10 \\
\hline 518 & LH IIIA2-LH IIIB & squat jug & Gjerstad et al. 1934-1937, 553: no. 69. Plate 88: row 2:2 \\
\hline 519 & LH IIIA2-LH IIIB & globular jug & Gjerstad et al. 1934-1937, 553: no. 74, Plate 88: row 2 no. 5 \\
\hline 520 & LH IIIB & shallow bowl & Gjerstad et al. 1934-1937, 553: no. 76, Plate 88: row 3:4 \\
\hline 521 & LH IIIB & shallow bowl & Gjerstad et al. 1934-1937, 553: no. 79, Plate 88: row 3:5 \\
\hline 522 & LH IIIB & shallow bowl & Gjerstad et al. 1934-1937, 553: no. 80, Plate 88 \\
\hline 523 & LH IIIB & shallow bowl & Gjerstad et al. 1934-1937, 553: no. 86, Plate 88: row 2:10 \\
\hline 524 & LH IIIB & shallow bowl & Gjerstad et al. 1934-1937, 553: no. 87, Plate 88: row 3:7 \\
\hline 525 & LH IIIA2-LH IIIB & shallow cup & Gjerstad et al. 1934-1937, 554: no. 96, Plate 88: row 2:9 \\
\hline 526 & LH IIIA2-LH IIIB & shallow cup & Gjerstad et al. 1934-1937, 554: no. 104 , Plate 88: row 2:7 \\
\hline 527 & LH IIIB & conical cup & Gjerstad et al. 1934-1937, 554: no. 110, Plate 88: row 2:12 \\
\hline 528 & LH IIIA2-LH IIIB & jug & Gjerstad et al. 1934-1937, 554: no. 113 (not illustrated) \\
\hline 529 & LH IIIB & shallow stemmed bowl & Gjerstad et al. 1934-1937, 554: no. 115 , Plate 88: row 2:8 \\
\hline 530 & LH IIIA2-LH IIIB & globular jug & Gjerstad et al. 1934-1937, 554: no. 124, Plate 88: row 2:6 \\
\hline 531 & LH IIIB & shallow bowl & Gjerstad et al. 1934-1937, 554: no. 4, Plate 90: row 6:3 \\
\hline 532 & LH IIIB & wide-necked jug & Gjerstad et al. 1934-1937, 554-555: no. 5, Plate 90: row 3:1 \\
\hline 533 & LH IIIB & amphoroid krater & Gjerstad et al. 1934-1937, 555: no. 6, Plate 90: row 1:4 \\
\hline 534 & LH IIIB & one-handled bowl & Gjerstad et al. 1934-1937, 555: no. 7, Plate 90: row 5:5 \\
\hline 535 & $\mathrm{LH} I I \mathrm{~B}$ & shallow bowl & Gjerstad et al. 1934-1937, 555: no. 18, Plate 90: row 4:12 \\
\hline 536 & LH IIIB & piriform jar & Gjerstad et al. 1934-1937, 555: no. 19, Plate 90: row 3:3 \\
\hline 537 & LH IIIA2-LH IIB & globular jug & Gjerstad et al. 1934-1937, 555: no. 21, Plate 90: row 4:5 \\
\hline 538 & LH IIIA2-LH IIIB & shallow cup & Gjerstad et al. 1934-1937, 555: no. 22, Plate 90: row 6:2 \\
\hline 539 & LH IIIB & shallow bowl & Gjerstad et al. 1934-1937, 555: no. 23, Plate 90: row 6:6 \\
\hline 540 & LH IIIA2-LH IIIB & globular jug & Gjerstad et al. 1934-1937, 555: no. 25, Plate 90: row 4:10 \\
\hline 541 & LH IIIB & squat stirrup jar & Gjerstad et al. 1934-1937, 555: no. 26, Plate 90: row 4:9 \\
\hline 542 & LH IIIB & shallow bowl & Gjerstad et al. 1934-1937, 555: no. 27, Plate 90: row 5:3 \\
\hline 543 & $\mathrm{LH} I I \mathrm{~B}$ & shallow bowl & Gjerstad et al. 1934-1937, 555: no. 28, Plate 90: row 6:4 \\
\hline 544 & $\mathrm{LH} I I \mathrm{~B}$ & large piriform jar & Gjerstad et al. 1934-1937, 555: no. 31, Plate 90: row 3:5 \\
\hline 545 & LH IIIB & conical stirrup jar & Gjerstad et al. 1934-1937, 556: no. 33, Plate 90: row 4:8 \\
\hline 546 & LH IIIB & large piriform jar & Gjerstad et al. 1934-1937, 556: no. 35, Plate 90, row 3:6 \\
\hline 547 & LH IIIB & conical cup & Gjerstad et al. 1934-1937, 556: no. 38, Plate 90: row 6:1 \\
\hline 548 & $\mathrm{LH} I I \mathrm{~B}$ & piriform jar with vertical handles & Gjerstad et al. 1934-1937, 556: no. 40, Plate 90: row 3:10 \\
\hline 549 & $\mathrm{LH} I I \mathrm{~B}$ & ring-based krater & Gjerstad et al. 1934-1937, 556: no. 43, Plate 90, row 1:7 \\
\hline 550 & LH IIIB & ring-based krater & Gjerstad et al. 1934-1937, 556: no. 44, Plate 90: row 1:1 \\
\hline 551 & LH IIIB & ring-based krater & Gjerstad et al. 1934-1937, 556: no. 45, Plate 90: row 1:2 \\
\hline 552 & LH IIIB & ring-based krater & Gjerstad et al. 1934-1937, 556: no. 46, Plate 90: row 1:3 \\
\hline 553 & $\mathrm{LH} I I I \mathrm{~B}$ & ring-based krater & Gjerstad et al. 1934-1937, 556: no. 47, Plate 90: row 1:5 \\
\hline 554 & LH IIIB & ring-based krater & Gjerstad et al. 1934-1937, 556: no. 48, Plate 90: row 2:4 \\
\hline 555 & LH IIIB & ring-based krater & Gjerstad et al. 1934-1937, 556: no. 49, Plate 90: row 2:7 \\
\hline
\end{tabular}




\begin{tabular}{|c|c|c|c|}
\hline ID & date & shape & published \\
\hline 556 & LH IIIB & ring-based krater & Gjerstad et al. 1934-1937, 556: no. 50, Plate 90: row 1:6 \\
\hline 557 & LM IIIB & deep stemmed bowl & Gjerstad et al. 1934-1937, 556: no. 51: Plate 90: row 2:6 \\
\hline 558 & LM IIIB & amphoroid krater & Gjerstad et al. 1934-1937, 556: no. 52, Plate 90: row 2:5 \\
\hline 559 & LH IIIB & large stirrup jar & Gjerstad et al. 1934-1937, 556: no. 53: Plate 90: row 2:2 \\
\hline 560 & LH IIIB & large stirrup jar & Gjerstad et al. 1934-1937, 556: no. 54, Plate 90: row 2:8 \\
\hline 561 & LH IIIB & large stirrup jar & Gjerstad et al. 1934-1937, 556: no. 55, Plate 109: no. 6 \\
\hline 562 & LH IIIB & large stirrup jar & Gjerstad et al. 1934-1937, 556: no. 56, Plate 90: row 2:1 \\
\hline 563 & LH IIIB & large piriform jar & Gjerstad et al. 1934-1937, 556: no. 57, Plate 90: row 3:7 \\
\hline 564 & LH IIIB & large piriform jar & Gjerstad et al. 1934-1937, 556: no. 58, plate 90: row 2:9 \\
\hline 565 & LH IIIB & large piriform jar & Gjerstad et al. 1934-1937, 556-557 no. 59, Plate 90: row 3:9 \\
\hline 566 & LH IIIB & large piriform jar & Gjerstad et al. 1934-1937, 557: no. 60, Plate 90: row 3:4 \\
\hline 567 & LH IIIB & shallow bowl & Gjerstad et al. 1934-1937, 557: no. 62, Plate 90: row 5:9 \\
\hline 568 & LH IIIB & squat stirrup jar & Gjerstad et al. 1934-1937, 557: no. 63: Plate 90: row 4:6 \\
\hline 569 & LH IIIB & squat stirrup jar & Gjerstad et al. 1934-1937, 557: no. 64, Plate 90: row 4:7 \\
\hline 570 & LH IIIB & piriform jar & Gjerstad et al. 1934-1937, 557: no. 64, Plate 90: row 3:2 \\
\hline 571 & LH IIIB & shallow bowl & Gjerstad et al. 1934-1937, 557: no. 66, Plate 90: row 6:5 \\
\hline 572 & LH IIIB & shallow bowl & Gjerstad et al. 1934-1937, 557: no. 67, Plate 90: row 5:1 \\
\hline 573 & LH IIIB & shallow bowl & Gjerstad et al. 1934-1937, 557: no. 67, Plate 90: row 4:12 \\
\hline 574 & LH IIIB & shallow bowl & Gjerstad et al. 1934-1937, 557: no. 69, Plate 90: row 4:13 \\
\hline 575 & LH IIIB & shallow bowl & Gjerstad et al. 1934-1937, 557: no. 70, Plate 90: row 5:1 \\
\hline 576 & LH IIIB & shallow bowl & Gjerstad et al. 1934-1937, 557: no. 71, Plate 90: row 5:4 \\
\hline 577 & LH IIIB & shallow bowl & Gjerstad et al. 1934-1937, 557: no. 72, Plate 90: row 5:6 \\
\hline 578 & LH IIIB & shallow bowl & Gjerstad et al. 1934-1937, 557: no. 73, Plate 90: row 5:8 \\
\hline 579 & LH IIIB & wide-necked jug & Gjerstad et al. 1934-1937, 557: no. 74, Plate 90: row 3:11 \\
\hline 580 & LH IIIB & shallow bowl & Gjerstad et al. 1934-1937, 557: no. 75, Plate 90: row 5:7 \\
\hline 581 & LH IIIB & shallow stemmed bowl & Gjerstad et al. 1934-1937, 557: no. 76, Plate 90: row 4:2 \\
\hline 582 & LH IIIB & large piriform jar & Gjerstad et al. 1934-1937, 557: no. 77, Plate 90: row 3:8 \\
\hline 583 & LH IIIB & ring-based krater & Karageorghis 1960b, 156-157, Plate 14 \\
\hline 584 & LH IIIB & conical stirrup jar & Gjerstad et al. 1934-1937, 562: no. 5, Plate 91: row 5:8 \\
\hline 585 & LH IIIA2-LH IIIB & shallow cup & Gjerstad et al. 1934-1937, 562: no. 9, Plate 91: row 5:3 \\
\hline 586 & $\mathrm{LH} I I I B$ & globular stirrup jar & Gjerstad et al. 1934-1937, 562: no. 14, Plate 91: row 5:7 \\
\hline 587 & LH IIIB & narrow-necked jug & Gjerstad et al. 1934-1937, 562: no. 16, Plate 91: row 6:4 \\
\hline 588 & LH IIIB & one-handled bowl & Gjerstad et al. 1934-1937, 562: no. 16, Plate 91: row 5:5 \\
\hline 589 & LH IIIB & large piriform jar & Gjerstad et al. 1934-1937, 562-563: no. 20, Plate 91: row 4:9 \\
\hline 590 & LH IIIA2-LH IIIB & shallow cup & Gjerstad et al. 1934-1937, 563: no. 23, Plate 91: row 5:12 \\
\hline 591 & LH IIIB & piriform jar & Gjerstad et al. 1934-1937, 563: no. 30, Plate 91: row 4:10 \\
\hline 592 & LH IIIA2-LH IIIB & globular stirrup jar & Gjerstad et al. 1934-1937, 563: no. 31, Plate 91: row 6:5 \\
\hline 593 & LH IIIA2-LH IIIB & globular flask, horizontal type & Gjerstad et al. 1934-1937, 563: no. 39, Plate 91: row 4:12 \\
\hline 594 & LH IIIB & conical cup & Gjerstad et al. 1934-1937, 563: no. 46, Plate 91: row 5:1 \\
\hline 595 & LH IIIB & ring-based krater & Gjerstad et al. 1934-1937, 564: no. 62, Plate 91: row 3:5 \\
\hline 596 & LH IIIB & cup with horizontal handles & Gjerstad et al. 1934-1937, 564: no. 65, Plate 91: row 5:3 \\
\hline 597 & LH IIIB & ring-based krater & Gjerstad et al. 1934-1937, 564: no. 66, Plate 91: row 3:3 \\
\hline 598 & LH IIIA2-LH IIIB & shallow cup & Gjerstad et al. 1934-1937, 564: no. 67, Plate 91: row 5:13 \\
\hline 599 & LH IIIB & conical cup & Gjerstad et al. 1934-1937, 564: no. 82, Plate 91: row 5:2 \\
\hline 600 & LH IIIB & globular stirrup jar & Gjerstad et al. 1934-1937, 564-565: no. 85, Plate 91: row 5:10 \\
\hline 601 & LH IIIA2-LH IIIB & shallow cup & Gjerstad et al. 1934-1937, 565: no. 88, Plate 91: row 5:14 \\
\hline 602 & LH IIIB & globular stirrup jar & Gjerstad et al. 1934-1937, 565: no. 89, Plate 91: row 5:9 \\
\hline 603 & LH IIIA2-LH IIIB & globular stirrup jar & Gjerstad et al. 1934-1937, 565: no. 90, Plate 91: row 5:11 \\
\hline 604 & LH IIIA2-LH IIIB & shallow cup & Gjerstad et al. 1934-1937, 565: no. 97, Plate 91: row 6:1 \\
\hline 605 & LH IIIB & conical stirrup jar & Gjerstad et al. 1934-1937, 565: no. 98, Plate 91: row 4:13 \\
\hline 606 & LH IIIA2-LH IIIB & shallow cup & Gjerstad et al. 1934-1937, 565: no. 99, Plate 91: row 6:6 \\
\hline
\end{tabular}




\begin{tabular}{|c|c|c|c|}
\hline ID & date & shape & published \\
\hline 607 & LH IIIB & conical cup & Gjerstad et al. 1934-1937, 565: no. 109, Plate 91 \\
\hline 608 & LH IIIA2-LH IIIB & globular flask, horizontal type & Gjerstad et al. 1934-1937, 565: no. 111, Plate 91: row 4:11 \\
\hline 609 & LH IIIA2-LH IIIB & shallow cup & Gjerstad et al. 1934-1937, 565: no. 114, Plate 91 \\
\hline 610 & $\mathrm{LH} \| \mathrm{IIB}$ & squat stirrup jar & Gjerstad et al. 1934-1937, 565: no. 119, Plate 91: row 5:6 \\
\hline 611 & LH IIIB & conical cup & Gjerstad et al. 1934-1937, 566: no. 129, Plate 91: row 5:4 \\
\hline 612 & LH IIIA2-LH IIIB & piriform jar & Åström 1972b, 305: sherd in Stockholm (not illustrated) \\
\hline 613 & LH IIIA2-LH IIIB & straight-sided alabastron & Gjerstad et al. 1934-1937, 574 no. 2, Plate 87.4: no. 6 \\
\hline 614 & LH IIIA2-LH IIIB & shallow cup & Gjerstad et al. 1934-1937, 574: no. 3, Plate 87.4: no. 2 \\
\hline 615 & LH IIIA2-LH IIIB & shallow cup & Gjerstad et al. 1934-1937, 574: no. 4, Plate 87.4: no. 1 \\
\hline 616 & LH IIIA2-LH IIIB & shallow cup & Gjerstad et al. 1934-1937, 574: no. 8, Plate 87.4: no. 8 \\
\hline 617 & $\mathrm{LH}$ IIIA2 & piriform jar & Åström 1972b, 303: no. 47q (not illustrated) \\
\hline 618 & LH IIIA2 & piriform jar & Karageorghis 1963, IIC, Plate 18: no. 8 \\
\hline 619 & $\mathrm{LH} \| \mathrm{II} 2$ & piriform jar & Karageorghis 1963, IIC, Plate 18: no. 7 \\
\hline 620 & LH IIIA2 & piriform jar & Smith 1925, IICb, Plate 1: no. 5 \\
\hline 621 & $\mathrm{LH} \| \mathrm{II} 2$ & piriform jar & Walters 1912, 94: no. C465 \\
\hline 622 & LH IIIA2-LH IIIB & jug & Schaeffer 1936a, 80 fig. 33.2: no. 2, 139: T.10: no. 2 \\
\hline 623 & LH IIIA2-LH IIIB & globular jug & Schaeffer 1936a, 88 fig 36: bottom right, 140: T. 12: no. 10 \\
\hline 624 & LH IIIA2-LH IIIB & globular jug & Schaeffer 1936a, 141: no. 19 (not illustrated) \\
\hline 625 & LH IIIA1-LH IIIA2 & piriform jar & Schaeffer 1936a, 88 fig 36: no. 21, 141: no. 21 \\
\hline 626 & LH IIIA2-LH IIIB & piriform jar & Schaeffer 1936a, 88 fig 36: no. 22, 141: no. 22 \\
\hline 627 & LH IIIA2-LH IIIB & globular flask, horizontal type & Schaeffer 1936a, 88 fig. 36: no. 23 \\
\hline 628 & LH IIIB & shallow bowl & Schaeffer 1936a, 88 fig. 36: row 5:1, 141: no. 31 \\
\hline 629 & LH IIIB & shallow bowl & Schaeffer 1936a, 88 fig. 36: row 5:2, 141: no. 32 \\
\hline 630 & LH IIIB & shallow bowl & Schaeffer 1936a, 88 fig. 36: row 5:3, 141: no. 33 \\
\hline 631 & LH IIIA2 & conical piriform stirrup jar & Schaeffer 1936a, 141: no. 34, Plate 33: no. 3 \\
\hline 632 & LH IIIA2-LH IIIB & straight-sided alabastron & Schaeffer 1936a, 88 fig. 36: row 6:4, 141: no. 35 \\
\hline 633 & LH IIIB & large stirrup jar & Schaeffer 1936a, 91 fig. 37: top right, 141: no. 36 \\
\hline 634 & LH IIIB & large stirrup jar & Schaeffer 1936a, 91 fig. 37: top left \\
\hline 635 & LH IIIB & ring-based krater & Schaeffer 1936a, 91 fig. 37: down left, 141: no. 38 \\
\hline 636 & LH IIIB & ring-based krater & Schaeffer 1936a, 91 fig. 37: down right, 141: no. 39 \\
\hline 637 & LH IIIA2-LH IIIB & shallow cup & Schaeffer 1936a, 88 fig. 36: row 6:1 \\
\hline 638 & LH IIIA2-LH IIIB & shallow cup & Schaeffer 1936a, 88 fig. 36: row 6:2 \\
\hline 639 & LH IIIA2-LH IIIB & shallow cup & Schaeffer 1936a, 88 fig. 36: row 6 right \\
\hline 640 & LH IIIA2-LH IIIB & shallow cup & Schaeffer 1952, 22: no. 17 \\
\hline 641 & LH IIIA1 & piriform jar & Schaeffer 1952, 22: no. 1 \\
\hline 642 & LH IIIA2-LH IIIB & piriform jar & Schaeffer 1952, 22: no. 3 \\
\hline 643 & LH IIIB & fragment & Schaeffer 1952, 22: no. 2 \\
\hline 644 & LH IIIB & deep bowl & Schaeffer 1952, 22: no. 6 \\
\hline 645 & LH IIIA2 & amphoroid krater & Schaeffer 1952, 22: no. 8 \\
\hline 646 & LH IIIB & deep bowl & Schaeffer 1952, 22: no. 11 \\
\hline 647 & LH IIIB & piriform jar & Schaeffer 1952, 22: no. 23 \\
\hline 648 & LH IIIA2-LH IIIB & straight-sided alabastron & Schaeffer 1952, 118, fig 49: no. 2 \\
\hline 649 & LH IIIA2 & conical piriform stirrup jar & Schaeffer 1952, 118, fig. 49: no. 3 \\
\hline 650 & LH IIIA2-LH IIIB & shallow cup & Schaeffer 1952, 118, fig. 49: no. 5 \\
\hline 651 & LH IIIA2 & piriform jar & Schaeffer 1952, 118, fig. 49: no. 6 \\
\hline 652 & LH IIIA2 & piriform jar & Schaeffer 1952, 118, fig. 49: no. 7 \\
\hline 653 & LH IIIA2 & piriform jar & Schaeffer 1952, 118, fig. 49: no. 8 \\
\hline 654 & LH IIIA2 & conical piriform stirrup jar & Schaeffer 1952, 118, fig. 49: no. 9 \\
\hline 655 & LH IIIA2-LH IIIB & globular stirrup jar & Schaeffer 1952, 118, fig. 49: no. 13 \\
\hline 656 & $\mathrm{LH} \| \mathrm{II} 2$ & piriform jar & Schaeffer 1952, 118 fig. 50: no. 7 \\
\hline 657 & LH IIIA1-LH IIIA2 & piriform jar & Schaeffer 1952, 118 fig. 50: no. 9 \\
\hline
\end{tabular}




\begin{tabular}{|c|c|c|c|}
\hline ID & date & shape & published \\
\hline 658 & LH IIIA2 & piriform jar & Schaeffer 1952, 118 fig. 50: no. 10 \\
\hline 659 & LH IIIA2 & amphoroid krater & Schaeffer 1952, 119 fig. 51 \\
\hline 660 & LH IIIA2 & deep krater & Schaeffer 1952, 122 fig. 53, Plate 16 \\
\hline 661 & LH IIIA2 & amphoroid krater & Coche de la Ferté 1951, 13, Plate 1: no. 1 \\
\hline 662 & LH IIIA2 & amphoroid krater & Coche de la Ferté 1951, 12, Plate 1: no. 2 \\
\hline 663 & LH IIIA2-LH IIIB & shallow cup & Schaeffer 1952, 142, 147: no. 57, fig. 61: no. 5 \\
\hline 664 & LH IIB-LH IIIA1 & piriform jar & Schaeffer 1952, 150: no. 123, fig. 62: no. 5 \\
\hline 665 & LH IIB-LH IIIA1 & piriform jar & Schaeffer 1952, 144 fig. 62: no. 6 \\
\hline 666 & LH IIIA2 & piriform jar & Schaeffer 1952, 144 fig. $62:$ no. 7 \\
\hline 667 & LH IIIA2 & piriform jar & Schaeffer 1952, 144 fig. 62: no. 8 \\
\hline 668 & LH IIIA1-LH IIIA2 & piriform jar & Schaeffer 1952, 144 fig. 62: no. 9 \\
\hline 669 & LH IIIA2-LH IIIB & shallow cup & Schaeffer 1952, 144 fig. 62: no. 12, 150: no. 117 \\
\hline 670 & LH IIIA2-LH IIIB & shallow cup & Schaeffer 1952, 144 fig. 62: no. 13,149 : no. 110 \\
\hline 671 & LH IIIA2-LH IIIB & shallow cup & Schaeffer 1952, 149: no. 115 (not illustrated) \\
\hline 672 & LH IIIA2-LH IIIB & globular stirrup jar & Schaeffer 1952, 144 fig. 62: no. 14 \\
\hline 673 & LH IIIB & globular stirrup jar & Schaeffer 1952, 144 fig. 62: no. 15 \\
\hline 674 & LH IIIA2-LH IIIB & straight-sided alabastron & Schaeffer 1952, 144 fig 62: no. 16 \\
\hline 675 & LH IIIA2-LH IIIB & shallow cup & Schaeffer 1952, 144 fig. 62: no. 17 \\
\hline 676 & LH IIIA2 & conical piriform stirrup jar & Schaeffer 1952, 150: no. 128 (not illustrated) \\
\hline 677 & & stirrup jar & Schaeffer 1952, 141: no. 11 (not illustrated) \\
\hline 678 & & stirrup jar & Schaeffer 1952, 141: no. 14 (not illustrated) \\
\hline 679 & LH IIIA2-LH IIIB & globular stirrup jar & Schaeffer 1952, 149: no. 103 \\
\hline 680 & LH IIIA2-LH IIIB & piriform jar & Schaeffer 1952, 166: no. 41 (not illustrated) \\
\hline 681 & LH IIIB & squat stirrup jar & Schaeffer 1952, 164 fig. 67: no. 50, 167: no. 50 \\
\hline 682 & LH IIIB & squat stirrup jar & Schaeffer 1952, 164, 167, fig. 67: no. 54 \\
\hline 683 & LH IIIB & shallow bowl & Schaeffer 1952, 164, 167, fig. 67: no. 58 \\
\hline 684 & LH IIIB & piriform jar & Schaeffer 1952, 164, 167, fig. 67: no. 57 \\
\hline 685 & LH IIIA2-LH IIIB & small globular jug & Schaeffer 1952, 168-169, fig. 68: no. 59 \\
\hline 686 & LH IIIA2-LH IIIB & shallow cup & Schaeffer 1952, 168-169, fig. 68: no. 60 \\
\hline 687 & LH IIIA2-LH IIIB & globular stirrup jar & Schaeffer 1952, 168, 170: no. 85 \\
\hline 688 & LH IIIA2 & piriform jar & Schaeffer 1952, 168, 173: no. 101 \\
\hline 689 & LH IIIA2-LH IIIB & semi-globular cup & Schaeffer 1952, 172-173: no. 115 \\
\hline 690 & LH IIIA2 & piriform jar & Schaeffer 1952, 178, 183: no. 203 \\
\hline 691 & LH IIIB & shallow bowl & Schaeffer 1952, 178, 186: no. 224 \\
\hline 692 & LH IIIB & stirrup jar & Schaeffer 1952, 180, 189, fig. 71: no. 229 \\
\hline 693 & LH IIIB & piriform jar & Schaeffer 1952, 180, 189, fig. 71: no. 231 \\
\hline 694 & LH IIIA2-LH IIIB & semi-globular cup & Schaeffer 1952, 180, 189, fig. 71: no. 232 \\
\hline 695 & LH IIIB-LH IIIC & one-handled cup & Schaeffer 1952, 180, 189, fig. 71: no. 233 \\
\hline 696 & LH IIIB & conical stirrup jar & Schaeffer 1952, 180, 189, fig. 71: no. 234 \\
\hline 697 & LH IIIB & cup with horizontal handle & Schaeffer 1952, 180, 191, fig. 71: no. 237 \\
\hline 698 & LH IIIA2-LH IIIB & piriform jar & Schaeffer 1952, 180, 191, fig. 71: no. 255 \\
\hline 699 & LH IIIA2-LH IIIB & shallow cup & Schaeffer 1952, 180, 191, fig. 71: no. 258 \\
\hline 700 & LH IIIA2 & piriform jar & Schaeffer 1952, 182, 194, fig. 73: no. 324 \\
\hline 701 & LH IIIB2-LH IIICe & straight-sided alabastron & Schaeffer 1952, 180, 196, fig. 71: no. 261 \\
\hline 702 & LH IIIA2 & deep krater & Karageorghis 1958, 384, Plate 98: no. 1 \\
\hline 703 & LH IIIA2 & amphoroid krater & Coche de la Ferté 1951, 13, Plate 1: no. 7 \\
\hline 704 & LH IIIB & large stirrup jar & Coche de la Ferté 1951, 48, Plate 5: no. 3 \\
\hline 705 & LH III & stirrup jar & Schaeffer 1952, 253, Plate 93: no. 28 \\
\hline 706 & LH IIIB & piriform jar & Schaeffer 1952, 253, Plate 93: no. 35 \\
\hline 707 & LH III & fragment & Schaeffer 1952, 253, Plate 93: no. 42 \\
\hline 708 & LH III & fragment & Schaeffer 1952, 253, Plate 93: no. 48 \\
\hline
\end{tabular}




\begin{tabular}{|c|c|c|c|}
\hline ID & date & shape & published \\
\hline 709 & LH III & fragment & Schaeffer 1952, 257, Plate 94: no. 24 \\
\hline 710 & LH IIIA2-LH IIIB & piriform jar & Schaeffer 1952, 257, Plate 94: no. 25 \\
\hline 711 & LH III & stirrup jar & Schaeffer 1952, 259, Plate 96: no. 39 \\
\hline 712 & LH III & piriform jar & Schaeffer 1952, 259, Plate 96: no. 10 \\
\hline 713 & LH IIIB & hydria & Schaeffer 1952, 283 fig. 93 \\
\hline 714 & LH IIIB & fragment & Coche de la Ferté 1951, 17, Plate 2: no. 2 \\
\hline 715 & LH IIIB & fragment & Coche de la Ferté 1951, 17, Plate 2: no. 3 \\
\hline 716 & LH IIIB2-LH IIIC & deep bowl & Coche de la Ferté 1951, 16, Plate 2: no. 5 \\
\hline 717 & LH IIIB-LH IIIC & deep bowl & Coche de la Ferté 1951, 17, Plate 2: no. 4 \\
\hline 718 & LH III & fragment & Coche de la Ferté 1951, Plate 2: bottom right \\
\hline 719 & LH IIIB-LH IIIC & deep bowl & Coche de la Ferté 1951, 18, Plate 9: no. 2 \\
\hline 720 & LH IIIB-LH IIIC & krater & Coche de la Ferté 1951, Plate 9: no. 3 \\
\hline 721 & LH IIIB-LH IIIC & krater & Coche de la Ferté 1951, Plate 9: no. 4 \\
\hline 722 & LH IIIB2 & fragment & Coche de la Ferté 1951, Plate 9: no. 5 \\
\hline 723 & LH IIIB2 & fragment & Coche de la Ferté 1951, Plate 9: no. 6 \\
\hline 724 & LH IIIA2 & amphoroid krater & Megaw 1957, 44 (not illustrated) \\
\hline 725 & LH IIIA2 & amphoroid krater & Nicolaou 1968-1969, 42 (not illustrated) \\
\hline 726 & LM IIIB & fragment & Forsdyke 1911, 112-113 fig. 3 \\
\hline 727 & LH IIIA1 & large piriform jar & Furumark 1941a, 498 under IIA, 589: no. 31:19 \\
\hline 728 & $\mathrm{LH} I I I B$ & large piriform jar & Ure \& Ure 1954, IIIA, 3, Plate 1: no. 23 \\
\hline 729 & LH IIIB & large piriform jar & Ure \& Ure 1954, IIIA, 3, Plate 1: no. 25 \\
\hline 730 & LH IIIA2 & amphoroid krater & Mayence \& Verhoogen 1929, IIIA, Plate 3: no. 15 \\
\hline 731 & LH IIIA2 & amphoroid krater & Mayence \& Verhoogen 1929, IIIA, Plate 3: nos. 6-7 \\
\hline 732 & LH IIIB & conical piriform stirrup jar & Mayence 1926, IIIA, PI. 1: no. 7a-b \\
\hline 733 & LH IIIA2-LH IIIB & amphoroid krater & Åström 1972b, 316: no. 53-55I (not illustrated) \\
\hline 734 & LH IIIB & amphoroid krater & Mayence \& Verhooge 1929, IIIA, Plate 3: no. 1 \\
\hline 735 & LH IIIA2 & amphoroid beaked jug & Walters 1912, 116 fig. 207: no. C600 \\
\hline 736 & LH IIIA2 & globular stirrup jar & Karageorghis1967, IIC, Plate 21: no. 3 \\
\hline 737 & LH IIIA2-LH IIIB & shallow cup & Karageorghis 1963, IIC, Plate 27: no. 6 \\
\hline 738 & LH IIIB & ring-based krater & Ure \& Ure 1954, IIIA, Plate 1: no. 20 \\
\hline 739 & LH IIIB & ring-based krater & Ure \& Ure 1954, IIIA, Plate 1: no. 24 \\
\hline 740 & LH IIIB & ring-based krater & Ure \& Ure 1954, IIIA, Plate 1: no. 9 \\
\hline 741 & LH IIIB & ring-based krater & Ure \& Ure 1954, IIIA, Plate 1: no. 21 \\
\hline 742 & LH IIIB & ring-based krater & Ure \& Ure 1954, IIIA, Plate 1: no. 26 \\
\hline 743 & LH IIIA2-LH IIIB & shallow cup & Walters 1912, 123 fig. 230: no. C641 \\
\hline 744 & LH IIIB & amphoroid krater & Mayence \& Verhoogen 1929, IIIA, Plate 3: no. 9 \\
\hline 745 & LH IIIB & squat stirrup jar & Åström 1972b, 345: no. 179d (not illustrated) \\
\hline 746 & LH IIIB & ring-based krater & Åström 1972b, 372: no. 281×3 (not illustrated) \\
\hline 747 & LH IIIB & shallow bowl & Smith 1925, IICb, Plate 5: no. 20 \\
\hline 748 & LH IIIB & shallow bowl & Åström 1972b, 379: no. 296c2 \\
\hline 749 & LH IIB & rounded alabastron & Catling 1964, 36 (not illustrated) \\
\hline 750 & LH IIIA2-LH IIIB & globular stirrup jar & Åström 1972b, 340: no. 171m2 (not illustrated) \\
\hline 751 & LH IIIB & ring-based krater & Karageorghis 1965a, 248 fig. 55: no. 3 \\
\hline 752 & $\mathrm{LH} I I \mathrm{~A} 2$ & amphoroid krater & Karageorghis 1966, 303-305 fig. 16b \\
\hline 753 & LH IIIA2-LH IIIB & amphoroid krater & Karageorghis 1966, 305 fig. 16a \\
\hline 754 & LH IIIA2 & amphoroid krater & Karageorghis 1966, 305 fig. 16C \\
\hline 755 & LH IIIB & ring-based krater & Karageorghis 1963, IIC, Plate 13: no. 4 (1958/II-17/5) \\
\hline 756 & LH IIIA2 & amphoroid krater & Nicolaou 1968, 372 \\
\hline 757 & LH III & fragment & Karageorghis 1967, 515 (not illustrated) \\
\hline 758 & & fragment & Johnstone 1971, 66: fig. 9: no. 2 \\
\hline 759 & LH IIIB-LH IIIC & bowl & Johnstone 1971, 63-64, fig. 7: no. 5 \\
\hline
\end{tabular}




\begin{tabular}{|c|c|c|c|}
\hline ID & date & shape & published \\
\hline 760 & LH IIIA2-LH IIIB & straight-sided alabastron & Johnstone 1971, 66: fig. 9: no. 2 \\
\hline 761 & LH IIIB & piriform jar & Johnstone 1971, $72-73$ fig. 14: no. 14 \\
\hline 762 & LH IIIB & fragment & Johnstone 1971, $72-73$ fig. 14: no. 9 \\
\hline 763 & LH IIIB-LH IIIC & bowl & Johnstone 1971, $72-73$ fig. 14: no. 4 \\
\hline 764 & LH IIIA2-LH IIIB & piriform jar & Johnstone 1971, 99-100: fig 23: no. 146 \\
\hline 765 & LH IIIA2 & piriform jar & Johnstone 1971, 99-100 fig. 23: no. 147 \\
\hline 766 & LH IIIA2 & piriform jar & Johnstone 1971, 100-101 fig. 23: no. 148 \\
\hline 767 & LH IIIA2 & piriform jar & Johnstone 1971, 100-101 fig. 23: no. 149 \\
\hline 768 & LH IIIA2 & piriform jar & Johnstone 1971, 100-101 fig. 23: no. 150 \\
\hline 769 & LH IIIA2-LH IIIB & globular stirrup jar & Johnstone 1971, 100, 102 fig. 23: no. 151 \\
\hline 770 & LH IIIA2-LH IIIB & globular flask, vertical type & Johnstone 1971, 100, 102 fig. 23: no. 152 \\
\hline 771 & LH IIIB & piriform jar & Johnstone 1971, 100, 102 fig. 23: no. 153 \\
\hline 772 & LH IIIA2-LH IIIB & small globular jug & Johnstone 1971, 102-103 fig. 24: no. 154 \\
\hline 773 & LH IIIA2 & handleless cup & Johnstone 102-103 fig 24: no. 156 (not illustrated) \\
\hline 774 & LH IIIA2-LH IIIB & shallow cup & Johnstone 1971, 102-104 fig. 24: no. 159 \\
\hline 775 & LH IIIB-LH IIIC & cylindrical jug with trefoil mouth & Johnstone 1971, 103-104 fig. 24: no. 155 \\
\hline 776 & LH III & bowl & Johnstone 1971, 104: no. 157 (not illustrated) \\
\hline 777 & LH III & fragment & Johnstone 1971, 105 no. D5, 108 fig. 25: no. 16 \& 19 \\
\hline 778 & LH III & bowl & Johnstone 1971, 104: no. 160 (not illustrated) \\
\hline 779 & LH IIIB-LH IIIC & deep bowl & Johnstone 1971, 106: no. 161, 108 fig. 25: no. 11 \\
\hline 780 & LH IIIB-LH IIIC & bowl & Johnstone 1971, 104: no. 162, 105, 107 fig. 25: no. 26 \\
\hline 781 & LH III & bowl & Johnstone 1971, 104: no. 163 (not illustrated) \\
\hline 782 & LH III & fragment & Johnstone 1971, 104, 107: no. 167 (not illustrated) \\
\hline 783 & LH III & jar & Johnstone 1971, 106: no. 169 (not illustrated) \\
\hline 784 & LH IIIB & deep bowl & Johnstone 1971, 105: no. 170, 106, 109 (D3), fig. 25: no. 1 \\
\hline 785 & LH III & bowl & Johnstone 1971, 106: no. 171 (not illustrated) \\
\hline 786 & LH IIIB-LH IIIC & bowl & Johnstone 1971, 105-106: no. 172, fig. 25: no. 10 \\
\hline 787 & LH III & jar & Johnstone 1971, 106: no. 173 (not illustrated) \\
\hline 788 & LH III & bowl & Johnstone 1971, 104: no. 174 (not illustrated) \\
\hline 789 & LH III & fragment & Johnstone 1971, 107: no. 175 (not illustrated) \\
\hline 790 & LH IIIB & fragment & Johnstone 1971, 107: no. 176 (not illustrated) \\
\hline 791 & LH III & bowl & Johnstone 1971, 106: no. 177 \\
\hline 792 & LH III & fragment & Johnstone 1971, 103, 107: no. 178, 108 fig. 42: no. D42 \\
\hline 793 & LH III & fragment & Johnstone 1971, 107: no. 179, 108 fig. 42: second of D42 \\
\hline 794 & LH III & fragment & Johnstone 1971, 107: 180, 108 fig. 25: no. 2 \\
\hline 795 & LH III & fragment & Johnstone 1971, 107: no. 181 (not illustrated) \\
\hline 796 & LH III & fragment & Johnstone 1971, 107: no. 182 (not illustrated) \\
\hline 797 & LH III & fragment & Johnstone 1971, 107: no. 183 (not illustrated) \\
\hline 798 & LH III & fragment & Johnstone 1971, 105, 107: no. 184, 108 (D19) fig. 25: no. 22 \\
\hline 799 & LH III & bowl & Johnstone 1971, 104: no. 185 (not illustrated) \\
\hline 800 & LH III & fragment & Johnstone 1971, 107: no. 186 (not illustrated) \\
\hline 801 & LH III & fragment & Johnstone 1971, 107: no. 187 (not illustrated) \\
\hline 802 & LH III & jar & Johnstone 1971, 106: no. 188 (not illustrated) \\
\hline 803 & LH IIIB-LH IIIC & ring-based krater & Johnstone 1971, 105: no. 189, 106 fig. 25: no. 20 \\
\hline 804 & LH III & fragment & Johnstone 1971, 107: no. 190 (not illustrated) \\
\hline 805 & LH III & bowl & Johnstone 1971, 104: no. 191 (not illustrated) \\
\hline 806 & LH III & bowl & Johnstone 1971, 104: no. 192 (not illustrated) \\
\hline 807 & LH III & juglet & Johnstone 1971, 107: no. 193 \\
\hline 808 & LH III & fragment & Johnstone 1971, 107: no, 194 \\
\hline 809 & LH III & fragment & Johnstone 1971, 107: no. 195 \\
\hline 810 & LH III & fragment & Johnstone 1971, 107: no. 196 \\
\hline
\end{tabular}




\begin{tabular}{|c|c|c|c|}
\hline ID & date & shape & published \\
\hline 811 & LH III & fragment & Johnstone 1971, 107: no. 197 \\
\hline 812 & LH III & fragment & Johnstone 1971, 107: no. 198 \\
\hline 813 & LH III & fragment & Johnstone 1971, 107: no. 199 \\
\hline 814 & LH III & fragment & Johnstone 1971, 107: no. 200 \\
\hline 815 & LH III & fragment & Johnstone 1971, 107: no. 201 \\
\hline 816 & LH III & fragment & Johnstone 1971, 107: no. 202 \\
\hline 817 & LH III & fragment & Johnstone 1971, 107: no. 203 \\
\hline 818 & LH III & fragment & Johnstone 1971, 105, 107: no. 204, 108 fig. 25: no. 15 \\
\hline 819 & LH III & fragment & Johnstone 1971, 107: no. 205 \\
\hline 820 & LH III & fragment & Johnstone 1971, 107: no. 206 \\
\hline 821 & LH III & fragment & Johnstone 1971, 107: no. 207, 108 fig. 25: no. 13 \\
\hline 822 & LH III & fragment & Johnstone 1971, 107: no. 208 \\
\hline 823 & LH III & fragment & Johnstone 1971, 107: no. 209 \\
\hline 824 & LH III & fragment & Johnstone 1971, 107: no. 210 \\
\hline 825 & LH III & juglet & Johnstone 1971, 107: no. 211 \\
\hline 826 & LH III & juglet & Johnstone 1971, 107: no. 212 \\
\hline 827 & LH III & juglet & Johnstone 1971, 107: no. 213 \\
\hline 828 & LH III & fragment & Johnstone 1971, 107: no. 214 \\
\hline 829 & LH III & fragment & Johnstone 1971, 107: no. 215 \\
\hline 830 & LH IIIB & bowl & Johnstone 1971, 104-106: no. 352 fig. 25: no. 14 \\
\hline 831 & LH III & juglet & Johnstone 1971, 104, 107: no. 67 \\
\hline 832 & LH IIIB & stemmed cup & Johnstone 1971, 105, 107: no. 253 fig. 25: no. 27 \\
\hline 833 & LH IIIB-LH IIIC & fragment & Johnstone 1971, 105, 111 \\
\hline 834 & LH IIIA2-LH IIIB & stirrup jar & Johnstone 1971, 111 (not illustrated) \\
\hline 835 & LH III & fragment & Johnstone 1971, 110 (not illustrated) \\
\hline 836 & LH III & fragment & Johnstone 1971, 110 (not illustrated) \\
\hline 837 & LH III & fragment & Johnstone 1971,110 (not illustrated) \\
\hline 838 & LH III & fragment & Johnstone 1971, 110 (not illustrated) \\
\hline 839 & LH III & fragment & Johnstone 1971, 110 (not illustrated) \\
\hline 840 & LH III & fragment & Johnstone 1971, 110 (not illustrated) \\
\hline 841 & LH III & fragment & Johnstone 1971, 110 (not illustrated) \\
\hline 842 & LH III & fragment & Johnstone 1971,110 (not illustrated) \\
\hline 843 & LH III & fragment & Johnstone 1971, 110 (not illustrated) \\
\hline 844 & LH III & fragment & Johnstone 1971, 110 (not illustrated) \\
\hline 845 & LH III & fragment & Johnstone 1971, 110 (not illustrated) \\
\hline 846 & LH III & fragment & Johnstone 1971, 110 (not illustrated) \\
\hline 847 & LH III & fragment & Johnstone 1971, 110 (not illustrated) \\
\hline 848 & LH III & fragment & Johnstone 1971, 110 (not illustrated) \\
\hline 849 & LH III & fragment & Johnstone 1971, 110 (not illustrated) \\
\hline 850 & LH III & fragment & Johnstone 1971, 110 (not illustrated) \\
\hline 851 & LH III & fragment & Johnstone 1971, 110 (not illustrated) \\
\hline 852 & LH III & fragment & Johnstone 1971, 110 (not illustrated) \\
\hline 853 & LH III & fragment & Johnstone 1971, 110 (not illustrated) \\
\hline 854 & LH III & fragment & Johnstone 1971, 110 (not illustrated) \\
\hline 855 & LH III & fragment & Johnstone 1971, 110 (not illustrated) \\
\hline 856 & LH III & fragment & Johnstone 1971, 110 (not illustrated) \\
\hline 857 & LH III & fragment & Johnstone 1971, 110 (not illustrated) \\
\hline 858 & LH III & fragment & Johnstone 1971, 110 (not illustrated) \\
\hline 859 & LH III & fragment & Johnstone 1971, 110 (not illustrated) \\
\hline 860 & LH III & fragment & Johnstone 1971, 110 (not illustrated) \\
\hline 861 & LH III & fragment & Johnstone 1971, 110 (not illustrated) \\
\hline
\end{tabular}




\begin{tabular}{|c|c|c|c|}
\hline ID & date & shape & published \\
\hline 862 & LH IIIB & small globular jug & Karageorghis 1971, 128 \\
\hline 863 & LH IIIB & bowl & Courtois 1971,199 fig. 45B \\
\hline 864 & LH IIIA2-LH IIIB & globular flask, vertical type & Courtois 1971,199 fig. $45 \mathrm{c}$ \\
\hline 865 & LH IIB-LH IIIA1 & rounded alabastron & Courtois 1971,199 fig. $45 \mathrm{e}$ \\
\hline 866 & LH IIIA2-LH IIIB & fragment & Courtois 1971, 199 fig. $45 n$ \\
\hline 867 & LH IIIB & shallow stemmed bowl & Courtois 1971, 206-208, fig. 52 \\
\hline 868 & LH IIIB & & Courtois 1971, 210 (not illustrated) \\
\hline 869 & LH IIIA1 & rounded alabastron & Courtois 1981, 85: no. 38, 92, 110-111 fig. 56-57 \\
\hline 870 & LH IIIA2 & piriform jar & Courtois 1981, 141: no. 242, 234 fig. 137-138: no. 1 \\
\hline 871 & LH IIIA2 & piriform jar & Courtois 1981, 141: no. 242, 234-235 fig. 137-138: no. 2 \\
\hline 872 & LH IIIA2 & piriform jar & Courtois 1981, 141-142: no. 244, 234-235 fig. 137-138: no. 3 \\
\hline 873 & LH IIIB & piriform jar & Courtois 1981, 142: no. 245, 234-235 fig. 137-138: no. 4 \\
\hline 874 & LH IIIA2 & piriform jar & Courtois 1981,142 : no. 246,235 fig. 138 : no. 5, 236 fig. 139: no. 1 \\
\hline 875 & LH IIIA2 & piriform jar & Courtois 1981, 142: no. 247, fig. 138: no. 6, 236 fig. 139: no. 2 \\
\hline 876 & LH IIIA2 & piriform jar & Courtois 1981, 142: no. 248, 235 fig. 138: no. 7, 236 fig. 139: no. 3 \\
\hline 877 & LH IIIA2 & piriform jar & Courtois 1981, 142: no. 249, 235 fig. 138: no. 8, 236 fig. 139: no. 4 \\
\hline 878 & LH IIIA2 & piriform jar & Courtois 1981, 142: no. 250, 236 fig. 139: no. 5, 237 fig. 140: no. 1 \\
\hline 879 & LH IIIB & piriform jar & Courtois 1981, 142: no. 251, 234 fig. 137: no. 6, 238 fig. 141: no. 1 \\
\hline 880 & LH IIIA2-LH IIIB & piriform jar & Courtois 1981, 142: no. 252, 234 fig. 137: no. 5, 238 fig. 141: no. 2 \\
\hline 881 & LH IIIA2-LH IIIB & globular flask, vertical type & Courtois 1981, 142: no. 253, 236 fig. 139: no. 6, 238 fig. 141: no. 3 \\
\hline 882 & LH IIIB & straight-sided alabastron & Courtois 1981, 142: no. 254, 239 fig. 142: no. 4, 240: fig. 143: no. 1 \\
\hline 883 & LH IIIB & straight-sided alabastron & Courtois 1981, 142: no. 255, 239 fig. 142: no. 1, 240 fig. 143: no. 1 \\
\hline 884 & LH IIIA2 & straight-sided stirrup jar & Courtois 1981, 142: no. 256, 239 fig. 142: no. 2, 240 fig. 143: no. 3 \\
\hline 885 & LH IIIA2 & straight-sided stirrup jar & Courtois 1981, 142: no. 257, 239 fig. 142: no. 3, 240 fig. 143: no. 4 \\
\hline 886 & LH IIIB & squat stirrup jar & Courtois 1981, 142-3: no. 258, 239 fig. 142: no. 5 \\
\hline 887 & LH IIIB & squat stirrup jar & Courtois 1981, 143: no. 259, 240 fig. 143: no. 6, 241 fig. 144: no. 1 \\
\hline 888 & LH IIIB & flask horizontal type & Courtois 1981, 143: no. 260, 240 fig. 143: no. 7, 241 fig. 144: no. 4 \\
\hline 889 & LH IIIB & globular stirrup jar & Courtois 1981, 143: no. 261, 241 fig. 144: no. 2, 242 fig. 145: no. 1 \\
\hline 890 & LH IIIB & globular stirrup jar & Courtois 1981, 143: no. 262, 241: fig. 144: no. 5 \\
\hline 891 & LH IIIB & globular stirrup jar & Courtois 1981, 143: no. 262, 241 fig. 144: no. 6, 242 fig. 145: no. 3 \\
\hline 892 & LH IIIB & squat stirrup jar & Courtois 1981, 143: no. 264, 241 fig. 144: no. 3, 242 fig. 146: no. 1 \\
\hline 893 & LH IIIB & globular stirrup jar & Courtois 1981, 143: no. 265, 242 fig. 146: no. 2, 243 fig. 147: no. 3 \\
\hline 894 & LH IIIB & squat stirrup jar & Courtois 1981, 143: no. 267, 242 fig. 146: no. 4, 243 fig. 147: no. 5 \\
\hline 895 & LH IIIA2 & conical piriform stirrup jar & Courtois 1981, 143: no. 268, 243 fig. 147: no. 2 \\
\hline 896 & LH IIIA2-LH IIIB & small globular jug & Courtois 1981, 143: no. 269, 243 fig. 147: no. 4, 246 fig. 150: no. 2 \\
\hline 897 & LH IIIB & small globular jug & Courtois 1981, 143: no. 270, 243 fig. 147: no. 6, 246 fig. 150: no. 1 \\
\hline 898 & LH IIIB & shallow cup & Courtois 1981, 143: no. 271, 247 fig. 151: no. 1, 248 fig. 152: no. 1 \\
\hline 899 & LH IIIA1 & shallow cup & Courtois 1981, 143: no. 272, 247 fig. 151: no. 3, 248 fig. 152: no. 2 \\
\hline 900 & LH IIIB & shallow cup & Courtois 1981, 143: no. 273, 247 fig. 151: no. 4, 248 fig. 152: no. 3 \\
\hline 901 & LH IIIB & shallow cup & Courtois 1981, 143: no. 274,247 fig. 151: no. 2 \\
\hline 902 & LH IIIA2 & shallow cup & Courtois 1981, 143-144: no. 275, 247 fig. 151: no. 5 \\
\hline 903 & LH IIIA2 & shallow cup & Courtois 1981, 144: no. 276, 247 fig. 151: no. 6, 248 fig. 152: no. 6 \\
\hline 904 & LH IIIA2 & shallow cup & Courtois 1981, 144: no. 277, 247 fig. 151: no. 7 \\
\hline 905 & LH IIIA2-LH IIIB & shallow cup & Courtois 1981, 144: no. 278, 247 fig. 151: no. 8 \\
\hline 906 & LH IIIA2-LH IIIB & shallow cup & Courtois 1981, 144: no. 279, 248 fig. 152: no. 9 \\
\hline 907 & LH IIIA2 & shallow cup & Courtois 1981, 144: no. 280, 248 fig. 152: no. 10 \\
\hline 908 & LH IIIB & shallow cup & Courtois 1981, 144: no. 281, 249 fg. 153: no. 4 \\
\hline 909 & LH IIIB & shallow cup & Courtois 1981, 144: no. 282, 251 fig. 155: no. 5 \\
\hline 910 & LH IIIB & shallow cup & Courtois 1981, 144: no. 283, 250 fig. 154: no. 2 \\
\hline 911 & LH IIIA2-LH IIIB & ostrich egg rhyton & Courtois 1981, 144: no. 284, 246 fig. 150: no. 3, 255 fig. 159A \\
\hline 912 & LH IIIB & shallow bowl & Courtois 1981, 144: no. 85, 254 fig. 158: no. 2, 256 fig. 160: no. 2 \\
\hline
\end{tabular}




\begin{tabular}{|c|c|c|c|}
\hline ID & date & shape & published \\
\hline 913 & LH IIIB & globular stirrup jar & Courtois 1981, 285: no. 15, 288 fig. 175: no. 2 \\
\hline 914 & LH IIIB & squat stirrup jar & Courtois 1981, 285: no. 13, 289 fig. 176: no. 13 \\
\hline 915 & LH IIIB & squat stirrup jar & Lagarce \& Lagarce 1985, 130-131 fig. 39: no. 224 \\
\hline 916 & LH IIIA2 & globular stirrup jar & Lagarce \& Lagarce 1985, 130-131 fig. 39: no. 226 \\
\hline 917 & LH IIIA2 late & globular stirrup jar & Lagarce \& Lagarce 1985, 130-131 fig. 39: no. 226 \\
\hline 918 & LH IIIA2 & globular stirrup jar & Lagarce \& Lagarce 1985, 130, 131 fig. 40: no. 227 \\
\hline 919 & LH IIIA2-LH IIIB & squat stirrup jar & Lagarce \& Lagarce 1985, 132-133 fig. 40: no. 228 \\
\hline 920 & LH IIIA2-LH IIIB & piriform jar & Lagarce \& Lagarce 1985, 132-133 fig. 40: no. 229 \\
\hline 921 & LH IIIA2-LH IIIB & piriform jar & Lagarce \& Lagarce 1985, 132-133 fig. 40: no. 230 \\
\hline 922 & LH IIIA2-LH IIIB & piriform jar & Lagarce \& Lagarce 1985, 132-133 fig. 40: no. 231 \\
\hline 923 & LH IIIA2 late & one-handled bowl & Lagarce \& Lagarce 1985, 132-133 fig. 40: no. 232 \\
\hline 924 & LH IIIB & shallow bowl & Lagarce \& Lagarce 1985, 132, 134-135 fig. 41: no. 233 \\
\hline 925 & LH IIIB & chalice & Lagarce \& Lagarce 1985, 133-134 fig. 40: no. 234 \\
\hline 926 & LH IIIA2-LH IIIB & kylix & Lagarce \& Lagarce 1985, 134-135 fig. 40: no. 235 \\
\hline 927 & LH IIIA2-LH IIIB & kylix & Lagarce \& Lagarce 1985, 134-135 fig. 40: no. 236 \\
\hline 928 & LH IIIA2-LH IIIB & large piriform jar & Lagarce \& Lagarce 1985, 134-135 fig. 40: no. 238 \\
\hline 929 & LH IIIA2-LH IIIB & amphoroid krater & Lagarce \& Lagarce 1985, 135-136 fig. 40: no. 239 \\
\hline 930 & LH I & semi-globular cup & Dikaios 1969, 229-230, Plate 58: no. 26 \\
\hline 931 & LH I & semi-globular cup & Dikaios 1969, 230, Plate 58: no. 27 \\
\hline 932 & $\mathrm{LH} I$ & rounded alabastron & Dikaios 1969, 230, Plate 58: no. 28 \\
\hline 933 & LH IIIA1 & rounded alabastron & Dikaios 1969, 230, Plate 58: no. 29 \\
\hline 934 & LH IIIA1-LH IIIA2 & shallow cup & Dikaios 1969, 237, Plate 61: no. 1 \\
\hline 935 & LH IIIA1-LH IIIA2 & shallow cup & Dikaios 1969, 237, Plate 61: no. 2 \\
\hline 936 & LH IIIA1-LH IIIA2 & shallow cup & Dikaios 1969, 237, Plate 61: no. 7 \\
\hline 937 & LH IIIA2 & shallow cup & Dikaios 1969, 237, Plate 61: no. 19 \\
\hline 938 & LH IIIA2 late & shallow cup & Dikaios 1969, 237, Plate 61: no. 20 \\
\hline 939 & LH IIIA2-LH IIIB & shallow cup & Dikaios 1969, 237, Plate 61: no. 22 \\
\hline 940 & LH IIIA2-LH IIIB & shallow cup & Dikaios 1969, 237, Plate 61: no. 21 \\
\hline 941 & LH IIIA2-LH IIIB & shallow cup & Dikaios 1969, 237, Plate 61: no. 23 \\
\hline 942 & LH IIIA2 & beaked jug & Dikaios 1969, 238, Plate 61: no. 11 \\
\hline 943 & LH IIIA2-LH IIIB & jug with cut-away neck & Dikaios 1969, 238, Plate 61: no. 13 \\
\hline 944 & LH IIIA2 & conical piriform stirrup jar & Dikaios 1969, 238, Plate 61: no. 4 \\
\hline 945 & LH IIIA2 & stirrup jar & Dikaios 1969, 238, Plate 61: nos. 9, 12, 16 \\
\hline 946 & LH IIIA2 early & amphoroid krater & Dikaios 1969, 238, Plate 61: no. 6 \\
\hline 947 & LH IIIA2 early & amphoroid krater & Dikaios 1969, 238, Plate 61: no. 8 \\
\hline 948 & LH IIIA2 early & amphoroid krater & Dikaios 1969, 238, Plate 61: no. 10 \\
\hline 949 & LH IIIA2 late & amphoroid krater & Dikaios 1969, 238, Plate 61: no. 24 \\
\hline 950 & LH IIIA2 & amphoroid krater & Dikaios 1969, 238, Plate 61: no. 3 \\
\hline 951 & LH IIIA2 & amphoroid krater & Dikaios 1969, 238, Plate 61: no. 25 \\
\hline 952 & LH IIIA2 & amphoroid krater & Dikaios 1969, 238, Plate 61: no. 26 \\
\hline 953 & LH IIIA2 & fragment & Dikaios 1969, 238, Plate 61: no. 27 \\
\hline 954 & LH IIIA2 & amphoroid krater & Dikaios 1969, 238, Plate 61: no. 28 \\
\hline 955 & LH IIIA2 & fragment & Dikaios 1969, 238, Plate 61: no. 29 \\
\hline 956 & LH IIIA2 & amphoroid krater & Dikaios 1969, 238, Plate 61: no. 17 \\
\hline 957 & LH IIIA2 & piriform jar & Dikaios 1969, 238-239, Plate 61: no. 14 \\
\hline 958 & LH IIIA2-LH IIIB & fragment & Dikaios 1969, 239, Plate 61: no. 5 \\
\hline 959 & LH IIIA2-LH IIIB & fragment & Dikaios 1969, 239, Plate 61: no. 18 \\
\hline 960 & LH IIIA1-LH IIIA2 & shallow cup & Dikaios 1969, 239, Plate 61: no. 33 \\
\hline 961 & LH IIIA2 early & shallow cup & Dikaios 1969, 239, Plate 61: no. 32 \\
\hline 962 & LH IIIA2 & one-handled bowl & Dikaios 1969, 239, Plate 61: no. 34 \\
\hline 963 & LH IIIA1-LH IIIA2 & piriform jar & Dikaios 1969, 239, Plate 61: no. 30 \\
\hline
\end{tabular}




\begin{tabular}{|c|c|c|c|}
\hline ID & date & shape & published \\
\hline 964 & LH IIIA2 early & piriform jar & Dikaios 1969, 239, Plate 61: no. 31 \\
\hline 965 & LH IIIA2 early & piriform jar & Dikaios 1969, 239, Plate 61: no. 31A \\
\hline 966 & LH IIIA2 & stirrup jar & Dikaios 1969, 239, Plate 61: no. 37 \\
\hline 967 & LH IIIA2 & amphoroid krater & Dikaios 1969, 239, Plate 61: no. 38 \\
\hline 968 & LH IIIA2 & amphoroid krater & Dikaios 1969, 239, Plate 61: no. 35 \\
\hline 969 & LH IIIA2 & krater & Dikaios 1969, 239, Plate 61: no. 36 \\
\hline 970 & LH IIB-LH IIIA1 & stemmed cup & Dikaios 1969, 245, Plate 65: no. 17 \\
\hline 971 & LH IIB-LH IIIA1 & stemmed cup & Dikaios 1969, 245, Plate 65: no. 22, 22A \\
\hline 972 & LH IIIA1 & stemmed cup & Dikaios 1969, 245, Plate 65: no. 18, 19 \\
\hline 973 & LH IIIA2-LH IIIB & shallow cup & Dikaios 1969, 245, Plate 65: no. 23 \\
\hline 974 & LH IIIA2-LH IIIB & shallow cup & Dikaios 1969, 245, Plate 65: no. 24 \\
\hline 975 & LH IIIA2-LH IIIB & shallow cup & Dikaios 1969, 245, Plate 65: no. 25 \\
\hline 976 & LH IIIA2 & kylix & Dikaios 1969, 245, Plate 65: no. 31 \\
\hline 977 & LH IIIA2 & amphoroid krater & Dikaios 1969, 246, Plate 65: no. 20 \\
\hline 978 & LH IIIA2 & amphoroid krater & Dikaios 1969, 246, Plate 65: no. 27, 28 \\
\hline 979 & LH IIIA2 & amphoroid krater & Dikaios 1969, 246, Plate 65: no. 30 \\
\hline 980 & LH IIIA2 & fragment & Dikaios 1969, 246, Plate 65: no. 26 \\
\hline 981 & LH IIIA2 & fragment & Dikaios 1969, 246, Plate 65: no. 29 \\
\hline 982 & LH IIIB late & deep bowl & Dikaios 1969, 246, Plate 65: no. 21 \\
\hline 983 & LH IIIB & shallow cup & Dikaios 1969, 246, Plate 66: no. 1 \\
\hline 984 & LH IIIB & shallow cup & Dikaios 1969, 246, Plate 66: no. 2 \\
\hline 985 & LH IIIB & cylindrical cup & Dikaios 1969, 246, Plate 66: no. 13 \\
\hline 986 & LH IIIB & shallow bowl & Dikaios 1969, 246, Plate 66: no. 3 \\
\hline 987 & LH IIIB & shallow bowl & Dikaios 1969, 246, Plate 66: no. 5 \\
\hline 988 & LH IIIB & shallow bowl & Dikaios 1969, 146, Plate 66: no. 6 \\
\hline 989 & LH IIIB & shallow bowl & Dikaios 1969, 246, Plate 66: no. 9 \\
\hline 990 & LH IIIB & shallow bowl & Dikaios 1969, 246, Plate 66: no. 10 \\
\hline 991 & LH IIIB & shallow bowl & Dikaios 1969, 246, Plate 66: no. 11 \\
\hline 992 & LH IIIB & shallow bowl & Dikaios 1969, 246, Plate 66: no. 20 \\
\hline 993 & LH IIIB & shallow bowl & Dikaios 1969, 246, Plate 66: no. 21 \\
\hline 994 & LH IIIB & shallow bowl & Dikaios 1969, 246, Plate 66: no. 27 \\
\hline 995 & LH IIIB & kylix & Dikaios 1969, 246, Plate 66: no. 23 \\
\hline 996 & LH IIIB & jug & Dikaios 1969, 246, Plate 66: no. 7 \\
\hline 997 & LH IIIB & jug & Dikaios 1969, 246, Plate 66: no. 8 \\
\hline 998 & LH IIIB & stirrup jar & Dikaios 1969, 246, Plate 66: no. 17 \\
\hline 999 & LH IIIB & jug & Dikaios 1969, 246, Plate 66: no. 19 \\
\hline 1000 & LH IIIB & fragment & Dikaios 1969, 246, Plate 66: no. 19 \\
\hline 1001 & LH IIIA2-LH IIIB & piriform jar & Dikaios 1969, 246, Plate 66: no. 24 \\
\hline 1002 & LH IIIA2-LH IIIB & piriform jar & Dikaios 1969, 246, Plate 66: no. 26 \\
\hline 1003 & LH IIIA2-LH IIIB & amphoroid krater & Dikaios 1969, 246, Plate 66: no. 12 \\
\hline 1004 & LH IIIB & krater & Dikaios 1969, 246, Plate 66: no. 14 \\
\hline 1005 & LH IIIB & fragment & Dikaios 1969, 246, Plate 66: no. 15 \\
\hline 1006 & LH IIIB & ring-based krater & Dikaios 1969, 246, Plate 66: no. 25 \\
\hline 1007 & LM III & large stirrup jar & Dikaios 1969, 247, Plate 66: no. 29 \\
\hline 1008 & LM III & large stirrup jar & Dikaios 1969, 247, Plate 66: no. 29A \\
\hline 1009 & LM III & large stirrup jar & Dikaios 1969, 247, Plate 66: no. 22 \\
\hline 1010 & LM III & large stirrup jar & Dikaios 1969, 247, Plate 66: no. 31 \\
\hline 1011 & LH IIIA2 & shallow cup & Dikaios 1969, 247, Plate 66: no. 31 \\
\hline 1012 & LH IIIA2 & shallow cup & Dikaios 1969, 247, Plate 66: no. 33 \\
\hline 1013 & LH IIIA2 & shallow cup & Dikaios 1969, 247, Plate 66: no. 34 \\
\hline 1014 & LH IIIA2 & shallow cup & Dikaios 1969, 247, Plate 66: no. 32 \\
\hline
\end{tabular}




\begin{tabular}{|c|c|c|c|}
\hline ID & date & shape & published \\
\hline 1015 & LH IIIA2 & shallow cup & Dikaios 1969, 247, Plate 66: no. 35 \\
\hline 1016 & LH IIIA2 & shallow cup & Dikaios 1969, 247, Plate 66: no. 36 \\
\hline 1017 & LH IIIA2 & shallow cup & Dikaios 1969, 247, Plate 66: no. 37 \\
\hline 1018 & LH IIIA2 & shallow cup & Dikaios 1969, 247, Plate 66: no. 43 \\
\hline 1019 & LH IIIA2 & shallow cup & Dikaios 1969, 247, Plate 67: no. 11 \\
\hline 1020 & LH IIIA2 & amphoroid krater & Dikaios 1969, 247, Plate 66: no. 38 \\
\hline 1021 & LH IIIA2 & amphoroid krater & Dikaios 1969, 247, Plate 66: no. 41 \\
\hline 1022 & LH IIIA2 & amphoroid krater & Dikaios 1969, 247, Plate 66: no. 42 \\
\hline 1023 & LH IIIA2 & krater & Dikaios 1969, 247, Plate 66: no. 40 \\
\hline 1024 & LH IIIA2 & kylix & Dikaios 1969, 247, Plate 67: no. 1, 3 \\
\hline 1025 & LH IIIB & ring-based krater & Dikaios 1969, 247-248, Plate 66: no. 44 \\
\hline 1026 & LH IIIB & ring-based krater & Dikaios 1969, 248, Plate 66: no. 45 \\
\hline 1027 & LH IIIB & shallow cup & Dikaios 1969, 248, Plate 67: no. 18 \\
\hline 1028 & LH IIIB & shallow cup & Dikaios 1969, 248, Plate 67: no. 19 \\
\hline 1029 & LH IIIB-LH IIIC & deep bowl & Dikaios 1969, 248, Plate 67: no. 27 \\
\hline 1030 & $\mathrm{LH} I I I \mathrm{~B}$ & shallow bowl & Dikaios 1969, 248, Plate 67: no. 8 \\
\hline 1031 & LH IIIB & shallow bowl & Dikaios 1969, 248, Plate 67: no. 29 \\
\hline 1032 & LH IIIB & shallow bowl & Dikaios 1969, 248, Plate 67: no. 21 \\
\hline 1033 & LH IIIB & shallow bowl & Dikaios 1969, 248, Plate 67: no. 5 \\
\hline 1034 & LH IIIB & shallow bowl & Dikaios 1969, 248, Plate 67: no. 9 \\
\hline 1035 & LH IIIB & shallow bowl & Dikaios 1969, 248, Plate 67: no. 30 \\
\hline 1036 & LH IIIB & shallow bowl & Dikaios 1969, 248, Plate 66: no. 30, Plate 67: no.: 22 \\
\hline 1037 & LH IIIB & shallow bowl & Dikaios 1969, 248, Plate 67: no. 24 \\
\hline 1038 & LH IIIB & chalice & Dikaios 1969, 248, Plate 67: no. 20 \\
\hline 1039 & LH IIIB & piriform jar & Dikaios 1969, 248, Plate 67: no. 10 \\
\hline 1040 & LH IIIB & small globular jug & Dikaios 1969, 248, Plate 67: no. 14 \\
\hline 1041 & LH IIIB & stirrup jar & Dikaios 1969, 248, Plate 67: no. 17 \\
\hline 1042 & LH IIIA2-LH IIIB & squat stirrup jar & Dikaios 1969, 248, Plate 67: no. 12 \\
\hline 1043 & LH IIIB & fragment & Dikaios 1969, 248, Plate 67: no. 15 \\
\hline 1044 & LH IIIB & fragment & Dikaios 1969, 248, Plate 67: no. 16 \\
\hline 1045 & LM IIIB & large stirrup jar & Dikaios 1969, 248, Plate 67: no. 28 \\
\hline 1046 & LH IIIB & bull's head rhyton & Dikaios 1969, 248, Plate 67: no. 7 \\
\hline 1047 & LH IIIB & shallow bowl & Dikaios 1969, 260, Plate 69: no. 37 \\
\hline 1048 & LH IIIB & amphoroid krater & Dikaios 1969, 260, Plate 69: no. 34 \\
\hline 1049 & LH IIIB & shallow bowl & Dikaios 1969, 260, Plate 69: no. 27 \\
\hline 1050 & LH IIIB & shallow bowl & Dikaios 1969, 260, Plate 69: no. 39 \\
\hline 1051 & LH IIIB & kylix & Dikaios 1969, 260, Plate 69: no. 44 \\
\hline 1052 & LH IIIB & fragment & Dikaios 1969, 260, Plate 69: no. 46 \\
\hline 1053 & LH IIIB & fragment & Dikaios 1969, 260, Plate 69: no. 47 \\
\hline 1054 & LH IIIB & fragment & Dikaios 1969, 260, Plate 69: no. 48 \\
\hline 1055 & LH IIIB & cup & Dikaios 1969, 260, Plate 70: nos. 21, 24 \\
\hline 1056 & LH IIIB & shallow bowl & Dikaios 1969, 260, Plate 70: no. 23 \\
\hline 1057 & LH IIIA2 & stemmed cup & Dikaios 1969, 261, Plate 70: no. 13 \\
\hline 1058 & LH IIIA2 & globular flask, vertical type & Dikaios 1969, 261, Plate 70: no. 10 \\
\hline 1059 & LH IIIB & stirrup jar & Dikaios 1969, 261, Plate 70: no. 15 \\
\hline 1060 & LH IIIB & shallow bowl & Dikaios 1969, 261, Plate 70: no. 16 \\
\hline 1061 & LH IIIB & shallow bowl & Dikaios 1969, 261, Plate 69: no. 6 \\
\hline 1062 & LH IIIB & fragment & Dikaios 1969, 261, Plate 69: no. 7 \\
\hline 1063 & LH IIIB & piriform jar & Dikaios 1969, 261, Plate 69: no. 8 \\
\hline 1064 & LH IIIB & conical rhyton & Dikaios 1969, 261, Plate 69: no. 20 \\
\hline 1065 & LH IIIB & kylix & Dikaios 1969, 261, Plate 69: no. 18 \\
\hline
\end{tabular}




\begin{tabular}{|c|c|c|c|}
\hline ID & date & shape & published \\
\hline 1066 & LM IIIB & large stirrup jar & Dikaios 1969, 261, Plate 69: no. 21 \\
\hline 1067 & $\mathrm{LH} I I I A 2$ & amphoroid krater & Dikaios 1969, 262, Plate 70: no. 27 \\
\hline 1068 & LH IIIA2 & amphoroid krater & Dikaios 1969, 262, Plate 70: no. 28 \\
\hline 1069 & LH IIIA2 & amphoroid krater & Dikaios 1969, 262, Plate 70: no. 38 \\
\hline 1070 & LH IIIA2-LH IIIB & stirrup jar & Dikaios 1969, 262, Plate 70: no. 34 \\
\hline 1071 & LH IIIB & ring-based krater & Dikaios 1969, 262, Plate 70: no. 35 \\
\hline 1072 & LH IIIB & large piriform jar & Dikaios 1969, 262, Plate 70: no. 36 \\
\hline 1073 & LH IIIB & large piriform jar & Dikaios 1969, 262, Plate 70: no. 37 \\
\hline 1074 & LH IIIB & shallow bowl & Dikaios 1969, 262, Plate 70: no. 29 \\
\hline 1075 & LH IIIB & shallow bowl & Dikaios 1969, 262, Plate 70: no. 31 \\
\hline 1076 & LH IIIA2-LH IIIB & fragment & Dikaios 1969, 262, Plate 70: no. 31 \\
\hline 1077 & LH IIIA2 & fragment & Dikaios 1969, 262, Plate 70: no. 32 \\
\hline 1078 & LH IIIA2-LH IIIB & fragment & Dikaios 1969, 262, Plate 70: no. 33 \\
\hline 1079 & LH IIIA2-LH IIIB & fragment & Dikaios 1969, 262, Plate 71: no. 1 \\
\hline 1080 & LH IIIA2-LH IIIB & fragment & Dikaios 1969, 262, Plate 71: no. 2 \\
\hline 1081 & LH IIIA2 & amphoroid krater & Dikaios 1969, 262, Plate 71: no. 3 \\
\hline 1082 & LH IIIB & piriform jar & Dikaios 1969, 262, Plate 71: no. 7 \\
\hline 1083 & LH IIIB & shallow bowl & Dikaios 1969, 263, Plate 71: no. 4 \\
\hline 1084 & LM IIIB & large stirrup jar & Dikaios 1969, 263, Plate 71: no. 16 \\
\hline 1085 & LM IIIB & large stirrup jar & Dikaios 1969, 263, Plate 71: no. 17 \\
\hline 1086 & LH IIIA1 & shallow cup & Dikaios 1969, 265, Plate 72: no. 24 \\
\hline 1087 & LH IIIA2 & shallow cup & Dikaios 1969, 265, Plate 72: no. 23 \\
\hline 1088 & LH IIIA2 & shallow cup & Dikaios 1969, 265, Plate 72: no. 29 \\
\hline 1089 & LH IIIA2-LH IIIB & straight-sided alabastron & Dikaios 1969, 265, Plate 72: no. 27 \\
\hline 1090 & LH IIIA2 & amphoroid krater & Dikaios 1969, 265, Plate 72: no. 41 \\
\hline 1091 & LH IIIA2 & piriform jar & Dikaios 1969, 265, Plate 72: no. 42A \\
\hline 1092 & LH IIIA2 & fragment & Dikaios 1969, 265-266, Plate 72: no. 28 \\
\hline 1093 & LH IIIA2 & fragment & Dikaios 1969, 266, Plate 72: no. 32 \\
\hline 1094 & LH IIIA2 & deep stemmed bowl & Dikaios 1969, 266, Plate 72: nos. 40, 40A \\
\hline 1095 & LH IIIB & shallow cup & Dikaios 1969, 266, Plate 72: no. 30 \\
\hline 1096 & LH IIIB & deep bowl & Dikaios 1969, 266, Plate 73: no. 16 \\
\hline 1097 & LH IIIB & shallow bowl & Dikaios 1969, 266, Plate 72: no. 33 \\
\hline 1098 & LH IIIB & shallow bowl & Dikaios 1969, 266, Plate 73: no. 7 \\
\hline 1099 & LH IIIB & ring-based krater & Dikaios 1969, 266, Plate 72: no. 34 \\
\hline 1100 & LH IIIB & ring-based krater & Dikaios 1969, 266, Plate 72: no. 45 \\
\hline 1101 & LH IIIB & ring-based krater & Dikaios 1969, 266, Plate 72: no. 39 \\
\hline 1102 & LH IIIB & ring-based krater & Dikaios 1969, 266, Plate 72: no. 43 \\
\hline 1103 & LH IIIB & ring-based krater & Dikaios 1969, 266, Plate 72: no. 44 \\
\hline 1104 & LH IIIB & ring-based krater & Dikaios 1969, 266, Plate 73: no. 4 \\
\hline 1105 & LH IIIB & kylix & Dikaios 1969, 266, Plate 73: no. 2 \\
\hline 1106 & LH IIIB & kylix & Dikaios 1969, 266, Plate 73: no. 3 \\
\hline 1107 & LH IIIB & carinated conical cup & Dikaios 1969, 266, Plate 72: no. 31 \\
\hline 1108 & LH IIIA2 & fragment & Dikaios 1969, 266, Plate 72: no. 26 \\
\hline 1109 & $\mathrm{LH} \| \mathrm{II} 2$ & fragment & Dikaios 1969, 266, Plate 72: no. 25 \\
\hline 1110 & LH IIIA2 & fragment & Dikaios 1969, 266, Plate 72: no. 37 \\
\hline 1111 & LH IIIA2 & ring-based krater & Dikaios 1969, 266, Plate 72: no. 36 \\
\hline 1112 & LH IIIA2 & fragment & Dikaios 1969, 266, Plate 72: no. 42 \\
\hline 1113 & LH IIIB & straight-sided alabastron & Dikaios 1969, 266, Plate 73: no. 1 \\
\hline 1114 & LH IIIB & jug & Dikaios 1969, 266, Plate 73: no. 9 \\
\hline 1115 & LH IIIB & jug & Dikaios 1969, 266, Plate 73: no. 12 \\
\hline 1116 & LH IIIB & jug & Dikaios 1969, 266, Plate 73: no. 11 \\
\hline
\end{tabular}




\begin{tabular}{|c|c|c|c|}
\hline ID & date & shape & published \\
\hline 1117 & LH IIIB & lentoid flask & Dikaios 1969, 266, Plate 73: no. 13 \\
\hline 1118 & LH IIIB & one-handled lentoid flask & Dikaios 1969, 266, Plate 73: no. 14 \\
\hline 1119 & LH IIIB & piriform jar & Dikaios 1969, 266, Plate 73: no. 8 \\
\hline 1120 & LH IIIB & piriform jar & Dikaios 1969, 266, Plate 73: no. 10 \\
\hline 1121 & LH IIIB & piriform jar & Dikaios 1969, 266, Plate 73: no. 15 \\
\hline 1122 & LH IIIB & fragment & Dikaios 1969, 266, Plate 73: no. 6 \\
\hline 1123 & LH IIIB & fragment & Dikaios 1969, 266, Plate 73: no. 5 \\
\hline 1124 & LH IIIB & ring-based krater & Dikaios 1969, 280, Plate 78: no. 15 \\
\hline 1125 & LH IIIB & piriform jar & Dikaios 1969, 281, Plate 78: no. 1 \\
\hline 1126 & LH IIIB & stirrup jar & Dikaios 1969, 281, Plate 78: no. 4 \\
\hline 1127 & LH IIIB & ring-based krater & Dikaios 1969, 281, Plate 78: no. 6 \\
\hline 1128 & LH IIIB & fragment & Dikaios 1969, 281, Plate 78: no. 5 \\
\hline 1129 & LH IIIB & piriform jar & Dikaios 1969, 281, Plate 78: no. 14 \\
\hline 1130 & LH IIIB & shallow bowl & Dikaios 1969, 281, Plate 78: no. 14 \\
\hline 1131 & LH IIIA2 & shallow cup & Dikaios 1969, 283, Plate 80: no. 10 \\
\hline 1132 & LH IIIA2 & shallow cup & Dikaios 1969, 283, Plate 80: no. 13 \\
\hline 1133 & LH IIIA2 & shallow cup & Dikaios 1969, 283, Plate 80: no. 11 \\
\hline 1134 & LH IIIA2 & shallow cup & Dikaios 1969, 283, Plate 80: no. 15 \\
\hline 1135 & LH IIIA2 & amphoroid krater & Dikaios 1969, 283, Plate 80, nos. 14, 20 \\
\hline 1136 & $\mathrm{LH} \| \mathrm{IIB}$ & shallow cup & Dikaios 1969, 284, Plate 80: no. 19 \\
\hline 1137 & LH IIIB & shallow bowl & Dikaios 1969, 284, Plate 80: no. 26 \\
\hline 1138 & LH IIIB & shallow bowl & Dikaios 1969, 284, Plate 80: no. 28 \\
\hline 1139 & LH IIIB & ring-based krater & Dikaios 1969, 284, Plate 80: no. 21 \\
\hline 1140 & LH IIIB & ring-based krater & Dikaios 1969, 284, Plate 80: no. 25 \\
\hline 1141 & LH IIIB & jug & Dikaios 1969, 284, Plate 80: no. 27 \\
\hline 1142 & LM IIIB & large stirrup jar & Dikaios 1969, 284, Plate 80: no. 24 \\
\hline 1143 & LH IIIB & bridge-spouted bowl & Dikaios 1969, 284, Plate 80: no. 32 \\
\hline 1144 & LH IIIB & ring-based krater & Dikaios 1969, 298, Plate 85: no. 1 \\
\hline 1145 & LH IIIB & fragment & Dikaios 1969, 298, Plate 85: no. 4 \\
\hline 1146 & LH IIIB & shallow bowl & Dikaios 1969, 298, Plate 85: no. 8 \\
\hline 1147 & LH IIIB & shallow bowl & Dikaios 1969, 298, Plate 85: no. 9 \\
\hline 1148 & LH IIIB & shallow bowl & Dikaios 1969, 298, Plate 85: no. 6 \\
\hline 1149 & LH IIIB & shallow bowl & Dikaios 1969, 298, Plate 85: no. 11 \\
\hline 1150 & LH IIIB & rhyton & Dikaios 1969, 298, Plate 85: no. 5 \\
\hline 1151 & LH IIIA2 & stirrup jar & Dikaios 1969, 308, Plate 87: no. 6 \\
\hline 1152 & LH IIIA2 & stirrup jar & Dikaios 1969, 308, Plate 87: no. 12 \\
\hline 1153 & LH IIIA1-LH IIIA2 & shallow cup & Dikaios 1969, 308, Plate 87: no. 8 \\
\hline 1154 & LH IIIA2 & shallow cup & Dikaios 1969, 308, Plate 87: no. 14 \\
\hline 1155 & LH IIIA2 & shallow cup & Dikaios 1969, 308, Plate 87: no. 16 \\
\hline 1156 & LH IIIA2 & piriform jar & Dikaios 1969, 308, Plate 87: no. 17 \\
\hline 1157 & LH IIIA2-LH IIIB & jug with cut-away neck & Dikaios 1969, 308, Plate 87: no. 18 \\
\hline 1158 & LH IIIA2 & shallow cup & Dikaios 1969, 308, Plate 87: no. 26 \\
\hline 1159 & LH IIIA2 & shallow cup & Dikaios 1969, 308, Plate 87: no. 27 \\
\hline 1160 & LH IIIA2-LH IIIB & stirrup jar & Dikaios 1969, 308, Plate 87: no. 29 \\
\hline 1161 & LH IIIA2-LH IIIB & shallow cup & Dikaios 1969, 308, Plate 87: no. 25 \\
\hline 1162 & LH IIIB & shallow cup & Dikaios 1969, 309, Plate 87: no. 31 \\
\hline 1163 & LH IIIB & shallow cup & Dikaios 1969, 309, Plate 87: no. 32 \\
\hline 1164 & LH IIIB & cup & Dikaios 1969, 309, Plate 97: no. 34 \\
\hline 1165 & LH IIIB & shallow bowl & Dikaios 1969, 309, Plate 87: no. 35 \\
\hline 1166 & LH IIIB & cup & Dikaios 1969, 309, Plate 87: no. 39 \\
\hline 1167 & LH IIIB & jug & Dikaios 1969, 309, Plate 87: no. 40 \\
\hline
\end{tabular}




\begin{tabular}{|c|c|c|c|}
\hline ID & date & shape & published \\
\hline 1168 & LH IIIA2 & fragment & Dikaios 1969, Plate 67: no. 13 \\
\hline 1169 & LH IIIB & shallow bowl & Dikaios 1969, 309, Plate 87: no. 45 \\
\hline 1170 & LH IIIB & shallow bowl & Dikaios 1969, 309, Plate 87: no. 46 \\
\hline 1171 & LH IIIA2 & amphoroid krater & Dikaios 1969, 177 (not illustrated) \\
\hline 1172 & LH IIIB & fragment & Dikaios 1969, 309, Plate 87: no. 49 \\
\hline 1173 & LH IIIA2-LH IIIB & globular flask, vertical type & Dikaios 1969, 309, Plate 87: no. 50 \\
\hline 1174 & LH IIIB & bowl & Dikaios 1969, 309, Plate 87: no. 51 \\
\hline 1175 & LH IIIB & bowl & Dikaios 1969, 309, Plate 87: no. 55 \\
\hline 1176 & LH IIIB & bowl & Dikaios 1969, 309, Plate 87: no. 56 \\
\hline 1177 & LH IIIB & fragment & Dikaios 1969, 309, Plate 88: no. 1 \\
\hline 1178 & LH IIIB & fragment & Dikaios 1969, 309, Plate 88: no. 4 \\
\hline 1179 & LH IIIB & fragment & Dikaios 1969, 309, Plate 88: no. 5 \\
\hline 1180 & LH IIIB & bowl & Dikaios 1969, 309, Plate 88: no. 2 \\
\hline 1181 & LH IIIB & stirrup jar & Dikaios 1969, 309, Plate 88: no. 3 \\
\hline 1182 & LM IIIB & large stirrup jar & Dikaios 1969, 309, Plate 88: no. 6 \\
\hline 1183 & LH IIIB & stirrup jar & Dikaios 1969, 309, Plate 88: no. 15 \\
\hline 1184 & LH IIIB & shallow bowl & Dikaios 1969, 309, Plate 88: no. 18 \\
\hline 1185 & LH IIIB & bowl & Dikaios 1969, 309, Plate 88: no. 19 \\
\hline 1186 & LH IIIB & fragment & Dikaios 1969, 310, Plate 88: no. 40 \\
\hline 1187 & LH IIIB & fragment & Dikaios 1969, 310, Plate 88: no. 41 \\
\hline 1188 & LH IIIB & fragment & Dikaios 1969, 310, Plate 88: no. 47 \\
\hline 1189 & LH IIIA1-LH IIIA2 & shallow cup & Dikaios 1969, 310, Plate 91: no. 1 \\
\hline 1190 & LH IIIA2 & shallow cup & Dikaios 1969, 310, Plate 91: no. 2 \\
\hline 1191 & $\mathrm{LH} I I I A 2$ & deep krater & Dikaios 1969, 310, Plate 91: no. 3 \\
\hline 1192 & LH IIIA2 & krater & Dikaios 1969, 310, Plate 91: no. 4 \\
\hline 1193 & LH IIIA2 & shallow cup & Dikaios 1969, 310, Plate 91: no. 5 \\
\hline 1194 & LH IIIA1-LH IIIA2 & shallow cup & Dikaios 1969, 310, Plate 91: no. 7 \\
\hline 1195 & LH IIIA2 & globular flask, vertical type & Dikaios 1969, 310, Plate 91: no. 6 \\
\hline 1196 & LH IIIA2 & shallow cup & Dikaios 1969, 310, Plate 91: no. 8 \\
\hline 1197 & LH IIIA2-LH IIIB & stirrup jar & Dikaios 1969, 310, Plate 91: no. 9 \\
\hline 1198 & LH IIIA2 & shallow cup & Dikaios 1969, 310, Plate 91: no. 11 \\
\hline 1199 & LH IIIA2-LH IIIB & shallow cup & Dikaios 1969, 310, Plate 91: no. 10 \\
\hline 1200 & LH IIIA2 & shallow cup & Dikaios 1969, 310, Plate 91: no. 13 \\
\hline 1201 & LH IIIA2 & shallow cup & Dikaios 1969, 310, Plate 91: no. 14 \\
\hline 1202 & LH IIIA2-LH IIIB & shallow cup & Dikaios 1969, 310, Plate 91: no. 15 \\
\hline 1203 & LH IIIA2 & piriform jar & Dikaios 1969, 310, Plate 91: no. 16 \\
\hline 1204 & LH IIIA2 & shallow cup & Dikaios 1969, 310-311, Plate 91: no. 17 \\
\hline 1205 & LH IIIA2 & amphoroid krater & Dikaios 1969, 311, Plate 91: no. 12 \\
\hline 1206 & LH IIIB & shallow bowl & Dikaios 1969, 311, Plate 91: no. 18 \\
\hline 1207 & LM IIIB & large stirrup jar & Dikaios 1969, 311, Plate 91: no. 21 \\
\hline 1208 & LH IIIB & shallow bowl & Dikaios 1969, 311, Plate 91: no. 22 \\
\hline 1209 & LH IIIB & jug & Dikaios 1969, 311, Plate 91: no. 23 \\
\hline 1210 & LH IIIB & shallow bowl & Dikaios 1969, 312, Plate 92: nos. 1, 2 \\
\hline 1211 & LH IIIB & bowl & Dikaios 1969, 312, Plate 92: no. 3 \\
\hline 1212 & LH IIIB & shallow cup & Dikaios 1969, 312, Plate 92: no. 4 \\
\hline 1213 & LH IIIA2-LH IIIB & piriform jar & Dikaios 1969, 312, Plate 92: no. 5 \\
\hline 1214 & LH IIIB & piriform jar & Dikaios 1969, 312, Plate 92: no. 6 \\
\hline 1215 & LH IIIA2 & fragment & Dikaios 1969, 312, Plate 92: no. 7 \\
\hline 1216 & LH IIIB & fragment & Dikaios 1969, 312, Plate 92: no. 8 \\
\hline 1217 & LH IIIA2 & piriform jar & Dikaios 1969, 312, Plate 92: no. 10 \\
\hline 1218 & LH IIIA2-LH IIIB & fragment & Dikaios 1969, 312, Plate 92: np. 11 \\
\hline
\end{tabular}




\begin{tabular}{|c|c|c|c|}
\hline ID & date & shape & ublished \\
\hline 1219 & LM IIIB & large stirrup jar & Dikaios 1969, 312, Plate 92: no. 12 \\
\hline 1220 & LH IIIB & semi-globular cup with horizontal handle & Dikaios 1969, 312, Plate 92: no. 9 \\
\hline 1221 & LH IIIB & shallow cup & Dikaios 1969, 312, Plate 92: no. 14 \\
\hline 1222 & LH IIIB & shallow bowl & Dikaios 1969, 312, Plate 92: nos. 15, 16 \\
\hline 1223 & LH IIIB & large piriform jar & Dikaios 1969, 312, Plate 93: no. 17 \\
\hline 1224 & $\mathrm{LH} \| \mathrm{Ib}$ & piriform jar & Dikaios 1969, 312, Plate 92: no. 28 \\
\hline 1225 & LH IIIA2-LH IIIB & shallow cup & Dikaios 1969, 312, Plate 92: no. 20 \\
\hline 1226 & LH IIIA2-LH IIIB & shallow cup & Dikaios 1969, 312, Plate 92: no. 24 \\
\hline 1227 & LH IIIB & fragment & Dikaios 1969, 312, Plate 92: no. 26 \\
\hline 1228 & LH IIIB & fragment & Dikaios 1969, 312, Plate 92: no. 27 \\
\hline 1229 & LH IIIB & cup & Dikaios 1969, 312, Plate 92: no. 23 \\
\hline 1230 & LH IIIB & cup & Dikaios 1969, 312, Plate 92: no. 22 \\
\hline 1231 & LH IIIB & cup & Dikaios 1969, 312, Plate 92: no. 21 \\
\hline 1232 & LH IIIB & cup & Dikaios 1969, 312, Plate 92: no. 29 \\
\hline 1233 & LM IIIB & large piriform jar & Dikaios 1969, 312, Plate 92: no. 25 \\
\hline 1234 & LH IIIB & fragment & Dikaios 1969, 312, Plate 92: no. 30 \\
\hline 1235 & LH IIIB & fragment & Dikaios 1969, 312, Plate 92: no. 31 \\
\hline 1236 & LH IIIB & fragment & Dikaios 1969, 312, Plate 92: no. 32 \\
\hline 1237 & LH IIIB & fragment & Dikaios 1969, 312, Plate 92: no. 33 \\
\hline 1238 & LH IIIB & fragment & Dikaios 1969, 312, Plate 92: no. 35 \\
\hline 1239 & LH IIIA2-LH IIIB & shallow cup & Dikaios 1969, 312, Plate 92: no. 34 \\
\hline 1240 & LH IIIB & jug & Dikaios 1969, 313, Plate 93: no. 1 \\
\hline 1241 & LH IIIB & shallow bowl & Dikaios 1969, 313, Plate 93: no. 2 \\
\hline 1242 & LH IIIB & shallow cup & Dikaios 1969, 313, Plate 93: no. 2 \\
\hline 1243 & LH IIIB & fragment & Dikaios 1969, 313, Plate 93: no. 4 \\
\hline 1244 & LH IIIB & fragment & Dikaios 1969, 313, Plate 93: no. 8 \\
\hline 1245 & LH IIIB & fragment & Dikaios 1969, 313, Plate 93: no. 11 \\
\hline 1246 & LH IIIB-LH IIIC1a & deep bowl & Dikaios 1969, 313, Plate 93: no. 5 \\
\hline 1247 & LH IIIB & shallow bowl & Dikaios 1969, 313, Plate 93: no. 6 \\
\hline 1248 & LH IIIB & shallow bowl & Dikaios 1969, 313, Plate 93: no. 10 \\
\hline 1249 & LH IIIB & shallow bowl & Dikaios 1969, 313, Plate 93: no. 12 \\
\hline 1250 & LH IIIB & bowl & Dikaios 1969, 313, Plate 93: no. 9 \\
\hline 1251 & LH IIIB & bowl & Dikaios 1969, 313, Plate 93: no. 13 \\
\hline 1252 & LH IIIB & bowl & Dikaios 1969, 313, Plate 93: no. 7 \\
\hline 1253 & LM IIIB & large stirrup jar & Dikaios 1969, 313, Plate 93: no. 14 \\
\hline 1254 & LH IIIB & fragment & Dikaios 1969, 313, Plate 93: no. 15 \\
\hline 1255 & LH IIIB & shallow bowl & Dikaios 1969, 313, Plate 93: no. 17 \\
\hline 1256 & LH IIIB & shallow bowl & Dikaios 1969, 313, Plate 93: no. 19 \\
\hline 1257 & LH IIIB & bowl & Dikaios 1969, 313, Plate 93: no. 20 \\
\hline 1258 & LH IIIB & ring-based krater & Dikaios 1969, 313, Plate 93: no. 22 \\
\hline 1259 & LH IIIB & ring-based krater & Dikaios 1969, 313, Plate 93: no. 21 \\
\hline 1260 & LH IIIB & ring-based krater & Dikaios 1969, 314, Plate 93: no. 26 \\
\hline 1261 & LH IIIB & shallow bowl & Dikaios 1969, 314, Plate 93: no. 35 \\
\hline 1262 & LH IIIB & shallow bowl & Dikaios 1969, 314, Plate 94: no. 1 \\
\hline 1263 & LH IIIB & shallow bowl & Dikaios 1969, 314, Plate 94: no. 2 \\
\hline 1264 & LH IIIB & shallow bowl & Dikaios 1969, 314, Plate 94: no. 5 \\
\hline 1265 & LH IIIB & shallow bowl & Dikaios 1969, 314, Plate 94: no. 16 \\
\hline 1266 & LH IIIB & piriform jar & Dikaios 1969, 314, Plate 94: no. 26 \\
\hline 1267 & LH IIIB & large piriform jar & Dikaios 1969, 315, Plate 94: no. 8 \\
\hline 1268 & LH IIIB & bowl & Dikaios 1969, 316, Plate 95: no. 2 \\
\hline 1269 & LH IIIB & fragment & Dikaios 1969, 316, Plate 95: no. 6 \\
\hline
\end{tabular}




\begin{tabular}{|c|c|c|c|}
\hline ID & date & shape & published \\
\hline 1270 & LH IIIA2 & globular flask, horizontal type & Dikaios 1969, 316, Plate 95: no. 14 \\
\hline 1271 & LH IIIB & shallow bowl & Dikaios 1969, 316, Plate 95: no. 12 \\
\hline 1272 & LH IIIA2-LH IIIB & fragment & Dikaios 1969, 316, Plate 95: no. 15 \\
\hline 1273 & LH IIIB & stirrup jar & Dikaios 1969, 316, Plate 95: no. 16 \\
\hline 1274 & LH IIIB & shallow bowl & Dikaios 1969, 317, Plate 96: no. 2 \\
\hline 1275 & LH IIIB & shallow stemmed bowl & Dikaios 1969, 317, Plate 96: no. 6 \\
\hline 1276 & LH IIIB & jug & Dikaios 1969, 317, Plate 97: no. 1 \\
\hline 1277 & LH IIIA2 & amphoroid krater & Dikaios 1969, 317, Plate 97: no. 2 \\
\hline 1278 & LH IIIB-LH IIIC & shallow bowl & Dikaios 1969, 317, Plate 97: no. 3 \\
\hline 1279 & LH IIIB & shallow bowl & Dikaios 1969, 317, Plate 97: no. 4 \\
\hline 1280 & LH IIIA2-LH IIIB & amphoroid krater & Dikaios 1969, 317, Plate 97: no. 5 \\
\hline 1281 & LH IIIB & ring-based krater & Dikaios 1969, 317, Plate 97: no. 6 \\
\hline 1282 & LH IIIB & ring-based krater & Dikaios 1969, 317, Plate 97: no. 7 \\
\hline 1283 & LH IIIA2 & amphoroid krater & Dikaios 1969, 317, Plate 97: no. 8 \\
\hline 1284 & LH IIIB & shallow bowl & Dikaios 1969, 317, Plate 97: no. 9 \\
\hline 1285 & LH IIIB & shallow bowl & Dikaios 1969, 317, Plate 97: no. 13 \\
\hline 1286 & LH IIIB & kylix & Dikaios 1969, 317, Plate 97: no. 12 \\
\hline 1287 & LH IIIB & shallow bowl & Dikaios 1969, 318, Plate 98: no. 16 \\
\hline 1288 & LH IIIB-LH IIIC1a & deep bowl & Dikaios 1969, 318, Plate 98: no. 18 \\
\hline 1289 & LH IIIB & fragment & Dikaios 1969, 318, Plate 98: no. 19 \\
\hline 1290 & LH IIIB & shallow bowl & Dikaios 1969, 318, Plate 98: no. 20 \\
\hline 1291 & LH IIIB & shallow bowl & Dikaios 1969, 318, Plate 98: no. 23 \\
\hline 1292 & LH IIIB & ring-based krater & Dikaios 1969, 318, Plate 98: no. 21 \\
\hline 1293 & LM IIIB & large stirrup jar & Dikaios 1969, 318, Plate 98: no. 22 \\
\hline 1294 & LH IIIB & fragment & Dikaios 1969, 318, Plate 98: no. 28 \\
\hline 1295 & LH IIIB & shallow bowl & Dikaios 1969, 318, Plate 98: no. 25 \\
\hline 1296 & LH IIIB & cup & Dikaios 1969, 318, Plate 98: no. 27 \\
\hline 1297 & LH IIIB & shallow bowl & Dikaios 1969, 319, Plate 98: no. 29 \\
\hline 1298 & LH IIIB & shallow bowl & Dikaios 1969, 319, Plate 98: no. 30 \\
\hline 1299 & LH IIIB & shallow bowl & Dikaios 1969, 319, Plate 98: no. 39 \\
\hline 1300 & LH IIIB & jug & Dikaios 1969, 319, Plate 98: no. 33 \\
\hline 1301 & LH IIIB & jug & Dikaios 1969, 319, Plate 98: no. 38 \\
\hline 1302 & LH IIIA2-LH IIIB & amphoroid krater & Dikaios 1969, 319, Plate 99: no. 11 \\
\hline 1303 & LH IIIB & stirrup jar & Dikaios 1969, 319, Plate 99: no. 18 \\
\hline 1304 & LH IIIB & fragment & Dikaios 1969, 319, Plate 99: no. 19 \\
\hline 1305 & LH IIIB & shallow bowl & Dikaios 1969, 319, Plate 99: no. 22 \\
\hline 1306 & LH IIIB & shallow bowl & Dikaios 1969, 319, Plate 99: no. 23 \\
\hline 1307 & LH IIIB & bowl & Dikaios 1969, 320, Plate 99: no. 46 \\
\hline 1308 & LH IIIA2 & shallow cup & Dikaios 1969, 321, Plate 100: no. 12 \\
\hline 1309 & LH IIIB & fragment & Dikaios 1969, 321, Plate 100: no. 13 \\
\hline 1310 & LH IIIA2-LH IIIB & amphoroid krater & Dikaios 1969, 321, Plate 100: no. 17 \\
\hline 1311 & LH IIIB & bowl & Dikaios 1969, 321, Plate 100: no. 21 \\
\hline 1312 & LH IIIA2-LH IIIB & semi-globular cup & Dikaios 1969, 322, Plate 101: no. 37 \\
\hline 1313 & LH IIIB & fragment & Dikaios 1969, 322, Plate 101: no. 1 \\
\hline 1314 & LH IIIB & fragment & Dikaios 1969, 322, Plate 101: no. 6 \\
\hline 1315 & LH IIIB & shallow bowl & Dikaios 1969, 322, Plate 101: no. 7 \\
\hline 1316 & LH IIIB & shallow bowl & Dikaios 1969, 322, Plate 101: no. 21 \\
\hline 1317 & LH IIIB & shallow bowl & Dikaios 1969, 322, Plate 101: no. 22 \\
\hline 1318 & LH IIIB & cup & Dikaios 1969, Plate 87: no. 57 \\
\hline 1319 & LH IIIB & ring-based krater & Dikaios 1969, 329, Plate 109.1 \\
\hline 1320 & LH IIIB & shallow cup & Dikaios 1969, 329, Plate 109.2 \\
\hline
\end{tabular}




\begin{tabular}{|c|c|c|c|}
\hline ID & date & shape & published \\
\hline 1321 & LM IIIB & large stirrup jar & Dikaios 1969, 329, Plate 109.3 \\
\hline 1322 & LH IIIA2 & amphoroid krater & Dikaios 1969, 330, Plate 110: no. 1 \\
\hline 1323 & LH IIIA2 & bull's head rhyton & Dikaios 1969, 330, Plate 110: nos. 2, 3 \\
\hline 1324 & LH IIIA2 & one-handled bowl & Dikaios 1969, 330, Plate 110: no. 4 \\
\hline 1325 & LH IIIA2 & piriform jar & Dikaios 1969, 330, Plate 110: no. 5 \\
\hline 1326 & LM IIIB & large stirrup jar & Dikaios 1969, 330, Plate 110: no. 7 \\
\hline 1327 & LH IIIB & wide-necked globular jug & Dikaios 1969, 330, Plate 110: no. 8 \\
\hline 1328 & LH IIIB & shallow cup & Dikaios 1969, 335: no. 11, Plate 192: no. 14 \\
\hline 1329 & LH IIIB & deep bowl & Dikaios 1969, 335: no. 18, Plate 192: no. 5 \\
\hline 1330 & LH IIIB & ring-based krater & Dikaios 1969, 335: no. 19, Plate 192: no. 16 \\
\hline 1331 & LH IIIA2 & straight-sided alabastron & Dikaios 1969, 339: no. 27, Plate 296: no. 31 \\
\hline 1332 & LH IIIB & shallow bowl & Dikaios 1969, 339: no. 28, Plate 196: no. 28 \\
\hline 1333 & LH IIIA2 & straight-sided alabastron & Dikaios 1969, 339: no. 41, Plate 196: no. 30 \\
\hline 1334 & LH IIIB & small globular jug & Dikaios 1969, 343: no. 158, Plate 196: no. 17 \\
\hline 1335 & LH IIIB & conical cup & Dikaios 1969, 343: no. 159, Plate 196; no. 21 \\
\hline 1336 & LM IIIB & large stirrup jar & Dikaios 1969, 343: no. 160, Plate 196: no. 16 \\
\hline 1337 & LH IIIB & stemmed shallow bowl & Dikaios 1969, 343: no. 168, Plate 195: no. 47 \\
\hline 1338 & LH IIIB & shallow bowl & Dikaios 1969, 343: no. 170, Plate 196: no. 19 \\
\hline 1339 & LH IIIB & shallow bowl & Dikaios 1969, 343: no. 171, Plate 196: no. 29 \\
\hline 1340 & LH IIIA2 & shallow cup & Dikaios 1969, 343; no. 172, Plate 196: no. 20 \\
\hline 1341 & LH IIIA1 & shallow cup & Dikaios 1969, 343: no. 173, Plate 196: no. 17A \\
\hline 1342 & LH IIIA2 & shallow cup & Dikaios 1969, 344: no. 174, Plate 196: no. 26 \\
\hline 1343 & LH IIIA2-LH IIIB & shallow cup & Dikaios 1969, 344: no. 175, Plate 196: no. 25 \\
\hline 1344 & LH IIIA2-LH IIIB & shallow cup & Dikaios 1969, 344: no. 176, Plate 196: no. 27 \\
\hline 1345 & LH IIIB & conical cup & Dikaios 1969, 344: no. 177, Plate 196: no. 24 \\
\hline 1346 & LH IIIA2 & piriform jar & Dikaios 1969, 344-345: no. 178, Plate 196: no. 33 \\
\hline 1347 & LH IIIA2 & piriform jar & Dikaios 1969, 345: no. 179, Plate 196: no. 32 \\
\hline 1348 & LH IIIA2 & conical piriform stirrup jar & Dikaios 1969, 345-346: no. 180, Plate 196: no. 34 \\
\hline 1349 & LH IIIA2-LH IIIB & globular stirrup jar & Dikaios 1969, 346: no. 181, Plate 196: no. 36 \\
\hline 1350 & LH IIIA2-LH IIIB & globular stirrup jar & Dikaios 1969, 346, Plate 196: no. 35 \\
\hline 1351 & LH IIIB & large piriform jar & Dikaios 1969, 346: no. 183, Plate 196: no. 18 \\
\hline 1352 & LH IIIA2 & one-handled bowl & Dikaios 1969, 354: no. 4A, Plate 199: no. 4 \\
\hline 1353 & LH IIIA2 & amphoroid krater & Dikaios 1969, 354: nos. 4b-i, Plate 199: nos. 5-12 \\
\hline 1354 & LH IIIB & conical cup & Dikaios 1969, 355: no. 4, Plates 199: no. 20, 200: nos. 11-12 \\
\hline 1355 & LH IIIB & conical stirrup jar & Dikaios 1969, 355: no. 8, Plate 199: no. 17, 200: nos. 4-5 \\
\hline 1356 & LH IIIB & bowl & Dikaios 1969, 355: no. 10, Plate 199: no. 26 \\
\hline 1357 & LH IIIB & bowl & Dikaios 1969, 355-356: no. 12, Plates 199: no. 12, 200: no. 3 \\
\hline 1358 & LH IIIB & stirrup jar & Dikaios 1969, 356: no. 18, Plates 199: no. 16, 200: no. 1 \\
\hline 1359 & LH IIIB & shallow cup & Dikaios 1969, 366: no. 3, Plate 211: no. 12 \\
\hline 1360 & LH IIIB & shallow bowl & Dikaios 1969, 366: no. 4, Plate 211: no. 13 \\
\hline 1361 & LH IIIB & shallow cup & Dikaios 1969, 366: no. 6, Plate 211: no. 11 \\
\hline 1362 & LH IIIB & shallow cup & Dikaios 1969, 366: no. 8, Plate 211: no. 10 \\
\hline 1363 & LH IIIB & shallow bowl & Dikaios 1969, 366: no. 10, Plate 211: no. 15 \\
\hline 1364 & LH IIIB & shallow bowl & Dikaios 1969, 366: no. 11, Plate 211: no. 16 \\
\hline 1365 & LH IIIA2 & shallow cup & Dikaios 1969, 366: no. 20, Plate 211: no. 8 \\
\hline 1366 & LH IIIA2 & amphoroid krater & Dikaios 1969, 367: no. 23, Plates 203: no. 19, 204, 204A \\
\hline 1367 & LH IIIA2-LH IIIB & shallow cup & Dikaios 1969, 367: no. 24, Plate 211: no. 6 \\
\hline 1368 & LH IIIA2-LH IIIB & shallow cup & Dikaios 1969, 367: no. 37, Plate 211: no. 5 \\
\hline 1369 & LH IIIB & squat stirrup jar & Dikaios 1969, 367: no. 45, Plate 211: no. 19 \\
\hline 1370 & LH IIIA2 & shallow cup & Dikaios 1969, 368: no. 46, Plate 211: no. 4 \\
\hline 1371 & LH IIIB & one-handled bowl & Dikaios 1969, 368: no. 61, Plate 211: no. 25 \\
\hline
\end{tabular}




\begin{tabular}{|c|c|c|c|}
\hline ID & date & shape & published \\
\hline 1372 & LH IIIB & squat stirrup jar & Dikaios 1969, 369: no. 68, Plate 210: no. 45 \\
\hline 1373 & LH IIIB & straight-sided alabastron & Dikaios 1969, 369: no. 70, Plate 211: no. 26 \\
\hline 1374 & LH IIIA2-LH IIIB & shallow cup & Dikaios 1969, 369: no. 74, Plate 211: no. 9 \\
\hline 1375 & LH IIIB & globular stirrup jar & Dikaios 1969, 369: no. 78, Plate 211: no. 20 \\
\hline 1376 & LH IIIA2 & piriform jar & Dikaios 1969, 369: no. 79, Plate 210: no. 46 \\
\hline 1377 & LH IIIA2 & shallow cup & Dikaios 1969, 369: no. 80, Plate 211: no. 1 \\
\hline 1378 & LH IIIA2 & ostrich egg rhyton & Dikaios 1969, 370: no. 108, Plate 210: nos. 47, 48 \\
\hline 1379 & LH IIIA2 & straight-sided alabastron & Dikaios 1969, 371: no. 122, Plate 211: no. 21 \\
\hline 1380 & LH IIIA2 & piriform jar & Dikaios 1969, 371: no. 123, Plate 211: no. 22 \\
\hline 1381 & LH IIIA2-LH IIIB & straight-sided alabastron & Dikaios 1969, 372: no. 233, Plate 210: no. 49 \\
\hline 1382 & LH IIIA2 & shallow cup & Dikaios 1969, 372: no. 143, Plate 211: no. 3 \\
\hline 1383 & LH IIIA2 & piriform jar & Dikaios 1969, 372: no. 147, Plate 210: no. 44 \\
\hline 1384 & LH IIIA2 & shallow cup & Dikaios 1969, 373: no. 154, Plate 211: no. 2 \\
\hline 1385 & LH IIIA2 & piriform jar & Dikaios 1969, 374: no. 196, Plate 208: no. 17 \\
\hline 1386 & LH IIIA2 & amphoroid krater & Dikaios 1969, 375: no. 200, Plate 203: no. 13, 223: no. 12, 225 \\
\hline 1387 & LH IIIA1 & shallow cup & Dikaios 1969, 375: no. 209, Plate 208: no. 4 \\
\hline 1388 & LH IIIA2 & shallow cup & Dikaios 1969, 375: no. 211, Plate 208: no. 1 \\
\hline 1389 & LH IIIA1 & straight-sided alabastron & Dikaios 1969, 376: no. 218, Plate 207: no. 41 \\
\hline 1390 & $\mathrm{LH} \| \mathrm{II} 2$ & piriform jar & Dikaios 1969, 376: no. 220, Plate 208: no. 15 \\
\hline 1391 & LH IIIA2 & piriform jar & Dikaios 1969, 376: no. 230, Plate 208: no. 10 \\
\hline 1392 & LH IIIA2 & piriform jar & Dikaios 1969, 376: no. 233, Plate 208: no. 11 \\
\hline 1393 & LH IIIA2-LH IIIB & globular stirrup jar & Dikaios 1969, 377: no. 238, Plate 207: nos. 42.43 \\
\hline 1394 & LH IIIA1 & shallow cup & Dikaios 1969, 377: no. 248, Plate 208: no. 3 \\
\hline 1395 & LH IIIA2-LH IIIB & shallow cup & Dikaios 1969, 377: no. 252, Plate 208: no. 7 \\
\hline 1396 & LH IIIA2 & shallow cup & Dikaios 1969, 377-378: no. 253, Plate 208: no. 2 \\
\hline 1397 & LH IIIA2-LH IIIB & piriform jar & Dikaios 1969, 378: no. 271, Plate 208: no. 14 \\
\hline 1398 & LH IIIA2 & piriform jar & Dikaios 1969, 378: no. 272, Plate 208: no. 12 \\
\hline 1399 & LH IIIA2-LH IIIB & shallow cup & Dikaios 1969, 379: no. 286, Plate 208: no. 5 \\
\hline 1400 & LH IIIA2-LH IIIB & globular stirrup jar & Dikaios 1969, 379: no. 287, Plate 208: no. 19 \\
\hline 1401 & LH IIIA2-LH IIIB & globular stirrup jar & Dikaios 1969, 380: no. 303, Plate 208: no. 13 \\
\hline 1402 & LH IIIA2 & straight-sided alabastron & Dikaios 1969, 380: no. 305, Plate 208: no. 21 \\
\hline 1403 & LH IIIA2-LH IIIB & shallow cup & Dikaios 1969, 380: no. 306, Plate 203: no. 32 \\
\hline 1404 & LH IIIA2 & shallow cup & Dikaios 1969, 380: no. 308, Plate 203: no. 26 \\
\hline 1405 & LH IIIA2 & piriform jar & Dikaios 1969, 380: no. 313, Plate 203: no. 33 \\
\hline 1406 & $\mathrm{LH} I I I A 2$ & shallow cup & Dikaios 1969, 383: no. 375, Plate 203: no. 28 \\
\hline 1407 & LH IIIA2 & piriform jar & Dikaios 1969, 383: no. 377, Plate 203: no. 30 \\
\hline 1408 & LH IIIA1 & shallow cup & Dikaios 1969, 383: no. 378, Plate 203: no. 27 \\
\hline 1409 & $\mathrm{LH} I I I A 2$ & piriform jar & Dikaios 1969, 383: no. 382, Plate 203: no. 31 \\
\hline 1410 & LH IIIA2 & shallow cup & Dikaios 1969, 384: no. 397, Plate 203: no. 25 \\
\hline 1411 & $\mathrm{LH} \| \mathrm{IA} 2$ & shallow cup & Dikaios 1969, 388: no. 505, Plates 209: no. 27, 212: no. 15 \\
\hline 1412 & LH IIIB & kylix & Dikaios 1969, 394: no. 10, Plate 213: no. 10 \\
\hline 1413 & LH IIIA2 & cup & Dikaios 1969, 395: no. 12, Plates 200: no. 9, 213: no. 11 \\
\hline 1414 & LH IIIA2-LH IIIB & piriform jar & Dikaios 1969, 395: no. 14, Plate 213: no. 5 \\
\hline 1415 & LH IIIB & stirrup jar & Dikaios 1969, 395: no. 17, Plate 213: no. 14 \\
\hline 1416 & LH IIIB & cup & Dikaios 1969, 395: no. 18, Plate 213: no. 15 \\
\hline 1417 & LH IIIB & fragment & Dikaios 1969, 395: no. 19, Plate 213: no. 16 \\
\hline 1418 & LH IIIB & stirrup jar & Dikaios 1969, 395: no. 20, Plate 213: no. 17 \\
\hline 1419 & LH IIIB & cylindrical cup & Dikaios 1969, 396: no. 1, Plate 214: no. 1 \\
\hline 1420 & LH IIIB & cylindrical jug & Dikaios 1969, 397: no. 2, Plate 214: no. 2 \\
\hline 1421 & LH IIIB-LH IIIC & fragment & Dikaios 1969, 403: no. 8, Plate 215: no. 13 \\
\hline 1422 & LH IIIB-LH IIIC & fragment & Dikaios 1969, 403: no. 9, Plate 215: no. 13 \\
\hline
\end{tabular}




\begin{tabular}{|c|c|c|c|}
\hline ID & date & shape & published \\
\hline 1423 & LH IIIA1 & shallow cup & Dikaios 1969, 411: no. 31, Plates 216: no. 16, 217: no. 7 \\
\hline 1424 & LH IIIB & amphoroid krater & Courtois, Lagarce \& Lagarce 1986, 58, Plate 16: no. 1 \\
\hline 1425 & & fragment & Courtois, Lagarce \& Lagarce 1986, 58 (not illustrated) \\
\hline 1426 & & fragment & Åström 1972b, 383: E.7 suppl (not illustrated) \\
\hline 1427 & & fragment & Åström 1972b, 383: CypMus 1959/II-3/3 (not illustrated) \\
\hline 1428 & & fragment & Åström 1972b, 383: Europa (not illustrated) \\
\hline 1429 & LH IIIA1 & large piriform jar & Sieveking \& Hackl 1912, 4, Tafel 3: no. 28 \\
\hline 1430 & LH IIIB & amphoroid krater & Catling \& Millett 1965, 222: no. 10, Plate 59: no. 5 \\
\hline 1431 & LH IIIA2-LH IIIB & piriform jar & Dikaios 1969, Plate 82: no. 15 \\
\hline 1432 & LH III & stemmed cup & Åström 1972b, 367: E.21, suppl. (not illustrated) \\
\hline 1433 & LH IIIB & ring-based krater & Åström 1972b, 371: no. 281 k3 (not illustrated) \\
\hline 1434 & LH III & fragment & Millett \& Catling 1966, 93-94 Plate 1: no. 14 \\
\hline 1435 & LH III & fragment & Millett \& Catling 1966, 93-94 Plate 1: no. 15 \\
\hline 1436 & LH III & fragment & Millett \& Catling 1966, 93-94 Plate 1: no. 16 \\
\hline 1437 & LH III & fragment & Millett \& Catling 1966, 93-94 Plate 1: no. 17 \\
\hline 1438 & $\mathrm{LH} \| \mathrm{I}$ & fragment & Millett \& Catling 1966, 93-94 Plate 1: no. 18 \\
\hline 1439 & LH III & fragment & Millett \& Catling 1966, 93-94 Plate 1: no. 19 \\
\hline 1440 & LH III & fragment & Millett \& Catling 1966, 93-94 Plate 1: no. 20 \\
\hline 1441 & LH III & fragment & Millett \& Catling 1966, 93-94 Plate 1: no. 21 \\
\hline 1442 & LM III & fragment & Millett \& Catling 1966, 93-94 Plate 1: no. 22 \\
\hline 1443 & LH III & fragment & Millett \& Catling 1966, 93-94 Plate 1: no. 23 \\
\hline 1444 & LH III & fragment & Millett \& Catling 1966, 93-94 Plate 1: no. 24 \\
\hline 1445 & LH III & fragment & Millett \& Catling 1966, 93-94 Plate 1: no. 25 \\
\hline 1446 & LH IIIB & amphoroid krater & Mossberg 1975, 119-120 fig. 1: no. 1, fig. 4 \\
\hline 1447 & LH III & fragment & Mossberg 1975, 119-120 fig. 1: no. 2 \\
\hline 1448 & LH IIIA2-LH IIIB & amphoroid krater & Dikaios 1969, Plate 61: no. 15 \\
\hline 1449 & LH IIIA2-LH IIIB & fragment & Dikaios 1969, plate 87: no. 21 \\
\hline 1450 & & krater & Murray, Smith \& Walters 1900, 3 (not illustrated) \\
\hline 1451 & LH IIIA2 & small jug & Andersson 1980, 25: no. 712a \\
\hline 1452 & LH IIIA2-LH IIIB & conical piriform stirrup jar & Andersson 1980, 25: no. 712b \\
\hline 1453 & LH IIIA2-LH IIIB & conical piriform stirrup jar & Andresson 1980, 25: no. 712c \\
\hline 1454 & LH IIIA2 & conical piriform stirrup jar & Andersson 1980, 25: no. 712d \\
\hline 1455 & $\mathrm{LH} \| \mathrm{II} 2$ & globular stirrup jar & Andersson 1980, 26: no. 712e \\
\hline 1456 & $\mathrm{LH} I I \mathrm{~A} 2$ & squat stirrup jar & Andersson 1980, 26: no. $712 f$ \\
\hline 1457 & $\mathrm{LH} \| \mathrm{II} 2$ & globular flask, horizontal type & Andersson 1980, 26: no. $712 \mathrm{~g}$ \\
\hline 1458 & $\mathrm{LH} I I \mathrm{~A} 2$ & straight-sided alabastron & Andersson 1980, 26: no. $712 \mathrm{~h}$ \\
\hline 1459 & LH IIIA1-LH IIIA2 & shallow cup & Andersson 1980, 26: no. 712i \\
\hline 1460 & LH IIIA2 & shallow cup & Andersson 1980, 26: no. $712 \mathrm{j}$ \\
\hline 1461 & LH IIIA2-LH IIIB & shallow cup & Andersson 1980, 26: no. 712k \\
\hline 1462 & LH IIIB & shallow bowl & Andersson 1980, 26: no. 712l \\
\hline 1463 & LH IIIB-LH IIIC & shallow bowl & Andersson 1980, 26: no. 712m \\
\hline 1464 & LH IIIA2 & piriform jug with cut-away neck & Andersson 1980, 27: no. 355a \\
\hline 1465 & LH IIIB & squat stirrup jar & Andersson 1980, 30: no. $713 f$ \\
\hline 1466 & LH IIIB-LH IIIC & ring-based krater & Andersson 1980, 30: no. $713 \mathrm{~g}$ \\
\hline
\end{tabular}


Catalogue V cont.

\section{Mycenaean figurines}

\begin{tabular}{llll}
\hline ID & date & sort & published \\
\hline 2001 & LH IIIA-LH IIIB & bovine & Murray, Smith \& Walters 1900, fig. 17 no. 157 \\
2002 LH IIIB & chariot & Murray, Smith \& Walters 1900, 54 (not illustrated) \\
2003 LH IIIB-LH IIIC & female & Coche de la Ferté 1951, 18, Plate 7: no. 1 \\
2004 LH IIIB & bovine & Coche de la Ferté 1951, 20-21, Plate 7: no. 5 \\
2005 LH IIIB-LH IIIC & bovine & Schaeffer 1952, 22 no. 14 \\
2006 LH IIIB & female & Dikaios 1969, plate 131: no. 34 \\
\hline
\end{tabular}




\section{Catalogue VI: Mycenaean pottery at Athienou}

1 Mycenaean vessels and fragments

\begin{tabular}{|c|c|c|c|}
\hline ID & date & shape & published \\
\hline 1 & LH IIIA2-LH IIIB & straight-sided alabastron & Åström 1972b, 325 (not illustrated) \\
\hline 2 & & stirrup jar & Åström 1972b, 348 (not illustrated) \\
\hline 3 & LH IIIB & one-handled kylix & Åström 1972b, 366: no. 267b (not illustrated) \\
\hline 4 & & fragment & Åström 1972b, 383 (not illustrated) \\
\hline 5 & LH IIIB & shallow cup & Dothan \& Ben-Tor 1983, 46-47 fig 12: no. $1(3039 / 2)$ \\
\hline 6 & LH IIIB & shallow cup & Dothan \& Ben-Tor 1983, 46-47 fig. 12: no. 2 (3039/1) \\
\hline 7 & LH IIIB & shallow bowl & Dothan \& Ben-Tor 1983, $48-49$ fig. 13: no. 2 (2158) \\
\hline 8 & LH IIIB & shallow bowl & Dothan \& Ben-Tor 1983, 48-49 fig. 13: no. 3 (2135) \\
\hline 9 & LH IIIB & ring-based krater & Dothan \& Ben-Tor 1983, 48-49 fig. 13: no. 1 (2130) \\
\hline 10 & LH IIIB & large stirrup jar & Dothan \& Ben-Tor 1983, $48-49$ fig. 13: no. 4 (2134) \\
\hline 11 & LH IIIB & hand-made miniature jug & Dothan \& Ben-Tor 1983, 49-50 fig. 14: no. 1 (976) \\
\hline 12 & LH IIIB & hand-made miniature jug & Dothan \& Ben-Tor 1983, 49-50 fig. 14: no. 2 (992) \\
\hline 13 & LH IIIB & hand-made miniature jug & Dothan \& Ben Tor 1983, 49-50 fig. 14: no. 3 (319) \\
\hline 14 & $\mathrm{LH} I I I B$ & hand-made miniature jug & Dothan \& Ben-Tor 1983, 49-50 fig. 14: no. 4 (1367) \\
\hline 15 & LH IIIB & hand-made miniature jug & Dothan \& Ben-Tor 1983, 49-50 fig. 14: no. 5 (1530/10) \\
\hline 16 & LH IIIB & hand-made miniature jug & Dothan \& Ben-Tor 1983, 49-50 fig. 14: no. 6 (1790) \\
\hline 17 & LH IIIB & small globular jug & Dothan \& Ben-Tor 1983, 49-50 fig. 14: no. 8 (3078) \\
\hline 18 & LH IIIA2-LH IIIB & deep stemmed bowl & Dothan \& Ben-Tor 1983, 49-50 fig. 14: no. 9 (826) \\
\hline 19 & LH IIIA2-LH IIIB & \multicolumn{2}{|c|}{ small piriform jug with cut-away neckDothan \& Ben-Tor 1983, 49-50 fig. 14: no. 10 (283) } \\
\hline 20 & LH IIIB & fragment & Dothan \& Ben-Tor 1983, 49-50 fig. 14: no. 11 (7156/4) \\
\hline 21 & $\mathrm{LH} I I I B$ & fragment & Dothan \& Ben-Tor 1983, 49-50 fig. 14: no. 12 (7256/18) \\
\hline 22 & LM IIIA-LM IIIB & fragment & Dothan \& Ben-Tor 1983, 49-50 fig. 14: no. 13 (3131) \\
\hline 23 & $\mathrm{LH} I I I B$ & cylindrical jug & Dothan \& Ben-Tor 1983, 49-50 fig. 14: no. 14 (2151) \\
\hline 24 & LM IIIB & large stirrup jar & Dothan \& Ben-Tor 1983, 51-52 fig. 15: no. 1 (2156) \\
\hline 25 & LM IIIB & large stirrup jar & Dothan \& Ben-Tor 1983, 51-52 fig. 51: no. 2 (3112) \\
\hline
\end{tabular}


Catalogue VII: Mycenaean pottery at Apliki

\section{Mycenaean vessels and fragments}

\begin{tabular}{|c|c|c|c|}
\hline ID & date & shape & published \\
\hline 1 & LH IIIA2-LH IIIB & semi-globular cup & Taylor 1952, 137 fig. 5: no. 5, 154: A 2:43 \\
\hline 2 & LH IIIA2-LH IIIB & shallow cup & Taylor 1952, 154: A 1: filling, Plate 28a:3 \\
\hline 3 & LH IIIC early & semi-globular cup & Taylor 1952, 145 fig 10: no. 2, 154: B I pit:4 \\
\hline 4 & & cup & Taylor 1952, 154 (not illustrated) \\
\hline 5 & LH IIIB-LH IIIC & deep bowl & Taylor 1952, 154 Plate 28b:1 \\
\hline 6 & LH IIIB-LH IIIC & cylindrical cup & Taylor 1952, 154, Plate 28b:2 \\
\hline 7 & LH IIIB & cylindrical cup & Taylor 1952, 145 fig 10: no. 3, 154: B I pit:5 \\
\hline 8 & LH IIIC early & carinated cup & Taylor 1952, 137 fig 5: no. 13, 154: A 3W:11 \\
\hline 9 & LH IIIC early & carinated cup & Taylor 1952, 154 (not illustrated) \\
\hline 10 & LH IIIB-LH IIIC & shallow bowl & Taylor 1952, 147 fig 11: no. 10, 154: B III:9 \\
\hline 11 & LH IIIB & shallow bowl & Taylor 1952, 154: A1 filling, Plate 28a:1 \\
\hline 12 & LH IIIB-LH IIIC & shallow bowl & Taylor 1952, 147 fig. 11: no. 7, 154 Plate 26a:1 \\
\hline 13 & LH IIIB-LH IIIC & shallow bowl & Taylor 1952, 137 fig. 5: no. 1, 154: A 2:26 \\
\hline 14 & LH IIIB-LH IIIC & shallow bowl & Taylor 1952, 154: A 2:28 (not illustrated) \\
\hline 15 & LH IIIB-LH IIIC & shallow bowl & Taylor 1952, 137: fig. 5: no. 18, 154-155: A 3W:31 \\
\hline 16 & LH IIIB-LH IIIC & shallow bowl & Taylor 1952, 155, Plate 28b: 3-4 \\
\hline 17 & LH IIIB-LH IIIC & shallow bowl & Taylor 1952, 155 (not illustrated) \\
\hline 18 & LH IIIB-LH IIIC & shallow bowl & Taylor 1952, 155 (not illustrated) \\
\hline 19 & LH IIIB-LH IIIC & deep bowl & Taylor 1952, 155 A1 filling, Plate 28a:4 \\
\hline 20 & LH IIIB-LH IIIC & deep bowl & Taylor 1952, 155, Plate 28a:5 \\
\hline 21 & LH IIIB-LH IIIC & deep bowl & Taylor 1952, 137 fig. 5: no. 4, 155: A 2:4 \\
\hline 22 & LH IIIB-LH IIIC & deep bowl & Taylor 1952, 155: A 3W:8 (not illustrated) \\
\hline 23 & $\mathrm{LH} I I \mathrm{C}$ & one-handled bowl & Taylor 1952, 145: fig 10: no. 4, 155: B I pit:2 \\
\hline 24 & LH IIIB & round-bottomed bowl & Taylor 1952, 155: A 2:14 (not illustrated) \\
\hline 25 & $\mathrm{LH} I I I B$ & round-bottomed bowl & Taylor 1952, 137 fig. 5: no. 7, 155: no. A 2:16a \\
\hline 26 & LH IIIB-LH IIIC & stemmed cup & Taylor 1952, 155: A 1: filling, Plate 28a:6 \\
\hline 27 & LH IIIB & stemmed cup & Taylor 1952, 155: A 1: filling, Plate 28a:7 \\
\hline 28 & LH IIIB & stemmed cup & Taylor 1952, 145 fig. 10: no. 8, 156: B I, pit:6 \\
\hline 29 & & stemmed cup & Taylor 1952, 156: B III pit:11(not illustrated) \\
\hline 30 & & stemmed cup & Taylor 1952, 156 (not illustrated) \\
\hline 31 & LH IIIB-LH IIIC & jug & Taylor 1952, 137 fig. 5: no. 9, 156: A 2:16b \\
\hline 32 & LH IIIB & narrow-necked jug & Taylor 1952, 137 fig. 5: no. 3, 156: A 2:27 \\
\hline 33 & LH IIIB & narrow-necked jug & Taylor 1952, 141 fig.7: no. 1, 156: A 3:6 \\
\hline 34 & LH IIIB-LH IIIC & narrow-necked jug & Taylor 1952, 137 fig 5: no. 14, 156: A 3W:9 \\
\hline 35 & $\mathrm{LH} I I I B$ & narrow-necked jug & Taylor 1952, 137 fig. 5: no. 12, 156:A 3W12 \\
\hline 36 & LH IIIB & narrow-necked jug & Taylor 1952, 141 fig. 7: no. 3, 156: A 5:6 \\
\hline 37 & LH IIIB & narrow-necked jug & Taylor 1952, 141 fig 7: no. 2, 156: A 8:4 \\
\hline 38 & LH IIIB-LH IIIC & jug & Taylor 1952, 156: A 1: filling, Plate 28b:6 \\
\hline 39 & $\mathrm{LH} \| \mathrm{IB}$ & lentoid flask & Taylor 1952, 137 fig 5: no. 2, 156: A 2:24 \\
\hline 40 & LH IIIB-LH IIIC & stirrup jar & Taylor 1952, 156: A 1: filling, Plate 28b:7 \\
\hline 41 & LH IIIB-LH IIIC & stirrup jar & Taylor 1952, 156 (not illustrated) \\
\hline 42 & LH IIIB & large piriform jar & Taylor 1952, 156: A 1: below floor, Plate 28a:2 \\
\hline 43 & LH IIIB & jar & Taylor 1952, 157: A 2:33 (not illustrated) \\
\hline 44 & LH IIIB-LH IIIC & deep bowl & Taylor 1952, 157, Plate 28b:5 \\
\hline 45 & $\mathrm{LH} \| I \mathrm{C}$ & ring-based krater & Taylor 1952, 141 fig. 7: no. 6, 157: A 7:2 \\
\hline 46 & & fragment & Taylor 1952, 144 (not illustrated) \\
\hline 47 & & jar & Taylor 1952, 146 (not illustrated) \\
\hline 48 & & fragment & Taylor 1952, 146 (not illustrated) \\
\hline
\end{tabular}


Catalogue VII cont.

\begin{tabular}{|c|c|c|c|}
\hline & date & shape & published \\
\hline 49 & & bowl & Taylor 1952, 148 (not illustrated) \\
\hline 50 & & fragment & Taylor 1952, 148 (not illustrated) \\
\hline 51 & & fragment & Taylor 1952, 148 (not illustrated) \\
\hline 52 & & cup & Taylor 1952, 148 (not illustrated) \\
\hline 53 & & goblet & Taylor 1952, 148 (not illustrated) \\
\hline
\end{tabular}




\section{Catalogue VIII: Mycenaean pottery at Lipari}

\section{Mycenaean vessels and fragments}

\begin{tabular}{|c|c|c|c|}
\hline ID & date & shape & published \\
\hline 1 & LH IIIB-LH IIIC & amphoriskos & Bernabò-Brea \& Cavalier 1980, 44: cat. no. 281, Plate 245: 5, 246: 1 \\
\hline 2 & $\mathrm{LH} I I \mathrm{C}$ & fragment & Bernabò-Brea \& Cavalier 1980, 49: cat. no. 290, Plate 245: no. 9 \\
\hline 3 & LH IIIB & fragment & Bernabò-Brea \& Cavalier 1980, 57: cat no. 278, 279, Plate 245: no. 3 \\
\hline 4 & & fragment & Bernabò-Brea \& Cavalier 1980, 57: cat no. 319, Plate 244: nos. 7-8 \\
\hline 5 & LH III & fragment & Bernabò-Brea \& Cavalier 1980, 62: cat no. 315 (not illustrated) \\
\hline 6 & LH III & fragment & Bernabò-Brea \& Cavalier 1980, 64: cat no. 318, Plate 244: no. 6 \\
\hline 7 & LH IIIB & bowl & Bernabò-Brea \& Cavalier 1980, 64: cat no. 276, Plate 245: no. 1 \\
\hline 8 & LH IIIB-LH IIIC & fragment & Bernabò-Brea \& Cavalier 1980, 65: cat no. 284,Plate 245: no. 4 \\
\hline 9 & $\mathrm{LH} I I \mathrm{C}$ & deep bowl & Bernabò-Brea \& Cavalier 1980, 84: cat no. 289, Plate 245: no. 8 \\
\hline 10 & & fragment & Bernabò-Brea \& Cavalier 1980, 84: cat. no. 317, Plate 244: no. 9 \\
\hline 11 & LH III & fragment & Bernabò-Brea \& Cavalier 1980, 87: cat. no. 316, Plate 244: no. 5 \\
\hline 12 & $\mathrm{LH} I I I C$ & fragment & Bernabò-Brea \& Cavalier 1980, 102: cat. no. 294, Plate 244: no. 4 \\
\hline 13 & LH IIIB-LH IIIC & jug & Bernabò-Brea \& Cavalier 1980, 109: cat. no. 281, Plate191। \\
\hline 14 & LH IIIB-LH IIIC & cup & Bernabò-Brea \& Cavalier 1980, 109: cat. no. 282, Plate 191k \\
\hline 15 & & fragment & Bernabò-Brea \& Cavalier 1980, 119: cat. no. 298, Plate 192d \\
\hline 16 & LH IIIB & fragment & Bernabò-Brea \& Cavalier 1980, 120: cat. no. 275, Plate 191h \\
\hline 17 & LH IIIB & fragment & Bernabò-Brea \& Cavalier 1980, 126: cat. no. 268, Plate 191d \\
\hline 18 & LH IIIB & amphora & Bernabò-Brea \& Cavalier 1980, 128: cat. no. 269, Plate 191c \\
\hline 19 & LH IIIB & deep bowl & Bernabò-Brea \& Cavalier 1980, 134: cat. nos. 271-272, Plate 191e \\
\hline 20 & LH III & fragment & Bernabò-Brea \& Cavalier 1980, 134: cat. no. 296, Plate $192 f$ \\
\hline 21 & $\mathrm{LH} I I I B$ & deep bowl & Bernabò-Brea \& Cavalier 1980, 134: cat. no. 273, Plate 191i \\
\hline 22 & LH IIIC & bowl & Bernabò-Brea \& Cavalier 1980, 134: cat. no. 285, Plate 191m \\
\hline 23 & & fragment & Bernabò-Brea \& Cavalier 1980, 134: cat. no. 295, Plate 192h \\
\hline 24 & LH III & fragment & Bernabò-Brea \& Cavalier 1980, 134: cat. no. 297, Plate 192c \\
\hline 25 & $\mathrm{LH} I I I$ & fragment & Bernabò-Brea \& Cavalier 1980, 134: cat. no. 299, Plate 192b \\
\hline 26 & $\mathrm{LH} I I I$ & fragment & Bernabò-Brea \& Cavalier 1980, 134: cat. no 300, Plate 192e \\
\hline 27 & LH IIIB & amphora & Bernabò-Brea \& Cavalier 1980, 134: cat no. 270, Plate 191b \\
\hline 28 & LH IIIB-LH IIIC & kylix & Bernabò-Brea \& Cavalier 1980, 134: cat no. 314, Plate $191 \mathrm{f}$ \\
\hline 29 & & fragments & Bernabò-Brea \& Cavalier 1980, 155: cat nos. 302-306, Plate 1921 \\
\hline 30 & LH III & fragment & Bernabò-Brea \& Cavalier 1980, 156: cat no. 307, Plate 192i \\
\hline 31 & LH III & fragment & Bernabò-Brea \& Cavalier 1980, 156: cat. no. 308, Plate 192j \\
\hline 32 & LH III & fragments & Bernabò-Brea \& Cavalier 1980, 156: cat. nos. 309-312, Plate 192m-o \\
\hline 33 & LH III & fragment & Bernabò-Brea \& Cavalier 1980, 156: cat no 313, Plate 192k \\
\hline 34 & LH IIIB-LH IIIC & deep bowl & Bernabò-Brea \& Cavalier 1980, 156: cat no. 280, Plate 191j \\
\hline 35 & LH IIIB & stemmed bowl & Bernabò-Brea \& Cavalier 1980, 156: cat no. 274, Plate 191g \\
\hline 36 & LH III & & Bernabò-Brea \& Cavalier 1980, 158: cat no. 301, Plate 192g \\
\hline 37 & LH IIIB & shallow cup & Bernabò-Brea \& Cavalier 1980, 164: cat. no. 266, Plate 162: no. 3 \\
\hline 38 & LH IIIA2-LH IIIB & fragment & Bernabò-Brea \& Cavalier 1980, 164: cat. no. 226, Plate 162: no. 18 \\
\hline 39 & $\mathrm{LH} I I I A 2$ & jug & Bernabò-Brea \& Cavalier 1980, 165: cat no. 183, Plate 157: no. 15 \\
\hline 40 & LH IIIA2 & jug & Bernabò-Brea \& Cavalier 1980, 165 (not illustrated) \\
\hline 41 & & fragment & Bernabò-Brea \& Cavalier 1980, 165: cat. no. 227, Plate 162: no. 11 \\
\hline 42 & & fragments & Bernabò-Brea \& Cavalier 1980, 165: cat. no. 228-229 (not illustrated) \\
\hline 43 & & fragment & Bernabò-Brea \& Cavalier 1980, 165: cat. no. 230, Plate 162: no. 19 \\
\hline 44 & LH IIIA2-LH IIIB & fragment & Bernabò-Brea \& Cavalier 1980, 165: cat. no. 214, Plate 160: no. 12 \\
\hline 45 & LH IIIB & cup & Bernabò-Brea \& Cavalier 1980, 165: cat. no. 267, Plate 162: no. 6 \\
\hline 46 & LM I & hole-mouthed jar & Bernabò-Brea \& Cavalier 1980, 165: cat. no. 3, Plate 140: no. 3 \\
\hline 47 & LH I-LH II & fragment & Bernabò-Brea \& Cavalier 1980, 167: cat. no. 63, Plate 146: no. 2 \\
\hline 48 & LH I-LH II & vapheio cup & Bernabò-Brea \& Cavalier 1980, 167: cat. no. 70, Plate 146: no. 15 \\
\hline
\end{tabular}




\begin{tabular}{|c|c|c|c|}
\hline ID & date & shape & published \\
\hline 49 & LH IIB-LH IIIA1 & fragment & Bernabò-Brea \& Cavalier 1980, 167: cat. no. 110, Plate 150: no. 14 \\
\hline 50 & LH IIIA2-LH IIIB & amphoroid krater & Bernabò-Brea \& Cavalier 1980, 170: cat. no. 208, Plate 160: no. 6 \\
\hline 51 & & fragment & Bernabò-Brea \& Cavalier 1980, 170: cat. no. 237, Plate 162: no. 13 \\
\hline 52 & $\mathrm{LH}$ & fragment & Bernabò-Brea \& Cavalier 1980, 171: cat. no. 30, Plate 142: no. 19 \\
\hline 53 & LH II & rounded alabastron & Bernabò-Brea \& Cavalier 1980, 171: cat. no. 85, Plate 158: no. 9 \\
\hline 54 & LH II & vapheio cup & Bernabò-Brea \& Cavalier 1980, 171: cat. no. 86, Plate 158: no. 12 \\
\hline 55 & LH IIB-LH IIIA1 & jug & Bernabò-Brea \& Cavalier 1980, 171: cat. no. 112, Plate 150: no. 16 \\
\hline 56 & LH IIA1-LH IIIA2 & jug & Bernabò-Brea \& Cavalier 1980, 171: cat no. 169 (not illustrated) \\
\hline 57 & LH IIIA2-LH IIIB & shallow cup & Bernabò-Brea \& Cavalier 1980, 171: cat no. 204, Plate 160: no. 3 \\
\hline 58 & LH IIIA2-LH IIIB & fragment & Bernabò-Brea \& Cavalier 1980, 171: cat no. 202, Plate 160: no. 1 \\
\hline 59 & LH IIIA2-LH IIIB & cup or bowl & Bernabò-Brea \& Cavalier 1980, 171: cat no. 205, Plate 160: no. 4 \\
\hline 60 & $\mathrm{LH} I I I C$ & fragment & Bernabò-Brea \& Cavalier 1980, 171, no. 7822 , Plate 152: no. 25 \\
\hline 61 & LH IIIB & fragment & Bernabò-Brea \& Cavalier 1980, 172: cat. no. 262, Plate 162: no. 2 \\
\hline 62 & & fragment & Bernabò-Brea \& Cavalier 1980, 172: cat no. 159, Plate 152: no. 19 \\
\hline 63 & & fragment & Bernabò-Brea \& Cavalier 1980, 172: cat no. 76, Plate 46: no. 16 \\
\hline 64 & $\mathrm{LH} \|$ & vapheio cup & Bernabò-Brea \& Cavalier 1980, 173: cat. no. 51, Plate 146: no. 9 \\
\hline 65 & LH IIIA & jug & Bernabò-Brea \& Cavalier 1980, 175-176: cat. nos. 176-177, Plate 157 \\
\hline \multicolumn{4}{|c|}{ nos. $7,8,16$} \\
\hline 66 & LH IIIA1-LH IIIA2 & shallow cup & Bernabò-Brea \& Cavalier 1980, 176: cat no. 191, Plate 157: no. 2 \\
\hline 67 & $\mathrm{LH} \| \mathrm{IB}$ & stirrup jar & Bernabò-Brea \& Cavalier 1980, 176: cat no. 261, Plate 162: no. 1 \\
\hline 68 & & fragment & Bernabò-Brea \& Cavalier 1980, 176: cat no. 231, Plate 162; no. 26 \\
\hline 69 & & fragment & Bernabò-Brea \& Cavalier 1980, 176: cat no. 232, Plate 162: no. 14 \\
\hline 70 & & fragment & Bernabò-Brea \& Cavalier 1980, 176: cat no. 233, Plate 162: no. 22 \\
\hline 71 & & fragments & Bernabò-Brea \& Cavalier 1980, 176: cat. no 164, Plate 152 \\
\hline 72 & LH IIIA & jug & Bernabò-Brea \& Cavalier 1980, 177: cat no. 179, Plate 157: nos. 12- \\
\hline \multicolumn{4}{|l|}{13} \\
\hline 73 & & fragment & Bernabò-Brea \& Cavalier 1980, 177: cat no. 123, Plate 150: no. 27 \\
\hline 74 & & fragment & Bernabò-Brea \& Cavalier 1980, 177: cat. no. 163 (not illustrated) \\
\hline 75 & & fragment & Bernabò-Brea \& Cavalier 1980, 177: cat. no. 161, Plate 152: no. 21 \\
\hline 76 & & fragment & Bernabò-Brea \& Cavalier 1980, 177: cat. no. 112, Plate 140: no. 12 \\
\hline 77 & $\mathrm{LH} \|$ & fragment & Bernabò-Brea \& Cavalier 1980, 179: cat no. 90, Plate 148: no. 14 \\
\hline 78 & LH IIIA & jug & Bernabò-Brea \& Cavalier 1980, 179: cat nos. 170-171 (not illustrated) \\
\hline 79 & & fragment & Bernabò-Brea \& Cavalier 1980, 179: cat no. 248 (not illustrated) \\
\hline 80 & LH IIIA & jug & Bernabò-Brea \& Cavalier 1980, 179: cat no. 174 (not illustrated) \\
\hline 81 & $\mathrm{LHI}$ & jar & Bernabò-Brea \& Cavalier 1980, 179: cat nos. 6-7 (not illustrated) \\
\hline 82 & LH IIIA1 & shallow cup & Bernabò-Brea \& Cavalier 1980, 180: cat. no. 120, Plate 150: no. 23 \\
\hline 83 & & fragment & Bernabò-Brea \& Cavalier 1980, 180: cat. no. 165 (not illustrated) \\
\hline 84 & LH IIIA2-LH IIIB & cup & Bernabò-Brea \& Cavalier 1980, 182: cat no. 223, Plate 160: no. 22 \\
\hline 85 & $\mathrm{LH} \|$ & vapheio cup & Bernabò-Brea \& Cavalier 1980, 182: cat. no. 238, Plate 162: no. 21 \\
\hline 86 & LH IIIA & jug & Bernabò-Brea \& Cavalier 1980, 183: cat. no. 172 (not illustrated) \\
\hline 87 & $\mathrm{LH} I I I A$ & jug & Bernabò-Brea \& Cavalier 1980, 183: cat. no. 178, Plate 157: no. 17 \\
\hline 88 & LH IIIA2-LH IIIB & shallow cup & Bernabò-Brea \& Cavalier 1980, 183: cat. no. 206, Plate 160: no. 5 \\
\hline 89 & & fragment & Bernabò-Brea \& Cavalier 1980, 183: cat. no. 239, Plate 162: no. 23 \\
\hline 90 & & fragment & Bernabò-Brea \& Cavalier 1980, 183: cat. no. 240 (not illustrated) \\
\hline 91 & $\mathrm{LH} \|$ & fragment & Bernabò-Brea \& Cavalier 1980, 185: cat. no. 89, Plate 148: no. 13 \\
\hline 92 & LH IIIA2-LH IIIB & fragment & Bernabò-Brea \& Cavalier 1980, 185: cat. no. 213, Plate 160: no. 11 \\
\hline 93 & LH IIIB & miniature jug & Bernabò-Brea \& Cavalier 1980, 185: cat. no. 203, Plate 160: no. 2 \\
\hline 94 & LH IIIA2-LH IIIB & fragment & Bernabò-Brea \& Cavalier 1980, 185: cat. no. 215, Plate 160: no. 13 \\
\hline 95 & & fragment & Bernabò-Brea \& Cavalier 1980, 185: cat. no. 241, Plate 162: no. 16 \\
\hline 96 & & fragment & Bernabò-Brea \& Cavalier 1980, 185: cat. no. 242, Plate 162: no. 12 \\
\hline 97 & LH IIIA & jug & Bernabò-Brea \& Cavalier 1980, 185: cat. no. 173, Plate 157: no. 19 \\
\hline
\end{tabular}




\begin{tabular}{|c|c|c|c|}
\hline ID & date & shape & published \\
\hline 98 & & fragment & Bernabò-Brea \& Cavalier 1980, 185: cat. no: 243, Plate 162: no. 25 \\
\hline 99 & & fragment & Bernabò-Brea \& Cavalier 1980, 185: cat no. 244, Plate 162: no. 17 \\
\hline 100 & & fragment & Bernabò-Brea \& Cavalier 1980, 185: cat no. 246 (not illustrated) \\
\hline 101 & & fragment & Bernabò-Brea \& Cavalier 1980, 185: cat no. 245 (not illustrated) \\
\hline 102 & & carinated cup & Bernabò-Brea \& Cavalier 1980, 185: cat no. 9, Plate 140: no. 10 \\
\hline 103 & & amphora & Bernabò-Brea \& Cavalier 1980, 185: cat. no. 11, Plate 140: no. 11 \\
\hline 104 & LH IIIA & jug & $\begin{array}{l}\text { Bernabò-Brea \& Cavalier 1980, 187: cat. no. 181, Plate 157: nos. 4, 5, } \\
11,14,18\end{array}$ \\
\hline 105 & & fragment & Bernabò-Brea \& Cavalier 1980, 187: cat no. 235 (not illustrated) \\
\hline 106 & & fragment & Bernabò-Brea \& Cavalier 1980, 187: cat no. 234, Plate 162: no. 24 \\
\hline 107 & LH IIIB & fragment & Bernabò-Brea \& Cavalier 1980, 187: cat. no. 264, Plate 162: no. 4 \\
\hline 108 & & fragment & Bernabò-Brea \& Cavalier 1980, 187: cat. no. 236 (not illustrated) \\
\hline 109 & LH I & jar & Bernabò-Brea \& Cavalier 1980, 187: cat no. 5, Plate 140: no. 8 \\
\hline 110 & LH IIIB & fragment & Bernabò-Brea \& Cavalier 1980, 189: cat. no. 265, Plate 162: no. 5 \\
\hline 111 & LH IIIA2-LH IIIB & fragment & Bernabò-Brea \& Cavalier 1980, 189: cat. no. 209, Plate 160: no. 7 \\
\hline 112 & $\mathrm{LH} \| \mathrm{IA} 2$ & kylix & Bernabò-Brea \& Cavalier 1980, 189: cat. no. 193, Plate 159: no. 6 \\
\hline 113 & LH III & fragment & Bernabò-Brea \& Cavalier 1980, 189: cat. no. 252 (not illustrated) \\
\hline 114 & LH II-LH IIIA1 & goblet & Bernabò-Brea \& Cavalier 1980, 190: cat. no. 119, Plate 150: no. 21 \\
\hline 115 & LH IIIA2-LH IIIB & shallow cup & Bernabò-Brea \& Cavalier 1980, 191: cat. no. 116, Plate 150: no. 18 \\
\hline 116 & & fragment & Bernabò-Brea \& Cavalier 1980, 191: cat. no. 253, Plate 162: no. 15 \\
\hline 117 & & fragment & Bernabò-Brea \& Cavalier 1980, 191: cat. no. 249 (not illustrated) \\
\hline 118 & & fragment & Bernabò-Brea \& Cavalier 1980, 191: cat. no. 250 (not illustrated) \\
\hline 119 & & large jar & Bernabò-Brea \& Cavalier 1980, 191: cat. no. 251 (not illustrated) \\
\hline 120 & LH IIIA1 & large piriform jar & Bernabò-Brea \& Cavalier 1980, 191: cat. no. 185, Plate 158: no. 3 \\
\hline 121 & $\mathrm{LH} I I \mathrm{~A} 2$ & deep krater & Bernabò-Brea \& Cavalier 1980, 196: cat. no. 216, Plate 160: no. 14 \\
\hline 122 & LH IIIA2-LH IIIB & fragment & Bernabò-Brea \& Cavalier 1980, 196: cat. no. 221, Plate 160: no. 18 \\
\hline 123 & & fragment & Bernabò-Brea \& Cavalier 1980, 196: cat. no. 225, Plate 160: no. 23 \\
\hline 124 & LH I-LH II & shallow cup & Bernabò-Brea \& Cavalier 1980, 196: cat. 74, Plate 146: no. 13 \\
\hline 125 & LH IIIA2-LH IIIB & piriform jar & $\begin{array}{l}\text { Bernabò-Brea \& Cavalier 1980, 197: cat. nos. 217-218, Plate 160: 15- } \\
16\end{array}$ \\
\hline 126 & LH I-LH II & cup & Bernabò-Brea \& Cavalier 1980, 197: cat. no. 71, Plate 146: no. 12 \\
\hline 127 & & fragment & Bernabò-Brea \& Cavalier 1980, 197: cat. no. 257 (not illustrated) \\
\hline 128 & LH IIIA2-LH IIIB & bowl or cup & Bernabò-Brea \& Cavalier 1980, 197: cat. no. 187, Plate 159: no. 7 \\
\hline 129 & & fragment & Bernabò-Brea \& Cavalier 1980, 197: cat. no. 258 (not illustrated) \\
\hline 130 & $\mathrm{LHI}$ & fragment & Bernabò-Brea \& Cavalier 1980, 197: cat. no. 14, Plate 142: no. 3 \\
\hline 131 & $\mathrm{LH} I$ & fragment & Bernabò-Brea \& Cavalier 1980, 197: cat. no. 15, Plate 142: no. 1 \\
\hline 132 & LH IIIA2-LH IIIB & cup or bowl & Bernabò-Brea \& Cavalier 1980, 197: cat. no. 207, Plate 162: no. 8 \\
\hline 133 & LH IIB-LH IIIA1 & rounded alabastron & Bernabò-Brea \& Cavalier 1980, 197: cat. no. 105, Plate 150: no. 9 \\
\hline 134 & LH I & cup & Bernabò-Brea \& Cavalier 1980, 197: cat. no. 33, Plate 142: no. 21 \\
\hline 135 & LH I-LH II & cup & Bernabò-Brea \& Cavalier 1980, 197: cat. no. 73, Plate 144: no. 11 \\
\hline 136 & LH IIIA1-LH IIIA2 & shallow cup & Bernabò-Brea \& Cavalier 1980, 197: cat. no. 113, Plate 150: no. 17 \\
\hline 137 & LH IIIA1 & shallow cup & Bernabò-Brea \& Cavalier 1980, 197: cat. no. 184, Plate 157: no. 3 \\
\hline 138 & & fragment & Bernabò-Brea \& Cavalier 1980, 197: cat. no. 162, Plate 152: no. 20 \\
\hline 139 & LH II-LH IIIA & rounded alabastron & Bernabò-Brea \& Cavalier 1980, 197: cat. no. 107, Plate 150: no. 11 \\
\hline 140 & LH I & squat jug & Bernabò-Brea \& Cavalier 1980, 197: cat. no. 65, Plate 146: no. 4 \\
\hline 141 & & fragment & Bernabò-Brea \& Cavalier 1980, 197: cat. no. 153, Plate 152: no. 17 \\
\hline 142 & & fragment & Bernabò-Brea \& Cavalier 1980, 197: cat. no. 154, Plate 152: no. 24 \\
\hline 143 & LH II-LH IIIA1 & cup or kylix & Bernabò-Brea \& Cavalier 1980, 197: cat. no. 122, Plate 150: no. 24 \\
\hline 144 & & fragment & Bernabò-Brea \& Cavalier 1980, 197: cat. no. 155 (not illustrated) \\
\hline 145 & & fragment & Bernabò-Brea \& Cavalier 1980, 197: cat. no. 156 (not illustrated) \\
\hline 146 & & fragment & Bernabò-Brea \& Cavalier 1980, 197: cat. no. 166 (not illustrated) \\
\hline
\end{tabular}




\begin{tabular}{|c|c|c|c|}
\hline ID & date & shape & published \\
\hline 147 & LH I & fragment & Bernabò-Brea \& Cavalier 1980, 197: cat. no. 31, Plate 142: no. 20 \\
\hline 148 & $\mathrm{LH} I I \mathrm{~A} 2$ & large piriform jar & Bernabò-Brea \& Cavalier 1980, 197: cat. no. 168, Plates 154-155 \\
\hline 149 & LH IIA & shallow cup & Bernabò-Brea \& Cavalier 1980, 197: cat. no. 72, Plate 146: no. 10 \\
\hline 150 & LH IIIA2-LH IIIB & shallow cup & Bernabò-Brea \& Cavalier 1980, 204: cat. no. 191, Plate 159: no. 8 \\
\hline 151 & LH IIIA2-LH IIIB & fragment & Bernabò-Brea \& Cavalier 1980, 204: cat. no. 219, Plate 160: no. 19 \\
\hline 152 & & fragment & Bernabò-Brea \& Cavalier 1980, 204: cat. no. 259 (not illustrated) \\
\hline 153 & LH III & fragment & Bernabò-Brea \& Cavalier 1980, 204: cat. no. 260 (not illustrated) \\
\hline 154 & & large piriform jar & Bernabò-Brea \& Cavalier 1980, 204: cat. no. 111, Plate 150: no. 15 \\
\hline 155 & LH II & cup & Bernabò-Brea \& Cavalier 1980, 205: cat. no. 88, Plate 148: no. 11 \\
\hline 156 & LH IIIA2 & mug & Bernabò-Brea \& Cavalier 1980, 205: cat. no. 190, Plate 159: no. 4 \\
\hline 157 & LH IIIA2-LH IIIB & fragment & Bernabò-Brea \& Cavalier 1980, 205: cat. no. 210, Plate 160: no. 8 \\
\hline 158 & LH IIIA2-LH IIIB & fragment & Bernabò-Brea \& Cavalier 1980, 205: cat. no. 212, Plate 160: no. 10 \\
\hline 159 & $\mathrm{LH} I \mathrm{H}$ & squat jug & Bernabò-Brea \& Cavalier 1980, 205: cat. no. 84, Plate 148: no. 8 \\
\hline 160 & & fragment & Bernabò-Brea \& Cavalier 1980, 205: cat. no. 186, Plate 159: no. 1 \\
\hline 161 & & fragment & Bernabò-Brea \& Cavalier 1980, 205: cat. no. 211, Plate 160: no. 9 \\
\hline 162 & LH II & vapheio cup & Bernabò-Brea \& Cavalier 1980, 205: cat. no. 68, Plate 146: no. 5 \\
\hline 163 & $\mathrm{LH}$ IIIA2 & fragment & Bernabò-Brea \& Cavalier 1980, 205: cat. no. 188, Plate 159: no. 5 \\
\hline 164 & & fragment & Bernabò-Brea \& Cavalier 1980, 205: cat. no. 189, Plate 159: no. 3 \\
\hline 165 & & fragment & Bernabò-Brea \& Cavalier 1980, 205: cat. no. 255, Plate 162: no. 9 \\
\hline 166 & & fragment & Bernabò-Brea \& Cavalier 1980, 205: cat. no. 255, Plate 162: no. 10 \\
\hline 167 & LH IIIA2 & kylix & Bernabò-Brea \& Cavalier 1980, 206: cat. nos. 200-201, Plate 191a \\
\hline 168 & LH II-LH IIIA1 & semi-globular cup & Bernabò-Brea \& Cavalier 1980, 208: cat. nos. 114-115, Plate 150: no. \\
\hline \multicolumn{4}{|l|}{22} \\
\hline 169 & LH II & vapheio cup & Bernabò-Brea \& Cavalier 1980, 208: cat no. 34, Plate 142: no. 22 \\
\hline 170 & & cup or bowl & Bernabò-Brea \& Cavalier 1980, 208: cat. no. 108, Plate 150: no. 12 \\
\hline 171 & $\mathrm{LH} I \mathrm{I}$ & cup & Bernabò-Brea \& Cavalier 1980, 210: cat. no. 87, Plate 148: no. 10 \\
\hline 172 & LH II & bowl & Bernabò-Brea \& Cavalier 1980, 218-219: cat. no. 79, Plate 148: no. 4 \\
\hline 173 & LH IIIA1 & goblet & Bernabò-Brea \& Cavalier 1980, 222: cat. no. 167, Plate 157: no. 1 \\
\hline 174 & & fragment & Bernabò-Brea \& Cavalier 1980, 222: cat. no. 104, Plate 150: no. 8 \\
\hline 175 & & fragment & Bernabò-Brea \& Cavalier 1980, 222: cat. no. 103, Plate 150: no. 7 \\
\hline 176 & $\mathrm{LH} \|$ & vapheio cup & Bernabò-Brea \& Cavalier 1980, 222: cat. no. 50, Plate 144: no. 15 \\
\hline 177 & LH I-LH IIA & semi-globular cup & Bernabò-Brea \& Cavalier 1980, 222: cat. no. 54, Plate 144: no. 21 \\
\hline 178 & LH I-LH IIA & semi-globular cup & Bernabò-Brea \& Cavalier 1980, 222: cat. no. 55, Plate 144: no. 18 \\
\hline 179 & LH I-LH II & fragment & Bernabò-Brea \& Cavalier 1980, 222: cat. no. 61, Plate 144: no. 20 \\
\hline 180 & LH I-LH II & fragment & Bernabò-Brea \& Cavalier 1980, 222: cat. no. 62, Plate 144: no. 19 \\
\hline 181 & LH I-LH II & rounded alabastron & Bernabò-Brea \& Cavalier 1980, 222: cat. no. 37, Plate 144: no. 1 \\
\hline 182 & LH I-LH II & rounded alabastron & Bernabò-Brea \& Cavalier 1980, 222: cat. no. 39, Plate 144: no. 4 \\
\hline 183 & LH I & fragment & Bernabò-Brea \& Cavalier 1980, 222: cat. no. 19, Plate 142: no. 10 \\
\hline 184 & LH II & vapheio cup & Bernabò-Brea \& Cavalier 1980, 222: cat. no. 25, Plate 142: no. 15 \\
\hline 185 & LH I-LH II & rounded alabastron & Bernabò-Brea \& Cavalier 1980, 222: cat. no. 35, Plate 146: no. 1 \\
\hline 186 & & fragment & Bernabò-Brea \& Cavalier 1980, 222: cat. no. 137, Plate 152: no. 1 \\
\hline 187 & & fragment & Bernabò-Brea \& Cavalier 1980, 222: cat. no. 138, Plate 152: no. 2 \\
\hline 188 & & fragment & Bernabò-Brea \& Cavalier 1980, 222: cat. no. 139, Plate 152: no. 3 \\
\hline 189 & & fragment & Bernabò-Brea \& Cavalier 1980, 222: cat. no. 141, Plate 152: no. 5 \\
\hline 190 & & fragments & Bernabò-Brea \& Cavalier 1980, 222: cat. no. 146 (not illustrated) \\
\hline 191 & & fragment & Bernabò-Brea \& Cavalier 1980, 222: cat. no. 147 (not illustrated) \\
\hline 192 & LM I-LM II & fragment & Bernabò-Brea \& Cavalier 1980, 222: cat. no. 2, Plate 140: no. 2 \\
\hline 193 & & fragment & Bernabò-Brea \& Cavalier 1980, 222: cat. no. 10, Plate 140: no. 9 \\
\hline 194 & & fragment & Bernabò-Brea \& Cavalier 1980, 223: cat. no. 140, Plate 152: no. 4 \\
\hline 195 & & fragment & Bernabò-Brea \& Cavalier 1980, 224: cat. no. 142, Plate 152: no. 7 \\
\hline 196 & & fragment & Bernabò-Brea \& Cavalier 1980, 224: cat. no. 143, Plate 152: no. 9 \\
\hline
\end{tabular}




\begin{tabular}{|c|c|c|c|}
\hline ID & date & shape & published \\
\hline 197 & & fragment & Bernabò-Brea \& Cavalier 1980, 224: cat. no. 144, Plate 152: no. 8 \\
\hline 198 & LH I-LH II & vapheio cup & Bernabò-Brea \& Cavalier 1980, 224: cat. no. 52, Plate 144: no. 16 \\
\hline 199 & & fragment & Bernabò-Brea \& Cavalier 1980, 224: cat. no. 148 (not illustrated) \\
\hline 200 & LH I-LH II & fragment & Bernabò-Brea \& Cavalier 1980, 224: cat. no. 44, Plate 144: no. 7 \\
\hline 201 & & fragment & Bernabò-Brea \& Cavalier 1980, 224: cat. no. 149 (not illustrated) \\
\hline 202 & LM I-LM II & fragment & Bernabò-Brea \& Cavalier 1980, 224: cat. no. 4, Plate 140: no. 3 \\
\hline 203 & & cup or kylix & Bernabò-Brea \& Cavalier 1980, 224: cat. no. 97, Plate 150: no. 2 \\
\hline 204 & & fragment & Bernabò-Brea \& Cavalier 1980, 224: cat. no. 64, Plate 146: no. 3 \\
\hline 205 & & fragment & Bernabò-Brea \& Cavalier 1980, 224: cat. no. 157, Plate 152: no. 18 \\
\hline 206 & & fragment & Bernabò-Brea \& Cavalier 1980, 224: cat. no. 158, Plate 152: no. 22 \\
\hline 207 & LH I-LH II & vapheio cup & Bernabò-Brea \& Cavalier 1980, 224: cat. no. 29, Plate 142: no. 16 \\
\hline 208 & LH I-LH II & vapheio cup & Bernabò-Brea \& Cavalier 1980, 229: cat. no. 48, Plate 144: no. 13 \\
\hline 209 & LH IIB & goblet & Bernabò-Brea \& Cavalier 1980, 229: cat. no. 82, Plate 148: no. 3 \\
\hline 210 & LH I-LH II & vapheio cup & Bernabò-Brea \& Cavalier 1980, 229: cat. no. 49, Plate 144: no. 14 \\
\hline 211 & LH I-LH II & fragment & Bernabò-Brea \& Cavalier 1980, 233: cat. no. 43, Plate 144: no. 8 \\
\hline 212 & LH IIA & bridge-spouted jug & Bernabò-Brea \& Cavalier 1980, 233: cat. no. 47, Plate 144: no. 12 \\
\hline 213 & LH I-LH IIA & semi-globular cup & Bernabò-Brea \& Cavalier 1980, 233: cat, no. 53, Plate 144: no. 17 \\
\hline 214 & $\mathrm{LH} \|$ & semi-globular cup & Bernabò-Brea \& Cavalier 1980, 233: cat. no. 96, plate 148: no. 20 \\
\hline 215 & & cup or kylix & Bernabò-Brea \& Cavalier 1980, 233: cat. no. 98, Plate 150: no. 1 \\
\hline 216 & LH II & semi-globular cup & Bernabò-Brea \& Cavalier 1980, 233: cat. no. 95, Plate 148: no. 19 \\
\hline 217 & & fragment & Bernabò-Brea \& Cavalier 1980, 233: cat. no. 132, Plate 152: no. 6 \\
\hline 218 & LH IIIA & jug & Bernabò-Brea \& Cavalier 1980, 233: cat. no. 180, Plate 157: no. 10 \\
\hline 219 & LH I & jar & Bernabò-Brea \& Cavalier 1980, 234: cat. no. 13, Plate 140: no. 4 \\
\hline 220 & & fragment & Bernabò-Brea \& Cavalier 1980, 235: cat. no. 150 (not illustrated) \\
\hline 221 & LH IIB-LH IIIA1 & shallow cup & Bernabò-Brea \& Cavalier 1980, 235: cat. no. 94, Plate 148: no. 18 \\
\hline 222 & & fragment & Bernabò-Brea \& Cavalier 1980, 237: cat. no. 151 (not illustrated) \\
\hline 223 & LH I-LH II & vapheio cup & Bernabò-Brea \& Cavalier 1980, 237: cat. no. 26, Plate 142: no. 13 \\
\hline 224 & & fragment & Bernabò-Brea \& Cavalier 1980, 237, cat. no. 133, Plate 152: no. 13 \\
\hline 225 & $\mathrm{LHI}$ & jar & Bernabò-Brea \& Cavalier 1980, 237: cat. no. 12, Plate 140: no. 7 \\
\hline 226 & & fragment & Bernabò-Brea \& Cavalier 1980, 238: cat. no. 134, Plate 152: no. 14 \\
\hline 227 & $\mathrm{LHI}$ & fragments & $\begin{array}{l}\text { Bernabò-Brea \& Cavalier 1980, 239: cat. nos. 20-21, Plate 142: nos. } \\
\text { 7-9 }\end{array}$ \\
\hline 228 & LH IA & semi-globular cup & Bernabò-Brea \& Cavalier 1980, 246: cat. no. 23, Plate 142: no. 12 \\
\hline 229 & & fragment & Bernabò-Brea \& Cavalier 1980, 246: cat. no. 101, Plate 150: no. 5 \\
\hline 230 & & fragment & Bernabò-Brea \& Cavalier 1980, 246: cat. no. 102, Plate no. 150: no. 6 \\
\hline 231 & $\mathrm{LH} I$ & hole-mouthed jar & Bernabò-Brea \& Cavalier 1980, 246: cat. no. 16, Plate 142: no. 4 \\
\hline 232 & LH I-LH II & fragment & Bernabò-Brea \& Cavalier 1980, 246: cat. no. 41, Plate 144: no. 5 \\
\hline 233 & & fragment & Bernabò-Brea \& Cavalier 1980, 246: cat. no. 152 (not illustrated) \\
\hline 234 & & fragment & Bernabò-Brea \& Cavalier 1980, 246: cat. no. 145 (not illustrated) \\
\hline 235 & LM I & jug & Bernabò-Brea \& Cavalier 1980, 246: cat. no. 1, Plate 140: no. 1 \\
\hline 236 & LH I-LH II & fragment & Bernabò-Brea \& Cavalier 1980, 247: cat. no. 45, Plate 140: no. 5 \\
\hline 237 & LH II & semi-globular cup & Bernabò-Brea \& Cavalier 1980, 248: cat. no. 80, Plate 148: no. 5 \\
\hline 238 & LH IIA & semi-globular cup & Bernabò-Brea \& Cavalier 1980, 248, cat. no. 59, Plate 144: no. 24 \\
\hline 239 & & fragment & Bernabò-Brea \& Cavalier 1980, 248: cat. no. 129 (not illustrated) \\
\hline 240 & & kylix & Bernabò-Brea \& Cavalier 1980, 248: cat. no. 130 (not illustrated) \\
\hline 241 & & fragment & Bernabò-Brea \& Cavalier 1980, 248: cat. no. 128 (not illustrated) \\
\hline 242 & LH I-LH IIA & semi-globular cup & Bernabò-Brea \& Cavalier 1980, 251: cat. no. 57, Plate 145: no. 23 \\
\hline 243 & & fragment & Bernabò-Brea \& Cavalier 1980, 251: cat. no. 131 (not illustrated) \\
\hline 244 & LH I-LH II & kylix & Bernabò-Brea \& Cavalier 1980, 251: cat. no. 60. Plate 144: no. 25 \\
\hline 245 & LH I-LH IIA & semi-globular cup & Bernabò-Brea \& Cavalier 1980, 254: cat. no. 58, Plate 144: no. 22 \\
\hline 246 & & fragment & Bernabò-Brea \& Cavalier 1980, 254: cat. no, 46, Plate 144: no. 9 \\
\hline
\end{tabular}




\begin{tabular}{|c|c|c|c|}
\hline ID & date & shape & published \\
\hline 247 & LH II & fragment & Bernabò-Brea \& Cavalier 1980, 256: cat. no. 83, Plate 148: no. 7 \\
\hline 248 & & fragment & Bernabò-Brea \& Cavalier 1980, 264: no. 4710a (not illustrated) \\
\hline 249 & LH III & fragment & Bernabò-Brea \& Cavalier 1980, 272: cat. no. 220, Plate 160: no. 17 \\
\hline 250 & LH IIIB & fragment & Bernabò-Brea \& Cavalier 1980, 293: cat. no.: 277, Plate 245: no. 2 \\
\hline 251 & LH IIIC & ring-based krater & Bernabò-Brea \& Cavalier 1980, 308: cat. no. 287, Plate 245: no. 6 \\
\hline 252 & LH I & fragment & Bernabò-Brea \& Cavalier 1980, 316: cat. no. 18, Plate 142: no. 6 \\
\hline 253 & LH I & bowl & Bernabò-Brea \& Cavalier 1980, 316: cat. no. 17, Plate 142: no. 5 \\
\hline 254 & LH I-LH IIA & semi-globular cup & Bernabò-Brea \& Cavalier 1980, 316: cat. no. 22, Plate 142: no. 11 \\
\hline 255 & LH I-LH II & vapheio cup & Bernabò-Brea \& Cavalier 1980, 316: cat. no. 27, Plate 142: no. 18 \\
\hline 256 & LH I-LH IIA & semi-globular cup & Bernabò-Brea \& Cavalier 1980, 316: cat. no. 56, Plate 144: no. 11 \\
\hline 257 & LH I-LH II & fragment & Bernabò-Brea \& Cavalier 1980, 316: cat. no. 42, Plate 144: no. 6 \\
\hline 258 & & fragment & Bernabò-Brea \& Cavalier 1980, 316: cat. no. 91, Plate 148: no. 15 \\
\hline 259 & & cup or kylix & Bernabò-Brea \& Cavalier 1980, 316: cat. no. 100, Plate 150: no. 3 \\
\hline 260 & & cup or kylix & Bernabò-Brea \& Cavalier 1980, 316: cat. no. 99, Plate 150: no. 4 \\
\hline 261 & LH I-LH II & rounded alabastron & Bernabò-Brea \& Cavalier 1980, 316: cat. no. 40, Plate 144: no. 10 \\
\hline 262 & & cup & Bernabò-Brea \& Cavalier 1980, 316: cat. no. 135, Plate 152: no. 11 \\
\hline 263 & LH IIB & jug with cut-away neck & Bernabò-Brea \& Cavalier 1980, 316: cat. no. 92, Plate 148: no. 17 \\
\hline 264 & & cup & Bernabò-Brea \& Cavalier 1980, 316: cat. no. 94, Plate 148: no. 16 \\
\hline 265 & LH I-LH II & vapheio cup & Bernabò-Brea \& Cavalier 1980, 316: cat. no. 28, Plate 142: no. 17 \\
\hline 266 & $\mathrm{LH} \|$ & jar & Bernabò-Brea \& Cavalier 1980, 316: cat. no. 77, Plate 148: no. 1 \\
\hline 267 & & fragment & Bernabò-Brea \& Cavalier 1980, 323: cat. no. 160, Plate 152: no. 23 \\
\hline 268 & LH IIIC & fragment & Bernabò-Brea \& Cavalier 1980, 323, cat. no. 293, Plate 254: no. 3 \\
\hline 269 & & fragment & Bernabò-Brea \& Cavalier 1980, 323: cat. no. 224, Plate 160: no. 21 \\
\hline 270 & $\mathrm{LH} I I \mathrm{C}$ & cup & Bernabò-Brea \& Cavalier 1980, 323: cat. no. 292, Plate 244: no. 2 \\
\hline 271 & LH I-LH II & rounded alabastron & Bernabò-Brea \& Cavalier 1980, 352: cat. no. 36, Plate 144: no. 2 \\
\hline 272 & & fragment & Bernabò-Brea \& Cavalier 1980, 352: cat. no. 125, Plate 152: no. 15 \\
\hline 273 & LH IIA & semi-globular cup & Bernabò-Brea \& Cavalier 1980, 376: cat. no. 81, Plate 148: no. 6 \\
\hline 274 & LH I & cup & Bernabò-Brea \& Cavalier 1980, 379: cat. no. 32, Plate 140: no. 6 \\
\hline 275 & LH I-LH II & rounded alabastron & Bernabò-Brea \& Cavalier 1980, 398: cat. no. 38, Plate 144: no. 3 \\
\hline 276 & & fragment & Bernabò-Brea \& Cavalier 1980, 398: cat. no. 136, Plate 152: no. 10 \\
\hline 277 & LH I-LH II & vapheio cup & Taylour 1958: 20: no. 12, Plate 8: no. 4 \\
\hline 278 & LH I-LH II & vapheio cup & Taylour 1980, 798: cat. no. 66, Plate 146: no. 6 \\
\hline 279 & LH I-LH II & vapheio cup & Taylour 1980, 798: cat. no. 67, Plate 146: no. 7 \\
\hline 280 & LH I-LH II & vapheio cup & Taylour 1980, 798: cat. no. 69, Plate 146: no. 8 \\
\hline 281 & LH II & goblet & Taylour 1980, 798: cat. no. 75, Plate 146: no. 14 \\
\hline 282 & LH II & fragment & Taylour 1980, 799: cat. no. 78, Plate 148: no. 2 \\
\hline 283 & LH II-LH IIIA1 & rounded alabastron & Taylour 1980, 801: cat. no. 106, Plate 150: no. 10 \\
\hline 284 & LH II-LH IIIA1 & fragment & Taylour 1958, 28: no. 47, Plate 5: no. 21 \\
\hline 285 & LH IIB-LH IIIA1 & shallow cup & Taylour 1980, 802: cat. nos. 117-118, Plate 150: no. 19 \\
\hline 286 & & fragment & Taylour 1980, 802: cat. no. 124, Plate 150: no. 26 \\
\hline 287 & & fragment & Taylour 1980, 802: cat. no. 126, Plate 152: no. 16 \\
\hline 288 & & fragment & Taylour 1980, 802: cat. no. 127 (not illustrated) \\
\hline 289 & LH IIIA1-LH IIIA2 & kylix & Taylour 1980, 806: cat. nos. 194-196, Plate 159: no. 2 \\
\hline 290 & LH IIIA1-LH IIIA2 & kylix & Taylour 1980, 806: cat. nos. 197-199, Plate 159: nos. 9-11 \\
\hline 291 & LH IIIA2-LH IIIB & cup & Taylour 1958, 38: no. 90, Plate 3: no. 17 \\
\hline 292 & & fragment & Taylour 1980, 810: cat. no. 254 (not illustrated) \\
\hline 293 & LH IIIB & fragment & Taylour 1958, 40: no. 102, Plate 6-17 \\
\hline 294 & LH IIIC & ring-based krater & Taylour 1958, 41: no. 108, Plate 6: no. 22, 25 \\
\hline 295 & $\mathrm{LH} I I \mathrm{C}$ & ring-based krater & Taylour 1958, 42: no. 110, Plate 6: no. 24 \\
\hline 296 & LH IIIC & cup & Taylour 1958, 42: no. 112, Plate 6: no. 27 \\
\hline 297 & & fragment & Taylour 1980, 815: cat. no. 321, Plate 159: no. 13 \\
\hline
\end{tabular}




\begin{tabular}{|c|c|c|c|}
\hline ID & date & shape & published \\
\hline 298 & & fragment & Taylour 1980, 815: cat. no. 322, Plate 159: no. 12 \\
\hline 299 & & fragment & Taylour 1980, 815: cat. no. 323, Plate 159: no. 14 \\
\hline 300 & & fragment & Taylour 1980, 815: cat. no. 324, Plate 246: no. 5 \\
\hline 301 & & fragment & Taylour 1980, 815: cat. no. 325 (not illustrated) \\
\hline 302 & & fragment & Taylour 1980, 815: cat. no. 326 (not illustrated) \\
\hline 303 & LH IIIA1-LH IIIA2 & fragment & Cavalier \& Vagnetti 1984, 145: no. 1, Plate II: no. 1 \\
\hline 304 & LH IIIA1 & cup or kylix & Cavalier \& Vagnetti 1984, 146: no. 2, Plate II: no. 2 \\
\hline 305 & & fragment & Cavalier \& Vagnetti 1984, 144: no. 10498 \\
\hline 306 & & fragment & Cavalier \& Vagnetti 1984, 146: no. 1, Plate 2: no. 3 \\
\hline 307 & & fragment & Cavalier \& Vagnetti 1984, 146: no. 2, Plate 2: no. 4 \\
\hline 308 & LH IIA & rounded alabastron & Cavalier \& Vagnetti 1984, 146: no. 3, Plate 2: no. 5 \\
\hline 309 & & fragments & Cavalier \& Vagnetti 1984, 146-147: nos. 4a-b, Plate 2: nos. 6,8 \\
\hline 310 & LH IIA & jug with cut-away neck & Cavalier \& Vagnetti 1984, 147: no. 5, Plate 2: no. 10 \\
\hline 311 & & jug & Cavalier \& Vagnetti 1984, 147: no. 6, Plate 2: no. 7 \\
\hline 312 & & fragment & Cavalier \& Vagnetti 1984, 147: no. 7, Plate 2: no. 9 \\
\hline 313 & LH I-LH IIA & semi-globular cup & Cavalier \& Vagnetti 1984, 147: no. 8, Plate 3: no. 1 \\
\hline 314 & LH I-LH II & fragment & Cavalier \& Vagnetti 1984, 147: no. 9, Plate 3: no. 2 \\
\hline 315 & LH I-LH II & vapheio cup & Cavalier \& Vagnetti 1984, 147: no. 10, Plate 3: no. 5 \\
\hline 316 & & fragment & Cavalier \& Vagnetti 1984, 147: no. 11, Plate 3: no. 3 \\
\hline 317 & & fragment & Cavalier \& Vagnetti 1984, 147: no. 12, Plate 3: no. 4 \\
\hline 318 & & fragments & Cavalier \& Vagnetti 1984, 148: nos. 13a-d (not illustrated) \\
\hline \multicolumn{4}{|c|}{2 Mycenaean figurine } \\
\hline ID & date & sort & published \\
\hline 501 & LH IIIA2 & female & Bernabò-Brea \& Cavalier 1980, 176, Plate 158: no. 2 \\
\hline
\end{tabular}




\section{Catalogue IX: Mycenaean pottery at Thapsos}

Mycenaean vessels and fragments

\begin{tabular}{|c|c|c|c|}
\hline ID & date & shape & published \\
\hline 1 & LH IIIA1-LH IIIA2 & small piriform jar & Orsi 1895, 97-98, Plate IV: no. 3 \\
\hline 2 & LH IIIA2-LH IIIB & straight-sided alabastron & Orsi 1895, 98-99, fig. 4 \\
\hline 3 & LH IIIA2-LH IIIB & two-handled piriform jar & Orsi 1895, 99 (not illustrated) \\
\hline 4 & LH IIIA2-LH IIIB & small globular jug & Orsi 1895, 99 (not illustrated) \\
\hline 5 & LH IIIA2-LH IIIB & straight-sided alabastron & Orsi 1895, 103 (not illustrated) \\
\hline 6 & LH IIIA2 & small piriform jar & Orsi 1895, 105, Plate IV: no. 12 \\
\hline 7 & LH IIIA1 & small piriform jar & Orsi 1895, 106, Plate IV: no. 8 \\
\hline 8 & $\mathrm{LH}$ IIIA2 & small piriform jar & Orsi 1895, 112 (not illustrated) \\
\hline 9 & LH IIIA2-LH IIIB & small piriform jar & Orsi 1895, 115 (not illustrated) \\
\hline 10 & & fragment & Orsi 1895, 117 (not illustrated) \\
\hline 11 & & fragment & Orsi 1895, 117 (not illustrated) \\
\hline 12 & $\mathrm{LH} \| \mathrm{II} 2$ & narrow-necked beaked jug & Orsi 1895, 121, Plate V: no. 4 \\
\hline 13 & $\mathrm{LH}$ IIIA2 & small piriform jar & Orsi 1895, 127, Plate V: no. 12 \\
\hline 14 & & amphora & Orsi 1895, 128 (not illustrated \\
\hline 15 & LH IIIA2-LH IIIB & globular stirrup jar & Orsi 1895, 129, fig. 42 \\
\hline 16 & LH IIIA2-LH IIIB & small piriform jar & Orsi 1895 133, fig. 49 \\
\hline 17 & LH IIIA2 & beaked globular jug & Orsi 1895, 135, Plate V: no. 17 \\
\hline 18 & LH IIIA1-LH IIIA2 & small piriform jar & Orsi 1895, 135, Plate V; no. 18 \\
\hline 19 & LH IIIA2 & small piriform jar & Orsi 1895, 135 , Plate 5: no. 24 \\
\hline 20 & LH IIIA2-LH IIIB & straight-sided alabastron & Orsi 1895, 136, fig. 52 \\
\hline 21 & & stirrup jar & Arias 1936-1937, 58: no. 7 (not illustrated) \\
\hline 22 & & alabastron & Arias 1936-1937, 59: no. 17 (not illustrated) \\
\hline 23 & & small piriform jar & Arias 1936-1937, 59: no. 20 (not illustrated) \\
\hline 24 & LH IIIA2 & small piriform jar & Taylour 1958, 58: no. 10 (not illustrated) \\
\hline 25 & LH IIIA1 & squat alabastron & Gentili 1953, 216 (not illustrated) \\
\hline 26 & LH IIIA2-LH IIIB & straight-sided alabastron & Taylour 1958, 60: no. 18 \\
\hline 27 & & fragment & Bernabo-Brea 1966, 113 \\
\hline 28 & & fragment & Bernabo-Brea 1966, 113 \\
\hline 29 & LH IIIA2 & straight-sided alabastron & Voza 1972, 196: no. 1, fig. 12a \\
\hline 30 & LH IIIA2-LH IIIB & straight-sided alabastron & Voza 1972, 197: no. 2, fig. 12b \\
\hline 31 & LH IIIA2-LH IIIB & rounded alabastron & Voza 1972, 197: no. 3, fig. 12c \\
\hline 32 & LH IIIA2-LH IIIB & piriform jar & Voza 1972, 197: no. 4, fig. 12d \\
\hline 33 & LH IIIA2 & piriform jar & Voza 1972, 197: no. 5, fig. 12e \\
\hline 34 & LH IIIA2 & small piriform jar & Voza 1972, 197: no. 6, fig. $12 f$ \\
\hline 35 & LH IIIA2 & shallow cup & Voza 1973b, 35-36: no. 82, Tav. VI \\
\hline 36 & LH IIIA2-LH IIIB & stemmed cup & Voza 1973b, 36: no. 83, Tav. VI \\
\hline 37 & LH IIIA2-LH IIIB & deep bowl & Voza 1973b, 36: no. 84, Tav. VI \\
\hline 38 & LH IIIA2 & small piriform jar & Voza 1973b, 40: no. 117 (not illustrated) \\
\hline
\end{tabular}




\section{Catalogue X: Mycenaean pottery at Mycenaean pottery at Broglio di Trebisacce}

1 Mycenaean imported vessels and fragments

\begin{tabular}{llll}
\hline ID & date & shape & published \\
\hline 1 & LH IIIA2-LH IIIB & straight-sided alabastron & Vagnetti 1982b, 120-121: no. 11, Tav 23.11 \\
2 & LH IIIA1-LH IIIA2 & jar & Vagnetti 1982b, 122-123, no. 16, Tav. 24.3 \\
3 & & jar & Vagnetti 1982c, 102-103: no. 13, Tav. 24.2 \\
4 & LH IIIB-LH IIIC & fragment & Vagnetti 1984a, 165-166: no. 5, Tav. 39.4 \\
5 & LH IIIA & fragment & Vagnetti 1984b, 174, 177: no. 27, Tav, 47.8 \\
6 & LH IIIB2-LH IIIC & cup/bowl & Vagnetti \& Panichelli 1994, 376-377: no. 18, Tav. 71.1 \\
7 & LH IIIC & fragment & Vagnetti \& Panichelli 1994, 378-379: no. 46, Tav. 72.3 \\
8 & LH IIIB2-LH IIIC & fragments & Vagnetti \& Panichelli 1994, 378-379: no. 48, Tav. 72.5 \\
9 & LH IIIB & amphora & Vagnetti \& Panichelli 1994, 380, 382: no. 76, Tav. 73.12 \\
10 & LH IIIB & amphora & Vagnetti \& Panichelli 1994, 380, 382: no. 78, Tav. 73.13 \\
11 & LH IIIB & amphora & Vagnetti \& Panichelli 1994, 382-383:no. 79, Tav. 74.2 \\
12 & LH IIIB & stirrup jar & Vagnetti \& Panichelli 1994, 384-385: no. 102, Tav. 75.11 \\
\hline
\end{tabular}

2 Mycenaean-type vessels and fragments of local manufacture

\begin{tabular}{|c|c|c|c|}
\hline ID & date & shape & published \\
\hline 1001 & & fragment & Vagnetti 1982b, 119-120: no. 1, Tav. 23.1 \\
\hline 1002 & & fragment & Vagnetti 1982b, 119-120: no. 2, Tav. 23.2 \\
\hline 1003 & LH IIIB2-LH IIIC & collar-necked jar & Vagnetti 1982b, 119-120: no. 3, Tav. 23.3 \\
\hline 1004 & & amphora & Vagnetti 1982b, 119-120: no. 4, Tav. 23.4 \\
\hline 1005 & LH IIIA & fragment & Vagnetti 1982b, 119-120: no. 5, Tav. 23.5; 121-122: no. 14 \\
\hline 1006 & LH IIIB-LH IIIC & deep bowl & Vagnetti 1982b, 119-120: no. 6, Tav. 23.6 \\
\hline 1007 & & amphora & Vagnetti 1982b, 119-120: no. 7, Tav. 23.7 \\
\hline 1008 & & stirrup jar & Vagnetti 1982b, 119-120: no. 8, Tav. 23.8 \\
\hline 1009 & & fragment & Vagnetti 1982b, 120-121: no. 9, Tav. 23.9 \\
\hline 1010 & & fragment & Vagnetti 1982b, 120-121: no. 10, Tav. 23.10 \\
\hline 1011 & & cup/bowl & Vagnetti 1982b, 121-122: no. 12, Tav. 24.1 \\
\hline 1012 & & fragment & Vagnetti 1982b, 121-122: no. 15, Tav. 24.5 \\
\hline 1013 & LH IIIB & mug & Vagnetti 1982c, 99, 101: no. 1, Tav. 23.1 \\
\hline 1014 & & cup & Vagnetti 1982c, 99, 101: no. 2, Tav. 23.2 \\
\hline 1015 & & stirrup jar & Vagnetti 1982c, 100-101: no. 3, Tav. 23.4 \\
\hline 1016 & & fragment & Vagnetti 1982c, 100-101: no. 4, Tav. 23.8 \\
\hline 1017 & & fragment & Vagnetti 1982c, 100-101: no. 5, Tav. 23.3 \\
\hline 1018 & & fragment & Vagnetti 1982c, 100-101: no. 6, Tav. 23.6 \\
\hline 1019 & LM IIIB & amphora & Vagnetti 1984b, 175-176: no. 21, Tav. 48.1 \\
\hline 1020 & & fragment & Vagnetti 1982c, 100-101: no. 8, Tav. 23.10 \\
\hline 1021 & LH IIIB & stirrup jar & Vagnetti 1982c, 100-101: no. 9, Tav. 23.9 \\
\hline 1022 & & fragment & Vagnetti 1982c, 100-101: no. 10, Tav. 23.5 \\
\hline 1023 & LH IIIB & carinated cup & Vagnetti 1982c, 100-102: no. 11, Tav. 23.11 \\
\hline 1024 & & fragment & Vagnetti 1982c, 102-103: no. 12, Tav. 24.1 \\
\hline 1025 & LM IIIB-LM IIIC & amphora & Vagnetti 1982c, 102-103: no. 14, Tav. 24.7 \\
\hline 1026 & & amphora & Vagnetti 1982c, 102-103: no. 15, Tav. 24.5 \\
\hline 1027 & & fragment & Vagnetti 1982c, 102-103: no. 16, Tav. 24.6 \\
\hline 1028 & & fragment & Vagnetti 1982c, 102-103: no. 17, Tav. 24.3 \\
\hline 1029 & LH IIIB-LH IIIC & deep bowl & Vagnetti 1982c, 102, 104: no. 18, Tav. 25.1 \\
\hline 1030 & LH IIIB & cup/bowl & Vagnetti 1982c, 102-103: no. 19, Tav. 24.4 \\
\hline
\end{tabular}




\begin{tabular}{|c|c|c|c|}
\hline ID & date & shape & published \\
\hline 1031 & & fragment & Vagnetti 1982c, 102, 105: no. 20, Tav. 25.2 \\
\hline 1032 & & fragment & Vagnetti 1982c, 102, 105: no. 21, Tav. 25.3 \\
\hline 1033 & LM IIIB & amphoriskos & Vagnetti 1982c, 104-105: no. 22, Tav. 25.6, 8 \\
\hline 1034 & & fragment & Vagnetti 1982c, 104-105: no. 23, Tav. 25.4 \\
\hline 1035 & & fragment & Vagnetti 1984b, 179, 181: no. 39, Tav. 51.3 \\
\hline 1036 & & fragment & Vagnetti 1982c, 104-105: no. 25, Tav. 25.10 \\
\hline 1037 & & fragment & Vagnetti 1982c, 104-105: no. 26, Tav. 25.5 \\
\hline 1038 & & fragment & Vagnetti 1982c, 104, 107: no. 27, Tav. 26.4 \\
\hline 1039 & & fragment & Vagnetti 1982c, 104-105: no. 28, Tav. 25.9 \\
\hline 1040 & & fragment & Vagnetti 1982c, 104, 107: no. 29, Tav. 26.5 \\
\hline 1041 & & fragment & Vagnetti 1982c, 104, 107: no. 30, Tav. 26.10 \\
\hline 1042 & & & Vagnetti 1982c, 104, 107: no. 31, Tav. 26.1 \\
\hline 1043 & & fragment & Vagnetti 1982c, 104, 107: no. 32, Tav. 26.3 \\
\hline 1044 & & fragment & Vagnetti 1982c, 104, 107: no. 33, Tav. 26.8 \\
\hline 1045 & LH IIIB-LH IIIC & deep bowl & Vagnetti 1984a, 164-165: no. 1, Tav. 39.1 \\
\hline 1046 & LH IIIB-LH IIIC & deep bowl & Vagnetti 1984a, 164-165: no. 2, Tav. 39.2 \\
\hline 1047 & & fragment & Vagnetti 1984a, 164-165: no. 3, Tav. 47.1 \\
\hline 1048 & & fragment & Vagnetti 1984a, 165-166: no. 4, Tav. 39.3 \\
\hline 1049 & LM IIIB & amphora & Vagnetti 1984b, 173, 178: no. 15, Tav. 49.3. \\
\hline 1050 & & fragment & Vagnetti 1984a, 165-166: no. 7, Tav. 39.5 \\
\hline 1051 & & fragment & Vagnetti 1984a, 165-166: no. 8, Tav. 39.6 \\
\hline 1052 & & fragment & Vagnetti 1984a, 165-166: no. 9, Tav. 39.7 \\
\hline 1053 & & fragment & Vagnetti 1984a, 165-166: no. 10, Tav. 39.8 \\
\hline 1054 & LH IIIB2-LH IIIC & collar-necked jar & Vagnetti 1984a, 165-166: no. 11, Tav. 39.9 \\
\hline 1055 & & fragment & Vagnetti 1984a, 165-166: no. 12, Tav. 39.14 \\
\hline 1056 & & fragment & Vagnetti 1984a, 165, 168: no. 13, Tav. 39.15 \\
\hline 1057 & & fragment & Vagnetti 1984a, 165, 168: no. 14, Tav. 39.10 \\
\hline 1058 & & fragment & Vagnetti 1984a, 165, 168: no. 15, Tav. 39.11 \\
\hline 1059 & & fragment & Vagnetti 1984a, 165, 168: no. 16, Tav. 39.12 \\
\hline 1060 & & fragment & Vagnetti 1984a, 165, 168: no. 17, Tav. 39.13 \\
\hline 1061 & LH IIIC & carinated cup & Vagnetti 1984a, 167-168: no. 18, Tav. 40.1 \\
\hline 1062 & & fragment & Vagnetti 1984a, 167-168: no. 19, Tav. 40.9 \\
\hline 1063 & LH IIIC & fragment & Vagnetti 1984a, 168-169: no. 20, Tav. 41.3 \\
\hline 1064 & & fragment & Vagnetti 1984a, 167-168: no. 21, Tav. 40.3 \\
\hline 1065 & & fragment & Vagnetti 1984a, 167-168: no. 22, Tav. 40.5 \\
\hline 1066 & & fragment & Vagnetti 1984a, 167-168: no. 23, Tav. 40.4 \\
\hline 1067 & & fragment & Vagnetti 1984a, 167-168: no. 24, Tav. 40.7 \\
\hline 1068 & & fragment & Vagnetti 1984a, 167-168: no. 25, Tav. 40.6 \\
\hline 1069 & & fragment & Vagnetti 1984a, 167, 170: no. 26, Tav. 40.8 \\
\hline 1070 & LH IIIC & krater/bowl & Vagnetti 1984a, 169-170: no. 27, Tav. 41.1 \\
\hline 1071 & & fragment & Vagnetti 1984a, 167, 170: no. 28, Tav. 40.2 \\
\hline 1072 & LH IIIC & collar-necked jar & Vagnetti 1984a, 169-170: no. 30, Tav. 41.2 \\
\hline 1073 & & bowl/cup & Vagnetti 1984a, 170-171: no. 31, Tav. 42.1 \\
\hline 1074 & & fragment & Vagnetti 1984a, 170-171: no. 32, Tav. 42.6 \\
\hline 1075 & & fragment & Vagnetti 1984a, 170-171: no. 34, Tav. 42.15 \\
\hline 1076 & LH IIIB-LH IIIC & deep bowl & Vagnetti 1984a, 170-171: no. 35, Tav. 42.2 \\
\hline 1077 & & fragment & Vagnetti 1984a, 171-172: no 36, Tav. 42.4 \\
\hline 1078 & & fragment & Vagnetti 1984a, 171-172: no. 37, Tav. 42.5 \\
\hline 1079 & LH IIIB & shallow cup & Vagnetti 1984a, 171-172: no. 38, Tav. 42.14 \\
\hline 1080 & LH IIIA2-LH IIIB & fragment & Vagnetti 1984a, 171-172: no. 41, Tav. 42.9 \\
\hline 1081 & LM IIIB & amphora & Vagnetti 1984a, 171-172: no. 42, Tav. 42.16 \\
\hline
\end{tabular}




\begin{tabular}{|c|c|c|c|}
\hline ID & date & shape & published \\
\hline 1082 & LH IIIC & fragment & Vagnetti 1984a, 171-172: no. 43, Tav. 42.7 \\
\hline 1083 & & fragment & Vagnetti 1984a, 171-172: no. 44, Tav. 42.11 \\
\hline 1084 & & fragment & Vagnetti 1984a, 171-172: no. 45, Tav. 42.8 \\
\hline 1085 & & fragment & Vagnetti 1984a, 171-172: no. 46 , Tav. 42.12 \\
\hline 1086 & & fragment & Vagnetti 1984a, 171-172: no. 47, Tav. 42.3 \\
\hline 1087 & & fragment & Vagnetti 1984a, 171-172: no. 48 , Tav. 42.10 \\
\hline 1088 & & fragment & Vagnetti 1984a, 172-173: no. 49, Tav. 43.1 \\
\hline 1089 & & fragment & Vagnetti 1984a, 173-174: no. 50, Tav. 43.2 \\
\hline 1090 & & fragment & Vagnetti 1984a, 173-174: no. 51, Tav. 43.3 \\
\hline 1091 & & fragment & Vagnetti 1984a, 171, 174: no. 52, Tav. 42.13 \\
\hline 1092 & & fragment & Vagnetti 1984a, 173-174: no. 53, Tav. 43.7 \\
\hline 1093 & & fragment & Vagnetti 1984a, 173-174: no. 54, Tav. 43.6 \\
\hline 1094 & & fragment & Vagnetti 1984a, 173-174: no. 55, Tav. 43.5 \\
\hline 1095 & & fragment & Vagnetti 1984a, 173-174: no. 56, Tav. 43.9 \\
\hline 1096 & & fragment & Vagnetti 1984a, 173-174: no. 57, Tav. 43.11 \\
\hline 1097 & & fragment & Vagnetti 1984a, 173-174: no. 58, Tav. 43.8 \\
\hline 1098 & & fragment & Vagnetti 1984a, 173-174: no. 59, Tav. 43.4 \\
\hline 1099 & LH IIIB-LH IIIC & amphora & Vagnetti 1984a, 173-174: no. 60, Tav. 43.10 \\
\hline 1100 & & fragment & Vagnetti 1984a, 173-174: no. 61, Tav. 43.12 \\
\hline 1101 & LH IIIB-LH IIIC & deep bowl & Vagnetti 1984a, 174-175: no. 62, Tav. 44.1 \\
\hline 1102 & LH IIIB-LH IIIC & fragment & Vagnetti 1984a, 174, 176: no. 63, Tav. 45.1 \\
\hline 1103 & & cup & Vagnetti 1984a, 174-175: no. 64, Tav. 44.2 \\
\hline 1104 & LH IIIB1 & jug & Vagnetti 1984a, 175-176: no. 65, Tav. 44.6 \\
\hline 1105 & LM IIB & fragment & Vagnetti 1984a, 176-177: no. 66, Tav. 45.2 \\
\hline 1106 & LM IIIB & amphora & Vagnetti 1984a, 176-177: no. 67, Tav. 45.3-4 \\
\hline 1107 & LH IIIC & amphora & Vagnetti 1984a, 175-176: no. 68, Tav. 44.3 \\
\hline 1108 & & fragment & Vagnetti \& Panichelli 1994, 390, 393: no. 138, Tav. 79.9 \\
\hline 1109 & & fragment & Vagnetti \& Panichelli 1994, 390, 393: no. 139, Tav. 79.10 \\
\hline 1110 & LH IIIB1 & fragment & Vagnetti 1984a, 175-176: no. 71, Tav. 44.8 \\
\hline 1111 & LH IIIC & fragment & Vagnetti 1984a, 175-176: no. 72, Tav. 44.10 \\
\hline 1112 & LH IIIC & fragment & Vagnetti 1984a, 175-176: no. 73 , Tav. 44.12 \\
\hline 1113 & & fragment & Vagnetti 1984a, 175-176: no. 74, Tav. 44.5 \\
\hline 1114 & & fragment & Vagnetti 1984a, 175-176: no. 75, Tav. 44.11 \\
\hline 1115 & & fragment & Vagnetti 1984a, 175-176: no. 76, Tav. 44.7 \\
\hline 1116 & & fragment & Vagnetti 1984a, 176-177: no. 77, Tav. $45.5,7$ \\
\hline 1117 & & fragment & Vagnetti 1984a, 177-178: no. 78, Tav. 45.6 \\
\hline 1118 & & fragment & Vagnetti 1984a, 178-179: no. 79, Tav. 46.1 \\
\hline 1119 & & fragment & Vagnetti 1984a, 178-179: no. 80, Tav. 46.2 \\
\hline 1120 & & fragment & Vagnetti 1984a, 178-179: no. 81, Tav. 46.3 \\
\hline 1121 & & fragment & Vagnetti 1984a, 178-179: no. 82, Tav. 46.4 \\
\hline 1122 & & fragment & Vagnetti 1984a, 178-179: no. 83, Tav. 46.5 \\
\hline 1123 & & fragment & Vagnetti 1984a, 178-179: no. 84, Tav. 46.6 \\
\hline 1124 & & fragment & Vagnetti 1984a, 178-179: no. 85 \\
\hline 1125 & & fragment & Vagnetti 1984a, 178-179: no. 86, Tav. 46.12 \\
\hline 1126 & & fragment & Vagnetti 1984a, 178-179: no. 87, Tav. 46.11 \\
\hline 1127 & & fragment & Vagnetti 1984a, 178-179: no. 88, Tav. 46.13 \\
\hline 1128 & & fragment & Vagnetti 1984a, 178-179: no. 89, Tav. 46.14 \\
\hline 1129 & & fragment & Vagnetti 1984a, 178-179: no. 90, Tav. 46.10 \\
\hline 1130 & & fragment & Vagnetti 1984a, 178-179: no. 91, Tav. 46.7 \\
\hline 1131 & & fragment & Vagnetti 1984a, 178-179: no. 92, Tav. 46.8 \\
\hline 1132 & & fragment & Vagnetti 1984a, 178-179: no. 93, Tav. 46.9 \\
\hline
\end{tabular}




\begin{tabular}{|c|c|c|c|}
\hline ID & date & shape & published \\
\hline 1133 & & fragment & Vagnetti 1984b, 169-170: no. 1, Tav. 45.1 \\
\hline 1134 & & fragment & Vagnetti 1984b, 169-170: no. 2, Tav. 45.4 \\
\hline 1135 & LH IIIA2 & fragment & Vagnetti 1984b, 169, 171-172: no. 3, Tav. 46.1 \\
\hline 1136 & & fragment & Vagnetti 1984b, 170-171: no. 4, Tav, 45.10 \\
\hline 1137 & & bowl & Vagnetti 1984b, 170-171: no. 5, Tav. 45.9 \\
\hline 1138 & & fragment & Vagnetti 1984b, 171-172: no. 6, Tav. 46.2 \\
\hline 1139 & & fragment & Vagnetti 1984b, 170-171: no. 7, Tav. 45.3 \\
\hline 1140 & LH IIIB & stirrup jar & Vagnetti 1984b, 170-171: no. 8, Tav. 45.6 \\
\hline 1141 & & fragment & Vagnetti 1984b, 170-171: no. 9, Tav. 45.11 \\
\hline 1142 & & fragment & Vagnetti 1984b, 170-171: no. 10, Tav. 45.2 \\
\hline 1143 & & fragment & Vagnetti 1984b, 170-171: no. 11, Tav. 45.5 \\
\hline 1144 & & jar & Vagnetti 1984b, 171, 173: no. 12, Tav. 45.8 \\
\hline 1145 & LH IIIC & deep bowl & Vagnetti 1984b, 171, 173: no. 13, Tav. 45.7 \\
\hline 1146 & LM IIIB & amphora & Vagnetti 1984b, 172-173: no. 14, Tav. 46.3 \\
\hline 1147 & & fragment & Vagnetti 1984b, 174-175: no. 16, Tav. 47.1 \\
\hline 1148 & LH IIIB-LH IIIC & deep bowl & Vagnetti 1984b, 174-175: no. 17, Tav. 47.3 \\
\hline 1149 & & fragment & Vagnetti 1984b, 174-175: no. 18, Tav. 47.4 \\
\hline 1150 & & fragment & Vagnetti 1984b, 174-175: no. 19, Tav. 47.5 \\
\hline 1151 & LH IIIC & deep bowl & Vagnetti 1984b, 174-175: no. 20, Tav. 47.7 \\
\hline 1152 & LM IIIB & amphora & Vagnetti 1984b, 175-177: no. 22, Tav, 48.2 \\
\hline 1153 & LM IIIB & amphora & Vagnetti 1984b, 177, 180: no. 23, Tav. 50.1-2 \\
\hline 1154 & LM IIIB & amphora & Vagnetti 1984b, 175, 177: no. 24, Tav. 47.11 \\
\hline 1155 & LH IIIC & amphora & Vagnetti 1984b, 177-178: no. 25, Tav. 49.2 \\
\hline 1156 & LM IIIB-LM IIIC & amphora & Vagnetti 1984b, 175, 177: no. 26, Tav. 47.10 \\
\hline 1157 & & fragment & Vagnetti 1984b, 175, 177: no. 28 , Tav. 47.12 \\
\hline 1158 & & fragment & Vagnetti 1984b, 175, 177: no. 29, Tav. 47.15 \\
\hline 1159 & & fragment & Vagnetti 1984b, 177, 181: no. 30, Tav. 51.4 \\
\hline 1160 & & fragment & Vagnetti 1984b, 175, 177, 179: no. 31, Tav. 47.6 \\
\hline 1161 & & fragment & Vagnetti 1984b, 175, 179: no. 32, Tav. 47.13 \\
\hline 1162 & & fragment & Vagnetti 1984b, 175, 179: no. 33, Tav. 47.9 \\
\hline 1163 & LH IIIB-LH IIIC & deep bowl & Vagnetti 1984b, 175, 179: no. 34, Tav, 47.2 \\
\hline 1164 & LM IIIB & amphora & Vagnetti 1984b, 179, 182: no. 35, Tav. 51.1 \\
\hline 1165 & & fragment & Vagnetti 1984b, 175, 179: no. 37, Tav. 47.14 \\
\hline 1166 & LH IIIC & carinated cup & Vagnetti 1984b, 179, 182: no. 38, Tav. 51.2 \\
\hline 1167 & LM IIIB-LM IIIC & amphoriskos & Vagnetti 1984b, 179-182: no. 40, Tav. 50.3 \\
\hline 1168 & LH IIIB-LH IIIC & deep bowl & Vagnetti 1984b, 181, 184: no. 41, Tav. 52.1 \\
\hline 1169 & LH IIIB & mug & Vagnetti 1984b, 181, 184: no. 42, Tav. 52.2 \\
\hline 1170 & & cup & Vagnetti 1984b, 181, 184: no. 43, Tav. 52.3 \\
\hline 1171 & & cup or bowl & Vagnetti 1984b, 181, 184: no. 44, Tav. 52.4 \\
\hline 1172 & & fragment & Vagnetti 1984b, 181, 184: no. 45, Tav. 52.5 \\
\hline 1173 & LH IIIB-LH IIIC & amphora & Vagnetti 1984b, 181, 184: no. 46, Tav. 52.6 \\
\hline 1174 & & fragment & Vagnetti 1984b, 181, 184: no. 47, Tav. 52.7 \\
\hline 1175 & & fragment & Vagnetti 1984b, 181, 184: no. 48, Tav. 52.8 \\
\hline 1176 & & fragment & Vagnetti 1984b, 181, 186: no. 49, Tav. 53.6 \\
\hline 1177 & & fragment & Vagnetti 1984b, 183, 186: no. 50, Tav. 53.2 \\
\hline 1178 & & fragment & Vagnetti 1984b, 183, 186: no. 51, Tav. 53.3 \\
\hline 1179 & & fragment & Vagnetti 1984b, 183, 186: no. 52, Tav. 53.1 \\
\hline 1180 & & fragment & Vagnetti 1984b, 183, 186: no. 53, Tav. 53.3 \\
\hline 1181 & & fragment & Vagnetti 1984b, 183, 186: no. 54, Tav. 53.5 \\
\hline 1182 & LH IIIB & mug & Vagnetti 1984b, 183, 188: no. 55, Tav. 54.1 \\
\hline 1183 & LH IIIB-LH IIIC & amphora & Vagnetti 1984b, 183, 188: no. 56, Tav. 54.3 \\
\hline
\end{tabular}




\begin{tabular}{|c|c|c|c|}
\hline ID & date & shape & published \\
\hline 1184 & LH IIIB-LH IIIC & amphora & Vagnetti 1984b, 183, 188: no. 57, Tav. 54.2 \\
\hline 1185 & & fragment & Vagnetti 1984b, 183, 188: no. 58, Tav. 54.4 \\
\hline 1186 & & fragment & Vagnetti 1984b, 183, 188: no. 59, Tav. 54.5 \\
\hline 1187 & & fragment & Vagnetti 1984b, 183, 188: no. 60, Tav. 54.6 \\
\hline 1188 & & fragment & Vagnetti 1984b, 185, 188: no. 61, Tav. 54.7 \\
\hline 1189 & LH IIIB-LH IIIC & amphora & Vagnetti 1984b, 185, 188: no. 62, Tav. 54.10 \\
\hline 1190 & & fragment & Vagnetti 1984b, 185, 188: no. 63, Tav. 54.9 \\
\hline 1191 & & fragment & Vagnetti 1984b, 185, 188: no. 64, Tav. 54.8 \\
\hline 1192 & & fragment & Vagnetti 1984b, 185, 190: no. 65, Tav. 55.1 \\
\hline 1193 & & jar & Vagnetti 1984b, 185, 190: no. 66, Tav. 55.2 \\
\hline 1194 & & fragment & Vagnetti 1984b, 185, 190: no. 67, Tav. 55.3 \\
\hline 1195 & & fragment & Vagnetti 1984b, 185, 190: no. 68, Tav. 55.4 \\
\hline 1196 & & fragment & Vagnetti 1984b, 185, 190: no. 69, Tav. 55.10 \\
\hline 1197 & & fragment & Vagnetti 1984b, 185, 190: no. 70, Tav. 55.5 \\
\hline 1198 & & fragment & Vagnetti 1984b, 185, 190: no. 71, Tav. 55.6 \\
\hline 1199 & & fragment & Vagnetti 1984b, 185, 190: no. 72, Tav. 55.7 \\
\hline 1200 & & fragment & Vagnetti 1984b, 185, 190: no. 73, Tav. 55.8 \\
\hline 1201 & & fragment & Vagnetti 1984b, 185, 190: no. 74, Tav. 55.11 \\
\hline 1202 & & fragment & Vagnetti 1984b, 185, 187, 190: no. 75, Tav. 55.12 \\
\hline 1203 & & fragment & Vagnetti 1984b, 187, 190: no. 76, Tav. 55.9 \\
\hline 1204 & LH IIIA & fragment & Vagnetti \& Panichelli 1994, 374-375: no. 1, Tav. 70.1 \\
\hline 1205 & LH IIIB2-LH IIIC & fragment & Vagnetti \& Panichelli 1994, 374-375: no. 2, Tav. 70.2 \\
\hline 1206 & & fragment & Vagnetti \& Panichelli 1994, 374-375: no. 3, Tav. 70.3 \\
\hline 1207 & & jug & Vagnetti \& Panichelli 1994, 374-375: no. 4, Tav. 70.4 \\
\hline 1208 & & fragment & Vagnetti \& Panichelli 1994, 374-375: no. 5, Tav. 70.5 \\
\hline \multirow[t]{2}{*}{1209} & & fragment & Vagnetti 1982b, 121-122: no. 13, Tav. 24.4; Vagnetti \& Panichelli \\
\hline & & & 1994, 374-375: no. 6, Tav. 70.6 \\
\hline 1210 & & fragment & Vagnetti \& Panichelli 1994, 374-375: no. 7, Tav. 70.7 \\
\hline 1211 & & fragment & Vagnetti \& Panichelli 1994, 374-375: no. 8, Tav. 70.8 \\
\hline 1212 & & fragment & Vagnetti \& Panichelli 1994, 374-375: no. 9, Tav. 70.9 \\
\hline 1213 & LH IIIB2-LH IIIC & fragment & Vagnetti \& Panichelli 1994, 374-375: no. 10, Tav. 70.11 \\
\hline 1214 & & fragment & Vagnetti \& Panichelli 1994, 374-375: no. 11, Tav. 70.10 \\
\hline 1215 & & fragment & Vagnetti \& Panichelli 1994, 374 \\
\hline 1216 & LH IIIB2-LH IIIC e & collar-necked jar & Vagnetti \& Panichelli 1994, 374-375: no. 12, Tav. 70.12 \\
\hline 1217 & LM IIIB & fragment & Vagnetti \& Panichelli 1994, 374-375: no. 13, Tav. 70.14 \\
\hline 1218 & & fragment & Vagnetti \& Panichelli 1994, 374-375: no. 14, Tav. 70.13 \\
\hline 1219 & & fragment & Vagnetti \& Panichelli 1994, 374-375: no. 15, Tav. 70.15 \\
\hline 1220 & & fragment & Vagnetti \& Panichelli 1994, 374-375: no. 16, Tav. 70.16 \\
\hline 1221 & & fragment & Vagnetti \& Panichelli 1994, 374-375: no. 17, Tav. 70.17 \\
\hline 1222 & & fragment & Vagnetti \& Panichelli 1994, 376-377: no. 19, Tav. 71.2 \\
\hline 1223 & LH IIIB & fragment & Vagnetti \& Panichelli 1994, 376-377: no. 20, Tav. 71.3 \\
\hline 1224 & & fragment & Vagnetti \& Panichelli 1994, 376-377: no. 21, Tav. 71.4 \\
\hline 1225 & & fragment & Vagnetti \& Panichelli 1994, 376-377: no. 22, Tav. 71.5 \\
\hline 1226 & & fragment & Vagnetti \& Panichelli 1994, 376-377: no. 23, Tav. 71.6 \\
\hline 1227 & & fragment & Vagnetti \& Panichelli 1994, 376-377: no. 24, Tav. 71.8 \\
\hline 1228 & & fragment & Vagnetti \& Panichelli 1994, 376-377: no. 25, Tav. 71.7 \\
\hline 1229 & LH IIIB-LH IIIC & bowl & Vagnetti \& Panichelli 1994, 376-377: no. 26, Tav. 71.9 \\
\hline 1230 & & fragment & Vagnetti \& Panichelli 1994, 377 \\
\hline 1231 & & fragment & Vagnetti \& Panichelli 1994, 377 \\
\hline 1232 & & fragment & Vagnetti \& Panichelli 1994, 377: no. 27 \\
\hline 1233 & & fragment & Vagnetti \& Panichelli 1994, 377 \\
\hline
\end{tabular}




\begin{tabular}{|c|c|c|c|}
\hline ID & date & shape & published \\
\hline 1234 & & fragment & Vagnetti \& Panichelli 1994, 377 \\
\hline 1235 & LH IIIB-LH IIIC & collar-necked jar & Vagnetti \& Panichelli 1994, 376-377: no. 28, Tav. 71.10 \\
\hline 1236 & & fragment & Vagnetti \& Panichelli 1994, 376-377: no. 29, Tav. 71.11 \\
\hline 1237 & & fragment & Vagnetti \& Panichelli 1994, 376-377: no. 30, Tav. 71.12 \\
\hline 1238 & & fragment & Vagnetti \& Panichelli 1994, 377 \\
\hline 1239 & LH IIIB-LH IIIC & deep bowl & Vagnetti \& Panichelli 1994, 376-377: no. 31, Tav. 71.13 \\
\hline 1240 & & fragment & Vagnetti \& Panichelli 1994, 377 \\
\hline 1241 & LH IIIB & deep bowl & Vagnetti \& Panichelli 1994, 376-377: no. 33, Tav. 71.16 \\
\hline 1242 & & fragment & Vagnetti \& Panichelli 1994, 378: no. 34 \\
\hline 1243 & LH IIIB-LH IIIC & amphora & Vagnetti \& Panichelli 1994, 376, 378: no. 35, Tav. 71.14 \\
\hline 1244 & LH IIIB-LH IIIC & fragment & Vagnetti \& Panichelli 1994, 376, 378: no. 36, Tav. 71.15 \\
\hline 1245 & & fragment & Vagnetti \& Panichelli 1994, 376, 378: no. 37, Tav. 71.19 \\
\hline 1246 & & fragment & Vagnetti \& Panichelli 1994, 376, 378: no. 38, Tav. 71.17 \\
\hline 1247 & & fragment & Vagnetti \& Panichelli 1994, 376, 378: no. 39, Tav. 71.18 \\
\hline 1248 & LH IIIB-LH IIIC & amphora & Vagnetti \& Panichelli 1994, 376, 378: no. 40, Tav. 71.20 \\
\hline 1249 & & fragment & Vagnetti \& Panichelli 1994, 376, 378: no. 41, Tav. 71.21 \\
\hline 1250 & LH IIIB-LH IIIC & deep bowl & Vagnetti \& Panichelli 1994, 376, 378: no. 42, Tav. 71.24 \\
\hline 1251 & LM IIIA & fragment & Vagnetti \& Panichelli 1994, 376, 378: no. 43, Tav. 71.22 \\
\hline 1252 & & fragment & Vagnetti \& Panichelli 1994, 376, 378: no. 44, Tav. 71.23 \\
\hline 1253 & LH IIIB-LH IIIC & collar-necked jar & Vagnetti \& Panichelli 1994, 378-379: no. 45, Tav. 72.1 \\
\hline 1254 & & fragment & Vagnetti \& Panichelli 1994, 378-379: no. 47, Tav. 72.4 \\
\hline 1255 & & fragment & Vagnetti \& Panichelli 1994, 378-379: no. 49, Tav. 72.2 \\
\hline 1256 & & fragment & Vagnetti \& Panichelli 1994, 378-379: no. 50, Tav. 72.6 \\
\hline 1257 & & fragment & Vagnetti \& Panichelli 1994, 378-379: no. 51, Tav. 72.7 \\
\hline 1258 & & fragment & Vagnetti \& Panichelli 1994, 378-379: no. 52, Tav. 72.8 \\
\hline 1259 & LH IIIB & fragment & Vagnetti \& Panichelli 1994, 378-379: no. 53, Tav. 72.9 \\
\hline 1260 & & fragment & Vagnetti \& Panichelli 1994, 378-379, 381: no. 54, Tav. 72.10 \\
\hline 1261 & LH III & fragment & Vagnetti \& Panichelli 1994, 379, 381: no. 55, Tav. 72.11 \\
\hline 1262 & & fragment & Vagnetti \& Panichelli 1994, 379, 381: no. 56, Tav. 72.12 \\
\hline 1263 & & fragment & Vagnetti \& Panichelli 1994, 379, 381: no. 57, Tav. 72.13 \\
\hline 1264 & & fragment & Vagnetti \& Panichelli 1994, 379, 381: no. 58, Tav. 72.14 \\
\hline 1265 & & fragment & Vagnetti \& Panichelli 1994, 379, 381: no. 59, Tav. 72.15 \\
\hline 1266 & & fragment & Vagnetti \& Panichelli 1994, 381 \\
\hline 1267 & LM IIIB & carinated cup & Vagnetti \& Panichelli 1994, 379, 381: no. 60, Tav. 72.18 \\
\hline 1268 & & cup & Vagnetti \& Panichelli 1994, 379, 381: no. 61, Tav. 72.16 \\
\hline 1269 & & cup & Vagnetti \& Panichelli 1994, 379, 381: no. 62, Tav. 72.17 \\
\hline 1270 & & cup & Vagnetti \& Panichelli 1994, 379, 381: no. 63, Tav. 72.19 \\
\hline 1271 & & fragment & Vagnetti \& Panichelli 1994, 379, 381: no. 64, tav. 72.20 \\
\hline 1272 & & jar & Vagnetti \& Panichelli 1994, 380-381: no. 65, Tav. 73.1 \\
\hline 1273 & LH IIIB2-LH IIIC & collar necked jar & Vagnetti \& Panichelli 1994, 380-381: no. 66, Tav. 73.2 \\
\hline 1274 & & fragment & Vagnetti \& Panichelli 1994, 380-381: no. 67: Tav. 73.3 \\
\hline 1275 & & fragment & Vagnetti \& Panichelli 1994, 381: no. 68 \\
\hline 1276 & & fragment & Vagnetti \& Panichelli 1994, 380-381: no. 69, Tav. 73.6 \\
\hline 1277 & & fragment & Vagnetti \& Panichelli 1994, 380-381: no. 70, Tav. 73.4 \\
\hline 1278 & LH IIIA & mug & Vagnetti \& Panichelli 1994, 380-381: no. 71, Tav. 73.5 \\
\hline 1279 & & fragment & Vagnetti \& Panichelli 1994, 380-381: no. 72, Tav. 73.7 \\
\hline 1280 & & fragment & Vagnetti \& Panichelli 1994, 380-382: no. 73, Tav. 73.8 \\
\hline 1281 & & fragment & Vagnetti \& Panichelli 1994, 380, 382: no. 74, Tav. 73.9 \\
\hline 1282 & LH IIIB-LH IIIC & amphora & Vagnetti \& Panichelli 1994, 380, 382: no. 75, Tav. 73.10-11 \\
\hline 1283 & LH IIIB-LH IIIC & amphora & Vagnetti \& Panichelli 1994, 382-383: no. 77, Tav. 74.1 \\
\hline 1284 & & jar & Vagnetti \& Panichelli 1994, 382-383: no. 80, Tav. 74.3 \\
\hline
\end{tabular}




\begin{tabular}{|c|c|c|c|}
\hline ID & date & shape & published \\
\hline 1285 & LH IIIC & fragments & Vagnetti \& Panichelli 1994, 382-383: no. 81, Tav. 74.4 \\
\hline 1286 & LH IIIB & fragments & Vagnetti \& Panichelli 1994, 382-383: no. 82, Tav. 74.5 \\
\hline 1287 & & fragment & Vagnetti \& Panichelli 1994, 382, 384: no. 83, Tav. 75.1 \\
\hline 1288 & & fragment & Vagnetti \& Panichelli 1994, 382, 384: no. 84, Tav. 75.2 \\
\hline 1289 & LH IIIC & deep bowl & Vagnetti \& Panichelli 1994, 382, 384: no. 85, Tav. 75.12 \\
\hline 1290 & LH IIIB & conical cup & Vagnetti \& Panichelli 1994, 382, 384: no. 86, Tav. 75.4 \\
\hline 1291 & LH IIIB2-LH IIIC & collar-necked jar & Vagnetti \& Panichelli 1994, 382, 384: no. 87, Tav. 75.3 \\
\hline 1292 & LH IIIB2-LH IIIC & collar necked jar & Vagnetti \& Panichelli 1994, 382, 384-385: no. 88, Tav. 75.5 \\
\hline 1293 & LH IIIB & amphora & Vagnetti \& Panichelli 1994, 385-386: no. 89, Tav. 76.1 \\
\hline 1294 & LM IIIB-LM IIIC & amphora & Vagnetti \& Panichelli 1994, 385-386: no. 90, Tav. 76.2 \\
\hline 1295 & LM IIIB-LM IIIC & amphora & Vagnetti \& Panichelli 1994, 385-386: no, 91, Tav. 76.3 \\
\hline 1296 & & fragment & Vagnetti \& Panichelli 1994, 384-385: no. 92, Tav. 75.13 \\
\hline 1297 & LM IIIA2-LM IIIB & fragment & Vagnetti \& Panichelli 1994, 384-385: no. 93, Tav. 75.7 \\
\hline 1298 & LH IIIC & fragment & Vagnetti \& Panichelli 1994, 385, 387: no. 94, Tav. 77.1 \\
\hline 1299 & & fragment & Vagnetti \& Panichelli 1994, 384-385: no. 95: Tav. 75.16 \\
\hline 1300 & & fragment & Vagnetti \& Panichelli 1994, 384-385: no. 96, Tav. 75.6 \\
\hline 1301 & & fragment & Vagnetti \& Panichelli 1994, 384-385: no. 97, Tav. 75.17 \\
\hline 1302 & & fragment & Vagnetti \& Panichelli 1994, 384-385: no. 98, Tav. 75.15 \\
\hline 1303 & & fragment & Vagnetti \& Panichelli 1994, 384-385: no. 99, Tav. 75.8 \\
\hline 1304 & LH IIIB-LH IIIC & fragment & Vagnetti \& Panichelli 1994, 384-385: no. 100, Tav. 75.9 \\
\hline 1305 & & fragment & Vagnetti \& Panichelli 1994, 384-385: no. 101, Tav. 75.10 \\
\hline 1306 & LH IIIC & kylix & Vagnetti \& Panichelli 1994, 384, 389: no. 103, Tav. 75.18 \\
\hline 1307 & & fragment & Vagnetti \& Panichelli 1994, 384, 389: no. 104, Tav. 75.14 \\
\hline 1308 & & amphora & Vagnetti \& Panichelli 1994, 384, 389: no. 106, Tav, 75.19 \\
\hline 1309 & & fragment & Vagnetti \& Panichelli 1994, 388-389: no. 107, Tav. 78.1 \\
\hline 1310 & LH IIIB2-LH IIIC & deep bowl & Vagnetti \& Panichelli 1994, 388-389: no. 108, Tav. 78.2 \\
\hline 1311 & LH IIIB2-LH IIIC & deep bowl & Vagnetti \& Panichelli 1994, 388-389: no. 109, Tav. 78.3 \\
\hline 1312 & LH IIIB2-LH IIIC & deep bowl & Vagnetti \& Panichelli 1994, 388-389: no. 110, Tav. 78.9 \\
\hline 1313 & LH IIIB2-LH IIIC & deep bowl & Vagnetti \& Panichelli 1994, 388-389: no. 111, Tav. 78.4 \\
\hline 1314 & & fragment & Vagnetti \& Panichelli 1994, 388-389: no. 112, Tav. 78.5 \\
\hline 1315 & & fragment & Vagnetti \& Panichelli 1994, 388-389: no. 113, Tav. 78.6 \\
\hline 1316 & & fragment & Vagnetti \& Panichelli 1994, 388-389: no. 114, Tav. 78.8 \\
\hline 1317 & & stirrup jar & Vagnetti \& Panichelli 1994, 388-389: no. 115, Tav. 78.7 \\
\hline 1318 & LH IIIC & amphora & Vagnetti \& Panichelli 1994, 388-389: no. 116, Tav. 77.2 \\
\hline 1319 & LH IIIB2-LH IIIC & collar-necked jar & Vagnetti \& Panichelli 1994, 388-389: no. 117, Tav. 78.10 \\
\hline 1320 & LH IIIB-LH IIIC & amphora & Vagnetti \& Panichelli 1994, 388-389: no. 118, Tav. 78.11 \\
\hline 1321 & LH IIIB-LH IIIC & amphora & Vagnetti \& Panichelli 1994, 388-389: no. 119, Tav. 78.12 \\
\hline 1322 & LH IIIC & fragment & Vagnetti \& Panichelli 1994, 388-390: no. 120, Tav. 78.13 \\
\hline 1323 & & fragment & Vagnetti \& Panichelli 1994, 388, 390: no. 121, Tav. 78.16 \\
\hline 1324 & & fragment & Vagnetti \& Panichelli 1994, 388, 390: no. 122, Tav. 78.14 \\
\hline 1325 & LH IIIC & amphoroid krater & Vagnetti \& Panichelli 1994, 388, 390: no. 123, Tav. 78.17 \\
\hline 1326 & LH IIIB-LH IIIC & amphora & Vagnetti \& Panichelli 1994, 388, 390: no. 124, Tav. 78.19 \\
\hline 1327 & LH IIIB-LH IIIC & amphora & Vagnetti \& Panichelli 1994, 387, 390: no. 125: Tav. 77.3 \\
\hline 1328 & LH IIIC & fragment & Vagnetti \& Panichelli 1994, 388, 390: no. 126: Tav. 78.15 \\
\hline 1329 & & fragment & Vagnetti \& Panichelli 1994, 388, 390: no. 127, Tav. 78.18 \\
\hline 1330 & & fragment & Vagnetti \& Panichelli 1994, 390-391: no. 128, Tav. 79.1 \\
\hline 1331 & & fragment & Vagnetti \& Panichelli 1994, 390-391: no. 129, tav. 79.2 \\
\hline 1332 & & fragment & Vagnetti \& Panichelli 1994, 390-391: no. 131, Tav. 79.3 \\
\hline 1333 & & fragment & Vagnetti \& Panichelli 1994, 390-391: no. 132, Tav. 79.4 \\
\hline 1334 & LH IIIC & amphora & Vagnetti \& Panichelli 1994, 390-391: no. 133, Tav. 79.13 \\
\hline 1335 & LH IIIC & fragment & Vagnetti \& Panichelli 1994, 390-391: no. 134, Tav. 79.5 \\
\hline
\end{tabular}


Catalogue $X$ cont.

\begin{tabular}{|c|c|c|c|}
\hline & date & shape & published \\
\hline 1336 & & fragment & Vagnetti \& Panichelli 1994, 390-391: no, 135, Tav. 79.6 \\
\hline 1337 & & fragment & Vagnetti \& Panichelli 1994, 390-391: no. 136, Tav. 79.7 \\
\hline 1338 & & fragment & Vagnetti \& Panichelli 1994, 390-391, 393: no. 137, Tav. 79.8 \\
\hline 1339 & & fragment & Vagnetti \& Panichelli 1994, 391, 393: no. 140, Tav. 79.11 \\
\hline 1340 & & fragment & Vagnetti \& Panichelli 1994, 393: no. 141 \\
\hline
\end{tabular}


REFERENCES 



\section{R E F E R E N C E S}

Abbreviations follow Archäologische Anzeiger 1997, 611-628. Titles not included there were taken from the American Journal of Archaeology 95 (1991), 4-16. In addition the following abbreviations are used:

$\begin{array}{ll}\text { APEF } & =\text { Annual of the Palestine Exploration Fund } \\ \text { ArchRep } & =\text { Archaeological Reports } \\ \text { RSO } & =\text { Ras Shamra-Ougarit } \\ S B A & =\text { Saarbrücker Beiträge zur Altertumskunde } \\ \text { SCE } & =\text { Swedish Cyprus Expedition }\end{array}$

Adams, W.Y. 1968 “Invasion, diffusion, evolution”, Antiquity 42, 194-215.

Adelman, C.M. 1989 "A Late Cypriot IIC tomb: Idalion tomb I.76: artifactual remains with some historical observations", American expedition to Idalion 1973-1980 (Stager, L.E., A.M. Walker eds.), Oriental Institute Communication 24, Chicago, 138-201.

Adler, W. 1994 Kamid el-Loz 11. Das 'Schatzhaus' im Palastbereich. Die Befunde des Königsgrabes, SBA 47, Bonn.

Agata, A.L. d' 1997 "L'unità culturale e i fenomeni di acculturazione: la media età del Bronzo", Prima Sicilia. Alle origini della società Siciliana, Palermo, 447-457.

Åkerström, Å, 1987 Berbati 2: the pictorial pottery, Stockholm.

Albright, W.F. 1930-1931 "The excavation of Tell Beit Mirsim in Palestine I: the pottery of the first three campaigns", $A A S O R$ 12, 1-89.

Albright, W.F. 1931-1932 "The Syro-Mesopotamian god Sulman-Esmun and related figures”, AfO 7, 164-169.

Ålin, P. 1978 "Idalion. Pottery from the excavations of the Swedish Cyprus expedition", OpAth 12, 91109.

Anati, E. 1959 "Excavations at the cemetery of Tell Abu Hawam (1952)", 'Atiqot 2, 89-102.

Andersson, K. 1980 "Supplementary material from Enkomi tombs 3, 7, 11 and 18 SC", MedelhavsmusB $15,25-31$.

Anderson, W.P. 1988 Sarepta I. The Late Bronze and Iron Age Strata of area II, Y, Beyrouth.

Angle, M., A. Zarratini 1987 "L'insediamento protostorico di Casale Nuovo", ArchLaz 8, 250-252.

Angle, M., A.M Conti, R. Dottarelli, A. Gianni, C. Persiani, L. Vagnetti, R.E. Jones, L. Costantini 1993 "Prime testimonianze micenee nel Latium Vetus", PP 48, 190-217.

Annabi, C. 1996 "Une trouvaille mycénienne à Carthage", CedacCarthage 15, 54-55.

Anson, D. 1980 "Composition and provenance of Rude Style and related wares", RDAC, 109-127.

Appadurai, A. 1986 "Introduction: commodities and the politics of value", The social life of things: commodities in cultural perspective (Appadurai, A. ed.), Cambridge, 3-63.

Arafat, K., C. Morgan 1994 "Athens, Etruria and the Heuneburg: mutual misconceptions in the study of Greek-barbarian relations", Classical Greece. Ancient histories and modern ideologies (Morris, I. ed.), Cambridge, 108-134.

Arancio, M.L., V. Buffa, I. Damiani, A. Tagliacozzo, F. Trucco, L. Vagnetti 1995 "L’Abitato di Torre Mordillo nel quadro dello svilluppo dell'insediamento protostorico nell'Alto Ionio (Sibaritide)", Settlement and economy in Italy 1500 BC - AD 500 (Christie, N. ed.), Oxford, 1995, 227-239.

Arias, P. 1936-1937 "Vestigia dell'arte egeo-micenea in Sicilia", BPI NS 1, 58-64. 
Artzy, M. 1985 "Merchandise and merchantmen: on ships and shipping in the Late Bronze Age Levant",

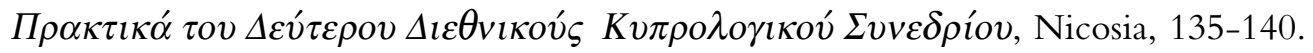

Artzy, M. 1997 "Nomads of the Sea", Res Maritimae. Cyprus and the eastern Mediterranean from prehistory to late antiquity (Swiny, S., R.L. Hohlfelder, H. Wylde Swiney eds.), CAARI Monograph series 1, Atlanta, 1-16.

Asaro, F., I. Perlman 1973 "Provenience studies of Mycenaean pottery employing neutron activation analysis", The Mycenaeans in the Eastern Mediterranean, Nicosia, 215-224.

Asaro, F., I. Perlman, M. Dothan 1971 "An introductory study of Mycenaean IIIC:1 ware from Tel Ashdod", Archaeometry 13, 169-175.

Astour, M.C. 1964 "Semitic names in the Greek world and Greek names in the Semitic world", JNES 23, 190-203.

Astour, M.C. 1970 "Ma'hadou, the harbour town of Ugarit", Journal of economical and social history of the orient 13, 113-127.

Astour, M.C. 1981 "Ugarit and the great powers", Ugarit in retrospect; fifty years of Ugarit and Ugaritica (Young, G.D. ed.), Winona Lake, 3-29.

Åström, P. 1966 Excavations at Kalopsidha and Ayios Iakovos in Cyprus, SIMA 2, Lund.

Åström, L. 1972 “The Late Cypriot Bronze Age. Other arts and Crafts”, SCE IV. part ID, Lund, 473 622.

Åström, L. 1983 “Area 6, trench Ecd-e 395-9”, Hala Sultan Tekke 8. Excavations 1971-79, SIMA 45:8, Göteborg, 145-168.

Åström, P. 1966 Excavations at Kalopsidha and Ayios Iakovos in Cyprus, SIMA 2, Lund.

Åström, P. 1972a The Middle Cypriot Bronze Age, SCE IV 1b, Lund.

Åström, P. 1972b The Late Cypriot Bronze Age, SCE IV 1c, Lund.

Åström, P. 1973 "Comments on the corpus of Mycenaean pottery in Cyprus", 'The Mycenaeans in the eastern Mediterranean, Nicosia, 122-127.

Åström, P. 1976 “Finds from Hala Sultan Tekke in Nicosia”, Hala Sultan Tekke 1, SIMA 45:1, Göteborg, 35-60.

Åström, P. 1983 “Chamber tombs”, Hala Sultan Tekke 8. Excavations 1971 and 1979, SIMA 45:8, Göteborg, 145-168.

Åström, P. 1985 "Hala Sultan Tekke”, Archaeology in Cyprus 1960-1985 (Karageorghis, V. ed.), Nicosia, 173-181.

Åström, P. 1986a "Hala Sultan Tekke and its foreign relations", Cyprus between the Orient and the Occident (Karageorghis, V. ed.), Nicosia, 63-66.

Åström, P. 1986b "Hala Sultan Tekke - an international harbour town of the Late Cypriot Bronze Age", OpAth 16, 7-17.

Åström, P. 1989 Katydhata, SIMA 86, Göteborg.

Åström, P. 1996 "Hala Sultan Tekke - a Late Cypriote harbour town”, Late Bronze Age settlement in Cyprus: function and relationships (Åström, P., E. Herscher eds.), SIMA Pocket-book 126, Jonsered, 9-14.

Åström, P. 1998 "Ceramics: influences east and west", The Aegean and the orient in the second millennium (Cline, E., D. Harris-Cline eds.), AEGEUM 18, Liège, 257-263.

Badre, L. 1990 “Area II”, Berytus 38, 55-86.

Bailey, D.M. 1976 "The British museum excavations at Hala Sultan Tekke in 1897 and 1898. The material in the British museum", Hala Sultan Tekke 1, SIMA 45:1, Göteborg, 4-32.

Balensi, J. 1980 Les fouilles de R.W. Hamilton à Tell Abu Hawam effectuées en 1932-1933 pour la compte du département des Antiquités de la Palestine sous mandat Brittanique. Niveaux IV et V. Dossier sur l'histoire 
d'un port Méditerranéen durant les ages du Bronze et de Fer (?1600-950 environ av. J.C.), Strassbourg 1980. (Unpublished $\mathrm{PhD}$ thesis.)

Balmuth, M. 1992 “ Archaeology in Sardinia”, AJA 96, 663-697.

Baramki, D.C. 1958 "A Late Bronze Age tomb at Sarafend, ancient Sarepta”, Berytus 12, 129-142.

Barber, R.L.N. 1992 "The origins of the Mycenaean palace”, $\Phi_{l} \lambda \circ \lambda \alpha \kappa \omega v$. Lakonian studies in honour of Hector Catling (Sanders, J.M. ed.), London, 11-23.

Barbieri, U., R. Peroni, F. Trucco 1984 "La campagna di scavo 1982", Nuove ricerche sulla protostoria della Sibaritide, Roma, 13-45.

Barker, G., S. Stoddart 1994 “The Bronze Age of central Italy: ca. 2000-900 BC”, Development and decline in the Mediterranean Bronze Age (Mathers, C., S. Stoddart), Sheffield, 145-165.

Bass, G.F. 1967 Cape Gelidonya: a Bronze Age shipwreck, Philadelphia.

Bass, G.F. 1987 "Oldest known shipwreck reveals splendors of the Bronze Age”, National geographic 1726 (Dec.), 692-733.

Bass, G.F. 1991 "Evidence of trade from Bronze Age shipwrecks", Bronze Age trade in the Mediterranean (Gale, N. ed.), SIMA 90, Göteborg, 69-82.

Baumgartel, E. 1951 "The cave of Manacorra, monte Gargano. Part I”, BSR 19, 1-30.

Baumgartel. E. 1953 "The cave of Manacorra, Monte Gargano. part II", BSR 21, 1-31.

Beck, P. 1989a "Cylinder seals from the temple in area H", Hazor III-IV. An account of the third and fourth seasons of excavations 1957-1958 (Text) (Yadin, Y., et al.), Jerusalem, 310-321.

Beck, P. 1989b "Stone ritual artifacts and statues from areas A and H", Hazor III-IV. An account of the third and fourth seasons of excavations 1957-1958 (Text) (Yadin, Y., et al.), Jerusalem, 322-338.

Beck, P., M. Kochavi 1985 "A dated assemblage of the late 13th century BCE from the Egyptian residency at Aphek", TelAvivJA 12-1, 29-42.

Belardelli, C. 1984 "La ceramica grigia", Nuove ricerche sulla protostoria della Sibaritide, Roma, 124-158.

Belardelli, C. 1993 "Aegean-type pottery from Coppa Nevigata, Apulia”, Wace and Blegen. Pottery as evidence for trade in the Aegean Bronze Age (Zerner, C. et al. eds.), Amsterdam, 347-352.

Belardelli, C. 1994: “La ceramica grigia”, Enotri e micenei nella Sibaritide, II (Peroni, R., F. Trucco eds.), Taranto, 265-346.

Belardelli, C., V. Buffa, M. Carrara Jacoli, F. Gandolfo, C. Giardino, G. Manchia, S. Panichelli, P. Pascucci, P. Tenaglia, L. Vagnetti 1994 "Nuovi siti e materiali archeologici”, Enotri e micenei nella Sibaritide, II (Peroni, R., F. Trucco eds.), Taranto, 661-782.

Bell, M.R. 1982 "Preliminary report on the Mycenaean pottery from Deir el-Medina (1979-1980)", ASAE 68, 142-163.

Bell, M.R. 1983 "Egyptian imitations of Aegean vases", Göttinger Miszellen 63, 13-24.

Ben-Arieh, S., G. Edelstein 1977 “Tombs near the Persian garden”, 'Atiqot 12, 1-8.

Ben-Tor, A. 1980 "Yoqne'am regional project - looks beyond the tell”, BiblArchRev 6, 30-44.

Ben-Tor, A. 1992a "Tel Hazor 1992", IEJ 42, 254-260.

Ben-Tor, A. 1992b "The Hazor tablet: foreword”, IEJ 42, 17-20.

Ben-Tor, A. 1994 “Tel Hazor - 1991”, Excavations and surveys in Israel 13, 12-13.

Ben-Tor, A. 1995 “Tel Hazor - 1992/1993”, Excavations and surveys in Israel 14, 9-13.

Ben-Tor, A. 1996 “Tel Hazor - 1994”, Excavations and surveys in Israel 15, 12-14.

Ben-Tor, A. 1998 "The fall of Canaanite Hazor - the "who" and "when" questions", Mediterranean peoples in transition. Thirteenth to early tenth centuries BCE. In honor of Professor Trude Dothan (Gitin, S., A. Mazar, E. Stern eds.), Jerusalem, 456-467.

Ben-Tor, A. Bonfil, R. Garfinkel, Y., Greenberg, R., Maeir, A.M., A. Mazar 1997 Hazor V. An accountof the fifth season of excavation 1968, Jerusalem. 
Ben-Tor, A., R. Rosenthal 1977 “The first season of excavations at Tell Yoqne'am”, IEJ 28, 57-82.

Benson, J.L. 1972 Bamboula at Kourion. The necropolis and the finds. Excavated by J.F. Daniel, Philadelphia.

Benzi, M. 1988 "Mycenaean Rhodes: a summary", Archaeology in the Dodecanese (Dietz, S., Papadopoulos, I. eds.), Copenhagen, 59-72.

Benzi, M. 1992 Rodi e la civiltá micenea, Roma.

Benzi M. 1996 "Problems of the Mycenaean expansion in the south-eastern Aegean", Atti e memorie del secondo congresso internazionale di micenologia (De Miro, E., L. Godart, A. Sacconi eds.), Roma, 947978.

Benzi, M., G. Graziado, G. 1982 "Note sulla provenieza delle ceramiche egee rinvenute in Italia meridionale", АПАРXAI, nuove ricerche e studi sulla Magna Grecia e la Sicilia antica in onore di Paolo Arias I, Pisa, 19-33.

Benzi, M., G. Graziado 1996 "Late Mycenaean pottery from Punto Meliso (Santa Maria di Leuca)”, Atti e memorie del secondo congresso internazionale di micenologia (De Miro, E., L. Godart, A. Sacconi eds.), Roma, 1523-1529.

Bergonzi, G. 1985 "Southern Italy and the Aegean during the Late Bronze Age: economic strategies and specialised craft products", Papers in Italian archaeology IV. The Cambridge conference part iii. Patterns in protohistory (Malone, C., S. Stoddart eds.), BAR I.S. 245, Oxford, 389-398.

Bergonzi, G., A. Cardarelli 1982a "L'abitato di Broglio: topografia ed ambiente", Ricerche sulla protostoria della Sibaritide 1, Cahiers du Centre Jean Bérard VII, Naples, 35-41.

Bergonzi, G., A. Cardarelli 1982b "L'età del bronzo media e recente a Broglio: risultati della campagne 1979”, Ricerche sulla protostoria della Sibaritide 1, Cahiers du Centre Jean Bérard VII, Naples, 51-93.

Bergonzi, G., A. Cardarelli 1982c "Due produzioni dell'artigianato specializzato: la ceramica grigia e i dolii cordonati", Ricerche sulla protostoria della Sibaritide 2, Cahiers du Centre Jean Bérard VIII, Naples, 63-98.

Bergonzi, G., A. Cardarelli 1984 "Due produzioni dell'artigianato specializzato: ceramica grigia e dolii per derrate", Ricerche sulla protostoria della Sibaritide 3, Roma, 101-163.

Bernabò-Brea, L. 1958 La Sicilia prima dei Greci, Milano.

Bernabò-Brea, L. 1966 "Thapsos (Augusta-Siracusa)”, BdA 1-2, 113-114.

Bernabò-Brea, L. 1966, "Abitato neolitico e insediamento maltese dell'età del bronzo nell'isola di Ognina (Siracusa) e i rapporti fra la Sicilia e Malta dal XVI al XIII sec. a. C.", Kokalos 12, 40-69.

Bernabò-Brea, L. 1970 “Thapsos. Primi indizi dell'abitato dell'età del bronzo”, Adriatica praehistoria et antiqua. Zbornik Radova posvec' en Grgi Novaku (Mirosavljeic', M., D. Rendic-Miovcevi?, M. Sui? eds.), Zagreb, 139-150.

Bernabò-Brea, L. 1976-1977 “Eolie, Sicilia e Malta nell'età del Bronzo”, Kokalos 33-110.

Bernabò-Brea, L. 1978 "Alcune considerazioni sul carico di ceramiche dell'età del bronzo Pignataro di Fuori e sugli antichi scali marittimi dell'Isola di Lipari”, SicArch 36, 36-42.

Bernabò-Brea, L. 1979 "L'età del bronzo tarda e finale nelle isole Eolie" Atti del XXI Riunione scientifica: Il Bronzo Finale in Italia, Firenze, 571-597.

Bernabò-Brea, L. 1985 "Lipari, i vulcani, l'inferno e San Bartolomeo. Le isole Eolie dal tardoantico ai Normanni”, ArchStorSic, 25-89.

Bernabò-Brea, L., M. Cavalier 1960 Meligunis-Lipàra I. La stazione preistorica della contrada Diana e la necropoli protostorica di Lipari, Palermo.

Bernabò-Brea, L., M. Cavalier 1968 Meligunis-Lipàra III, Palermo.

Bernabò-Brea, L., M. Cavalier 1976 Il castello di Lipari e il museo archeologico eoliano, Palermo.

Bernabò-Brea, L., M. Cavalier 1980 Meligunis-Lipàra IV. L'acropoli di Lipari nella preistoria, Palermo.

Betancourt, P.P. 1987 "Dating the Aegean Late Bronze Age", Archaeometry 29, 45-49. 
Betancourt, P.P. 1990 "High chronology or low chronology: the archaeological evidence", Thera and the Aegean world III vol. 3 (Hardy, D.A., A.C. Renfrew eds.), London, 19-23.

Bianco, S. 1991-1992 "Nuovi dati da Calabria, Basilicata e Puglias meriodonale", RdA 10, 509-513.

Biancofiore, F. 1967 La civiltà micenea nell'Italia meridionale: la ceramica, Roma.

Bienkowski, P. 1987 "The role of Hazor in the Late Bronze Age", PEQ 119, 50-61.

Bietti Sestieri, A.M. 1973 "The metal industry of continental Italy, 13th-11th century, and its Aegean connections", ProcPrehistSoc 39, 383-424.

Bietti Sestieri, A.M. 1980-1981 "La Sicilia e le isole Eolie e i loro rapporti con le regioni tirreniche dell'Italia continentale dal neolitico alla colonizzazione greca", Kokalos 26-27 I, 8-66.

Bietti Sestieri, A.M. 1982, "Fratessina”, Magna Grecia e mondo miceneo. Nuovi documenti (Vagnetti, L. ed.), Taranto, 201-207.

Bietti Sestieri, A.M. 1983 "Central and southern Italy in the Late Bronze Age", Crossroads of the Mediterranean (Hackens T., N.D. Holloway, R.R. Holloway eds.), Louvai-la-Neuve/Providence, 55-122.

Bietti Sestieri, A.M. 1988 “"The Mycenaean connection' and its impact on the central Mediterranean societies", DialA 6, 23-51.

Bietti Sestieri, A.M. 1997 "Sviluppi culturali e socio-politici differenziali nella tarda età del Bronzo della Sicilia”, Prima Sicilia. Alle origini della società Siciliana, Palermo, 473-491.

Bikai, P.M. 1978 The pottery of Tyre, Warminster.

Binford, L.R. 1971 "Mortuary practice: their study and potential", Approaches to the social dimensions of mortuary practices, Memoirs of the society for American archaeology 25, 6-29.

Bintliff, J.L. 1977 Natural environment and human settlement in prehistoric Greece, BAR I.S. 28i, Oxford.

Biran, A. 1970 “A Mycenaean charioteer vase from Tel Dan”, IEJ 20, 92-103.

Biran, A. 1993 "Dan”, The New Encyclopedia of Archaeological Excavations in the Holy Land, Jerusalem, 323332.

Biran, A. 1994a Biblical Dan, Jerusalem.

Biran, A. 1994b “Tel Dan 1991”, Excavations and surveys in Israel 13, 8-11.

Bittel, K 1957 Boghazköy III, Stuttgart.

Blegen, C.W., M. Rawson, W. Taylour, W.P. Donovan 1973 The palace of Nestor at Pylos in western Messenia III, Princeton.

Bliss, F.J. 1898 A mound of many cities, or: Tell el Hesy excavated, London.

Bocuccia, P. 1998 “Punta le Terrare: i sondaggi del 1966 e il saggio X 1972”, Documenti dell'età del Bronzo. Ricerche lungo il versante adriatico pugliese (Cinquepalmi, A., F. Radina eds.), Fasano di Brindisi, 175-183.

Bounni, A., E. Lagarce, J. Lagarce, N. Saliby 1976 "Rapport préliminaire sur la première campagne de fouilles (1975) à Ibn Hani”, Syria 53, 233-279.

Bounni, A. E. Lagarce, J. Lagarce, N. Saliby, E. Badre 1979 "Rapport préliminaire sur la troisième campagne de fouilles (1977) à Ibn Hani”, Syria 56, 217-291.

Bounni, A. E. Lagarce, J. Lagarce, N. Saliby, E. Badre 1981 "Rapport préliminaire sur la quatrième campagne de fouilles (1978) à Ibn Hani”, Syria 58, 215-297

Bounni, A., J. Lagarce, E. Lagarce, N. Saliby 1987 Ras Ibn Hani: archéologie et histoire, Damas.

Bourdieu, P. 1977 Outline of a theory of practice, Cambridge.

Bourdieu, P. 1984 Distinction. A social critique of the judgement of taste, Cambridge Mass.

Bourdieu, P. 1989 “De sociale ruimte en de genese van 'klassen””, Opstellen over smaak, habitus en het veldbegrip, (Bourdieu, P. ed.), Amsterdam, 142-170.

Bourke, S.J. 1997 "Pre-classical Pella in Jordan: a conspectus of ten years' work", PEQ 129, 94-115. 
Boysal, Y. 1969 Katalog der Vasen im Museum in Bodrum Ankara.

Braudel, F. 1972 The Mediterranean and the Mediterranean world in the age of Philip II, London.

Brown, J.A. 1981 "The search for rank in prehistoric burials", The archaeology of death (Chapman, R., I. Kinnes, K. Randsborg eds.), Cambridge, 25-37.

Bryan, B.M. 1996 "Art, empire and the end of the Late Bronze Age", The study of the ancient Near East in the 21st century, Winona Lake, 38-79.

Bryan, N.D., E.B. French, S.M.A. Hoffman. V.J. Robinson 1997 "Pottery sources in Bronze Age Cyprus: a provenance study by neutron activation", RDAC, 31-64.

Bryce, T. R 1998 The kingdom of the Hittites, Oxford.

Buchholz H.-G. 1974 “Ägäische Funde und Kultureinflüsse in den Randgebieten des Mittelmeers. Forschungsbericht über Ausgrabungen und Neufunde 1960-1970”, AA 1974, 325-462.

Buchholz H.-G. 1984-1985 “Ägäische Kämme”, ActaPraehistA 16/17, 91-142.

Buchholz H.-G. 1988 "Der Metallhandel des zweiten Jahrtausends im Mittelmeerraum", Society and economy in the eastern Mediterranean (c. 1500-1000 BC) (Heltzer, M., E. Lipinski eds.), Leuven, 1988, $187-228$.

Buchholz H.-G. 1993 "Aspects of art and iconography: Anatolia and its neighbours", Studies in honour of Nimet Özgüç (Mellink, M.J., E. Porada, T. Özgüç eds.), Ankara, 91-106.

Buchner, G., M. Marazzi, S. Tusa, A. Zarattini, A. Cazzella, F. di Gennaro 1978 “Testi e monumenti: l'isola di Vivara. Nuove ricerche, PdP 33, 197-240.

Buffa, V. 1984a "I dolii cordonati", Nuove ricerche sulla protostoria della Sibaritide, Roma, 159-168.

Buffa, V. 1984b "I materiali del bronzo finale e della prima età del ferro", Ricerche sulla protostoria della Sibaritide, 3, Roma, 185-231.

Buffa, V. 1994a "I materiali del Bronzo finale e della prima età el ferro", Enotri e micenei nella Sibaritide, I (Peroni, R., F. Trucco eds.), Taranto, 455-570.

Buffa, V. 1994b “I bronzi”, Enotri e micenei nella Sibaritide I (Peroni, R., F. Trucco eds.), Taranto, 571576.

Buffa, V., R. Peroni 1982 "Ricognizione di altri siti", Ricerche sulla protostoria della Sibaritide 2, Cahiers du Centre Jean Bérard VIII, Naples, 147-188.

Bunimovitz, S. 1995 "On the edge of empires - Late Bronze Age (1500-1200 BCE)", The archaeology of society in the Holy Land (Levy, T.E. ed.), London, 320-331.

Bunimowitz, S., Z. Lederman 1993 “Beth Shemesh”, NewEncArchExcHL 1, Jerusalem, 249-253.

Cadogan, G. 1973 "Patterns in the distribution of Mycenaean pottery in the eastern Mediterranean", The Mycenaeans in the eastern Mediterranean, Nicosia, 166-174.

Cadogan, G. 1989 “Maroni and the monuments”, Early society in Cyprus (Peltenburg, E. ed.), Edinburgh, 43-51.

Cadogan, G. 1991 “Cypriot Bronze Age pottery and the Aegean”, Cypriot ceramics. Reading the prehistoric record (Barlow, J.A., B. Bolger, B. Kling eds.), Philadelphia, 169-172.

Cadogan, G. 1992 “Maroni VI”, RDAC, 51-58,

Cadogan, G. 1993 "Cyprus, Mycenaean pottery, trade and colonisation”, Wace and Blegen. Pottery as evidence for trade in the Aegean Bronze Age (Zerner, C. et al. eds.), Amsterdam, 91-99.

Cadogan, G. 1996 “Maroni: change in Late Bronze Age Cyprus”, Late Bronze Age settlement in Cyprus: function and relationships (Åström, P., E. Herscher eds.), SIMA Pocket-book 126, Jonsered, 15-22.

Callot, O. 1986 "La région nord du palais royal d'Ugarit", CRAI 1986, 735-755.

Callot, O. 1994 La tranchée "Ville Sud". Études d'architecture domestique, RSO X, Paris. 
Callot, O., M. Yon, 1995 "Urbanisme et Architecture", Le pays d’Ougarit autour de 1200 av. J.C. (Yon, M., M. Snycer, P. Bordreuil, eds.), RSO XI, Paris, 155-168.

Calvet, Y., B. Geyer 1987 "l'Eau dans l'habitat", Le centre de la ville, 38ème-44ème campagne (1978-1984) sous la direction de Marguerite Yon, RSO III, Paris, 129-156.

Capofierri, B., C. Giardino 1984a "I materiali dell'età del bronzo media e recente", Ricerche sulla protostoria della Sibaritide 3, Roma, 28-100.

Capofieri, B., Giardino, C. 1984b "I materiali dell'età del Bronzo media e recente", Nuove ricerche sulla protostoria della Sibaritide, Roma, 46-123.

Casson, L. 1973 Ships and seamanship in the ancient world, Princeton.

Castellana, G. 1993-1994a "Notizia preliminare sui recenti rintrovamenti di materiali egeo-micenei nel territorio agrigentino", Kokalos 39-40, 48-57.

Castellana, G. 1993-1994b "Ricerche nel territorio di Palma di Montechiaro, Riobera, Menfi e Farara", Kokalos 39-40, 735-753.

Castellana, G. 1999, "La produzione dello zolfo nel santuario castelluciano di Monet Grande e I con-

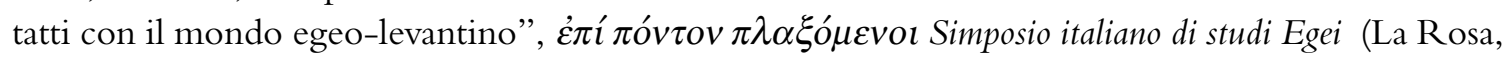
V., D. Palermo, L. Vagnetti eds.), Roma, 423-438.

Cataldo, L., F. Radina, B. Wilkens 1989 "L'insediamento protostorico di Giovinazzo (Bari). Considerazioni sulle facies protoappenninica e appenninica nell' Italia sud-orientale”, RScPreist 42, 171-240.

Catling, H.W 1957, “The Bronze Age pottery”, Myrtou-Pigadhes. A Late Bronze Age sanctuary in Cyprus (Taylor, J. du Plat), Oxford, 26-59.

Catling, H.W. 1961 “A new bronze sword from Cyprus”, Antiquity 35, 115-122.

Catling, H.W. 1962 "Patterns of settlement in Bronze Age Cyprus", OpAth IV, 129-169.

Catling, H.W. 1964 Cypriot bronzework in the Mycenaean world, Oxford.

Catling, H.W. 1966 "Cyprus in the Neolithic and Bronze Age periods", CAH 43.

Catling, H.W. 1975 “A new sanctuary at Enkomi?”, RDAC, 50-53.

Catling, H.W. 1979 "Reflections upon the interpretation of the archaeological evidence for the history of Cyprus", Studies presented in memory of Porphyrios Dikaios (Karageorghis, V. ed.), Nicosia, 194205.

Catling, H.W. 1980 Cyprus and the west 1600-1050 BC (I. sanders memorial Lecture), Sheffield.

Catling, H.W. 1982 "The ancient topography of the Yalias valley", RDAC, 227-236.

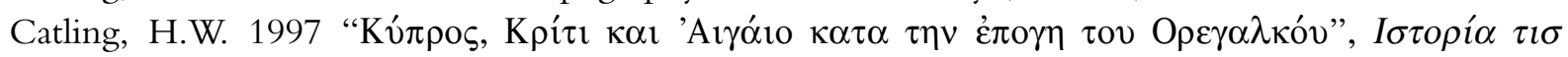

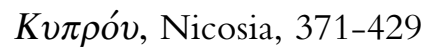

Catling, H.W., J.F. Cherry, R.E. Jones, J.T. Killen 1980 “The Linear B inscribed stirrup jars and west Crete", BSA 75, 49-113.

Catling, H.W., R.E. Jones, A. Millett 1978 "Composition and provenance problems in some Late Bronze Age pottery found in Cyprus", RDAC, 70-90.

Catling, H.W., V. Karageorghis 1960 "Minoika in Cyprus”, BSA 55, 109-127.

Catling, H.W., A. Millett 1965 "A study in the composition patterns of Mycenaean pictorial pottery from Cyprus”, BSA 60, 212-224.

Catling, H.W., E.E. Richards, A.E. Blin-Stoyle 1963 "Correlations between composition and provenance of Mycenaean and Minoan pottery", BSA 58, 94-115.

Caubet, A. 1982a "La céramique", Meskéné-Emar: dix ans de traveaux 1972-1982 (Beyer, D. ed.), 71-86.

Caubet, A., J.C. Courtois, V. Karageorghis 1987 "Enkomi (fouilles Schaeffer 1934-1966): inventaire complémentaire", RDAC 1987, 23-48.

Cavalier, M. 1957 "Salina: a prehistoric village in the Aeolian islands", Antiquity 31, 9-14. 
Cavalier, M. 1970 "La stazione preistorica di Tindari”, BPI 79, 61-93.

Cavalier, M. 1980 "Appendix I. La necropoli a incinerazione dell'età di Capo Graziano nella contrada Diana”, Meligunis-Lipara IV: l'acropoli di Lipari nella preistoria (Bernabò-Brea, L., M. Cavalier), Palermo, 721-731.

Cavalier, M. 1992-1993 “Twenty years of archaeological research in the Aeolian islands”, Mediterranean Archaeology 5/6, 5-13.

Cavalier, M., L. Vagnetti 1983 "Frammenti di ceramica "matt-painted" policroma da Filicudi (Isole Eolie)", MEFRA 95 (1983, 335-344.

Cavalier, M., L. Vagnetti 1984 "Materiali micenei vecchi e nuovi dall'acropoli di Lipari", SMEA 25, 143-154.

Cavallari, F.S. 1880 "Thapsos. Appendice alla memoria: le città e le opere di escavazione in Sicilia anteriore ai Greci”, Archivio storico Siciliana 5, 121-133.

Cazzella, A., M. Moscoloni 1987 "Età del Bronzo. La ricerca archeologica”, Coppa Nevigata e il suo territorio. Testimonianze archeologiche dal VII al II millennio a. C. (Cassano, S.M., A. Cazzella, A. Manferedini, M. Moscoloni eds.), Roma, 109-190.

Cazzella, A., M. Moscoloni 1994 "I contesti di rinvenimento e il significato della presenza delle ceramiche d'importazione e di alcuni reperti metallici alla Punta Mezzogiorno", Vivara. Centro commerciale mediterraneo dell'età del bronzo II. Le tracce dei contatti con il mondo egeo (scavi 1976-1982) (Marazzi, M., Tusa, S. eds.), Ricerche di storia, epigrafia e archeologia mediterranea 3, 107-116.

Chadwick, J. 1976 The Mycenaean world, Cambridge.

Cherry, J., A.B. Knapp 1991 "Quantitative provenance studies and Bronze Age trade in the Mediterranean: some preliminary reflections”, Bronze Age trade in the Mediterranean (Gale, N. ed.), SIMA 90, Göteborg, 92-111.

Childe, V.G. 1925 Dawn of European civilisation, London.

Ciabatti, E. 1985 "Note conclusive concernenti lo scavo di un relitto dell'età del bronzo nella baia di Lipari”, Arqueologia submarina, Madrid, 303-311.

Cipolloni Sampò, M. 1986 "Le tombe di Toppo Daguzzo (Basilicata Nord-Orientale). Considerazioni sulle continuità della media età del Bronzo nel sud-est Italiano", Traffici micenei nel Mediterraneo (Marazzi, M., S.Tusa, L. Vagnetti eds.), Taranto, 27-35.

Cipolloni Sampò, M. 1987 "Manifestazioni funerarie e strutture sociale", ScAnt 1, 55-119.

Cipolloni Sampò, M. 1991-1992 "Le sepolture collettive nel sud-est italiano", $R d A$ 10, 281-285.

Cline, E.H. 1994 Sailing the wine-dark sea. International trade and the Late Bronze Age Aegean, BAR I.S. 591, Oxford.

Coche de la Ferté, E. 1951 Essai de classification de la céramique mycénienne d'Enkomi (campagnes 1946 et 1947), Paris.

Contenson, H. de, E. Lagarce, J. Lagarce, R. Stucky 1972 "Rapport préliminaire sur la xxxiie campagne de fouilles (1971) à Ras Shamra", Syria 49, 1-33.

Contenson, H. de, J.C. Courtois, E. Lagarce, J. Lagarce, R. Stucky 1973b "Rapport préliminaire sur la xxxiiie campagne de fouilles à Ras Shamra", AAS 23, 121-143.

Contenson, H. de, J.C. Courtois, E. Lagarce, J. Lagarce, R. Stucky 1974 "La 34ème campagne de fouilles à Ras Shamra en 1973. Rapport préliminaire”, Syria 51, 1-30.

Coppola, D., A. Cinquepalmi 1998 “Torre Santa Sabina”, Documenti dell'età del Bronzo. Ricerche lungo il versante adriatico pugliese (Cinquepalmi, A., F. Radina eds.), Fasano di Brindisi, 147-162.

Courbin, P. 1986 "Bassit", Syria 63, 175-220.

Courtois J.C. 1968 “Les cités-etats de phenicie au IIème millénaire”, Archeologia 20, 19-35. 
Courtois, J.C. 1969 "La maison du prêtre aux modèles de poumon et de foies d'Ugarit", Ugaritica VI (Schaeffer, C.F.A. ed.), Paris, 91-119.

Courtois, J.C. 1971 "Le sanctuaire du dieu au lingot d'Enkomi-Alasia”, Alasia I (Schaeffer, C.F.A. ed.), Paris, 151-362.

Courtois, J.C. 1973 “Sur divers groupes de vases mycéniens en Méditerranée Orientale”, The Mycenaeans in the eastern Mediterranean, Nicosia, 137-165.

Courtois, J.C. 1974 "Ugarit. Grid, strata and find locations", ZDPV 90, 97-114.

Courtois, J.C. 1979a "Ras Shamra - Archéologie", Supplément au dictionnaire de la Bible, Paris, cols. 11261295.

Courtois, J.C. 1979b "l’Architecture domestique à Ugarit au bronze récent” UgaritF 11, 105-134.

Courtois, J.C. 1981 Alasia II. Les tombes d’Enkomi. Le mobilier funéraire, Paris.

Courtois, J.C. 1982 'L'Activité métallurgique et les bronzes d'Enkomi au Bronze Récent (1650-1100 avant J.C.), Early metallurgy in Cyprus 4000-500 BC (Muhly, J.D., R. Maddin, V. Karageorghis eds.), Nicosia, 155-174.

Courtois, J.C. 1984 Alasia III. Les objets des niveaux stratifiée d'Enkomi: fouilles C.F.A. Schaeffer (19471970), Paris.

Courtois, J.C. 1990 "Yabninu et le Palais Sud d'Ugarit", Syria 67, 103-142.

Courtois, J.C., L. Courtois 1978 "Corpus céramique de Ras Shamra-Ugarit. Niveaux historique d'Ugarit", Ugaritica VII (Schaeffer, C.F.A. ed.), Paris, 192-370.

Courtois, J.C., J. Lagarce, E. Lagarce 1986 Enkomi et le Bronze Récent à Chypre, Nicosia.

Courtois, L. 1969 "Le mobilier funéraire céramique de la tombe 4253 de Bronze Récent (Ville Sud d'Ugarit)", Ugaritica VI (Schaeffer, C.F.A. ed.), Paris, 120-137.

Cowen, J.D. 1955 "Eine Einführung in die Geschichte der bronzenen Griffzungenschwerter in Süddeutschland und den angrenzenden Gebieten”, Berichte de Römisch-Germanischen Kommision, 52155.

Crielaard, J.P. 1994 “Les Mycéniens et les poèmes épiques d’Homère”, Les Mycéniens. Des Grecs du IIe millénaire. Doss AParis 195, 126-134.

Crouwel, J.H. 1991 "Mycenaean pictorial pottery from Cyprus in Oxford”, OxfJA 10, 45-55.

Crouwel, J.H., C.E. Morris 1985 "Mycenaean pictorial pottery from Tell Atchana (Alalakh)", BSA 80, $85-98$.

Dalton, G. 1975 “Karl Polanyi's analysis of long-distance trade and his wider paradigm”, Ancient civilisation and trade (Sabloff, J.A., C.C. Lamberg-Karlovsky, eds.), Albuquerque, 63-132.

Daviau, P.M.M. 1993 Houses and their furnishings in Late Bronze Age Palestine, Sheffield.

Davis, E. 1973 The Vapheio cups and Aegean gold and silver ware, New York.

Dawkins, R.M. 1904 "Mycenaean vases at Torcello", JHS 24, 125-128.

Day, P.M., H.W. Haskell 1995 "Transport stirrup jars from Thebes as evidence for trade in the Late Bronze Age III”, Trade and production in premonetary Greece: aspects of trade (Gillis, C. Ch. Risberg, B. Sjöberg eds.), SIMA Pocket-book 134, Jonsered, 87-110.

Demas, M. 1985 “The architecture”, Excavations at Kition V. The pre-Phoenician levels I (Karageorghis, V., M. Demas eds.), Nicosia, 5-164.

De Miro, E. 1996 "Recenti ritrovamenti micenei nell'agrigentino e il villaggio di Cannatello", Atti e memorie del secondo congresso internazionale di micenologia (De Miro, E., Godart, L., Sacconi eds.), Roma, 995-1011.

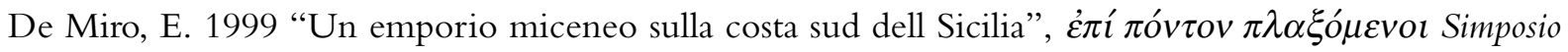
italiano di studi Egei (La Rosa, V., D. Palermo, L. Vagnetti eds.), Roma, 439-449. 
De Siena, A. 1986 “Termitito”, Traffici micenei nel Mediterraneo (Marazzi, M., S. Tusa, L. Vagnetti eds.), Taranto, 41-48.

De Siena, A, S. Bianco 1982 “Termitito (Montalbano Ionico, Matera), )" Magna Grecia e mondo miceneo. Nuovi documenti (Vagnetti, L. ed.), Taranto, 69-94.

De Vaux, R. 1951 "La troisième campagne de fouilles à Tell el Far'ah près de Naplouse”, Revue Biblique $58,566-590$.

Demakopoulou, K., J.H. Crouwel 1984 "Some Mycenaean pictorial pottery from Boeotia", BSA 79, 37-48.

Demas, M. 1985 “The architecture”, Excavations at Kition V. The pre-Phoenician levels I (Karageorghis, V., M. Demas eds.), Nicosia, 5-164.

Deubner, O. 1957 “Die griechische Scherben von Babylon”, Das Babylon der Spätzeit (Wetzel, F., E. Schmidt, A. Mallwitz), Berlin, 51-58.

Di Gennaro, F. 1997 “Collegamenti tra Eolie e coste Tirreniche nell'età del Bronzo”, Prima Sicilia. Alle origini della società Siciliana, Palermo, 421-428.

Dickinson, O.T.P.K. 1977 The origins of Mycenaean civilisation, SIMA 49, Göteborg.

Dickinson, O.T.P.K. 1994 The Aegean Bronze Age, Cambridge.

Dietz, S. 1991 The Argolid at the transition to the Mycenaean age, Copenhagen.

Dikaios, P. 1969 Enkomi. Excavations 1948-1958. Vol.I: the architectural remains; the tombs, Mainz am Rhein.

Dikaios, P. 1971 Enkomi. Excavations 1948-1958. Vol. II: chronology, summary, conclusions, catalogue, appendix, Mainz am Rhein.

Dornemann, R.H. 1983 The archaeology of the Transjordan in the Bronze and Iron Ages, Milwaukee.

Dothan, M. 1971 "Ashdod II-III. The second and third seasons of excavations 1963-1965, soundings in 1967”, 'Atiqot (English series) 9-10, Jerusalem.

Dothan, M. 1993 “Ashdod”, NewEncArchExcHL vol. 1, Jerusalem, 93-102.

Dothan, M., D.N. Freedman 1967 Ashdod I. The first season of excavation, 'Atiqot 7, Jerusalem.

Dothan, M., Y. Porath 1996 "Ashdod V. Excavation of area G. The fourth-sixth seasons of excavations, 1968-1970", 'Atiqot 23, Jerusalem.

Dothan, T.K., A. Ben-Tor 1983 Excavations at Athienou, Cyprus 1971-1972, QEDEM 16, Jerusalem.

Dunbabin, T.J. 1948 “Minos and Daidalos in Sicily”, BSR 16, 1-18.

Earle, T.K., 1982 "Prehistoric economics and the archaeology of exchange", Contexts for prehistoric exchange (Ericson, J.E. and T.K. Earle eds.), New York/London, 1-12.

Echt, R. 1984 Kamid el-Loz 5: die Stratigraphie, SBA 34, Bonn.

Elliot Smith, G. 1933 The diffusion of culture, London.

Epstein, S., S. Gutman 1972 "The Golan”, Judea, Samaria and the Golan archaeological survey 1968 (Kochavi, M. ed.), Jerusalem.

Eriksson, K. 1991 "Red Lustrous Wheelmade Ware: a product of Late Bronze Age Cyprus”, Cypriot ceramics. Reading the prehistoric record (Barlow, J.A., B. Bolger, B. Kling eds.), Philadelphia, 81-96.

Evans, A. 1906 The prehistoric tombs of Knossos, London.

Evans, A. 1935 The palace of Minos IV, London.

Evans, J.D. 1959 Malta, London.

Falconer, S.E. 1994 "The development and decline of Bronze Age civilisation in the southern Levant. A reassesment of urbanism and ruralism", Development and decline in the Mediterranean Bronze Age (Mathers, C., S. Stoddart, S.), Sheffield, 305-333. 
Farnoux, A., J. Driessen 1997 "La Crète mycénienne ou les noces d'Ariane et de Thésée”, La Crète mycénienne (Driessen, J., A. Farnoux eds.), BCH Suppl. 30, Athènes, 1-7.

Ferrarese Ceruti, M.L. 1979 "Ceramica micenea in Sardegna (notizia preliminare)", RScPreist 34, 243253.

Ferrarese Ceruti, M.L. 1986 "I vani c, p, q del complesso nuragico di Antigori (Sarroch - Cagliari)", Traffici micenei nel Mediterraneo (Marazzi, M., S.Tusa, L. Vagnetti eds.), Taranto, 183-192.

Ferrarese-Ceruti, M.L., R. Assorgia 1982 "Il complesso nuragico di Antigori”, Magna Grecia e mondo miceneo. Nuovi documenti (Vagnetti, L. ed.), Taranto, 167-176.

Fimmen, D. 1924 Die Kretisch-MYkenische Kultur, Leipzig/Berlin.

Finley, M.I. 1982 Economy and society in ancient Greece, New York.

Fisher, E.A. 1988 A comparison of Mycenaean pottery from Apulia with Mycenaean pottery from western Greece, AnnArbor.

Fisher, W.B. 1978 The middle east: a physical, social and regional geography, London.

Forrer, E.O. 1939 “Appendix II”, Early pottery of the Jebeleh region (Ehrich, A.M.H.), Philadelphia, 113125.

Forsdyke, E.J. 1911 "Minoan pottery from Cyprus and the origin of the Mycenaean style", JHS, 110118.

Fortin, M. 1984 “The Enkomi tower”, Levant 16, 173-176.

Foster, B.R. 1987 "The Late Bronze Age palace economy: a view from the east.", The function of the Minoan palaces (Hägg, R., N. Marinatos eds.), Stockholm, 11-19.

Foucault-Forest, C. 1996 l'Habitat privé en Palestine au Bronze Moyen et Bronze Récent, BAR I.S. 625, Oxford.

Francis, P. Jr. 1996 “The beads that did not buy Manhattan” One man's trash is another man's treasure. The metamorphosis of the European utensil in the new world (Van Dongen, A. ed.), Rotterdam, 53-69.

Franco, M.C. 1996 "Salento ed Egeo: note preliminari sull' insediamento protostorico di Punta le Terrare", Atti e memorie del secondo congresso internazionale di micenologia (De Miro, E., Godart, L., Sacconi eds.), Roma, 1561-1570.

Frank, A.G. 1993 "Bronze Age world system cyles", CurrAnthr 34-4, 383-429.

Frankel, D., H.W. Catling 1976 "Material from Hala Sultan Tekke in the Ashmolean museum, Oxford”, Hala Sultan Tekke 1, SIMA 45:1, Göteborg, 63-69.

Franken, H.J. 1961 “The excavations at Deir 'Alla in Jordan, 2nd season”, VT 11, 361-372.

Franken, H.J. 1992 Excavations at Tell Deir 'Alla: The Late Bronze Age sanctuary, Leuven.

French, E.B. 1971 “The development of Mycenaean terracotta figurines”, BSA 66, 101-187.

French, E.B. 1986 "Mycenaean Greece and the Mediterranean world", Traffici micenei nel Mediterraneo (Marazzi, M., S.Tusa, L. Vagnetti eds.), Taranto, 277-282.

French, E.B. 1991 "Tracing exports of Mycenaean pottery: the Manchester contribution”, Bronze Age trade in the Mediterranean (Gale, N.H. ed.), SIMA 90, Jonsered, 121-126.

French, E.B. 1993 “Turkey and the east Aegean”, Wace and Blegen. Pottery as evidence for trade in the Aegean Bronze Age (Zerner, C. et al. eds.), Amsterdam, 155-158.

French, E.B, P. Åström, 1980 “A colloquium on Late Cypriot III sites”, RDAC, 267-269.

French. E.B., G.W.A. Newton, V.J. Robinson, A. Scourtelli 1984 "Provenance of Late Helladic IIIB pottery from the Argolid", Ancient Greek and related pottery (Brijder H.A.G. ed.), 12-15.

Frisch, B., G. Mansfeld, W.R. Thiele 1985 Die Werkstättten der spätbronzezeitlichen Paläste, SBA 33, Bonn. Fritz, V. 1971, "Erwägungen zu den Spätbronzeitlichen Quadratbau bei Amman”, ZDPV 87, 140-152.

Fritz, V. 1973 "Das Ende der spätbronzezeitlichen Stadt Hazor stratum XIII und die biblische Überlieferung in Josua II und Richter 4", UgaritF 5, 123-139. 
Frizell, B. 1977 “Area 21”, Hala Sultan Tekke 3, SIMA 45:3, Göteborg, 30-57.

Furtwängler, A., G. Löschke 1886 Mykenische Vasen. Vorhellenische Thongefässe aus dem Gebiete des Mitelmeeres, Berlin.

Furumark, A. 1941a The Mycenaean pottery. Analysis and classification, Stockholm.

Furumark, A. 1941b The chronology of Mycenaean pottery, Stockholm.

Furumark, A. 1965 “The excavations at Sinda. Some historical results”, OpAth 6, 99-116.

Gal, Z. 1992 Lower Galilee during the Iron Age, Winona Lake.

Gale, N. 1991 "Copper oxhide ingots: their origin and their place in the Bronze Age metals trade in the Meditrranean”, Bronze Age trade in the Mediterranean (Gale, N. ed.), SIMA 90, Göteborg, 197-239.

Galili, E., N. Shmueli, M. Artzy, 1986 "Bronze Age ship's cargo of copper and tin” IntJNautA, 25-37.

Galaty, M.L., W.A. Parkinson 1999 "Putting Mycenaean palaces in their place. An introduction", Rethinking Mycenaean palaces. New interpretations of an old idea (Galaty, M.L., W.A. parkinson eds.), Los Angeles, 1-8.

Garstang, J. 1931 The foundations of Bible History: Joshua, Judges, London.

Gentili, V.G. 1953 “Thapsos insula (Sicilia, Siracusa)", FastiA 6, 215-216.

Giannitrapani, E. 1997 "Rapporti tra Sicilia e Malta durante l'età del Bronzo”, Prima Sicilia. Alle origini della società Siciliana, Palermo, 429-443.

Giardino, C. 1982 "I materiali dell'età del Bronzo Media e recente", Ricerche sulla protostoria della Sibaritide 2, Cahiers du Centre Jean Bérard VIII, Naples, 25-62.

Giardino, C 1994a "I materiali dell'età del bronzo recente", Enotri e micenei nella Sibaritide I (Peroni, R., F. Trucco eds.), Taranto, 185-264.

Giardino, C. 1994b "Strategie insediamentali e sviluppi economici nell'area campana del Bronzo medio in relazione ai traffici transmarini", Vivara. Centro commerciale mediterraneo dell'età del bronzo II. Le tracce dei contatti con il mondo egeo (scavi 1976-1982) (Marazzi, M., Tusa, S. eds.), Ricerche di storia, epigrafia e archeologia mediterranea 3, 66-98.

Gillis, C. 1995 "Trade in the Late Bronze Age", Trade and production in premonetary Greece: aspects of trade (Gillis, C. Risberg and B. Sjöberg eds.), SIMA Pocket-book 134, Jonsered, 61-86.

Gilmour, G. 1992 "Mycenaean IIIA and IIIB pottery in the Levant and Cyprus", RDAC, 113-128.

Giveon, R. 1983 "Egyptian scarab and finger ring", Excavations at Athienou, Cyprus 1971-1972, QEDEM 16 (T. Dothan \& A. Ben-Tor), Jerusalem, 121.

Gjerstad, E. 1926 Studies on prehistoric Cyprus, Uppsala.

Gjerstad, E., J. Lindres, E. Sjöqvist, A. Westholm 1934 The Swedish Cyprus Expedition. Finds and results of the Excavations in Cyprus 1927-1931. Vol. I, Stockholm.

Gjerstad, E., J. Lindres, E. Sjöqvist, A. Westholm 1935 The Swedish Cyprus Expedition. Finds and results of the Excavations in Cyprus 1927-1931. Vol II, Stockholm.

Gjerstad, E., J. Lindres, E. Sjöqvist, A. Westholm 1937 The Swedish Cyprus Expedition. Finds and results of the Excavations in Cyprus 1927-1931. Vol. III, Stockholm.

Glennie, P. 1995 "Consumption within historical studies", Acknowledging consumption. A review of new studies (Miller, D. ed.), London \& New York., 164-203.

Gödecken, K.B. 1988 "A contribution to the early history of Miletus. The settlement in Mycenaean times and its connections overseas", Problems in Greek prehistory (French, E.B., K.A. Wardle eds.), Bristol, 1988.

Goldwasser, O. 1989 " Some Egyptian finds from Hazor: scarabs, scarab impressions and a stele fragment", Hazor III-IV. An account of the third and fourth seasons of excavations 1957-1958 (Text) (Yadin, Y. et al.), Jerusalem, 339-345. 
Gonen, R. 1984 "Urban Canaan in the Late Bronze period”, BASOR 253, 61-73.

Gonen, R. 1992 Burial patterns and cultural diversity in Late Bronze Age Canaan, Winona Lake.

Gorgoglione, M.A. 1996 "La civiltà micenea nel golfo di Taranto: il saggio di S. Domenico", Atti e memorie del secondo congresso internazionale di micenologia (De Miro, E., L Godart, A. Sacconi eds.), Roma, 1571-1579.

Grant, E. 1929 Beth Shemesh, Haverford.

Grant, E., G.E. Wright 1938 Ain Shems excavations (Palestine), Part IV (pottery), Haverford.

Graziado, G. 1991 "The process of social stratification at Mycenae in the shaft grave period: a comparative examination of the evidence", AJA 97, 403-440.

Graziado, G. 1995 “Egina, Rodi e Cipro: rapporti inter-insulari agli inizi del tardo bronzo?”, SMEA 36, 7-27.

Graziado, G. 1997 "Le presenze cipriote in Italia nel quadro del commercio mediterraneo dei secoli XIV e XIII a.C.”, StClOr 46-2, 681-719.

Gregori, B., G. Palumbo 1986 "Presenze micenee in Siria-Palestina", Traffici micenei nel Mediterraneo (Marazzi, M., S. Tusa, L. Vagnetti eds.), Taranto, 365-388.

Gregory, C.A. 1982 Gifts and commodities, London.

Gunneweg, J. F. Asaro, H.V. Michel, I. Perlman 1992 "On the origin of a Mycenaean IIIA chariot krater and other related Mycenaean pottery from tomb 387 at Laish/Dan", EretzIsr 23, 54-63.

Gunneweg, J., T. Dothan, I. Perlman, S. Gitin 1986 "On the origin of pottery from Tel Miqne-Ekron", BASOR 264, 3-16.

Gurney, O.R. 1990 The Hittites, Harmondsworth.

Guy, P.L.O., R.M. Engberg 1938 Megiddo Tombs, Chicago.

Hachmann, R. 1970 Kamid el-Loz 1966/67, Bonn.

Hachmann, R. 1978a "Rapport préliminaire sur les fouilles au tell de Kamid el-Loz de 1969 à 1972", BullMusBeyr 30, 7-26.

Hachmann, R. 1978b "Rapport préliminaire sur les fouilles au tell de Kamid el-Loz en 1973", BullMusBeyr 30, 27-42.

Hachmann, R. 1980 Bericht über die Ergebnisse der Ausgrabungen in Kamid el-Loz in den Jahren 1968-1970, SBA 22, Bonn.

Hachmann, R. 1982 Kamid el-Loz 1971-1974, SBA 32, Bonn.

Hachmann, R., A. Kuschke 1966 Kamid el-Loz 1963-1964, SBA 3, Bonn.

Hadjicosti, M. 1997 "The kingdom of Idalion in the light of new evidence", BASOR 308, 49-63.

Hadjisavvas, S. 1986 "Alassa. A new Late Cypriot site”, RDAC, 62-67.

Hadjisavvas, S. 1989 "A Late Cypriot community at Alassa”, Early society in Cyprus (Peltenburg, E. ed.), Edinburgh, 32-42.

Hadjisavvas, S. 1996 “Alassa: a regional centre of Alasia?”, Late Bronze Age settlement in Cyprus: function and relationships (Åström, P., E. Herscher eds.), SIMA Pocket-book 126, Jonsered, 23-38.

Håkansson, N. 1989 "Early remains in area 8", Hala Sultan Tekke 9. Trenches 1972-1987 with an index for volumes 1-9, SIMA 45:9, Göteborg 1989, 14-33.

Hallam, B.R., S.E. Warren, A.C. Renfrew 1976 "Obsidian in the western Mediterranean", ProcPrehistSoc 42, 85-110.

Halstead, P. 1988 "On redistribution and the origin of Minoan - Mycenaean palatial economies", Problems in Greek prehistory (French, E.B, K.A. Wardle eds.), Bristol, 519-530.

Halstead, P. 1992a "The Mycenaean economy: making the most of the gaps in the evidence", ProcCambrPhilSoc 38, 57-86. 
Halstead, P. 1992b "Agriculture in the Bronze Age Aegean: towards a model of palatial economy", Agriculture in ancient Greece (Wells, B. ed.), Stockholm, 105-17.

Hamilton, R.W. 1934-1935 "Excavations at Tell Abu Hawam”, QDAP 4, 1-69.

Hankey, V. 1967 "Mycenaean pottery in the Middle East: notes on finds since 1951”, BSA 62, 107-147.

Hankey, V. 1970 "Mycenaean trade with the south east Mediterranean", MelBeyrouth 46, 11-30.

Hankey, V. 1973 "The Aegean deposit at el-Amarna", The Mycenaeans in the eastern Mediterranean, Nicosia, 122-127.

Hankey, V. 1974 "A Late Bronze Age temple at Amman 1: the Aegean pottery", Levant 6, 131-178.

Hankey, V. 1979 "Crete, Cyprus and the south-east Mediterranean", The relations between Cyprus and Crete, ca 2000-500 BC (Karageorghis, V. ed.), Nicosia, 144-157.

Hankey, V. 1981a "The Aegean interest in El Amarna”, JMedAnthrA 1 (1981), 38-49.

Hankey, V. 1981b "Imported vessels of the Late Bronze Age at high places", Temples and high places in biblical times (Biran, A. ed.), Jerusalem, 108-117.

Hankey, V. 1984 “The Mycenaean pottery”, Excavations at Tell Mevorakh (1973-1976), Part II: the Bronze Age (Stern, E. ed.), Jerusalem, 20-21.

Hankey, V. 1993a "Pottery as evidence for trade: the Levant from the mouth of the Orontes to the Egyptian border", Wace and Blegen. Pottery as evidence for trade in the Aegean Bronze Age (Zerner, C. et al. eds.), Amsterdam, 101-108.

Hankey, V. 1993b "Pottery as evidence for trade: Egypt", Wace and Blegen. Pottery as evidence for trade in the Aegean Bronze Age (Zerner, C. et al. eds..), Amsterdam, 109-115.

Hankey, V. 1993c "The Mycenaean pottery", The Late Bronze Age garrison at Beth Shan: A study of levels VII and VIII, Philadelphia, 1993, 103-110.

Hankey, V. 1995a "Stirrup jars at El Amarna", Egypt, the Aegean and the Levant (Davies, W.V., L. Schofield), London, 116-124.

Hankey, V. 1995b "A Late Bronze Age temple at Amman Airport: small finds and pottery discovered in 1955", Trade, contact and the movement of peoples in the eastern Mediterranean. Studies in honour of Basil Hennessy (Bourke, S., J.P. Descoedres eds.), Mediterranean Archaeology Supplement 3, Sydney, 169-185.

Hankey, V. 1997 “Aegean pottery at El-Amarna: shapes and decorative motifs", Ancient Egypt, the Aegean and the near East. Studies in honour of Martha Rhodes Bell I (Phillips, J., L. Bell, B.B. William, J. Hoch, R. Leprohon eds.), 193-218.

Hankey, V., A. Leonard Jr. 1989 “Ägypten und die Levante. Ägäische Importe des 2. Jahrtausends v. Chr.", Tübinger Atlas des Vorderen Orients B III 4/5.

Harding, A.F. 1984 The Mycenaeans and Europe, Bath.

Harding, G.L., B.S.J. Isserlin 1953 “An early Iron Age tomb from Madaba”, APEF 6, 27-47.

Haskell, H.W. 1985 "the origin of the Aegean stirrup jar and its earliest evolution and distribution (MBIII-LBI)", AJA 89, 221-9.

Haskell, H.W. 1990 "Late Bronze Age trade: transport stirrup jars”, AJA 94, 298.

Haskell, H.W. 1997 "Mycenaeans at Knossos: patterns in the evidence", La Crète mycénienne (Driessen, J., A. Farnoux eds.), BCH Suppl. 30, Athènes, 187-193.

Helbaek, H. 1962 "Late Cypriot vegetable diet at Apliki", OpAth 4, 171-186.

Helck, W. 1962 Die Beziehungen Aegyptens zu Vorderasien, Wiesbaden.

Hellbing, L. 1979 Alasia problems, SIMA 57, Göteborg.

Heltzer, M. 1978 Goods, prices and the organization of trade in Ugarit, Wiesbaden.

Hennessy, J.B. 1963 Stephania. A Middle and Late Bronze Age cemetery in Cyprus, London. 
Herr, L.G. 1983 “The Amman Airport structure and the geopolitics of ancient Transjordan”, BiblArch 46, 223-229.

Herscher, E. 1984 "The pottery of Maroni and regionalism in Late Bronze Age Cyprus", Cyprus at the close of the Late Bronze Age (Karageorghis, V., J.D. Muhly eds.), Nicosia, 23-28.

Herscher, E. 1998 “Archaeology in Cyprus”, AJA 102, 309-354.

Hiller, S. 1978 “Levanto-Mykenische Kelche - zur Herkunft der Gefässform”, RDAC, 91-102.

Hirschfeld, N. 1993 "Incised marks (post-firing) on Aegean wares", Wace and Blegen. Pottery as evidence for trade in the Aegean Bronze Age 1939-1989 (C. Zerner et al. eds.), Amsterdam, 311-318

Hirschfeld, N. 1996 "Cypriots in the Mycenaean Aegean", Atti e memorie del secondo congresso internazionale di micenologia (De Miro, E., L. Godart. A. Sacconi), IncGr 98-1, Roma, 289-297.

Hirschfeld, N. 1999 Potmarks of the Late Bronze Age eastern Mediterranean, Austin (Unpublished dissertation University of Texas).

Hirschfeld, N. 2000a "Introduction to the catalogue", Céramiques mycéniennes" RSO XIII, Paris/Nicosia, 67-73.

Hirschfeld, N. 2000b “The catalogue”, Céramiques mycéniennes” RSO XIII, Paris/Nicosia, 75-161.

Hodder, I. 1982a "Towards a contextual approach to prehistoric exchange", Contexts for prehistoric exchange (Ericson, J.E. and T.K. Earle eds.), New York/London, 199-211.

Hodder, I. 1982b The present past. An introduction to anthropology for archaeologsts, London.

Hodder, I. 1987 "The contextual analysis of symbolic meanings", The archaeology of contextual meanings (Hodder, I. ed.), Cambridge, 1-10.

Hodder, I. 1992 Theory and practice in archaeology, London.

Hugh-Jones, S. 1992 "Yesterday's luxuries, tomorrow's necessities: business and barter in northwest Amazonia”, Barter, exchange and value. An anthropological approach (Humphrey, C., S. Hugh-Jones eds.), Cambridge, 42-74.

Hult, G. 1978 “Area 8. The 1974 campaign”, Hala Sultan Tekke 4. Excavations in area 8 in 1974 and 1975, SIMA 45:4, Göteborg, 1-15.

Hult, G. 1981 Hala Sultan Tekke 7. Excavations in area 8 in 1977, SIMA 45:7, Göteborg.

Hult, G. 1983 Bronze Age ashlar masonry in the eastern Mediterranean. Cyprus, Ugarit and neighbouring regions, SIMA 66, Göteborg.

Humphrey, C., S. Hugh-Jones 1992 "Barter, exchange and value", Barter, exchange and value. An anthropological approach (Humphrey, C., S. Hugh-Jones eds.), Cambridge, 1-20.

Ibrahim, M.M. 1976 “Third season of excavations at Sahab”, AAJ 20, 69-82.

Ibrahim, M.M. 1997 "Sahab", Oxford encyclopedia of archaeology of the ancient Near East IV, Oxford, 450452.

Ibrahim, M.M., G. Van der Kooij 1997 “Excavations at Tell Deir Alla; seasons 1987 and 1994”, AAJ 41, 95-114.

Ilan, D. 1996 "Dan”, Oxford encyclopedia of archaeology in the ancient Near East, Oxford, 108.

Immerwahr, S.A. 1945 "Three Mycenaean vases from Cyprus in the Metropolitan Museum of Art", AJA 49, 534-556.

Immerwahr, S.A. 1960 "Mycenaean trade and colonization", Archaeology 13, 4-13.

Ionas, I. 1984a "Stratigraphies of Enkomi”, RDAC, 50-65.

Ionas, I. 1984b "L'architecture réligieuse au Chypriote Récent (Kition et Enkomi)", Temples et sanctuaires, Lyon, 97-105.

Ionas, I. 1985 “The altar at Myrtou-Pigadhes. A re-examination of its reconstruction”, RDAC, 137-142. 
James, F.W, P.E. McGovern 1993 The Late Bronze Egyptian garrison at Beth Shan: A study of levels VII and VIII, Philadelphia.

Johnson, J. 1980 Maroni de Chypre, SIMA 59, Göteborg.

Johnstone, W. 1971 “A Late Bronze Age tholos tomb at Enkomi”, Alasia I (Schaeffer, C.F.A. ed.), Paris, 51-122.

Jones, R.E. 1986a Greek and Cypriot pottery. A review of scientific studies, Athens.

Jones, R.E. 1986b "Chemical analysis of Aegean-type Late Bronze Age pottery found in Italy", Traffici micenei nel Mediterraneo (Marazzi, M., S.Tusa, L. Vagnetti eds.), Taranto, 205-214.

Jones, R.E. 1994 "Chemical analysis of the Aegean painted and unpainted wares from Vivara", Vivara. Centro commerciale mediterraneo dell'età del bronzo II. Le tracce dei contatti con il mondo egeo (scavi 19761982) (Marazzi, M., S. Tusa eds.), Ricerche di storia, epigrafia e archeologia mediterranea 3, 303-316.

Jones, R.E., L. Vagnetti 1991 "Traders and craftsmen in the central Mediterranean: archaeological evidence and archaeometric research", Bronze Age trade in the Mediterranean (Gale, N. ed.), SIMA 90, Göteborg, 127-147.

Jones, R.E., L. Vagnetti 1992 "Traders and craftsmen in the central Mediterranean: archaeological evidence and archaeometric research (an addendum)", BSA 87, 211-217.

Jones, R.E., L. Lazzarini, M. Mariottini, E. Eduardo Orvini 1994 "Appendice: studio minero-petrografico e chimico di ceramiche protostoriche da Brogli di Trebisacce (Sibari)", Enotri e micenei nella Sibaritide I (Peroni, R., F. Trucco eds.), Taranto, 413-454.

Kafafi, Z. 1977 Late Bronze Age pottery in Jordan (East Bank): 1575-1200 BC, Amman. (Unpublished Masters thesis, University of Jordan.)

Kantor, H.J. 1947 The Aegean and the orient in the second millennium B.C., AIA Monograph 1, Bloomington.

Karageorghis, V. 1958 "Myth and epic in Mycenaean vase painting”, AJA 62, 383-387.

Karageorghis, V. 1959 "Chronique de fouilles et découvertes archéologiques à Chypre en 1958”, BCH 83, 336-361.

Karageorghis, V. 1960a "Fouilles de Kition 1959. Études sur les origines de la ville" BCH 84, 504-588.

Karageorghis, V. 1960b "Supplementary notes on the Mycenaean vases from the Swedish tombs at Enkomi”, OpAth 3, 135-153.

Karageorghis, V. 1963 Corpus Vasorum Antiquorum, Cyprus I: Cyprus Museum (Nicosia), Larnaca District Museum, Nicosia.

Karageorghis, V. 1964 "A Late Cypriot tomb at Angastina”, RDAC 1-27.

Karageorghis, V. 1965a Nouveaux documents pour l'étude du Bronze Récent à Chypre, Paris.

Karageorghis, V. 1965b "A Late Cypriot tomb at Tamassos”, RDAC, 11-29.

Karageorghis, V. 1966 "Chronique des fouilles et découvertes archéologiques à Chypre en 1965”, BCH 90, 298-389.

Karageorghis, V. 1971 “A Mycenaean painter of bulls and protomes”, Alasia I (Schaeffer, C.F.A. ed.), Paris, 123-132.

Karageorghis, V. 1972 “A 'snake house’ from Enkomi”, RDAC, 109-112.

Karageorghis, V. 1974 Excavations at Kition I. The tombs, Nicosia.

Karageorghis, V. 1976 “Two Late Bronze Age tombs from Hala Sultan Tekke”, Hala Sultan Tekke 1, SIMA 45:1, Göteborg, 71-90.

Karageorghis, V. 1981 “Aegean and derivative wares”, Kition IV. The non-Cypriote pottery, Nicosia, 1-15. Karageorghis, V. 1982a Cyprus. From the Stone Age to the Romans, London.

Karageorghis, V. 1982b “A Late Mycenaean IIIB chariot krater from Cyprus”, RDAC, 77-82. 
Karageorghis, V. 1985a "Catalogue and discussion of finds, area I", Kition V. The pre-Phoenician levels II. (Karageorghis, V. ed.), Nicosia, 1-87.

Karageorghis, V. 1985b "Catalogue and discussion of finds, area II”, Kition V. The pre-Phoenician levels II. (Karageorghis, V. ed.), Nicosia, 88-242.

Karageorghis, V. 1985c "Kition ivories and various bone objects", Kition V. The Pre-Phoenician Levels. II (V. Karageorghis, V, M. Demas), Nicosia, 329-339.

Karageorghis, V. 1990 The end of the Late Bronze Age in Cyprus, Nicosia.

Karageorghis, V. 1998 "Note on a Mycenaean IIIB rhyton from Ugarit", $A A, 1-3$.

Karageorghis, V. 2000, Mycenaean and other sherds in the Louvre”, Céramiques mycéniennes" RSO XIII, Paris/Nicosia, 37-65.

Karageorghis, V., M. Demas 1984 Pyla-Kokkinokremos. A late 13th century BC fortified settlement in Cyprus, Nicosia.

Karageorghis, V., M. Demas 1988 Excavations at Maa-Palaeokastro 1979-1986, Nicosia.

Kelm, G.L., A. Mazar 1995 Timnah. A Biblical City in the Sorek Valley, Winona Lake.

Kelso, J.L. 1968 The excavation of Bethel (1934-1960), Cambridge.

Kemp, B.J., R.S. Merrillees 1980 Minoan pottery in second millennium Egypt, Mainz am Rhein.

Keswani, P.S. 1989a Mortuary ritual and social hierarchy in Bronze Age Cyprus, University of Michigan. (Unpublished $\mathrm{PhD}$. thesis.)

Keswani, P.S. 1989b "Dimensions of social hierarchy in Late Bronze Age Cyprus: an analysis of the mortuary data from Enkomi", JMedA 2/1, 49-86.

Keswani, P.S. 1993 "Models of local exchange in Late Bronze Age Cyprus” BASOR 192, 73-83.

Keswani, P.S. 1996 "Hierarchies, heterarchies and urbanization processes: the view from Bronze Age Cyprus", JMedA 9/2, 211-250.

Khalifeh, I.A. 1988 Sarepta II. The Late Bronze and Iron Age Periods of Area II, X, Beyrouth.

Kilian-Dirlmeier, I. 1993 Die Schwerter in Griechenland (ausserhalb der Peloponnes), Bulgarien und Albanien, PräBRF IV, 12, Stuttgart.

Kilian, K. 1986 "Il confine settentrionale della civiltà micenea nella tardo età del bronzo", Traffici micenei nel Mediterraneo (Marazzi, M., S.Tusa, L. Vagnetti eds.), Taranto, 283-301.

Kilian, K. 1987 "L'Architecture des résidences mycéniennes: origine et extension d'un structure du pouvoir politique pendant l'âge du Bronze Récent", Le système palatial en orient, en Grèce et à Rome (Levy, E. ed.), Strasbourg, 203-217.

Kilian, K. 1988 "The emergence of 'Wanax' ideology in the Mycenaean palaces", OJA 7, 291-302.

Kilian, K. 1990 "Mycenaean colonization: norm and variety", Greek colonists and native populations (Descoeudres, J.P. ed.), Oxford, 445-467.

Killebrew, A.E. 1998 "Aegean and Aegean-style material culture in Canaan during the 14th-12th centuries BC: trade colonization, diffusion or migration?, The Aegean and the orient in the second millennium. (Cline, E., D. Harris-Cline eds.), AEGEUM 18, Liège, 149-170.

Kinet, D., 1981: Ugarit. Geschichte und Kultur einer Stadt in der Umwelt des Alten Testaments, Stuttgart (Stuttgarter Bibelstudien 104).

King, R. 1997 "Introduction: an essay on Mediterraneanism”, The Mediterranean. Environment and society (King, R., L. Proudfoot, B. Smith eds.), London, 1-11.

Kitchen, K.A. 1987 “The basics of Egyptian chronology in relation to the Bronze Age”, High, Middle or Low ? vol I (Åström, P. ed.), SIMA Pocket-book 56, Göteborg, 37-55.

Kling, B. 1987 "Pottery classification and relative chronology of the LCIIC-LCIIIA periods", Western Cyprus: connections (Rupp, D.W. ed.), SIMA 77, Göteborg, 97-113.

Kling, B. 1989 Mycenaean IIIC:1b and related pottery in Cyprus, SIMA 87, Göterborg. 
Kling, B. 1991 "A terminology for the matt-painted wheelmade pottery of Late Cypriot IIC-IIIA", Cypriot ceramics. Reading the prehistoric record (Barlow, J.A., B. Bolger, B. Kling eds.), Philadelphia, 181-184.

Knapp, A.B. 1985 "Alashiya, Caphtor/Keftiu and eastern mediterranean trade: recent studies in Cypriot archaeology and history", JFA 12, 231-250.

Knapp, A.B. 1986a "Production, exchange and socio-political complexity on Bronze Age Cyprus", OxfJA 5 (1986), 35-60.

Knapp, A.B. 1986b Copper production and divine protection: archaeology, Ideology and social complexity on Bronze Age Cyprus, SIMA Pocket-Book 42, Göteborg.

Knapp, A.B. 1988a, "Copper production and eastern Mediterranean trade: the rise of complex society on Cyprus", State and society: emergence and development of social hierarchy and political centralisation (J. Gledhill, B. Bender, M.T. Larsen eds.), London, 149-169.

Knapp, A.B. 1988b "Hoards d'oeuvres: of metals and men on Bronze Age Cyprus", OxfJA 7, 147-176

Knapp, A.B. 1991 "Spice, drugs, grain and grog: organic goods in Bronze Age east Mediterranean trade", Bronze Age trade in the Mediterranean (Gale, N. ed.), SIMA 90, Göteborg, 21-68.

Knapp, A.B. 1993 "Thalassocracies in Bronze Age eastern Mediterranean trade: making and breaking a myth", WorldA 24-3, 332-347.

Knapp, A.B. 1996a "Power and ideology on prehistoric Cyprus", Religion and power in the ancient Greek world (Hellström, P., B. Alroth), Uppsala, 9-25.

Knapp, A.B. 1996b "Introduction", Sources for the history of Cyprus II: Near Eastern and Aegean texts from the third to first millennia BC (Knapp, A.B. ed.), New York, 1-15.

Knapp, A.B. 1997 The archaeology of Late Bronze Age Cypriot society. The study of settlement, survey and landscape, Glasgow.

Knapp, A.B., S. Antoniadou 1998 "Archaeology, politics and the cultural heritage of Cyprus", Archaeology under fire. Nationalism, politics and heritage in the eastern mediterranean and Middle East (Meskell, L. ed.), London, 13-43.

Knapp, A.B., J.F. Cherry 1994 Provenience studies and Bronze Age Cyprus. Production, exchange and politicoeconomic change, Madison.

Knapp, A.B., P. Duerden, R.V.S. Wright, P. Grave 1988 "Ceramic production and social change: archaeometric analysis of Bronze Age pottery from Jordan”, JMedA 1/2, 57-113.

Kochavi, M. (ed.) 1972 Judaea, Samaria and the Golan archaeological survey 1967-1968, Jerusalem.

Kochavi, M. 1981 "The history and archaeology of Aphek-Antipatris, Biblical city in the Sharon plain", BiblArch 44, 75-86.

Koehl, R.B. 1981 "The function of Aegean Bronze Age rhyta", Sanctuaries and cults in the Aegean Bronze Age (Hägg, R., N. Marinatos eds.), Stockholm, 179-187.

Koehl, R.B. 1985 Sarepta III. The imported Bronze and Iron Age wares from area II, X, Beirut.

Koehl, R.B. 1986 "The Mycenaean and Cypriot pottery”, The Late Bronze and Early Iron Ages of central transjordan: the Baq'ah valley Project 1977-1981, Philadelphia, 194-210.

Koehl, R.B., Yellin, J. 1982 "The origin and provenience of Mycenaean 'Simple Style' pottery", AJA 86, 273.

Kohl, P. 1987 "The ancient economy, transferable technologies and the Bronze Age World System: a view from the northeastern frontier of the Ancient Near East", Center and periphery in the ancient world (Rowlands, M., M. Larsen, K. Kristiansen eds.), Cambridge, 13-24.

Kopytoff, I. 1986 "The cultural biography of things: commoditization as process", The social life of things. Commodities in cultural perspective (Appadurai, A. ed.), Cambridge, 64-91. 
Kromholz, S.F. 1982 The Bronze Age necropolis at Ayia Pareskevi (Nicosia). Unpublished tombs in the Cyprus Museum, SIMA Pocket-book 17, Göteborg.

Krzyszkowska, O. 1992 “A 'new' mirror handle from Cyprus”, BSA 87, 237-242.

Kuschke, A. 1962 "Bericht über eine Sondage im Palastgarten von Ugarit-Ras Shamra", Ugaritica IV (Schaeffer, C.F.A. ed.), Paris, 252-299.

Lagarce, J. 1982 “Ras Ibn Hani au Bronze Récent: problèmes et perspectives”, La Syrie au Bronze Récent: (proto)histoire du Levant, Paris, 29-36.

Lagarce, J., E. Lagarce 1985 Alasia IV. Deux tombes du Chypriote Récent d'Enkomi (tombe 1851 et 1907) Paris.

Lagarce, J., E. Lagarce, A. Bounni, N. Saliby 1983 "Les fouilles à Ras Ibn Hani en Syrie (campagnes de 1980, 1981 et 1982)", CRAI, 32-42.

Lambert, J.B., C.D. McLaughlin, A. Leonard 1978 "X-ray photoelectron spectroscopic analysis of the Mycenaean pottery from Megiddo", Archaeometry 20, 107-122.

Lambrou-Phillipson, C. 1990a Hellenorientalia. The Near Eastern presence in the Bronze Age Aegean, 30001100 BC, SIMA Pocket-book 95, Göteborg.

Lambrou-Phillipsson, C. 1990b "Thera in the mythology of the classical tradition: an archaeological approach", Thera and the Aegean world III, vol. I: archaeology (Hardy, D.A ed.), London, 162-170.

Lattanzi, E., Vagnetti, L. 1983-1984 "Documenti micenei dalla Motta”, AttiMemMagnaGr NS 24-25, 157-160.

Leighton, R. 1999 Siciliy before history. An archaeological survey from the Palaeolithic to the Iron Age, London.

Leonard Jr., A. 1981 "Considerations of morphological variation in the Mycenaean pottery from the south-east Mediterranean”, BASOR 241, 87-101.

Leonard Jr., A. 1987 "The significance of the Mycenaean pottery found east of the Jordan river", Studies in the history and archaeology of Jordan III (Hadidi, A. ed.), Amman, 261-266.

Leonard Jr., A. 1989 "Archaeological sources for the history of Palestine. The Late Bronze Age", BiblArch 52-1, 4-39.

Leonard Jr., A. 1994 An index to the Late Bronze Age pottery from Syria-Palestine, SIMA 114, Jonsered.

Leonard, A., E.H. Cline 1998 "The Aegean pottery at Megiddo: an appraisal and reanalysis", BASOR 309, 1-37.

Leonard Jr., A., M. Hughes, A. Middleton, L. Schofield 1993 “The making of Aegean stirrup jars: technique, tradition and trade", $B S A$ 88, 105-123.

Levi, S.T., R.E. Jones, L. Lazzarini, M. Sonnino, L. Vagnetti 1998 "The production and distribution of protohistoric pottery in Italy: the case of the plain of Sybaris", Proceedings of the XIIIth congress 4, Forli, 435-444.

Linder, E. 1981 "Ugarit: a Canaanite thalassocracy", Ugarit in retrospect. Fifty years of Ugarit and Ugaritica (Young, G. ed.), Winona Lake, 32-42.

Liverani, M. 1979 "Ras Shamra - histoire", Supplement au dictionnaire de la Bible, Paris, cols. 1295-1348.

Liverani, M. 1972 "Elementi 'irrazionali' nel commercio amarniano”, OA 11, 297-317.

Liverani, M. 1986 "La ceramica e I testi: commercio miceneo e politico orientale", Traffici micenei nel Mediterraneo (Marazzi, M., S.Tusa, L. Vagnetti eds.), Taranto, 405-412.

Liverani, M. 1987 "The collapse of the Near Eastern regional system at the end of the Bronze Age: the case of Syria", Centre and periphery in the ancient world (Rowlands, M., M. Larsen, K. Kristiansen eds.), Cambridge, 66-73.

Liverani, M. 1988 Antico oriente: storia, società, economia, Bari.

Liverani, M. 1990 Prestige and interest. International relations in the Near East ca. 1600-1100 BC, Padova. 
Lollini, D.G. 1982 "Treazzano di Monsampolo (Castel di Lama, Ascoli Piceno)” Magna Grecia e mondo miceneo. Nuovi documenti (Vagnetti, L. ed.), Taranto, 197-199.

Lolos, G., Ch. Pennas, Ch., G. Vichos 1995 “Der Schiffsfund von Kap Iria (Golf von Argos)”, In Poseidons Reich. Archäologie unter Wasser, Mainz am Rhein, 59-62.

Lo Porto, F.G. 1963 "La stazione protostorica di Porto Perone", NSc 350, 280-380.

Lo Porto, F.G. 1964 "Satyrion (Taranto). Scavi e ricerche nel luogo del più insediamento laconico in Puglia", NSc 18, 177-279.

Lo Porto, F.G. 1967 "Il "dolmen a galleria” di Giovinazzo", BPI 76 137-173.

Lo Porto, F.G. 1986 "Le importazioni micenee in Puglia. Bilancio di un decennio di scavi”, Traffici micenei nel Mediterraneo (Marazzi, M., S.Tusa, L. Vagnetti eds.), Taranto, 14.

Lo Porto, F.G. 1993 "Il tumulo di Torre Santa Sabina nel Brindisino alle luce di nuove indagine", Magna Grecia 28 4/6, 8-12.

Lo Schiavo, F. 1981 "Economia e società nell'età dei nuraghi”, Ichnussa. La Sardegna dalle origini all età classica (Pugliese Carratelli, G. ed.), Milano, 255-341.

Lo Schiavo, F., E. Macnamara, L. Vagnetti 1985 "Late Cypriot imports to Italy and their influence on local bronzework", BSR 53, 1-71.

Loud, G. 1948 Megiddo II, seasons of 1935-39, Chicago.

Lubsen Admiraal, S. 1982 "Late Bronze Age tombs from Dromolaxia", RDAC, 39-59.

Lukesh, S.S. 1983 "Italy and the Apennine culture", Crossroads of the Mediterranean (Hackens T., N.D. Holloway, R.R. Holloway eds.), Louvain-la-Neuve/Providence, 13-54.

MacAlister, R.A.S. 1912 The excavation of Gezer: 1902-1905 and 1907-1909. Vols. I-III, London.

MacKenzie, D. 1911 "Excavations at Ain Shems", APEF 1, 41-94.

Mackenzie, D. 1912-1913 "Excavations at Ain Shems (Beth Shemesh)", APEF 2, 1-100.

MacQueen, J.G. 1986 The Hittites and their contemporaries in Asia Minor, Boulder.

Maddin, R., J.D. Muhly, T. Stech Wheeler 1983 “Metal working”, Excavations at Athienou, Cyprus 19711972, QEDEM 16 (T. Dothan \& A. Ben-Tor), Jerusalem, 132-138.

Maier, F.G. 1984, Alt-Paphos auf Cypern. Ausgrabungen zur Geschichte von Stadt und Heiligtum 1966-1981, Trierer Winckelmannprogramm 6, Mainz am Rhein.

Maier, F.G. 1985 “A note on shallow bowls", RDAC, 122-125.

Maier, F.G., M.C. von Wartburg 1985 "Reconstructing history from the earth, ca. 2800 BC-1600 AD. Excavating at Palaepaphos 1966-1984”, Archaeology in Cyprus 1960-1985 (Karageorghis, V. ed.), Nicosia, 142-172.

Maier, F.G., V. Karageorghis 1984 Paphos. History and Archaeology, Nicosia, 1984.

Mallet, J. 1987 "Le temple aux rhytons", Le centre de la ville, 38ème-44ème campagne (1978-1984) sous la direction de Marguerite Yon, RSO III, Paris, 213-248.

Malone, C. S. Stoddart, R. Whitehouse 1994 "The Bronze Age of southern Italy, Sicily and Malta: c. 2000-800 BC", Development and decline in the Mediterranean Bronze Age (Mathers, C., S. Stoddart, S.), Sheffield, 167-194.

Manning, S.W. 1988 “The Bronze Age eruption of Thera: absolute dating, Aegean chronology and Mediterranean cultural interrelations", JMedA 1, 17-82.

Manning, S.W. 1989 "The eruption of Thera: date and implications", Thera and the Aegean world III, vol. I: archaeology (Hardy, D.A. ed.), London, 29-40.

Manning, S.W. 1990 "The Thera eruption: the third congress and the problem of the date", Archaeometry 32, 91-100. 
Manning, S.W. 1991 "Response to J.D. Muhly on problems of chronology in the Aegean Late Bronze Age", JMedA 4, 249-262.

Manning, S.W. 1998 "Changing pasts and socio-political cognition in Late Bronze Age Cyprus", The past in the past. The reuse of ancient monuments (Bradley, R., H. Williams eds), WorldArch 30, 39-58.

Manning, S.W., S.J. Monks 1998 "Late Cypriot tombs at Maroni Tsarroukkas, Cyprus”, BSA 93, 297351.

Marazzi, M. 1988 "La più antica marineria in occidente; dossier sulle rotte commerciali nel basso Tirreno fino al golfo di Napoli nei secoli XVI-XV a.C.", DialArch NS 6, 5-22.

Marazzi, M. 1993a "The early Aegean-Mycenaean presence in the Gulf of Naples: past and recent discoveries", Wace and Blegen. Pottery as evidence for trade in the Aegean Bronze Age (Zerner, C. et al. eds.), Amsterdam, 335-342.

Marazzi, M. 1993b "Brevi note sulle ceramiche greco-egee", Origini 17, 402-405.

Marazzi, M. 1994 "Vivara e le prime navigazioni egeo-micenee in occidente", Vivara. Centro commerciale mediterraneo dell'età del bronzo II. Le tracce dei contatti con il mondo egeo (scavi 1976-1982) (Marazzi, M., S. Tusa eds.), Ricerche di storia, epigrafia e archeologia mediterranea 3, 17-54..

Marazzi, M. 1995 "Un isola nel golfo. Le ricerche in corso a Vivara rivelano l'importante ruolo svolto dall'isoletta dell'Arcipelago Flegreo nei commerci Mediterranei agli Albori dell'età micenea", Archeo 10-9, 92-99.

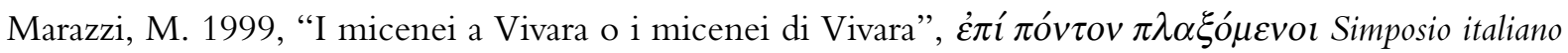
di studi Egei (La Rosa, V., D. Palermo, L. Vagnetti eds.), Roma, 415-421.

Marazzi, M., L. Re 1986 “Importazioni egeo-micenee dall'isola di Vivara (Procida)", Traffici micenei nel Mediterraneo (Marazzi, M., S.Tusa, L. Vagnetti eds.), Taranto, 155-173.

Marazzi, M., S. Tusa 1979 “Die mykenischen Penetration im westlichen Mittelmerraum”, Klio 61, 309351.

Marchegay, S. 1999, Les tombes construites d'Ougarit, Lyon (Unpublished Ph.D thesis Universite Lyon-2.)

Marfoe, L. 1995 Kamid el-Loz 13. The prehistoric and early historic context of the site, SBA 41, Bonn.

Margueron, J. 1977 "Ras Shamra 1975 et 1976. Rapport préliminaire sur les campagnes d'automne", Syria 54, 151-188.

Marino, D.A., S. Festuccia 1995 "Siti costieri dal Bronzo Medio al Bronzo Finale nella Calabria centroorientale", Settlement and economy in Italy 1500 BC - AD 500 (Christie, N. ed.), Oxford, 1995, 227-239.

Martin, A.M. 1999 "Ex oriente lux. El comercio micénico en el Mediterráneo central y occidental (1625-1100 AC)", Complutum 10, 1-35.

Martin de la Cruz, J.C. 1988 "Mykenische Keramik aus bronzezeitlichen Siedlungsschichten von Montoro am Guadalquivir", MM 29, 77-92.

Martin de la Cruz, J.C. 1990 "Die erste mykenische Keramik von der iberische Halbinsel”, PZ 65, 4648.

Masson, E. 1970 "La plus ancienne tablette chypro-minoenne (Enkomi 1955), Minos 10, 63-77.

Masson, E. 1971a Études de vingt-six boules d'argile inscrites trouvées à Enkomi et Hala Sultan Tekke (Chypre), SIMA 31.1, Göteborg.

Masson. E. 1971b "Rouleau inscrit chypro-minoenne trouvé à Enkomi en 1967”, Alasia I (Schaeffer, C.F.A. ed.), Paris, 479-504.

Masson, E. 1994 "Le pays des Hittites", Les Hittites. Civilisation indo-européenne à fleur de roche. DossArchParis 193 (mai), 40-61.

Matthäus, H. 1985 Metalgefässe und Gefässuntersätze der Bronzezeit, der geometrischen und archaischen Perioden auf Cypern, PräBRF II, 8, München. 
Mauceri, I. 1877 "Relazione sulla necropoli del Fusco in Siracusa", Annali dell'Istituto di Correspondenza Archeologica 49, 37-58.

Mayence, F. 1926 Corpus Vasorum Antiqorum. Belgique I: Bruxelles, Musées Royaux du Cinquantaire, Paris

Mayence, F., V. Verhoogen 1929 Corpus Vasorum Antiquorum. Belgique III: Bruxelles, Musées Royaux d’Art et d'Histoire, Bruxelles.

McCAdams, R. 1974 “Anthropological perspectives on ancient trade", CurrAnthr 15-3, 239-258.

McDonald, B. 1988 The Wadi el-Hasa archaeological survey 1979-1983, west central Jordan, Ontario.

McDonald, B. 1992 The southern ghors and north-east 'Arabah archaeological survey, Sheffield.

McGovern, P.E. 1986 The Late Bronze and Early Iron Ages of central transjordan: the Baq'ah Valley Project 1977-1981, Philadelphia.

McGovern, P.E. 1992 "Settlement patterns of the Late Bronze and Iron Ages", Studies in the history and archaeology of Jordan 4 (Haidi, A. ed.), Amman, 179-183.

McGrail, S. 1989 "The shipment of traded goods and of ballast in antiquity", OxfJA 8, 353-358.

McNicoll, A.W., P.C. Edwards, J. Hanbury-Tenison, J.B. Hennessy, T.F. Potts, R.H. Smith, A. Walmsey, P. Watson 1992 Pella in Jordan 2, Sydney.

Mee, C. 1978 "Aegean trade and settlement in Anatolia in the second millennium BC", AnatSt 28, 121 156.

Mee, C. 1982 Rhodes in the Bronze Age. An archaeological survey, Warminster.

Megaw, A.H.S. 1957 “Archaeology in Cyprus 1957”, ArchRep, 43-50.

Megaw, A.H.S. 1959 “Archaeology in Cyprus”, ArchRep 5 (1985), 25-34.

Melas M. 1989 "Etics, emics and empathy in archaeological theory", The meaning of things. Material culture and symbolic expression (Hodder, I. ed.), London, 137-155.

Melas, M. 1993 "Ideology, pottery, trade and society in the Aegean Bronze Age", Wace and Blegen. Pottery as evidence for trade in the Aegean Bronze Age 1939-1989 (C. Zerner et al. eds.), Amsterdam, 369-376.

Merrillees, R.S. 1987 Alashiya revisisted, Cahiers de la Revue Biblique 22, Paris.

Merrillees, R.S. 1992 "The government of Cyprus in the Late Bronze Age”, Acta Kypria 3 (Åström, P. ed.), SIMA Pocket-book 120, Göteborg, 310-328.

Miller, D. 1985 Artefacts as categories. A study of ceramic variability in central India, Cambridge.

Miller, D. 1987 Material culture and mass consumption, Oxford.

Miller, D. 1995 "Consumption as the vanguard of history. A polemic by way of an introduction, Acknowledging consumption. A review of new studies (Miller, D. ed.), London \& New York., 1-57.

Miller, E.B. 1984 Zoomorphic vases in the Bronze Age Aegean, AnnArbor.

Miller, J.M. 1991 Archaeological survey of the Kerak plateau, Atlanta.

Millett, A., H.W. Catling 1966 "Composition and provenance: a challenge", Archaeometry 9 (1966), 9297.

Mommsen, H., T. Beier, U. Diehl, C. Podzuweit 1992 "Provenance determination of Mycenaean sherds found in Tell el-Amarna by Neutron Activation Analysis", JASc 19, 295-302.

Monchambert, J.Y. 1983 "La céramique de fabrication locale à Ougarit à la fin du bronze récent: quelques exemples", Syria 60, 25-45.

Monloup, T. 1987 "Figurines de terre-cuite", Le centre de la ville, 38ème-44ème campagne (1978-1984) sous la direction de Marguerite Yon, RSO III, Paris, 307-328.

Morgan. L. 1988 The miniature wall paintings of Thera: a study in Aegean culture and iconography, Cambridge.

Morris, I. 1987 Burial and ancient society. The rise of the Greek city state, Cambridge.

Morris, I. 1992 Death-ritual and social structure in classical antiquity, Cambridge. 
Moscetta, M.P. 1988 "Il ripostiglio di Lipari: nuove considerazioni per un inquadramento cronologico e culturale", DialArch 6, 53-78.

Mossberg, E. 1975 "Sherds from Enkomi tomb 5 and Ayios Iakovos tombs 3 and 5", OpAth 11, 119128.

Mountjoy, P.A. 1981 Four early Mycenaean wells from the south slope of the acropolis at Athens, Miscellanea Graeca 4, Gent.

Mountjoy, P.A. 1986 Mycenaean Decorated Pottery: A Guide to Identification, SIMA 73, Göteborg.

Mountjoy, P.A. 1990 "Regional Mycenaean pottery “, BSA 85, 245-270.

Mountjoy, P.A. 1993 Mycenaean pottery: An introduction, Oxford.

Mountjoy, P.A. 1999 Regional Mycenaean decorated pottery, Leidorf.

Muhly, J.D. 1989 “The organization of the copper industry in Late Bronze Age Cyprus", Early society in Cyprus (Peltenburg, E.J. ed.), Edinburgh, 298-314.

Muhly, J.D., R. Maddin and T. Stech 1988 "Cyprus, Crete and Sardinia: copper ox-hide ingots and the Bronze Age metals trade", RDAC 1988-I, 281-298.

Murray, A.S., A.H. Smith, H.B. Walters 1900 Excavations in Cyprus, London.

Myres, J.L. 1897 "Excavations in Cyprus in 1894", JHS 17, 134-173.

Myres, J.L. 1945 “Excavations in Cyprus 1913”, BSA 40-41, 53-98.

Myres, J.L., M. Ohnefalsch-Richter 1899 A catalogue of the Cyprus Museum, Oxford.

Nava, M.L. 1982 “Molinella (Vieste, Foggia)”, Magna Grecia e mondo miceneo. Nuovi documenti (Vagnetti, L. ed.), Taranto, 43-44.

Negbi, O. 1986 “The climax of urban development in Bronze Age Cyprus", RDAC, 97-121.

Negbi, O, M. Negbi 1993, Stirrup jars versus canaanite jars: their contents and reciprocal trade, in C. Zerner (ed.), Wace and Blegen. Pottery as Evidence for Trade in the Aegean Bronze Age, Amsterdam, 319329.

Nicolaou, K. 1968-1969 “Archaeology in Cyprus 1966-1969”, ArchRep, 40-54.

Nicolaou, K. 1973 "The first Mycenaeans in Cyprus", The Mycenaeans in the eastern Mediterranean, Nicosia, 51-61.

Niemeyer, W.F. 1997 “The Mycenaean potter's quarter at Miletus”, Techn? I, Aegeum 16, 347-351.

Niemeyer, W.F. 1998 "The Mycenaeans in western Anatolia and the problem of the origins of the Sea Peoples", Mediterranean peoples in transition. Thirteenth to early tenth century BCE. In honor of Professor Trude Dothan (Gitin, S., A. Mazar, E. Stern eds.), Jerusalem, 17-65.

Niklasson-Sönnerby, K. 1989 “Squares I and IV”, Hala Sultan Tekke 9. Trenches 1972-1987 with an index for volumes 1-9, SIMA 45:9, Göteborg, 68-86.

O'Shea, J. 1981 "Social configurations and the archaeological study of mortuary practices: a case study", The archaeology of death (Chapman, R., I. Kinnes, K. Randsborg eds.), Cambridge, 39-52.

Öbrink, U. 1979 Hala Sultan Tekke 6, SIMA 45:6, Göteborg.

Öbrink, U. 1983 "A well of the early 14th century BC", Hala Sultan Tekke 8. Excavations 1971-1979, SIMA 45:8, Göteborg, 16-58.

Oren, E.D. 1984 “Governors' Residencies in Canaan under the New Kingdom: a case-study of Egyptian administration", JSSEA 14, 37-56.

Oren, E.D. 1993 “Tel Sera”, NewEncArchExcHL vol. 4, 1329-1335.

Oren, E.D., E. Netzer 1974 “Tell Sera”, IEJ 24, 264-266.

Orsi, P. 1893 "Necropoli sicula presso Siracusa con vasi e bronzi micenei”, MonAnt 2, 5-36.

Orsi, P. 1895 “Thapsos”, MonAnt 6, 90-150. 
Orsi, P. 1899 "Sicilia", NSc, 26-42.

Orsi, P. 1902 "Molinello", NSc, 411-434.

Orsi, P. 1906 "Nuovi documenti della civiltà premicenea e micenea in Italia”, Ausonia 1, 5-12.

Orsi, P. 1909 "Floridia. Sepulcreto siculo con vaso miceneo", NSc, 374-378.

Östenberg, C.E. 1967 Luni sul Mignone e problemi della preistoria d'Italia, Lund.

Overbeck, J.C.J., S. Swiney 1972 Two Cypriot Bronze Age sites at Kafkallia (Dhali), SIMA 33, Göteborg.

Ozgünel, C. 1997 Mykenische Keramik in Anatolien, Asia Minor Studien 23, Bonn.

Palaima, T.G. 1989 "Cypro-Minoan scripts: problems of historical context", Problems in decipherment (Duhoux, Y., T. Palaima, J. Bennett eds.), Louvain-la-Neuve, 121-187.

Palaima, T.G. 1991 "Maritime matters in the Linear B tablets", Thalassa. L' égee prehistorique et la mer (Laffineur, R., L. Basch eds), Aegeum 3, Liège, 273-309.

Panichelli, S., Re, L. 1994 "Ceramiche d'importazione egea di fabbrica fine a pittura brillante e opaca", Vivara. Centro commerciale mediterraneo dell'età del bronzo II. Le tracce dei contatti con il mondo egeo (scavi 1976-1982) (Marazzi, M., S. Tusa eds.), Ricerche di storia, epigrafia e archeologia mediterranea 3, 173220.

Parry, J., M. Bloch 1989 "Introduction: money and the morality of exchange, Money and the morality of exchange (Parry, J., M. Bloch eds.), Cambridge, 1-32.

Pecorella , P.E. 1977 Le tombe dell'età del bronzo tardo della necropoli a mare di Ayia Irini "Paleokastro", Roma.

Pellegrini, E., M. Piperno 1998 "Il sacrificio del capriolo", Archeo 14.2, 40-46.

Peltenburg, E.J. 1974 “The glazed vases”, Excavations at Kition I. The tombs (V. Karageorghis), Nicosia, 105-143.

Peltenburg, E.J. 1985 “Appendix II. Glazed vessels from Bronze and Iron Age Kition”, Excavations at Kition V: the pre-Phoenician levels II (Karageorghis, V.), Nicosia, 255-279.

Peroni, R. 1982a "Prospettive", Ricerche sulla protostoria della Sibaritide 2, Cahiers du Centre Jean Bérard VIII, Naples, 1-4.

Peroni, R. 1982b "La campagna di scavo 1980", Ricerche sulla protostoria della Sibaritide 2, Cahiers du Centre Jean Bérard VIII, Naples, 5-24.

Peroni, R. 1983 "Presenze micenee e forme socio-economiche nell'Italia protostorica”, Magna Grecia e mondo miceneo. AttiTaranto 22, 211-335.

Peroni, R. 1984 “La campagna dello scavo 1981”, Ricerche sulla protostoria della Sibaritide 3, Roma, 9-27.

Peroni, R. 1994a Introduzione alla protostoria italiana, Roma/Bari.

Peroni, R. 1994b "La comunità enotrie della Sibaritide ed i loro rapporti con i navigatori egei”, Enotri e micenei nella Sibaritide, II (Peroni, R., F. Trucco eds.), Taranto, 831-879.

Peroni, R., B. Trucco 1994 "Le campagne di scavo 1983-1985”, Enotri e micenei nella Sibaritide (Peroni, R., F. Trucco eds.), Taranto, 21-84.

Peroni, R., L. Vagnetti 1982 “Ricognizione di altri siti”, Ricerche sulla protostoria della Sibaritide 1, Cahiers du Centre Jean Bérard VII, Naples, 153-163.

Peroni, R., A. Vanzetti 1993 "Broglio di Trebisacce (CS). Scavi 1990-1992, AttiTaranto 32, 137-145.

Peroni, R., A. Vanzetti 1998 Broglio di Trebisacce 1990-1994. Elementi e problemi nuovi dalle recenti campagne di scavo, Rubettino.

Pieridou, A. 1966 "A tomb group from Lapithos 'Ayia Anastasia”, RDAC, 1-12.

Ploug, G. 1973 Sukas II: the Aegean, Corinthian and eastern Greek pottery and terracottas, Kobenhavn.

Polanyi, K. 1957 “The economy as instituted process”, Trade and market in early empires (Polanyi, K., C.M. Arensberg and H.W. Pearson eds.), Glencoe, 243-269. 
Popham, M. 1979 "Connections between Crete and Cyprus between 1300-1100 BC", The relations between Cyprus and Crete, Nicosia, 179-191.

Porada, E. 1981/1982 "The cylinder seals from Thebes in Boeotia”, AfO 28, 1-70.

Porada, E. 1983 "Cylinder seals”, Excavations at Athienou, Cyprus 1971-1972, QEDEM 16 (T. Dothan \& A. Ben-Tor), Jerusalem, 120-121.

Pottier, E. 1907 "Documents céramique du musée de Louvre”, BCH 31, 228-269.

Poursat, J.C. 1977 Les ivoires mycéniens. Essai sur la formation d’un art mycénien, Paris.

Pritchard, J.B. 1980 The cemetery at Tell es-Saidiyeh, Jordan, Philadelphia.

Pugliese Carratelli, G. 1958 "Per la storia della relazioni micenei con l'Italia”, PP 13, 205-220.

Pulak, C. 1988 “The Bronze Age shipwreck at Ulu Burun, Turkey”, AJA 92, 1-37.

Pulak, C. 1995 "das Schiffswrack von Uluburun”, In Poseidons Reich. Archäologie unter Wasser, Mainz am Rhein, 43-58.

Pulak, C. 1997 “The Ulu Burun shipwreck”, Res Maritimae. Cyprus and the eastern Mediterranean from prehistory to late antiquity (Swiny, S., R.L. Hohlfelder, H. Wylde Swiney eds.), CAARI Monograph series 1, Atlanta, 233-262.

Quagliati, Q. 1900 “Taranto: relazione degli scavi archeologici si eseguirono nel 1899 in un abitato terramaricolo, allo Scoglio del Tonno, presso la città”, NSc, 411-464.

Quilici, L. 1990 La tomba dell'età del bronzo tardo dell'abitato di Paleokastro presso Ayia Irini, Roma.

Radina, F., A. Battisti 1987 "Un intervento di archeologia urbana a Giovinazzo”, Taras 7, 67-77.

Re, L. 1993 "Early Mycenaean plain and coarse ware from Italy", Wace and Blegen. Pottery as evidence for trade in the Aegean Bronze Age (Zerner, C. et al. eds.), Amsterdam, 331-334.

Re, L. 1994 "Ceramiche di fabbrica corrente di tradizione mesoelladica e ceramiche corrente micenea", Vivara. Centro commerciale mediterraneo dell'età del bronzo II. Le tracce dei contatti con il mondo egeo (scavi 1976-1982) (Marazzi, M., Tusa, S. eds.), Ricerche di storia, epigrafia e archeologia mediterranea 3, 221 221-301.

Re, L. 1999 "I più antichi contatti micenei nel Mediterraneo: un confronto fra Oriente e Occidente",

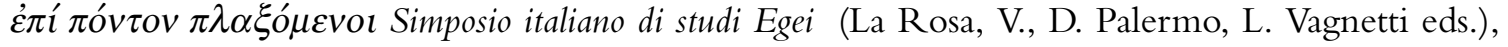
Roma, 405-413.

Renfrew, A.C. 1972 The emergence of civilisation, London.

Renfrew, A.C. 1975 "Trade as action at a distance: questions of integration and communication", Ancient civilisation and trade (Sabloff, J.A., C.C. Lamberg-Karlovsky, eds.), Albuquerque, 3-9.

Renfrew, A.C., J.E. Dixon, J.R. Cahn 1968 "Further analysis of Near Eastern obsidians", ProcPrehistSoc 34, 319-331.

Renfrew, C. 1977 "Retrospect and prospect", Mycenaean geography (Bintliff, J.L. ed.), Cambridge.

Rice, P.M.1987 Pottery analysis. A sourcebook, Chicago.

Riis, P.J. 1959 “l'Activité de la mission archéologique Danoise sur la côte phénicienne en 1958”, AAS 8-9, 107-132.

Riis, P.J. 1960 "l’Activité de la mission archéologique Danoise sur la côte phénicienne en 1959", AAS 10, 111-133.

Riis, P.J. 1970 Sukas I. The nort-east sanctuary and the first settling of the Greeks in Syria and Palestine, Copenhagen.

Riis, P.J., J. Jensen 1996 Sukas X. The Bronze and Early Iron Age remains at the southern harbour, Copenhagen. 
Rowlands, M. 1987 "Centre and periphery: a review of a concept", Centre and periphery in the ancient world (Rowlands, M., M. Larsen, K. Kristiansen eds.), Cambridge, 1-11.

Russell, P. 1989 "The fine ware ceramics: the settlement deposits in the west, central, east and southeast areas", Vasilikos valley project 3. Kalavasos-Ayios Dhimitrios II. Ceramics, objects, tombs, specialist studies (Todd, I.A. ed.), SIMA 71:3, Göteborg 1989, 1-11.

Rutter, J.B. 1990 "Pottery groups from Tsoungiza of the end of the Middle Bronze Age", Hesperia 59, $375-458$.

Rutter, J.B. 1993 “Prepalatial Bronze Age of the southern and central Greek mainland”, AJA 97 (1993), 745-797.

Saadé, G. 1979 Ougarit. Métropole Cananéenne, Lattaquié.

Saadé, G. 1979-1980 “A la récherche des villes et villages du royaum ougaritique”, AAAS 29-30, 215230.

Saadé, G. 1995 “Le port d'Ougarit”, Le pays d'Ougarit autour de 1200 av. J.C. (Yon, M., M. Snycer, P. Bordreuil, eds.), RSO XI, Paris, 211-225.

Saidah, R. 1993-1994 "Beirut in the Bronze Age: the Kharji tombs", Berytus 41, 137-210.

Saliby, N. 1979-1980 “Une tombe d'Ugarit découverte fortuitement en 1970”, AAS 29-30, 105-139.

Salles, J.F. 1980 Le nécropole "K" de Byblos, Lyon.

Salles, J.F. 1987 "Deux nouvelles tombes de Ras Shamra”, Le centre de la ville, 38ème-44ème campagne (1978-1984) sous la direction de Marguerite Yon, RSO III, Paris, 157-195.

Salles, J.F., 1995: Rituel mortuaire et rituel social à Ras Shamra/Ougarit, in Campbell, S., A. Green (eds.), The Archaeology of Death in the Ancient Near East, Oxford (Oxbow Monographs 51), 171-184.

Sasson, J.M. 1966 "Canaanite maritime involvement in the second millennium BC", JAOS 86, 126-138.

Schachermeyer, F. 1979 "Baustufen und historische Perioden in Enkomi”, Studies Presented in memory of Porphyrios Dikaios, Nicosia, 60-62.

Schaeffer, C.F.A. 1929 "Les fouilles de Minet el-Bieda et de Ras Shamra (campagne du printemps 1929). Rapport sommaire", Syria 10, 285-303.

Schaeffer, C.F.A. 1931 "Les fouilles de Minet el-Beida et de Ras Shamra. Deuxième campagne (printemps 1930). Rapport sommaire", Syria 12, 1-14.

Schaeffer, C.F.A. 1932 "Les fouilles de Minet-el-Beida et de Ras-Shamra. Troisième campagne (printemps 1931). Rapport sommaire", Syria 13, 1-27.

Schaeffer, C.F.A. 1933 "Les fouilles de Minet-el-Beida et de Ras-Shamra. Quatrième campagne (printemps 1932). Rapport sommaire”, Syria 14, 93-127.

Schaeffer, C.F.A. 1935 "Les fouilles de Ras Shamra-Ugarit. Sixième campagne (printemps 1934). Rapport Sommaire”, Syria 16, 141-176.

Schaeffer, C.F.A. 1936a Missions en Chypre 1932-1935, Paris.

Schaeffer, C.F.A. 1936b "Les fouilles de Ras Shamra-Ugarit. Septième campagne (printemps 1935). Rapport Sommaire", Syria 17, 105-149.

Schaeffer, C.F.A. 1938 "Les fouilles de Ras Shamra-Ugarit. Neuvième campagne (printemps 1937). Rapport sommaire", Syria 19, 313-327.

Schaeffer, C.F.A. 1939a Ugaritica, Paris.

Schaeffer, C.F.A. 1939b "Les fouilles de Ras Shamra-Ugarit. Dixième et onzième campagnes (automne et hiver 1938-1939)", Syria 20, 277-295.

Schaeffer, C.F.A. 1949 Ugaritica II, Paris.

Schaeffer, C.F.A. 1951a "Reprise des recherches à Ras Shamra-Ugarit. Sondages de 1948 et campagne de 1950", Syria 28, 1-21. 
Schaeffer, C.F.A. 1952, Enkomi-Alasia. Nouvelles missions à Chypre 1946-1950, Paris.

Schaeffer, C.F.A. 1956, Ugaritica III, Paris.

Schaeffer, C.F.A. 1962b "Fouilles et découvertes des xviiie et xixe campagnes 1954-1955", Ugaritica IV (Schaeffer, C.F.A. ed.), Paris, 1-148.

Schaeffer, C.F.A. 1963a "Neue Entdeckungen in Ugarit (23. und 24. Kampagne, 1960-1961), AfO 20, 206-215.

Schaeffer, C.F.A. 1963b "La xxive campagne de fouilles à Ras Shamra-Ugarit 1961”, AAS 13, 123-134.

Schaeffer, C.F.A. 1966 "Neue Entdeckungen und Funde in Ugarit (1963-1964)", AfO 21, 131-137.

Schallin, A.-L. 1993 Islands under influence. The Cyclades in the Late Bronze Age and the nature of the Mycenaean presence, SIMA 91, Jonsered.

Schofield, L., R.B. Parkinson 1994 "Of helmets and heretics: a possible Egyptian representation of Mycenaean warriors on a papyrus", BSA 89, 157-170.

Schulte-Campbell, C.C. 1989 "A Late Cypriot IIC tomb: Idalion tomb I.76. Introduction and skeletal remains", American expedition to Idalion 1973-1980 (L. E. Stager, A.M. Walker eds.), Oriental Institute Communication 24, Chicago, 119-137.

Shelmerdine, C.W. 1984 “The perfume industry at Pylos”, Pylos comes alive (C.W. Shelmerdine, T.G. Palaima eds.), New York, 81-95.

Sherratt A., E.S. Sherratt 1991 "From luxuries to commodities: the nature of Bronze Age trading systems", Bronze Age trade in the Mediterranean (Gale, N. ed.), SIMA 90, Göteborg, 351-386.

Sherratt, E.S. 1980 "Regional variation in the pottery of Late Helladic IIIB", BSA 75, 175-202.

Sherratt, E.S. 1982 "Patterns of contact: manufacture and distribution of Mycenaean pottery 1400-1100 BC", Interaction and acculturation in the Mediterranean (Best, J.G.P, N.M.W. de Vries eds.), Amsterdam, 179-195.

Sherratt, E.S. 1991 "Cypriot pottery of Aegean type in LCII-III: problems of classification, chronology and interpretation", Cypriot Ceramics. Reading the prehistoric record (Barlow, J.A., B. Bolger, B. Kling eds.), Philadelphia, 185-198.

Sherratt E.S. 1994a "Commerce, iron and ideology: metallurgical innovation in 12th-11th century Cyprus", Cyprus in the 11th century BC (Karageorghis, V. ed.), Nicosia, 59-106.

Sherratt E.S. 1994b "Patterns of contact between the Aegean and Cyprus in the 13th and 12th centuries

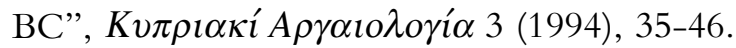

Sherratt, E.S. 1998 “'Sea peoples' and the economic structure of the late second millennium in the eastern Mediterranean", Mediterranean peoples in transition. Thirteenth to early tenth centuries BCE. In honor of Professor Trude Dothan (Gitin, S., A. Mazar, E. Stern eds.), Jerusalem, 292-313.

Sherratt, E.S. 1999 "E pur si muove: pots, markets and values in the second millennium Mediterranean", The complex past of pottery. Production, circulation and consumption of Mycenaean and Greek pottery (sixteenth to early fifth centuries BC) (Crielaard, J.P., V. Stissi, G.J. van Wijngaarden eds.), Amsterdam, 163-211.

Sherratt, E.S., J.H. Crouwel 1987 "Mycenaean pottery from Cilicia in Oxford”, OxfJA 6, 325-352.

Sieveking, J., R. Hackl 1912 Die königliche Vasensammlung zu München I: die älteren nichtattischen Vasen, München.

Sinopoli, C.M. 1991 Approaches to archaeological ceramics, New York.

Sjöqvist, E. 1934 “Ajios Iakovos” SCE I, 302-370.

Sjöqvist, E. 1940 Problems of the Late Cypriot Bronze Age, Stockholm.

Smith, A.H. 1925 Corpus Vasorum Antiquorum. Great Britain I: British Museum, London 1925.

Smith, Th.R. 1987 Mycenaean trade and interaction in the west central Mediterranean 1600-1000 BC, BAR I.S. 371, Oxford. 
Snodgrass, A.M. 1991 "Bronze Age exchange: a minimalist position", Bronze Age trade in the Mediterranean (Gale, N. ed.), SIMA 90, Göteborg, 15-20.

South, A.K. 1984 "Kalavasos-Ayios Dhimitrios 1983”, RDAC, 14-41.

South, A.K. 1987 "Vasilikos valley and the west", Western Cyprus: connections (Rupp, D.W. ed.), SIMA 77, Göteborg, 83-95.

South, A.K. 1988 "Kalavassos-Ayios Dhimitrios 1987: an important ceramic group from building X", RDAC, 223-228.

South, A.K. 1989 "From copper to kingship: aspects of Bronze Age society in Cyprus", Early society in Cyprus (Peltenburg, E. ed.), Edinburgh, 315-324.

South, A.K. 1991 "Kalavasos-Ayios Dhimitrios 1990", RDAC, 131-139.

South, A.K. 1997 "Kalavasos-Ayios Dhimitrios 1992-1996”, RDAC 1997, 151-175.

South, A.K., P. Russell 1989 "Tombs 1-7 and 10", Vasilikos valley project 3. Kalavasos-Ayios Dhimitrios II. Ceramics, objects, tombs, specialist studies (Todd, I.A. ed.), SIMA 71:3, Göteborg 1989, 41-57.

South, A.K. P. Russel, P. Schuster Keswani 1989 "Catalogue of finds", Vasilikos valley project 3. KalavasosAyios Dhimitrios II. Ceramics, objects, tombs, specialist studies (Todd, I.A. ed.), SIMA 71:3, Göteborg 1989, 59-147.

South, A.K., P. Russell 1993 "Mycenaean pottery and social hierarchy at Kallavasos-Ayios Dhimitrios, Cyprus", Wace and Blegen. Pottery as evidence for trade in the Aegean Bronze Age (Zerner, C. et al. ed.), Amsterdam, 303-310.

Spencer, H. 1896 The principles of sociology III, London.

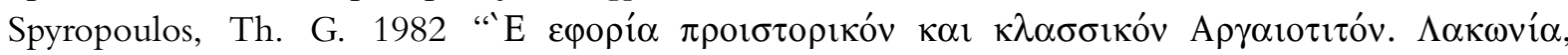
Арк $\alpha$ ía", ADelt 37B, 111-121.

Starkey, J.L., L. Harding 1932 Beth-Pelet II. Prehistoric Cemetery, London.

Stech, T. 1982 "Urban metallurgy in Late Bronze Age Cyprus", Early metallurgy in Cyprus 4000-500 BC (Muhly, J.D., R. Maddin, V. Karageorghis eds.), Nicosia, 105-115.

Steel, L. 1998 "The social impact of Mycenaean imported pottery in Cyprus", BSA 93, 285-296.

Steel, L. 1999a "Wine kraters and chariots: the Mycenaean pictorial style reconsidered", Meletemata. Studies in Aegean archaeology presented to Malcolm H. Wiener as he enters his 65th year, AEGEUM 20, Liège/Austin, 803-811.

Steel, L. 1999b “A reappraisal of Mycenaean pottery from Cyprus”, La céramique mycénienne entre l'Égee et le Levant. Données récentes. (Unpublished summaries of lectures held at the round table conference at Lyon in memory of Vronwy Hankey, 20 March 1999.)

Steinberg, A, F. Koucky 1974 "Preliminary metallurgurgical research on the ancient copper industry", American expedition to Idalion, Cyprus. First preliminary report: seasons of 1971 and 1972 (L.E. Stager, A. Walker, G. Ernest Wright eds.), Cambridge, Mass., 149-78.

Stella, L.A. 1958 "La scoperta di Greco miceneo e la preistoria di Sicilia”, $\operatorname{ArchCl} 10,279-285$.

Stern, E. 1984 Excavations at Tell Mevorakh (1973-1976). Part II: the Bronze Age, Qedem 18, Jerusalem.

Strathern, M. 1992 "Qualified value: the perspective of gift-exchange", Barter, exchange and value. An anthropological approach (Humphrey, C., S. Hugh-Jones eds.), Cambridge, 169-191

Stubbings, F.H. 1951 Mycenaean pottery from the Levant, Cambridge.

Tagliacozzo, A. 1994 "I dati archeozoologici: economia di allevamento e caccia a Broglio di Trebisacce", Enotri e micenei nella Sibaritide II (Peroni, R., F. Trucco eds.), Taranto, 587-652.

Tarragon, J. M. de 1995, “Temples et pratiques rituelles”, Le pays d'Ougarit autour de 1200 av. J.C. (Yon, M., M. Snycer, P. Bordreuil, eds.), RSO XI, Paris, 203-210.

Taylor, J. du Plat 1940 "Mines where the Mycenaeans got their copper”, ILN 196, 251. 
Taylor, J. du Plat 1952 “A Late Bronze Age settlement at Apliki, Cyprus”, AntJ 32, 133-167.

Taylor, J. du Plat 1957 Myrtou-Pigadhes. A Late Bronze Age sanctuary in Cyprus, Oxford.

Taylour, W. 1958 Mycenaean pottery in Italy and adjacent areas, Cambridge.

Taylour, W. 1980 “Appendix III: Aegean sherds found at Lipari”, Meligunis-Lipara IV: L'Acropoli di Lipari nella preistoria (Bernabò-Brea, L., M. Cavalier), 793-817.

Tenaglia, P. 1994 "I dolii cordonati", Enotri e micenei nella Sibaritide, I (Peroni, R., F. Trucco eds.), Taranto, 347-372.

Thiersch, H. 1908 "Die Neueren Ausgrabungen in Palästina”, $A A$ 23, 344-413.

Thiersch, H. 1909 "Die Neueren Ausgrabungen in Palästina”, $A A$ 24, 346-406.

Thomas, N. 1991 Entangled objects, Cambridge Mass.

Thomas, N. 1992 "Politicised values: the cultural dynamics of peripheral exchange", Barter, exchange and value. An anthropological approach (Humphrey, C., S. Hugh-Jones eds.), Cambridge, 21-41.

Thompson, M. 1979 Rubbish theory: the creation and destruction of value, Oxford.

Todd, I.A. 1986a "Vasilikos valley project; preliminary Report 1980-1984", RDAC, 12-17.

Todd, I.A. 1988 "Kalavasos-Mangia: rescue excavations at a Late Bronze Age cemetery", RDAC, 201222.

Toueir, K. 1975 "Découverte d'une tombe mycénienne à Ras Ibn Hani près d'Ugarit-Ras Shamra", Archeologia 88, 67-71.

Toumazou, M.K., R.W. Yerkes, P. Kardulias 1998 “Athienou archaeological project: interim report of investigations in the Malloura valley", JFA 25.

Tournavitou, I. 1992 "Practical use and social function: a neglected aspect of Mycenaean pottery", BSA 87, 181-210.

Tournavitou, I. 1995 “The shaft grave phenomenon. a dead end?”, Trade and production in premonetary Greece: aspects of trade (Gillis, C., C. Risberg, B. Sjöberg eds.), SIMA Pocket-book 134, Jonsered, 111-123.

Trigger, B.G., B.J. Kemp, D. O’Connor, A.B. Lloyd 1983 Ancient Egypt. A social history, Cambridge.

Trucco, B. 1994 "Le strutture", Enotri e micenei nella Sibaritide (Peroni, R., F. Trucco eds.), Taranto, 85106.

Tubb, J.N. 1990 "Excavations at Tell es-Saidiyeh", Archaeology and the Bible (Tubb, J.N., R.L. Chapman eds.), London, 94-110.

Tubb, J.N. 1997 "Tell es-Saidiyeh”, Oxford encyclopedia of archaeology of the Ancient Near East IV, Oxford, $452-455$.

Tufnell, O. 1958 Lachish IV: the Bronze Age, Oxford.

Tusa, S. 1983 La Sicilia nella preistoria, Palermo.

Tusa, S. 1986 "Dinamiche storiche nel territorio selinuntino nel II millennio alle luce delle recenti ricerche in contrada Marcita (Castelvetrano)", Traffici micenei nel Mediterraneo (Marazzi, M., S.Tusa, L. Vagnetti eds.), Taranto,133-140.

Tusa, S. 1991a "Scavi alla Punta d'Alaca", Vivara. Centro commerciale mediterraneo dell'età del bronzo I. Gli scavi dal 1976 al 1982, Ricerche di storia, epigrafia e archeologia mediterranea 1, 75-93.

Tusa, S. 1994 "Contestualità delle ceramiche importate nell'ambito dell'insediamento di Punta d'Alaca", Vivara. Centro commerciale mediterraneo dell'età del bronzo II. Le tracce dei contatti con il mondo egeo (scavi 1976-1982) (Marazzi, M., S. Tusa eds.), Ricerche di storia, epigrafia e archeologia mediterranea 3, 117 122.

Tylor, E.B. 1878 Researches into the early history of mankind and the development of civilisation, London.

Ure, P.N., A.D. Ure 1954 Corpus Vasorum Antiquorum. Great Britain 12: University of Reading, London. Ussishkin, D 1993 NewEncArchExcHL 3, Jerusalem 897-911. 
Vagnetti, L. 1970 "I micenei in Italia, la documentazione archeologica”, PP 25, 359-380.

Vagnetti, L. 1982a "Quindici anni di studi e ricerche sulle relazioni tra il mondo Egeo e l'Italia protostorica”, Magna Grecia e mondo miceneo. Nuovi documenti (Vagnetti, L. ed.), Taranto, 9-40.

Vagnetti, L. 1982b "I frammenti micenei", Ricerche sulla protostoria della Sibaritide 1, Cahiers du Centre Jean Bérard VII, Napoli, 119-128.

Vagnetti, L. 1982c "Ceramica micenea e ceramica dipinta dell'età del bronzo", Ricerche sulla protostoria della Sibaritide 2, Cahiers du Centre Jean Bérard VIII, Naples, 99-113.

Vagnetti, L. 1984a "Ceramica micenea e ceramica dipinta dell'età del bronzo", Ricerche sulla protostoria della Sibaritide 3, Roma, 164-184.

Vagnetti, L. 1984b “ceramica di importazione egea e ceramica dipinta dell'età del bronzo”, Nuove ricerche sulla protostoria della Sibaritide, Roma, 169-196.

Vagnetti, L. 1986 "Cypriot elements beyond the Aegean in the Bronze Age", Cyprus between the orient and the occident (Karageorghis, V. ed.), Nicosia, 201-216.

Vagnetti, L. 1987 "Frammento miceneo", Klearchos, 113-116.

Vagnetti, L. 1989 “Alcuni pezzi importati e I pezzi di bronzo”, La Grotta Cardini (Praia a mare - Cosenza): giacimento del bronzo (Bernabò-Brea, L. ed.), 159-162.

Vagnetti, L. 1991 “Appendice III. Le ceramiche egeo-micenee”, Meligunis-Lipára VI. Filicudi: insediamenti dell'età del bronzo (Bernabò-Brea, L, M. Cavalier), Palermo, 263-296.

Vagnetti, L. 1993 "Mycenaean pottery in Italy: fifty years of study", Wace and Blegen. Pottery as evidence for trade in the Aegean Bronze Age (Zerner, C. et al. eds.), Amsterdam, 143-152.

Vagnetti, L. 1998 Le relazioni fra il versante adriatico pugliese e l'area egea alla luce delle ricerche recenti", Documenti dell'età del Bronzo. Ricerche lungo il versante adriatico pugliese (Cinquepalmi, A., F. Radina eds.), Fasano di Brindisi, 273-286.

Vagnetti, L. 1999 "Mycenaean pottery in the central Mediterranean: imports and local production in their context", The complex past of pottery. Production, circulation and consumption of Mycenaean and Greek pottery (sixteenth to early fifth centuries BC) (Crielaard, J.P., V. Stissi, G.J. van Wijngaarden eds.), Amsterdam, 137-161.

Vagnetti, L., R.E. Jones 1988 Towards the identification of local Mycenaean pottery in Italy, Problems in Greek prehistory French, E.B., K.A. Wardle eds.), Bristol, 335-348.

Vagnetti, L., F. Lo Schiavo 1989 “Late Bronze Age long-distance trade in the Mediterranean”, Early society in Cyprus (Peltenburg, E.J. ed.), Edinburgh, 217-243.

Vagnetti, L., S. Panichelli 1994 "Ceramica egea importata e di produzione locale", Enotri e micenei nella Sibaritide I (Peroni, R., F. Trucco eds.), Taranto, 373-413.

Vallino, F.O. 1984 “Attività agropastorali, basi elementari ed ipotesi demografiche”, Nuove ricerche sulla protostoria della Sibaritide, Roma, 305-316.

Vallois, H.V., D. Ferembach 1962 "Les restes humain de Ras Shamra et de Minet el-Beida: étude anthropologique", Ugaritica IV (Schaeffer, C.F.A. ed.), Paris, 565-622.

Van der Kooij, G., M.M. Ibrahim (eds.) 1989 Picking up the threads... A continuing review of excavations at Deir Alla, Jordan, Leiden.

Van der Steen, E.J. 1996 "The central east Jordan valley in the Late Bronze and Early Iron Ages", BASOR 302, 51-74.

Van der Steen, E.J. 1997 "Pots and potters in the central Jordan valley", AAJ 41, 81-92.

Van der Toorn, K. 1995a "The domestic cult at Emar", JCunSt 47, 35-49.

Van der Toorn, K. 1995b "Theology, priests and worship in Canaan and ancient Israel”, Civilisations of the ancient Near East (J.M. Sasson ed.), New York, 2043-2058. 
Van Dongen, A. 1996 “"The curiosity of the world”, One man's trash is another man's treasure (Van Dongen, A. et al. eds.), Rotterdam, 11-25.

Van Soldt, W.H. 1986 Studies in the Akkadian of Ugarit: dating and grammar, Leiden. (Unpublished Ph.D. thesis.)

Van Wijngaarden, G.J. 1999a "The complex past of pottery: an introduction", The complex past of pottery. Production, circulation and consumption of Mycenaean and Greek pottery (sixteenth to early fifth centuries $B C$ ) (Crielaard, J.P., V. Stissi, G.J. van Wijngaarden eds.), Amsterdam, 1-19.

Van Wijngaarden, G.J. 1999b "Production, circulation and consumption of Mycenaean pottery (sixteenth to twelfth centuries BC)", The complex past of pottery. Production, circulation and consumption of Mycenaean and Greek pottery (sixteenth to early fifth centuries BC) (Crielaard, J.P., V. Stissi, G.J. van Wijngaarden eds.), Amsterdam, 21-47.

Van Wijngaarden, G.J. 1999c "An archaeological approach to the concept of value: Mycenaean pottery at Ugarit (Syria)", Archaeological Dialogues 6, 2-23.

Veblen, T. 1899 The theory of the leisure class. An economic study of institutions, New York.

Vermeule, E. 1974 Toumba tou Skourou. The mound of darkness, Boston.

Vermeule, E., V. Karageorghis 1982 Mycenaean pictorial vase painting, Cambridge Mass.

Vermeule, E., F.Z. Wolsky 1978 "New Aegean relations with Cyprus: the Minoan and Mycenaean pottery from Toumba tou Skourou", ProcPhilsoc 122, 294-317.

Vermeule, E. 1980 "Minoan relations with Cyprus: the Late Minoan I pottery from Toumba tou Skourou, Morphou", Temple university Aegean symposium 5, 22-24.

Vermeule, E.T., Wolsky, F.Z. 1990 Toumba tou Skourou. A Bronze Age potters' quarter on Morphou bay in Cyprus, Boston.

Vichos, Y., Y. Lolos 1997 "The Cypro-Mycenaean wreck at Point Iria in the Argolic gulf: first thoughts on the origin and the nature of the vessels", Res Maritimae. Cyprus and the eastern Mediterranean from prehistory to late antiquity (Swiny, S., R.L. Hohlfelder, H. Wylde Swiney eds.), CAARI Monograph series 1, Atlanta, 321-337.

Voutsaki, S. 1995 "Value and exchange in premonetary societies: anthropological debates and Aegean archaeology", Trade and production in premonetary Greece: aspects of trade (Gillis, C., C. Risberg, B. Sjöberg eds.), SIMA Pocket-book 134, Jonsered, 7-17.

Voutsaki, S. 1997 "The creation of value and prestige in the Aegean Late Bronze Age", Journal of European Archaeology 5, 34-52.

Voza, G. 1972 "Thapsos. Primi risultati delle più recenti scoperte”, Atti del XIV riunione scientifica dell' istituto Italiano di preistoria e protostoria, Firenze, 175-204.

Voza, G. 1973a "Thapsos. Resconto sulle campagne di scavo del 1970-1971”, Atti del XV riunione scientifica dell' istituto Italiano di preistoria e protostoria, Firenze, 133-175.

Voza, G. 1973b Archeologia nella Sicilia sud-orientale, Napoli.

Voza, G. 1976-1977 “L'attività della soprintendenza alle antichità della Sicilia orientale II”, Kokalos 2122, 551-606.

Voza, G. 1980-1981 "L'attività della Soprintendenza alle antichità della Sicilia orientale”, Kokalos 26-27, 674-693.

Voza, G. 1985 "I contatti precoloniali col mondo Greco", Sikanie: storia e civiltà della Sicilia Greca, Milano, 543-561.

Wallerstein, I. 1974 The modern world-system: capitalist agriculture and the origins of the European world-economy in the sixteenth century, New York. 
Walters, H.B. 1912 Catalogue of the Greek and Etruscan vases in the British Museum I-II. Cypriot, Italian and Etruscan pottery, London.

Warren, P.M. 1969 Minoan stone vases, Cambridge.

Warren, P. 1996 "The Aegean and the limits of radiocarbon dating", ActaA 67, 283-290.

Warren, P., V. Hankey 1989 Aegean Bronze Age chronology, Bristol.

Webb, J., D. Frankel 1994 "Making and impression: storage and surplus finance in Late Bronze Age Cyprus", JMedA 7.1, 5-26.

Weinberg, S.S. 1983 Bamboula at Kourion. The architecture, Philadelphia.

Welch, F.B. 1899-1900 "The influence of the Aegean civilisation on south Palestine", BSA 6, 117-124.

Whitehouse, R. 1973 “The earliest towns in peninsular Italy”, The explanation of culture change: models in prehistory (Renfrew, C. ed.), Cambridge, 617-624.

Whitehouse, R. 1990 "Caves and cult in Neolithic southern Italy", Accordia research papers 1, 19-37.

Whitehouse, R. 1992 Underground religion. Cult and culture in prehistoric Italy, London

Whitley, J. 1994 "Protoattic pottery: a contextual approach", Classical Greece. Ancient histories and modern ideologies (Morris, I. ed.), Cambridge, 51-70.

Wiener, M.H. 1998 "The absolute chronology of Late Helladic IIIA2”, Sardinian and Aegean chronology. Towards the resolution of relative and absolute dating in the Mediterranean (Balmuth, M.S., R.H. Tykot eds.), Oxford, 309-319.

Wiesner, P. 1989 "Style and changing relations between the individual and society", The meaning of things. Material culture and symbolic expression (Hodder, I. ed.), 56-63.

Williams, J.L. 1980 "Appendix VII: a petrological examination of the prehistoric pottery from the excavations in the Castello and Diana plain of Lipari”, Meligunis-Lipara IV: L'acropoli di Lipari nella preistoria (Bernabò-Brea, L., M. Cavalier), 847-868.

Witzel, A. 1979 "Finds from the area of Dromolaxia", RDAC 181-197.

Wolff, S.R. 1996 "Archaeology in Israel”, AJA 100, 725-768.

Woolley, C.L. 1921 "La Phénicie et les peuples Égéen”, Syria 2, 177-194.

Woolley, C.L. 1955 Alalakh. An account of the excavations at Tell Atchana in the Hatay 1937-1949, London.

Yadin, Y. 1972 Hazor; with a Chapter on Israelite Megiddo, London.

Yadin, Y., Y. Aharoni, R. Amiran, T. Dothan, I. Dunayevsky, J. Perrot 1958 Hazor I. An account of the first season of excavations 1955, Jerusalem.

Yadin, Y., Y. Aharoni, R. Amiran, T. Dothan, I. Dunayevsky, J. Perrot 1960 Hazor II. An account of the second season of excavations 1956, Jerusalem.

Yadin, Y., Y. Aharoni, R. Amiran, T. Dothan, M. Dothan, I. Dunayevsky, J. Perrot 1961 Hazor III-IV. An account of the third and fourth seasons of excavations 1957-1958 (Plates), Jerusalem.

Yadin, Y., Y. Aharoni, R. Amiran, A. Ben-Tor (ed.), M. Dothan, T. Dothan, I. Dunayevsky, S. Geva, E. Stern 1989 Hazor III-IV. An account of the third and fourth seasons of excavations 1957-1958 (Text), Jerusalem.

Yannai, A. 1983 Studies on trade between the Levant and the Aegean in the 14th to 12th centuries BC, Oxford. (Unpublished $\mathrm{PhD}$ thesis.)

Yon, M. 1982 Recherches sur la civilisation ougaritique: fouilles de Ras Shamra 1979”, La Syrie au Bronze Récent, Paris, 9-16.

Yon, M. 1986 "Instruments de culte en Méditerranée orientale" Cyprus between the Orient and the Occident (Karageorghis, V. ed.), Nicosia, 265-288.

Yon, M. 1987 "Les rhytons du sanctuaire", Le centre de la ville, 38ème-44ème campagne (1978-1984) sous la direction de Marguerite Yon, RSO III, Paris, 343-350. 
Yon, M. 1992a "Ugarit: the urban habitat. The present state of the archaeological picture", BASOR 286, 19-32.

Yon, M. 1992b "The end of the kingdom of Ugarit", The crisis years: the 12th century from beyond the Danube to the Tigris (Ward, W.A., M.S. Joukowsky eds.), Dubuque, 111-122.

Yon, M. 1995 "Communication. La maison d'Ourtenou dans le quartier sud d'Ougarit (fouilles 1994)", CRAI 1995, 427-449.

Yon, M. 1997a La cité d'Ougarit sur le tell de Ras Shamra, Paris.

Yon, M. 1997b "Ougarit et le port de Mahadou/Minet el-Beida", Res Maritimae. Cyprus and the eastern Mediterranean from prehistory to late antiquity (Swiny, S., R.L. Hohlfelder, H. Wylde Swiney eds.), CAARI Monograph series 1, Atlanta, 357-369.

Yon, M. 2000 "Répartition et contextes", Céramiques mycéniennes” RSO XIII, Paris/Nicosia, 1-35.

Yon, M., A. Caubet 1990 "Appendix II: les céramiques importées de l'ouest”, Berytus 38, 98-118.

Yon, M., A. Caubet, J. Mallet 1982 "Ras Shamra-Ougarit. 38, 39 et 40ème campagnes (1978, 1979, 1980)", Syria 59, 169-195.

Yon, M., A. Caubet, J. Mallet, P. Lombard, C. Doumet, P. Desfarges 1983 "Fouilles de Ras ShamraOugarit 1981-1983 (41e, 42e, et 43e campagnes)", Syria 60, 201-224.

Yon, M., J. Gachet, P. Lombard 1987 "Fouilles de Ras Shamra-Ougarit 1984-1987 (44ème-47ème campagnes)", Syria 64, 171-191.

Yon, M., J. Gachet, P. Lombard, J. Mallet 1990 "Fouilles de la 48ème campagne (1988) à Ras ShamraOugarit", Syria 67, 1-29.

Yon, M., P. Lombard, M. Renisio 1987 "l'Organisation de l'habitat; les maisons A, B et E”, Le centre de la ville, 38ème-44ème campagne (1978-1984) sous la direction de Marguerite Yon, RSO III, Paris, 11129.

Zaccagnini, C. 1973 Lo scambio dei doni nel Vicino Oriente durante i secoli XV-XIII, Roma.

Zaccagnini, C. 1976 "La circolazione dei beni”, L'alba della civiltà. Società, economia e pensiero nel Vicino Oriente antico II: l'economia (Liverani, M., F. Mario Falese, C. Zaccagnini eds.), Torino, 425-582.

Zaccagnini, C. 1984 "Transfers of movable property in Nuzi”, Circulation of goods in non-palatial context in the ancient Near East (Archi, A. ed.), Roma, 139-159.

Zaccagnini, C. 1987 "Aspects of ceremonial exchange in the Near East during the late second millennium BC”, Centre and periphery in the ancient World (Rowlands, M., M. Larsen, K. Kristiansen eds.), Cambridge, 57-65. 

I N D E X 



\section{GEOGRAPHICAL NAMES *}

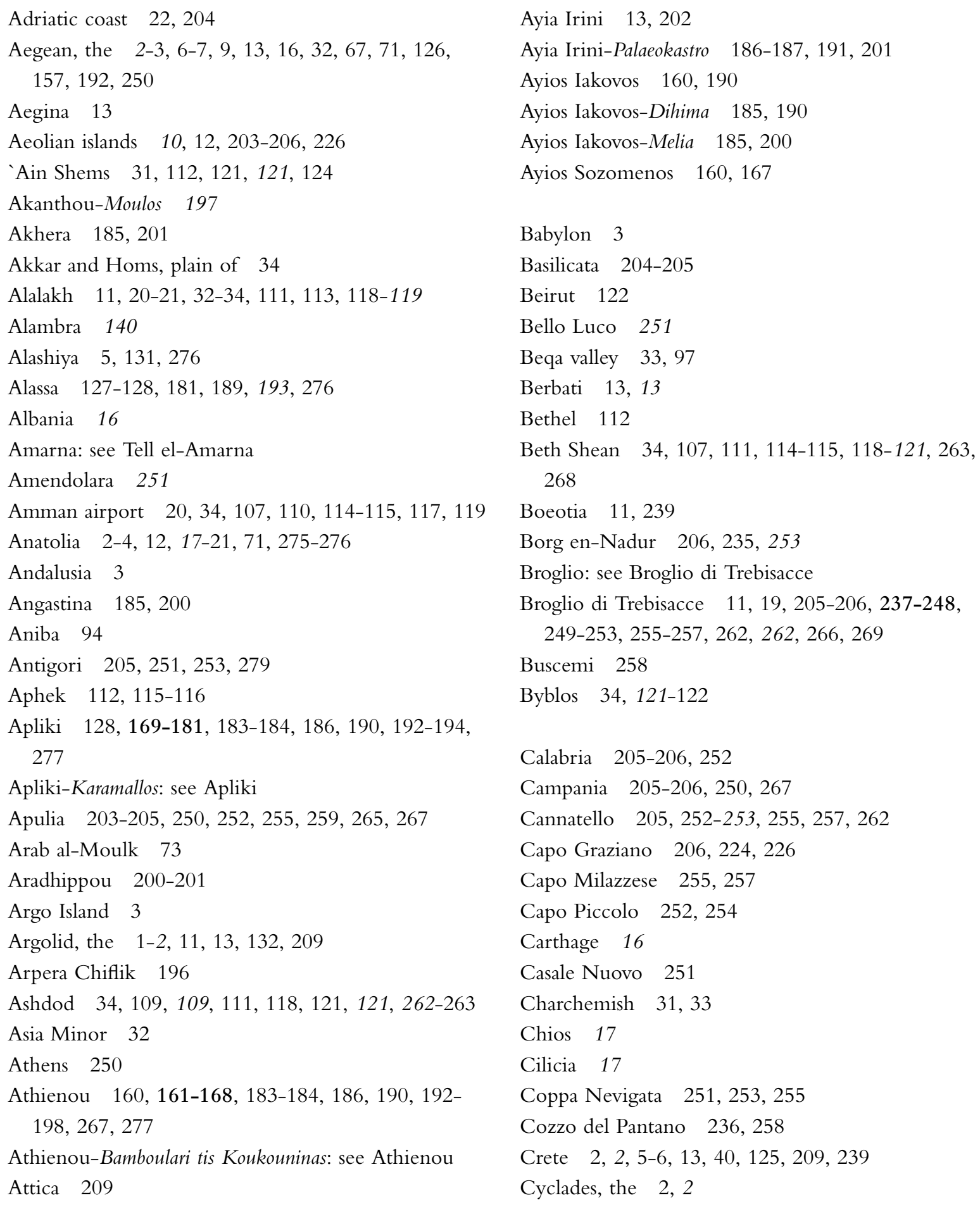

* In both indexes: Italics refer to the footnotes on the page in question; Bold refers to full chapters. 
Cyprus 3, 5-6, 9-10, 12-13, 16-22, 29, 32-33, 40, 71, 123, 125-202, 206, 235, 261-272, 275-279

Deir 'Alla 34-35, 109-110, 115-116, 119, 263, 265 278

Deir el-Medina 19

Dhenia-Kafkalla 197

Dhikomo 187

Dhikomo-Onisia 186

Dodecanese, the 2, 13, 32, 262

Dothan 34

Dromoloxia 201

Dromoloxia-Trypes 200

East, the Near 6, 7, 32, 194

Egypt 2-5, 7, 11-12, 16-22, 39, 71, 94, 100, 102, 105-106, 123-124, 157, 159, 159, 275-276

El-Hesy 31

El Llanete de los Moros 3

Enkomi 11, 13, 16, 19, 125-128, 183-196, 198-201, 262, 265-269, 271-272, 276

Enkomi-Ayios Iakovos 129-160, 192

Euphrates 3, 33

Filicudi 203-204, 226-227, 250-251, 254, 256-258, 262

Floridia 236, 258

Francavilla Marittima 248

Galinoporni 196

Gargano Peninsula 205

Garife 31

Gaza 17

$$
\text { - strip } 33
$$

Gelidonya, Cape 2, 6

Genoa 205

Gezer 31

Gilead 99, 106

Giovinazzo 250, 252, 258

Greece 1-3, 10-13, 16, 16, 29, 32-33, 123, 125, 131, 203-205, 224, 230, 239, 264, 279

Greek mainland 6, 9, 11

Grotta Manaccora 250, 258

Guadalquivir valley 3
Haifa 2

Hala Sultan Tekke 19, 126-128, 139-140, 183-184, 186-189, 191-192, 195-197, 199-200

Hazor 34-35, 75-97, 109-110, 113, 115-119, 121, $121,122,124,263,266-268$

Hittite 34, 39, 71, 157, 276

Idalion 140, 186, 197-198, 200

Iraq 3

Iria 2

Ischia 206

Isopata 6

Israel 16-17, 31-33, 116

Italy $3,5,9-13,16-19,21-22,29,33,127,203-$ 259, 261-268, 270-272, 275, 278-279, 181, 185, 188,195

Jebel Ansariyeh 34

Jezreel valley 116

Jordan 16-17, 31-32, 100

Jordan river 33

Jordan valley 33-34, 75, 96-97

Kafkallia 200

Kalavasos 127, 189-190, 193, 195, 200

Kalavasos-Ayios Dhimitrios 126-128, 181, 183-184, 187-190, 193-197, 200, 265-266, 268-271, 276

Kalavasos-Mangia 195, 200

Kalopsidha 160, 185-186, 188, 197

Kamid el-Loz 34, 97, 110-111, 113-121, 268-269

Katydhata 180, 187, 202

Kerak plateau 116

Khan Selim 97

Kinneret 96

Kition 11, 19, 126-128, 139-140, 183-184, $187-$ 188, 190, 195-200, 270

Klavdhia 196, 200-201

Knossos 6, 279

Kouklia 11, 11, 127, 181, 185-186, 188, 190, 195197

Kouklia-Palaeopaphos: see Kouklia

Kourion 127, 183, 185, 188-189, 192-193, 197, 200

Kourion-Bamboula 139, 183, 185, 188-189, 192, 195-196, 199, 262

Kythera 11 
Lachisch 34, 76, 114-115, 117, 120, 121, 124

Laisch: see Tell Dan

Lapithos-Ayia Anastasia 197, 197

Larnaca 196, 200-201

Latium 206, 253, 255

Lattakia 37,73

Laxia tou Riou 200

Lebanon 16-17, 31-34

Lesbos 17

Levant, the 2-4, 9-10, 12-13, 17-21, 29, 31-124, 127, 157, 159, 205-206, 224, 261-272, 275-276, 278-279

Lipari 203-204, 206, 207-227, 249-258, 262, 264, 266,272

Locris 239

Loutros-Adhkia 180

Luni Sul Mignone 255, 257

Maa-Palaeokastro 181, 188, 192, 194

Madaba 107

Madre Chiesa di Gaffa 252

Magnisi 229

Maiorana 236

Malta 16, 17, 203, 206-207, 235

Manaccora 267

Mantissa 197

Marathasa river 169

Marche, Le 3

Maroni 126-127, 140, 184-186, 191-192, 195, 197, 199-201

Maroni-Vournes 128, 181, 183, 188-189, 193, 276

Matrensa 236, 258

Mediterranean, the 2, 4, 6-7, 9, 15-17

Mediterranean, eastern 4-6, 10-12, 21, 32, 77

Mediterranean, central: see Italy

Megiddo 20, 34, 111, 113, 116-119, 121, 121, 123, 268

Mesaoria 127, 129, 160

Mesaoria plain 127, 168

Meskene-Emar 3, 79

Messenia 209

Milia 160, 187, 202

Milena 258

Miletus 10-11, 19

Milocca 258

Minet el-Beida: see Ugarit
Molinello 236

Molinella 254, 258

Monte Grande 205, 250, 252, 254, 256, 263, 279

Morphou 127, 180

Morphou-Toumba tou Skourou: see Toumba tou

Skourou

Mycenae 1, 5, 15

Myrtou-Pigadhes 139, 185, 188, 190, 192-193, 196197, 270

Myrtou-Stephania 196-197, 202

Naples 205, 251

Nicosia-Ayia Pareskevi 160, 168, 185, 187, 200

Nile, the 16

Nitovikla-Korovia 197

Nubia 3, 17, 21, 94

Nuraghe Antigori 249-250, 253, 255, 257

Nuraghe Arrubiu 204, 206

Ognina 207

Orontes 33

Orontes valley 34

Palestine 16, 31-32, 34, 100, 106, 268

Panarea 203, 221, 224, 226-227, 252, 257

Pella 107, 112

Peloponnese, the 2, 11, 13, 77, 100, 125, 239

Pendayia 180

Piemonte 205

Po-area, the 3

Politiko 185, 201

Portella 227

Porto Perone-Saturo 203, 250-257

Praia a Mare 258

Psilatos-Moutti 196

Punta d'Alaca 254, 256, 257

Punta Le Terrare 250, 252, 256, 263

Punta Meliso di Leuca 253

Punta Mezzogiorno 256

Punta Milazzese 226

Pyla 186

Pyla-Kokkinokremos 127, 185, 188, 192-193, 196197, 201

Pyla-Verghi 185, 196, 200-201

Pylos 1 
Qat'at ar-Rouss 73

Ras el-Bassit 73, 116-117, 119

Ras Ibn Hani 34, 73, 112-113, 118

Ras Shamra: see Ugarit

Rhodes 2, 2, 125, 203

Russia, southern 3

Sahab 107, 119

Salina 224, 226-227, 252

San Domenico 255-256

Santa Maria del Castello di Castrovillari 251

Santa Maria di Leuca 251

Saqqara 21

Sardinia $5,17,17,22,203-206,223,225-226,253$, $255,257,279$

Sarepta 34, 109-111, 116-118, 120-124

Sassano 17, 205, 250, 258-259, 267

Scalo di Furno 251, 255

Serro dei Cianfi 227

Shechem 34

Sicilia 225

Sicily $12,17,17,19,23,203-207,223,225-226$, $229,236,250,252-253,255-259,263$

Sidon 121

Sinai 17,31

Sinda 139, 160, 185-186, 198

Soloi 180

Sorek valley 112

Spain 3, 16

Sudan 16

Sybaris 237, 239

Sybaris plain 205

Syracusa 258

Syracuse 205, 207, 229, 236

Syria 3, 6, 16-17, 20, 31-34, 94

Taranto $238,249,251,254,256$

Taranto-Scoglio del Tonno 11, 13, 203, 205, 249 250, 252-255, 262, 264-265, 272

Tell Abu Hawam 11, 13, 19, 32, 34, 109-111, 114, 118, 120-122, 124, 263, 269

Tell Atchana 32

Tell Batash 112, 115-116

Tell Beit Mirsim 32

Tell Dab'a-Qantir 19
Tell Dan 11, 96, 110, 112, 119, 121, 123-124

Tell Darouk 73

Tell Deir 'Alla 99-107, 117

Tell el-Amarna 5, 11, 13, 16, 19, 102, 159

Tell el-Far'ah 122

Tell es-Hesi 121

Tell es-Safiyeh 31

Tell es-Saidiyeh 11, 34, 107, 123-124

Tell es-Salihyeh 120, 120

Tell Irbid 107

Tell Kazel 34, 120-121

Tell Mevorakh 114-115

Tell Miqne 262

Tell Miqne-Ekron 106

Tell Nahr al-'Arab 73

Tell Nami 106

Tell Qasis 116

Tell Qiri 116

Tell Sera' $110,115,120$

Tell Sukas 34, 73, 111, 118, 121, 121

Tell Ta'anek 117, 121

Tell Yoqne'am 116

Termitito 11, 205-206, 249-251, 253, 255, 257, 264, 279

Thapsos 205-206, 208, 229-236, 249-250, 252-254, 257-259, 262, 266-267, 271-272, 279

Thebes 1, 21, 278

Timpone della Motta see Francavilla Marittima

Tindari 225

Tiryns 1

Tiryns-Asine 13

Torre Castelluccia 251, 253

Torre del Mordillo 248, 251

Torre Santa Sabina 250, 252-253, 258-259, 271-272

Toumba tou Skourou 13, 126-127, 135, 180-181, 186-189, 191, 201-202, 267

Transjordan 21, 33-34, 99, 106-107, 115, 119, 268

Treazzano di Monsampolo 3

Troodos mountains 127

Troy 3, 7, 16, 19

Tunisia 16

Turkey 2, 6, 16, 31

Tyre $111,118,121,121$

Ugarit 5-6, 11, 13, 13, 16, 19, 31-32, 34-35, 37-73, 109-115, 118-124, 129, 261, 263, 266-270, 277 
Ulu Burun 2, 5, 6, 277, 280

Umm ad-Dananir 107, 122

Veneto, the 3

Vetta della Montagnola 226

Vivara 204-206, 249-252, 254, 256, 262, 266, 279
Wadi Arabah 116

Wadi el Hasá 116

West Bank 17

Yalias valley 167 


\section{S U B J E C T S}

administered trade 24

Aegean style pottery 96

Aegean-type vessel 72

Aeolian islands, society of the 227

alabaster 70, 94, 94, 104, 115, 123-124, 154-155,

157, 199

altar 188

Amarna tablets 96

amber 224, 247, 278

amulet 278

antique 117

arrowhead 167

ashlar tomb 151

Ausonio I 208-209, 212-213, 215, 221, 223-224,

$226-227,255$

Ausonio II 209, 212

basalt vessels 86,88

bead 104, 146

bone comb 175, 179, 278

bothros 165

bronze $86,114,123,154,157,167,175,190-191$,

199, 218-219, 223, 233-234, 247, 259

bronze bowl 94

bronze jewellery 233-234

bronze knife 259

bull's head rhyton 56, 139-141, 147-148, 156

Canaanite 76, 279

capitalism 24

Capo Graziano Culture 207, 212-219, 224, 226227,257

carnelian 123

ceramica grigia 238, 245-247, 251, 256, 270

ceramic production 6,12

ceremonial exchange 276

ceremonial vessel: see Mycenaean ritual vessel

chariot $121,154,195$

chariot krater 9, 114, 119, 125, 148-149, 195

chariot scene 50,142,146, 148, 155

chronology 3, 9-10 coarse ware 9-10, 49, 71-72, 83, 132, 141-142, 146 , $149,158,162,164,193,196-198,204,226,243-$

244, 247, 250-251, 256, 262-263, 269

colonisation 1,7

colonist 5

coloniser 6

colony 7

commerce 6

commercialisation 4

commodity 267

consumption $1,23,27,28,29,71,111,150,158$,

$193,248,268-269,280$

context $44-46,48-49,51,58-59,63-64,79,81-84$, 95, 104, 107, 134, 137

contextual archaeology 29

copper $5,127,131,145-147,149,157,160-161$, 167, 169-170, 177, 181, 275, 277

craft-production $\quad 6,128$

cuneiform script $4,4,39,46,62,112,131$

cult $\quad 65,71,79,103,118,122,129,198,267$

cultural significance $29,71,109-124,183-202,205$, 249-259, 261-274

cylinder seal $88,105,112,114,115,123,146,147$, 148, 154, 167, 277, 278

Cypro-Minoan script $131,143,147,189$

diadem 167

diffusionism 23

dining 193-194, 276

dinner vessel: see Mycenaean dinner vessel

diplomacy 4, 39

distribution pattern $34,201,127,261$

distribution, restricted 122, 272

dolium 238, 245-248, 251, 256

dolmen 258

dromos 212, 223, 232

economy, international 4

effort expenditure 151

electrum 72, 123

élite $4,26,73,114,124,128,131,149,155,160$, 
162, 168, 181, 189-190, 193-194, 196, 198, 201, 255-256, 265-272, 276

emulation 267, 276

enchytrismos 67,229

evolutionism 23

exchange $4,5,7,23-24,27-29,95,117,119,127$ -

128, 131, 160, 167-169, 181, 184, 224-227, 248,

264, 266, 270, 272-273, 275-280

- ceremonial 276

- international 107

- long-distance 6

- maritime 127

- market 24

- network 263

- regional 96

- system 261

fabric 105,278

faience $72,72,94,105,114-115,120,122-124$,

151, 154-157, 159, 159, 165, 167, 190, 199, 224, 227, 277-278

fibula 167,223

figurine: see Mycenaean figurine

foundation offering 114

funerary analysis 66

- ceremony 68, 155

- context 66-71, 92-94, 150-156, 231

gift exchange 4, 24, 28

glass $5,123,147,155,157,159,190,199,224$,

$224,227,233,235,277-278$

glass beads $2,5,155,224,224,233,278$

glass paste 199,224

gold $72,123,130,154-155,175,179,191,199$, 233-234

'Governor's Residency' 107, 112, 115

grey ware: see ceramica grigia

hedgehog rhyton 185

heirloom 117

heterarchical social organisation 128

iconography 33,50

international exchange 107

Iliad 2

imitation 12, 33, 72-73, 96, 104, 125, 158

impasto $219,221,223,225-226,245,247-248,259$,

271 imperialism 23

ivory $2,5,58,61,71,123,154-155,157,166-167$, 179, 199, 277

jewellery 277

kiln 90-91, 218, 225

koine 2

larnax 178

Levanto-Helladic 10-12, 230, 264, 267

limestone disk 85

Linear B tablet: see linear decoration

linear fragment: see linear decoration

linear decoration $6,49,51,72,83-84,141,173$,

203, 215, 243-245

long-distance exchange $6-7,24,26$

mansion 54, 62, 64, 65, 73

manufacture 7,11

maritime exchange 127

market-exchange 24

material culture 23, 27, 65, 106, 127, 157, 209, 247, $266,267,272$

matt-painted pottery $209,215-216,221,226,250$

251, 254, 256, 258, 263, 270

matt-painted: see matt-painted pottery

mediterraneanism 16

merchant 5-7

metal 7, 26, 127, 143, 154, 165, 167, 181, 195, 199, $224,235,256,273$

metal production 161

Milazzese Culture 207-208, 212-213, 216, 219, 224, 226-227, 252, 254, 257

mining 160, 169

Mycenaean dinner vessel 15, 47-48, 64-65, 67, 69, 72, 81-84, 88, 92-93, 95, 102, 109-110, 114, 118119, 122, 137, 139, 146, 153, 158, 160, 164, 173, 173, 177, 184-186, 188-189, 192-195, 201, 214, 233, 235, 243, 245, 248, 251-254, 257, 263, 266, 268-269, 271, 277-278

Mycenaean figurine $15,42,48-49,58,63-65,67$, 69-72, 76, 82, 86-88, 91-92, 94, 109-111, 113$114,121-122,131,133,139-140,153,156,184$ 186, 197-198, 209, 220, 253, 263, 270, 273, 278

Mycenaean palaces 1-2 
Mycenaean pictorial pottery $10-12,50-51,54,56-$ 58, 63-64, 69, 69, 72, 83, 83, 89, 118-119, 123, 126, 131, 142, 149, 154-155, 158, 159, 167, 174, 184, 194-196, 200, 233, 253, 264, 269, 271-273, 276, 279

Mycenaean ritual vessel $15,48,81,102,120,139$ 140, 153, 184, 186, 197, 253, 263-264

Mycenaean storage vessel 15, 15, 47-48, 64-65, 67, 72, 81-82, 84, 84, 90, 92, 96, 102, 109-111, 114, 118-119, 122, 137-139, 146, 153, 160, 164, 173, 179, 184-186, 188-189, 192-194, 201, 214, 233, 243, 251-254, 257, 263, 268-269, 271, 278

Neutron Activation analyses 132

New Archaeology 25

obsidian 26

Odyssey 2

on-site distribution $41,77-84,101-103,133-143$, 163-165, 171-174, 210-216, 239-244

ostrich egg 277

palace $3-6,38-39,43,62,64-65,67,78,80,113-$ 114, 118, 266-267, 276, 279

patterned ware 49-51, 72, 83-84, 86, 92, 95, 141, $165,174,215,244-245$

petrology 40

Philistine ware 31

'Phoenicians' 6

pictorial: see Mycenaean pictorial pottery

plain ware 9-10, 83, 141, 215-216

plastic decoration $51,72,141$

'ports of trade' 110

potter 11,271

pottery production 90, 90-91, 225

prestige good 64,267

reciprocity 24

red burnished ware 256

redistribution 6,24

regional exchange 96

religion 115,256

ritual shape: see ritual vessel

ritual vessel: see Mycenaean ritual vessel

'Rude or Pastoral Style' 12, 40, 58, 126, 131-132, 159, 159, 195, 195, 200 sanctuary $60-61,79,106,160-161,164-165,167$, 185, 190, 196

scarab 58, 88, 90, 94, 105, 112, 122-123, 157, 167, $277-278$

seal 104-105, 120, 154, 157, 175, 179, 278

- cylinder 88, 105, 112, 114-115, 123, 146-148, $154,167,277-278$

serpentine 179

settlement context 52-66, 84-92, 103-104, 143-150, 165-167, 174-179, 217-223, 244-247

ship 7,7

shipwreck 2, 277

shrine $79,90,115$

significance, cultural 29, 71, 109-124, 183-202, 205, 249-259, 261-274

signet ring 154

silver 5, 72, 123, 146, 155, 157, 191

'Simple Style' 77

situla handle 167

slag 179

social hierarchy 128

social status 154

social strategy 28,95

spatial analysis 25,41

spatial distribution $133,137,158$

spectography 40

spindle whorl $165,175,217-218,221,223$

'staple finance' 169

steatite 114,176

stratigraphy $\quad 46,80,136,211,213$

stone $148,157,199,227,278$

stone bead $88,148,154,165$

stone cylinder seal 123

stone tool 174-176, 178

stone vessels 3, 223

storage facility 128

storage pottery: see Mycenaean storage vessel

subsistence 256

substantivism 24

sumptuary strategy 272

symbolism 29

tamkars 4

temple $23,75,78-80,82-84,87-88,95,99,110$

111, 114-115, 117-118, 120, 190, 267

textile 273 


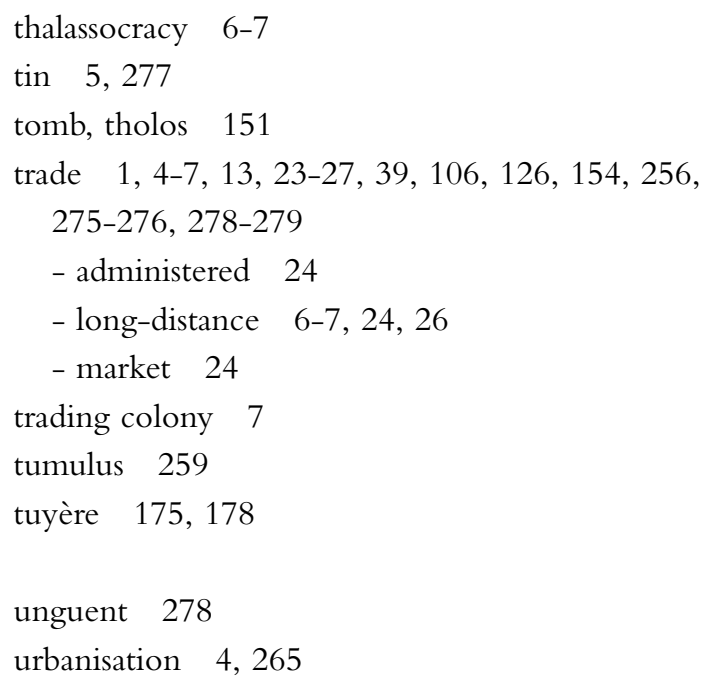

value $27,273,278$

wall bracket $58,146,167,174-175,278$

wealth finance $168,181,236$

wheel 106

White Painted Wheelmade III Ware 131

wine 278

World System theory 26-27

writing 4

zoomorphic vessel 50,83

- rhyton 50, 55, 110, 114, 120, 120, 151, 156, 185,197 
